\title{
Chelation-Assisted C-H Activation by Ruthenium and Osmium Catalysts and Recyclable Hybrid Catalysts
}

\author{
Dissertation \\ for the award of the degree \\ "Doctor rerum naturalium" \\ of the Georg-August-Universität Göttingen
}

within the doctoral program of chemistry

of the Georg-August-Universität School of Science (GAUSS)

Submitted by

Isaac Choi

From Seoul (Republic of Korea)

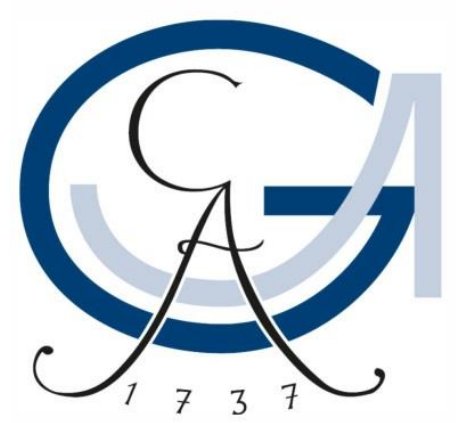

Göttingen, 2021 


\section{Thesis Committee}

Prof. Dr. Lutz Ackermann, Institute of Organic and Biomolecular Chemistry

Prof. Dr. Shoubhik Das, Department of Chemistry, University of Antwerp

\section{Members of the Examination Board}

Reviewer: Prof. Dr. Lutz Ackermann, Institute of Organic and Biomolecular Chemistry

Second Reviewer: Prof. Dr. Shoubhik Das, Department of Chemistry, University of Antwerp

\section{Further members of the Examination Board}

Prof. Dr. Manuel Alcarazo, Institute of Organic and Biomolecular Chemistry

Jun.-Prof. Dr. Johannes C. L. Walker, Institute of Organic and Biomolecular Chemistry

Dr. Michael John, Institute of Organic and Biomolecular Chemistry

Dr. Daniel Janßen-Müller, Institute of Organic and Biomolecular Chemistry

Date of the oral examination: 24. 09. 2021 


\section{Contents}

1. Introduction ......................................................................................................................................................

1.1 Homogeneous Metal-Catalyzed C-H Functionalization...................................................2

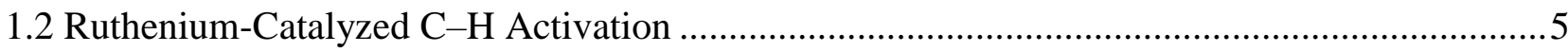

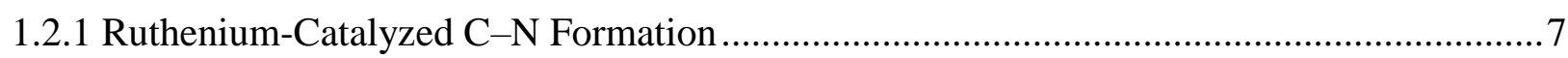

1.2.2 Ruthenium-Catalyzed Distal C-H Functionalization ...................................................23

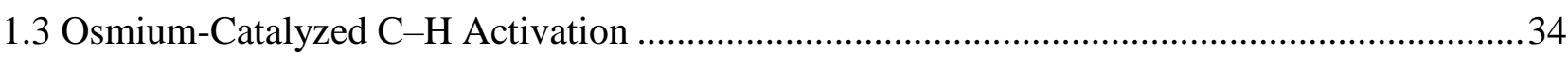

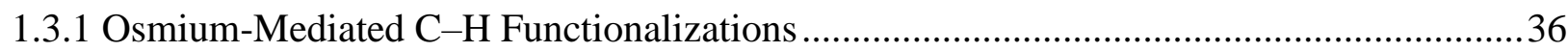

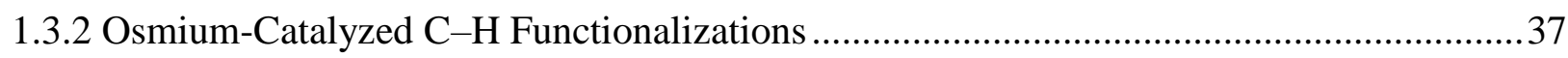

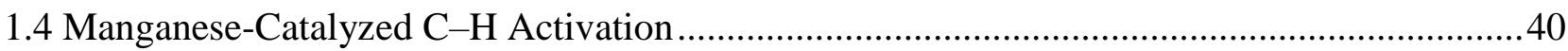

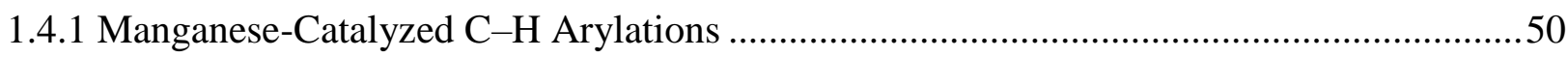

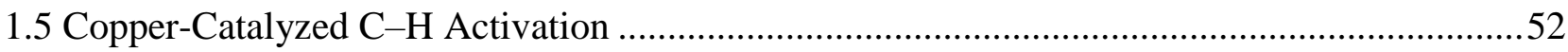

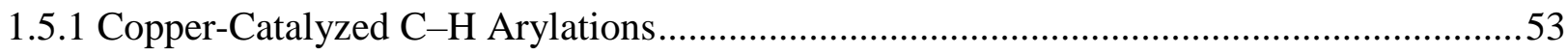

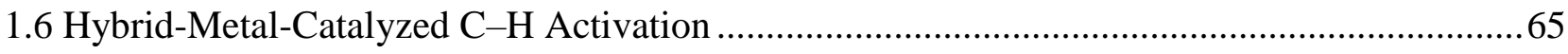

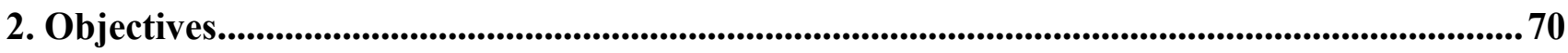

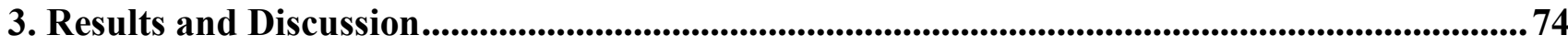

3.1 Ruthenium(II)-Catalyzed C7-H Amidations and Alkenylations of Indoles ........................... 74

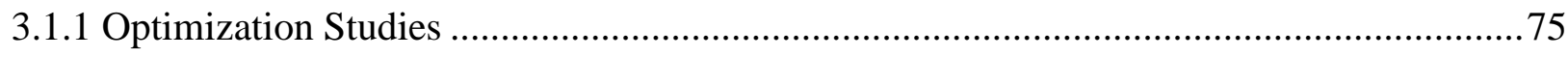

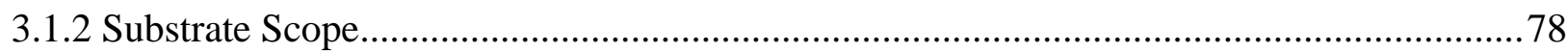

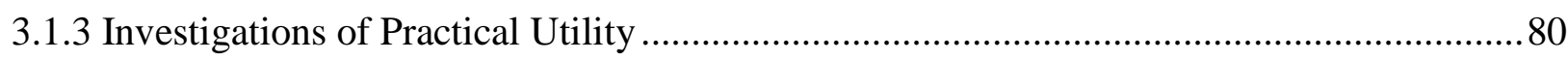

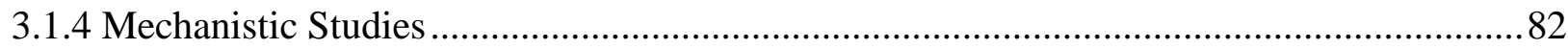

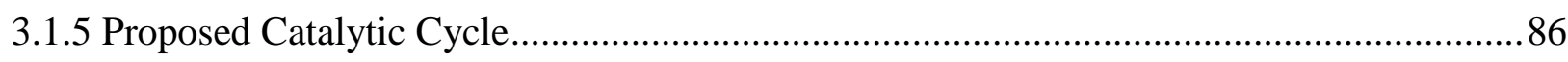


3.2 Ruthenium(II)-Catalyzed C4/C6-H Dual Alkylations of Indoles .87

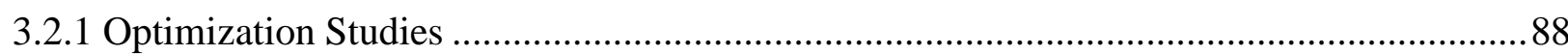

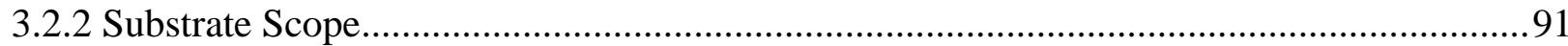

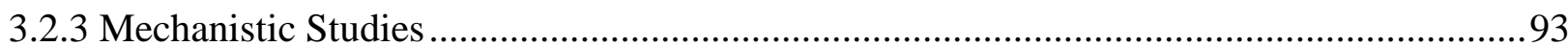

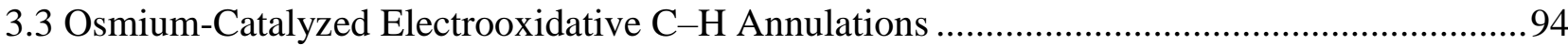

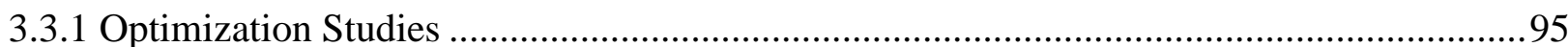

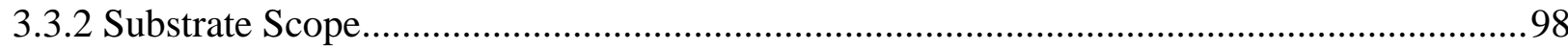

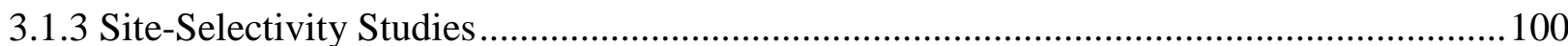

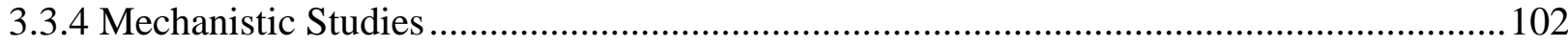

3.4 Photo-Induced C-H Arylation by Reusable Heterogeneous Copper Catalyst .........................111

3.4.1 Preparation of Hybrid Copper Catalyst .................................................................... 112

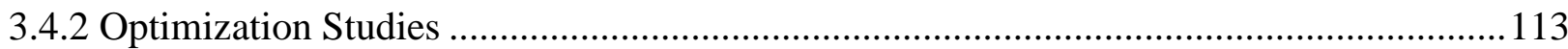

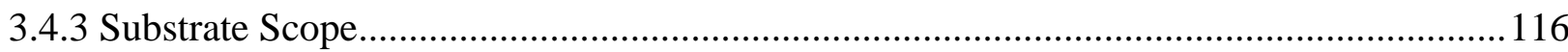

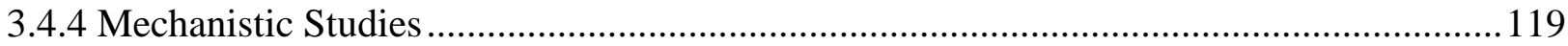

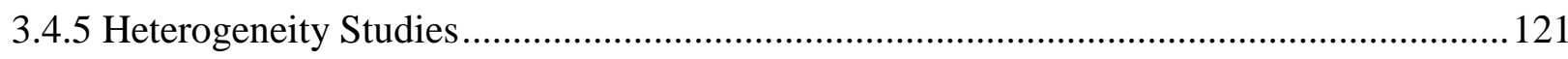

3.4.6 Characterization of Hybrid Copper Catalyst ............................................................... 123

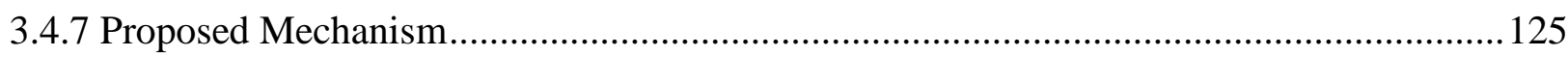

3.5 Distal C-H Activation by Reusable Heterogeneous Ruthenium Catalyst ............................126

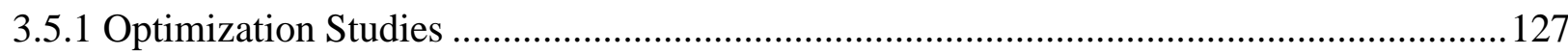

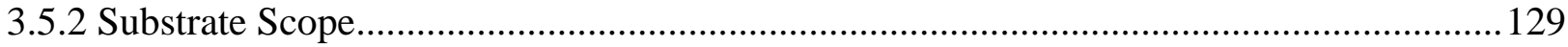

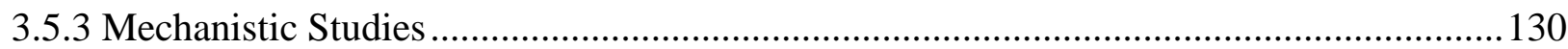

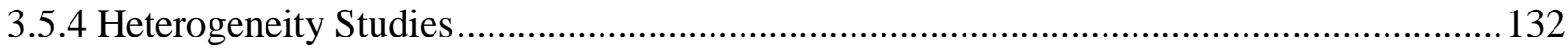

3.5.5 Characterizations of Hybrid Ruthenium Catalyst....................................................... 134

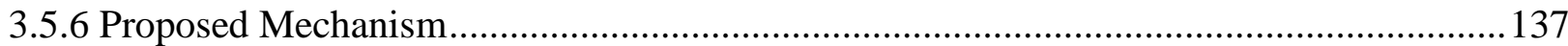


3.6 C-H Arylations and Alkylations by Reusable Heterogeneous Manganese Catalyst 138

3.6.1 Preparation of Hybrid Manganese Catalyst 139

3.6.2 Optimization Studies 140

3.6.3 Substrate Scope 142

3.6.4 Heterogeneity Studies

3.6.5 Characterizations of Heterogeneous Catalyst 146

4. Summary and Outlook 147

5. Experimental Data 151

5.1 General Remarks 151

5.2 General Procedures 155

5.2.1 General Procedure A: Ruthenium-Catalyzed C7-H Indole Amidations 155

5.2.2 General Procedure B: Ruthenium-Catalyzed C7-H Indole Alkenylations 155

5.2.3 General Procedure C: Ruthenium-Catalyzed C4-H/C6-H Indole Dual Alkylations........ 155

5.2.4 General Procedure D: Osmium-Catalyzed Electrooxidative [4+1] C-H annulations....... 155

5.2.5 General Procedure E: Osmium-Catalyzed Electrooxidative [4+2] C-H annulations ....... 156

5.2.6 General Procedure F: Photo-Induced Hybrid Copper-Catalyzed C-H Arylations (1)......156

5.2.7 General Procedure G: Photo-Induced Hybrid Copper-Catalyzed C-H Arylations (2) ..... 156

5.2.8 General Procedure H: Photo-Induced Hybrid Copper-Catalyzed C-H Arylations (3) ..... 157

5.2.9 General Procedure I: Hybrid Ruthenium-Catalyzed meta-C-H Alkylation 157

5.2.10 General Procedure J: Hybrid Manganese-Catalyzed C-H Arylations 157

5.2.11 General Procedure K: Hybrid Manganese-Catalyzed C-H Alkylations 157

5.3 Ruthenium(II)-Catalyzed C7-H Amidations and Alkenylations of Indoles 159

5.3.1 Characterization Data 159

5.3.2 Various Attempted C7-H Activations 179 


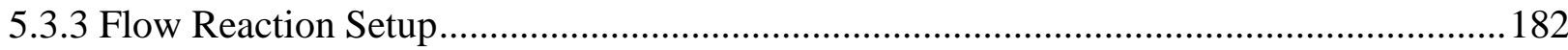

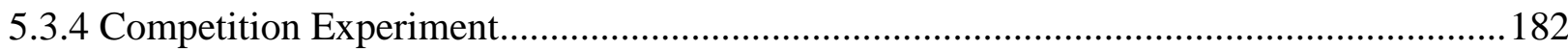

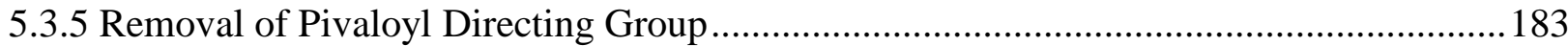

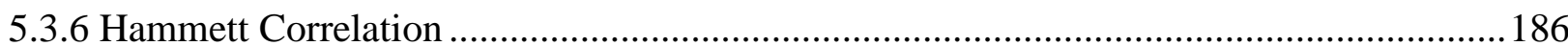

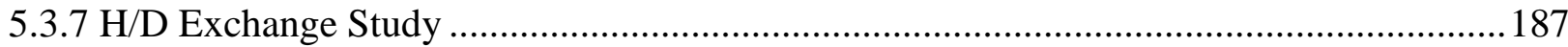

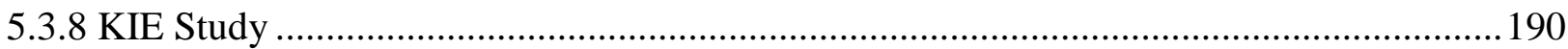

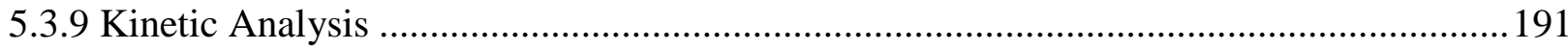

5.4 Ruthenium(II)-Catalyzed C4/C6-H Dual Alkylations of Indoles......................................... 194

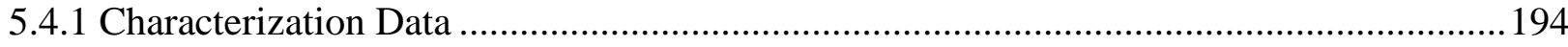

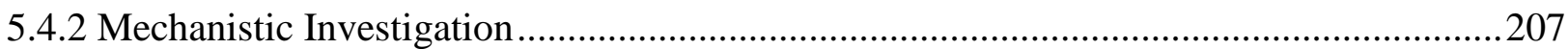

5.5 Osmium-Catalyzed Electrooxidative C-H Annulations ...................................................209

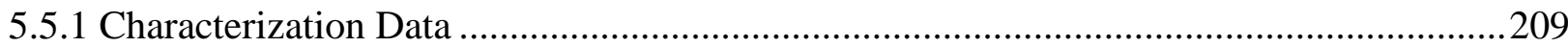

5.5.2 Reaction Comparison with External Oxidant .........................................................229

5.5.3 Selectivity Comparison with Different Catalysis (1) ................................................230

5.5.4 Selectivity Comparison with Different Catalysis (2) .................................................232

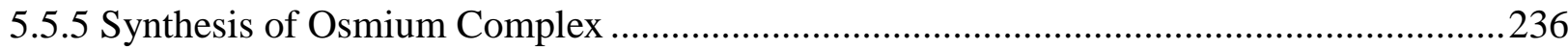

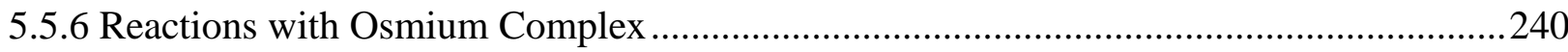

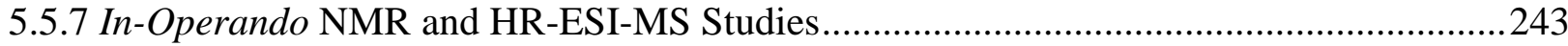

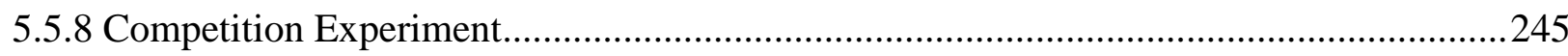

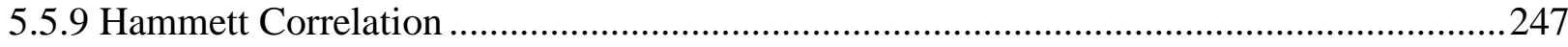

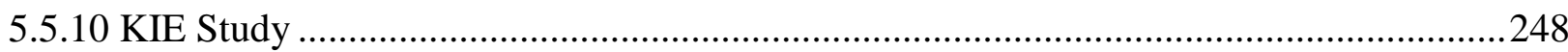

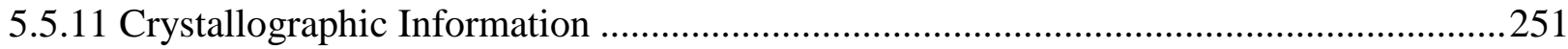

5.6 Photo-Induced C-H Arylation by Reusable Heterogeneous Copper Catalyst ........................256

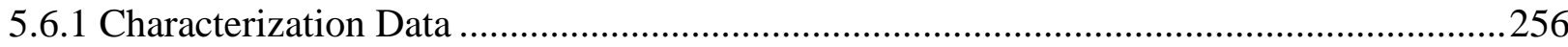




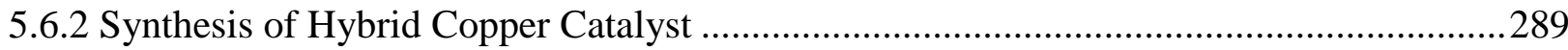

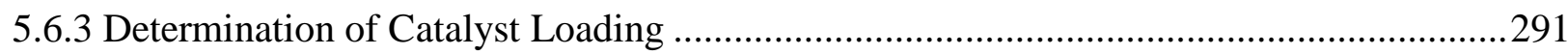

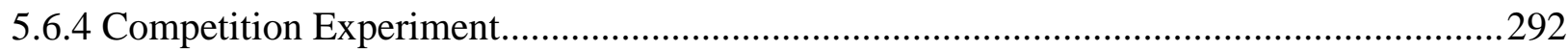

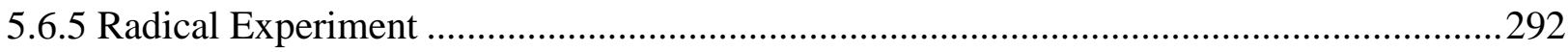

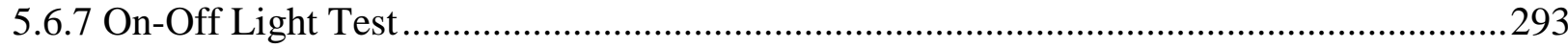

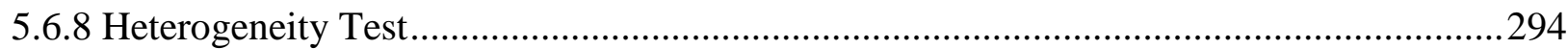

5.7 Distal C-H Activation by Reusable Heterogeneous Ruthenium Catalysis............................296

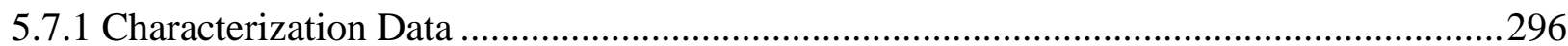

5.7.2 Preparation of Hybrid Ruthenium Catalyst .......................................................... 310

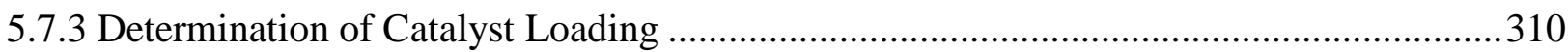

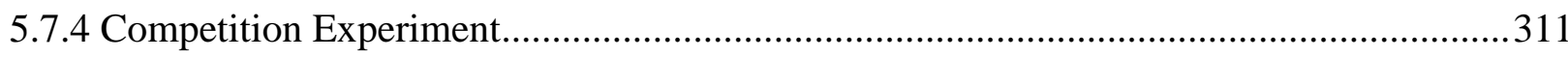

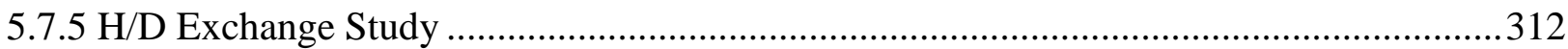

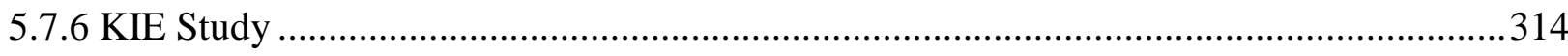

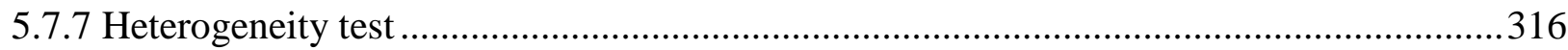

5.8 C-H Arylations and Alkylations by Reusable Heterogeneous Manganese Catalyst ...............320

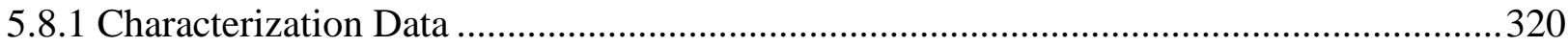

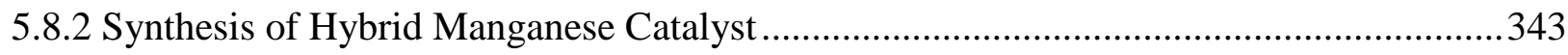

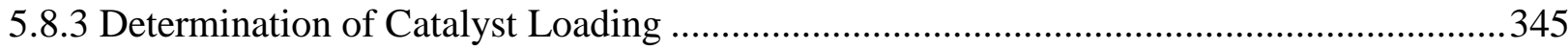

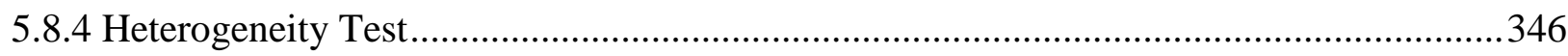

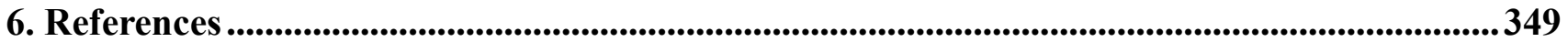

7. Appendix: NMR Spectra ..............................................................................................................................377 


\section{List of Abbreviateions}

\begin{tabular}{|c|c|}
\hline Ac & acetyl \\
\hline acac & acetyl acetonate \\
\hline Alk & alkyl \\
\hline AMLA & ambiphilic metal-ligand activation \\
\hline aq. & aqueous \\
\hline Ar & aryl \\
\hline atm & atmospheric pressure \\
\hline BHT & 2,6-di-tert-butyl-4-methylphenol \\
\hline BIES & base-assisted internal electrophilic substitution \\
\hline $\mathrm{Bn}$ & benzyl \\
\hline Boc & tert-butyloxycarbonyl \\
\hline $\mathrm{Bu}$ & butyl \\
\hline $\mathrm{Bz}$ & benzoyl \\
\hline calc. & calculated \\
\hline cat. & catalytic \\
\hline CMD & concerted metalation deprotonation \\
\hline conv. & conversion \\
\hline $\mathrm{Cp}^{*}$ & cyclopentadienyl \\
\hline $\mathrm{Cy}$ & cyclohexyl \\
\hline$\delta$ & chemical shift \\
\hline $\mathrm{d}$ & doublet \\
\hline DCB & dichlorobutane \\
\hline DCE & 1,2-dichloroethane \\
\hline DCM & dichloromethane \\
\hline
\end{tabular}




\begin{tabular}{|c|c|}
\hline dd & doublet of doublet \\
\hline DFT & density functional theory \\
\hline DG & directing group \\
\hline DME & dimethoxyethane \\
\hline DMF & $N, N$-dimethylformamide \\
\hline DMSO & dimethyl sulfoxide \\
\hline DMPU & 1,3-dimethyl-3,4,5,6-tetrahydro-2(1H)-pyrimidinone \\
\hline $\mathrm{dt}$ & doublet of triplet \\
\hline EI & electron ionization \\
\hline equiv & equivalent \\
\hline ES & electrophilic substitution \\
\hline ESI & electronspray ionization \\
\hline Et & ethyl \\
\hline FG & functional group \\
\hline g & gram \\
\hline GC & gas chromatography \\
\hline $\mathrm{h}$ & hour \\
\hline Hal & halogen \\
\hline Het & hetero atom \\
\hline Hept & heptyl \\
\hline Hex & hexyl \\
\hline HPLC & high performance liquid chromatography \\
\hline HR-MS & high resolution mass spectrometry \\
\hline $\mathrm{Hz}$ & Hertz \\
\hline$i$ & iso \\
\hline IR & infrared spectroscopy \\
\hline IES & internal electrophilic substitution \\
\hline$J$ & coupling constant \\
\hline
\end{tabular}




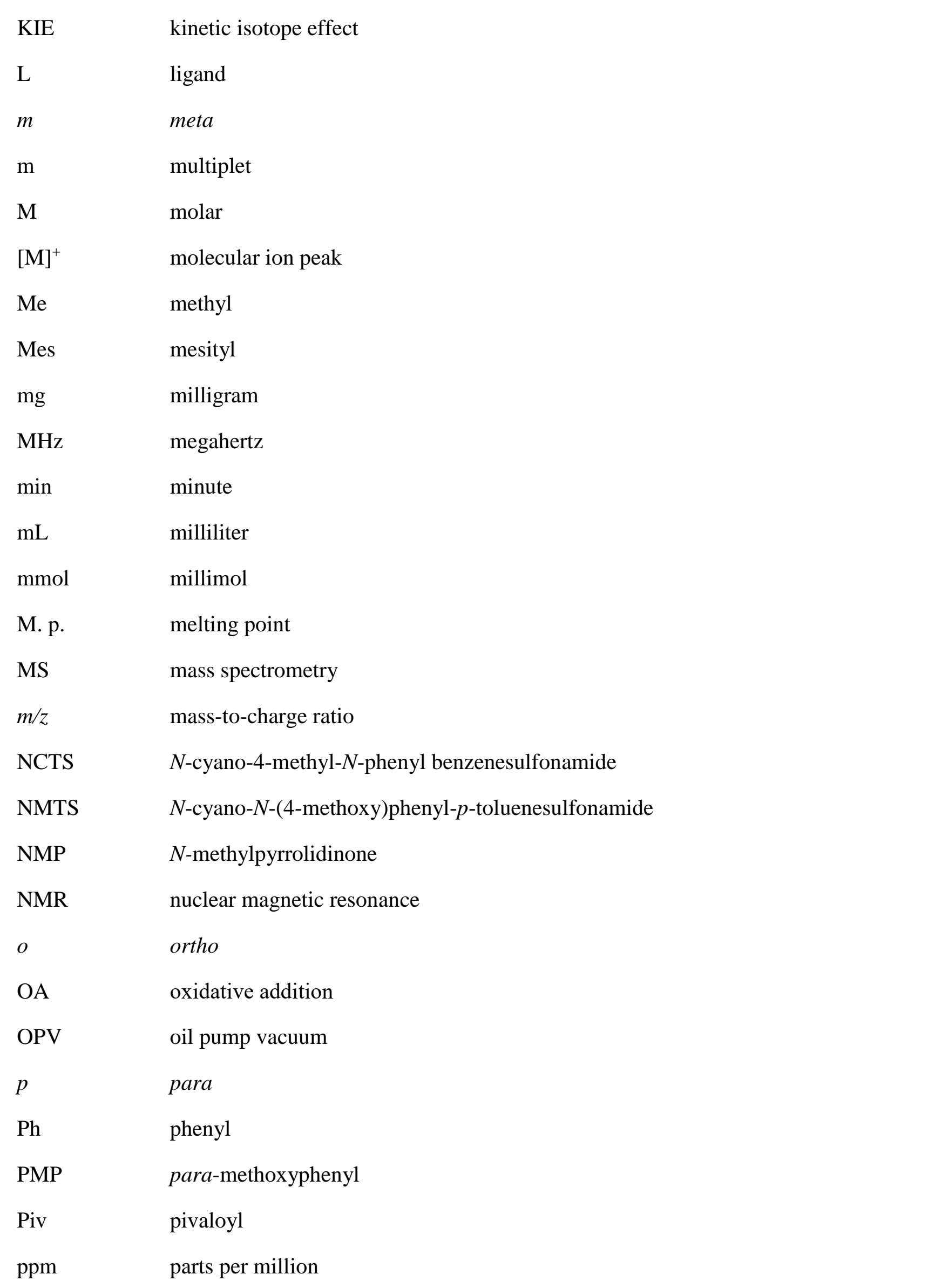




\begin{tabular}{|c|c|}
\hline $\operatorname{Pr}$ & propyl \\
\hline PTSA & $p$-Toluenesulfonic acid \\
\hline py & pyridyl \\
\hline pym & pyrimidine \\
\hline pyr & pyrazol \\
\hline q & quartet \\
\hline RT & room temperature \\
\hline s & singlet \\
\hline sat. & saturated \\
\hline SPS & solvent purification system \\
\hline$t$ & tert \\
\hline $\mathrm{t}$ & triplet \\
\hline $\mathrm{T}$ & temperature \\
\hline THF & tetrahydrofuran \\
\hline TLC & thin layer chromatography \\
\hline $\mathrm{TM}$ & transition metal \\
\hline TMEDA & tetramethylethylenediamine \\
\hline TMP & 2,2,6,6-tetramethylpiperidine \\
\hline TMS & trimethylsilyl \\
\hline Ts & para-toluenesulfonyl \\
\hline TS & transition state \\
\hline$w t \%$ & weight by volume \\
\hline
\end{tabular}




\section{Introduction}

During the last century, tremendous advances in organic synthesis have been accomplished, allowing our life to be fertile, convenient, and efficient. For instance, crop protection products enable an unprecedented increase in the agricultural production output, while the development of pharmaceuticals saves many people's lives. In addition, petroleum becomes an inevitable part of our daily life, while materials are found everywhere around us. These enormous progress in organic chemistry, however, have brought about a series of problems related to environmental pollution and resource depletion by generating toxic materials and consuming a huge amount of energy.

In order to alleviate the dark side of the chemical reactions, a new approach toward resource- ${ }^{[1]}$ stepand atom-economical ${ }^{[2]}$ synthetic methodologies are in high demand. In 1998, Anastas and Warner proposed the "12 Principles of Green Chemistry", ${ }^{[3]}$ which provides chemists with a general guideline for sustainable chemistry, which advises synthetic chemists to pursue environmentally benign chemical processes (Scheme 1.1.1). In this regard, catalysis helps to operate the chemical reactions with a reduced amount of chemicals in lieu of its excess uses, thus setting the stage for resource economical synthesis. Furthermore, direct utilization of easily accessible chemicals without prefunctionalization assists to achieve step- and atom-efficiency in the chemistry process. Additionally, mild reaction conditions and less toxic chemicals are expected to provide safer chemical processes. ${ }^{[4]}$

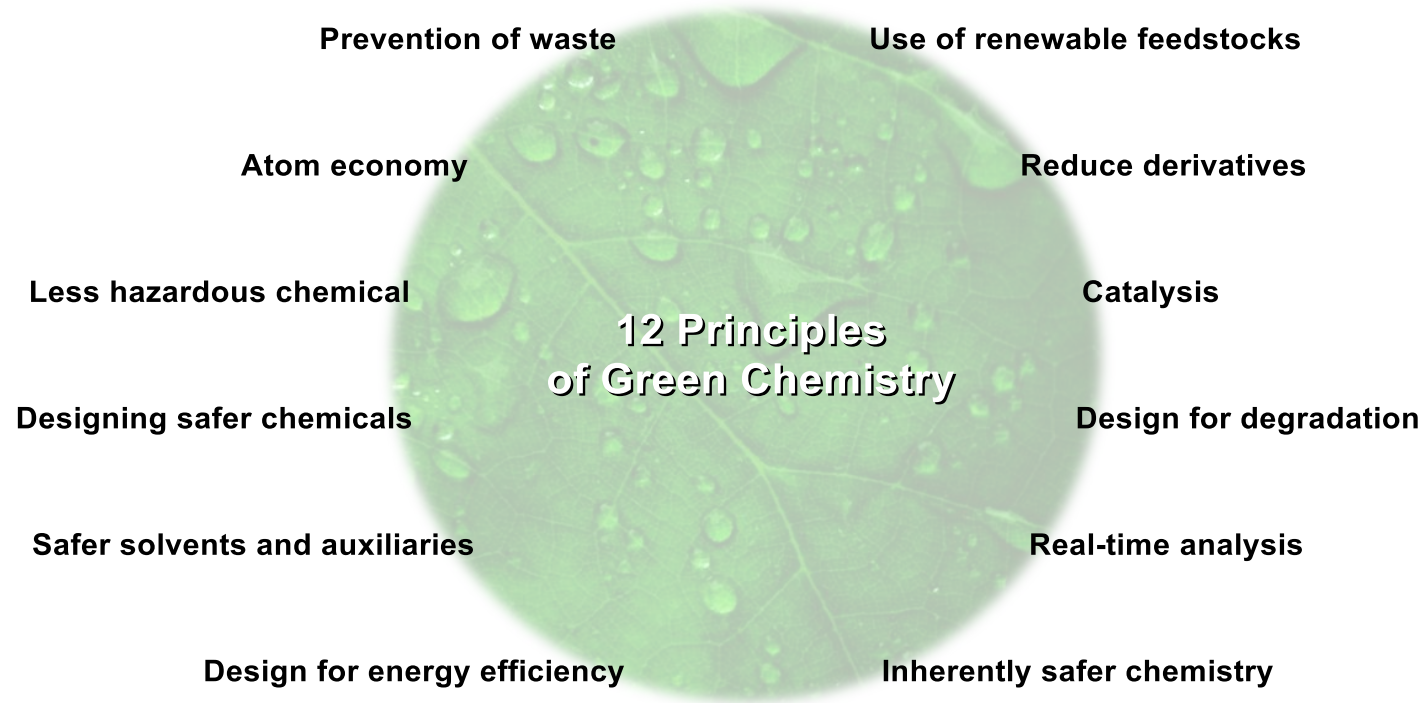

Scheme 1.1.1 The 12 Principles of Green Chemistry. 


\subsection{Homogeneous Metal-Catalyzed C-H Functionalization}

Since hydrocarbons are omnipresent structural units in organic compounds, the utilization of $\mathrm{C}-\mathrm{H}$ bonds of hydrocarbons has great potential. Thereby, organic chemists have had utmost interests in the transformation of hydrocarbons to useful and high-valued compounds by straightforward and sustainable methods. Previously, a significant achievement of catalysis for $\mathrm{C}-\mathrm{C}$ bond and $\mathrm{C}-\mathrm{Het}$ bond formations has been made by transition metals (Scheme 1.1.2a), ${ }^{[5]}$ leading to the development of numerous name reactions, such as the Suzuki-Miyaura, ${ }^{[6]}$ Negishi, ${ }^{[7]}$ Mizoroki-Heck, ${ }^{[8]}$ KumadaCorriu, ${ }^{[9]}$ Hiyama, ${ }^{[10]}$ Stille, ${ }^{[11]}$ and Sonogashira-Hagihara ${ }^{[12]}$ cross-couplings as well as the TsujiTrost reaction, ${ }^{[13]}$ the Goldberg-Ullmann amination, ${ }^{[14]}$ and the related Buchwald-Hartwig reaction. ${ }^{[15]}$ The importance of the palladium-catalyzed chemical transformations was recognized by the Nobel Prize in Chemistry awarded collectively to Heck, Negishi, and Suzuki in 2010. ${ }^{[16]}$

a) Cross-coupling

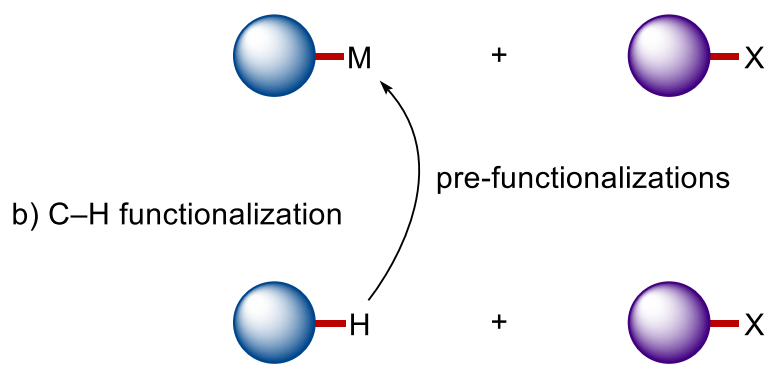

c) Oxidative $\mathrm{C}-\mathrm{H} / \mathrm{C}-\mathrm{H}$ functionalization
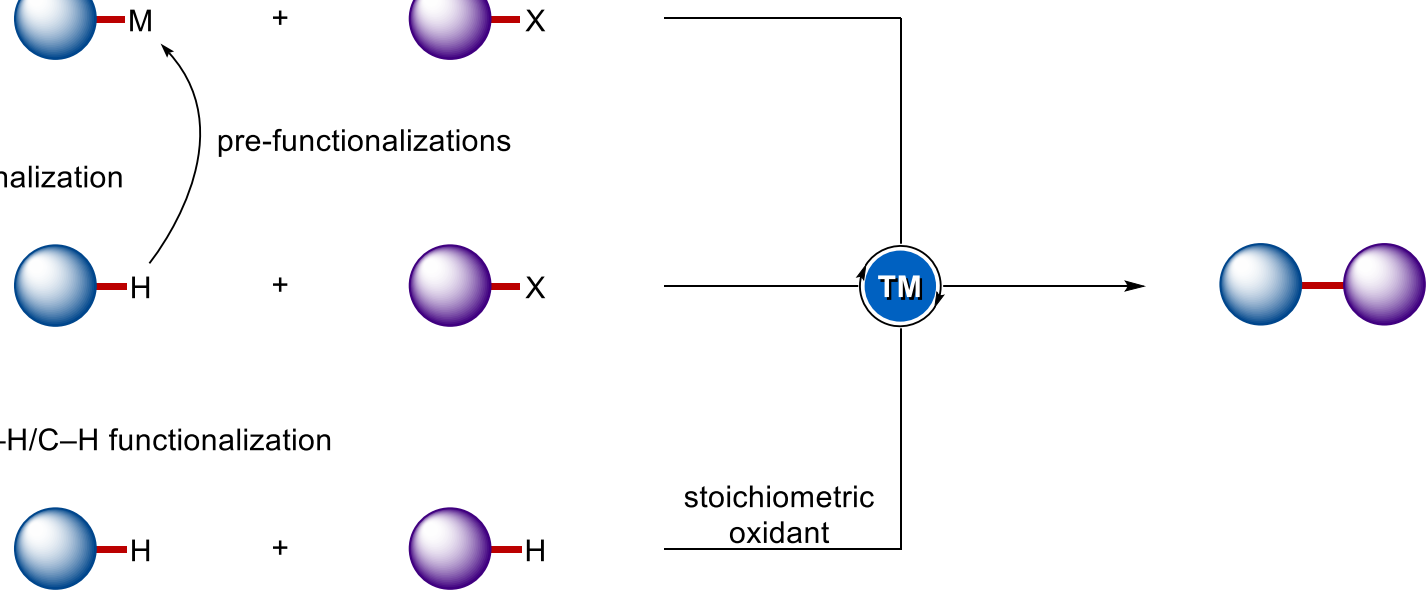

Scheme 1.1.2 Metal-catalyzed cross-coupling versus $\mathrm{C}-\mathrm{H}$ functionalization.

Although these palladium catalyses enabled to change paradigm of $\mathrm{C}-\mathrm{C}$ bond formation reactions (Scheme 1.1.2a), there still existed a drawback where pre-functionalization should be involved, which impedes fulfilling atom- and step-economy as well as user-friendly access. For instance, organostannane reagents used in the Stille coupling are highly toxic, while organomagnesium reagents in the Kumada-Corriu cross-coupling or organozinc reagents in the Negishi cross-coupling are air- and moisture-sensitive. Additionally, the preparation and the use of the organometallic reagents generate 
stoichiometric byproducts. In order to obviate such disadvantages of classical cross-coupling reactions, a new approach, namely $\mathrm{C}-\mathrm{H}$ functionalization, was introduced to the synthetic community. ${ }^{[17]}$ With this strategy, the organometallic nucleophile is directly replaced by an inert $\mathrm{C}-\mathrm{H}$ bond, thereby forming a new $\mathrm{C}-\mathrm{C}$ bond (Scheme 1.1.2b) ${ }^{[18]}$ Additionally, oxidative $\mathrm{C}-\mathrm{H} / \mathrm{C}-\mathrm{H}$ functionalization allowed for another scenario for $\mathrm{C}-\mathrm{C}$ bond formation in the presence of a stoichiometric oxidant (Scheme $1.1 .2 \mathrm{c}){ }^{[19]}$

Since $\mathrm{C}-\mathrm{H}$ functionalization methods provide a sustainable approach for chemical transformation, synthetic chemists became interested in its detailed mechanistic understandings. Except metalloradical or metal carbene/nitrene outer-sphere mechanisms, the organometallic $\mathrm{C}-\mathrm{H}$ cleavage is proposed to proceed via five different possible pathways: (i) oxidative addition; (ii) $\sigma$-bond metathesis; (iii) electrophilic substitution; (iv) concerted metalation deprotonation (CMD); (v) base-assisted internal electrophilic substitution (BIES) (Scheme 1.1.3). ${ }^{[20]}$

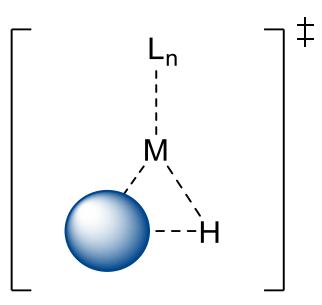

Oxidative Addtion

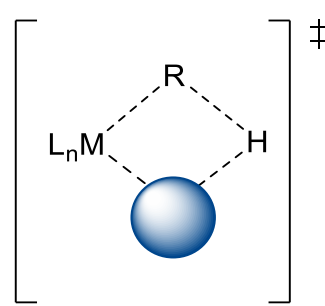

$\sigma$-Bond Metathesis

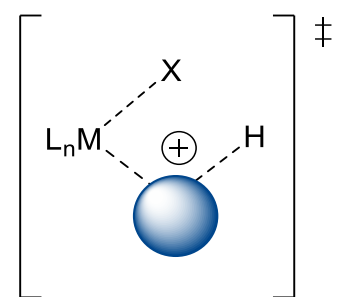

Electrophilic Substitution

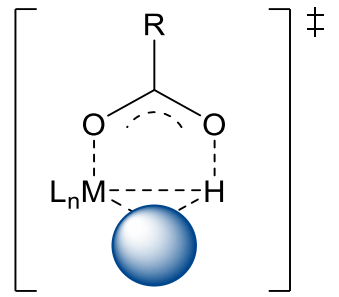

CMD

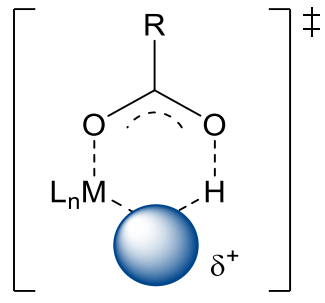

BIES

Scheme 1.1.3 Five different modes of $\mathrm{C}-\mathrm{H}$ bond cleavage process.

Among these plausible $\mathrm{C}-\mathrm{H}$ scission pathways, base-assisted metallation models have been most generally accepted for transition metal-catalyzed $\mathrm{C}-\mathrm{H}$ activation reactions. In this regard, transition state structure and partial charge accumulation are key criteria to subcategorize the base-assisted metallation manifold. Fagnou and Gorelsky proposed a concerted metallation deprotonation (CMD) 
pathway, in which the formation of a deprotonative transition state is suggested in the case where $\mathrm{C}-$ $\mathrm{H}$ bond cleavage step is proposed to be a rate-demermining step. ${ }^{[21]}$ In a similar way, Macgregor and Davies proposed ambiphilic metal ligand activation (AMLA) pathway where agostic interaction occurs between the metal center and the $\mathrm{C}-\mathrm{H}$ bond. ${ }^{[22]}$ In sharp contrast, Ackermann proposed base-assisted internal electrophilic substitution (BIES), featuring that competition experiments between electronically differentiated substrates show the preferred functionalization of the more electron-rich substrate. ${ }^{[23]}$ Notably, this finding cannot be explained by the deprotonative pathway through kinetic C-H acidity. ${ }^{[24]}$

Based on these proposals, general catalytic cycles for the transition metal-catalyzed C-H functionalization can be envisaged, while the mechanistic details can vary reactions (Scheme 1.1.4).

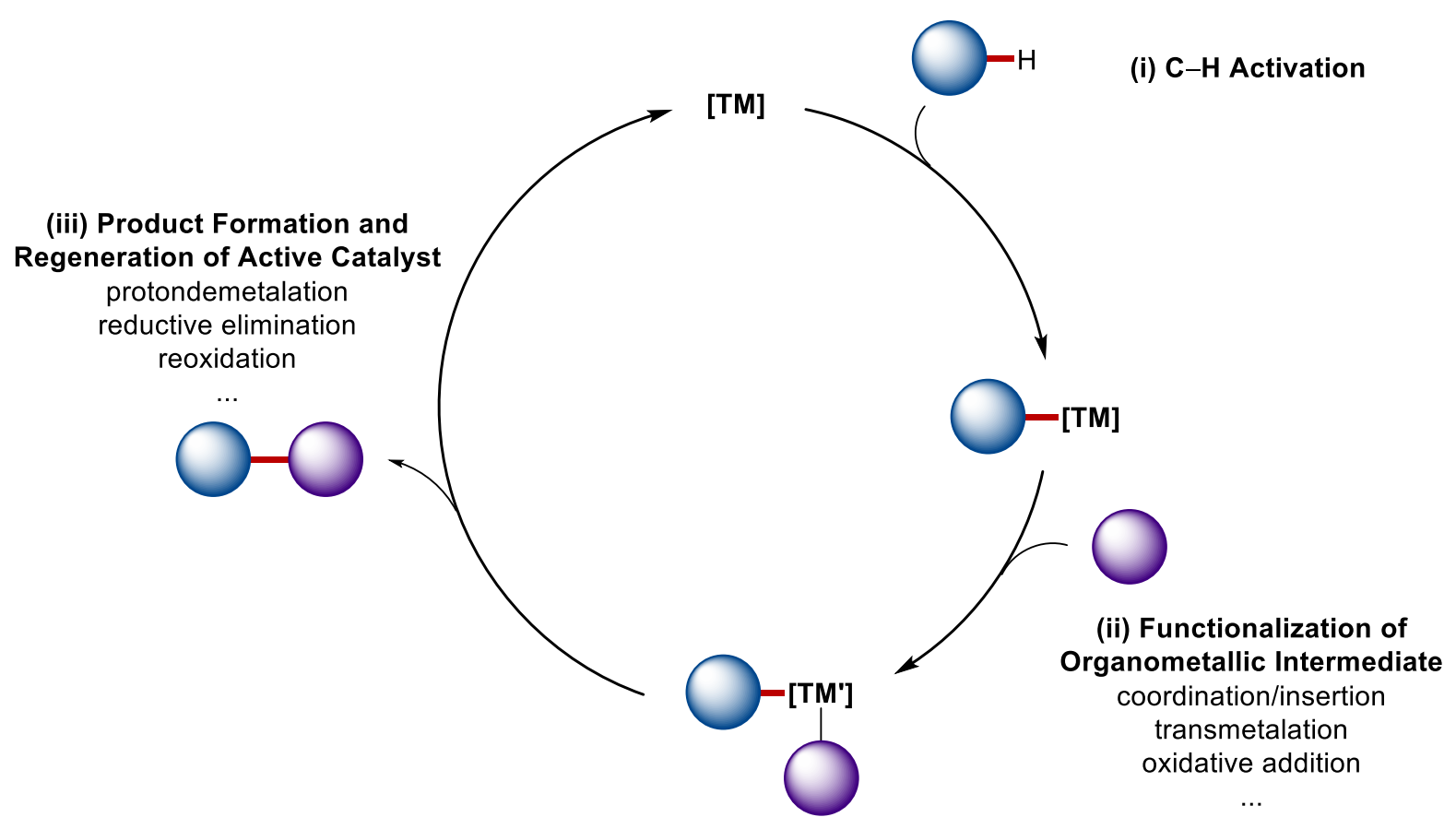

Scheme 1.1.4 General catalytic pathways for transition metal-catalyzed C-H activation reactions.

In the following chapters, $\mathrm{C}-\mathrm{H}$ activation reactions using representative metals, including ruthenium, osmium, manganese, and copper are described. Beyond homogeneous realm, recyclable hybrid metalcatalyzed $\mathrm{C}-\mathrm{H}$ activation approach will be presented. 


\subsection{Ruthenium-Catalyzed C-H Activation}

Transition metal-catalyzed $\mathrm{C}-\mathrm{H}$ functionalization has gained enormous attention with precious $4 \mathrm{~d}$ and $5 \mathrm{~d}$ metal catalysis, such as rhodium, ${ }^{[25]}$ palladium, ${ }^{[26]}$ and iridium, ${ }^{[27]}$ providing the direct transformation from omnipresent $\mathrm{C}-\mathrm{H}$ bonds to new $\mathrm{C}-\mathrm{C}$ or $\mathrm{C}-\mathrm{Het}$ bonds. In sharp contrast, ruthenium has recently come into the spotlight due to its cost-effectiveness and unique selectivities and reactivities. ${ }^{[28]}$ The first example of the stoichiometric $\mathrm{C}-\mathrm{H}$ activation with ruthenium complex was reported by Chatt and Davidson, with sodium naphthalene salts by in-situ generated ruthenium(0) complex, which was in equilibrium between 3 and $\mathbf{4}$ (Scheme 1.2.1). ${ }^{[29]}$
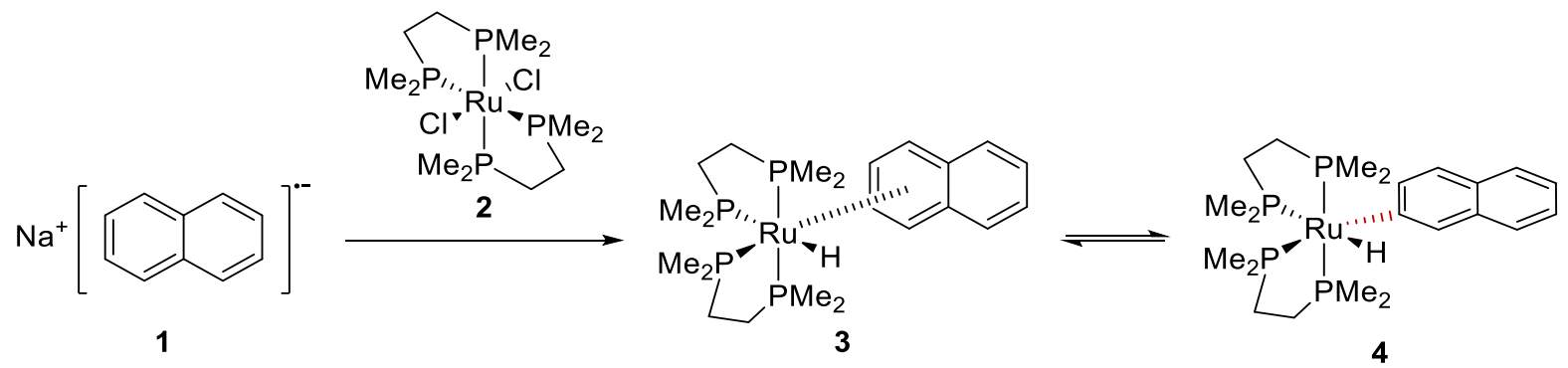

Scheme 1.2.1 Ruthenium-mediated C-H functionalization.

The first ruthenium-catalyzed C-H activation was arguably reported by Lewis and Smith in 1986 (Scheme 1.2.2). ${ }^{[30]}$ In this study, the ortho-position of phenol 5 was functionalized with ethylene gas 6, affording mono-alkylated 8 and di-alkylated phenol 9 with the aid of phosphites as transient directing group.

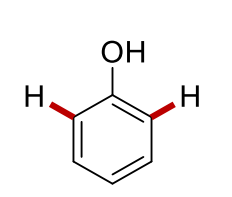

5

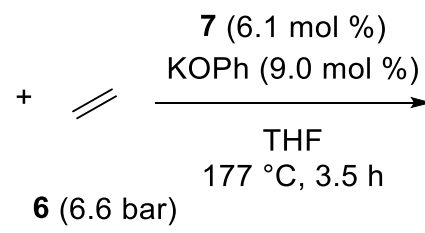

6 (6.6 bar)

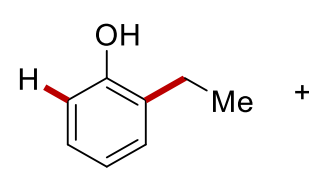

8

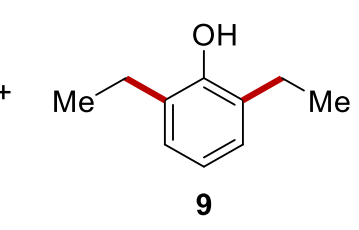

9

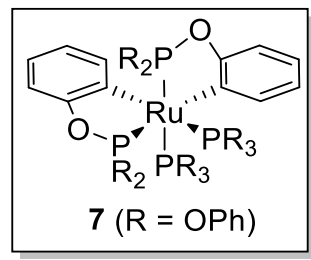

Scheme 1.2.2 The first catalytic $\mathrm{C}-\mathrm{H}$ activation with the ruthenium complex.

In 1993, Kakiuchi and Murai showed ruthenium-catalyzed C-H hydroarylations with aromatic ketones

10 and alkenes 11 (Scheme 1.2.3). ${ }^{[31]}$ With the aid of weak $O$-coordination, the $\mathrm{C}-\mathrm{H}$ bond cleavage 
occurred via a five-membered ruthenacycle formation, which was later rationalized by DFT studies from the Morokuma group. ${ }^{[32]}$ This achievement was key to enable other researchers to develop related ruthenium-catalyzed $\mathrm{C}-\mathrm{H}$ activations.<smiles>[R]C(=O)c1ccccc1</smiles>

10

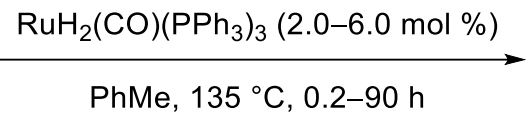

11<smiles>[R]CCc1ccccc1C([R])=O</smiles>

12

Scheme 1.2.3 Ruthenium-catalyzed direct $\mathrm{C}-\mathrm{H}$ hydroarylation.

Inspired by base-assisted metalation manifold by Shaw $^{[33]}$ and Davies, ${ }^{[34]}$ Ackermann ${ }^{[23,20 a]}$ demonstrated a significant advance in ruthenium catalysis, in which carboxylate assistance played the key role in the $\mathrm{C}-\mathrm{H}$ activation process (Scheme 1.2.4). ${ }^{[35]}$ Importantly, the mechanistic rationale of the carboxylate-assisted ruthenium-catalyzed $\mathrm{C}-\mathrm{H}$ activation was suggested to proceed via a sixmembered transition state. ${ }^{[36 a, 21 b, 36 b]}$<smiles>COc1ccc(Br)cc1</smiles>

13

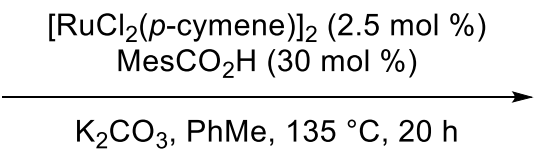

${ }^{\circ} \mathrm{C}, 20 \mathrm{~h}$

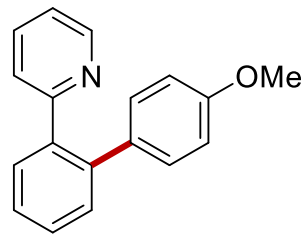

15

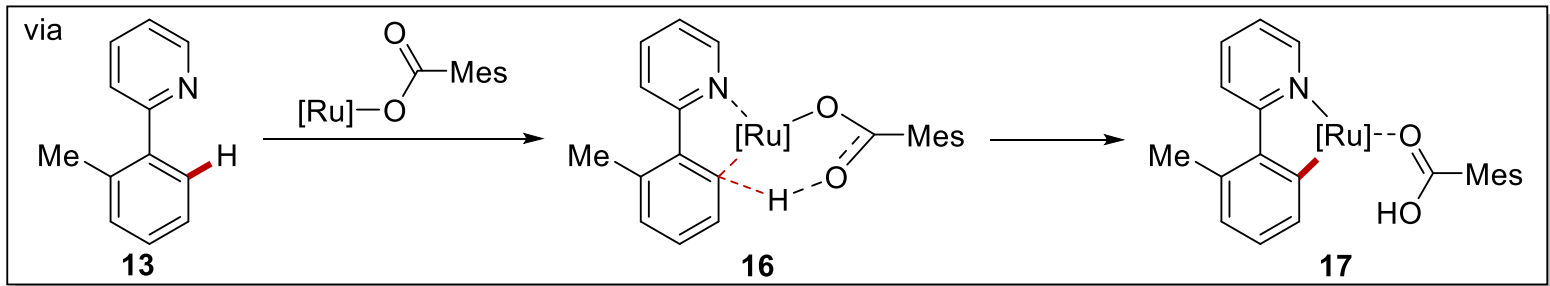

Scheme 1.2.4 Base-assisted ruthenium-catalyzed C-H activation.

While the thus established ruthenium(II)-catalysis has enabled various types of $\mathrm{C}-\mathrm{H}$ activation reactions, ${ }^{[17]} \mathrm{C}-\mathrm{N}$ formation and distal $\mathrm{C}-\mathrm{C}$ formation reactions are to be covered in the following chapters. 


\subsubsection{Ruthenium-Catalyzed C-N Formation}

Carbon-nitrogen bonds are prevalent in a plethora of pharmaceuticals, natural products, and biologically active compounds. ${ }^{[37]}$ For this reason, there is a strong demand to achieve sustainable and selective $\mathrm{C}-\mathrm{N}$ bond formation reactions. Among the conventional approaches toward $\mathrm{C}-\mathrm{N}$ bond formations, copper-catalyzed Goldberg-Ullmann amination reactions ${ }^{[14 a, 38 a, 14 b, 38 b]}$ and palladiumcatalyzed Buchwald-Hartwig amination reactions ${ }^{[39]}$ have been utilized, giving synthetic chemists a facile method for a broad range of aryl amines (Scheme 1.2.5).

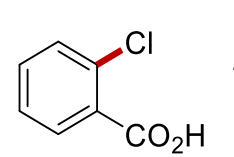

18<smiles>O=C(O)c1ccccc1Br</smiles>

21<smiles>Brc1ccccc1</smiles>

22<smiles>Nc1ccccc1</smiles>

19<smiles>Nc1ccccc1</smiles>

19

$$
\begin{gathered}
R^{1} \\
\text { IN }{ }_{-R^{2}}
\end{gathered}
$$

23

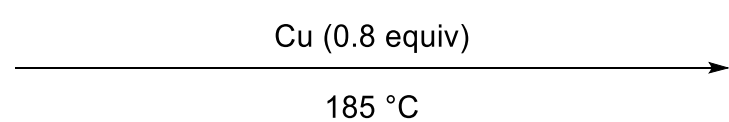

$185^{\circ} \mathrm{C}$

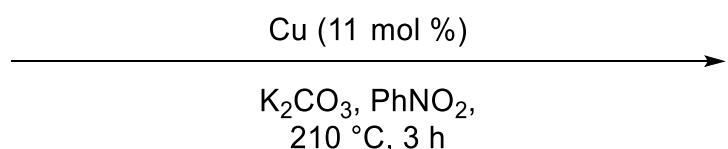

$210^{\circ} \mathrm{C}, 3 \mathrm{~h}$

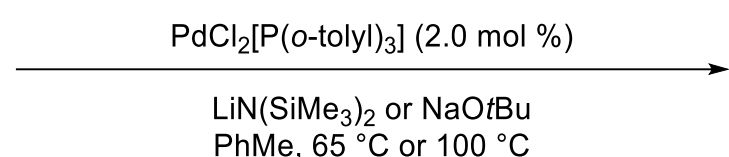

PhMe, $65^{\circ} \mathrm{C}$ or $100^{\circ} \mathrm{C}$<smiles>O=C(O)c1ccccc1Nc1ccccc1</smiles>

20: $60 \%$<smiles>O=C(O)c1ccccc1Nc1ccccc1</smiles>

20: $99 \%$<smiles>[R]N([R])c1ccccc1</smiles>

24

Scheme 1.2.5 Copper and palladium-catalyzed aminations.

Although these aminations provided easy access to $\mathrm{C}-\mathrm{N}$ bond formations, such approaches have highly relied on the pre-functionaliztion of substrates, producing inherently stoichiometric amounts of byproducts. In stark contrast, the transition metal-catalyzed $\mathrm{C}-\mathrm{H}$ activation approach was able to overcome the limitation, thereby offering synthetic and economic efficiency. The initial contributions for $\mathrm{C}-\mathrm{H}$ aminations had mainly been achieved by precious metals, such as rhodium, ${ }^{[40]}$ palladium, ${ }^{[41]}$ and iridium. ${ }^{[42]}$ Thereby, the motivation of the search for inexpensive, but active metal catalysts to utilizing ruthenium complexes for $\mathrm{C}-\mathrm{N}$ bond formations.

Ruthenium-catalyzed $\mathrm{C}-\mathrm{H}$ amination reactions can be categorized by three realms (Scheme 1.2.6). The inner-sphere mechanism is generally involved in the formation of organometallic intermediate 
including Metal- $\mathrm{C}$ bond and thus generated ruthenacycle complexes is subsequently engaged in $\mathrm{C}-\mathrm{N}$ bond forming process. The outer-sphere mechanism ${ }^{[43]}$ commonly represents $\mathrm{C}-\mathrm{H}$ insertion catalysis, in which ruthenium-nitrenoid species react with a coupling partner, resulting in $\mathrm{C}-\mathrm{H}$ aminations. The third approach is to utilize ruthenium-based photoredox catalysis via a single electron transfer process, in which the organoradical species indirectly generated upon irradiation interacts with a substrate, thus giving amidated products.

a) Inner-sphere $\mathrm{C}-\mathrm{H}$ activation<smiles>C1=CCCCCC1</smiles>
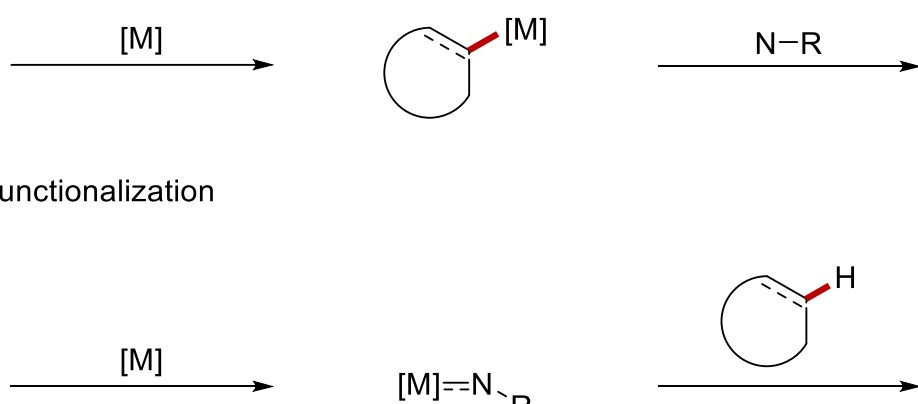

$[\mathrm{M}]=-\mathrm{N}_{-\mathrm{R}}$
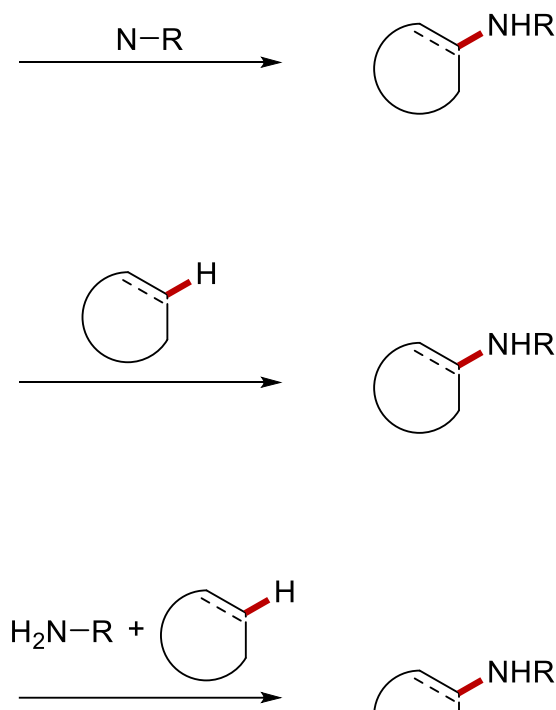

b) Outer-sphere $\mathrm{C}-\mathrm{H}$ functionalization

$$
N-R
$$

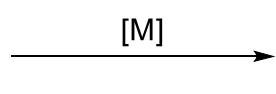

c) Single electron transfer mechanism

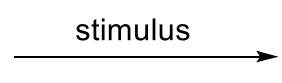

$\left[M^{n \pm 1}\right]$

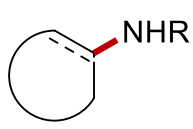

Scheme 1.2.6 Different modes of $\mathrm{C}-\mathrm{N}$ formations.

Notably, in a general scenario of amination reactions, $\mathrm{C}\left(\mathrm{sp}^{2}\right)-\mathrm{H}(\sim 113 \mathrm{kcal} / \mathrm{mol})$ and $\mathrm{N}-\mathrm{H}(\sim 108$ $\mathrm{kcal} / \mathrm{mol})$ bonds are transformed to new $\mathrm{C}-\mathrm{N}(\sim 103 \mathrm{kcal} / \mathrm{mol})$ and $\mathrm{H}-\mathrm{H}(\sim 104 \mathrm{kcal} / \mathrm{mol})$ bonds, which is thermodynamically uphill process. ${ }^{[44]}$ Therefore, a selection of reaction components is the key to success for the amination reactions.

In 2013, Ackermann and co-workers successfully showed $\mathrm{C}-\mathrm{H}$ amidations of arenes with tosyl azide 26 as an amidating reagent (Scheme 1.2.7). ${ }^{[45]}$ With the aid of pyrazole directing groups, ortho $\mathrm{C}-\mathrm{H}$ bonds of arenes 25 could be selectively functionalized. Detailed mechanistic studies revealed that electrophilic-type ruthenation was likely operative and the $\mathrm{C}-\mathrm{H}$ scission process was reversible. Based on their mechanistic studies, the catalytic cycle was proposed. Thus, ruthenium cation species $\mathbf{3 0}$ is $\mathrm{in}$ situ generated, which enables to form five-membered ruthenacycle $\mathbf{3 1}$. Thereafter, tosyl azide $\mathbf{2 6}$ is 
coordinated to the ruthenium center. Insertion followed by protodemetallation affords the amidated product 27 and regenerates the active catalyst $\mathbf{3 0}$.<smiles>c1ccc(-n2cccn2)cc1</smiles>

25

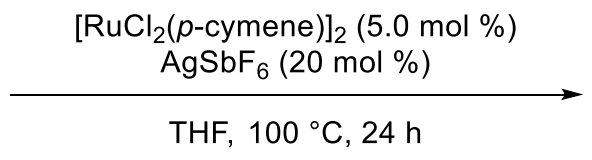

26

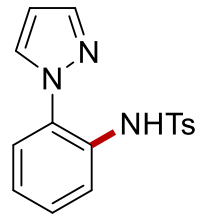

27

a) competition experiment<smiles>Cc1ccc(-n2cccn2)c([18F])c1</smiles>

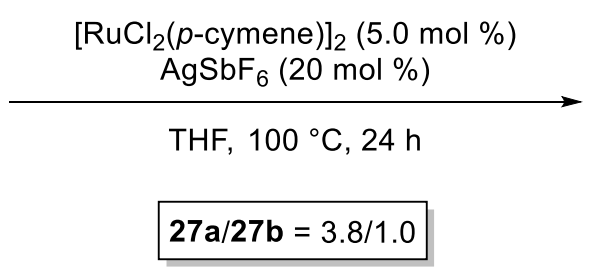<smiles>Cc1ccc(-n2cccn2)c(NS(=O)(=O)c2ccccc2)c1</smiles>

27a

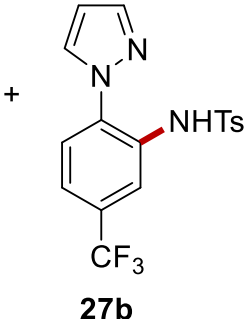

27b

b) KIE experiment<smiles>Oc1ccc([18O])cc1-c1ccccn1</smiles>

$[\mathrm{D}]_{5}-\mathbf{2 8}$

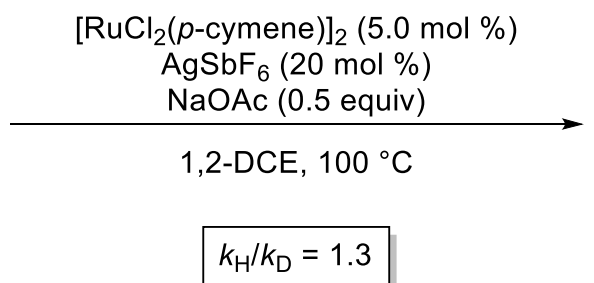
$\mathrm{AgSbF}_{6}(20 \mathrm{~mol} \%)$ $\mathrm{NaOAc}$ ( 0.5 equiv)

$$
k_{\mathrm{H}} / k_{\mathrm{D}}=1.3
$$

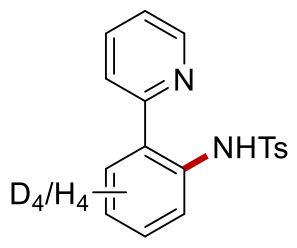

$[D]_{4}-29$

c) Proposed mechanism

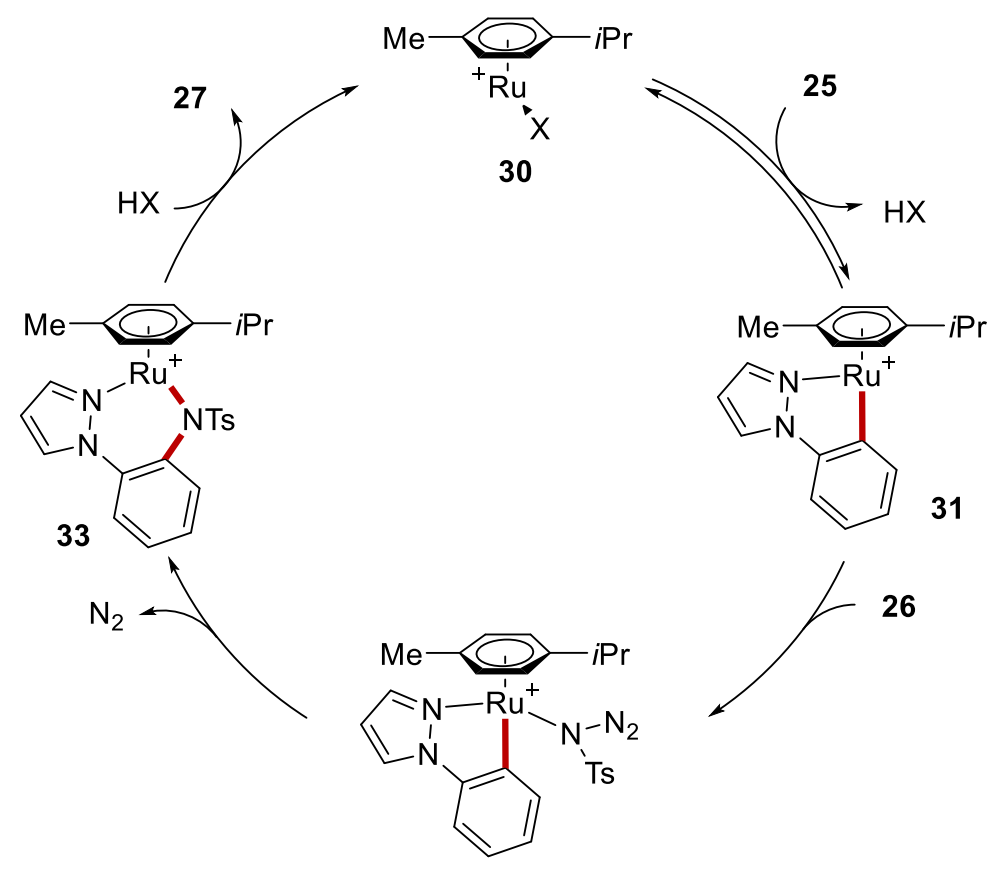

32

Scheme 1.2.7 C-H amidation of arenes 25 with tosyl azide $\mathbf{2 6}$. 
Using a strong directing group strategy, Ding ${ }^{[46]}$ and Chen ${ }^{[47]}$ independently reported $\mathrm{C}-\mathrm{H}$ amidation, in which benzothiazoles and triazole directing groups were employed although one ortho- or metaposition was required to be sterically blocked to inhibit difunctionalizations of the arenes $\mathbf{3 4}$ or $\mathbf{3 6}$ (Scheme 1.2.8).

a) Ding (2014)

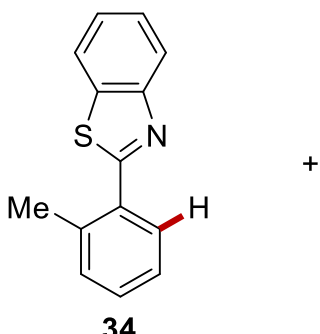

34
$\mathrm{TsN}_{3}$

26

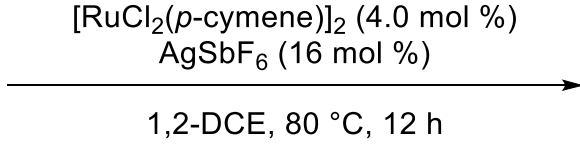

$\left[\mathrm{RuCl}_{2}(p \text {-cymene })\right]_{2}(5.0 \mathrm{~mol} \%)$ $\mathrm{AgSbF}_{6}(20 \mathrm{~mol} \%)$<smiles>Cc1cccc(-n2nccn2)c1</smiles>

$\mathrm{TsN}_{3}$

26

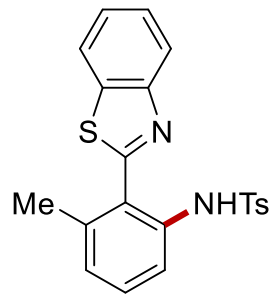

35

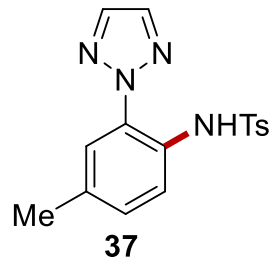

Scheme 1.2.8 C-N bond formation using strong $N$-directing groups.

Instead of strongly coordinating directing groups, weak coordination also allowed for efficient $\mathrm{C}-\mathrm{H}$ amination reactions. In 2013, Chang and co-workers showed that amide or ketone based substrates were effective for the $\mathrm{C}\left(\mathrm{sp}^{2}\right)-\mathrm{H}$ amidations (Scheme 1.2.9). ${ }^{[48]}$<smiles>[R]C(=O)c1ccccc1</smiles>

38<smiles>CCCCNC(=O)c1ccccc1NCCCC</smiles>

39a: $89 \%$

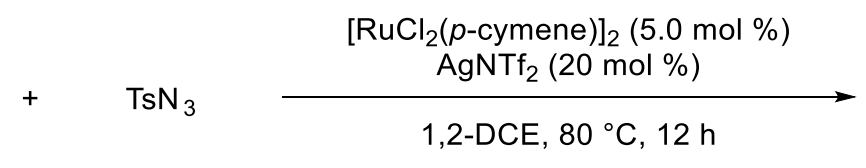

26<smiles>CC(C)Nc1ccccc1C(=O)Nc1ccccc1</smiles>

39b: $61 \%$<smiles>CCCCNc1ccccc1C(=O)C(C)(C)C</smiles>

39c: $81 \%$ (with $\mathrm{NaOAc}$ )<smiles>O=C(Cl)c1ccccc1N[Sn]</smiles>

39d: $87 \%$ (with $\mathrm{NaOAc}$ )<smiles>[R]C(=O)c1ccccc1N[13F]</smiles>

39<smiles>O=C(c1ccccc1)c1ccccc1NC(F)(F)F</smiles>

39e: $52 \%$ (with $\mathrm{NaOAc}$ )

Scheme 1.2.9 $\mathrm{C}-\mathrm{H}$ amidations by weak $O$-coordination. 
Similar to the approach presented by Chang, Jiao also reported $\mathrm{C}-\mathrm{H}$ amidations of the aromatic ketone 40, in which a catalytic amount of copper acetate was used as addition to in-situ form a ruthenium(II)carboxylate complex (Scheme 1.2.10). ${ }^{[49]}$
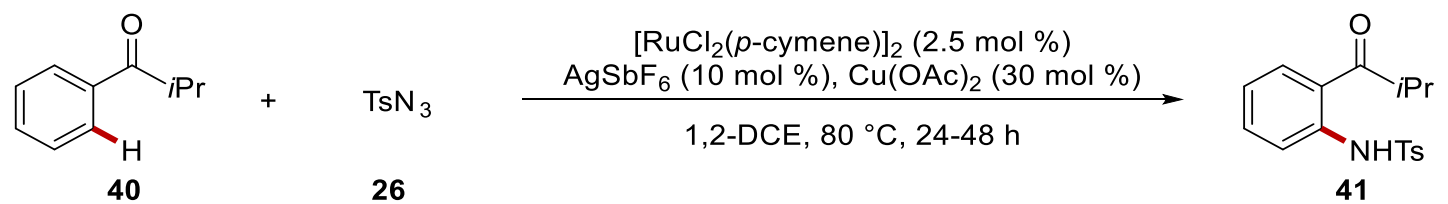

Scheme 1.2.10 Ketones as a directing group for ruthenium-catalyzed $\mathrm{C}-\mathrm{N}$ bond formation.

In 2014, Kim disclosed ruthenium-catalyzed C-H amidations of xanthones $\mathbf{4 2}$, which enabled to access mono-amidated xanthones 43 as a sole product (Scheme 1.2.11). ${ }^{[50]}$ Notably, the thus synthesized nitrogenated products were screened for growth inhibition activity against human breast cancer MCF7 cells.<smiles>O=c1c2ccccc2oc2ccccc12</smiles>

42
$\left[\mathrm{RuCl}_{2}(p \text {-cymene })\right]_{2}(5.0 \mathrm{~mol} \%)$ $\underset{\mathrm{AgSbF}_{6}(20 \mathrm{~mol} \%), \mathrm{CuOAc}(30 \mathrm{~mol} \%)}{\mathrm{CH}_{2} \mathrm{Cl}_{2}, 100^{\circ} \mathrm{C}, 15 \mathrm{~h}}$<smiles>O=c1c2ccccc2oc2cccc([AsH3])c12</smiles>

43

Scheme 1.2.11 Ruthenium-catalyzed $\mathrm{C}-\mathrm{H}$ amidation of xanthones $\mathbf{4 2}$.

At the same time, Zhu reported ruthenium-catalyzed $\mathrm{C} 7-\mathrm{H}$ amidation of indolines $\mathbf{4 4}$ through the installation of a ketone directing group (Scheme 1.2.12). ${ }^{[51]}$ Here, six-membered metallacycles were presumably formed, enabling direct access toward C7 indoline functionalizations.<smiles>CC(=O)N1CCc2ccccc21</smiles>

44

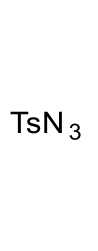

26<smiles>CC(=O)N1CCc2cccc(NC3CCCCC3)c21</smiles>

45

Scheme 1.2.12 Ruthenium-catalyzed $\mathrm{C} 7-\mathrm{N}$ bond formation of indoline 44 . 
Interestingly, Sahoo used sufoximine directing group strategy which had been commonly used for rhodium catalysis (Scheme 1.2.13). ${ }^{[52]}$ Particularly, the reported method was used for the synthesis of a potent medication, namely Ataciguat, which had been studied for calcific aortic valve stenosis. ${ }^{[53]}$

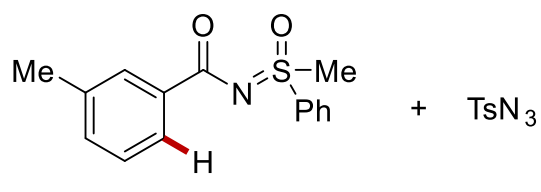

45

26

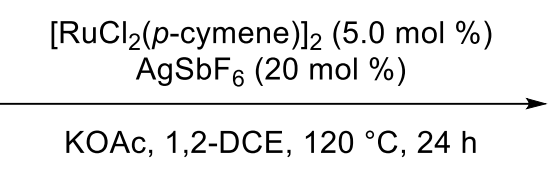

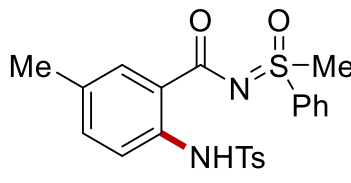

46

a) Synthesis of Ataciguat (HMR 1766)<smiles>[M]S(=O)(=NC(=O)c1cccc(Cl)c1)c1ccccc1</smiles>

47<smiles>O=S(=O)(O[Na])c1ccc(Cl)s1</smiles>

48

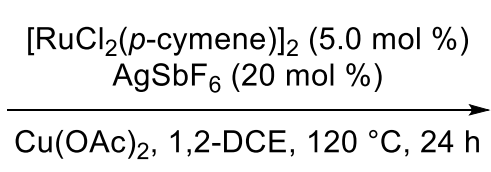

$\mathrm{Cu}(\mathrm{OAc})_{2}, 1,2-\mathrm{DCE}, 120^{\circ} \mathrm{C}, 24 \mathrm{~h}$<smiles>Cc1ccc(NS(=O)(=O)c2ccc(Cl)s2)c(C(=O)N=S(C)(=O)c2ccccc2)c1</smiles>

49: $41 \%$ $\mathrm{NaOH}$ $\mathrm{MeOH} / \mathrm{H}_{2} \mathrm{O}$ $60^{\circ} \mathrm{C}, 6 \mathrm{~h}$<smiles>COc1ccc(NS(=O)(=O)c2ccc(Cl)s2)c(C(=O)Nc2ccc(S(=O)(=O)N3CCOCC3)cc2)c1</smiles>

Ataciguat 52: $60 \%$

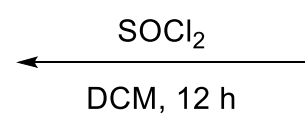

Scheme 1.2.13 Sulfoximine directing group approach for $\mathrm{C}-\mathrm{H}$ amidation and its use for natural product synthesis.

Other organic azides and hydroxylamines were also viable for ruthenium-catalyzed amidations. Chang thus showed the use of acyl azides $\mathbf{5 3}$ as an aminating reagent for ruthenium-catalyzed amidation reactions (Scheme 1.2.14). ${ }^{[54]}$ Although benzoyl azides 53 are prone to undergo Curtius rearrangement, mechanistic studies revealed that facile $\mathrm{C}-\mathrm{H}$ ruthenations enabled the direct amidation. 


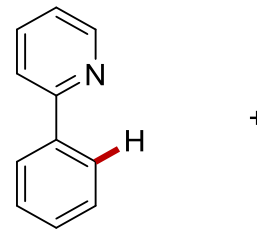

28<smiles>NC(=O)c1ccccc1</smiles>

53<smiles>O=C(Nc1ccccc1-c1ccccn1)c1ccccc1</smiles>

54

Scheme 1.2.14 C-H amidations with acyl azides 53 .

Additionally, the Yu group used $O$-benzoylhydroxylamines 56 as an amine source, providing ortho$\mathrm{C}-\mathrm{H}$ aminations of benzamides 55 under mild conditions at room temperature (Scheme 1.2.15). ${ }^{[5]}$<smiles>Cc1ccccc1C(=O)Nc1c(F)c(F)c(C(F)(F)F)c(F)c1F</smiles>

55<smiles>O=C(OCc1ccccc1)N1CCOCC1</smiles>

56

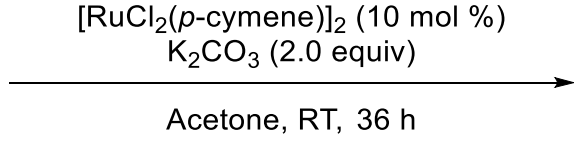

Scheme 1.2.15 $\mathrm{C}-\mathrm{H}$ amidations through $\mathrm{N}-\mathrm{O}$ bond cleavage.

Ackermann showed ruthenium(II)carboxylate-catalyzed C-H imidations with $(N-\mathrm{OTs})$ phthalimide $\mathbf{5 8}$ as the amination source (Scheme 1.2.16). ${ }^{[56]}$ Notable, a wide range of substrates was presented. A simple additional step allowed for easy access to aminophenones $\mathbf{6 0}$. The catalytic cycle has been also proposed, in which an in-situ generated the cationic ruthenium(II)carboxylate catalyst $\mathbf{6 1}$ forms cyclometalated intermediate $\mathbf{6 2}$. The subsequent imidating reagent coordinates followed by the $\mathrm{N}-\mathrm{O}$ cleavage to deliver the cationic complex 64. Lastly, the active ruthenium catalyst 61 is regenerated while liberating the desired product $\mathbf{5 9}$. 


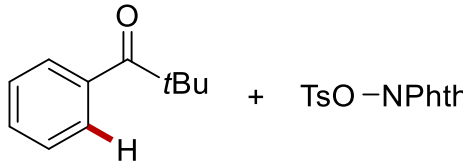

$38 \mathrm{c}$
$\left[\mathrm{RuCl}_{2}(p \text {-cymene })\right]_{2}(5.0 \mathrm{~mol} \%)$ $\mathrm{AgSbF}_{6}(20 \mathrm{~mol} \%), \mathrm{Cu}(\mathrm{OAc})_{2} \cdot \mathrm{H}_{2} \mathrm{O}(50 \mathrm{~mol} \%)$

1,4-dioxane, $100^{\circ} \mathrm{C}, 24 \mathrm{~h}$<smiles>CC(C)(C)C(=O)c1ccccc1Nc1ccccc1</smiles>

59

a) Selected examples<smiles>CC(C)(C)C(=O)c1ccccc1Nc1ccccc1</smiles>

59a: $78 \%$<smiles>CC(C)(C)C(=O)c1ccc(I)cc1Nc1ccccc1</smiles>

59b: $53 \%$<smiles>CC(C)(C)C(=O)c1cc(F)ccc1N=P</smiles>

59c: $54 \%$<smiles>CC(C)(C)C(=O)c1c(N=P)ccc2ccccc12</smiles>

59d: $56 \%$<smiles>CC(C)(C)C(=O)c1ccsc1Nc1ccccc1</smiles>

59e: $59 \%$

b) Facile access to primary aminophenones $\mathbf{6 0}$

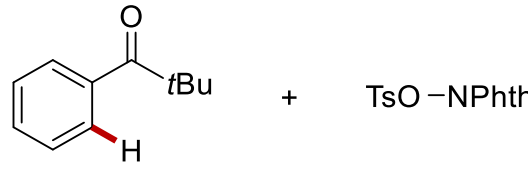

$38 \mathrm{c}$

58

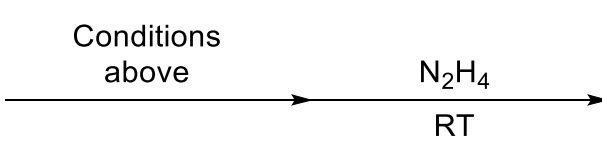<smiles>CC(C)(C)C(=O)c1ccccc1N</smiles>

60: $69 \%$

c) Proposed mechanism

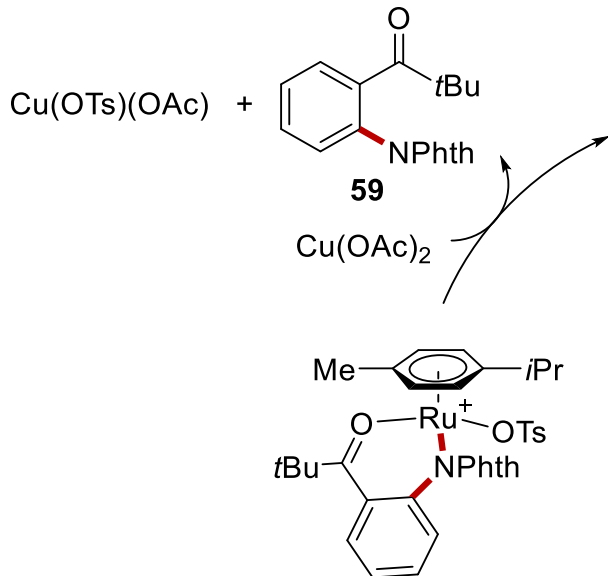

64

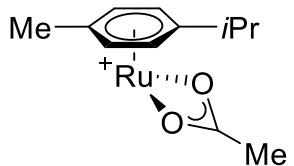

61<smiles>C=C(C)C(=O)O</smiles><smiles>Cc1ccc(C(C)C)c(Br)c1C(=O)Oc1ccccc1C(C)(C)C</smiles>

62

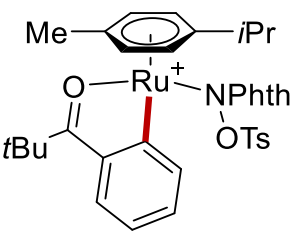

63

Scheme 1.2.16 Ruthenium-catalyzed $\mathrm{C}-\mathrm{H}$ amidation of arenes 38c with $(N-\mathrm{OTs})$ phthalimide 58. 
As the second manifold of $\mathrm{C}-\mathrm{H}$ amination, various ruthenium-nitrenoid formation strategies were employed. In 1997, Che $\mathrm{e}^{[57]}$ and co-workers showed that stoichiometric use of bis(tosyl)imidoruthenium(VI) porphyrin complex 62 enabled amino group transfer, which was later highlighted by detailed mechanistic studies as well as by the scope of aziridinations and $\mathrm{C}-\mathrm{H}$ amidations (Scheme 1.2.17)..$^{[58]}$

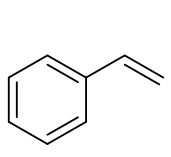

61<smiles>CCc1ccccc1</smiles>

64

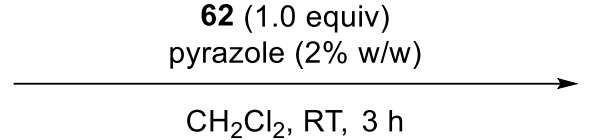

$\mathrm{CH}_{2} \mathrm{Cl}_{2}, \mathrm{RT}, 3 \mathrm{~h}$

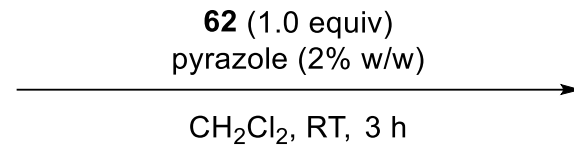

$\mathrm{CH}_{2} \mathrm{Cl}_{2}, \mathrm{RT}, 3 \mathrm{~h}$

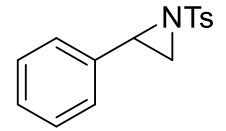

63: $75 \%$<smiles>CC(N)c1ccccc1</smiles>

65: $78 \%$

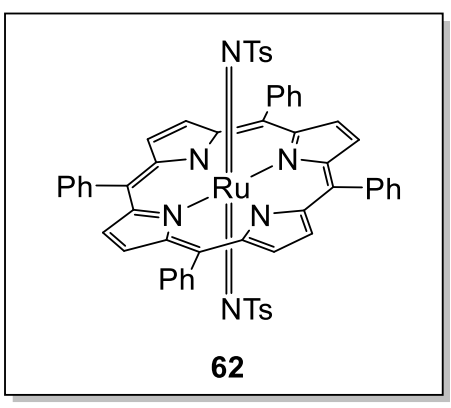

62

Scheme 1.2.17 Stoichiometric C-N bond formation with ruthenium-porphyrin complex 62.

Two years later, Che reported the ruthenium(II) porphyrin-catalyzed $\mathrm{C}-\mathrm{H}$ amidations with exceptionally high turnovers (Scheme 1.2.18). ${ }^{[59]}$ The combination of PIDA and tosylamide 67 or the direct use of $\mathrm{N}$-tosyliminobenzyliodinane $\mathbf{6 8}$ enabled a broad range of $\mathrm{C}-\mathrm{H}$ bond formations.<smiles>[CH2]Cc1ccccc1</smiles>

64

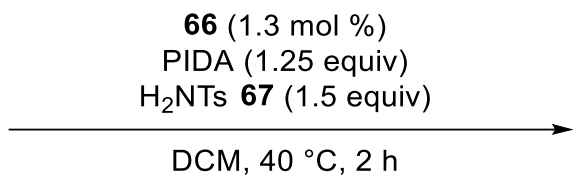
with $\mathrm{Phl}=\mathrm{NTs}$ 68, 65: $86 \%$ (instead of PIDA and $\mathrm{H}_{2} \mathrm{NTs} 67$ )

65: $81 \%$

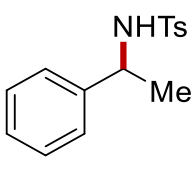

Scheme 1.2.18 Ruthenium-catalyzed $\mathrm{C}-\mathrm{N}$ bond formation.

Around the same time, the same research group disclosed asymmetric $\mathrm{C}-\mathrm{N}$ bond formations catalyzed by chiral ruthenium complex 69 (Scheme 1.2.19). ${ }^{[60]}$ While the dimethanoanthracene-based porphyrin macrocycle induced relatively low enantioselectivity ( $6 \%$ ee to $48 \% e e$ ), the stoichiometric use of bis(tosyl)imidoruthenium species enabled slightly increased yield and entiomeric excess. 
<smiles>[O-][N+]c1ccccc1</smiles>

64

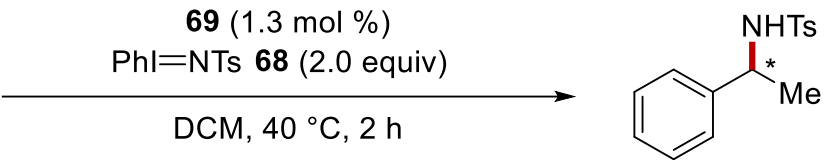

65

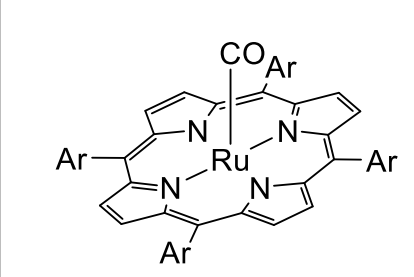

69

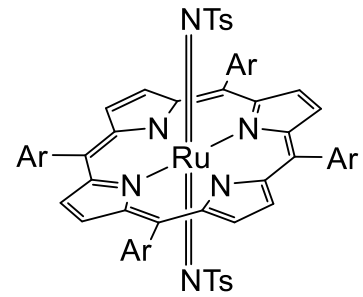

70<smiles></smiles>

65

with 69: $23 \%, 43 \%$ ee with 70 : $54 \%, 43 \%$ ee<smiles>COc1ccc(C(=[W])N[Sb])cc1</smiles>

$65 a$

with 69: $45 \%, 33 \%$ ee with $70: 68 \%, 33 \%$ ee<smiles>[AsH3-][C@@H]1Cc2ccccc21</smiles>

65b

with $69: 28 \%, 6 \%$ ee with $70: 70 \%, 15 \%$ ee<smiles>CC(=[NH2+])c1ccc2ccccc2c1</smiles>

$65 \mathrm{c}$

with 69: $45 \%, 48 \%$ ee with $70: 78 \%, 58 \% \mathrm{ee}^{a}$

a Stoichiometric reactions with $\mathbf{7 0}$ in absence of $\mathbf{6 9}$.

Scheme 1.2.19 Enantioselective ruthenium-catalyzed $\mathrm{C}-\mathrm{H}$ amidation.

In 2008, Group of Blakey reported enantioselective ruthenium-catalyzed $\mathrm{C}-\mathrm{H}$ amidations, in which the chiral pybox ligand was employed to construct cyclosulfamates under mild conditions (Scheme 1.2.20). ${ }^{[61]}$ In the presence of hypervalent iodine oxidant, the benzylic $\mathrm{C}-\mathrm{H}$ bond was selectively transformed to a new $\mathrm{C}-\mathrm{N}$ bond, while a five-membered sulfamate was not observed.<smiles>NS(=O)(=O)OCCC([Tl])c1ccccc1</smiles>

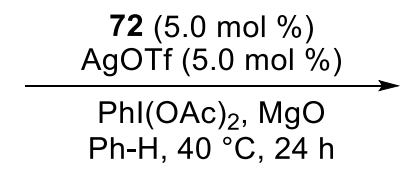

$\mathrm{Ph}-\mathrm{H}, 40^{\circ} \mathrm{C}, 24 \mathrm{~h}$ 71<smiles>O=S1(=O)NC(c2ccccc2)=CCO1</smiles>

73: $84 \%, 84 \%$ ee

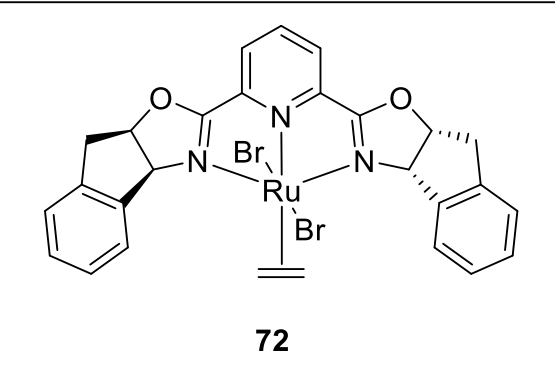

Scheme 1.2.20 Enantioselective cyclosulfamate synthesis by ruthenium-pybox catalyst 72 . 
The next year, Gallo and co-workers revealed $\mathrm{C}\left(\mathrm{sp}^{3}\right)-\mathrm{H}$ amidations at the vinyl position with aryl azides 75 (Scheme 1.2.21). ${ }^{[62]}$ Notably, the isolated stable ruthenium(IV) intermediate $\mathbf{7 8}$ allowed for detailed mechanistic investigation by means of spectrometric analyses. Later, independent DFT studies showed two possible mechanisms, in which a pathway through monoimido $\mathrm{Ru}(\mathrm{IV})$ species formation cannot be ruled out. ${ }^{[63]}$

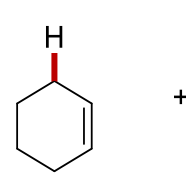

74

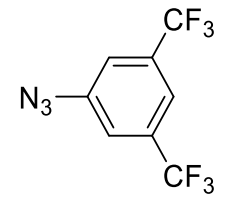

75

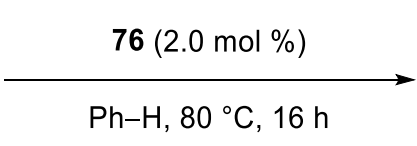

$\mathrm{Ph}-\mathrm{H}, 80^{\circ} \mathrm{C}, 16 \mathrm{~h}$

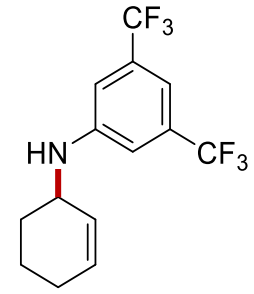

77: $75 \%$

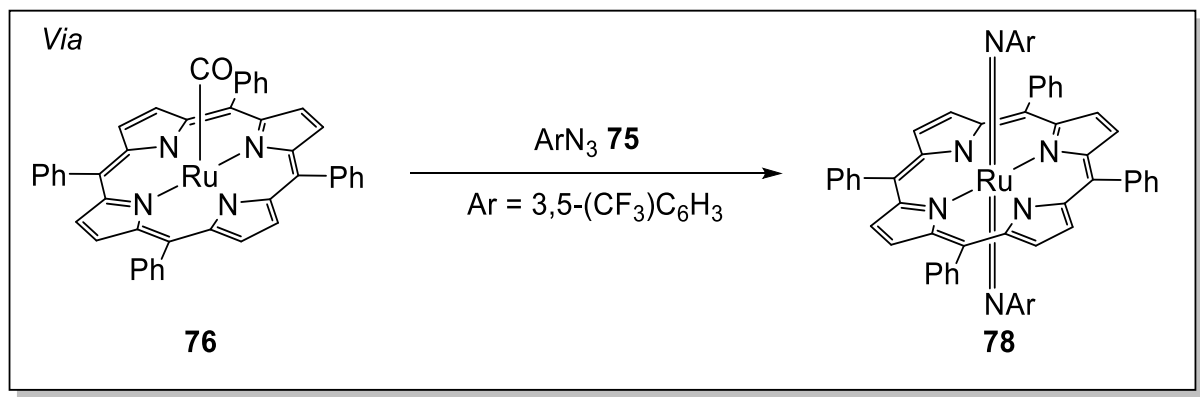

Scheme 1.2.21 Ruthenium-catalyzed $\mathrm{C}\left(\mathrm{sp}^{3}\right)-\mathrm{H}$ amination.

In 2011, Du Bois disclosed diruthenium(II/III)-catalyzed ring-closing allylic $\mathrm{C}-\mathrm{H}$ aminations (Scheme 1.2.22). ${ }^{[64]}$ Taking advantage of the mixed valent ruthenium complex $\mathbf{8 0}$, a one-electron oxidation could be achieved by catalytic atom-transfer process. Additionally, the selectivity toward $\mathrm{C}-\mathrm{H}$ insertion process over aziridination was analyzed by computational studies.<smiles>C/C=C/CCCOS(N)(=O)=O</smiles>

79

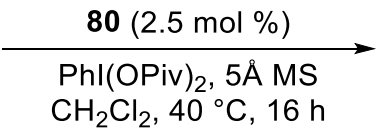

$\mathrm{CH}_{2} \mathrm{Cl}_{2}, 40^{\circ} \mathrm{C}, 16 \mathrm{~h}$<smiles>C/C=C/C1CCOS(=O)(=O)N1</smiles>

81: $60 \%$<smiles>CC1C2CCCOS(=O)(=O)N12</smiles>

82: $8 \%$

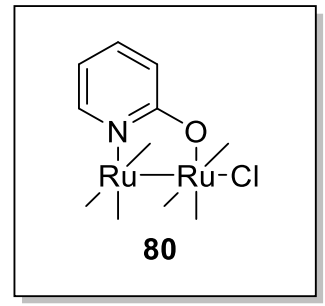

Scheme 1.2.22 Diruthenium complex-catalyzed intramolecular $\mathrm{C}-\mathrm{H}$ amidation. 
In 2013, Katsuki reported enantioselective intermolecular benzylic amidation using the salen-based chiral ruthenium(II) complex 84 (Scheme 1.2.23). ${ }^{[65]}$ Interestingly, an analogous iridium catalyst fell short in delivering the desired product.

$\overbrace{\mathrm{Me}}^{\mathrm{C}}+\mathrm{N}_{3}-\mathrm{SES}$

64

83

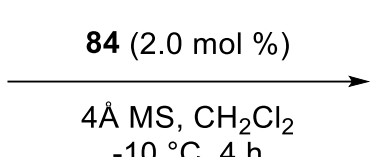

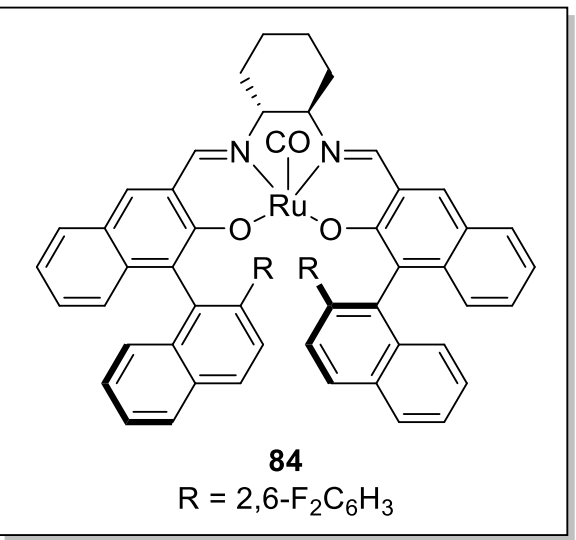

85: $77 \%, 96 \%$ ee

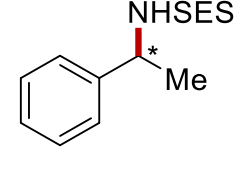

$$
\mathrm{R}=2,6-\mathrm{F}_{2} \mathrm{C}_{6} \mathrm{H}_{3}
$$

a) Analogous reaction with iridium complex $\mathbf{x x x}$

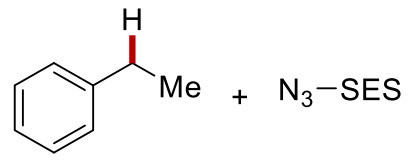

64

83

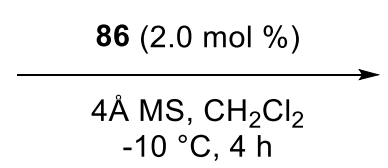<smiles>C=[SH](=S)NC(=[W])c1ccccc1</smiles>

85: $<1 \%$

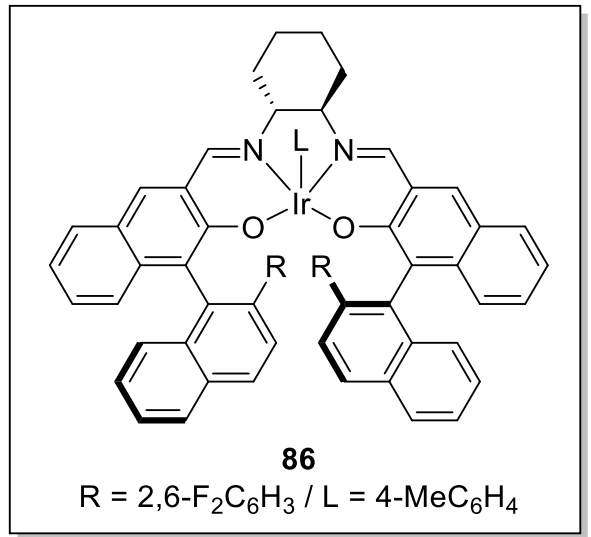

Scheme 1.2.23 Enantioselective C-H amidation with salen complexes 84 and 86 .

Recently, Meggers showed asymmetric intramolecular $\mathrm{C}-\mathrm{H}$ amination by a chiral-at-metal ruthenium complex, affording five-membered heterocycles with high enantioselectivity (Scheme 1.2.24). ${ }^{66]}$ Notably, high catalytic efficiency $(\mathrm{TON}=740)$ was also accomplished. Detailed mechanistic studies revealed that the concerted singlet ruthenium-nitrenoid insertion process is likely to be operative. 
<smiles>NCC(=O)N(Cc1ccccc1)c1ccccc1</smiles>

87

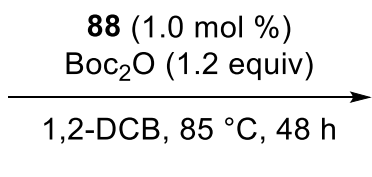

89: $80 \%, 91 \%$ ee

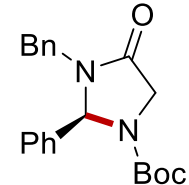

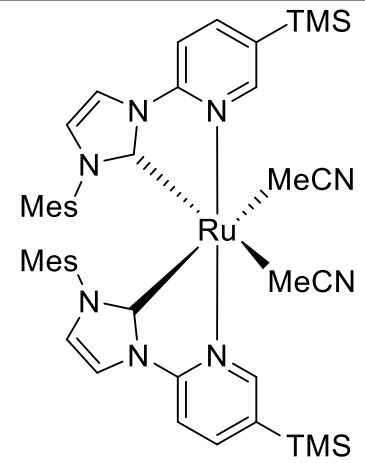

88 a) KIE study<smiles>[2H]C([2H])(c1ccccc1)N(Cc1ccccc1)C(=O)CN</smiles>

$[D]_{n}-87$

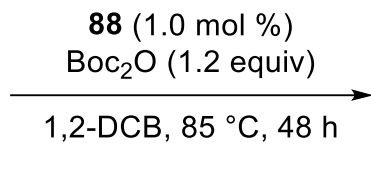

$[D]_{n}-89 a:[D]_{n}-89 b=1.5: 1$<smiles>[2H]C(C)(C)N1C(=O)CN(C([2H])([2H])c2ccccc2)[C@H]1c1ccccc1</smiles>

$[\mathrm{D}]_{\mathrm{n}}-89 \mathrm{a}$<smiles>[2H]C(C)(C)OC(=O)N1CC(=O)N(C(c2ccccc2)c2ccccc2)[C@H]1c1ccccc1</smiles>

$[D]_{n}-89 b$

Scheme 1.2.24 Enantioselective intramolecular $\mathrm{C}-\mathrm{N}$ bond formation.

Very recently, $\mathrm{Yu}$ and co-workers reported ruthenium-catalyzed enantioselective $\gamma$-lactam formation via intramolecular $\mathrm{C}-\mathrm{N}$ bond formation (Scheme 1.2 .25$).{ }^{[67]}$ The nitrene $\mathrm{C}-\mathrm{H}$ insertion process was enabled by a chiral diphenylethylene diamine-based ligands, which bear an electron-withdrawing arylsulfonyl substituent. Similar to Chang's report, ${ }^{[54]}$ the competing Curtius-type rearrangement was not observed.<smiles>O=c1onc(CCC(c2ccccc2)c2ccccc2)o1</smiles>

90
[RuCl 2 (p-cymene)L] $91(10 \mathrm{~mol} \%)$

DCE, $40{ }^{\circ} \mathrm{C}, 5 \mathrm{~h}$

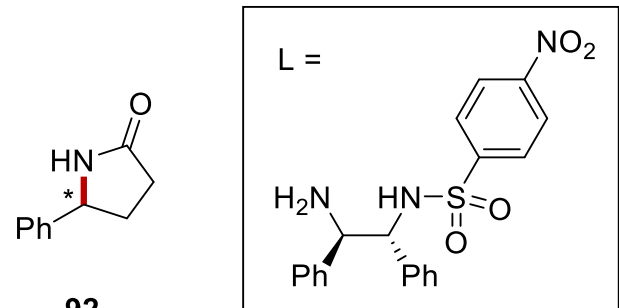<smiles>O=C1CCC(c2ccccc2)N1</smiles>

92a: $92 \%, 94 \%$ ee<smiles>O=C1CCC(c2ccc([N+](=O)[O-])cc2)N1</smiles>

92b: $80 \%, 98 \%$ ee<smiles>O=C1CC[C@H](c2ccc(Br)cc2)N1</smiles>

92c: $90 \%, 97 \%$ ee<smiles>O=C1CCC(C#Cc2ccccc2)N1</smiles>

92d: $90 \%, 41 \%$ ee<smiles>O=C1CC[C@@H](/C=C/c2ccccc2)N1</smiles>

92e: $67 \%, 81 \%$ ee

Scheme 1.2.25 Ruthenium-catalyzed enantioselective $\gamma$-lactam synthesis. 
As the last approach toward $\mathrm{C}-\mathrm{N}$ bond formation, single electron transfer manifold through photoredox catalysis has recently gained major attention due to its sustainability, even though it has been scarcely reported for amidation reactions.

In 2015, Studer showed visible-light-induced C-H amidation and imidation by using ruthenium-based photocatalyst 95 (Scheme 1.2.26). ${ }^{[68]} \mathrm{N}$-aminopyridinium salts were employed as an amidyl radical source 101 through a deaminative process, allowing divergent $\mathrm{C}-\mathrm{N}$ bond formations.<smiles>c1ccccc1</smiles>

93<smiles></smiles>

97<smiles>Cc1cc(C)[n+](N=P)c(C)c1</smiles>

94

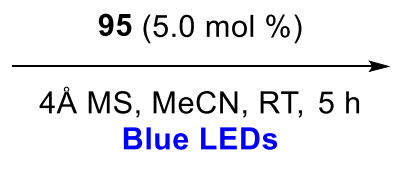

Blue LEDs<smiles>P=Nc1ccccc1</smiles>

96: $49 \%$

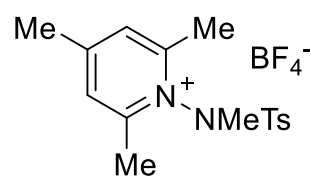

94

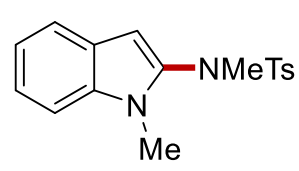

98: $56 \%$

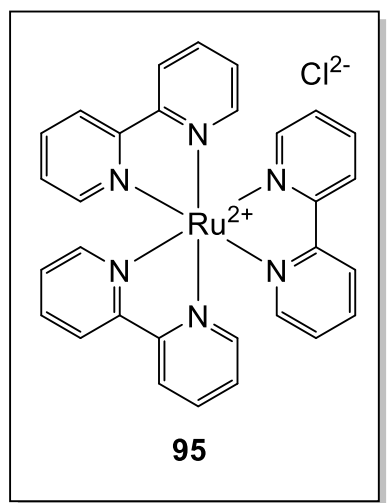

95

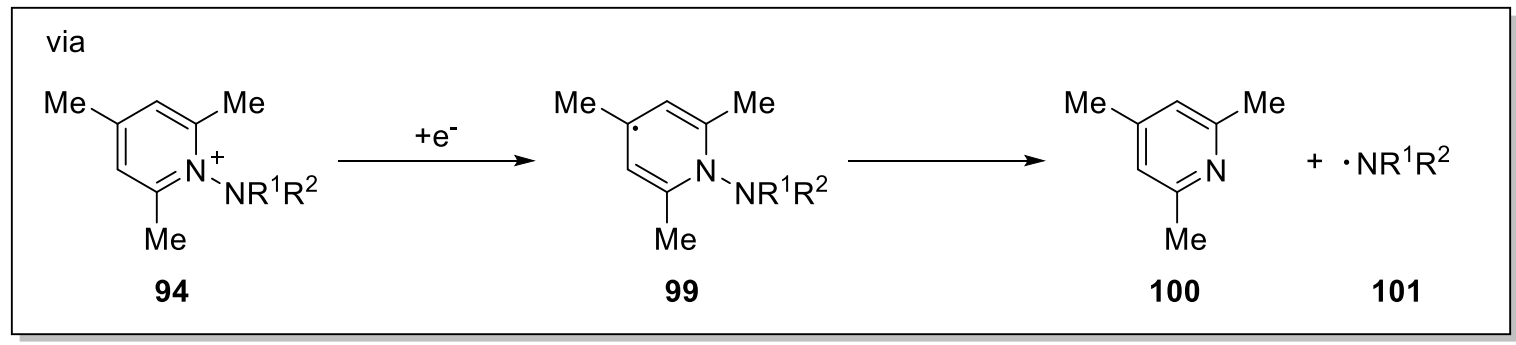

Scheme 1.2.26 Visible-light-induced deaminative $\mathrm{C}-\mathrm{H}$ amidation.

In 2017, Itami and Murakami reported photoredox ruthenium-catalyzed $\mathrm{C}-\mathrm{H} / \mathrm{N}-\mathrm{H}$ coupling by bluelight irradiation (Scheme 1.2.27). ${ }^{[69]}$ Thus, a wide range of polycyclic aromatic hydrocarbons was transformed to aryl amines through the oxidation of sulfonimides by the photoredox catalyst $\mathbf{9 5}$. Additionally, catalytic cycle was proposed based on the detailed mechanistic studies by means of cyclovoltametric analyses. 


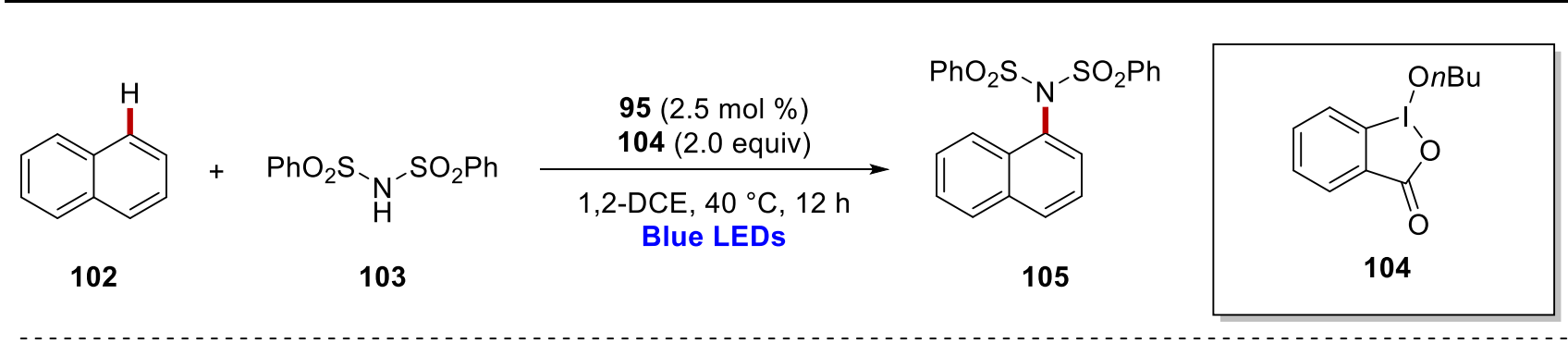

a) Substrate scope<smiles>O=S(=O)(c1ccccc1)N(c1cccc2ccccc12)S(=O)(=O)c1ccccc1</smiles>

105a: $79 \%$<smiles>O=S(=O)(c1ccccc1)N(c1cc2ccccc2c2ccccc12)S(=O)(=O)c1ccccc1</smiles>

105b: $70 \%$<smiles>O=S(=O)(c1ccccc1)N(c1ccccc1)c1ccc2ccc3cccc4ccc1c2c34</smiles>

105c: $35 \%$<smiles></smiles>

105d: $52 \%$

b) Proposed mechanism<smiles>c1ccc2ccccc2c1</smiles>

102<smiles>O=S(=O)(NS(=O)(=O)c1ccccc1)c1ccccc1</smiles><smiles>[Mg][Mg][Mg]</smiles><smiles>CCCCOI1OC(=O)c2ccccc21</smiles>

$\mathrm{PhO}_{2} \mathrm{~S}_{-} \mathrm{N}^{-\mathrm{SO}_{2}} \mathrm{Ph}$<smiles>Nc1cccc2ccccc12</smiles>

105

Blue LEDs<smiles>O=S(=O)(c1ccccc1)N(C1[C]C=Cc2ccccc21)S(=O)(=O)c1ccccc1</smiles><smiles>CCC(C)[PH2+]</smiles><smiles>O=C1O[I-]c2ccccc21</smiles>

$\mathrm{PhO}_{2} \mathrm{~S}-\mathrm{N}_{-}-\mathrm{SO}_{2} \mathrm{Ph}$<smiles>NC1[CH+]C=Cc2ccccc21</smiles>

Scheme 1.2.27 Photo-induced $\mathrm{C}-\mathrm{H} / \mathrm{N}-\mathrm{H}$ coupling by ruthenium-based photocatalyst 95 .

Inspired by cation pool methods of Yoshida, ${ }^{[70]}$ Morofuki and Kano very recently disclosed photocatalytic $\mathrm{C}-\mathrm{H}$ aminations of aromatic compounds 106 (Scheme 1.2.28). ${ }^{[71]}$ Taking advantage of substrates with higher oxidation potentials than the reduction potential of the oxidation state of the ruthenium-based photocatalyst 108 among other photocatalysts, 109 and 110, a variety of functional group tolerance was described, while featuring high regioselectivity in $\mathrm{C}-\mathrm{H}$ aminations. 

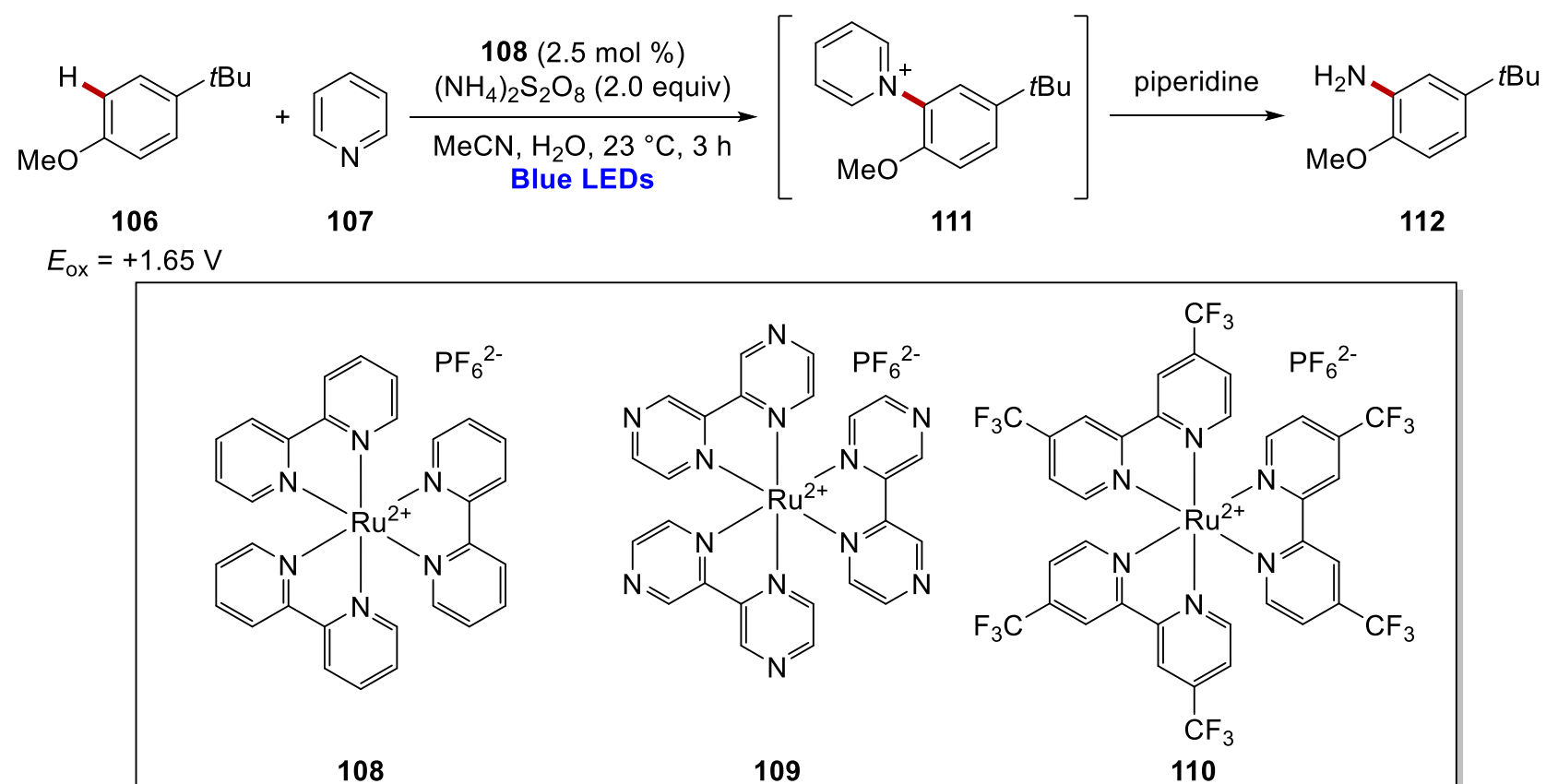

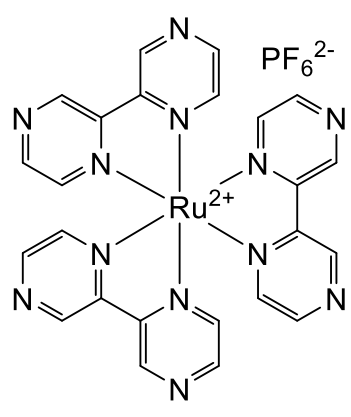

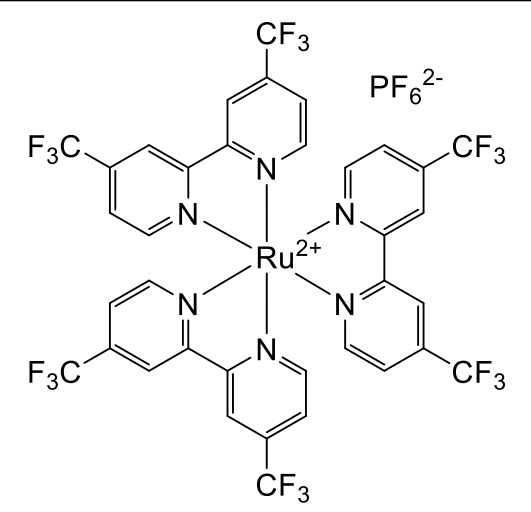

$E_{\text {red }}\left(\mathrm{Ru}^{\mathrm{III}} / \mathrm{Ru}^{\mathrm{II}}\right)=+1.37 \mathrm{~V}$

109

110

$E_{\text {red }}\left(\mathrm{Ru}^{\mathrm{III}} / \mathrm{Ru} \mathrm{u}^{\mathrm{II}}\right)=+1.79 \mathrm{~V}$

$E_{\text {red }}\left(R u^{\prime \prime \prime} / R u^{\prime l}\right)=+2.05 \mathrm{~V}$

a) Substrate scope<smiles>COc1ccc(C(C)(C)C)cc1N</smiles>

with 108, 112: $97 \%$

with 109, 112: $40 \%$ with 110,112 : $47 \%$<smiles>COc1ccc(I)cc1N</smiles>

with $108,112 a$ : $73 \%$<smiles>COc1ccc(Br)cc1N</smiles>

with $108,112 b$ : $46 \%$<smiles>COc1ccc(C(=O)c2ccccc2)cc1N</smiles>

with $108,112 c$ : $91 \%$

Gram scale: $92 \%(1.15 \mathrm{~g})$

Scheme 1.2.28 Oxidative $\mathrm{C}-\mathrm{H}$ amination by the ruthenium photocatalyst $\mathbf{1 0 8}$ under visible-lightinduced conditions. 


\subsubsection{Ruthenium-Catalyzed Distal C-H Functionalization}

Ruthenium-catalyzed $\mathrm{C}-\mathrm{H}$ activation has generally provided robust methods for ortho-selective $\mathrm{C}-\mathrm{H}$ functionalization for new $\mathrm{C}-\mathrm{C}$ bond or $\mathrm{C}-\mathrm{Het}$ bond formations via a proximity-induced approach. In sharp contrast, $\mathrm{C}-\mathrm{H}$ functionalizations at distal positions of arenes have been considerably less investigated (Scheme 1.2.29). ${ }^{[72 \mathrm{a}-\mathrm{e}, 26 \mathrm{e}, 72 \mathrm{f}]}$ In most methods, either the intrinsic electronic properties of substrates $^{[73]}$ or less atom-economical templates ${ }^{[74]}$ and ligands ${ }^{[75,26 f]}$ have been utilized to guide selectivity. Also, such reactions required cost-intensive metals, such as iridium and palladium catalysts. In stark contrast, ruthenium complexes have recently gained major attention for distal $\mathrm{C}-\mathrm{H}$ functionalizations, in which $\mathrm{C}-\mathrm{H}$ ruthenation results in remote $m e t a$-functionalizations. ${ }^{[76,72 \mathrm{~d}]}$

(a) steric control

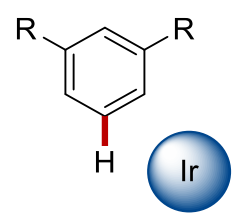

(b) template-assisted

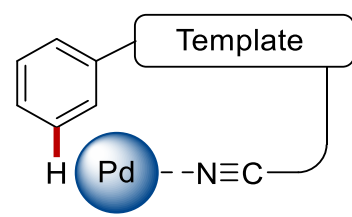

(c) non-covalent interaction

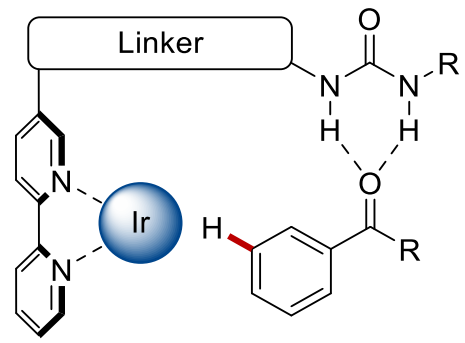

(d) transient mediator

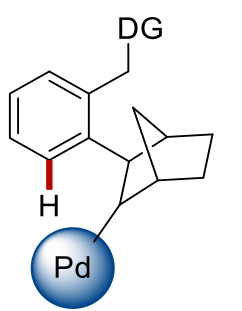

(e) remote $\sigma$-activation<smiles>[R]C1CCCCCC1c1ccccc1-c1ccccn1</smiles>

Scheme 1.2.29 Strategies for distal $\mathrm{C}-\mathrm{H}$ functionalizations.

Early examples of distal functionalization were reported by Roper and Wright in a stoichiometric manner (Scheme 1.2.30a). ${ }^{[77]}$ Thereafter, van Koten employed a similar stoichiometric approach for halogenations of cyclometalated ruthenium complexes (Scheme 1.2.30b). ${ }^{[78]}$ 
a) Roper and Wright

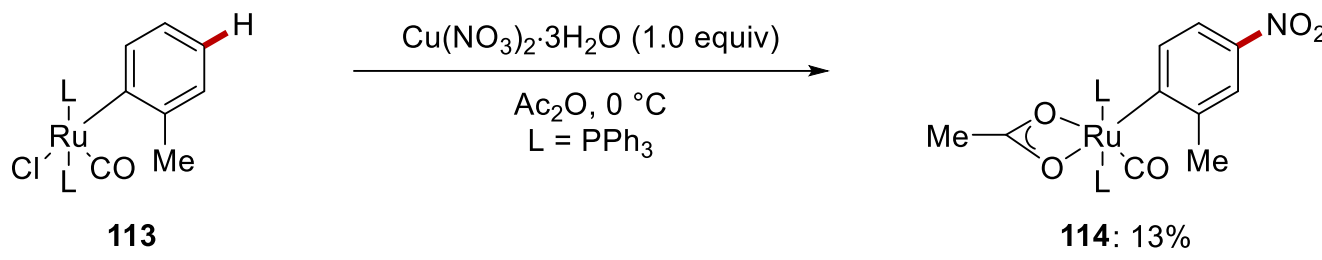

b) van Koten

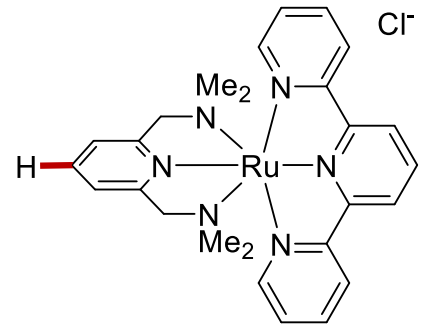

115

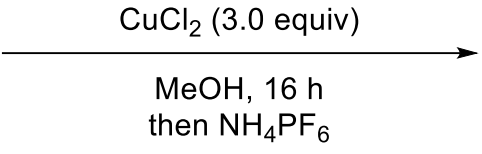

then $\mathrm{NH}_{4} \mathrm{PF}_{6}$

Scheme 1.2.30 Stoichiometric distal C-H functionalization of ruthenium complexes.

Thereafter, the groups of Coudret, ${ }^{[79]}$ Roper/Wright, ${ }^{[80]}$ and van Koten ${ }^{[78]}$ extended this method towards oxidative transformations of cyclometalated ruthenium complexes.

In 2011, Ackermann observed the first catalytic meta-C-H functionalization by $\mathrm{C}-\mathrm{H}$ ruthenation (Scheme 1.2.31). ${ }^{[35 \mathrm{e}]}$ Albeit in low yield, the result became a milestone for the further developments of ruthenium-catalyzed distal functionalizations.

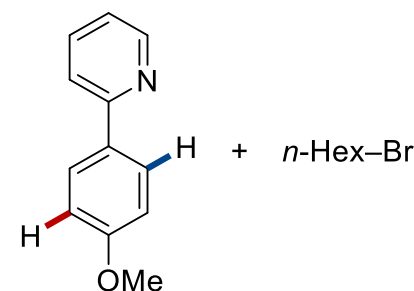

117

118

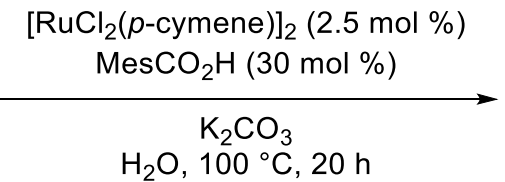

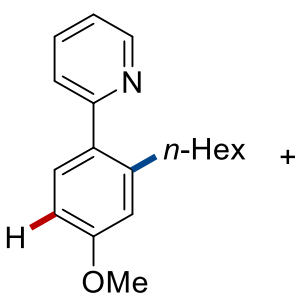

119: $45 \%$

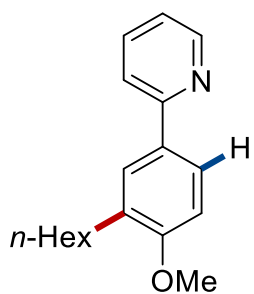

120: $7 \%$

Scheme 1.2.31 The first observation of ruthenium-catalyzed meta-C-H alkylation.

At the same time, Li showed the para-selective, oxidative $\mathrm{C}-\mathrm{H} / \mathrm{C}-\mathrm{H}$ alkylation of arenes $\mathbf{2 8}$, albeit with limited selectivity. ${ }^{[81]}$ In contrast, Ackermann disclosed a general strategy for meta-C-H alkylations via carboxylate-assisted ortho-ruthenation, featuring excellent levels of unusual metaposition-selectivity of arenes 28 (Scheme 1.2.32). ${ }^{[82]}$ Mechanistic investigations revealed that the 
transformation occurred via reversible $\mathrm{C}-\mathrm{H}$ ruthenation, while the use of typical radical scavenger TEMPO inhibited the meta-C-H alkylation. Notably, direct meta-alkylation with enantiomerically enriched substrate showed that a racemization of the chiral organic electrophile occurred under the reaction conditions.

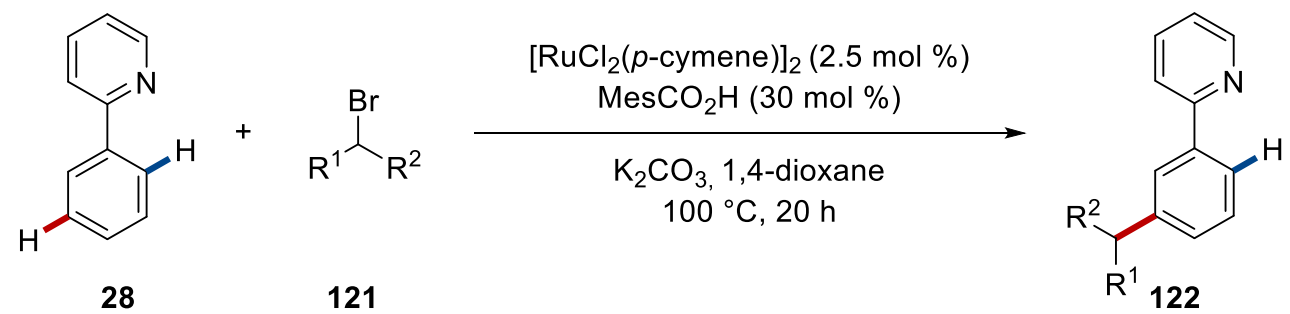

a) Substrate scope<smiles>CCCCC(C)c1cc(-c2ccccn2)ccc1OC</smiles>

122a: $70 \%$<smiles>c1ccc(-c2cccc(C3CCCCCC3)c2)nc1</smiles>

122b: $76 \%$<smiles>CCCC(C)c1cc(-c2ccccn2)ccc1C(F)(F)F</smiles>

122c: $55 \%$<smiles>COC(=O)c1ccc(-c2ccccn2)cc1C(C)C(C)C</smiles>

122d: $63 \%$

b) Mechanistic studies<smiles>[2H]C=CC(C)Br</smiles>

$[\mathrm{D}]_{5}-28$

$121 \mathrm{a}$
$\left[\mathrm{RuCl}_{2} \text { (p-cymene) }\right]_{2}(2.5 \mathrm{~mol} \%)$ $\mathrm{MesCO}_{2} \mathrm{H}(30 \mathrm{~mol} \%)$

$\mathrm{K}_{2} \mathrm{CO}_{3}$, 1,4-dioxane $100^{\circ} \mathrm{C}, 20 \mathrm{~h}$<smiles>[2H]c1c([2H])c([2H])c(-c2ccccn2)c([18OH])c1[2H]</smiles>

$[D]_{n}-28: 29 \%$

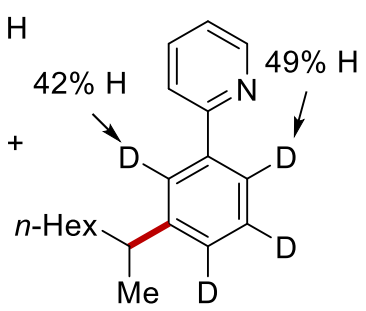

$[D]_{n}-122 e: 54 \%$<smiles>c1ccc(-c2ccccn2)cc1</smiles>

28

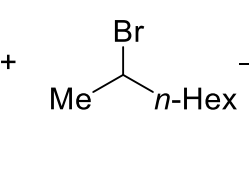

$121 \mathrm{a}$

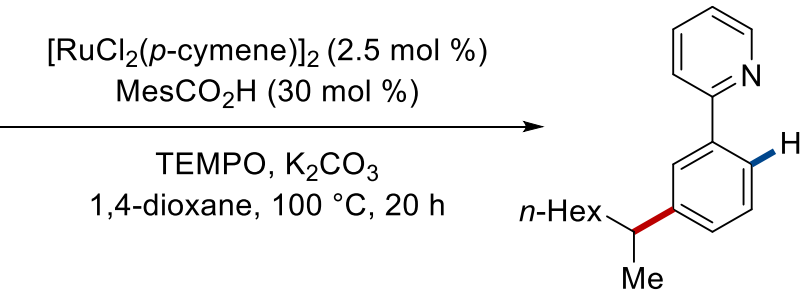

122e: $10 \%$

Scheme 1.2.32 Ruthenium-catalyzed meta-C-H alkylations with secondary alkyl bromide 121a.

Distal $\mathrm{C}-\mathrm{C}$ bond formation was not limited to secondary alkylation, but tertiary alkyl halides also were viable reaction partners. In 2015, Ackermann ${ }^{[83]}$ and then Frost ${ }^{[84]}$ independently showed the ruthenium-catalyzed meta-C-H alkylations with tertiary alkyl bromides 124 (Scheme 1.2.33). Notably, 
Ackermann firstly used monoprotected amino acids (MPAA), illustrating the importance of carboxylate assistance.

a) Ackermann (2015)<smiles>Cc1ccc([18F])cc1NC(=O)O</smiles>

123<smiles>[C+]c1cccc(-c2ccccn2)c1</smiles>

28

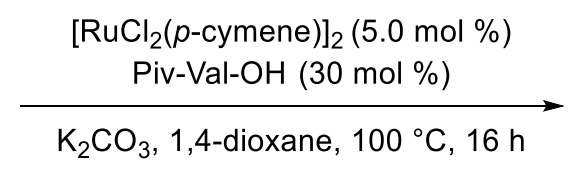

124<smiles></smiles>

125: $53 \%$

b) Frost (2015)<smiles>COc1ccc(-c2ccccn2)cc1</smiles>

117

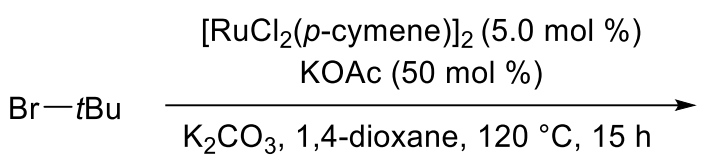

124<smiles>CC(C)(C)c1cccc(-c2ccccn2)c1</smiles>

126: $66 \%$

Scheme 1.2.33 Ruthenium-catalyzed meta-C-H alkylations with tertiary bromides $\mathbf{1 2 4}$.

Two years later, Ackermann and co-workers reported meta-C-H functionalizations of ketimines $\mathbf{1 2 8}$ (Scheme 1.2.34) ${ }^{\left[{ }^{[5]}\right.}$ It was not until then that the majority of the ruthenium-catalyzed meta-C-C bond formation reaction had highly relied on $N$-containing strong directing groups, which were not readily modified under mild conditions. However, this reaction allowed for the access to meta-functionalizaed aryl ketones $\mathbf{1 3 0}$ from imines through acidic work-up. Moreover, various alkyl halides including tertiary and secondary bromides $\mathbf{1 2 9}$ were found to be viable alkylating reagents. 


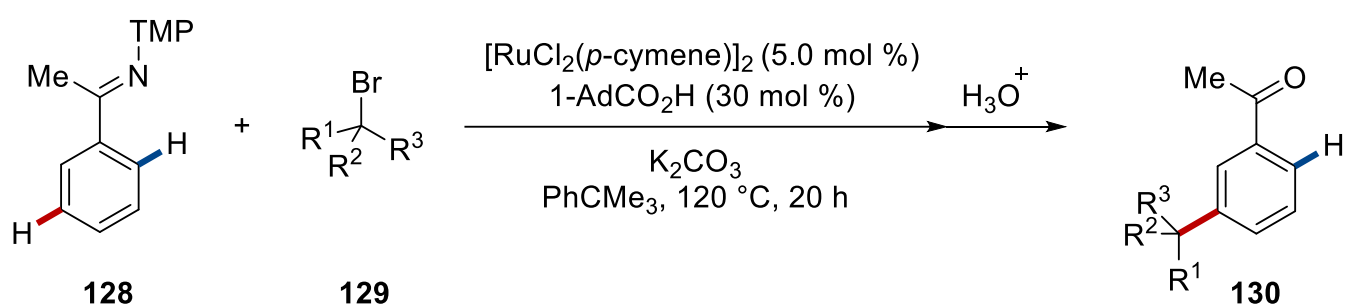<smiles>COC(=O)c1cccc(C(C)(C)C)c1</smiles>

130a: $71 \%$<smiles>CC(=O)c1ccc(F)c(C2(C)CCCCC2)c1</smiles>

130b: $73 \%$<smiles>CC(=O)c1ccc(N2CCOCC2)c(C2CCCCCC2)c1</smiles>

130c: $58 \%$<smiles>CC(=O)c1cc(C(C)C)c2ccccc2c1</smiles>

130d: $84 \%$

Scheme 1.2.34 Ruthenium-catalyzed distal $\mathrm{C}-\mathrm{H}$ functionalization with the aid of a removable directing group.

Additionally, azobenzenes $\mathbf{1 3 1}{ }^{[86]}$ and pyridylphenol $\mathbf{1 3 4} 4^{[87]}$ were introduced for ruthenium-catalyzed remote $\mathrm{C}-\mathrm{H}$ alkylations, in which the directing groups were transformed to other interesting functional groups, such as anilines and phenols, respectively (Scheme 1.2.35).

a) Yang/Li (2017)

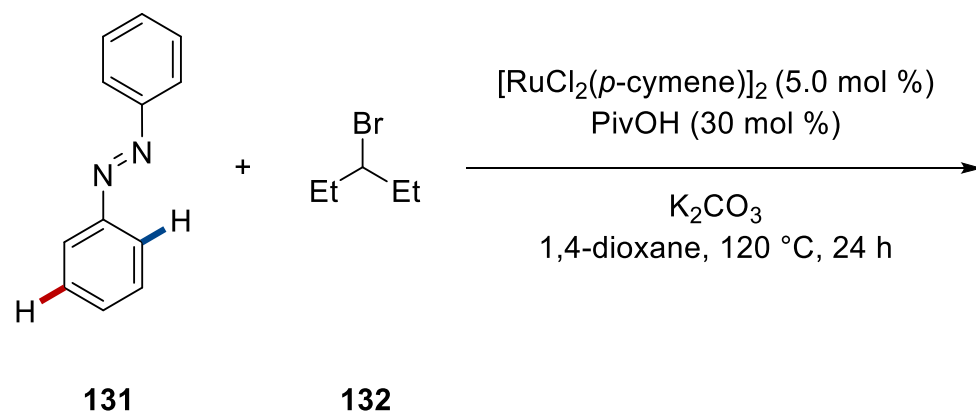<smiles>CCC(CC)c1ccc(/N=N/c2ccccc2)c(/C=N\c2ccccc2)c1</smiles>

133: $76 \%$

b) Li (2017)<smiles>c1ccc(Oc2ccccn2)cc1</smiles>

134<smiles>CCC(Br)CC</smiles>

132

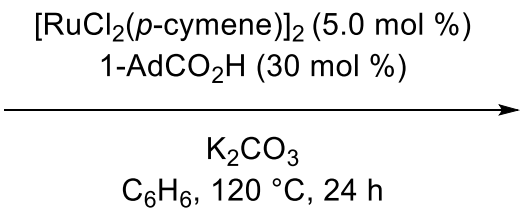

$\mathrm{C}_{6} \mathrm{H}_{6}, 120^{\circ} \mathrm{C}, 24 \mathrm{~h}$<smiles>CCC(CC)c1cccc(Oc2ccccn2)c1</smiles>

135: $73 \%$

Scheme 1.2.35 Distal C-H functionalization of azobenzene 131 and pyridylphenol 134 . 
In 2017, the group of Ackermann accomplished the first remote $\mathrm{C}-\mathrm{H}$ mono- and difluoromethylation through the combination of ruthenium(II) carboxylate and a phosphine ligand (Scheme 1.2.36). ${ }^{[8]}$ Various directing groups, such as pyridines, pyrimidines, pyrazoles, and purine, efficiently afforded meta-decorated fluoromethylated products. It is noteworthy that the difluoromethylations did not occur at the kinetically more acidic $\mathrm{C} 8-\mathrm{H}$ positions of the purine motif. Around the same time, Wang group showed a similar approach for ruthenium-catalyzed remote mono- and difluoromethylations, utilizing a ruthenium and palladium bimetallic catalysis. ${ }^{[89]}$

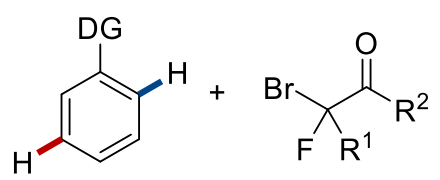

136

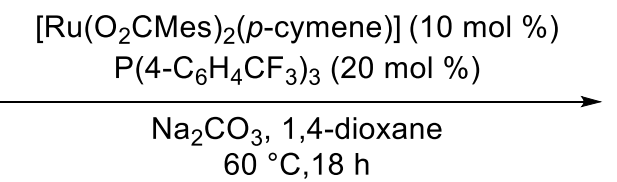
$60^{\circ} \mathrm{C}, 18 \mathrm{~h}$

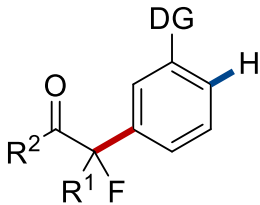

138<smiles>CCOC(=O)c1cccc(-c2ccccn2)c1</smiles>

138a: $71 \%$<smiles>CCOC(=O)c1cccc(-c2ncccn2)c1</smiles>

138b: $77 \%$<smiles>CCOC(=O)C(F)(F)c1cccc(-c2ncnc3c2ncn3-c2ccccc2)c1</smiles>

138e: $63 \%$

Scheme 1.2.36 Ruthenium-catalyzed meta-C-H difluoroalkylations.

Ackermann and co-workers disclosed sequential meta-/ortho-C-H difunctionalizations in 2018 (Scheme 1.2.37). ${ }^{[90]}$ Thus, the double $\mathrm{C}-\mathrm{H}$ activation proved viable in a one-pot fashion, providing operationally simple twofold $\mathrm{C}-\mathrm{H}$ functionalizations. In addition, detailed mechanistic studies provided strong support for homolytic $\mathrm{C}-\mathrm{X}$ bond cleavage and facile $\mathrm{C}-\mathrm{H}$ ruthenation, while a radical Fukui indices based on computational density functional theory (DFT) analysis supported a radical pathway. 


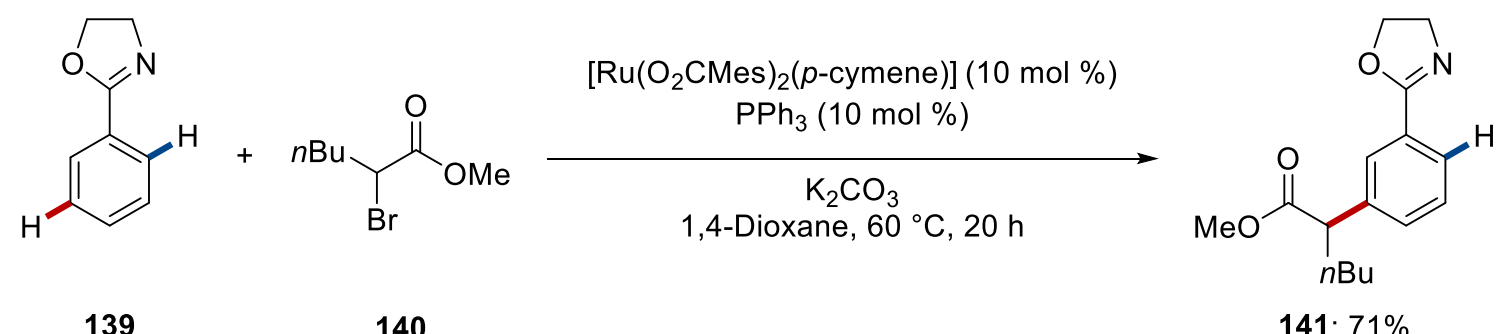

a) Sequential reaction

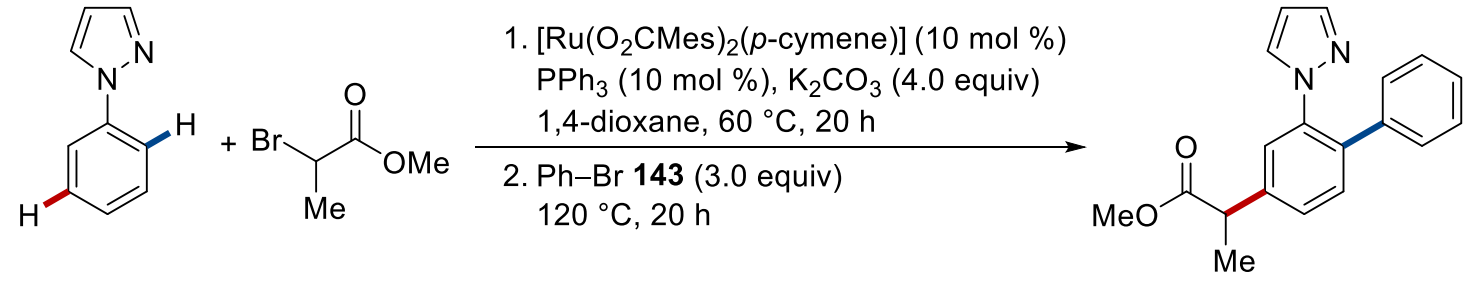

25

142

144: $58 \%$

b) Proposed mechanism

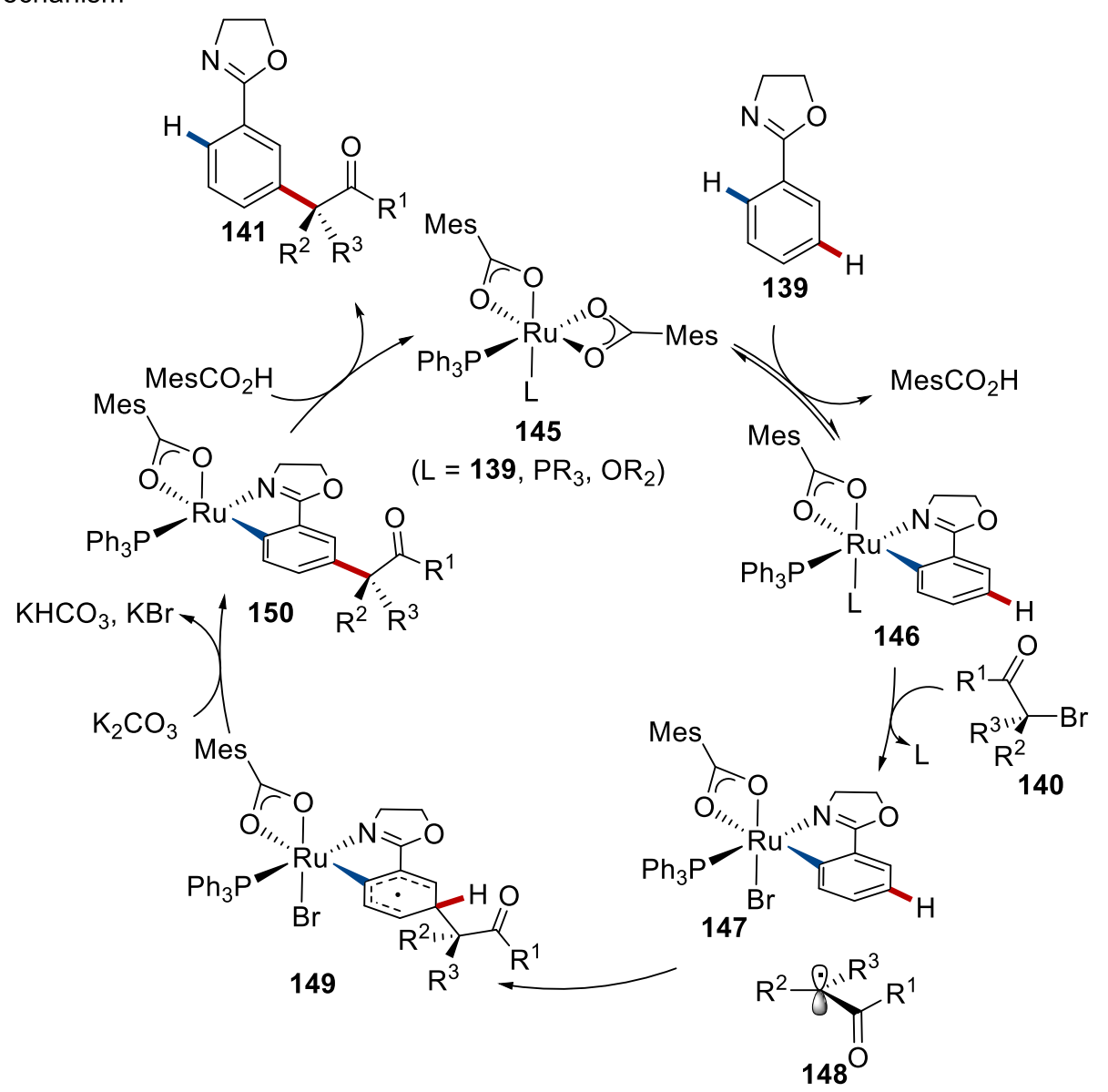

Scheme 1.2.37 Distal C-H alkylation via ruthenium (II/III) catalysis and sequential strategy for dual functionalizations

The established cooperative use of phosphine and carboxylate ligands in ruthenium catalysis was further extended to three-component meta-C-H functionalizations (Scheme 1.2.38). ${ }^{[91]}$ 


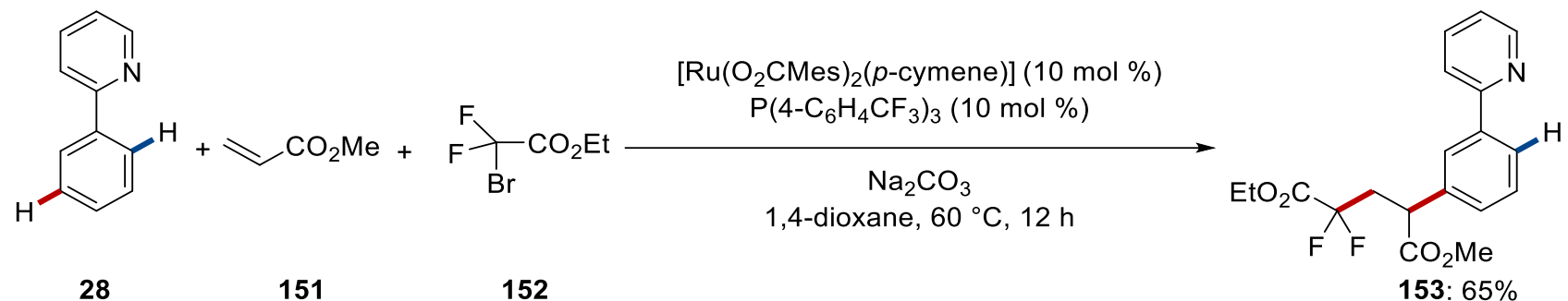

Scheme 1.2.38 Three-component ruthenium-catalyzed meta-C-H alkylation.

It is noteworthy that since the arene-ligand-free phosphine-coordinated ruthenium complexes are catalytically competent species, the complex can be directly employed for the synergistic ruthenium(II)-catalyzed remote $\mathrm{C}-\mathrm{H}$ functionalizations. Thus, Ackermann and co-workers reported that well-defined arene-ligand-free ruthenium complex $\mathrm{Ru}(\mathrm{OAc})_{2}\left(\mathrm{PPh}_{3}\right)_{2}$ was used for meta-C-H alkylations (Scheme 1.2.39). ${ }^{[92]}$
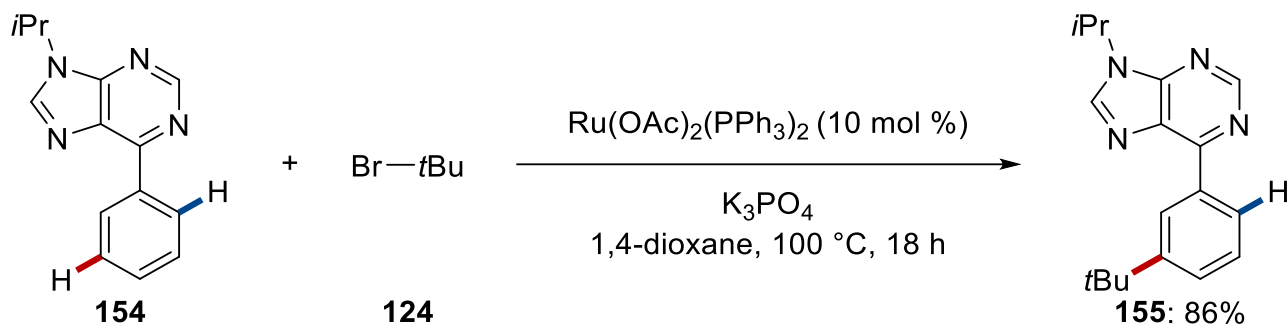

Scheme 1.2.39 Arene-ligand-free ruthenium(II/III) manifold for meta-C-H alkylation.

Among distal $\mathrm{C}-\mathrm{C}$ bond formation in ruthenium catalysis, meta- $\mathrm{C}-\mathrm{H}$ acylation was disclosed by Wang using $\alpha$-oxocarboxylic acid 156 (Scheme 1.2.40) ${ }^{[93]}$ In the presence of silver salt and persulfates, oxidative decarboxylation of the activated ketoacids $\mathbf{1 5 6}$ generated an acyl radical, leading to the ruthenium-catalyzed remote functionalizations.<smiles>[C+]c1cccc(-c2ccccn2)c1</smiles>

28<smiles>O=C(O)C(=O)c1ccccc1</smiles>

156<smiles>O=C(c1ccccc1)c1cccc(-c2ccccn2)c1</smiles>

Scheme 1.2.40 Decarboxylative ruthenium-catalyzed meta-selective C-H acylation. 
Very recently, the group of Ackermann reported on visible-light-induced ruthenium-catalyzed meta$\mathrm{C}-\mathrm{H}$ alkylation at ambient temperature (Scheme 1.2.41). ${ }^{[94]}$ Notably, the photocatalytic reactions were performed under exceedingly mild reaction conditions at ambient temperature and without any additional exogeneous photocatalysts. Around the same time, Greaney also reported similar remote $\mathrm{C}-$ $\mathrm{H}$ alkylations with alkyl iodide under visible-light induced conditions. ${ }^{[95]}$<smiles>c1ccc(-c2ccccn2)cc1</smiles>

28

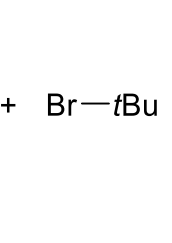

124

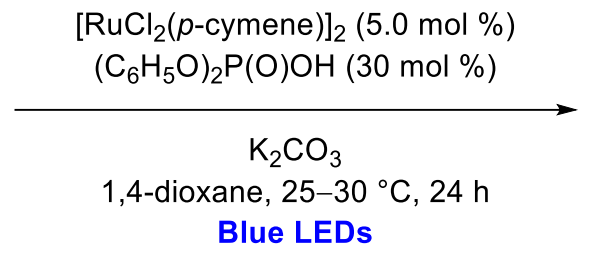

Blue LEDs<smiles>CC(C)(C)c1cccc(-c2ccccn2)c1</smiles>

126

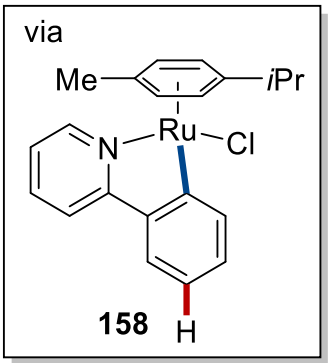

Scheme 1.2.41 Visible-light-induced ruthenium-catalyzed meta-C-H alkylation.

In addition to the aforementioned site-selective distal $\mathrm{C}-\mathrm{C}$ bond formation, ruthenium catalysis enabled other meta-functionalizations, such as sulfonylations, ${ }^{[96]}$ halogenations, ${ }^{[97]}$ and nitrations (Scheme 1.2.42). ${ }^{[98]}$<smiles>Brc1cccc(-c2ccccn2)c1</smiles>

159

[Ackermann / Greany / Huang]<smiles>O=[N+]([O-])c1cccc(-c2ccccn2)c1</smiles>

[Ackermann / Zhang]<smiles>Clc1cccc(-c2ccccn2)c1</smiles>

160

[Maheswaran / Zhang]

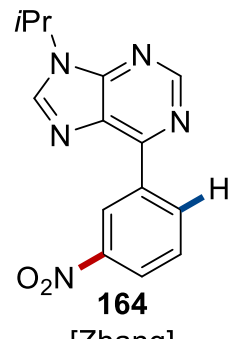

[Zhang]<smiles>[3H]c1cccc(-c2ccccn2)c1</smiles>

161

[Frost]<smiles>CO/N=C(\C)c1cccc([N+](=O)[O-])c1</smiles>

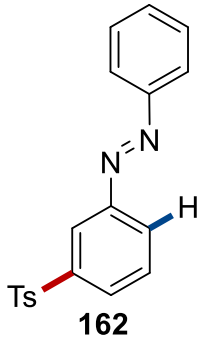

[Wang and $\mathrm{Li}]$

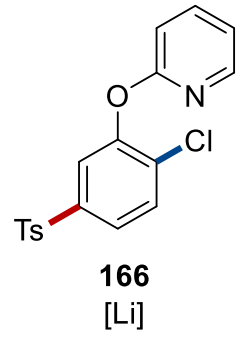

Scheme 1.2.42 Ruthenium-catalyzed distal $\mathrm{C}-\mathrm{H}$ functionalizations, halogenations, sulfonylations, and nitrations. 
In contrast to the indisputable progress in meta-selective $\mathrm{C}-\mathrm{H}$ functionalizations, general procedures for ruthenium-catalyzed para-C-H functionalization are under developed. Frost ${ }^{[99]}$ and Ackermann ${ }^{[90]}$ independently reported on ruthenium-catalyzed para-C-H alkylations of pyrimidylanilines 167 with $\alpha$-halo carbonyl compound 168 (Scheme 1.2.43). Notably, Frost suggested that the formation of fourmembered ruthenacycle $\mathbf{1 7 0}$ is the key intermediate.

a) Frost (2017)
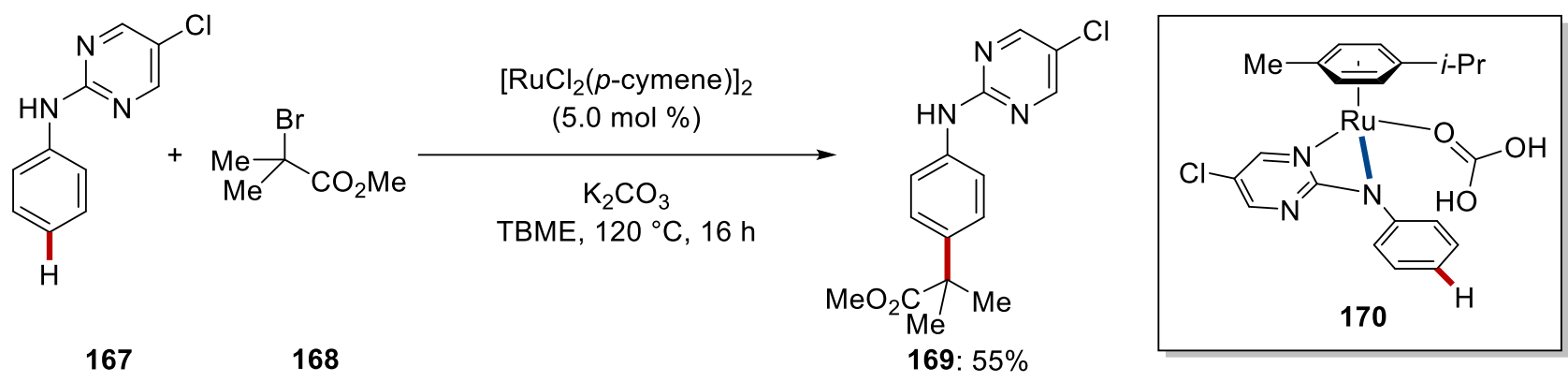

b) Ackermann (2018)

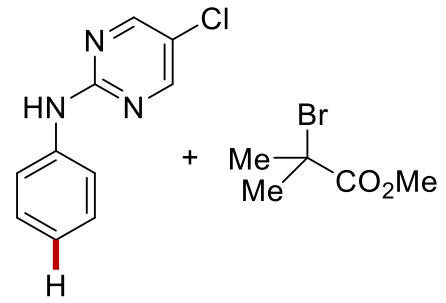

167

168

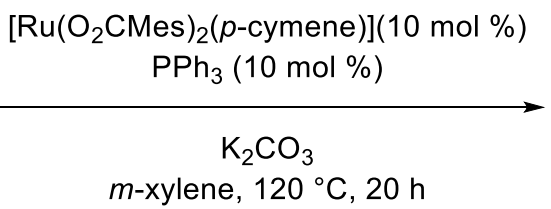

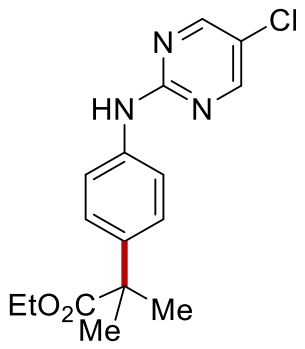

169: $56 \%$

Scheme 1.2.43 Ruthenium-catalyzed para-C-H alkylations.

Later, Zhao/Lan and Liang utilized a similar ruthenium-catalyzed para-C-H functionalization method to achieve mono- and difluoroalkylations (Scheme 1.2.44). ${ }^{[100]}$ Unlike the mechanistic hypothesis offered by Frost, Zhao/Lan proposed that ortho-C-H ruthenation enabled the para-selectivity, although detailed experimental support was not provided. 
a) Zhao/Lan<smiles>COC(=O)C(F)(F)Br</smiles>

$\left[\mathrm{RuCl}_{2}(p \text {-cymene })\right]_{2}(5.0 \mathrm{~mol} \%)$ $\mathrm{AgNTf}_{2}(20 \mathrm{~mol} \%)$

$1-\mathrm{AdCO}_{2} \mathrm{H}(20 \mathrm{~mol} \%)$

$\mathrm{K}_{2} \mathrm{CO}_{3}$

DCE, $120^{\circ} \mathrm{C}, 48 \mathrm{~h}$

171

152<smiles>CCNC(=O)Nc1ccc(C(F)(F)C(=O)OCC)cc1</smiles>

172: $87 \%$<smiles>CO/N=C(\C)c1ccccc1</smiles>

$\left[\mathrm{RuCl}_{2}(p \text {-cymene })\right]_{2}(5.0 \mathrm{~mol} \%)$ $\mathrm{AgNTf}_{2}(20 \mathrm{~mol} \%)$ Ac-lle-OH (30 mol \%) $\mathrm{Na}_{2} \mathrm{CO}_{3}$ DCE, $150{ }^{\circ} \mathrm{C}, 48 \mathrm{~h}$

173 152

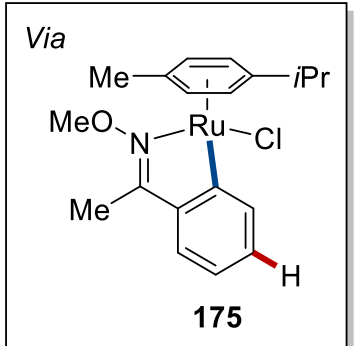<smiles>CCOC(=O)C(F)(F)c1ccc(/C(C)=N/OC)cc1</smiles>

174: $86 \%$

b) Liang<smiles>c1ccc(Nc2ncccn2)cc1</smiles><smiles>COC(OC)C(F)(F)Br</smiles>

123
$\left[\mathrm{Ru}\left(\mathrm{O}_{2} \mathrm{CMes}\right)_{2}(p\right.$-cymene $\left.)\right](10 \mathrm{~mol} \%)$

$$
\mathrm{Na}_{2} \mathrm{CO}_{3}
$$

PhMe, $120^{\circ} \mathrm{C}, 18 \mathrm{~h}$

152<smiles>CCOC(=O)C(F)(F)c1ccc(Nc2ncccn2)cc1</smiles>

176: $58 \%$

Scheme 1.2.44 Ruthenium-catalyzed para-C-H difluoromethylations. 


\subsection{Osmium-Catalyzed C-H Activation}

Osmium is the heaviest and rarest element in the earth's crust, with a concentration of approximately 0.05 parts per billion. ${ }^{[101]}$ Osmium complexes - for instance, osmium tetroxide - are often considered toxic. In addition, osmium forms relatively strong Os-C bonds due to the stability in its higher oxidation state. For these reasons, osmium is a less attractive metal for catalysis compared to other group 8 metals $^{[102]}$

Interestingly, osmium complexes have been introduced for useful chemical transformations. ${ }^{[103]}$ As major example, inspired by the pioneering work by Criegee,${ }^{[104]}$ Sharpless significantly expanded this realm to osmium-catalyzed enantioselective dihydroxylations (Scheme 1.3.1). ${ }^{[105]}$

a) Criegee

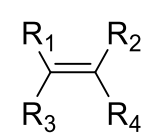

177
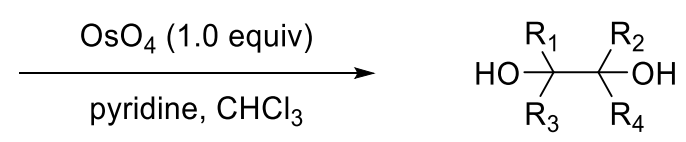

178

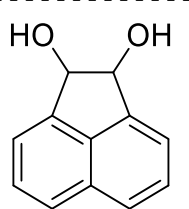

178a: $98 \%$<smiles>OC1Cc2ccccc2C1O</smiles>

178b: $99 \%$<smiles>OC1CCc2ccccc2C1O</smiles>

178c: $89 \%$<smiles>OC12CCCCC1(O)CCCC2</smiles>

178d: $96 \%$

b) Sharpless

$$
\mathrm{Ph} \leftrightharpoons \mathrm{Ph} \underset{\text { 2) } \mathrm{LiAlH}_{4}}{\stackrel{\text { 1) } \mathrm{OsO}_{4}, 180, \mathrm{PhMe}}{\longrightarrow}}
$$

179
181: $88 \%, 97 \%$ ee<smiles>O[C@H](c1ccccc1)[C@H](O)c1ccccc1</smiles>

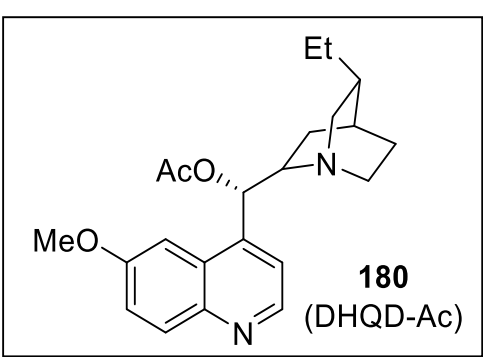

Scheme 1.3.1 Representative examples of chemical transformation with osmium tetroxide.

$\mathrm{C}-\mathrm{H}$ functionalizations by osmium complexes have also emerged as a powerful toolbox for chemical transformations. In 1973, Bruce disclosed the formation of osmacycle complex through $\mathrm{C}-\mathrm{H}$ bond cleavage of benzo[ $h]$ quinolone 183 (Scheme 1.3.2). ${ }^{[106]}$ 


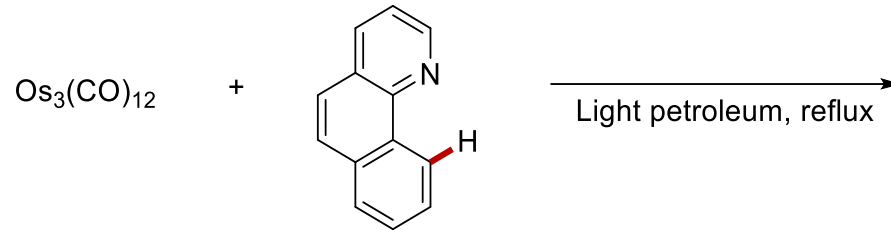

182

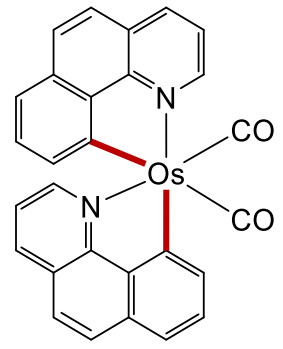

184: $33 \%$

Scheme 1.3.2 Synthesis of osmacycle complex 184 .

On the basis of this work, well-defined osmacycles were successfully isolated in a stoichiometric fashion (Scheme 1.3.3). ${ }^{[107]}$ Thus, $N$-, $P$ - and $O$-directing groups are coordinated to the osmium center, leading to $\mathrm{C}-\mathrm{H}$ cleavage, resulting in the formation of osmacycle $\mathbf{1 8 5}-\mathbf{1 9 0}$.

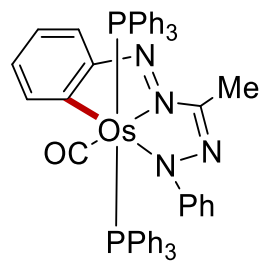

185

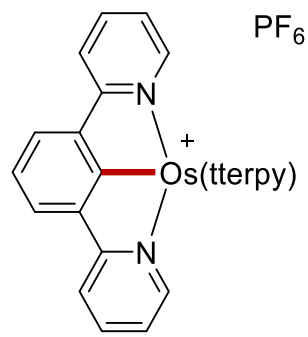

188

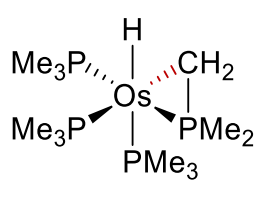

186

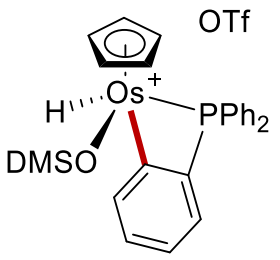

189<smiles>CO[Sb](O)(OC)(OC(=O)c1ccccc1C(C)C)c1ccc(C)cc1</smiles>

187

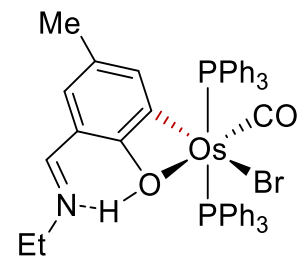

190

Scheme 1.3.3 Osmacycles 185-190. 


\subsubsection{Osmium-Mediated C-H Functionalizations}

With this progress in the stoichiometric formation of osmacycles, such complexes were subjected to subsequent C-H functionalizations. In 1999, Roper and Wright disclosed an electrophilic substitutiontype C-H bromination and nitration of 2-(2'-pyridyl)phenyl osmium complex 191 (Scheme 1.3.4). ${ }^{[80 \mathrm{a}]}$ The $\mathrm{C}-\mathrm{H}$ functionalizations of osmium complex 191 selectively occurred at the position para-to-theosmium center. Interestingly, while the excess use of bromination source provided a ligand exchange from phosphine to pyridine, the prolonged reaction time in the nitration afforded dual $\mathrm{C}-\mathrm{H}$ functionalized product 193. With brominated osmium complex 194, further diversifications were also presented, thus generating carboxylated 196 or stannylated osmium complex 197.

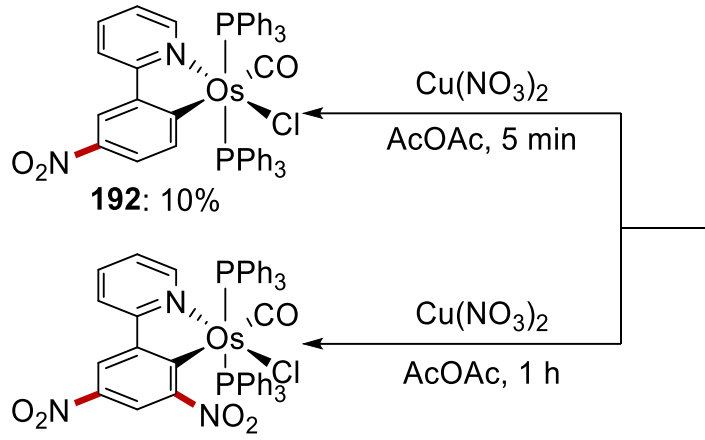

193: $36 \%$

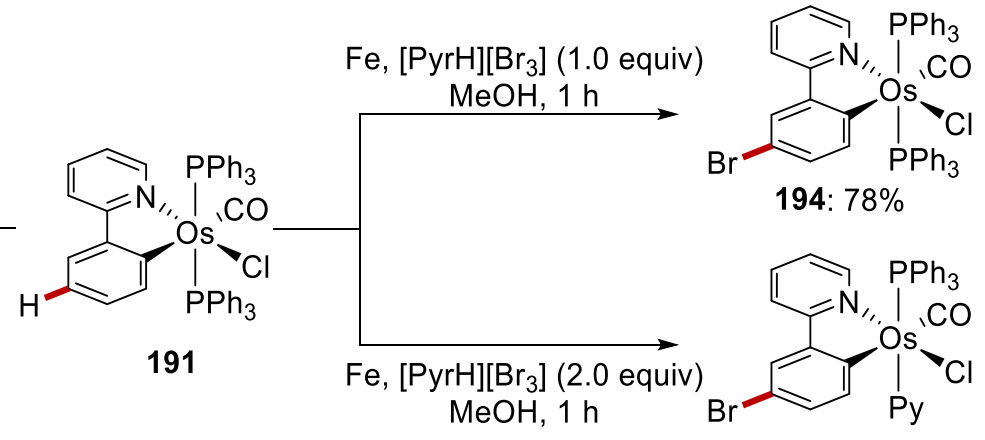

195: $31 \%$<smiles>O=P(O)(Oc1ccc(Br)cc1-c1ccccn1)P(=O)(P)c1ccccc1</smiles>

194

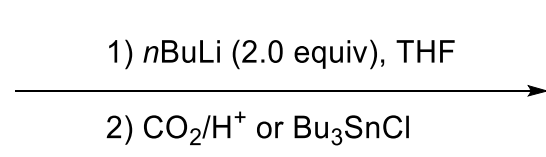

2) $\mathrm{CO}_{2} / \mathrm{H}^{+}$or $\mathrm{Bu}_{3} \mathrm{SnCl}$

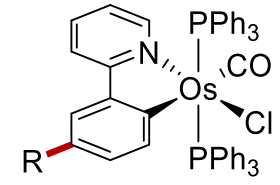

$196\left(\mathrm{R}=\mathrm{CO}_{2} \mathrm{H}\right): 26 \%$

$197\left(\mathrm{R}=\mathrm{Bu}_{3} \mathrm{Sn}\right): 46 \%$

Scheme 1.3.4 meta-C-H functionalizations from osmacycle complex 191. 


\subsubsection{Osmium-Catalyzed C-H Functionalizations}

Despite the aforementioned advances in stoichiometric osmacycle synthesis and its reactions, osmium complexes have rarely been used for catalytic $\mathrm{C}-\mathrm{H}$ functionalization. In 2007, Iida disclosed osmium(II) porphyrin complex-catalyzed oxidative $\mathrm{C}-\mathrm{H}$ oxygenation of steroid 198 (Scheme 1.3.5) ${ }^{[108]}$ In this study, the least hindered tertiary $\mathrm{C}-\mathrm{H}$ bond was selectively transformed, albeit with low efficiency. Additional reports also showed that pentacyclic triterpenoids 201 were converted to oxygenated product 202. ${ }^{[109]}$<smiles>CC(=O)CC[C@H](C)[C@H]1CCC2C3CC[C@H]4C[C@H](OC(C)=O)CC[C@]4(C)[C@H]3CC[C@]21C</smiles>

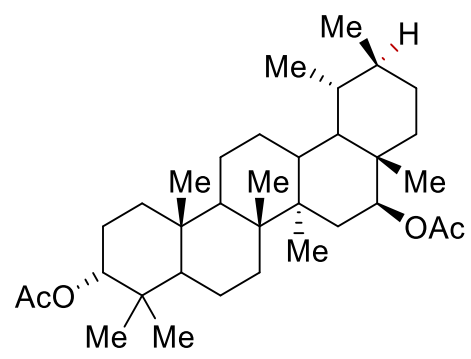

201
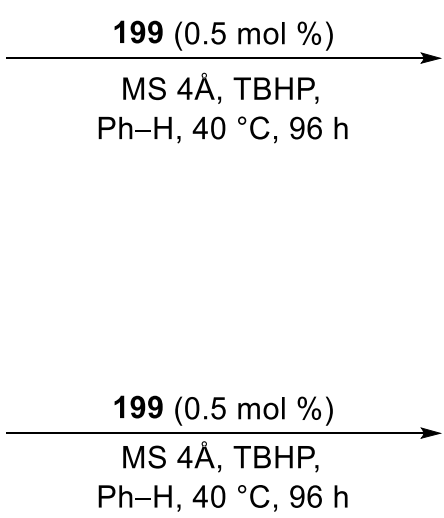

$\mathrm{Ph}-\mathrm{H}, 40^{\circ} \mathrm{C}, 96 \mathrm{~h}$

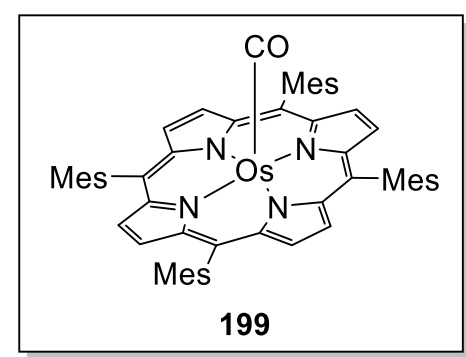<smiles>CC(=O)CC[C@H](C)[C@H]1CCC2C3CC[C@]4(O)C[C@@H](OC(C)=O)CC[C@]4(C)[C@H]3CC[C@]21C</smiles>

200: $32 \%$

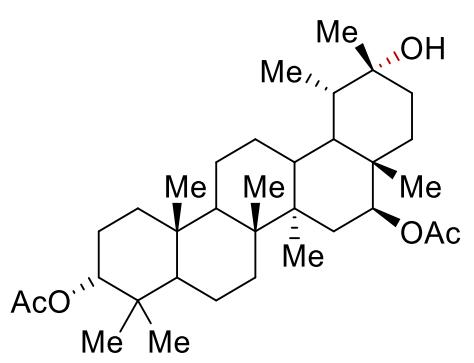

202: $50 \%$

Scheme 1.3.5 Osmium porphyrin-catalyzed $\mathrm{C}-\mathrm{H}$ oxygenations.

In 2020, Meggers and co-workers disclosed osmium-catalyzed enantioselective $\mathrm{C}-\mathrm{H}$ amidation (Scheme 1.3.6). ${ }^{[110]}$ As an extension of their previous studies, newly synthesized non-C2-symmetric chiral-at-osmium complex 204 provided amidated products 205 and 207. 
<smiles>O=S(=O)(CCCc1ccccc1)O[Na]</smiles>

203<smiles>NC(=O)OCCc1ccccc1</smiles>

206

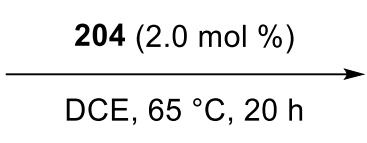

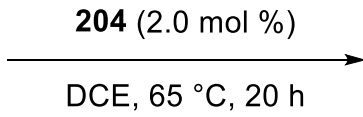<smiles>O=S1(=O)CCC(c2ccccc2)N1</smiles>

205: $96 \%, 92: 8$ er<smiles>O=C1N[C@H](c2ccccc2)CO1</smiles>

207: $86 \%, 89: 11$ er

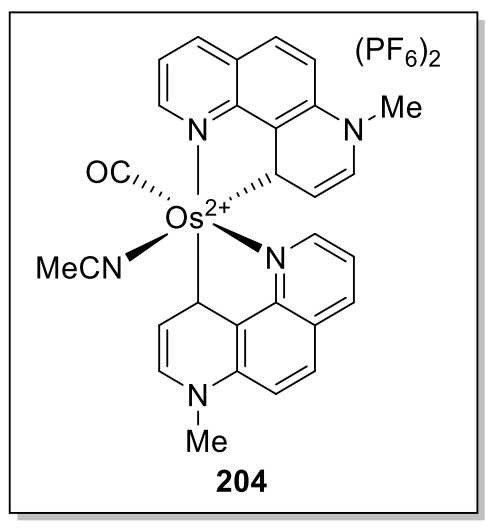

Scheme 1.3.6 Enantioselective C-H amidations with chiral-at-osmium catalyst 204 .

In 2020, the Rovis group showcased near-infrared-induced photocatalysis regime utilizing an osmiumbased photocatalyst 210 (Scheme 1.3.7). ${ }^{[111]}$ Unlike ruthenium-based polypyridyl photocatalysts, osmium analogous featured a spin-forbidden $\mathrm{S}_{0} \rightarrow \mathrm{T}_{1}$ excitation in the near-infrared region, thereby increasing light penetration into the reaction medium.<smiles>O=C1CCCN1c1ccccc1</smiles>

208

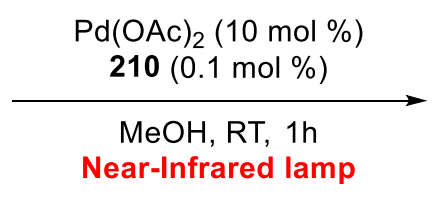

209

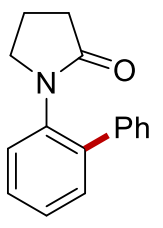

211: $91 \%$

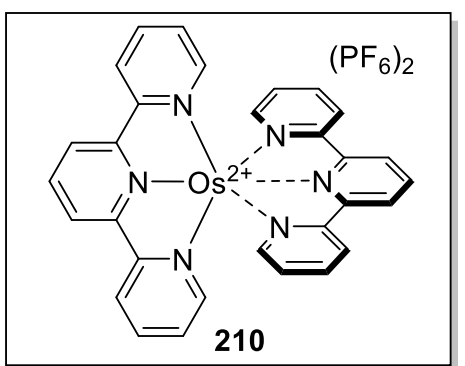

Scheme 1.3.7 Near-infrared photo-catalyzed C-H arylations with osmium-based photocatalyst 210.

Recently, Yi and co-workers reported on unprecedented osmium(II)-catalyzed C-H activation (Scheme 1.3.8). ${ }^{[112]}$ While transition metal-catalyzed $\mathrm{C}-\mathrm{H}$ annulation has been well established, ${ }^{[113]}$ the osmium complex was firstly employed in this study. Notably, the use of internal oxidant brought about less atom efficiency in this reaction, while a wide range of substrates was amenable. Additionally, experimental mechanistic studies revealed that the $\mathrm{C}-\mathrm{H}$ bond scission process is irreversible, while osmium(II) carboxylate-assisted C-H activation was studied by computational DFT analysis. 


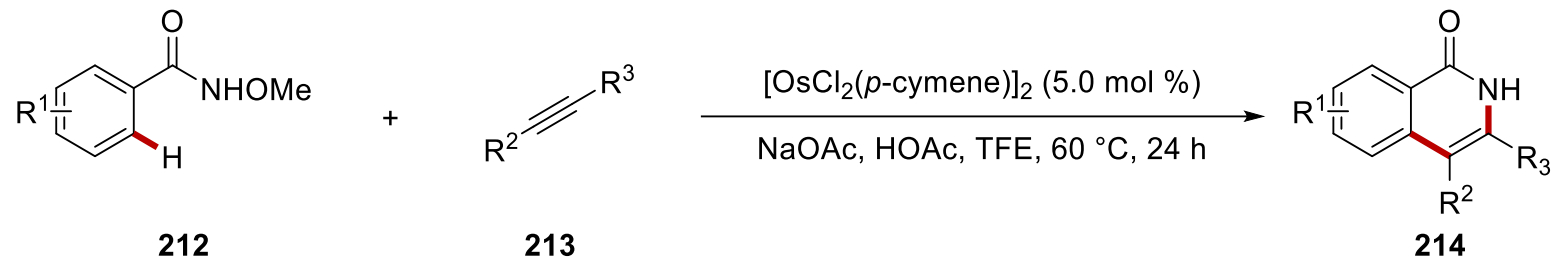<smiles>O=c1[nH]c(-c2ccccc2)c(-c2ccccc2)c2ccccc12</smiles>

214a: $85 \%$<smiles>Cc1ccc(-c2[nH]c(=O)c3ccccc3c2-c2ccc(C)cc2)cc1</smiles>

214e: $65 \%$<smiles>Cc1ccc2c(=O)[nH]c(-c3ccccc3)c(-c3ccccc3)c2c1</smiles>

214b: $83 \%$<smiles>O=c1[nH]c(-c2cccs2)c(-c2cccs2)c2ccccc12</smiles>

214f: $45 \%$<smiles>N#Cc1ccc2c(=O)[nH]c(-c3ccccc3)c(-c3ccccc3)c2c1</smiles>

214c: $59 \%$<smiles>CCc1c(-c2ccccc2)[nH]c(=O)c2ccccc12</smiles>

214g: $88 \%$<smiles>O=c1[nH]c(-c2ccccc2)c(-c2ccccc2)c2cc([N+](=O)[O-])ccc12</smiles>

214d: $53 \%$<smiles>CC(=O)c1[nH]c(=O)c2ccccc2c1C</smiles>

214h: $85 \%$

Scheme 1.3.8 Osmium-catalyzed alkyne annulations. 


\subsection{Manganese-Catalyzed C-H Activation}

As the twelfth most abundant element in the earth's crust, manganese has a huge potential for sustainable, low toxic and cost-effective $\mathrm{C}-\mathrm{H}$ activation. ${ }^{[14]}$ In addition, a wide range of oxidation states of manganese from -3 to +7 enables various coordination geometries. ${ }^{[115]}$ Notably, manganese complexes have been widely used in epoxidation reactions ${ }^{[116]}$ and radical-type $\mathrm{C}-\mathrm{H}$ functionalizations, ${ }^{[17]}$ but limitedly employed in cross-coupling, ${ }^{[118]}$ Together with these indisputable advances, organometallic $\mathrm{C}-\mathrm{H}$ functionalizations have recently emerged as a powerful toolbox for chemical transformations.

In 1970, Stone and Bruce reported the stoichiometric manganese-mediated C-H activation of azobenzene (Scheme 1.4.1). ${ }^{[119]}$ Thus, manganacycle 217 was synthesized in 93\% yield from $\mathrm{MnMe}(\mathrm{CO})_{5}(\mathbf{2 1 6})$.

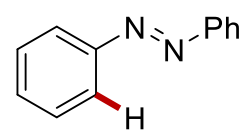

215

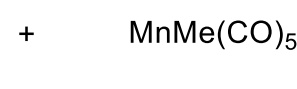

216

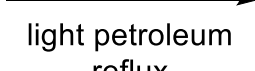

reflux

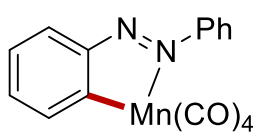

217: $93 \%$

Scheme 1.4.1 Stoichiometric C-H activation with manganese.

On the basis of this work, a plethora of well-defined manganacycles was successfully prepared in a stoichiometric fashion (Scheme 1.4.2). ${ }^{[120]}$ Thus, the directing groups are coordinated to the manganese center, leading to $\mathrm{C}-\mathrm{H}$ cleavage followed by manganacycle formations.

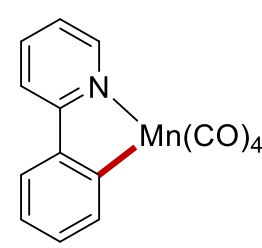

218

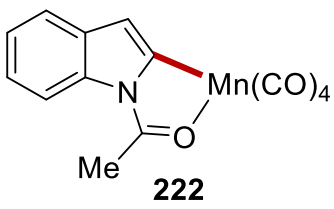

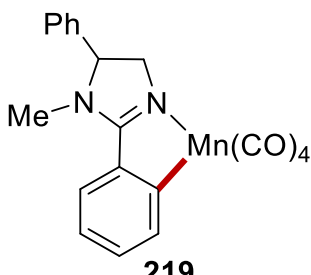

219

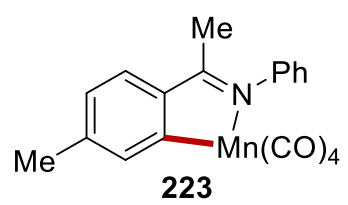<smiles>CN1Cc2ccccc2N1C(=O)[O-]</smiles>

220<smiles>O=[N+]([O-])c1ccccc1OP(O)O</smiles>

224<smiles>CN(C)c1onc2ccccc12</smiles>

221<smiles>O=C([O-])[N+]1O[PH](c2ccccc2)(c2ccccc2)c2ccccc21</smiles>

225

Scheme 1.4.2 Well-defined manganacycles. 
Despite the indisputable progress, manganese-catalyzed $\mathrm{C}-\mathrm{H}$ activation had been put in the shade before Kuninobu and Takai disclosed a seminal study in 2007. ${ }^{[121]}$ Thereby, a manganese(I) complex catalytically enabled C-H activation of arenes 226 with aldehydes 227 and $\mathrm{Et}_{3} \mathrm{SiH}$, affording silylated alcohols 228. Additionally, the catalytic cycle was proposed, in which $\mathrm{Mn}-\mathrm{C}$ bond was suggested as a manganese(III)-hydride species $\mathbf{2 2 9}$ is formed via an oxidative addition. The exact structure of the active catalyst has thus far remained elusive, while recent manganese-catalyzed hydroarylation reactions are generally proposed to undergo redox-neutral isohypsic pathway. Thereafter, a migratory insertion followed by reductive eliminations afforded the desired product $\mathbf{2 2 8}$.<smiles>[R]C1CN(C)C(c2ccccc2C)=N1</smiles>

a) Substrate scope<smiles>[R]C=O</smiles>

227

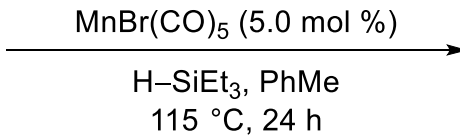

$115^{\circ} \mathrm{C}, 24 \mathrm{~h}$<smiles>[R]C1CN(C)C(c2ccccc2C([R])OCC)=N1</smiles>

228 228a: $60 \%(d e: 60 \%)$

Proposed mechanism<smiles>CCOC(c1ccccc1)c1ccccc1C1=N[C@@H](Cc2ccccc2)CN1C</smiles>

228b: $72 \%(d e: 30 \%)$<smiles>CCOC(c1ccccc1)c1ccccc1C1=NC(C(C)C)CN1C</smiles>

228c: $80 \%$ (de: $95 \%)$<smiles>CCOC(c1ccccc1C1=NC(C(C)C)CN1C)C(C)C</smiles>

228d: $68 \%($ de: $38 \%)$

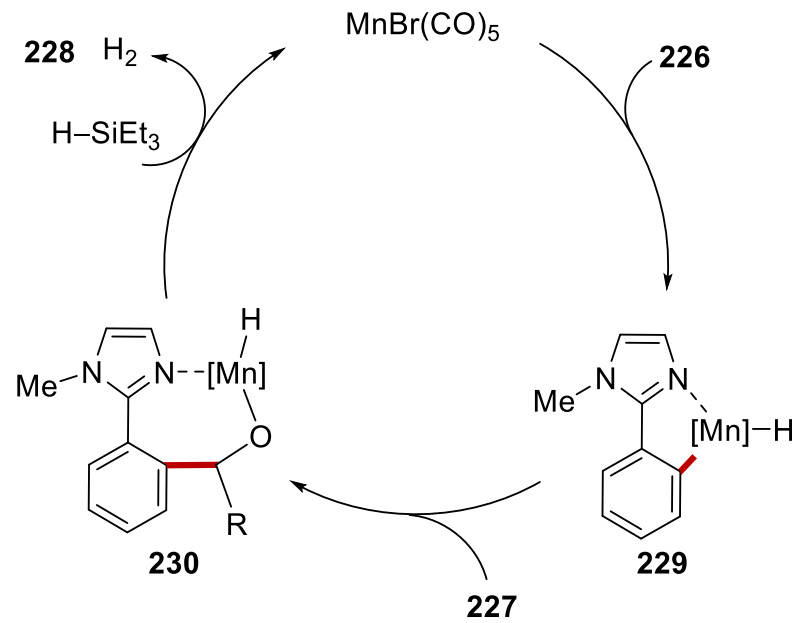

Scheme 1.4.3 Manganese-catalyzed $\mathrm{C}-\mathrm{H}$ addition to aldehydes 227 and proposed mechanism. 
In 2013, Wang showcased manganese-catalyzed C-H alkenylation of arenes $\mathbf{2 2 9}$ with terminal alkynes 230 (Scheme 1.4.4). ${ }^{[122]}$ The hydroarylation manifold was functional group tolerate. Detailed experimental mechanistic studies along with computational DFT studies suggested that the reaction proceeds through the formation of five-membered manganacycle $\mathbf{2 3 2}$ followed by seven-membered intermediate 233 construction. $^{[123]}$<smiles>[R17]c1ccccc1-c1ccccn1</smiles>

229<smiles></smiles>

230

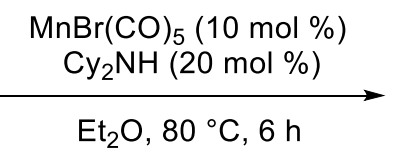

$\mathrm{R}^{1 / 1}$

a) Substrate scope<smiles>C(=C/c1ccccc1-c1ccccc1)\c1ccccc1</smiles>

231a: $76 \%$<smiles>FC(F)(F)c1ccccc1/C=C/c1ccccc1-c1ccccn1</smiles>

231b: $65 \%$<smiles>C(=C/c1cccc2ccccc12)\c1ccc2ccccc2c1</smiles>

231c: $78 \%$<smiles>COc1ccccc1/C=C/c1cc(Br)ccc1-c1ccccn1</smiles>

231d: $82 \%$<smiles>COc1ccccc1/C=C/c1cc(I)ccc1-c1ccccn1</smiles>

231e: $77 \%$

b) Proposed mechanism

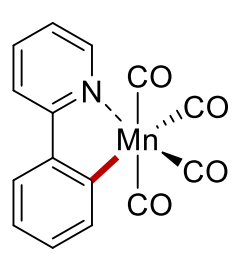

232

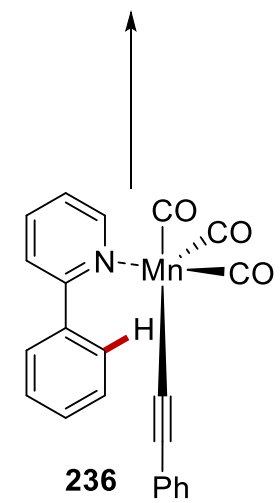
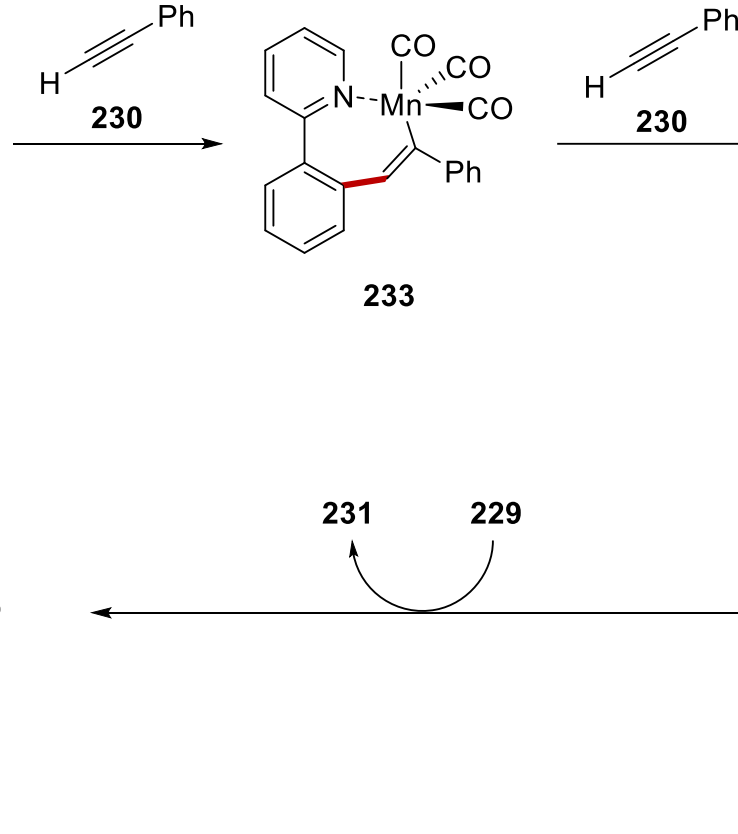

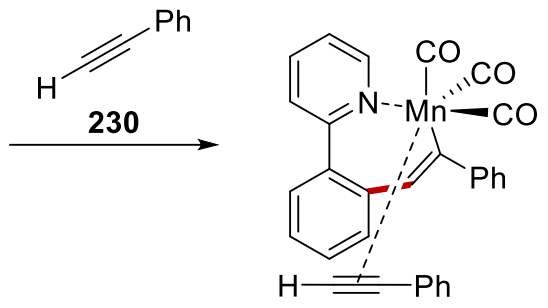

234

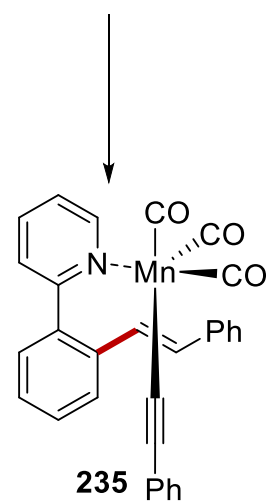

Scheme 1.4.4 Manganese-catalyzed C-H alkenylations of arenes 229. 
Then, researchers utilized different combinations of arenes and alkynes, providing synthetically useful products. For instance, while manganese-catalyzed annulation reactions with various types of alkynes were reported by Ackermann, ${ }^{[124]}$ Wang $^{[125]}$ among others, ${ }^{[126]}$ Glorius showed the manganesecatalyzed $\mathrm{C}-\mathrm{H}$ allenylation of indoles by using propargylic carbonate. ${ }^{[127]}$ Recently, Ackermann and coworkers employed bromo alkynes $\mathbf{2 3 8}$, for the first time, delivering alkynylated heteroarenes 239 by manganese catalysis (Scheme 1.4.5). ${ }^{[128]}$ Notably, this reaction manifold was extended to feature peptide modification, thus providing acyclic and cyclic alkynylated peptides under epimerization-free reaction conditions. Based on detailed mechanistic studies, they proposed a plausible catalytic cycle, in which the substrate $\mathbf{2 3 7}$ undergoes facile and reversible $\mathrm{C}-\mathrm{H}$ manganesation, followed by alkyne migratory insertion and $\beta$-Br-elimination.

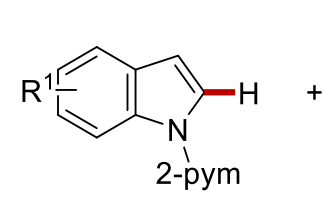

237

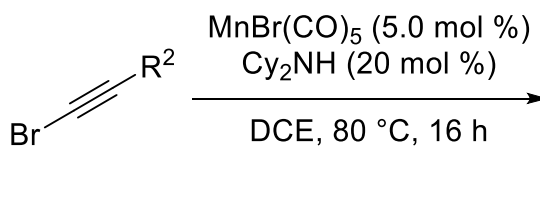

238

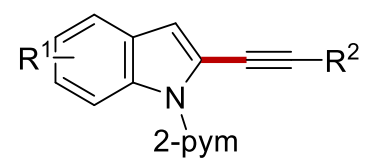

239<smiles>[Z20]n1c(C#CC(F)F)cc2ccccc21</smiles>

239a: 99\%<smiles>O=[N+]([O-])c1ccc2c(c1)cc(C#C[In])n2[18OH]</smiles>

239b: $63 \%$<smiles>C#Cc1cc2ccccc2n1P</smiles>

239c: $95 \%^{a}$<smiles>Brc1ccccc1C#Cc1cc2ccccc2n1[PbH]</smiles>

239d: $99 \%^{\mathrm{a}}$<smiles>[M]C(NC(=O)C(NC(=O)C(Cc1c(C#C[I+](C)(F)F)n([PH2+])c2ccccc12)NC(=O)OCc1ccccc1)C([M])C)C(=O)NCC(=O)N[C@@H](Cc1c[nH]c2ccccc12)C(=O)OC</smiles>

239e: $73 \%$ (with $0.05 \mathrm{~mol} \% \mathrm{BPh}_{3}$ )

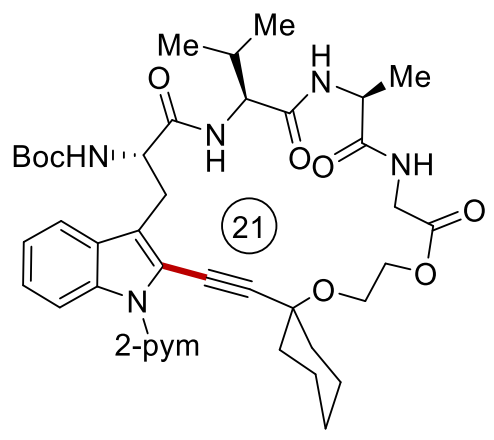

239f: $53 \%$ (with $0.05 \mathrm{~mol}^{\%} \mathrm{BPh}_{3}$ )

Scheme 1.4.5 Manganese-catalyzed C-H alkynylations with alkynyl bromides 238 . 
The manganese(I) catalysis was not limited to reactions with alkynes. Indeed, the manganese-catalyzed hydroarylation process was also applied to feature alkenes as coupling partners. In 2014, Wang and co-workers developed the manganese-catalyzed direct aromatic $\mathrm{C}-\mathrm{H}$ conjugate addition to $\alpha, \beta$ unsaturated carbonyls (Scheme 1.4.6). ${ }^{[129]}$<smiles>c1ccc(-c2ccccn2)cc1</smiles>

28

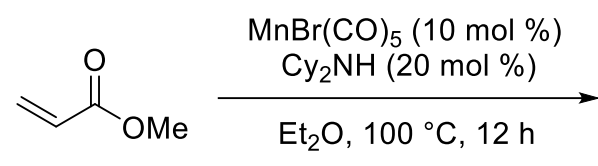

240

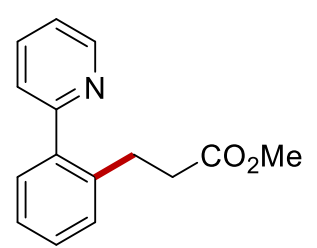

241: $85 \%$

Scheme 1.4.6 Manganese-catalyzed C-H alkylation with acrylates 240 .

As an extension of this approach, in 2017, Song reported manganese-catalyzed hydroarylations of indoles 242 with maleimides 243 (Scheme 1.4.7a). ${ }^{[130]}$ Later, Glorius employed in-situ generated $\alpha, \beta$ unsaturated carbonyls from $\alpha$-diazoketones 245 with the aid of silver additives (Scheme 1.4.7b). ${ }^{[131]}$

a) Song (2017)<smiles>[R4][X]</smiles>

b) Glorius (2018)<smiles>c1ccc(-n2ccc3ccccc32)nc1</smiles>

242<smiles>O=C1C=CC(=O)N1Pc1ccccc1</smiles>

243

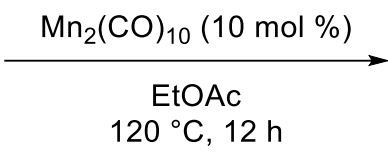

$120^{\circ} \mathrm{C}, 12 \mathrm{~h}$<smiles>CC(=N)C(=O)c1ccccc1</smiles>

245<smiles>O=C1CC(c2cc3ccccc3n2-c2ccccn2)C(=O)N1c1ccccc1</smiles>

244: $90 \%$

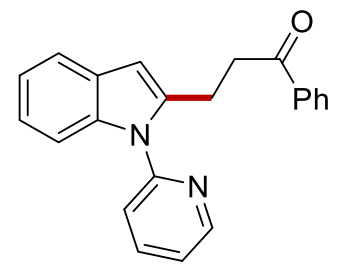

246: $99 \%$

Scheme 1.4.7 C-H alkylations or arenes 242 via manganese-catalyzed hydroarylation manifold.

In 2016, Ackermann and co-workers disclosed manganese-catalyzed C-H allylations of arenes 247 with allyl carbonates 248 (Scheme 1.4.8). ${ }^{[132]}$ While valuable functional groups, including halides, cyano, and carbonyls were tolerated, secondary interaction with a meta-substituent enabled the 
synthesis of 1,2,3-substituted arene 249c. While mechanistic investigation showed that $\mathrm{C}-\mathrm{H}$ the manganesation process is not involved in the rate-determining step, a base-assisted intramolecular electrophilic-type substitution (BIES) regime for manganese-catalyzed $\mathrm{C}-\mathrm{H}$ allylation was proposed by among other competition experiments.

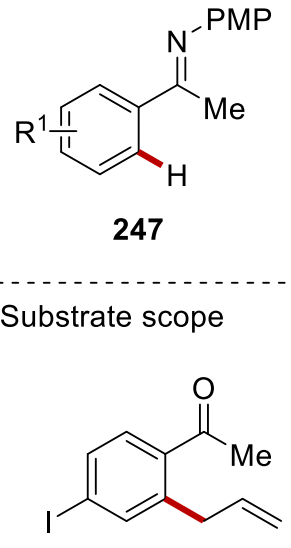

249a: $83 \%$

a) Substrate scope<smiles>[R]C([R])(C=C)OC(=O)OC</smiles>

248

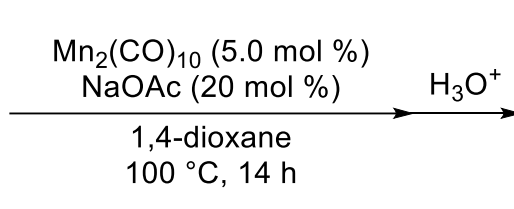

$100^{\circ} \mathrm{C}, 14 \mathrm{~h}$

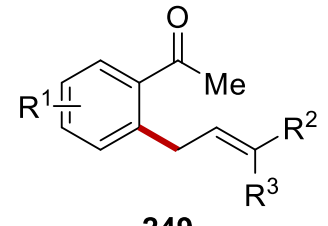

249

b) Kinetic isotope effect study<smiles>C=CCc1cc(C#N)ccc1C(C)=O</smiles>

249b: $87 \%$<smiles>C=CCc1c(C(=O)[N+](=O)[O-])ccc2c1OCO2</smiles>

249c: $67 \%$<smiles>CC(=O)c1ccc(C)cc1CC=C(C)C</smiles>

249d: $67 \%$

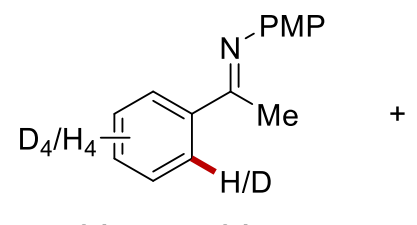

$247 /[D]_{5}-247$<smiles>C=CCOC(=O)OC</smiles>

248a

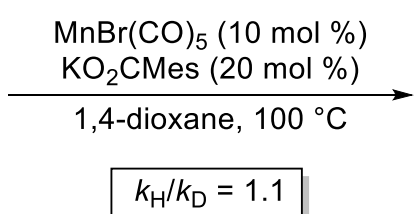<smiles>C=CCc1cc([N+](=O)[O-])ccc1/C(C)=N/N=P</smiles>

$249 \mathrm{e} /[\mathrm{D}]_{4}-249 \mathrm{e}$

c) Competition experiment<smiles>COc1ccc(/C(N)=N/OCc2ccccc2)cc1</smiles>

$247 \mathrm{f} / 247 \mathrm{~g}$

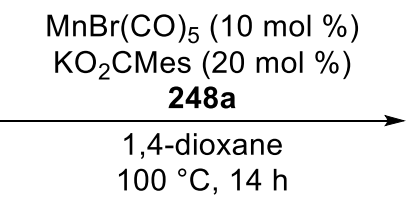

$100{ }^{\circ} \mathrm{C}, 14 \mathrm{~h}$

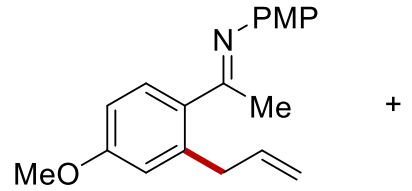

249f: $61 \%$<smiles>C=CCc1cc(F)ccc1/C(N)=N/N=P</smiles>

249g: $32 \%$

Scheme 1.4.8 Manganese-catalyzed C-H allylations.

In 2017, the same group reported manganese-catalyzed decarboxylative $\mathrm{C}-\mathrm{H}$ allylations of heteroarenes $\mathbf{2 4 2}$ and arenes $\mathbf{2 4 7 d}$ with dioxolanones 250 (Scheme 1.4.9). ${ }^{[133]}$ Thus, $\mathrm{C}-\mathrm{H} / \mathrm{C}-\mathrm{O}$ bond cleavages with concomitant formation of $\mathrm{CO}_{2}$ delivered the desired allyl alcohols $\mathbf{2 5 1}$ or $\mathbf{2 5 2}$ with high levels of the site- and chemo-selectivity. Later, this manganese catalysis manifold was further extended to include $\mathrm{C}-\mathrm{H} / \mathrm{C}-\mathrm{C}$ activation, affording allylated heteroarenes 254 (Scheme 1.4.9). ${ }^{[134]}$ 

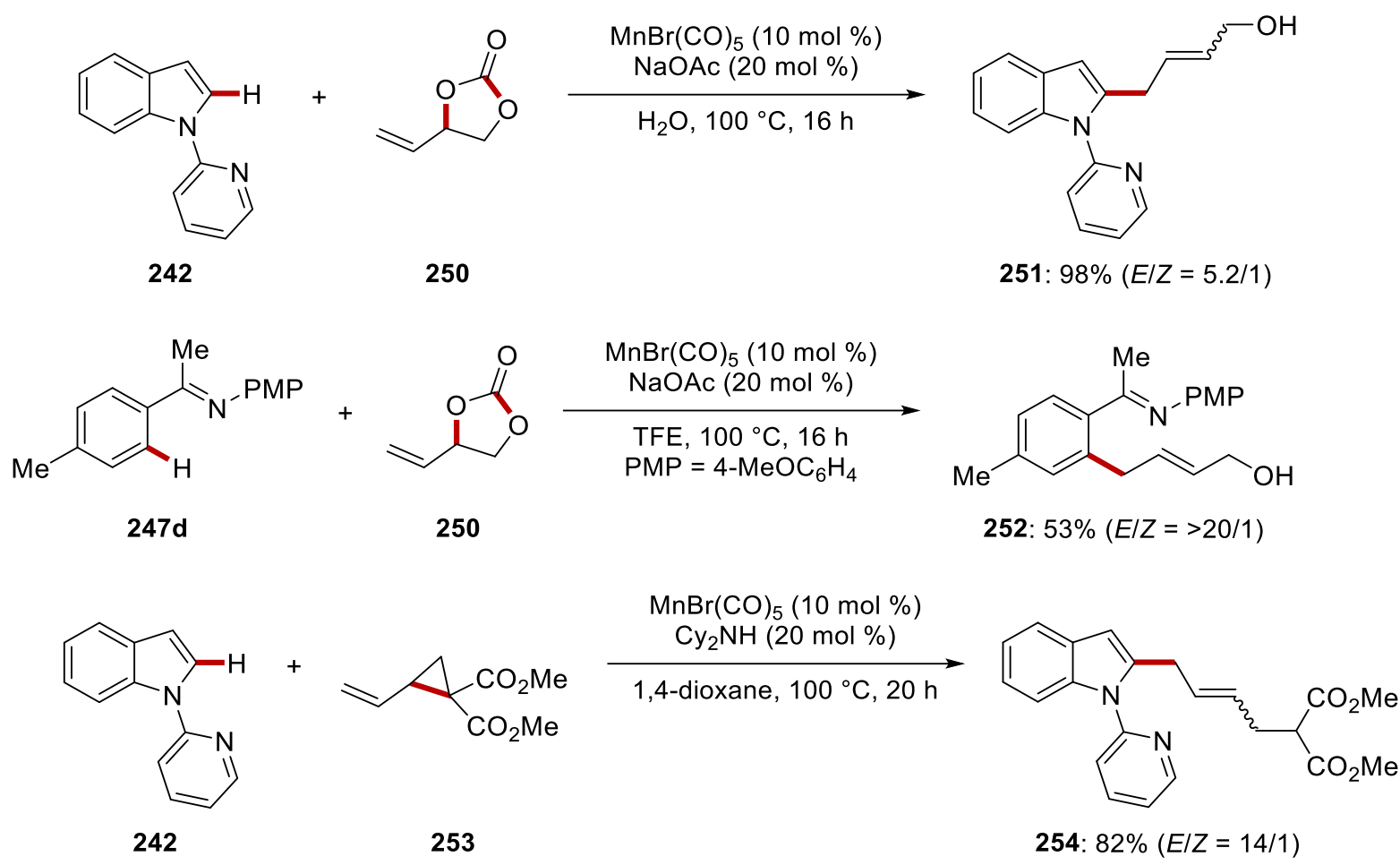

Scheme 1.4.9 Manganese-catalyzed $\mathrm{C}-\mathrm{H}$ allylation via $\mathrm{C}-\mathrm{H} / \mathrm{C}-\mathrm{O}$ or $\mathrm{C}-\mathrm{H} / \mathrm{C}-\mathrm{C}$ cleavage.

Thereafter, Glorius reported a similar manganese-catalyzed $\mathrm{C}-\mathrm{H}$ allylation. ${ }^{[135]}$ Along the same lines, Wang $^{[136]}$ and Zhang ${ }^{[137]}$ independently reported manganese-catalyzed $\mathrm{C}-\mathrm{H}$ allylation reactions with allenes and perfluoroallyl bromides as coupling partners respectively.

Manganese-catalyzed $\mathrm{C}-\mathrm{H}$ functionalizations with substrates including $\mathrm{C}-\mathrm{C}$ double bonds are not limited to allylations. Indeed, Ackermann and coworkers developed manganese-catalyzed $\mathrm{C}-\mathrm{H}$ annulation $^{[138]}$ of arenes 247 with acrylates 255, affording cis- $\beta$-amino acid esters 256 (Scheme 1.4.10). ${ }^{[139]}$ This interesting transformation involved the formation of a nucleophilic manganese intermediate, followed by intramolecular nucleophilic addition to the iminyl carbon. The operationally simple transformation featured high catalytic efficacy, good functional group tolerance, and an excellent cis stereoselectivity. 

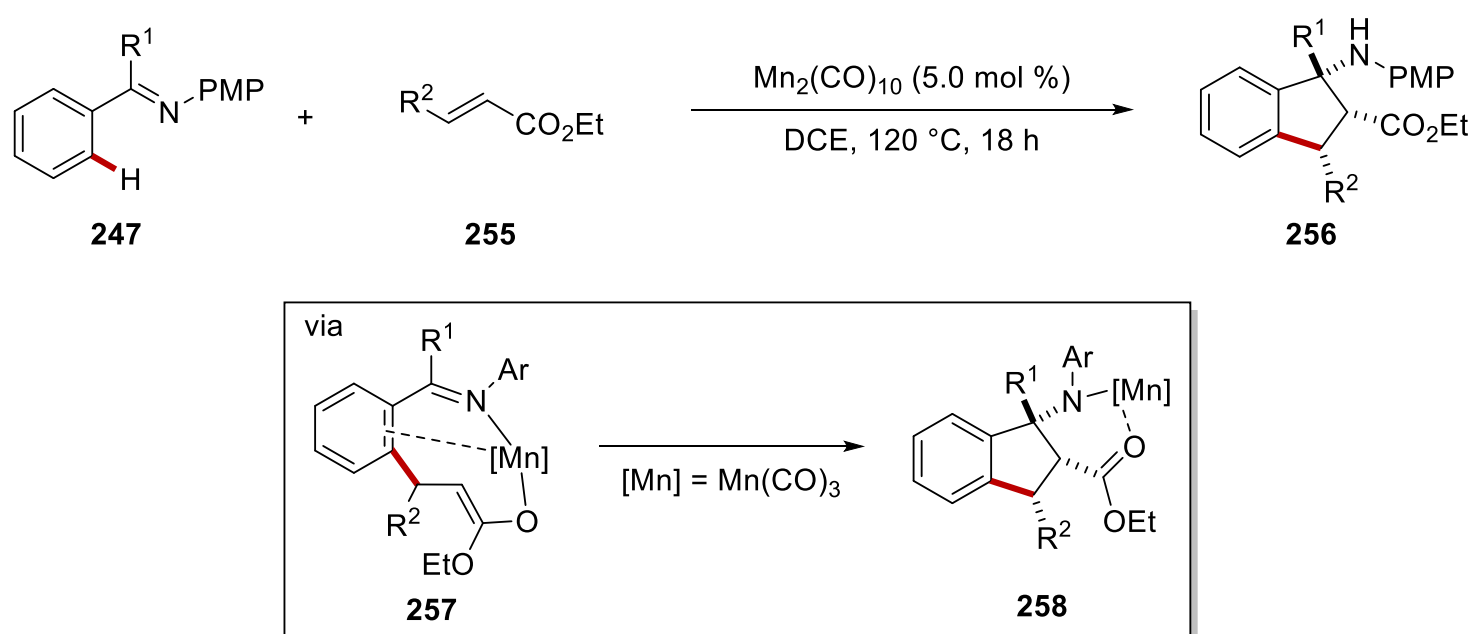

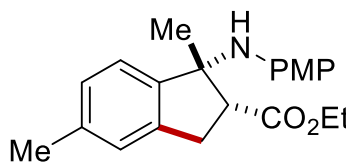

256a: $94 \%$<smiles>[R16]N[C@@]1(CC)c2ccccc2C[C@@H]1OCC</smiles>

256b: $85 \%$<smiles>[R16]N[C@]1(C)c2ccc(Br)cc2C[C@@H]1C(=O)OC</smiles>

256c: $68 \%$

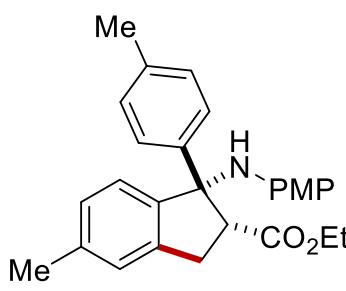

256d: $72 \%$

Scheme 1.4.10 Manganese-catalyzed alkene annulations.

Allenes are a class of unique compounds with two $\pi$-orbitals perpendicular to each other at the centered carbon. These unique features of allenes have been also introduced into manganese-catalyzed $\mathrm{C}-\mathrm{H}$ activation reactions, thereby producing interesting and useful chemical transformations. While Glorius reported manganese-catalyzed $\mathrm{C}-\mathrm{H}$ propagylation with bromoallenes with the aid of a borane-based Lewis acid, ${ }^{[140]}$ Wang $^{[141]}$ and Rueping, ${ }^{[142]}$ among others, ${ }^{[143]}$ showcased $\mathrm{C}-\mathrm{H}$ annulations of heteroarenes with allene moieties via Smiles rearrangement.

Apart from $\mathrm{C}-\mathrm{C}$ multiple bonds, electrophilic $\mathrm{C}-\mathrm{Het}$ multiple bonds were also found to be viable reaction partners. ${ }^{[144]}$ Thus, aldehydes, imines, or nitrile-containing substrates were introduced to the manganese-catalyzed hydroarylation reactions. In 2015, Ackermann and coworkers reported manganese-catalyzed $\mathrm{C}-\mathrm{H}$ aminocarbonylation of heteroarenes $\mathbf{2 4 2}$ with isocyanates $\mathbf{2 5 9}$, featuring a broad range of functional groups (Scheme 1.4.11). ${ }^{[145]}$ In addition, traceless removal of the pyridiyl directing group was achieved, enabling expedient access to $\mathrm{C} 2-\mathrm{H}$ functionalized indoles $\mathbf{2 6 0}$. 
<smiles>[Y20]n1c([1H])cc2c[R]#ccc21</smiles>

242
$\mathrm{O}_{\mathrm{C}_{\mathrm{N}^{-}}} \mathrm{R}^{2} \underset{\mathrm{Et}_{2} \mathrm{O}, 100^{\circ} \mathrm{C}, 16 \mathrm{~h}}{\stackrel{\mathrm{MnBr}(\mathrm{CO})_{5}(10 \mathrm{~mol} \%)}{\longrightarrow}}$

259<smiles>[R]NC(=O)c1cc2c(n1[Y60])C=[R1]=C=C2</smiles>

260

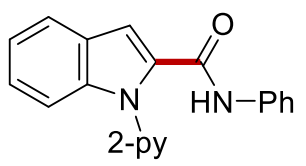

260a: $95 \%$

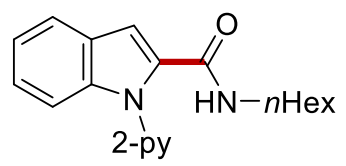

260b: $61 \%$

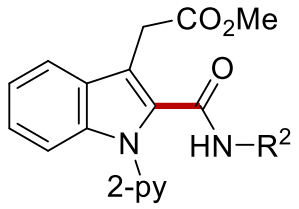

260c: $62 \%$

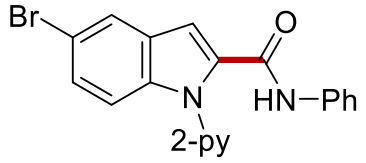

260d: $78 \%$

Scheme 1.4.11 Manganese-catalyzed $\mathrm{C}-\mathrm{H}$ aminocarbonylations.

Around the same time, the Wang group showed the manganese-catalyzed Grignard-type nucleophilic addition to aldehydes $\mathbf{2 6 1}$ or nitriles $\mathbf{2 6 3}$, providing benzylic alcohols 262 or ketones 264 , respectively (Scheme 1.4.12). ${ }^{[146]}$<smiles>c1ccc(-c2ccccn2)cc1</smiles>

28<smiles>c1ccc(-c2ccccn2)cc1</smiles>

28<smiles>O=Cc1ccccc1</smiles>

261

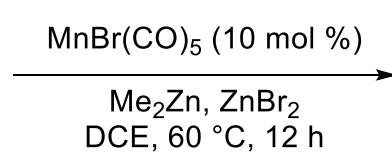

DCE, $60{ }^{\circ} \mathrm{C}, 12 \mathrm{~h}$

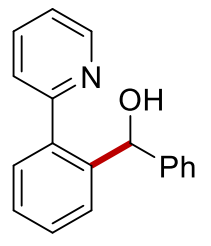

262: $81 \%$

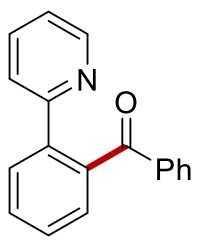

264: $77 \%$

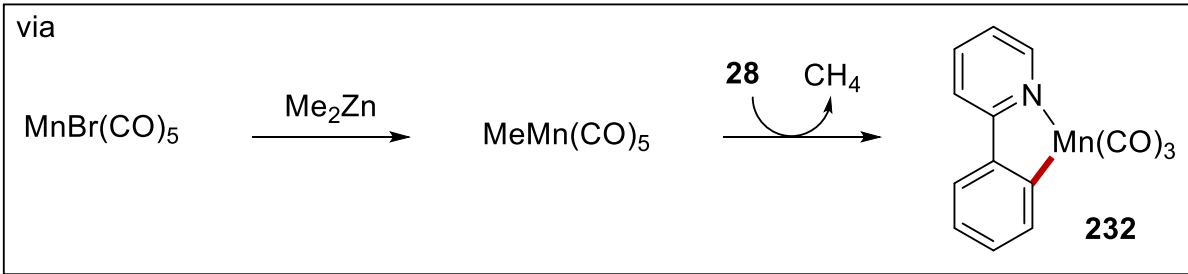

Scheme 1.4.12 Manganese-catalyzed C-H addition of arenes 28 to aldehydes 261 or nitriles 263 . 
Ackermann $^{[147]}$ and others ${ }^{[148]}$ additionally reported manganese-catalyzed hydroarylations with substrates having electrophilic C-Het multiple bonds (Scheme 1.4.13).

a) Ackermann

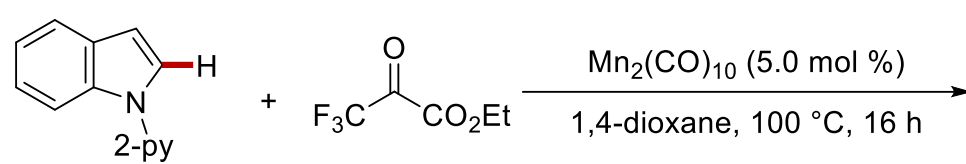

242<smiles>[R6]n1ccc2ccccc21</smiles>

242
265<smiles>[Sb]=[N+]=Cc1ccccc1</smiles>

267<smiles>[R6]n1c(C(O)(C(=O)OCC)C(F)(F)F)cc2ccccc21</smiles>

266: $90 \%$<smiles>[Y6]n1c(C(NS)c2ccccc2)cc2ccccc21</smiles>

268: $88 \%$

b) Glorius<smiles>[R20]n1ccc2ccccc21</smiles>

242

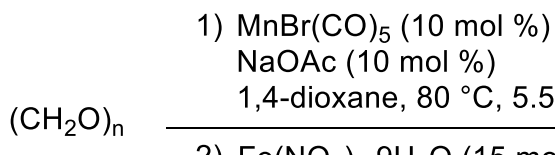

269<smiles>[Y6]n1c(C=O)cc2ccccc21</smiles>

270: $88 \%$

c) Wang<smiles>CC(C)(C)C(=O)c1ccccc1</smiles>

$38 c$<smiles>O=S(=O)(/N=C/c1ccccc1)c1cccs1</smiles>

271

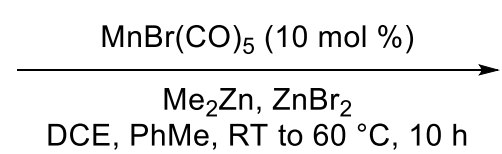

DCE, PhMe, RT to $60^{\circ} \mathrm{C}, 10 \mathrm{~h}$<smiles>O=S(=O)(NC(c1ccccc1)c1ccccc1Pc1ccccc1)c1ccccc1</smiles>

272: $80 \%$

Scheme 1.4.13 Manganese-catalyzed hydroarylation with carbonyl groups 265, 269 or imines 267, 271. 


\subsubsection{Manganese-Catalyzed C-H Arylations}

Manganese(I)-catalyzed $\mathrm{C}-\mathrm{H}$ activation of arenes has been generally governed by isohypsic mechanisms, which often impedes redox active catalysis. For this reason, manganese-catalyzed $\mathrm{C}-\mathrm{H}$ arylation reaction requires a different approach.

Ackermann and coworkers disclosed a manganese-catalyzed $\mathrm{C}-\mathrm{H}$ arylation by using a user-friendly and scalable flow technique (Scheme 1.4.14). ${ }^{[149]}$ The combination of the manganese salts $\mathrm{MnCl}_{2}$ and neocuproine allowed for expedient $\mathrm{C}-\mathrm{H}$ arylations of azines 273 with a broad substrate scope. On the basis of detailed experimental and computational studies, a Mn(II/III/I) manifold was proposed to be operative. Interestingly, the same group, later, reported electrochemical manganese-catalyzed $\mathrm{C}-\mathrm{H}$ arylations, in which electricity could replace the external oxidant DCIB. ${ }^{[150]}$

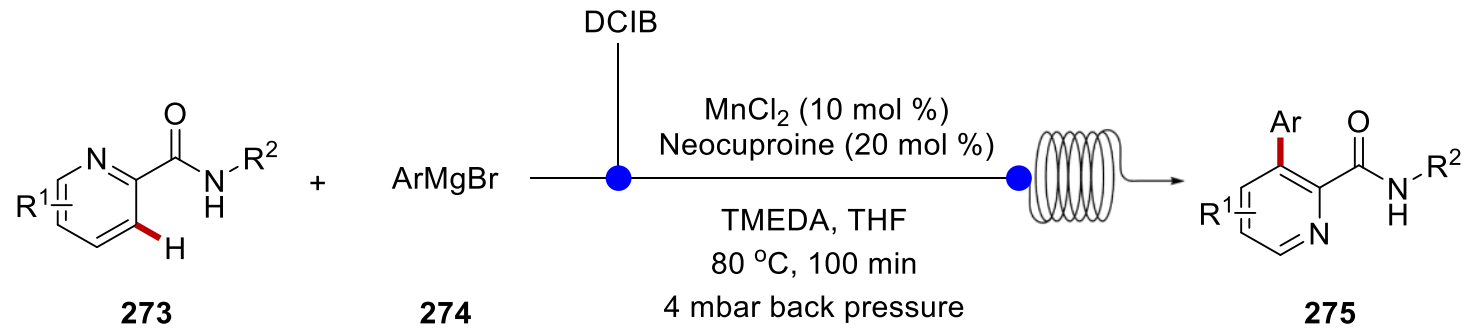

a) Substrate scope<smiles>CCCCNC(=O)c1ncccc1-c1ccc(OC)cc1</smiles>

275a: $74 \%$<smiles>COc1ccc(-c2cccnc2C(=O)NCc2ccccc2)cc1</smiles>

275b: $65 \%$<smiles>CCCCNC(=O)c1ncccc1-c1ccc(N(C)C)cc1</smiles>

275c: $55 \%$<smiles>CCCCNC(=O)c1ncncc1-c1ccc(OC)cc1</smiles>

275d: $50 \%$<smiles>CCCCNC(=O)c1cncc(C)c1-c1ccc(OC)cc1</smiles>

275e: $80 \%$

Scheme 1.4.14 Manganese-catalyzed $\mathrm{C}-\mathrm{H}$ arylations using flow technique.

More recently, Ackermann developed photo-induced manganese-catalyzed $\mathrm{C}-\mathrm{H}$ arylations by flowchemistry (Scheme 1.4.15). ${ }^{[151]}$ Thus, a plethora of aryldiazonium salts $\mathbf{2 7 6}$ was transformed to biaryls 278 under the optimized conditions. The robustness of the manganese-catalyzed $\mathrm{C}-\mathrm{H}$ arylation in continuous photoflow was extended to feature heteroarenes $(\mathbf{2 7 8 e - 2 7 8 h})$ with high functional group tolerance. Interestingly, an intermolecular kinetic isotope effect was not observed, indicating a nonkinetically relevant $\mathrm{C}-\mathrm{H}$ cleavage. 


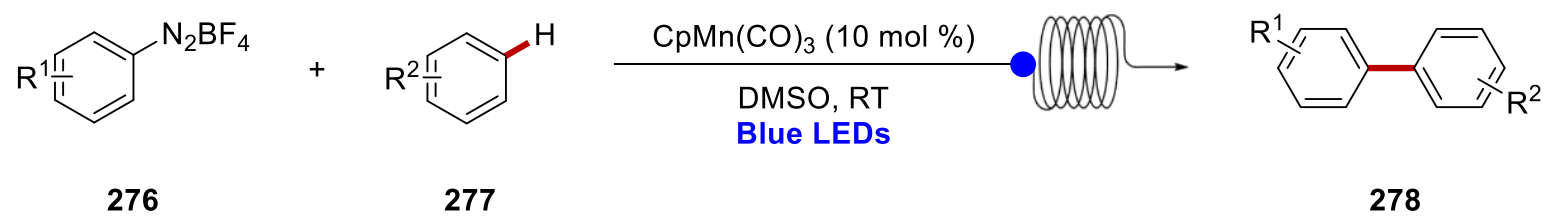

a) Substrate scope

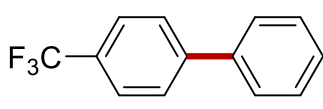

278a: $62 \%$

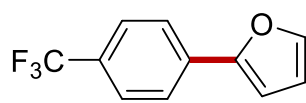

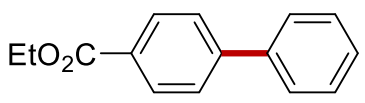

278b: $61 \%$

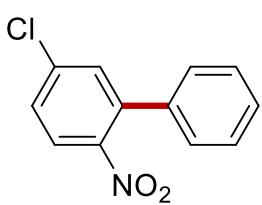

278c: $71 \%$<smiles>Cc1cc(C)c(-c2ccc(C(F)(F)F)cc2)c(C)c1</smiles>

278d: $54 \%$<smiles>Fc1ccc(-c2cccs2)cc1</smiles>

Boc<smiles>FC(F)(F)c1ccc(-c2ccc[nH]2)cc1</smiles>

278h: $62 \%$

278e: $78 \%$

278f: $52 \%$

278g: $59 \%$

b) Kinetic study

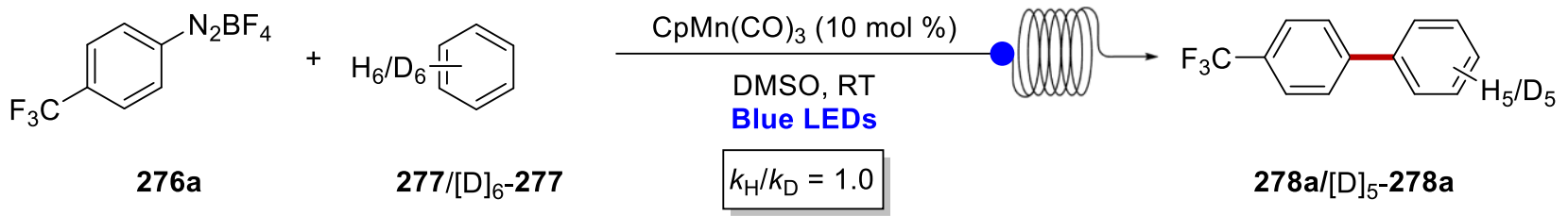

Scheme 1.4.15 Visible-light-induced manganese-catalyzed $\mathrm{C}-\mathrm{H}$ arylations in flow. 


\subsection{Copper-Catalyzed C-H Activation}

Similar to manganese, copper is an inexpensive and environmentally benign element. In addition, its readily accessible oxidation states from 0 to +3 provide new bond formation processes through radical or one- and two-electron transfer processes. ${ }^{[152]}$ With these inherent benefits, copper catalysis has emerged as an important tool for organic reactions with a long history. Starting from the Glaser coupling, ${ }^{[153]}$ copper-mediated reaction enabled a plethora of chemical transformations. Hence, copper has played a significant role in catalysis. Inspired by the pioneering work of Ullmann and Goldberg from 1901 to 1906 (Scheme 1.5.1), ${ }^{[154]}$ a variety of transformation by copper catalysis have been achieved. ${ }^{[155]}$

a) Ullmann (1901)<smiles>O=[N+]([O-])c1ccccc1Br</smiles>

279

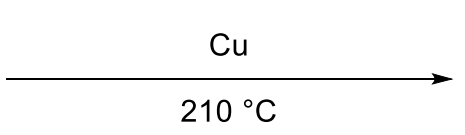

b) Ullmann (1905)<smiles>Oc1ccccc1</smiles>

281

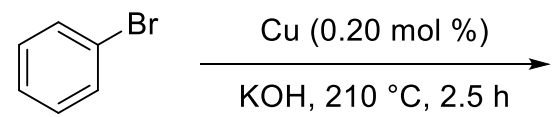

282<smiles>O=[N+]([O-])c1ccccc1-c1ccccc1[N+](=O)[O-]</smiles>

280: $76 \%$

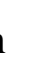




\subsubsection{Copper-Catalyzed C-H Arylations}

In 1901, Ullmann disclosed the first arylation using a stoichiometric amount of copper via reductive coupling. ${ }^{[38 b]}$ Thereafter, Ullmann reported copper-catalyzed $\mathrm{N}-\mathrm{H}$ arylations of anilines as well as $\mathrm{O}-$ H arylations of phenol. ${ }^{[38 a, 14 b]}$ In 1906, Goldberg additionally revealed copper-catalyzed aminations with anilines or amides. ${ }^{[14 \mathrm{a}]} \mathrm{With}$ these pioneering reports, copper enabled $\mathrm{C}-\mathrm{C}, \mathrm{C}-\mathrm{N}$, and $\mathrm{C}-\mathrm{O}$ bond formations, which became a milestone for the development of copper-catalyzed $\mathrm{C}-\mathrm{H}$ arylations.

Copper-catalyzed $\mathrm{C}-\mathrm{H}$ arylation can be categorized by four different approaches, including (i) the use of electrophilic reagents, (ii) the use of nucleophilic reagents, (iii) the use of carboxylic acids for decarboxylations, and (iv) cross-dehydrogenative couplings.

a) Electrophilic coupling partners

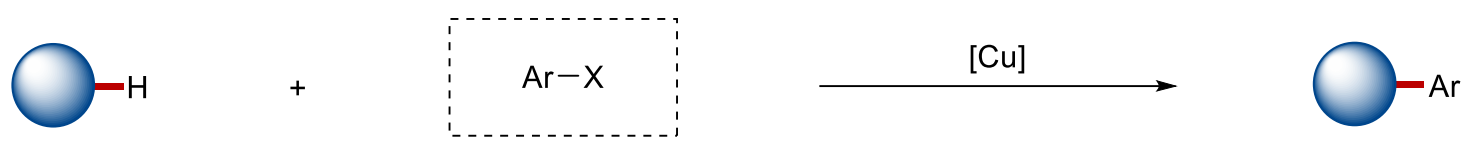

b) Arylations with nucleophilic coupling partners
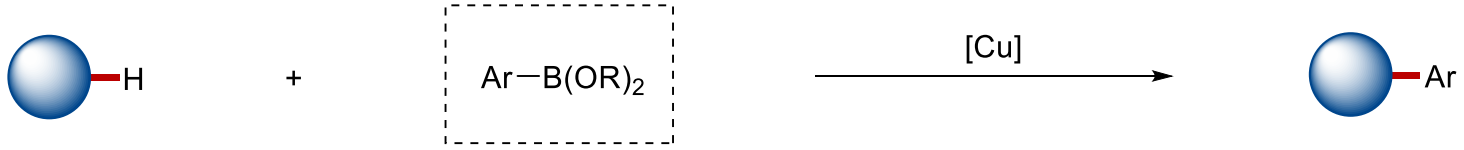

c) Decarboxylative arylations
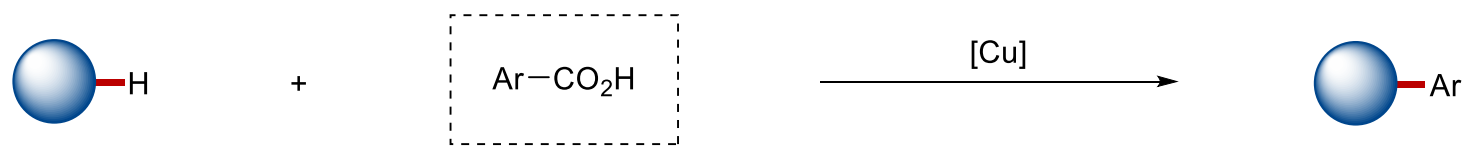

d) Cross-dehydrogenative arylations

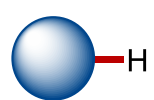

$+$

$\mathrm{Ar}-\mathrm{H}$
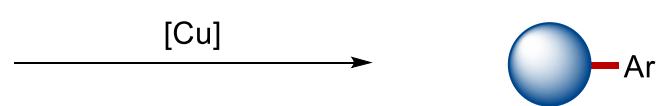

Scheme 1.5.2 Strategies for copper-catalyzed C-H arylations.

Nilsson ${ }^{[156]}$ and Wahen ${ }^{[157]}$ reported an early C-H arylation with copper complexes in 1968 and in 1973 respectively. Although the stoichiometric use of copper complex was required in presence of the palladium(II) catalyst, Miura clearly showed that copper enabled a switch in the site-selectivity of C- 
$\mathrm{H}$ arylations (Scheme 1.5.3). ${ }^{[158]}$ Notably, since C5-H arylation of $N$-methylimidazole 284 occurs via an electrophilic palladation, the copper complex plays a significant role in the C2-H arylations. ${ }^{[159]}$ Interestingly, $\mathrm{N}$-methylbenzimidazole only showed $\mathrm{C} 2-\mathrm{H}$ arylation with stoichiometric use of copper iodide in absence of the palladium(II) catalyst.

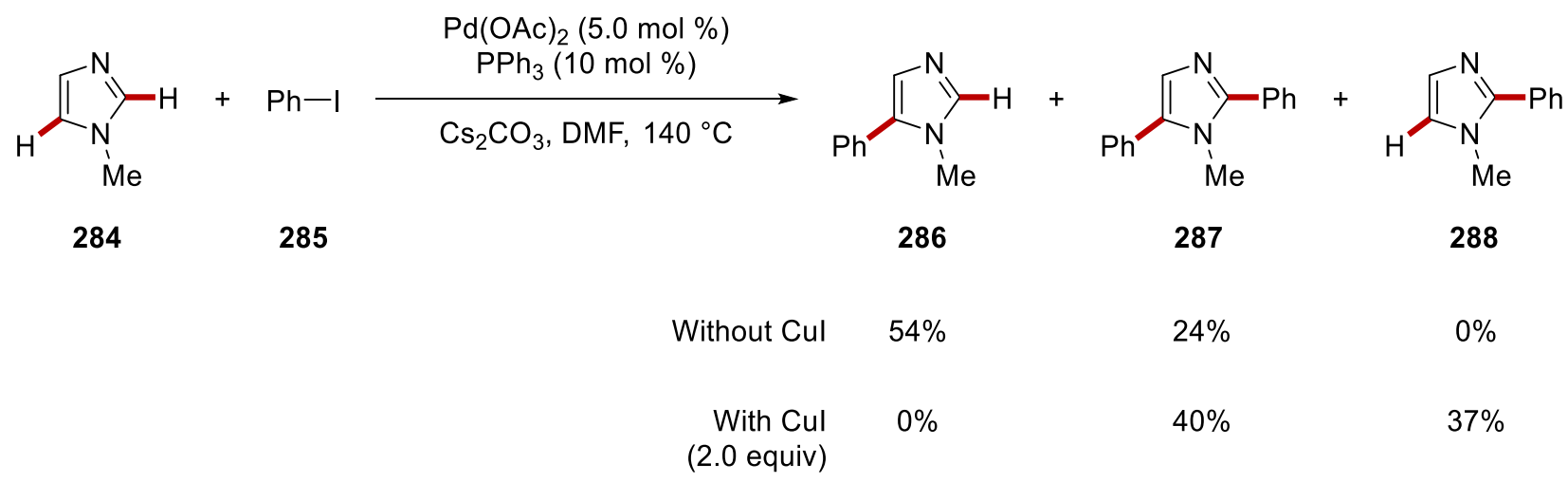

Scheme 1.5.3 The effect of copper additives in palladium-catalyzed C-H arylation.

These findings allowed researchers to envisage the involvement of catalytic organocopper intermediates in the $\mathrm{C}-\mathrm{H}$ arylation reactions. Inspired by these studies, Daugulis disclosed coppercatalyzed $\mathrm{C}-\mathrm{H}$ arylation of electron-rich heterocycles, including oxazoles, benzoxazoles, thiazoles, and benzothiazoles (Scheme 1.5.4). ${ }^{[160]}$ The combination of lithium alkoxide bases and aryl iodides enabled sustainable $\mathrm{C}-\mathrm{H}$ arylations, while other aryl halides or tosylates fell short in delivering the desired arylated product. In their mechanistic proposal, deprotonation followed by lithium-copper transmetallation affords organocopper species, while the involvement of arynes intermediates could be ruled out through mechanistic investigations. 


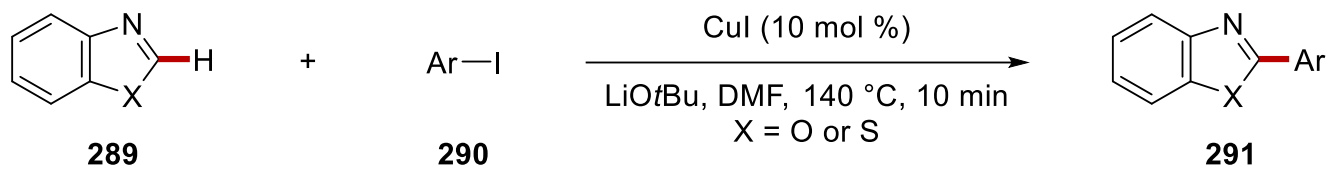

a) Selected examples

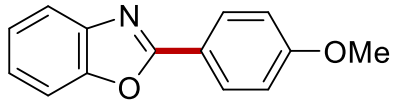

291a: $80 \%$

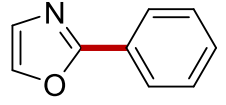

291b: $59 \%$

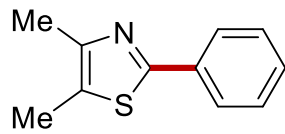

291c: $84 \%$

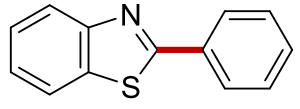

291d: $82 \%$

b) Mechanistic investigations<smiles>[2H]c1c([2H])c([2H])c(I)c([2H])c1[2H]</smiles>

292<smiles>Cc1nc(I)sc1C</smiles>

292
$[D]_{5}-290 b$<smiles>[2H]c1c([2H])c([2H])c(I)c([2H])c1[2H]</smiles>

$[D]_{5}-290 b$
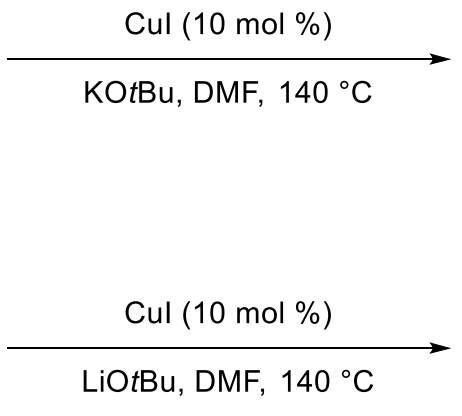<smiles>[2H]c1c([2H])c(-c2nc(C)c(C)s2)c([2H])c([2H])c1C</smiles>

$[D]_{5}-293: 35 \%$<smiles>[2H]c1c([2H])c([2H])c(-c2nc(C)c(C)s2)c([2H])c1[2H]</smiles>

$[D]_{5}-293: 80 \%$

Scheme 1.5.4 Copper-catalyzed C-H arylations.

Then, the same group reported copper-catalyzed $\mathrm{C}-\mathrm{H}$ arylations of electron-deficient as well as polyfluorinated arenes, ${ }^{[161]}$ which was further extended to the new methods where both electron-rich and electron-poor heterocycles could be employed as viable substrates (Scheme 1.5.5). ${ }^{[162]}$ Pentafluorophenyl copper intermediate 297 was separately prepared with the aid of phenanthroline ligand. The copper complex 297 was transformed to the biaryl product in a stoichiometric fashion, which showed to conclude that $\mathrm{C}-\mathrm{H}$ cuperation is the key to the success of the copper-catalyzed $\mathrm{C}-\mathrm{H}$ arylations. Notably, while the early example of copper-catalyzed $\mathrm{C}-\mathrm{H}$ activation was proposed to proceed via SET mechanisms, this study proposed organometallic $\mathrm{C}-\mathrm{Cu}$ intermediates. 


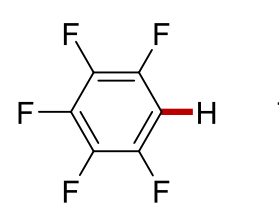

294

$$
\begin{gathered}
\text { Cul }(10 \mathrm{~mol} \%) \\
\text { Phenanthroline }(10 \mathrm{~mol} \%) \\
\underset{\mathrm{K}_{3} \mathrm{PO}_{4}, \mathrm{DMF} / x y l e n e, 140{ }^{\circ} \mathrm{C}}{\longrightarrow}
\end{gathered}
$$

295

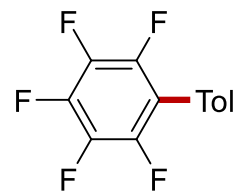

296: $91 \%$

a) Mechanistic studies

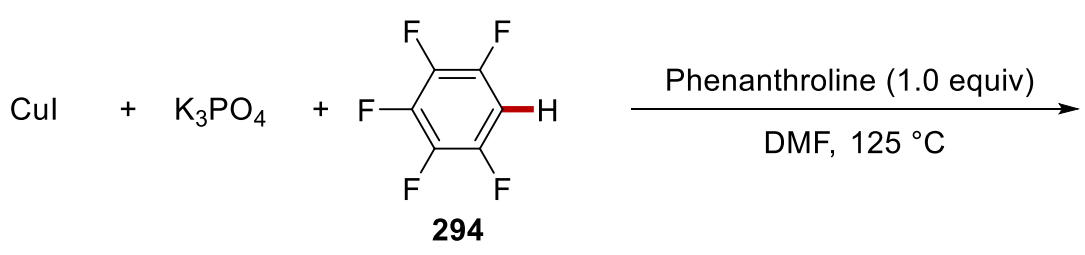<smiles></smiles>

297

(Detected by ${ }^{19} \mathrm{~F}$ NMR)

Scheme 1.5.5 Copper-catalyzed C-H arylations of perfluoroarene 294 .

Concurrently, Ackermann disclosed the copper-catalyzed C-H arylation of triazoles 298 (Scheme 1.5.6). ${ }^{[163]}$ The 1,2,3-triazoles 298 were readily obtained by copper-catalyzed click reaction followed by $\mathrm{C}-\mathrm{H}$ arylation, establishing multicomponent protocols to synthesized a variety of fully substituted triazoles.

a) Two-components reaction

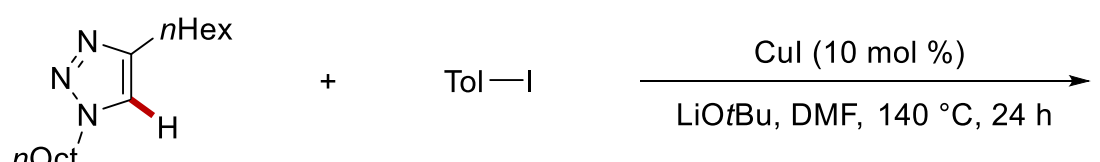

$$
298
$$

295

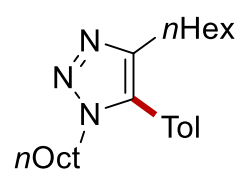

299: $74 \%$

b) Three-component reaction

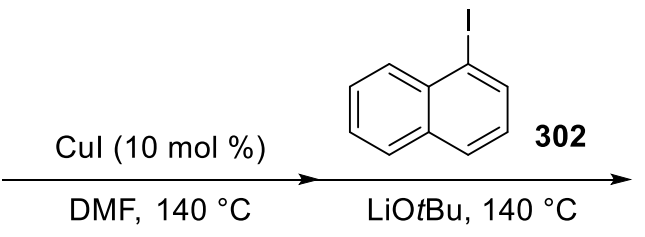

300

c) Four-component reaction

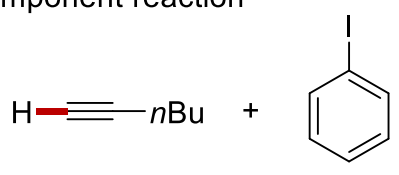
285

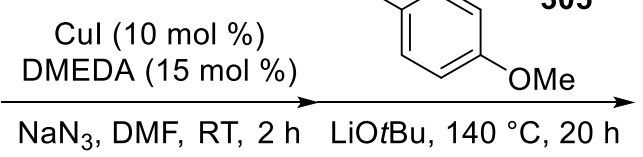

$\mathrm{Ph}$<smiles>c1ccc(Cn2nnc(-c3ccccc3)c2-c2cccc3ccccc23)cc1</smiles>

303: $84 \%$<smiles>CCCCc1nnn(-c2ccccc2)c1-c1ccc(OC)cc1</smiles>

306: $73 \%$

Scheme 1.5.6 Multi-component copper-catalyzed C-H arylations. 
Inspired by these studies by Daugulis, Miura, and Ackermann, a plethora of $\mathrm{C}-\mathrm{H}$ arylation studies was reported with various heterocycles, including azoles, ${ }^{[164]}$ benzotriazepines, ${ }^{[165]}$ caffeine, ${ }^{[166]}$ uracil, ${ }^{[167]}$ among others. ${ }^{[168]}$

In 2016, Ackermann and coworkers reported unprecedented photo-induced copper-catalyzed $\mathrm{C}-\mathrm{H}$ arylation under exceedingly mild conditions at room temperature (Scheme 1.5.7). ${ }^{[169]}$ Additionally, this manifold was further extended to the reaction under visible light conditions with a iridium photocatalyst.

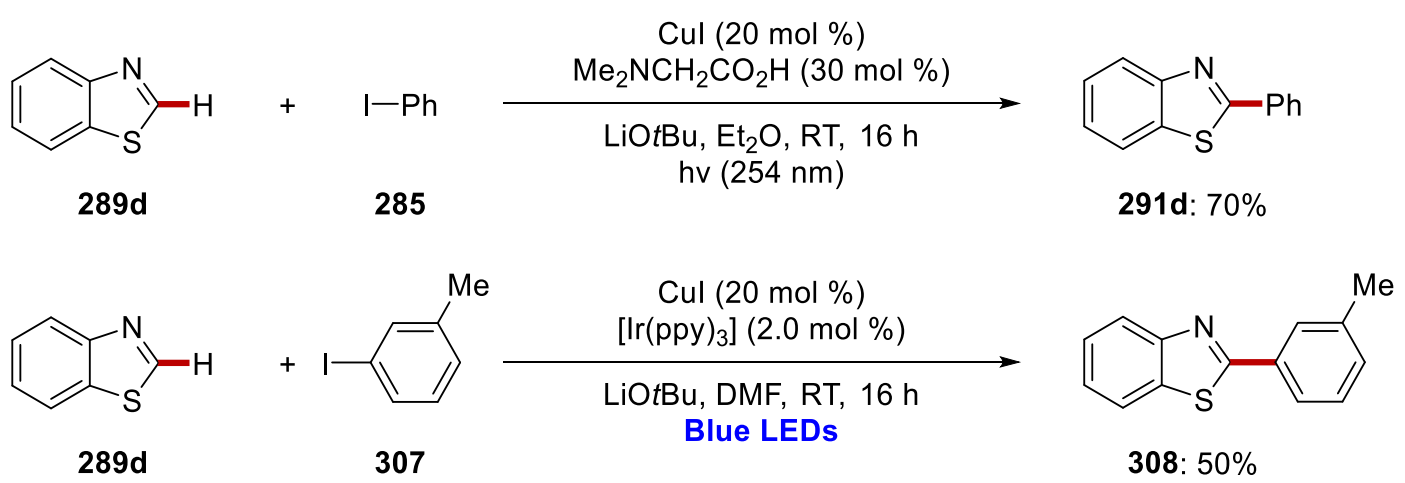

Scheme 1.5.7 Photo-induced copper-catalyzed C-H arylations.

With these aforementioned established studies, intramolecular approaches of copper-catalyzed $\mathrm{C}-\mathrm{H}$ arylations were also developed. Namely, Ackermann showed the intramolecular $\mathrm{C}-\mathrm{H} / \mathrm{C}-\mathrm{X}$ activation, in which the construction of fully substituted cyclic 1,2,3-triazoles 311 was successfully achieved through [3+2] azide-alkyne cycloadditions followed by $\mathrm{C}-\mathrm{H}$ activation (Scheme 1.5.8). ${ }^{[170]}$

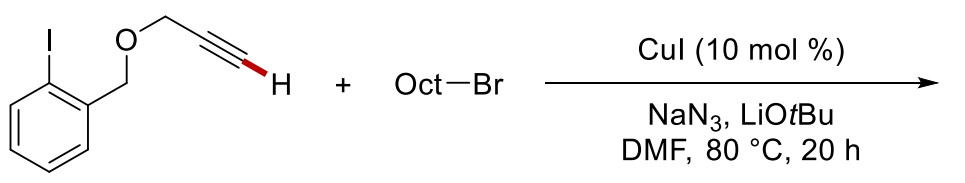

309

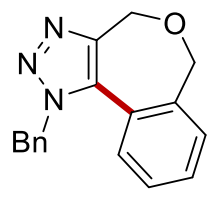

311: $75 \%$

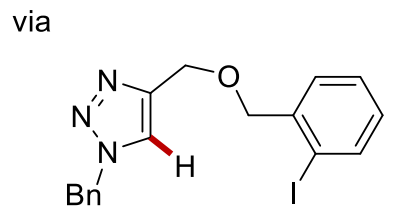

Scheme 1.5.8 Three-component intramolecular copper-catalyzed C-H arylation. 
The use of electrophilic reagents was not limited to aryl halides, but was extended to include diaryliodonium salts. In 2008, Gaunt disclosed a copper-catalyzed divergent $\mathrm{C}-\mathrm{H}$ arylation of indoles 312 with diphenyliodonium salt 313(Scheme 1.5.9). ${ }^{[171]}$ Thus, $\mathrm{C} 2-\mathrm{H}$ and $\mathrm{C} 3-\mathrm{H}$ of indoles could be independently functionalized under slightly different conditions. They also proposed possible reaction mechanisms for each functionalization, starting from the key aryl-copper(III) intermediate. Notably, the established method was further applied to the synthesis of alkaloid dictyodendrin B. $^{[172]}$<smiles>CN1C(=Cc2ccccc2)c2ccccc21</smiles>

314

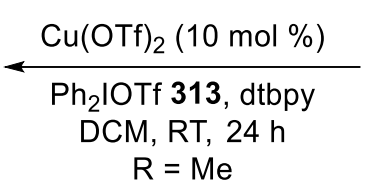

$\mathrm{R}=\mathrm{Me}$<smiles>[R]n1ccc2ccccc21</smiles>

312

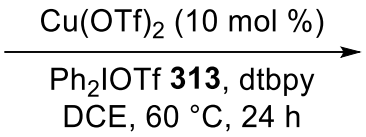

$\mathrm{R}=\mathrm{Ac}$

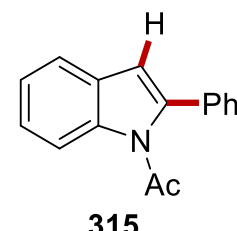

315

Scheme 1.5.9 Divergent copper-catalyzed C-H arylations of indole 312 with diaryliodonium salt 313 .

Gaunt also expanded the copper catalysis using diaryliodonium salts to $\mathrm{C}-\mathrm{H}$ arylation, particularly providing meta-C-H functionalizations of arenes (Scheme 1.5.10). ${ }^{[173,73 c]}$ The catalytic cycle was proposed as two different pathways; oxycuperation mechanism and Mizoroki-Heck-type mechanism. ${ }^{[174]}$<smiles>Cc1ccccc1N=N</smiles>

316<smiles>[R]C(=O)Cc1ccccc1C</smiles>

318
$+\mathrm{Phl}_{2} \mathrm{OTf} \quad \stackrel{\mathrm{Cu}(\mathrm{OTf})_{2}(10 \mathrm{~mol} \%)}{\mathrm{DCE}, 70{ }^{\circ} \mathrm{C}, 20 \mathrm{~h}}$

313

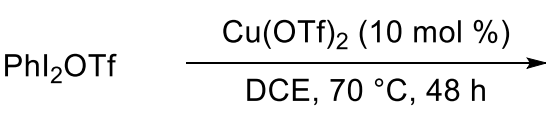<smiles>Cc1ccc(-c2ccccc2)cc1N=N</smiles>

317: $79 \%$<smiles>[R]C(=O)Cc1cc(-c2ccccc2)ccc1C</smiles>

$319(\mathrm{R}=\mathrm{NMeOMe}): 84 \%(48 \mathrm{~h})$

$320(R=M e): \quad 50 \%(24 h)$

Scheme 1.5.10 Copper-catalyzed C-H arylations with diphenyliodonium salt 313 .

Later, Gaunt reported para-C-H arylations of anisole and anilines using copper catalysis with diphenyliodonium salts 313. ${ }^{[175]}$ 
As the use of nucleophile organometallic reagents, in 2008, Itami showed the copper-mediated $\mathrm{C}-\mathrm{H}$ arylation of arenes 321 and heteroarenes 312 with aryl boronic acids 322 (Scheme 1.5.11). ${ }^{[176]}$ Afterwards, this reaction manifold was extended for the arylation of various heteroarene with aryl boronic esters as well as aryl Grignard reagents. ${ }^{[177]}$<smiles>COc1cc(OC)cc(OC)c1</smiles>

321<smiles>Cn1c(F)cc2ccccc21</smiles>

312 $+\quad \operatorname{PhB}(\mathrm{OH})_{2}$

322

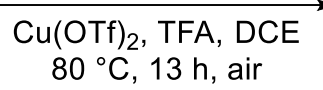
$80^{\circ} \mathrm{C}, 13 \mathrm{~h}$, air

\section{$\mathrm{Cu}(\mathrm{OTf})_{2}, \mathrm{TFA}, \mathrm{DCE}$} $80^{\circ} \mathrm{C}, 13 \mathrm{~h}$, air<smiles>COc1cc(OC)c(-c2ccccc2)c(OC)c1</smiles>

323: $68 \%$<smiles>Cn1c(-c2ccccc2)c(-c2ccccc2)c2ccccc21</smiles>

324: $54 \%$

Scheme 1.5.11 Copper-mediated C-H arylations with aryl boronic acid $\mathbf{3 2 2}$.

In 2014, Dai and Yu group disclosed oxidative C-H arylations with organoboron reagents with the aid of a bidentate directing group (Scheme 1.5.12a). ${ }^{[178]}$ Thereafter, Wang reported the copper-catalyzed $\mathrm{C}-\mathrm{H}$ arylation of azacalix[1] arene[3]-pyridines 332 with aryl boronic acids 322 (Scheme 1.5.12b). ${ }^{[179]}$ Interestingly, these two studies proposed slightly different catalytic mechanisms. In Yu's study, the reaction was proposed to proceed through aryl copper(III) intermediates followed by reductive elimination and oxidation, regenerating the active copper(II) species. However, Wang performed stoichiometric reactions with independently prepared well-defined copper(II) and copper(III) intermediates, but interestingly, only the reaction with the copper(II) compound $\mathbf{3 3 4}$ afforded the arylated product $\mathbf{3 3 3}$. 
a) Yu's work and their proposed mechanism<smiles>O=C(Nc1ccccc1C1=NCCO1)c1ccccc1</smiles>

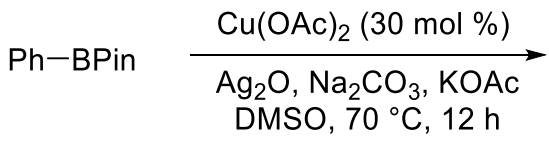

326<smiles>O=C(Nc1ccccc1C1=NCCO1)c1ccccc1-c1ccccc1</smiles>

327: $70 \%$

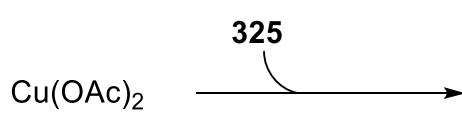<smiles>O=C(c1ccccc1Cl)N1CCOC1c1ccccc1N1CCOCC1</smiles>
$\mathrm{Cu}(\mathrm{OAc})_{2} \mathrm{CuOAc}$

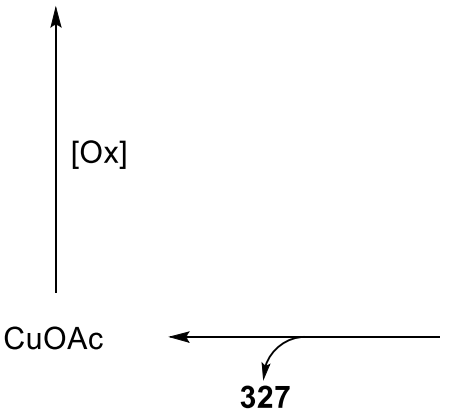

328<smiles>CC(=O)O[Al-]1(C(=O)O)N(C(=O)c2ccccc2)c2ccccc2C2OCCN21</smiles>

329<smiles>[134Os]CC1CC1</smiles><smiles>O=C(c1ccccc1-c1ccccc1)N1[Al]N2CCOC2=C2C=CC=CN21</smiles><smiles></smiles>

331

330

b) Wang's work and their proposed mechanism<smiles>CN(C)c1cccc(N(C)c2cccc(N(C)c3cccc(N(C)c4cccc(N(C)c5ccccc5)n4)n3)n2)n1</smiles>

332

322

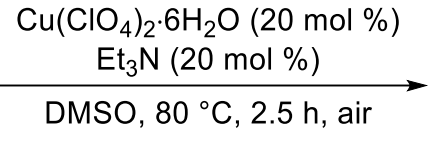<smiles></smiles>

334<smiles>CN(c1ccccc1)c1cccc(N(C)c2cccc(N(C)c3cccc(N(C)c4cccc(N(C)c5cccc(N(C)c6ccccc6)n5)n4)n3)n2)c1</smiles>

333<smiles>CN(c1ccccc1)c1cccc(N(C)c2cccc(N(C)c3cccc(N(C)c4cccc(N(C)c5ccccc5)n4)n3)n2)n1</smiles>

333: $90 \%$<smiles></smiles>

335

Scheme 1.5.12 Copper-catalyzed and mediated C-H arylations. 
For the third type of copper-catalyzed $\mathrm{C}-\mathrm{H}$ arylations, decarboxylation of aryl carboxylic acid has also emerged as a viable arylating method. ${ }^{[180]}$ Hoover and coworkers reported decarboxylative arylations by copper catalysis in 2015 (Scheme 1.5.13a). ${ }^{[181]}$ In the next year, Maiti reported a similar coppercatalyzed C-H arylation via decarboxylation (Scheme 1.5.13b). ${ }^{[182]}$

a) Hoover (2015)<smiles>Cc1nc2ccccc2o1</smiles>

289

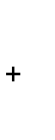<smiles>O=C(O)c1ccccc1[N+](=O)[O-]</smiles>

336<smiles></smiles>

337: $68 \%$

b) Maiti (2016)<smiles>c1ccc2sccc2c1</smiles>

338

$\mathrm{CuCl}(10 \mathrm{~mol} \%)$ $\underset{\mathrm{AgO}, \mathrm{Cs}_{2} \mathrm{CO}_{3}}{\stackrel{\text { 1,10-phen }(10 \mathrm{~mol} \%)}{\longrightarrow}}$

$\mathrm{CuCl}(10 \mathrm{~mol} \%)$ 1,10-phen $(10 \mathrm{~mol} \%)$ $\mathrm{K}_{2} \mathrm{CO}_{3}, \mathrm{PhMe}$ $140^{\circ} \mathrm{C}, 24 \mathrm{~h}, \mathrm{O}_{2}$

336<smiles>O=[N+]([O-])c1ccccc1-c1cc2ccccc2s1</smiles>

339: $83 \%$

Scheme 1.5.13 Decarboxylative copper-catalyzed C-H arylations.

This arylation could be extended to arenes with bidentate directing group. Shi reported decarboxylative copper-catalyzed $\mathrm{C}-\mathrm{H}$ arylation enabled by the (pyridin-2-yl)isopropyl amine (PIP-amine) directing group (Scheme 1.5.14a). ${ }^{[183]}$ Hirano and Miura also reported a similar reactivity with the 8aminoquinoline-based bidentate auxiliary (Scheme 1.5.14b). ${ }^{[184]}$

a) Shi (2015)<smiles>CC(C)(NC(=O)c1ccccc1)c1ccccn1</smiles>

340

b) Hirano and Miura (2017)<smiles>O=C(Nc1cccc2cccnc12)c1ccccc1</smiles>

343<smiles>Cc1csc(C(=O)O)c1</smiles>

341<smiles>O=C(O)c1ccccc1[N+](=O)[O-]</smiles>

336

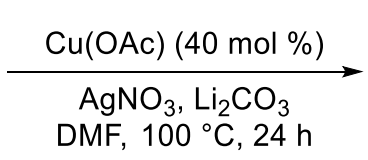

DMF, $100^{\circ} \mathrm{C}, 24 \mathrm{~h}$<smiles>Cc1csc(-c2ccccc2C(=O)NC(C)(C)c2ccccn2)c1</smiles>

342: $82 \%$<smiles>O=C(Nc1cccc2cccnc12)c1ccccc1-c1ccccc1[N+](=O)[O-]</smiles>

344: $74 \%$

Scheme 1.5.14 Bidentate directing group enabling decarboxylative $\mathrm{C}-\mathrm{H}$ arylations. 
The fourth method for copper-catalyzed $\mathrm{C}-\mathrm{H}$ arylations are dehydrogenative $\mathrm{C}-\mathrm{H} / \mathrm{C}-\mathrm{H}$ arylation. Although this approach does not require prefunctionalization of substrates, the achievement of selectivity control is the key challenging issue. ${ }^{[185]}$ In this regard, while copper-catalyzed oxidative C$\mathrm{H} / \mathrm{C}-\mathrm{H}$ arylations for homo-couplings could be readily achieved, ${ }^{[186]}$ unsymmetric biaryl formation commonly required electronic bias of two starting materials ${ }^{[187]}$ or intramolecular settings (Scheme $1.5 .15) \cdot[188]$

a) Daugulis (2009)<smiles>c1ccc2occc2c1</smiles>

345

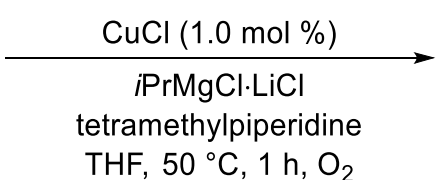

312

$$
\underset{\mathrm{Me}}{\stackrel{\mathrm{Cu}(\mathrm{OAc})_{2}(10 \mathrm{~mol} \%)}{\mathrm{Ag}_{2} \mathrm{CO}_{3}(20 \mathrm{~mol} \mathrm{\%})}}
$$<smiles>c1ccc2oc(-c3cc4ccccc4o3)cc2c1</smiles>

346: $82 \%$

b) Mori (2010)

c) Daugulis (2011)<smiles>COc1cc(C)c(C)cc1C</smiles><smiles>N#Cc1cccs1</smiles>

349

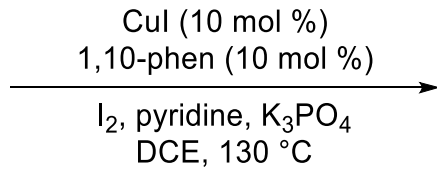

CuBr, 1,10-phen, LiOtBu MeCN, RT, $14 \mathrm{~h}, \mathrm{O}_{2}$

d) Bolm (2013)<smiles>c1ccc(-c2nnc(-c3ccccc3)o2)cc1</smiles>

351 294<smiles>Fc1ccc(F)c(F)c1F</smiles><smiles>COc1cc(C)c(-c2ccc(C#N)s2)cc1OC</smiles>

350: $72 \%$<smiles>Cn1c(-c2nc3ccccc3n2C)nc2ccccc21</smiles>

347: $71 \%$

e) Lee (2017)<smiles>O=c1cnc2ccccc2o1</smiles>

353<smiles>c1ccc2[nH]ccc2c1</smiles>

354
$\mathrm{Cu}(\mathrm{OAc})_{2}, \mathrm{AcOH}, \mathrm{o}$-xylene $150{ }^{\circ} \mathrm{C}, 20 \mathrm{~h}$<smiles>Fc1c(F)c(F)c(-c2nnc(-c3ccccc3)o2)c(F)c1F</smiles>

352: $65 \%$

Scheme 1.5.15 Dehydrogenative copper-mediated $\mathrm{C}-\mathrm{H}$ arylations. 
This arylation manifold could also be extended to arenes using suitable directing groups (Scheme $1.5 .16) .{ }^{[189]}$

a) Yu (2006)<smiles>c1ccc(-c2ccccn2)cc1</smiles>

28

\section{$\mathrm{Cu}(\mathrm{OAc})_{2}, \mathrm{I}_{2}, \mathrm{MeCN}$} $130^{\circ} \mathrm{C}, 24 \mathrm{~h}$, air

$\mathrm{Cu}(\mathrm{OAc})_{2}, \mathrm{AgNO}_{3}, \mathrm{PhMe}$ $130{ }^{\circ} \mathrm{C}, 24 \mathrm{~h}$, air
$\mathrm{Cu}(\mathrm{OAc})_{2}$, LiOtBu, PhMe $120{ }^{\circ} \mathrm{C}, 72 \mathrm{~h}$, air<smiles>c1ccc(-c2ccccc2-c2ccccc2-c2ccccn2)nc1</smiles>

357: $85 \%$

b) Jiang (2016)<smiles>c1cnc(-n2ccc3ccccc32)nc1</smiles><smiles>c1cnc(-n2c(-c3cc4ccccc4n3-c3ncccn3)cc3ccccc32)nc1</smiles>

237

358: $82 \%$

c) Jain (2017)<smiles>[O-][n+]1ccccc1-c1ccccc1</smiles>

359<smiles>[O-][n+]1c(-c2ccccc2)cccc1-c1cccc(-c2ccccc2)[n+]1[O-]</smiles>

360: $90 \%$

d) Hirano and Miura (2011)<smiles>COc1cccc(-c2ccccn2)c1[OH+]</smiles>

361<smiles>c1ccc2ocnc2c1</smiles>

289
$\mathrm{Cu}(\mathrm{OAc})_{2}$, PivOH, o-xylene $150{ }^{\circ} \mathrm{C}, 20 \mathrm{~h}$, air

$\mathrm{Cu}(\mathrm{OAc})_{2}, \mathrm{AcOH}, \mathrm{o}$-xylene $150^{\circ} \mathrm{C}, 20 \mathrm{~h}$, air<smiles>COc1cccc(-c2nc3ccccc3o2)c1-c1ccccn1</smiles>

362: $59 \%$

e) Hirano and Miura (2012)<smiles>c1cnc(-n2ccc3ccccc32)nc1</smiles>

237<smiles>c1ccc2nc3oc(cccc2c1)C3</smiles>

289<smiles>c1cnc(-n2c(-c3nc4ccccc4o3)cc3ccccc32)nc1</smiles>

363: $59 \%$

Scheme 1.5.16 Dehydrogenative copper-mediated C-H/C-H arylations. 
Furthermore, the bidentate directing group enabled various $\mathrm{C}-\mathrm{H} / \mathrm{C}-\mathrm{H}$ cleavage (Scheme 1.5.17). ${ }^{[190]}$

a) Sun (2013)<smiles>O=C(Nc1cccc2cccnc12)c1ccccc1</smiles>

343

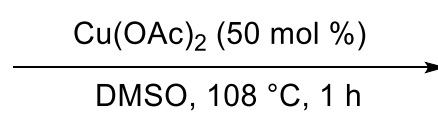

$\mathrm{Cu}(\mathrm{OAc})_{2} \cdot \mathrm{H}_{2} \mathrm{O}$ o-xylene, $135^{\circ} \mathrm{C}, 4 \mathrm{~h}$<smiles>O=C(Nc1cccc2cccnc12)c1ccccc1-c1ccccc1C(=O)Nc1cccc2cccnc12</smiles>

364: $61 \%$

a) Hirano and Miura (2013)<smiles>O=CCc1ccccc1F</smiles>

365<smiles>c1ccc2sccc2c1</smiles>

338<smiles>O=C(Nc1cccc2cccnc12)c1c(F)cccc1-c1cc2ccccc2s1</smiles>

366: $95 \%$

a) Shi (2015)<smiles>CC(C)(NC(=O)c1ccccc1)c1ccccn1</smiles>

340<smiles>c1ccc2sccc2c1</smiles>

338

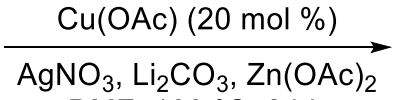

DMF, $100^{\circ} \mathrm{C}, 24 \mathrm{~h}$<smiles>CC(C)(NC(=O)c1ccccc1-c1cc2ccccc2s1)c1ccccn1</smiles>

367: $82 \%$

a) Baidya (2018)<smiles>O=C(Nc1ccccc1-n1cccn1)c1ccccc1</smiles>

368<smiles>Fc1ccc(F)c(F)c1F</smiles>

294

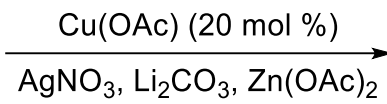
DMF, $100^{\circ} \mathrm{C}, 24 \mathrm{~h}$

369: $82 \%$ $\left(\mathrm{Ar}=\mathrm{C}_{6} \mathrm{~F}_{5}\right)$

Scheme 1.5.17 Copper-catalyzed cross-dehydrogenative C-H arylations. 


\subsection{Hybrid-Metal-Catalyzed C-H Activation}

While there are indisputable and considerable advances in homogeneous metal-catalyzed $\mathrm{C}-\mathrm{H}$ functionalization, the homogeneous catalytic process possessed inherent disadvantages of difficult catalyst reusability, which can be directly connected to environmental issues as well as economical concerns in the industries. ${ }^{[191]}$ In sharp contrast, the advent of heterogeneous catalysts enabled a shift of paradigm. The heterogeneous catalyst basically consisted of different phases ${ }^{[192]}$ which are exposed to the reacting chemicals, allowing the recovery of the catalyst. ${ }^{[193]}$ Thereby, heterogeneous catalysis often provides sustainable pathways toward molecular syntheses. ${ }^{[194]}$

In 1817, the first heterogeneous catalysis was discovered by the Cornish chemist Humphry Davy who identified that gas burning could occur without a flame in presence of platinum wire in his research on miner's safety lamps. ${ }^{[195]}$ A few years later, Döbereiner discovered the reaction of hydrogen gas with a platinum sponge could produce a flame at room temperature. ${ }^{[196]}$ At the end of the 1990 s, the Deacon process was developed, which generated chlorine from hydrochloric acid with the copper salt $\mathrm{CuCl}_{2}$ as a catalyst. ${ }^{[197]}$ This discovery provided a catalytic approach as well as a sustainable replacement of the previous process using stoichiometric $\mathrm{MnO}_{2}$. At the beginning of the twentieth century, the HaberBosch process was developed, in which iron oxide carriers accompanied with promoters could catalyze the ammonia production. ${ }^{[198]}$

Thereafter, a number of recyclable and reusable heterogeneous catalysts have been developed, which could also recently be used for $\mathrm{C}-\mathrm{H}$ activation chemistry. ${ }^{[199]}$

The first example of heterogeneous metal-catalyzed $\mathrm{C}-\mathrm{H}$ activation was disclosed by Nakamura in 1982 (Scheme 1.6.1). ${ }^{[200]}$ In this report, palladium on charcoal catalyzed C-H arylations of heteroarenes $\mathbf{3 7 0}$ with aryl iodides $\mathbf{2 8 5}$, while recyclability and heterogeneity of the catalyst were not studied.<smiles>[M]Oc1noc([18OH])c1[Na]</smiles>

370

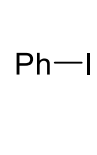

285
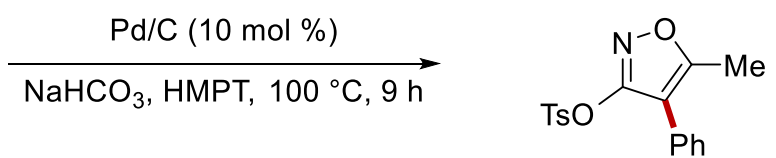

371: $44 \%$

Scheme 1.6.1 The first heterogeneous palladium-catalyzed $\mathrm{C}-\mathrm{H}$ arylation. 
In 2005, Fagnou extended heterogeneous palladium catalysis to intra- and intermolecular $\mathrm{C}-\mathrm{H}$ arylations (Scheme 1.6.2). ${ }^{[201]}$ Here, a wide range of substrate scopes was presented with Pearlman's catalyst, while a three-phase test revealed that a homogeneous process is likely operative.<smiles>Ic1ccccc1COc1ccccc1</smiles>

372<smiles>c1cscn1</smiles>

374

$$
\underset{\mathrm{KOAc}, \mathrm{DMA}, 145^{\circ} \mathrm{C}, 12 \mathrm{~h}}{\stackrel{\mathrm{Pd}(\mathrm{OH})_{2} / \mathrm{C}(10 \mathrm{~mol} \%)}{\longrightarrow}}
$$

$\mathrm{Ph}-\mathrm{Br}$

282<smiles>c1ccc2c(c1)COc1ccccc1-2</smiles>

373: $82 \%$<smiles>c1ccc(-c2nccs2)cc1</smiles>

375: $82 \%$

Scheme 1.6.2 The seminal example of recyclable heterogeneous palladium-catalyzed $\mathrm{C}-\mathrm{H}$ arylation.

In 2017, Ackermann and Vaccaro reported heterogeneous palladium-catalyzed Fujiwara-Moritani reaction in continuous flow (Scheme 1.6.3). Thus, a tailor-made flow reactor set the stage to not only reuse the catalyst but also scale the reaction, while detailed ICP-OES analysis of the reaction medium only showed less than 5 ppm of palladium leaching. In addition, various heterogeneity tests, such as hot-filtration and $\operatorname{Hg}(0)$ poisoning, provide a strong support for the heterogeneous nature of the developed catalysis.<smiles>CNc1ccccc1</smiles>

376<smiles>C=CC(=O)OCCCC</smiles>

377

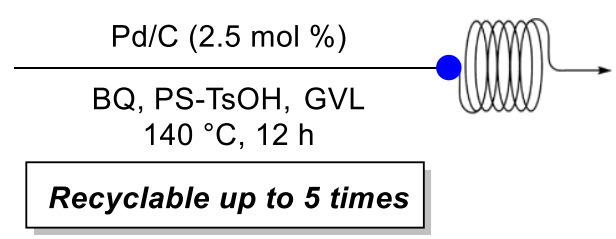

378: $95 \%$

Scheme 1.6.3 Heterogeneous palladium-catalyzed Fujiwara-Moritani reaction in flow.

Inspired by these early examples, the heterogeneous catalysis realm in $\mathrm{C}-\mathrm{H}$ activation was expanded to feature not only palladium catalysis but also other transition metal catalysis. In 2010, Wada and Inoue disclosed heterogeneous ruthenium-catalyzed $\mathrm{C}-\mathrm{H}$ arylation, in which they utilized cerium(IV) 
oxide support to immobilize the ruthenium catalyst (Scheme 1.6.4). ${ }^{[202]}$ Although the developed heterogeneous ruthenium catalyst was required to perform reactivation for the reuse, later, this reaction manifold could be efficiently introduced to $\mathrm{C}-\mathrm{H}$ hydroarylation reactions. ${ }^{[203]}$<smiles>c1ccc2ncccc2c1</smiles>

183<smiles>CC(C)(C)C(=O)c1ccccc1</smiles>

$38 \mathrm{c}$

$$
\mathrm{Ph}-\mathrm{Cl} \stackrel{3 \mathrm{PPh}_{3}-\mathrm{Ru} / \mathrm{CeO}_{2}(5.0 \mathrm{~mol} \%)}{\underset{\mathrm{K}_{2} \mathrm{CO}_{3}, \mathrm{NMP}, 140{ }^{\circ} \mathrm{C}, 12 \mathrm{~h}}{\longrightarrow}}
$$

379

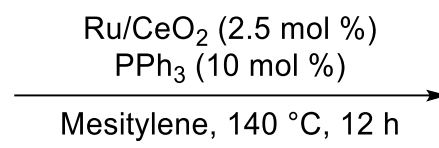

381<smiles>c1ccc(-c2cccc3ccc4cccnc4c23)cc1</smiles>

380: $82 \%$<smiles>CCO[SiH2]CCc1ccccc1C(=O)C(C)(C)C</smiles>

382: $84 \%$

Scheme 1.6.4 Heterogeneous ruthenium-catalyzed $\mathrm{C}-\mathrm{H}$ activations.

In 2017, Ackermann developed heterogeneous ruthenium-catalyzed meta-C-H bromination of purines 154 (Scheme 1.6.5). ${ }^{[98 c]}$ In this study, the silica-based heterogeneous ruthenium catalyst was highly recyclable without a significant loss of reactivity and selectivity, while a broad range of functional groups was tolerated, which set the stage of direct fluorescent labeling of purines.<smiles>[R]c1ccccc1-c1ncnc2c1ncn2[R]</smiles>

154

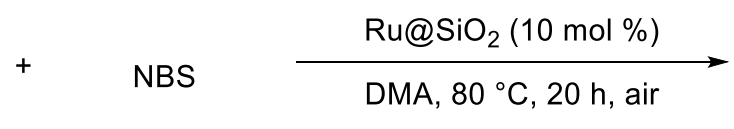

383<smiles>CC(C)n1cnc2c(-c3ccc(F)c(Br)c3)ncnc21</smiles>

384b: $55 \%$<smiles>CCCCn1cnc2c(-c3cccc(Br)c3)ncnc21</smiles>

384c: $62 \%$<smiles>Brc1cccc(-c2ncnc3c2ncn3-c2ccccc2)c1</smiles>

384d: $53 \%$

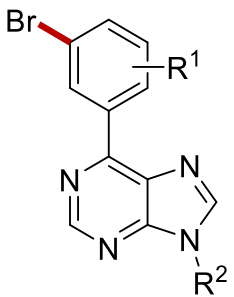

384

Scheme 1.6.5 Heterogeneous ruthenium-catalyzed meta-C-H brominations. 
Despite indisputable advances in heterogeneous catalysis for $\mathrm{C}-\mathrm{H}$ activation, it remains a critical concern that such catalysis is restricted by the surface area of the supported catalyst due to the physical limitation of active site. To overcome this disadvantage, researchers devised a new concept - hybrid catalysts cooperating inorganic materials and homogeneous catalysts - expecting to have a designable and tailorable heterogeneous catalyst while being recyclable and reusable. ${ }^{[204]}$

In 2005, Davies reported a strategy for the immobilization of chiral dirhodium(II) catalysts (Scheme 1.6.6) ${ }^{[205]}$ In this study, various dirhodium catalysts were anchored to pyridine-containing resin by a simple preparation, which was directly employed for $\mathrm{C}-\mathrm{H}$ arylation reactions in a reusable manner.

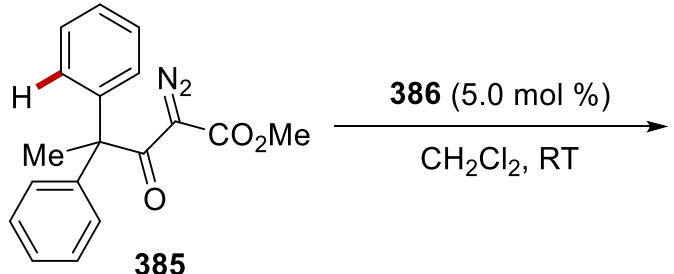

385

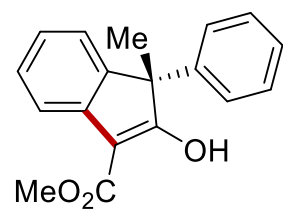

387

$1^{\text {st }}$ run: $80 \%, 93 \%$ ee $2^{\text {nd }}$ run: $75 \%, 93 \%$ ee $3^{\text {rd }}$ run: $75 \%, 93 \%$ ee

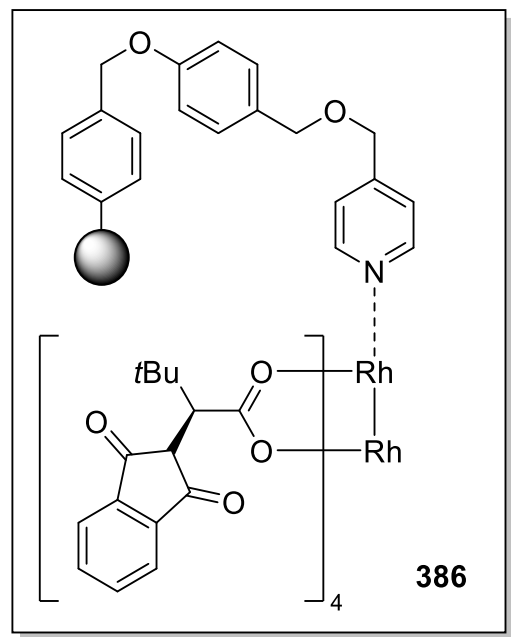

Scheme 1.6.6 Hybrid rhodium catalyst for enantioselective C-H arylation.

Thereafter, Jones and Davies developed silica-based hybrid dirhodium(II) catalyst for $\mathrm{C}\left(\mathrm{sp}^{3}\right)-\mathrm{H}$ functionalizations. ${ }^{[206]}$ In contrast to the previous report, ${ }^{[207]}$ this study described covalent anchoring approach, enabling to have a more stable hybrid rhodium catalyst. Later, this reaction manifold was further extended to introduce a continuous flow technique, in which the dirhodium complexes were immobilized inside of a hollow fiber flow reactor, thus providing potential scalability and sustainability. ${ }^{[208]}$

In 2016, Jones and $\mathrm{Yu}$ reported polymer-supported hybrid palladium catalyst for $\mathrm{C}\left(\mathrm{sp}^{3}\right)-\mathrm{H}$ arylations (Scheme 1.6.7). ${ }^{[209]}$ While ample substrates scope with a wide range of functional group tolerance was described, the hybrid palladium catalyst was efficiently reusable only up to the two times. 
<smiles>N[C@@H](C(=O)Nc1c(F)c(F)c(C(F)(F)F)c(F)c1F)C(c1ccccc1)c1ccccc1</smiles>

387

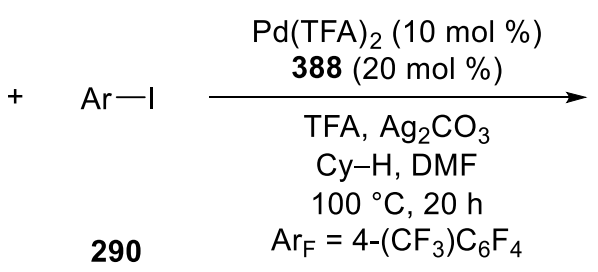

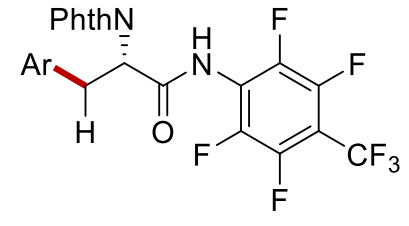

389

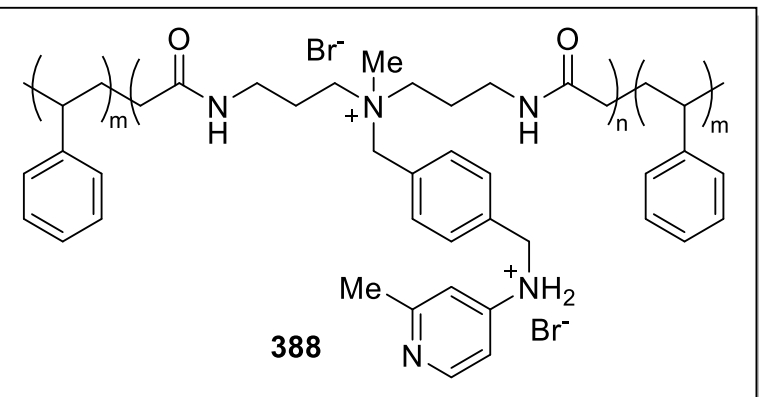

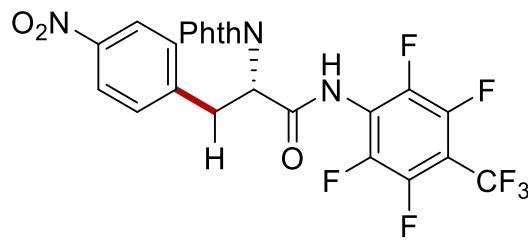

389a: $50 \%$

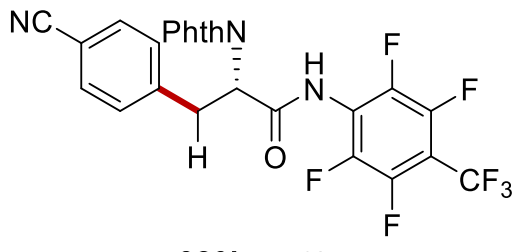

389b: $50 \%$

Scheme 1.6.7 Hybrid palladium-catalyzed C $\left(\mathrm{sp}^{3}\right)-\mathrm{H}$ arylation. 


\section{Objectives}

Transition metal-catalyzed $\mathrm{C}-\mathrm{H}$ activations have emerged as a robust toolbox for synthetic chemistry. ${ }^{[18 \mathrm{~b}, 18 \mathrm{i}, 18 \mathrm{j}]}$ The development of new synthetic pathways and approaches is in high demand. In this regard, Ackermann and coworkers have presented remarkable achievements during the last two decades, [210a, 72d, 113c, 20a, 210b, 210c] which have focused on the development of new and sustainable catalysis in a wide range of metals. Thus, the objective of this thesis was to aim at the development of cost-effective and environmentally-sound homogeneous and recyclable hybrid metal-catalyzed $\mathrm{C}-\mathrm{H}$ activations, along with mechanistic understandings and characterizations.

Indole benzenoid functionalizations have recently gained major attention from organic chemists, since such methods enable access biologically active molecules. For this reason, we became interested in exploring ruthenium-catalyzed $\mathrm{C} 7-\mathrm{H}$ indole amidations and alkenylations with the aid of a removable directing group under mild reaction conditions (Scheme 2.1.1). ${ }^{[211]}$
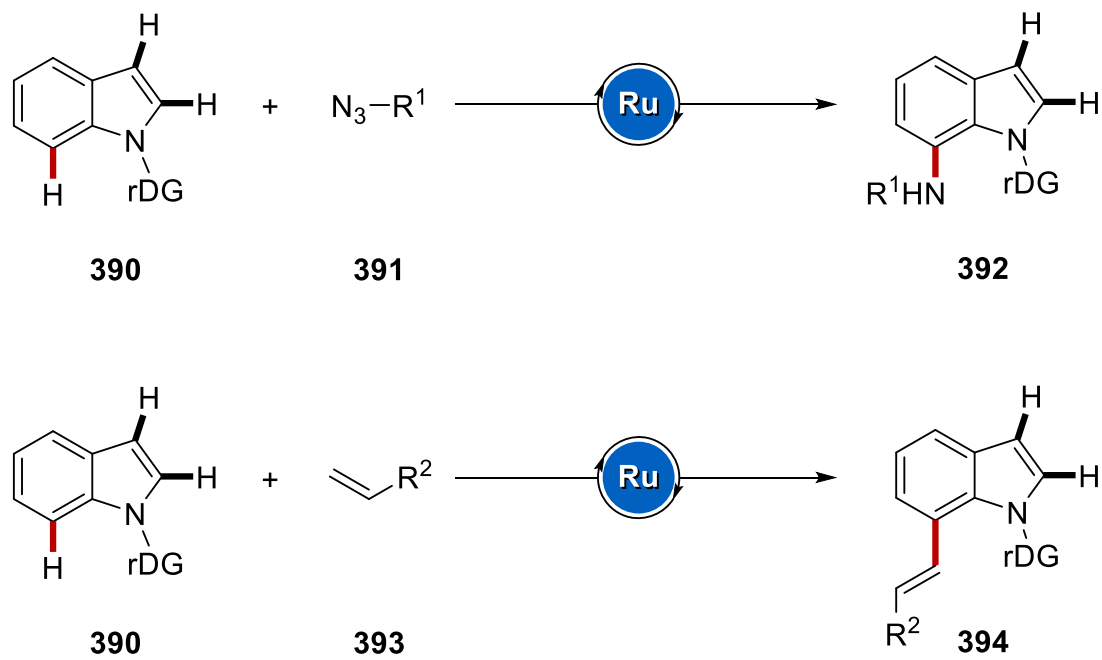

Scheme 2.1.1 Ruthenium-catalyzed C7-H indole amidation and alkenylation.

Beyond thus developed $\mathrm{C} 7-\mathrm{H}$ indole activations, we also sought for a general synthetic pathway to functionalize other bonds of the indole motif. Thus, inspired by great progress in ruthenium-catalyzed distal $\mathrm{C}-\mathrm{H}$ functionalization by Ackermann and coworkers, we developed site-selective dual C4H/C6-H alkylations of indoles (Scheme 2.1.2). ${ }^{[212]}$ 


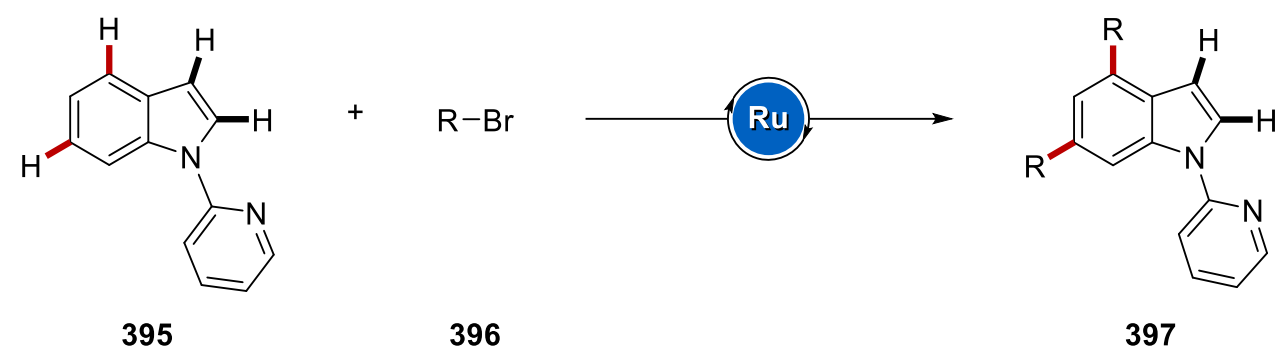

Scheme 2.1.2 Ruthenium-catalyzed C4-H/C6-H dual alkylations.

While ruthenium and iron among group 8 metals have been extensively studied for $\mathrm{C}-\mathrm{H}$ activation, osmium-catalyzed $\mathrm{C}-\mathrm{H}$ activation is under developed. Motivated by the recent trend of electrochemical methods for $\mathrm{C}-\mathrm{H}$ activation, which has been mainly developed by Ackermann and coworkers, we became interested in electrochemical osmium-catalyzed $\mathrm{C}-\mathrm{H}$ activation (Scheme 2.1.3). Thereby, osmium catalyst enabled [4+1] and [4+2] annulations under electrooxidative conditions.<smiles>[R]C=C[C+]=C</smiles><smiles>[R]C#[R]C(=O)O</smiles>

01
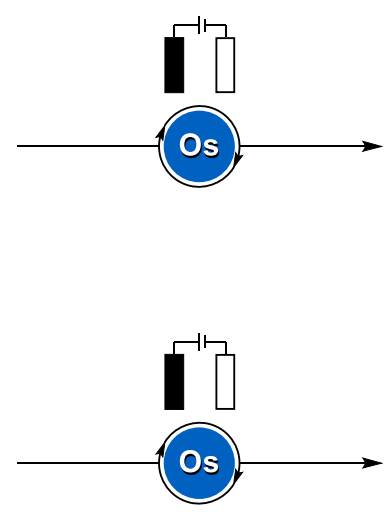
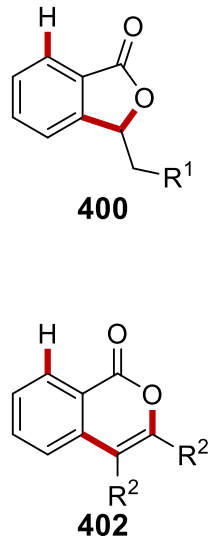

Scheme 2.1.3 Osmium-catalyzed electrooxidative $\mathrm{C}-\mathrm{H}$ activation.

Despite enormous advances in homogeneous catalysis for $\mathrm{C}-\mathrm{H}$ activation, recyclable heterogeneous catalysis has emerged as a powerful tool to improve sustainability. Particularly, the combination of organic ligands immobilized onto inorganic support, namely hybrid catalyst, enabled to tune the heterogeneous catalyst and simultaneously provide recyclability. In this regard, we became intrigued to develop hybrid metal-catalyzed $\mathrm{C}-\mathrm{H}$ activation. 
On the basis of Ackermann's report in $2016,{ }^{[169]}$ we developed recyclable hybrid copper catalyst for photo-induced C-H arylation (Scheme 2.1.4). ${ }^{[213]}$ The SBA-15 silica-based hybrid copper catalyst enabled a wide range of arylations of heterocycles under exceedingly mild conditions at room temperature and was reusable at least up to five times.

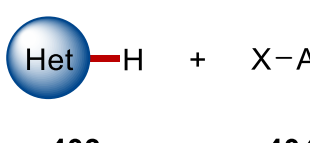

403

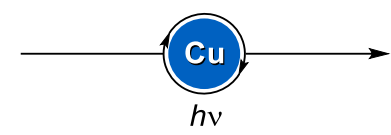

404

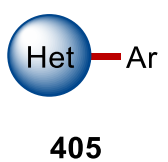

405

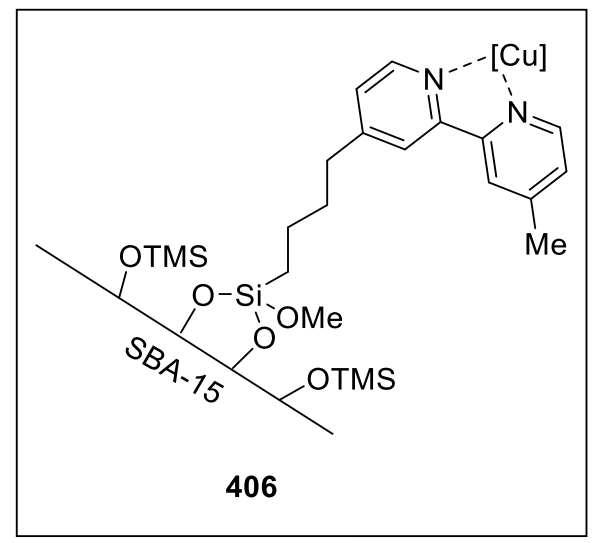

Scheme 2.1.4 Recyclable hybrid copper-catalyzed C-H arylation.

Based on the concept of hybrid catalysis, we envisaged site-selective $\mathrm{C}-\mathrm{H}$ activation with hybrid metal catalysts. Especially, Ackermann and coworkers have recently presented numerous studies about ruthenium-catalyzed meta-C-H functionalization with the aid of phosphine ligand as a key component for the reaction. Thus, we introduced phosphine-based polymers to immobilize ruthenium(II) catalyst, enabling distal C-H functionalizations (Scheme 2.1.5). ${ }^{[214]}$<smiles>c1ccc(-c2ccccn2)cc1</smiles>

407
$+\mathrm{Br}-\mathrm{R}$

408

\section{Ru}

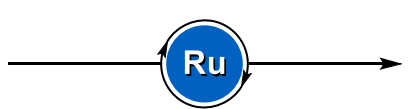<smiles>[R]c1cccc(-c2ccccn2)c1</smiles>

409

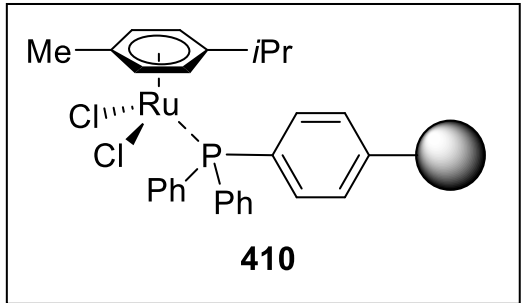

Scheme 2.1.5 Recyclable ruthenium-catalyzed meta-C-H alkylation.

During the past decades, the activation of inert $\mathrm{C}-\mathrm{H}$ bonds has been predominantly made with the aid of noble $4 \mathrm{~d}$ and $5 \mathrm{~d}$ transition metals. ${ }^{[215 \mathrm{a}-\mathrm{c}, 210 \mathrm{~b}, 215 \mathrm{~d}]}$ In sharp contrast, the introduction of Earth-abundant 3d metal catalysts, particularly manganese, allows for sustainable and cost-effective $\mathrm{C}-\mathrm{H}$ 
activations. ${ }^{[216]}$ Here, we envisioned adding the value of heterogeneity to manganese catalysis. Thus, we developed a hybrid manganese catalyst, providing $\mathrm{C}-\mathrm{H}$ arylation and $\mathrm{C}-\mathrm{H}$ alkylation in a reusable manner (Scheme 2.1.6).<smiles>[R]NC(=O)c1ncccc1[14CH3]</smiles>
411 412<smiles>[R]NC(=O)c1cccnc1[Z11]</smiles>
414

\section{Mn}

Mn<smiles>[R]NC(=O)c1ncccc1CCc1ccc(C)cc1</smiles>

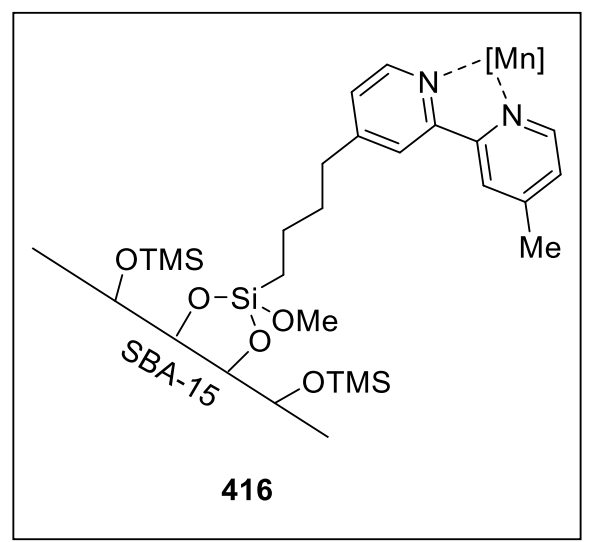

Scheme 2.1.6 Hybrid manganese-catalyzed C-H arylation and alkylation. 


\section{Results and Discussion}

\subsection{Ruthenium(II)-Catalyzed C7-H Amidations and Alkenylations of Indoles}

Substituted indoles ${ }^{[217]}$ are a key structural motif in a plethora of important bio-relevant compounds, drugs, and pharmaceuticals (Scheme 3.1.1). ${ }^{[218]}$ Since the precise synthesis of structural complex indoles having substituent groups in a specific position is often challenging, various researches have tested site-selective indole functionalizations. While $\mathrm{C} 2$ - or $\mathrm{C} 3$-selective functionalizations have been widely established, ${ }^{[219]} \mathrm{C} 7$-manifolds, ${ }^{[220]}$ particularly by ruthenium catalysis, have thus far remained elusive.<smiles>[Y4]C1NC(=O)C(Cc2c[nH]c3c(CC=C(C)C)cccc23)NC1=O</smiles>

Terezine D<smiles>CNC(=O)c1cccc2c(C(=O)C(=O)N3CCN(C(=O)c4ccccc4)CC3)c[nH]c12</smiles>

Inhibitor of HIV-1<smiles>CCCCOC(C)(C)Cc1c(C)c(CC(=O)O)c(C)c2cc[nH]c12</smiles>

MDAT2 inhibitor<smiles>COc1ccc(C(C)c2ccc(O)cc2)c2[nH]cc(CC#N)c12</smiles>

Inhibitor of influenza virus A/Hanfang/359/95<smiles>O=C(Oc1cncc(Cl)c1)c1cccc2cc[nH]c12</smiles>

Inhibitor of SARS-CoV<smiles>O=C(/C=C/c1c[nH]c2c(O)cccc12)N/C=C/c1c[nH]c2ccccc12</smiles>

Inhibitor of HSV II<smiles>NS(=O)(=O)c1ccc(S(=O)(=O)Nc2cccc3c(Cl)c[nH]c23)cc1</smiles>

E7070 (Indisulam)

Scheme 3.1.1 Bioactive C7-functionalized indoles. 


\subsubsection{Optimization Studies}

The $\mathrm{C} 7-\mathrm{H}$ functionalization of indole $\mathbf{3 9 2}$ was envisaged with the aid of pivaloyl directing group (Table 3.1.1). In this context, organic azide 391 was used as the amidating reagent for ruthenium(II) catalysis. Particularly, the use of a ruthenium catalyst together with metal acetate and silver salts was expected to in-situ generate a cationic ruthenium(II)-carboxylate. Also, $N$-pivaloyl orienting group was expected to enable the formation of a six-membered ruthenacycle. The optimization studies were commenced by testing solvents. While various reaction mediums, including ethereal (entries 1-2) and alcoholic solvents (entries 3-4) as well as other solvents (entries 5-12) were attempted. Unfortunately, the desired product was not detected. Only when DCE, DCM, or TFE were used as the solvent, the C7-H amidated product 392 was formed (entries 13-15). It is noteworthy that the nitrogenated product was selectively formed at the $\mathrm{C} 7-\mathrm{H}$ position as the sole product, while the $\mathrm{C} 2-\mathrm{H}$ bond remained unmodified. Next, the effect of the reaction temperature was explored. Interestingly, while the decrease in the temperature to $40{ }^{\circ} \mathrm{C}$ provided an increase in the yield, temperature lower than $40{ }^{\circ} \mathrm{C}$ were not beneficial (entries 16-19). Bases fell short in providing the desired product in a high yield (entries 20 22). Although the use of $\mathrm{AgNTf}_{2}$ showed comparable results (entry 23), $\mathrm{AgSbF}_{6}$ was chosen for the issue of cost. The employment of $\mathrm{Ru}(\mathrm{OAc})_{2}(p \text {-cymene })_{2}$ allowed to avoid additional acetate sources (entry 24), not only highlighting the importance of the ruthenium(II)biscarboxylate catalysis regime. While prolonged reaction time provided increased $\mathrm{C} 7-\mathrm{H}$ amidated indole production (entry 25), elevated temperature gave unsatisfactory results (entry 26). 
Table 3.1.1 Optimization of the ruthenium(II)-catalyzed C7-H amidation ${ }^{[\mathrm{a}]}$

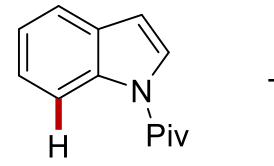

390

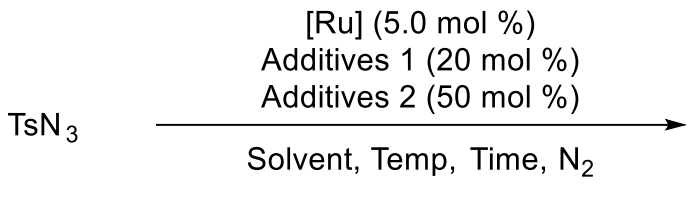

391

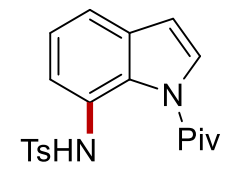

392

\begin{tabular}{|c|c|c|c|c|c|c|c|}
\hline Entry & {$[\mathrm{Ru}]$} & $\begin{array}{c}\text { Additive } \\
1\end{array}$ & $\begin{array}{c}\text { Additive } \\
2\end{array}$ & Solvent & $\begin{array}{l}\text { Temp } \\
\left({ }^{\circ} \mathrm{C}\right)\end{array}$ & $\begin{array}{l}\text { Time } \\
\text { (h) }\end{array}$ & $\begin{array}{l}\text { Yield } \\
(\%)\end{array}$ \\
\hline 1 & {$\left[\mathrm{RuCl}_{2}(p \text {-cymene })\right]_{2}$} & $\mathrm{AgSbF}_{6}$ & $\mathrm{AgOAc}$ & 1,4-dioxane & 60 & 16 & NR \\
\hline 2 & {$\left[\mathrm{RuCl}_{2}(p \text {-cymene })\right]_{2}$} & $\mathrm{AgSbF}_{6}$ & $\mathrm{AgOAc}$ & DME & 60 & 16 & NR \\
\hline 3 & {$\left[\mathrm{RuCl}_{2}(p \text {-cymene })\right]_{2}$} & $\mathrm{AgSbF}_{6}$ & $\mathrm{AgOAc}$ & $\mathrm{MeOH}$ & 60 & 16 & NR \\
\hline 4 & {$\left[\mathrm{RuCl}_{2}(p \text {-cymene })\right]_{2}$} & $\mathrm{AgSbF}_{6}$ & $\mathrm{AgOAc}$ & $t \mathrm{AmOH}$ & 60 & 16 & NR \\
\hline 5 & {$\left[\mathrm{RuCl}_{2}(p \text {-cymene })\right]_{2}$} & $\mathrm{AgSbF}_{6}$ & $\mathrm{AgOAc}$ & $o$-xylene & 60 & 16 & NR \\
\hline 6 & {$\left[\mathrm{RuCl}_{2}(p \text {-cymene })\right]_{2}$} & $\mathrm{AgSbF}_{6}$ & $\mathrm{AgOAc}$ & NMP & 60 & 16 & NR \\
\hline 7 & {$\left[\mathrm{RuCl}_{2}(p \text {-cymene })\right]_{2}$} & $\mathrm{AgSbF}_{6}$ & $\mathrm{AgOAc}$ & DMA & 60 & 16 & NR \\
\hline 8 & {$\left[\mathrm{RuCl}_{2}(p \text {-cymene })\right]_{2}$} & $\mathrm{AgSbF}_{6}$ & $\mathrm{AgOAc}$ & DMF & 60 & 16 & NR \\
\hline 9 & {$\left[\mathrm{RuCl}_{2}(p \text {-cymene })\right]_{2}$} & $\mathrm{AgSbF}_{6}$ & $\mathrm{AgOAc}$ & DMSO & 60 & 16 & NR \\
\hline 10 & {$\left[\mathrm{RuCl}_{2}(p \text {-cymene })\right]_{2}$} & $\mathrm{AgSbF}_{6}$ & $\mathrm{AgOAc}$ & $\mathrm{MeCN}$ & 60 & 16 & NR \\
\hline 11 & {$\left[\mathrm{RuCl}_{2}(p \text {-cymene })\right]_{2}$} & $\mathrm{AgSbF}_{6}$ & $\mathrm{AgOAc}$ & $\mathrm{CHCl}_{3}$ & 60 & 16 & NR \\
\hline 12 & {$\left[\mathrm{RuCl}_{2}(p \text {-cymene })\right]_{2}$} & $\mathrm{AgSbF}_{6}$ & $\mathrm{AgOAc}$ & $\mathrm{CCl}_{4}$ & 60 & 16 & NR \\
\hline 13 & {$\left[\mathrm{RuCl}_{2}(p \text {-cymene })\right]_{2}$} & $\mathrm{AgSbF}_{6}$ & $\mathrm{AgOAc}$ & DCE & 60 & 16 & 25 \\
\hline 14 & {$\left[\mathrm{RuCl}_{2}(p \text {-cymene })\right]_{2}$} & $\mathrm{AgSbF}_{6}$ & $\mathrm{AgOAc}$ & DCM & 60 & 16 & 42 \\
\hline 15 & {$\left[\mathrm{RuCl}_{2}(p \text {-cymene })\right]_{2}$} & $\mathrm{AgSbF}_{6}$ & $\mathrm{AgOAc}$ & TFE & 60 & 16 & 41 \\
\hline 16 & {$\left[\mathrm{RuCl}_{2}(p \text {-cymene })\right]_{2}$} & $\mathrm{AgSbF}_{6}$ & $\mathrm{AgOAc}$ & TFE & 50 & 16 & 52 \\
\hline 17 & {$\left[\mathrm{RuCl}_{2}(p \text {-cymene })\right]_{2}$} & $\mathrm{AgSbF}_{6}$ & $\mathrm{AgOAc}$ & TFE & 40 & 16 & 60 \\
\hline 18 & {$\left[\mathrm{RuCl}_{2}(p \text {-cymene })\right]_{2}$} & $\mathrm{AgSbF}_{6}$ & $\mathrm{AgOAc}$ & TFE & 30 & 16 & 54 \\
\hline 19 & {$\left[\mathrm{RuCl}_{2}(p \text {-cymene })\right]_{2}$} & $\mathrm{AgSbF}_{6}$ & $\mathrm{AgOAc}$ & TFE & 25 & 16 & 32 \\
\hline 20 & {$\left[\mathrm{RuCl}_{2}(p \text {-cymene })\right]_{2}$} & $\mathrm{AgSbF}_{6}$ & $\mathrm{CsOAc}$ & TFE & 40 & 16 & trace \\
\hline 21 & {$\left[\mathrm{RuCl}_{2}(p \text {-cymene })\right]_{2}$} & $\mathrm{AgSbF}_{6}$ & LiOAc & TFE & 40 & 16 & 32 \\
\hline
\end{tabular}




\begin{tabular}{cccccccc}
\hline 22 & {$\left[\mathrm{RuCl}_{2}(p \text {-cymene })\right]_{2}$} & $\mathrm{AgSbF}_{6}$ & $\mathrm{AgOTFA}$ & $\mathrm{TFE}$ & 40 & 16 & NR \\
23 & {$\left[\mathrm{RuCl}_{2}(p \text {-cymene })\right]_{2}$} & $\mathrm{AgNTf}_{2}{ }^{[c]}$ & $\mathrm{AgOAc}$ & $\mathrm{TFE}$ & 40 & 16 & 63 \\
$24^{[\mathrm{b}]}$ & $\mathrm{Ru}(\mathrm{OAc})_{2}(p$-cymene $)$ & $\mathrm{AgSbF}_{6}$ & -- & $\mathrm{TFE}$ & 40 & 16 & 64 \\
$\mathbf{2 5}^{[\mathbf{b}]}$ & $\mathbf{R u}(\mathbf{O A c})_{2}(p$-cymene $)$ & $\mathbf{A g S b F}_{6}$ & -- & TFE & $\mathbf{4 0}$ & $\mathbf{2 4}$ & $\mathbf{7 8}$ \\
$26^{[\mathrm{b}]}$ & $\mathrm{Ru}(\mathrm{OAc})_{2}(p$-cymene $)$ & $\mathrm{AgSbF}_{6}$ & -- & TFE & 60 & 24 & 48 \\
\hline
\end{tabular}

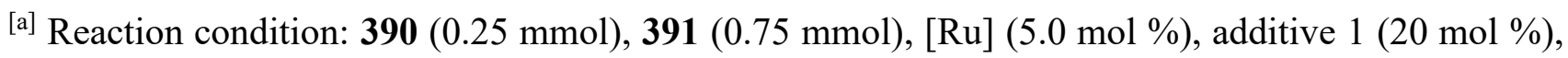
additive $2(50 \mathrm{~mol} \%)$, solvent $(1.0 \mathrm{~mL})$, isolated yield. ${ }^{[\mathrm{b}]}[\mathrm{Ru}](10 \mathrm{~mol} \%) .{ }^{[\mathrm{c}]}$ Price comparison (in Sigma-Aldrich): $\mathrm{AgSbF}_{6}: \$ 60.10 / 5 \mathrm{~g}, \mathrm{AgNTF}_{2}: \$ 476.00 / 5 \mathrm{~g}$.

Thereafter, the indole $N$-substituent pattern was examined, and a variety of ketones, amide, ester, phosphine oxide, sulfone, and pyridine were explored (Scheme 3.1.2). Interestingly, only the $N$ pivaloyl indole 390 provided the $\mathrm{C} 7-\mathrm{H}$ amidation product, illustrating the importance of steric and electronic effects of the $\mathrm{N}$-substituent for enabling the indole $\mathrm{C} 7-\mathrm{H}$ activation.
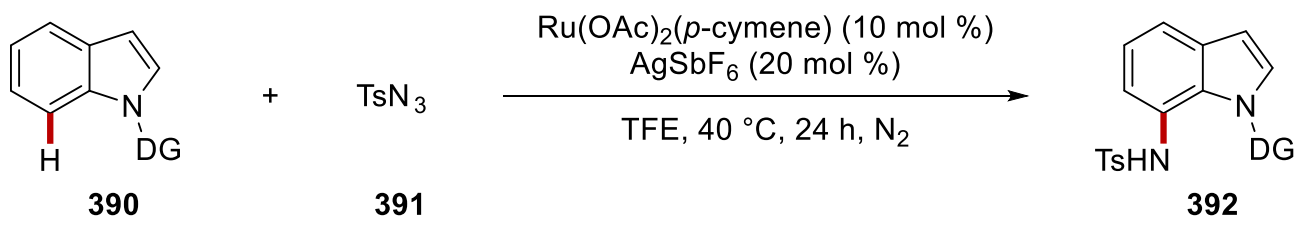

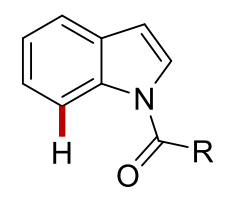

$R=t B u(390 a): \quad 78 \%$

$\mathrm{R}=\mathrm{Me}(390 \mathrm{~b}): \quad 0 \%$

$\mathrm{R}=\mathrm{NHtBu}(\mathbf{3 9 0 \mathrm { c } )}): 0 \%$

$\mathrm{R}=\mathrm{OtBu}(\mathbf{3 9 0 d}): 0 \%$<smiles>CC(C)(C)P(=O)(n1ccc2ccccc21)C(C)(C)C</smiles>

390e: $0 \%$<smiles>O=S(=O)([Hg])n1ccc2ccccc21</smiles>

390f: $0 \%$

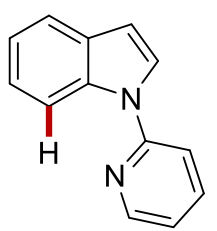

390g: $0 \%$

Scheme 3.1.2 Examination of $N$-substitution pattern. 


\subsubsection{Substrate Scope}

With the optimized reaction conditions in hand, the scope of the $\mathrm{C} 7-\mathrm{H}$ functionalization was explored with various indoles 390 and organic azides 391 (Scheme 3.1.3). Differently substituted indoles 390 bearing alkyl and alkoxy groups at the C3-, C4-, C5-, and C6-position were site-selectively transformed into the desired $\mathrm{C} 7-\mathrm{H}$ nitrogenated products. It is noteworthy that indole 390e having labile aldehyde group was efficiently transformed to the desired product 392e and synthetically valuable halogen functional groups were tolerated under the optimized reaction conditions (392d, 392g-392k). The ruthenium(II)biscarboxylate-catalyzed $\mathrm{C} 7-\mathrm{H}$ activation also tolerated various azides bearing arenesulfonyl (3921-392m) and alkanesulfonyl groups (392n-392o).
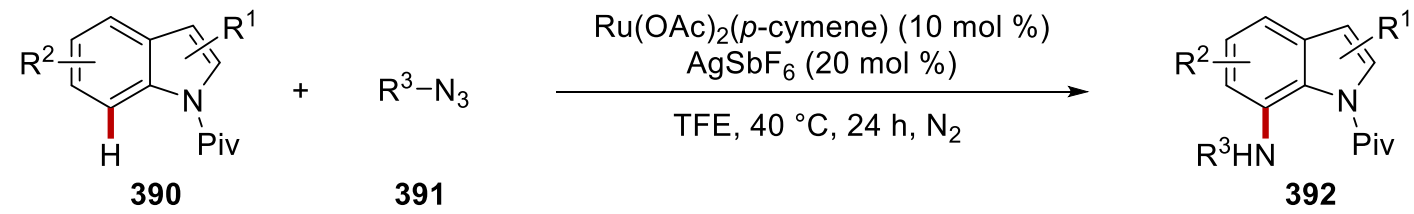

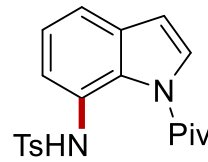

392a: $78 \%$<smiles></smiles>

392f: $71 \%$<smiles></smiles>

392k: $69 \%$<smiles></smiles>

392b: $42 \%$<smiles>Nc1cc(F)cc2ccn(P)c12</smiles>

392g: $49 \%$<smiles>O=S(=O)(Nc1cccc2ccn(-c3ccccc3)c12)c1cccc(Br)c1</smiles>

392I: $80 \%$<smiles>Cc1ccc(N)c2c1ccn2Pc1ccccn1</smiles>

392c: $69 \%$

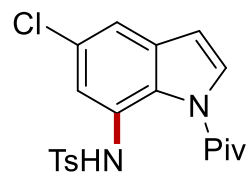

392h: 76\%<smiles></smiles>

392m: $59 \%$<smiles>Nc1ccc(Br)c2ccn(Pc3ccccc3)c12</smiles>

392d: $40 \%$

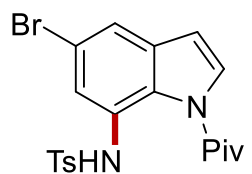

392i: $82 \%$<smiles>CCCCNn1ccc2cccc(NS(C)(=O)=O)c21</smiles>

392n: $68 \%$<smiles>N#P([Na])n1ccc2c(C=O)ccc(N)c21</smiles>

392e: $81 \%$<smiles>Cc1cc(N)c2c(ccn2P)c1</smiles>

392j: $85 \%$

Scheme 3.1.3 Scope of ruthenium-catalyzed C7-N formation of indoles $\mathbf{3 9 0}$. 
The robustness of the ruthenium(II)-catalyzed $\mathrm{C} 7-\mathrm{H}$ activation was further reflected by the $\mathrm{C} 7-\mathrm{H}$ alkenylation of $N$-pivaloyl indoles 390 with acrylates 393 through a redox process (Scheme 3.1.4). Thus, the site-selective alkenylated products 394 were efficiently obtained under slightly modified reaction conditions using copper(II) acetate as the oxidant. A variety of substituted indoles 390 bearing alkyl or halogen groups and different acrylates $\mathbf{3 9 3}$ were fully tolerated, thus efficiently giving into the desired indole-7-alkenyl derivatives 394 with excellent site-selectivity.

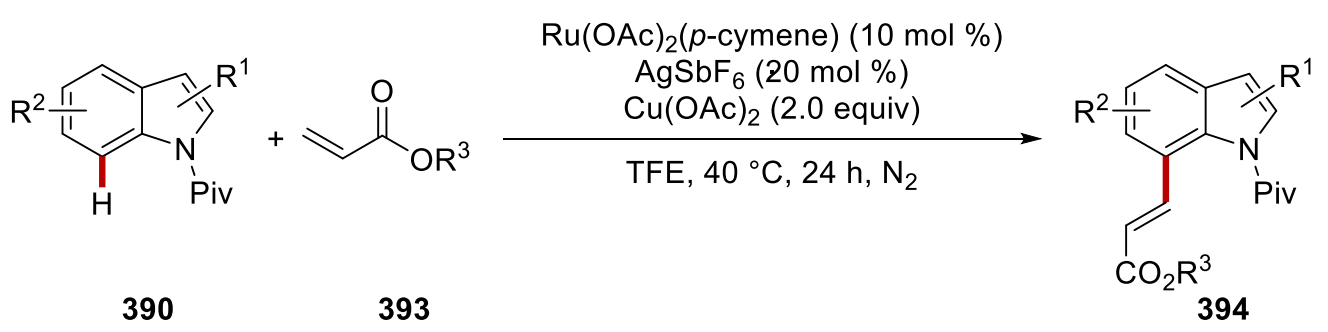

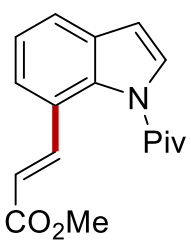

394a: $75 \%$<smiles>CC(=O)/C=C/c1ccc(Br)c2ccn(P)c12</smiles>

394e: $69 \%$<smiles>CC(=O)OC=Cc1cc(Br)cc2ccn(P)c12</smiles>

394i: $72 \%$<smiles></smiles>

394b: $37 \%$<smiles>COC(=O)/C=C/c1cc(C)cc2ccn(-c3ccccc3)c12</smiles>

394f: $66 \%$<smiles>C#P(CC)n1ccc2cccc(C=COCC)c21</smiles>

394j: $70 \%$

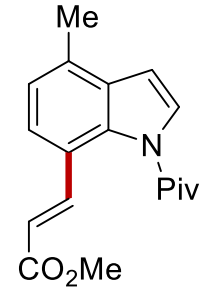

394c: $56 \%$<smiles>COC(=O)/C=C/c1cc(OC)cc2ccn(-c3ccccc3)c12</smiles>

394g: $63 \%$<smiles>C=C(/C=C/c1cccc2ccn(CCCCC)c12)OCC</smiles>

394k: $61 \%$<smiles></smiles>

394d: $53 \%$<smiles>CCCCCn1ccc2cc(Cl)cc(/C=C/C(C)=O)c21</smiles>

394h: $69 \%$<smiles></smiles>

394I: $66 \%$

Scheme 3.1.4 Scope of ruthenium-catalyzed C7-C bond formation of indoles 390 . 


\subsubsection{Investigations of Practical Utility}

The traceless removal of the $N$-pivaloyl motif was performed to showcase the practical utility into the established carboxylate-assisted ruthenium(II)-catalyzed C7-H activation (Scheme 3.1.5). Thus, the pivaloyl orienting group was readily removed at room temperature. It is noteworthy that the traceless removal of $\mathrm{N}$-pivaloyl directing group could also sequentially be carried out in a one-pot strategy.<smiles>[Mg][Mg]Nc1cccc2ccn(P)c12</smiles>

$392 a$<smiles>Pn1ccc2ccccc21</smiles>

$390 \mathrm{a}$
$\mathrm{NEt}_{3}(0.5 \mathrm{~mL}), \mathrm{MeOH}(0.5 \mathrm{~mL}), \mathrm{RT}, 12 \mathrm{~h}$

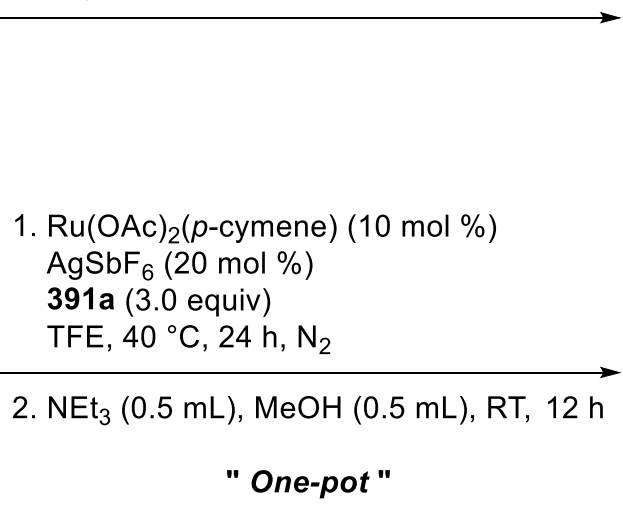

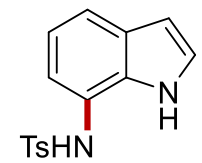

417: $95 \%$

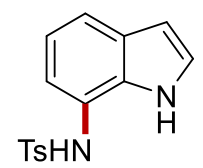

417: $73 \%$<smiles>CC(=O)/C=C/c1cccc2ccn(-c3ccccc3)c12</smiles>

$\mathrm{NEt}_{3}(0.5 \mathrm{~mL}), \mathrm{MeOH}(0.5 \mathrm{~mL}), \mathrm{RT}, 12 \mathrm{~h}$

$394 a$<smiles>CC(=O)C=Cc1cccc2cc[nH]c12</smiles>

418: $96 \%$

1. $\mathrm{Ru}(\mathrm{OAc})_{2}(p$-cymene) $(10 \mathrm{~mol} \%)$

$\mathrm{AgSbF}_{6}(20 \mathrm{~mol} \%)$

$\mathrm{Cu}(\mathrm{OAc})_{2}$ (2.0 equiv)

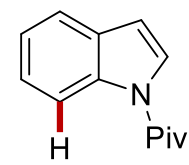

393a (3.0 equiv)

TFE, $40^{\circ} \mathrm{C}, 24 \mathrm{~h}, \mathrm{~N}_{2}$

2. $\mathrm{NEt}_{3}(0.5 \mathrm{~mL}), \mathrm{MeOH}(0.5 \mathrm{~mL}), \mathrm{RT}, 12 \mathrm{~h}$

" One-pot "

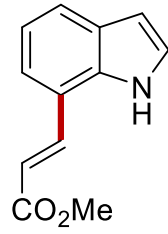

418: $68 \%$

Scheme 3.1.5 The traceless removal of $N$-pivaloyl orienting group and a one-pot process. 
Additionally, the ruthenium(II)-catalyzed C7-H amidation and alkenylation could be easily conducted on a gram scale without significant loss of catalytic efficacy, thereby highlighting the robustness of the ruthenium(II)biscarboxylate catalysis (Scheme 3.1.6).
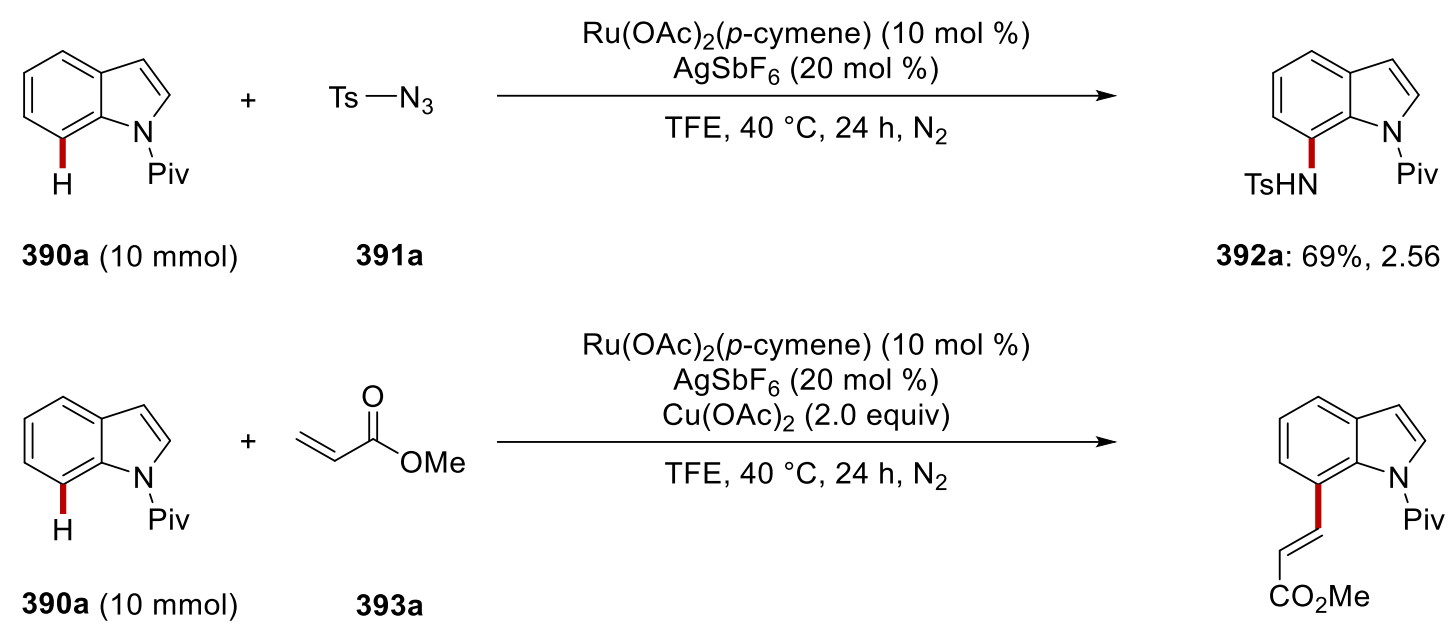

392a: $69 \%, 2.56 \mathrm{~g}$

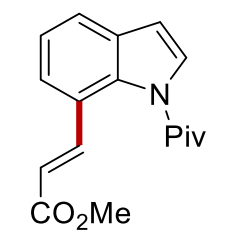

394a: $78 \%, 2.22 \mathrm{~g}$

Scheme 3.1.6 Gram-scale C7-H indole activations.

Flow technology provides organic chemists with tremendous benefits, including an improved heat and mass transfer, reaction safeness, and scalability. ${ }^{[21]}$ The $\mathrm{C} 7-\mathrm{H}$ activation of indoles was indeed demonstrated in a flow set-up, giving the desired amidated product 392 without loss of efficiency and selectivity at shortened reaction time (Scheme 3.1.7).

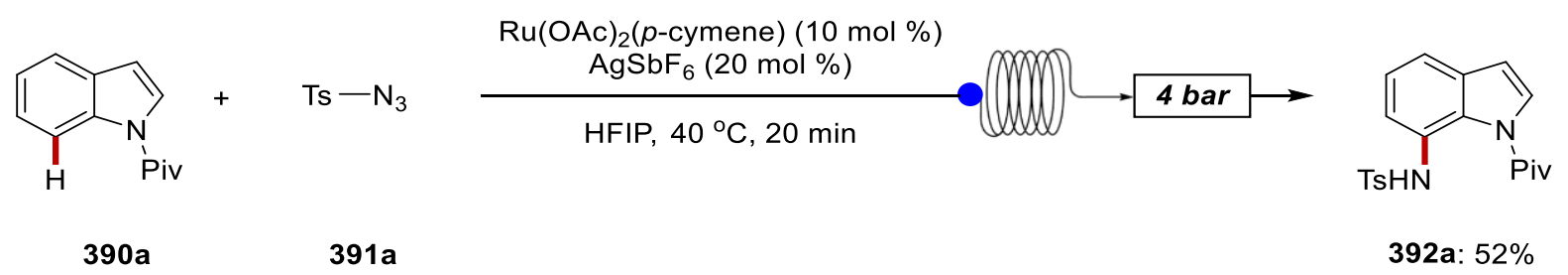

Scheme 3.1.7 Scalable flow reaction for $\mathrm{C} 7-\mathrm{H}$ amidation of indole. 


\subsubsection{Mechanistic Studies}

Given the unique robustness, broad applicability, and synthetic utility of the unprecedented carboxylate-assisted ruthenium(II)-catalyzed C7-H activation, we became interested in delineating its mode of action. To this end, intermolecular competition experiments with differently substituted $\mathrm{N}$ pivaloyl indoles 390 were conducted (Scheme 3.1.8). Thus, electron-rich substrate possessed an inherent higher reactivity, proposing that a concerted metalation deprotonation (CMD) less likely, while providing support for a base-assisted internal electrophile-type substitution (BIES) manifold. ${ }^{[23]}$

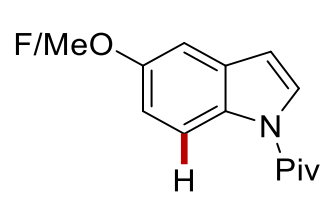

390

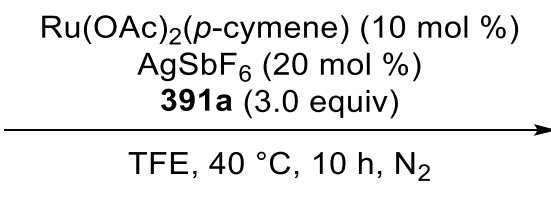



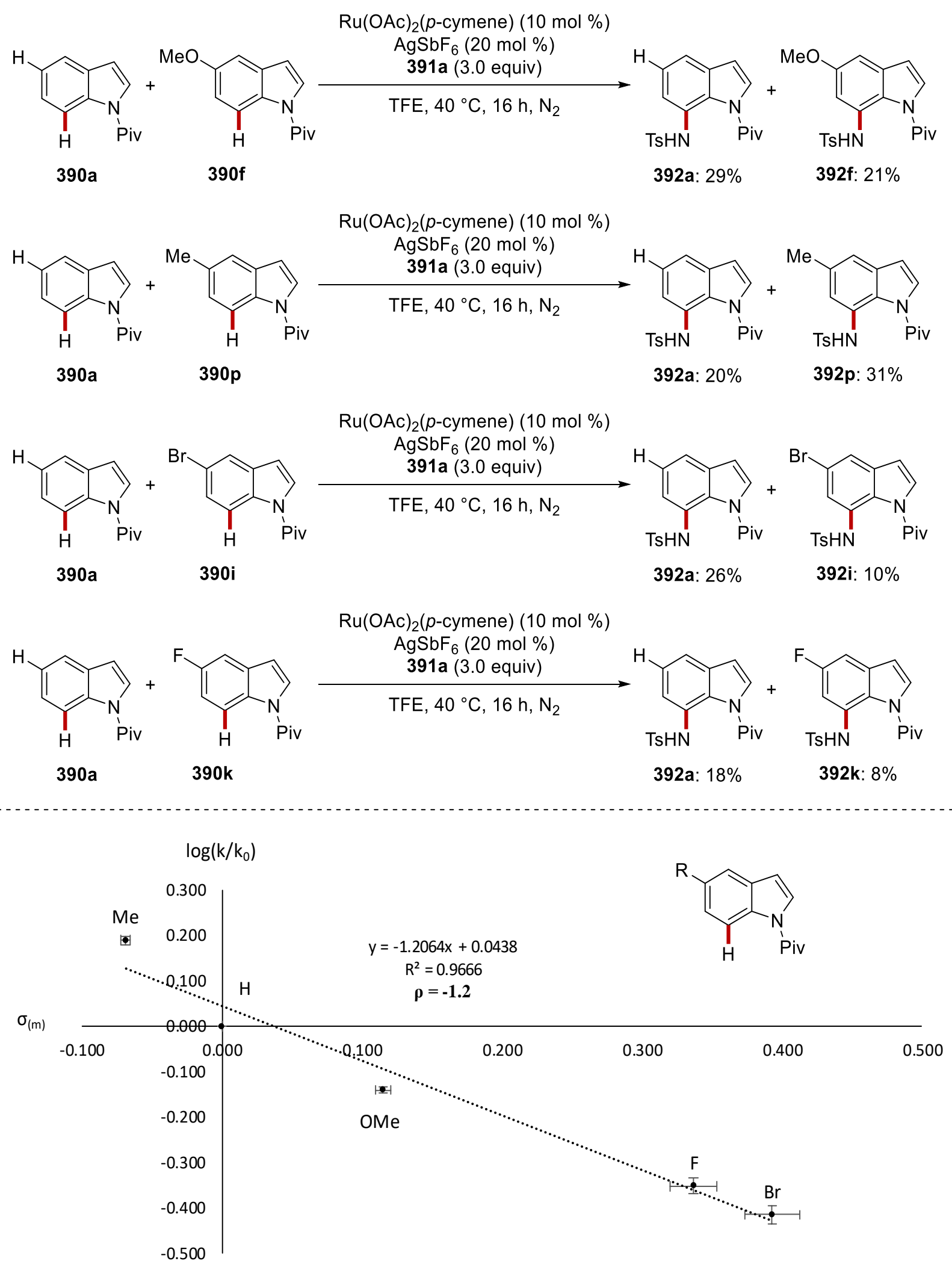

Scheme 3.1.9 Independent reactions for Hammett plot analysis. 
Furthermore, we performed the $\mathrm{C} 7-\mathrm{H}$ activation in the presence of isotopically labeled TFE (Scheme 3.1.10). H/D-scrambling in the C7- and C2-position was observed in the absence of substrate 391a, indicating the reversible nature of the $\mathrm{C}-\mathrm{H}$ bond cleavage event. Also, a $\mathrm{H} / \mathrm{D}$ exchange experiment in the presence of 391a provided evidence for a facile $\mathrm{C}-\mathrm{H}$ cleavage.<smiles>N#[PH]n1ccc2ccccc21</smiles>

$390 a$

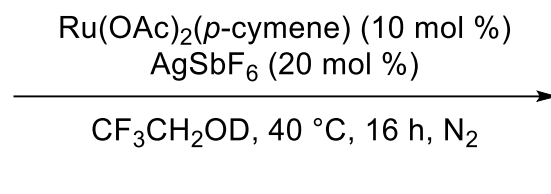

$$
\begin{gathered}
\mathrm{Ru}(\mathrm{OAc})_{2}(p \text {-cymene })(10 \mathrm{~mol} \%) \\
\mathrm{AgSbF}_{6}(20 \mathrm{~mol} \%) \\
391 \mathrm{a}(3.0 \text { equiv })
\end{gathered}
$$

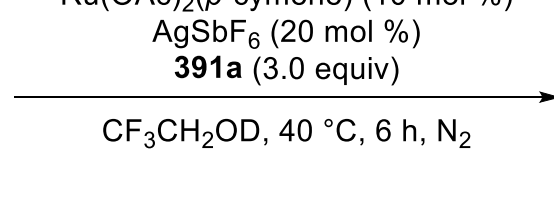$$
\overbrace{\mathrm{H}}
$$

$390 a$

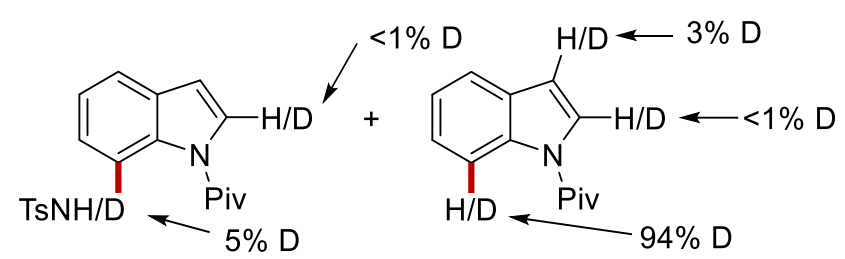

$[D]_{n}-392 a: 23 \%$

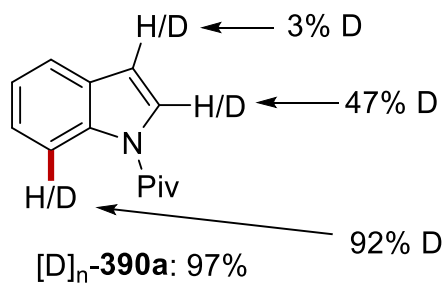

$[D]_{n}-390 a: 49 \%$

Scheme 3.1.10 H/D exchange studies.

Subsequently, independent reactions performed with substrate 390a and isotopically labeled compound $[\mathrm{D}]_{4}-\mathbf{3 9 0 a}$ showed a primary kinetic isotope effect $(\mathrm{KIE})$ of $k_{\mathrm{H}} / k_{\mathrm{D}} \approx 1.1$, giving a support for a fast C7-H scission (Scheme 3.1.11).
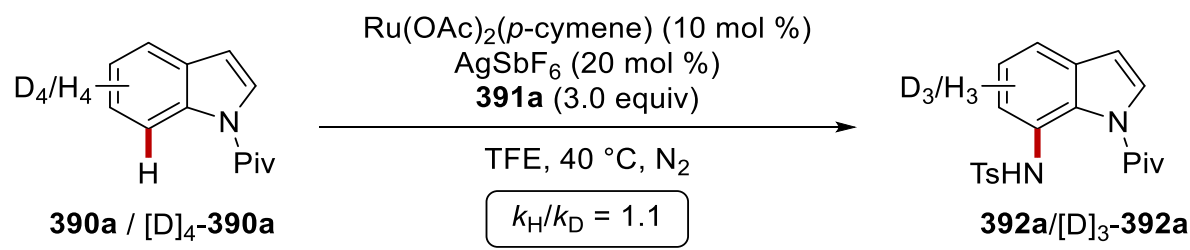

Scheme 3.1.11 KIE study.

In good agreement with this finding, detailed kinetic experiments unraveled a zero-order dependence of the reaction rate on the $N$-pivaloyl indole $390 \mathrm{a}$, while a first-order dependence was observed for the concentration of the tosyl azide 391a as well as the catalyst $\mathrm{Ru}(\mathrm{OAc})_{2}(p$-cymene) (Scheme 3.1.12). 


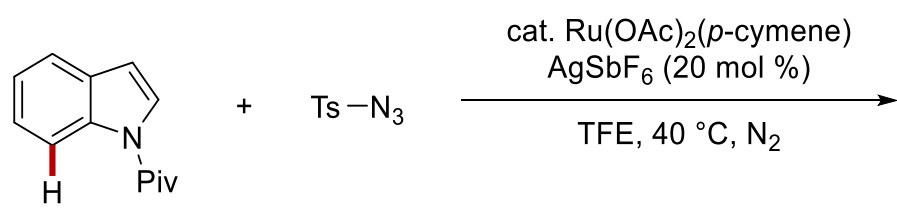

$390 \mathrm{a}$
$391 a$

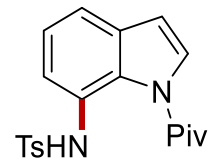

392

Order in $\mathbf{3 9 0 a}$
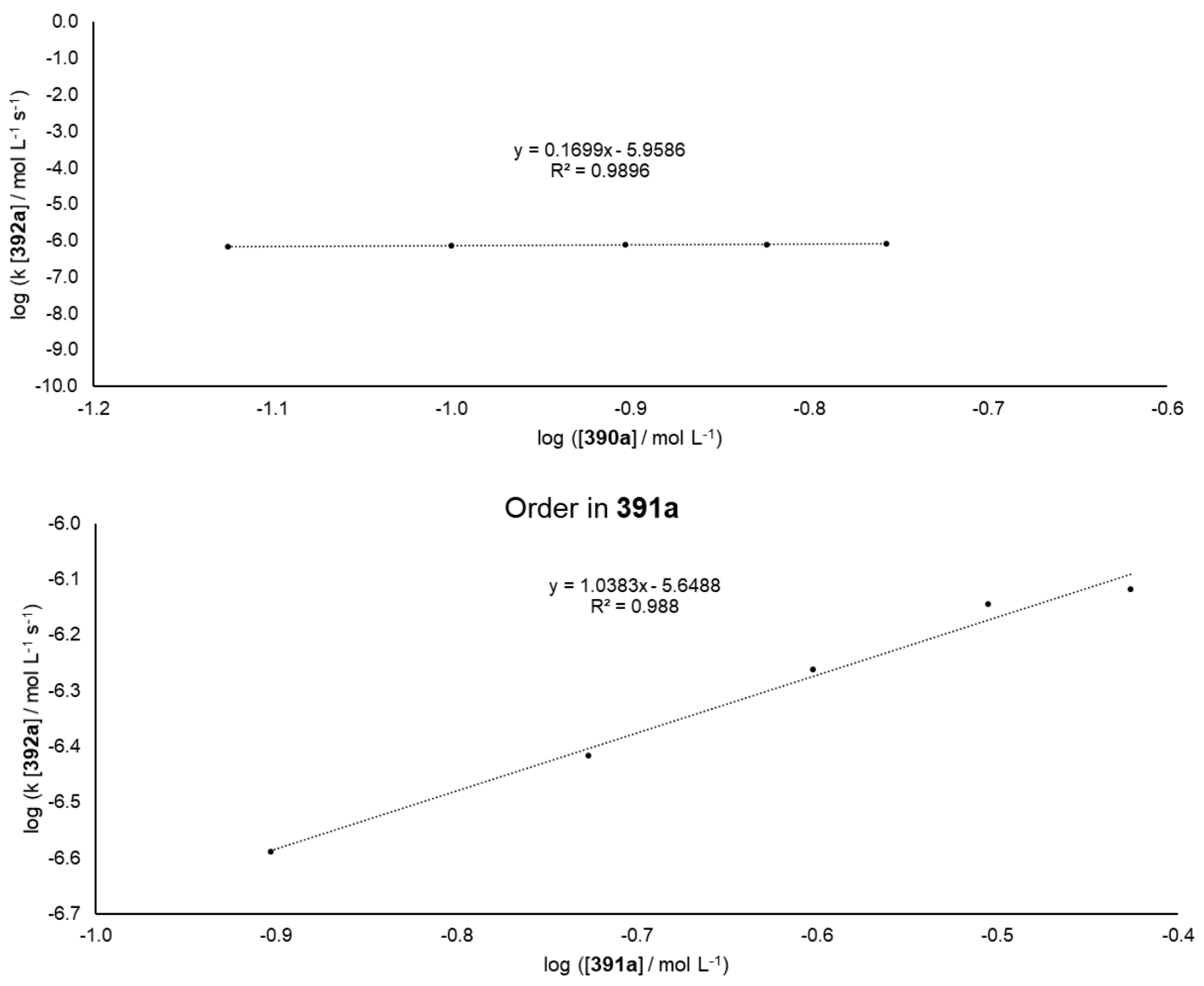

Order in $\mathrm{Ru}(\mathrm{OAc})_{2}($ p-cymene $)$

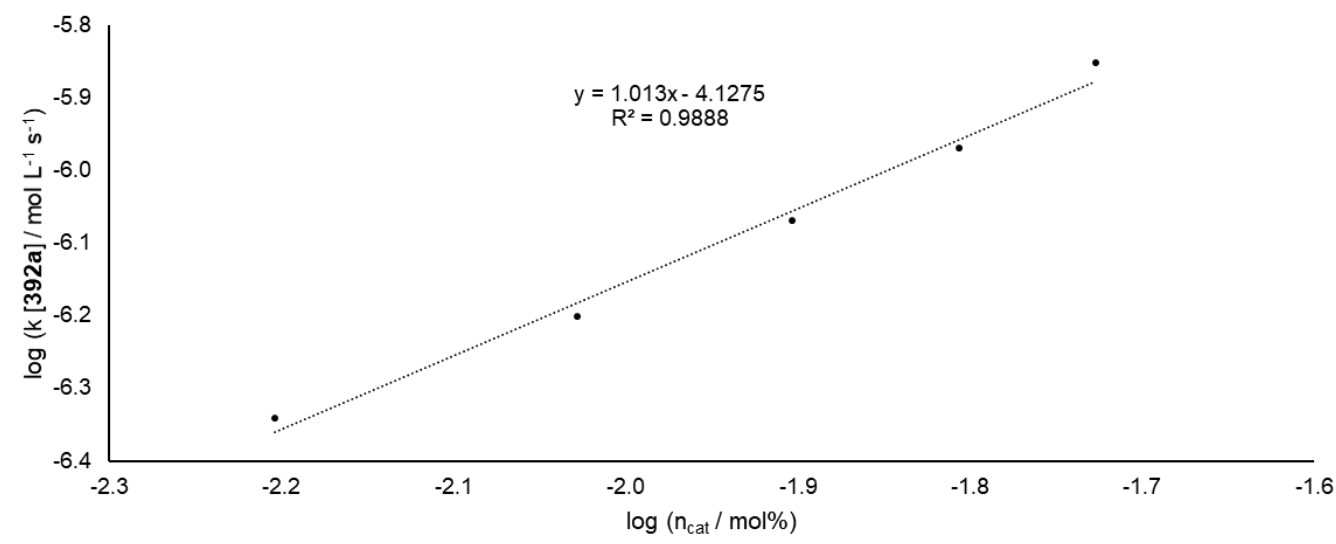

Scheme 3.1.12 Detailed kinetic experiments. 


\subsubsection{Proposed Catalytic Cycle}

On the basis of our detailed experimental mechanistic studies, a plausible catalytic cycle for the carboxylate-assisted ruthenium(II)-catalyzed C7-H indole activation is proposed in Scheme 3.1.13. The mechanism rationale commences with the coordination of substrate 391 a to the active ruthenium catalyst 419 to form ruthenium amide intermediate 420 , which previously has been often described as the latter step after $\mathrm{C}-\mathrm{H}$ activation. $\mathrm{C}-\mathrm{H}$ activation occurs through a BIES mechanism, preferentially leading to ruthenium(II) species 423 rather than 422 . The intermediate $\mathbf{4 2 3}$ is transformed to ruthenium(II) amido intermediate $\mathbf{4 2 4}$ via amido insertion. Finally, a proto-demetalation affords product 392 and regenerates the active catalyst 419.

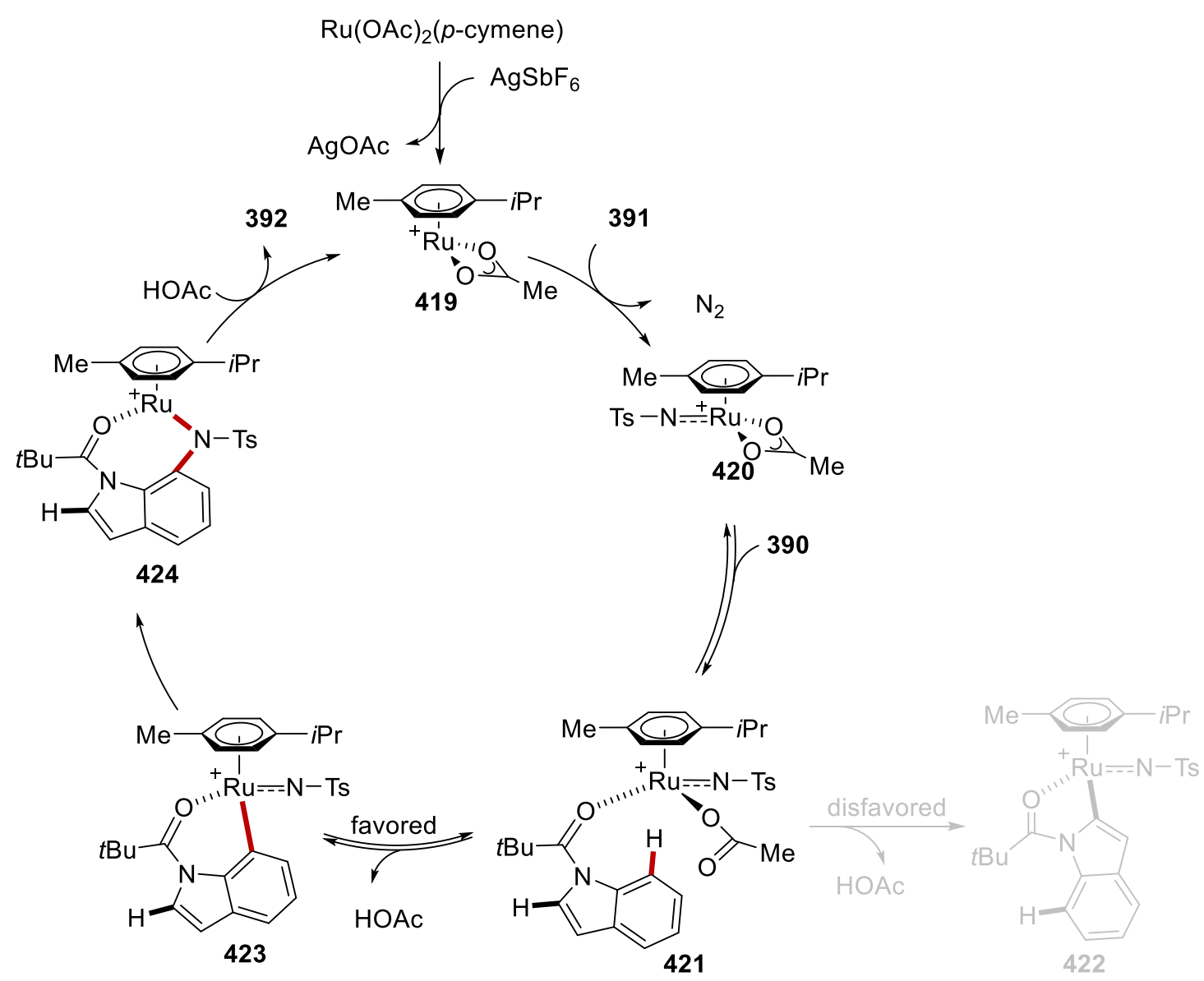

Scheme 3.1.13 Proposed catalytic cycle. 


\subsection{Ruthenium(II)-Catalyzed C4/C6-H Dual Alkylations of Indoles}

The $\mathrm{C} 2-\mathrm{H}$ and $\mathrm{C} 3-\mathrm{H}$ bonds of indoles has been widely modified by both direct and directed $\mathrm{C}-\mathrm{H}$ functionalization methods. ${ }^{[222,219]}$ In sharp contrast, site-selective $\mathrm{C}-\mathrm{H}$ functionalization on the benzenoid ring has remained challenging. Particularly, $\mathrm{C} 4-\mathrm{H}$ or $\mathrm{C} 6-\mathrm{H}$ functionalized indole scaffolds exhibit noteworthy medical or agrochemical properties (Scheme 3.2.1). ${ }^{[223]}$ As a consequence, there is a continued interest for general strategies providing easy access to C4/C6-substituted indoles in a sustainable fashion.

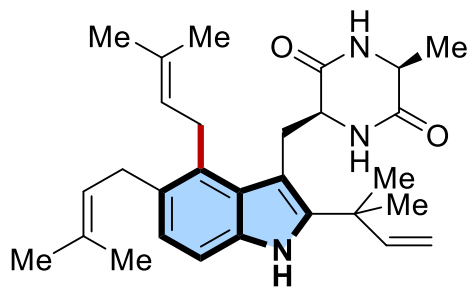

Variecolorin L

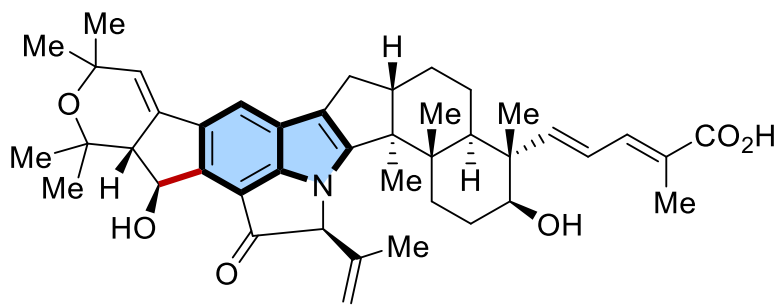

Nodulisporic Acid A

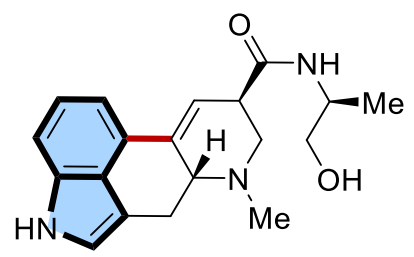

Ergometrine<smiles>CCc1cc2c(c3[nH]ccc13)C(C)CC2C</smiles>

trans-Trikentrin A

Scheme 3.2.1 Bioactive compounds with C4/C6 functionalized indoles.

While different methods have provided access to C4 and C6-functionalized indoles by Prabhu, ${ }^{[224]}$ Shi, ${ }^{[225]} \mathrm{Yu},{ }^{[226]}$ and Baran ${ }^{[227]}$ among others, ${ }^{[228]}$ challenging dual functionalizations of C4- and C6-H bonds of indoles have thus far remained elusive. 


\subsubsection{Optimization Studies}

At the outset, various reaction conditions were probed for the envisioned ruthenium(II)-catalyzed C4/C6-H alkylations of indole 395 with ethyl 2-bromoisobutyrate (396) (Table 3.2.1). In the initial studies with $\mathrm{RuCl}_{2}\left(\mathrm{PPh}_{3}\right)(p$-cymene) as the catalyst, the $\mathrm{C} 3$-alkylated product 425 was formed as a byproduct, likely obtained via electrophilic substitution (entry 1). While KOAc as the base was crucial to obtain a good conversion in the absence of acetic acid (entries 2-3), C3-alkylated product 425 was still observed. Thus, we focused our optimization towards reducing the formation of the C3functionalized product $\mathbf{4 2 5}$, while increasing the desired $\mathrm{C} 4 / \mathrm{C} 6-\mathrm{H}$ alkylated product 397. Although arene-liand-free ruthenium complex $\mathrm{RuCl}_{2}\left(\mathrm{PPh}_{3}\right)_{3}$ with different bases showed a poor reactivity (entries 4-6), $\mathrm{Ru}(\mathrm{OAc})_{2}\left(\mathrm{PPh}_{3}\right)_{2}$ demonstrated effective conversion to the desired product 397 (entry 7). Among various bases, such as acetates (entries 7-10), carbonate (entry 11), and phosphate (entry 12), $\mathrm{NaOAc}$ gave the most effective reactivity while reducing the formation of by-product $\mathbf{4 2 5}$ (entry 8). Furthermore, among a variety of solvents, DCE proved to be the most efficient for $\mathrm{C} 4 / \mathrm{C} 6-\mathrm{H}$ alkylation (entries 13-16). Interestingly, as the reaction temperature was decreased, both the reactivity and the selectivity were significantly improved (entries 16-20). Although the arene-containing ruthenium catalyst was again probed under the optimized conditions, it afforded a less satisfactory result, highlighting the unique feature of arene-ligand-free ruthenium catalysis (entry 21). 
Table 3.2.1 Optimization of the ruthenium(II)-catalyzed dual alkylation ${ }^{[\mathrm{a}]}$
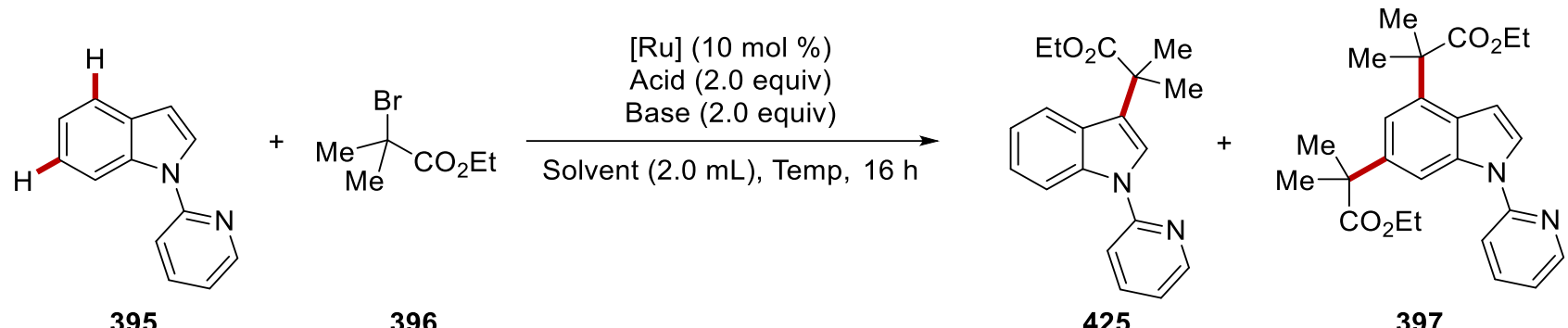

395

396

425

397

\begin{tabular}{|c|c|c|c|c|c|c|c|c|}
\hline \multirow{2}{*}{ Entry } & \multirow{2}{*}[\mathrm{Ru}]{} & \multirow{2}{*}{ Acid } & \multirow{2}{*}{ Base } & \multirow{2}{*}{ Solvent } & \multirow{2}{*}{$\begin{array}{l}\text { Temp } \\
\left({ }^{\circ} \mathrm{C}\right)\end{array}$} & \multicolumn{3}{|c|}{ Yield (\%) } \\
\hline & & & & & & 395 & 425 & 397 \\
\hline 1 & $\mathrm{RuCl}_{2} \mathrm{PPh}_{3}(p$-cymene $)$ & HOAc & KOAc & THF & 120 & trace & 19 & 58 \\
\hline 2 & $\mathrm{RuCl}_{2} \mathrm{PPh}_{3}(p$-cymene $)$ & -- & KOAc & $\mathrm{THF}$ & 120 & 4 & 23 & 58 \\
\hline 3 & $\mathrm{RuCl}_{2} \mathrm{PPh}_{3}(p$-cymene $)$ & HOAc & -- & THF & 120 & 94 & 0 & 0 \\
\hline 4 & $\mathrm{RuCl}_{2}\left(\mathrm{PPh}_{3}\right)_{3}$ & -- & KOAc & THF & 120 & 82 & trace & 5 \\
\hline 5 & $\mathrm{RuCl}_{2}\left(\mathrm{PPh}_{3}\right)_{3}$ & -- & $\mathrm{K}_{2} \mathrm{CO}_{3}$ & THF & 120 & 76 & 2 & 14 \\
\hline 6 & $\mathrm{RuCl}_{2}\left(\mathrm{PPh}_{3}\right)_{3}$ & -- & $\mathrm{K}_{3} \mathrm{PO}_{4}$ & THF & 120 & 70 & 3 & 15 \\
\hline 7 & $\mathrm{Ru}(\mathrm{OAc})_{2}\left(\mathrm{PPh}_{3}\right)_{2}$ & -- & KOAc & THF & 120 & 26 & 13 & 43 \\
\hline 8 & $\mathrm{Ru}(\mathrm{OAc})_{2}\left(\mathrm{PPh}_{3}\right)_{2}$ & -- & $\mathrm{NaOAc}$ & THF & 120 & 32 & 4 & 46 \\
\hline 9 & $\mathrm{Ru}(\mathrm{OAc})_{2}\left(\mathrm{PPh}_{3}\right)_{2}$ & -- & LiOAc & THF & 120 & 80 & trace & 16 \\
\hline 10 & $\mathrm{Ru}(\mathrm{OAc})_{2}\left(\mathrm{PPh}_{3}\right)_{2}$ & -- & $\mathrm{CsOAc}$ & THF & 120 & 84 & 4 & 10 \\
\hline 11 & $\mathrm{Ru}(\mathrm{OAc})_{2}\left(\mathrm{PPh}_{3}\right)_{2}$ & & $\mathrm{~K}_{2} \mathrm{CO}_{3}$ & THF & 120 & 85 & 3 & trace \\
\hline 12 & $\mathrm{Ru}(\mathrm{OAc})_{2}\left(\mathrm{PPh}_{3}\right)_{2}$ & & $\mathrm{~K}_{3} \mathrm{PO}_{4}$ & THF & 120 & 86 & trace & trace \\
\hline 13 & $\mathrm{Ru}(\mathrm{OAc})_{2}\left(\mathrm{PPh}_{3}\right)_{2}$ & -- & $\mathrm{NaOAc}$ & 1,4-dioxane & 120 & 8 & 33 & 53 \\
\hline 14 & $\mathrm{Ru}(\mathrm{OAc})_{2}\left(\mathrm{PPh}_{3}\right)_{2}$ & -- & $\mathrm{NaOAc}$ & $\mathrm{PhMe}$ & 120 & 0 & 23 & 50 \\
\hline 15 & $\mathrm{Ru}(\mathrm{OAc})_{2}\left(\mathrm{PPh}_{3}\right)_{2}$ & -- & $\mathrm{NaOAc}$ & $\mathrm{PhCF}_{3}$ & 120 & 0 & 21 & 59 \\
\hline 16 & $\mathrm{Ru}(\mathrm{OAc})_{2}\left(\mathrm{PPh}_{3}\right)_{2}$ & -- & $\mathrm{NaOAc}$ & DCE & 120 & 0 & 8 & 63 \\
\hline 17 & $\mathrm{Ru}(\mathrm{OAc})_{2}\left(\mathrm{PPh}_{3}\right)_{2}$ & -- & $\mathrm{NaOAc}$ & DCE & 100 & 0 & 12 & 65 \\
\hline 18 & $\mathrm{Ru}(\mathrm{OAc})_{2}\left(\mathrm{PPh}_{3}\right)_{2}$ & -- & $\mathrm{NaOAc}$ & DCE & 80 & 0 & 11 & 72 \\
\hline 19 & $\mathrm{Ru}(\mathrm{OAc})_{2}\left(\mathrm{PPh}_{3}\right)_{2}$ & -- & NaOAc & DCE & 70 & $\mathbf{0}$ & 4 & 80 (77) \\
\hline
\end{tabular}




\begin{tabular}{ccccccccc}
\hline 20 & $\mathrm{Ru}(\mathrm{OAc})_{2}\left(\mathrm{PPh}_{3}\right)_{2}$ & -- & $\mathrm{NaOAc}$ & $\mathrm{DCE}$ & 60 & 58 & 10 & 24 \\
21 & $\mathrm{RuCl}_{2} \mathrm{PPh}_{3}(p$-cymene $)$ & -- & $\mathrm{NaOAc}$ & $\mathrm{DCE}$ & 70 & 64 & 5 & 4 \\
\hline
\end{tabular}

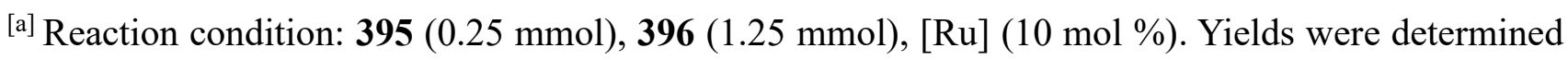
by ${ }^{1} \mathrm{H} \mathrm{NMR}$ with $\mathrm{CH}_{2} \mathrm{Br}_{2}$ as an internal standard. Isolated yield in the parenthesis.

Thereafter, we examined the effect of the $N$-substituent pattern in indoles $\mathbf{3 9 5}$ on the outcome of the reaction (Scheme 3.2.2). Hence, indoles 395 with a variety of orienting groups, such as pyridine (395a) amides (395b) and (395c), phosphine oxide (395d), and phosphine (395e), as well as free-indole (395f) were subjected to the established reaction conditions for the $\mathrm{C} 4 / \mathrm{C} 6-\mathrm{H}$ distal functionalizations of the heterocycle. Interestingly, only the pyridine group afforded the desired $\mathrm{C} 4 / \mathrm{C} 6-\mathrm{H}$ alkylation product 397, clearly demonstrating the unique ability of the pyridine directing group in this transformation. These results illustrated the importance of the five-membered ruthenacycles formation by the $N\left(\mathrm{sp}^{2}\right)$ group for allowing for C4/C6-H double functionalizations.

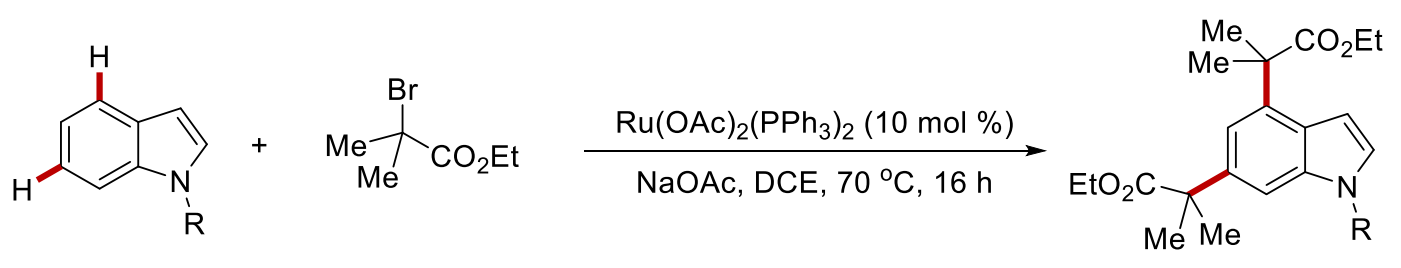

395

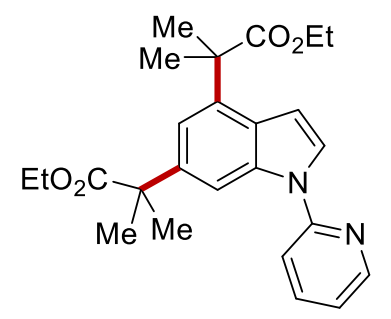

395a: $77 \%$<smiles>CCOC(=O)C(C)(C)c1cc(C(C)(C)C(C)(C)C)c2ccn(P(=O)(CC(C)(C)C)C(C)(C)C)c2c1</smiles>

395d: $0 \%$

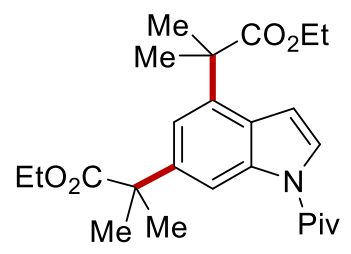

395b: $0 \%$

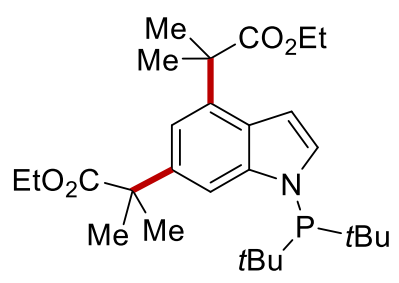

395e: $0 \%$<smiles>CCOC(=O)C(C)(C)c1cc(C(C)(C)OCC)cc2c1ccn2C(=O)c1ccccn1</smiles>

395c: $0 \%$

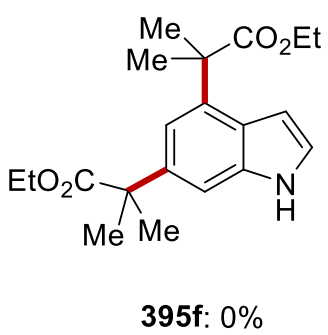

Scheme 3.2.2 Examination of $N$-substitution pattern. 


\subsubsection{Substrate Scope}

With the optimal reaction conditions in hand, we next explored the versatility of the $\mathrm{C} 4 / \mathrm{C} 6-\mathrm{H}$ functionalization with a set of representative indoles 395 and alkyl bromides 396 (Scheme 3.2.3). Indeed, alkyl bromides 396 having different types of alkyl groups were selectively transformed into the desired C4/C6-H double alkylated products 397. Notably, a synthetically valuable aryl iodide was fully tolerated under the reaction conditions. It is noteworthy that the reaction could be easily conducted on a gram scale without significant loss of catalytic efficacy.
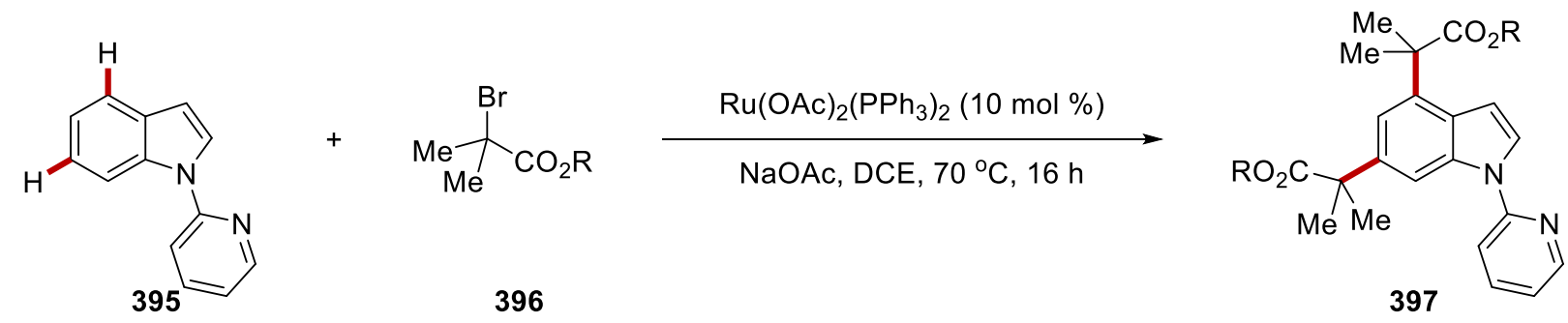

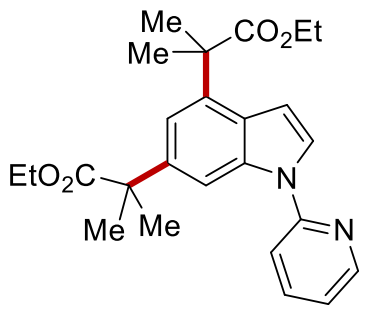

397a: $77 \%$

(Gram scale: $70 \%, 1.48 \mathrm{~g}$ )

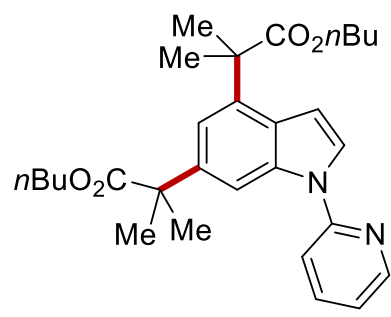

397e: $85 \%$

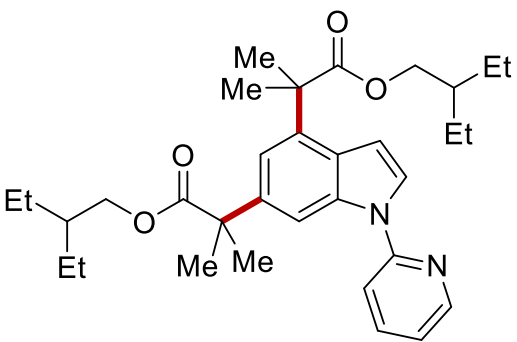

397h: $89 \%$

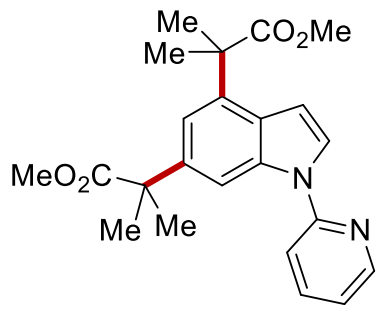

397b: $81 \%$

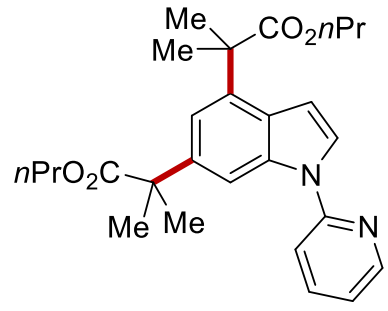

397c: $69 \%$<smiles>CC(C)OC(=O)C(C)(C)c1cc(C(C)(C)C(=O)OC(C)C)c2ccn(-c3ccccn3)c2c1</smiles>

397d: $72 \%$

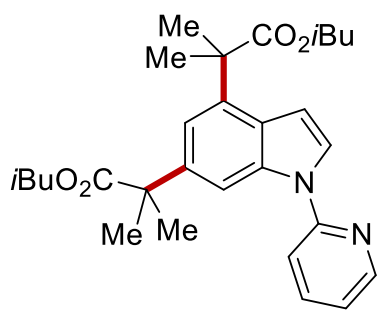

397f: $76 \%$<smiles>COCCOC(=O)C(C)(C)c1cc(C(C)(C)C(=O)OCCOC)c2ccn(-c3ccccn3)c2c1</smiles>

397g: $85 \%$<smiles></smiles>

397i: $63 \%$

Scheme 3.2.3 C4-H/C6-H alkylations with differently substituted alkyl bromides 396. 
This reaction manifold was further extended to exploit natural product-derived alkyl bromides, including menthol 396k, rose oil 3961, estrone 396m, and galactopyranose 396n, providing selectively C4-H and C6-H dual functionalized indoles 397k-397n without racemization (Scheme 3.2.4).<smiles>c1ccc(-n2ccc3ccccc32)nc1</smiles>

395<smiles>[R]OC(=O)C(C)(C)Br</smiles>

396

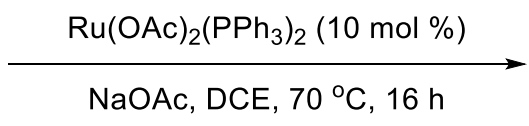

$\mathrm{NaOAc}, \mathrm{DCE}, 70^{\circ} \mathrm{C}, 16 \mathrm{~h}$

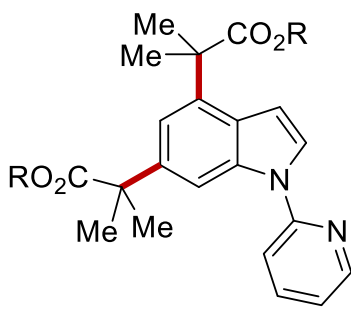

397<smiles>CC1CCC(C(C)C)C(OC(=O)C(C)(C)c2cc(C(C)(C)C(=O)OC3CC(C)CCC3C(C)C)c3ccn(-c4ccccn4)c3c2)C1</smiles>

$397 \mathbf{k}: 85 \%$

(From Menthol)<smiles>CC(C)(C(=O)OCCc1ccccc1)c1cc(C(C)(C)C(=O)OCCc2ccccc2)c2ccn(-c3ccccn3)c2c1</smiles>

397I: $64 \%$

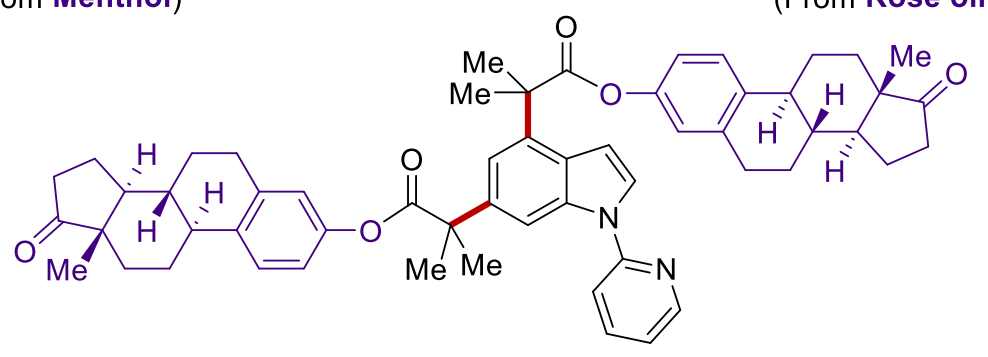

397m: 79\% (From Estrone)<smiles>CC1(C)O[C@H]2[C@H]3OC(C)(C)O[C@@H]3[C@H](COC(=O)C(C)(C)c3cc(C(C)(C)C(=O)OC[C@H]4O[C@@H]5OC(C)(C)O[C@H]5[C@H]5OC(C)(C)O[C@@H]54)c4ccn(-c5ccccn5)c4c3)O[C@@H]2O1</smiles>

Scheme 3.2.4 Dual C-H alkylations of indoles 395 with natural product motifs. 


\subsubsection{Mechanistic Studies}

Given the unique features of the unprecedented arene-ligand-free ruthenium-catalyzed dual C4/C6-H alkylations, we became interested in deciphering its mode of action (Scheme 3.2.4). To this end, we performed the $\mathrm{C} 4 / \mathrm{C} 6-\mathrm{H}$ alkylation in the presence of isotopically labeled $\mathrm{D}_{2} \mathrm{O}$ under the optimized reaction conditions (Scheme 3.2.5a). Hence, H/D-scrambling was only observed in the $\mathrm{C} 2-$ and $\mathrm{C} 3-$ $\mathrm{H}$ positions, while the $\mathrm{C} 7-\mathrm{H}$ position was not deuterated. This finding clearly proved that $\mathrm{C} 2-\mathrm{H}$ bond scission occurs in a reversible fashion and indicates that $\mathrm{C} 4 / \mathrm{C} 6-\mathrm{H}$ double alkylations were presumably governed by the C2-ruthenation event. Further experiments showed that the C7-H blocked substrate 395b efficiently underwent the $\mathrm{C} 4 / \mathrm{C} 6-\mathrm{H}$ alkylation process, showing a C7-metallation-initiated distalfunctionalization unlikely to be operative (Scheme 3.2.5b).

(a) $H / D$ exchange study<smiles>[H][R10]n1ccc2ccccc21</smiles>

$$
\mathrm{Ru}(\mathrm{OAc})_{2}\left(\mathrm{PPh}_{3}\right)_{2}(10 \mathrm{~mol} \%)
$$$$
396 a \text { (5.0 equiv) }
$$

$\mathrm{NaOAc}, \mathrm{D}_{2} \mathrm{O}$ (10 equiv), DCE $70{ }^{\circ} \mathrm{C}, 16 \mathrm{~h}$

$395 a$

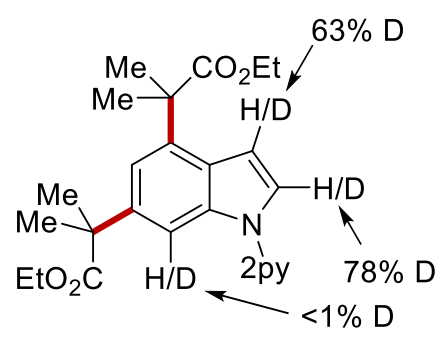

$[D]_{n}-397 a: 75 \%$

(b) Experiment with C7-blocked substrate 395b<smiles>Cc1ccc2ccn([GaH2])c2c1</smiles>

$395 b$

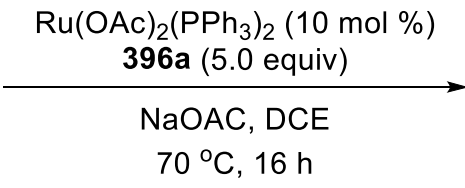

$70^{\circ} \mathrm{C}, 16 \mathrm{~h}$

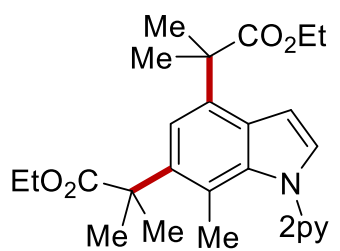

3970: $71 \%$

Scheme 3.2.5 Mechanistic investigations for $\mathrm{C} 4 / \mathrm{C} 6-\mathrm{H}$ functionalizations. 


\subsection{Osmium-Catalyzed Electrooxidative C-H Annulations}

Carboxylate-assisted ${ }^{[20 \mathrm{a}]}$ oxidative $\mathrm{C}-\mathrm{H}$ annulations by weak $O$-coordination have been realized by consecutive $\mathrm{C}-\mathrm{H}$ and $\mathrm{O}-\mathrm{H}$ bond scission of aromatic carboxylic acids. With pioneering contributions in rhodium, ruthenium, and iridium catalysis by Miura/Satoh, ${ }^{[229]}$ Ackermann, ${ }^{[230]}$ and Ison ${ }^{[231]}$ among others, ${ }^{[232]}$ the modular assembly of five- or six-membered heterocycles has been established. ${ }^{[233,215 \mathrm{~d}]}$ However, these reactions require the additional use of stoichiometric chemical oxidants, such as copper(II) or silver(I) salts, to facilitate the redox processes. To overcome this disadvantage, metallaelectrocatalysis has recently emerged as a sustainable platform. ${ }^{\text {[234a-d, 1a, 234e-n] }}$ Specifically, C$\mathrm{H}$ activations enabled by electricity, facilitating the crucial catalysts reoxidation by an anodic event, allowed for a variety of oxidative chemical transformations, thus avoiding cost-intensive or toxic chemical oxidants. ${ }^{[235]}$ Recently, Ackermann ${ }^{[236]}$ and others ${ }^{[237]}$ have developed electrooxidative C-H annulations by ruthenium, rhodium, and iridium catalysts (Scheme 3.3.1).

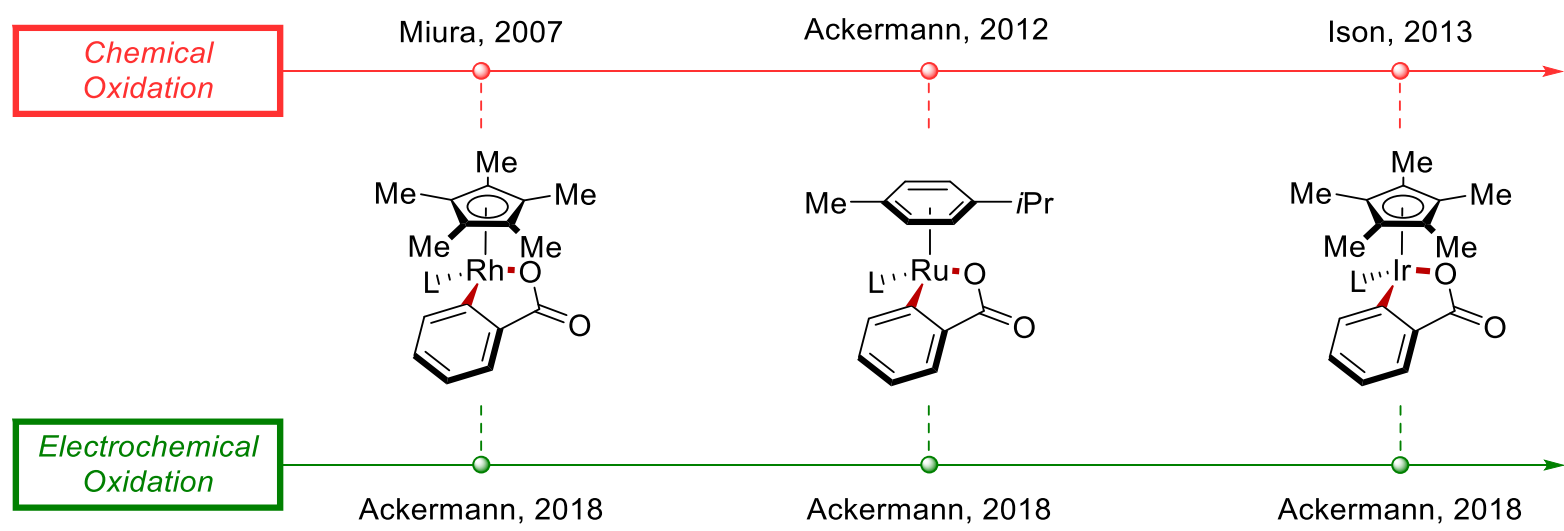

Scheme 3.3.1 Timeline of C-H annulations by rhodium(III), ruthenium(II), and iridium(III) catalysis: chemical oxidants versus electrocatalysis. 


\subsubsection{Optimization Studies}

Reaction conditions for osmium(II)-catalyzed oxidative $\mathrm{C}-\mathrm{H}$ activations were tested with $o$-toluic acid (398) and $n$-butyl acrylate (399) in an undivided cell setup with a graphite felt (GF) anode and a platinum plate cathode (Table 3.3.1). We were delighted to observe that the desired annulated product 400 was obtained in $75 \%$ yield in HFIP and $\mathrm{H}_{2} \mathrm{O}$ as the solvent mixture along with the use of KI as an additive (entry 1). A variety of additives, such as representative redox mediators (entries 2-4), alkali metal-based salts (entries 5-8), organic salts (entry 9), and iodine (entry 10), were subjected to the osmaelectro-catalyzed $\mathrm{C}-\mathrm{H}$ annulation. Here, non-toxic and inexpensive $\mathrm{KI}$ provided optimal efficiency, while the increased amount of KI did not result in the increase of the yield. Other bases, such as $\mathrm{NaOAc}$ or NaOPiv, gave lower reactivity (entries 12-13). Interestingly, while the rhodium and the iridium catalyst which were used for analogous reactions did not provide satisfactory results, the use of the ruthenium catalyst afforded a higher yield than the osmium catalyst (entries 17-19). Control experiments highlighted the importance of the catalyst, electricity, and the additive for electrooxidative $\mathrm{C}-\mathrm{H}$ annulation reaction (entries 20-22).

Table 3.3.1 Optimization of the osmium(II)-catalyzed electrooxidative $\mathrm{C}-\mathrm{H}$ activation ${ }^{[\mathrm{a}]}$

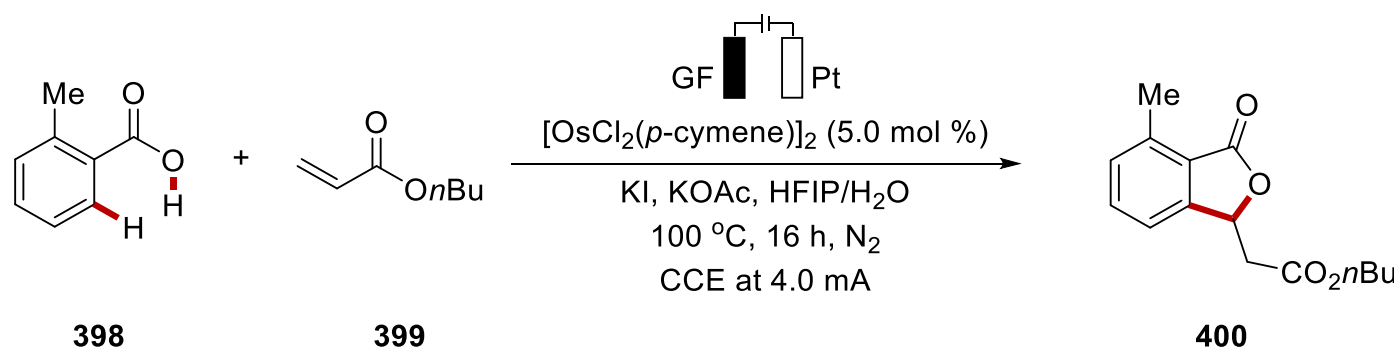

\begin{tabular}{cccccc}
\hline Entry & Base & Additive & Solvent (ratio) & Temp $\left({ }^{\circ} \mathrm{C}\right)$ & Yield (\%) \\
\hline $\mathbf{1}$ & KOAc & KI & HFIP $/ \mathbf{H}_{2} \mathrm{O}(\mathbf{1} / \mathbf{1})$ & $\mathbf{1 0 0}$ & $\mathbf{7 7}(\mathbf{7 5})$ \\
2 & KOAc & $\mathrm{BQ}$ & $\mathrm{HFIP} / \mathrm{H}_{2} \mathrm{O}(1 / 1)$ & 100 & 0 \\
3 & KOAc & $\mathrm{Fc}$ & $\mathrm{HFIP} / \mathrm{H}_{2} \mathrm{O}(1 / 1)$ & 100 & 0 \\
4 & KOAc & $\mathrm{HOBt}$ & $\mathrm{HFIP} / \mathrm{H}_{2} \mathrm{O}(1 / 1)$ & 100 & 0 \\
5 & KOAc & $\mathrm{NaI}$ & $\mathrm{HFIP} / \mathrm{H}_{2} \mathrm{O}(1 / 1)$ & 100 & 29
\end{tabular}




\begin{tabular}{|c|c|c|c|c|c|}
\hline 6 & KOAc & $\mathrm{KPF}_{6}$ & $\mathrm{HFIP} / \mathrm{H}_{2} \mathrm{O}(1 / 1)$ & 100 & 38 \\
\hline 7 & KOAc & $\mathrm{KSbF}_{6}$ & $\mathrm{HFIP} / \mathrm{H}_{2} \mathrm{O}(1 / 1)$ & 100 & 54 \\
\hline 8 & KOAc & $\mathrm{NaSbF}_{6}$ & $\mathrm{HFIP} / \mathrm{H}_{2} \mathrm{O}(1 / 1)$ & 100 & 60 \\
\hline 9 & KOAc & $n \mathrm{BuN}_{4} \mathrm{I}$ & $\mathrm{HFIP} / \mathrm{H}_{2} \mathrm{O}(1 / 1)$ & 100 & 20 \\
\hline 10 & KOAc & $\mathrm{I}_{2}$ & $\mathrm{HFIP} / \mathrm{H}_{2} \mathrm{O}(1 / 1)$ & 100 & 23 \\
\hline 11 & KOAc & KI & $\mathrm{HFIP} / \mathrm{H}_{2} \mathrm{O}(1 / 1)$ & 100 & $76^{[\mathrm{b}]}$ \\
\hline 12 & NOAc & KI & $\mathrm{HFIP} / \mathrm{H}_{2} \mathrm{O}(1 / 1)$ & 100 & 36 \\
\hline 13 & NOPiv & KI & $\mathrm{HFIP} / \mathrm{H}_{2} \mathrm{O}(1 / 1)$ & 100 & 38 \\
\hline 14 & KOAc & KI & $\mathrm{HFIP} / \mathrm{H}_{2} \mathrm{O}(1 / 1)$ & 60 & 35 \\
\hline 15 & KOAc & KI & $\mathrm{HFIP} / \mathrm{H}_{2} \mathrm{O}(1 / 1)$ & 25 & 0 \\
\hline 16 & KOAc & KI & $\mathrm{HFIP} / \mathrm{H}_{2} \mathrm{O}(3 / 1)$ & 100 & 76 \\
\hline 17 & KOAc & KI & $\mathrm{HFIP} / \mathrm{H}_{2} \mathrm{O}(1 / 1)$ & 100 & $7^{[\mathrm{c}]}$ \\
\hline 18 & KOAc & KI & $\mathrm{HFIP} / \mathrm{H}_{2} \mathrm{O}(1 / 1)$ & 100 & $16^{[\mathrm{d}]}$ \\
\hline 19 & KOAc & KI & $\mathrm{HFIP} / \mathrm{H}_{2} \mathrm{O}(1 / 1)$ & 100 & $90^{[\mathrm{e}]}$ \\
\hline 20 & KOAc & KI & $\mathrm{HFIP} / \mathrm{H}_{2} \mathrm{O}(1 / 1)$ & 100 & $0^{[\mathrm{f}]}$ \\
\hline 21 & KOAc & KI & $\mathrm{HFIP} / \mathrm{H}_{2} \mathrm{O}(1 / 1)$ & 100 & $6^{[\mathrm{g}]}$ \\
\hline 22 & KOAc & -- & $\mathrm{HFIP} / \mathrm{H}_{2} \mathrm{O}(1 / 1)$ & 100 & 11 \\
\hline
\end{tabular}

[a] Reaction conditions: $398(0.20 \mathrm{mmol}), 399(0.60 \mathrm{mmol}),\left[\mathrm{OsCl}_{2}(p \text {-cymene })\right]_{2}(5.0 \mathrm{~mol} \%)$, base (2.0 equiv), additive (2.0 equiv), solvent mixture $(4.0 \mathrm{~mL}), 100^{\circ} \mathrm{C}, 16 \mathrm{~h}$. Yield was determined by ${ }^{1} \mathrm{H} \mathrm{NMR}$ with $\mathrm{CH}_{2} \mathrm{Br}_{2}$ as the internal standard. Yield in the parenthesis is isolated yield. [b] $\mathrm{KI}$ (4.0 equiv) was used. [c] [Cp* $\left.\mathrm{RhCl}_{2}\right]_{2}(2.5 \mathrm{~mol} \%)$ was used. [d] [Cp* $\left.\mathrm{IrCl}_{2}\right]_{2}(2.5 \mathrm{~mol} \%)$ was used. [e] $\left[\mathrm{RuCl}_{2}(p \text {-cymene })\right]_{2}(5.0 \mathrm{~mol} \%)$ was used. [f] Without catalyst. [g] Without electricity. The reaction was equipped with electrodes, but no electricity. GF = Graphite Felt. HFIP = Hexafluoroisopropyl alcohol. $\mathrm{BQ}=$ Benzoquinone. $\mathrm{Fc}=$ Ferrocene. $\mathrm{HOBt}=$ Hydroxybenzotriazole.

To highlight the advantages of the electrochemical approach, a set of experiments were carried out under air or with commonly employed chemical oxidants, such as $\mathrm{AgOAc}, \mathrm{Cu}(\mathrm{OAc})_{2}, \mathrm{Mn}(\mathrm{OAc})_{3}$, $\mathrm{PhI}(\mathrm{OAc})_{2}$, or $\mathrm{K}_{2} \mathrm{~S}_{2} \mathrm{O}_{8}$ (Scheme 3.3.2). All of the attempts met with unsatisfactory results, showing 
that electricity not only played a crucial role in sustainable oxidation, but also gave optimal and unique efficiency for the osmium-catalyzed oxidative $\mathrm{C}-\mathrm{H}$ annulation.<smiles>Cc1ccccc1C(=O)O</smiles>

$398 \mathrm{a}$<smiles>C=CC(=O)OCCCC</smiles>

$399 a$

\section{Electricity}

vs.

Chemical oxidant

\section{Os}

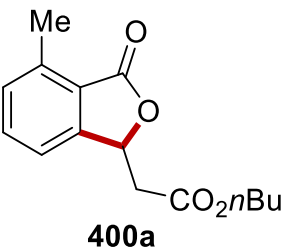

[Reaction conditions]

Electricity: $\left[\mathrm{OsCl}_{2}(p \text {-cymene })\right]_{2}(5.0 \mathrm{~mol} \%), \mathrm{KI}, \mathrm{KOAc}, \mathrm{HFIP} / \mathrm{H}_{2} \mathrm{O}, 100^{\circ} \mathrm{C}, 16 \mathrm{~h}, \mathrm{~N}_{2}, \mathrm{CCE}$ at $4.0 \mathrm{~mA}$ Chemical oxidant: $\left[\mathrm{OsCl}_{2}(p \text {-cymene })\right]_{2}(5.0 \mathrm{~mol} \%)$, oxidant, $\mathrm{KOAc}, \mathrm{HFIP} / \mathrm{H}_{2} \mathrm{O}, 100^{\circ} \mathrm{C}, 16 \mathrm{~h}, \mathrm{~N}_{2}$

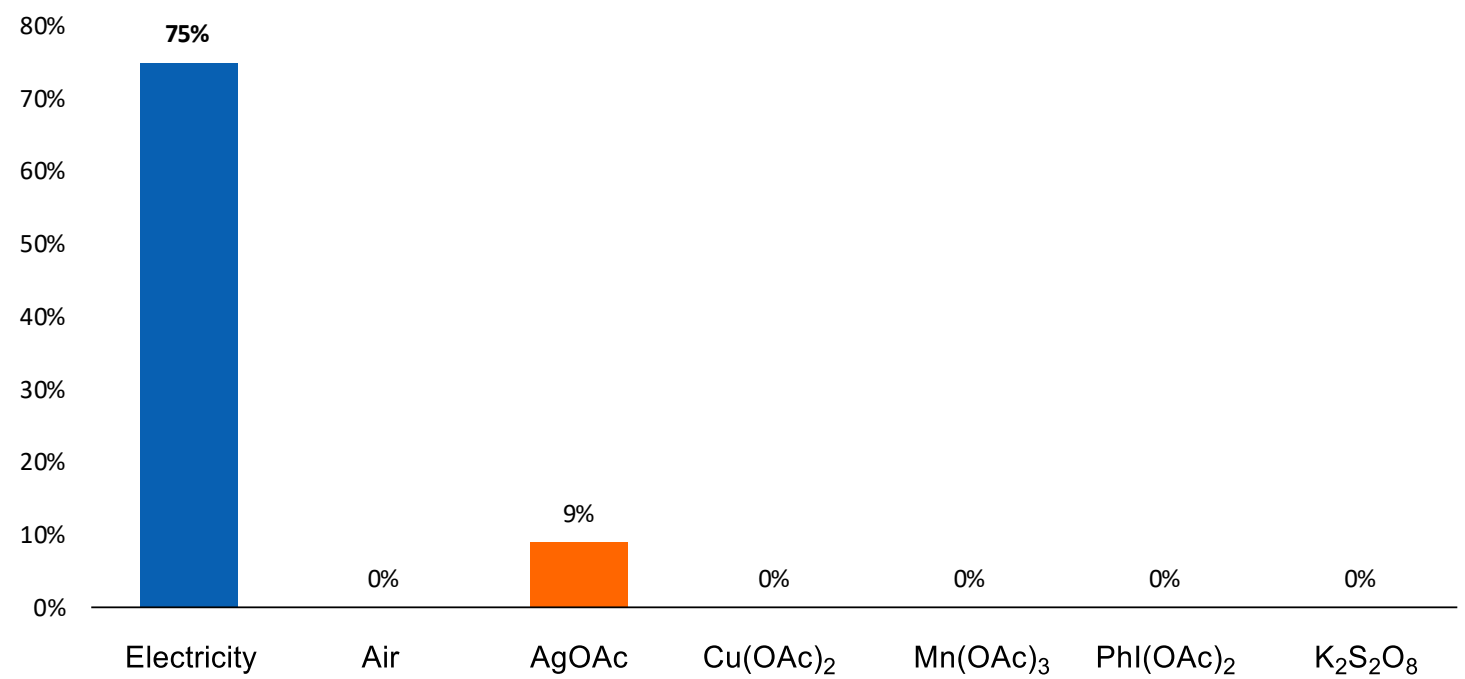

Scheme 3.3.2 Comparison between electricity and representative chemical oxidants. 


\subsubsection{Substrate Scope}

Next, we explored the viable substrate scope of the electrochemical osmium-catalyzed [4+1] and [4+2] $\mathrm{C}-\mathrm{H} / \mathrm{O}-\mathrm{H}$ annulations of benzoic acids 398 with alkenes 399 and alkynes 400 (Scheme 3.3.3). A wide range of benzoic acids gave the desired heterocycles, fully tolerating valuable functional groups, such as halides (400d, 400f, 400g, 400m, 400n, 400o, and 400p) or basic amines (400i and 400q). Notably, the $\mathrm{C}-\mathrm{H}$ activation with the substrate having two competing olefins selectively afforded a single annulated product $\mathbf{4 0 0 x}$.
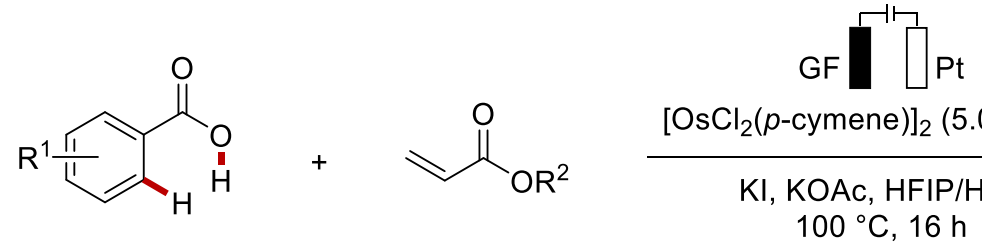

$\left[\mathrm{OsCl}{ }_{2}(p \text {-cymene })\right]_{2}(5.0 \mathrm{~mol} \%)$

$$
\begin{gathered}
\mathrm{KI}, \mathrm{KOAC}, \mathrm{HFIP} / \mathrm{H}_{2} \mathrm{O} \\
100{ }^{\circ} \mathrm{C}, 16 \mathrm{~h} \\
\mathrm{CCE}=4.0 \mathrm{~mA}
\end{gathered}
$$
398 399

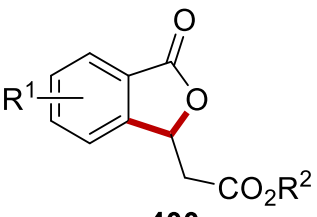
400
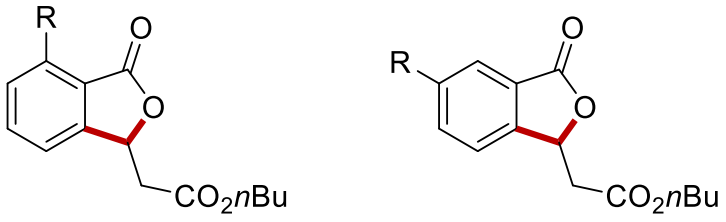

$\mathrm{R}=\mathrm{Me}(\mathbf{4 0 0 \mathrm { e } )}): 77 \%$

$\mathrm{R}=\mathrm{Cl}(\mathbf{4 0 0 f}): 77 \%$

$\mathrm{R}=\mathrm{Br}(\mathbf{4 0 0 \mathrm { g } )}: \mathbf{7 7 \%}$

$\mathrm{R}=\operatorname{Ph}(\mathbf{4 0 0 \mathrm { c } )}: 65 \%$

$R=\operatorname{Br}(\mathbf{4 0 0 d}): 49 \%$<smiles>[R]c1ccc2c(c1)C(CC(=O)OCCC)OC2=O</smiles>

$\mathrm{R}=\mathrm{Me}(400 \mathrm{j}): 82 \%$

$\mathrm{R}=t \mathrm{Bu}(400 \mathrm{k}): 67 \%$

$\mathrm{R}=\mathrm{OMe}(400 \mathrm{I}): 85 \%$<smiles>[R]OC(=O)CC1OC(=O)c2c(C)cccc21</smiles>

$R=t B u(400 t): 38 \%$

$\mathrm{R}=n \mathrm{Hex}(400 \mathrm{u}): 80 \%$<smiles>[R]c1ccc2c(c1)C(CC(=O)OCCC)OC2=O</smiles>

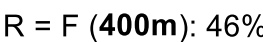

$\mathrm{R}=\mathrm{Cl}(400 \mathrm{n}): 50 \%$

$R=I(400 p): 61 \%$<smiles>CCC(CC)COC(=O)CC1OC(=O)c2c(C)cccc21</smiles>

400w: $65 \%$
$\mathrm{R}=\mathrm{Br}(\mathbf{4 0 0 0}): 53 \%$<smiles>CCCOC(=O)CC1OC(=O)c2cc(C(F)(F)F)ccc21</smiles>

400h: $53 \%$<smiles>CCCOC(=O)CC1OC(=O)c2cc(N(C)C)ccc21</smiles>

400i: $68 \%$<smiles>CCCOC(=O)CC1OC(=O)c2ccc(N(C)C)cc21</smiles>

400q: $84 \%$<smiles>CCCOC(=O)CC1OC(=O)c2c1ccc1ccccc21</smiles>

400s: $74 \%$<smiles>C=C(C)CCOC(=O)CC1OC(=O)c2c(C)cccc21</smiles>

400x: $78 \%$<smiles>Cc1cccc2c1C(=O)OC2CC(=O)OCCc1ccccc1</smiles>

400y: $71 \%$

Scheme 3.3.3 Substrate scope for electrooxidative osmium-catalyzed [4+1] annulations. 
The annulation manifold was not limited to the assembly of five-membered rings, but six-membered heterocycle assembly with differently-substituted alkynes $\mathbf{4 0 1}$ was also found to be viable, thus providing the extension of conjugated $\pi$-system. Thereby, differently substituted alkynes $\mathbf{4 0 1}$ having alkyl (402a), methoxy (402c) or halides (402d) groups were fully acceptable by the optimized osmium catalysis (Scheme 3.3.4).

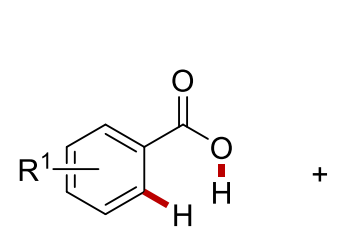

398

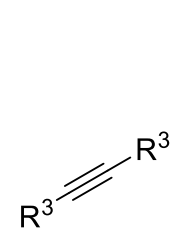

401
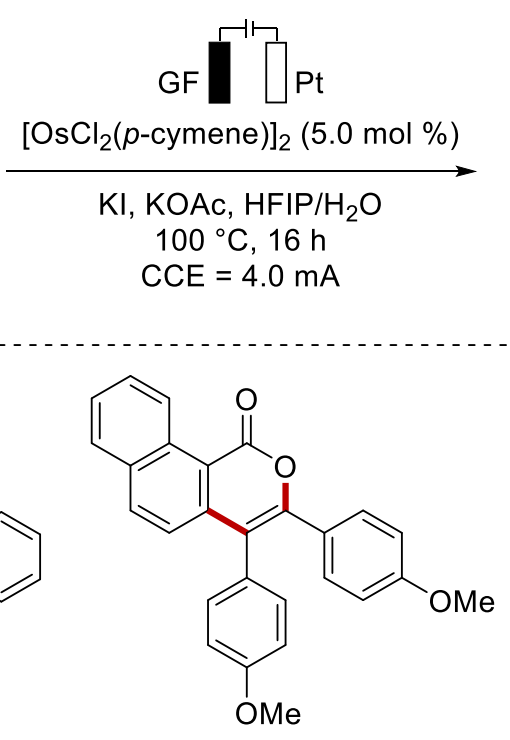

402c: $82 \%$

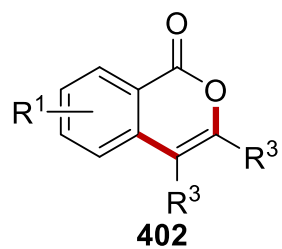

402

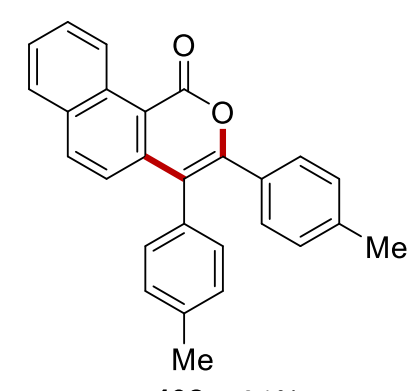

402a: $81 \%$<smiles>O=c1oc(-c2ccccc2)c(-c2ccccc2)c2ccc3ccccc3c12</smiles>

402b: $88 \%$<smiles>O=c1oc(-c2ccc(F)cc2)c(-c2ccc(F)cc2)c2ccc3ccccc3c12</smiles>

402d: $85 \%$

Scheme 3.3.4 Substrate scope for electrooxidative osmium-catalyzed [4+2] annulations. 


\subsubsection{Site-Selectivity Studies}

Inspired by the unprecedented reactivity, we were interested to interrogate the selectivity feature (Figure 3.3.5). To this end, we performed a series of metallaelectro-catalyzed reactions with benzoic acid 398b possessing two accessible ortho- $\mathrm{C}-\mathrm{H}$ bonds. First, we assessed the catalysts that were already used for the electrooxidative $\mathrm{C}-\mathrm{H}$ annulation reactions. Thus, the rhodium, iridium, and ruthenium catalysts were examined, giving 68\%/13\% (5.2:1), 74\%/10\% (7.4:1), and 59\%/9\% (6.3:1) of mono- and difunctionalized product $\mathbf{4 0 0 b}$ and $\mathbf{4 2 6}$, respectively. In sharp contrast, the use of the osmium electrocatalysis showed a significantly improved mono-selectivity.
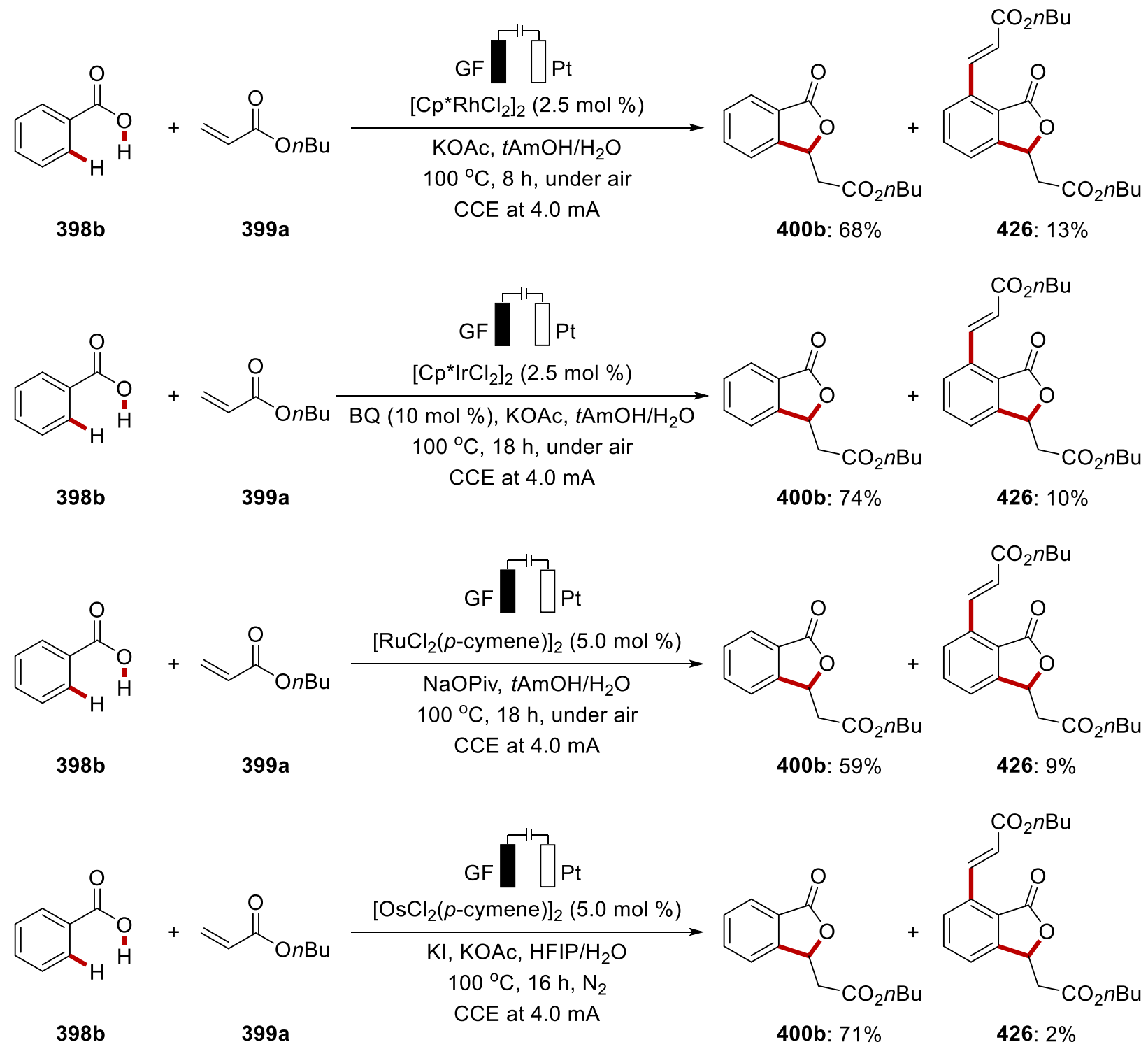

Scheme 3.3.5 Selectivity comparisons by different catalysis. 
The excellent chemo-selectivity was also observed in the H/D scrambling experiments in the presence of an isotopically labelled solvent (Scheme 3.3.6). Ruthenium dimer $\left[\mathrm{RuCl}_{2}(p \text {-cymene) }]_{2}\right.$ showed comparable deuterations on $\mathrm{C} 2-\mathrm{H}$ and $\mathrm{C} 6-\mathrm{H}$ of 3-trifluoromethyl benzoic acid (398h) with and without $n$-butyl acrylate (399a). However, the osmium-electrocatalysis provided significantly increased deuteration at the $\mathrm{C} 6-\mathrm{H}$ position as compared to sterically hindered $\mathrm{C} 2-\mathrm{H}$ position.

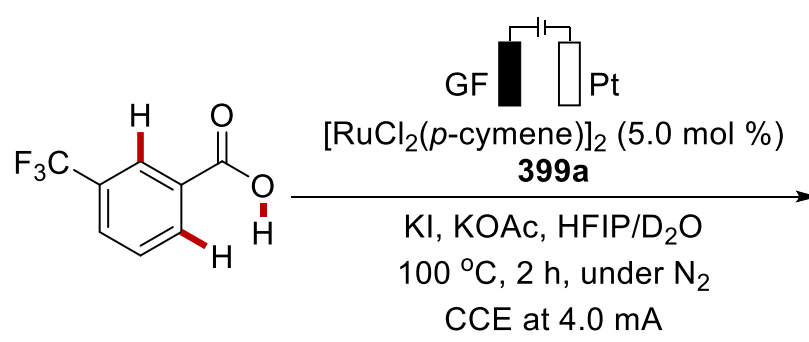

$398 \mathrm{~h}$

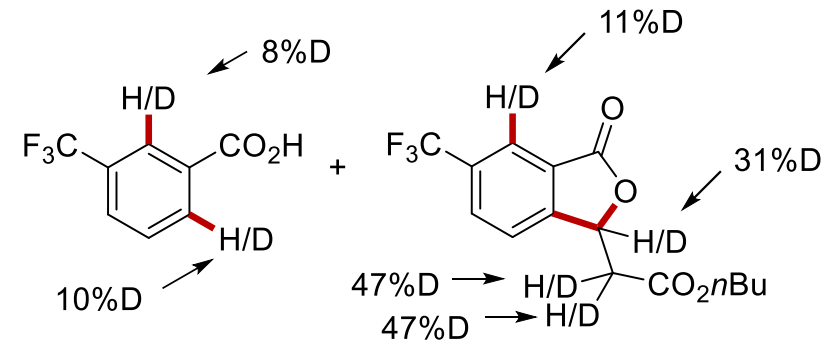

$[D]_{n}-398 h: 65 \%$ $[D]_{n}-400 h: 22 \%$

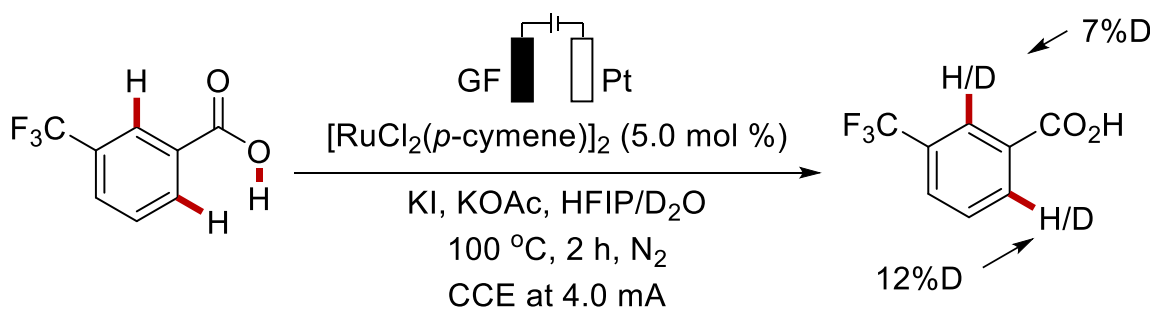

$398 \mathrm{~h}$

$[D]_{n}-398 h: 89 \%$

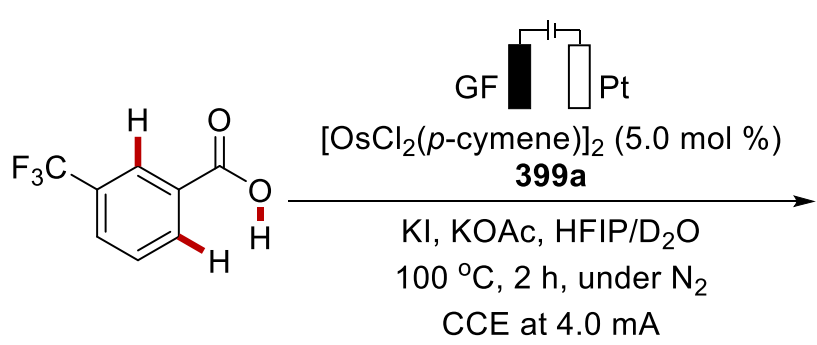

398h

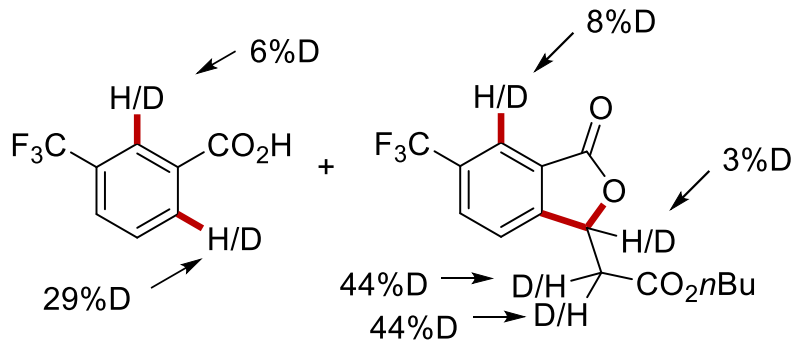

$[D]_{n}-398 h: 65 \%$

$[D]_{n}-400 h: 22 \%$

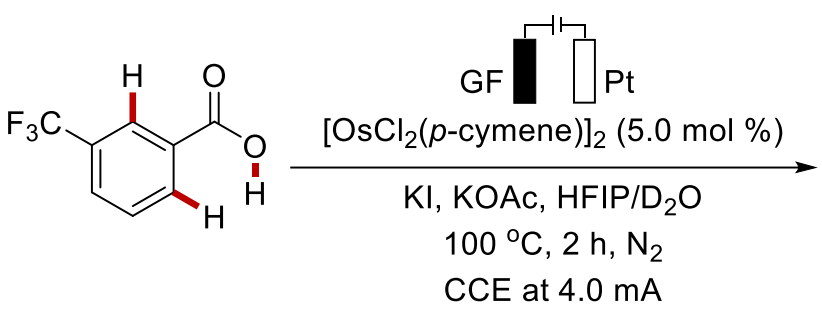

$398 \mathrm{~h}$<smiles>O=C(O)c1c(O)ccc(C(F)(F)F)c1PO</smiles>

$[D]_{n}-398 h: 89 \%$

Scheme 3.3.6 Reaction comparisons for H/D exchange experiments. 


\subsubsection{Mechanistic Studies}

Subsequently, we set out to study the working mode of the electrooxidative osmium-catalyzed C-H activation. To this end, novel key intermediates, 430 and 431, were independently prepared (Scheme 3.3.7). It is noteworthy that these osmium complexes have not been obtained earlier and the structures were characterized by X-ray crystallographic analyses.

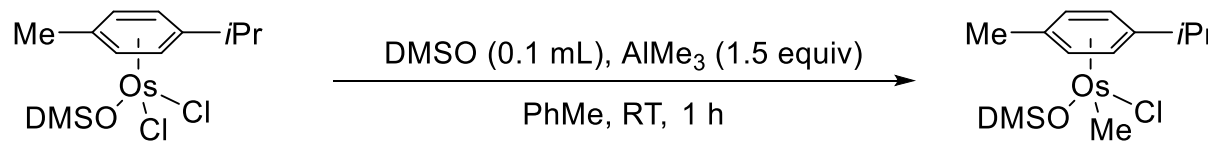

427

428
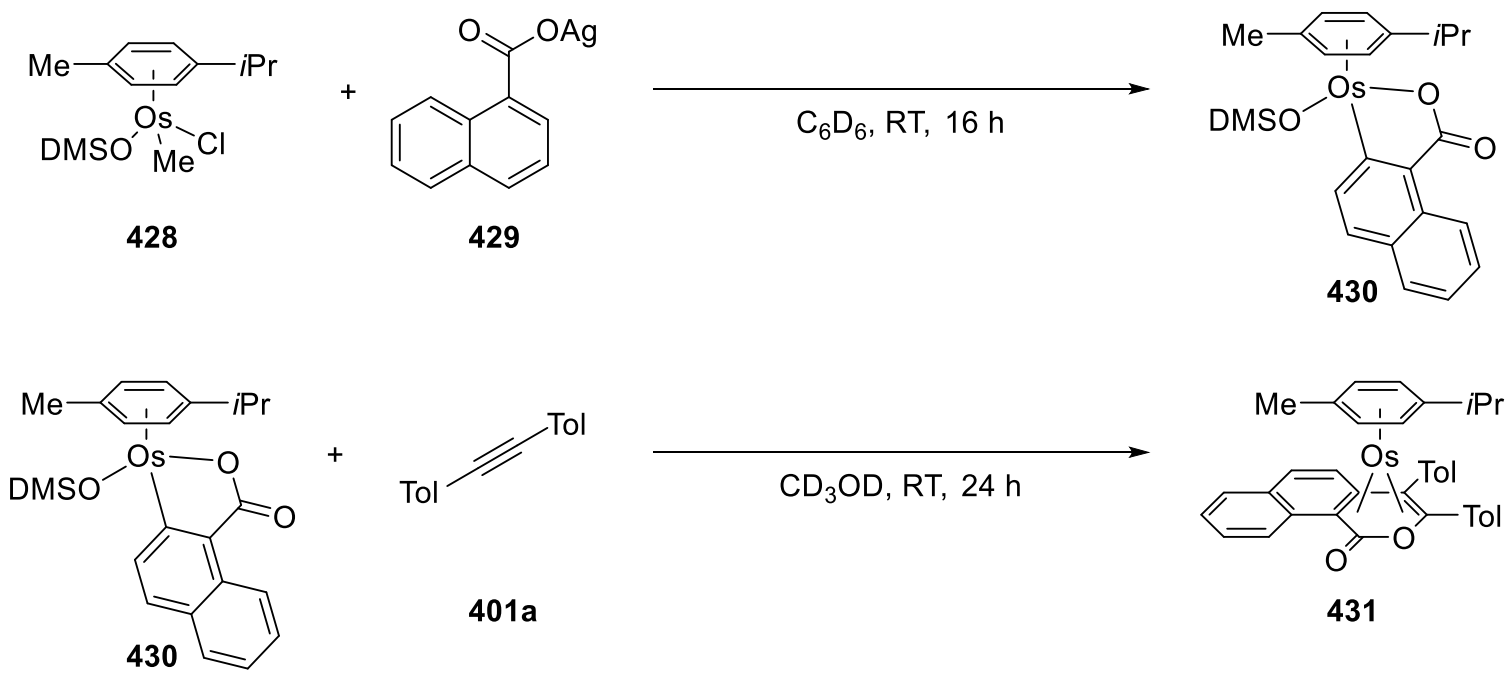

431

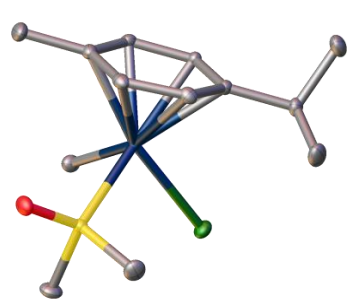

428

(CCDC 2085921)

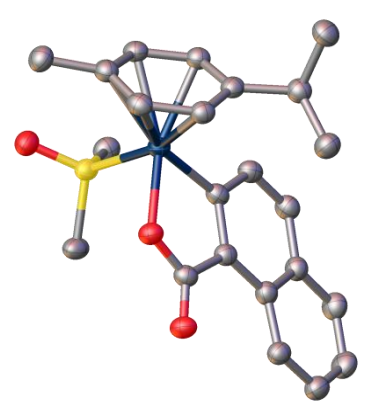

430

(CCDC 2085919)

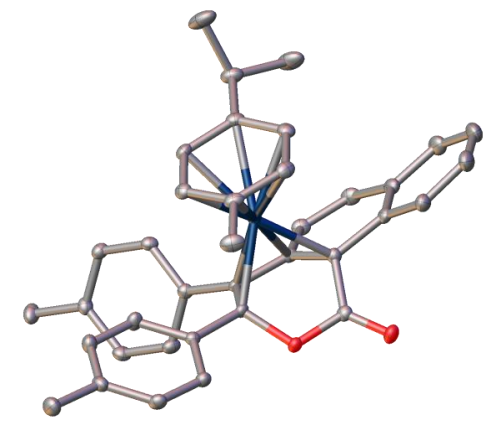

431

(CCDC 2085920)

Scheme 3.3.7 Synthesis of osmacomplexes and their X-ray structures.

The thus synthesized osmium complexes were found to be competent to afford the desired products 400s and 402a in both stoichiometric and catalytic reactions (Scheme 3.3.8). The five-membered 
osmium complex $\mathbf{4 3 0}$ was transformed to the desired product under the optimized conditions, while osmium(0) sandwich complex was converted to the annulated product in the presence of $\mathrm{KI}_{\text {or }} \mathrm{NaSbF}_{6}$. The synthesized osmium complex 430 was also used as a catalyst, providing the [4+1] or [4+2] cycloadditions product under the optimized conditions.

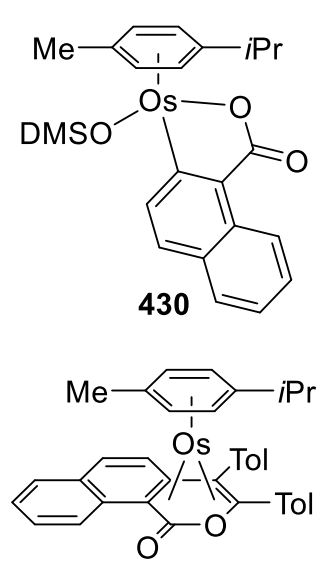

431

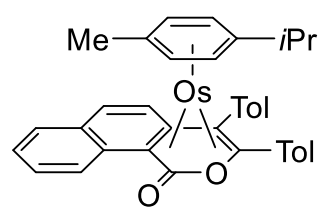

431<smiles>O=C(O)c1cccc2ccccc12</smiles>

$398 \mathrm{~s}$<smiles>O=C(O)c1cccc2ccccc12</smiles>

$398 s$<smiles>C=CC(=O)O[13CH3]</smiles>

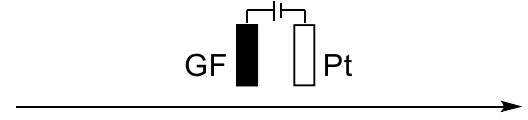

$\mathrm{KI}, \mathrm{KOAC}, \mathrm{HFIP} / \mathrm{H}_{2} \mathrm{O}$ $100^{\circ} \mathrm{C}, 16 \mathrm{~h}, \mathrm{~N}_{2}$ CCE at $4.0 \mathrm{~mA}$

$399 a$
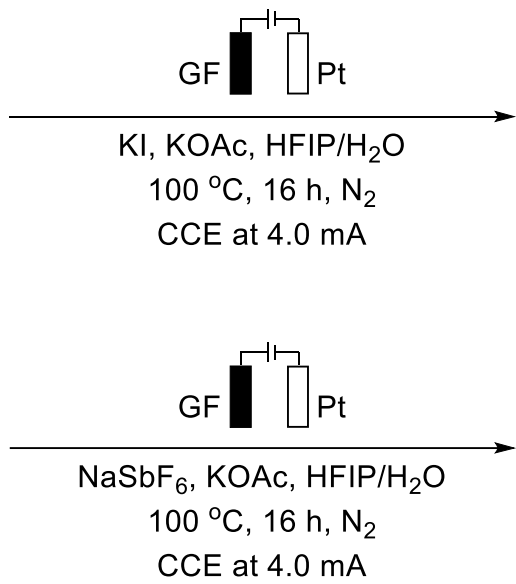

CCE at $4.0 \mathrm{~mA}$

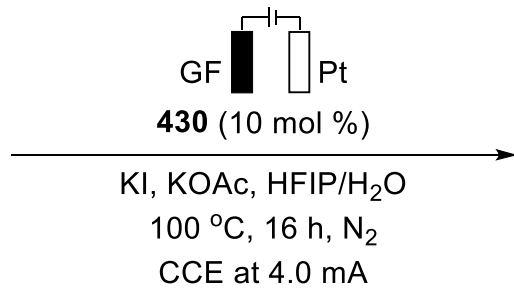

$399 a$

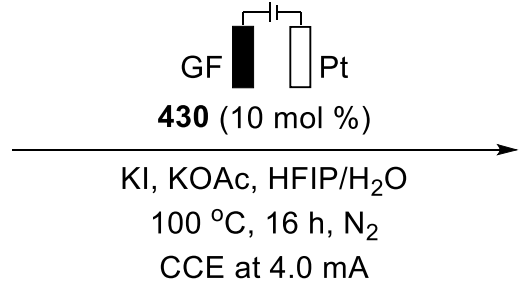

401a<smiles>CCCOC(=O)CC1OC(=O)c2c1ccc1ccccc21</smiles>

400s: $85 \%$<smiles>O=c1oc(Cl)c(Br)c2ccc3ccccc3c12</smiles>

402a: $94 \%$<smiles>O=c1oc([GeH2])c([GeH3])c2ccc3ccccc3c12</smiles>

402a: $73 \%$<smiles>CCCCOC(=O)CC1OC(=O)c2c1ccc1ccccc21</smiles>

400s: $79 \%$<smiles>O=c1oc([GeH2])c([GeH2])c2ccc3ccccc3c12</smiles>

402a: $73 \%$

Scheme 3.3.8 Stoichiometric and catalytic reactions with the synthesized osmacomplexes $430-431$. 
Furthermore, with the assistance of Dr. Antonis M. Messinis of the Ackermann group, high resolutionelectrospray ionization-mass spectrometric (HR-ESI-MS) analysis was performed, demonstrating the successive formation and consumption of key reaction species (Scheme 3.3.9).
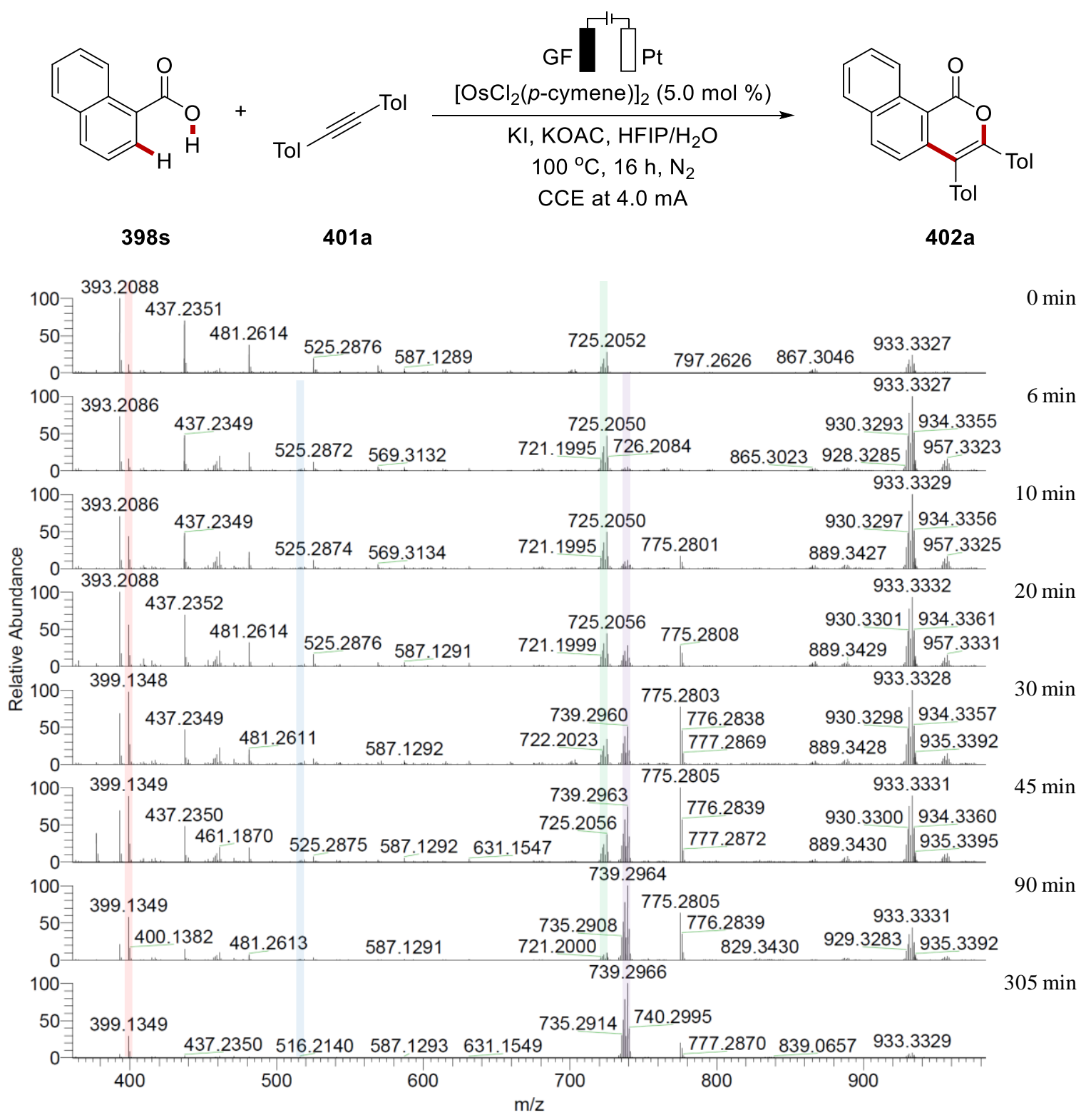

Scheme 3.3.9 HR-ESI-MS study of electrooxidative osmium-catalyzed C-H annulation.

By detailed investigation of the isotopic patterns, we could analyze each component, in which red, blue, green, and purple bars correspond to the annulation product $\mathbf{4 0 2 a}$, the cyclometalated osmium intermediate 432, the sandwich osmium(0) intermediate 431 with its possible isomers, and alkynecoordinated osmium intermediate 433, respectively (Scheme 3.3.10). 


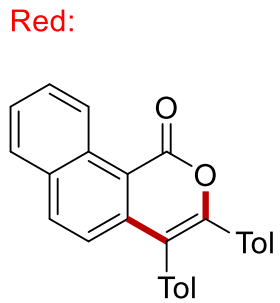

$402 a$

$[\mathrm{M}+\mathrm{Na}]=399.1361$

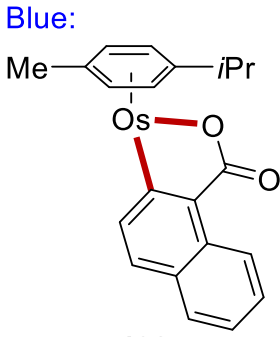

432

$[\mathrm{M}+\mathrm{Na}]=519.0976$

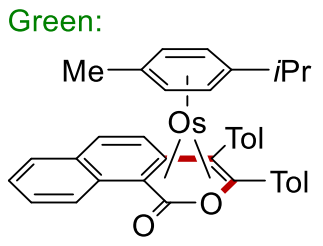

Purple:

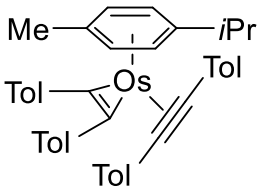

or isomers

431

$[\mathrm{M}+\mathrm{Na}]=725.2071$
433

$[\mathrm{M}+\mathrm{Na}]=761.2799$

Scheme 3.3.10 Investigation of the isotopic patterns from HR-ESI-MS study.

Additionally, Dr. Antonis M. Messinis of the Ackermann group performed in-operando NMR studies with the isolated osmium complex 430 and alkyne 401a, which highlighted the formation of the osmium(0) sandwich complex, along with the consumption of complex 430 and alkyne $401 a$ (Scheme 3.3.11). Here, we were not able to observe an induction period and the seven-membered intermediate formed by the migratory insertion of alkyne 401a was hardly observed. These results presumably suggest the facile formation of the osmium(0) complex 431 after the insertion step.

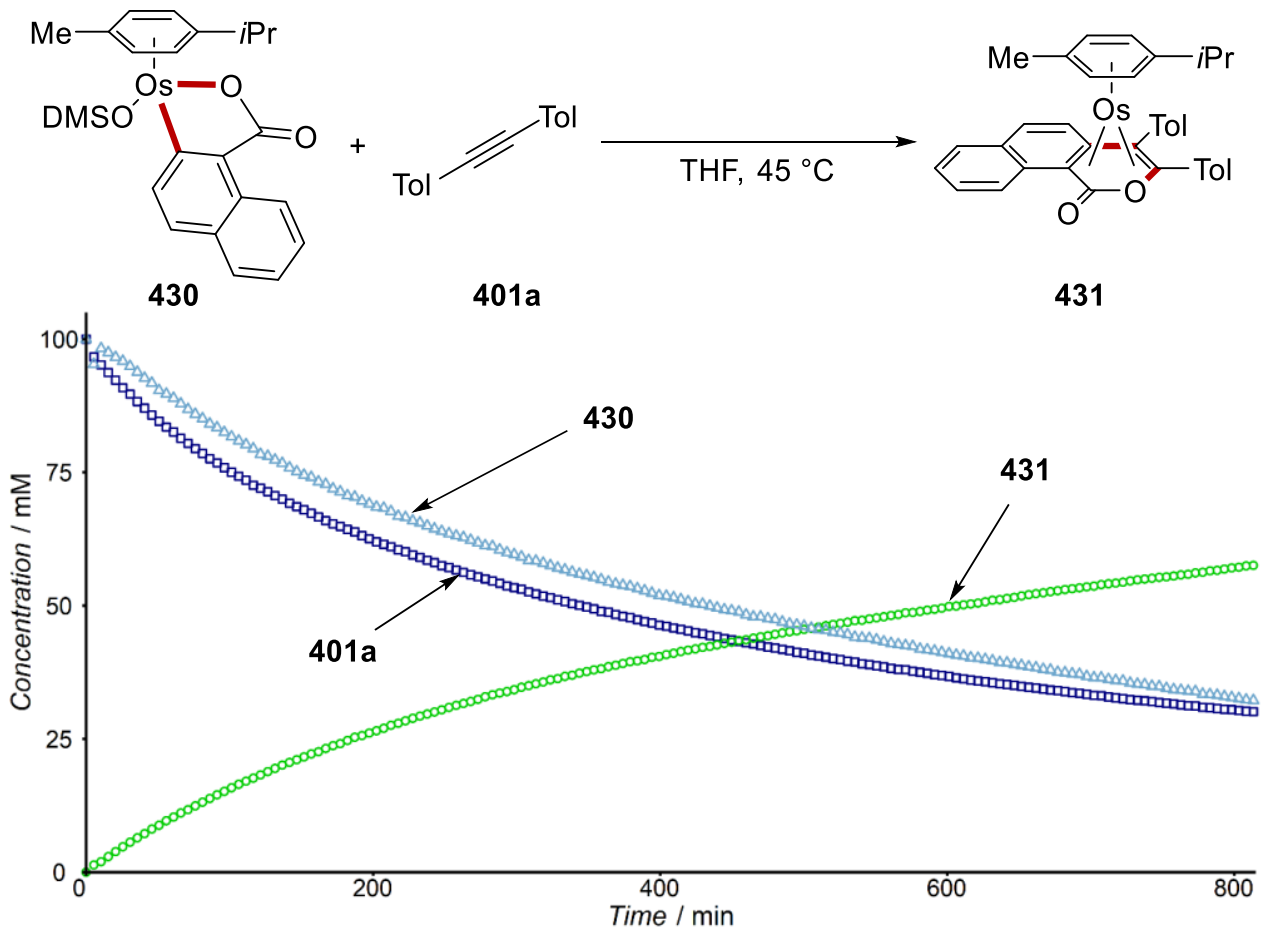

Scheme 3.3.11 In-operando NMR study with osmacomplex 430 and alkyne 401a. 
Thereafter, Xiaoyan Hou of the Ackermann group performed cyclic voltammetric analysis for the oxidation potential of the osmium(0) sandwich complex 431, showing that the oxidation event occurred at $\mathrm{E}=0.58 \mathrm{~V}$ vs. $\mathrm{Fc} / \mathrm{Fc}^{+}$(Scheme 3.3.12). This oxidation potential is slightly lower than the ruthenium( $(0)$ to ruthenium(II) oxidation potential of the previously reported ruthenaelectro-catalyzed $\mathrm{C}-\mathrm{H}$ annulation. ${ }^{[236 \mathrm{f}]}$

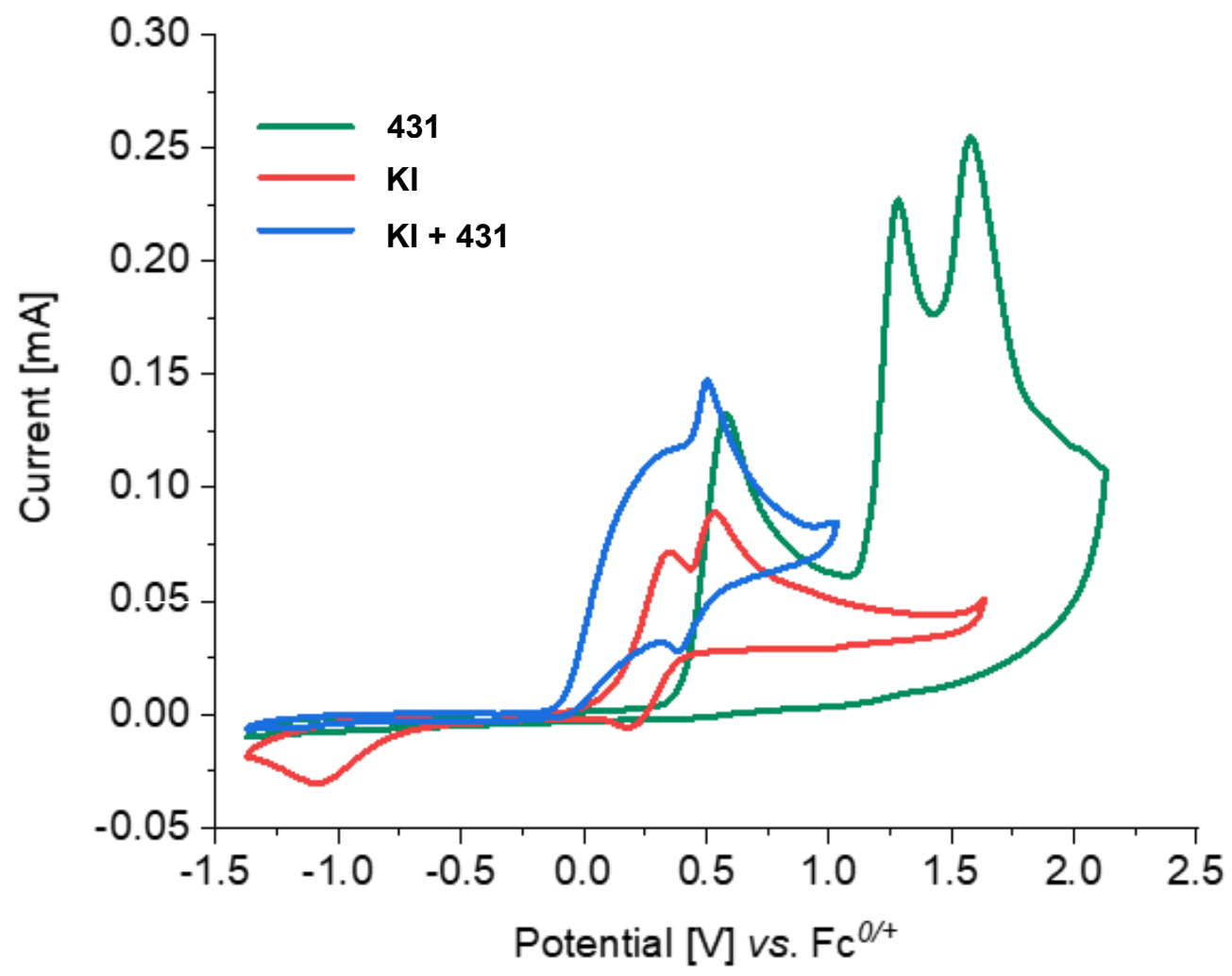

Scheme 3.3.12 Cyclic voltammetry measurement.

Next, an intermolecular competition experiment with differently substituted benzoic acids (398e and 398h) was carried out (Scheme 3.3.13a). The competition experiment showed that electron-donating

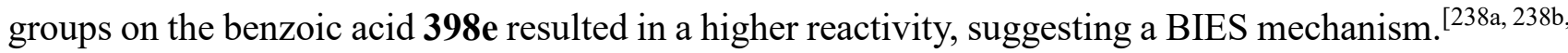
24a, 238c] Additionally, an intermolecular competition experiment with differently substituted alkynes 401a and 401d was also performed (Scheme 3.3.13b), in which an alkyne 401a having electrondonating groups afforded less product. 
a) Competition experiment between different benzoic acids<smiles>Cc1cccc(C(=O)O)c1</smiles>

$398 \mathrm{e}(0.1 \mathrm{mmol})$

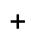<smiles>O=C(O)c1cccc(C(F)(F)F)c1</smiles>

$398 \mathrm{~h}(0.1 \mathrm{mmol})$

b) Competition experiment between different alkynes

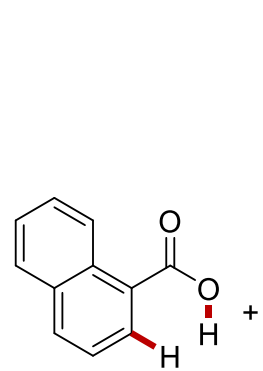

398s (0.2 mmol)
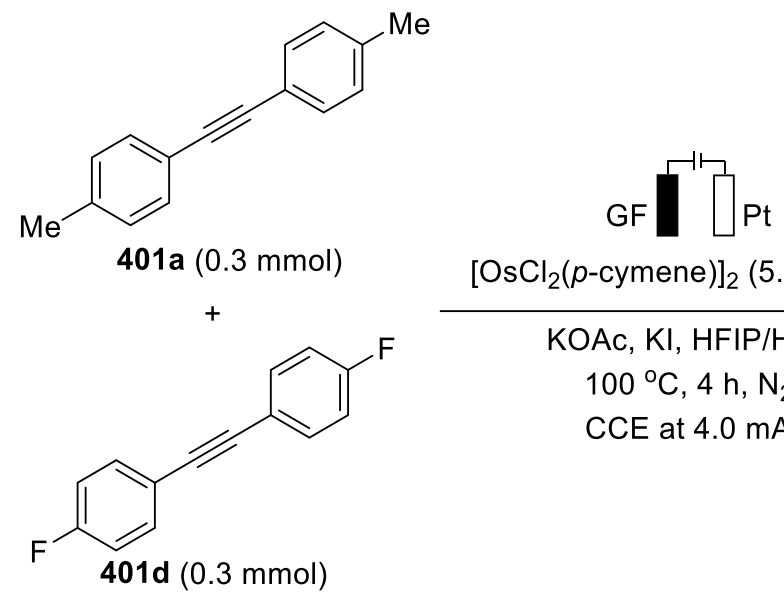

$\left[\mathrm{OsCl}_{2}(p \text {-cymene })\right]_{2}(5.0 \mathrm{~mol} \%)$

$\mathrm{KOAc}, \mathrm{KI}, \mathrm{HFIP} / \mathrm{H}_{2} \mathrm{O}$

$100^{\circ} \mathrm{C}, 4 \mathrm{~h}, \mathrm{~N}_{2}$

CCE at $4.0 \mathrm{~mA}$

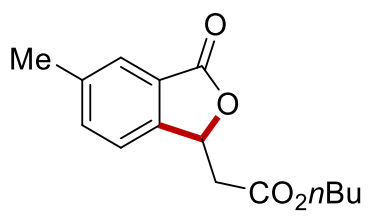

400e: $26 \%$<smiles>CCCOC(=O)CC1OC(=O)c2cc(C(F)(F)F)ccc21</smiles>

400h: $14 \%$

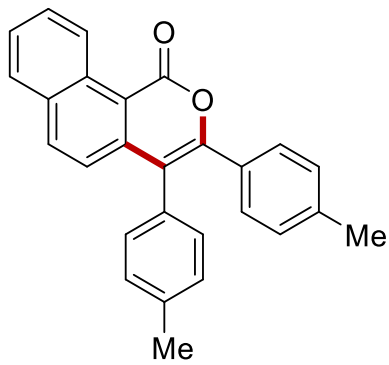

402a: $24 \%$

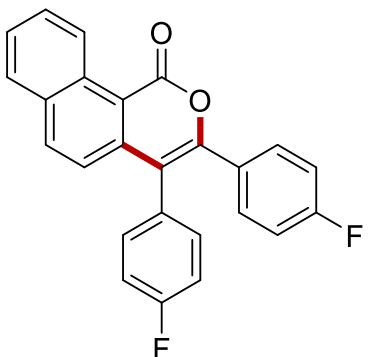

402d: $42 \%$

Scheme 3.3.13 Competition experiments.

A series of reactions with differently decorated benzoic acids in the meta-position to the $\mathrm{C}-\mathrm{H}$ bond to be cleaved provided a linear Hammett correlation with a negative $\rho$ value (Scheme 3.3.14). This result indicates that an electrophilic mechanism is likely operative in the $\mathrm{C}-\mathrm{H}$ cleavage. 


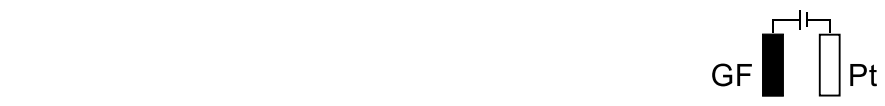<smiles>O=C(O)c1ccccc1</smiles>

$398 b$<smiles>COc1ccc(C(=O)O)cc1</smiles>

3981

$\left[\mathrm{OsCl}{ }_{2}(p \text {-cymene })\right]_{2}(5.0 \mathrm{~mol} \%)$

KOAc, KI, HFIP/ $\mathrm{H}_{2} \mathrm{O}$

$100{ }^{\circ} \mathrm{C}, 3 \mathrm{~h}, \mathrm{~N}_{2}$

$\mathrm{CCE}$ at $4.0 \mathrm{~mA}$<smiles>CCCOC(=O)CC1OC(=O)c2ccccc21</smiles>

400b: $37 \%$<smiles>CCCOC(=O)CC1OC(=O)c2ccc(OC)cc21</smiles>

400I: $38 \%$

\section{$\mathrm{GF} \mathrm{Pt}$}

$\left[\mathrm{OsCl}_{2}(p \text {-cymene })\right]_{2}(5.0 \mathrm{~mol} \%)$<smiles>Cc1ccc(C(=O)O)cc1</smiles>
399a

KOAc, KI, HFIP/ $\mathrm{H}_{2} \mathrm{O}$ $100^{\circ} \mathrm{C}, 3 \mathrm{~h}, \mathrm{~N}_{2}$ CCE at $4.0 \mathrm{~mA}$

$398 b$

398j<smiles>CCCOC(=O)CC1OC(=O)c2ccccc21</smiles>

400b: $21 \%$<smiles>CCCOC(=O)CC1OC(=O)c2ccc(C)cc21</smiles>

400j: $27 \%$

\section{$\mathrm{GF}$}<smiles>O=C(O)c1ccc(Br)cc1C(=O)O</smiles>

$398 b$

3980
$\left[\mathrm{OsCl}{ }_{2}(p \text {-cymene })\right]_{2}(5.0 \mathrm{~mol} \%)$ $399 a$

KOAc, KI, HFIP/ $\mathrm{H}_{2} \mathrm{O}$ $100{ }^{\circ} \mathrm{C}, 3 \mathrm{~h}, \mathrm{~N}_{2}$ CCE at $4.0 \mathrm{~mA}$<smiles>CCCOC(=O)CC1OC(=O)c2ccccc21</smiles>

400b: $26 \%$<smiles>CCCOC(=O)CC1OC(=O)c2ccc(Br)cc21</smiles>

400o: $17 \%$

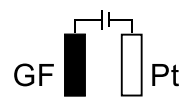<smiles>O=C(O)c1ccccc1</smiles>

$398 b$<smiles>O=C(O)c1ccc(F)cc1</smiles>

$398 m$
$\left[\mathrm{OsCl}_{2}(p \text {-cymene })\right]_{2}(5.0 \mathrm{~mol} \%)$

KOAc, KI, HFIP/ $\mathrm{H}_{2} \mathrm{O}$ $100{ }^{\circ} \mathrm{C}, 3 \mathrm{~h}, \mathrm{~N}_{2}$ CCE at $4.0 \mathrm{~mA}$

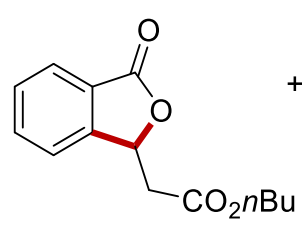

400b: $24 \%$<smiles>CCCOC(=O)CC1OC(=O)c2ccc(F)cc21</smiles>

400m: $18 \%$

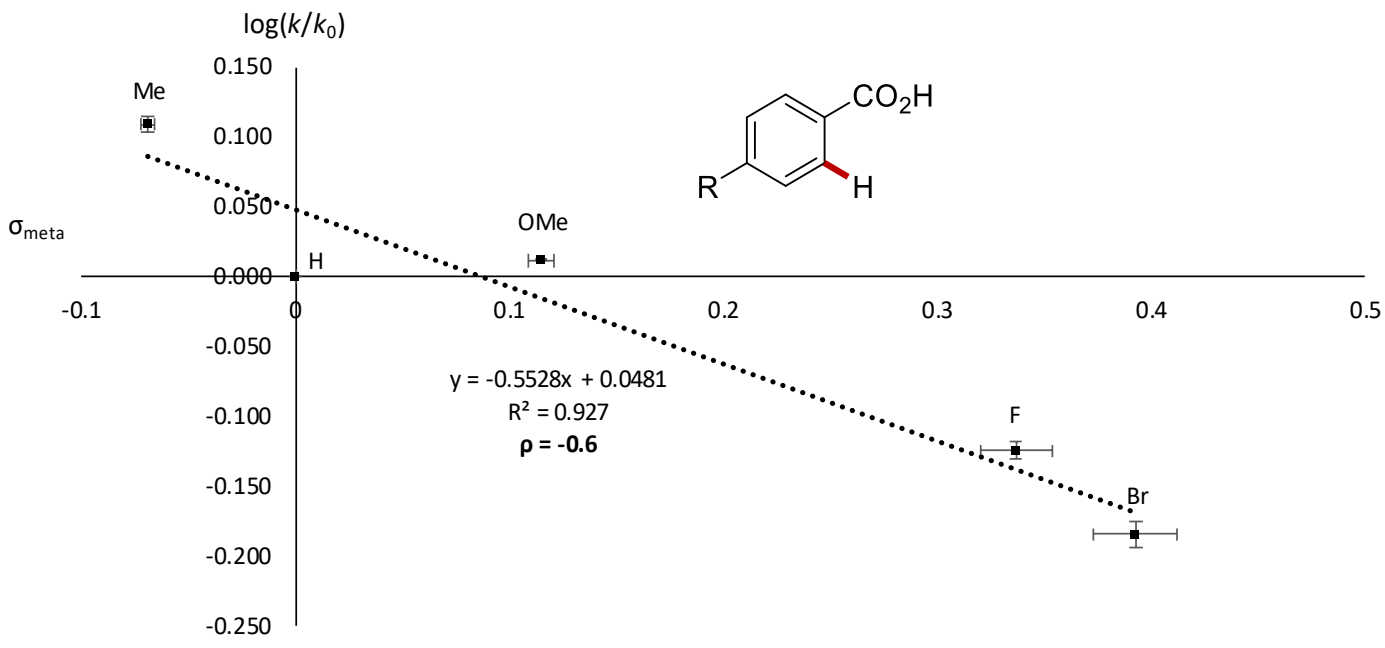

Scheme 3.3.14 Hammett correlation. 
Subsequently, an intermolecular competition experiment and a pair of parallel reactions were performed with $o$-toluic acid 398a and the isotopically labelled compound [D]7-398a to determine the kinetic isotope effect (Scheme 3.3.15). In both cases, a negligible KIE of $\mathrm{k}_{\mathrm{H}} / \mathrm{k}_{\mathrm{D}} \approx 1.1$ and 1.2 were observed, respectively, suggesting a facile $\mathrm{C}-\mathrm{H}$ scission.<smiles>Cc1cc([18OH])ccc1C(=O)O</smiles>

$398 \mathrm{a}$ and $\left[\mathrm{D}_{7}\right]-398 \mathrm{a}$
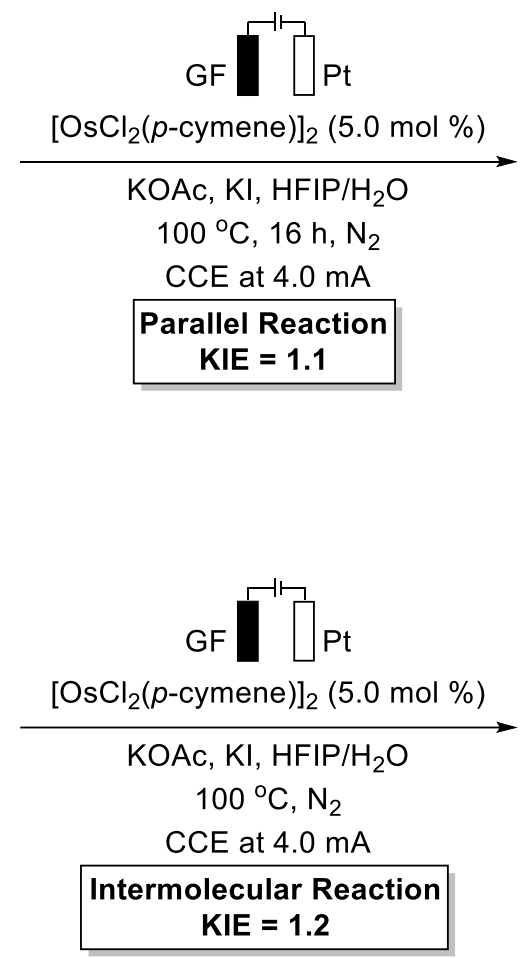<smiles>CCOCCC1OC(=O)C2=C(C(C)(C)C)C=[13C]2C=C1C</smiles>

400a and $[D]_{n}-400 a: 71 \%$<smiles>Cc1cc([18OH])ccc1C(=O)O</smiles>

$398 \mathrm{a}$ or $[D]_{7}-398 \mathbf{a}$ 399a<smiles>C=CC(=O)OCCCC</smiles><smiles>CCOCCC1OC(=O)C2=C(C(C)(C)C)C=[13C]2C=C1C</smiles>

$400 \mathrm{a}$ or $[D]_{\mathrm{n}}-400 \mathrm{a}$

Scheme 3.3.15 Experiments for kinetic isotope effect.

On the basis of our mechanistic findings, a plausible catalytic cycle for the osmaelectro-catalyzed C$\mathrm{H}$ activation is depicted in Scheme 3.3.16. The mechanistic rationale commences with a facile $\mathrm{C}-\mathrm{H}$ bond cleavage, which gives osmacycle 434. Thereafter, migratory insertion of alkenes 399 or alkynes 401 occurs, which enables the formation of intermediate 435 or 437 , respectively. Next, reductive elimination delivers osmium(0) sandwich complex 436 or 438 . Finally, the key anodic oxidation regenerates the catalytically active complex 434, while liberating the desired product $\mathbf{4 0 0}$ or $\mathbf{4 0 2}$. 


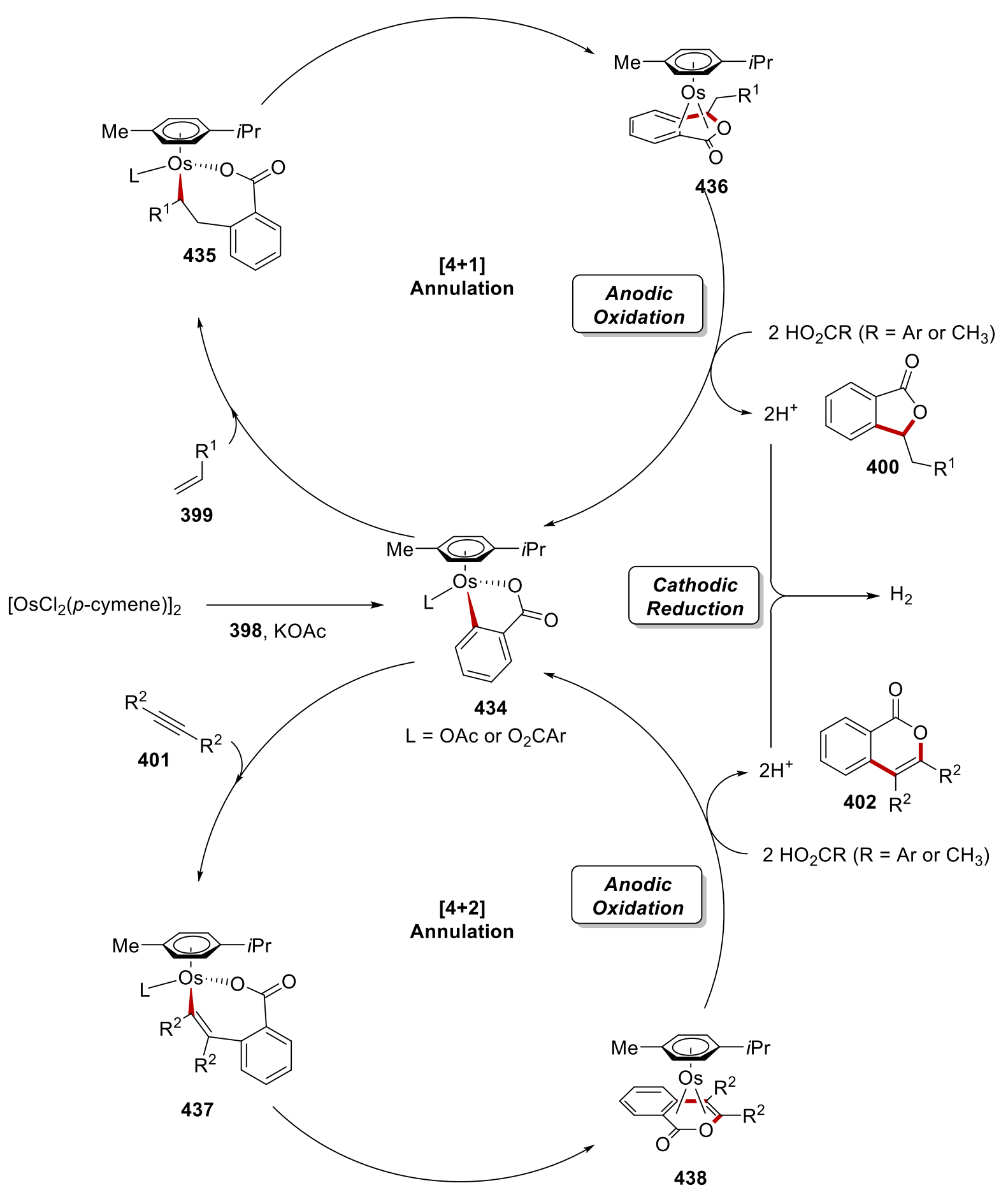

Scheme 3.3.16 Proposed catalytic cycle. 


\subsection{Photo-Induced C-H Arylation by Reusable Heterogeneous Copper Catalyst}

Recently, significant progress was realized in $\mathrm{C}-\mathrm{H}$ activation chemistry with the aid of Earth-abundant, cost-effective $3 \mathrm{~d}$ metal catalysts. ${ }^{[216]}$ Among the $3 \mathrm{~d}$ metals, copper has emerged as a viable metal for C-H activation. ${ }^{[152 b, 155 c, 189 \mathrm{~g}, 239]}$ Particularly, copper-catalyzed C-H arylations have been extensively investigated with notable contributions by Daugulis, ${ }^{[160,161,162]}$ Miura $^{[240]}$ and Ackermann, ${ }^{[163]}$ among others. Despite these major advances, copper-catalyzed $\mathrm{C}-\mathrm{H}$ activation with aryl halides has been severely restricted by their harsh reaction conditions with reaction temperatures commonly ranging from 120 to $160{ }^{\circ} \mathrm{C}$.

In recent years, photocatalysis ${ }^{[241]}$ has been identified as an increasingly powerful approach towards various sustainable organic syntheses, ${ }^{[242]}$ such as $\mathrm{C}-\mathrm{N}$ bond formations, immensely elaborated by $\mathrm{Fu},{ }^{[243]}$ MacMillan, ${ }^{[244]}$ and Kobayashi. ${ }^{[245]}$ Thus, Photoredox-catalyzed C-H functionalizations proved viable, albeit predominantly relying on precious transition metals, such as rhodium, palladium, and ruthenium complexes. ${ }^{[94,246]}$ In contrast, the Ackermann group has very recently devised photoinduced $\mathrm{C}-\mathrm{H}$ arylations and chalcogenations by less toxic base metal catalysts. ${ }^{[247,169]}$ In spite of notable progress, photo-induced organometallic $\mathrm{C}-\mathrm{H}$ activations were thus far limited to homogeneous catalysis, often leading to undesired trace metal impurities in the target products, and, more importantly, inherently preventing the catalysts from their reuse. While selected silica-supported catalysts ${ }^{[204 a, 248 a-}$ c, 192h, 248d-f, 204b, 193b, 193m, 248g, 248h] were developed by Jones/Davies ${ }^{[208,249,206]}$ and Sawamura ${ }^{[250]}$ with non-excited-state reactivity, heterogeneous catalysis for photo-induced $\mathrm{C}-\mathrm{H}$ activation has thus far unfortunately proven elusive. 


\subsubsection{Preparation of Hybrid Copper Catalyst}

The hybrid copper catalyst $\mathbf{4 0 6}$ was synthesized by a modified procedure from Christopher's study (Scheme 3.4.1). ${ }^{[249 \mathrm{a}]}$ To construct a linker, LDA deprotonated a C-H bond of a methyl group of 4,4'dimethyl-2,2'-dipyridyl (439), which underwent a substitution reaction with (3-chloropropyl)trimethoxysilane (440). The thus synthesized linker 441 was grafted on SBA-15 in toluene by heating, giving the tethered linker 442. Since the covalently anchored linker 442 contains hydroxyl groups on the surface, the end-capping procedure was subsequently carried out with hexamethyldisilazane, providing the globally protected hydroxyl groups. Lastly, $\mathrm{CuI}$ was used as a catalyst precursor for the metallation step, thus generating hybrid copper catalyst 406.

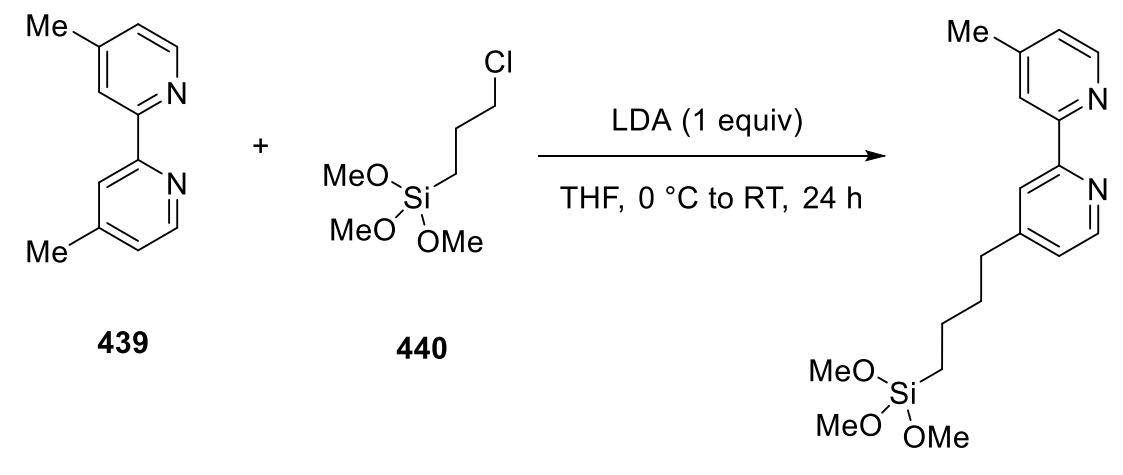

441

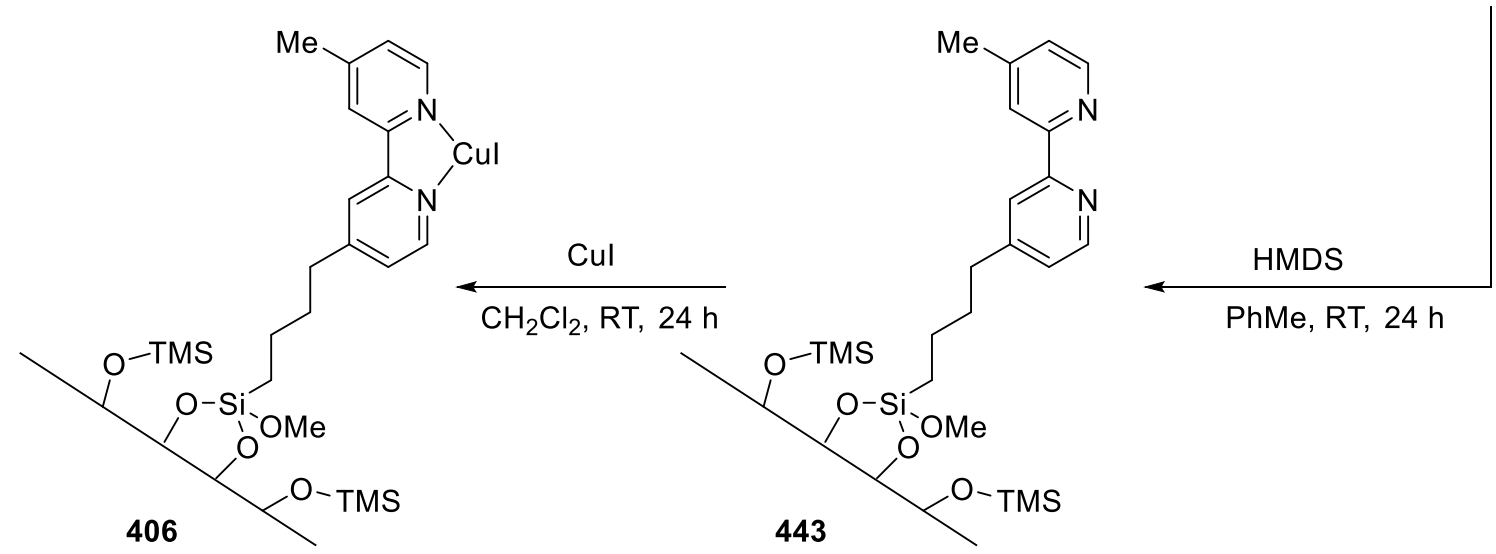

Scheme 3.4.1 Preparation of hybrid copper catalyst. 


\subsubsection{Optimization Studies}

Next, we probed representative reaction conditions for the envisioned $\mathrm{C}-\mathrm{H}$ arylation of heteroarenes using the hybrid copper catalyst $\mathbf{4 0 6}$ (Table 3.4.1). Thereby, the desired C-H arylated product 405 was obtained under mild photo-induced conditions (entry 1). The re-isolated hybrid copper catalyst 406 was used for the next run to test the reusability and provided a comparable result to the initial run (entry 2). While the sole use of copper iodide fell short in efficiently delivering the desired product (entry 3 ), the mixture of copper iodide and the bipyridine ligand 439 or the tethered linker 443 provided a lower reactivity (entries 4-5). The thus optimized hybrid catalyst was efficiently employed in the reaction with benzoxazoles $\mathbf{4 4 4}$, showing the robustness of photo-induced hybrid copper-catalyzed $\mathrm{C}$ $\mathrm{H}$ arylations (entry 6). Control experiments, excluding key reaction components, highlighted the essential role of the hybrid copper catalyst $\mathbf{4 0 6}$ as well as of the light source for $\mathrm{C}-\mathrm{H}$ the arylation (entries 7-9).

Table 3.4.1 Optimization of photo-induced C-H arylation by reusable heterogeneous copper catalyst ${ }^{[\mathrm{a}]}$

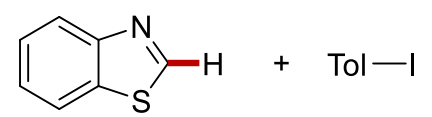

403

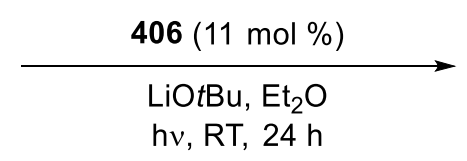
hv, RT, $24 \mathrm{~h}$<smiles>[Al]c1nc2ccccc2s1</smiles>

405

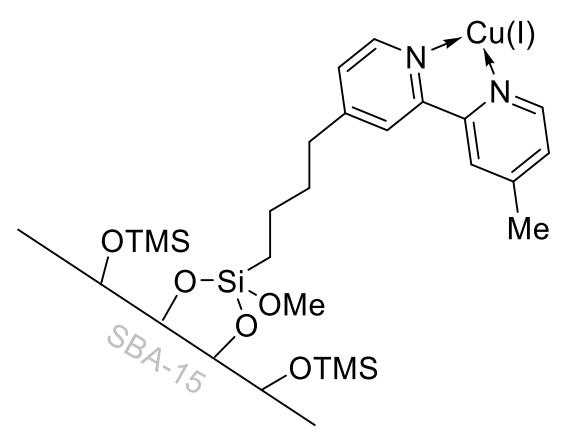

406

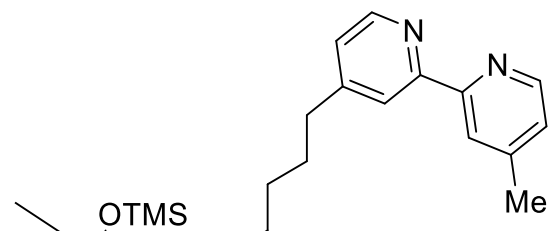

\begin{tabular}{ccc}
\hline Entry & Deviation from the standard reaction conditions & Yield (\%) \\
\hline 1 & None & $93^{[\mathrm{b}]}$ \\
2 & reused catalyst of entry 1406 & $85^{[\mathrm{b}]}$ \\
3 & $\mathrm{CuI}$ instead of $\mathbf{4 0 6}$ & 58 \\
4 & $\mathrm{CuI}+4,4^{\prime}$ '-dimethyl-2,2' -dipyridyl instead $\mathbf{4 3 9}$ of $\mathbf{4 0 6}$ & 50
\end{tabular}




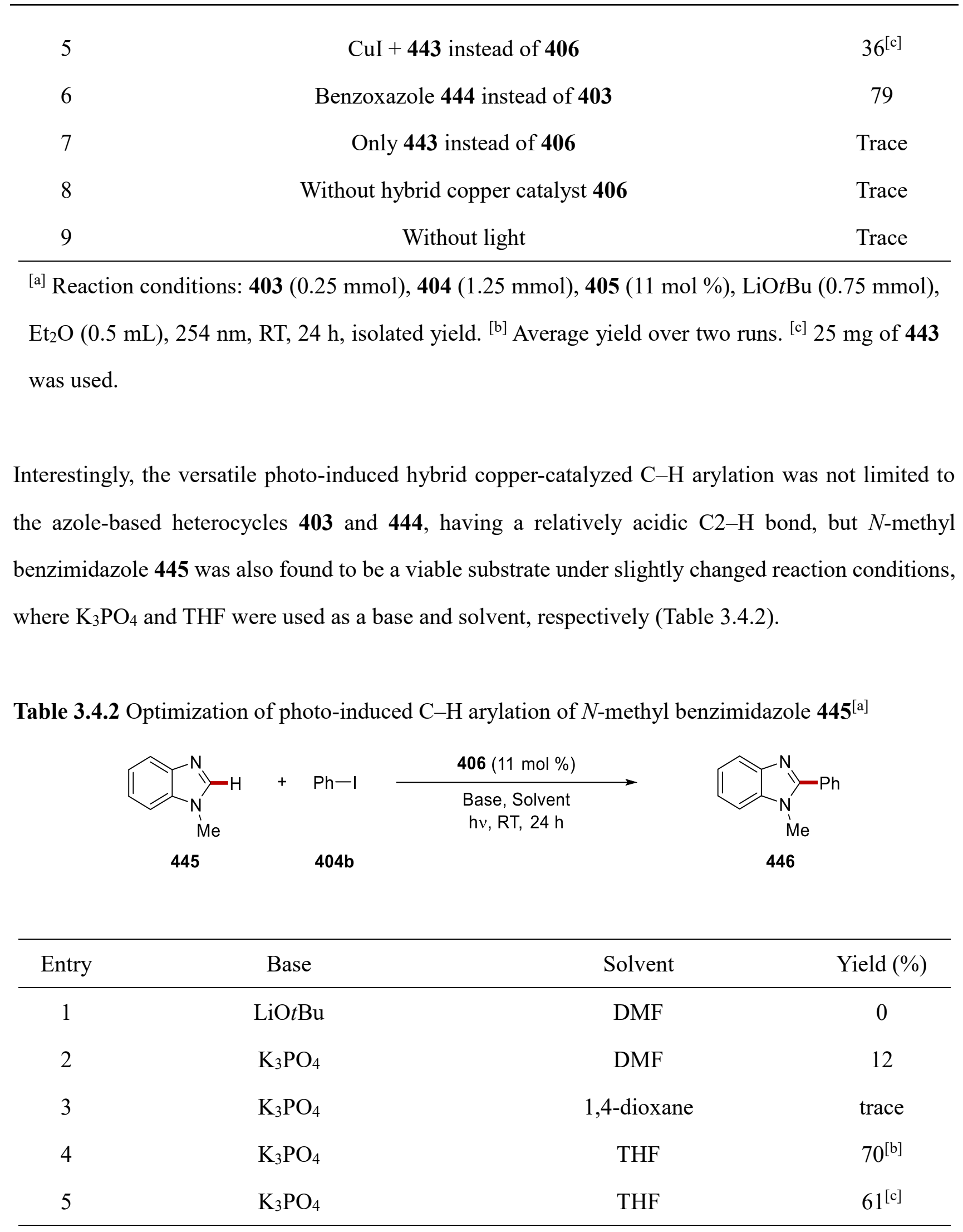

${ }^{[a]}$ Reaction conditions: 445 (0.25 mmol), 404b (1.25 mmol), 406 (11 mol \%), base (0.75 mmol), solvent $(1.0 \mathrm{~mL}), 254 \mathrm{~nm}$, RT, $24 \mathrm{~h}$, isolated yield. ${ }^{[\mathrm{b}]}$ Average yield over two runs. ${ }^{[\mathrm{c}]}$ With the reused 406. 
Additionally, the photo-induced heterogeneous $\mathrm{C}-\mathrm{H}$ arylation manifold could be extended to the use of more cost-effective aryl bromides 447 (Table 3.4.3). Among various attempts employing different bases, $\mathrm{Cs}_{2} \mathrm{CO}_{3}$ proved most efficient, affording $59 \%$ of $\mathrm{C}-\mathrm{H}$ arylated product 446 under photo-induced conditions, and a subsequent reaction with the re-isolated hybrid copper catalyst $\mathbf{4 0 6}$ provided only a slightly lower yield. The use of relatively weak carbonate bases should prove instrumental for applications to substrates with sensitive functional groups.

Table 3.4.3 Optimization of photo-induced C-H arylation with aryl bromide $447^{[\mathrm{a}]}$

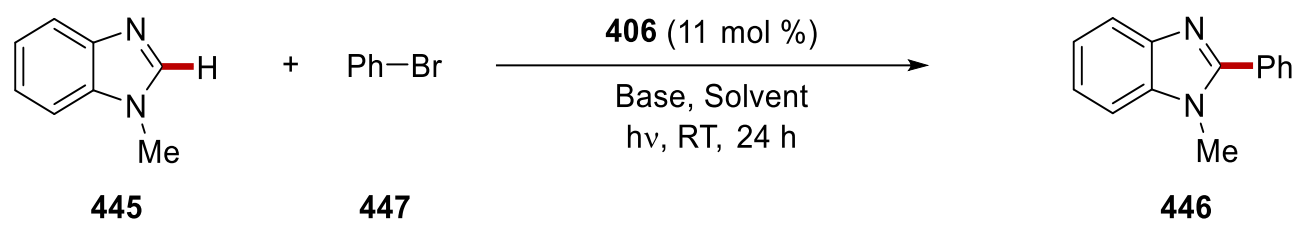

\begin{tabular}{cccc}
\hline Entry & $\mathrm{Base}$ & Solvent & Yield (\%) \\
\hline 1 & $\mathrm{LiO} t \mathrm{Bu}$ & $\mathrm{Et}_{2} \mathrm{O}$ & 0 \\
2 & $\mathrm{KO} t \mathrm{Bu}$ & $\mathrm{Et}_{2} \mathrm{O}$ & 0 \\
3 & $\mathrm{Li}_{2} \mathrm{CO}_{3}$ & $\mathrm{Et}_{2} \mathrm{O}$ & trace \\
4 & $\mathrm{Na}_{2} \mathrm{CO}_{3}$ & $\mathrm{Et}_{2} \mathrm{O}$ & trace \\
5 & $\mathrm{~K}_{2} \mathrm{CO}_{3}$ & $\mathrm{Et}_{2} \mathrm{O}$ & 21 \\
6 & $\mathrm{Cs}_{2} \mathrm{CO}_{3}$ & $\mathrm{Et}_{2} \mathrm{O}$ & $59^{[\mathrm{b}]}$ \\
7 & $\mathrm{Cs}_{2} \mathrm{CO}_{3}$ & $\mathrm{Et}_{2} \mathrm{O}$ & $47^{[\mathrm{c}]}$ \\
\hline
\end{tabular}

${ }^{[a] ~ R e a c t i o n ~ c o n d i t i o n s: ~} 445$ (0.25 mmol), 447 (1.25 mmol), 406 (11 mol \%), base (0.75 mmol), solvent $(1.0 \mathrm{~mL}), 254 \mathrm{~nm}$, RT, $24 \mathrm{~h}$, isolated yield. ${ }^{[\mathrm{b}]}$ Average yield over two runs. ${ }^{[\mathrm{c}]}$ With the reused 406. 


\subsubsection{Substrate Scope}

We explored the versatility of the hybrid copper catalysis for the photo-induced $\mathrm{C}-\mathrm{H}$ arylation of thiazoles $\mathbf{4 0 3}$ with diversely substituted aryl iodides $\mathbf{4 0 4}$ (Scheme 3.4.2). Thus, we gladly observed high functional group tolerance, including both electron-rich and electron-deficient aryl halides. Particularly, valuable halide functional groups, such as bromo or chloro arenes, remained unreacted, thereby providing high chemoselectivity for $\mathrm{C}-\mathrm{H}$ arylations.

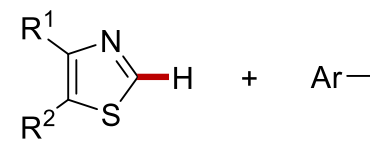

403

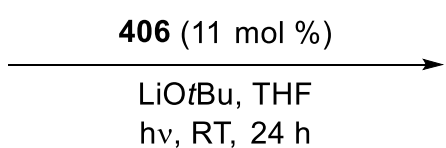

404

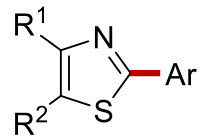

405

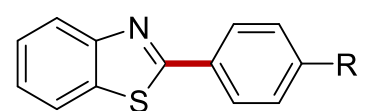

$\mathrm{R}=\mathrm{Me}(\mathbf{4 0 5 a}): \quad 93 \%$

$\mathrm{R}=\mathrm{H}(\mathbf{4 0 5 b}): \quad 94 \%$

$\mathrm{R}=\mathrm{OMe}(\mathbf{4 0 5 c}): \quad 79 \%$

$\mathrm{R}=\mathrm{CF}_{3}(\mathbf{4 0 5 d}): \quad 93 \%$

$R=F(405 e): \quad 95 \%$

$\mathrm{R}=\mathrm{Cl}(\mathbf{4 0 5 f}): \quad 92 \%$

$\mathrm{R}=\mathrm{Br}(\mathbf{4 0 5 g}): \quad 91 \%$

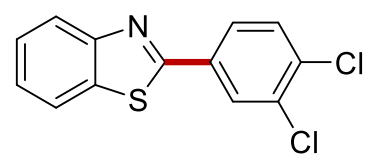

405t: $53 \%$

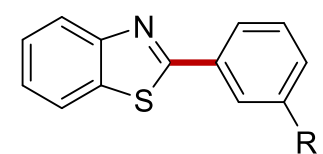

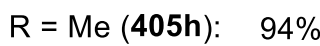

$\mathrm{R}=\mathrm{OMe}(\mathbf{4 0 5 i}): \quad 76 \%$

$\mathrm{R}=\mathrm{CF}_{3}(\mathbf{4 0 5 \mathrm { j } ) :} \quad 76 \%$

$\mathrm{R}=\mathrm{F}(\mathbf{4 0 5 k}): \quad 91 \%$

$\mathrm{R}=\mathrm{Cl}(405 \mathrm{I}): \quad 65 \%$

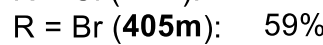

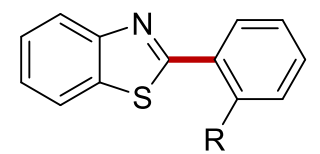

$R=\operatorname{Me~(405n):~} \quad 36 \%$

$\mathrm{R}=\mathrm{OMe}$ (4050): $36 \%$

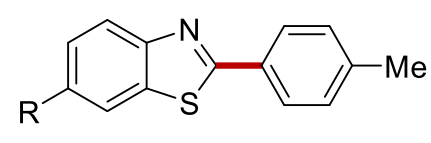

$\mathrm{R}=\mathrm{OMe}(405 p): 55 \%$

$\mathrm{R}=\mathrm{F}(\mathbf{4 0 5 q}): \quad 95 \%$

$\mathrm{R}=\mathrm{Cl}(\mathbf{4 0 5 r}): \quad 86 \%$.

$\mathrm{R}=\mathrm{Br}(\mathbf{4 0 5 s )}) \quad 66 \%$

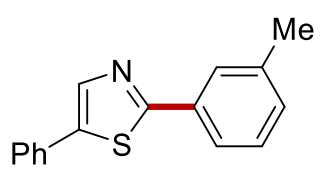

405w: $83 \%$

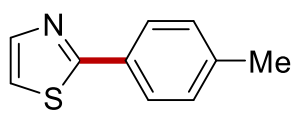

405u: $88 \%$

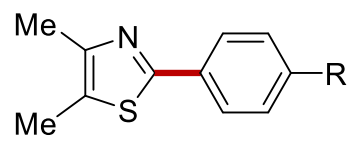

$\mathrm{R}=\mathrm{Me}(\mathbf{4 0 5 x}): \quad 86 \%$ $\mathrm{R}=\mathrm{Cl}(\mathbf{4 0 5 y}): \quad 87 \%$

Scheme 3.4.2 Scope of hybrid copper-catalyzed C-H arylation of (benzo)thiazoles $\mathbf{4 0 3}$ with aryl iodide 404.

The hybrid copper catalysis manifold was also demonstrated with (benz)oxazoles 444 under photoinduced conditions (Scheme 3.4.3). Likewise, a wide range of functional groups tolerance was depicted with a set of diversely decorated aryl iodides $\mathbf{4 0 4}$. Notably, with this approach, facile and sustainable access to the alkaloid natural product texamine $\mathbf{4 4 7 m}$ was realized. 


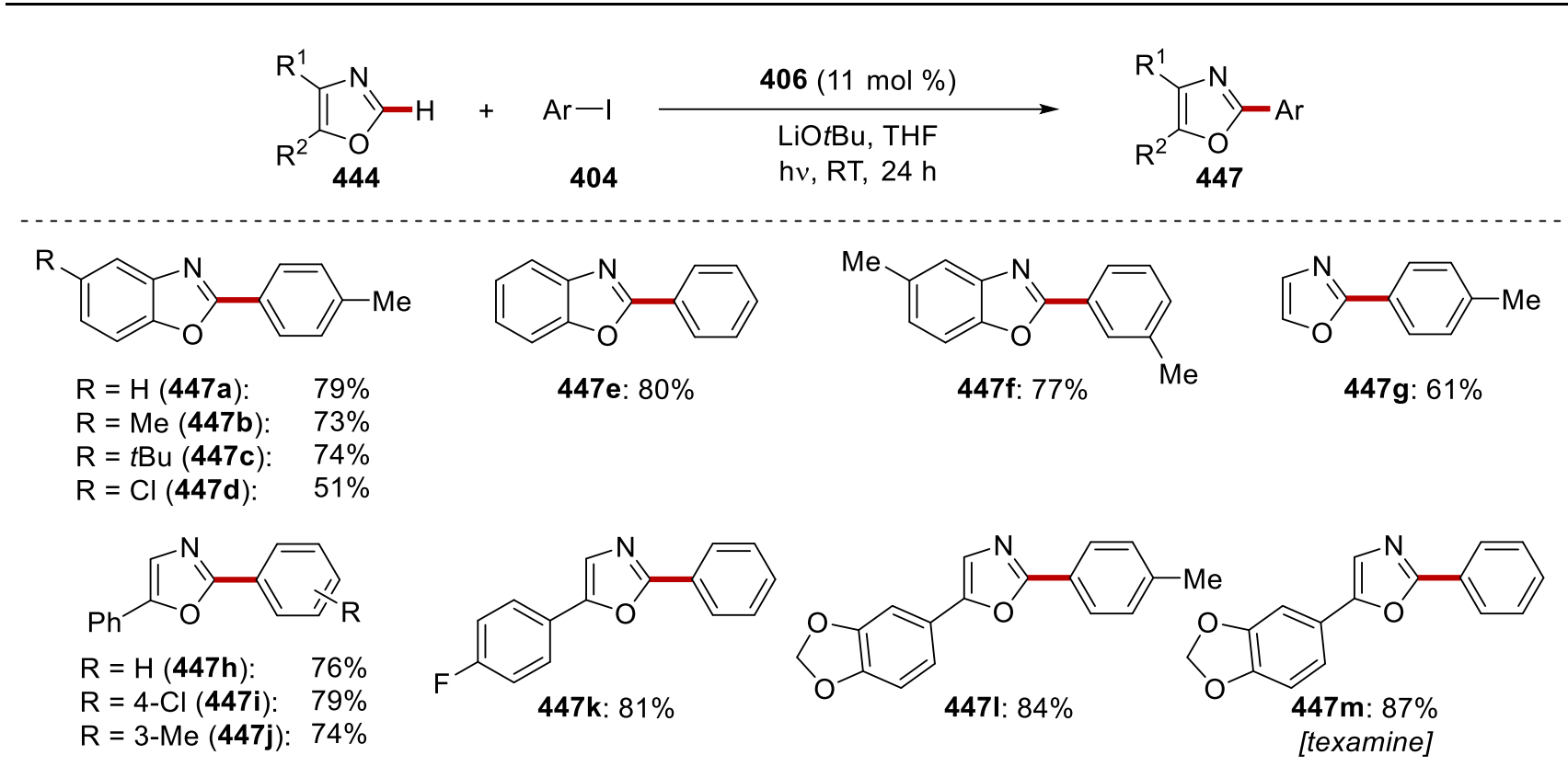

Scheme 3.4.3 Substrate scope for heterogeneous photo-induced C-H arylation of (benz)oxazole 444.

The heterogeneous photocatalysis for $\mathrm{C}-\mathrm{H}$ arylation of $\mathrm{N}$-methyl benzimidazoles 445 efficiently provided the $\mathrm{C} 2-\mathrm{H}$ arylated products 446 with a variety of aryl iodides 404 (Scheme 3.4.4). Besides valuable halides groups, this catalytic system tolerated sensitive functional groups, such as ketones 446e and ester 446f, by the use of the weak base $\mathrm{K}_{3} \mathrm{PO}_{4}$ instead of $\mathrm{LiO} t \mathrm{Bu}$. Additionally, a steroid derivative was converted to the arylated product $\mathbf{4 4 6 \mathbf { j }}$ by the photo-induced hybrid copper catalysis.
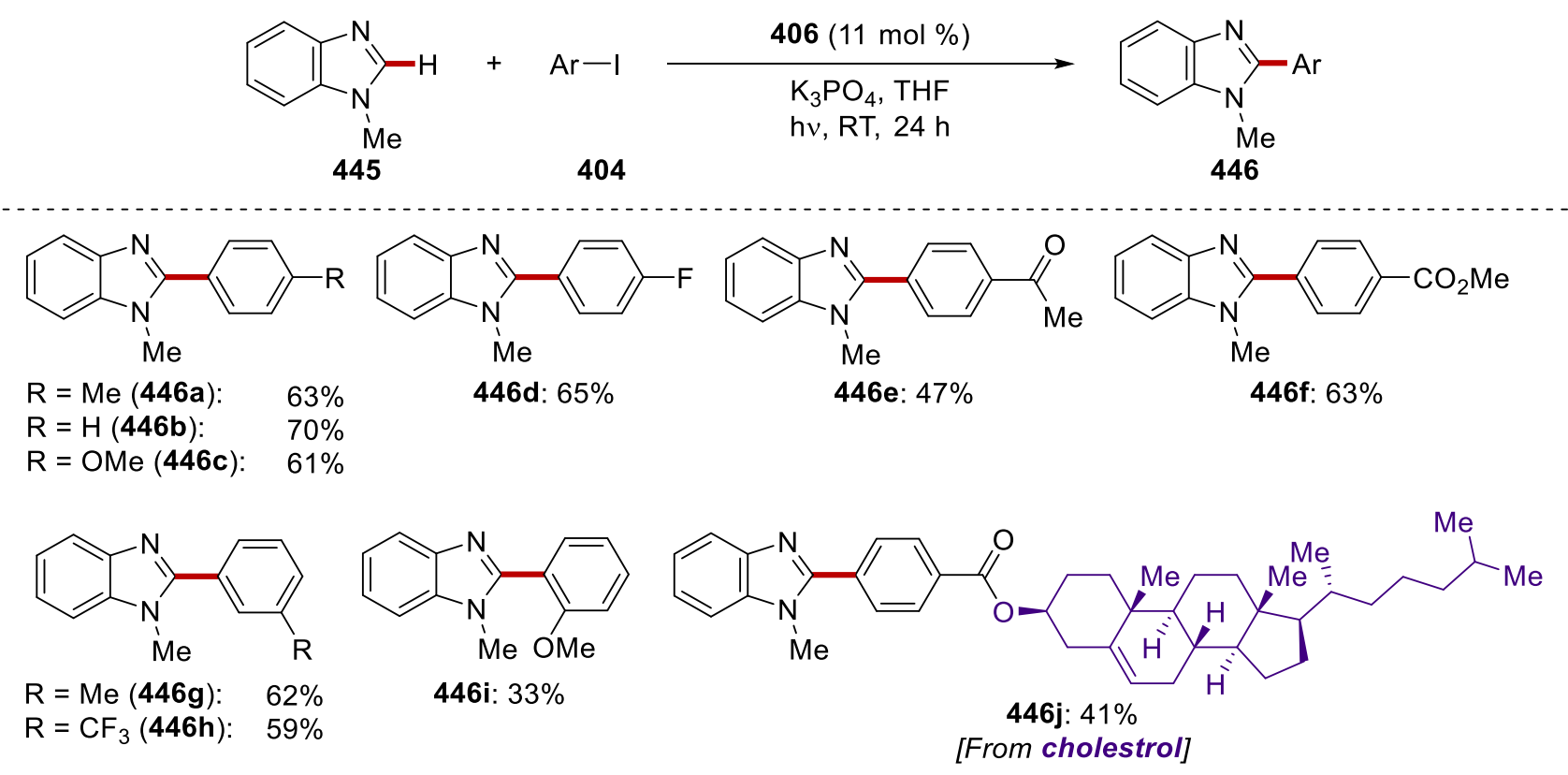

Scheme 3.4.4 Hybrid copper-catalyzed C-H arylations of $N$-methyl benzimidazole 445. 
Under the slightly modified condition, aryl bromides 447 were fully acceptable for the direct arylation by the heterogeneous photocatalysis (Scheme 3.4.5). Interestingly, benzothiazole 403 and $N$-methyl benzimidazoles 445 were transformed to the arylated products 405 and 446, respectively. Consequently, the robustness of the photo-induced $\mathrm{C}-\mathrm{H}$ arylation by hybrid-copper catalyst was shown by mild and sustainable catalysis along with ample substrate scope.
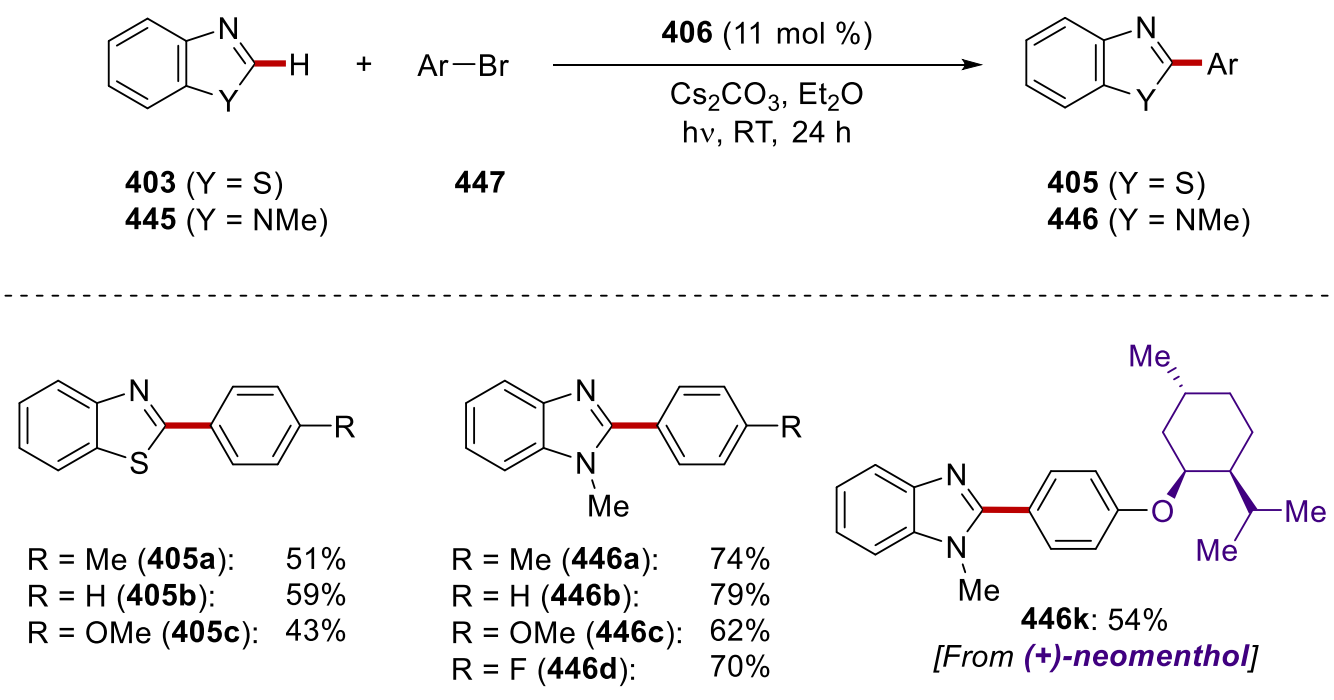

Scheme 3.4.5 Photo-induced hybrid copper-catalyzed C-H arylations with aryl bromides 447. 


\subsubsection{Mechanistic Studies}

To gain mechanistic insights, an intermolecular competition experiment was performed with differently substituted aryl iodides 404c and 404e (Scheme 3.4.6) Here, it was found that the electrondeficient aryl iodide $\mathbf{4 0 4}$ underwent faster direct arylation. This result suggests the oxidative addition of the aryl halide onto the copper(I) intermediate to be rate-determining.
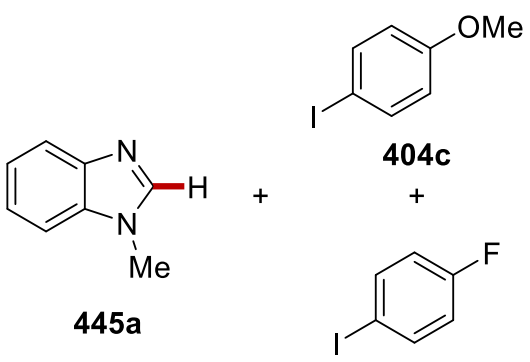

$404 e$

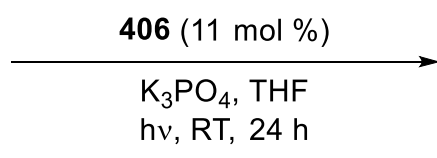

$\mathrm{K}_{3} \mathrm{PO}_{4}, \mathrm{THF}$
$\mathrm{h} v, \mathrm{RT}, 24 \mathrm{~h}$

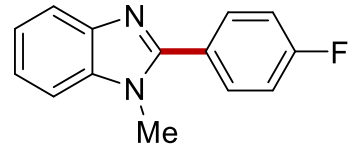

446d: $59 \%$

Scheme 3.4.6 Intermolecular competition experiment.

Furthermore, the reaction in the presence of representative radical scavenger TEMPO probed a SETtype regime by resulting in significant inhibition of the photo-induced hybrid-copper catalysis for $\mathrm{C}$ $\mathrm{H}$ arylation (Scheme 3.4.7).

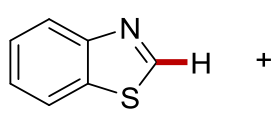

$403 a$<smiles>COc1ccc(I)cc1</smiles>

404c

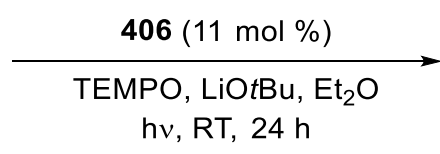

hv, RT, $24 \mathrm{~h}$

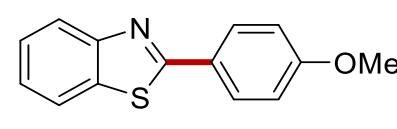

405c: $14 \%$

Scheme 3.4.7 Radical experiment.

Finally, we probed the photo-induced $\mathrm{C}-\mathrm{H}$ arylation by an on-off experiment, in which the light source was turned off every two hours. This study highlighted that the hybrid-copper-catalyzed $\mathrm{C}-\mathrm{H}$ arylation was fully suppressed in the absence of light, and simultaneously showed that constant irradiation is required for effective product formation (Scheme 3.4.8). 

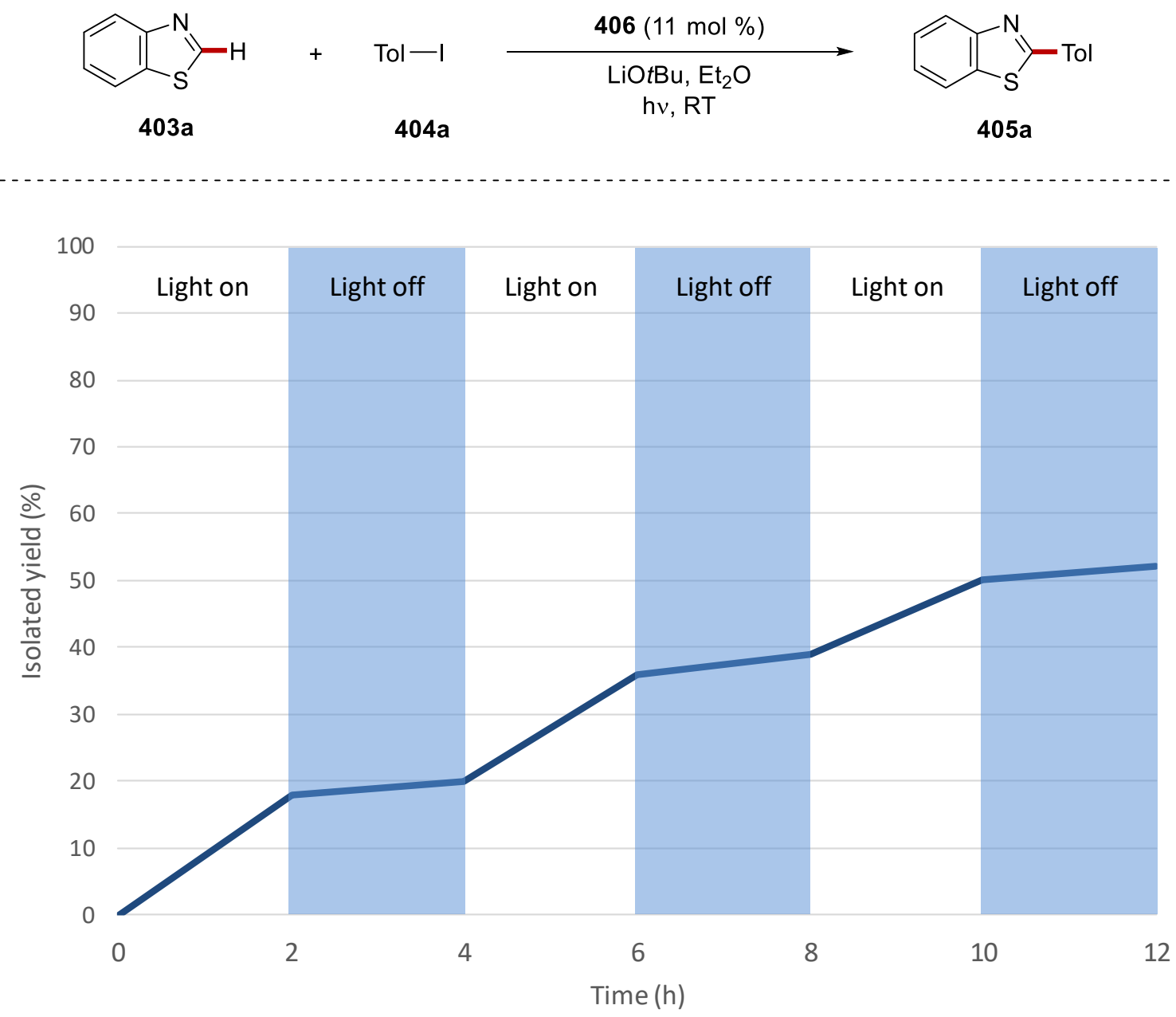

Scheme 3.4.8 On-off light experiments for photo-induced hybrid-copper-catalyzed C-H arylation. 


\subsubsection{Heterogeneity Studies}

Next, we became intrigued to probing potential reusable nature. We were delighted to observe that the hybrid copper catalyst $\mathbf{4 0 6}$ could be recycled without a significant loss of catalytic efficacy over the five runs of the reaction (Scheme 3.4.9). Especially, this approach enabled us to construct the natural product $\mathbf{4 4 7} \mathrm{m}$ in a sustainable fashion. Within a collaboration with Dr. Volker Karius, a ICP-OES analysis of the reaction mixture was performed, thus revealing that less than 4 ppm of copper was detected in the solution.
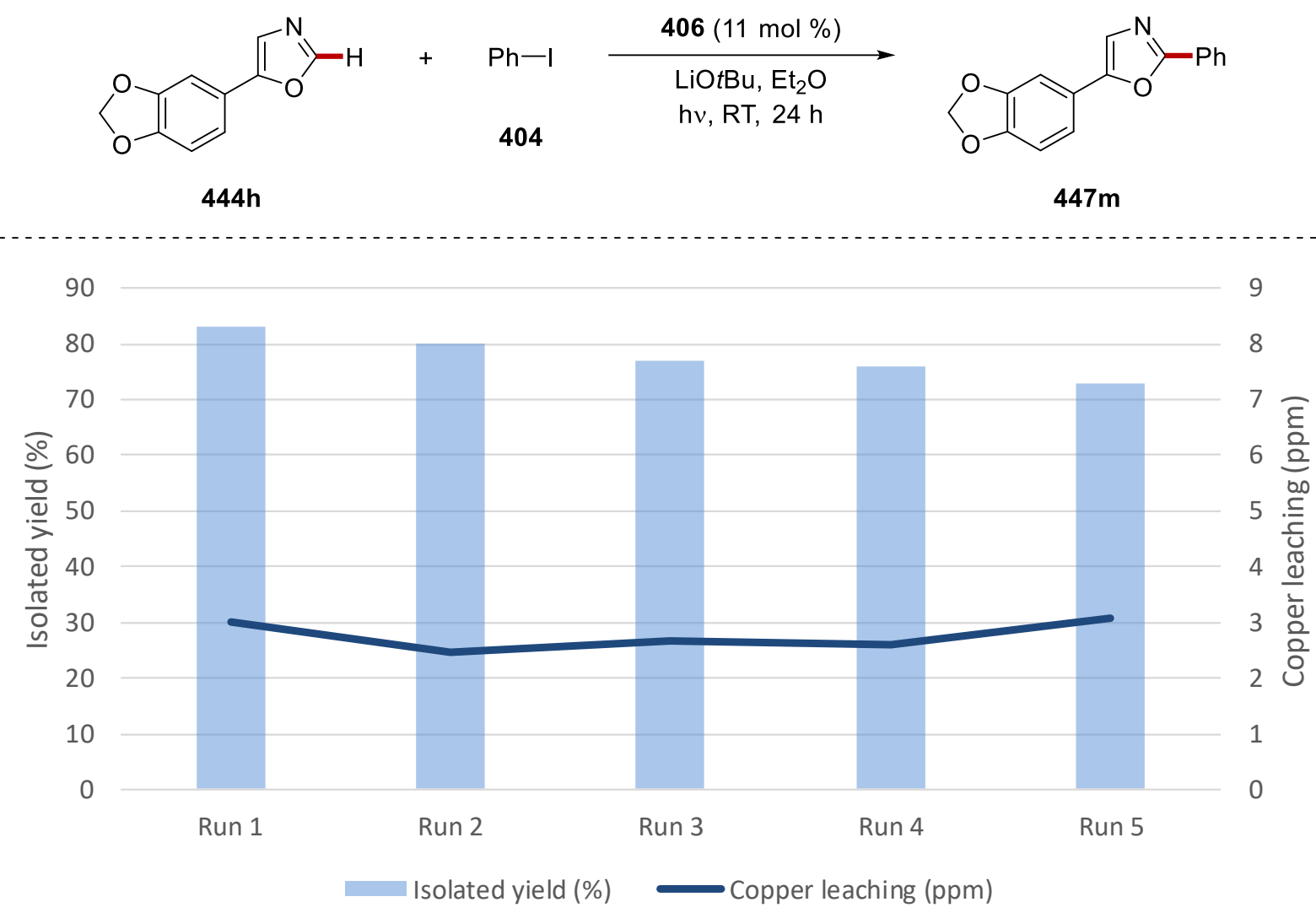

Scheme 3.4.9 Reuse test for the hybrid-copper catalyzed photo-induced C-H arylation.

Additionally, the reusability was also demonstrated in a gram-scale reaction (Scheme 3.4.10a). The classical heterogeneity experiment, a filtration test (Scheme 3.4.10b), was performed, reflecting homogeneous catalysis not to be operative. 
a) Scaled reuse test

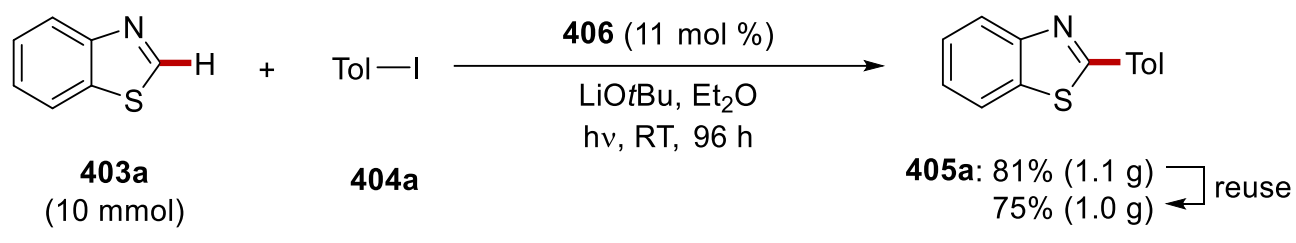

b) Filtration test

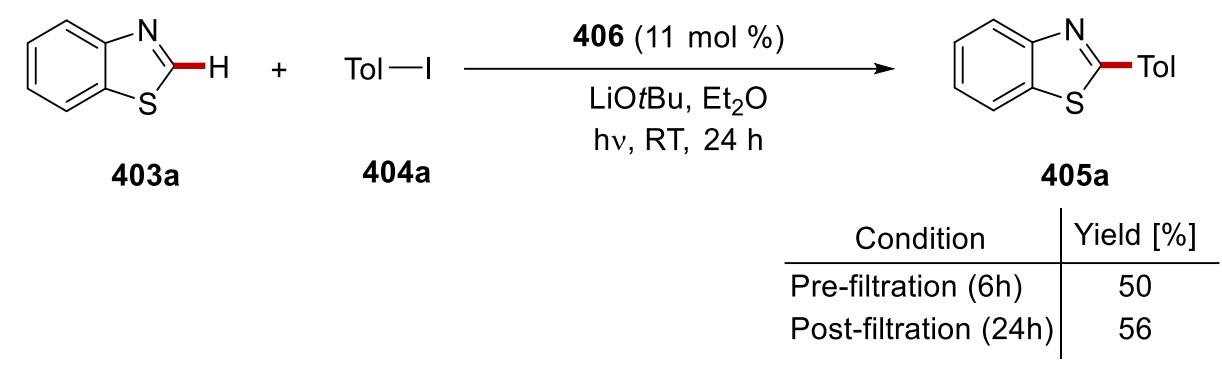

Scheme 3.4.10 Reuse test and filtration test. 


\subsubsection{Characterization of Hybrid Copper Catalyst}

In a collaboration with Prof. Dr. Wolfgang Viöl and Dr. Robert Köhler, X-ray photoelectron spectroscopic analysis was performed (Scheme 3.4.11). In this study, the $\mathrm{Cu} 2 \mathrm{p}_{3 / 2}$ peak was investigated for the determination of the oxidation state of copper. The peaks of the hybrid copper catalyst 406 and the reused hybrid copper catalyst were located at $932.6 \mathrm{eV}$, indicating the presence of either $\mathrm{Cu}(0)$ or $\mathrm{Cu}(\mathrm{I})$. For the differentiation of $\mathrm{Cu}(0)$ and $\mathrm{Cu}(\mathrm{I})$, the $\mathrm{Cu} \mathrm{LMM}$-Auger peak was additionally analyzed. The measured $\mathrm{Cu}$ LMM peaks were compared with the reported results, which clearly revealed $\mathrm{Cu}(\mathrm{I})$ of the oxidation state of hybrid copper catalyst $\mathbf{4 0 6}$ as well as the reused hybrid copper catalyst. These results showed that the oxidation state of the hybrid catalyst was not changed after the photo-induced $\mathrm{C}-\mathrm{H}$ arylation reaction.
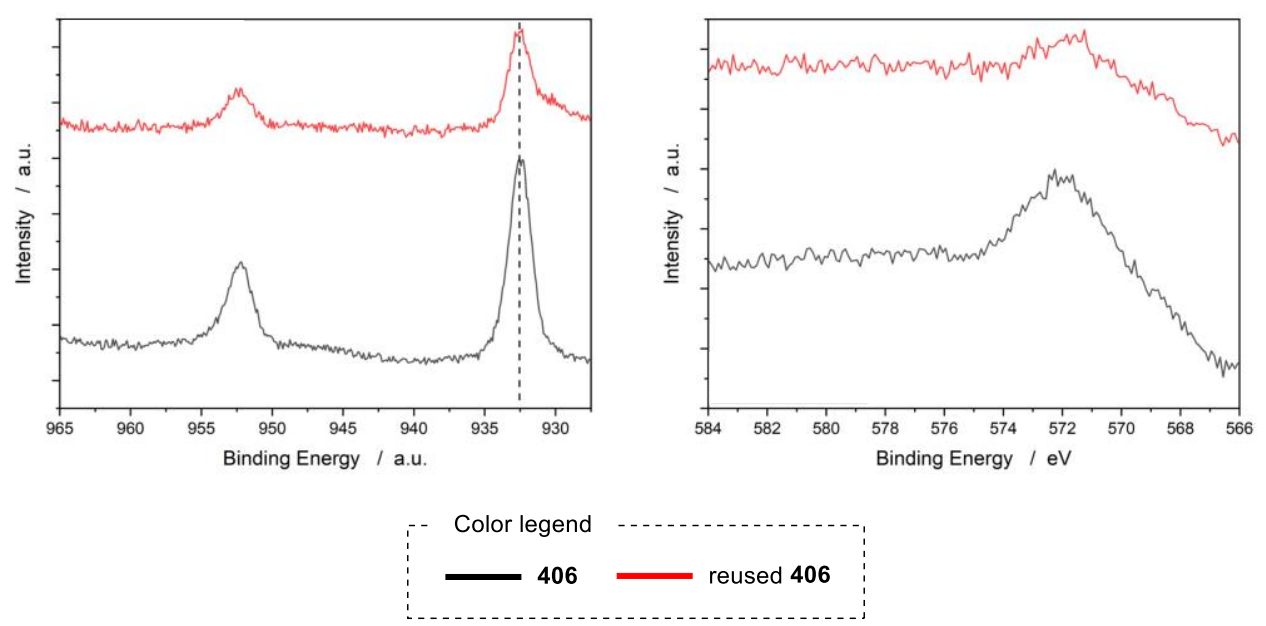

Scheme 3.4.11 X-ray photoelectron spectroscopic (XPS) analysis of 406 and reused 406.

In a collaboration with Prof. Dr. Christian Jooss and Gaurav Lole, detailed transmission electron microscopic studies were performed (Scheme 3.4.12). Thereby, SBA-15, 443, the hybrid copper catalyst 406, and the reused hybrid copper catalyst were subjected to the microscopic analyses. TEM images of the SBA-15 and $\mathbf{4 0 6}$ showed homogenously ordered one-dimensional mesoporous channels with homogeneous morphology, which was observed by the striped contrast with the average distance of $10.2 \mathrm{~nm}$ between the centers of the one-dimensional mesoporous channel and its adjacent channel (Scheme 3.4.12I-VI). TEM images of the hybrid copper catalyst 406 revealed that the highly ordered 
structure of SBA-15 was preserved and a tendency of aggregation was not observed (Scheme 3.4.12VII-XII). TEM analysis of the reused hybrid copper catalyst also showed that there were no copper nanoparticles formed by agglomeration while ordered striped contrast remained unchanged in the one-dimensional mesoporous channels (Figure 3.4.12). These results highlighted the outstanding reusability and stability during the preparation of the hybrid copper catalyst $\mathbf{4 0 6}$ as well as the course of the photo-induced $\mathrm{C}-\mathrm{H}$ arylations.

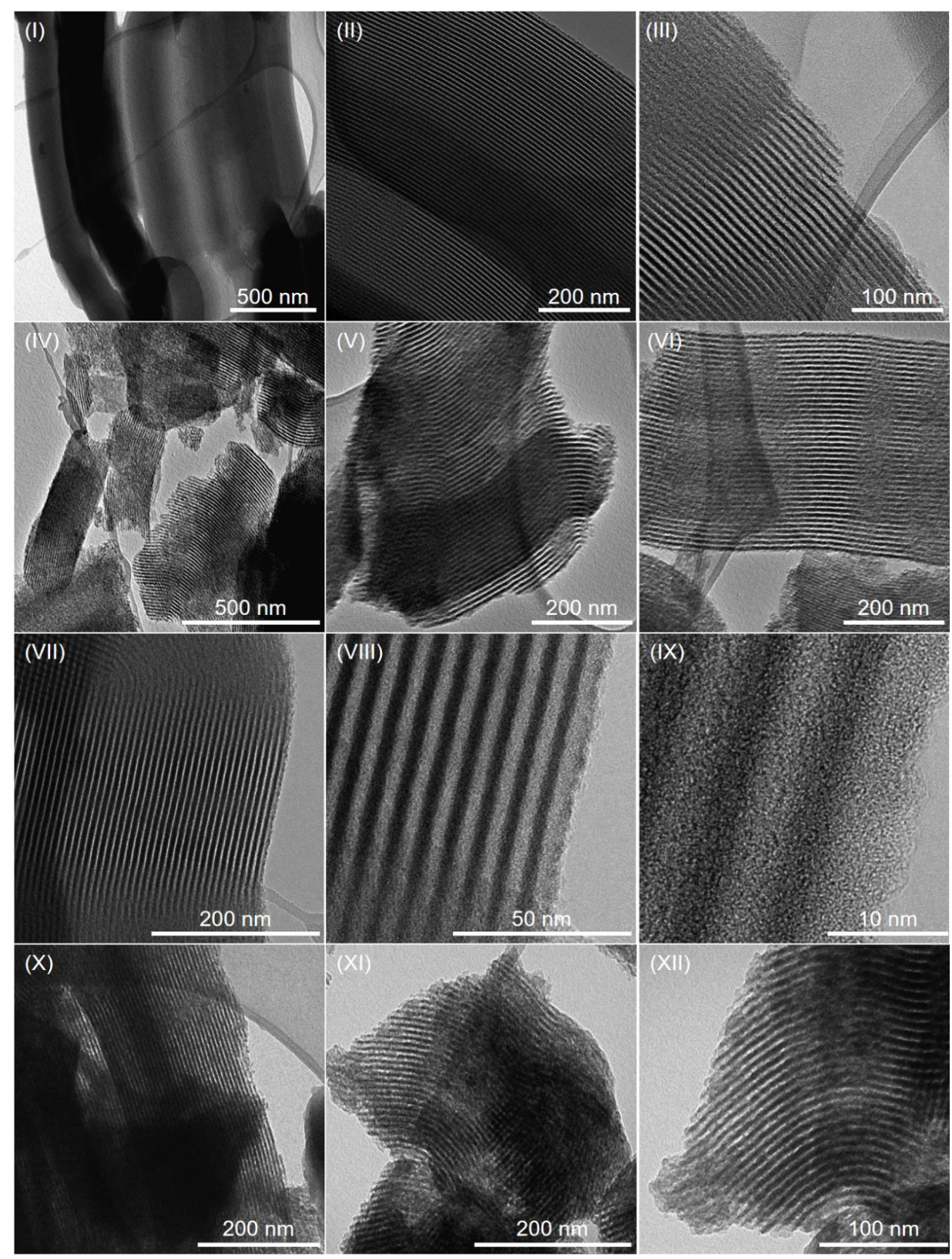

Scheme 3.4.12 Transmission electron microscopic (TEM) studies of hybrid copper catalysts 406. 


\subsubsection{Proposed Mechanism}

On the basis of our detailed mechanistic studies and the characterization of the hybrid copper catalyst, a plausible catalytic cycle for the photo-induced heterogeneous $\mathrm{C}-\mathrm{H}$ arylation is proposed in Scheme 3.4.13. The mechanistic rationale commences with hybrid copper(I) catalyst $\mathbf{4 0 6}$ and $N$-Methyl benzimidazole 445, forming copper complex 447 with the aid of a base. Irradiation of the copper complex 447 leads to a photo-excited state 448 , followed by a SET process involving aryl iodides 404 generating intermediate 449. Finally, subsequent reductive elimination affords arylated product 446, while simultaneously regenerating the hybrid copper(I) catalyst.

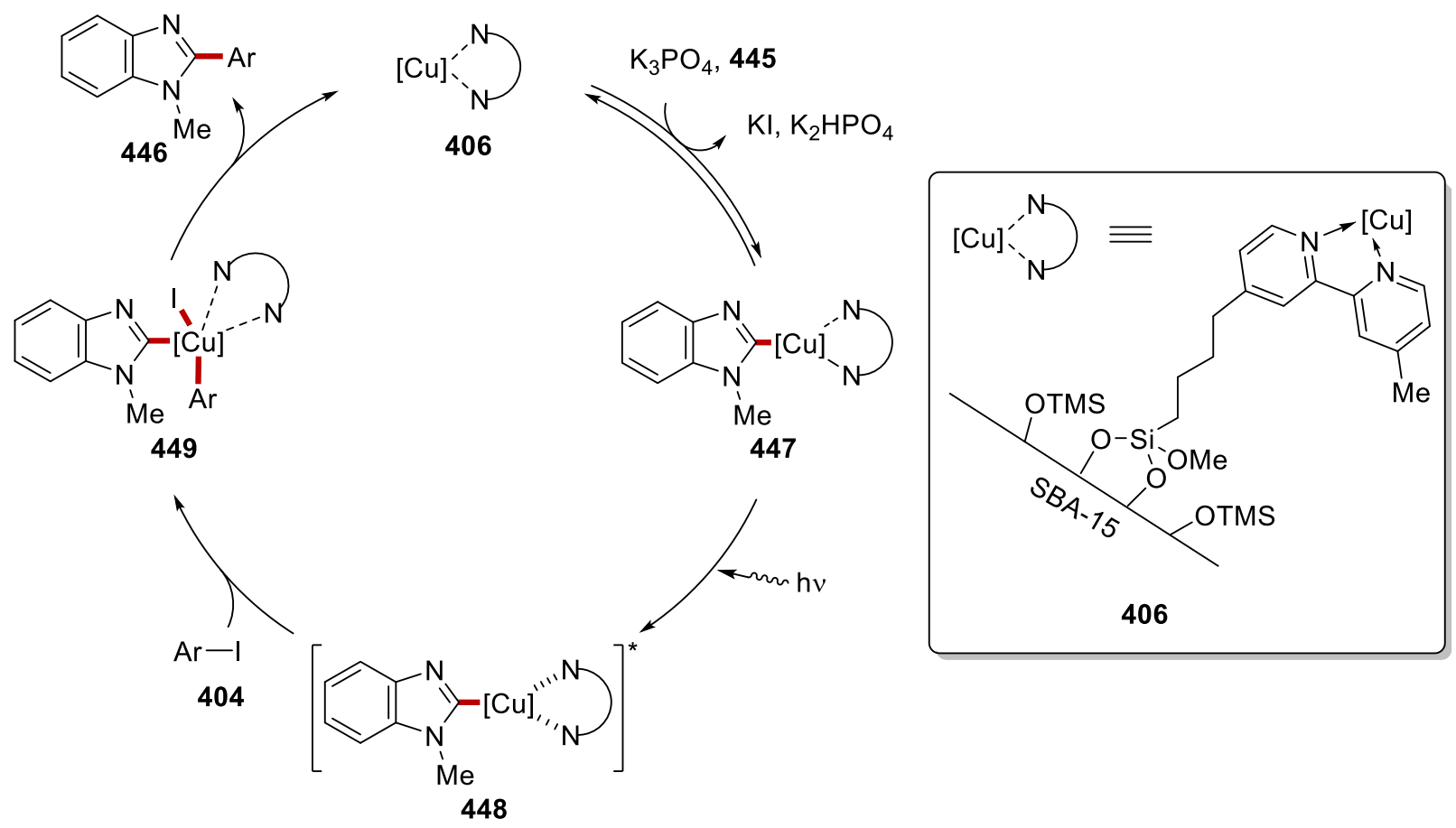

Scheme 3.4.13 Proposed catalytic cycle of photo-induced hybrid copper-catalyzed C-H arylation. 


\subsection{Distal C-H Activation by Reusable Heterogeneous Ruthenium Catalyst}

A plethora of ortho-selective aromatic $\mathrm{C}-\mathrm{H}$ functionalizations has been accomplished by proximityinduced $\mathrm{C}-\mathrm{H}$ activation through chelation assistance. ${ }^{[20 \mathrm{a}]} \mathrm{In}$ sharp contrast, distal $\mathrm{C}-\mathrm{H}$ functionalizations continue to be challenging with considerable momentum gained by steric control, template assistance, weak hydrogen bonding, or transient mediator as described in the Chapter 1.2.2. Recently, Ackermann, ${ }^{[82,83,85,88,90,92,251]}$ Greaney, ${ }^{[252]}$ and Frost ${ }^{[72 f, 96 \mathrm{~d}]}$ among others ${ }^{[253]}$ developed site-selective $\mathrm{C}-\mathrm{H}$ functionalization via ruthenium-catalyzed $\sigma$-activation, allowing meta- and parafunctionalization of arenes. ${ }^{[72 c,}{ }^{72 d]}$ In spite of recent notable progress, the realm of $\mathrm{C}-\mathrm{H}$ functionalizations was thus far considerably limited to homogeneous catalysis. Taking advantage of the use of phosphine ligands in the ruthenium-catalyzed distal functionalizations, ${ }^{[88,251]}$ we envisaged using phosphine-based polymer support to immobilize the ruthenium catalyst (Scheme 3.5.1).

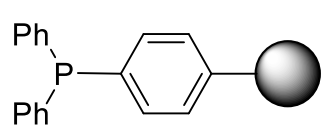

448

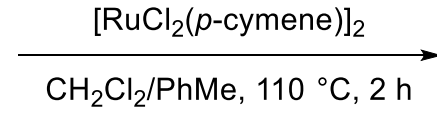

$\mathrm{CH}_{2} \mathrm{Cl}_{2} / \mathrm{PhMe}, 110^{\circ} \mathrm{C}, 2 \mathrm{~h}$

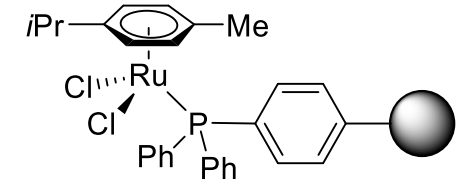

410

Scheme 3.5.1 Preparation of the hybrid ruthenium catalyst. 


\subsubsection{Optimization Studies}

We initiated our studies by probing various reaction conditions with the thus synthesized polymerbased hybrid ruthenium catalyst for the meta-C-H alkylation of arene 407 (Table 3.5.1). First, we explored different types of bases in 1,4-dioxane as the solvent at $100{ }^{\circ} \mathrm{C}$ (entries $\left.1-5\right)$. However, it was found that the addition of acid was not necessary for the ruthenium-catalyzed meta-C-H alkylation, while KOAc provided better conversion among various bases (entries 6-10). After a considerable testing of solvents and reaction temperatures, we were delighted to obtain the optimized conditions where the use of 2-MeTHF as the solvent and $60{ }^{\circ} \mathrm{C}$ of reaction temperature could provide $70 \%$ of isolated yield (entries 11-15). Notably, biomass-derived 2-MeTHF is considered as a green alternative to THF, and can be produced from renewable resources. ${ }^{[254]}$ A control experiment confirmed the essential role of the recyclable hybrid-ruthenium catalyst (entry 16), while the recyclability of the hybrid ruthenium catalyst $\mathbf{4 1 0}$ was proved (entry 17).

Table 3.5.1 Optimization studies for hybrid-ruthenium-catalyzed meta-C-H alkylation. ${ }^{[\mathrm{a}]}$<smiles>c1ccc(-c2ccccn2)cc1</smiles>

407<smiles>CCOC(C)Br</smiles>

408

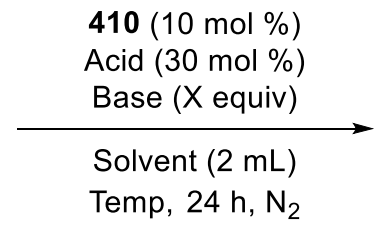

Temp, $24 \mathrm{~h}, \mathrm{~N}_{2}$

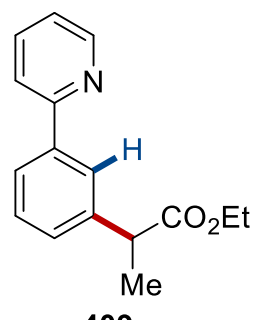

409

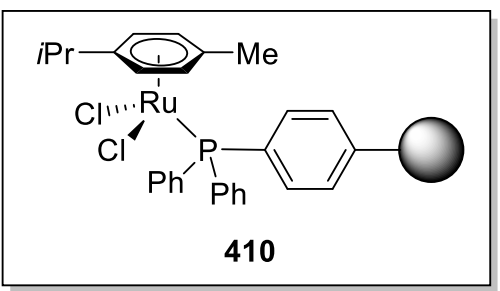

410

\begin{tabular}{|c|c|c|c|c|c|}
\hline Entry & Acid & Base ( $\mathrm{X}$ equiv) & Solvent & Temp $\left({ }^{\circ} \mathrm{C}\right)$ & Yield $(\%)^{\mathrm{a}}$ \\
\hline 1 & $\mathrm{MesCO}_{2} \mathrm{H}$ & $\mathrm{Na}_{2} \mathrm{CO}_{3}(1.0)$ & 1,4-Dioxane & 100 & 31 \\
\hline 2 & $\mathrm{MesCO}_{2} \mathrm{H}$ & $\mathrm{K}_{2} \mathrm{CO}_{3}(1.0)$ & 1,4-Dioxane & 100 & 32 \\
\hline 3 & $\mathrm{MesCO}_{2} \mathrm{H}$ & $\mathrm{K}_{3} \mathrm{PO}_{4}(1.0)$ & 1,4-Dioxane & 100 & 40 \\
\hline 4 & $\mathrm{MesCO}_{2} \mathrm{H}$ & $\mathrm{NaOAc}(1.0)$ & 1,4-Dioxane & 100 & 25 \\
\hline 5 & $\mathrm{MesCO}_{2} \mathrm{H}$ & KOAc (1.0) & 1,4-Dioxane & 100 & 11 \\
\hline 6 & -- & $\mathrm{K}_{2} \mathrm{CO}_{3}(1.0)$ & 1,4-Dioxane & 100 & trace \\
\hline 7 & -- & $\mathrm{Na}_{2} \mathrm{CO}_{3}(1.0)$ & 1,4-Dioxane & 100 & 21 \\
\hline
\end{tabular}




\begin{tabular}{|c|c|c|c|c|c|}
\hline 8 & -- & $\mathrm{K}_{3} \mathrm{PO}_{4}(1.0)$ & 1,4-Dioxane & 100 & 31 \\
\hline 9 & -- & KOAc (1.0) & 1,4-Dioxane & 100 & 33 \\
\hline 10 & -- & KOAc (1.0) & 1,4-Dioxane & 80 & 40 \\
\hline 11 & -- & KOAc (1.0) & $\mathrm{PhCMe}_{3}$ & 80 & 25 \\
\hline 12 & -- & KOAc (1.0) & 2-MeTHF & 80 & 44 \\
\hline 13 & -- & KOAc (2.0) & 2-MeTHF & 80 & 61 \\
\hline 14 & -- & KOAc (2.0) & 2-MeTHF & 60 & 70 \\
\hline 15 & -- & KOAc (2.0) & 2-MeTHF & 40 & 53 \\
\hline 16 & -- & KOAc (2.0) & 2-MeTHF & 60 & $0^{[\mathrm{b}]}$ \\
\hline 17 & -- & KOAc (2.0) & 2-MeTHF & 60 & $69^{[\mathrm{c}]}$ \\
\hline
\end{tabular}

${ }^{[\mathrm{a}]}$ Reaction conditions: $407(0.25 \mathrm{mmol}), \mathbf{4 0 8}(0.75 \mathrm{mmol}), \mathbf{4 1 0}(10 \mathrm{~mol} \%)$, solvent $(1.0 \mathrm{~mL}), 24 \mathrm{~h}$, isolated yield. ${ }^{[b]}$ Without 410. ${ }^{[c]}$ With the reused 410.

The optimized heterogeneous catalyst was not limited to substrates bearing the pyridine directing group. Indeed, other directing groups, such as pyrimidines, oxazolines, pyrazoles, and purines were acceptable for the hybrid ruthenium-catalyzed meta-C-H alkylation (Scheme 3.5.2).
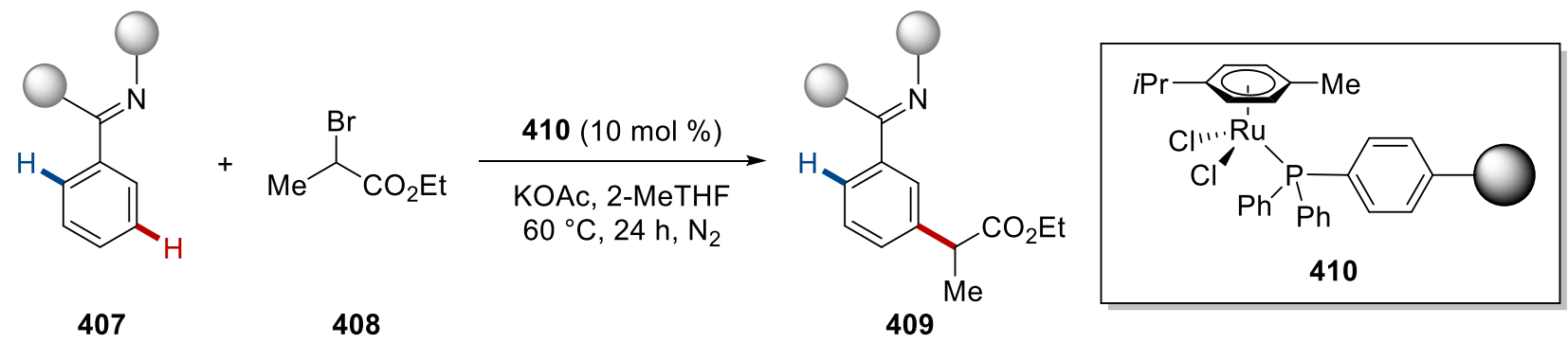

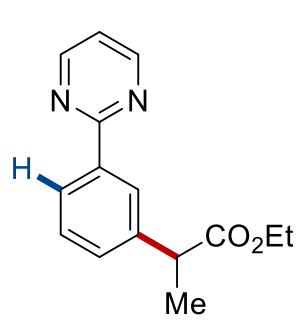

409b: $63 \%$

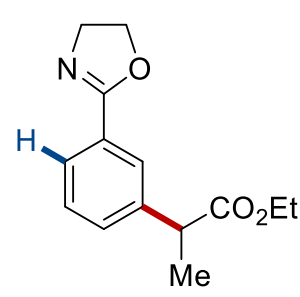

409c: $55 \%$

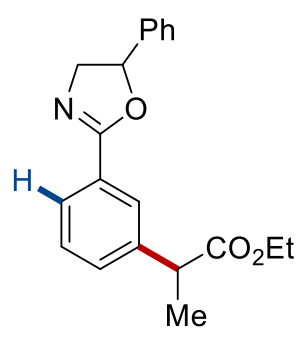

409d: $69 \%$

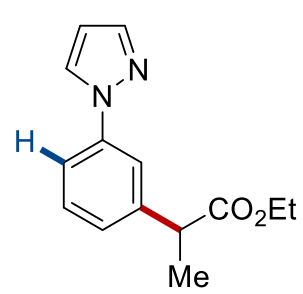

409e: $56 \%$<smiles>CCOC(=O)C(C)c1cccc(-c2ncnc3c2ncn3C(C)C)c1</smiles>

409f: $92 \%$

Scheme 3.5.2 Different directing groups for hybrid ruthenium-catalyzed meta-C-H alkylation. 


\subsubsection{Substrate Scope}

We commenced exploring the versatility of the hybrid-ruthenium-catalyzed meta-C-H functionalization with a set of representative arenes 407 (Scheme 3.5.3). Differently substituted arenes 407 bearing electron-deficient and electron-rich functional groups were position-selectively transformed to the desired meta-functionalized products 408. Distal meta-C-H alkylation by the hybrid ruthenium catalyst 410 tolerated various alkyl bromides $\mathbf{4 0 8}$, including valuable functional groups, featuring halides, ethers, esters, and amides, while natural product derivatives $\mathbf{4 0 9 p}$ and $\mathbf{4 0 9 q}$ were selectively converted.<smiles>[R][X]1cc(F)cc(-c2ccccn2)c1</smiles>
407<smiles>[R]C([R])([R])Br</smiles>

408
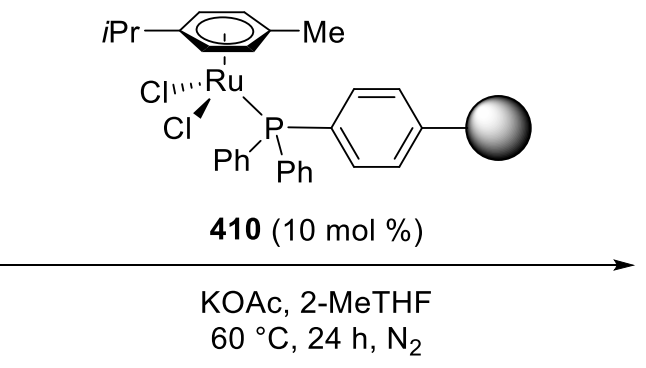

$60{ }^{\circ} \mathrm{C}, 24 \mathrm{~h}, \mathrm{~N}_{2}$

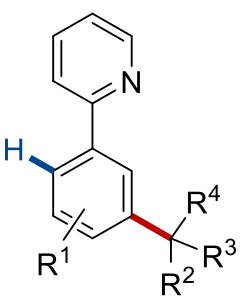

409<smiles>[R]c1ccc(-c2ccccn2)cc1C(C)OCC</smiles>

$\mathrm{R}=\mathrm{H}(\mathbf{4 0 9} \mathrm{a}): \quad 70 \%$

$\mathrm{R}=\mathrm{Me}(\mathbf{4 0 9 g}): \quad 72 \%$

$\mathrm{R}=$ OMe $(409 \mathrm{~h}): \quad 88 \%$

$\mathrm{R}=\mathrm{Cl}(409 \mathrm{i}): \quad 54 \%$

$\mathrm{R}=\mathrm{CO}_{2} \mathrm{Et}(\mathbf{4 0 9 j}): 60 \%$<smiles>[R]OC(=O)C(C)c1cccc(-c2ccccn2)c1</smiles>

$\mathrm{R}=\mathrm{Me}$ (409k): $71 \%$

$\mathrm{R}=i-\mathrm{Bu}$ (409I): $64 \%$<smiles>CC(=O)C(C)c1cccc(-c2ccccn2)c1</smiles>

409m: $58 \%$<smiles>CCNC(=O)C(C)c1cccc(-c2ccccn2)c1</smiles>

409n: $70 \%$<smiles>CCOC(=O)C(C)(C)c1cccc(-c2ccccn2)c1</smiles>

409o: $64 \%$<smiles>CC1CC[C@H](C(C)C)[C@H](OC(=O)C(C)c2cccc(-c3ccccn3)c2)C1</smiles>

409p: $64 \%$ [From menthol]

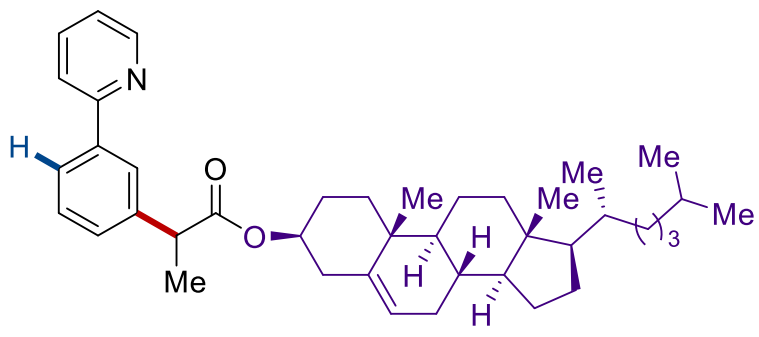

409q: $63 \%$ [From cholestrol]

Scheme 3.5.3 Substrate scope for hybrid ruthenium-catalyzed meta-C-H alkylations. 


\subsubsection{Mechanistic Studies}

Furthermore, we performed detailed mechanistic studies to elucidate the hybrid ruthenium catalyst's mode of action. To this end, an intermolecular competition experiment was carried out, revealing that the electron-rich arene $\mathbf{4 0 7} \mathbf{k}$ was preferentially reacted (Scheme 3.5.4). This result suggests that a BIES-type $\mathrm{C}-\mathrm{H}$ metalation pathway is involved in the hybrid ruthenium-catalyzed meta-C-H alkylation.<smiles>Oc1ccc(C2=NCCO2)cc1F</smiles>

407k/407I<smiles>CCOC(C)Br</smiles>

$408 \mathrm{a}$

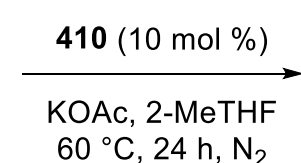

$60^{\circ} \mathrm{C}, 24 \mathrm{~h}, \mathrm{~N}_{2}$<smiles>CCOC(=O)C(C)c1cc(C2=NCCO2)ccc1OC</smiles>

409r: $33 \%$<smiles>CCOC(=O)C(C)c1cc(C2=NCCO2)ccc1F</smiles>

409s: $19 \%$

Scheme 3.5.4 Competition experiment between arenes 407k and 407l.

Additionally, the reaction in the presence of isotopically labelled $\mathrm{CD}_{3} \mathrm{OD}$ afforded $69 \%$ of deuteration in the reisolated substrate $[D]_{n}-407 k$ and $72 \%$ and $49 \%$ of deuteration in the ortho-positions of the desired product 409r (Scheme 3.5.5). These experimental results provided a strong support for a reversible $\mathrm{C}-\mathrm{H}$ activation.<smiles>COc1ccc(C2=NCCO2)cc1</smiles>

407k<smiles>[C+]C(C)C(Br)OCC</smiles>

$408 a$

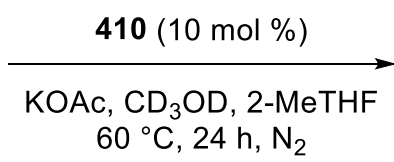

$60^{\circ} \mathrm{C}, 24 \mathrm{~h}, \mathrm{~N}_{2}$<smiles>COc1cc2c(C=[18O])c(c1)OCCN2</smiles>

$[D]_{n}-407 k: 23 \%$

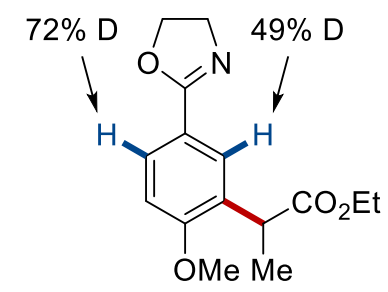

[D] $]_{n}-409 r: 71 \%$

Scheme 3.5.5 H/D exchange study. 
In addition, the KIE was studied, indicating a primary isotope effect in both competition and independent experiments (Scheme 3.5.6). This study clearly revealed that $\mathrm{C}-\mathrm{H}$ cleavages at the ortho and meta positions are not kinetically relevant.<smiles>[13CH3]c1cc([18OH])c([18OH])c(-n2cccn2)c1</smiles>

and $[D]_{5}-407 d$<smiles>[13CH3]c1cc([18OH])c([18OH])c(-n2cccn2)c1</smiles><smiles>CCOC(C)Br</smiles>

$408 a$

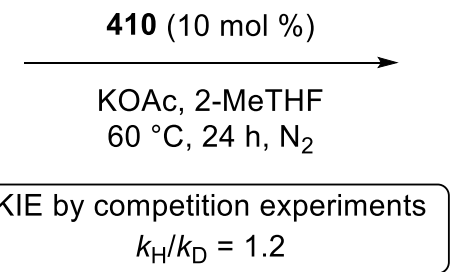
$k_{\mathrm{H}} / k_{\mathrm{D}}=1.2$ or

$\mathrm{H}_{3} / \mathrm{D}_{3}$

$$
[D]_{5}-407 d
$$<smiles>CCOC(=O)C(C)Br</smiles>

408a

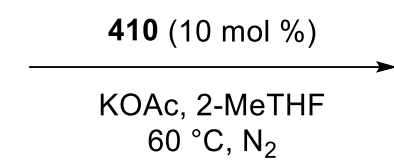

KIE by independent experiments $k_{\mathrm{H}} / k_{\mathrm{D}}=1.2$<smiles></smiles>

409d and $[D]_{n}-409 d: 49 \%$

Scheme 3.5.6 Kinetic isotope effect studies. 


\subsubsection{Heterogeneity Studies}

To probe the heterogeneity of the hybrid-ruthenium-catalyst, a variety of experiments were conducted. We were hence delighted to observe that the hybrid-ruthenium featured an excellent reusability, enabling practical access to meta-C-H alkylated arenes (Scheme 3.5.7). Industries and pharma companies performing large-scale reactions or flow applications in homogeneous catalysis mainly are concerned with the removal of metal impurities, which are detrimental to synthetic and economic efficiency, while the well-designed heterogeneous catalysts could avoid the additional processes by a simple separation. Within a collaboration with Dr. Volker Karius, less than 8 ppm of ruthenium was detected by ICP-OES studies of the reaction mixture, reflecting a negligible leaching of the transition metal.
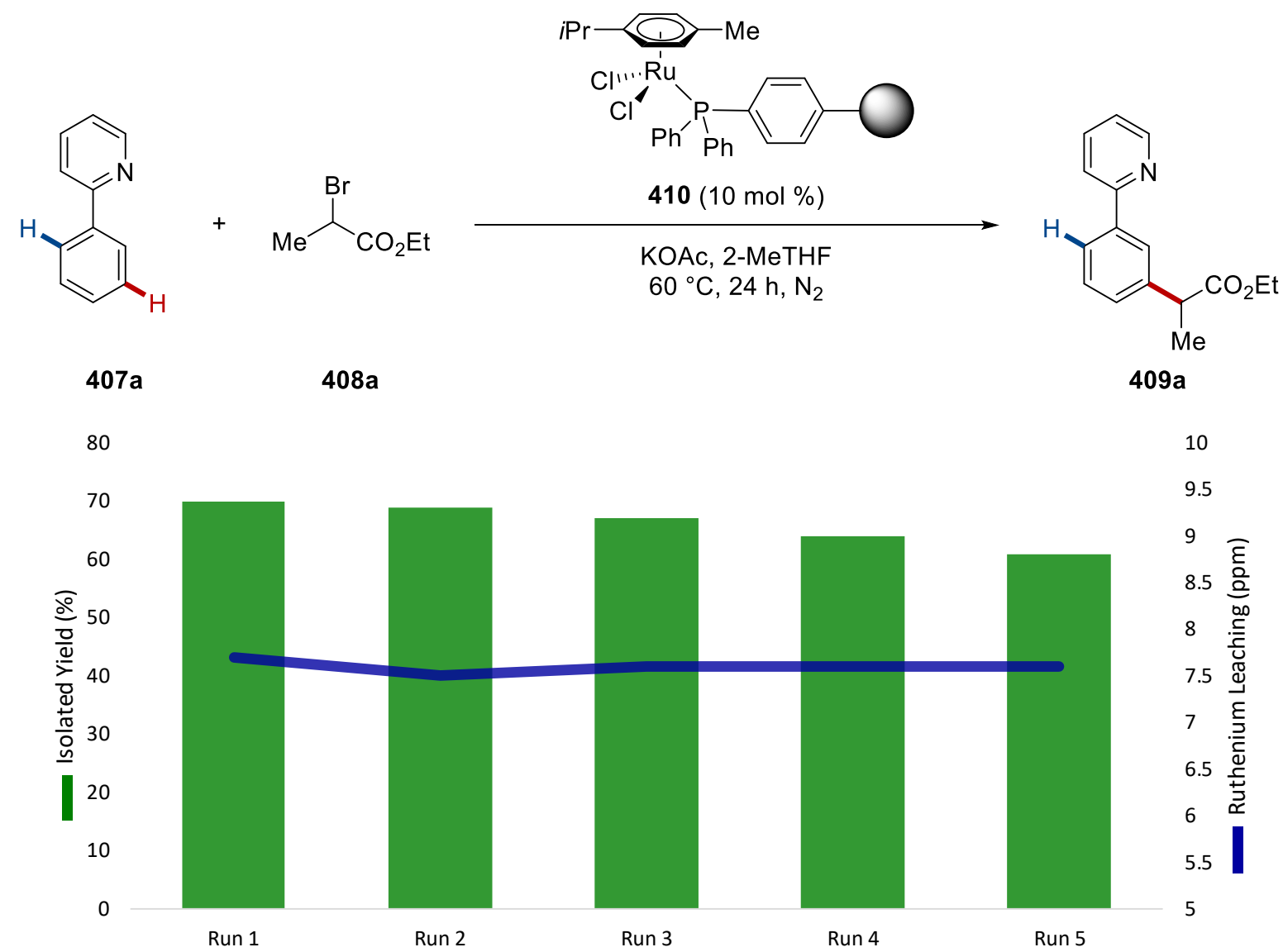

Scheme 3.5.7 Reuse test for hybrid ruthenium-catalyzed meta-C-H alkylation and the determination of ruthenium leaching. 
The sustainable feature of the hybrid-ruthenium catalysis was also mirrored by a gram-scale reaction, maintaining a high efficiency with position-selectivity and reusability of the hybrid-ruthenium catalyst (Scheme 3.5.8).<smiles>c1ccc(-c2ccccn2)cc1</smiles>

$407 a$<smiles>CCOC(C)Br</smiles>

$408 a$

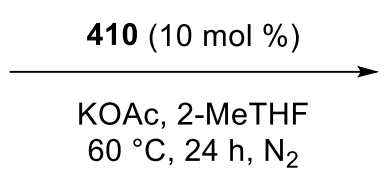

$60{ }^{\circ} \mathrm{C}, 24 \mathrm{~h}, \mathrm{~N}_{2}$<smiles>CCOC(=O)C(C)c1cccc(-c2ccccn2)c1</smiles>

409a

First run: $\quad 80 \%(2.04 \mathrm{~g})$

Second run: $76 \%$ (1.94 g)

Scheme 3.5.8 Scaled reuse test.

Additionally, a hot-filtration test demonstrated that the physical removal of the hybrid-ruthenium catalyst completely inhibited the hybrid catalysis for meta-C-H alkylation (Scheme 3.5.9).<smiles>c1ccc(-c2ccccn2)cc1</smiles>

407a<smiles>CCOC(=O)C(C)Br</smiles>

$408 a$

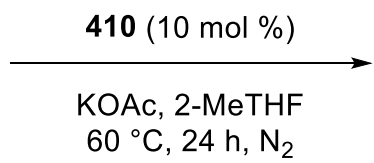<smiles>CCOC(C)c1cccc(-c2ccccn2)c1</smiles>

409a

\begin{tabular}{c|c|c|c} 
409a Yield (\%) & $2 \mathrm{~h}$ & $4 \mathrm{~h}$ & $24 \mathrm{~h}$ \\
\hline Standard reaction & 32 & 48 & 70 \\
Hot filtration after 2 $\mathrm{h}$ & 32 & 33 & 33 \\
Hot filtration after 4 h & -- & 48 & 50
\end{tabular}

Scheme 3.5.9 Hot filtration test. 


\subsubsection{Characterizations of Hybrid Ruthenium Catalyst}

Given the unique features of recyclable and reusable hybrid ruthenium catalyst $\mathbf{4 1 0}$, we sought to determine its chemical and physical properties. Within a collaboration with the Loren group, we conducted detailed solid-state NMR spectroscopic studies of the $448, \mathrm{RuCl}_{2} \mathrm{PPh}_{3}(p$-cymene), 410 , and reused 410 (Scheme 3.5.10). Interestingly, ${ }^{13} \mathrm{C}$ and ${ }^{31} \mathrm{P}$ NMR spectra showed similar chemical shifts among $\mathrm{RuCl}_{2} \mathrm{PPh}_{3}(p$-cymene), 410, and the reused 410, providing a strong evidence that the coordination of ruthenium by phosphorus remained stable during the course of the hybrid-ruthenium catalysis.

a) ${ }^{13} \mathrm{C}$ spectra with $\mathrm{H}-\mathrm{C}$ cross polarization

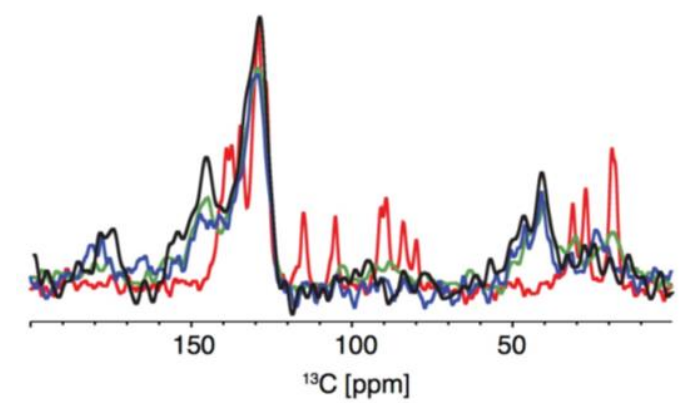

b) ${ }^{31} \mathrm{P}$ spectra

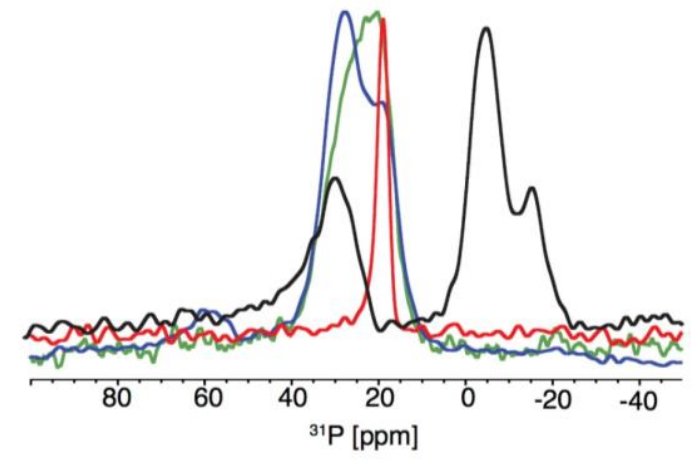

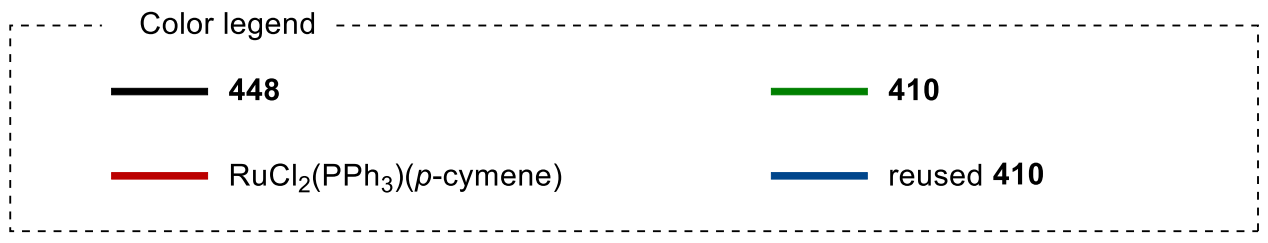

Scheme 3.5.10 Solid-state NMR analysis

Furthermore, with the assistance of the Alauzun group, the powder X-ray diffraction (PXRD) patterns of the 410 identified two very wide peaks around $10^{\circ}$ and $20^{\circ}$ showing the amorphous support, whereas the formation of crystalline ruthenium compounds, for example, ruthenium oxide, was not detected (Scheme 3.5.11). The PXRD patterns from the reused 410 confirmed crystalline KBr (JCPDS 730381) as an insoluble byproduct in 2-MeTHF, while the residue was proven to be innocuous to the reusability of the hybrid-ruthenium catalyst. 


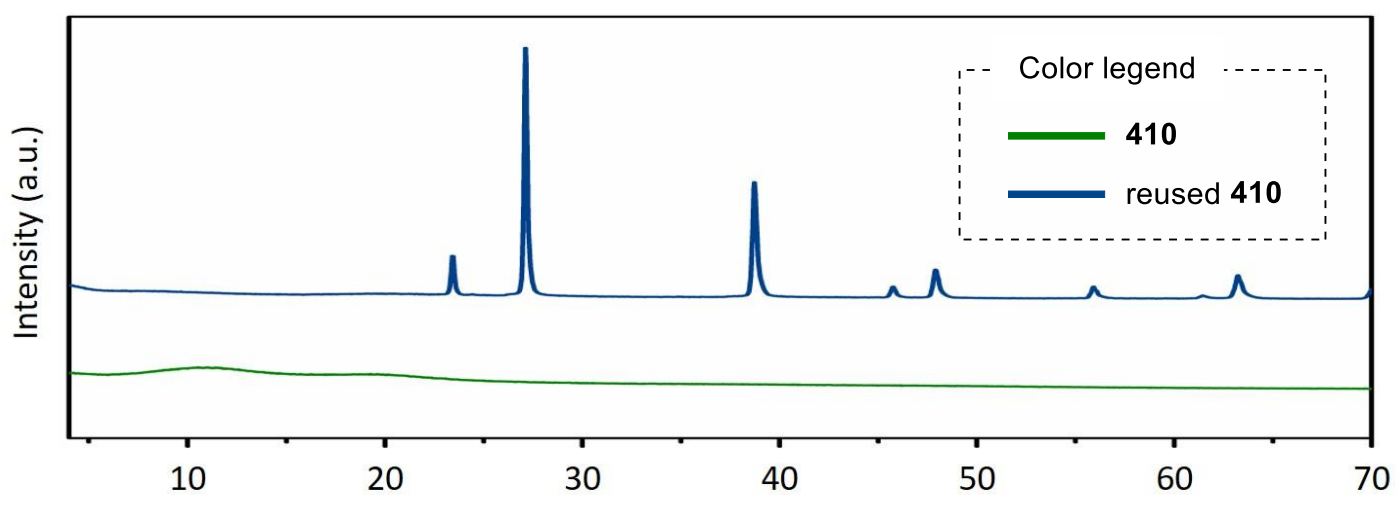

Scheme 3.5.11 Powder X-ray diffraction studies.

Dr. Alauzun and Dr. Wang also performed X-ray photoelectron spectroscopy to determine the oxidation state of ruthenium from 410 and the reused 410 (Scheme 3.5.12). In this analysis, the peak of $\mathrm{Ru} 3 \mathrm{~d} 5 / 2$ at $281.1 \mathrm{eV}$ from the surface of both catalysts was observed, which corresponds to ruthenium(II) species.

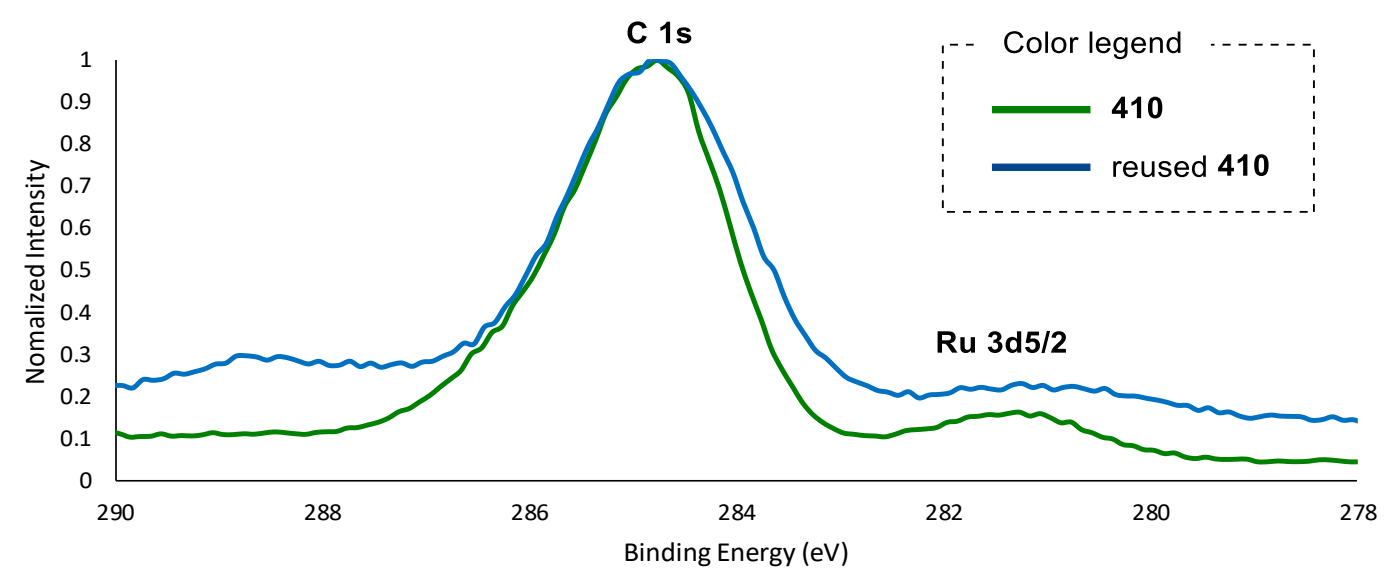

Scheme 3.5.12 X-ray photoelectron spectroscopic analysis.

Additionally, the Alauzun group performed detailed microscopic studies, including scanning electron microscopy (SEM), transmission electron microscopy (TEM), and transmission electron microscopy energy-dispersive X-ray spectroscopy (TEM-EDX) studies of the hybrid catalyst $\mathbf{4 1 0}$ and the reused catalyst 410 (Scheme 3.5.13). SEM analysis of the 410 revealed non-aggregated spheres up to $100 \mu \mathrm{m}$ in diameter with a relatively smooth surface. The reused 410 in SEM studies showed innocent $\mathrm{KBr}$ on 
the surface previously detected by PXRD. TEM analysis of the 410 and the reused 410 revealed that both hybrid catalysts have homogeneous non-porous amorphous morphology.

a) Scanning electron microscopy analysis

i) Hybrid ruthenium catalyst $\mathbf{4 1 0}$

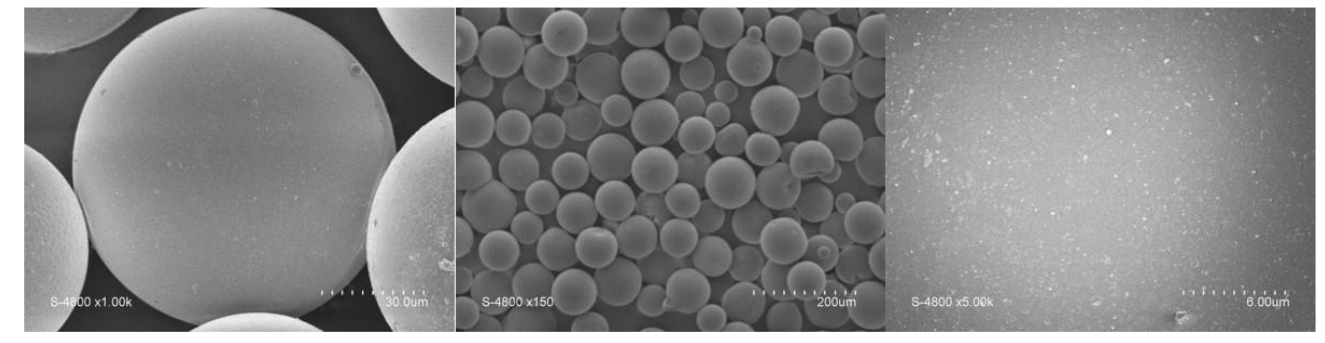

ii) Reused hybrid ruthenium catalyst $\mathbf{4 1 0}$

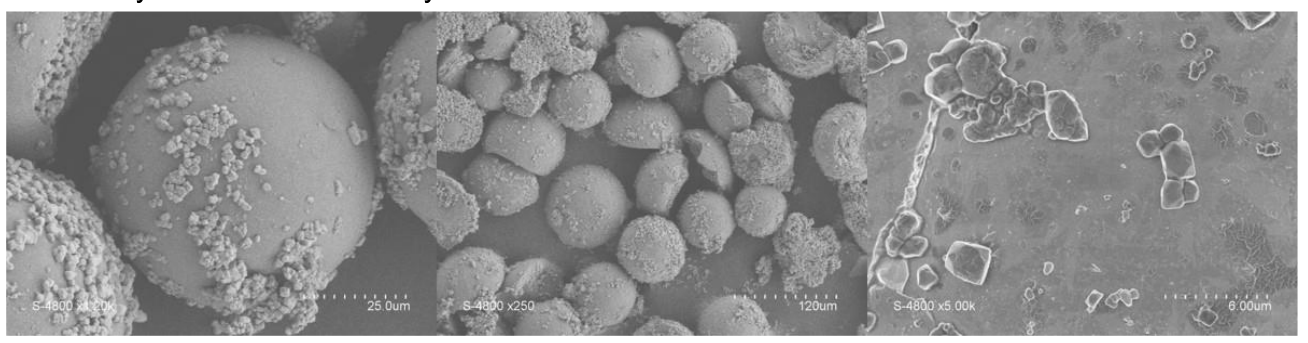

b) Transmission electron microscopy analysis

i) Hybrid ruthenium catalyst $\mathbf{4 1 0}$

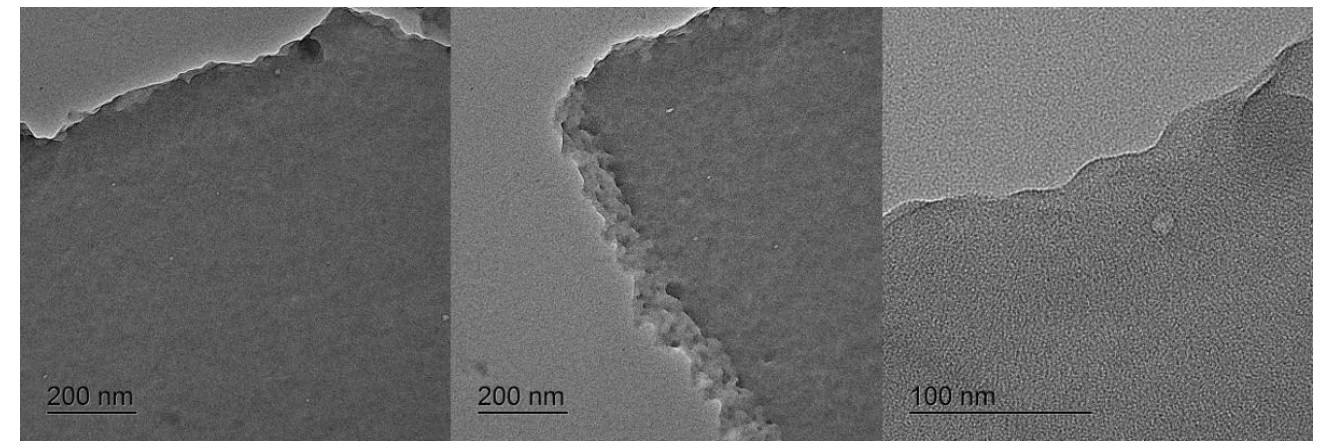

ii) Reused hybrid ruthenium catalyst $\mathbf{4 1 0}$

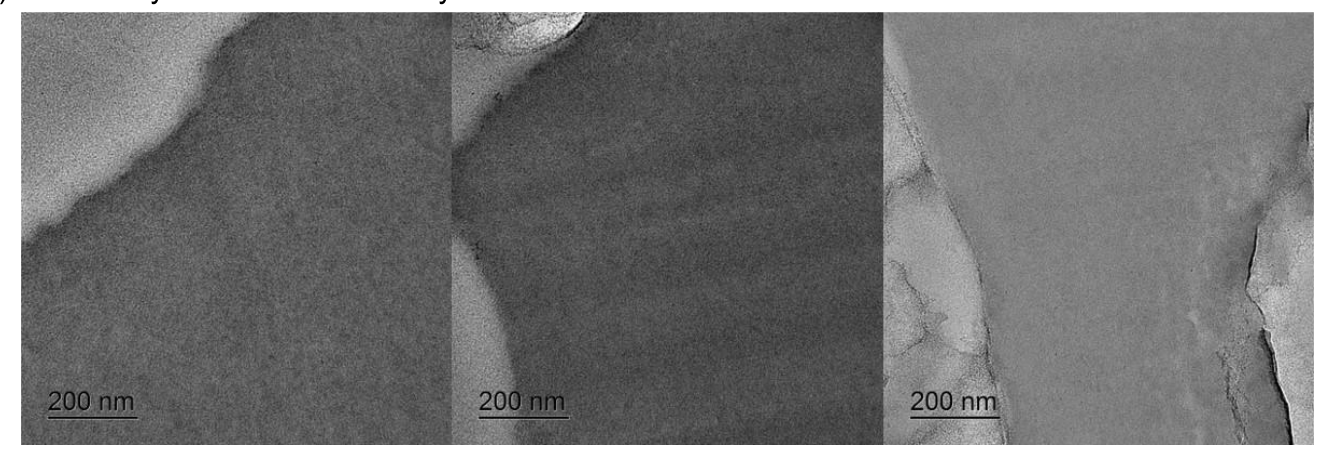

Scheme 3.5.12 X-ray photoelectron spectroscopic analysis. 


\subsubsection{Proposed Mechanism}

On the basis of our detailed experimental mechanistic studies along with the spectroscopic and microscopic characterization of the hybrid-ruthenium catalyst, a plausible catalytic cycle for the heterogeneous meta-C-H alkylation is proposed in Scheme 3.5.13. The mechanistic rationale commences by a carboxylate-assisted, BIES-C-H ruthenation. Subsequently, ruthenium(III) intermediate is generated via a single electron transfer from the ruthenium(II) complex 449 to the alkyl halide 408. The alkyl radical attacks the aromatic moiety at the para-position to ruthenium, giving intermediate 451. Thereafter, aromatization followed by protodemetallation delivers the desired metaalkylated product 409 and regenerates the catalytically active ruthenium hybrid catalyst 449 .

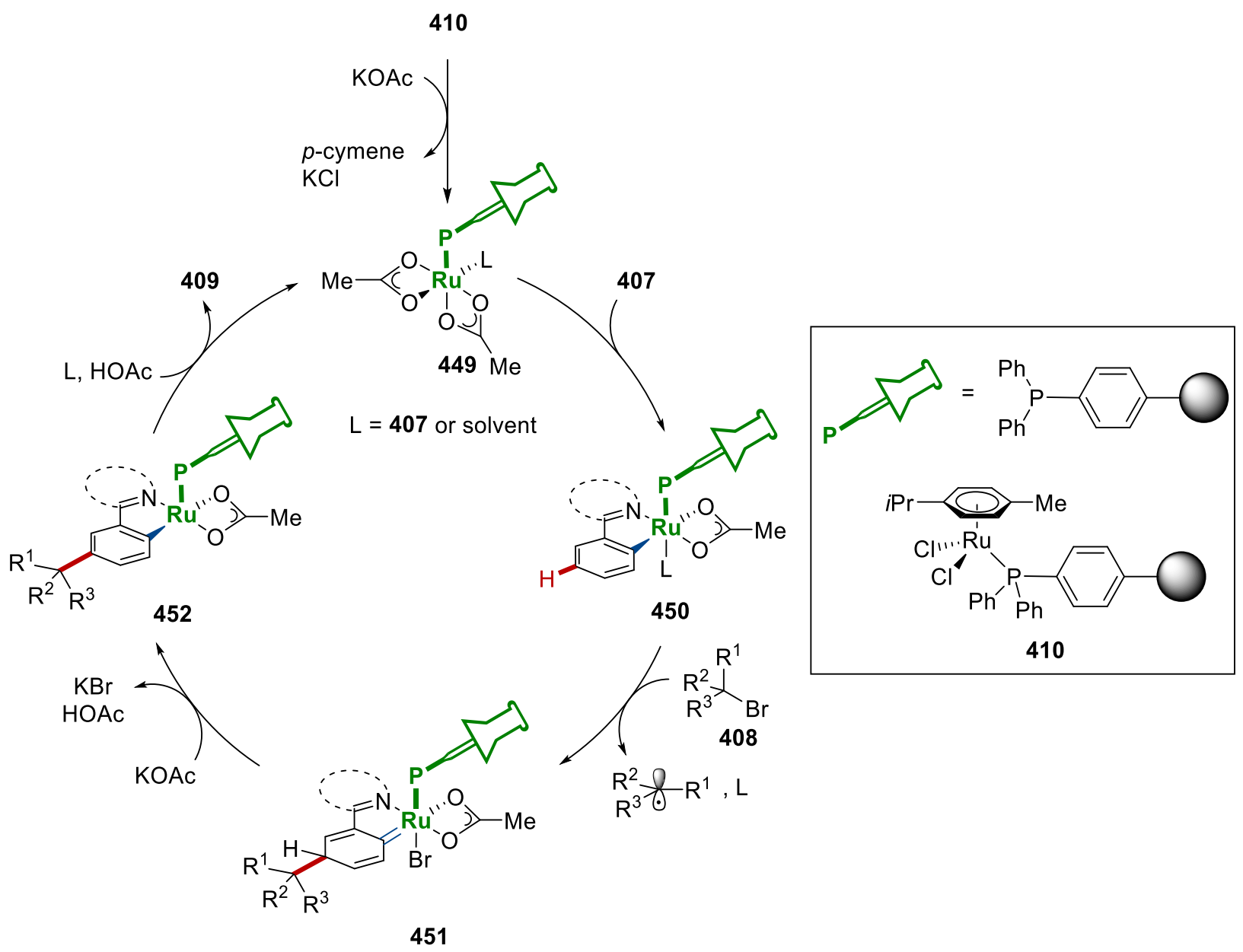

Scheme 3.5.13 Proposed mechanism of hybrid ruthenium-catalyzed meta-C-H alkylation. 


\subsection{C-H Arylations and Alkylations by Reusable Heterogeneous Manganese}

\section{Catalyst}

Azines are key structural motifs in a plethora of bio-relevant, pharmaceuticals, and drugs. ${ }^{[217,}{ }^{255]}$ Particularly, C3-H functionalized pyridine scaffolds broadly exhibit numerous biological activities (Scheme 3.6.1). ${ }^{[256]}$ Consequently, there is a continued strong demand for efficient $\mathrm{C}-\mathrm{H}$ functionalizations of pyridines in a sustainable manner. ${ }^{[257]}$

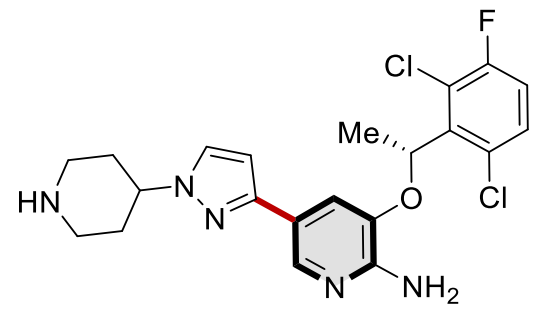

Crizotinib

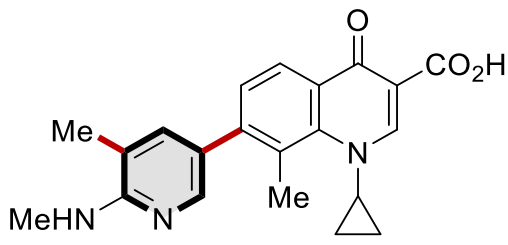

Ozenoxacin<smiles>Cc1c(OCC(F)(F)F)ccnc1CS(=O)c1nc2ccccc2[nH]1</smiles>

Lansoprazole

Scheme 3.6.1 Selected bio-active drugs containing $\mathrm{C} 3-\mathrm{H}$ functionalized pyridine motifs.

Earth-abundant $3 \mathrm{~d}$ metal catalysts provide prospect for less toxic metals in $\mathrm{C}-\mathrm{H}$ activations ${ }^{[216]}$ with notable advances in manganese-catalyzed $\mathrm{C}-\mathrm{H}$ activation ${ }^{[258,168 \mathrm{c}]}$ by Kuninobu/Takai, ${ }^{[259]}$ Wang, ${ }^{[260,}$ ${ }^{122]}$ and Ackermann, ${ }^{[261,128,132,147 b, 186 b]}$ among others. ${ }^{[140,262,127]}$ Despite the indisputable progress, manganese-catalyzed-C-H functionalizations continue to be largely limited to homogeneous catalysis. 


\subsubsection{Preparation of Hybrid Manganese Catalyst}

The hybrid manganese catalyst $\mathbf{4 1 6}$ was synthesized under a modified protocol from Christopher (Scheme 3.6.2) ${ }^{[249 \mathrm{a}]}$ To construct the linker, LDA deprotonated a C-H bond of a methyl group of 4,4'dimethyl-2,2'-dipyridyl (439), which underwent a substitution reaction with (3-chloropropyl)trimethoxysilane (440). The thus obtained linker 441 was grafted on SBA-15 in toluene under the reflux conditions, giving the tethered linker 442. Since the covalently anchored ligand 442 contains hydroxyl groups on the surface, the end-capping procedure was subsequently carried out with HMDS. Lastly, $\mathrm{MnCl}_{2}$ was used as a catalyst precursor for the metallation step, thus giving the hybrid manganese catalyst 416.<smiles>Cc1ccnc(-c2cc(C)ccn2)c1</smiles>

439<smiles>CCCC[Si](OC)(OC)OC</smiles>

440

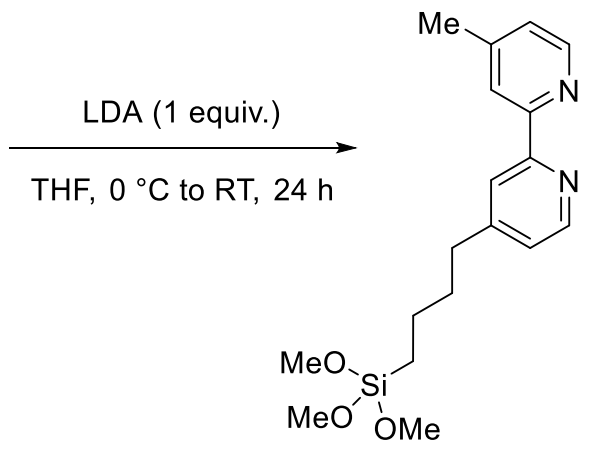

441

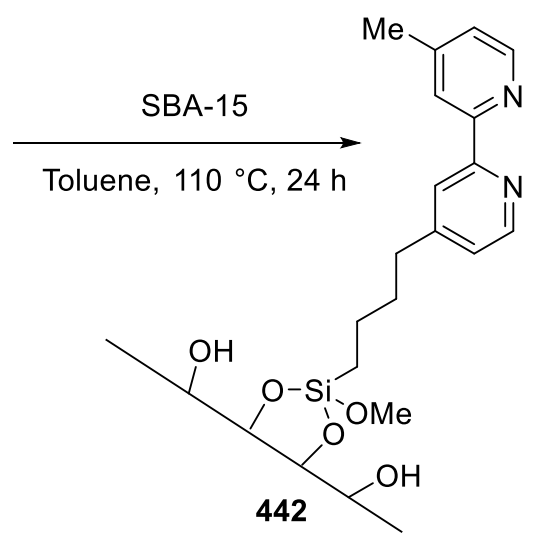

442

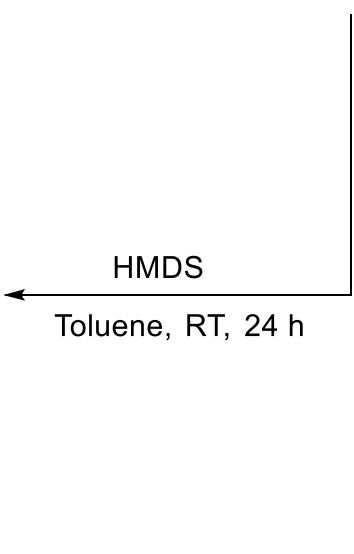

Scheme 3.6.2 Preparation of hybrid manganese catalyst. 


\subsubsection{Optimization Studies}

Next, we probed various reaction conditions for the envisioned $\mathrm{C}-\mathrm{H}$ arylation of pyridines $\mathbf{4 1 1}$ with the synthesized hybrid-manganese catalyst 416 (Table 3.6.1). We were pleased to observe that the desired arylated product $\mathbf{4 1 3}$ was obtained (entry 1). It is noteworthy that the hybrid catalyst could be successfully recycled and reused (entry 2). In contrast, the use of simple $\mathrm{MnCl}_{2}$ provided unsatisfactory results (entry 3). Control experiments verified the essential role of the hybrid-manganese catalyst, the ligand, and the DCB oxidant for $\mathrm{C}-\mathrm{H}$ arylations (entries 4-7).

Table 3.6.1 Establishing C-H arylation by hybrid-manganese catalyst.<smiles>CCCCNC(=O)c1ccccn1</smiles>

411
$+\mathrm{ArMgBr}$

412

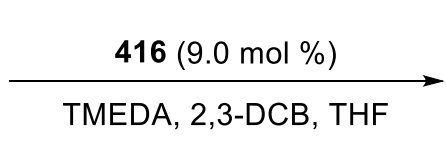
$70{ }^{\circ} \mathrm{C}, 16 \mathrm{~h}, \mathrm{~N}_{2}$ $\mathrm{Ar}=4-\mathrm{MeOC}_{6} \mathrm{H}_{4}$<smiles>CCCCNC(=O)c1ncccc1Br</smiles>

413
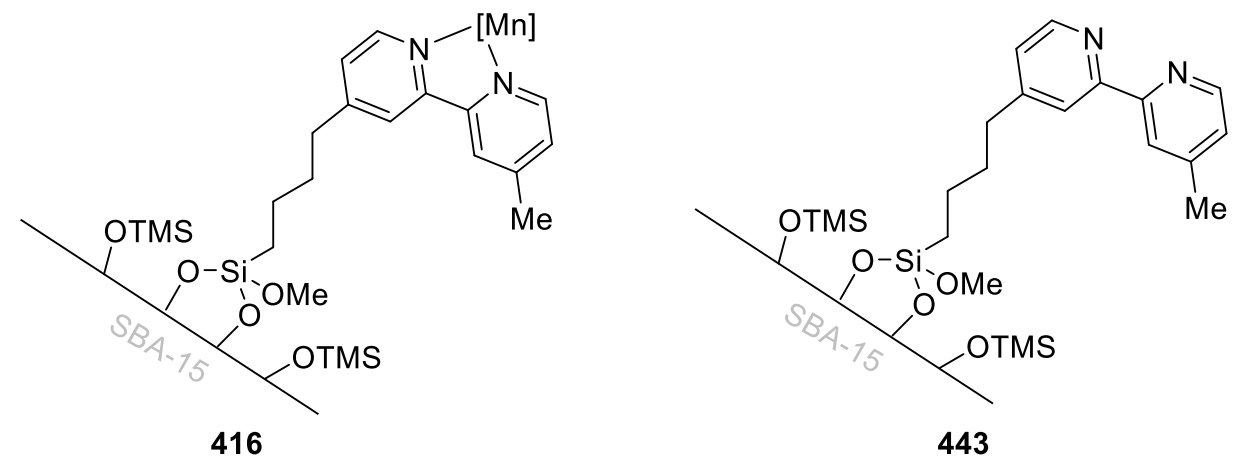

\begin{tabular}{ccc}
\hline Entry & Deviation from standard condition & Yield (\%) \\
\hline 1 & Standard conditions & 80 \\
2 & Second run with the reused 416 & 75 \\
3 & $\mathrm{MnCl}_{2}$ as catalyst & 17 \\
4 & Immobilized ligand $\mathbf{4 4 3}$ instead of 416 & NR \\
5 & Without $\mathbf{4 1 6}$ & $\mathrm{NR}$ \\
6 & Without TMEDA & 43
\end{tabular}


[a] Reaction conditions: 411 (0.25 mmol), 412 (1.00 mmol, $1.0 \mathrm{M}$ in THF), 416 (9.0 mol \%), TMEDA (0.50 mmol), 2,3-DCB $(0.75 \mathrm{mmol}), 70{ }^{\circ} \mathrm{C}, 16 \mathrm{~h}$, under $\mathrm{N}_{2}$ atmosphere, isolated yields. TMEDA $=$ Tetramethylethylenediamine. $2,3-\mathrm{DCB}=2,3$-Dichlorobutane. $\mathrm{NR}=$ No Reaction.

Thereafter, we probed the effect exerted by changing the substitution pattern on the azines 411 (Scheme 3.6.3). Differently decorated heteroarenes, such as structural isomeric azines (411a, 411b, and 411c) or diazines (411d and 411e), were thus subjected to the optimized reaction conditions for the $\mathrm{C}-\mathrm{H}$ arylation. While the picolinic amide 411a gave an effective transformation, other heteroarenes afforded lower conversion.

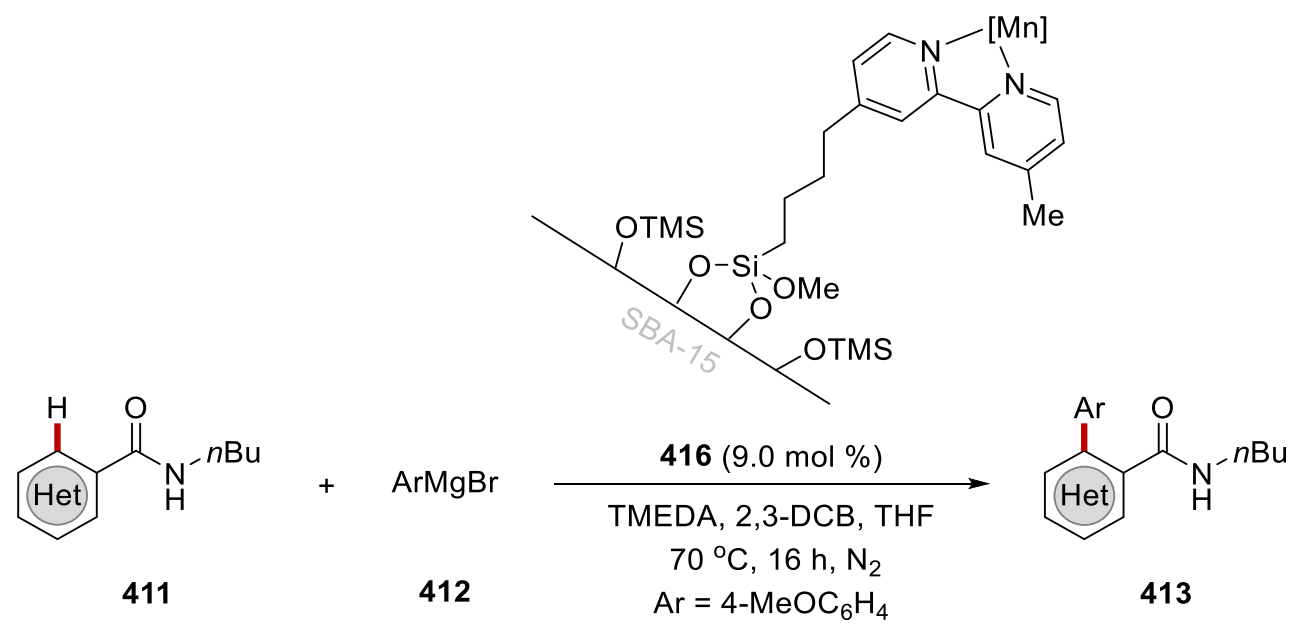

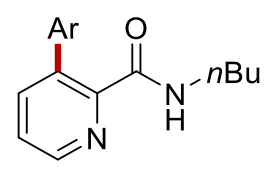

413a: $80 \%$<smiles>CCCCCCCCNC(=O)c1cnccc1Br</smiles>

413b: $34 \%$<smiles>CCCCNC(=O)c1ccncc1Br</smiles>

413c: $30 \%$<smiles>CCCCNC(=O)c1nccnc1Br</smiles>

413d: $21 \%$<smiles>CCCCNC(=O)c1ncncc1Br</smiles>

413e: $0 \%$

Scheme 3.6.3 Examination of heteroarenes effect. 


\subsubsection{Substrate Scope}

With the optimized reaction conditions in hand, we set out to explore the catalytic performance in the C3-H arylations of azines 411 (Scheme 3.6.4). Various pyridines 411 were efficiently converted to the desired C3-arylated product $\mathbf{4 1 3}$ by weak amide-chelation assistance, while alkyl, benzyl, and aryl substituted amides were fully tolerated.

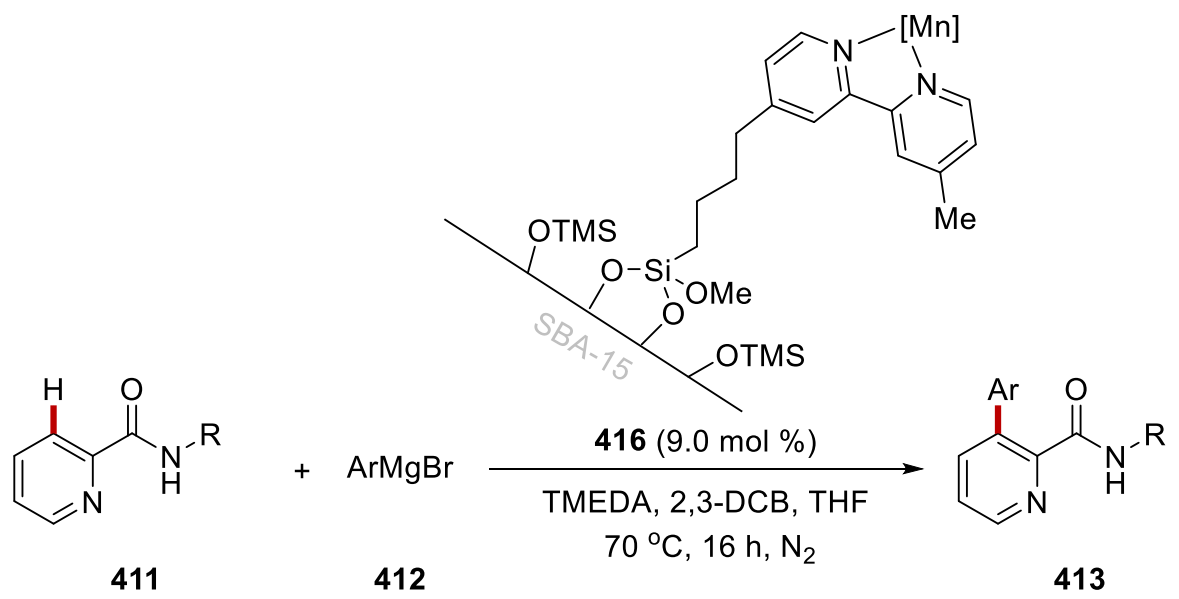<smiles>CCCCCCCCCNC(=O)c1ncccc1-c1ccc(OC)cc1</smiles>

413a: $80 \%$<smiles>COc1ccc(-c2cccnc2C(=O)NC2CCCc3ccccc32)cc1</smiles>

413i: $78 \%$<smiles>CCCCNC(=O)c1ncc(-c2ccccc2)cc1-c1ccc(OC)cc1</smiles>

413f: $51 \%$<smiles>COc1ccc(-c2cccnc2C(=O)NCc2ccccc2)cc1</smiles>

413j: $76 \%$<smiles>COc1ccc(-c2cccnc2C(=O)NCc2ccccc2)cc1</smiles>

413g: $85 \%$<smiles>COc1ccc(CNC(=O)c2ncccc2-c2ccc(OC)cc2)cc1</smiles>

413k: $75 \%$<smiles>COc1ccc(-c2cccnc2C(=O)NC2CCCCC2)cc1</smiles>

413h: $72 \%$<smiles>COc1ccc(-c2cccnc2C(=O)N[Ge]2CCCCC2)cc1</smiles>

413I: $64 \%$<smiles>COc1ccc(NC(=O)c2ncccc2-c2ccc(OC)cc2)cc1</smiles>

413m: $59 \%$<smiles>CCCCNC(=O)c1ncccc1-c1ccc(C(C)(C)C)cc1</smiles>

413n: $84 \%$<smiles>CCCCNC(=O)c1ncccc1-c1ccc(Oc2ccccc2)cc1</smiles>

413o: $95 \%$

Scheme 3.6.4 Substrate scope of hybrid manganese-catalyzed $\mathrm{C}-\mathrm{H}$ arylation. 
Additionally, the versatility of the hybrid-manganese catalysis was highlighted by $\mathrm{C}-\mathrm{H}$ alkylations, providing a broadly applicable strategy (Scheme 3.6.5). Therefore, the robust hybrid-manganesecatalyzed $\mathrm{C}-\mathrm{H}$ functionalization enabled direct primary alkylations. It is noteworthy that the hybridmanganese catalysis also enabled the installation of the methyl group ${ }^{[263]}$ onto azines 411. Furthermore, challenging secondary alkylations proved viable, including cyclopropylation $\mathbf{4 1 5 g}$ and cyclobutylation 415h, while isomerizations were not observed.

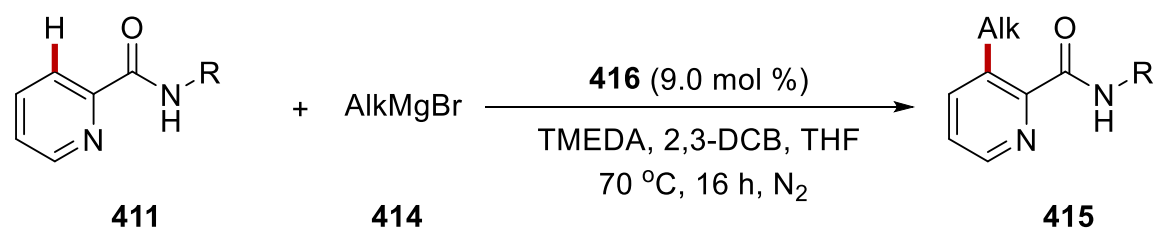

- Primary C-H alkylations -

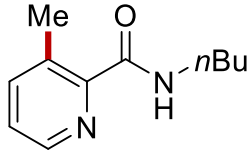

415a: $79 \%$<smiles>CCCCNC(=O)c1ncccc1CC</smiles>

415b: $68 \%$

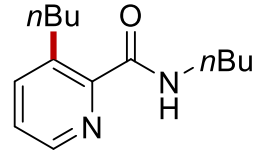

415c: $89 \%$<smiles>CCCCNC(=O)c1ncccc1OCCC</smiles>

415d: $74 \%$

- Secondary C-H alkylations -<smiles>CCCCNC(=O)c1ncccc1C(C)C</smiles>

415e: $65 \%$<smiles>CCCCCCCCCNC(=O)c1ncccc1C1CCCC1</smiles>

415i: $64 \%$<smiles>O=C(NC1CCCc2ccccc21)c1ncccc1Cl</smiles>

415m: $82 \%$<smiles>CCCCNC(=O)c1ncccc1C(CCCC)CCCC</smiles>

415f: $56 \%$<smiles>CCCCNC(=O)c1ncccc1Cl</smiles>

415j: $82 \%$<smiles>O=C(NCc1ccccc1)c1ncccc1Cl</smiles>

415n: $41 \%$<smiles>O=C(NCc1ccccc1F)c1ncccc1Cl</smiles>

415q: $67 \%$

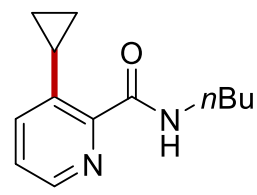

415g: $70 \%$<smiles>CCCCNC(=O)c1ncccc1C1CCCCCC1</smiles>

415k: $54 \%$<smiles>CCCCNC(=O)c1ncccc1C1CCC1</smiles>

415h: $84 \%$<smiles>O=C(NC1CCCCC1)c1ncccc1Cl</smiles>

415I: $69 \%$<smiles>COc1ccc(CNC(=O)c2ncccc2C2CCCCC2)cc1</smiles>

415o: $52 \%$

415p: $42 \%$

Scheme 3.6.5 Substrate scope of hybrid manganese-catalyzed C-H alkylation. 


\subsubsection{Heterogeneity Studies}

A reuse test for $\mathrm{C}-\mathrm{H}$ arylation was performed and we observed that the hybrid-manganese catalyst was recyclable and could be reused up to at least three times (Scheme 3.6.6). Within a collaboration with Dr. Volker Karius, less than 1 ppm of manganese was detected by ICP-OES studies of the reaction mixture, reflecting negligible leaching of the transition metal during the course of catalysis.

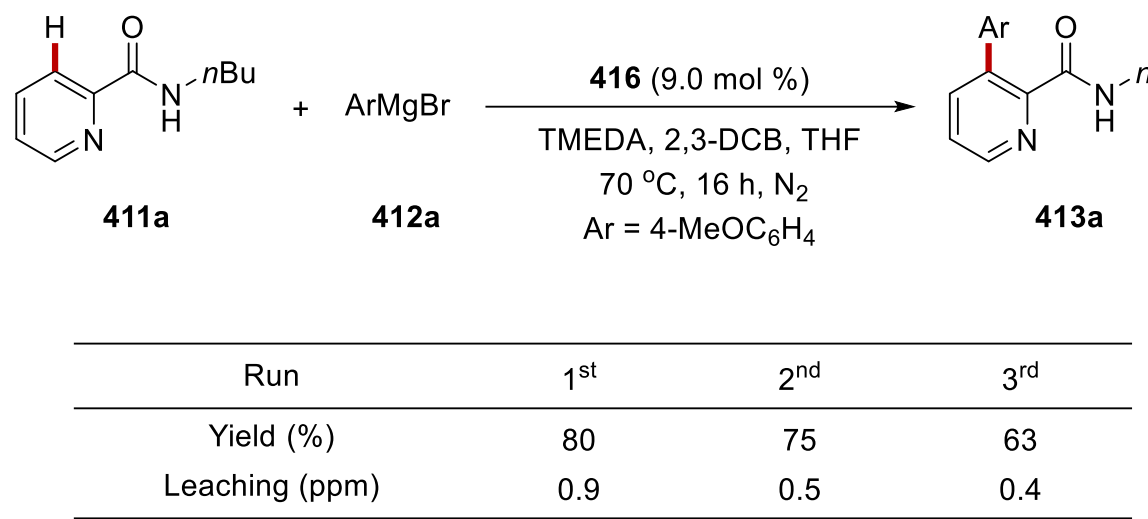

Scheme 3.6.6 Reuse test of hybrid manganese-catalyzed $\mathrm{C}-\mathrm{H}$ arylation and the determination of manganese leaching.

The reusable nature of the hybrid manganese catalyst $\mathbf{4 1 6}$ was not only found for the $\mathrm{C}-\mathrm{H}$ arylation reactions. Indeed, the hybrid manganese catalyst $\mathbf{4 1 6}$ was recyclable in a $\mathrm{C}-\mathrm{H}$ alkylation reaction at least up to three time, although a decrease in the yield was observed.

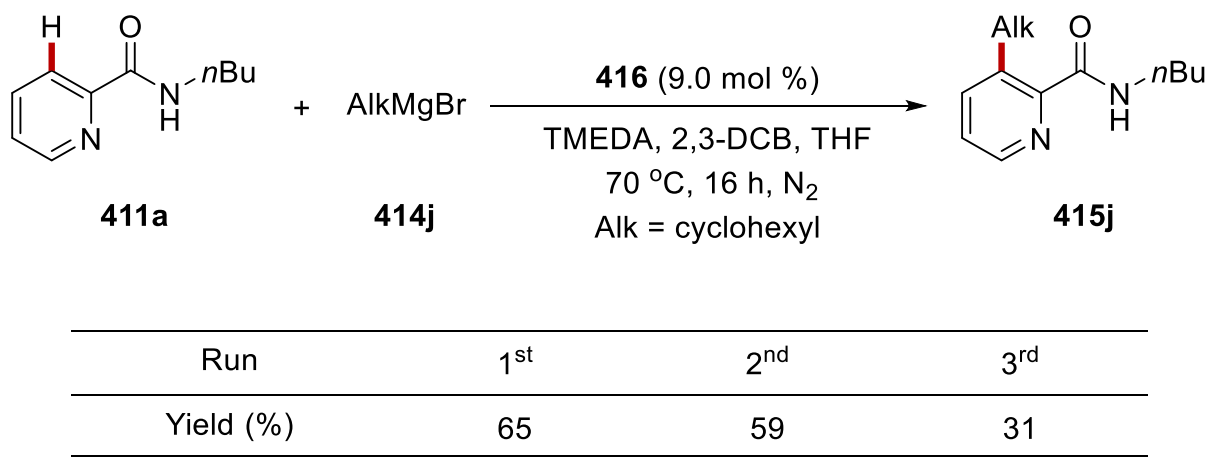

Scheme 3.6.6 Reuse test of hybrid manganese-catalyzed $\mathrm{C}-\mathrm{H}$ arylation and the determination of manganese leaching. 
The addition of mercury and a hot-filtration test were subsequently probed, showing that the hybridmanganese-catalyzed $\mathrm{C}-\mathrm{H}$ arylation was operating by heterogeneous catalysis (Scheme 3.6.7).

a) Mercury test

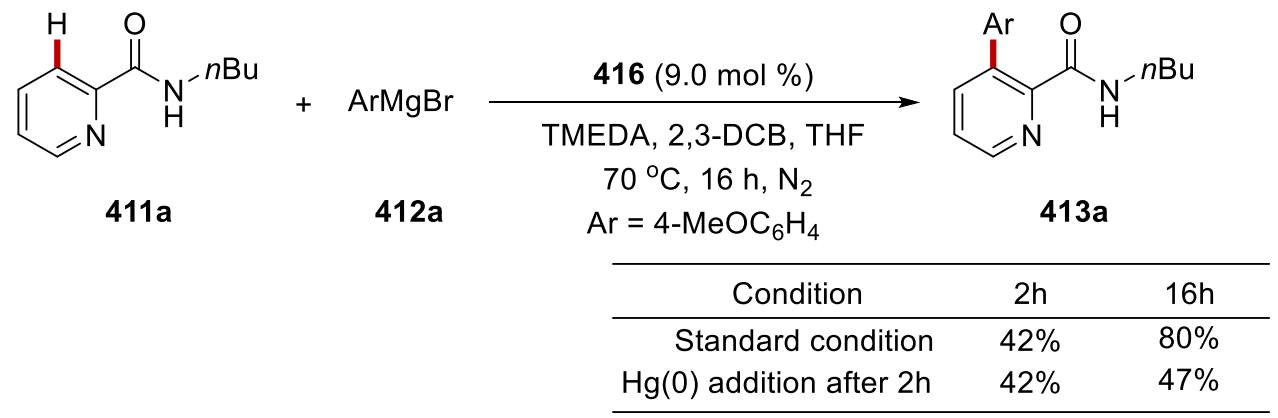

b) Hot-filtration test

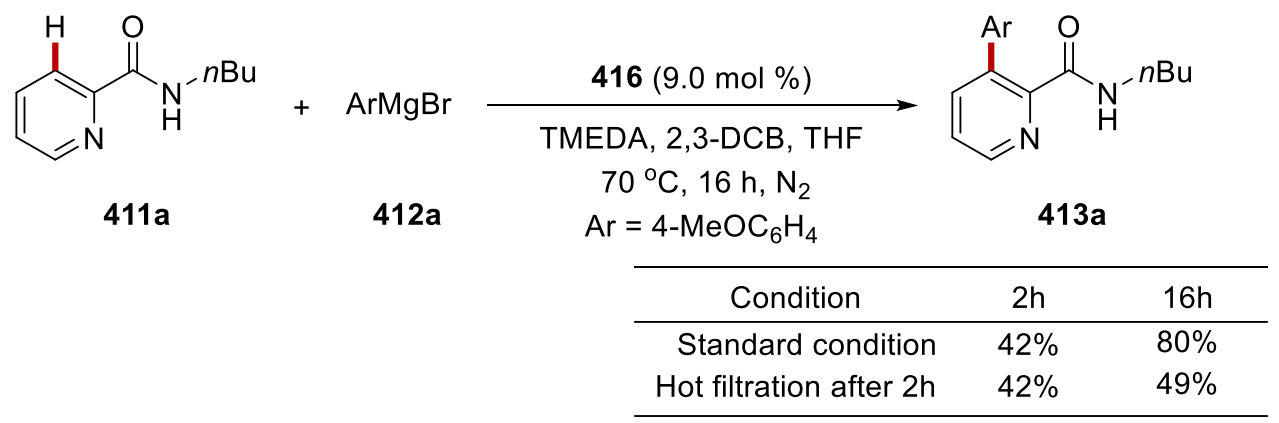

Scheme 3.6.7 Various heterogeneity tests. 


\subsubsection{Characterizations of Heterogeneous Catalyst}

Thereafter, the pristine ligand-support 443, the hybrid-manganese catalyst 416, and reused 416 were characterized in detail by TEM techniques to determine the morphological properties (Scheme 3.6.8). Thereby, we observed highly ordered one-dimensional mesoporous channels without morphological agglomeration or disorder during the process of end-capping or the binding of the manganese.

a) TEM analysis of $\mathbf{4 4 3}$
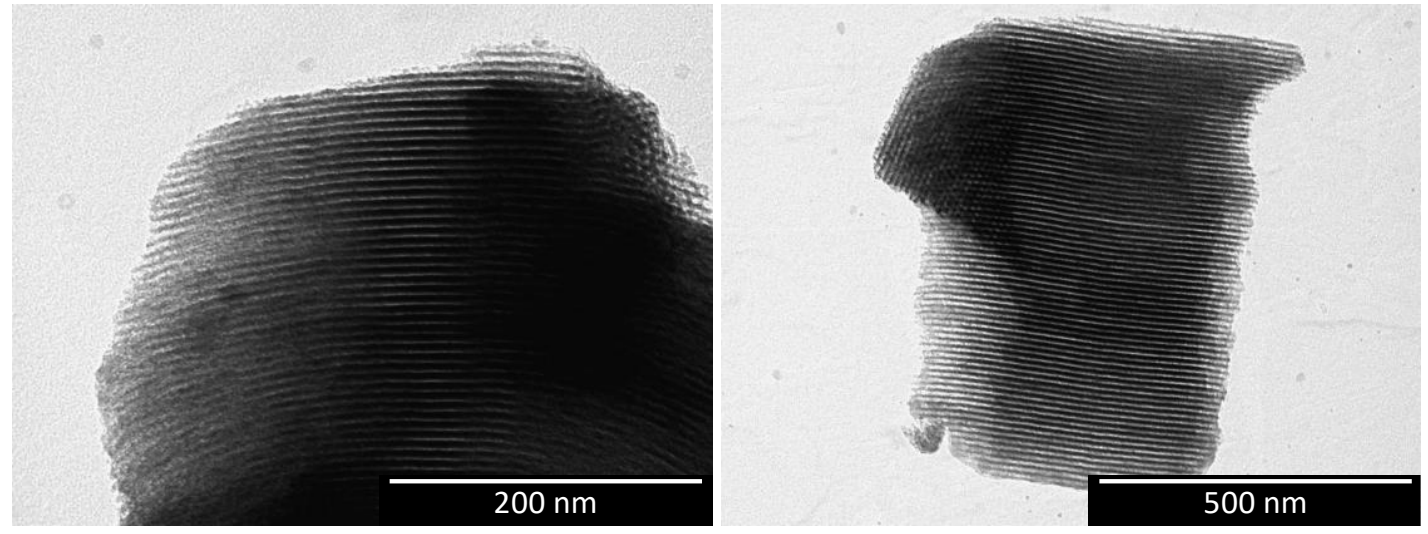

b) TEM analysis of $\mathbf{4 1 6}$
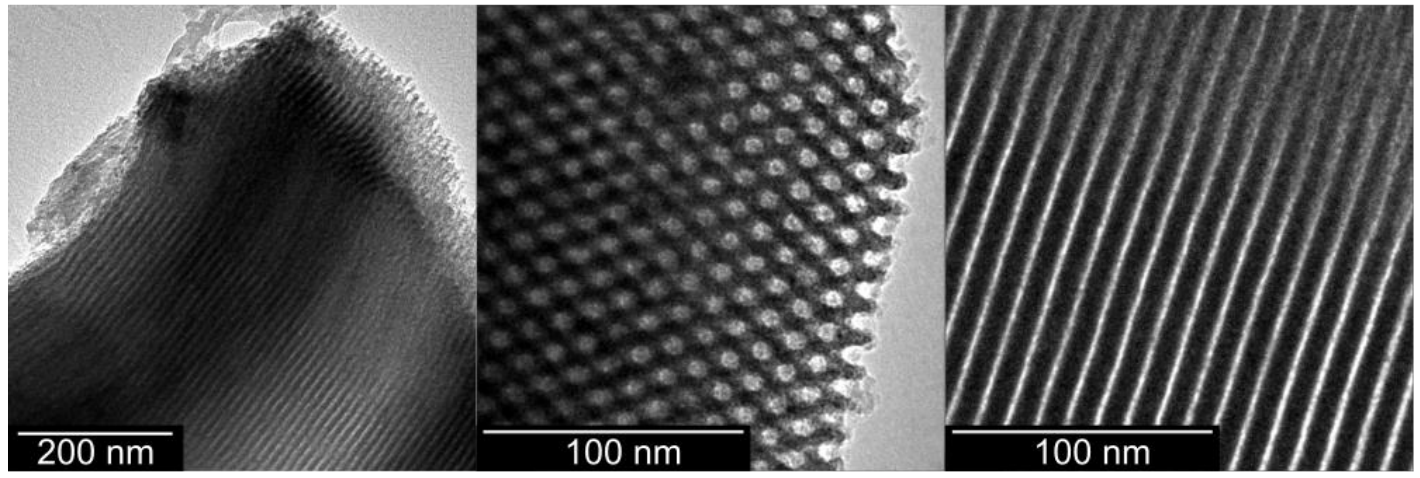

c) TEM analysis of reused $\mathbf{4 1 6}$

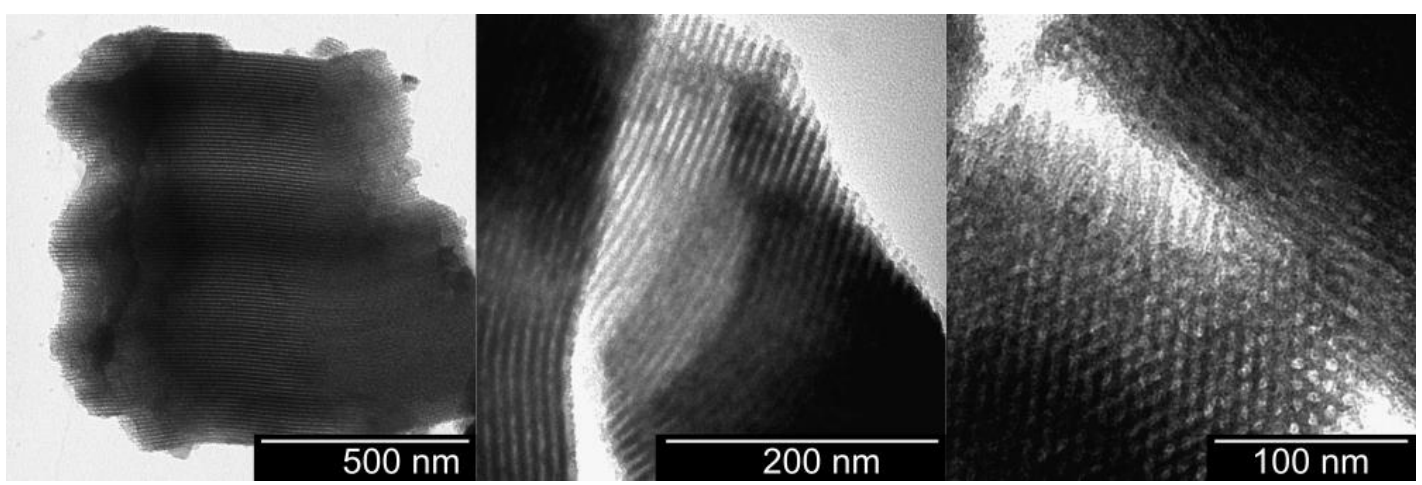

Scheme 3.6.8 Microscopic analysis of hybrid manganese catalysts. 


\section{Summary and Outlook}

Classical $\mathrm{C}-\mathrm{C}$ or $\mathrm{C}-\mathrm{Het}$ bond formation reactions have been considered to be user-friendly methods, while pre-functionalizations are generally accompanied for desired reactivities and selectivities. In stark contrast, metal-catalyzed $\mathrm{C}-\mathrm{H}$ activation enabled direct $\mathrm{C}-\mathrm{C}$ or $\mathrm{C}-\mathrm{Het}$ bond formation in an atom- and step-economical fashion. In addition to this emerging synthesis tool, photochemistry and electrochemistry have recently added a great value to the $\mathrm{C}-\mathrm{H}$ activation manifold. Furthermore, hybrid catalysis allows for recyclability and reusability of the catalyst, resulting in the accomplishment of environmentally-sound syntheses.

In the first project, ruthenium(II)carboxylate-catalyzed $\mathrm{C} 7-\mathrm{H}$ indole functionalization was achieved via challenging six-membered ruthenacycles (Scheme 4.1.1). Notable features of this development were a wide substrate scope, including $\mathrm{C}-\mathrm{C}$ and $\mathrm{C}-\mathrm{N}$ bond formation at $\mathrm{C} 7$ position of indoles with a tolerance of various functional groups under mild conditions. The detailed kinetic study by spectroscopic and spectrometric analyses highlighted the importance of ruthenium nitrenoid intermediate for the unique $\mathrm{C} 7-\mathrm{H}$ amidation. Additionally, the traceless removal of the pivaloyl group, utilization of flow technique, and gram-scale reaction clearly showed the robustness and versatility of the ruthenium-catalyzed $\mathrm{C} 7-\mathrm{H}$ activations.
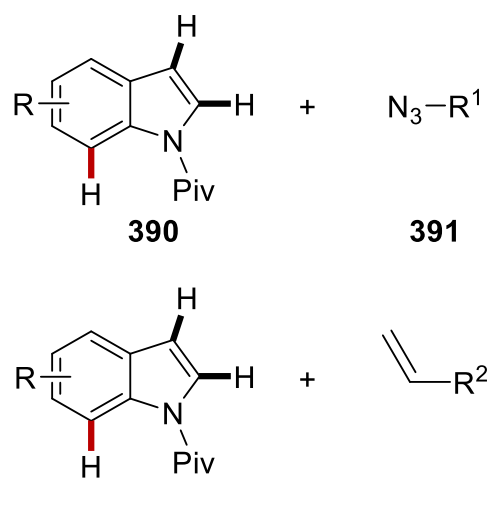

390
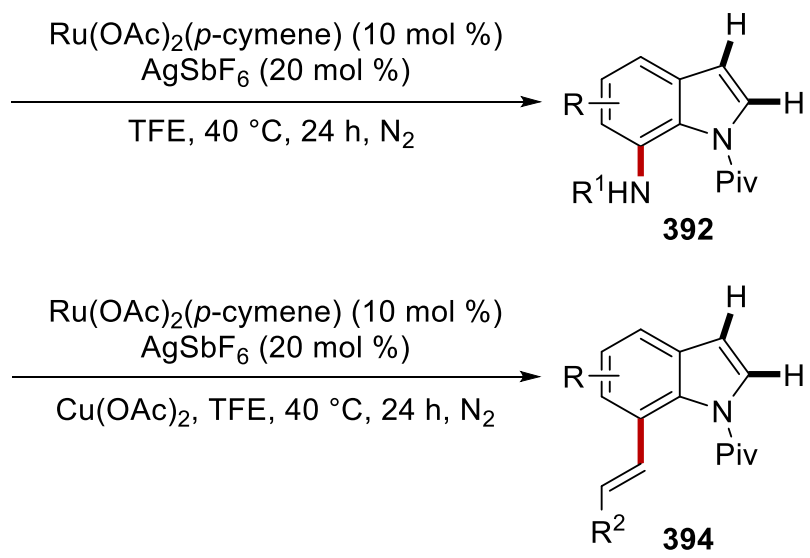

Scheme 4.1.1 Ruthenium(II)-catalyzed C7-H indole amidation and alkenylation. 
In the second project, arene-ligand-free ruthenium(II)-catalyzed remote $\mathrm{C} 4 / \mathrm{C} 6-\mathrm{H}$ functionalization of indoles benzenoid was developed (Scheme 4.1.2). The unique ruthenium catalysis enabled double $\mathrm{C}-$ $\mathrm{C}$ bond formation with excellent levels of site-selectivity. The versatility and robustness of the ruthenium catalysis were demonstrated by ample substrate scope and a gram-scale reaction. Additionally, the mechanistic investigation highlighted the key importance of C2-ruthenation, affording unique $\mathrm{C} 4 / \mathrm{C} 6-\mathrm{H}$ double indole alkylations.<smiles>C[C+](C)c1cccc(-n2ccc3ccccc32)n1</smiles>

395<smiles>[R]OC(C)(C)Br</smiles>

396

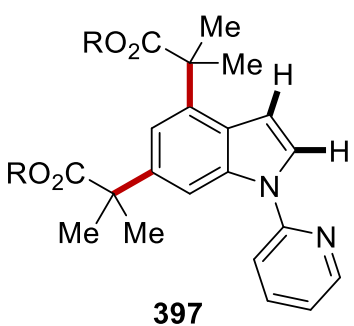

397

Scheme 4.1.2 Ruthenium(II)-catalyzed C4-H/C6-H dual indole alkylations.

In the third project, electrochemical osmium(II)-catalyzed $\mathrm{C}-\mathrm{H}$ annulations were accomplished (Scheme 4.1.3). Weak $O$-coordination enabled to provide ample substrate scope for [4+1] and [4+2] annulations under osmaelectrooxidative $\mathrm{C}-\mathrm{H}$ activation. Notably, detailed reaction comparison with other transition metal catalytic systems highlighted advantageous characteristics of the osmium catalysis. Also, spectrometric, spectroscopic, and kinetic studies revealed the electrocatalytic mode of action.

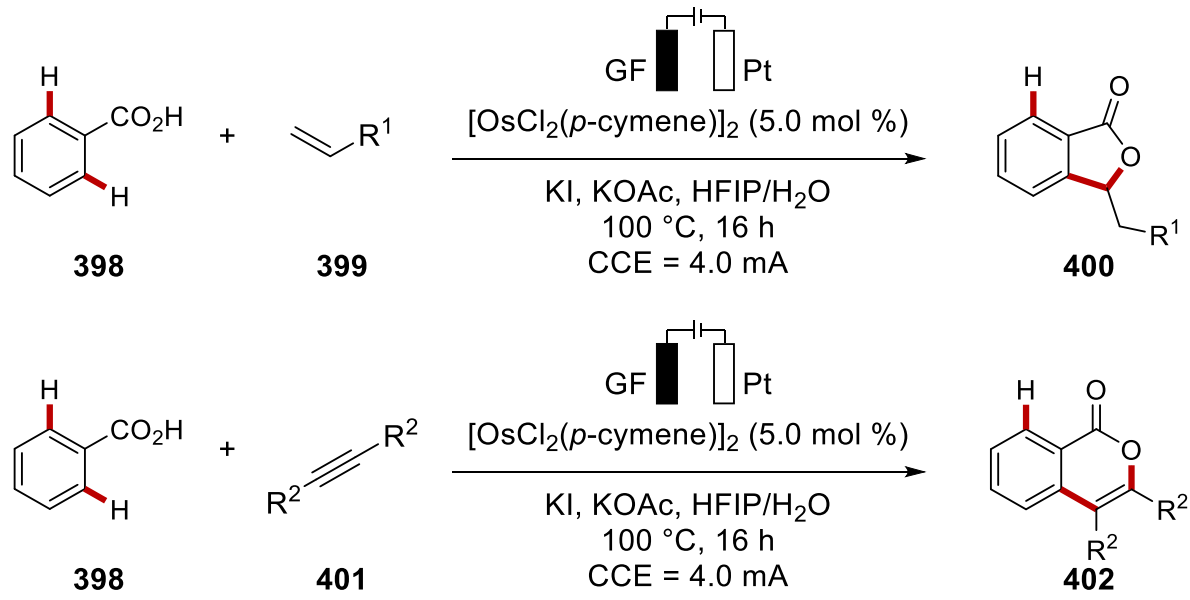

Scheme 4.1.3 Electrooxidative osmium-catalyzed C-H annulation. 
In the fourth project, a photo-induced $\mathrm{C}-\mathrm{H}$ arylation by hybrid copper catalysis was achieved under exceedingly mild reaction conditions at room temperature (Scheme 4.1.4). The hybrid copper catalyst enabled site-selective $\mathrm{C}-\mathrm{H}$ arylations with ample scope, including a wide range of functional group tolerance. Also, the hybrid copper catalyst was reusable without significant loss of catalytic efficacy, the heterogeneity of which was experimentally proved. Detailed microscopic and spectroscopic analyses showed the physical and chemical stability of the hybrid copper catalyst for photoinduced $\mathrm{C}-\mathrm{H}$ arylation.

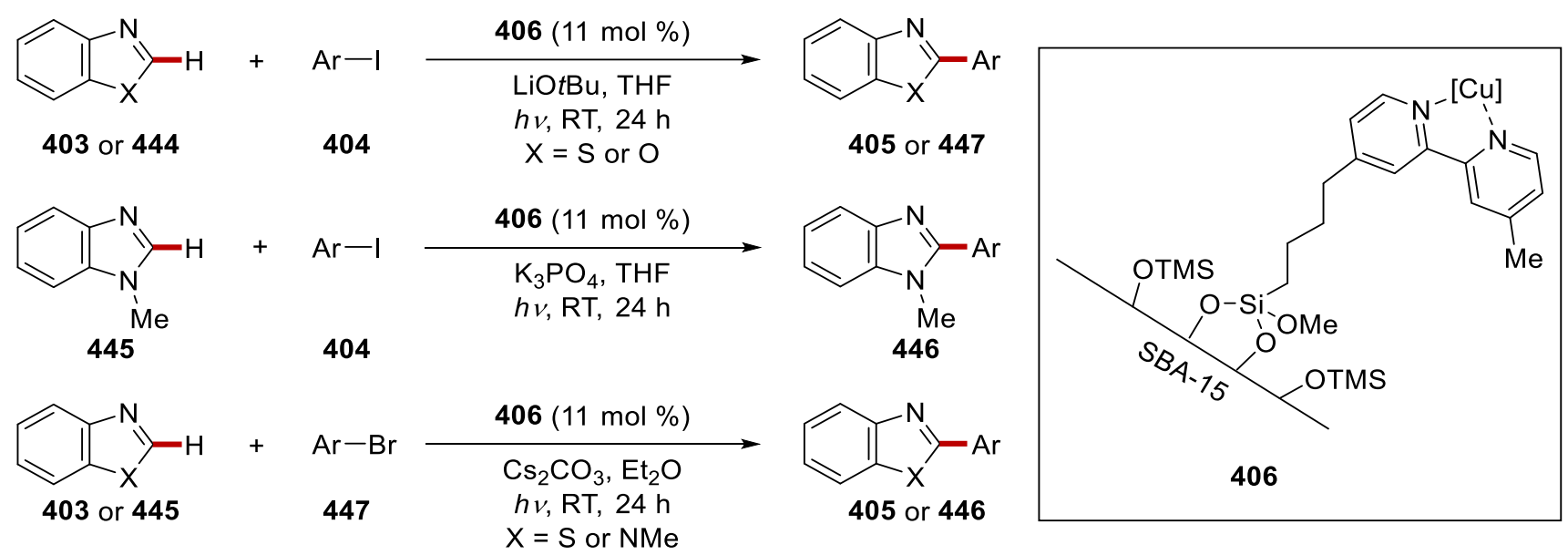

Scheme 4.1.4 Photo-induced copper-catalyzed heterogeneous $\mathrm{C}-\mathrm{H}$ arylation.

In the fifth project, a recyclable ruthenium hybrid catalyst was developed for remote $\mathrm{C}-\mathrm{H}$ functionalizations (Scheme 4.1.5). The hybrid ruthenium catalyst featured remarkable robustness towards meta-C-H alkylations, while the catalyst was highly recyclable. Microscopic and spectroscopic analyses together with mechanistic studies delineated the excellent physical and chemical properties of the hybrid ruthenium catalyst for position-selective $\mathrm{C}-\mathrm{H}$ functionalization.<smiles>c1ccc(-c2ccccn2)cc1</smiles>

407
${ }_{\mathrm{R}^{1}}^{\mathrm{Br}} \mathrm{R}^{2} \mathrm{R}^{3}$

408

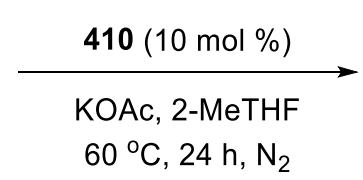

$60^{\circ} \mathrm{C}, 24 \mathrm{~h}, \mathrm{~N}_{2}$

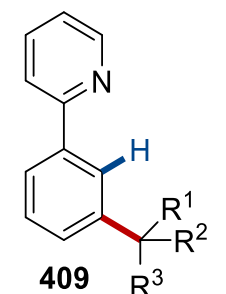

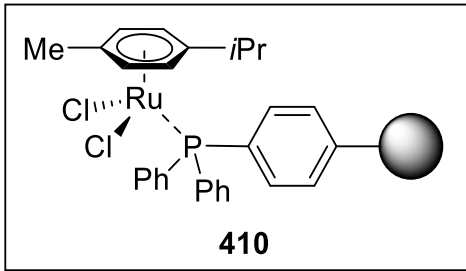

Scheme 4.1.5 Hybrid ruthenium(II)-catalyzed meta-C-H alkylation. 
In the last project, a recyclable hybrid manganese catalyst was described for $\mathrm{C}-\mathrm{H}$ arylation and alkylation of azines (Scheme 4.1.6). The hybrid manganese catalyst showed a remarkable catalytic performance towards site-selective $\mathrm{C} 3-\mathrm{H}$ arylations and $\mathrm{C} 3-\mathrm{H}$ alkylations of azines by weak amidechelation assistance in a reusable fashion. Detailed heterogeneity investigations and characterizations of the hybrid-manganese catalyst reflected its stability during the course of azine $\mathrm{C}-\mathrm{H}$ activation.<smiles>[R]NC(=O)c1ccccn1</smiles>

411<smiles>[Mg][Mg]Br</smiles>

412

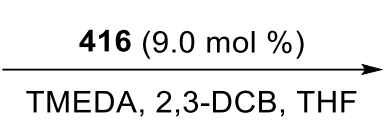
$70^{\circ} \mathrm{C}, 16 \mathrm{~h}, \mathrm{~N}_{2}$<smiles>[R]NC(=O)c1ncccc1Br</smiles>

413<smiles>[R]NC(=O)c1ccccn1</smiles>

411<smiles>CC(C)[Mg][Mg]</smiles>
$70^{\circ} \mathrm{C}, 16 \mathrm{~h}, \mathrm{~N}_{2}$<smiles>[R]NC(=O)c1ncccc1[AlH2]</smiles>

415

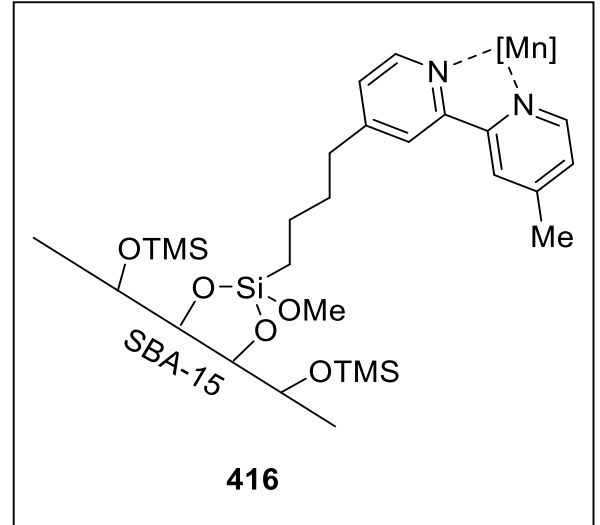

Scheme 4.1.6 Hybrid manganese-catalyzed $\mathrm{C}-\mathrm{H}$ arylation and alkylation. 


\section{Experimental Data}

\subsection{General Remarks}

Reactions involving air- or moisture-sensitive compounds were conducted under an atmosphere of nitrogen using pre-dried glassware and standard Schlenk or glovebox techniques. If not otherwise noted, yields refer to isolated compounds, estimated to be $>95 \%$ pure by GC and NMR.

\section{Vacuum}

The following average pressure was measured on the used rotary vane pump RD4 from Vacuubrand ${ }^{\circledR}$ : $0.8 \times 10^{-1}$ mbar (uncorrected value).

\section{Melting points}

Melting points were measured on a Stuart ${ }^{\circledR}$ Melting Point Apparatus SMP3 from Barloworld Scientific. All values are uncorrected.

\section{Liquid Chromatography}

Analytical thin layer chromatography (TLC) was performed on TLC Silica gel 60 F254 from Merck with detection at $254 \mathrm{~nm}$ or $360 \mathrm{~nm}$ or developed by treatment with a $\mathrm{KMnO}_{4}$ solution followed by careful warming. Preparative chromatographic separations were carried out on Merck Geduran ${ }^{\circledR}$ SI 60 (40-63 $\mu \mathrm{m}, 70-230$ mesh ASTM) silica gel.

\section{Gas Chromatography}

Gas chromatographic analysis (GC) was performed on an Agilent 7890A or 7890B GC System equipped with an Agilent HP-5 column ( $30 \mathrm{~m}, 0.320 \mathrm{~mm}$ diameter, $0.25 \mu \mathrm{m}$ film thickness) and a flame-ionization detector (FID) using hydrogen as the carrier gas. Gas chromatography coupled with mass spectrometry (GC-MS) was performed on the same instrument equipped with an Agilent 5875C Triple-Axis-Detector or an Agilent 5977B MSD. Mass spectra were obtained with electron-ionization (EI) at $70 \mathrm{eV}$ in positive ion mode. 


\section{Mass Spectrometry}

Electron-ionization (EI) mass spectra were recorded on a time-of flight mass spectrometer AccuTOFTM from Jeol at $70 \mathrm{eV}$. Electrospray-ionization (ESI) mass spectra were recorded on a quadrupole timeof-flight maXis or on a time-of-flight mass spectrometer microTOF, both from Bruker Daltonic. The ratios of mass to charge $(\mathrm{m} / \mathrm{z})$ are reported and the intensity relative to the base peak $(\mathrm{I}=100)$ is given in parenthesis.

\section{Infrared Spectroscopy}

Infrared (IR) spectra of were measured on a Bruker Alpha-P FT-IR spectrometer with a diamond ATR probe in the range of $4000-400 \mathrm{~cm}^{-1}$. In-situ IR measurements were performed with a Mettler-Toledo ReactIR 15 spectrometer equipped with a diamond ATR probe and an MCT detector. Spectra were acquired using Mettler-Toledo iC IR software version 7.0.297 in the range of $650-2200 \mathrm{~cm}^{-1}$ with a 4 $\mathrm{cm}^{-1}$ resolution. A Pearson's Correction was used as baseline correction in all measurements.

\section{Nuclear Magnetic Resonance Spectroscopy}

Nuclear magnetic resonance (NMR) spectra were recorded on Varian MercuryPlus ${ }^{\mathrm{TM}}$ 300, Bruker Avance $^{\text {TM }}$ III 300, Avance III HD 300, Avance III 400, Avance III HD 400, Avance Neo 400, Avance III HD 500 and Bruker Avance Neo 600 spectrometer. Unless stated otherwise, all measurements were performed at $298 \mathrm{~K}$. Chemical shifts $(\delta)$ are reported relative to tetramethylsilane and are referenced using the residual proton or carbon solvent signal. ${ }^{[264]}$

Table 5.1.1 Chemical shifts of common deuterated solvents.

\begin{tabular}{|c|c|c|}
\hline Solvent & ${ }^{1} \mathbf{H}$ NMR & ${ }^{13} \mathrm{C}$ NMR \\
\hline $\mathrm{CDCl}_{3}$ & $7.26 \mathrm{ppm}$ & $77.16 \mathrm{ppm}$ \\
\hline DMSO-d $_{6}$ & $2.50 \mathrm{ppm}$ & $39.52 \mathrm{ppm}$ \\
\hline Acetone- $\mathrm{d}_{6}$ & $2.05 \mathrm{ppm}$ & 206.7, $29.92 \mathrm{ppm}$ \\
\hline Methanol-d 4 & $4.78,3.31 \mathrm{ppm}$ & $49.15 \mathrm{ppm}$ \\
\hline THF-d 8 & $3.58,1.73 \mathrm{ppm}$ & $67.57,25.37 \mathrm{ppm}$ \\
\hline
\end{tabular}




\section{Data Analysis and Plots}

Data analysis and plotting were performed using Microsoft Excel 2016 software.

\section{Solvents}

All solvents used for work-up and purification were distilled prior to use. Solvents used in reactions involving air- or moisture-sensitive compounds were dried and stored under an inert atmosphere of nitrogen or argon according to the following standard procedures: Solvents purified by solvent purification system (SPS-800) from M. Braun: Toluene, tetrahydrofuran, diethylether, dichloromethane and N,N-dimethylformamide. Solvents dried and distilled over $\mathrm{CaH}_{2}$ : 1,2dichloroethane, $N, N$-dimethylacetamide and $N$-methyl-2-pyrrolidone. Solvents dried over $4 \AA$ molecular sieves and degassed using multiple cycles of freeze-pump-thaw: $t$-Amylalcohol, $o-, m-, p$ xylene, 1,4-dioxane, 1,2-dimethoxyethane, $n$-butyl ether, methanol, trifluoroethanol, and hexafluoroisopropanol, 2-methyltetrahydrofuran, $n$-hexane, toluene- $\mathrm{d}_{8}$, and THF- $\mathrm{d}_{8}$. Water was degassed before its use applying repeated freeze-pump-thaw cycles.

\section{Electrochemistry}

Platinum electrodes $\left(10 \mathrm{~mm} \times 25 \mathrm{~mm} \times 0.125 \mathrm{~mm}, 99.9 \%\right.$; obtained from ChemPur ${ }^{\circledR}$ Karlsruhe, Germany) and CF electrodes $(10 \mathrm{~mm} \times 25 \mathrm{~mm} \times 6 \mathrm{~mm}$, SIGRACELL®GFA 6 EA, obtained from SGL Carbon, Wiesbaden, Germany) were connected using stainless steel adapters. Electrolysis was conducted using an AXIOMET AX-3003P potentiostat in constant current mode, CV studies were performed using a Metrohm Autolab PGSTAT204 workstation and Nova 2.0 software.

\section{Reagents}

Reagents obtained from commercial sources with a purity $>95 \%$ were used without further purification unless stated otherwise. The following compounds were synthesized according to previously reported procedures: 390, ${ }^{[265,266]} \mathbf{3 9 1},{ }^{[265,266]} \mathbf{4 1 2},{ }^{[267]}$ and $\mathbf{4 1 4}{ }^{[267]}$ 
The following compounds were kindly synthesized and/or provided by the persons listed below:

Karsten Rauch: $\left[\mathrm{RuCl}_{2}(p \text {-cymene })\right]_{2}$ and $\left[\mathrm{Ru}(\mathrm{OAc})_{2} p\right.$-cymene]

Dr. Uttam Dhawa: 399

Dr. Nikolaos Kaplaneris: 395, 396, 402, and 407

Dr. Julian Koeller: 404 and 444

Dr. Valentin Mueller: 407

Dr. Cuiju Zhu: 411 and 413 


\subsection{General Procedures}

\subsubsection{General Procedure A: Ruthenium-Catalyzed C7-H Indole Amidations}

A suspension of $N$-pivaloyl indoles 390 ( $0.25 \mathrm{mmol}, 1.0$ equiv), organic azides 391 (0.75 mmol, 3.0 equiv), $\mathrm{Ru}(\mathrm{OAc})_{2}\left(p\right.$-cymene) $(10 \mathrm{~mol} \%), \mathrm{AgSbF}_{6}(20 \mathrm{~mol} \%)$, in TFE $(1.0 \mathrm{~mL})$ was stirred at $40{ }^{\circ} \mathrm{C}$ for $24 \mathrm{~h}$ under $\mathrm{N}_{2}$. After cooling to ambient temperature, the mixture was concentrated in vacuo. Purification by column chromatography on silica gel afforded the desired products 392 .

\subsubsection{General Procedure B: Ruthenium-Catalyzed C7-H Indole Alkenylations}

A suspension of $N$-pivaloyl indoles 390 ( $0.25 \mathrm{mmol}, 1.0$ equiv), acrylates 393 ( $0.75 \mathrm{mmol}, 3.0$ equiv), $\mathrm{Ru}(\mathrm{OAc})_{2}\left(p\right.$-cymene) $(10 \mathrm{~mol} \%), \mathrm{AgSbF}_{6}(20 \mathrm{~mol} \%)$, and $\mathrm{Cu}(\mathrm{OAc})_{2}(0.50 \mathrm{mmol}, 2.0$ equiv) in TFE $(1.0 \mathrm{~mL})$ was stirred at $40{ }^{\circ} \mathrm{C}$ for $24 \mathrm{~h}$ under $\mathrm{N}_{2}$. After cooling to ambient temperature, the mixture was concentrated in vacuo. Purification by column chromatography on silica gel afforded the desired products 394 .

\subsubsection{General Procedure C: Ruthenium-Catalyzed C4-H/C6-H Indole Dual Alkylations}

A suspension of 1-(pyridin-2-yl)-1H-indoles (395) (0.25 mmol, 1.0 equiv), alkyl bromides 396 (1.25 mmol, 5 equiv), $\mathrm{Ru}(\mathrm{OAc})_{2}\left(\mathrm{PPh}_{3}\right)_{2}(10 \mathrm{~mol} \%)$, and $\mathrm{NaOAc}(0.50 \mathrm{mmol}, 2.0$ equiv) in DCE $(2.0 \mathrm{~mL})$ was stirred at $70{ }^{\circ} \mathrm{C}$ for $16 \mathrm{~h}$ under $\mathrm{N}_{2}$. After cooling to room temperature, the mixture was concentrated in vacuo. Purification by column chromatography on silica gel afforded the desired products 397.

\subsubsection{General Procedure D: Osmium-Catalyzed Electrooxidative [4+1] C-H annulations}

A suspension of benzoic acids 398 (0.20 mmol), olefins 399 (3.0 equiv), [ $\mathrm{OsCl}_{2}(p \text {-cymene) }]_{2}(5.0$ mol \%), KI (0.40 mmol, 2.0 equiv), and KOAc (0.40 mmol, 2.0 equiv) in HFIP (2.0 mL) and $\mathrm{H}_{2} \mathrm{O}(2.0$ $\mathrm{mL}$ ) was stirred at $100{ }^{\circ} \mathrm{C}$ for $16 \mathrm{~h}$ at $4.0 \mathrm{~mA}$ of a constant current under $\mathrm{N}_{2}$. After cooling to ambient temperature, the electrodes were washed with ethyl acetate $(3 \times 10 \mathrm{~mL})$. The reaction mixtures were extracted with brine $(20 \mathrm{~mL})$, dried over $\mathrm{Na}_{2} \mathrm{SO}_{4}$, and concentrated under reduced pressure. Purification by column chromatography on silica gel afforded the desired products $\mathbf{4 0 0}$. 


\subsubsection{General Procedure E: Osmium-Catalyzed Electrooxidative [4+2] C-H annulations}

A suspension of benzoic acids $398(0.20 \mathrm{mmol})$, alkynes 401 (3.0 equiv), [ $\mathrm{OsCl}_{2}(p \text {-cymene) }]_{2}(5.0$ mol \%), KI (0.40 mmol, 2.0 equiv), and KOAc (0.40 mmol, 2.0 equiv) in HFIP (2.0 mL) and $\mathrm{H}_{2} \mathrm{O}(2.0$ $\mathrm{mL}$ ) was stirred at $100{ }^{\circ} \mathrm{C}$ for $16 \mathrm{~h}$ at $4.0 \mathrm{~mA}$ of a constant current under $\mathrm{N}_{2}$. After cooling to ambient temperature, the electrodes were washed with ethyl acetate $(3 \times 10 \mathrm{~mL})$. The reaction mixtures were extracted with brine $(20 \mathrm{~mL})$, dried over $\mathrm{Na}_{2} \mathrm{SO}_{4}$, and concentrated under reduced pressure. Purification by column chromatography on silica gel afforded the desired products $\mathbf{4 0 2}$.

\subsubsection{General Procedure F: Photo-Induced Hybrid Copper-Catalyzed C-H Arylations (1)}

To a pre-dried $10 \mathrm{~mL}$ quartz tube was added azoles $\mathbf{4 0 3}$ ( $0.25 \mathrm{mmol}, 1.0$ equiv), aryl iodide 404 (1.25 mmol, 5.0 equiv), 406 (30 mg, $11 \mathrm{~mol} \%), \mathrm{LiO} t \mathrm{Bu}$ (0.75 mmol, 3.0 equiv), and $\mathrm{Et}_{2} \mathrm{O}(0.5 \mathrm{~mL})$ under $\mathrm{N}_{2}$ atmosphere. The tube was sealed and stirred under $254 \mathrm{~nm}$ irradiation in a Luzchem LZC-ICH2 photoreactor at ambient temperature for $24 \mathrm{~h}$. The temperature was determined to be $30{ }^{\circ} \mathrm{C}$ in the reaction mixture. Afterwards, the solvent was removed under reduced pressure. Purification by column chromatography on silica gel afforded the desired products 405.

\subsubsection{General Procedure G: Photo-Induced Hybrid Copper-Catalyzed C-H Arylations (2)}

To a pre-dried $10 \mathrm{~mL}$ quartz tube was added $N$-methyl benzimidazole (445) (0.25 mmol), aryl iodide 404 (1.25 mmol), 406 (30 mg, $11 \mathrm{~mol} \%), \mathrm{K}_{3} \mathrm{PO}_{4}$ (0.75 mmol, 3.0 equiv), and THF (0.5 mL) under $\mathrm{N}_{2}$ atmosphere. The tube was sealed and stirred under $254 \mathrm{~nm}$ irradiation in a Luzchem LZC-ICH2 photoreactor at ambient temperature for $24 \mathrm{~h}$. The temperature was determined to be $30{ }^{\circ} \mathrm{C}$ in the reaction mixture. Afterwards, the solvent was removed under reduced pressure. Purification by column chromatography on silica gel afforded the desired products 446. 


\subsubsection{General Procedure H: Photo-Induced Hybrid Copper-Catalyzed C-H Arylations (3)}

To a pre-dried $10 \mathrm{~mL}$ quartz tube was added heterocycles 403 or 445 (0.25 mmol, 1.0 equiv), aryl bromide 447 (1.25 mmol, 5.0 equiv), 406 (30 mg, $11 \mathrm{~mol} \%$ ), $\mathrm{Cs}_{2} \mathrm{CO}_{3}$ (0.75 mmol, 3.0 equiv), and $\mathrm{Et}_{2} \mathrm{O}(0.5 \mathrm{~mL})$ under $\mathrm{N}_{2}$ atmosphere. The tube was sealed and stirred under $254 \mathrm{~nm}$ irradiation in a Luzchem LZC-ICH2 photoreactor at ambient temperature for $24 \mathrm{~h}$. The temperature was determined to be $30{ }^{\circ} \mathrm{C}$ in the reaction mixture. Afterwards, the solvent was removed under reduced pressure. Purification by column chromatography on silica gel afforded the desired products 405 or 446 .

\subsubsection{General Procedure I: Hybrid Ruthenium-Catalyzed meta-C-H Alkylation}

A suspension of arenes 407 (0.25 mmol, 1.0 equiv), alkyl halides 408 (0.75 mmol, 3.0 equiv), 410 (30.0 mg, $10 \mathrm{~mol} \%)$ and KOAc $\left(0.50 \mathrm{mmol}, 2.0\right.$ equiv) in 2-MeTHF $(2.0 \mathrm{~mL})$ was stirred at $60{ }^{\circ} \mathrm{C}$ for $24 \mathrm{~h}$ under $\mathrm{N}_{2}$. After cooling to ambient temperature, the mixture was concentrated in vacuo. Purification by column chromatography on silica gel afforded the desired products 409 .

\subsubsection{General Procedure J: Hybrid Manganese-Catalyzed C-H Arylations}

A suspension of picolinamides 411 (0.25 mmol, 1.0 equiv), aryl Grignards 412 (4 equiv, $1.0 \mathrm{~mL}, 1.0$ $\mathrm{M}$ in THF) was added to a pre-dried Schlenk tube at room temperature under $\mathrm{N}_{2}$. After stirring for 10 min, 416 (30 mg, $9.0 \mathrm{~mol} \%$ ), TMEDA ( $0.50 \mathrm{mmol}, 2.0$ equiv) and 2,3-DCB (0.75 mmol, 3.0 equiv) were added to the suspension under $\mathrm{N}_{2}$. The Schlenk tube was transferred to pre-heated oil bath $\left(70{ }^{\circ} \mathrm{C}\right)$ and stirred for $16 \mathrm{~h}$. After cooling to ambient temperature, saturated aqueous $\mathrm{NH}_{4} \mathrm{Cl}(15 \mathrm{~mL})$ was added and the reaction mixture was extracted with EtOAc $(3 \times 15 \mathrm{~mL})$. The combined organic layers were dried over $\mathrm{Na}_{2} \mathrm{SO}_{4}$, filtered, and concentrated in vacuo. Purification by column chromatography on silica gel afforded the desired products $\mathbf{4 1 5}$.

\subsubsection{General Procedure K: Hybrid Manganese-Catalyzed C-H Alkylations}

A suspension of picolinamides 411 ( 0.25 mmol, 1.0 equiv), alkly Grignards 414 (4 equiv, $1.0 \mathrm{~mL}, 1.0$ $\mathrm{M}$ in THF) was added to a pre-dried Schlenk tube at room temperature under $\mathrm{N}_{2}$. After stirring for 10 min, 416 (30 mg, $9.0 \mathrm{~mol} \%$ ), TMEDA (0.50 mmol, 2.0 equiv) and 2,3-DCB (0.75 mmol, 3.0 equiv) 
were added to the suspension under $\mathrm{N}_{2}$. The Schlenk tube was transferred to pre-heated oil bath $\left(70{ }^{\circ} \mathrm{C}\right)$ and stirred for $16 \mathrm{~h}$. After cooling to ambient temperature, saturated aqueous $\mathrm{NH}_{4} \mathrm{Cl}(15 \mathrm{~mL})$ was added and the reaction mixture was extracted with EtOAc $(3 \times 15 \mathrm{~mL})$. The combined organic layers were dried over $\mathrm{Na}_{2} \mathrm{SO}_{4}$, filtered, and concentrated in vacuo. Purification by column chromatography on silica gel afforded the desired products 415. 


\subsection{Ruthenium(II)-Catalyzed C7-H Amidations and Alkenylations of Indoles}

\subsubsection{Characterization Data}

4-Methyl-N-(1-pivaloyl-1H-indol-7-yl)benzenesulfonamide (392a)<smiles>Nc1cccc2ccn(P)c12</smiles>

The General Procedure A was followed using $N$-pivaloyl indole 390a (50.3 mg, $0.25 \mathrm{mmol})$, tosyl azide 391a (148 mg, $0.75 \mathrm{mmol}), \mathrm{Ru}(\mathrm{OAc})_{2}\left(p\right.$-cymene) $(8.8 \mathrm{mg}, 10 \mathrm{~mol} \%)$ and $\mathrm{AgSbF}_{6}(17.2 \mathrm{mg}, 20$ mol \%) in TFE (1.0 mL). Purification by column chromatography on silica gel ( $n$-hexane/EtOAc: $4 / 1)$ yielded 392a (72.2 mg, 78\%) as a light brown solid.

M. p. $120^{\circ} \mathrm{C}$.

${ }^{1} \mathbf{H}$ NMR $\left(400 \mathrm{MHz}, \mathrm{CDCl}_{3}\right) \delta 9.21(\mathrm{~s}, 1 \mathrm{H}), 7.51(\mathrm{dd}, J=7.8,1.2 \mathrm{~Hz}, 1 \mathrm{H}), 7.49(\mathrm{~d}, J=4.0 \mathrm{~Hz}, 1 \mathrm{H})$, $7.38(\mathrm{ddd}, J=8.3,4.0,2.2 \mathrm{~Hz}, 2 \mathrm{H}), 7.35(\mathrm{dd}, J=7.8,1.2 \mathrm{~Hz}, 1 \mathrm{H}), 7.28(\mathrm{t}, J=7.8 \mathrm{~Hz}, 1 \mathrm{H}), 7.08-7.03$ (m, 2H), $6.55(\mathrm{~d}, J=4.0 \mathrm{~Hz}, 1 \mathrm{H}), 2.27(\mathrm{~s}, 3 \mathrm{H}), 1.35(\mathrm{~s}, 9 \mathrm{H})$.

${ }^{13}$ C NMR (100 MHz, $\left.\mathrm{CDCl}_{3}\right) \delta 179.2\left(\mathrm{C}_{\mathrm{q}}\right), 143.1\left(\mathrm{C}_{\mathrm{q}}\right), 137.4\left(\mathrm{C}_{\mathrm{q}}\right), 132.2\left(\mathrm{C}_{\mathrm{q}}\right), 129.3\left(\mathrm{C}_{\mathrm{q}}\right), 129.3(\mathrm{CH})$, $126.7(\mathrm{CH}), 126.4(\mathrm{CH}), 125.1(\mathrm{CH}), 125.1\left(\mathrm{C}_{\mathrm{q}}\right), 122.8(\mathrm{CH}), 118.7(\mathrm{CH}), 109.2(\mathrm{CH}), 41.6\left(\mathrm{C}_{\mathrm{q}}\right), 28.9$ $\left(\mathrm{CH}_{3}\right), 21.3\left(\mathrm{CH}_{3}\right)$.

IR (ATR): 3174, 2991, 1745, 1570, 1322, 1164, 1099, 901, 818, $712 \mathrm{~cm}^{-1}$.

MS (ESI) $m / z$ (relative intensity): $371(34)[\mathrm{M}+\mathrm{H}]^{+}, 393(60)[\mathrm{M}+\mathrm{Na}]^{+}$.

HR-MS (ESI) $\mathrm{C}_{20} \mathrm{H}_{23} \mathrm{~N}_{2} \mathrm{O}_{3} \mathrm{~S}$ [M+H] $]^{+}: 371.1427$, found: 371.1424 .

The spectral data were in accordance with those reported in the literature. ${ }^{[42 \mathrm{~g}]}$

4-Methyl- $N$-(3-methyl-1-pivaloyl-1H-indol-7-yl)benzenesulfonamide (392b)<smiles>Cc1cn(Pc2ccccn2)c2c(N)cccc12</smiles>

The General Procedure A was followed using 2,2-dimethyl-1-(3-methyl-1H-indol-1-yl)propan-1-one 390b (53.8 mg, $0.25 \mathrm{mmol})$, tosyl azide 391a (148 mg, $0.75 \mathrm{mmol}), \mathrm{Ru}(\mathrm{OAc})_{2}(p$-cymene) (8.8 mg, 10 
mol \%) and $\mathrm{AgSbF}_{6}(17.2 \mathrm{mg}, 20 \mathrm{~mol} \%)$ in TFE (1.0 mL). Purification by column chromatography on silica gel ( $n$-hexane/EtOAc: $4 / 1)$ yielded 392b (40.4 mg, 42\%) as a light yellow solid.

M. p. $135^{\circ} \mathrm{C}$.

${ }^{1}$ H NMR $\left(400 \mathrm{MHz} \mathrm{CDCl}_{3}\right) \delta 9.43(\mathrm{~s}, 1 \mathrm{H}), 7.52(\mathrm{dd}, J=7.1,1.9 \mathrm{~Hz}, 1 \mathrm{H}), 7.40(\mathrm{ddd}, J=8.0,1.9,1.7$ $\mathrm{Hz}, 2 \mathrm{H}), 7.30-7.23(\mathrm{~m}, 3 \mathrm{H}), 7.06(\mathrm{dd}, J=8.0,1.7 \mathrm{~Hz}, 2 \mathrm{H}), 2.28(\mathrm{~s}, 3 \mathrm{H}), 2.19(\mathrm{~s}, 3 \mathrm{H}), 1.34$ (s, 9H).

${ }^{13}$ C NMR $\left(100 \mathrm{MHz}, \mathrm{CDCl}_{3}\right) \delta 178.8\left(\mathrm{C}_{\mathrm{q}}\right), 143.0\left(\mathrm{C}_{\mathrm{q}}\right), 137.5\left(\mathrm{C}_{\mathrm{q}}\right), 133.2\left(\mathrm{C}_{\mathrm{q}}\right), 129.6\left(\mathrm{C}_{\mathrm{q}}\right), 129.3(\mathrm{CH})$, $126.8(\mathrm{CH}), 125.2\left(\mathrm{C}_{\mathrm{q}}\right), 124.9(\mathrm{CH}), 123.3(\mathrm{CH}), 122.6(\mathrm{CH}), 118.1\left(\mathrm{C}_{\mathrm{q}}\right), 116.4(\mathrm{CH}), 41.4\left(\mathrm{C}_{\mathrm{q}}\right), 28.9$ $\left(\mathrm{CH}_{3}\right), 21.4\left(\mathrm{CH}_{3}\right), 9.7\left(\mathrm{CH}_{3}\right)$.

IR (ATR): 2975, 1665, 1440, 1342, 1162, 1091, 968, 909, 766, $554 \mathrm{~cm}^{-1}$.

MS (ESI) $m / z$ (relative intensity): $385(34)[\mathrm{M}+\mathrm{H}]^{+}, 407(66)[\mathrm{M}+\mathrm{Na}]^{+}$.

HR-MS (ESI) $\mathrm{C}_{21} \mathrm{H}_{25} \mathrm{~N}_{2} \mathrm{O}_{3} \mathrm{~S}[\mathrm{M}+\mathrm{H}]^{+}: 385.1582$, found: 385.1580 .

The spectral data were in accordance with those reported in the literature. ${ }^{[42 \mathrm{~g}]}$

\section{4-Methyl- $N$-(4-methyl-1-pivaloyl-1H-indol-7-yl)benzenesulfonamide (392c)}<smiles>Cc1ccc(N)c2c1ccn2PN</smiles>

The General Procedure A was followed using 2,2-dimethyl-1-(4-methyl-1 $H$-indol-1-yl)propan-1-one 390c (53.8 mg, $0.25 \mathrm{mmol})$, tosyl azide 391a (148 mg, $0.75 \mathrm{mmol}), \mathrm{Ru}(\mathrm{OAc})_{2}(p$-cymene) $(8.8 \mathrm{mg}, 10$ mol \%) and $\mathrm{AgSbF}_{6}(17.2 \mathrm{mg}, 20 \mathrm{~mol} \%)$ in TFE (1.0 mL). Purification by column chromatography on silica gel ( $n$-hexane/EtOAc: $4 / 1)$ yielded 392c (66.3 mg, 69\%) as a light yellow solid.

M. p. $165^{\circ} \mathrm{C}$.

${ }^{1}$ H NMR $\left(400 \mathrm{MHz}, \mathrm{CDCl}_{3}\right) \delta 8.95(\mathrm{~s}, 1 \mathrm{H}), 7.47(\mathrm{~d}, J=4.0 \mathrm{~Hz}, 1 \mathrm{H}), 7.39(\mathrm{~d}, J=8.2 \mathrm{~Hz}, 1 \mathrm{H}), 7.36$ $(\mathrm{dd}, J=8.2,1.8 \mathrm{~Hz}, 2 \mathrm{H}), 7.08(\mathrm{~d}, J=8.2 \mathrm{~Hz}, 1 \mathrm{H}), 7.07-7.03(\mathrm{~m}, 2 \mathrm{H}), 6.58(\mathrm{~d}, J=4.0 \mathrm{~Hz}, 1 \mathrm{H}), 2.45$ (s, 3H), $2.28(\mathrm{~s}, 3 \mathrm{H}), 1.33(\mathrm{~s}, 9 \mathrm{H})$.

${ }^{13}$ C NMR $\left(100 \mathrm{MHz}, \mathrm{CDCl}_{3}\right) \delta 179.20\left(\mathrm{C}_{\mathrm{q}}\right), 142.95\left(\mathrm{C}_{\mathrm{q}}\right), 137.57\left(\mathrm{C}_{\mathrm{q}}\right), 131.37\left(\mathrm{C}_{\mathrm{q}}\right), 129.37\left(\mathrm{C}_{\mathrm{q}}\right), 129.24$ $(\mathrm{CH}), 128.31\left(\mathrm{C}_{\mathrm{q}}\right), 126.77(\mathrm{CH}), 125.81(\mathrm{CH}), 125.56(\mathrm{CH}), 123.42(\mathrm{CH}), 122.61\left(\mathrm{C}_{\mathrm{q}}\right), 107.48(\mathrm{CH})$, 
$41.58\left(\mathrm{C}_{\mathrm{q}}\right), 28.92\left(\mathrm{CH}_{3}\right), 21.33\left(\mathrm{CH}_{3}\right), 18.11\left(\mathrm{CH}_{3}\right)$.

IR (ATR): 3193, 2977, 1671, 1498, 1329, 1164, 1091, 899, 814, $721 \mathrm{~cm}^{-1}$.

MS (ESI) $m / z$ (relative intensity): $385(66)[\mathrm{M}+\mathrm{H}]^{+}, 407(34)[\mathrm{M}+\mathrm{Na}]^{+}$.

HR-MS (ESI) $\mathrm{C}_{21} \mathrm{H}_{25} \mathrm{~N}_{2} \mathrm{O}_{3} \mathrm{~S}[\mathrm{M}+\mathrm{H}]^{+}:$385.1585, found: 385.1583 .

The spectral data were in accordance with those reported in the literature. ${ }^{[42 \mathrm{~g}]}$

\section{$N$-(4-Bromo-1-pivaloyl-1H-indol-7-yl)-4-methylbenzenesulfonamide (392d)}<smiles>Pn1ccc2c(Br)ccc(N[123I])c21</smiles>

The General Procedure A was followed using 1-(4-bromo-1H-indol-1-yl)-2,2-dimethylpropan-1-one 390d (70.0 mg, $0.25 \mathrm{mmol})$, tosyl azide 391a (148 mg, $0.75 \mathrm{mmol}), \mathrm{Ru}(\mathrm{OAc})_{2}(p$-cymene) $(8.8 \mathrm{mg}, 10$ mol \%) and $\mathrm{AgSbF}_{6}(17.2 \mathrm{mg}, 20 \mathrm{~mol} \%)$ in TFE (1.0 mL). Purification by column chromatography on silica gel ( $n$-hexane/EtOAc: 4/1) yielded 392d (44.9 mg, 40\%) as a light yellow solid.

M. p. $143^{\circ} \mathrm{C}$.

${ }^{1}$ H NMR $\left(400 \mathrm{MHz}, \mathrm{CDCl}_{3}\right) \delta 8.99(\mathrm{~s}, 1 \mathrm{H}), 7.55(\mathrm{~d}, J=4.0 \mathrm{~Hz}, 1 \mathrm{H}), 7.44-7.40(\mathrm{~d}, J=8.6,2 \mathrm{H}), 7.38$ $(\mathrm{d}, J=8.6,2 \mathrm{H}), 7.14-7.05(\mathrm{~m}, 2 \mathrm{H}), 6.65(\mathrm{~d}, J=4.0 \mathrm{~Hz}, 1 \mathrm{H}), 2.29(\mathrm{~s}, 3 \mathrm{H}), 1.35(\mathrm{~s}, 9 \mathrm{H})$.

${ }^{13} \mathrm{C}$ NMR $\left(100 \mathrm{MHz}, \mathrm{CDCl}_{3}\right) \delta 179.5\left(\mathrm{C}_{\mathrm{q}}\right), 143.4\left(\mathrm{C}_{\mathrm{q}}\right), 137.2\left(\mathrm{C}_{\mathrm{q}}\right), 132.3\left(\mathrm{C}_{\mathrm{q}}\right), 129.7\left(\mathrm{C}_{\mathrm{q}}\right), 129.4(\mathrm{CH})$, $127.9(\mathrm{CH}), 126.9(\mathrm{CH}), 126.7(\mathrm{CH}), 124.4\left(\mathrm{C}_{\mathrm{q}}\right), 123.6(\mathrm{CH}), 112.2\left(\mathrm{C}_{\mathrm{q}}\right), 109.1(\mathrm{CH}), 41.8\left(\mathrm{C}_{\mathrm{q}}\right), 28.8$ $\left(\mathrm{CH}_{3}\right), 21.3\left(\mathrm{CH}_{3}\right)$.

IR (ATR): 3190, 2976, 1679, 1478, 1328, 1164, 1090, 910, 867, $670 \mathrm{~cm}^{-1}$.

MS (ESI) $m / z$ (relative intensity): $449(100)\left({ }^{79} \mathrm{Br}\right)[\mathrm{M}+\mathrm{H}]^{+}, 451(100)\left({ }^{81} \mathrm{Br}\right)[\mathrm{M}+\mathrm{H}]^{+}$.

HR-MS (ESI) $\mathrm{C}_{20} \mathrm{H}_{22}{ }^{79} \mathrm{BrN}_{2} \mathrm{O}_{3} \mathrm{~S}[\mathrm{M}+\mathrm{H}]^{+}:$449.0534, found: 449.0529.

The spectral data were in accordance with those reported in the literature. ${ }^{[42 \mathrm{~g}]}$ 
$N$-(4-Formyl-1-pivaloyl-1H-indol-7-yl)-4-methylbenzenesulfonamide (392e)<smiles>Nc1ccc(C=O)c2ccn(P)c12</smiles>

The General Procedure A was followed using 1-pivaloyl-1 $H$-indole-4-carbaldehyde 390e (57.3 mg, $0.25 \mathrm{mmol})$, tosyl azide 391a (148 $\mathrm{mg}, 0.75 \mathrm{mmol}), \mathrm{Ru}(\mathrm{OAc})_{2}(p$-cymene) $(8.8 \mathrm{mg}, 10 \mathrm{~mol} \%)$ and $\mathrm{AgSbF}_{6}(17.2 \mathrm{mg}, 20 \mathrm{~mol} \%)$ in TFE $(1.0 \mathrm{~mL})$. Purification by column chromatography on silica gel ( $n$-hexane/EtOAc: $4 / 1)$ yielded 392e (80.7 mg, 81\%) as a light yellow solid.

M. p. $125^{\circ} \mathrm{C}$.

${ }^{1} \mathbf{H}$ NMR $\left(400 \mathrm{MHz}, \mathrm{CDCl}_{3}\right) \delta 10.28(\mathrm{~s}, 1 \mathrm{H}), 9.78(\mathrm{~s}, 1 \mathrm{H}), 8.81(\mathrm{~d}, J=8.2 \mathrm{~Hz}, 1 \mathrm{H}), 8.09$ (m, 1H), 7.67 $(\mathrm{dd}, J=7.5,1.1 \mathrm{~Hz}, 1 \mathrm{H}), 7.64(\mathrm{~d}, J=8.2,2.0 \mathrm{~Hz}, 2 \mathrm{H}), 7.44(\mathrm{dd}, J=8.2,7.5 \mathrm{~Hz}, 1 \mathrm{H}), 7.12-7.09(\mathrm{~m}$, $2 \mathrm{H}), 2.28(\mathrm{~s}, 3 \mathrm{H}), 1.51(\mathrm{~s}, 9 \mathrm{H})$.

${ }^{13} \mathrm{C}$ NMR $\left(100 \mathrm{MHz}, \mathrm{CDCl}_{3}\right) \delta 195.7(\mathrm{CH}), 177.2\left(\mathrm{C}_{\mathrm{q}}\right), 143.6\left(\mathrm{C}_{\mathrm{q}}\right), 136.3\left(\mathrm{C}_{\mathrm{q}}\right), 136.0\left(\mathrm{C}_{\mathrm{q}}\right), 134.0(\mathrm{CH})$, 129.4 (CH), $128.3\left(\mathrm{C}_{\mathrm{q}}\right), 127.1(\mathrm{CH}), 125.1(\mathrm{CH}), 124.6(\mathrm{CH}), 121.8\left(\mathrm{C}_{\mathrm{q}}\right), 120.1\left(\mathrm{C}_{\mathrm{q}}\right), 117.4(\mathrm{CH}), 41.6$ $\left(\mathrm{C}_{\mathrm{q}}\right), 28.5\left(\mathrm{CH}_{3}\right), 21.4\left(\mathrm{CH}_{3}\right)$.

IR (ATR): 3180, 2742, 1670, 1303, 1264, 1164, 1091, 905, 732, $547 \mathrm{~cm}^{-1}$.

MS (ESI) $m / z$ (relative intensity): $399(30)[\mathrm{M}+\mathrm{H}]^{+}, 421(70)[\mathrm{M}+\mathrm{Na}]^{+}$.

HR-MS (ESI) $\mathrm{C}_{21} \mathrm{H}_{23} \mathrm{~N}_{2} \mathrm{O}_{4} \mathrm{~S}[\mathrm{M}+\mathrm{H}]^{+}:$399.1372, found: 399.1373.

The spectral data were in accordance with those reported in the literature. ${ }^{[42 \mathrm{~g}]}$

$N$-(5-Methoxy-1-pivaloyl-1 $H$-indol-7-yl)-4-methylbenzenesulfonamide (392f)<smiles>COc1cc(N)c2c(ccn2P)c1</smiles>

The General Procedure A was followed using 1-(5-methoxy-1 $H$-indol-1-yl)-2,2-dimethylpropan-1one $390 \mathrm{f}$ (57.8 mg, $0.25 \mathrm{mmol})$, tosyl azide $391 \mathrm{a}(148 \mathrm{mg}, 0.75 \mathrm{mmol}), \mathrm{Ru}(\mathrm{OAc})_{2}(p$-cymene $)(8.8 \mathrm{mg}$, $10 \mathrm{~mol} \%)$ and $\mathrm{AgSbF}_{6}(17.2 \mathrm{mg}, 20 \mathrm{~mol} \%)$ in TFE (1.0 mL). Purification by column chromatography on silica gel ( $n$-hexane/EtOAc: $4 / 1)$ yielded $392 f(71.1 \mathrm{mg}, 71 \%)$ as a light yellow solid. 
M. p. $128^{\circ} \mathrm{C}$.

${ }^{1} \mathbf{H}$ NMR $\left(400 \mathrm{MHz}, \mathrm{CDCl}_{3}\right) \delta 9.62(\mathrm{~s}, 1 \mathrm{H}), 7.47$ (d, $\left.J=3.9 \mathrm{~Hz}, 1 \mathrm{H}\right), 7.45(\mathrm{ddd}, J=8.2,3.9,1.9 \mathrm{~Hz}$, 2H), $7.14(\mathrm{dd}, J=2.5,0.5 \mathrm{~Hz}, 1 \mathrm{H}), 7.08(\mathrm{dd}, J=8.2,1.9 \mathrm{~Hz}, 2 \mathrm{H}), 6.79(\mathrm{~d}, J=2.5 \mathrm{~Hz}, 1 \mathrm{H}), 6.46(\mathrm{~d}, J$ $=3.9 \mathrm{~Hz}, 1 \mathrm{H}), 3.82(\mathrm{~s}, 3 \mathrm{H}), 2.28(\mathrm{~s}, 3 \mathrm{H}), 1.35(\mathrm{~s}, 9 \mathrm{H})$.

${ }^{13}$ C NMR $\left(100 \mathrm{MHz}, \mathrm{CDCl}_{3}\right) \delta 178.8\left(\mathrm{C}_{\mathrm{q}}\right), 157.4\left(\mathrm{C}_{\mathrm{q}}\right), 143.1\left(\mathrm{C}_{\mathrm{q}}\right), 137.4\left(\mathrm{C}_{\mathrm{q}}\right), 133.0\left(\mathrm{C}_{\mathrm{q}}\right), 129.3(\mathrm{CH})$, $127.2(\mathrm{CH}), 126.9(\mathrm{CH}), 126.1\left(\mathrm{C}_{\mathrm{q}}\right), 123.6\left(\mathrm{C}_{\mathrm{q}}\right), 109.4(\mathrm{CH}), 109.3(\mathrm{CH}), 101.8(\mathrm{CH}), 55.7\left(\mathrm{CH}_{3}\right), 41.5$ $\left(\mathrm{C}_{\mathrm{q}}\right), 29.0\left(\mathrm{CH}_{3}\right), 21.4\left(\mathrm{CH}_{3}\right)$.

IR (ATR): 3182, 2976, 1663, 1614, 1287, 1160, 1090, 1041, 905, $739 \mathrm{~cm}^{-1}$.

MS (ESI) $m / z$ (relative intensity): $401(66)[\mathrm{M}+\mathrm{H}]^{+}, 423(34)[\mathrm{M}+\mathrm{Na}]^{+}$.

HR-MS (ESI) $\mathrm{C}_{21} \mathrm{H}_{25} \mathrm{~N}_{2} \mathrm{O}_{4} \mathrm{~S}[\mathrm{M}+\mathrm{H}]^{+}:$401.1528, found: 401.1530 .

The spectral data were in accordance with those reported in the literature. ${ }^{[42 \mathrm{~g}]}$

$N$-(5-Fluoro-1-pivaloyl-1 $H$-indol-7-yl)-4-methylbenzenesulfonamide (392g)<smiles>Nc1cc(F)cc2ccn(P)c12</smiles>

The General Procedure A was followed using 1-(5-fluoro-1H-indol-1-yl)-2,2-dimethylpropan-1-one $390 \mathrm{~g}$ (54.8 mg, $0.25 \mathrm{mmol})$, tosyl azide $391 \mathrm{a}(148 \mathrm{mg}, 0.75 \mathrm{mmol}), \mathrm{Ru}(\mathrm{OAc})_{2}(p$-cymene) $(8.8 \mathrm{mg}, 10$ mol \%) and $\mathrm{AgSbF}_{6}(17.2 \mathrm{mg}, 20 \mathrm{~mol} \%)$ in TFE (1.0 mL). Purification by column chromatography on silica gel ( $n$-hexane/EtOAc: 4/1) yielded 392g (47.6 mg, 49\%) as a light yellow solid.

M. p. $125^{\circ} \mathrm{C}$.

${ }^{1} \mathbf{H}$ NMR $\left(500 \mathrm{MHz}, \mathrm{CDCl}_{3}\right) \delta 9.55(\mathrm{~s}, 1 \mathrm{H}), 7.56(\mathrm{~d}, J=3.9 \mathrm{~Hz}, 1 \mathrm{H}), 7.49(\mathrm{ddd}, J=8.3,3.9,2.0 \mathrm{~Hz}$, 2H), 7.28 (ddd, $J=10.5,2.6,0.5 \mathrm{~Hz}, 1 \mathrm{H}), 7.15-7.09(\mathrm{~m}, 2 \mathrm{H}), 6.98(\mathrm{dd}, J=7.5,2.6 \mathrm{~Hz}, 1 \mathrm{H}), 6.51$ (d, $J=3.9 \mathrm{~Hz}, 1 \mathrm{H}), 2.30(\mathrm{~s}, 3 \mathrm{H}), 1.38(\mathrm{~s}, 9 \mathrm{H})$.

${ }^{13} \mathrm{C}$ NMR $\left(125 \mathrm{MHz}, \mathrm{CDCl}_{3}\right) \delta 179.2\left(\mathrm{C}_{\mathrm{q}}\right), 160.0\left(\mathrm{~d}, J_{\mathrm{C}-\mathrm{F}}=242.2 \mathrm{~Hz}, \mathrm{C}_{\mathrm{q}}\right), 143.4\left(\mathrm{C}_{\mathrm{q}}\right), 137.1\left(\mathrm{C}_{\mathrm{q}}\right)$, $132.9\left(\mathrm{~d}, J_{\mathrm{C}-\mathrm{F}}=11.1 \mathrm{~Hz}, \mathrm{C}_{\mathrm{q}}\right), 129.4(\mathrm{CH}), 128.0(\mathrm{CH}), 126.8(\mathrm{CH}), 126.5\left(\mathrm{~d}, J_{\mathrm{C}-\mathrm{F}}=12.0 \mathrm{~Hz}, \mathrm{C}_{\mathrm{q}}\right), 125.2$ $\left(\mathrm{d}, J_{\mathrm{C}-\mathrm{F}}=2.0 \mathrm{~Hz}, \mathrm{C}_{\mathrm{q}}\right), 109.2\left(\mathrm{~d}, J_{\mathrm{C}-\mathrm{F}}=4.1 \mathrm{~Hz}, \mathrm{CH}\right), 109.1\left(\mathrm{~d}, J_{\mathrm{C}-\mathrm{F}}=28.2 \mathrm{~Hz}, \mathrm{CH}\right), 103.7\left(\mathrm{~d}, J_{\mathrm{C}-\mathrm{F}}=\right.$ 23.6 Hz, $\mathrm{CH}), 41.7\left(\mathrm{C}_{\mathrm{q}}\right), 29.0\left(\mathrm{CH}_{3}\right), 21.4\left(\mathrm{CH}_{3}\right)$.

${ }^{19}$ F NMR $\left(471 \mathrm{MHz}, \mathrm{CDCl}_{3}\right) \delta-116.82(\mathrm{dd}, J=10.8,7.5 \mathrm{~Hz})$. 
IR (ATR): 3179, 2997, 1622, 1609, 1310, 1089, 1090, 1053, 899, 817, $739 \mathrm{~cm}^{-1}$.

MS (ESI) $m / z$ (relative intensity): $389(33)[\mathrm{M}+\mathrm{H}]^{+}, 411(66)[\mathrm{M}+\mathrm{Na}]^{+}$.

HR-MS (ESI) $\mathrm{C}_{21} \mathrm{H}_{25} \mathrm{~N}_{2} \mathrm{O}_{4} \mathrm{~S}[\mathrm{M}+\mathrm{H}]^{+}: 389.1329$, found: 389.1330 .

The spectral data were in accordance with those reported in the literature. ${ }^{[42 \mathrm{~g}]}$

$N$-(5-Chloro-1-pivaloyl-1 $H$-indol-7-yl)-4-methylbenzenesulfonamide (392h)<smiles>Pn1ccc2cc(Cl)cc([123I-])c21</smiles>

The General Procedure A was followed using 1-(5-chloro-1H-indol-1-yl)-2,2-dimethylpropan-1-one 390h (58.9 mg, $0.25 \mathrm{mmol})$, tosyl azide 391a (148 mg, $0.75 \mathrm{mmol}), \mathrm{Ru}(\mathrm{OAc})_{2}(p$-cymene) (8.8 mg, 10 mol \%) and $\mathrm{AgSbF}_{6}(17.2 \mathrm{mg}, 20 \mathrm{~mol} \%)$ in TFE (1.0 mL). Purification by column chromatography on silica gel ( $n$-hexane/EtOAc: 4/1) yielded 392h (76.9 mg, 76\%) as a light yellow solid.

M. p. $150^{\circ} \mathrm{C}$.

${ }^{1}$ H NMR $\left(400 \mathrm{MHz}, \mathrm{CDCl}_{3}\right) \delta 9.36(\mathrm{~s}, 1 \mathrm{H}), 7.53(\mathrm{dd}, J=3.9,0.5 \mathrm{~Hz}, 1 \mathrm{H}), 7.50(\mathrm{dd}, J=2.1,0.5 \mathrm{~Hz}$, $1 \mathrm{H}), 7.45(\mathrm{ddd}, J=8.2,3.9,2.1 \mathrm{~Hz}, 2 \mathrm{H}), 7.29(\mathrm{~d}, J=2.1 \mathrm{~Hz}, 1 \mathrm{H}), 7.13-7.06(\mathrm{~m}, 2 \mathrm{H}), 6.49(\mathrm{~d}, J=$ $3.9 \mathrm{~Hz}, 1 \mathrm{H}), 2.29$ (s, 3H), 1.35 (s, 9H).

${ }^{13}$ C NMR $\left(100 \mathrm{MHz}, \mathrm{CDCl}_{3}\right) \delta 179.3\left(\mathrm{C}_{\mathrm{q}}\right), 143.5\left(\mathrm{C}_{\mathrm{q}}\right), 137.1\left(\mathrm{C}_{\mathrm{q}}\right), 133.1\left(\mathrm{C}_{\mathrm{q}}\right), 130.5\left(\mathrm{C}_{\mathrm{q}}\right), 129.4(\mathrm{CH})$, $127.7(\mathrm{CH}), 127.6\left(\mathrm{C}_{\mathrm{q}}\right), 126.8(\mathrm{CH}), 126.1\left(\mathrm{C}_{\mathrm{q}}\right), 121.7(\mathrm{CH}), 117.9(\mathrm{CH}), 108.7(\mathrm{CH}), 41.7\left(\mathrm{C}_{\mathrm{q}}\right), 28.9$ $\left(\mathrm{CH}_{3}\right), 21.4\left(\mathrm{CH}_{3}\right)$.

IR (ATR): 3210, 2980, 1674, 1581, 1404, 1332, 1163, 1091, 904, $792 \mathrm{~cm}^{-1}$.

MS (ESI) $m / z$ (relative intensity): $405(80)[\mathrm{M}+\mathrm{H}]^{+}, 809(20)[2 \mathrm{M}+\mathrm{H}]^{+}$.

HR-MS (ESI) $\mathrm{C}_{20} \mathrm{H}_{22}{ }^{35} \mathrm{ClN}_{2} \mathrm{O}_{3} \mathrm{~S}[\mathrm{M}+\mathrm{H}]^{+}:$405.1034, found: 405.1034 .

The spectral data were in accordance with those reported in the literature. ${ }^{[42 \mathrm{~g}]}$

$N$-(5-Bromo-1-pivaloyl-1 $H$-indol-7-yl)-4-methylbenzenesulfonamide (392i)<smiles>Pn1ccc2cc(Br)cc(N[123I])c21</smiles> 
The General Procedure A was followed using 1-(5-bromo-1 $H$-indol-1-yl)-2,2-dimethylpropan-1-one 390i (70.0 mg, $0.25 \mathrm{mmol})$, tosyl azide 391a (148 mg, $0.75 \mathrm{mmol}), \mathrm{Ru}(\mathrm{OAc})_{2}(p$-cymene) $(8.8 \mathrm{mg}, 10$ mol \%) and $\mathrm{AgSbF}_{6}(17.2 \mathrm{mg}, 20 \mathrm{~mol} \%)$ in TFE (1.0 mL). Purification by column chromatography on silica gel ( $n$-hexane/EtOAc: $4 / 1)$ yielded $392 \mathbf{i}(92.1 \mathrm{mg}, 82 \%)$ as a light yellow solid.

M. p. $160^{\circ} \mathrm{C}$.

${ }^{1} \mathbf{H}$ NMR $\left(400 \mathrm{MHz}, \mathrm{CDCl}_{3}\right) \delta 9.31(\mathrm{~s}, 1 \mathrm{H}), 7.63(\mathrm{~d}, J=1.9 \mathrm{~Hz}, 1 \mathrm{H}), 7.51(\mathrm{~d}, J=3.9 \mathrm{~Hz}, 1 \mathrm{H}), 7.45$ $(\mathrm{dd}, J=7.1,1.9 \mathrm{~Hz}, 3 \mathrm{H}), 7.09$ (d, $J=7.8 \mathrm{~Hz}, 2 \mathrm{H}), 6.49$ (d, J = 3.9 Hz, 1H), 2.29 (s, 3H), 1.35 (s, 9H). ${ }^{13}$ C NMR $\left(100 \mathrm{MHz}, \mathrm{CDCl}_{3}\right) \delta 179.3\left(\mathrm{C}_{\mathrm{q}}\right), 143.5\left(\mathrm{C}_{\mathrm{q}}\right), 137.1\left(\mathrm{C}_{\mathrm{q}}\right), 133.5\left(\mathrm{C}_{\mathrm{q}}\right), 129.4(\mathrm{CH}), 128.0\left(\mathrm{C}_{\mathrm{q}}\right)$, 127.6 (CH), $126.8(\mathrm{CH}), 126.2\left(\mathrm{C}_{\mathrm{q}}\right), 124.4(\mathrm{CH}), 121.0(\mathrm{CH}), 118.0\left(\mathrm{C}_{\mathrm{q}}\right), 108.5(\mathrm{CH}), 41.7\left(\mathrm{C}_{\mathrm{q}}\right), 28.8$ $\left(\mathrm{CH}_{3}\right), 21.4\left(\mathrm{CH}_{3}\right)$.

IR (ATR): 3180, 2978, 1637, 1579, 1330, 1299, 1160, 1089, 903, $852 \mathrm{~cm}^{-1}$.

MS (ESI) $m / z$ (relative intensity): $449(100)\left({ }^{79} \mathrm{Br}\right)[\mathrm{M}+\mathrm{H}]^{+}, 451(100)\left({ }^{81} \mathrm{Br}\right)[\mathrm{M}+\mathrm{H}]^{+}$.

HR-MS (ESI) $\mathrm{C}_{20} \mathrm{H}_{22}{ }^{79} \mathrm{BrN}_{2} \mathrm{O}_{3} \mathrm{~S}[\mathrm{M}+\mathrm{H}]^{+}:$449.0531, found: 449.0529 .

The spectral data were in accordance with those reported in the literature. ${ }^{[42 \mathrm{~g}]}$

\section{$N$-(5-Iodo-1-pivaloyl-1 $H$-indol-7-yl)-4-methylbenzenesulfonamide (392j)}

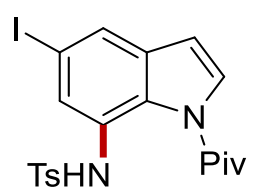

The General Procedure A was followed using 1-(5-iodo-1H-indol-1-yl)-2,2-dimethylpropan-1-one 390j ( $81.8 \mathrm{mg}, 0.25 \mathrm{mmol})$, tosyl azide 391a (148 mg, $0.75 \mathrm{mmol}), \mathrm{Ru}(\mathrm{OAc})_{2}(p$-cymene) (8.8 mg, 10 mol \%) and $\mathrm{AgSbF}_{6}(17.2 \mathrm{mg}, 20 \mathrm{~mol} \%)$ in TFE (1.0 mL). Purification by column chromatography on silica gel ( $n$-hexane/EtOAc: 4/1) yielded 392j (105.4 mg, 85\%) as a light yellow solid.

M. p. $160^{\circ} \mathrm{C}$.

${ }^{1} \mathbf{H}$ NMR $\left(400 \mathrm{MHz}, \mathrm{CDCl}_{3}\right) \delta 9.20(\mathrm{~s}, 1 \mathrm{H}), 7.77(\mathrm{dd}, J=1.6,0.4 \mathrm{~Hz}, 1 \mathrm{H}), 7.67(\mathrm{~d}, J=1.6 \mathrm{~Hz}, 1 \mathrm{H})$, $7.48(\mathrm{~d}, J=3.9 \mathrm{~Hz}, 1 \mathrm{H}), 7.45(\mathrm{ddd}, J=8.3,3.9,1.6 \mathrm{~Hz}, 2 \mathrm{H}), 7.13-7.08(\mathrm{~m}, 2 \mathrm{H}), 6.48(\mathrm{~d}, J=3.9 \mathrm{~Hz}$, 1H), $2.30(\mathrm{~s}, 3 \mathrm{H}), 1.36(\mathrm{~s}, 9 \mathrm{H})$.

${ }^{13} \mathbf{C}$ NMR $\left(100 \mathrm{MHz}, \mathrm{CDCl}_{3}\right) \delta 179.3\left(\mathrm{C}_{\mathrm{q}}\right), 143.4\left(\mathrm{C}_{\mathrm{q}}\right), 137.2\left(\mathrm{C}_{\mathrm{q}}\right), 133.9\left(\mathrm{C}_{\mathrm{q}}\right), 130.2(\mathrm{CH}), 129.4(\mathrm{CH})$, $128.9\left(\mathrm{C}_{\mathrm{q}}\right), 127.3(\mathrm{CH}), 127.2(\mathrm{CH}), 126.9(\mathrm{CH}), 126.3\left(\mathrm{C}_{\mathrm{q}}\right), 108.2(\mathrm{CH}), 88.5\left(\mathrm{C}_{\mathrm{q}}\right), 41.8\left(\mathrm{C}_{\mathrm{q}}\right), 28.9$ 
$\left(\mathrm{CH}_{3}\right), 21.4\left(\mathrm{CH}_{3}\right)$.

IR (ATR): $3187,2977,1674,1575,1331,1164,1090,905,812,716 \mathrm{~cm}^{-1}$.

MS (ESI) $m / z$ (relative intensity): $497(70)[\mathrm{M}+\mathrm{H}]^{+}, 519(30)[\mathrm{M}+\mathrm{Na}]^{+}$.

HR-MS (ESI) $\mathrm{C}_{20} \mathrm{H}_{22} \mathrm{IN}_{2} \mathrm{O}_{3} \mathrm{~S}[\mathrm{M}+\mathrm{H}]^{+}:$497.0388, found: 497.0390.

$N$-(6-Fluoro-1-pivaloyl-1 $H$-indol-7-yl)-4-methylbenzenesulfonamide (392k)

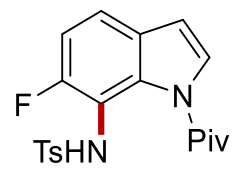

The general procedure was followed using 1-(6-fluoro-1H-indol-1-yl)-2,2-dimethylpropan-1-one 390k (54.8 mg, $0.25 \mathrm{mmol})$, tosyl azide 391a (148 mg, $0.75 \mathrm{mmol}), \mathrm{Ru}(\mathrm{OAc})_{2}(p$-cymene) (8.8 mg, 10 mol \%) and $\mathrm{AgSbF}_{6}(17.2 \mathrm{mg}, 20 \mathrm{~mol} \%)$ in TFE (1.0 mL). Purification by column chromatography on silica gel ( $n$-hexane/EtOAc: 4/1) yielded 392k (67.0 mg, 69\%) as a light yellow solid.

M. p. $125^{\circ} \mathrm{C}$.

${ }^{1} \mathbf{H}$ NMR $\left(400 \mathrm{MHz}, \mathrm{CDCl}_{3}\right) \delta 7.80(\mathrm{~s}, 1 \mathrm{H}), 7.57(\mathrm{ddd}, J=8.4,3.8,1.5 \mathrm{~Hz}, 2 \mathrm{H}), 7.54(\mathrm{~d}, J=3.8 \mathrm{~Hz}$, 1H), $7.40(\mathrm{dd}, J=8.4,4.9 \mathrm{~Hz}, 1 \mathrm{H}), 7.20-7.16(\mathrm{~m}, 2 \mathrm{H}), 7.11(\mathrm{dd}, J=10.0,8.5 \mathrm{~Hz}, 1 \mathrm{H}), 6.56(\mathrm{~d}, J=$ $3.8 \mathrm{~Hz}, 1 \mathrm{H}), 2.36(\mathrm{~s}, 3 \mathrm{H}), 1.41(\mathrm{~s}, 9 \mathrm{H})$.

${ }^{13}$ C NMR $\left(100 \mathrm{MHz}, \mathrm{CDCl}_{3}\right) \delta 179.5\left(\mathrm{C}_{\mathrm{q}}\right), 157.7\left(\mathrm{~d}, J_{\mathrm{C}-\mathrm{F}}=246.9 \mathrm{~Hz}, \mathrm{C}_{\mathrm{q}}\right), 143.6\left(\mathrm{C}_{\mathrm{q}}\right), 137.7\left(\mathrm{C}_{\mathrm{q}}\right)$, $132.9\left(\mathrm{~d}, J_{\mathrm{C}-\mathrm{F}}=3.7 \mathrm{~Hz}, \mathrm{C}_{\mathrm{q}}\right), 129.5(\mathrm{CH}), 128.1\left(\mathrm{~d}, J_{\mathrm{C}-\mathrm{F}}=1.9 \mathrm{~Hz}, \mathrm{C}_{\mathrm{q}}\right), 127.4(\mathrm{CH}), 127.0\left(\mathrm{~d}, J_{\mathrm{C}-\mathrm{F}}=3.8\right.$ $\mathrm{Hz}, \mathrm{CH}), 120.4\left(\mathrm{~d}, J_{\mathrm{C}-\mathrm{F}}=9.8 \mathrm{~Hz}, \mathrm{CH}\right), 113.6\left(\mathrm{~d}, J_{\mathrm{C}-\mathrm{F}}=24.1 \mathrm{~Hz}, \mathrm{CH}\right), 113.4\left(\mathrm{~d}, J_{\mathrm{C}-\mathrm{F}}=17.5 \mathrm{~Hz}, \mathrm{C}_{\mathrm{q}}\right)$, $108.4\left(\mathrm{~d}, J_{\mathrm{C}-\mathrm{F}}=1.6 \mathrm{~Hz}, \mathrm{CH}\right), 41.8\left(\mathrm{C}_{\mathrm{q}}\right), 29.0\left(\mathrm{CH}_{3}\right), 21.6\left(\mathrm{CH}_{3}\right)$.

${ }^{19}$ F NMR $\left(282 \mathrm{MHz}, \mathrm{CDCl}_{3}\right) \delta-121.9(\mathrm{dd}, J=10.1,4.9 \mathrm{~Hz})$.

IR (ATR): 3181, 2978, 1675, 1406, 1305, 1164, 1091, 899, 813, $739 \mathrm{~cm}^{-1}$.

MS (ESI) $m / z$ (relative intensity): $389(30)[\mathrm{M}+\mathrm{H}]^{+}, 411(70)[\mathrm{M}+\mathrm{Na}]^{+}$.

HR-MS (ESI) $\mathrm{C}_{20} \mathrm{H}_{21} \mathrm{FN}_{2} \mathrm{O}_{3} \mathrm{~S}[\mathrm{M}+\mathrm{H}]^{+}:$389.1330, found: 389.1330 .

The spectral data were in accordance with those reported in the literature. ${ }^{[42 \mathrm{~g}]}$ 
3-Bromo- $N$-(1-pivaloyl-1H-indol-7-yl)benzenesulfonamide (392I)<smiles>O=S(=O)(Nc1cccc2ccn(P)c12)c1cccc(Br)c1</smiles>

The General Procedure A was followed using $N$-pivaloyl indole 390a (50.3 mg, $0.25 \mathrm{mmol}), 3$ bromobenzenesulfonyl azide $391 b$ (197 mg, $0.75 \mathrm{mmol}), \mathrm{Ru}(\mathrm{OAc})_{2}(p$-cymene) $(8.8 \mathrm{mg}, 10 \mathrm{~mol} \%)$ and $\mathrm{AgSbF}_{6}(17.2 \mathrm{mg}, 20 \mathrm{~mol} \%)$ in TFE $(1.0 \mathrm{~mL})$. Purification by column chromatography on silica gel ( $n$-hexane/EtOAc: 4/1) yielded 3921 (87.1 mg, 80\%) as a dark yellow solid.

M. p. $105^{\circ} \mathrm{C}$.

${ }^{1}$ H NMR $\left(400 \mathrm{MHz}, \mathrm{CDCl}_{3}\right) \delta 9.42(\mathrm{~s}, 1 \mathrm{H}), 7.68(\mathrm{ddd}, J=1.9,1.7,0.4 \mathrm{~Hz}, 1 \mathrm{H}), 7.52(\mathrm{ddd}, J=3.9$, 1.9, $1.3 \mathrm{~Hz}, 3 \mathrm{H}), 7.40(\mathrm{dd}, J=7.8,1.3 \mathrm{~Hz}, 1 \mathrm{H}), 7.30$ (t, $J=7.8 \mathrm{~Hz}, 1 \mathrm{H}), 7.28$ (ddd, $J=7.8,1.7,1.0$ $\mathrm{Hz}, 1 \mathrm{H}), 7.10$ (t, $J=7.8 \mathrm{~Hz}, 1 \mathrm{H}), 6.57$ (d, $J=3.9 \mathrm{~Hz}, 1 \mathrm{H}), 1.37$ (s, 9H).

${ }^{13}$ C NMR $\left(100 \mathrm{MHz}, \mathrm{CDCl}_{3}\right) \delta 179.3\left(\mathrm{C}_{\mathrm{q}}\right), 142.0\left(\mathrm{C}_{\mathrm{q}}\right), 135.4(\mathrm{CH}), 132.3\left(\mathrm{C}_{\mathrm{q}}\right), 130.1(\mathrm{CH}), 129.6$ $(\mathrm{CH}), 129.4\left(\mathrm{C}_{\mathrm{q}}\right), 126.6(\mathrm{CH}), 125.3(\mathrm{CH}), 125.2(\mathrm{CH}), 124.5\left(\mathrm{C}_{\mathrm{q}}\right), 122.9(\mathrm{CH}), 122.7\left(\mathrm{C}_{\mathrm{q}}\right), 119.2(\mathrm{CH})$, $109.4(\mathrm{CH}), 41.7\left(\mathrm{C}_{\mathrm{q}}\right), 29.0\left(\mathrm{CH}_{3}\right)$.

IR (ATR): 3180, 2988, 1671, 1479, 1301, 1264, 1168, 1084, 731, $565 \mathrm{~cm}^{-1}$.

MS (ESI) $m / z$ (relative intensity): $435(100)\left({ }^{79} \mathrm{Br}\right)[\mathrm{M}+\mathrm{H}]^{+}, 437(100)\left({ }^{81} \mathrm{Br}\right)[\mathrm{M}+\mathrm{H}]^{+}$.

HR-MS (ESI) $\mathrm{C}_{19} \mathrm{H}_{20}{ }^{79} \mathrm{BrN}_{2} \mathrm{O}_{3} \mathrm{~S}[\mathrm{M}+\mathrm{H}]^{+}:$435.0372, found: 435.0373.

\section{$N$-(1-Pivaloyl-1H-indol-7-yl)benzenesulfonamide (392 m)}<smiles>O=S(=O)(Nc1cccc2ccn(P)c12)c1ccccc1</smiles>

The General Procedure A was followed using $N$-pivaloyl indole 390a (50.3 mg, $0.25 \mathrm{mmol})$, benzenesulfonyl azide 391c (137 mg, $0.75 \mathrm{mmol}), \mathrm{Ru}(\mathrm{OAc})_{2}(p$-cymene) $(8.8 \mathrm{mg}, 10 \mathrm{~mol} \%)$ and $\mathrm{AgSbF}_{6}(17.2 \mathrm{mg}, 20 \mathrm{~mol} \%)$ in TFE $(1.0 \mathrm{~mL})$. Purification by column chromatography on silica gel 
( $n$-hexane/EtOAc: $4 / 1)$ yielded 392m (52.6 mg, 59\%) as a light yellow solid.

M. p. $134^{\circ} \mathrm{C}$.

${ }^{1} \mathbf{H}$ NMR $\left(400 \mathrm{MHz}, \mathrm{CDCl}_{3}\right) \delta 9.27(\mathrm{~s}, 1 \mathrm{H}), 7.53(\mathrm{dd}, J=7.7,1.3 \mathrm{~Hz}, 1 \mathrm{H}), 7.51-7.49(\mathrm{~m}, 2 \mathrm{H}), 7.48$ $(\mathrm{d}, J=3.9 \mathrm{~Hz}, 1 \mathrm{H}), 7.39(\mathrm{ddd}, J=7.7,2.6,1.3 \mathrm{~Hz}, 1 \mathrm{H}), 7.36(\mathrm{dd}, J=7.7,1.3 \mathrm{~Hz}, 1 \mathrm{H}), 7.28(\mathrm{t}, J=7.7$ $\mathrm{Hz}, 1 \mathrm{H}) 7.29-7.23(\mathrm{~m}, 2 \mathrm{H}), 6.54(\mathrm{~d}, J=3.9 \mathrm{~Hz}, 1 \mathrm{H}), 1.35(\mathrm{~s}, 9 \mathrm{H})$.

${ }^{13}$ C NMR $\left(100 \mathrm{MHz}, \mathrm{CDCl}_{3}\right) \delta 179.3\left(\mathrm{C}_{\mathrm{q}}\right), 140.30\left(\mathrm{C}_{\mathrm{q}}\right), 132.4(\mathrm{CH}), 132.2\left(\mathrm{C}_{\mathrm{q}}\right), 129.4\left(\mathrm{C}_{\mathrm{q}}\right), 128.7$ $(\mathrm{CH}), 126.7(\mathrm{CH}), 126.5(\mathrm{CH}), 125.2(\mathrm{CH}), 125.0\left(\mathrm{C}_{\mathrm{q}}\right), 122.8(\mathrm{CH}), 118.9(\mathrm{CH}), 109.3(\mathrm{CH}), 41.6\left(\mathrm{C}_{\mathrm{q}}\right)$, $29.0\left(\mathrm{CH}_{3}\right)$.

IR (ATR): 3174, 2976, 1667, 1446, 1326, 1299, 1160, 1090, 904, $716 \mathrm{~cm}^{-1}$.

MS (ESI) $m / z$ (relative intensity): $357(30)[\mathrm{M}+\mathrm{H}]^{+}, 379(70)[\mathrm{M}+\mathrm{Na}]^{+}$.

HR-MS (ESI) $\mathrm{C}_{19} \mathrm{H}_{21} \mathrm{~N}_{2} \mathrm{O}_{3} \mathrm{~S}[\mathrm{M}+\mathrm{H}]^{+}: 357.1269$, found: 357.1267 .

The spectral data were in accordance with those reported in the literature. ${ }^{[42 \mathrm{~g}]}$

\section{$N$-(1-Pivaloyl-1H-indol-7-yl)methanesulfonamide (392n)}

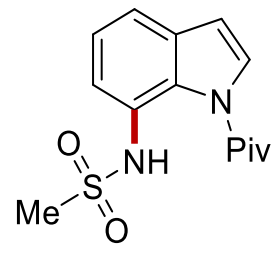

The General Procedure A was followed using $N$-pivaloyl indole 390a (50.3 mg, $0.25 \mathrm{mmol})$, methanesulfonyl azide 391d (90.8 $\mathrm{mg}, 0.75 \mathrm{mmol}), \mathrm{Ru}(\mathrm{OAc})_{2}(p$-cymene) $(8.8 \mathrm{mg}, 10 \mathrm{~mol} \%)$ and $\mathrm{AgSbF}_{6}(17.2 \mathrm{mg}, 20 \mathrm{~mol} \%)$ in TFE $(1.0 \mathrm{~mL})$. Purification by column chromatography on silica gel ( $n$-hexane/EtOAc: 4/1) yielded 392n (50.0 mg, 68\%) as a light yellow liquid.

${ }^{1} \mathbf{H}$ NMR $\left(400 \mathrm{MHz}, \mathrm{CDCl}_{3}\right) \delta 9.01(\mathrm{~s}, 1 \mathrm{H}), 7.71(\mathrm{~d}, J=3.9 \mathrm{~Hz}, 1 \mathrm{H}), 7.49(\mathrm{dd}, J=7.8,1.3 \mathrm{~Hz}, 1 \mathrm{H})$, $7.40(\mathrm{dd}, J=7.8,1.3 \mathrm{~Hz}, 1 \mathrm{H}), 7.31$ (t, $J=7.8 \mathrm{~Hz}, 1 \mathrm{H}), 6.67$ (d, $J=3.9 \mathrm{~Hz}, 1 \mathrm{H}), 2.90(\mathrm{~s}, 3 \mathrm{H}), 1.54$ (s, $9 \mathrm{H})$.

${ }^{13} \mathrm{C}$ NMR $\left(100 \mathrm{MHz}, \mathrm{CDCl}_{3}\right) \delta 179.9\left(\mathrm{C}_{\mathrm{q}}\right), 132.7\left(\mathrm{C}_{\mathrm{q}}\right), 128.9\left(\mathrm{C}_{\mathrm{q}}\right), 126.8(\mathrm{CH}), 125.5\left(\mathrm{C}_{\mathrm{q}}\right), 125.3(\mathrm{CH})$, 120.6 (CH), $118.6(\mathrm{CH}), 109.4(\mathrm{CH}), 42.0\left(\mathrm{C}_{\mathrm{q}}\right), 39.8\left(\mathrm{CH}_{3}\right), 29.2\left(\mathrm{CH}_{3}\right)$.

IR (ATR): 3196, 2976, 1670, 1590, 1359, 1317, 1153, 905, 755, $510 \mathrm{~cm}^{-1}$. MS (ESI) $m / z$ (relative intensity): $295(10)[\mathrm{M}+\mathrm{H}]^{+}, 317(90)[\mathrm{M}+\mathrm{Na}]^{+}$. 
HR-MS (ESI) $\mathrm{C}_{14} \mathrm{H}_{19} \mathrm{~N}_{2} \mathrm{O}_{3} \mathrm{~S}[\mathrm{M}+\mathrm{H}]^{+}$: 295.1111, found: 295.1111 .

The spectral data were in accordance with those reported in the literature. ${ }^{[42 \mathrm{~g}]}$

\section{$N$-(1-Pivaloyl-1H-indol-7-yl)cyclohexanesulfonamide (3920)}

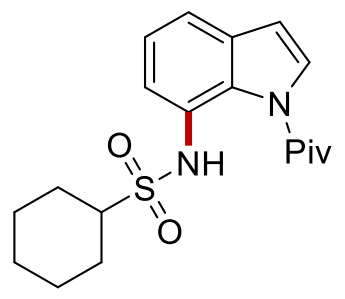

The General Procedure A was followed using $N$-pivaloyl indole 390a (50.3 mg, $0.25 \mathrm{mmol})$, cyclohexanesulfonyl azide 391e (142 mg, $0.75 \mathrm{mmol}), \mathrm{Ru}(\mathrm{OAc})_{2}(p$-cymene) $(8.8 \mathrm{mg}, 10 \mathrm{~mol} \%)$ and $\mathrm{AgSbF}_{6}(17.2 \mathrm{mg}, 20 \mathrm{~mol} \%)$ in TFE $(1.0 \mathrm{~mL})$. Purification by column chromatography on silica gel (n-hexane/EtOAc: 4/1) yielded 3920 (48.9 mg, 54\%) as a light yellow solid.

M. p. $113^{\circ} \mathrm{C}$.

${ }^{1} \mathbf{H}$ NMR $\left(400 \mathrm{MHz}, \mathrm{CDCl}_{3}\right) \delta 8.72(\mathrm{~s}, 1 \mathrm{H}), 7.69(\mathrm{~d}, J=3.9 \mathrm{~Hz}, 1 \mathrm{H}), 7.53(\mathrm{dd}, J=7.7,1.3 \mathrm{~Hz}, 1 \mathrm{H})$, $7.35(\mathrm{dd}, J=7.7,1.3 \mathrm{~Hz}, 1 \mathrm{H}), 7.27(\mathrm{t}, J=7.3 \mathrm{~Hz}, 1 \mathrm{H}), 6.65(\mathrm{~d}, J=3.9 \mathrm{~Hz}, 1 \mathrm{H}), 2.88(\mathrm{tt}, J=12.1,3.5$ $\mathrm{Hz}, 1 \mathrm{H}), 2.18-2.03(\mathrm{~m}, 2 \mathrm{H}), 1.86-1.77(\mathrm{~m}, 2 \mathrm{H}), 1.67-1.54(\mathrm{~m}, 2 \mathrm{H}), 1.53(\mathrm{~s}, 9 \mathrm{H}), 1.49-1.52(\mathrm{~m}$, $2 \mathrm{H}), 1.19-1.10(\mathrm{~m}, 2 \mathrm{H})$.

${ }^{13}$ C NMR $\left(100 \mathrm{MHz}, \mathrm{CDCl}_{3}\right) \delta 180.0\left(\mathrm{C}_{\mathrm{q}}\right), 132.5\left(\mathrm{C}_{\mathrm{q}}\right), 128.5\left(\mathrm{C}_{\mathrm{q}}\right), 126.6(\mathrm{CH}), 125.9\left(\mathrm{C}_{\mathrm{q}}\right), 125.3(\mathrm{CH})$, $119.7(\mathrm{CH}), 117.9(\mathrm{CH}), 109.4(\mathrm{CH}), 60.7(\mathrm{CH}), 42.0\left(\mathrm{C}_{\mathrm{q}}\right), 29.2\left(\mathrm{CH}_{3}\right), 26.3\left(\mathrm{CH}_{2}\right), 25.1\left(\mathrm{CH}_{2}\right), 25.1$ $\left(\mathrm{CH}_{2}\right)$.

IR (ATR): 3188, 2945, 1552, 1413, 1391, 1135, 909, 723, $405 \mathrm{~cm}^{-1}$.

MS (ESI) $m / z$ (relative intensity): $363(10)[\mathrm{M}+\mathrm{H}]^{+}, 385(90)[\mathrm{M}+\mathrm{Na}]^{+}$.

HR-MS (ESI) $\mathrm{C}_{19} \mathrm{H}_{27} \mathrm{~N}_{2} \mathrm{O}_{3} \mathrm{~S}[\mathrm{M}+\mathrm{H}]^{+}:$363.1738, found: 363.1737 .

\section{Methyl-3-(1-pivaloyl-1H-indol-7-yl)acrylate (394a)}

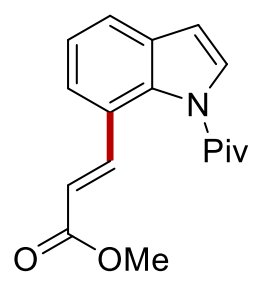


The General Procedure B was followed using $N$-pivaloyl indole 390a (50.3 mg, $0.25 \mathrm{mmol})$, methyl acrylate 393a (64.6 mg, $0.75 \mathrm{mmol}), \mathrm{Ru}(\mathrm{OAc})_{2}\left(p\right.$-cymene) $(8.8 \mathrm{mg}, 10 \mathrm{~mol} \%), \mathrm{AgSbF}_{6}(17.2 \mathrm{mg}, 20$ $\mathrm{mol} \%)$ and $\mathrm{Cu}(\mathrm{OAc})_{2}(90.8 \mathrm{mg}, 2$ equiv) in TFE $(1.0 \mathrm{~mL})$. Purification by column chromatography on silica gel ( $n$-hexane/EtOAc: $10 / 1)$ yielded 394a (53.5 mg, 75\%) as a light yellow solid.

M. p. $121^{\circ} \mathrm{C}$.

${ }^{1} \mathbf{H}$ NMR $\left(400 \mathrm{MHz}, \mathrm{CDCl}_{3}\right) \delta 7.81(\mathrm{~d}, J=15.7 \mathrm{~Hz}, 1 \mathrm{H}), 7.58(\mathrm{~d}, J=7.6 \mathrm{~Hz}, 1 \mathrm{H}), 7.57(\mathrm{~d}, J=3.8 \mathrm{~Hz}$, $1 \mathrm{H}), 7.44(\mathrm{~d}, J=7.6,1 \mathrm{H}), 7.26(\mathrm{t}, J=7.6 \mathrm{~Hz}, 1 \mathrm{H}), 6.62(\mathrm{~d}, J=3.8 \mathrm{~Hz}, 1 \mathrm{H}), 6.28(\mathrm{~d}, J=15.7 \mathrm{~Hz}, 1 \mathrm{H})$, $3.79(\mathrm{~s}, 3 \mathrm{H}), 1.54(\mathrm{~s}, 9 \mathrm{H})$.

${ }^{13} \mathrm{C} \mathrm{NMR}\left(100 \mathrm{MHz}, \mathrm{CDCl}_{3}\right) \delta 179.4\left(\mathrm{C}_{\mathrm{q}}\right), 167.4\left(\mathrm{C}_{\mathrm{q}}\right), 143.3(\mathrm{CH}), 134.8\left(\mathrm{C}_{\mathrm{q}}\right), 131.2\left(\mathrm{C}_{\mathrm{q}}\right), 126.5(\mathrm{CH})$, 124.0 (CH), $123.5(\mathrm{CH}), 123.2\left(\mathrm{C}_{\mathrm{q}}\right), 122.4(\mathrm{CH}), 117.2(\mathrm{CH}), 107.5(\mathrm{CH}), 51.6\left(\mathrm{CH}_{3}\right), 42.0\left(\mathrm{C}_{\mathrm{q}}\right), 29.0$ $\left(\mathrm{CH}_{3}\right)$.

IR (ATR): 2958, 2156, 1704, 1636, 1312, 1309, 1167, 949, 753, $592 \mathrm{~cm}^{-1}$.

MS (ESI) $m / z$ (relative intensity): $286(10)[\mathrm{M}+\mathrm{H}]^{+}, 308(90)[\mathrm{M}+\mathrm{Na}]^{+}$.

HR-MS (ESI) $\mathrm{C}_{17} \mathrm{H}_{20} \mathrm{NO}_{3}[\mathrm{M}+\mathrm{H}]^{+}:$: 286.1437, found: 286.1438 .

The spectral data were in accordance with those reported in the literature. ${ }^{[265]}$

Methyl-3-(3-methyl-1-pivaloyl-1H-indol-7-yl)acrylate (394b)

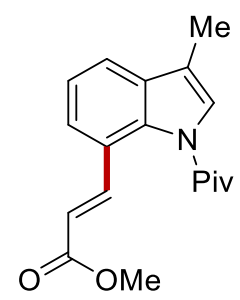

The General Procedure B was followed using 2,2-dimethyl-1-(3-methyl-1 $H$-indol-1-yl)propan-1-one 390b (53.8 mg, $0.25 \mathrm{mmol})$, methyl acrylate 393a (64.6 mg, $0.75 \mathrm{mmol}), \mathrm{Ru}(\mathrm{OAc})_{2}(p$-cymene) $(8.8$ $\mathrm{mg}, 10 \mathrm{~mol} \%), \mathrm{AgSbF}_{6}(17.2 \mathrm{mg}, 20 \mathrm{~mol} \%)$ and $\mathrm{Cu}(\mathrm{OAc})_{2}(90.8 \mathrm{mg}, 2$ equiv) in TFE $(1.0 \mathrm{~mL})$. Purification by column chromatography on silica gel ( $n$-hexane/EtOAc: 10/1) yielded 394b $(27.7 \mathrm{mg}$, $37 \%)$ as a light yellow solid.

M. p. $107^{\circ} \mathrm{C}$.

${ }^{1} \mathbf{H}$ NMR $\left(400 \mathrm{MHz}, \mathrm{CDCl}_{3}\right) \delta 7.81(\mathrm{~d}, J=15.8 \mathrm{~Hz}, 1 \mathrm{H}), 7.50(\mathrm{dd}, J=7.7,1.2 \mathrm{~Hz}, 1 \mathrm{H}), 7.45(\mathrm{~d}, J=$ 
$7.7 \mathrm{~Hz}, 1 \mathrm{H}), 7.35(\mathrm{q}, J=1.2 \mathrm{~Hz}, 1 \mathrm{H}), 7.28(\mathrm{t}, J=7.7 \mathrm{~Hz}, 1 \mathrm{H}), 6.26(\mathrm{~d}, J=15.8 \mathrm{~Hz}, 1 \mathrm{H}), 3.78(\mathrm{~s}, 3 \mathrm{H})$, $2.27(\mathrm{~s}, 3 \mathrm{H}), 1.52(\mathrm{~s}, 9 \mathrm{H})$.

${ }^{13} \mathrm{C}$ NMR $\left(100 \mathrm{MHz}, \mathrm{CDCl}_{3}\right) \delta 179.0\left(\mathrm{C}_{\mathrm{q}}\right), 167.5\left(\mathrm{C}_{\mathrm{q}}\right), 143.6(\mathrm{CH}), 135.4\left(\mathrm{C}_{\mathrm{q}}\right), 132.3\left(\mathrm{C}_{\mathrm{q}}\right), 124.1(\mathrm{CH})$, 123.6 (CH), $123.4\left(\mathrm{C}_{\mathrm{q}}\right), 123.3(\mathrm{CH}), 120.3(\mathrm{CH}), 116.9(\mathrm{CH}), 116.6\left(\mathrm{C}_{\mathrm{q}}\right), 51.6\left(\mathrm{CH}_{3}\right), 41.8\left(\mathrm{C}_{\mathrm{q}}\right), 29.0$ $\left(\mathrm{CH}_{3}\right), 9.7\left(\mathrm{CH}_{3}\right)$.

IR (ATR): 2970, 2169, 1711, 1434, 1371, 1265, 1170, 1038, 906, $731 \mathrm{~cm}^{-1}$.

MS (ESI) $m / z$ (relative intensity): $300(10)[\mathrm{M}+\mathrm{H}]^{+}, 322(34)[\mathrm{M}+\mathrm{Na}]^{+}$.

HR-MS (ESI) $\mathrm{C}_{18} \mathrm{H}_{22} \mathrm{NO}_{3}[\mathrm{M}+\mathrm{H}]^{+}: 300.1594$, found: 300.1594 .

\section{Methyl-3-(4-methyl-1-pivaloyl-1 $H$-indol-7-yl)acrylate (394c)}

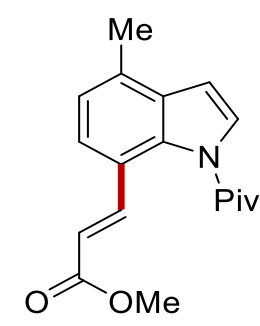

The General Procedure B was followed using 2,2-dimethyl-1-(4-methyl-1 $H$-indol-1-yl)propan-1-one 390c $(53.8 \mathrm{mg}, 0.25 \mathrm{mmol})$, methyl acrylate 393a $(64.6 \mathrm{mg}, 0.75 \mathrm{mmol}), \mathrm{Ru}(\mathrm{OAc})_{2}(p$-cymene $)(8.8$ $\mathrm{mg}, 10 \mathrm{~mol} \%), \operatorname{AgSbF}_{6}(17.2 \mathrm{mg}, 20 \mathrm{~mol} \%)$ and $\mathrm{Cu}(\mathrm{OAc})_{2}(90.8 \mathrm{mg}, 2$ equiv) in TFE (1.0 mL). Purification by column chromatography on silica gel ( $n$-hexane/EtOAc: 10/1) yielded 394c (41.9 mg, $56 \%$ ) as a light yellow solid.

M. p. $113^{\circ} \mathrm{C}$.

${ }^{1} \mathbf{H}$ NMR $\left(400 \mathrm{MHz}, \mathrm{CDCl}_{3}\right) \delta 7.73(\mathrm{~d}, J=15.7 \mathrm{~Hz}, 1 \mathrm{H}), 7.51(\mathrm{~d}, J=3.8 \mathrm{~Hz}, 1 \mathrm{H}), 7.32(\mathrm{~d}, J=7.9 \mathrm{~Hz}$, 1H), $7.02(\mathrm{ddd}, J=7.9,1.4,0.7 \mathrm{~Hz}, 1 \mathrm{H}), 6.59(\mathrm{~d}, J=3.8 \mathrm{~Hz}, 1 \mathrm{H}), 6.20(\mathrm{~d}, J=15.7 \mathrm{~Hz}, 1 \mathrm{H}), 3.73$ (s, $3 \mathrm{H}), 2.47(\mathrm{~s}, 3 \mathrm{H}), 1.49(\mathrm{~s}, 9 \mathrm{H})$.

${ }^{13} \mathrm{C}$ NMR $\left(100 \mathrm{MHz}, \mathrm{CDCl}_{3}\right) \delta 179.7\left(\mathrm{C}_{\mathrm{q}}\right), 167.6\left(\mathrm{C}_{\mathrm{q}}\right), 143.3(\mathrm{CH}), 134.6\left(\mathrm{C}_{\mathrm{q}}\right), 132.5\left(\mathrm{C}_{\mathrm{q}}\right), 130.8\left(\mathrm{C}_{\mathrm{q}}\right)$, $125.9(\mathrm{CH}), 124.1(\mathrm{CH}), 124.0(\mathrm{CH}), 120.8\left(\mathrm{C}_{\mathrm{q}}\right), 116.3(\mathrm{CH}), 105.8(\mathrm{CH}), 51.5\left(\mathrm{CH}_{3}\right), 42.1\left(\mathrm{C}_{\mathrm{q}}\right), 29.0$ $\left(\mathrm{CH}_{3}\right), 18.6\left(\mathrm{CH}_{3}\right)$.

IR (ATR): 2969, 1706, 1633, 1264, 1159, 1080, 900, 730, 616, $444 \mathrm{~cm}^{-1}$.

MS (ESI) $m / z$ (relative intensity): $300(66)[\mathrm{M}+\mathrm{H}]^{+}, 322(34)[\mathrm{M}+\mathrm{Na}]^{+}$. 
HR-MS (ESI) $\mathrm{C}_{18} \mathrm{H}_{22} \mathrm{NO}_{3}[\mathrm{M}+\mathrm{H}]^{+}: 300.1598$, found: 300.1596 .

The spectral data were in accordance with those reported in the literature. ${ }^{[265]}$

\section{Methyl-3-(4-methoxy-1-pivaloyl-1H-indol-7-yl)acrylate (394d)}<smiles>COC(=O)/C=C/c1ccc(OC)c2ccn(P)c12</smiles>

The General Procedure B was followed using 1-(4-methoxy-1H-indol-1-yl)-2,2-dimethylpropan-1one 390d (57.8 mg, $0.25 \mathrm{mmol})$, methyl acrylate 393a (64.6 mg, $0.75 \mathrm{mmol}), \mathrm{Ru}(\mathrm{OAc})_{2}(p$-cymene) (8.8 mg, $10 \mathrm{~mol} \%), \mathrm{AgSbF}_{6}(17.2 \mathrm{mg}, 20 \mathrm{~mol} \%)$ and $\mathrm{Cu}(\mathrm{OAc})_{2}(90.8 \mathrm{mg}, 2$ equiv) in TFE (1.0 mL). Purification by column chromatography on silica gel ( $n$-hexane/EtOAc: $10 / 1)$ yielded 394d (41.8 mg, $53 \%)$ as a light yellow solid.

M. p. $132^{\circ} \mathrm{C}$.

${ }^{1} \mathbf{H}$ NMR $\left(400 \mathrm{MHz}, \mathrm{CDCl}_{3}\right) \delta 7.75(\mathrm{~d}, J=15.7 \mathrm{~Hz}, 1 \mathrm{H}), 7.46(\mathrm{~d}, J=3.7 \mathrm{~Hz}, 1 \mathrm{H}), 7.43(\mathrm{~d}, J=8.3 \mathrm{~Hz}$, 1H), $6.73(\mathrm{~d}, J=3.7 \mathrm{~Hz}, 1 \mathrm{H}), 6.69(\mathrm{~d}, J=8.3 \mathrm{~Hz}, 1 \mathrm{H}), 6.18(\mathrm{~d}, J=15.7 \mathrm{~Hz}, 1 \mathrm{H}), 3.94(\mathrm{~s}, 3 \mathrm{H}), 3.77$ (s, $3 \mathrm{H}), 1.53(\mathrm{~s}, 9 \mathrm{H})$.

${ }^{13} \mathrm{C} \mathrm{NMR}\left(100 \mathrm{MHz}, \mathrm{CDCl}_{3}\right) \delta 179.8\left(\mathrm{C}_{\mathrm{q}}\right), 167.7\left(\mathrm{C}_{\mathrm{q}}\right), 154.6\left(\mathrm{C}_{\mathrm{q}}\right), 142.9(\mathrm{CH}), 136.2\left(\mathrm{C}_{\mathrm{q}}\right), 125.6(\mathrm{CH})$, $125.0(\mathrm{CH}), 121.3\left(\mathrm{C}_{\mathrm{q}}\right), 116.4\left(\mathrm{C}_{\mathrm{q}}\right), 115.1(\mathrm{CH}), 104.3(\mathrm{CH}), 103.8(\mathrm{CH}), 55.6\left(\mathrm{CH}_{3}\right), 51.5\left(\mathrm{CH}_{3}\right), 42.2$ $\left(\mathrm{C}_{\mathrm{q}}\right), 28.9\left(\mathrm{CH}_{3}\right)$.

IR (ATR): 2967, 1706, 1601, 1498, 1262, 1156, 1065, 901, 731, $584 \mathrm{~cm}^{-1}$.

MS (ESI) $m / z$ (relative intensity): $316(10)[\mathrm{M}+\mathrm{H}]^{+}, 338(34)[\mathrm{M}+\mathrm{Na}]^{+}$.

HR-MS (ESI) $\mathrm{C}_{18} \mathrm{H}_{22} \mathrm{NO}_{4}[\mathrm{M}+\mathrm{H}]^{+}: 316.1539$, found: 316.1540 .

The spectral data were in accordance with those reported in the literature. ${ }^{[265]}$ 
Methyl-3-(4-bromo-1-pivaloyl-1 $H$-indol-7-yl)acrylate (394e)<smiles>COC(=O)/C=C/c1ccc(Br)c2ccn(P)c12</smiles>

The General Procedure B was followed using 1-(4-bromo-1 H-indol-1-yl)-2,2-dimethylpropan-1-one 390e $(70.0 \mathrm{mg}, 0.25 \mathrm{mmol})$, methyl acrylate 393a $(64.6 \mathrm{mg}, 0.75 \mathrm{mmol}), \mathrm{Ru}(\mathrm{OAc})_{2}(p$-cymene $)(8.8$ $\mathrm{mg}, 10 \mathrm{~mol} \%), \operatorname{AgSbF}_{6}(17.2 \mathrm{mg}, 20 \mathrm{~mol} \%)$ and $\mathrm{Cu}(\mathrm{OAc})_{2}(90.8 \mathrm{mg}, 2$ equiv) in TFE (1.0 mL). Purification by column chromatography on silica gel ( $n$-hexane/EtOAc: $10 / 1)$ yielded 394e (62.8 mg, $69 \%$ ) as a light yellow solid.

M. p. $101^{\circ} \mathrm{C}$.

${ }^{1} \mathbf{H}$ NMR $\left(400 \mathrm{MHz}, \mathrm{CDCl}_{3}\right) \delta 7.70(\mathrm{~d}, J=15.7 \mathrm{~Hz}, 1 \mathrm{H}), 7.60(\mathrm{dd}, J=3.7,0.4 \mathrm{~Hz}, 1 \mathrm{H}), 7.42(\mathrm{dd}, J=$ 8.1, $0.4 \mathrm{~Hz}, 1 \mathrm{H}), 7.28(\mathrm{ddd}, J=8.1,1.1,0.4 \mathrm{~Hz}, 1 \mathrm{H}), 6.70(\mathrm{~d}, J=3.7 \mathrm{~Hz}, 1 \mathrm{H}), 6.26(\mathrm{~d}, J=15.7 \mathrm{~Hz}$, 1H), $3.78(\mathrm{~s}, 3 \mathrm{H}), 1.50(\mathrm{~s}, 9 \mathrm{H})$.

${ }^{13} \mathrm{C}$ NMR $\left(100 \mathrm{MHz}, \mathrm{CDCl}_{3}\right) \delta 179.5\left(\mathrm{C}_{\mathrm{q}}\right), 167.2\left(\mathrm{C}_{\mathrm{q}}\right), 142.2(\mathrm{CH}), 134.9\left(\mathrm{C}_{\mathrm{q}}\right), 131.7\left(\mathrm{C}_{\mathrm{q}}\right), 126.9(\mathrm{CH})$, $126.4(\mathrm{CH}), 124.7(\mathrm{CH}), 122.3\left(\mathrm{C}_{\mathrm{q}}\right), 117.8(\mathrm{CH}), 116.5\left(\mathrm{C}_{\mathrm{q}}\right), 107.4(\mathrm{CH}), 51.7\left(\mathrm{CH}_{3}\right), 42.2\left(\mathrm{C}_{\mathrm{q}}\right), 28.8$ $\left(\mathrm{CH}_{3}\right)$.

IR (ATR): 2968, 1041, 1714, 1475, 1263, 1170, 1009, 875, 703, $534 \mathrm{~cm}^{-1}$.

MS (ESI) $m / z$ (relative intensity): $364(10)\left({ }^{79} \mathrm{Br}\right)[\mathrm{M}+\mathrm{H}]+, 366(10)\left({ }^{81} \mathrm{Br}\right)[\mathrm{M}+\mathrm{H}]+, 386(90)\left({ }^{79} \mathrm{Br}\right)$ $[\mathrm{M}+\mathrm{Na}]^{+}, 388(90)\left({ }^{81} \mathrm{Br}\right)[\mathrm{M}+\mathrm{Na}]^{+}$.

HR-MS (ESI) $\mathrm{C}_{17} \mathrm{H}_{19}{ }^{79} \mathrm{BrNO}_{3}[\mathrm{M}+\mathrm{H}]^{+}:$364.0553, found: 364.0554 .

The spectral data were in accordance with those reported in the literature. ${ }^{[265]}$

Methyl-3-(5-methyl-1-pivaloyl-1 $H$-indol-7-yl)acrylate (394f)<smiles>COC(=O)/C=C/c1cc(C)cc2ccn(P(=O)(O)c3ccccc3)c12</smiles> 
The General Procedure B was followed using 1-(5-methyl-1 $H$-indol-1-yl)-2,2-dimethylpropan-1-one 390f (53.8 mg, $0.25 \mathrm{mmol})$, methyl acrylate 393a (64.6 mg, $0.75 \mathrm{mmol}), \mathrm{Ru}(\mathrm{OAc})_{2}(p$-cymene) $(8.8$ $\mathrm{mg}, 10 \mathrm{~mol} \%), \operatorname{AgSbF}_{6}(17.2 \mathrm{mg}, 20 \mathrm{~mol} \%)$ and $\mathrm{Cu}(\mathrm{OAc})_{2}(90.8 \mathrm{mg}, 2$ equiv) in TFE (1.0 mL). Purification by column chromatography on silica gel ( $n$-hexane/EtOAc: $10 / 1)$ yielded 394f (49.4 mg, $66 \%$ ) as a light yellow solid.

M. p. $121^{\circ} \mathrm{C}$.

${ }^{1} \mathbf{H}$ NMR $\left(400 \mathrm{MHz}, \mathrm{CDCl}_{3}\right) \delta 7.80(\mathrm{~d}, J=15.7 \mathrm{~Hz}, 1 \mathrm{H}), 7.54(\mathrm{~d}, J=3.7 \mathrm{~Hz}, 1 \mathrm{H}), 7.35-7.36(\mathrm{~m}$, 1H), $7.27-7.26(\mathrm{~m}, 1 \mathrm{H}), 6.53(\mathrm{~d}, J=3.7 \mathrm{~Hz}, 1 \mathrm{H}), 6.25(\mathrm{~d}, J=15.7 \mathrm{~Hz}, 1 \mathrm{H}), 3.78(\mathrm{~s}, 3 \mathrm{H}), 2.42(\mathrm{~s}$, $3 \mathrm{H}), 1.53(\mathrm{~s}, 9 \mathrm{H})$.

${ }^{13} \mathrm{C}$ NMR $\left(100 \mathrm{MHz}, \mathrm{CDCl}_{3}\right) \delta 179.2\left(\mathrm{C}_{\mathrm{q}}\right), 167.5\left(\mathrm{C}_{\mathrm{q}}\right), 143.5(\mathrm{CH}), 133.2\left(\mathrm{C}_{\mathrm{q}}\right), 133.1\left(\mathrm{C}_{\mathrm{q}}\right), 131.6\left(\mathrm{C}_{\mathrm{q}}\right)$, $126.6(\mathrm{CH}), 125.6(\mathrm{CH}), 122.9\left(\mathrm{C}_{\mathrm{q}}\right), 122.4(\mathrm{CH}), 117.0(\mathrm{CH}), 107.3(\mathrm{CH}), 51.6\left(\mathrm{CH}_{3}\right), 41.9\left(\mathrm{C}_{\mathrm{q}}\right), 29.0$ $\left(\mathrm{CH}_{3}\right), 21.1\left(\mathrm{CH}_{3}\right)$.

IR (ATR): 2973, 1709, 1612, 1495, 1301, 1257, 1168, 902, 713, $622 \mathrm{~cm}^{-1}$.

MS (ESI) $m / z$ (relative intensity): $300(10)[\mathrm{M}+\mathrm{H}]^{+}, 322(90)[\mathrm{M}+\mathrm{Na}]^{+}$.

HR-MS (ESI) $\mathrm{C}_{18} \mathrm{H}_{22} \mathrm{NO}_{3}[\mathrm{M}+\mathrm{H}]^{+}: 300.1599$, found: 300.1597 .

Methyl-3-(5-methoxy-1-pivaloyl-1 $H$-indol-7-yl)acrylate (394g)<smiles>COC(=O)/C=C/c1cc(OC)cc2ccn([PH](=O)(=O)c3ccccc3)c12</smiles>

The General Procedure B was followed using 1-(5-methoxy-1H-indol-1-yl)-2,2-dimethylpropan-1one 390g (57.8 mg, $0.25 \mathrm{mmol})$, methyl acrylate 393a (64.6 mg, $0.75 \mathrm{mmol}), \mathrm{Ru}(\mathrm{OAc})_{2}(p$-cymene) (8.8 mg, $10 \mathrm{~mol} \%), \operatorname{AgSbF}_{6}(17.2 \mathrm{mg}, 20 \mathrm{~mol} \%)$ and $\mathrm{Cu}(\mathrm{OAc})_{2}(90.8 \mathrm{mg}, 2$ equiv) in TFE $(1.0 \mathrm{~mL})$. Purification by column chromatography on silica gel ( $n$-hexane/EtOAc: 10/1) yielded 394g (49.7 mg, $63 \%$ ) as a light yellow solid.

M. p. $102^{\circ} \mathrm{C}$.

${ }^{1} \mathbf{H}$ NMR $\left(400 \mathrm{MHz}, \mathrm{CDCl}_{3}\right) \delta 7.80(\mathrm{~d}, J=15.7 \mathrm{~Hz}, 1 \mathrm{H}), 7.56(\mathrm{~d}, J=3.7 \mathrm{~Hz}, 1 \mathrm{H}), 7.05(\mathrm{~m}, 2 \mathrm{H}), 6.53$ 
$(\mathrm{d}, J=3.7 \mathrm{~Hz}, 1 \mathrm{H}), 6.25(\mathrm{~d}, J=15.7 \mathrm{~Hz}, 1 \mathrm{H}), 3.84(\mathrm{~s}, 3 \mathrm{H}), 3.78(\mathrm{~s}, 3 \mathrm{H}), 1.52(\mathrm{~s}, J=4.5 \mathrm{~Hz}, 9 \mathrm{H})$.

${ }^{13}$ C NMR $\left(100 \mathrm{MHz}, \mathrm{CDCl}_{3}\right) \delta 178.9\left(\mathrm{C}_{\mathrm{q}}\right), 167.3\left(\mathrm{C}_{\mathrm{q}}\right), 156.4\left(\mathrm{C}_{\mathrm{q}}\right), 143.2(\mathrm{CH}), 132.4\left(\mathrm{C}_{\mathrm{q}}\right), 129.8\left(\mathrm{C}_{\mathrm{q}}\right)$, $127.3(\mathrm{CH}), 124.1\left(\mathrm{C}_{\mathrm{q}}\right), 117.5(\mathrm{CH}), 112.3(\mathrm{CH}), 107.5(\mathrm{CH}), 105.2(\mathrm{CH}), 55.8\left(\mathrm{CH}_{3}\right), 51.6\left(\mathrm{CH}_{3}\right)$, $41.8\left(\mathrm{C}_{\mathrm{q}}\right), 29.0\left(\mathrm{CH}_{3}\right)$.

IR (ATR): 2970, 1713, 1620, 1487, 1315, 1260, 1043, 902, 722, $691 \mathrm{~cm}^{-1}$.

MS (ESI) $m / z$ (relative intensity): $316(20)[\mathrm{M}+\mathrm{H}]^{+}, 338(80)[\mathrm{M}+\mathrm{Na}]^{+}$.

HR-MS (ESI) $\mathrm{C}_{18} \mathrm{H}_{22} \mathrm{NO}_{4}[\mathrm{M}+\mathrm{H}]^{+}: 316.1541$, found: 316.1543 .

The spectral data were in accordance with those reported in the literature. ${ }^{[265]}$

Methyl-3-(5-chloro-1-pivaloyl-1 $H$-indol-7-yl)acrylate (394h)<smiles>COC(=O)/C=C/c1cc(Cl)cc2ccn(P)c12</smiles>

The General Procedure B was followed using 1-(5-chloro-1 $H$-indol-1-yl)-2,2-dimethylpropan-1-one 390h (58.9 mg, $0.25 \mathrm{mmol})$, methyl acrylate 393a (64.6 mg, $0.75 \mathrm{mmol}), \mathrm{Ru}(\mathrm{OAc})_{2}(p$-cymene) $(8.8$ $\mathrm{mg}, 10 \mathrm{~mol} \%), \operatorname{AgSbF}_{6}(17.2 \mathrm{mg}, 20 \mathrm{~mol} \%)$ and $\mathrm{Cu}(\mathrm{OAc})_{2}(90.8 \mathrm{mg}, 2$ equiv) in TFE (1.0 mL). Purification by column chromatography on silica gel ( $n$-hexane/EtOAc: 10/1) yielded 394h (55.2 mg, $69 \%$ ) as a light yellow solid.

M. p. $105^{\circ} \mathrm{C}$.

${ }^{1} \mathbf{H}$ NMR $\left(400 \mathrm{MHz}, \mathrm{CDCl}_{3}\right) \delta 7.72(\mathrm{~d}, J=15.7 \mathrm{~Hz}, 1 \mathrm{H}), 7.59(\mathrm{dd}, J=3.7,0.5 \mathrm{~Hz}, 1 \mathrm{H}), 7.53(\mathrm{~d}, J=$ $2.0 \mathrm{~Hz}, 1 \mathrm{H}), 7.39(\mathrm{dd}, J=2.0,0.5 \mathrm{~Hz}, 1 \mathrm{H}), 6.55(\mathrm{~d}, J=3.7 \mathrm{~Hz}, 1 \mathrm{H}), 6.26(\mathrm{~d}, J=15.7 \mathrm{~Hz}, 1 \mathrm{H}), 3.79$ $(\mathrm{s}, 3 \mathrm{H}), 1.52(\mathrm{~s}, 9 \mathrm{H})$.

${ }^{13}$ C NMR $\left(100 \mathrm{MHz}, \mathrm{CDCl}_{3}\right) \delta 179.2\left(\mathrm{C}_{\mathrm{q}}\right), 167.0\left(\mathrm{C}_{\mathrm{q}}\right), 142.0(\mathrm{CH}), 133.2\left(\mathrm{C}_{\mathrm{q}}\right), 132.4\left(\mathrm{C}_{\mathrm{q}}\right), 129.1\left(\mathrm{C}_{\mathrm{q}}\right)$, 127.7 (CH), $124.4\left(\mathrm{C}_{\mathrm{q}}\right), 123.8(\mathrm{CH}), 121.6(\mathrm{CH}), 118.4(\mathrm{CH}), 106.8(\mathrm{CH}), 51.7\left(\mathrm{CH}_{3}\right), 42.1\left(\mathrm{C}_{\mathrm{q}}\right), 28.9$ $\left(\mathrm{CH}_{3}\right)$.

IR (ATR): 2971, 1707, 1639, 1400, 1259, 1166, 1043, 905, 811, $714 \mathrm{~cm}^{-1}$.

MS (ESI) $m / z$ (relative intensity): $320(10)[\mathrm{M}+\mathrm{H}]^{+}, 342(90)[\mathrm{M}+\mathrm{Na}]^{+}$. 
HR-MS (ESI) $\mathrm{C}_{17} \mathrm{H}_{19}{ }^{35} \mathrm{ClNO}_{3}[\mathrm{M}+\mathrm{H}]^{+}:$320.1043, found: 320.1045 .

The spectral data were in accordance with those reported in the literature. ${ }^{[265]}$

\section{Methyl-3-(5-bromo-1-pivaloyl-1H-indol-7-yl)acrylate (394i)}<smiles>COC(=O)/C=C/c1cc(Br)cc2ccn(P(=O)(O)c3ccccc3)c12</smiles>

The General Procedure B was followed using 1-(5-bromo-1 $H$-indol-1-yl)-2,2-dimethylpropan-1-one 390i (70.0 mg, $0.25 \mathrm{mmol})$, methyl acrylate 393a (64.6 mg, $0.75 \mathrm{mmol}), \mathrm{Ru}(\mathrm{OAc})_{2}(p$-cymene) $(8.8$ $\mathrm{mg}, 10 \mathrm{~mol} \%), \mathrm{AgSbF}_{6}(17.2 \mathrm{mg}, 20 \mathrm{~mol} \%)$ and $\mathrm{Cu}(\mathrm{OAc})_{2}(90.8 \mathrm{mg}, 2$ equiv) in TFE (1.0 mL). Purification by column chromatography on silica gel ( $n$-hexane/EtOAc: $10 / 1)$ yielded 394i $(65.6 \mathrm{mg}$, $72 \%)$ as a light yellow solid.

M. p. $97^{\circ} \mathrm{C}$.

${ }^{1} \mathbf{H}$ NMR $\left(400 \mathrm{MHz}, \mathrm{CDCl}_{3}\right) \delta 7.71(\mathrm{~d}, J=15.7 \mathrm{~Hz}, 1 \mathrm{H}), 7.69(\mathrm{t}, J=1.9 \mathrm{~Hz}, 1 \mathrm{H}), 7.57(\mathrm{~d}, J=3.8 \mathrm{~Hz}$, 1H), $7.52(\mathrm{ddd}, J=1.9,1.1,0.6 \mathrm{~Hz}, 1 \mathrm{H}), 6.56(\mathrm{~d}, J=3.8 \mathrm{~Hz}, 1 \mathrm{H}), 6.26(\mathrm{~d}, J=15.7 \mathrm{~Hz}, 1 \mathrm{H}), 3.79(\mathrm{~s}$, $3 \mathrm{H}), 1.51(\mathrm{~s}, 9 \mathrm{H})$.

${ }^{13} \mathrm{C}$ NMR $\left(100 \mathrm{MHz}, \mathrm{CDCl}_{3}\right) \delta 179.2\left(\mathrm{C}_{\mathrm{q}}\right), 167.0\left(\mathrm{C}_{\mathrm{q}}\right), 141.9(\mathrm{CH}), 133.6\left(\mathrm{C}_{\mathrm{q}}\right), 132.8\left(\mathrm{C}_{\mathrm{q}}\right), 127.6(\mathrm{CH})$, $126.4(\mathrm{CH}), 124.7\left(\mathrm{C}_{\mathrm{q}}\right), 124.6(\mathrm{CH}), 118.5(\mathrm{CH}), 116.7\left(\mathrm{C}_{\mathrm{q}}\right), 106.8(\mathrm{CH}), 51.7\left(\mathrm{CH}_{3}\right), 42.1\left(\mathrm{C}_{\mathrm{q}}\right), 28.9$ $\left(\mathrm{CH}_{3}\right)$.

IR (ATR): 2971, 1706, 1444, 1399, 1285, 1258, 1165, 1042, 904, $809 \mathrm{~cm}^{-1}$.

MS (ESI) $m / z$ (relative intensity): $364(10)\left({ }^{79} \mathrm{Br}\right)[\mathrm{M}+\mathrm{H}]^{+}, 366(10)\left({ }^{81} \mathrm{Br}\right)[\mathrm{M}+\mathrm{H}]+{ }^{+}, 386(90)\left({ }^{79} \mathrm{Br}\right)$ $[\mathrm{M}+\mathrm{H}]^{+}, 388(90)\left({ }^{81} \mathrm{Br}\right)[\mathrm{M}+\mathrm{H}]^{+}$

HR-MS (ESI) $\mathrm{C}_{17} \mathrm{H}_{19}{ }^{79} \mathrm{BrNO}_{3}[\mathrm{M}+\mathrm{H}]^{+}:$364.0547, found: 364.0544 .

The spectral data were in accordance with those reported in the literature. ${ }^{[265]}$ 


\section{Ethyl-3-(1-pivaloyl-1H-indol-7-yl)acrylate (394j)}

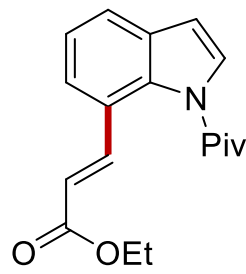

The General Procedure B was followed using $N$-pivaloyl indole 390j (50.3 mg, $0.25 \mathrm{mmol}$ ), ethyl acrylate 393b (75.1 mg, $0.75 \mathrm{mmol}), \mathrm{Ru}(\mathrm{OAc})_{2}\left(p\right.$-cymene) $(8.8 \mathrm{mg}, 10 \mathrm{~mol} \%), \mathrm{AgSbF}_{6}(17.2 \mathrm{mg}, 20$ mol \%) and $\mathrm{Cu}(\mathrm{OAc})_{2}(90.8 \mathrm{mg}, 2$ equiv) in TFE $(1.0 \mathrm{~mL})$. Purification by column chromatography on silica gel ( $n$-hexane/EtOAc: $10 / 1)$ yielded 394j (52.4 mg, 70\%) as a light yellow solid.

M. p. $76^{\circ} \mathrm{C}$.

${ }^{1} \mathbf{H}$ NMR $\left(400 \mathrm{MHz}, \mathrm{CDCl}_{3}\right) \delta 7.79(\mathrm{~d}, J=15.8 \mathrm{~Hz}, 1 \mathrm{H}), 7.57(\mathrm{dd}, J=7.7,0.6 \mathrm{~Hz}, 1 \mathrm{H}) 7.56(\mathrm{~d}, J=$ $3.8 \mathrm{~Hz}, 1 \mathrm{H}), 7.45(\mathrm{ddd}, J=7.7,1.4,0.6 \mathrm{~Hz}, 1 \mathrm{H}), 7.25(\mathrm{t}, J=7.7 \mathrm{~Hz}, 1 \mathrm{H}), 6.61(\mathrm{~d}, J=3.8 \mathrm{~Hz}, 1 \mathrm{H})$, $6.27(\mathrm{~d}, J=15.8 \mathrm{~Hz}, 1 \mathrm{H}), 4.24(\mathrm{q}, J=7.1 \mathrm{~Hz}, 2 \mathrm{H}), 1.54(\mathrm{~s}, 9 \mathrm{H}), 1.32(\mathrm{t}, J=7.1 \mathrm{~Hz}, 3 \mathrm{H})$.

${ }^{13} \mathrm{C}$ NMR $\left(100 \mathrm{MHz}, \mathrm{CDCl}_{3}\right) \delta 179.5\left(\mathrm{C}_{\mathrm{q}}\right), 166.9\left(\mathrm{C}_{\mathrm{q}}\right), 142.9(\mathrm{CH}), 134.8\left(\mathrm{C}_{\mathrm{q}}\right), 131.2\left(\mathrm{C}_{\mathrm{q}}\right), 126.5(\mathrm{CH})$, $123.9(\mathrm{CH}), 123.5(\mathrm{CH}), 123.3\left(\mathrm{C}_{\mathrm{q}}\right), 122.3(\mathrm{CH}), 117.7(\mathrm{CH}), 107.4(\mathrm{CH}), 60.3\left(\mathrm{CH}_{2}\right), 42.1\left(\mathrm{C}_{\mathrm{q}}\right), 29.0$ $\left(\mathrm{CH}_{3}\right), 14.3\left(\mathrm{CH}_{3}\right)$.

IR (ATR): 2975, 1703, 1635, 1477, 1413, 1286, 1268, 1164, 1038, $715 \mathrm{~cm}^{-1}$.

MS (ESI) $m / z$ (relative intensity): $300(34)[\mathrm{M}+\mathrm{H}]^{+}, 322(66)[\mathrm{M}+\mathrm{Na}]^{+}$.

HR-MS (ESI) $\mathrm{C}_{18} \mathrm{H}_{22} \mathrm{NO}_{3}[\mathrm{M}+\mathrm{H}]^{+}: 300.1595$, found: 300.1594 .

\section{Butyl-3-(1-pivaloyl-1H-indol-7-yl)acrylate (394k)}

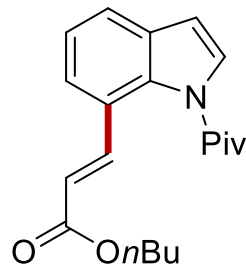

The General Procedure B was followed using $N$-pivaloyl indole 390k (50.3 mg, $0.25 \mathrm{mmol}$ ), butyl acrylate 393c (96.1 mg, $0.75 \mathrm{mmol}), \mathrm{Ru}(\mathrm{OAc})_{2}\left(p\right.$-cymene) $(8.8 \mathrm{mg}, 10 \mathrm{~mol} \%), \mathrm{AgSbF}_{6}(17.2 \mathrm{mg}, 20$ mol \%) and $\mathrm{Cu}(\mathrm{OAc})_{2}(90.8 \mathrm{mg}, 2$ equiv) in TFE $(1.0 \mathrm{~mL})$. Purification by column chromatography on silica gel ( $n$-hexane/EtOAc: 10/1) yielded 394k (49.9 mg, 61\%) as a light yellow liquid.

${ }^{1} \mathbf{H}$ NMR $\left(400 \mathrm{MHz}, \mathrm{CDCl}_{3}\right) \delta 7.79(\mathrm{~d}, J=15.7 \mathrm{~Hz}, 1 \mathrm{H}), 7.58(\mathrm{~d}, J=3.8 \mathrm{~Hz}, 1 \mathrm{H}), 7.57(\mathrm{dd}, J=7.5$, 
$1.1 \mathrm{~Hz}, 1 \mathrm{H}), 7.45(\mathrm{ddd}, J=7.5,1.1,0.6 \mathrm{~Hz}, 1 \mathrm{H}), 7.25$ (dd, $J=7.5,0.6 \mathrm{~Hz}, 1 \mathrm{H}), 6.61(\mathrm{~d}, J=3.8 \mathrm{~Hz}$, $1 \mathrm{H}), 6.28(\mathrm{~d}, J=15.8 \mathrm{~Hz}, 1 \mathrm{H}), 4.19(\mathrm{t}, J=6.6 \mathrm{~Hz}, 2 \mathrm{H}), 1.73-1.62(\mathrm{~m}, 2 \mathrm{H}), 1.53(\mathrm{~s}, 9 \mathrm{H}), 1.48-1.38$ $(\mathrm{m}, 2 \mathrm{H}), 0.95(\mathrm{t}, \mathrm{J}=7.4 \mathrm{~Hz}, 3 \mathrm{H})$.

${ }^{13} \mathrm{C}$ NMR $\left(100 \mathrm{MHz}, \mathrm{CDCl}_{3}\right) \delta 179.3\left(\mathrm{C}_{\mathrm{q}}\right), 167.0\left(\mathrm{C}_{\mathrm{q}}\right), 142.9(\mathrm{CH}), 134.8\left(\mathrm{C}_{\mathrm{q}}\right), 131.2\left(\mathrm{C}_{\mathrm{q}}\right), 126.5(\mathrm{CH})$, 124.0 (CH), $123.5(\mathrm{CH}), 123.3\left(\mathrm{C}_{\mathrm{q}}\right), 122.3(\mathrm{CH}), 117.7(\mathrm{CH}), 107.5(\mathrm{CH}), 64.3\left(\mathrm{CH}_{2}\right), 42.0\left(\mathrm{C}_{\mathrm{q}}\right), 30.8$ $\left(\mathrm{CH}_{2}\right), 29.0\left(\mathrm{CH}_{3}\right), 19.2\left(\mathrm{CH}_{2}\right), 13.7\left(\mathrm{CH}_{3}\right)$.

IR (ATR): 2959, 1704, 1636, 1413, 1284, 1165, 1075, 906, 714, $583 \mathrm{~cm}^{-1}$.

MS (ESI) $m / z$ (relative intensity): $328(45)[\mathrm{M}+\mathrm{H}]^{+}, 350(55)[\mathrm{M}+\mathrm{Na}]^{+}$.

HR-MS (ESI) $\mathrm{C}_{20} \mathrm{H}_{26} \mathrm{NO}_{3}[\mathrm{M}+\mathrm{H}]^{+}: 328.1910$, found: 328.1907 .

The spectral data were in accordance with those reported in the literature. ${ }^{[265]}$

\section{Benzyl-3-(1-pivaloyl-1H-indol-7-yl)acrylate (394I)}

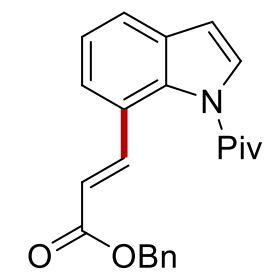

The General Procedure B was followed using $N$-pivaloyl indole 3901 (50.3 mg, 0.25 mmol), benzyl acrylate 393d (121.6 mg, $0.75 \mathrm{mmol}), \mathrm{Ru}(\mathrm{OAc})_{2}\left(p\right.$-cymene) $(8.8 \mathrm{mg}, 10 \mathrm{~mol} \%), \mathrm{AgSbF}_{6}(17.2 \mathrm{mg}$, $20 \mathrm{~mol} \%$ ) and $\mathrm{Cu}(\mathrm{OAc})_{2}(90.8 \mathrm{mg}, 2$ equiv) in TFE $(1.0 \mathrm{~mL})$. Purification by column chromatography on silica gel ( $n$-hexane/EtOAc: 10/1) yielded 3941 (59.6 mg, 66\%) as a light yellow liquid.

${ }^{1} \mathbf{H}$ NMR $\left(400 \mathrm{MHz}, \mathrm{CDCl}_{3}\right) \delta 7.86(\mathrm{~d}, J=15.7 \mathrm{~Hz}, 1 \mathrm{H}), 7.58(\mathrm{dd}, J=7.6,1.1 \mathrm{~Hz}, 1 \mathrm{H}), 7.57(\mathrm{~d}, J=$ $3.6 \mathrm{~Hz}, 1 \mathrm{H}) 7.45$ (ddd, $J=7.6,1.1,0.5 \mathrm{~Hz}, 1 \mathrm{H}), 7.43-7.39$ (m, 2H), $7.38-7.33$ (m, 3H), 7.26 (dd, $J$ $=7.6,0.5 \mathrm{~Hz}, 1 \mathrm{H}), 6.61(\mathrm{~d}, J=3.6 \mathrm{~Hz}, 1 \mathrm{H}), 6.34(\mathrm{~d}, J=15.7 \mathrm{~Hz}, 1 \mathrm{H}), 5.24(\mathrm{~s}, 2 \mathrm{H}), 1.50(\mathrm{~s}, 9 \mathrm{H})$.

${ }^{13}$ C NMR $\left(100 \mathrm{MHz}, \mathrm{CDCl}_{3}\right) \delta 179.3\left(\mathrm{C}_{\mathrm{q}}\right), 166.7\left(\mathrm{C}_{\mathrm{q}}\right), 143.6(\mathrm{CH}), 136.1\left(\mathrm{C}_{\mathrm{q}}\right), 134.8\left(\mathrm{C}_{\mathrm{q}}\right), 131.2\left(\mathrm{C}_{\mathrm{q}}\right)$, $128.2(\mathrm{CH}), 128.2(\mathrm{CH}), 128.1(\mathrm{CH}), 126.5(\mathrm{CH}), 124.0(\mathrm{CH}), 123.5(\mathrm{CH}), 123.2\left(\mathrm{C}_{\mathrm{q}}\right), 122.4(\mathrm{CH})$, 117.2 (CH), $107.5(\mathrm{CH}), 66.2\left(\mathrm{CH}_{2}\right), 42.0\left(\mathrm{C}_{\mathrm{q}}\right), 28.9\left(\mathrm{CH}_{3}\right)$.

IR (ATR): 2970, 1704, 1635, 1477, 1413, 1286, 1159, 1076, 980, $732 \mathrm{~cm}^{-1}$.

MS (ESI) $m / z$ (relative intensity): $362(55)[\mathrm{M}+\mathrm{H}]^{+}, 384(45)[\mathrm{M}+\mathrm{Na}]^{+}$.

HR-MS (ESI) $\mathrm{C}_{23} \mathrm{H}_{24} \mathrm{NO}_{3}[\mathrm{M}+\mathrm{H}]^{+}: 362.1753$, found: 362.1751 . 


\subsubsection{Various Attempted C7-H Activations}

Not only were $\mathrm{C} 7-\mathrm{H}$ amidations and alkenylations tried, but also a variety of coupling partners was chosen to gain a wider perspective toward more broadly applicable ruthenium(II)-catalyzed C7-H activation. Although different types of reactions such as hydroarylations, phosphorylations, trifluoromethylations, arylations, and halogenations among others were additionally attmpted, respective desired products were hardly observed, in which a part of the optimization study was displayed below (Scheme 5.3.1 - 5.3.5).

1) Hydroarylation

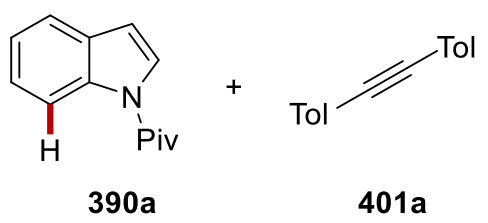

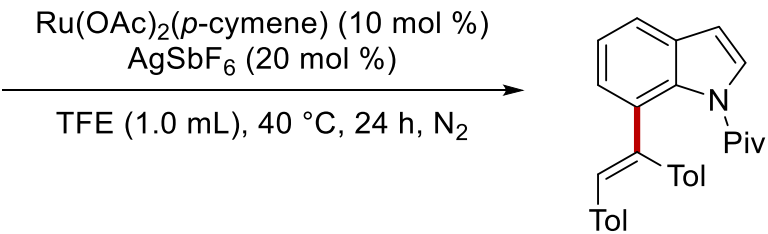

453: $0 \%$

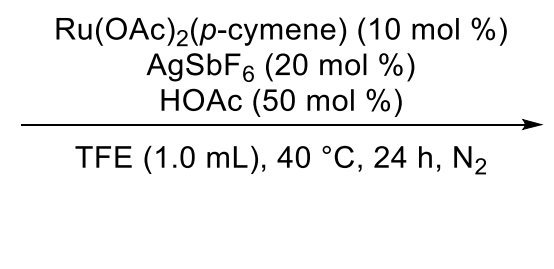

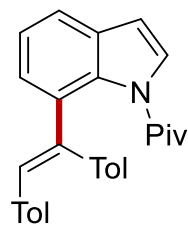

453: $0 \%$

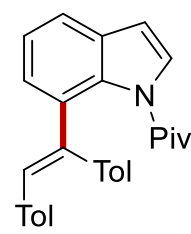

453: $0 \%$<smiles></smiles>

Scheme 5.3.1 Attampted ruthenium-catalyzed C7-H hydroaylations. 
2) Phosphorylation

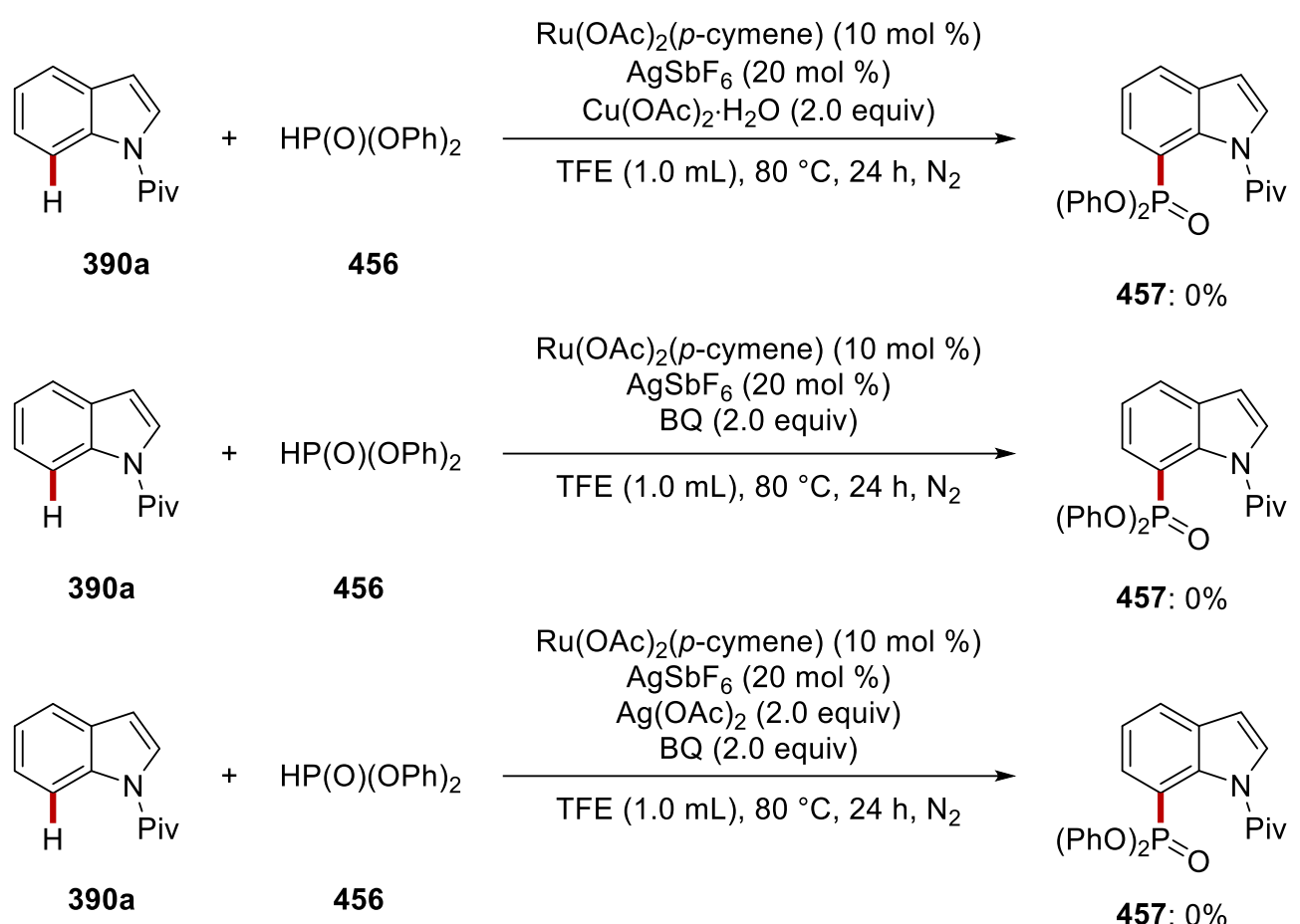

Scheme 5.3.2 Attampted ruthenium-catalyzed C7-H phsphorylations.

3) Trifluoromethylation<smiles></smiles>

$390 a$<smiles>N#[PH]n1ccc2ccccc21</smiles>

$390 a$<smiles>Nc1nccc2ccccc12</smiles>

$390 a$

458

458

$$
\begin{gathered}
\mathrm{Ru}(\mathrm{OAc})_{2}(p \text {-cymene })(10 \mathrm{~mol} \%) \\
\operatorname{AgSbF}_{6}(20 \mathrm{~mol} \%)
\end{gathered}
$$

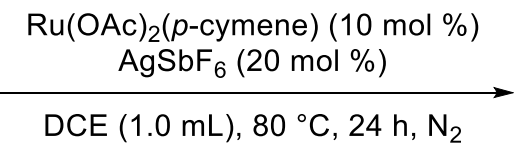<smiles>FC(F)(F)c1cccc2ccn(P)c12</smiles>

459: $0 \%$

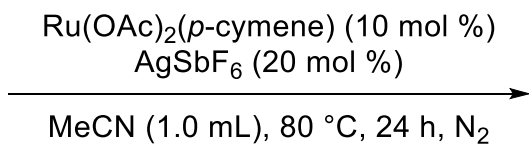<smiles>FC(F)(F)c1cccc2ccn(P)c12</smiles>

459: $0 \%$

Scheme 5.3.3 Attampted ruthenium-catalyzed C7-H trifluoromethylations. 
4) Arylation<smiles>O[Ga][123I]</smiles>

$390 a \quad 460$<smiles>O[Ga][123I]</smiles>

$390 a \quad 460$<smiles>O[Ga][Te]</smiles>

$390 a$

460<smiles></smiles>

$390 \mathrm{a} \quad 460$
$\left[\mathrm{RuCl}_{2}\right.$ (p-cymene)] (10 mol \%) $\mathrm{AgSbF}_{6}(20 \mathrm{~mol} \%)$

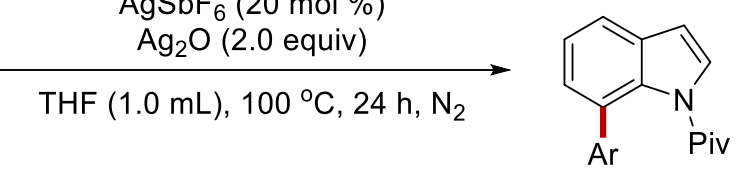

461: $0 \%$

[RuCl 2 (p-cymene)] (10 mol \%) $\mathrm{AgSbF}_{6}(20 \mathrm{~mol} \%)$

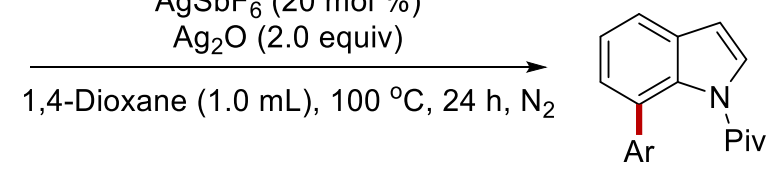

461: $0 \%$

Scheme 5.3.4 Attampted ruthenium-catalyzed C7-H arylations.

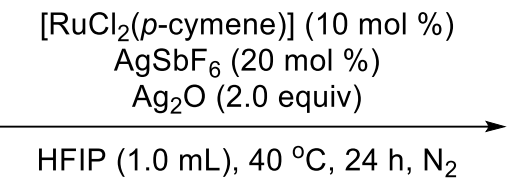<smiles>[Mg]c1cccc2ccn(P)c12</smiles>

461: $0 \%$

5) Halogenation

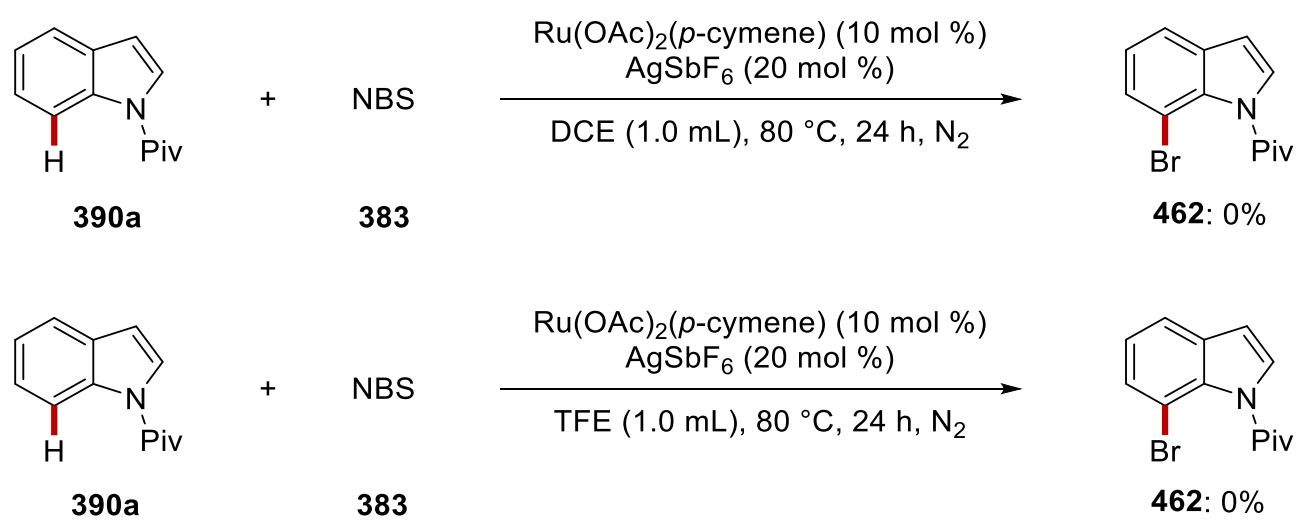

Scheme 5.3.5 Attampted ruthenium-catalyzed C7-H halogenations. 


\subsubsection{Flow Reaction Setup}

A Schleck tube was charged with a suspension of $N$-pivaloyl indole $390 \mathrm{a}(0.25 \mathrm{mmol}, 1.0$ equiv), tosyl azide 391a (0.75 mmol, 3.0 equiv), $\mathrm{Ru}(\mathrm{OAc})_{2}\left(p\right.$-cymene) $(10 \mathrm{~mol} \%), \mathrm{AgSbF}_{6}(20 \mathrm{~mol} \%)$, and TFE (1.0 mL) under air (Scheme 5.3.6). Subsequently, the solution was connected to the inlet of the $10 \mathrm{~mL}$ standard pre-heated reactor by a syringe pump (Vapourtec V-3). The flow rate, back pressure, and temperature were set at $500 \mu \mathrm{L} / \mathrm{min}$ (20 min residence time), $4.0 \mathrm{bar}$, and $40{ }^{\circ} \mathrm{C}$ respectively. Afterwards, the reaction mixture was automatically collected and concentrated in vacuo. Purification by column chromatography on silica gel afforded the desired products 392a.

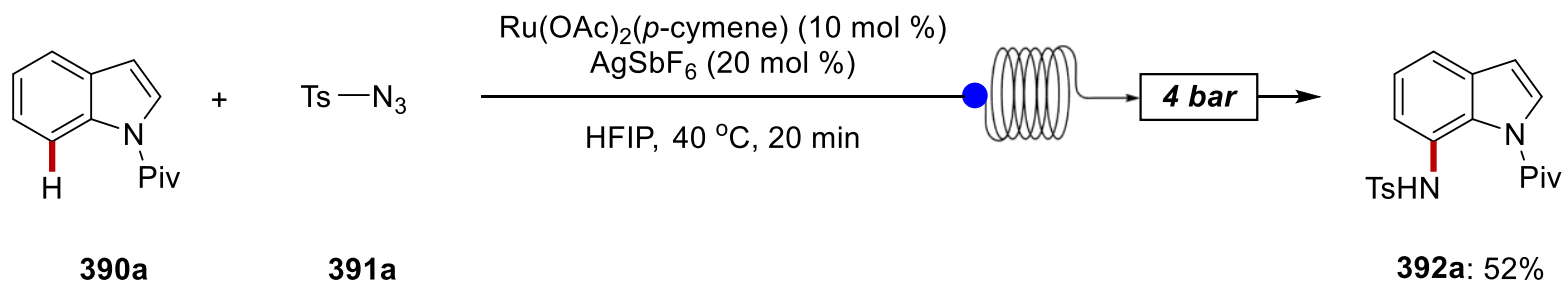

Scheme 5.3.6 Scalable flow reaction for $\mathrm{C} 7-\mathrm{H}$ amidation of indole.

\subsubsection{Competition Experiment}

A suspension of 1-(5-methoxy-1H-indol-1-yl)-2,2-dimethylpropan-1-one 390f ( 0.25 mmol, 1.0 equiv) and 1-(5-fluoro-1H-indol-1-yl)-2,2-dimethylpropan-1-one 390k (0.25 mmol, 1.0 equiv), tosyl azide (391a) (0.75 mmol, 3.0 equiv), $\mathrm{Ru}(\mathrm{OAc})_{2}\left(p\right.$-cymene) $(10 \mathrm{~mol} \%), \mathrm{AgSbF}_{6}(20 \mathrm{~mol} \%)$, in TFE (1.0 $\mathrm{mL}$ ) was stirred at $40{ }^{\circ} \mathrm{C}$ for $10 \mathrm{~h}$ under $\mathrm{N}_{2}$ (Scheme 5.3.7). After cooling to ambient temperature, the mixture was concentrated in vacuo. Purification by column chromatography on silica gel ( $n$ hexane/EtOAc: $20 / 1 \rightarrow 10 / 1 \rightarrow 4 / 1$ ) afforded the desired products $392 f$ and $\mathbf{3 9 2 g}$, respectively.

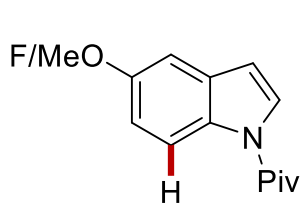

$390 f / 390 k$

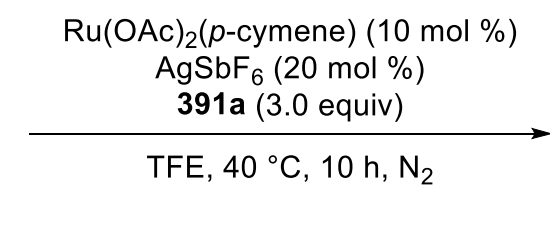

(1)

(a)

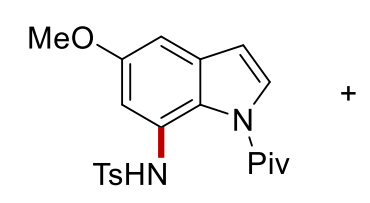

392f: $34 \%$

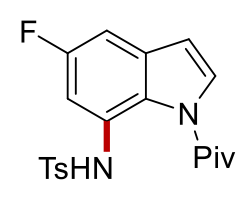

392g: $18 \%$

Scheme 5.3.7 Competition experiments. 


\subsubsection{Removal of Pivaloyl Directing Group}

1) Procedure for the traceless removal of pivaloyl group

A suspension of 4-methyl- $N$-(1-pivaloyl- $1 H$-indol-7-yl)benzenesulfonamide 392a $(0.25$ mmol, 1.0 equiv) or methyl-3-(1-pivaloyl-1H-indol-7-yl)acrylate 394a $\left(0.25 \mathrm{mmol}, 1.0\right.$ equiv) in $\mathrm{NEt}_{3}(0.5 \mathrm{~mL})$ and $\mathrm{MeOH}(0.5 \mathrm{~mL})$ was stirred at room temperature for $12 \mathrm{~h}$ (Scheme 5.3.8). The mixture was concentrated in vacuo. Purification by column chromatography on silica gel afforded the desired products 417 and 418 , respectively.

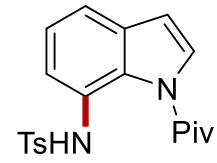

$392 a$<smiles>COCC=Cc1cccc2ccn([PH](=O)(=O)c3ccccc3)c12</smiles>

394a

$$
\mathrm{NEt}_{3}(0.5 \mathrm{~mL}), \mathrm{MeOH}(0.5 \mathrm{~mL}), \mathrm{RT}, 12 \mathrm{~h}
$$
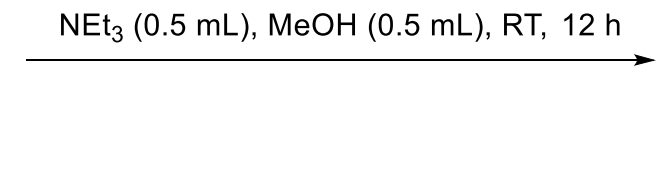

Scheme 5.3.8 Competition experiments.

2) Procedure for one-pot strategy of removal of pivaloyl group

Reactions were initially performed by using general procedure described in the general procedure. After cooling to ambient temperature, the solvent is removed by rotary evaporator. Triethylamine $(0.5$ $\mathrm{mL})$ and $\mathrm{MeOH}(0.5 \mathrm{~mL})$ were added and stirred at room temperature for $12 \mathrm{~h}$ (Scheme 5.3.9). The mixture was concentrated in vacuo. Purification by column chromatography on silica gel afforded the desired products 417 and 418 respectively. 


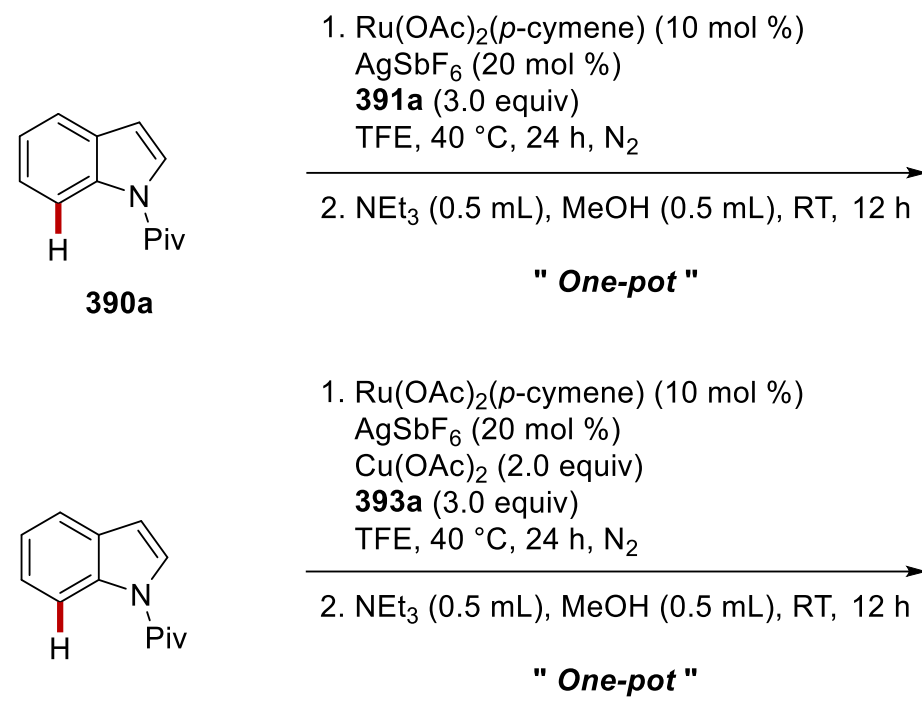

$390 a$
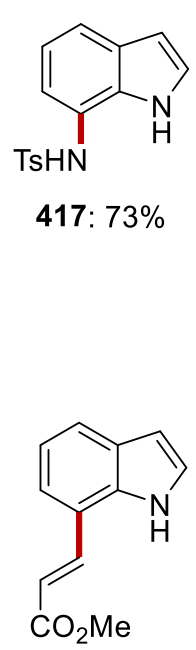

418: $68 \%$

Scheme 5.3.9 Competition experiments.

\section{$N$-(1H-Indol-7-yl)-4-methylbenzenesulfonamide (417)}<smiles>[AlH2]c1cccc2cc[nH]c12</smiles>

A suspension of 4-Methyl- $N$-(1-pivaloyl-1H-indol-7-yl)benzenesulfonamide 390a (92.6 mg, 0.25 mmol), triethylamine $(0.5 \mathrm{~mL})$ in $\mathrm{MeOH}(0.5 \mathrm{~mL})$ was stirred at room temperature for $12 \mathrm{~h}$. Purification by column chromatography on silica gel ( $n$-hexane/EtOAc: 10/1) yielded 417 (68.0 mg, $95 \%)$ as a light yellow solid.

M. p. $152^{\circ} \mathrm{C}$.

${ }^{1}$ H NMR (400 MHz, $\left.\mathrm{CDCl}_{3}\right) \delta 9.27(\mathrm{~s}, 1 \mathrm{H}), 7.53(\mathrm{ddd}, J=8.2,3.5,2.1 \mathrm{~Hz}, 2 \mathrm{H}), 7.46(\mathrm{ddd}, J=8.2$, 2.1, $0.9 \mathrm{~Hz}, 1 \mathrm{H}), 7.24(\mathrm{dd}, J=3.5,2.1 \mathrm{~Hz}, 1 \mathrm{H}), 7.15(\mathrm{ddd}, J=7.6,2.1,0.9 \mathrm{~Hz}, 2 \mathrm{H}), 6.83(\mathrm{t}, J=7.6$ $\mathrm{Hz}, 1 \mathrm{H}), 6.79(\mathrm{~s}, 1 \mathrm{H}), 6.52(\mathrm{dd}, J=3.5,2.1 \mathrm{~Hz}, 1 \mathrm{H}), 6.42(\mathrm{~d}, J=7.6 \mathrm{~Hz}, 1 \mathrm{H}), 2.34(\mathrm{~s}, 3 \mathrm{H})$.

${ }^{13} \mathrm{C} \mathrm{NMR}\left(100 \mathrm{MHz}, \mathrm{CDCl}_{3}\right) \delta 144.04\left(\mathrm{C}_{\mathrm{q}}\right), 134.77\left(\mathrm{C}_{\mathrm{q}}\right), 131.8\left(\mathrm{C}_{\mathrm{q}}\right), 130.06\left(\mathrm{C}_{\mathrm{q}}\right), 129.55(\mathrm{CH}), 127.37$ $(\mathrm{CH}), 125.25(\mathrm{CH}), 119.92\left(\mathrm{C}_{\mathrm{q}}\right), 119.78(\mathrm{CH}), 119.61(\mathrm{CH}), 117.87(\mathrm{CH}), 102.61(\mathrm{CH}), 21.53\left(\mathrm{CH}_{3}\right)$. IR (ATR): 3413, 3251, 2922, 1583, 1334, 1156, 1090, 1038, 730, $551 \mathrm{~cm}^{-1}$. MS (ESI) $m / z$ (relative intensity): $287(10)[\mathrm{M}+\mathrm{H}]^{+}, 309(90)[\mathrm{M}+\mathrm{Na}]^{+}$.

HR-MS (ESI) $\mathrm{C}_{15} \mathrm{H}_{15} \mathrm{~N}_{2} \mathrm{O}_{2} \mathrm{~S}[\mathrm{M}+\mathrm{H}]^{+}:$287.0847, found: 287.0847. 


\section{Methyl-3-(1H-indol-7-yl)acrylate (418)}

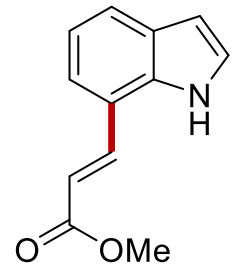

A suspension of Methyl-3-(1-pivaloyl- $1 H$-indol-7-yl)acrylate 394a (71.3 mg, $0.25 \mathrm{mmol})$, triethylamine $(0.5 \mathrm{~mL})$ in $\mathrm{MeOH}(0.5 \mathrm{~mL})$ was stirred at room temperature for $12 \mathrm{~h}$. Purification by column chromatography on silica gel ( $n$-hexane/EtOAc: $10 / 1)$ yielded $418(48.3 \mathrm{mg}, 96 \%)$ as a light yellow solid.

M. p. $101^{\circ} \mathrm{C}$.

${ }^{1} \mathbf{H}$ NMR $\left(400 \mathrm{MHz}, \mathrm{CDCl}_{3}\right) \delta 9.06(\mathrm{~s}, 1 \mathrm{H}), 8.13(\mathrm{~d}, J=16.0 \mathrm{~Hz}, 1 \mathrm{H}), 7.71(\mathrm{~d}, J=7.9 \mathrm{~Hz}, 1 \mathrm{H}), 7.43$ $(\mathrm{d}, J=7.9 \mathrm{~Hz}, 1 \mathrm{H}), 7.22(\mathrm{dd}, J=3.2,1.9 \mathrm{~Hz}, 1 \mathrm{H}), 7.15(\mathrm{t}, J=7.9 \mathrm{~Hz}, 1 \mathrm{H}), 6.61(\mathrm{dd}, J=3.2,1.9 \mathrm{~Hz}$, $1 \mathrm{H}), 6.57(\mathrm{~d}, J=16.0 \mathrm{~Hz}, 1 \mathrm{H}), 3.85(\mathrm{~s}, 3 \mathrm{H})$.

${ }^{13} \mathrm{C}$ NMR $\left(100 \mathrm{MHz}, \mathrm{CDCl}_{3}\right) \delta 168.0\left(\mathrm{C}_{\mathrm{q}}\right), 141.4(\mathrm{CH}), 134.3\left(\mathrm{C}_{\mathrm{q}}\right), 128.9\left(\mathrm{C}_{\mathrm{q}}\right), 124.9(\mathrm{CH}), 123.4$ $(\mathrm{CH}), 121.9(\mathrm{CH}), 120.0(\mathrm{CH}), 118.1\left(\mathrm{C}_{\mathrm{q}}\right), 117.3(\mathrm{CH}), 103.1(\mathrm{CH}), 51.8\left(\mathrm{CH}_{3}\right)$.

IR (ATR): 3431, 3339, 2949, 1691, 1308, 1264, 975, 796, 716, $429 \mathrm{~cm}^{-1}$.

MS (ESI) $m / z$ (relative intensity): $202(40)[\mathrm{M}+\mathrm{H}]^{+}, 224(60)[\mathrm{M}+\mathrm{Na}]^{+}$.

HR-MS (ESI) $\mathrm{C}_{12} \mathrm{H}_{12} \mathrm{NO}_{2}[\mathrm{M}+\mathrm{H}]^{+}:$202.0859, found: 202.0860 . 


\subsubsection{Hammett Correlation}

The General Procedure A was followed using electronically different substrates (Scheme 5.3.10).
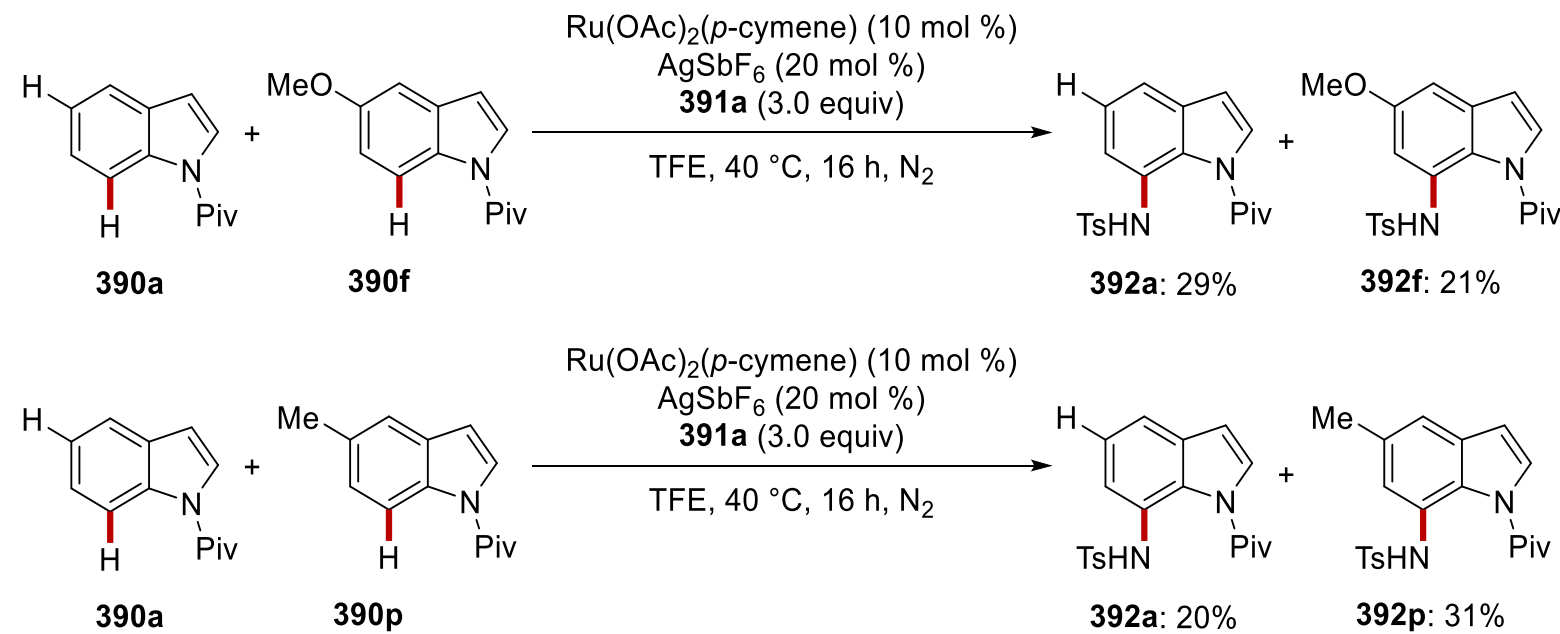

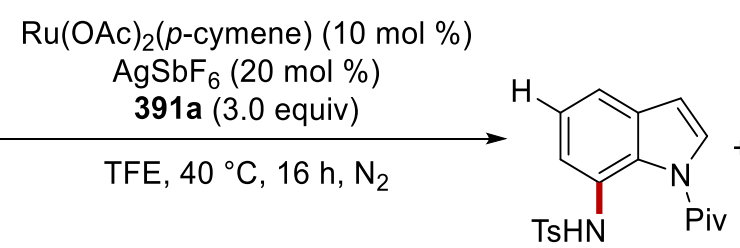

392a: $20 \%$

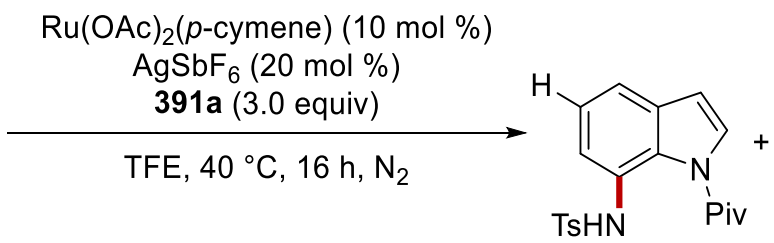

392a: $26 \%$
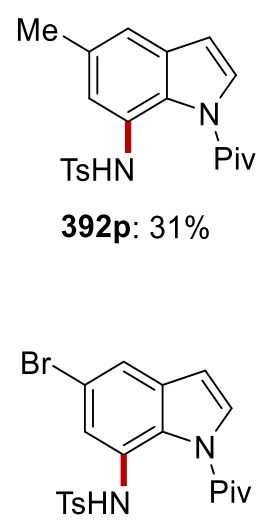

392i: $10 \%$<smiles>N#[PH]n1ccc2ccccc21</smiles>

$390 a$<smiles></smiles>

$390 \mathrm{i}$

$$
\mathrm{Ru}(\mathrm{OAc})_{2}(p \text {-cymene) }(10 \mathrm{~mol} \%)
$$<smiles>N#[PH]n1[c-]cc2ccccc21</smiles>

$390 \mathrm{a}$<smiles>NPn1ccc2ccc(F)cc21</smiles>

390k

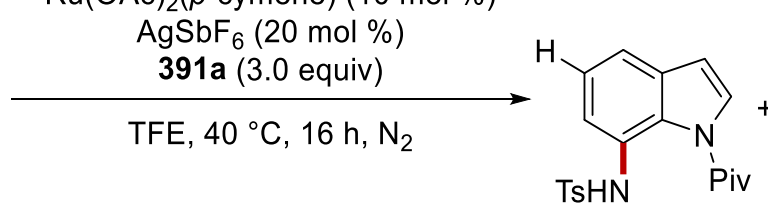

392a: $18 \%$<smiles>Nc1cc(F)cc2ccn(P)c12</smiles>

392k: $8 \%$

$\operatorname{og}\left(k / k_{0}\right)$
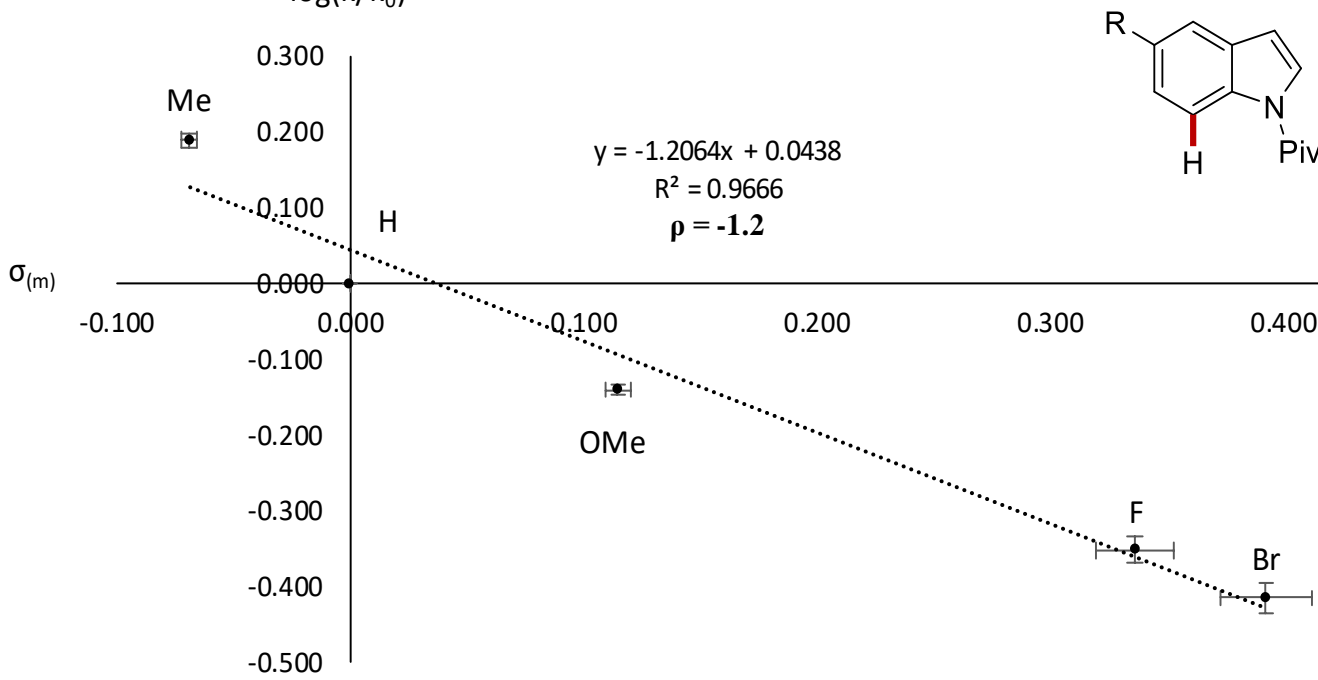

$$
\begin{gathered}
y=-1.2064 x+0.0438 \\
R^{2}=0.9666 \\
\rho=-1.2
\end{gathered}
$$

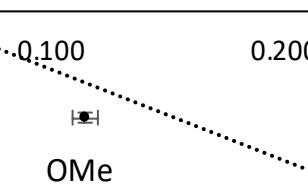

0.300

$$
0.400
$$

$-0.500$

Figure 5.3.10 Hammett correlation plot. 


\subsubsection{H/D Exchange Study}

1) Procedure for $\mathrm{H} / \mathrm{D}$ exchange experiment 1

A suspension of $N$-pivaloyl indole $\mathbf{3 9 0 a}\left(0.25 \mathrm{mmol}, 1.0\right.$ equiv), $\mathrm{Ru}(\mathrm{OAc})_{2}(p$-cymene) (10 mol \%), $\mathrm{AgSbF}_{6}(20 \mathrm{~mol} \%)$, in $[\mathrm{D}]_{1}-\mathrm{TFE}\left(\mathrm{CF}_{3} \mathrm{CH}_{2} \mathrm{OD}, 1.0 \mathrm{~mL}\right)$ was stirred at $40{ }^{\circ} \mathrm{C}$ for $16 \mathrm{~h}$ under $\mathrm{N}_{2}(\mathrm{Scheme}$ 5.3.11). After cooling to ambient temperature, the mixture was concentrated in vacuo. Purification by column chromatography on silica gel afforded the desired products $[D]_{\mathrm{n}}-\mathbf{3 9 0 a}$.
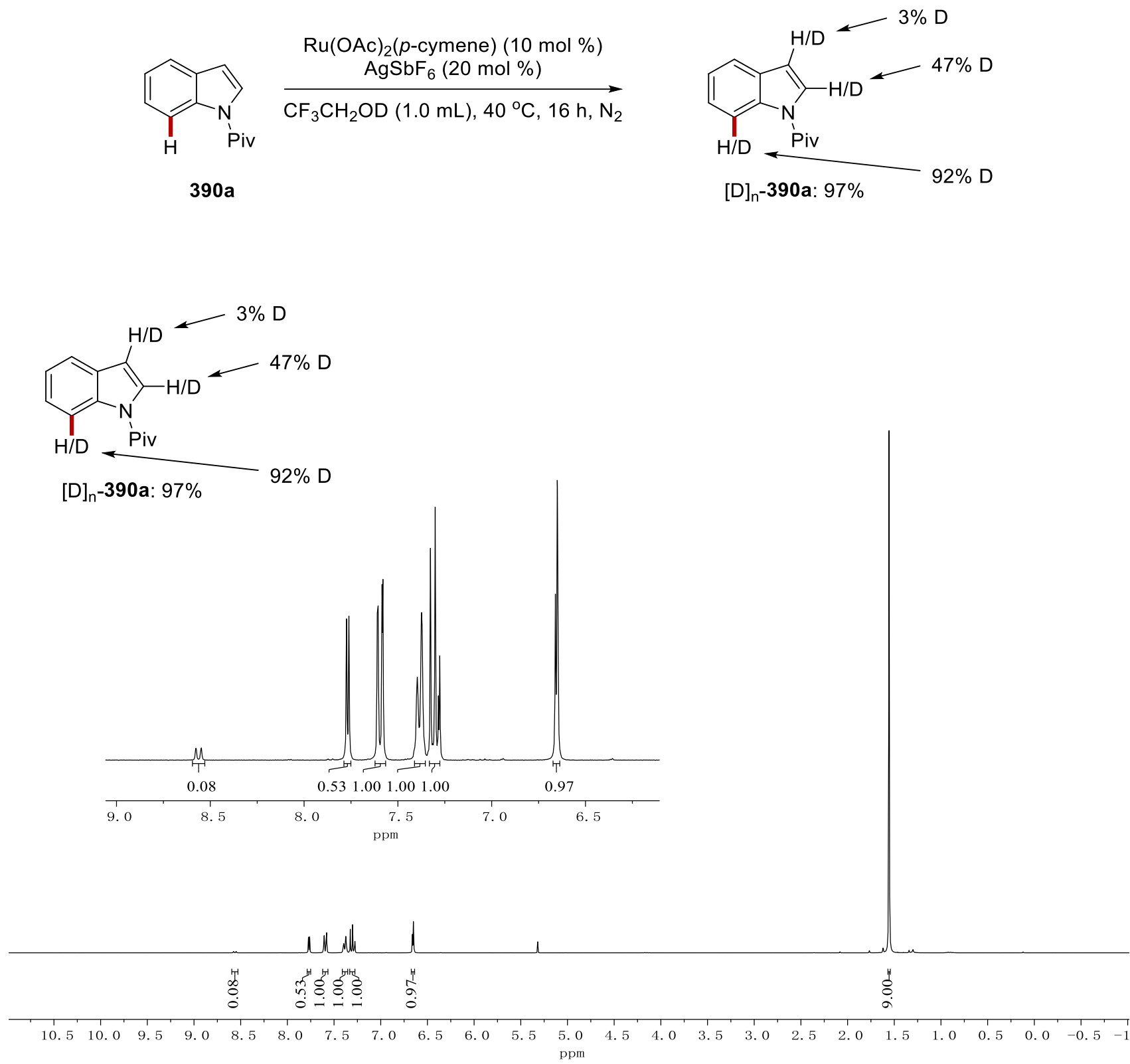

Scheme 5.3.11 H/D exchange study 1 . 
2) Procedure for $\mathrm{H} / \mathrm{D}$ exchange experiment 2

A suspension of $N$-pivaloyl indole 390a ( $0.25 \mathrm{mmol}, 1.0$ equiv), tosyl azide 391a $(0.75 \mathrm{mmol}, 3.0$ equiv), $\mathrm{Ru}(\mathrm{OAc})_{2}\left(p\right.$-cymene) $(10 \mathrm{~mol} \%), \mathrm{AgSbF}_{6}(20 \mathrm{~mol} \%)$, in $[\mathrm{D}]_{1}-\mathrm{TFE}\left(\mathrm{CF}_{3} \mathrm{CH}_{2} \mathrm{OD}, 1.0 \mathrm{~mL}\right)$ was stirred at $40{ }^{\circ} \mathrm{C}$ for $6 \mathrm{~h}$ under $\mathrm{N}_{2}$ (Scheme 5.3.12 and 5.3.13). After cooling to ambient temperature, the mixture is concentrated in vacuo. Purification by column chromatography on silica gel afforded the desired products $[\mathrm{D}]_{\mathrm{n}}-\mathbf{3 9 0 a}$ and $[\mathrm{D}]_{\mathrm{n}}-\mathbf{3 9 2 a}$.
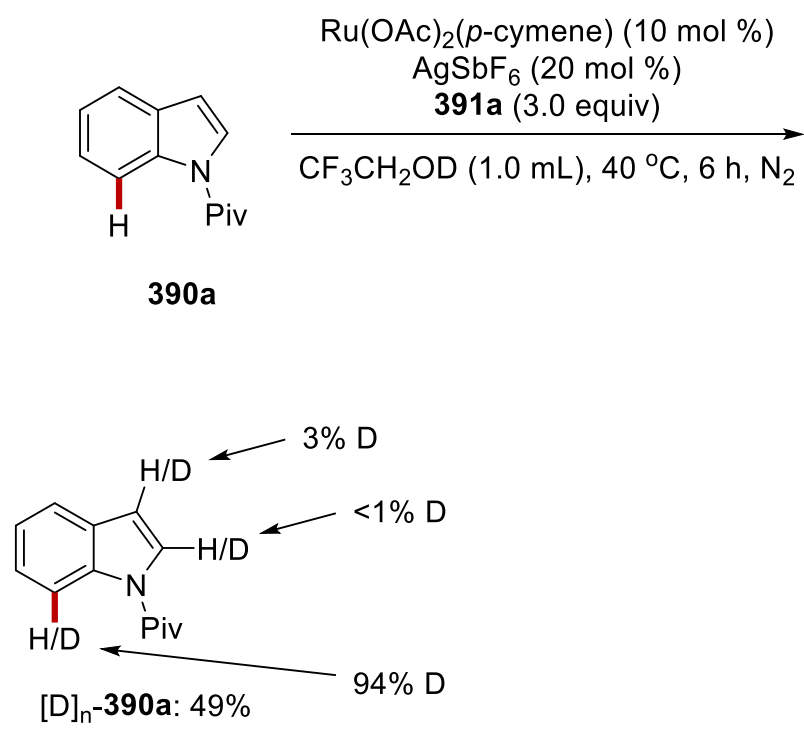
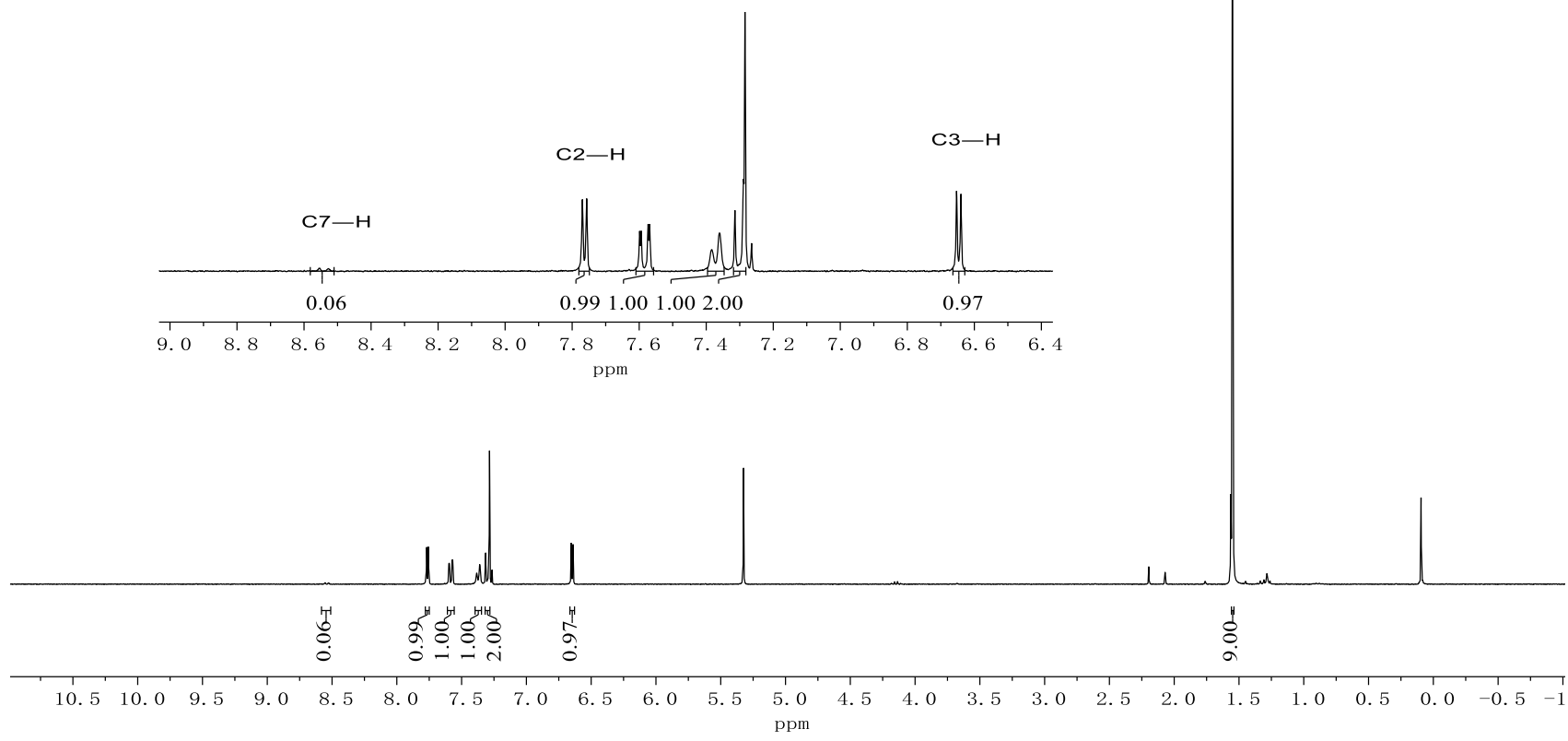

Scheme 5.3.12 H/D exchange study 2. 


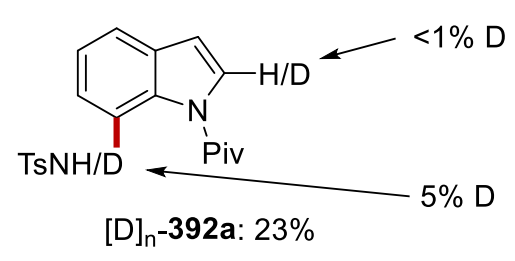
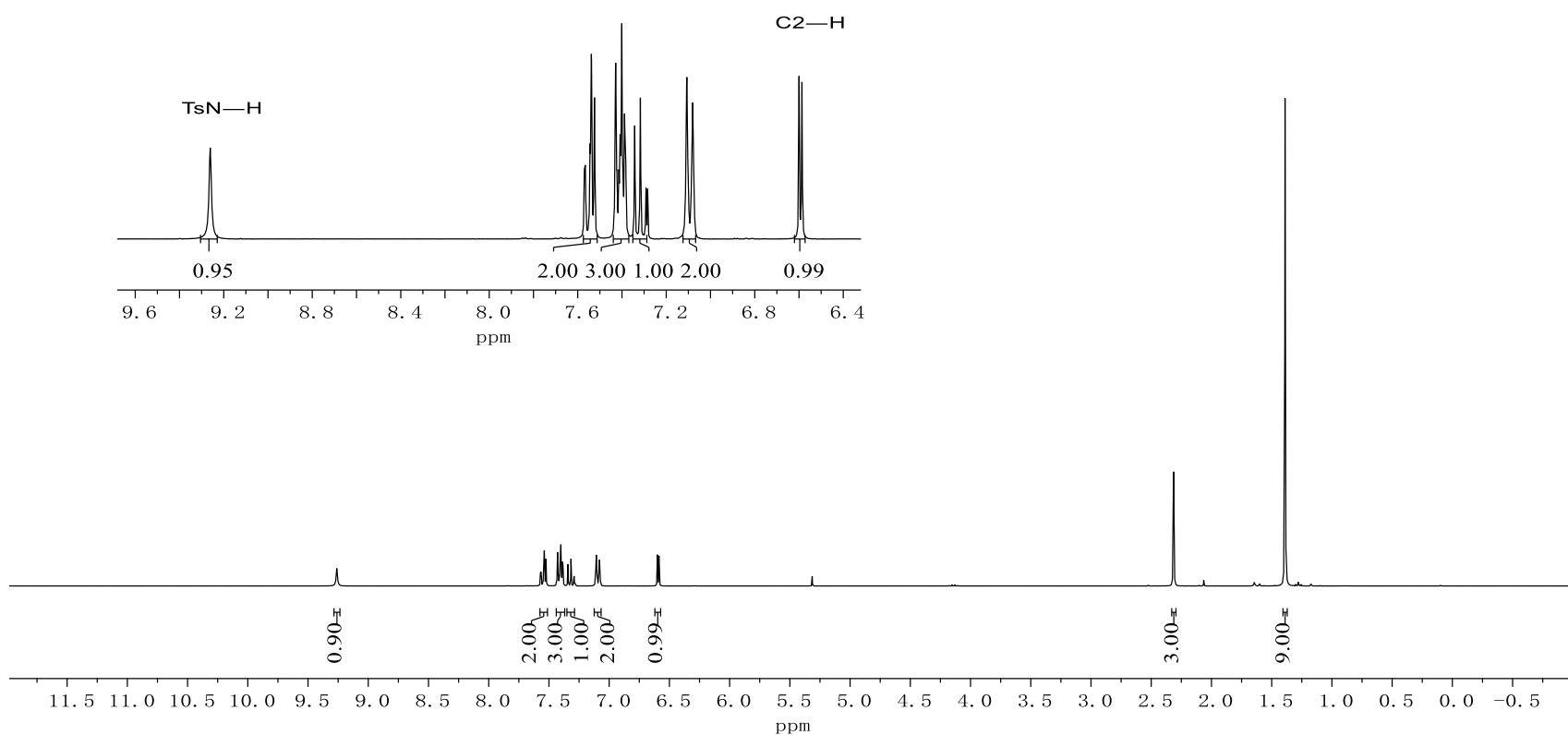

Scheme 5.3.13 H/D exchange study 3 . 


\subsubsection{KIE Study}

Two independent reactions using substrate 390a and $[\mathrm{D}]_{4-390 a}$ were performed to determine the KIE by comparison of the initial rates (Scheme 5.3.14). The conversion was determined by ${ }^{1} \mathrm{H}$ NMR spectroscopy using 1,3,5-trimethoxybezene as the internal standard. Blue line is for 392a and red line is for $[\mathrm{D}]_{3}-\mathbf{3 9 2 a}$.

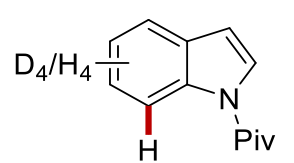

$390 \mathrm{a} /[\mathrm{D}]_{4}-390 \mathrm{a}$

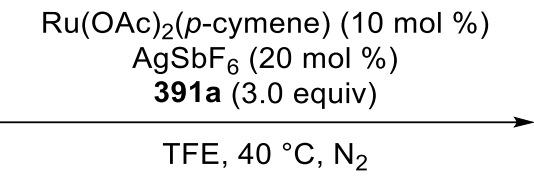

$k_{\mathrm{H}} / k_{\mathrm{D}}=1.1$

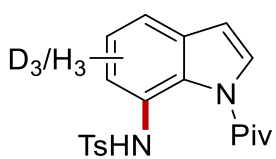

$392 a /[D]_{3}-392 a$

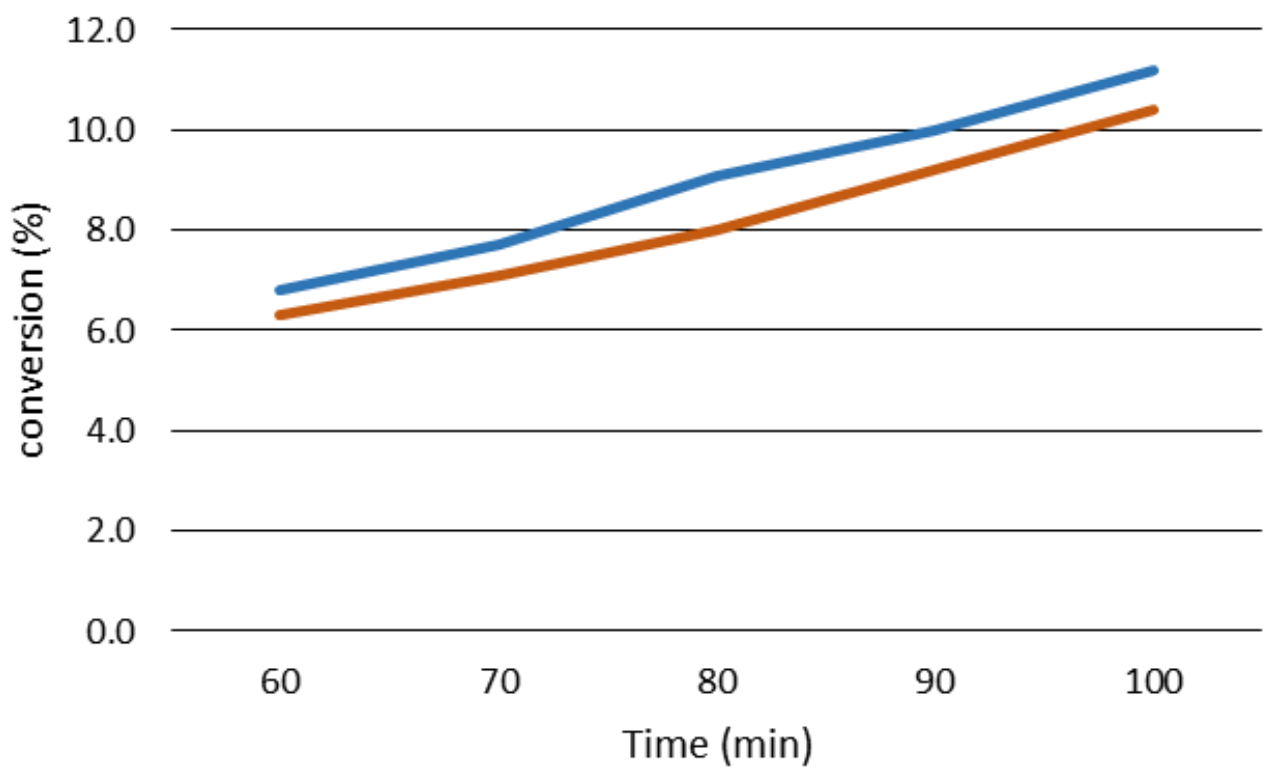

Figure 5.3.14 H/D exchange study. 


\subsubsection{Kinetic Analysis}

1) Reaction order with respect to $\mathbf{3 9 0 a}$

The reaction order with respect to 390a was examined using the initial rate method. A Schlenk-tube was charged with $N$-pivaloyl indole 390a $(0.15,0.20,0.25,0.30,0.35 \mathrm{mmol})$, tosyl azide $391 \mathrm{a}(0.75$ mmol $), \mathrm{Ru}(\mathrm{OAc})_{2}(p$-cymene $)(0.025 \mathrm{mmol})$ and 1,3,5-trimethoxybenzene $(0.25 \mathrm{mmol})$ under $\mathrm{N}_{2}$ condition (Table 5.3.1 and Scheme 5.3.15). TFE (2.0 mL) was added and the mixture was stirred at $40{ }^{\circ} \mathrm{C}$. Aliquots up to ca. $10 \%$ conversion $(25 \mu \mathrm{L} ; 30,40,50,60,70 \mathrm{~min})$ were periodically removed by a syringe and directly analyzed by gas chromatography.

Table 5.3.1 Kinetic analysis with respect to 390a.

\begin{tabular}{lllll} 
Entry & $\mathrm{k} / \mathrm{mol} \mathrm{L}^{-1} \mathrm{~s}^{-1} 10^{-6}$ & $\log \left(\mathrm{k} / \mathrm{mol} \mathrm{L}^{-1} \mathrm{~s}^{-1} 10^{-6}\right)$ & $\mathrm{c}$ & $\log (\mathrm{c})$ \\
\hline 1 & 0.7118 & -6.1476 & 0.075 & -1.1249 \\
2 & 0.7421 & -6.1295 & 0.1 & -1.0000 \\
3 & 0.7659 & -6.1158 & 0.125 & -0.9031 \\
4 & 0.7973 & -6.0984 & 0.15 & -0.8239 \\
5 & 0.8226 & -6.0848 & 0.175 & -0.7570
\end{tabular}

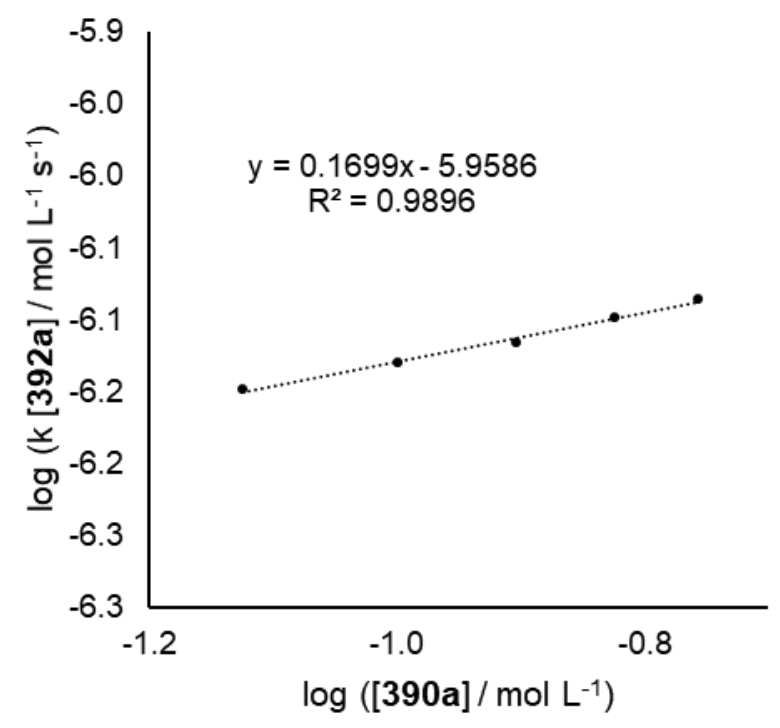

Figure 5.3.15 Kinetic analysis with respect to 390a. 
2) Reaction order with respect to $391 \mathrm{a}$

The reaction order with respect to 391a was examined using the initial rate method. A Schlenk-tube was charged with $N$-pivaloyl indole 390a $(0.25 \mathrm{mmol})$, tosyl azide 391a $(0.25,0.375,0.50,0.625,0.75$ mmol $), \mathrm{Ru}(\mathrm{OAc})_{2}(p$-cymene $)(0.025 \mathrm{mmol})$ and 1,3,5-trimethoxybenzene $(0.25 \mathrm{mmol})$ under $\mathrm{N}_{2}$ condition (Table 5.3.2 and Scheme 5.3.16). TFE $(2.0 \mathrm{~mL})$ was added and the mixture was stirred at $40{ }^{\circ} \mathrm{C}$. Aliquots up to ca. $10 \%$ conversion $(25 \mu \mathrm{L} ; 30,40,50,60,70 \mathrm{~min})$ were periodically removed by a syringe and directly analyzed by gas chromatography.

Table 5.3.2 Kinetic analysis with respect to 391a.

\begin{tabular}{lllll} 
Entry & $\mathrm{k} / \mathrm{mol} \mathrm{L}^{-1} \mathrm{~s}^{-1} 10^{-6}$ & $\log \left(\mathrm{k} / \mathrm{mol} \mathrm{L}^{-1} \mathrm{~s}^{-1} 10^{-6}\right)$ & $\mathrm{c}$ & $\log (\mathrm{c})$ \\
\hline 1 & 0.2584 & -6.5877 & 0.125 & -0.9031 \\
2 & 0.3831 & -6.4167 & 0.1875 & -0.7270 \\
3 & 0.5478 & -6.2614 & 0.25 & -0.6021 \\
4 & 0.7163 & -6.1449 & 0.3125 & -0.5051 \\
5 & 0.7621 & -6.1180 & 0.375 & -0.4260
\end{tabular}

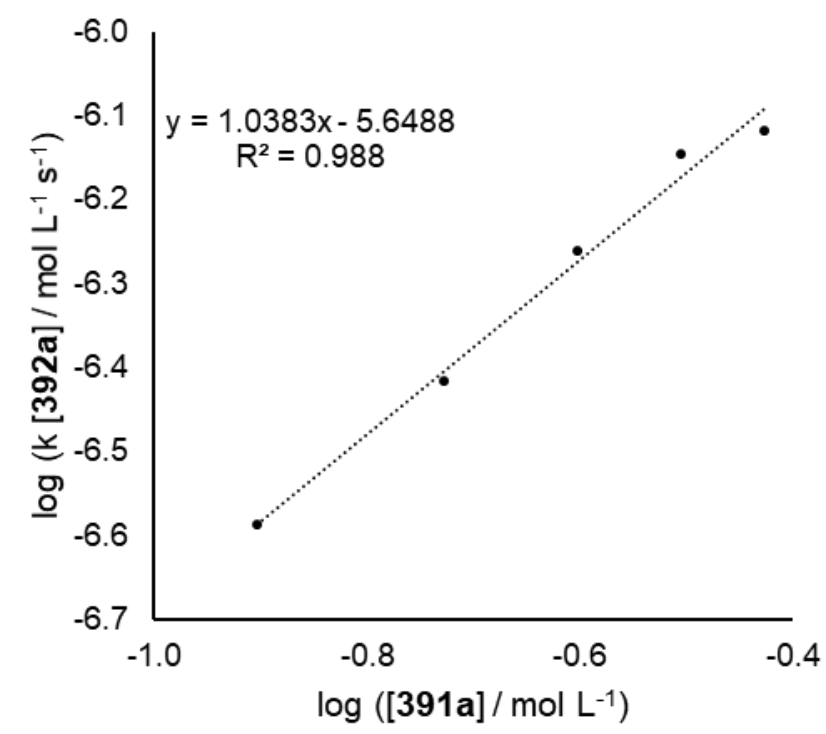

Figure 5.3.16 Kinetic analysis with respect to 391a. 
3) Reaction order with respect to $\mathrm{Ru}(\mathrm{OAc})_{2}(p$-cymene)

The reaction order with respect to $\mathrm{Ru}(\mathrm{OAc})_{2}(p$-cymene) was examined using the initial rate method. A Schlenk-tube was charged with $N$-pivaloyl indole 390a $(0.25 \mathrm{mmol})$, tosyl azide 391a $(0.75 \mathrm{mmol})$, $\mathrm{Ru}(\mathrm{OAc})_{2}(p$-cymene $) \quad(0.01250, \quad 0.01875, \quad 0.02500,0.03125, \quad 0.03750 \mathrm{mmol})$ and $1,3,5-$ trimethoxybenzene $(0.25 \mathrm{mmol})$ under $\mathrm{N}_{2}$ condition (Table 5.3.3 and Scheme 5.3.17). TFE (2.0 mL) was added and the mixture was stirred at $40{ }^{\circ} \mathrm{C}$. Aliquots up to ca. $10 \%$ conversion $(25 \mu \mathrm{L} ; 30,40,50$, $60,70 \mathrm{~min}$ ) were periodically removed by a syringe and directly analyzed by gas chromatography.

Table 5.3.3 Kinetic analysis with respect to $\mathrm{Ru}(\mathrm{OAc})_{2}(p$-cymene).

\begin{tabular}{lllll} 
Entry & $\mathrm{k} / \mathrm{mol} \mathrm{L}^{-1} \mathrm{~s}^{-1} 10^{-6}$ & $\log \left(\mathrm{k} / \mathrm{mol} \mathrm{L}^{-1} \mathrm{~s}^{-1} 10^{-6}\right)$ & $\mathrm{c}$ & $\log (\mathrm{c})$ \\
\hline 1 & 0.4556 & -6.3414 & 5 & -2.2041 \\
2 & 0.6298 & -6.2008 & 7.5 & -2.0280 \\
3 & 0.8541 & -6.0685 & 10 & -1.9031 \\
4 & 1.0745 & -5.9688 & 12.5 & -1.8062 \\
5 & 1.4067 & -5.8518 & 15 & -1.7270
\end{tabular}

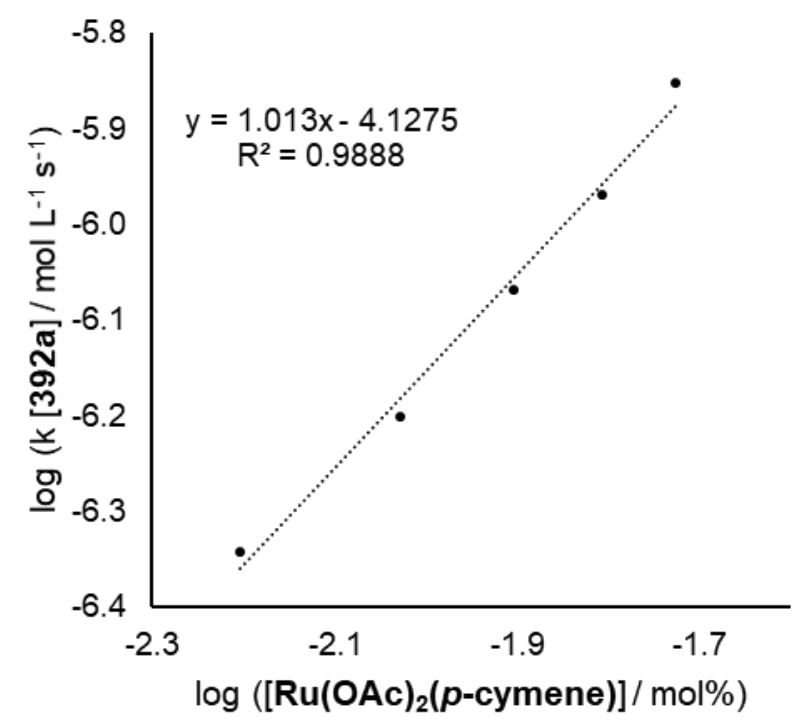

Figure 5.3.17 Kinetic analysis with respect to $\mathrm{Ru}(\mathrm{OAc})_{2}(p$-cymene). 


\subsection{Ruthenium(II)-Catalyzed C4/C6-H Dual Alkylations of Indoles}

\subsubsection{Characterization Data}

Diethyl 2,2'-[1-(pyridin-2-yl)-1H-indole-4,6-diyl]bis(2-methylpropanoate) (397a)<smiles>CCOC(=O)C(C)(C)c1cc(C(C)(C)C(=O)OCC)c2ccn(-c3ccccn3)c2c1</smiles>

The General Procedure C was followed using 1-(pyridin-2-yl)- $1 H$-indole 395a (48.6 mg, 0.25 mmol), ethyl 2-bromo-2-methylpropanoate 396a (243 mg, $1.25 \mathrm{mmol}), \mathrm{Ru}(\mathrm{OAc})_{2}\left(\mathrm{PPh}_{3}\right)_{2}(18.6 \mathrm{mg}, 10$ mol \%), NaOAc (41.0 mg, $0.50 \mathrm{mmol})$ in DCE $(2.0 \mathrm{~mL})$. Purification by column chromatography on silica gel ( $n$-hexane/EtOAc: $5 / 1)$ yielded 397a $(81.3 \mathrm{mg}, 77 \%)$ as colorless oil.

${ }^{1} \mathbf{H}$ NMR $\left(400 \mathrm{MHz}, \mathrm{CDCl}_{3}\right) \delta 8.55(\mathrm{ddd}, J=4.9,2.0,0.9 \mathrm{~Hz}, 1 \mathrm{H}), 8.10(\mathrm{dd}, J=1.6,0.9 \mathrm{~Hz}, 1 \mathrm{H})$, $7.80(\mathrm{ddd}, J=8.2,7.4,2.0 \mathrm{~Hz}, 1 \mathrm{H}), 7.60(\mathrm{~d}, J=3.6 \mathrm{~Hz}, 1 \mathrm{H}), 7.43(\mathrm{dd}, J=8.2,0.9 \mathrm{~Hz}, 1 \mathrm{H}), 7.16$ (ddd, $J=7.4,4.9,0.9 \mathrm{~Hz}, 1 \mathrm{H}), 7.13(\mathrm{~d}, J=1.6 \mathrm{~Hz}, 1 \mathrm{H}), 6.64(\mathrm{dd}, J=3.6,0.9 \mathrm{~Hz}, 1 \mathrm{H}), 4.12(\mathrm{q}, J=7.1 \mathrm{~Hz}$, 2H), 4.08 (q, $J=7.1 \mathrm{~Hz}, 2 \mathrm{H}), 1.65(\mathrm{~s}, 6 \mathrm{H}), 1.64(\mathrm{~s}, 6 \mathrm{H}), 1.16(\mathrm{t}, J=7.1 \mathrm{~Hz}, 3 \mathrm{H}), 1.09$ (t, $J=7.1 \mathrm{~Hz}$, $3 \mathrm{H})$.

${ }^{13}$ C NMR $\left(100 \mathrm{MHz}, \mathrm{CDCl}_{3}\right) \delta 177.7\left(\mathrm{C}_{\mathrm{q}}\right), 177.1\left(\mathrm{C}_{\mathrm{q}}\right), 152.4\left(\mathrm{C}_{\mathrm{q}}\right), 149.0(\mathrm{CH}), 139.7\left(\mathrm{C}_{\mathrm{q}}\right), 138.4(\mathrm{CH})$, $136.9\left(\mathrm{C}_{\mathrm{q}}\right), 135.4\left(\mathrm{C}_{\mathrm{q}}\right), 126.7\left(\mathrm{C}_{\mathrm{q}}\right), 125.8(\mathrm{CH}), 120.2(\mathrm{CH}), 115.7(\mathrm{CH}), 115.1(\mathrm{CH}), 108.4(\mathrm{CH}), 104.2$ $(\mathrm{CH}), 60.7\left(\mathrm{CH}_{2}\right), 60.6\left(\mathrm{CH}_{2}\right), 46.9\left(\mathrm{C}_{\mathrm{q}}\right), 46.5\left(\mathrm{C}_{\mathrm{q}}\right), 26.9\left(\mathrm{CH}_{3}\right), 26.3\left(\mathrm{CH}_{3}\right), 14.1\left(\mathrm{CH}_{3}\right), 14.0\left(\mathrm{CH}_{3}\right)$. IR (ATR): 2979, 1721, 1468, 1439, 1249, 1134, 1024, 912, 772, $717 \mathrm{~cm}^{-1}$. MS (ESI) $m / z$ (relative intensity): $423(70)[\mathrm{M}+\mathrm{H}]^{+}, 440(30)\left[\mathrm{M}+\mathrm{NH}_{4}\right]^{+}$. HR-MS (ESI) $\mathrm{C}_{25} \mathrm{H}_{31} \mathrm{~N}_{2} \mathrm{O}_{4}[\mathrm{M}+\mathrm{H}]^{+}$: 423.2278, found: 423.2282.

The spectral data were in accordance with those reported in the literature. ${ }^{[214]}$ 
Dimethyl 2,2'-[1-(pyridin-2-yl)-1H-indole-4,6-diyl]bis(2-methylpropanoate) (397b)

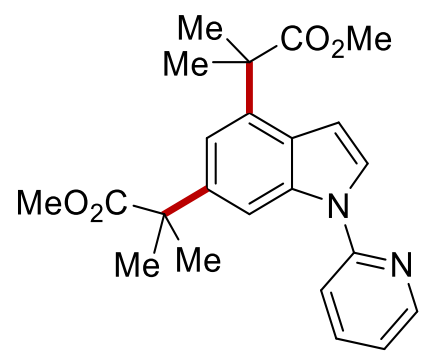

The General Procedure $\mathbf{C}$ was followed using 1-(pyridin-2-yl)-1H-indole 395a (48.6 mg, 0.25 mmol), methyl 2-bromo-2-methylpropanoate 396b (148 mg, $0.75 \mathrm{mmol}), \mathrm{Ru}(\mathrm{OAc})_{2}\left(\mathrm{PPh}_{3}\right)_{2}(18.6 \mathrm{mg}$, $10 \mathrm{~mol} \%), \mathrm{NaOAc}(41.0 \mathrm{mg}, 0.50 \mathrm{mmol})$ in DCE $(2.0 \mathrm{~mL})$. Purification by column chromatography on silica gel ( $n$-hexane/EtOAc: $5 / 1)$ yielded $397 \mathbf{b}$ (79.8 mg, 81\%) as colorless oil.

${ }^{1} \mathbf{H}$ NMR $\left(400 \mathrm{MHz}, \mathrm{CDCl}_{3}\right) \delta 8.55(\mathrm{ddd}, J=4.9,1.6,0.9 \mathrm{~Hz}, 1 \mathrm{H}), 8.09(\mathrm{dd}, J=1.6,0.9 \mathrm{~Hz}, 1 \mathrm{H})$, $7.81(\mathrm{ddd}, J=8.2,7.4,1.6 \mathrm{~Hz}, 1 \mathrm{H}), 7.61(\mathrm{~d}, J=3.6 \mathrm{~Hz}, 1 \mathrm{H}), 7.43(\mathrm{dd}, J=8.2,0.9 \mathrm{~Hz}, 1 \mathrm{H}), 7.16$ (ddd, $J=7.4,4.9,0.9 \mathrm{~Hz}, 1 \mathrm{H}), 7.13(\mathrm{~d}, J=1.6 \mathrm{~Hz}, 1 \mathrm{H}), 6.60(\mathrm{dd}, J=3.6,0.9 \mathrm{~Hz}, 1 \mathrm{H}), 3.64(\mathrm{~s}, 3 \mathrm{H}), 3.59$ $(\mathrm{s}, 3 \mathrm{H}), 1.67(\mathrm{~s}, 6 \mathrm{H}), 1.65(\mathrm{~s}, 6 \mathrm{H})$.

${ }^{13} \mathrm{C}$ NMR $\left(100 \mathrm{MHz}, \mathrm{CDCl}_{3}\right) \delta 178.3\left(\mathrm{C}_{\mathrm{q}}\right), 177.6\left(\mathrm{C}_{\mathrm{q}}\right), 152.3\left(\mathrm{C}_{\mathrm{q}}\right), 149.0(\mathrm{CH}), 139.5\left(\mathrm{C}_{\mathrm{q}}\right), 138.4(\mathrm{CH})$, $136.9\left(\mathrm{C}_{\mathrm{q}}\right), 135.3\left(\mathrm{C}_{\mathrm{q}}\right), 126.8\left(\mathrm{C}_{\mathrm{q}}\right), 126.1(\mathrm{CH}), 120.3(\mathrm{CH}), 115.4(\mathrm{CH}), 115.1(\mathrm{CH}), 108.6(\mathrm{CH}), 103.8$ $(\mathrm{CH}), 52.2\left(\mathrm{CH}_{3}\right), 52.1\left(\mathrm{CH}_{3}\right), 46.9\left(\mathrm{C}_{\mathrm{q}}\right), 46.5\left(\mathrm{C}_{\mathrm{q}}\right), 26.9\left(\mathrm{CH}_{3}\right), 26.3\left(\mathrm{CH}_{3}\right)$.

IR (ATR): 2976, 2949, 1729, 1721, 1469, 1436, 1250, 1130, 730, $719 \mathrm{~cm}^{-1}$.

MS (ESI) $m / z$ (relative intensity): $395(80)[\mathrm{M}+\mathrm{H}]^{+}, 412(20)\left[\mathrm{M}+\mathrm{NH}_{4}\right]^{+}$.

HR-MS (ESI) $\mathrm{C}_{23} \mathrm{H}_{27} \mathrm{~N}_{2} \mathrm{O}_{4}[\mathrm{M}+\mathrm{H}]^{+}:$395.1965, found: 395.1967 .

\section{Dipropyl 2,2'-[1-(pyridin-2-yl)-1H-indole-4,6-diyl]bis(2-methylpropanoate) (397c)}

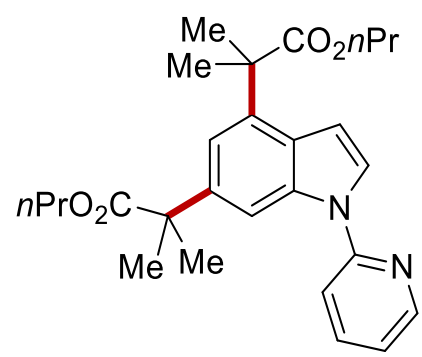

The General Procedure C was followed using 1-(pyridin-2-yl)-1H-indole 395a (48.6 mg, 0.25 mmol), propyl 2-bromo-2-methylpropanoate 396c (261 mg, $1.25 \mathrm{mmol}), \mathrm{Ru}(\mathrm{OAc})_{2}\left(\mathrm{PPh}_{3}\right)_{2}(18.6 \mathrm{mg}$, 
$10 \mathrm{~mol} \%)$, NaOAc (41.0 mg, $0.50 \mathrm{mmol})$ in DCE $(2.0 \mathrm{~mL})$. Purification by column chromatography on silica gel ( $n$-hexane/EtOAc: 5/1) yielded 397c (77.7 mg, 69\%) as colorless oil.

${ }^{1} \mathbf{H}$ NMR $\left(400 \mathrm{MHz}, \mathrm{CDCl}_{3}\right) \delta 8.55(\mathrm{ddd}, J=4.9,2.0,0.9 \mathrm{~Hz}, 1 \mathrm{H}), 8.10(\mathrm{dd}, J=1.6,0.9 \mathrm{~Hz}, 1 \mathrm{H})$, $7.80(\mathrm{ddd}, J=8.2,7.4,2.0 \mathrm{~Hz}, 1 \mathrm{H}), 7.60(\mathrm{~d}, J=3.6 \mathrm{~Hz}, 1 \mathrm{H}), 7.43(\mathrm{dd}, J=8.2,0.9 \mathrm{~Hz}, 1 \mathrm{H}), 7.15(\mathrm{ddd}$, $J=7.4,4.9,0.9 \mathrm{~Hz}, 1 \mathrm{H}), 7.14(\mathrm{~d}, J=1.6 \mathrm{~Hz}, 1 \mathrm{H}), 6.64(\mathrm{dd}, J=3.6,0.9 \mathrm{~Hz}, 1 \mathrm{H}), 4.01$ (t, $J=6.6 \mathrm{~Hz}$, 2H), $3.97(\mathrm{t}, J=6.6 \mathrm{~Hz}, 2 \mathrm{H}), 1.67(\mathrm{~s}, 6 \mathrm{H}), 1.65(\mathrm{~s}, 6 \mathrm{H}), 1.50-1.59(\mathrm{~m}, 2 \mathrm{H}), 1.43-1.51(\mathrm{~m}, 2 \mathrm{H}), 0.79$ (t, $J=7.4 \mathrm{~Hz}, 3 \mathrm{H}), 0.69$ (t, $J=7.4 \mathrm{~Hz}, 3 \mathrm{H})$.

${ }^{13} \mathrm{C} \mathrm{NMR}\left(100 \mathrm{MHz}, \mathrm{CDCl}_{3}\right) \delta 177.7\left(\mathrm{C}_{\mathrm{q}}\right), 177.2\left(\mathrm{C}_{\mathrm{q}}\right), 152.4\left(\mathrm{C}_{\mathrm{q}}\right), 149.0(\mathrm{CH}), 139.7\left(\mathrm{C}_{\mathrm{q}}\right), 138.3(\mathrm{CH})$, 137.0 $\left(\mathrm{C}_{\mathrm{q}}\right), 135.4\left(\mathrm{C}_{\mathrm{q}}\right), 126.7\left(\mathrm{C}_{\mathrm{q}}\right), 125.8(\mathrm{CH}), 120.2(\mathrm{CH}), 115.7(\mathrm{CH}), 115.1(\mathrm{CH}), 108.5(\mathrm{CH}), 104.2$ $(\mathrm{CH}), 66.3\left(\mathrm{CH}_{2}\right), 66.3\left(\mathrm{CH}_{2}\right), 46.9\left(\mathrm{C}_{\mathrm{q}}\right), 46.6\left(\mathrm{C}_{\mathrm{q}}\right), 26.9\left(\mathrm{CH}_{3}\right), 26.3\left(\mathrm{CH}_{3}\right), 21.9\left(\mathrm{CH}_{2}\right), 21.8\left(\mathrm{CH}_{2}\right)$, $10.4\left(\mathrm{CH}_{3}\right), 10.1\left(\mathrm{CH}_{3}\right)$.

IR (ATR): 2971, 2933, 2880, 1722, 1467, 1439, 1247, 1131, 773, $727 \mathrm{~cm}^{-1}$.

MS (ESI) $m / z$ (relative intensity): $451(66)[\mathrm{M}+\mathrm{H}]^{+}, 473(34)[\mathrm{M}+\mathrm{Na}]^{+}$.

HR-MS (ESI) $\mathrm{C}_{27} \mathrm{H}_{35} \mathrm{~N}_{2} \mathrm{O}_{4}[\mathrm{M}+\mathrm{H}]^{+}:$451.2595, found: 451.2591 .

Diisopropyl 2,2'-[1-(pyridin-2-yl)-1H-indole-4,6-diyl]bis(2-methylpropanoate) (397d)

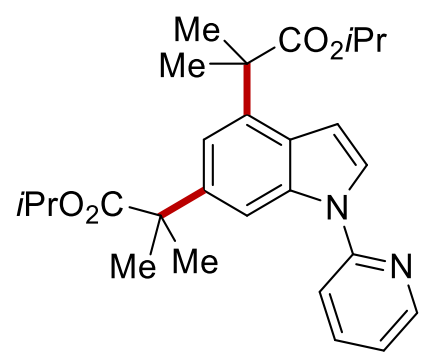

The General Procedure C was followed using 1-(pyridin-2-yl)- $1 H$-indole 395a (48.6 mg, 0.25 mmol), isopropyl 2-bromo-2-methylpropanoate 396d (261 mg, $1.25 \mathrm{mmol}), \mathrm{Ru}(\mathrm{OAc})_{2}\left(\mathrm{PPh}_{3}\right)_{2}(18.6$ $\mathrm{mg}, 10 \mathrm{~mol} \%)$, NaOAc (41.0 mg, $0.50 \mathrm{mmol})$ in DCE $(2.0 \mathrm{~mL})$. Purification by column chromatography on silica gel ( $n$-hexane/EtOAc: $5 / 1)$ yielded 397d $(81.1 \mathrm{mg}, 72 \%)$ as colorless oil.

${ }^{1} \mathbf{H}$ NMR $\left(400 \mathrm{MHz}, \mathrm{CDCl}_{3}\right) \delta 8.54(\mathrm{ddd}, J=4.9,1.9,0.9 \mathrm{~Hz}, 1 \mathrm{H}), 8.09$ (dd, $\left.J=1.6,0.9 \mathrm{~Hz}, 1 \mathrm{H}\right)$, $7.79(\mathrm{ddd}, J=8.3,7.4,2.0 \mathrm{~Hz}, 1 \mathrm{H}), 7.59$ (d, $J=3.6 \mathrm{~Hz}, 1 \mathrm{H}), 7.43(\mathrm{dd}, J=8.3,0.9 \mathrm{~Hz}, 1 \mathrm{H}), 7.14$ (ddd, $J=7.4,4.9,0.9 \mathrm{~Hz}, 1 \mathrm{H}), 7.10(\mathrm{~d}, J=1.6 \mathrm{~Hz}, 1 \mathrm{H}), 6.65(\mathrm{dd}, J=3.6,0.9 \mathrm{~Hz}, 1 \mathrm{H}), 4.94-5.05(\mathrm{~m}, 2 \mathrm{H})$, $1.65(\mathrm{~s}, 6 \mathrm{H}), 1.63(\mathrm{~s}, 6 \mathrm{H}), 1.14(\mathrm{~s}, 3 \mathrm{H}), 1.12(\mathrm{~s}, 3 \mathrm{H}), 1.03(\mathrm{~s}, 3 \mathrm{H}), 1.03(\mathrm{~s}, 3 \mathrm{H})$. 
${ }^{13} \mathrm{C} \mathrm{NMR}\left(100 \mathrm{MHz}, \mathrm{CDCl}_{3}\right) \delta 177.1\left(\mathrm{C}_{\mathrm{q}}\right), 176.6\left(\mathrm{C}_{\mathrm{q}}\right), 152.5\left(\mathrm{C}_{\mathrm{q}}\right), 148.9(\mathrm{CH}), 139.9\left(\mathrm{C}_{\mathrm{q}}\right), 138.3(\mathrm{CH})$, $137.0\left(\mathrm{C}_{\mathrm{q}}\right), 135.4\left(\mathrm{C}_{\mathrm{q}}\right), 126.6\left(\mathrm{C}_{\mathrm{q}}\right), 125.5(\mathrm{CH}), 120.1(\mathrm{CH}), 115.9(\mathrm{CH}), 115.0(\mathrm{CH}), 108.2(\mathrm{CH}), 104.4$ $(\mathrm{CH}), 67.9(\mathrm{CH}), 67.7(\mathrm{CH}), 46.9\left(\mathrm{C}_{\mathrm{q}}\right), 46.6\left(\mathrm{C}_{\mathrm{q}}\right), 26.8\left(\mathrm{CH}_{3}\right), 26.3\left(\mathrm{CH}_{3}\right), 21.5\left(\mathrm{CH}_{3}\right), 21.5\left(\mathrm{CH}_{3}\right)$. IR (ATR): 2978, 2934, 1713, 1573, 1469, 1439, 1253, 1152, 1104, 906, 729, $718 \mathrm{~cm}^{-1}$. MS (ESI) $m / z$ (relative intensity): $451(60)[\mathrm{M}+\mathrm{H}]^{+}, 473(40)[\mathrm{M}+\mathrm{Na}]^{+}$.

HR-MS (ESI) $\mathrm{C}_{27} \mathrm{H}_{35} \mathrm{~N}_{2} \mathrm{O}_{4}[\mathrm{M}+\mathrm{H}]^{+}:$451.2592, found: 451.2591.

\section{Dibutyl 2,2'-[1-(pyridin-2-yl)-1H-indole-4,6-diyl]bis(2-methylpropanoate) (397e)}

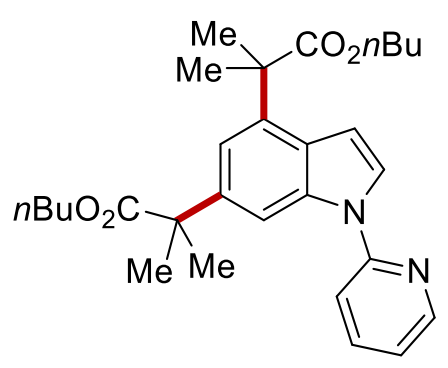

The General Procedure C was followed using 1-(pyridin-2-yl)- $1 H$-indole 395a (48.6 mg, 0.25 mmol), butyl 2-bromo-2-methylpropanoate 396e (279 mg, $1.25 \mathrm{mmol}), \mathrm{Ru}(\mathrm{OAc})_{2}\left(\mathrm{PPh}_{3}\right)_{2}(18.6 \mathrm{mg}, 10$ mol \%), NaOAc (41.0 mg, $0.50 \mathrm{mmol})$ in DCE $(2.0 \mathrm{~mL})$. Purification by column chromatography on silica gel ( $n$-hexane/EtOAc: $5 / 1)$ yielded 397e (101.7 mg, 85\%) as colorless oil.

${ }^{1} \mathbf{H}$ NMR $\left(400 \mathrm{MHz}, \mathrm{CDCl}_{3}\right) \delta 8.55(\mathrm{ddd}, J=4.8,2.0,0.9 \mathrm{~Hz}, 1 \mathrm{H}), 8.09$ (dd, $\left.J=1.6,0.9 \mathrm{~Hz}, 1 \mathrm{H}\right)$, $7.80(\mathrm{ddd}, J=8.2,7.3,2.0 \mathrm{~Hz}, 1 \mathrm{H}), 7.60(\mathrm{~d}, J=3.6 \mathrm{~Hz}, 1 \mathrm{H}), 7.43(\mathrm{dd}, J=8.2,0.9 \mathrm{~Hz}, 1 \mathrm{H}), 7.15(\mathrm{ddd}$, $J=7.3,4.8,0.9 \mathrm{~Hz}, 1 \mathrm{H}), 7.13(\mathrm{~d}, J=1.6 \mathrm{~Hz}, 1 \mathrm{H}), 6.64(\mathrm{dd}, J=3.6,0.9 \mathrm{~Hz}, 1 \mathrm{H}), 4.05(\mathrm{~d}, J=6.6 \mathrm{~Hz}$, 2H), $4.01(\mathrm{~d}, J=6.6 \mathrm{~Hz}, 2 \mathrm{H}), 1.67(\mathrm{~s}, 6 \mathrm{H}), 1.64(\mathrm{~s}, 6 \mathrm{H}), 1.51(\mathrm{dt}, J=14.4,6.6 \mathrm{~Hz}, 2 \mathrm{H}), 1.44(\mathrm{dt}, J=$ 14.4, 6.6 Hz, 2H), $1.24(\mathrm{dq}, J=14.4,7.4 \mathrm{~Hz}, 2 \mathrm{H}), 1.12(\mathrm{dq}, J=14.4,7.4 \mathrm{~Hz}, 2 \mathrm{H}), 0.81(\mathrm{t}, J=7.4 \mathrm{~Hz}$, $3 \mathrm{H}), 0.74(\mathrm{t}, J=7.4 \mathrm{~Hz}, 3 \mathrm{H})$.

${ }^{13}$ C NMR $\left(100 \mathrm{MHz}, \mathrm{CDCl}_{3}\right) \delta 177.7\left(\mathrm{C}_{\mathrm{q}}\right), 177.2\left(\mathrm{C}_{\mathrm{q}}\right), 152.4\left(\mathrm{C}_{\mathrm{q}}\right), 149.0(\mathrm{CH}), 139.7\left(\mathrm{C}_{\mathrm{q}}\right), 138.3(\mathrm{CH})$, $136.9\left(\mathrm{C}_{\mathrm{q}}\right), 135.4\left(\mathrm{C}_{\mathrm{q}}\right), 126.7\left(\mathrm{C}_{\mathrm{q}}\right), 125.8(\mathrm{CH}), 120.2(\mathrm{CH}), 115.7(\mathrm{CH}), 115.0(\mathrm{CH}), 108.5(\mathrm{CH}), 104.1$ $(\mathrm{CH}), 64.6\left(\mathrm{CH}_{2}\right), 64.5\left(\mathrm{CH}_{2}\right), 46.9\left(\mathrm{C}_{\mathrm{q}}\right), 46.6\left(\mathrm{C}_{\mathrm{q}}\right), 30.6\left(\mathrm{CH}_{2}\right), 30.4\left(\mathrm{CH}_{2}\right), 26.9\left(\mathrm{CH}_{3}\right), 26.2\left(\mathrm{CH}_{3}\right)$, $19.0\left(\mathrm{CH}_{2}\right), 18.9\left(\mathrm{CH}_{2}\right), 13.6\left(\mathrm{CH}_{3}\right), 13.5\left(\mathrm{CH}_{3}\right)$.

IR (ATR): 2959, 2932, 2876, 1720, 1469, 1437, 1247, 1133, 730, $717 \mathrm{~cm}^{-1}$. MS (ESI) $m / z$ (relative intensity): $479(70)[\mathrm{M}+\mathrm{H}]^{+}, 501(30)[\mathrm{M}+\mathrm{Na}]^{+}$. 
HR-MS (ESI) $\mathrm{C}_{29} \mathrm{H}_{39} \mathrm{~N}_{2} \mathrm{O}_{4}[\mathrm{M}+\mathrm{H}]^{+}:$479.2907, found: 479.2904 .

Diisobutyl 2,2'-[1-(pyridin-2-yl)-1H-indole-4,6-diyl]bis(2-methylpropanoate) (397f)<smiles>CCOC(=O)C(C)(C)c1cc(C(C)(C)C(C)(C)C)c2ccn(-c3ccccn3)c2c1</smiles>

The General Procedure C was followed using 1-(pyridin-2-yl)- $1 H$-indole 395a (48.6 mg, 0.25 $\mathrm{mmol}$ ), isobutyl 2-bromo-2-methylpropanoate $396 \mathbf{f}$ (243 mg, $1.25 \mathrm{mmol}), \mathrm{Ru}(\mathrm{OAc})_{2}\left(\mathrm{PPh}_{3}\right)_{2}(18.6 \mathrm{mg}$, $10 \mathrm{~mol} \%), \mathrm{NaOAc}(41.0 \mathrm{mg}, 0.50 \mathrm{mmol})$ in DCE $(2.0 \mathrm{~mL})$. Purification by column chromatography on silica gel ( $n$-hexane/EtOAc: 5/1) yielded 397f (90.9 mg, 76\%) as colorless oil.

${ }^{1}$ H NMR $\left(400 \mathrm{MHz}^{\mathrm{CDCl}} 3\right) \delta 8.55(\mathrm{ddd}, J=4.9,2.0,0.9 \mathrm{~Hz}, 1 \mathrm{H}), 8.14-8.07$ (m, 1H), 7.79 (ddd, $J$ $=8.2,7.3,1.9 \mathrm{~Hz}, 1 \mathrm{H}), 7.59(\mathrm{~d}, J=3.5 \mathrm{~Hz}, 1 \mathrm{H}), 7.43(\mathrm{dd}, J=8.2,1.0 \mathrm{~Hz}, 1 \mathrm{H}), 7.15(\mathrm{ddd}, J=7.4$, 4.9, $0.9 \mathrm{~Hz}, 1 \mathrm{H}), 7.11(\mathrm{~d}, J=1.6 \mathrm{~Hz}, 1 \mathrm{H}), 6.66(\mathrm{dd}, J=3.6,0.8 \mathrm{~Hz}, 1 \mathrm{H}), 4.75-4.87(\mathrm{~m}, 2 \mathrm{H}), 1.66$ (s, $3 \mathrm{H}), 1.65(\mathrm{~s}, 3 \mathrm{H}), 1.64(\mathrm{~s}, 3 \mathrm{H}), 1.63(\mathrm{~s}, 3 \mathrm{H}), 1.50-1.40(\mathrm{~m}, 2 \mathrm{H}), 1.39-1.30(\mathrm{~m}, 2 \mathrm{H}), 1.09(\mathrm{dd}, J=$ 6.3, $1.0 \mathrm{~Hz}, 3 \mathrm{H}), 1.01(\mathrm{dd}, J=6.3,2.4 \mathrm{~Hz}, 3 \mathrm{H}), 0.74(\mathrm{td}, J=7.4,1.2 \mathrm{~Hz}, 3 \mathrm{H}), 0.61(\mathrm{td}, J=7.4,5.0$ $\mathrm{Hz}, 3 \mathrm{H})$.

${ }^{13} \mathrm{C} \mathrm{NMR}\left(100 \mathrm{MHz}, \mathrm{CDCl}_{3}\right) \delta 177.3\left(\mathrm{C}_{\mathrm{q}}\right), 176.8\left(\mathrm{C}_{\mathrm{q}}\right), 152.5\left(\mathrm{C}_{\mathrm{q}}\right), 149.0(\mathrm{CH}), 139.9\left(\mathrm{C}_{\mathrm{q}}\right), 138.3(\mathrm{CH})$, $137.0\left(\mathrm{C}_{\mathrm{q}}\right), 135.4\left(\mathrm{C}_{\mathrm{q}}\right), 126.6\left(\mathrm{C}_{\mathrm{q}}\right), 125.5(\mathrm{CH}), 120.1(\mathrm{CH}), 115.9(\mathrm{CH}), 115.0(\mathrm{CH}), 108.2(\mathrm{CH}), 104.5$ $(\mathrm{CH}), 72.5(\mathrm{CH}), 72.3(\mathrm{CH}), 47.0\left(\mathrm{C}_{\mathrm{q}}\right), 46.6\left(\mathrm{C}_{\mathrm{q}}\right), 28.7\left(\mathrm{CH}_{2}\right), 28.6\left(\mathrm{CH}_{2}\right), 26.9\left(\mathrm{CH}_{3}\right), 26.2\left(\mathrm{CH}_{3}\right), 19.2$ $\left(\mathrm{CH}_{3}\right), 19.1\left(\mathrm{CH}_{3}\right), 9.72\left(\mathrm{CH}_{3}\right), 9.42\left(\mathrm{CH}_{3}\right)$.

IR (ATR): 2973, 2935, 2878, 1715, 1470, 1437, 1250, 1150, 1110, $733 \mathrm{~cm}^{-1}$.

MS (ESI) $m / z$ (relative intensity): $479(66)[\mathrm{M}+\mathrm{H}]^{+}, 501(34)[\mathrm{M}+\mathrm{Na}]^{+}$.

HR-MS (ESI) $\mathrm{C}_{29} \mathrm{H}_{39} \mathrm{~N}_{2} \mathrm{O}_{4}[\mathrm{M}+\mathrm{H}]^{+}:$479.2905, found: 479.2904 . 
Bis(2-methoxyethyl) 2,2'-[1-(pyridin-2-yl)-1H-indole-4,6-diyl]bis(2-methylpropanoate) (397g)<smiles>COCCOC(=O)C(C)(C)c1cc(C(C)(C)C(=O)OCCOC)c2ccn(-c3ccccn3)c2c1</smiles>

The General Procedure $\mathbf{C}$ was followed using 1-(pyridin-2-yl)-1H-indole 395a (48.6 mg, 0.25 mmol), 2-methoxyethyl 2-bromo-2-methylpropanoate $396 \mathrm{~g}(281 \mathrm{mg}, 1.25 \mathrm{mmol}), \mathrm{Ru}(\mathrm{OAc})_{2}\left(\mathrm{PPh}_{3}\right)_{2}$ (18.6 mg, $10 \mathrm{~mol} \%)$, NaOAc $(41.0 \mathrm{mg}, 0.50 \mathrm{mmol})$ in DCE $(2.0 \mathrm{~mL})$. Purification by column chromatography on silica gel ( $n$-hexane/EtOAc: 5/1) yielded $397 \mathbf{g}(103 \mathrm{mg}, 85 \%)$ as colorless oil.

${ }^{1} \mathbf{H}$ NMR $\left(400 \mathrm{MHz}, \mathrm{CDCl}_{3}\right) \delta 8.55(\mathrm{ddd}, J=4.8,1.9,0.8 \mathrm{~Hz}, 1 \mathrm{H}), 8.08(\mathrm{dd}, J=1.6,0.8 \mathrm{~Hz}, 1 \mathrm{H})$, $7.81(\mathrm{ddd}, J=8.2,7.4,1.9 \mathrm{~Hz}, 1 \mathrm{H}), 7.61$ (d, $J=3.5 \mathrm{~Hz}, 1 \mathrm{H}), 7.44(\mathrm{dd}, J=8.2,0.9 \mathrm{~Hz}, 1 \mathrm{H}), 7.22-$ $7.10(\mathrm{~m}, 2 \mathrm{H}), 6.65(\mathrm{dd}, J=3.5,0.8 \mathrm{~Hz}, 1 \mathrm{H}), 4.28-4.06(\mathrm{~m}, 4 \mathrm{H}), 3.55-3.47(\mathrm{~m}, 2 \mathrm{H}), 3.47-3.37(\mathrm{~m}$, 2H), $3.21(\mathrm{~s}, 3 \mathrm{H}), 3.14(\mathrm{~s}, 3 \mathrm{H}), 1.69(\mathrm{~s}, 6 \mathrm{H}), 1.66(\mathrm{~s}, 6 \mathrm{H})$.

${ }^{13}$ C NMR (100 MHz, $\left.\mathrm{CDCl}_{3}\right) \delta \delta 177.6\left(\mathrm{C}_{\mathrm{q}}\right), 177.0\left(\mathrm{C}_{\mathrm{q}}\right), 152.4\left(\mathrm{C}_{\mathrm{q}}\right), 149.1(\mathrm{CH}), 139.5\left(\mathrm{C}_{\mathrm{q}}\right), 138.4$ $(\mathrm{CH}), 136.8\left(\mathrm{C}_{\mathrm{q}}\right), 135.4\left(\mathrm{C}_{\mathrm{q}}\right), 126.8\left(\mathrm{C}_{\mathrm{q}}\right), 126.0(\mathrm{CH}), 120.3(\mathrm{CH}), 115.7(\mathrm{CH}), 115.1(\mathrm{CH}), 108.7(\mathrm{CH})$, 104.1 (CH), $70.3\left(\mathrm{CH}_{2}\right), 70.3\left(\mathrm{CH}_{2}\right), 64.0\left(\mathrm{CH}_{2}\right), 63.8\left(\mathrm{CH}_{2}\right), 58.8\left(\mathrm{CH}_{3}\right), 58.8\left(\mathrm{CH}_{3}\right), 46.9\left(\mathrm{C}_{\mathrm{q}}\right), 46.6$ $\left(\mathrm{C}_{\mathrm{q}}\right), 26.9\left(\mathrm{CH}_{3}\right), 26.2\left(\mathrm{CH}_{3}\right)$.

IR (ATR): 2981, 2928, 1727, 1584, 1470, 1441, 1250, 1194, 1153, $1125 \mathrm{~cm}^{-1}$.

MS (ESI) $m / z$ (relative intensity): $483(70)[\mathrm{M}+\mathrm{H}]^{+}, 500(30)\left[\mathrm{M}+\mathrm{NH}_{4}\right]^{+}$.

HR-MS (ESI) $\mathrm{C}_{27} \mathrm{H}_{35} \mathrm{~N}_{2} \mathrm{O}_{6}[\mathrm{M}+\mathrm{H}]^{+}$: 483.2491, found: 483.2490 .

Bis(2-ethylbutyl) 2,2'-[1-(pyridin-2-yl)-1H-indole-4,6-diyl]bis(2-methylpropanoate) (397h)<smiles>CCC(CC)COC(=O)C(C)(C)c1cc(C(C)(C)C(=O)OCC(CC)CC)c2ccn(-c3ccccn3)c2c1</smiles>

The General Procedure C was followed using 1-(pyridin-2-yl)- $1 H$-indole 395a (48.6 mg, 0.25 
mmol), 2-ethylbutyl 2-bromo-2-methylpropanoate 396h (314 mg, $1.25 \mathrm{mmol}), \mathrm{Ru}(\mathrm{OAc})_{2}\left(\mathrm{PPh}_{3}\right)_{2}(18.6$ $\mathrm{mg}, 10 \mathrm{~mol} \%)$, NaOAc $(41.0 \mathrm{mg}, 0.50 \mathrm{mmol})$ in DCE $(2.0 \mathrm{~mL})$. Purification by column chromatography on silica gel ( $n$-hexane/EtOAc: 5/1) yielded 397h (119 mg, 89\%) as colorless oil.

${ }^{1} \mathbf{H}$ NMR $\left(400 \mathrm{MHz}^{\left.\mathrm{CDCl}_{3}\right)} \delta 8.55(\mathrm{ddd}, J=4.9,2.0,0.9 \mathrm{~Hz}, 1 \mathrm{H}), 8.08(\mathrm{dd}, J=1.6,0.8 \mathrm{~Hz}, 1 \mathrm{H})\right.$, 7.79 (ddd, $J=8.2,7.4,2.0 \mathrm{~Hz}, 1 \mathrm{H}), 7.60$ (d, $J=3.6 \mathrm{~Hz}, 1 \mathrm{H}), 7.42(\mathrm{dd}, J=8.2,1.0 \mathrm{~Hz}, 1 \mathrm{H}), 7.17-$ $7.13(\mathrm{ddd}, J=7.4,4.9,0.9 \mathrm{~Hz}, 1 \mathrm{H}), \quad 7.16(\mathrm{~d}, J=1.6 \mathrm{~Hz}, 1 \mathrm{H}), 6.63(\mathrm{dd}, J=3.6,0.8 \mathrm{~Hz}, 1 \mathrm{H}), 3.96(\mathrm{~d}$, $J=5.7 \mathrm{~Hz}, 2 \mathrm{H}), 3.91(\mathrm{~d}, J=5.8 \mathrm{~Hz}, 2 \mathrm{H}), 1.67(\mathrm{~s}, 6 \mathrm{H}), 1.64(\mathrm{~s}, 6 \mathrm{H}), 1.45-1.39(\mathrm{~m}, 1 \mathrm{H}), 1.35-1.29$ $(\mathrm{m}, 1 \mathrm{H}), 1.24-1.17(\mathrm{~m}, 4 \mathrm{H}), 1.13-0.98(\mathrm{~m}, 4 \mathrm{H}), 0.75(\mathrm{t}, J=7.5 \mathrm{~Hz}, 6 \mathrm{H}), 0.65(\mathrm{t}, J=7.5 \mathrm{~Hz}, 6 \mathrm{H})$. ${ }^{13} \mathrm{C} \mathrm{NMR}\left(100 \mathrm{MHz}, \mathrm{CDCl}_{3}\right) \delta 177.8\left(\mathrm{C}_{\mathrm{q}}\right), 177.2\left(\mathrm{C}_{\mathrm{q}}\right), 152.4\left(\mathrm{C}_{\mathrm{q}}\right), 149.0(\mathrm{CH}), 139.7\left(\mathrm{C}_{\mathrm{q}}\right), 138.3(\mathrm{CH})$, $136.9\left(\mathrm{C}_{\mathrm{q}}\right), 135.4\left(\mathrm{C}_{\mathrm{q}}\right), 126.8\left(\mathrm{C}_{\mathrm{q}}\right), 125.8(\mathrm{CH}), 120.2(\mathrm{CH}), 115.6(\mathrm{CH}), 115.0(\mathrm{CH}), 108.5(\mathrm{CH}), 104.1$ $(\mathrm{CH}), 66.7\left(\mathrm{CH}_{2}\right), 66.6\left(\mathrm{CH}_{2}\right), 47.0\left(\mathrm{C}_{\mathrm{q}}\right), 46.6\left(\mathrm{C}_{\mathrm{q}}\right), 40.2(\mathrm{CH}), 40.0(\mathrm{CH}), 26.9\left(\mathrm{CH}_{3}\right), 26.1\left(\mathrm{CH}_{3}\right), 23.2$ $\left(\mathrm{CH}_{2}\right), 23.1\left(\mathrm{CH}_{2}\right), 10.9\left(\mathrm{CH}_{3}\right), 10.8\left(\mathrm{CH}_{3}\right)$.

IR (ATR): 2964, 2930, 2870, 1724, 1466, 1438, 1249, 1130, 992, $774 \mathrm{~cm}^{-1}$.

MS (ESI) $m / z$ (relative intensity): $535(70)[\mathrm{M}+\mathrm{H}]^{+}, 557(30)[\mathrm{M}+\mathrm{Na}]^{+}$.

HR-MS (ESI) $\mathrm{C}_{33} \mathrm{H}_{47} \mathrm{~N}_{2} \mathrm{O}_{4}[\mathrm{M}+\mathrm{H}]^{+}:$535.3533, found: 535.3530 .

Bis(4-phenylbutan-2-yl) 2,2'-[1-(pyridin-2-yl)-1H-indole-4,6-diyl]bis(2-methylpropanoate) (397i)

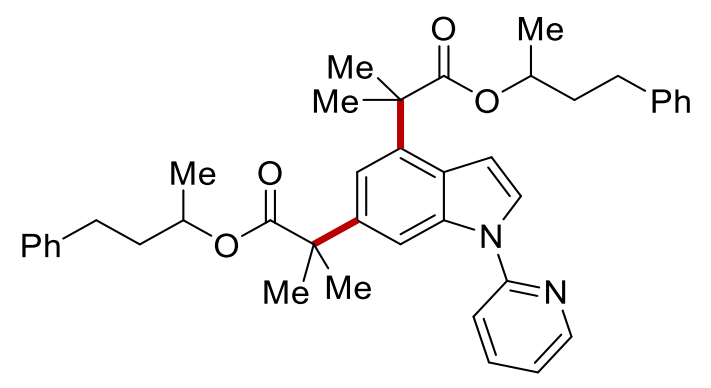

The General Procedure C was followed using 1-(pyridin-2-yl)-1H-indole 395a (48.6 mg, 0.25 mmol), 4-phenylbutan-2-yl 2-bromo-2-methylpropanoate $396 \mathbf{i} \quad(374 \quad \mathrm{mg}, \quad 1.25 \mathrm{mmol})$, $\mathrm{Ru}(\mathrm{OAc})_{2}\left(\mathrm{PPh}_{3}\right)_{2}(18.6 \mathrm{mg}, 10 \mathrm{~mol} \%)$, NaOAc $(41.0 \mathrm{mg}, 0.50 \mathrm{mmol})$ in DCE $(2.0 \mathrm{~mL})$. Purification by column chromatography on silica gel ( $n$-hexane/EtOAc: $5 / 1)$ yielded 397i $(99.4 \mathrm{mg}, 63 \%)$ as colorless oil.

${ }^{1} \mathbf{H}$ NMR $\left(400 \mathrm{MHz}, \mathrm{CDCl}_{3}\right) \delta 8.54(\mathrm{ddd}, J=4.9,1.9,0.7 \mathrm{~Hz}, 1 \mathrm{H}), 8.16(\mathrm{~d}, J=2.5 \mathrm{~Hz}, 1 \mathrm{H}), 7.80-$ $7.70(\mathrm{~m}, 1 \mathrm{H}), 7.60(\mathrm{dd}, J=3.6,1.7 \mathrm{~Hz}, 1 \mathrm{H}), 7.36(\mathrm{dd}, J=8.2,5.7 \mathrm{~Hz}, 1 \mathrm{H}), 7.22-7.18(\mathrm{~m}, 1 \mathrm{H}), 7.18$ 
- $7.15(\mathrm{~m}, 2 \mathrm{H}), 7.15-7.07(\mathrm{~m}, 5 \mathrm{H}), 7.00-6.96(\mathrm{~m}, 2 \mathrm{H}), 6.90-6.84(\mathrm{~m}, 2 \mathrm{H}), 6.71(\mathrm{~d}, J=3.7 \mathrm{~Hz}$, $1 \mathrm{H}), 4.98-4.80(\mathrm{~m}, 2 \mathrm{H}), 2.53-2.38(\mathrm{~m}, 2 \mathrm{H}), 2.32-2.15(\mathrm{~m}, 2 \mathrm{H}), 1.86-1.71(\mathrm{~m}, 2 \mathrm{H}), 1.70(\mathrm{~s}, 3 \mathrm{H})$, $1.69(\mathrm{~s}, 3 \mathrm{H}), 1.68(\mathrm{~s}, 3 \mathrm{H}), 1.67(\mathrm{~s}, 3 \mathrm{H}), 1.65-1.53(\mathrm{~m}, 2 \mathrm{H}), 1.13(\mathrm{dd}, J=6.3,1.8 \mathrm{~Hz}, 3 \mathrm{H}), 1.05(\mathrm{dd}$, $J=12.4,6.2 \mathrm{~Hz}, 3 \mathrm{H})$.

${ }^{13}$ C NMR $\left(100 \mathrm{MHz}, \mathrm{CDCl}_{3}\right) \delta 177.2\left(\mathrm{C}_{\mathrm{q}}\right), 176.7\left(\mathrm{C}_{\mathrm{q}}\right), 152.4\left(\mathrm{C}_{\mathrm{q}}\right), 149.0(\mathrm{CH}), 141.6\left(\mathrm{C}_{\mathrm{q}}\right), 141.5\left(\mathrm{C}_{\mathrm{q}}\right)$, $139.9\left(\mathrm{C}_{\mathrm{q}}\right), 138.3(\mathrm{CH}), 137.0\left(\mathrm{C}_{\mathrm{q}}\right), 135.5\left(\mathrm{C}_{\mathrm{q}}\right), 128.3(\mathrm{CH}), 128.3(\mathrm{CH}), 128.2(\mathrm{CH}), 128.2(\mathrm{CH})$, $126.7\left(\mathrm{C}_{\mathrm{q}}\right), 125.8(\mathrm{CH}), 125.7(\mathrm{CH}), 125.6(\mathrm{CH}), 120.2(\mathrm{CH}), 115.8(\mathrm{CH}), 115.0(\mathrm{CH}), 108.6(\mathrm{CH})$, $104.5(\mathrm{CH}), 70.6(\mathrm{CH}), 70.5(\mathrm{CH}), 47.0\left(\mathrm{C}_{\mathrm{q}}\right), 46.7\left(\mathrm{C}_{\mathrm{q}}\right), 37.6\left(\mathrm{CH}_{2}\right), 37.4\left(\mathrm{CH}_{2}\right), 31.7\left(\mathrm{CH}_{2}\right), 31.2$ $\left(\mathrm{CH}_{2}\right), 26.9\left(\mathrm{CH}_{3}\right), 26.2\left(\mathrm{CH}_{3}\right), 19.8\left(\mathrm{CH}_{3}\right), 19.7\left(\mathrm{CH}_{3}\right)$.

IR (ATR): 2976, 2935, 1719, 1466, 1442, 1250, 1155, 1127, 741, $726 \mathrm{~cm}^{-1}$.

MS (ESI) $m / z$ (relative intensity): $631(66)[\mathrm{M}+\mathrm{H}]^{+}, 653(34)[\mathrm{M}+\mathrm{Na}]^{+}$.

HR-MS (ESI) $\mathrm{C}_{41} \mathrm{H}_{47} \mathrm{~N}_{2} \mathrm{O}_{4}[\mathrm{M}+\mathrm{H}]^{+}:$631.3530, found: 631.3530 .

\section{Bis(4-iodobenzyl) 2,2'-[1-(pyridin-2-yl)-1H-indole-4,6-diyl]bis(2-methylpropanoate) (397j)}

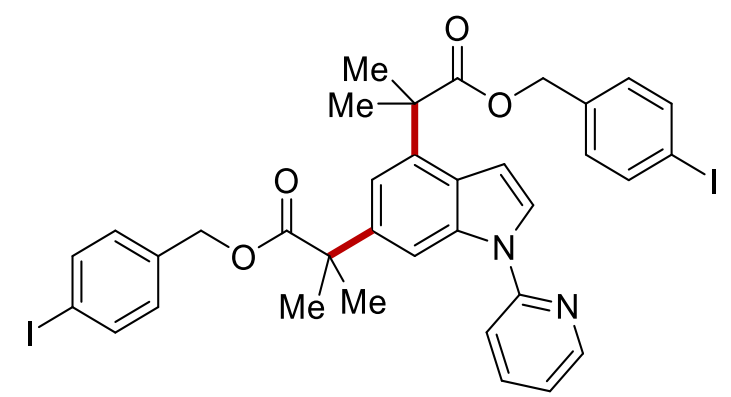

The General Procedure C was followed using 1-(pyridin-2-yl)-1H-indole 395a (48.6 mg, 0.25 mmol), 4-iodobenzyl 2-bromo-2-methylpropanoate 396j (479 mg, $1.25 \mathrm{mmol}), \mathrm{Ru}(\mathrm{OAc})_{2}\left(\mathrm{PPh}_{3}\right)_{2}(18.6$ $\mathrm{mg}, 10 \mathrm{~mol} \%)$, NaOAc (41.0 mg, $0.50 \mathrm{mmol})$ in DCE $(2.0 \mathrm{~mL})$. Purification by column chromatography on silica gel ( $n$-hexane/EtOAc: 5/1) yielded 397j (184 mg, 92\%) as colorless oil.

${ }^{1} \mathbf{H}$ NMR $\left(400 \mathrm{MHz}^{\mathrm{CDCl}}{ }_{3}\right) \delta 8.54(\mathrm{ddd}, J=4.9,2.0,0.9 \mathrm{~Hz}, 1 \mathrm{H}), 8.15(\mathrm{dd}, J=1.4,0.8 \mathrm{~Hz}, 1 \mathrm{H})$, $7.79(\mathrm{ddd}, J=8.2,7.4,2.0 \mathrm{~Hz}, 1 \mathrm{H}), 7.50(\mathrm{~d}, J=3.6 \mathrm{~Hz}, 1 \mathrm{H}), 7.47(\mathrm{~d}, J=8.3 \mathrm{~Hz}, 2 \mathrm{H}), 7.46(\mathrm{~d}, J=$ $8.3 \mathrm{~Hz}, 2 \mathrm{H}), 7.36(\mathrm{~d}, J=8.2 \mathrm{~Hz}, 1 \mathrm{H}), 7.17(\mathrm{ddd}, J=7.4,4.9,0.9 \mathrm{~Hz}, 1 \mathrm{H}), 7.08(\mathrm{~d}, J=1.6 \mathrm{~Hz}, 1 \mathrm{H})$, $6.87(\mathrm{~d}, J=8.3 \mathrm{~Hz}, 2 \mathrm{H}), 6.75(\mathrm{~d}, J=8.3 \mathrm{~Hz}, 2 \mathrm{H}), 6.48(\mathrm{dd}, J=3.6,0.8 \mathrm{~Hz}, 1 \mathrm{H}), 4.99(\mathrm{~s}, 2 \mathrm{H}), 4.97$ (s, 2H), $1.68(\mathrm{~s}, 6 \mathrm{H}), 1.63(\mathrm{~s}, 6 \mathrm{H})$.

${ }^{13} \mathbf{C}$ NMR $\left(100 \mathrm{MHz}, \mathrm{CDCl}_{3}\right) \delta 177.2\left(\mathrm{C}_{\mathrm{q}}\right), 176.7\left(\mathrm{C}_{\mathrm{q}}\right), 152.3\left(\mathrm{C}_{\mathrm{q}}\right), 149.0(\mathrm{CH}), 139.2\left(\mathrm{C}_{\mathrm{q}}\right), 138.4(\mathrm{CH})$, 
137.4 (CH), $137.2(\mathrm{CH}), 136.5\left(\mathrm{C}_{\mathrm{q}}\right), 135.8\left(\mathrm{C}_{\mathrm{q}}\right), 135.7\left(\mathrm{C}_{\mathrm{q}}\right), 135.4\left(\mathrm{C}_{\mathrm{q}}\right), 129.6(\mathrm{CH}), 129.5(\mathrm{CH}), 126.7$ $\left(\mathrm{C}_{\mathrm{q}}\right), 125.9(\mathrm{CH}), 120.3(\mathrm{CH}), 115.5(\mathrm{CH}), 115.0(\mathrm{CH}), 109.0(\mathrm{CH}), 103.9(\mathrm{CH}), 93.5\left(\mathrm{C}_{\mathrm{q}}\right), 93.4\left(\mathrm{C}_{\mathrm{q}}\right)$, 65.6 $\left(\mathrm{CH}_{2}\right), 65.5\left(\mathrm{CH}_{2}\right), 46.9\left(\mathrm{C}_{\mathrm{q}}\right), 46.5\left(\mathrm{C}_{\mathrm{q}}\right), 26.8\left(\mathrm{CH}_{3}\right), 26.0\left(\mathrm{CH}_{3}\right)$.

IR (ATR): 2976, 1722, 1466, 1441, 1314, 1247, 1132, 742, 726, $696 \mathrm{~cm}^{-1}$.

MS (ESI) $m / z$ (relative intensity): $799(66)[\mathrm{M}+\mathrm{H}]^{+}, 821(34)[\mathrm{M}+\mathrm{Na}]^{+}$.

HR-MS (ESI) $\mathrm{C}_{35} \mathrm{H}_{33} \mathrm{I}_{2} \mathrm{~N}_{2} \mathrm{O}_{4}[\mathrm{M}+\mathrm{H}]^{+}:$799.0526, found: 799.0524 .

\section{Bis $[(1 R, 2 S, 5 R)-2-i s o p r o p y l-5-m e t h y l c y c l o h e x y l] \quad 2,2^{\prime}-[1-(p y r i d i n-2-y l)-1 H$-indole-4,6-diyl $]$ bis(2-} methylpropanoate) (397k)

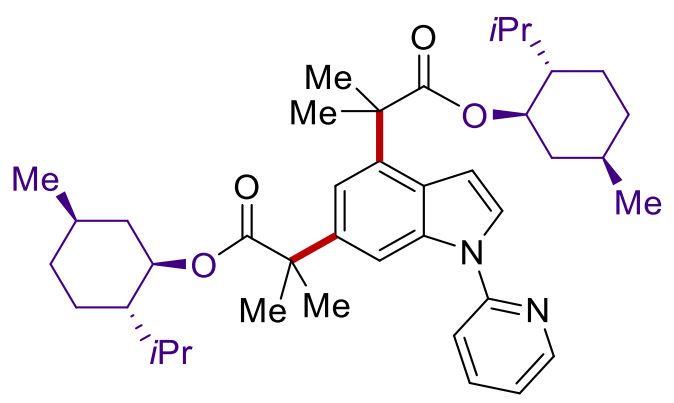

The General Procedure C was followed using 1-(pyridin-2-yl)- $1 H$-indole 395a (48.6 mg, 0.25 mmol), (1R,2S,5R)-2-isopropyl-5-methylcyclohexyl 2-bromo-2-methylpropanoate 396k (382 mg, $1.25 \mathrm{mmol}), \mathrm{Ru}(\mathrm{OAc})_{2}\left(\mathrm{PPh}_{3}\right)_{2}(18.6 \mathrm{mg}, 10 \mathrm{~mol} \%), \mathrm{NaOAc}(41.0 \mathrm{mg}, 0.50 \mathrm{mmol})$ in DCE $(2.0 \mathrm{~mL})$. Purification by column chromatography on silica gel ( $n$-hexane/EtOAc: $5 / 1)$ yielded 397k (137 mg, $85 \%$ ) as colorless oil.

${ }^{1} \mathrm{H}$ NMR $\left(400 \mathrm{MHz}, \mathrm{CDCl}_{3}\right) \delta 8.55(\mathrm{ddd}, J=4.9,2.0,0.8 \mathrm{~Hz}, 1 \mathrm{H}), 8.06(\mathrm{dd}, J=1.5,0.8 \mathrm{~Hz}, 1 \mathrm{H})$, $7.79(\mathrm{ddd}, J=8.2,7.3,1.9 \mathrm{~Hz}, 1 \mathrm{H}), 7.58(\mathrm{~d}, J=3.6 \mathrm{~Hz}, 1 \mathrm{H}), 7.42(\mathrm{~d}, J=8.2 \mathrm{~Hz}, 1 \mathrm{H}), 7.14(\mathrm{ddd}, J=$ 7.4, 4.9, $0.9 \mathrm{~Hz}, 1 \mathrm{H}), 7.09$ (d, $J=1.5 \mathrm{~Hz}, 1 \mathrm{H}), 6.68(\mathrm{dd}, J=3.6,0.8 \mathrm{~Hz}, 1 \mathrm{H}), 4.64$ (td, $J=10.9,4.3$ $\mathrm{Hz}, 1 \mathrm{H}), 4.53(\mathrm{td}, J=10.9,4.3 \mathrm{~Hz}, 1 \mathrm{H}), 2.09-1.86(\mathrm{~m}, 2 \mathrm{H}), 1.67(\mathrm{~s}, 3 \mathrm{H}), 1.65(\mathrm{~s}, 3 \mathrm{H}), 1.64(\mathrm{~s}, 3 \mathrm{H})$, $1.60(\mathrm{~s}, 3 \mathrm{H}), 1.58-1.47(\mathrm{~m}, 3 \mathrm{H}), 1.47-1.37(\mathrm{~m}, 2 \mathrm{H}), 1.35-1.29(\mathrm{~m}, 1 \mathrm{H}), 1.30-1.22(\mathrm{~m}, 1 \mathrm{H}), 1.17$ $-1.10(\mathrm{~m}, 1 \mathrm{H}), 1.03-0.86(\mathrm{~m}, 2 \mathrm{H}), 0.83(\mathrm{~d}, J=2.6 \mathrm{~Hz}, 3 \mathrm{H}), 0.81(\mathrm{~d}, J=2.6 \mathrm{~Hz}, 3 \mathrm{H}), 0.80-0.73$ $(\mathrm{m}, 6 \mathrm{H}), 0.71(\mathrm{~d}, J=7.0 \mathrm{~Hz}, 3 \mathrm{H}), 0.61(\mathrm{~d}, J=7.0 \mathrm{~Hz}, 3 \mathrm{H}), 0.59(\mathrm{~d}, J=7.0 \mathrm{~Hz}, 3 \mathrm{H}), 0.46(\mathrm{~d}, J=7.0$ $\mathrm{Hz}, 3 \mathrm{H})$.

${ }^{13} \mathrm{C} \mathrm{NMR}\left(100 \mathrm{MHz}, \mathrm{CDCl}_{3}\right) \delta 177.0\left(\mathrm{C}_{\mathrm{q}}\right), 176.8\left(\mathrm{C}_{\mathrm{q}}\right), 152.5\left(\mathrm{C}_{\mathrm{q}}\right), 149.0(\mathrm{CH}), 140.0\left(\mathrm{C}_{\mathrm{q}}\right), 138.3(\mathrm{CH})$, $136.8\left(\mathrm{C}_{\mathrm{q}}\right), 135.4\left(\mathrm{C}_{\mathrm{q}}\right), 126.7\left(\mathrm{C}_{\mathrm{q}}\right), 125.4(\mathrm{CH}), 120.1(\mathrm{CH}), 115.7(\mathrm{CH}), 115.0(\mathrm{CH}), 108.2(\mathrm{CH}), 104.7$ 
$(\mathrm{CH}), 74.6(\mathrm{CH}), 74.3(\mathrm{CH}), 47.1\left(\mathrm{CH}_{2}\right), 47.1\left(\mathrm{CH}_{2}\right), 46.8(\mathrm{CH}), 46.7(\mathrm{CH}), 40.5\left(\mathrm{C}_{\mathrm{q}}\right), 40.3\left(\mathrm{C}_{\mathrm{q}}\right), 34.2$ $\left(\mathrm{CH}_{2}\right), 47.1\left(\mathrm{CH}_{2}\right), 31.3(\mathrm{CH}), 31.3(\mathrm{CH}), 27.2\left(\mathrm{CH}_{3}\right), 26.8\left(\mathrm{CH}_{3}\right), 26.2(\mathrm{CH}), 26.0(\mathrm{CH}), 25.8\left(\mathrm{CH}_{3}\right)$, $23.1\left(\mathrm{CH}_{2}\right), 23.1\left(\mathrm{CH}_{2}\right), 22.0\left(\mathrm{CH}_{3}\right), 20.7\left(\mathrm{CH}_{3}\right), 15.9\left(\mathrm{CH}_{3}\right)$.

IR (ATR): 2975, 1724, 1474, 1465, 1439, 1245, 1127, 909, 772, $727 \mathrm{~cm}^{-1}$.

MS (ESI) m/z (relative intensity): $643(30)[\mathrm{M}+\mathrm{H}]^{+}, 660(70)\left[\mathrm{M}+\mathrm{NH}_{4}\right]^{+}$.

HR-MS (ESI) $\mathrm{C}_{41} \mathrm{H}_{59} \mathrm{~N}_{2} \mathrm{O}_{4}[\mathrm{M}+\mathrm{H}]^{+}:$643.4472, found: 643.4469.

\section{Diphenethyl 2,2'-[1-(pyridin-2-yl)-1H-indole-4,6-diyl]bis(2-methylpropanoate) (397l)}

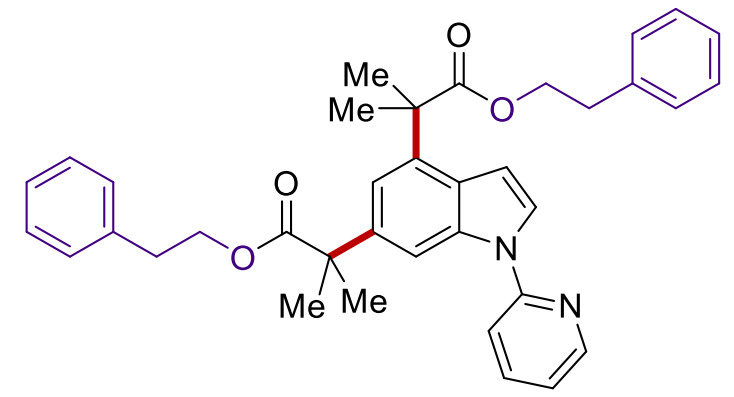

The General Procedure C was followed using 1-(pyridin-2-yl)- $1 H$-indole 395a (48.6 mg, 0.25 mmol), phenethyl 2-bromo-2-methylpropanoate 3961 (339 mg, $1.25 \mathrm{mmol}), \mathrm{Ru}(\mathrm{OAc})_{2}\left(\mathrm{PPh}_{3}\right)_{2}(18.6$ $\mathrm{mg}, 10 \mathrm{~mol} \%)$, NaOAc (41.0 $\mathrm{mg}, 0.50 \mathrm{mmol})$ in DCE (2.0 mL). Purification by column chromatography on silica gel ( $n$-hexane/EtOAc: 5/1) yielded 3971 (92.0 mg, 64\%) as colorless oil.

${ }^{1}$ H NMR $\left(400 \mathrm{MHz}, \mathrm{CDCl}_{3}\right) \delta 8.56(\mathrm{ddd}, J=4.9,2.0,0.9 \mathrm{~Hz}, 1 \mathrm{H}), 8.12(\mathrm{dd}, J=1.5,0.8 \mathrm{~Hz}, 1 \mathrm{H})$, $7.80(\mathrm{ddd}, J=8.3,7.4,2.0 \mathrm{~Hz}, 1 \mathrm{H}), 7.58(\mathrm{~d}, J=3.6 \mathrm{~Hz}, 1 \mathrm{H}), 7.39(\mathrm{~d}, J=8.3 \mathrm{~Hz}, 1 \mathrm{H}), 7.19-7.16(\mathrm{~m}$, 2H), $7.13-7.08(\mathrm{~m}, 6 \mathrm{H}), 7.02-6.98(\mathrm{~m}, 2 \mathrm{H}), 6.94-6.87(\mathrm{~m}, 2 \mathrm{H}), 6.58(\mathrm{dd}, J=3.6,0.9 \mathrm{~Hz}, 1 \mathrm{H})$, $4.25(\mathrm{t}, J=7.0 \mathrm{~Hz}, 2 \mathrm{H}), 4.20(\mathrm{t}, J=6.9 \mathrm{~Hz}, 2 \mathrm{H}), 2.81(\mathrm{t}, J=7.0 \mathrm{~Hz}, 2 \mathrm{H}), 2.72(\mathrm{t}, J=7.0 \mathrm{~Hz}, 2 \mathrm{H})$, $1.66(\mathrm{~s}, 6 \mathrm{H}), 1.65(\mathrm{~s}, 6 \mathrm{H})$.

${ }^{13} \mathrm{C}$ NMR $\left(100 \mathrm{MHz}, \mathrm{CDCl}_{3}\right) \delta 177.6\left(\mathrm{C}_{\mathrm{q}}\right), 177.0\left(\mathrm{C}_{\mathrm{q}}\right), 152.4\left(\mathrm{C}_{\mathrm{q}}\right), 149.0(\mathrm{CH}), 139.5\left(\mathrm{C}_{\mathrm{q}}\right), 138.3(\mathrm{CH})$, $137.8\left(\mathrm{C}_{\mathrm{q}}\right), 137.8\left(\mathrm{C}_{\mathrm{q}}\right), 136.8\left(\mathrm{C}_{\mathrm{q}}\right), 135.5\left(\mathrm{C}_{\mathrm{q}}\right), 128.9(\mathrm{CH}), 128.8(\mathrm{CH}), 128.2(\mathrm{CH}), 128.1(\mathrm{CH}), 126.8$ $\left(\mathrm{C}_{\mathrm{q}}\right), 126.3(\mathrm{CH}), 126.2(\mathrm{CH}), 125.9(\mathrm{CH}), 120.2(\mathrm{CH}), 115.5(\mathrm{CH}), 115.0(\mathrm{CH}), 108.8(\mathrm{CH}), 104.0$ $(\mathrm{CH}), 65.3\left(\mathrm{CH}_{2}\right), 65.2\left(\mathrm{CH}_{2}\right), 46.8\left(\mathrm{C}_{\mathrm{q}}\right), 46.5\left(\mathrm{C}_{\mathrm{q}}\right), 35.0\left(\mathrm{CH}_{2}\right), 34.9\left(\mathrm{CH}_{2}\right), 26.7\left(\mathrm{CH}_{3}\right), 26.2\left(\mathrm{CH}_{3}\right)$.

IR (ATR): 2954, 2927, 2869, 1710, 1470, 1437, 1251, 1139, 907, $731 \mathrm{~cm}^{-1}$.

MS (ESI) $m / z$ (relative intensity): $575(66)[\mathrm{M}+\mathrm{H}]^{+}, 597(34)[\mathrm{M}+\mathrm{Na}]^{+}$.

HR-MS (ESI) $\mathrm{C}_{37} \mathrm{H}_{39} \mathrm{~N}_{2} \mathrm{O}_{4}[\mathrm{M}+\mathrm{H}]^{+}:$575.2908, found: 575.2904. 


\section{Bis $[(8 R, 9 S, 13 S, 14 S)-13-m e t h y l-17-0 \times 0-7,8,9,11,12,13,14,15,16,17-d e c a h y d r o-6 H$-cyclopenta[a]} phenanthren-3-yl] 2,2'-[1-(pyridin-2-yl)-1H-indole-4,6-diyl]bis(2-methylpropanoate) (397m)

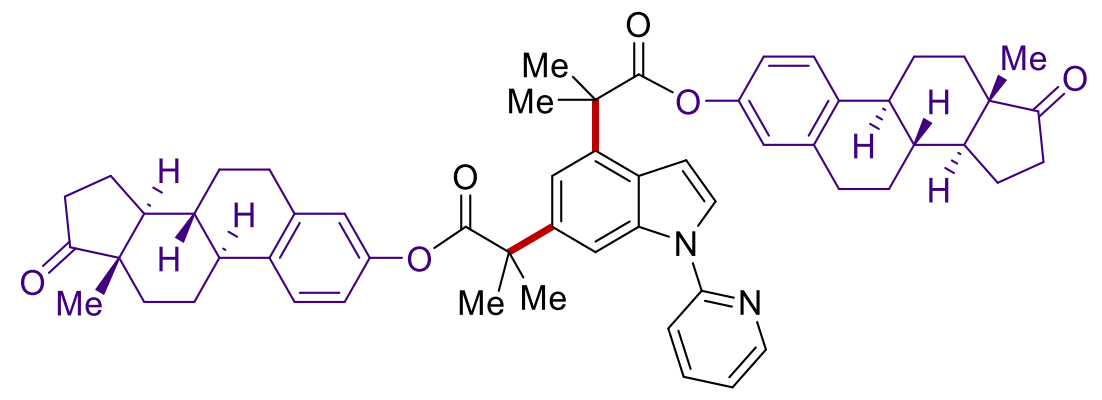

The General Procedure C was followed using 1-(pyridin-2-yl)-1H-indole 395a (48.6 mg, 0.25 mmol), $(8 R, 9 S, 13 S, 14 S)$-13-methyl-17-oxo-7,8,9,11,12,13,14,15,16,17-decahydro-6H-cyclo penta $[a]$ phenan-thren-3-yl 2-bromo-2-methylpropanoate $\quad 396 m \quad(524 \quad \mathrm{mg}, \quad 1.25 \mathrm{mmol})$, $\mathrm{Ru}(\mathrm{OAc})_{2}\left(\mathrm{PPh}_{3}\right)_{2}(18.6 \mathrm{mg}, 10 \mathrm{~mol} \%)$, NaOAc $(41.0 \mathrm{mg}, 0.50 \mathrm{mmol})$ in DCE (2.0 mL). Purification by column chromatography on silica gel ( $n$-hexane/EtOAc: $5 / 1)$ yielded 397m $(172.0 \mathrm{mg}, 79 \%)$ as colorless oil.

${ }^{1} \mathbf{H}$ NMR $\left(400 \mathrm{MHz}, \mathrm{CDCl}_{3}\right) \delta 8.58(\mathrm{ddd}, J=4.9,2.0,0.9 \mathrm{~Hz}, 1 \mathrm{H}), 8.33-8.25(\mathrm{~m}, 1 \mathrm{H}), 7.82(\mathrm{ddd}, J$ $=8.2,7.4,2.0 \mathrm{~Hz}, 1 \mathrm{H}), 7.70(\mathrm{~d}, J=3.6 \mathrm{~Hz}, 1 \mathrm{H}), 7.48(\mathrm{~d}, J=8.2 \mathrm{~Hz}, 1 \mathrm{H}), 7.34(\mathrm{~d}, J=1.6 \mathrm{~Hz}, 1 \mathrm{H})$, $7.19(\mathrm{ddd}, J=8.2,4.9,0.9,1 \mathrm{H}), 7.18-7.11(\mathrm{~m}, 2 \mathrm{H}), 6.82(\mathrm{dd}, J=3.6,0.8 \mathrm{~Hz}, 1 \mathrm{H}), 6.72(\mathrm{dd}, J=8.5$, $2.6 \mathrm{~Hz}, 1 \mathrm{H}), 6.68-6.60(\mathrm{~m}, 3 \mathrm{H}), 2.83-2.74(\mathrm{~m}, 4 \mathrm{H}), 2.49(\mathrm{~d}, J=8.9 \mathrm{~Hz}, 1 \mathrm{H}), 2.44(\mathrm{~d}, J=8.6 \mathrm{~Hz}$, $1 \mathrm{H}), 2.36-2.29(\mathrm{~m}, 2 \mathrm{H}), 2.25-2.17(\mathrm{~m}, 2 \mathrm{H}), 2.09(\mathrm{dd}, J=18.9,8.9 \mathrm{~Hz}, 2 \mathrm{H}), 2.04-1.98(\mathrm{~m}, 2 \mathrm{H})$, $1.98-1.89(\mathrm{~m}, 5 \mathrm{H}), 1.84(\mathrm{~s}, 6 \mathrm{H}), 1.80(\mathrm{~s}, 6 \mathrm{H}), 1.65-1.28(\mathrm{~m}, 11 \mathrm{H}), 0.86(\mathrm{~s}, 3 \mathrm{H}), 0.86(\mathrm{~s}, 3 \mathrm{H})$.

${ }^{13} \mathrm{C}$ NMR $\left(100 \mathrm{MHz}, \mathrm{CDCl}_{3}\right) \delta 220.6\left(\mathrm{C}_{\mathrm{q}}\right), 220.6\left(\mathrm{C}_{\mathrm{q}}\right), 176.6\left(\mathrm{C}_{\mathrm{q}}\right), 176.0\left(\mathrm{C}_{\mathrm{q}}\right), 152.4\left(\mathrm{C}_{\mathrm{q}}\right), 149.0(\mathrm{CH})$, $149.0(\mathrm{CH}), 148.9\left(\mathrm{C}_{\mathrm{q}}\right), 148.9\left(\mathrm{C}_{\mathrm{q}}\right), 139.3\left(\mathrm{C}_{\mathrm{q}}\right), 138.5(\mathrm{CH}), 137.7\left(\mathrm{C}_{\mathrm{q}}\right), 137.7\left(\mathrm{C}_{\mathrm{q}}\right), 137.0\left(\mathrm{C}_{\mathrm{q}}\right), 137.0$ $\left(\mathrm{C}_{\mathrm{q}}\right), 136.5\left(\mathrm{C}_{\mathrm{q}}\right), 135.6\left(\mathrm{C}_{\mathrm{q}}\right), 126.8\left(\mathrm{C}_{\mathrm{q}}\right), 126.1(\mathrm{CH}), 126.1(\mathrm{CH}), 121.4(\mathrm{CH}), 121.3(\mathrm{CH}), 120.3(\mathrm{CH})$, $118.7(\mathrm{CH}), 118.5(\mathrm{CH}), 115.7(\mathrm{CH}), 115.1(\mathrm{CH}), 109.0(\mathrm{CH}), 104.1(\mathrm{CH}), 50.3(\mathrm{CH}), 50.3(\mathrm{CH}), 47.9$ $\left(\mathrm{C}_{\mathrm{q}}\right), 47.9\left(\mathrm{C}_{\mathrm{q}}\right), 47.3\left(\mathrm{C}_{\mathrm{q}}\right), 46.8\left(\mathrm{C}_{\mathrm{q}}\right), 44.0(\mathrm{CH}), 44.0(\mathrm{CH}), 37.9(\mathrm{CH}), 37.9(\mathrm{CH}), 35.8\left(\mathrm{CH}_{2}\right), 35.8$ $\left(\mathrm{CH}_{2}\right), 31.5\left(\mathrm{CH}_{2}\right), 31.5\left(\mathrm{CH}_{2}\right), 29.3\left(\mathrm{CH}_{2}\right), 29.2\left(\mathrm{CH}_{2}\right), 26.7\left(\mathrm{CH}_{3}\right), 26.7\left(\mathrm{CH}_{3}\right), 26.3\left(\mathrm{CH}_{2}\right), 26.3\left(\mathrm{CH}_{2}\right)$, $26.3\left(\mathrm{CH}_{3}\right), 26.3\left(\mathrm{CH}_{3}\right), 25.7\left(\mathrm{CH}_{2}\right), 25.7\left(\mathrm{CH}_{2}\right), 21.5\left(\mathrm{CH}_{2}\right), 21.5\left(\mathrm{CH}_{2}\right), 13.7\left(\mathrm{CH}_{3}\right), 13.7\left(\mathrm{CH}_{3}\right)$.

IR (ATR): 2976, 2931, 1734, 1437, 1207, 1150, 1118, 908, 734, $722 \mathrm{~cm}^{-1}$.

MS (ESI) $m / z$ (relative intensity): $871(50)[\mathrm{M}+\mathrm{H}]^{+}, 888(90)\left[\mathrm{M}+\mathrm{NH}_{4}\right]^{+}$.

HR-MS (ESI) $\mathrm{C}_{57} \mathrm{H}_{63} \mathrm{~N}_{2} \mathrm{O}_{6}[\mathrm{M}+\mathrm{H}]^{+}$: 871.4665, found: 871.4681 . 
$\left[(4 a S, 5 S, 5 a R, 8 a R, 8 b S)-2,2,7,7-t e t r a m e t h y l t e t r a h y d r o-5 H\right.$-bis([1,3]dioxolo) $\left[4,5-b: 4^{\prime}, 5 '-d\right]$ pyran-

5-yl]methyl 2-methyl-2-(4-(2-methyl-1-oxo-1-([(4aR,5R,5aS,8aS,8bR)-2,2,7,7-tetramethyltetra hydro-5H-bis([1,3]dioxolo)[4,5-b:4',5'-d]pyran-5-yl]methoxy)propan-2-yl)-1-(pyridin-2-yl)-1Hindol-6-yl)propanoate (397n)

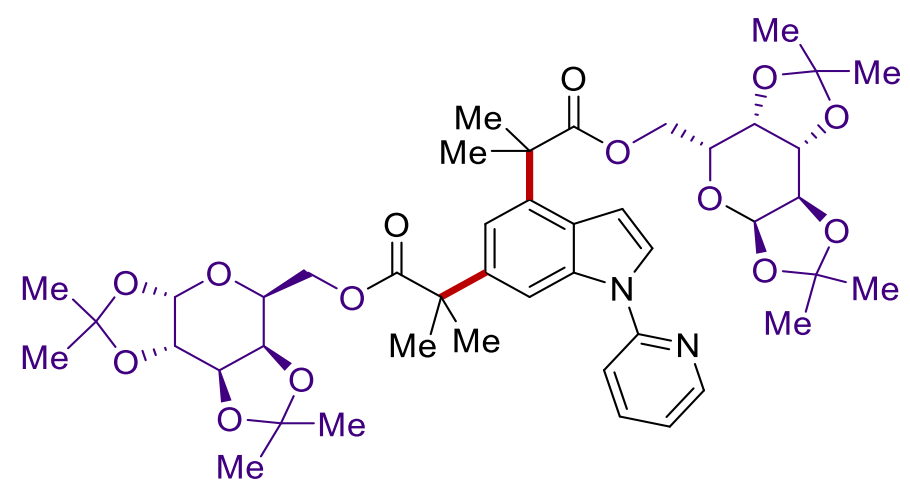

The General Procedure C was followed using 1-(pyridin-2-yl)-1H-indole 395a (48.6 mg, 0.25 mmol), ((3aR,5R,5aS,8aS,8bR)-2,2,7,7-tetramethyltetrahydro-5H-bis([1,3]dioxolo)[4,5-b:4',5'd]pyran-5-yl) methyl 2-bromo-2-methylpropanoate 396n (512 mg, $1.25 \mathrm{mmol}), \mathrm{Ru}(\mathrm{OAc})_{2}\left(\mathrm{PPh}_{3}\right)_{2}$ (18.6 mg, $10 \mathrm{~mol} \%)$, NaOAc $(41.0 \mathrm{mg}, 0.50 \mathrm{mmol})$ in DCE $(2.0 \mathrm{~mL})$. Purification by column chromatography on silica gel ( $n$-hexane/EtOAc: 5/1) yielded 397n (157.4 mg, 74\%) as colorless oil. ${ }^{1} \mathbf{H}$ NMR $\left(400 \mathrm{MHz}, \mathrm{CDCl}_{3}\right) \delta 8.54(\mathrm{ddd}, J=4.9,2.0,0.9 \mathrm{~Hz}, 1 \mathrm{H}), 8.08-8.07$ (m, 1H), $7.80(\mathrm{ddd}, J$ $=8.2,7.4,2.0 \mathrm{~Hz}, 1 \mathrm{H}), 7.59(\mathrm{~d}, J=3.6 \mathrm{~Hz}, 1 \mathrm{H}), 7.43(\mathrm{~d}, J=8.3 \mathrm{~Hz}, 1 \mathrm{H}), 7.17(\mathrm{~d}, J=1.3 \mathrm{~Hz}, 1 \mathrm{H})$, $7.15(\mathrm{ddd}, J=8.3,4.9,0.9 \mathrm{~Hz}, 1 \mathrm{H}), 6.62(\mathrm{dd}, J=3.5,0.9 \mathrm{~Hz}, 1 \mathrm{H}), 5.44(\mathrm{t}, J=4.9 \mathrm{~Hz}, 2 \mathrm{H}), 4.49(\mathrm{dd}$, $J=7.9,2.4 \mathrm{~Hz}, 1 \mathrm{H}), 4.43(\mathrm{dd}, J=7.9,2.4 \mathrm{~Hz}, 1 \mathrm{H}), 4.26-4.20(\mathrm{~m}, 4 \mathrm{H}), 4.19-4.13(\mathrm{~m}, 2 \mathrm{H}), 4.01$ $(\mathrm{dd}, J=7.9,1.8 \mathrm{~Hz}, 1 \mathrm{H}), 3.94(\mathrm{ddd}, J=7.2,5.1,1.8 \mathrm{~Hz}, 1 \mathrm{H}), 3.89(\mathrm{ddd}, J=7.2,5.1,1.8 \mathrm{~Hz}, 1 \mathrm{H})$, $3.86(\mathrm{dd}, J=7.9,1.8 \mathrm{~Hz}, 1 \mathrm{H}), 1.70(\mathrm{~s}, 3 \mathrm{H}), 1.67(\mathrm{~s}, 3 \mathrm{H}), 1.67(\mathrm{~s}, 3 \mathrm{H}), 1.64(\mathrm{~s}, 3 \mathrm{H}), 1.42(\mathrm{~s}, 3 \mathrm{H}), 1.37$ (s, 3H), $1.36(\mathrm{~s}, 3 \mathrm{H}), 1.35(\mathrm{~s}, 3 \mathrm{H}), 1.27(\mathrm{~s}, 3 \mathrm{H}), 1.25(\mathrm{~s}, 3 \mathrm{H}), 1.19(\mathrm{~s}, 3 \mathrm{H}), 1.19(\mathrm{~s}, 3 \mathrm{H})$.

${ }^{13} \mathrm{C} \mathrm{NMR}\left(100 \mathrm{MHz}, \mathrm{CDCl}_{3}\right) \delta 177.4\left(\mathrm{C}_{\mathrm{q}}\right), 176.8\left(\mathrm{C}_{\mathrm{q}}\right), 152.3\left(\mathrm{C}_{\mathrm{q}}\right), 149.1(\mathrm{CH}), 139.3\left(\mathrm{C}_{\mathrm{q}}\right), 138.4(\mathrm{CH})$, $136.7\left(\mathrm{C}_{\mathrm{q}}\right), 135.3\left(\mathrm{C}_{\mathrm{q}}\right), 126.8\left(\mathrm{C}_{\mathrm{q}}\right), 126.0(\mathrm{CH}), 120.2(\mathrm{CH}), 115.5(\mathrm{CH}), 115.0(\mathrm{CH}), 109.4\left(\mathrm{C}_{\mathrm{q}}\right), 109.3$ $\left(\mathrm{C}_{\mathrm{q}}\right), 108.9(\mathrm{CH}), 108.6\left(\mathrm{C}_{\mathrm{q}}\right), 108.6\left(\mathrm{C}_{\mathrm{q}}\right), 104.0(\mathrm{CH}), 96.2(\mathrm{CH}), 96.1(\mathrm{CH}), 70.8(\mathrm{CH}), 70.7(\mathrm{CH})$, $70.5(\mathrm{CH}), 70.5(\mathrm{CH}), 65.8(\mathrm{CH}), 65.7(\mathrm{CH}), 63.4\left(\mathrm{CH}_{2}\right), 63.3\left(\mathrm{CH}_{2}\right), 46.8\left(\mathrm{C}_{\mathrm{q}}\right), 46.6\left(\mathrm{C}_{\mathrm{q}}\right), 27.1\left(\mathrm{CH}_{3}\right)$, $26.6\left(\mathrm{CH}_{3}\right), 26.4\left(\mathrm{CH}_{3}\right), 26.1\left(\mathrm{CH}_{3}\right), 26.0\left(\mathrm{CH}_{3}\right), 25.8\left(\mathrm{CH}_{3}\right), 25.0\left(\mathrm{CH}_{3}\right), 24.2\left(\mathrm{CH}_{3}\right)$.

IR (ATR): 2991, 2936, 1210, 1132, 1112, 1066, 1009, 998, 888, $727 \mathrm{~cm}^{-1}$. 
MS (ESI) $m / z$ (relative intensity): $851(30)[\mathrm{M}+\mathrm{H}]^{+}, 868(70)\left[\mathrm{M}+\mathrm{NH}_{4}\right]^{+}$.

HR-MS (ESI) $\mathrm{C}_{45} \mathrm{H}_{59} \mathrm{~N}_{2} \mathrm{O}_{14}[\mathrm{M}+\mathrm{H}]^{+}:$851.3965, found: 851.3961 . 


\subsubsection{Mechanistic Investigation}

1) Procedure for $\mathrm{H} / \mathrm{D}$ exchange experiment

A suspension of 1-(pyridin-2-yl)-1H-indole 395a ( $0.25 \mathrm{mmol}, 1.0$ equiv), ethyl $\alpha$-bromoisobutyrate 396a (1.25 mmol, 5.0 equiv), $\mathrm{Ru}(\mathrm{OAc})_{2}\left(\mathrm{PPh}_{3}\right)_{2}(10 \mathrm{~mol} \%)$, $\mathrm{NaOAc}$ (2 equiv), and $\mathrm{D}_{2} \mathrm{O}$ (10 equiv) in $\operatorname{DCE}(2.0 \mathrm{~mL})$ was stirred at $70{ }^{\circ} \mathrm{C}$ for $16 \mathrm{~h}$ under $\mathrm{N}_{2}$ (Scheme 5.4.1). After cooling to room temperature, the mixture was concentrated in vacuo. Purification by column chromatography on silica gel afforded the desired product $[\mathrm{D}]_{\mathrm{n}} \mathbf{- 3 9 7 a}$.<smiles></smiles>

$395 a$

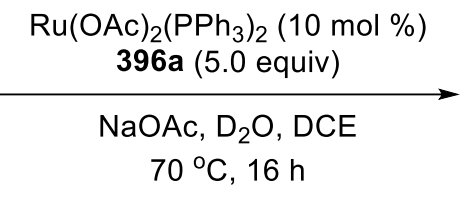

$70^{\circ} \mathrm{C}, 16 \mathrm{~h}$

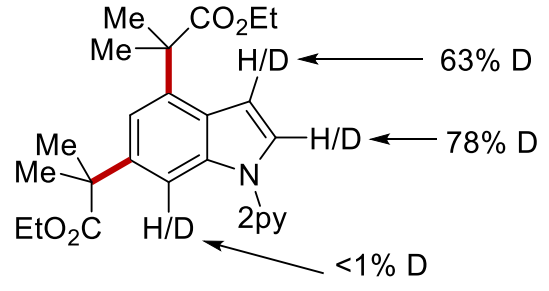

$[D]_{n}-397 a: 75 \%$

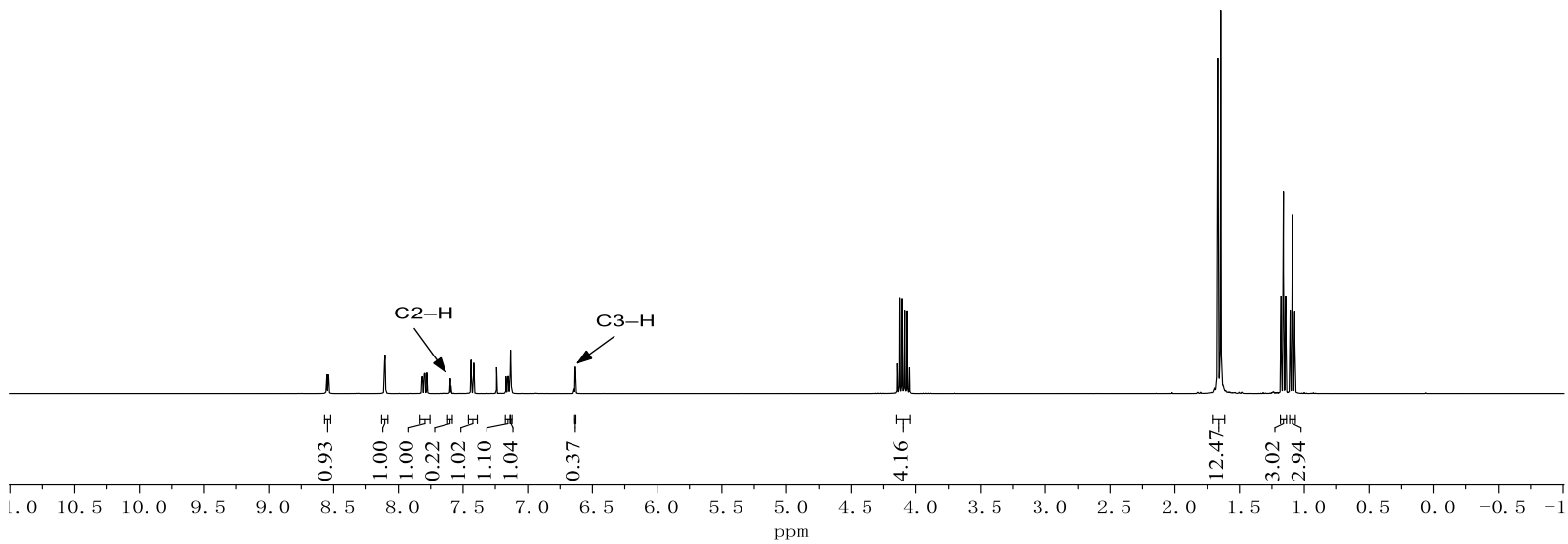

Scheme 5.4.1 H/D exchange study for ruthenium-catalyzed C4/C6-H alkylations.

2) Experiment with C7-blocked substrate

A suspension of 7-methyl-1-(pyridin-2-yl)- $1 H$-indole 395b (0.25 mmol, 1.0 equiv), ethyl $\alpha$ bromoisobutyrate 396a (1.25 mmol, 5.0 equiv), $\mathrm{Ru}(\mathrm{OAc})_{2}\left(\mathrm{PPh}_{3}\right)_{2}(10 \mathrm{~mol} \%)$, and $\mathrm{NaOAc}(0.50 \mathrm{mmol}$, 2 equiv) in DCE (2.0 mL) was stirred at $70{ }^{\circ} \mathrm{C}$ for $16 \mathrm{~h}$ under $\mathrm{N}_{2}$ (Scheme 5.4.2). After cooling to room 
temperature, the mixture is concentrated in vacuo. Purification by column chromatography on silica gel afforded the desired product $\mathbf{3 9 7 0 .}$
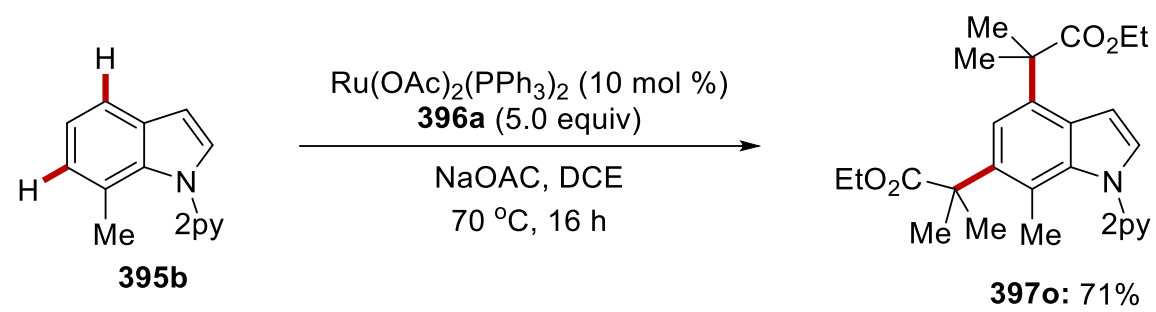

Scheme 5.4.2 ruthenium-catalyzed C4/C6-H alkylations with 395b.

Diethyl 2,2'-[7-methyl-1-(pyridin-2-yl)-1 H-indole-4,6-diyl]bis(2-methylpropanoate) (397o)<smiles>CCOC(=O)C(C)(C)c1cc(C(C)(C)C(C)(C)C)c2ccn(-c3ccccn3)c2c1C</smiles>

The General Procedure C was followed using 7-methyl-1-(pyridin-2-yl)-1H-indole 395b (52.1 mg, $0.25 \mathrm{mmol})$, Ethyl $\alpha$-bromoisobutyrate 396a (243 mg, $1.25 \mathrm{mmol}), \mathrm{Ru}(\mathrm{OAc})_{2}\left(\mathrm{PPh}_{3}\right)_{2}(18.6 \mathrm{mg}, 10 \mathrm{~mol}$ \%), NaOAc (41.0 mg, $0.50 \mathrm{mmol})$ in DCE $(2.0 \mathrm{~mL})$. Purification by column chromatography on silica gel ( $n$-hexane/EtOAc: $5 / 1)$ yielded $3970(84.0 \mathrm{mg}, 71 \%)$ as colorless oil.

${ }^{1} \mathbf{H}$ NMR $\left(400 \mathrm{MHz}^{\left.\mathrm{CDCl}_{3}\right)} \delta 8.52(\mathrm{ddd}, J=4.9,2.0,0.9 \mathrm{~Hz}, 1 \mathrm{H}), 7.75(\mathrm{ddd}, J=7.9,7.6,2.0 \mathrm{~Hz}\right.$, 1H), $7.24(\mathrm{ddd}, J=7.9,4.9,0.9 \mathrm{~Hz}, 1 \mathrm{H}), 7.23(\mathrm{dd}, J=4.9,4.9 \mathrm{~Hz}, 1 \mathrm{H}), 7.20(\mathrm{~s}, 1 \mathrm{H}), 7.19(\mathrm{ddd}, J=$ $7.9,0.9,0.9 \mathrm{~Hz}, 1 \mathrm{H}), 6.59(\mathrm{~d}, J=3.5 \mathrm{~Hz}, 1 \mathrm{H}), 4.11(\mathrm{q}, J=7.1 \mathrm{~Hz}, 2 \mathrm{H}), 4.11(\mathrm{q}, J=7.1 \mathrm{~Hz}, 2 \mathrm{H}), 1.83$ (s, 3H), $1.69(\mathrm{~s}, 6 \mathrm{H}), 1.61(\mathrm{~s}, 6 \mathrm{H}), 1.18(\mathrm{t}, J=7.1 \mathrm{~Hz}, 3 \mathrm{H}), 1.14(\mathrm{t}, J=7.1 \mathrm{~Hz}, 3 \mathrm{H})$.

${ }^{13} \mathrm{C} \mathrm{NMR}\left(100 \mathrm{MHz}, \mathrm{CDCl}_{3}\right) \delta 178.8\left(\mathrm{C}_{\mathrm{q}}\right), 178.0\left(\mathrm{C}_{\mathrm{q}}\right), 154.1\left(\mathrm{C}_{\mathrm{q}}\right), 148.7(\mathrm{CH}), 137.8\left(\mathrm{C}_{\mathrm{q}}\right), 137.7(\mathrm{CH})$, $137.1\left(\mathrm{C}_{\mathrm{q}}\right), 134.1\left(\mathrm{C}_{\mathrm{q}}\right), 130.4(\mathrm{CH}), 127.2\left(\mathrm{C}_{\mathrm{q}}\right), 121.9(\mathrm{CH}), 120.5(\mathrm{CH}), 119.1\left(\mathrm{C}_{\mathrm{q}}\right), 115.2(\mathrm{CH}), 103.2$ $(\mathrm{CH}), 60.7\left(\mathrm{CH}_{2}\right), 60.7\left(\mathrm{CH}_{2}\right), 46.9\left(\mathrm{C}_{\mathrm{q}}\right), 46.5\left(\mathrm{C}_{\mathrm{q}}\right), 27.9\left(\mathrm{CH}_{3}\right), 26.4\left(\mathrm{CH}_{3}\right), 17.4\left(\mathrm{CH}_{3}\right), 14.1\left(\mathrm{CH}_{3}\right)$. IR (ATR): 2975, 2945, 1732, 1720, 1468, 1438, 1250, 1150, 731, 720 $\mathrm{cm}^{-1}$.

MS (ESI) $m / z$ (relative intensity): $385(34)[\mathrm{M}+\mathrm{H}]^{+}, 407(66)[\mathrm{M}+\mathrm{Na}]^{+}$.

HR-MS (ESI) $\mathrm{C}_{26} \mathrm{H}_{33} \mathrm{~N}_{2} \mathrm{O}_{4}[\mathrm{M}+\mathrm{H}]^{+}: 385.1582$, found: 385.1580 . 


\subsection{Osmium-Catalyzed Electrooxidative C-H Annulations}

\subsubsection{Characterization Data}

Butyl 2-(4-methyl-3-oxo-1,3-dihydroisobenzofuran-1-yl)acetate (400a)<smiles>CCCOC(=O)CC1OC(=O)c2c(C)cccc21</smiles>

The General Procedure D was followed using 2-methylbenzoic acid 398a (27.2 mg, $0.20 \mathrm{mmol}), n$ butyl acrylate 399a (76.9 mg, $0.60 \mathrm{mmol}),\left[\mathrm{OsCl}_{2}(p \text {-cymene })\right]_{2}(7.9 \mathrm{mg}, 5.0 \mathrm{~mol} \%), \mathrm{KI}(66.4 \mathrm{mg}, 2.0$ equiv), KOAc (39.3 mg, 2.0 equiv) in HFIP $(2.0 \mathrm{~mL})$ and $\mathrm{H}_{2} \mathrm{O}(2.0 \mathrm{~mL})$. Purification by column chromatography on silica gel ( $n$-hexane/EtOAc: $8 / 1)$ yielded 400a $(39.3 \mathrm{mg}, 75 \%)$ as a colorless oil. ${ }^{1} \mathbf{H}$ NMR $\left(400 \mathrm{MHz}, \mathrm{CDCl}_{3}\right) \delta 7.49(\mathrm{t}, J=7.6 \mathrm{~Hz}, 1 \mathrm{H}), 7.24(\mathrm{ddd}, J=7.6,3.8,0.8 \mathrm{~Hz}, 2 \mathrm{H}), 5.77(\mathrm{t}, J$ $=6.5 \mathrm{~Hz}, 1 \mathrm{H}), 4.11(\mathrm{t}, J=6.5 \mathrm{~Hz}, 2 \mathrm{H}), 2.83(\mathrm{~d}, J=6.5 \mathrm{~Hz}, 2 \mathrm{H}), 2.64(\mathrm{~s}, 3 \mathrm{H}), 1.61-1.52(\mathrm{~m}, 2 \mathrm{H})$, $1.32(\mathrm{dq}, J=14.6,7.4 \mathrm{~Hz}, 2 \mathrm{H}), 0.88(\mathrm{t}, J=7.4 \mathrm{~Hz}, 3 \mathrm{H})$.

${ }^{13} \mathrm{C}$ NMR $\left(100 \mathrm{MHz}, \mathrm{CDCl}_{3}\right) \delta 170.0\left(\mathrm{C}_{\mathrm{q}}\right), 169.3\left(\mathrm{C}_{\mathrm{q}}\right), 149.2\left(\mathrm{C}_{\mathrm{q}}\right), 139.8\left(\mathrm{C}_{\mathrm{q}}\right), 133.9(\mathrm{CH}), 131.0(\mathrm{CH})$, $123.3\left(\mathrm{C}_{\mathrm{q}}\right), 119.2(\mathrm{CH}), 76.0(\mathrm{CH}), 65.0\left(\mathrm{CH}_{2}\right), 39.7\left(\mathrm{CH}_{2}\right), 30.4\left(\mathrm{CH}_{2}\right), 19.0\left(\mathrm{CH}_{2}\right), 17.2\left(\mathrm{CH}_{3}\right), 13.6$ $\left(\mathrm{CH}_{3}\right)$.

IR (ATR): 2960, 2927, 1745, 1711, 1519, 1371, 1321, 1065, 956, $608 \mathrm{~cm}^{-1}$.

MS (ESI) $m / z$ (relative intensity): $263(40)[\mathrm{M}+\mathrm{H}]^{+}, 285(60)[\mathrm{M}+\mathrm{Na}]^{+}$.

HR-MS (ESI) $\mathrm{C}_{15} \mathrm{H}_{19} \mathrm{O}_{4}[\mathrm{M}+\mathrm{H}]^{+}: 263.1279$, found: 263.1281 .

The spectral data were in accordance with those reported in the literature. ${ }^{[236 \mathrm{~h}]}$

Butyl 2-(3-oxo-1,3-dihydroisobenzofuran-1-yl)acetate (400b)

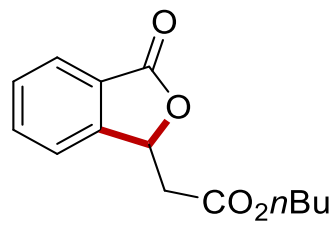

The General Procedure D was followed using benzoic acid 398b (24.4 mg, 0.20 mmol), $n$-butyl acrylate 399a (76.9 mg, $0.60 \mathrm{mmol}),\left[\mathrm{OsCl}_{2}(p \text {-cymene })\right]_{2}(7.9 \mathrm{mg}, 5.0 \mathrm{~mol} \%), \mathrm{KI}(66.4 \mathrm{mg}, 2.0 \mathrm{equiv})$, KOAc (39.3 mg, 2.0 equiv) in HFIP $(2.0 \mathrm{~mL})$ and $\mathrm{H}_{2} \mathrm{O}(2.0 \mathrm{~mL})$. Purification by column 
chromatography on silica gel ( $n$-hexane/EtOAc: $8 / 1)$ yielded $400 b(35.3 \mathrm{mg}, 71 \%)$ as a colorless oil. ${ }^{1} \mathbf{H}$ NMR $\left(400 \mathrm{MHz}, \mathrm{CDCl}_{3}\right) \delta 7.90(\mathrm{~d}, J=7.7 \mathrm{~Hz}, 1 \mathrm{H}), 7.66(\mathrm{dd}, J=7.5,1.1 \mathrm{~Hz}, 1 \mathrm{H}), 7.54(\mathrm{t}, J=7.5$ $\mathrm{Hz}, 1 \mathrm{H}), 7.48$ (ddd, J = 7.7, 1.1, $0.8 \mathrm{~Hz}, 1 \mathrm{H}), 5.87$ (t, $J=6.6 \mathrm{~Hz}, 1 \mathrm{H}), 4.14$ (t, $J=6.6 \mathrm{~Hz}, 2 \mathrm{H}), 2.98-$ $2.80(\mathrm{~m}, 2 \mathrm{H}), 1.69-1.54(\mathrm{~m}, 2 \mathrm{H}), 1.35(\mathrm{dq}, J=14.7,7.4 \mathrm{~Hz}, 2 \mathrm{H}), 0.91(\mathrm{t}, J=7.4 \mathrm{~Hz}, 3 \mathrm{H})$.

${ }^{13}$ C NMR $\left(100 \mathrm{MHz}, \mathrm{CDCl}_{3}\right) \delta 169.8\left(\mathrm{C}_{\mathrm{q}}\right), 169.3\left(\mathrm{C}_{\mathrm{q}}\right), 148.8\left(\mathrm{C}_{\mathrm{q}}\right), 134.2(\mathrm{CH}), 129.5(\mathrm{CH}), 126.0\left(\mathrm{C}_{\mathrm{q}}\right)$, $125.8(\mathrm{CH}), 122.1(\mathrm{CH}), 77.0(\mathrm{CH}), 65.2\left(\mathrm{CH}_{2}\right), 39.6\left(\mathrm{CH}_{2}\right), 30.5\left(\mathrm{CH}_{2}\right), 19.0\left(\mathrm{CH}_{2}\right), 13.6\left(\mathrm{CH}_{3}\right)$.

IR (ATR): 2959, 2933, 1759, 1599, 1466, 1288, 1172, 1059, 748, $571 \mathrm{~cm}^{-1}$.

MS (ESI) $m / z$ (relative intensity): $249(40)[\mathrm{M}+\mathrm{H}]^{+}, 271(60)[\mathrm{M}+\mathrm{Na}]^{+}$.

HR-MS (ESI) $\mathrm{C}_{14} \mathrm{H}_{17} \mathrm{O}_{4}[\mathrm{M}+\mathrm{H}]^{+}:$249.1124, found: 249.1121.

The spectral data were in accordance with those reported in the literature. ${ }^{[236 \mathrm{~h}]}$

\section{Butyl 2-(3-oxo-4-phenyl-1,3-dihydroisobenzofuran-1-yl)acetate (400c)}

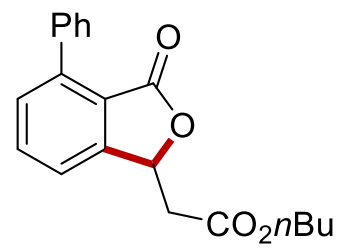

The General Procedure D was followed using 2-phenyl benzoic acid 398c (39.6 mg, $0.20 \mathrm{mmol}), n$ butyl acrylate 399a (76.9 mg, $0.60 \mathrm{mmol}),\left[\mathrm{OsCl}_{2}(p \text {-cymene })\right]_{2}(7.9 \mathrm{mg}, 5.0 \mathrm{~mol} \%), \mathrm{KI}(66.4 \mathrm{mg}, 2.0$ equiv), KOAc (39.3 mg, 2.0 equiv) in HFIP $(2.0 \mathrm{~mL})$ and $\mathrm{H}_{2} \mathrm{O}(2.0 \mathrm{~mL})$. Purification by column chromatography on silica gel ( $n$-hexane/EtOAc: 8/1) yielded 400c (42.2 mg, 65\%) as a colorless oil. ${ }^{1} \mathbf{H}$ NMR $\left(400 \mathrm{MHz}, \mathrm{CDCl}_{3}\right) \delta 7.72(\mathrm{t}, J=7.6 \mathrm{~Hz}, 1 \mathrm{H}), 7.59-7.43(\mathrm{~m}, 7 \mathrm{H}), 5.89(\mathrm{t}, J=6.5 \mathrm{~Hz}, 1 \mathrm{H})$, $4.20(\mathrm{t}, J=6.5 \mathrm{~Hz}, 2 \mathrm{H}), 2.96(\mathrm{dd}, J=6.5,1.5 \mathrm{~Hz}, 2 \mathrm{H}), 1.71-1.55(\mathrm{~m}, 2 \mathrm{H}), 1.47-1.32(\mathrm{~m}, 2 \mathrm{H}), 0.96$ (t, $J=7.3 \mathrm{~Hz}, 3 \mathrm{H})$.

${ }^{13} \mathrm{C}$ NMR $\left(100 \mathrm{MHz}, \mathrm{CDCl}_{3}\right) \delta 169.4\left(\mathrm{C}_{\mathrm{q}}\right), 168.6\left(\mathrm{C}_{\mathrm{q}}\right), 150.1\left(\mathrm{C}_{\mathrm{q}}\right), 143.0\left(\mathrm{C}_{\mathrm{q}}\right), 136.2\left(\mathrm{C}_{\mathrm{q}}\right), 134.0(\mathrm{CH})$, $131.3(\mathrm{CH}), 129.5(\mathrm{CH}), 128.4(\mathrm{CH}), 128.0(\mathrm{CH}), 121.9\left(\mathrm{C}_{\mathrm{q}}\right), 120.7(\mathrm{CH}), 75.6(\mathrm{CH}), 65.2\left(\mathrm{CH}_{2}\right), 39.8$ $\left(\mathrm{CH}_{2}\right), 30.5\left(\mathrm{CH}_{2}\right), 19.1\left(\mathrm{CH}_{2}\right), 13.7\left(\mathrm{CH}_{3}\right)$.

IR (ATR): 2959, 2931, 1760, 1575, 1308, 1236, 1199, 1015, 944, $697 \mathrm{~cm}^{-1}$.

MS (ESI) $m / z$ (relative intensity): $325(66)[\mathrm{M}+\mathrm{H}]^{+}, 347(34)[\mathrm{M}+\mathrm{Na}]^{+}$.

HR-MS (ESI) $\mathrm{C}_{20} \mathrm{H}_{21} \mathrm{O}_{4}[\mathrm{M}+\mathrm{H}]^{+}: 325.1435$, found: 325.1434 . 
The spectral data were in accordance with those reported in the literature. ${ }^{[236 \mathrm{~g}]}$

Butyl 2-(4-bromo-3-0xo-1,3-dihydroisobenzofuran-1-yl)acetate (400d)<smiles>CCOC(=O)CC1OC(=O)c2c(Br)cccc21</smiles>

The General Procedure D was followed using 2-bromo benzoic acid 398d (40.2 mg, $0.20 \mathrm{mmol}), n$ butyl acrylate 399a (76.9 mg, $0.60 \mathrm{mmol}),\left[\mathrm{OsCl}_{2}(p \text {-cymene })\right]_{2}(7.9 \mathrm{mg}, 5.0 \mathrm{~mol} \%), \mathrm{KI}(66.4 \mathrm{mg}, 2.0$ equiv), KOAc (39.3 mg, 2.0 equiv) in HFIP $(2.0 \mathrm{~mL})$ and $\mathrm{H}_{2} \mathrm{O}(2.0 \mathrm{~mL})$. Purification by column chromatography on silica gel ( $n$-hexane/EtOAc: $8 / 1$ ) yielded 400d (32.1 mg, 49\%) as a colorless oil. ${ }^{1} \mathbf{H}$ NMR $\left(400 \mathrm{MHz}, \mathrm{CDCl}_{3}\right) \delta 7.69(\mathrm{~d}, J=7.7 \mathrm{~Hz}, 1 \mathrm{H}), 7.49(\mathrm{t}, J=7.7 \mathrm{~Hz}, 1 \mathrm{H}), 7.43(\mathrm{~d}, J=7.6 \mathrm{~Hz}$, $1 \mathrm{H}), 5.79(\mathrm{t}, J=6.5 \mathrm{~Hz}, 1 \mathrm{H}), 4.13(\mathrm{t}, J=6.7 \mathrm{~Hz}, 2 \mathrm{H}), 2.99-2.81(\mathrm{~m}, 2 \mathrm{H}), 1.64-1.52(\mathrm{~m}, 2 \mathrm{H}), 1.34$ (dq, $J=14.6,7.4 \mathrm{~Hz}, 2 \mathrm{H}), 0.91(\mathrm{t}, J=7.4 \mathrm{~Hz}, 3 \mathrm{H})$.

${ }^{13}$ C NMR $\left(100 \mathrm{MHz}, \mathrm{CDCl}_{3}\right) \delta 169.1\left(\mathrm{C}_{\mathrm{q}}\right), 167.1\left(\mathrm{C}_{\mathrm{q}}\right), 151.2\left(\mathrm{C}_{\mathrm{q}}\right), 135.1(\mathrm{CH}), 134.3(\mathrm{CH}), 124.4\left(\mathrm{C}_{\mathrm{q}}\right)$, $121.2\left(\mathrm{C}_{\mathrm{q}}\right), 121.1(\mathrm{CH}), 75.3(\mathrm{CH}), 65.3\left(\mathrm{CH}_{2}\right), 39.4\left(\mathrm{CH}_{2}\right), 30.5\left(\mathrm{CH}_{2}\right), 19.0\left(\mathrm{CH}_{2}\right), 13.6\left(\mathrm{CH}_{3}\right)$.

IR (ATR): 2959, 2932, 1763, 1722, 1582, 1343, 1207, 1173, 1011, $679 \mathrm{~cm}^{-1}$.

MS (ESI) $m / z$ (relative intensity): $\left.327(66)\left({ }^{79} \mathrm{Br}\right)[\mathrm{M}+\mathrm{H}]\right]^{+}, 349(34)\left({ }^{79} \mathrm{Br}\right)[\mathrm{M}+\mathrm{Na}]^{+}$.

HR-MS (ESI) $\mathrm{C}_{14} \mathrm{H}_{16}{ }^{79} \mathrm{BrO}_{4}[\mathrm{M}+\mathrm{H}]^{+}: 327.0225$, found: 327.0226 .

The spectral data were in accordance with those reported in the literature. ${ }^{[266]}$

Butyl 2-(5-methyl-3-oxo-1,3-dihydroisobenzofuran-1-yl)acetate (400e)

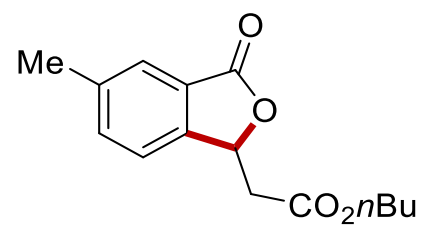

The General Procedure D was followed using 3-methyl benzoic acid 398e (27.2 mg, $0.20 \mathrm{mmol}), n$ butyl acrylate 399a (76.9 mg, $0.60 \mathrm{mmol}),\left[\mathrm{OsCl}_{2}(p \text {-cymene })\right]_{2}(7.9 \mathrm{mg}, 5.0 \mathrm{~mol} \%), \mathrm{KI}(66.4 \mathrm{mg}, 2.0$ equiv), KOAc (39.3 mg, 2.0 equiv) in HFIP $(2.0 \mathrm{~mL})$ and $\mathrm{H}_{2} \mathrm{O}(2.0 \mathrm{~mL})$. Purification by column chromatography on silica gel ( $n$-hexane/EtOAc: $8 / 1)$ yielded 400e $(51.7 \mathrm{mg}, 77 \%)$ as a colorless oil. 
${ }^{1} \mathbf{H}$ NMR $\left(400 \mathrm{MHz}, \mathrm{CDCl}_{3}\right) \delta 7.68(\mathrm{~s}, 1 \mathrm{H}), 7.46(\mathrm{ddd}, J=7.8,1.6,0.8 \mathrm{~Hz}, 1 \mathrm{H}), 7.35(\mathrm{~d}, J=7.8 \mathrm{~Hz}$, $1 \mathrm{H}), 5.82(\mathrm{t}, J=6.6 \mathrm{~Hz}, 1 \mathrm{H}), 4.14(\mathrm{t}, J=6.7 \mathrm{~Hz}, 2 \mathrm{H}), 2.94-2.76(\mathrm{~m}, 2 \mathrm{H}), 2.44(\mathrm{~s}, 3 \mathrm{H}), 1.64-1.55$ (m, 2H), $1.40-1.29(\mathrm{~m}, 2 \mathrm{H}), 0.91(\mathrm{t}, J=7.4 \mathrm{~Hz}, 3 \mathrm{H})$.

${ }^{13}$ C NMR $\left(100 \mathrm{MHz}, \mathrm{CDCl}_{3}\right) \delta 170.0\left(\mathrm{C}_{\mathrm{q}}\right), 169.4\left(\mathrm{C}_{\mathrm{q}}\right), 146.2\left(\mathrm{C}_{\mathrm{q}}\right), 139.9\left(\mathrm{C}_{\mathrm{q}}\right), 135.4(\mathrm{CH}), 126.1\left(\mathrm{C}_{\mathrm{q}}\right)$, $125.8(\mathrm{CH}), 121.7(\mathrm{CH}), 76.9(\mathrm{CH}), 65.1\left(\mathrm{CH}_{2}\right), 39.7\left(\mathrm{CH}_{2}\right), 30.5\left(\mathrm{CH}_{2}\right), 21.2\left(\mathrm{CH}_{3}\right), 19.1\left(\mathrm{CH}_{2}\right), 13.7$ $\left(\mathrm{CH}_{3}\right)$.

IR (ATR): 2960, 2929, 1771, 1733, 1495, 1290, 1154, 1009, 750, $557 \mathrm{~cm}^{-1}$.

MS (ESI) $m / z$ (relative intensity): $263(45)[\mathrm{M}+\mathrm{H}]^{+}, 285(55)[\mathrm{M}+\mathrm{Na}]^{+}$.

HR-MS (ESI) $\mathrm{C}_{15} \mathrm{H}_{19} \mathrm{O}_{4}[\mathrm{M}+\mathrm{H}]^{+}:$263.1281, found: 263.1278 .

The spectral data were in accordance with those reported in the literature. ${ }^{[236 \mathrm{~h}]}$

\section{Butyl 2-(5-chloro-3-oxo-1,3-dihydroisobenzofuran-1-yl)acetate (400f)}

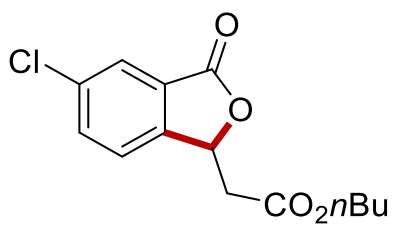

The General Procedure D was followed using 3-chloro benzoic acid 398f (31.4 mg, $0.20 \mathrm{mmol}), n$ butyl acrylate 399a (76.9 mg, $0.60 \mathrm{mmol}),\left[\mathrm{OsCl}_{2}(p \text {-cymene })\right]_{2}(7.9 \mathrm{mg}, 5.0 \mathrm{~mol} \%), \mathrm{KI}(66.4 \mathrm{mg}, 2.0$ equiv), KOAc (39.3 mg, 2.0 equiv) in HFIP $(2.0 \mathrm{~mL})$ and $\mathrm{H}_{2} \mathrm{O}(2.0 \mathrm{~mL})$. Purification by column chromatography on silica gel ( $n$-hexane/EtOAc: $8 / 1)$ yielded $400 f(24.3 \mathrm{mg}, 43 \%)$ as a colorless oil. ${ }^{1}$ H NMR $\left(400 \mathrm{MHz}, \mathrm{CDCl}_{3}\right) \delta 8.02(\mathrm{~s}, 1 \mathrm{H}), 7.77(\mathrm{~d}, J=8.1 \mathrm{~Hz}, 1 \mathrm{H}), 7.39(\mathrm{~d}, J=8.1 \mathrm{~Hz}, 1 \mathrm{H}), 5.81(\mathrm{t}$, $J=6.5 \mathrm{~Hz}, 1 \mathrm{H}), 4.14(\mathrm{t}, J=6.7 \mathrm{~Hz}, 2 \mathrm{H}), 3.00-2.78(\mathrm{~m}, 2 \mathrm{H}), 1.59(\mathrm{dt}, J=14.6,6.7 \mathrm{~Hz}, 2 \mathrm{H}), 1.34(\mathrm{dq}$, $J=14.6,7.4 \mathrm{~Hz}, 2 \mathrm{H}), 0.91(\mathrm{t}, J=7.4 \mathrm{~Hz}, 3 \mathrm{H})$.

${ }^{13}$ C NMR $\left(100 \mathrm{MHz}, \mathrm{CDCl}_{3}\right) \delta 169.1\left(\mathrm{C}_{\mathrm{q}}\right), 168.2\left(\mathrm{C}_{\mathrm{q}}\right), 147.4\left(\mathrm{C}_{\mathrm{q}}\right), 137.3(\mathrm{CH}), 128.8(\mathrm{CH}), 128.1\left(\mathrm{C}_{\mathrm{q}}\right)$, $123.8(\mathrm{CH}), 123.6\left(\mathrm{C}_{\mathrm{q}}\right), 76.9(\mathrm{CH}), 65.3\left(\mathrm{CH}_{2}\right), 39.2\left(\mathrm{CH}_{2}\right), 30.5\left(\mathrm{CH}_{2}\right), 19.0\left(\mathrm{CH}_{2}\right), 13.6\left(\mathrm{CH}_{3}\right)$.

IR (ATR): 2959, 2932, 1654, 1710, 1418, 1287, 1174, 1071, 1006, $771 \mathrm{~cm}^{-1}$.

MS (ESI) $m / z$ (relative intensity): $283(45)[\mathrm{M}+\mathrm{H}]^{+}, 305(55)[\mathrm{M}+\mathrm{Na}]^{+}$.

HR-MS (ESI) $\mathrm{C}_{14} \mathrm{H}_{16}{ }^{35} \mathrm{ClO}_{4}[\mathrm{M}+\mathrm{H}]^{+}:$283.0733, found: 283.0732 . 


\section{Butyl 2-(5-bromo-3-oxo-1,3-dihydroisobenzofuran-1-yl)acetate (400g)}

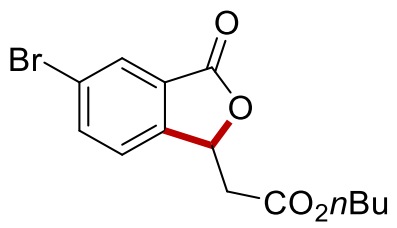

The General Procedure D was followed using 3-bromo benzoic acid 398g (40.2 mg, $0.20 \mathrm{mmol}), n$ butyl acrylate 399a (76.9 mg, $0.60 \mathrm{mmol}),\left[\mathrm{OsCl}_{2}(p \text {-cymene })\right]_{2}(7.9 \mathrm{mg}, 5.0 \mathrm{~mol} \%), \mathrm{KI}(66.4 \mathrm{mg}, 2.0$ equiv), KOAc (39.3 mg, 2.0 equiv) in HFIP $(2.0 \mathrm{~mL})$ and $\mathrm{H}_{2} \mathrm{O}(2.0 \mathrm{~mL})$. Purification by column chromatography on silica gel ( $n$-hexane/EtOAc: $8 / 1)$ yielded $\mathbf{4 0 0 g}(34.0 \mathrm{mg}, 52 \%)$ as a colorless oil. ${ }^{1} \mathbf{H}$ NMR $\left(400 \mathrm{MHz}, \mathrm{CDCl}_{3}\right) \delta 7.86(\mathrm{~s}, 1 \mathrm{H}), 7.62(\mathrm{~d}, J=8.2 \mathrm{~Hz}, 1 \mathrm{H}), 7.45(\mathrm{~d}, J=8.2 \mathrm{~Hz}, 1 \mathrm{H}), 5.84(\mathrm{t}$, $J=6.6 \mathrm{~Hz}, 1 \mathrm{H}), 4.14(\mathrm{t}, J=6.7 \mathrm{~Hz}, 2 \mathrm{H}), 3.00-2.78(\mathrm{~m}, 2 \mathrm{H}), 1.60(\mathrm{dt}, J=14.6,6.7 \mathrm{~Hz}, 2 \mathrm{H}), 1.34(\mathrm{dq}$, $J=14.6,7.4 \mathrm{~Hz}, 2 \mathrm{H}), 0.91(\mathrm{~s}, 3 \mathrm{H})$.

${ }^{13} \mathrm{C}$ NMR $\left(100 \mathrm{MHz}, \mathrm{CDCl}_{3}\right) \delta 169.1\left(\mathrm{C}_{\mathrm{q}}\right), 168.4\left(\mathrm{C}_{\mathrm{q}}\right), 146.9\left(\mathrm{C}_{\mathrm{q}}\right), 135.9\left(\mathrm{C}_{\mathrm{q}}\right), 134.5(\mathrm{CH}), 127.9\left(\mathrm{C}_{\mathrm{q}}\right)$, $125.8(\mathrm{CH}), 123.5(\mathrm{CH}), 76.8(\mathrm{CH}), 65.3\left(\mathrm{CH}_{2}\right), 39.3\left(\mathrm{CH}_{2}\right), 30.5\left(\mathrm{CH}_{2}\right), 19.0\left(\mathrm{CH}_{2}\right), 13.6\left(\mathrm{CH}_{3}\right)$.

IR (ATR): 2960, 2934, 1776, 1763, 1425, 1288, 1204, 1175, 1006, $832 \mathrm{~cm}^{-1}$.

MS (ESI) $m / z$ (relative intensity): $327(50)\left({ }^{79} \mathrm{Br}\right)[\mathrm{M}+\mathrm{H}]^{+}, 349(50)\left({ }^{79} \mathrm{Br}\right)[\mathrm{M}+\mathrm{Na}]^{+}$.

HR-MS (ESI) $\mathrm{C}_{14} \mathrm{H}_{16}{ }^{79} \mathrm{BrO}_{4}[\mathrm{M}+\mathrm{H}]^{+}:$327.0229, found: 327.0226.

\section{Butyl 2-(3-oxo-5-(trifluoromethyl)-1,3-dihydroisobenzofuran-1-yl)acetate (400h)}

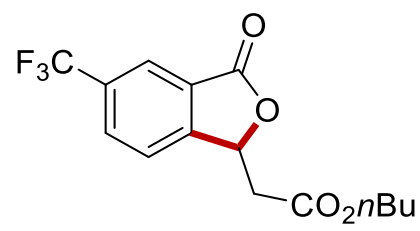

The General Procedure D was followed using 3-trifluoromethyl benzoic acid 398h $(38.0 \mathrm{mg}, 0.20$ mmol), $n$-butyl acrylate 399a (76.9 mg, $0.60 \mathrm{mmol}),\left[\mathrm{OsCl}_{2}(p \text {-cymene) }]_{2}(7.9 \mathrm{mg}, 5.0 \mathrm{~mol} \%), \mathrm{KI}\right.$ (66.4 mg, 2.0 equiv), KOAc (39.3 mg, 2.0 equiv) in $\mathrm{HFIP}(2.0 \mathrm{~mL})$ and $\mathrm{H}_{2} \mathrm{O}(2.0 \mathrm{~mL})$. Purification by column chromatography on silica gel ( $n$-hexane/EtOAc: $8 / 1)$ yielded $400 h(33.5 \mathrm{mg}, 53 \%)$ as a white solid.

M. p. $94{ }^{\circ} \mathrm{C}$

${ }^{1} \mathbf{H}$ NMR $\left(400 \mathrm{MHz}, \mathrm{CDCl}_{3}\right) \delta 8.16(\mathrm{~s}, 1 \mathrm{H}), 7.95-7.90(\mathrm{~m}, 1 \mathrm{H}), 7.69-7.65(\mathrm{~m}, 1 \mathrm{H}), 5.91(\mathrm{t}, J=6.5$ 
$\mathrm{Hz}, 1 \mathrm{H}), 4.14(\mathrm{t}, J=6.7 \mathrm{~Hz}, 2 \mathrm{H}), 3.05-2.82(\mathrm{~m}, 2 \mathrm{H}), 1.63-1.55(\mathrm{~m}, 2 \mathrm{H}), 1.34(\mathrm{dq}, J=14.7,7.4 \mathrm{~Hz}$, $2 \mathrm{H}), 0.91(\mathrm{t}, J=7.4 \mathrm{~Hz}, 3 \mathrm{H})$.

${ }^{13} \mathrm{C}$ NMR $\left(100 \mathrm{MHz}, \mathrm{CDCl}_{3}\right) \delta 168.9\left(\mathrm{C}_{\mathrm{q}}\right), 168.3\left(\mathrm{C}_{\mathrm{q}}\right), 151.9\left(\mathrm{C}_{\mathrm{q}}\right), 132.6\left(\mathrm{q}, J_{\mathrm{C}-\mathrm{F}}=33.5 \mathrm{~Hz}, \mathrm{C}_{\mathrm{q}}\right), 131.1$ $\left(\mathrm{q}, J_{\mathrm{C}-\mathrm{F}}=3.5 \mathrm{~Hz}, \mathrm{CH}\right), 127.0\left(\mathrm{C}_{\mathrm{q}}\right), 123.2(\mathrm{CH}), 123.2\left(\mathrm{~d}, J_{\mathrm{C}-\mathrm{F}}=272.8 \mathrm{~Hz}, \mathrm{C}_{\mathrm{q}}\right), 123.1\left(\mathrm{q}, J_{\mathrm{C}-\mathrm{F}}=4.1 \mathrm{~Hz}\right.$, $\mathrm{CH}), 77.0(\mathrm{CH}), 65.4\left(\mathrm{CH}_{2}\right), 39.0\left(\mathrm{CH}_{2}\right), 30.5\left(\mathrm{CH}_{2}\right), 19.0\left(\mathrm{CH}_{2}\right), 13.6\left(\mathrm{CH}_{3}\right)$.

${ }^{19}$ F NMR $\left(282 \mathrm{MHz}, \mathrm{CDCl}_{3}\right) \delta-62.6$.

IR (ATR): 2962, 2935, 1779, 1734, 1398, 1329, 1168, 1126, 1007, $615 \mathrm{~cm}^{-1}$.

MS (ESI) $m / z$ (relative intensity): $317(30)[\mathrm{M}+\mathrm{H}]^{+}, 339(70)[\mathrm{M}+\mathrm{Na}]^{+}$.

HR-MS (ESI) $\mathrm{C}_{15} \mathrm{H}_{16} \mathrm{~F}_{3} \mathrm{O}_{4}[\mathrm{M}+\mathrm{H}]^{+}:$317.0996, found: 317.0995 .

The spectral data were in accordance with those reported in the literature. ${ }^{[236 \mathrm{~g}]}$

\section{Butyl 2-(5-(dimethylamino)-3-oxo-1,3-dihydroisobenzofuran-1-yl)acetate (400i)}

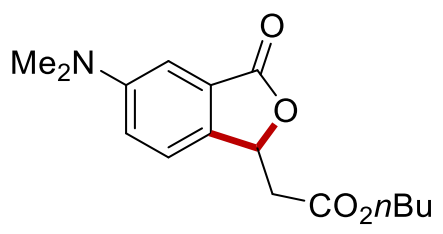

The General Procedure D was followed using 3-(dimethylamino)benzoic acid 398i (33.0 mg, 0.20 mmol), $n$-butyl acrylate 399a (76.9 mg, $0.60 \mathrm{mmol}),\left[\mathrm{OsCl}_{2}(p \text {-cymene) }]_{2}(7.9 \mathrm{mg}, 5.0 \mathrm{~mol} \%), \mathrm{KI}\right.$ (66.4 mg, 2.0 equiv), KOAc (39.3 mg, 2.0 equiv) in HFIP (2.0 mL) and $\mathrm{H}_{2} \mathrm{O}(2.0 \mathrm{~mL})$. Purification by column chromatography on silica gel ( $n$-hexane/EtOAc: $8 / 1)$ yielded 400i $(39.6 \mathrm{mg}, 68 \%)$ as a colorless oil.

${ }^{1} \mathbf{H}$ NMR $\left(400 \mathrm{MHz} \mathrm{CDCl}_{3}\right) \delta 7.27(\mathrm{~d}, J=8.5 \mathrm{~Hz}, 1 \mathrm{H}), 7.08(\mathrm{~d}, J=2.4 \mathrm{~Hz}, 1 \mathrm{H}), 6.98(\mathrm{dd}, J=8.5,2.4$ $\mathrm{Hz}, 1 \mathrm{H}), 5.77(\mathrm{t}, J=6.6 \mathrm{~Hz}, 1 \mathrm{H}), 4.14(\mathrm{t}, J=6.7 \mathrm{~Hz}, 2 \mathrm{H}), 3.00(\mathrm{~s}, 6 \mathrm{H}), 2.91-2.72(\mathrm{~m}, 2 \mathrm{H}), 1.65-$ $1.55(\mathrm{~m}, 2 \mathrm{H}), 1.35(\mathrm{dq}, J=14.7,7.4 \mathrm{~Hz}, 2 \mathrm{H}), 0.91(\mathrm{t}, J=7.4 \mathrm{~Hz}, 3 \mathrm{H})$.

${ }^{13} \mathrm{C}$ NMR $\left(100 \mathrm{MHz}, \mathrm{CDCl}_{3}\right) \delta 170.9\left(\mathrm{C}_{\mathrm{q}}\right), 169.6\left(\mathrm{C}_{\mathrm{q}}\right), 151.5\left(\mathrm{C}_{\mathrm{q}}\right), 136.2\left(\mathrm{C}_{\mathrm{q}}\right), 126.9\left(\mathrm{C}_{\mathrm{q}}\right), 122.3(\mathrm{CH})$, $118.7(\mathrm{CH}), 106.9(\mathrm{CH}), 76.9(\mathrm{CH}), 65.0\left(\mathrm{CH}_{2}\right), 40.6\left(\mathrm{CH}_{3}\right), 40.1\left(\mathrm{CH}_{2}\right), 30.5\left(\mathrm{CH}_{2}\right), 19.1\left(\mathrm{CH}_{2}\right), 13.7$ $\left(\mathrm{CH}_{3}\right)$.

IR (ATR): 2959, 2930, 1767, 1758, 1625, 1510, 1345, 1166, 776, $567 \mathrm{~cm}^{-1}$. MS (ESI) $m / z$ (relative intensity): $292(70)[\mathrm{M}+\mathrm{H}]^{+}, 314(30)[\mathrm{M}+\mathrm{Na}]^{+}$. 
HR-MS (ESI) $\mathrm{C}_{16} \mathrm{H}_{22} \mathrm{NO}_{4}[\mathrm{M}+\mathrm{H}]^{+}: 292.1545$, found: 292.1543 .

Butyl 2-(6-methyl-3-oxo-1,3-dihydroisobenzofuran-1-yl)acetate (400j)<smiles>CCOC(=O)CC1OC(=O)c2ccc(C)cc21</smiles>

The General Procedure D was followed using 4-methyl benzoic acid 398j (27.2 mg, $0.20 \mathrm{mmol}), n$ butyl acrylate 399a (76.9 mg, $0.60 \mathrm{mmol}),\left[\mathrm{OsCl}_{2}(p \text {-cymene })\right]_{2}(7.9 \mathrm{mg}, 5.0 \mathrm{~mol} \%), \mathrm{KI}(66.4 \mathrm{mg}, 2.0$ equiv), KOAc (39.3 mg, 2.0 equiv) in HFIP $(2.0 \mathrm{~mL})$ and $\mathrm{H}_{2} \mathrm{O}(2.0 \mathrm{~mL})$. Purification by column chromatography on silica gel ( $n$-hexane/EtOAc: $8 / 1)$ yielded $400 j$ (43.0 $\mathrm{mg}, 82 \%)$ as a colorless oil. ${ }^{1} \mathbf{H}$ NMR $\left(400 \mathrm{MHz}, \mathrm{CDCl}_{3}\right) \delta 7.76(\mathrm{~d}, J=7.8 \mathrm{~Hz}, 1 \mathrm{H}), 7.33(\mathrm{~d}, J=7.8 \mathrm{~Hz}, 1 \mathrm{H}), 7.28-7.22(\mathrm{~m}, 1 \mathrm{H})$, $5.80(\mathrm{t}, J=6.6 \mathrm{~Hz}, 1 \mathrm{H}), 4.14(\mathrm{t}, J=6.7 \mathrm{~Hz}, 2 \mathrm{H}), 2.93-2.77(\mathrm{~m}, 2 \mathrm{H}), 2.46(\mathrm{~s}, 3 \mathrm{H}), 1.64-1.56(\mathrm{~m}$, 2H), $1.35(\mathrm{dq}, J=14.7,7.4 \mathrm{~Hz}, 2 \mathrm{H}), 0.91$ (t, $J=7.4 \mathrm{~Hz}, 3 \mathrm{H})$.

${ }^{13}$ C NMR $\left(100 \mathrm{MHz}, \mathrm{CDCl}_{3}\right) \delta 169.9\left(\mathrm{C}_{\mathrm{q}}\right), 169.4\left(\mathrm{C}_{\mathrm{q}}\right), 149.4\left(\mathrm{C}_{\mathrm{q}}\right), 145.6\left(\mathrm{C}_{\mathrm{q}}\right), 130.7(\mathrm{CH}), 125.6(\mathrm{CH})$, $123.4\left(\mathrm{C}_{\mathrm{q}}\right), 122.4(\mathrm{CH}), 76.7(\mathrm{CH}), 65.2\left(\mathrm{CH}_{2}\right), 39.6\left(\mathrm{CH}_{2}\right), 30.5\left(\mathrm{CH}_{2}\right), 22.1\left(\mathrm{CH}_{3}\right), 19.1\left(\mathrm{CH}_{2}\right), 13.7$ $\left(\mathrm{CH}_{3}\right)$.

IR (ATR): 2960, 2932, 1768, 1758, 1617, 1314, 1279, 1166, 1012, $687 \mathrm{~cm}^{-1}$.

MS (ESI) $m / z$ (relative intensity): $263(60)[\mathrm{M}+\mathrm{H}]^{+}, 285(40)[\mathrm{M}+\mathrm{Na}]^{+}$.

HR-MS (ESI) $\mathrm{C}_{15} \mathrm{H}_{19} \mathrm{O}_{4}[\mathrm{M}+\mathrm{H}]^{+}: 263.1278$, found: 263.1278 .

The spectral data were in accordance with those reported in the literature. ${ }^{[236 \mathrm{~h}]}$

Butyl 2-(6-(tert-butyl)-3-oxo-1,3-dihydroisobenzofuran-1-yl)acetate (400k)<smiles>CCOC(=O)CC1OC(=O)c2ccc(C(C)(C)C)cc21</smiles>

The General Procedure D was followed using 4-tert-butyl benzoic acid 398k (35.6 mg, 0.20 mmol), $n$-butyl acrylate 399a (76.9 mg, $0.60 \mathrm{mmol}),\left[\mathrm{OsCl}_{2}(p \text {-cymene })\right]_{2}(7.9 \mathrm{mg}, 5.0 \mathrm{~mol} \%), \mathrm{KI}(66.4 \mathrm{mg}$, 2.0 equiv), KOAc (39.3 mg, 2.0 equiv) in $\mathrm{HFIP}(2.0 \mathrm{~mL})$ and $\mathrm{H}_{2} \mathrm{O}(2.0 \mathrm{~mL})$. Purification by column 
chromatography on silica gel ( $n$-hexane/EtOAc: $8 / 1)$ yielded 400k (40.8 $\mathrm{mg}, 67 \%)$ as a white solid. M. p. $96^{\circ} \mathrm{C}$

${ }^{1} \mathbf{H}$ NMR $\left(400 \mathrm{MHz}, \mathrm{CDCl}_{3}\right) \delta 7.81(\mathrm{~d}, J=8.2 \mathrm{~Hz}, 1 \mathrm{H}), 7.57(\mathrm{dd}, J=8.2,1.6 \mathrm{~Hz}, 1 \mathrm{H}), 7.47-7.42(\mathrm{~m}$, $1 \mathrm{H}), 5.84(\mathrm{t}, J=6.7 \mathrm{~Hz}, 1 \mathrm{H}), 4.15(\mathrm{td}, J=6.7,2.7 \mathrm{~Hz}, 2 \mathrm{H}), 2.96-2.80(\mathrm{~m}, 2 \mathrm{H}), 1.61(\mathrm{dt}, J=14.6,6.7$ $\mathrm{Hz}, 2 \mathrm{H}), 1.38-1.32(\mathrm{~m}, 2 \mathrm{H}), 1.34(\mathrm{~s}, 9 \mathrm{H}), 0.91(\mathrm{t}, J=7.4 \mathrm{~Hz}, 3 \mathrm{H})$.

${ }^{13}$ C NMR $\left(100 \mathrm{MHz}, \mathrm{CDCl}_{3}\right) \delta 169.9\left(\mathrm{C}_{\mathrm{q}}\right), 169.5\left(\mathrm{C}_{\mathrm{q}}\right), 158.7\left(\mathrm{C}_{\mathrm{q}}\right), 149.2\left(\mathrm{C}_{\mathrm{q}}\right), 127.2(\mathrm{CH}), 125.4(\mathrm{CH})$, $123.3\left(\mathrm{C}_{\mathrm{q}}\right), 118.5(\mathrm{CH}), 77.0(\mathrm{CH}), 65.1\left(\mathrm{CH}_{2}\right), 39.8\left(\mathrm{CH}_{2}\right), 35.6\left(\mathrm{C}_{\mathrm{q}}\right), 31.2\left(\mathrm{CH}_{3}\right), 30.6\left(\mathrm{CH}_{2}\right), 19.1$ $\left(\mathrm{CH}_{2}\right), 13.7\left(\mathrm{CH}_{3}\right)$.

IR (ATR): 2967, 2935, 1771, 1750, 1697, 1315, 1280, 1005, 874, $666 \mathrm{~cm}^{-1}$.

MS (ESI) $m / z$ (relative intensity): $305(60)[\mathrm{M}+\mathrm{H}]^{+}, 327(40)[\mathrm{M}+\mathrm{Na}]^{+}$.

HR-MS (ESI) $\mathrm{C}_{18} \mathrm{H}_{25} \mathrm{O}_{4}[\mathrm{M}+\mathrm{H}]^{+}: 305.1749$, found: 305.1747 .

The spectral data were in accordance with those reported in the literature. ${ }^{[236 \mathrm{~g}]}$

\section{Butyl 2-(6-methoxy-3-oxo-1,3-dihydroisobenzofuran-1-yl)acetate (4001)}

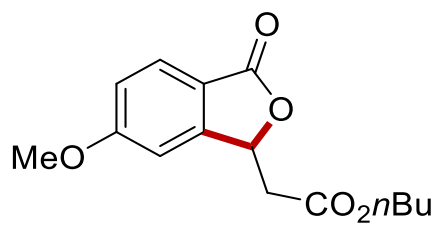

The General Procedure D was followed using 4-methoxybenzoic acid 3981 (30.4 mg, $0.20 \mathrm{mmol}), n$ butyl acrylate 399a (76.9 mg, $0.60 \mathrm{mmol}),\left[\mathrm{OsCl}_{2}(p \text {-cymene })\right]_{2}(7.9 \mathrm{mg}, 5.0 \mathrm{~mol} \%), \mathrm{KI}(66.4 \mathrm{mg}, 2.0$ equiv), KOAc (39.3 mg, 2.0 equiv) in HFIP $(2.0 \mathrm{~mL})$ and $\mathrm{H}_{2} \mathrm{O}(2.0 \mathrm{~mL})$. Purification by column chromatography on silica gel ( $n$-hexane/EtOAc: 8/1) yielded 4001 (47.3 mg, 85\%) as a colorless oil. ${ }^{1} \mathbf{H}$ NMR $\left(400 \mathrm{MHz}, \mathrm{CDCl}_{3}\right) \delta 7.79(\mathrm{~d}, J=8.6 \mathrm{~Hz}, 1 \mathrm{H}), 7.03(\mathrm{dd}, J=8.6,2.2 \mathrm{~Hz}, 1 \mathrm{H}), 6.91(\mathrm{~d}, J=2.2$ $\mathrm{Hz}, 1 \mathrm{H}), 5.78(\mathrm{t}, J=6.6 \mathrm{~Hz}, 1 \mathrm{H}), 4.15(\mathrm{t}, J=6.7 \mathrm{~Hz}, 2 \mathrm{H}), 3.87(\mathrm{~s}, 3 \mathrm{H}), 2.95-2.77(\mathrm{~m}, 2 \mathrm{H}), 1.64-$ $1.56(\mathrm{~m}, 2 \mathrm{H}), 1.35(\mathrm{dq}, J=14.6,7.4 \mathrm{~Hz}, 2 \mathrm{H}), 0.91(\mathrm{t}, J=7.4 \mathrm{~Hz}, 3 \mathrm{H})$.

${ }^{13} \mathrm{C}$ NMR $\left(100 \mathrm{MHz}, \mathrm{CDCl}_{3}\right) \delta 169.6\left(\mathrm{C}_{\mathrm{q}}\right), 169.4\left(\mathrm{C}_{\mathrm{q}}\right), 164.8\left(\mathrm{C}_{\mathrm{q}}\right), 151.6\left(\mathrm{C}_{\mathrm{q}}\right), 127.3(\mathrm{CH}), 118.2\left(\mathrm{C}_{\mathrm{q}}\right)$, $116.7(\mathrm{CH}), 106.2(\mathrm{CH}), 76.2(\mathrm{CH}), 65.2\left(\mathrm{CH}_{2}\right), 55.8\left(\mathrm{CH}_{3}\right), 39.6\left(\mathrm{CH}_{2}\right), 30.5\left(\mathrm{CH}_{2}\right), 19.1\left(\mathrm{CH}_{2}\right), 13.7$ $\left(\mathrm{CH}_{3}\right)$.

IR (ATR): 2960, 2935, 1759, 1731, 1605, 1460, 1359, 1281, 1253, 1007, $690 \mathrm{~cm}^{-1}$. 
MS (ESI) $m / z$ (relative intensity): $279(60)[\mathrm{M}+\mathrm{H}]^{+}, 301(40)[\mathrm{M}+\mathrm{Na}]^{+}$.

HR-MS (ESI) $\mathrm{C}_{15} \mathrm{H}_{19} \mathrm{O}_{5}[\mathrm{M}+\mathrm{H}]^{+}:$279.1229, found: 279.1227.

The spectral data were in accordance with those reported in the literature. ${ }^{[236 \mathrm{~g}]}$

\section{Butyl 2-(6-fluoro-3-oxo-1,3-dihydroisobenzofuran-1-yl)acetate (400m)}

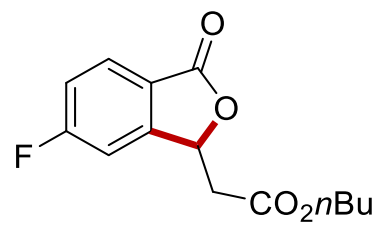

The General Procedure D was followed using 4-fluorobenzoic acid 398m (28.0 mg, $0.20 \mathrm{mmol}), n$ butyl acrylate 399a (76.9 mg, $0.60 \mathrm{mmol}),\left[\mathrm{OsCl}_{2}(p \text {-cymene })\right]_{2}(7.9 \mathrm{mg}, 5.0 \mathrm{~mol} \%), \mathrm{KI}(66.4 \mathrm{mg}, 2.0$ equiv), KOAc (39.3 mg, 2.0 equiv) in HFIP $(2.0 \mathrm{~mL})$ and $\mathrm{H}_{2} \mathrm{O}(2.0 \mathrm{~mL})$. Purification by column chromatography on silica gel ( $n$-hexane/EtOAc: $8 / 1)$ yielded $400 \mathrm{~m}(24.5 \mathrm{mg}, 46 \%)$ as a colorless oil. ${ }^{1} \mathbf{H}$ NMR $\left(400 \mathrm{MHz}, \mathrm{CDCl}_{3}\right) \delta 7.88(\mathrm{dd}, J=8.4,4.8 \mathrm{~Hz}, 1 \mathrm{H}), 7.25-7.17(\mathrm{~m}, 2 \mathrm{H}), 5.81(\mathrm{t}, J=6.6 \mathrm{~Hz}$, $1 \mathrm{H}), 4.15(\mathrm{t}, J=6.7 \mathrm{~Hz}, 2 \mathrm{H}), 3.02-2.78(\mathrm{~m}, 2 \mathrm{H}), 1.65-1.57(\mathrm{~m}, 2 \mathrm{H}), 1.35(\mathrm{dq}, J=14.7,7.4 \mathrm{~Hz}, 2 \mathrm{H})$, $0.91(\mathrm{t}, J=7.4 \mathrm{~Hz}, 3 \mathrm{H})$.

${ }^{13}$ C NMR $\left(100 \mathrm{MHz}, \mathrm{CDCl}_{3}\right) \delta 169.1\left(\mathrm{C}_{\mathrm{q}}\right), 168.2\left(\mathrm{~d}, J=75.8 \mathrm{~Hz}, \mathrm{C}_{\mathrm{q}}\right), 165.3\left(\mathrm{C}_{\mathrm{q}}\right), 151.6\left(\mathrm{~d}, J_{\mathrm{C}-\mathrm{F}}=10.3\right.$ $\left.\mathrm{Hz}, \mathrm{C}_{\mathrm{q}}\right), 128.2\left(\mathrm{~d}, J_{\mathrm{C}-\mathrm{F}}=10.4 \mathrm{~Hz}, \mathrm{CH}\right), 122.0\left(\mathrm{~d}, J_{\mathrm{C}-\mathrm{F}}=2.0 \mathrm{~Hz}, \mathrm{C}_{\mathrm{q}}\right), 117.8\left(\mathrm{~d}, J_{\mathrm{C}-\mathrm{F}}=24.0 \mathrm{~Hz}, \mathrm{CH}\right)$, $109.8\left(\mathrm{~d}, J_{\mathrm{C}-\mathrm{F}}=24.9 \mathrm{~Hz}, \mathrm{CH}\right), 76.2\left(\mathrm{~d}, J_{\mathrm{C}-\mathrm{F}}=2.9 \mathrm{~Hz}, \mathrm{CH}\right), 65.3\left(\mathrm{CH}_{2}\right), 39.2\left(\mathrm{CH}_{2}\right), 30.5\left(\mathrm{CH}_{2}\right), 19.0$ $\left(\mathrm{CH}_{2}\right), 13.6\left(\mathrm{CH}_{3}\right)$.

${ }^{19}$ F NMR $\left(282 \mathrm{MHz}, \mathrm{CDCl}_{3}\right) \delta-102.13(\mathrm{td}, J=8.4,4.9 \mathrm{~Hz})$.

IR (ATR): 2961, 1934, 1761, 1723, 1604, 1243, 1008, 882, 742, $682 \mathrm{~cm}^{-1}$.

MS (ESI) $m / z$ (relative intensity): $267(30)[\mathrm{M}+\mathrm{H}]^{+}, 289(70)[\mathrm{M}+\mathrm{Na}]^{+}$.

HR-MS (ESI) $\mathrm{C}_{14} \mathrm{H}_{16} \mathrm{FO}_{4}[\mathrm{M}+\mathrm{H}]^{+}:$267.1030, found: 267.1027.

The spectral data were in accordance with those reported in the literature. ${ }^{[236 \mathrm{~g}]}$ 


\section{Butyl 2-(6-chloro-3-oxo-1,3-dihydroisobenzofuran-1-yl)acetate (400n)}

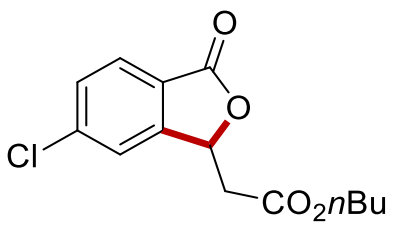

The General Procedure D was followed using 4-chlorobenzoic acid 398n (31.3 mg, $0.20 \mathrm{mmol}), n$ butyl acrylate 399a (76.9 mg, $0.60 \mathrm{mmol}),\left[\mathrm{OsCl}_{2}(p \text {-cymene })\right]_{2}(7.9 \mathrm{mg}, 5.0 \mathrm{~mol} \%), \mathrm{KI}(66.4 \mathrm{mg}, 2.0$ equiv), KOAc (39.3 mg, 2.0 equiv) in HFIP $(2.0 \mathrm{~mL})$ and $\mathrm{H}_{2} \mathrm{O}(2.0 \mathrm{~mL})$. Purification by column chromatography on silica gel ( $n$-hexane/EtOAc: $8 / 1)$ yielded 400n $(28.3 \mathrm{mg}, 50 \%)$ as a colorless oil. ${ }^{1} \mathbf{H}$ NMR $\left(400 \mathrm{MHz}, \mathrm{CDCl}_{3}\right) \delta 7.81(\mathrm{~d}, J=8.6 \mathrm{~Hz}, 1 \mathrm{H}), 7.53-7.49(\mathrm{~m}, 2 \mathrm{H}), 5.81(\mathrm{t}, J=6.6 \mathrm{~Hz}, 1 \mathrm{H})$, $4.14(\mathrm{t}, J=6.7 \mathrm{~Hz}, 2 \mathrm{H}), 3.01-2.78(\mathrm{~m}, 2 \mathrm{H}), 1.64-1.56(\mathrm{~m}, 2 \mathrm{H}), 1.35(\mathrm{dq}, J=14.7,7.4 \mathrm{~Hz}, 2 \mathrm{H}), 0.91$ $(\mathrm{t}, J=7.4 \mathrm{~Hz}, 3 \mathrm{H})$.

${ }^{13} \mathrm{C} \mathrm{NMR}\left(100 \mathrm{MHz}, \mathrm{CDCl}_{3}\right) \delta 169.1\left(\mathrm{C}_{\mathrm{q}}\right), 168.7\left(\mathrm{C}_{\mathrm{q}}\right), 150.4\left(\mathrm{C}_{\mathrm{q}}\right), 141.0\left(\mathrm{C}_{\mathrm{q}}\right), 130.3(\mathrm{CH}), 127.0(\mathrm{CH})$, $124.5\left(\mathrm{C}_{\mathrm{q}}\right), 122.8(\mathrm{CH}), 76.4(\mathrm{CH}), 65.3\left(\mathrm{CH}_{2}\right), 39.2\left(\mathrm{CH}_{2}\right), 30.5\left(\mathrm{CH}_{2}\right), 19.0\left(\mathrm{CH}_{2}\right), 13.6\left(\mathrm{CH}_{3}\right)$.

IR (ATR): 2960, 2932, 1768, 1722, 1617, 1314, 1166, 1012, 904, $687 \mathrm{~cm}^{-1}$.

MS (ESI) $m / z$ (relative intensity): $283(55)[\mathrm{M}+\mathrm{H}]^{+}, 305(45)[\mathrm{M}+\mathrm{Na}]^{+}$.

HR-MS (ESI) $\mathrm{C}_{14} \mathrm{H}_{16} \mathrm{ClO}_{4}[\mathrm{M}+\mathrm{H}]^{+}:$283.0733, found: 283.0732 .

The spectral data were in accordance with those reported in the literature. ${ }^{[236 \mathrm{~g}]}$

\section{Butyl 2-(6-bromo-3-oxo-1,3-dihydroisobenzofuran-1-yl)acetate (400o)}

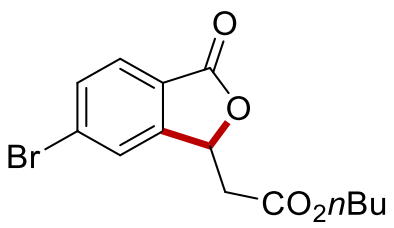

The General Procedure D was followed using 4-bromobenzoic acid 3980 (40.2 mg, $0.20 \mathrm{mmol}), n$ butyl acrylate 399a (76.9 mg, $0.60 \mathrm{mmol})$, [OsCl 2 (p-cymene) $]_{2}(7.9 \mathrm{mg}, 5.0 \mathrm{~mol} \%), \mathrm{KI}(66.4 \mathrm{mg}, 2.0$ equiv), KOAc (39.3 mg, 2.0 equiv) in HFIP $(2.0 \mathrm{~mL})$ and $\mathrm{H}_{2} \mathrm{O}(2.0 \mathrm{~mL})$. Purification by column chromatography on silica gel ( $n$-hexane/EtOAc: $8 / 1)$ yielded 4400 (34.7 $\mathrm{mg}, 53 \%)$ as a colorless oil. ${ }^{1} \mathbf{H}$ NMR $\left(400 \mathrm{MHz}, \mathrm{CDCl}_{3}\right) \delta 7.74(\mathrm{~d}, J=8.7 \mathrm{~Hz}, 1 \mathrm{H}), 7.69-7.66(\mathrm{~m}, 2 \mathrm{H}), 5.82(\mathrm{t}, J=6.6 \mathrm{~Hz}, 1 \mathrm{H})$, $4.15(\mathrm{t}, J=6.8 \mathrm{~Hz}, 2 \mathrm{H}), 3.02-2.77(\mathrm{~m}, 2 \mathrm{H}), 1.66-1.54(\mathrm{~m}, 2 \mathrm{H}), 1.35(\mathrm{dq}, J=14.7,7.4 \mathrm{~Hz}, 2 \mathrm{H}), 0.92$ 
(t, $J=7.4 \mathrm{~Hz}, 3 \mathrm{H})$.

${ }^{13} \mathrm{C} \mathrm{NMR}\left(100 \mathrm{MHz}, \mathrm{CDCl}_{3}\right) \delta 169.1\left(\mathrm{C}_{\mathrm{q}}\right), 168.8\left(\mathrm{C}_{\mathrm{q}}\right), 150.5\left(\mathrm{C}_{\mathrm{q}}\right), 133.2(\mathrm{CH}), 129.5\left(\mathrm{C}_{\mathrm{q}}\right), 127.1(\mathrm{CH})$, $125.8(\mathrm{CH}), 125.0\left(\mathrm{C}_{\mathrm{q}}\right), 76.3(\mathrm{CH}), 65.3\left(\mathrm{CH}_{2}\right), 39.2\left(\mathrm{CH}_{2}\right), 30.5\left(\mathrm{CH}_{2}\right), 19.1\left(\mathrm{CH}_{2}\right), 13.6\left(\mathrm{CH}_{3}\right)$.

IR (ATR): 2959, 2933, 1761, 1722, 1588, 1395, 1263, 1210, 1062, $781 \mathrm{~cm}^{-1}$.

MS (ESI) $m / z$ (relative intensity): $327(50)\left({ }^{79} \mathrm{Br}\right)[\mathrm{M}+\mathrm{H}]^{+}, 349(50)[\mathrm{M}+\mathrm{Na}]^{+}$.

HR-MS (ESI) $\mathrm{C}_{14} \mathrm{H}_{16}{ }^{79} \mathrm{BrO}_{4}[\mathrm{M}+\mathrm{H}]^{+}: 327.0231$, found: 327.0226 .

The spectral data were in accordance with those reported in the literature. ${ }^{[236 \mathrm{~g}]}$

\section{Butyl 2-(6-iodo-3-oxo-1,3-dihydroisobenzofuran-1-yl)acetate (400p)}

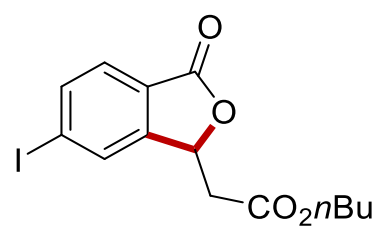

The General Procedure D was followed using 4-iodobenzoic acid 398p (49.6 mg, $0.20 \mathrm{mmol}), n$ butyl acrylate 399a (76.9 mg, $0.60 \mathrm{mmol})$, $\left[\mathrm{OsCl}_{2}(p \text {-cymene })\right]_{2}(7.9 \mathrm{mg}, 5.0 \mathrm{~mol} \%), \mathrm{KI}(66.4 \mathrm{mg}, 2.0$ equiv), KOAc (39.3 mg, 2.0 equiv) in HFIP $(2.0 \mathrm{~mL})$ and $\mathrm{H}_{2} \mathrm{O}(2.0 \mathrm{~mL})$. Purification by column chromatography on silica gel ( $n$-hexane/EtOAc: 8/1) yielded 400p (45.6 mg, 61\%) as a colorless oil. ${ }^{1}$ H NMR $\left(400 \mathrm{MHz}, \mathrm{CDCl}_{3}\right) \delta 7.90-7.87(\mathrm{~m}, 2 \mathrm{H}), 7.62-7.59(\mathrm{~m}, 1 \mathrm{H}), 5.80(\mathrm{t}, J=6.6 \mathrm{~Hz}, 1 \mathrm{H}), 4.15$ $(\mathrm{td}, J=6.7,1.6 \mathrm{~Hz}, 2 \mathrm{H}), 2.99-2.78(\mathrm{~m}, 2 \mathrm{H}), 1.64-1.57(\mathrm{~m}, 2 \mathrm{H}), 1.35(\mathrm{dq}, J=14.8,7.4 \mathrm{~Hz}, 2 \mathrm{H})$, $0.92(\mathrm{t}, J=7.4 \mathrm{~Hz}, 3 \mathrm{H})$.

${ }^{13}$ C NMR $\left(100 \mathrm{MHz}, \mathrm{CDCl}_{3}\right) \delta 169.1\left(\mathrm{C}_{\mathrm{q}}\right), 169.1\left(\mathrm{C}_{\mathrm{q}}\right), 150.4\left(\mathrm{C}_{\mathrm{q}}\right), 139.0(\mathrm{CH}), 131.7(\mathrm{CH}), 127.0$ $(\mathrm{CH}), 125.5\left(\mathrm{C}_{\mathrm{q}}\right), 102.1\left(\mathrm{C}_{\mathrm{q}}\right), 76.2(\mathrm{CH}), 65.3\left(\mathrm{CH}_{2}\right), 39.2\left(\mathrm{CH}_{2}\right), 30.5\left(\mathrm{CH}_{2}\right), 19.1\left(\mathrm{CH}_{2}\right), 13.7\left(\mathrm{CH}_{3}\right)$. IR (ATR): 2958, 2931, 1765, 1728, 1584, 1395, 1264, 1178, 1007, $678 \mathrm{~cm}^{-1}$.

MS (ESI) $m / z$ (relative intensity): $375(60)[\mathrm{M}+\mathrm{H}]^{+}, 397(40)[\mathrm{M}+\mathrm{Na}]^{+}$.

HR-MS (ESI) $\mathrm{C}_{14} \mathrm{H}_{16} \mathrm{IO}_{4}[\mathrm{M}+\mathrm{H}]^{+}:$375.0088, found: 375.0089. $\mathrm{C}_{14} \mathrm{H}_{15} \mathrm{IO}_{4} \mathrm{Na}[\mathrm{M}+\mathrm{Na}]^{+}: 396.9909$, found: 396.9907.

The spectral data were in accordance with those reported in the literature. ${ }^{[236 \mathrm{~g}]}$ 
Butyl 2-(6-(dimethylamino)-3-oxo-1,3-dihydroisobenzofuran-1-yl)acetate (400q)<smiles>CCOCC1OC(=O)c2ccc(N(C)C)cc21</smiles>

The General Procedure D was followed using 4-(dimethylamino)benzoic acid 398q (33.0 mg, 0.20 mmol), $n$-butyl acrylate 399a (76.9 mg, $0.60 \mathrm{mmol}),\left[\mathrm{OsCl}_{2}(p \text {-cymene) }]_{2}(7.9 \mathrm{mg}, 5.0 \mathrm{~mol} \%), \mathrm{KI}\right.$ (66.4 mg, 2.0 equiv), KOAc (39.3 mg, 2.0 equiv) in HFIP (2.0 mL) and $\mathrm{H}_{2} \mathrm{O}(2.0 \mathrm{~mL})$. Purification by column chromatography on silica gel ( $n$-hexane/EtOAc: $8 / 1)$ yielded 400q $(48.9 \mathrm{mg}, 84 \%)$ as a colorless oil.

${ }^{1} \mathbf{H}$ NMR $\left(400 \mathrm{MHz}, \mathrm{CDCl}_{3}\right) \delta 7.65(\mathrm{~d}, J=8.7 \mathrm{~Hz}, 1 \mathrm{H}), 6.72(\mathrm{dd}, J=8.7,2.2 \mathrm{~Hz}, 1 \mathrm{H}), 6.51(\mathrm{~d}, J=2.2$ $\mathrm{Hz}, 1 \mathrm{H}), 5.70(\mathrm{t}, J=6.6 \mathrm{~Hz}, 1 \mathrm{H}), 4.12(\mathrm{t}, J=6.7 \mathrm{~Hz}, 2 \mathrm{H}), 3.05(\mathrm{~s}, 6 \mathrm{H}), 2.82(\mathrm{dd}, J=6.6,4.2 \mathrm{~Hz}, 2 \mathrm{H})$, $1.63-1.54(\mathrm{~m}, 2 \mathrm{H}), 1.34(\mathrm{dq}, J=14.7,7.4 \mathrm{~Hz}, 2 \mathrm{H}), 0.89(\mathrm{t}, J=7.4 \mathrm{~Hz}, 3 \mathrm{H})$.

${ }^{13}$ C NMR $\left(100 \mathrm{MHz}, \mathrm{CDCl}_{3}\right) \delta 170.4\left(\mathrm{C}_{\mathrm{q}}\right), 169.7\left(\mathrm{C}_{\mathrm{q}}\right), 154.4\left(\mathrm{C}_{\mathrm{q}}\right), 151.7\left(\mathrm{C}_{\mathrm{q}}\right), 126.7(\mathrm{CH}), 113.0(\mathrm{CH})$, $112.3\left(\mathrm{C}_{\mathrm{q}}\right), 102.4(\mathrm{CH}), 76.2(\mathrm{CH}), 65.0\left(\mathrm{CH}_{2}\right), 40.3\left(\mathrm{CH}_{3}\right), 40.0\left(\mathrm{CH}_{2}\right), 30.5\left(\mathrm{CH}_{2}\right), 19.0\left(\mathrm{CH}_{2}\right), 13.6$ $\left(\mathrm{CH}_{3}\right)$.

IR (ATR): 2958, 2931, 1723, 1605, 1519, 1351, 1116, 1005, 791, $692 \mathrm{~cm}^{-1}$.

MS (ESI) $m / z$ (relative intensity): $292(60)[\mathrm{M}+\mathrm{H}]^{+}, 314(40)[\mathrm{M}+\mathrm{Na}]^{+}$.

HR-MS (ESI) $\mathrm{C}_{16} \mathrm{H}_{22} \mathrm{NO}_{4}[\mathrm{M}+\mathrm{H}]^{+}:$292.1544, found: 292.1543.

The spectral data were in accordance with those reported in the literature. ${ }^{[266]}$

Butyl 2-(1-oxo-1,3-dihydronaphtho[1,2-c]furan-3-yl)acetate (400s)

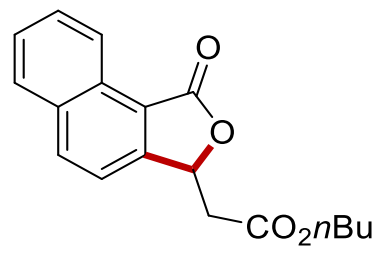

The General Procedure D was followed using naphthoic acid 398s (34.4 mg, 0.20 mmol), $n$-butyl acrylate 399a (76.9 mg, $0.60 \mathrm{mmol}),\left[\mathrm{OsCl}_{2}(p \text {-cymene) }]_{2}(7.9 \mathrm{mg}, 5.0 \mathrm{~mol} \%), \mathrm{KI}(66.4 \mathrm{mg}, 2.0\right.$ equiv), KOAc (39.3 mg, 2.0 equiv) in HFIP $(2.0 \mathrm{~mL})$ and $\mathrm{H}_{2} \mathrm{O}(2.0 \mathrm{~mL})$. Purification by column chromatography on silica gel ( $n$-hexane/EtOAc: $8 / 1)$ yielded 400s $(35.2 \mathrm{mg}, 74 \%)$ as a colorless oil. 
${ }^{1} \mathbf{H}$ NMR $\left(400 \mathrm{MHz}, \mathrm{CDCl}_{3}\right) \delta 8.99(\mathrm{~d}, J=8.3 \mathrm{~Hz}, 1 \mathrm{H}), 8.13(\mathrm{~d}, J=8.3 \mathrm{~Hz}, 1 \mathrm{H}), 7.95(\mathrm{~d}, J=8.3 \mathrm{~Hz}$, 1H), $7.72(\mathrm{ddd}, J=8.3,7.0,1.3 \mathrm{~Hz}, 1 \mathrm{H}), 7.63(\mathrm{ddd}, J=8.3,7.0,1.3 \mathrm{~Hz}, 1 \mathrm{H}), 7.51(\mathrm{~d}, J=8.3 \mathrm{~Hz}, 1 \mathrm{H})$, $5.94(\mathrm{t}, J=6.6 \mathrm{~Hz}, 1 \mathrm{H}), 4.16(\mathrm{t}, J=6.7 \mathrm{~Hz}, 2 \mathrm{H}), 2.94(\mathrm{~d}, J=6.6 \mathrm{~Hz}, 2 \mathrm{H}), 1.64-1.56(\mathrm{~m}, 2 \mathrm{H}), 1.34$ (dq, $J=14.9,7.4 \mathrm{~Hz}, 2 \mathrm{H}), 0.89$ (t, $J=7.4 \mathrm{~Hz}, 3 \mathrm{H})$.

${ }^{13}$ C NMR $\left(100 \mathrm{MHz}, \mathrm{CDCl}_{3}\right) \delta 170.1\left(\mathrm{C}_{\mathrm{q}}\right), 169.4\left(\mathrm{C}_{\mathrm{q}}\right), 150.4\left(\mathrm{C}_{\mathrm{q}}\right), 135.7(\mathrm{CH}), 133.5\left(\mathrm{C}_{\mathrm{q}}\right), 129.2(\mathrm{CH})$, $129.1\left(\mathrm{C}_{\mathrm{q}}\right), 128.4(\mathrm{CH}), 127.5(\mathrm{CH}), 123.6(\mathrm{CH}), 120.3\left(\mathrm{C}_{\mathrm{q}}\right), 118.4(\mathrm{CH}), 76.4(\mathrm{CH}), 65.2\left(\mathrm{CH}_{2}\right), 39.4$ $\left(\mathrm{CH}_{2}\right), 30.5\left(\mathrm{CH}_{2}\right), 19.1\left(\mathrm{CH}_{2}\right), 13.6\left(\mathrm{CH}_{3}\right)$.

IR (ATR): 2961, 2933, 1760, 1734, 1610, 1699, 1340, 1291, 1154, 1009, 844, $596 \mathrm{~cm}^{-1}$.

MS (ESI) $m / z$ (relative intensity): $299(70)[\mathrm{M}+\mathrm{H}]^{+}, 321(30)[\mathrm{M}+\mathrm{Na}]^{+}$.

HR-MS (ESI) $\mathrm{C}_{18} \mathrm{H}_{19} \mathrm{O}_{4}[\mathrm{M}+\mathrm{H}]^{+}:$299.1278, found: 299.1278 .

The spectral data were in accordance with those reported in the literature. ${ }^{[268]}$

tert-Butyl 2-(4-methyl-3-oxo-1,3-dihydroisobenzofuran-1-yl)acetate (400t)

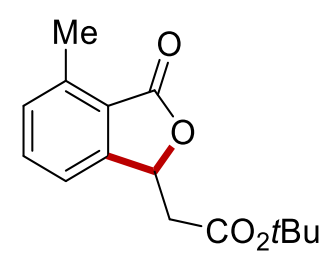

The General Procedure D was followed using 2-methylbenzoic acid 398t (27.2 mg, $0.20 \mathrm{mmol}), t$ butyl acrylate 399b (76.9 mg, $0.60 \mathrm{mmol})$, [OsCl $2(p \text {-cymene) }]_{2}(7.9 \mathrm{mg}, 5.0 \mathrm{~mol} \%), \mathrm{KI}(66.4 \mathrm{mg}, 2.0$ equiv), KOAc (39.3 mg, 2.0 equiv) in HFIP $(2.0 \mathrm{~mL})$ and $\mathrm{H}_{2} \mathrm{O}(2.0 \mathrm{~mL})$. Purification by column chromatography on silica gel ( $n$-hexane/EtOAc: 8/1) yielded 400t (19.9 mg, 38\%) as a colorless oil.

${ }^{1} \mathbf{H}$ NMR $\left(400 \mathrm{MHz}, \mathrm{CDCl}_{3}\right) \delta 7.50(\mathrm{t}, J=7.6 \mathrm{~Hz}, 1 \mathrm{H}), 7.30-7.22(\mathrm{~m}, 2 \mathrm{H}), 5.74(\mathrm{t}, J=6.4 \mathrm{~Hz}, 1 \mathrm{H})$, $2.79(\mathrm{dd}, J=6.4,2.7 \mathrm{~Hz}, 2 \mathrm{H}), 2.67$ (s, 3H), $1.42(\mathrm{~s}, 9 \mathrm{H})$.

${ }^{13} \mathrm{C} \mathrm{NMR}\left(100 \mathrm{MHz}, \mathrm{CDCl}_{3}\right) \delta 170.2\left(\mathrm{C}_{\mathrm{q}}\right), 168.5\left(\mathrm{C}_{\mathrm{q}}\right), 149.5\left(\mathrm{C}_{\mathrm{q}}\right), 139.8\left(\mathrm{C}_{\mathrm{q}}\right), 133.8(\mathrm{CH}), 131.0(\mathrm{CH})$, 123.6 $\left(\mathrm{C}_{\mathrm{q}}\right), 119.2(\mathrm{CH}), 81.9\left(\mathrm{C}_{\mathrm{q}}\right), 40.8(\mathrm{CH}), 29.7\left(\mathrm{CH}_{2}\right), 28.0\left(\mathrm{CH}_{3}\right), 17.3\left(\mathrm{CH}_{3}\right)$.

IR (ATR): 2959, 2931, 1760, 1722, 1486, 1304, 1210, 1157, 1005, $627 \mathrm{~cm}^{-1}$.

MS (ESI) $m / z$ (relative intensity): $263(45)[\mathrm{M}+\mathrm{H}]^{+}, 285(55)[\mathrm{M}+\mathrm{Na}]^{+}$.

HR-MS (ESI) $\mathrm{C}_{15} \mathrm{H}_{19} \mathrm{O}_{4}[\mathrm{M}+\mathrm{H}]^{+}: 263.1278$, found: 263.1278 .

The spectral data were in accordance with those reported in the literature. ${ }^{[236 \mathrm{~g}]}$ 


\section{Hexyl 2-(4-methyl-3-oxo-1,3-dihydroisobenzofuran-1-yl)acetate (400u)}

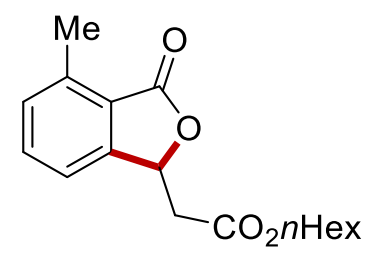

The General Procedure D was followed using 2-methylbenzoic acid 398u (27.2 mg, $0.20 \mathrm{mmol}), n$ hexyl acrylate 399c (93.7 mg, $0.60 \mathrm{mmol}),\left[\mathrm{OsCl}_{2}(p \text {-cymene })\right]_{2}(7.9 \mathrm{mg}, 5.0 \mathrm{~mol} \%), \mathrm{KI}(66.4 \mathrm{mg}, 2.0$ equiv), KOAc (39.3 mg, 2.0 equiv) in HFIP $(2.0 \mathrm{~mL})$ and $\mathrm{H}_{2} \mathrm{O}(2.0 \mathrm{~mL})$. Purification by column chromatography on silica gel ( $n$-hexane/EtOAc: $8 / 1)$ yielded $400 u(46.5 \mathrm{mg}, 80 \%)$ as a colorless oil. ${ }^{1} \mathbf{H}$ NMR $\left(400 \mathrm{MHz}, \mathrm{CDCl}_{3}\right) \delta 7.50(\mathrm{t}, J=7.6 \mathrm{~Hz}, 1 \mathrm{H}), 7.30-7.21(\mathrm{~m}, 2 \mathrm{H}), 5.79(\mathrm{t}, J=6.6 \mathrm{~Hz}, 1 \mathrm{H})$, $4.12(\mathrm{t}, J=6.8 \mathrm{~Hz}, 2 \mathrm{H}), 2.85(\mathrm{~d}, J=6.6 \mathrm{~Hz}, 2 \mathrm{H}), 2.66(\mathrm{~s}, 3 \mathrm{H}), 1.66-1.54(\mathrm{~m}, 2 \mathrm{H}), 1.37-1.22(\mathrm{~m}$, $6 \mathrm{H}), 0.86(\mathrm{t}, J=6.9 \mathrm{~Hz}, 3 \mathrm{H})$.

${ }^{13} \mathrm{C}$ NMR $\left(100 \mathrm{MHz}, \mathrm{CDCl}_{3}\right) \delta 170.0\left(\mathrm{C}_{\mathrm{q}}\right), 169.4\left(\mathrm{C}_{\mathrm{q}}\right), 149.3\left(\mathrm{C}_{\mathrm{q}}\right), 139.9\left(\mathrm{C}_{\mathrm{q}}\right), 133.9(\mathrm{CH}), 131.1(\mathrm{CH})$, $123.4\left(\mathrm{C}_{\mathrm{q}}\right), 119.2(\mathrm{CH}), 76.0(\mathrm{CH}), 65.4\left(\mathrm{CH}_{2}\right), 39.8\left(\mathrm{CH}_{2}\right), 31.4\left(\mathrm{CH}_{2}\right), 28.4\left(\mathrm{CH}_{2}\right), 25.5\left(\mathrm{CH}_{2}\right), 22.5$ $\left(\mathrm{CH}_{2}\right), 17.3\left(\mathrm{CH}_{3}\right), 14.0\left(\mathrm{CH}_{3}\right)$.

IR (ATR): 2960, 2935, 1763, 1739, 1601, 1448, 1328, 1175, 1057, 691 $\mathrm{cm}^{-1}$.

MS (ESI) $m / z$ (relative intensity): $291(70)[\mathrm{M}+\mathrm{H}]^{+}, 313(30)[\mathrm{M}+\mathrm{Na}]^{+}$.

HR-MS (ESI) $\mathrm{C}_{17} \mathrm{H}_{23} \mathrm{O}_{4}[\mathrm{M}+\mathrm{H}]^{+}:$291.1594, found: 291.1591 .

\section{Pentan-3-yl 2-(4-methyl-3-oxo-1,3-dihydroisobenzofuran-1-yl)acetate (400w)}

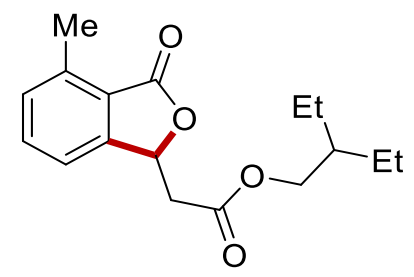

The General Procedure D was followed using 2-methylbenzoic acid 398w (27.2 mg, $0.20 \mathrm{mmol})$, pentan-3-yl acrylate 399d (85.3 mg, $0.60 \mathrm{mmol}),\left[\mathrm{OsCl}_{2}(p \text {-cymene) }]_{2}(7.9 \mathrm{mg}, 5.0 \mathrm{~mol} \%)\right.$, KI (66.4 mg, 2.0 equiv), KOAc (39.3 mg, 2.0 equiv) in HFIP $(2.0 \mathrm{~mL})$ and $\mathrm{H}_{2} \mathrm{O}(2.0 \mathrm{~mL})$. Purification by column chromatography on silica gel ( $n$-hexane/EtOAc: $8 / 1)$ yielded 400w $(35.9 \mathrm{mg}, 65 \%)$ as a colorless oil.

${ }^{1} \mathbf{H}$ NMR $\left(400 \mathrm{MHz}, \mathrm{CDCl}_{3}\right) \delta 7.50(\mathrm{~d}, J=7.6 \mathrm{~Hz}, 1 \mathrm{H}), 7.30-7.23(\mathrm{~m}, 2 \mathrm{H}), 5.79(\mathrm{t}, J=6.6 \mathrm{~Hz}, 1 \mathrm{H})$, 
$4.06(\mathrm{dd}, J=5.8,2.4 \mathrm{~Hz}, 2 \mathrm{H}), 2.86(\mathrm{~d}, J=6.6 \mathrm{~Hz}, 2 \mathrm{H}), 2.67(\mathrm{~s}, 3 \mathrm{H}), 1.50(\mathrm{dt}, J=12.6,6.4 \mathrm{~Hz}, 1 \mathrm{H})$, $1.38-1.25(\mathrm{~m}, 4 \mathrm{H}), 0.86(\mathrm{t}, J=7.4 \mathrm{~Hz}, 6 \mathrm{H})$.

${ }^{13} \mathrm{C}$ NMR $\left(100 \mathrm{MHz}, \mathrm{CDCl}_{3}\right) \delta 170.0\left(\mathrm{C}_{\mathrm{q}}\right), 169.5\left(\mathrm{C}_{\mathrm{q}}\right), 149.3\left(\mathrm{C}_{\mathrm{q}}\right), 139.9\left(\mathrm{C}_{\mathrm{q}}\right), 133.9(\mathrm{CH}), 131.1(\mathrm{CH})$, $123.4\left(\mathrm{C}_{\mathrm{q}}\right), 119.2(\mathrm{CH}), 76.0(\mathrm{CH}), 67.3\left(\mathrm{CH}_{2}\right), 40.2(\mathrm{CH}), 39.8\left(\mathrm{CH}_{2}\right), 23.2\left(\mathrm{CH}_{2}\right), 23.2\left(\mathrm{CH}_{2}\right), 17.3$ $\left(\mathrm{CH}_{3}\right), 11.0\left(\mathrm{CH}_{3}\right), 10.9\left(\mathrm{CH}_{3}\right)$.

IR (ATR): 2960, 2933, 1758, 1730, 1495, 1453, 1310, 1277, 1005, $690 \mathrm{~cm}^{-1}$.

MS (ESI) $m / z$ (relative intensity): $291(60)[\mathrm{M}+\mathrm{H}]^{+}, 313(40)[\mathrm{M}+\mathrm{Na}]^{+}$.

HR-MS (ESI) $\mathrm{C}_{17} \mathrm{H}_{23} \mathrm{O}_{4}[\mathrm{M}+\mathrm{H}]^{+}:$291.1595, found: 291.1591 .

\section{3-Methylbut-3-en-1-yl 2-(4-methyl-3-oxo-1,3-dihydroisobenzofuran-1-yl)acetate (400x)}

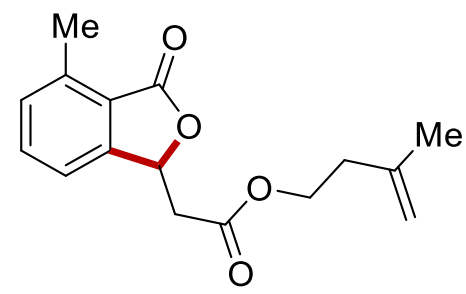

The General Procedure D was followed using 2-methylbenzoic acid 398x (27.2 mg, $0.20 \mathrm{mmol}), 3$ methylbut-3-en-1-yl acrylate 399e $(84.1 \mathrm{mg}, 0.60 \mathrm{mmol}),\left[\mathrm{OsCl}_{2}(p \text {-cymene })\right]_{2}(7.9 \mathrm{mg}, 5.0 \mathrm{~mol} \%)$, $\mathrm{KI}$ (66.4 mg, 2.0 equiv), KOAc (39.3 mg, 2.0 equiv) in $\mathrm{HFIP}(2.0 \mathrm{~mL})$ and $\mathrm{H}_{2} \mathrm{O}(2.0 \mathrm{~mL})$. Purification by column chromatography on silica gel ( $n$-hexane/EtOAc: $8 / 1)$ yielded $400 x(42.8 \mathrm{mg}, 78 \%)$ as a colorless oil.

${ }^{1} \mathbf{H}$ NMR $\left(400 \mathrm{MHz}, \mathrm{CDCl}_{3}\right) \delta 7.51(\mathrm{~d}, J=7.6 \mathrm{~Hz}, 1 \mathrm{H}), 7.30-7.23(\mathrm{~m}, 2 \mathrm{H}), 5.79(\mathrm{t}, J=6.6 \mathrm{~Hz}, 1 \mathrm{H})$, $4.82-4.76(\mathrm{~m}, 1 \mathrm{H}), 4.75-4.68(\mathrm{~m}, 1 \mathrm{H}), 4.26(\mathrm{t}, J=6.9 \mathrm{~Hz}, 2 \mathrm{H}), 2.85(\mathrm{~d}, J=6.6 \mathrm{~Hz}, 2 \mathrm{H}), 2.67(\mathrm{~s}$, $3 \mathrm{H}), 2.34(\mathrm{t}, J=6.9 \mathrm{~Hz}, 2 \mathrm{H}), 1.74(\mathrm{~s}, 3 \mathrm{H})$.

${ }^{13} \mathrm{C}$ NMR $\left(100 \mathrm{MHz}, \mathrm{CDCl}_{3}\right) \delta 170.0\left(\mathrm{C}_{\mathrm{q}}\right), 169.3\left(\mathrm{C}_{\mathrm{q}}\right), 149.2\left(\mathrm{C}_{\mathrm{q}}\right), 141.3\left(\mathrm{C}_{\mathrm{q}}\right), 140.0\left(\mathrm{C}_{\mathrm{q}}\right), 133.9(\mathrm{CH})$, 131.1(CH), $123.4\left(\mathrm{C}_{\mathrm{q}}\right), 119.2(\mathrm{CH}), 112.5\left(\mathrm{CH}_{2}\right), 76.0(\mathrm{CH}), 63.3\left(\mathrm{CH}_{2}\right), 39.8\left(\mathrm{CH}_{2}\right), 36.6\left(\mathrm{CH}_{2}\right), 22.4$ $\left(\mathrm{CH}_{3}\right), 17.3\left(\mathrm{CH}_{3}\right)$.

IR (ATR): 2959, 2933, 1760, 1735, 1599, 1467, 1345, 1170, 1005, 784, $698 \mathrm{~cm}^{-1}$.

MS (ESI) $m / z$ (relative intensity): $275(55)[\mathrm{M}+\mathrm{H}]^{+}, 297(45)[\mathrm{M}+\mathrm{Na}]^{+}$.

HR-MS (ESI) $\mathrm{C}_{16} \mathrm{H}_{19} \mathrm{O}_{4}[\mathrm{M}+\mathrm{H}]^{+}:$275.1282, found: 275.1278 . 


\section{Phenethyl 2-(4-methyl-3-oxo-1,3-dihydroisobenzofuran-1-yl)acetate (400y)}

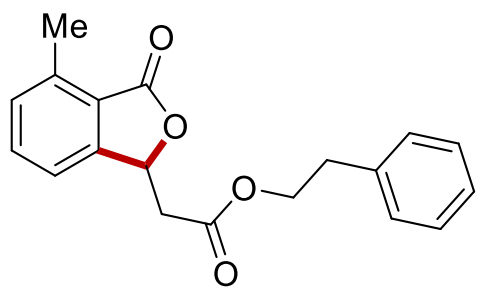

The General Procedure D was followed using 2-methylbenzoic acid 398y (27.2 mg, $0.20 \mathrm{mmol})$, phenethyl acrylate 399f $(85.9 \mathrm{mg}, 0.60 \mathrm{mmol}),\left[\mathrm{OsCl}_{2}(p \text {-cymene })\right]_{2}(7.9 \mathrm{mg}, 5.0 \mathrm{~mol} \%), \mathrm{KI}(66.4 \mathrm{mg}$, 2.0 equiv), KOAc (39.3 mg, 2.0 equiv) in $\mathrm{HFIP}(2.0 \mathrm{~mL})$ and $\mathrm{H}_{2} \mathrm{O}(2.0 \mathrm{~mL})$. Purification by column chromatography on silica gel ( $n$-hexane/EtOAc: $8 / 1)$ yielded $400 y(44.1 \mathrm{mg}, 71 \%)$ as a colorless oil. ${ }^{1} \mathbf{H}$ NMR $\left(400 \mathrm{MHz}, \mathrm{CDCl}_{3}\right) \delta 7.48(\mathrm{~d}, J=7.6 \mathrm{~Hz}, 1 \mathrm{H}), 7.31-7.24(\mathrm{~m}, 3 \mathrm{H}), 7.24-7.15(\mathrm{~m}, 4 \mathrm{H}), 5.76$ $(\mathrm{t}, J=7.0 \mathrm{~Hz}, 1 \mathrm{H}), 4.39-4.34(\mathrm{~m}, 2 \mathrm{H}), 2.94(\mathrm{~d}, J=7.0 \mathrm{~Hz}, 2 \mathrm{H}), 2.83(\mathrm{dd}, J=6.6,4.6 \mathrm{~Hz}, 2 \mathrm{H}), 2.67$ $(\mathrm{s}, 3 \mathrm{H})$.

${ }^{13}$ C NMR $\left(100 \mathrm{MHz}, \mathrm{CDCl}_{3}\right) \delta 170.0\left(\mathrm{C}_{\mathrm{q}}\right), 169.2\left(\mathrm{C}_{\mathrm{q}}\right), 149.2\left(\mathrm{C}_{\mathrm{q}}\right), 140.0\left(\mathrm{C}_{\mathrm{q}}\right), 137.4\left(\mathrm{C}_{\mathrm{q}}\right), 133.9(\mathrm{CH})$, $131.1(\mathrm{CH}), 128.8(\mathrm{CH}), 128.5(\mathrm{CH}), 126.6(\mathrm{CH}), 123.3\left(\mathrm{C}_{\mathrm{q}}\right), 119.2(\mathrm{CH}), 75.9(\mathrm{CH}), 65.6\left(\mathrm{CH}_{2}\right), 39.8$ $\left(\mathrm{CH}_{2}\right), 34.9\left(\mathrm{CH}_{2}\right), 17.3\left(\mathrm{CH}_{3}\right)$.

IR (ATR): 2959, 2931, 1765, 1730, 1605, 1344, 1277, 1137, 1010, 905, $686 \mathrm{~cm}^{-1}$.

MS (ESI) $m / z$ (relative intensity): $311(30)[\mathrm{M}+\mathrm{H}]^{+}, 333(70)[\mathrm{M}+\mathrm{Na}]^{+}$.

HR-MS (ESI) $\mathrm{C}_{19} \mathrm{H}_{19} \mathrm{O}_{4}[\mathrm{M}+\mathrm{H}]^{+}: 311.1280$, found: 311.1278 .

\section{3,4-Di-p-tolyl-1H-benzo[ $h]$ isochromen-1-one (402a)}

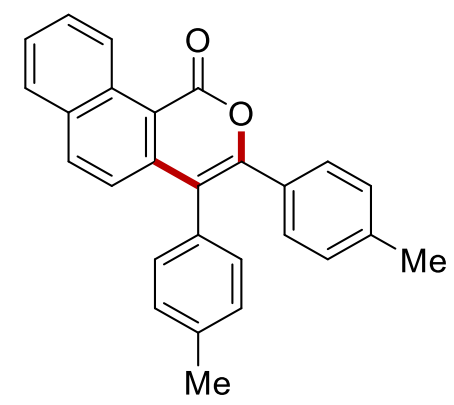

The General Procedure E was followed using naphthoic acid 398s (34.4 mg, $0.20 \mathrm{mmol}$ ), 1,2-di- $p$ tolylethyne $401 \mathrm{a}(123.8 \mathrm{mg}, 0.60 \mathrm{mmol}),\left[\mathrm{OsCl}_{2}(p \text {-cymene) }]_{2}(7.9 \mathrm{mg}, 5.0 \mathrm{~mol} \%)\right.$, KI (66.4 mg, 2.0 equiv), KOAc (39.3 mg, 2.0 equiv) in HFIP $(2.0 \mathrm{~mL})$ and $\mathrm{H}_{2} \mathrm{O}(2.0 \mathrm{~mL})$. Purification by column chromatography on silica gel ( $n$-hexane/EtOAc: $20 / 1)$ yielded 402a $(61.0 \mathrm{mg}, 81 \%)$ as a yellow solid. 
M. p. $197^{\circ} \mathrm{C}$

${ }^{1} \mathbf{H}$ NMR $\left(400 \mathrm{MHz}, \mathrm{CDCl}_{3}\right) \delta 9.84(\mathrm{~d}, J=8.7 \mathrm{~Hz}, 1 \mathrm{H}), 7.95(\mathrm{~d}, J=8.7 \mathrm{~Hz}, 1 \mathrm{H}), 7.84(\mathrm{~d}, J=8.0 \mathrm{~Hz}$, $1 \mathrm{H}), 7.76(\mathrm{ddd}, J=8.7,6.9,1.4 \mathrm{~Hz}, 1 \mathrm{H}), 7.59(\mathrm{ddd}, J=8.0,6.9,1.1 \mathrm{~Hz}, 1 \mathrm{H}), 7.29(\mathrm{~d}, J=8.0 \mathrm{~Hz}, 2 \mathrm{H})$, $7.25(\mathrm{~d}, J=6.9 \mathrm{~Hz}, 3 \mathrm{H}), 7.16(\mathrm{~d}, J=8.0 \mathrm{~Hz}, 2 \mathrm{H}), 7.01(\mathrm{~d}, J=8.0 \mathrm{~Hz}, 2 \mathrm{H}), 2.43(\mathrm{~s}, 3 \mathrm{H}), 2.28(\mathrm{~s}, 3 \mathrm{H})$.

${ }^{13}$ C NMR $\left(100 \mathrm{MHz}, \mathrm{CDCl}_{3}\right) \delta 161.5\left(\mathrm{C}_{\mathrm{q}}\right), 152.5\left(\mathrm{C}_{\mathrm{q}}\right), 141.4\left(\mathrm{C}_{\mathrm{q}}\right), 139.1\left(\mathrm{C}_{\mathrm{q}}\right), 137.8\left(\mathrm{C}_{\mathrm{q}}\right), 135.6(\mathrm{CH})$, $132.5\left(\mathrm{C}_{\mathrm{q}}\right), 131.8\left(\mathrm{C}_{\mathrm{q}}\right), 131.5\left(\mathrm{C}_{\mathrm{q}}\right), 131.2(\mathrm{CH}), 130.0\left(\mathrm{C}_{\mathrm{q}}\right), 129.9(\mathrm{CH}), 129.3(\mathrm{CH}), 129.0(\mathrm{CH}), 128.6$ $(\mathrm{CH}), 128.4(\mathrm{CH}), 130.0(\mathrm{CH}), 126.8(\mathrm{CH}), 122.7(\mathrm{CH}), 116.8\left(\mathrm{C}_{\mathrm{q}}\right), 113.7\left(\mathrm{C}_{\mathrm{q}}\right), 21.3\left(\mathrm{CH}_{3}\right), 21.3\left(\mathrm{CH}_{3}\right)$. IR (ATR): 3057, 1712, 1591, 1508, 1216, 1105, 921, 753, 636, $503 \mathrm{~cm}^{-1}$.

MS (ESI) $m / z$ (relative intensity): $377(100)[\mathrm{M}+\mathrm{H}]^{+}$.

HR-MS (ESI) $\mathrm{C}_{27} \mathrm{H}_{21} \mathrm{O}_{2}[\mathrm{M}+\mathrm{H}]^{+}: 377.1535$, found: 377.1536 .

\section{3,4-Diphenyl-1 $H$-benzo[ $h]$ isochromen-1-one (402b)}

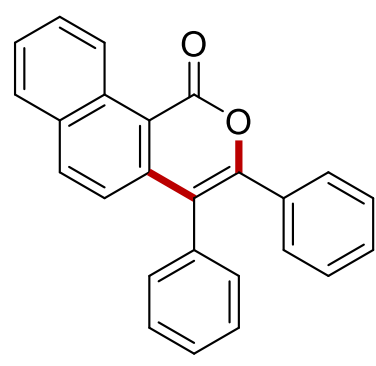

The General Procedure E was followed using 2-methyl benzoic acid 398s (34.4 mg, $0.20 \mathrm{mmol}$ ), 1,2diphenylethyne 401b (106.9 mg, $0.60 \mathrm{mmol})$, [OsCl 2 (p-cymene) $]_{2}(7.9 \mathrm{mg}, 5.0 \mathrm{~mol} \%), \mathrm{KI}$ (66.4 mg, 2.0 equiv), KOAc (39.3 mg, 2.0 equiv) in HFIP $(2.0 \mathrm{~mL})$ and $\mathrm{H}_{2} \mathrm{O}(2.0 \mathrm{~mL})$. Purification by column chromatography on silica gel ( $n$-hexane/EtOAc: $20 / 1)$ yielded $\mathbf{4 0 2 b}(61.3 \mathrm{mg}, 88 \%)$ as a white solid. M. p. $192{ }^{\circ} \mathrm{C}$

${ }^{1} \mathbf{H}$ NMR $\left(400 \mathrm{MHz}, \mathrm{CDCl}_{3}\right) \delta 9.85(\mathrm{~d}, J=8.7 \mathrm{~Hz}, 1 \mathrm{H}), 7.99(\mathrm{~d}, J=8.7 \mathrm{~Hz}, 1 \mathrm{H}), 7.87(\mathrm{~d}, J=7.9 \mathrm{~Hz}$, 1H), $7.78(\mathrm{ddd}, J=8.6,6.9,1.4 \mathrm{~Hz}, 1 \mathrm{H}), 7.62(\mathrm{ddd}, J=8.0,7.0,1.1 \mathrm{~Hz}, 1 \mathrm{H}), 7.47-7.41(\mathrm{~m}, 3 \mathrm{H})$, $7.40-7.34(\mathrm{~m}, 2 \mathrm{H}), 7.31-7.27(\mathrm{~m}, 2 \mathrm{H}), 7.26-7.17(\mathrm{~m}, 4 \mathrm{H})$.

${ }^{13} \mathrm{C}$ NMR $\left(100 \mathrm{MHz}, \mathrm{CDCl}_{3}\right) \delta 161.4\left(\mathrm{C}_{\mathrm{q}}\right), 152.5\left(\mathrm{C}_{\mathrm{q}}\right), 141.0\left(\mathrm{C}_{\mathrm{q}}\right), 135.8(\mathrm{CH}), 134.8\left(\mathrm{C}_{\mathrm{q}}\right), 132.8\left(\mathrm{C}_{\mathrm{q}}\right)$, $132.6\left(\mathrm{C}_{\mathrm{q}}\right), 131.5\left(\mathrm{C}_{\mathrm{q}}\right), 131.5(\mathrm{CH}), 129.5(\mathrm{CH}), 129.2(\mathrm{CH}), 129.1(\mathrm{CH}), 129.1(\mathrm{CH}), 128.4(\mathrm{CH})$, $128.2(\mathrm{CH}), 127.9(\mathrm{CH}), 127.1(\mathrm{CH}), 127.0(\mathrm{CH}), 122.7(\mathrm{CH}), 117.4\left(\mathrm{C}_{\mathrm{q}}\right), 114.0\left(\mathrm{C}_{\mathrm{q}}\right)$.

IR (ATR): 3026, 1702, 1590, 1510, 1430, 1215, 1105, 1019, 820, $503 \mathrm{~cm}^{-1}$. 
MS (ESI) $m / z$ (relative intensity): $349(100)[\mathrm{M}+\mathrm{H}]^{+}$.

HR-MS (ESI) $\mathrm{C}_{25} \mathrm{H}_{17} \mathrm{O}_{2}[\mathrm{M}+\mathrm{H}]^{+}:$349.1225, found: 349.1223 .

\section{3,4-Bis(4-methoxyphenyl)-1H-benzo $[h]$ isochromen-1-one (402c)}

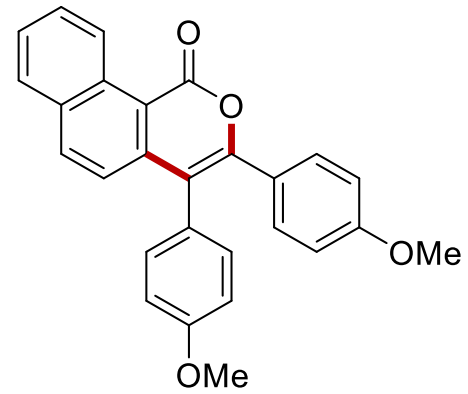

The General Procedure E was followed using 2-methyl benzoic acid 398s (34.4 mg, 0.20 mmol), 1,2bis(4-methoxyphenyl)ethyne 401c (142.9 mg, $0.60 \mathrm{mmol})$, [OsCl 2 (p-cymene) $]_{2}(7.9 \mathrm{mg}, 5.0 \mathrm{~mol} \%)$, $\mathrm{KI}$ (66.4 mg, 2.0 equiv), KOAc (39.3 mg, 2.0 equiv) in $\mathrm{HFIP}(2.0 \mathrm{~mL})$ and $\mathrm{H}_{2} \mathrm{O}(2.0 \mathrm{~mL})$. Purification by column chromatography on silica gel ( $n$-hexane/EtOAc: $20 / 1)$ yielded $402 \mathrm{c}(67.0 \mathrm{mg}, 82 \%)$ as an orange solid.

M. p. $217^{\circ} \mathrm{C}$

${ }^{1} \mathbf{H}$ NMR $\left(400 \mathrm{MHz}, \mathrm{CDCl}_{3}\right) \delta 9.82(\mathrm{~d}, J=8.6 \mathrm{~Hz}, 1 \mathrm{H}), 7.96(\mathrm{~d}, J=8.6 \mathrm{~Hz}, 1 \mathrm{H}), 7.84(\mathrm{~d}, J=8.0 \mathrm{~Hz}$, 1H), 7.75 (ddd, $J=8.6,6.9,1.4 \mathrm{~Hz}, 1 \mathrm{H}), 7.59$ (ddd, $J=8.0,6.9,1.1 \mathrm{~Hz}, 1 \mathrm{H}), 7.33(\mathrm{~d}, J=8.6 \mathrm{~Hz}, 2 \mathrm{H})$, $7.24(\mathrm{~d}, J=8.6 \mathrm{~Hz}, 1 \mathrm{H}), 7.18(\mathrm{~d}, J=8.6 \mathrm{~Hz}, 2 \mathrm{H}), 6.99(\mathrm{~d}, J=8.6 \mathrm{~Hz}, 2 \mathrm{H}), 6.73(\mathrm{~d}, J=8.6 \mathrm{~Hz}, 2 \mathrm{H})$, $3.86(\mathrm{~s}, 3 \mathrm{H}), 3.75(\mathrm{~s}, 3 \mathrm{H})$.

${ }^{13}$ C NMR $\left(100 \mathrm{MHz}, \mathrm{CDCl}_{3}\right) \delta 161.5\left(\mathrm{C}_{\mathrm{q}}\right), 160.0\left(\mathrm{C}_{\mathrm{q}}\right), 159.3\left(\mathrm{C}_{\mathrm{q}}\right), 152.5\left(\mathrm{C}_{\mathrm{q}}\right), 141.7\left(\mathrm{C}_{\mathrm{q}}\right), 135.7(\mathrm{CH})$, $132.5(\mathrm{CH}), 132.4\left(\mathrm{C}_{\mathrm{q}}\right), 131.6\left(\mathrm{C}_{\mathrm{q}}\right), 130.6(\mathrm{CH}), 129.3(\mathrm{CH}), 128.4(\mathrm{CH}), 127.0\left(\mathrm{C}_{\mathrm{q}}\right), 126.9(\mathrm{CH})$, $126.8(\mathrm{CH}), 125.3\left(\mathrm{C}_{\mathrm{q}}\right), 122.6(\mathrm{CH}), 115.8\left(\mathrm{C}_{\mathrm{q}}\right), 114.7(\mathrm{CH}), 113.5\left(\mathrm{C}_{\mathrm{q}}\right), 113.3(\mathrm{CH}), 55.3\left(\mathrm{CH}_{3}\right), 55.2$ $\left(\mathrm{CH}_{3}\right)$.

IR (ATR): 3203, 1703, 1510, 1441, 1247, 1177, 1091, 831, 765, $570 \mathrm{~cm}^{-1}$.

MS (ESI) $m / z$ (relative intensity): 409 (100) $[\mathrm{M}+\mathrm{H}]^{+}$.

HR-MS (ESI) $\mathrm{C}_{27} \mathrm{H}_{21} \mathrm{O}_{4}[\mathrm{M}+\mathrm{H}]^{+}:$409.1435, found: 409.1434 . 
3,4-Bis(4-fluorophenyl)-1H-benzo $[h]$ isochromen-1-one (402d)

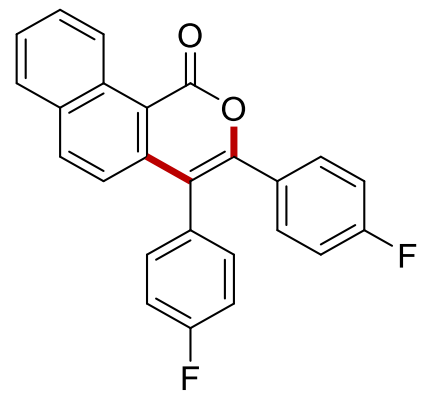

The General Procedure E was followed using 2-methyl benzoic acid 398s (34.4 mg, $0.20 \mathrm{mmol}$ ), 1,2bis(4-fluorophenyl)ethyne $401 \mathrm{D}$ (128.5 mg, $0.60 \mathrm{mmol})$, [OsCl $2(p \text {-cymene) }]_{2}(7.9 \mathrm{mg}, 5.0 \mathrm{~mol} \%), \mathrm{KI}$ (66.4 mg, 2.0 equiv), KOAc (39.3 mg, 2.0 equiv) in $\mathrm{HFIP}(2.0 \mathrm{~mL})$ and $\mathrm{H}_{2} \mathrm{O}(2.0 \mathrm{~mL})$. Purification by column chromatography on silica gel ( $n$-hexane/EtOAc: $20 / 1)$ yielded $402 d(65.3 \mathrm{mg}, 85 \%)$ as a yellow solid.

M. p. $196^{\circ} \mathrm{C}$

${ }^{1} \mathbf{H}$ NMR $\left(400 \mathrm{MHz}, \mathrm{CDCl}_{3}\right) \delta 9.85(\mathrm{dd}, J=8.7,1.0 \mathrm{~Hz}, 1 \mathrm{H}), 8.05(\mathrm{~d}, J=8.7 \mathrm{~Hz}, 1 \mathrm{H}), 7.91(\mathrm{~d}, J=8.0$ $\mathrm{Hz}, 1 \mathrm{H}), 7.82(\mathrm{ddd}, J=8.7,6.9,1.4 \mathrm{~Hz}, 1 \mathrm{H}), 7.67(\mathrm{ddd}, J=8.0,6.9,1.4 \mathrm{~Hz}, 1 \mathrm{H}), 7.38(\mathrm{dd}, J=9.0$, $5.3 \mathrm{~Hz}, 2 \mathrm{H}), 7.30(\mathrm{dd}, J=9.0,5.3 \mathrm{~Hz}, 2 \mathrm{H}), 7.23(\mathrm{~d}, J=8.7 \mathrm{~Hz}, 1 \mathrm{H}), 7.25-7.22(\mathrm{~m}, 2 \mathrm{H}), 6.99-6.93$ $(\mathrm{m}, 2 \mathrm{H})$.

${ }^{13} \mathrm{C}$ NMR $\left(100 \mathrm{MHz}, \mathrm{CDCl}_{3}\right) \delta 163.6\left(\mathrm{~d}, J_{\mathrm{C}-\mathrm{F}}=44.6 \mathrm{~Hz}, \mathrm{C}_{\mathrm{q}}\right), 161.9\left(\mathrm{~d}, J_{\mathrm{C}-\mathrm{F}}=42.2 \mathrm{~Hz}, \mathrm{C}_{\mathrm{q}}\right), 161.0\left(\mathrm{C}_{\mathrm{q}}\right)$, $151.8\left(\mathrm{C}_{\mathrm{q}}\right), 140.7\left(\mathrm{C}_{\mathrm{q}}\right), 136.1(\mathrm{CH}), 133.2\left(\mathrm{~d}, J_{\mathrm{C}-\mathrm{F}}=8.0 \mathrm{~Hz}, \mathrm{CH}\right), 132.6\left(\mathrm{C}_{\mathrm{q}}\right), 131.5\left(\mathrm{C}_{\mathrm{q}}\right), 131.2\left(\mathrm{~d}, J_{\mathrm{C}-}\right.$ $\mathrm{F}=8.5 \mathrm{~Hz}, \mathrm{CH}), 130.5\left(\mathrm{~d}, J_{\mathrm{C}-\mathrm{F}}=3.6 \mathrm{~Hz}, \mathrm{C}_{\mathrm{q}}\right), 129.6(\mathrm{CH}), 128.8\left(\mathrm{~d}, J_{\mathrm{C}-\mathrm{F}}=3.4 \mathrm{~Hz}, \mathrm{C}_{\mathrm{q}}\right), 128.5(\mathrm{CH})$, $127.2(\mathrm{CH}), 127.0(\mathrm{CH}), 122.3(\mathrm{CH}), 116.5\left(\mathrm{~d}, J_{\mathrm{C}-\mathrm{F}}=21.5 \mathrm{~Hz}, \mathrm{CH}\right), 116.3\left(\mathrm{C}_{\mathrm{q}}\right), 115.2\left(\mathrm{~d}, J_{\mathrm{C}-\mathrm{F}}=21.8\right.$ $\mathrm{Hz}, \mathrm{CH}), 113.9\left(\mathrm{C}_{\mathrm{q}}\right)$.

${ }^{19}$ F NMR $\left(282 \mathrm{MHz}, \mathrm{CDCl}_{3}\right) \delta-110.52,-112.72$.

IR (ATR): 3501, 1720, 1595, 1510, 1330, 1229, 1106, 833, 730, 530, $\mathrm{cm}^{-1}$.

MS (ESI) $m / z$ (relative intensity): $385(100)[\mathrm{M}+\mathrm{H}]^{+}$.

HR-MS (ESI) $\mathrm{C}_{25} \mathrm{H}_{15} \mathrm{~F}_{2} \mathrm{O}_{2}[\mathrm{M}+\mathrm{H}]^{+}: 385.1037$, found: 385.1035 . 
Butyl (E)-3-(1-(2-butoxy-2-oxoethyl)-3-oxo-1,3-dihydroisobenzofuran-4-yl)acrylate (426)

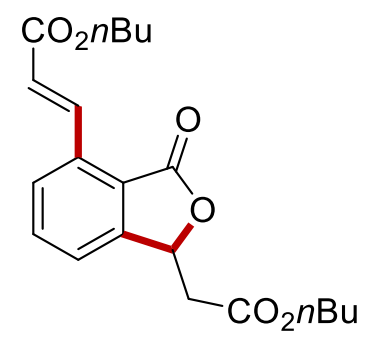

The General Procedure D was followed using benzoic acid 398b (24.4 mg, 0.20 mmol), n-butyl acrylate 399a (76.9 mg, $0.60 \mathrm{mmol}),\left[\mathrm{OsCl}_{2}(p \text {-cymene })\right]_{2}(7.9 \mathrm{mg}, 5.0 \mathrm{~mol} \%), \mathrm{KI}(66.4 \mathrm{mg}, 2.0 \mathrm{equiv})$, KOAc (39.3 mg, 2.0 equiv) in HFIP $(2.0 \mathrm{~mL})$ and $\mathrm{H}_{2} \mathrm{O}(2.0 \mathrm{~mL})$. Purification by column chromatography on silica gel ( $n$-hexane/EtOAc: $4 / 1)$ yielded $426(1.5 \mathrm{mg}, 2 \%)$ as a colorless oil.

${ }^{1} \mathbf{H}$ NMR $\left(400 \mathrm{MHz}, \mathrm{CDCl}_{3}\right) \delta 8.65(\mathrm{~d}, J=16.3 \mathrm{~Hz}, 1 \mathrm{H}), 7.73(\mathrm{~d}, J=8.3 \mathrm{~Hz}, 1 \mathrm{H}), 7.63(\mathrm{t}, J=7.6 \mathrm{~Hz}$, $1 \mathrm{H}), 7.46(\mathrm{~d}, J=7.6 \mathrm{~Hz}, 1 \mathrm{H}), 6.55(\mathrm{~d}, J=16.3 \mathrm{~Hz}, 1 \mathrm{H}), 5.80(\mathrm{t}, J=6.4 \mathrm{~Hz}, 1 \mathrm{H}), 4.17(\mathrm{t}, J=6.7 \mathrm{~Hz}$, 2H), $4.09(\mathrm{t}, J=6.7 \mathrm{~Hz}, 2 \mathrm{H}), 2.87(\mathrm{~d}, J=6.4 \mathrm{~Hz}, 2 \mathrm{H}), 1.69-1.61(\mathrm{~m}, 2 \mathrm{H}), 1.59-1.50(\mathrm{~m}, 2 \mathrm{H}), 1.39$ $(\mathrm{dq}, J=15.2,7.4 \mathrm{~Hz}, 2 \mathrm{H}), 1.29(\mathrm{dq}, J=14.7,7.4 \mathrm{~Hz}, 2 \mathrm{H}), 0.91(\mathrm{t}, J=7.4 \mathrm{~Hz}, 3 \mathrm{H}), 0.86(\mathrm{t}, J=7.4 \mathrm{~Hz}$, $3 \mathrm{H})$.

${ }^{13}$ C NMR $\left(100 \mathrm{MHz}, \mathrm{CDCl}_{3}\right) \delta 169.1\left(\mathrm{C}_{\mathrm{q}}\right), 168.8\left(\mathrm{C}_{\mathrm{q}}\right), 166.1\left(\mathrm{C}_{\mathrm{q}}\right), 149.6\left(\mathrm{C}_{\mathrm{q}}\right), 137.2(\mathrm{CH}), 134.9\left(\mathrm{C}_{\mathrm{q}}\right)$, $134.2(\mathrm{CH}), 126.5(\mathrm{CH}), 123.1\left(\mathrm{C}_{\mathrm{q}}\right), 123.0(\mathrm{CH}), 122.9(\mathrm{CH}), 76.0(\mathrm{CH}), 65.1\left(\mathrm{CH}_{2}\right), 64.6\left(\mathrm{CH}_{2}\right), 39.3$ $\left(\mathrm{CH}_{2}\right), 30.6\left(\mathrm{CH}_{2}\right), 30.4\left(\mathrm{CH}_{2}\right), 19.1\left(\mathrm{CH}_{2}\right), 18.9\left(\mathrm{CH}_{2}\right), 13.6\left(\mathrm{CH}_{3}\right), 13.5\left(\mathrm{CH}_{3}\right)$.

IR (ATR): 2960, 2936, 1771, 1730, 1487, 1281, 1172, 1109, 1005, 747, $686 \mathrm{~cm}^{-1}$.

MS (ESI) $m / z$ (relative intensity): $374(60)[\mathrm{M}+\mathrm{H}]^{+}, 396(40)[\mathrm{M}+\mathrm{Na}]^{+}$.

HR-MS (ESI) $\mathrm{C}_{21} \mathrm{H}_{27} \mathrm{O}_{6}[\mathrm{M}+\mathrm{H}]^{+}: 374.1729$, found: 374.1731 .

The spectral data were in accordance with those reported in the literature. ${ }^{[267]}$ 


\subsubsection{Reaction Comparison with External Oxidant}

A suspension of $o$-toluic acid 398a $(0.20 \mathrm{mmol}, 1.0$ equiv), $n$-butyl acrylate 399a $(0.60 \mathrm{mmol}, 3.0$ equiv), $\left[\mathrm{OsCl}_{2}(p \text {-cymene })\right]_{2}(5.0 \mathrm{~mol} \%)$, oxidant (0.40 mmol, 2.0 equiv), and $\mathrm{KOAc}(0.40 \mathrm{mmol}, 2.0$ equiv) in HFIP $(2.0 \mathrm{~mL})$ and $\mathrm{H}_{2} \mathrm{O}(2.0 \mathrm{~mL})$ was stirred at $100{ }^{\circ} \mathrm{C}$ for $16 \mathrm{~h}$ under $\mathrm{N}_{2}$ (Table 5.5.1). Chemical oxidants used were $\mathrm{AgOAc}, \mathrm{Cu}(\mathrm{OAc})_{2}, \mathrm{Mn}(\mathrm{OAc})_{3}, \mathrm{PhI}(\mathrm{OAc})_{2}$, and $\mathrm{K}_{2} \mathrm{~S}_{2} \mathrm{O}_{8}$. Additionally, the same reaction was performed under air as a terminal oxidant.

Table 5.5.1 Osmium-catalyzed $\mathrm{C}-\mathrm{H}$ annulations with external oxidants.<smiles>Cc1ccccc1C(=O)O</smiles>

$398 a$ 399a<smiles>C=CC(=O)OCCC</smiles>

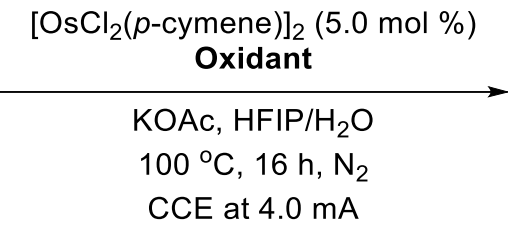

CCE at $4.0 \mathrm{~mA}$

Isolated yield

$\mathrm{Cu}(\mathrm{OAc})_{2}$

$\mathrm{Mn}(\mathrm{OAc})_{3}$

$\mathrm{PhI}(\mathrm{OAc})_{2}$
$0 \%$

AgOAc

$9 \%$

$0 \%$

$0 \%$

$0 \%$

$\mathrm{K}_{2} \mathrm{~S}_{2} \mathrm{O}_{8}$

Oxidant

Air

$0 \%$

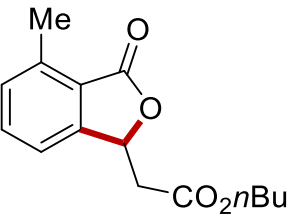

$400 a$ 


\subsubsection{Selectivity Comparison with Different Catalysis (1)}

1) Procedure for the reaction with $\left[\mathrm{Cp}^{*} \mathrm{RhCl}_{2}\right]_{2}$

A suspension of benzoic acid $\mathbf{3 9 8 b}$ ( $0.40 \mathrm{mmol}, 2.0$ equiv), $n$-butyl acrylate 399a $(0.20 \mathrm{mmol}, 0.20$ mmol), [Cp* $\left.\mathrm{RhCl}_{2}\right]_{2}(2.5 \mathrm{~mol} \%)$, and $\mathrm{KOAc}\left(0.40 \mathrm{mmol}, 2.0\right.$ equiv) in $t \mathrm{AmOH}(3.0 \mathrm{~mL})$ and $\mathrm{H}_{2} \mathrm{O}$ $(1.0 \mathrm{~mL})$ was stirred at $100{ }^{\circ} \mathrm{C}$ for $8 \mathrm{~h}$ at $4.0 \mathrm{~mA}$ of constant current under air (Scheme 5.5.1).

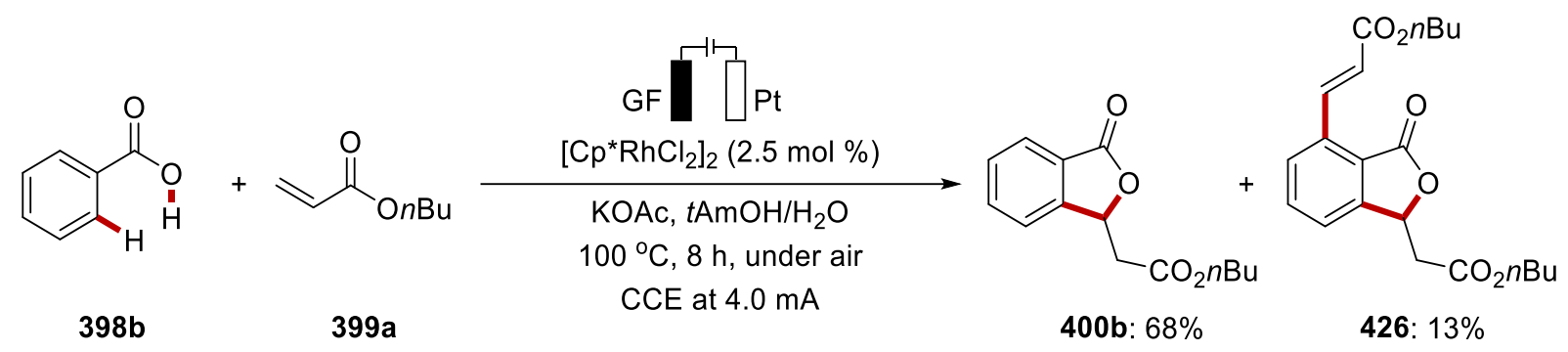

Scheme 5.5.1 Rhodium-catalyzed electrooxidative $\mathrm{C}-\mathrm{H}$ annulation.

2) Procedure for the reaction with $\left[\mathrm{Cp}^{*} \mathrm{IrCl}_{2}\right]_{2}$

A suspension of benzoic acid $\mathbf{3 9 8 b}(0.20 \mathrm{mmol}, 1.0$ equiv), $n$-butyl acrylate 399a ( $0.40 \mathrm{mmol}, 2.0$ equiv), $\left[\mathrm{Cp}^{*} \mathrm{IrCl}_{2}\right]_{2}(2.5 \mathrm{~mol} \%)$, benzoquinone (10 mol \%), KOAc (0.4 mmol, 2.0 equiv) in $t \mathrm{AmOH}$ (3.0 mL) and $\mathrm{H}_{2} \mathrm{O}(1.0 \mathrm{~mL})$ was stirred at $100{ }^{\circ} \mathrm{C}$ for $18 \mathrm{~h}$ at $4.0 \mathrm{~mA}$ of constant current under air (Scheme 5.5.2).

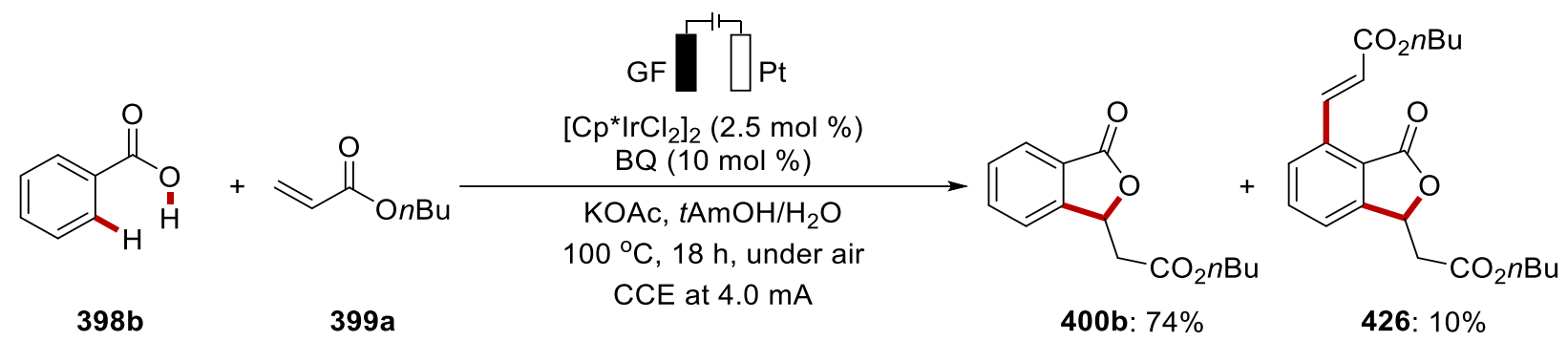

Scheme 5.5.2 Iridium-catalyzed electrooxidative C-H annulation. 
3) Procedure for the reaction with $\left[\mathrm{RuCl}_{2}(p \text {-cymene })\right]_{2}$

A suspension of benzoic acid $\mathbf{3 9 8 b}$ ( $0.40 \mathrm{mmol}, 2.0$ equiv), $n$-butyl acrylate 399a $(0.20 \mathrm{mmol}, 1.0$ equiv), $\left[\mathrm{RuCl}_{2}(p \text {-cymene) }]_{2}(5.0 \mathrm{~mol} \%)\right.$, and $\mathrm{NaOPiv}(0.40 \mathrm{mmo}, 2.0$ equiv) in $t \mathrm{AmOH}(3.0 \mathrm{~mL})$ and $\mathrm{H}_{2} \mathrm{O}(1.0 \mathrm{~mL})$ was stirred at $100{ }^{\circ} \mathrm{C}$ for $18 \mathrm{~h}$ at $4.0 \mathrm{~mA}$ of constant current under air (Scheme 5.5.3).<smiles>O=C(O)c1ccccc1F</smiles>

$398 b$<smiles>C=CC(=O)OCC</smiles>

$399 a$

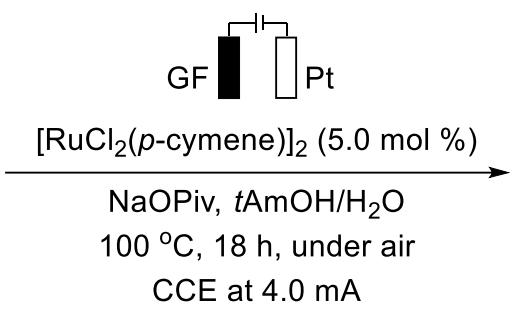

CCE at $4.0 \mathrm{~mA}$

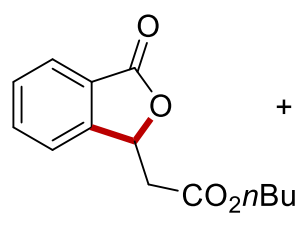

400b: $59 \%$

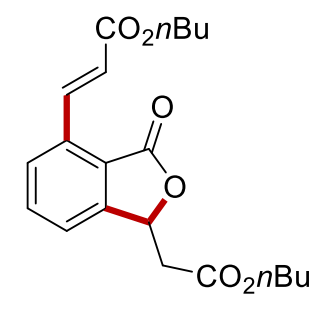

426: $9 \%$

Scheme 5.5.3 Ruthenium-catalyzed electrooxidative C-H annulation.

4) Procedure for the reaction with $\left[\mathrm{OsCl}_{2}(p \text {-cymene })\right]_{2}$

The General Procedure D was followed using benzoic acid 398b (0.20 mmol, 1.0 equiv), $n$-butyl acrylate 399a (0.60 mmol, 3.0 equiv), $\left[\mathrm{OsCl}_{2}(p \text {-cymene })\right]_{2}(5.0 \mathrm{~mol} \%), \mathrm{KI}(0.40 \mathrm{mmol}, 2.0$ equiv $)$, KOAc $(0.40 \mathrm{mmol}, 2.0$ equiv $)$ in $\operatorname{HFIP}(2.0 \mathrm{~mL})$ and $\mathrm{H}_{2} \mathrm{O}(2.0 \mathrm{~mL})$ at $100{ }^{\circ} \mathrm{C}$ for $16 \mathrm{~h}$ at $4.0 \mathrm{~mA}$ of constant current under $\mathrm{N}_{2}$ (Scheme 5.5.4).<smiles>O=C(O)c1ccccc1</smiles>

$398 b$

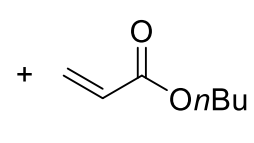

$399 a$

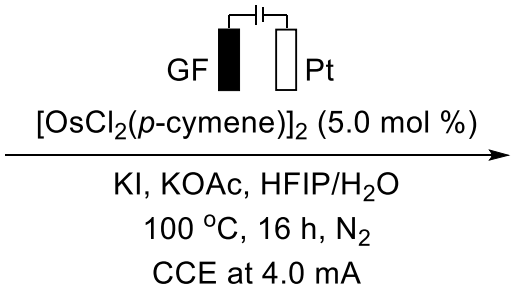

CCE at $4.0 \mathrm{~mA}$

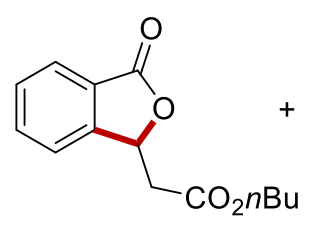

400b: $71 \%$<smiles>CCCCOC(=O)/C=C/c1cccc2c1C(=O)OC2CC(=O)OCCC</smiles>

426: $2 \%$

Scheme 5.5.4 Osmium-catalyzed electrooxidative C-H annulation. 


\subsubsection{Selectivity Comparison with Different Catalysis (2)}

1) Procedure for $\mathrm{H} / \mathrm{D}$ exchange studies: Ruthenium catalysis (1)

The General Procedure D was followed using 3-(trifluoromethyl)benzoic acid 398h $(0.20 \mathrm{mmol}, 1.0$ equiv), $n$-butyl acrylate 399a (0.60 mmol, 3.0 equiv), $\left[\mathrm{RuCl}_{2}(p \text {-cymene })\right]_{2}(5.0 \mathrm{~mol} \%), \mathrm{KI}(0.40 \mathrm{mmol}$, 2.0 equiv), KOAc ( $0.40 \mathrm{mmol}, 2.0$ equiv) in $\operatorname{HFIP}(1.0 \mathrm{~mL})$ and $\mathrm{D}_{2} \mathrm{O}(3.0 \mathrm{~mL})$ at $100{ }^{\circ} \mathrm{C}$ for $2 \mathrm{~h}$ at 4.0 $\mathrm{mA}$ of constant current under $\mathrm{N}_{2}$ (Scheme 5.5.5).

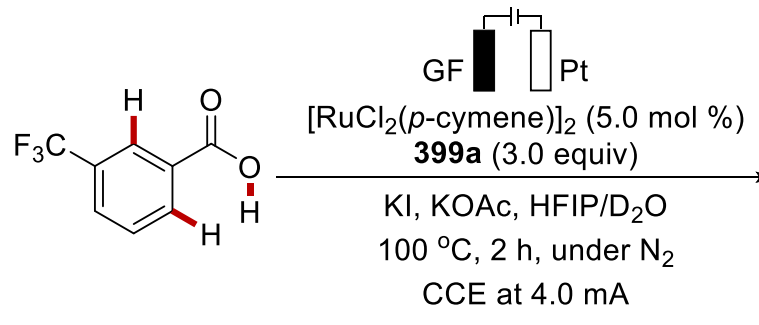

$398 \mathrm{~h}$<smiles>O=C(O)c1c(P)ccc(C(F)(F)F)c1[18O]c1ccccc1</smiles>

$[D]_{n}-398 h: 65 \%$

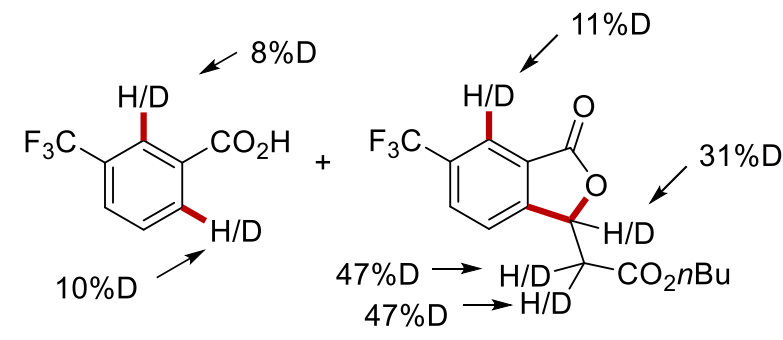

[D] $]_{n}-398 h: 65 \%$

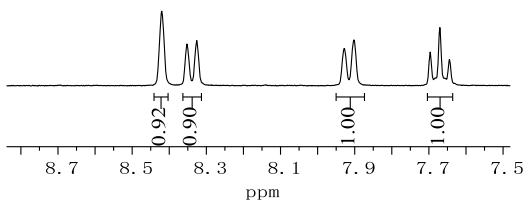

[D] $]_{n}-400 h: 22 \%$
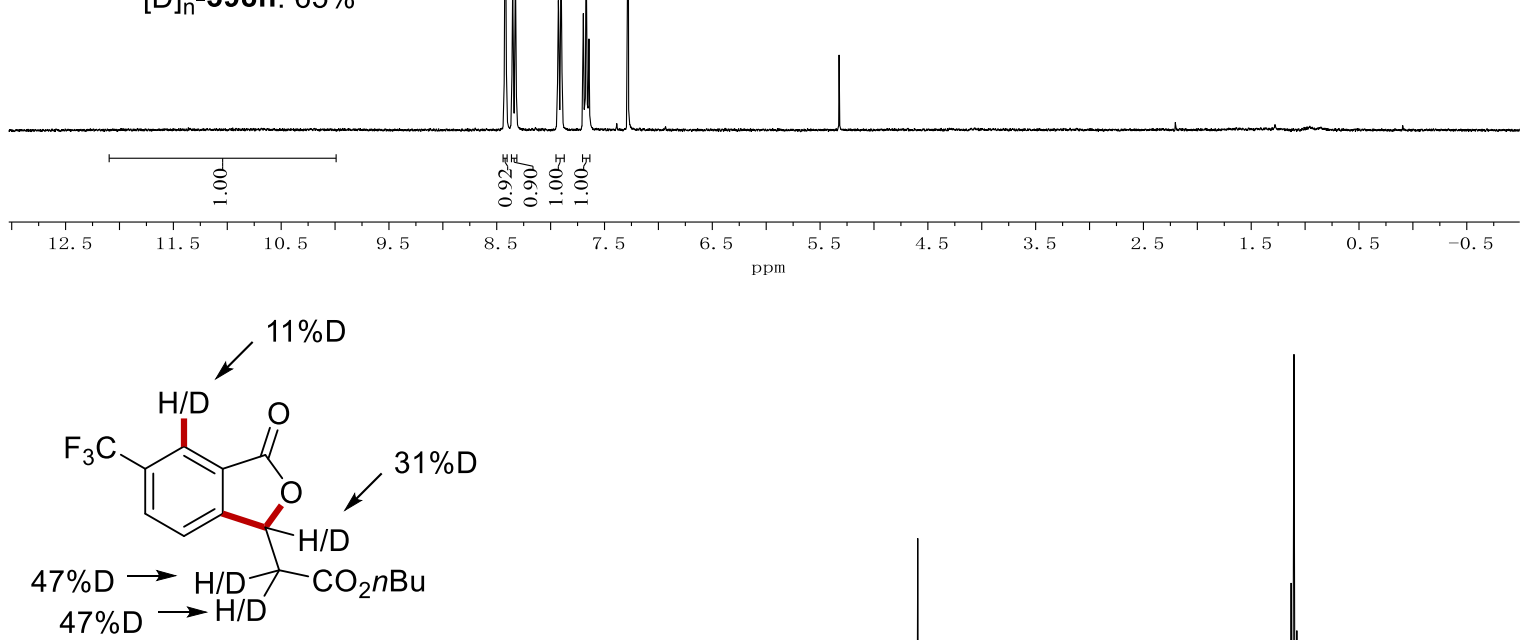

$[D]_{n}-400 h: 22 \%$

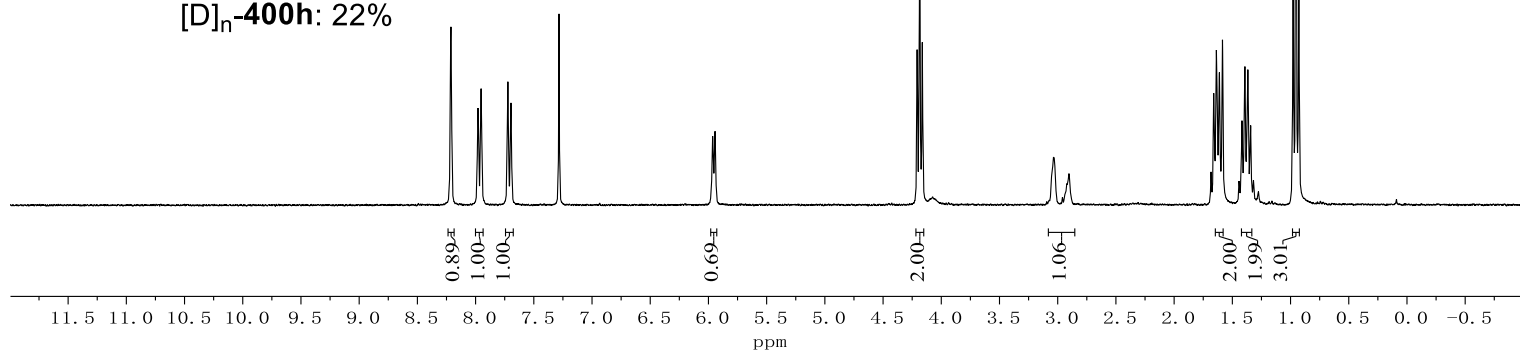

Scheme 5.5.5 H/D exchange study in electrochemical ruthenium catalysis 1 . 
2) Procedure for $\mathrm{H} / \mathrm{D}$ exchange studies: Ruthenium catalysis (2)

The General Procedure D was followed using 3-(trifluoromethyl)benzoic acid 398h (0.20 mmol, 1.0 equiv), $\left[\mathrm{RuCl}_{2}(p \text {-cymene })\right]_{2}(5.0 \mathrm{~mol} \%), \mathrm{KI}(0.40 \mathrm{mmol}, 2.0$ equiv $), \mathrm{KOAc}(0.40 \mathrm{mmol}, 2.0$ equiv $)$ in HFIP $(1.0 \mathrm{~mL})$ and $\mathrm{D}_{2} \mathrm{O}(3.0 \mathrm{~mL})$ at $100{ }^{\circ} \mathrm{C}$ for $2 \mathrm{~h}$ at $4.0 \mathrm{~mA}$ of constant current under $\mathrm{N}_{2}($ Scheme 5.5.6).<smiles>O=Cc1cccc(C(F)(F)F)c1</smiles>

$398 h$

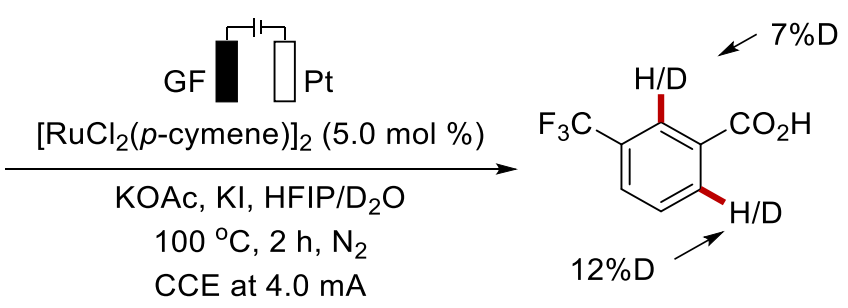

$[D]_{n}-398 h: 89 \%$<smiles>O=C(O)c1c(O)ccc(C(F)(F)F)c1O</smiles>

$[D]_{n}-398 h: 89 \%$
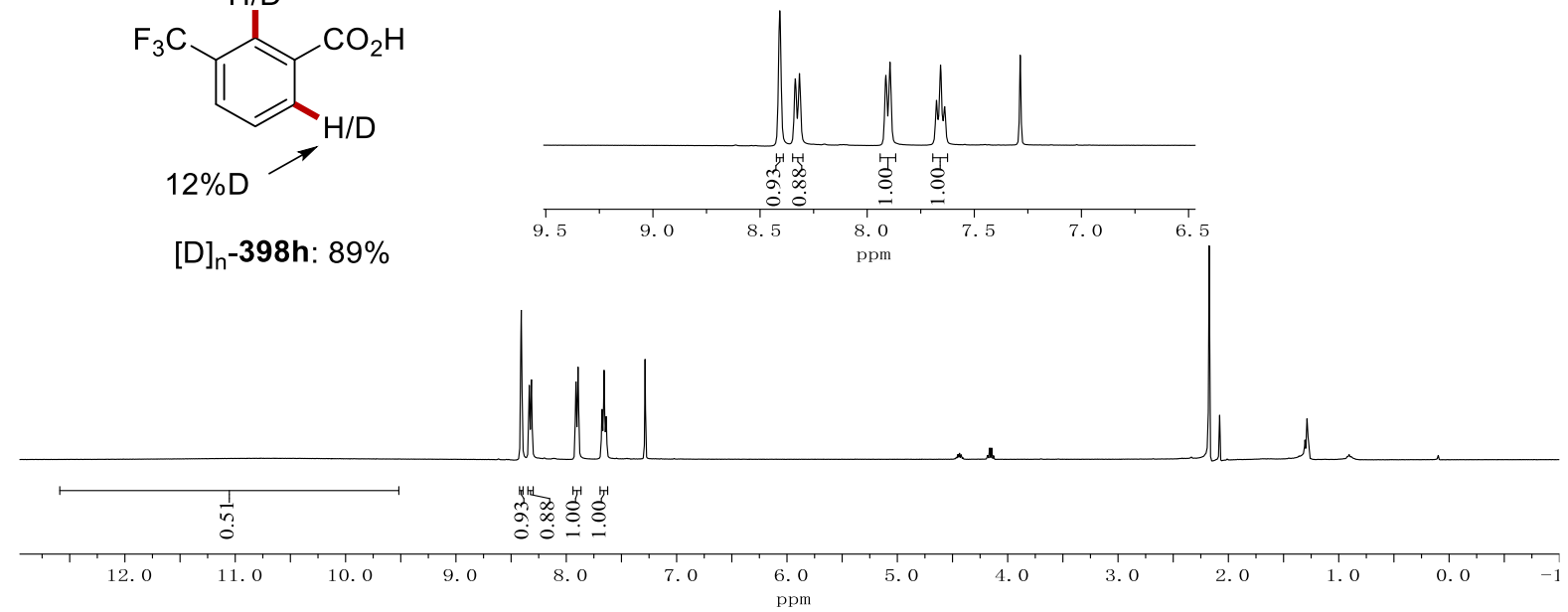

Scheme 5.5.6 H/D exchange study in electrochemical ruthenium catalysis 2 . 
3) Procedure for $\mathrm{H} / \mathrm{D}$ exchange studies: Osmium catalysis (1)

The General Procedure D was followed using 3-(trifluoromethyl)benzoic acid 398h (0.20 mmol, 1.0 equiv), $n$-butyl acrylate 399a ( $0.60 \mathrm{mmol}, 3.0$ equiv), $\left[\mathrm{OsCl}_{2}(p \text {-cymene })\right]_{2}(5.0 \mathrm{~mol} \%), \mathrm{KI}(0.40 \mathrm{mmol}$, 2.0 equiv $), \mathrm{KOAc}(0.40 \mathrm{mmol}, 2.0$ equiv $)$ in $\operatorname{HFIP}(1.0 \mathrm{~mL})$ and $\mathrm{D}_{2} \mathrm{O}(3.0 \mathrm{~mL})$ at $100{ }^{\circ} \mathrm{C}$ for $2 \mathrm{~h}$ at 4.0 $\mathrm{mA}$ of constant current under $\mathrm{N}_{2}$

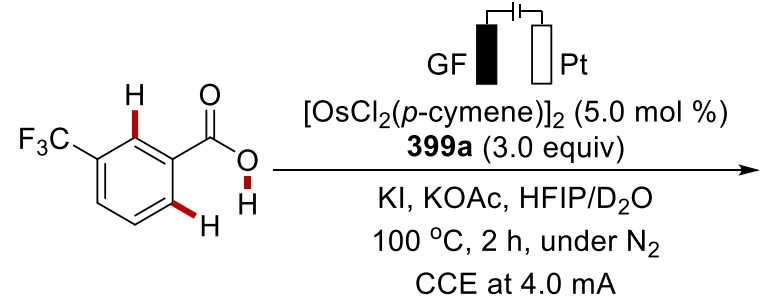

$398 \mathrm{~h}$

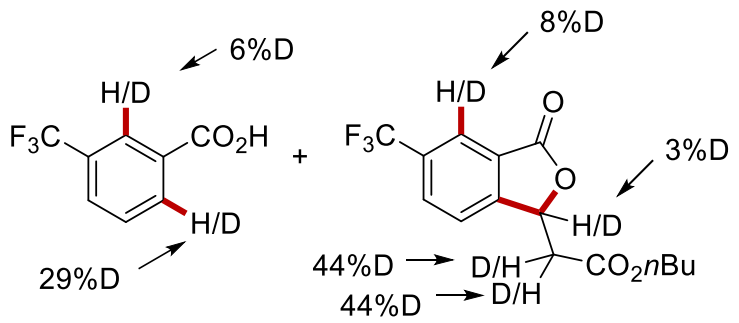

$[D]_{n}-398 h: 65 \%$

$[D]_{n}-400 h: 22 \%$<smiles>CCOc1ccc(C(F)(F)F)c(O)c1C(=O)O</smiles>

$[D]_{n}-398 h: 65 \%$
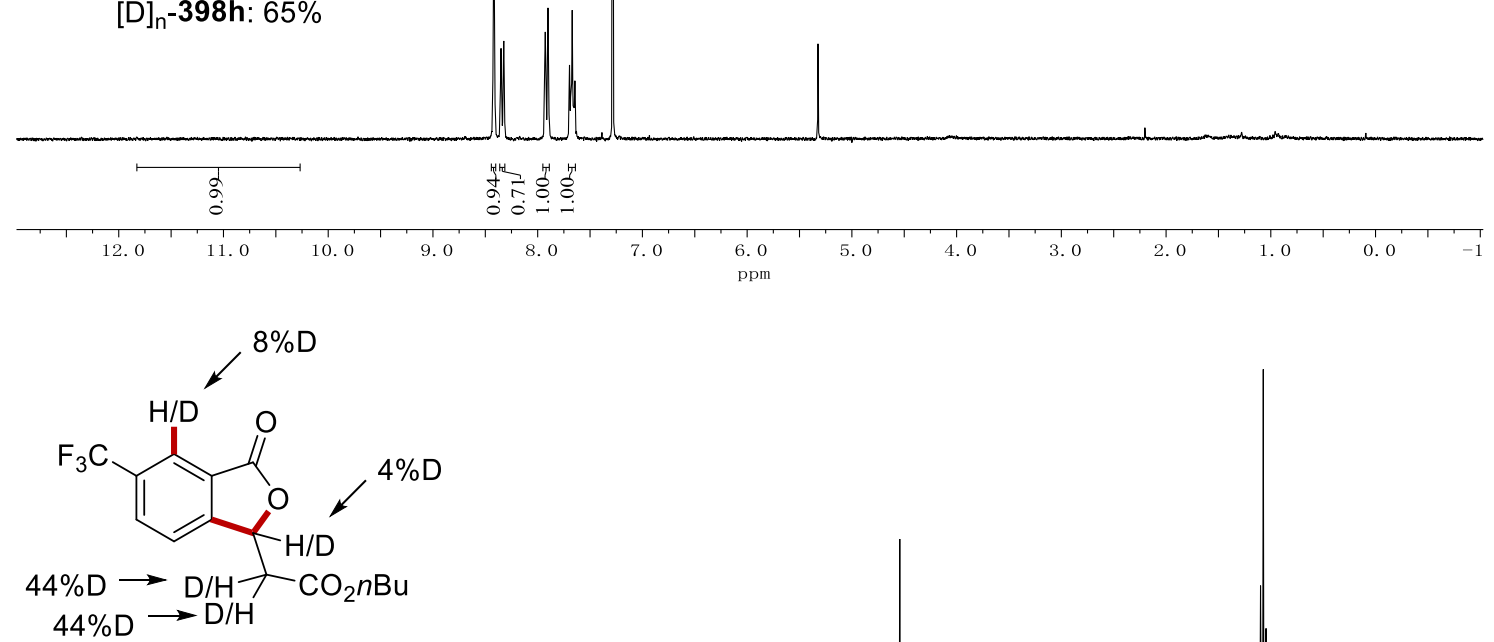

[D] $-400 h: 22 \%$

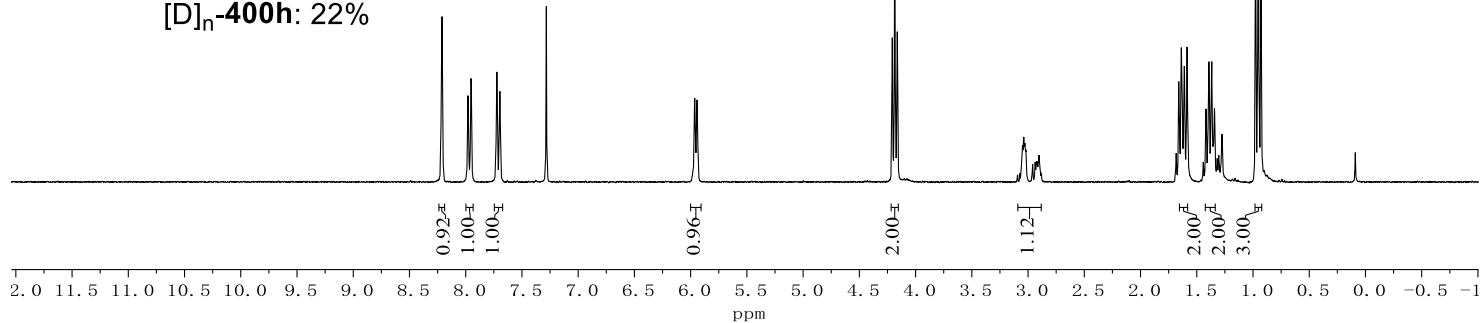

Scheme 5.5.7 H/D exchange study in electrochemical osmium catalysis 1 . 
4) Procedure for $\mathrm{H} / \mathrm{D}$ exchange studies: Osmium catalysis (2)

The General Procedure D was followed using 3-(trifluoromethyl)benzoic acid 398h (0.20 mmol, 1.0 equiv), $\left[\mathrm{OsCl}_{2}(p \text {-cymene })\right]_{2}(5.0 \mathrm{~mol} \%), \mathrm{KI}(0.40 \mathrm{mmol}, 2.0$ equiv $), \mathrm{KOAc}(0.40 \mathrm{mmol}, 2.0$ equiv $)$ in $\operatorname{HFIP}(1.0 \mathrm{~mL})$ and $\mathrm{D}_{2} \mathrm{O}(3.0 \mathrm{~mL})$ at $100{ }^{\circ} \mathrm{C}$ for $2 \mathrm{~h}$ at $4.0 \mathrm{~mA}$ of constant current under $\mathrm{N}_{2}$.

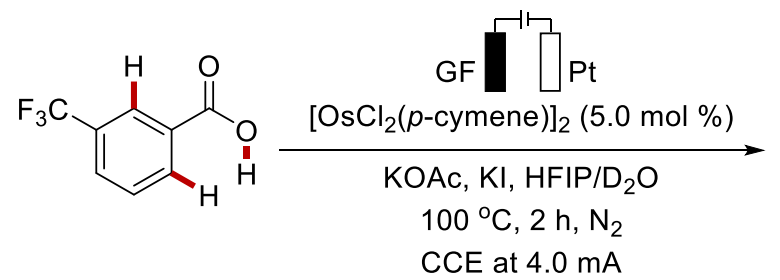

$398 \mathrm{~h}$

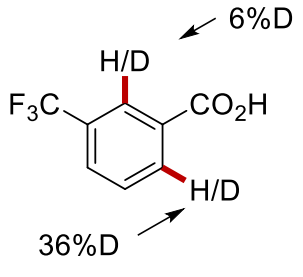

$[D]_{n}-398 h: 89 \%$

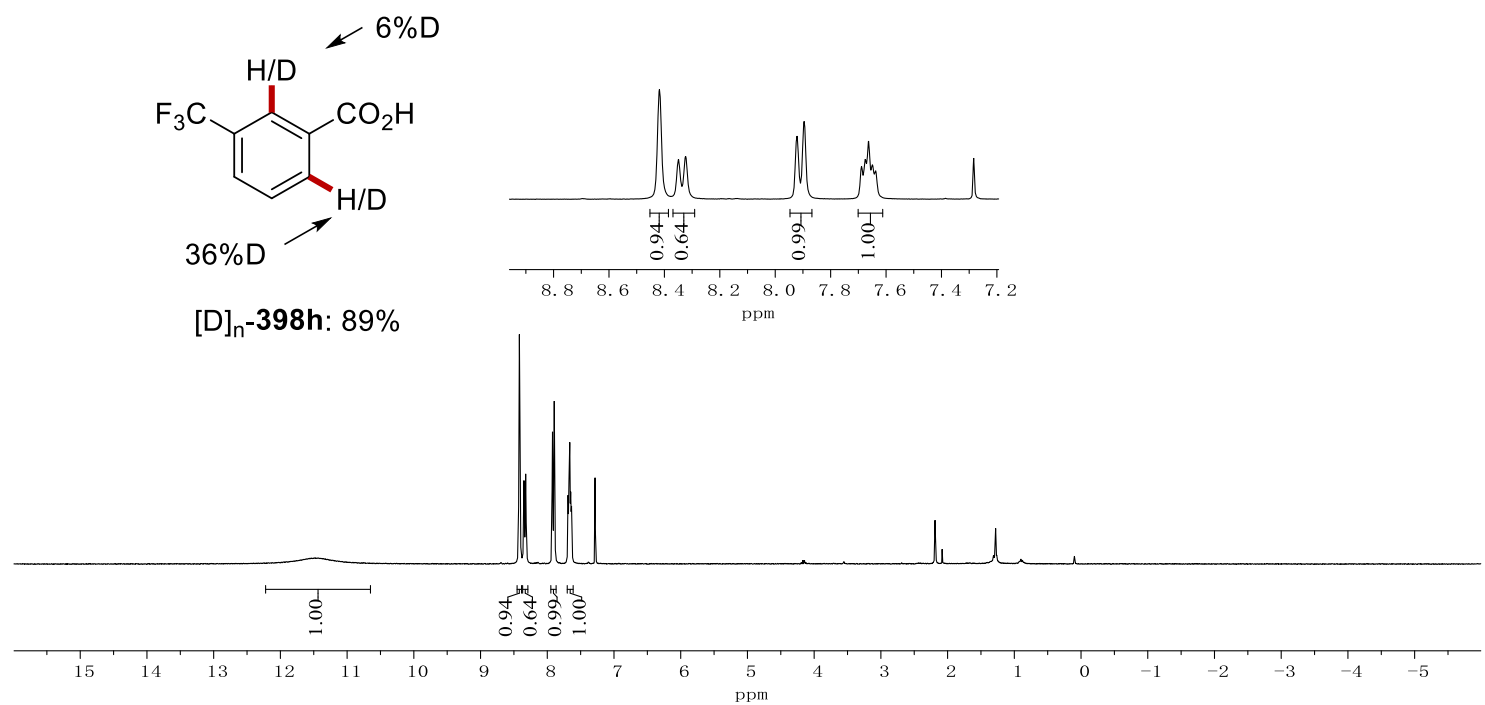

Scheme 5.5.8 H/D exchange study in electrochemical osmium catalysis 2. 


\subsubsection{Synthesis of Osmium Complex}

1) Procedure for the synthesis of $\left[\mathrm{OsCl}_{2}(p \text {-cymene })\right]_{2}$

A suspension of $\mathrm{OsCl}_{3} \cdot \mathrm{xH}_{2} \mathrm{O}(1.0 \mathrm{mmol}, 1.0$ equiv) and $\alpha$-terpinene $(9.0 \mathrm{mmol}, 9.0$ equiv $)$ in isopropanol $(5.0 \mathrm{~mL})$ was stirred at $85^{\circ} \mathrm{C}$ for $16 \mathrm{~h}$ under $\mathrm{N}_{2}$. Filtration (Por 3) with $\mathrm{MeOH}(3 \times 5 \mathrm{~mL})$ gave yellow solid, which was dried in vacuo for $6 \mathrm{~h}$ (Scheme 5.5.9).

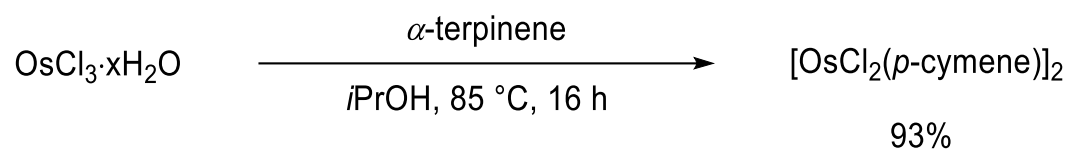

Scheme 5.5.9 Synthesis of $\left[\mathrm{OsCl}_{2}(p \text {-cymene })\right]_{2}$.

2) Procedure for the synthesis of $\mathrm{OsCl}_{2}(\mathrm{DMSO})(p$-cymene)

A suspension of dimethyl sulfoxide $(0.5 \mathrm{~mL})$ and $\left[\mathrm{OsCl}_{2}(p \text {-cymene })\right]_{2}(0.20 \mathrm{mmol})$ in dichloromethane $(5.0 \mathrm{~mL})$ was stirred at room temperature for $16 \mathrm{~h}$ under $\mathrm{N}_{2}$. The reaction mixture was concentrated in vacuo for $24 \mathrm{~h}$, giving reddish yellow solid (Scheme 5.5.10).

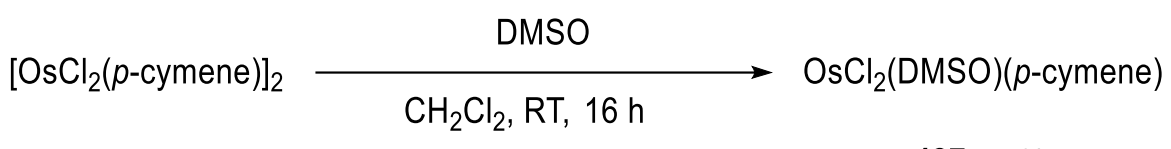

427: $97 \%$

Scheme 5.5.10 Synthesis of 427 .

3) Procedure for the synthesis of $\mathbf{4 2 8}$

To a solution of dimethyl sulfoxide $(0.1 \mathrm{~mL})$ and $\mathrm{OsCl}_{2}(\mathrm{DMSO})(p$-cymene $)(0.20 \mathrm{mmol})$ in $\mathrm{PhMe}$ was added dropwise $\mathrm{AlMe}_{3}(2.0 \mathrm{M}$ solution in PhMe, $0.15 \mathrm{~mL}$ ) in the glove box (Scheme 5.5.11). After stirring at room temperature for $30 \mathrm{~min}$, reaction vessel was taken out from the glove box. While stirring at room temperature for additional $20 \mathrm{~min}$, acetone $(1.0 \mathrm{~mL})$ and $\mathrm{H}_{2} \mathrm{O}(0.05 \mathrm{~mL})$ were added dropwise (Caution: This step generates gas). Afterwards, diethyl ether $(2.0 \mathrm{~mL})$ was added, then forming the white solid. A short $\mathrm{Na}_{2} \mathrm{SO}_{4}$ packed filter followed by PTFE filter (Simplepure ${ }^{\mathrm{TM}}, 0.22$ $\mu \mathrm{m}$ ) gave yellow solution which was vacuum evaporated for $16 \mathrm{~h}$, giving yellow sold. (Caution: Do not use rotary evaporator to remove solvents, which can give a color change of solution to dark brown.) 


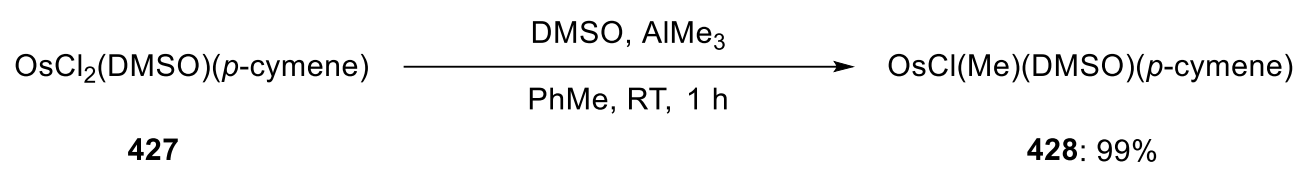

Scheme 5.5.11 Synthesis of $\mathbf{4 2 8}$.

OsCl(Me)(DMSO)(p-cymene) (428)

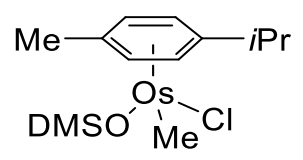

${ }^{1}$ H NMR $\left(400 \mathrm{MHz}\right.$, Benzene- $\left.d_{6}\right) \delta 5.06(\mathrm{~d}, J=5.5 \mathrm{~Hz}, 1 \mathrm{H}), 4.88(\mathrm{~d}, J=5.5 \mathrm{~Hz}, 1 \mathrm{H}), 4.84(\mathrm{~d}, J=5.5$ $\mathrm{Hz}, 1 \mathrm{H}), 4.67(\mathrm{~d}, J=5.5 \mathrm{~Hz}, 1 \mathrm{H}), 3.01(\mathrm{~s}, 3 \mathrm{H}), 2.66-2.59(\mathrm{~m}, 1 \mathrm{H}), 2.56(\mathrm{~s}, 3 \mathrm{H}), 1.86(\mathrm{~s}, 3 \mathrm{H}), 1.43$ (s, $3 \mathrm{H}), 1.05(\mathrm{~d}, J=7.0 \mathrm{~Hz}, 3 \mathrm{H}), 1.02(\mathrm{~d}, J=7.0 \mathrm{~Hz}, 3 \mathrm{H})$.

${ }^{13}$ C NMR (100 MHz, Benzene- $\left.d_{6}\right) \delta 99.7\left(\mathrm{C}_{\mathrm{q}}\right), 92.9\left(\mathrm{C}_{\mathrm{q}}\right), 84.5(\mathrm{CH}), 83.5(\mathrm{CH}), 76.2(\mathrm{CH}), 74.9(\mathrm{CH})$, $49.2\left(\mathrm{CH}_{3}\right), 40.7\left(\mathrm{CH}_{3}\right), 37.3\left(\mathrm{CH}_{3}\right), 30.4(\mathrm{CH}), 23.2\left(\mathrm{CH}_{3}\right), 21.9\left(\mathrm{CH}_{3}\right), 17.7\left(\mathrm{CH}_{3}\right),-16.0\left(\mathrm{CH}_{3}\right)$.

HR-MS (ESI) $\mathrm{C}_{13} \mathrm{H}_{23} \mathrm{ClOO}_{S} \mathrm{~S}$ [M]: 454.0755, found: 454.0764 .

4) Procedure for the synthesis of $\mathbf{4 3 0}$

A suspension of $\mathrm{OsCl}(\mathrm{Me})(\mathrm{DMSO})(p$-cymene) $(0.20 \mathrm{mmol}, 1.0$ equiv) and ((1-naphthoyl)oxy)silver 429 ( $0.22 \mathrm{mmol}, 1.1$ equiv) in $\mathrm{C}_{6} \mathrm{D}_{6}$ was stirred at room temperature for $16 \mathrm{~h}$ (Scheme 5.5.12). During the course of reaction, the aliquot was taken to monitor the reaction. When $\operatorname{OsCl}(\mathrm{Me})(\mathrm{DMSO})(p$ cymene) was fully consumed, the solution was filtered with benzene by PTFE filter (Simplepure ${ }^{\mathrm{TM}}$, $0.22 \mu \mathrm{m}$ ) to remove $\mathrm{AgCl}$ (Caution: Benzene is highly toxic. Please use it under ventilated condition). The filtrate was vacuum evaporated for $16 \mathrm{~h}$, giving yellow solid. (Caution: Do not use rotary evaporator to remove solvents, which may decompose the osmium complex.) The crystal structure of Os-I was obtained in THF in the glove box. 


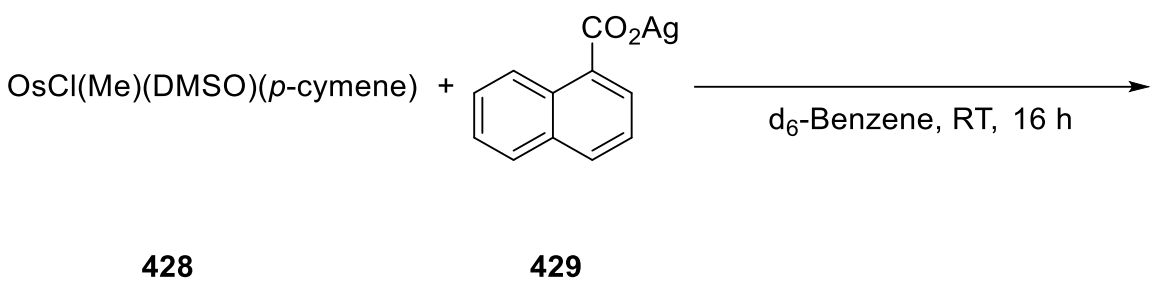

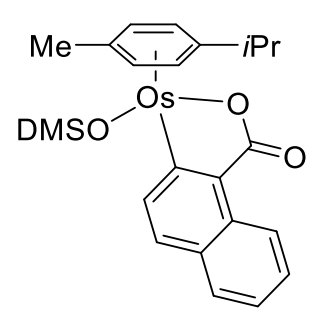

430: $99 \%$

Scheme 5.5.12 Synthesis of 430 .

Osmium complex 430

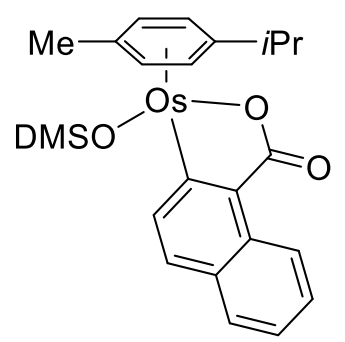

${ }^{1} \mathbf{H}$ NMR $\left(400 \mathrm{MHz}, \mathrm{CD}_{2} \mathrm{Cl}_{2}\right) \delta 9.45(\mathrm{~d}, J=8.2 \mathrm{~Hz}, 1 \mathrm{H}), 7.92(\mathrm{~d}, J=8.2 \mathrm{~Hz}, 1 \mathrm{H}), 7.76(\mathrm{~d}, J=8.2 \mathrm{~Hz}$, 1H), $7.67(\mathrm{~d}, J=8.2 \mathrm{~Hz}, 1 \mathrm{H}), 7.53-7.44(\mathrm{~m}, 1 \mathrm{H}), 7.39-7.30(\mathrm{~m}, 1 \mathrm{H}), 5.67-5.57(\mathrm{~m}, 3 \mathrm{H}), 5.51(\mathrm{~d}$, $J=5.7 \mathrm{~Hz}, 1 \mathrm{H}), 2.88-2.80(\mathrm{~m}, 1 \mathrm{H}), 2.82(\mathrm{~s}, 3 \mathrm{H}), 2.41(\mathrm{~s}, 3 \mathrm{H}), 2.30(\mathrm{~s}, 3 \mathrm{H}), 1.23(\mathrm{~d}, J=6.9 \mathrm{~Hz}, 3 \mathrm{H})$, $1.12(\mathrm{~d}, J=6.9 \mathrm{~Hz}, 3 \mathrm{H})$.

${ }^{13}$ C NMR $\left(100 \mathrm{MHz}, \mathrm{CD}_{2} \mathrm{Cl}_{2}\right) \delta 183.7\left(\mathrm{C}_{\mathrm{q}}\right), 160.1\left(\mathrm{C}_{\mathrm{q}}\right), 138.1(\mathrm{CH}), 133.3\left(\mathrm{C}_{\mathrm{q}}\right), 132.3\left(\mathrm{C}_{\mathrm{q}}\right), 131.2$ $(\mathrm{CH}), 129.8\left(\mathrm{C}_{\mathrm{q}}\right), 128.1(\mathrm{CH}), 126.7(\mathrm{CH}), 124.2(\mathrm{CH}), 123.1(\mathrm{CH}), 108.3\left(\mathrm{C}_{\mathrm{q}}\right), 98.9\left(\mathrm{C}_{\mathrm{q}}\right), 81.7(\mathrm{CH})$, 80.8(CH), 80.2(CH), 79.7(CH), $46.3\left(\mathrm{CH}_{3}\right), 42.3\left(\mathrm{CH}_{3}\right), 30.9(\mathrm{CH}), 22.6\left(\mathrm{CH}_{3}\right), 22.5\left(\mathrm{CH}_{3}\right), 18.5\left(\mathrm{CH}_{3}\right)$. HR-MS (ESI) $\mathrm{C}_{23} \mathrm{H}_{27} \mathrm{O}_{3} \mathrm{OsS}[\mathrm{M}+\mathrm{H}]^{+}:$575.1290, found: 575.1285 .

5) Procedure for the synthesis of $\mathbf{4 3 1}$

A suspension of 430 (0.20 mmol, 1.0 equiv) and 1,2-di-p-tolylethyne $401 \mathrm{a}(0.22 \mathrm{mmol}, 1.1$ equiv) in $\mathrm{CD}_{3} \mathrm{OD}$ was stirred at room temperature for $24 \mathrm{~h}$ (Scheme 5.5.13). During the course of reaction, the aliquot was taken to monitor the reaction. The solution was concentrated under reduced pressure. Purification by column chromatography on silica gel afforded the desired products 431 as a yellow solid. The crystal structure of $\mathbf{4 3 1}$ was obtained in DCM/hexane. 


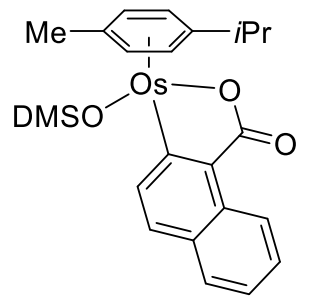

430

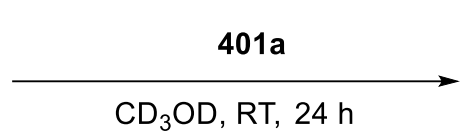

$\mathrm{CD}_{3} \mathrm{OD}, \mathrm{RT}, 24 \mathrm{~h}$

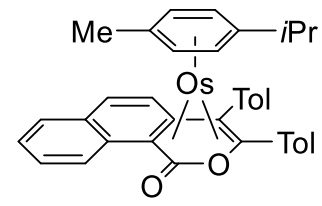

431: $79 \%$

Scheme 5.5.13 Synthesis of $\mathbf{4 3 1}$.

Osmium complex 431

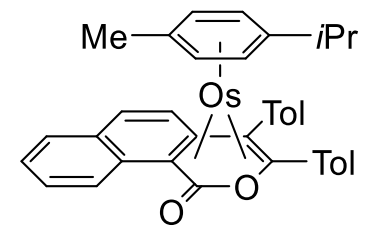

${ }^{1} \mathbf{H}$ NMR $\left(400 \mathrm{MHz}, \mathrm{CDCl}_{3}\right) \delta 8.12(\mathrm{~d}, J=7.9 \mathrm{~Hz}, 1 \mathrm{H}), 7.52-7.40(\mathrm{~m}, 2 \mathrm{H}), 7.36(\mathrm{~d}, J=7.9 \mathrm{~Hz}, 1 \mathrm{H})$, 7.29 (d, $J=7.0 \mathrm{~Hz}, 1 \mathrm{H}), 7.24-7.15(\mathrm{~m}, 1 \mathrm{H}), 7.09$ (d, $J=7.0 \mathrm{~Hz}, 1 \mathrm{H}), 7.01(\mathrm{~d}, J=6.2 \mathrm{~Hz}, 1 \mathrm{H}), 7.02$ $-6.98(\mathrm{~m}, 2 \mathrm{H}), 6.93(\mathrm{~d}, J=8.2 \mathrm{~Hz}, 2 \mathrm{H}), 6.84(\mathrm{~d}, J=8.2 \mathrm{~Hz}, 2 \mathrm{H}), 5.45(\mathrm{~d}, J=5.4 \mathrm{~Hz}, 1 \mathrm{H}), 5.39(\mathrm{~d}, J$ $=5.4 \mathrm{~Hz}, 1 \mathrm{H}), 3.91(\mathrm{~d}, J=5.4 \mathrm{~Hz}, 1 \mathrm{H}), 3.40(\mathrm{~d}, J=5.4 \mathrm{~Hz}, 1 \mathrm{H}), 2.37(\mathrm{~s}, 3 \mathrm{H}), 2.20(\mathrm{~s}, 3 \mathrm{H}), 1.67-1.59$ (m, 1H), $1.64(\mathrm{~s}, 3 \mathrm{H}), 1.13(\mathrm{~d}, J=6.8 \mathrm{~Hz}, 3 \mathrm{H}), 0.95(\mathrm{~d}, J=6.8 \mathrm{~Hz}, 3 \mathrm{H})$.

${ }^{13}$ C NMR $\left(100 \mathrm{MHz}, \mathrm{CDCl}_{3}\right) \delta 175.1\left(\mathrm{C}_{\mathrm{q}}\right), 140.2\left(\mathrm{C}_{\mathrm{q}}\right), 138.8\left(\mathrm{C}_{\mathrm{q}}\right), 137.0\left(\mathrm{C}_{\mathrm{q}}\right), 133.4\left(\mathrm{C}_{\mathrm{q}}\right), 133.1\left(\mathrm{C}_{\mathrm{q}}\right)$, $132.6(\mathrm{CH}), 131.5(\mathrm{CH}), 129.5(\mathrm{CH}), 129.3(\mathrm{CH}), 129.1\left(\mathrm{C}_{\mathrm{q}}\right), 128.7(\mathrm{CH}), 128.7(\mathrm{CH}), 127.6(\mathrm{CH})$, 127.6 (CH), $125.1(\mathrm{CH}), 125.0(\mathrm{CH}), 123.8(\mathrm{CH}), 110.0\left(\mathrm{C}_{\mathrm{q}}\right), 103.0\left(\mathrm{C}_{\mathrm{q}}\right), 92.2\left(\mathrm{C}_{\mathrm{q}}\right), 85.1\left(\mathrm{C}_{\mathrm{q}}\right), 79.0$ $(\mathrm{CH}), 79.0(\mathrm{CH}), 76.3\left(\mathrm{C}_{\mathrm{q}}\right), 74.2(\mathrm{CH}), 51.9\left(\mathrm{C}_{\mathrm{q}}\right), 30.1(\mathrm{CH}), 24.8\left(\mathrm{CH}_{3}\right), 21.6\left(\mathrm{CH}_{3}\right), 21.3\left(\mathrm{CH}_{3}\right), 20.9$ $\left(\mathrm{CH}_{3}\right), 17.5\left(\mathrm{CH}_{3}\right)$.

HR-MS (ESI) $\mathrm{C}_{37} \mathrm{H}_{35} \mathrm{O}_{2} \mathrm{Os}[\mathrm{M}+\mathrm{H}]^{+}$: 703.2249, found: 703.2236 . 


\subsubsection{Reactions with Osmium Complex}

1) Procedure for the stoichiometric reaction with $\mathbf{4 3 0}$

The General Procedure D was followed using 430 ( $0.1 \mathrm{mmol}, 1.0$ equiv), $n$-butyl acrylate 399a $(0.3$ mmol, 3.0 equiv), KI (0.4 mmol, 2.0 equiv), KOAc (0.4 mmol, 2.0 equiv) in $\mathrm{HFIP}(2.0 \mathrm{~mL})$ and $\mathrm{H}_{2} \mathrm{O}$ $(2.0 \mathrm{~mL})$ at $100{ }^{\circ} \mathrm{C}$ for $16 \mathrm{~h}$ at $4.0 \mathrm{~mA}$ of constant current under $\mathrm{N}_{2}$ (Scheme 5.5.14).

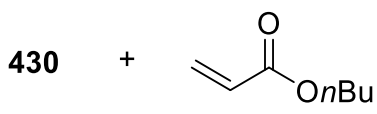

$399 a$

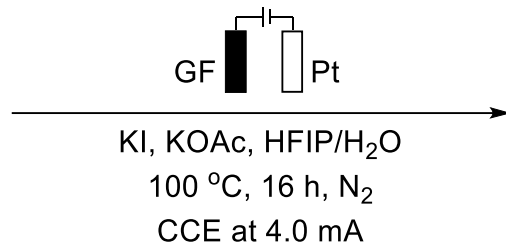

CCE at $4.0 \mathrm{~mA}$

Scheme 5.5.14 Stoichiometric reaction with osmium complex 430 .

2) Procedure for the stoichiometric reaction with $\mathbf{4 3 1}$

The General Procedure E was followed using 431 ( $0.1 \mathrm{mmol}, 1.0$ equiv), KI (0.2 mmol, 2.0 equiv), KOAc $(0.2 \mathrm{mmol}, 2.0$ equiv $)$ in HFIP $(2.0 \mathrm{~mL})$ and $\mathrm{H}_{2} \mathrm{O}(2.0 \mathrm{~mL})$ was stirred at $100{ }^{\circ} \mathrm{C}$ for $16 \mathrm{~h}$ at 4.0 $\mathrm{mA}$ of constant current under $\mathrm{N}_{2}$ (Scheme 5.5.15).

431

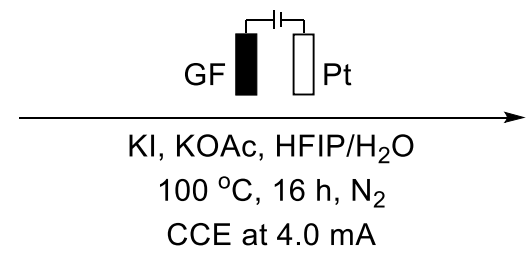

Scheme 5.5.15 Stoichiometric reaction with osmium complex 431 .

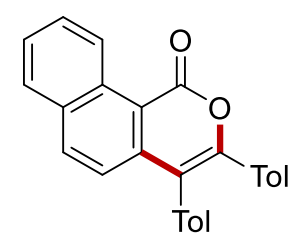

402a: $94 \%$ 
3) Procedure for the stoichiometric reaction with $\mathbf{4 3 1}$

The General Procedure E was followed using 431 ( $0.1 \mathrm{mmol}, 1.0$ equiv), $\mathrm{NaSbF}_{6}(0.2 \mathrm{mmol}, 2.0$ equiv), KOAc (0.2 mmol, 2.0 equiv) in $\operatorname{HFIP}(2.0 \mathrm{~mL})$ and $\mathrm{H}_{2} \mathrm{O}(2.0 \mathrm{~mL})$ was stirred at $100{ }^{\circ} \mathrm{C}$ for 16 $\mathrm{h}$ at $4.0 \mathrm{~mA}$ of constant current under $\mathrm{N}_{2}$ (Scheme 5.5.16).

431
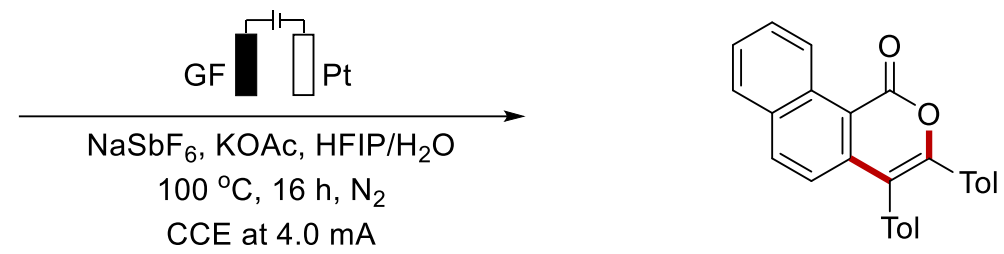

402a: $73 \%$

Scheme 5.5.16 Stoichiometric reaction with osmium complex 431 with $\mathrm{NaSbF}_{6}$.

4) Procedure for the catalytic reaction with $\mathbf{4 3 0}$

The General Procedure D was followed using naphthoic acid 398s ( $0.1 \mathrm{mmol}, 1.0$ equiv), $n$-butyl acrylate 399a ( $0.3 \mathrm{mmol}, 3.0$ equiv), 430 (10 mol \%), KI (0.2 mmol, 2.0 equiv), KOAc (0.2 mmol, 2.0 equiv) in $\mathrm{HFIP}(2.0 \mathrm{~mL})$ and $\mathrm{H}_{2} \mathrm{O}(2.0 \mathrm{~mL})$ at $100{ }^{\circ} \mathrm{C}$ for $16 \mathrm{~h}$ at $4.0 \mathrm{~mA}$ of constant current under $\mathrm{N}_{2}$ (Scheme 5.5.17).

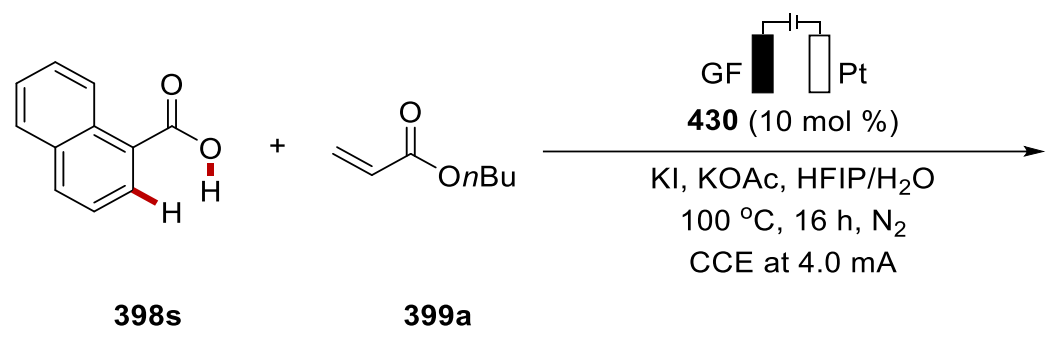

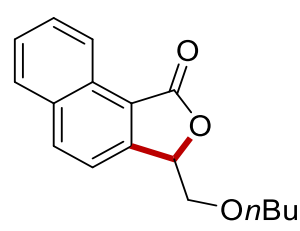

400s: $79 \%$

Scheme 5.5.17 Catalytic reaction with osmium complex 430 . 
5) Procedure for the catalytic reaction with $\mathbf{4 3 0}$

The General Procedure E was followed using naphthoic acid 430 ( $0.1 \mathrm{mmol}, 1.0$ equiv), 1,2-di- $p$ tolylethyne $401 \mathrm{a}(0.3 \mathrm{mmol}, 3.0$ equiv), 430 (10 mol \%), KI ( $0.2 \mathrm{mmol}, 2.0$ equiv), KOAc (0.2 mmol, 2.0 equiv $)$ in $\mathrm{HFIP}(2.0 \mathrm{~mL})$ and $\mathrm{H}_{2} \mathrm{O}(2.0 \mathrm{~mL})$ at $100{ }^{\circ} \mathrm{C}$ for $16 \mathrm{~h}$ at $4.0 \mathrm{~mA}$ of constant current under $\mathrm{N}_{2}$ (Scheme 5.5.18).<smiles>O=Cc1cccc2ccccc12</smiles>

$398 s$<smiles>[Ge]C#C[GeH3]</smiles>

401a

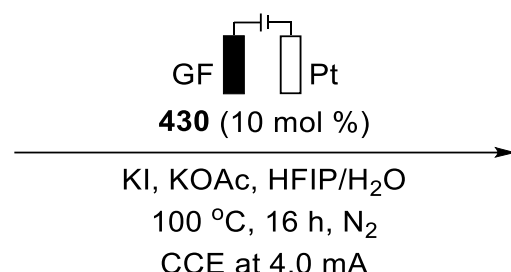

$\mathrm{CCE}$ at $4.0 \mathrm{~mA}$

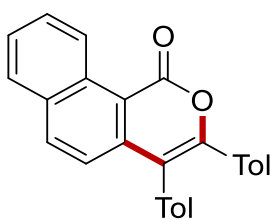

402a: $73 \%$

Scheme 5.5.18 Catalytic reaction with osmium complex 430 . 


\subsubsection{In-Operando NMR and HR-ESI-MS Studies}

In a nitrogen filled glove box, a screw top NMR tube was loaded with $430(0.050 \mathrm{mmol}), \mathbf{4 0 1 a}(0.050$ mmol), (1,3,5-trimethoxybenzene (500 mM stock solution in THF- $\left.\mathrm{d}_{8}, 0.0125 \mathrm{mmol}\right)$, and THF- $\mathrm{d}_{8}$ $(475.0 \mu \mathrm{L})$ (Scheme 5.5.19). An ${ }^{1} \mathrm{H}$ NMR (400 MHz) spectrum of the resulted solution was then obtained. Subsequently, alkyne $(0.050 \mathrm{mmol})$ was added and after homogenization, the progress of the reaction was monitored by ${ }^{1} \mathrm{H}$ NMR $(400 \mathrm{MHz})$ spectroscopy at $45^{\circ} \mathrm{C}$ by collecting spectra every five minutes for a total period of 15 hours ( 18 data points out of the 180 collected spectra are only presented below for clarity, Color legend: $\operatorname{Red}=430$, Blue $=431$, Green $=401 a)$.

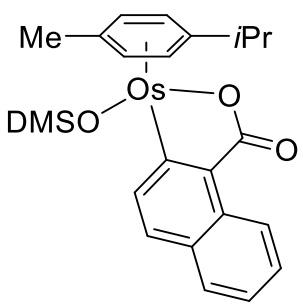

430

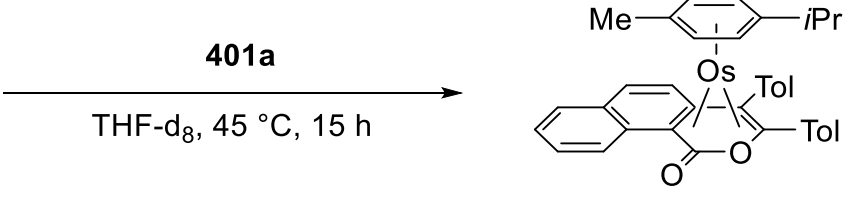

431

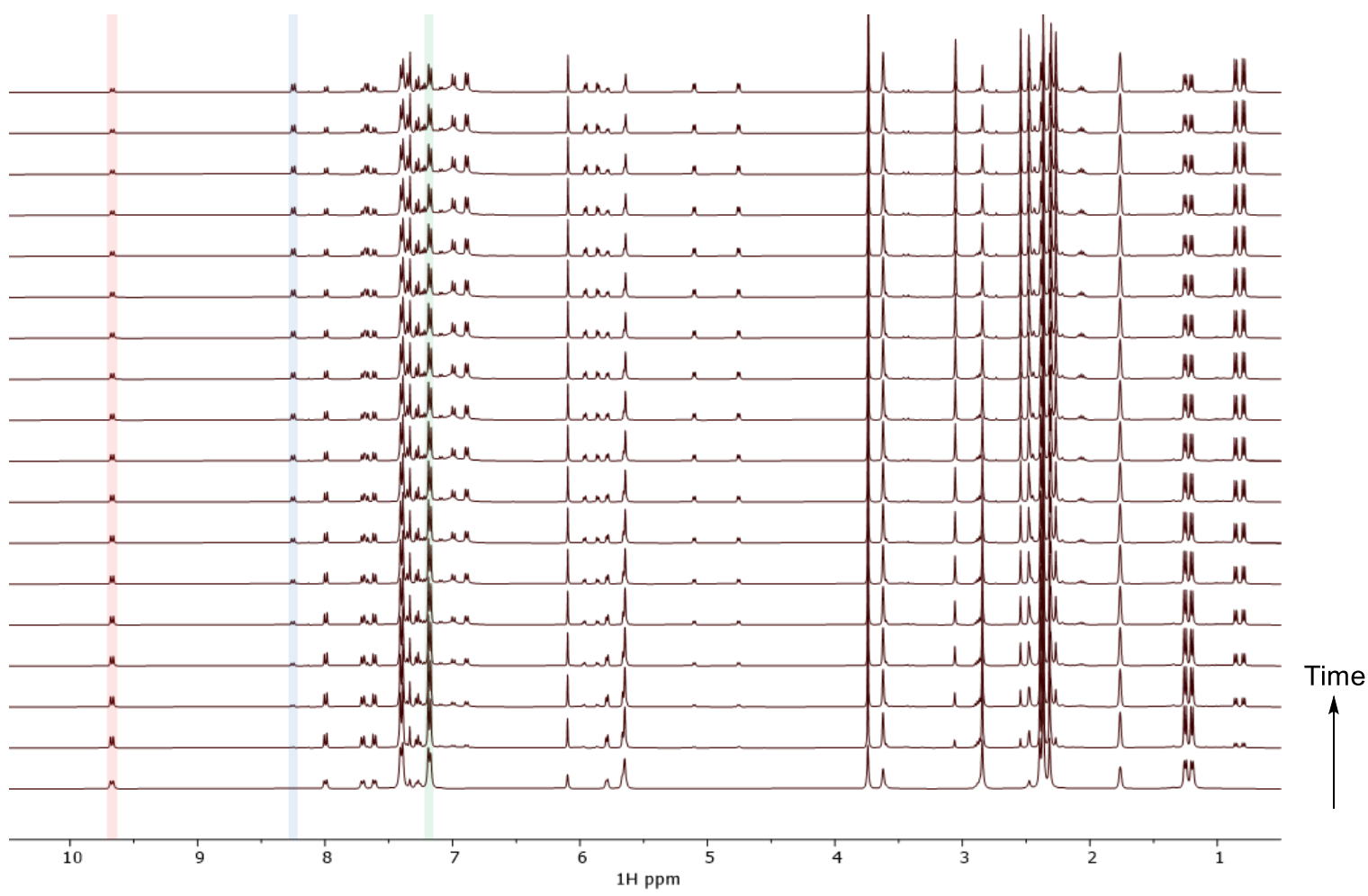

Scheme 5.5.19 In-operando NMR study. 
The General Procedure E was followed using naphthoic acid 398s (0.1 mmol), 1,2-di- $p$-tolylethyne 401a (3.0 equiv), $\left[\mathrm{OsCl}_{2}(p \text {-cymene) }]_{2}(5.0 \mathrm{~mol} \%), \mathrm{KI}(66.4 \mathrm{mg}, 2.0\right.$ equiv), $\mathrm{KOAc}(39.3 \mathrm{mg}, 2.0$ equiv) in HFIP $(2.0 \mathrm{~mL})$ and $\mathrm{H}_{2} \mathrm{O}(2.0 \mathrm{~mL})$ under $\mathrm{N}_{2}$ (Scheme 5.5.20). The reaction mixture was then left to stir at $100{ }^{\circ} \mathrm{C}$ for 1 minutes at which time a sample $\left(\mathrm{t}_{0}\right)$ was collected and analyzed by HR-ESIMS. Subsequently, the reaction was initiated by passing a constant current of $4.0 \mathrm{~mA}$ through the reaction mixture followed by sampling at time intervals for a total length of $425 \mathrm{~min}$. Each aliquot collected $(\sim 0.1 \mathrm{~mL})$ was passed through a pipette filled with $\mathrm{Na}_{2} \mathrm{SO}_{4}$ and diluted with THF prior to analysis.

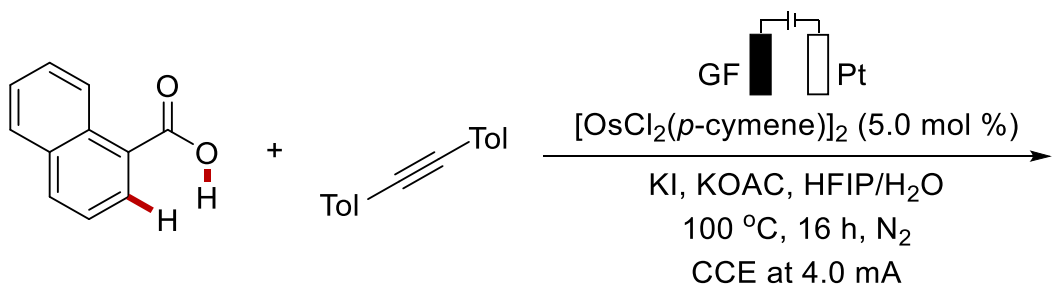

$398 s$

$401 \mathrm{a}$<smiles>O=c1oc(Cl)c(Br)c2ccc3ccccc3c12</smiles>

402a

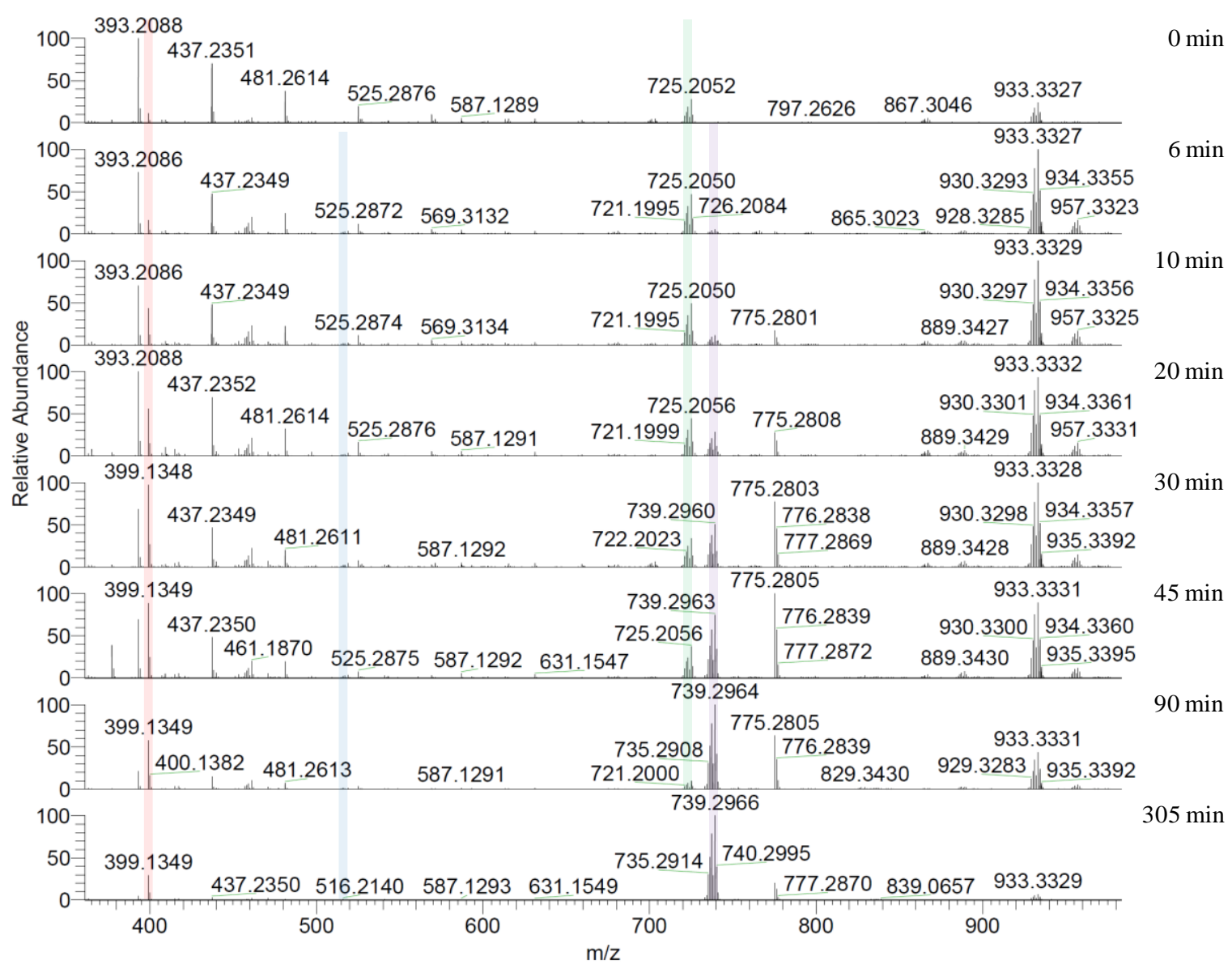

Scheme 5.5.20 HR-ESI-MS study. 


\subsubsection{Competition Experiment}

1) Procedure for competition experiment (1)

The General Procedure D was followed using 3-methyl benzoic acid 398e (0.1 mmol, 1.0 equiv), 3 trifluoromethyl benzoic acid 398h ( $0.1 \mathrm{mmol}, 1.0$ equiv), $n$-butyl acrylate 399a ( $0.3 \mathrm{mmol}, 3.0$ equiv), $\left[\mathrm{OsCl}_{2}(p \text {-cymene })\right]_{2}(5.0 \mathrm{~mol} \%), \mathrm{KI}(0.2 \mathrm{mmol}, 2.0$ equiv), KOAc $(0.2 \mathrm{mmol}, 2.0$ equiv $)$ in $\mathrm{HFIP}(2.0$ $\mathrm{mL})$ and $\mathrm{H}_{2} \mathrm{O}(2.0 \mathrm{~mL})$ at $100{ }^{\circ} \mathrm{C}$ for $4 \mathrm{~h}$ at $4.0 \mathrm{~mA}$ of constant current under $\mathrm{N}_{2}$ (Scheme 5.5.21). After cooling to ambient temperature, the electrodes were washed with ethyl acetate $(3 \times 10 \mathrm{~mL})$. The reaction mixtures were extracted with brine $(20 \mathrm{~mL})$, dried over $\mathrm{Na}_{2} \mathrm{SO}_{4}$, and concentrated under reduced pressure. The crude mixture was analyzed by ${ }^{1} \mathrm{H}$ NMR with $\mathrm{CH}_{2} \mathrm{Br}_{2}$ as the internal standard.<smiles>CC(F)(F)c1cccc(C(=O)O)c1</smiles>

$398 \mathrm{e} / 398 \mathrm{~h}$

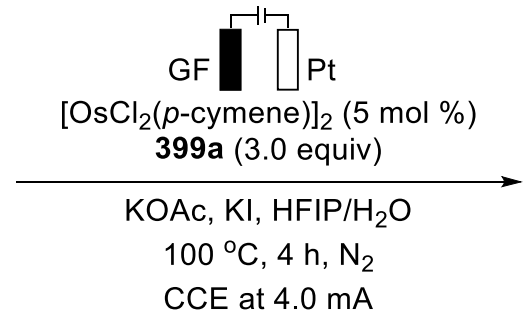

CCE at $4.0 \mathrm{~mA}$

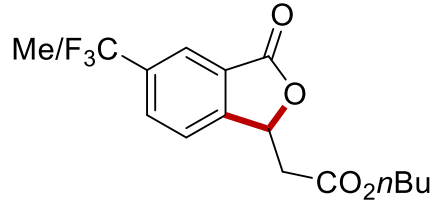

400e/400h: $14 \% / 26 \%$

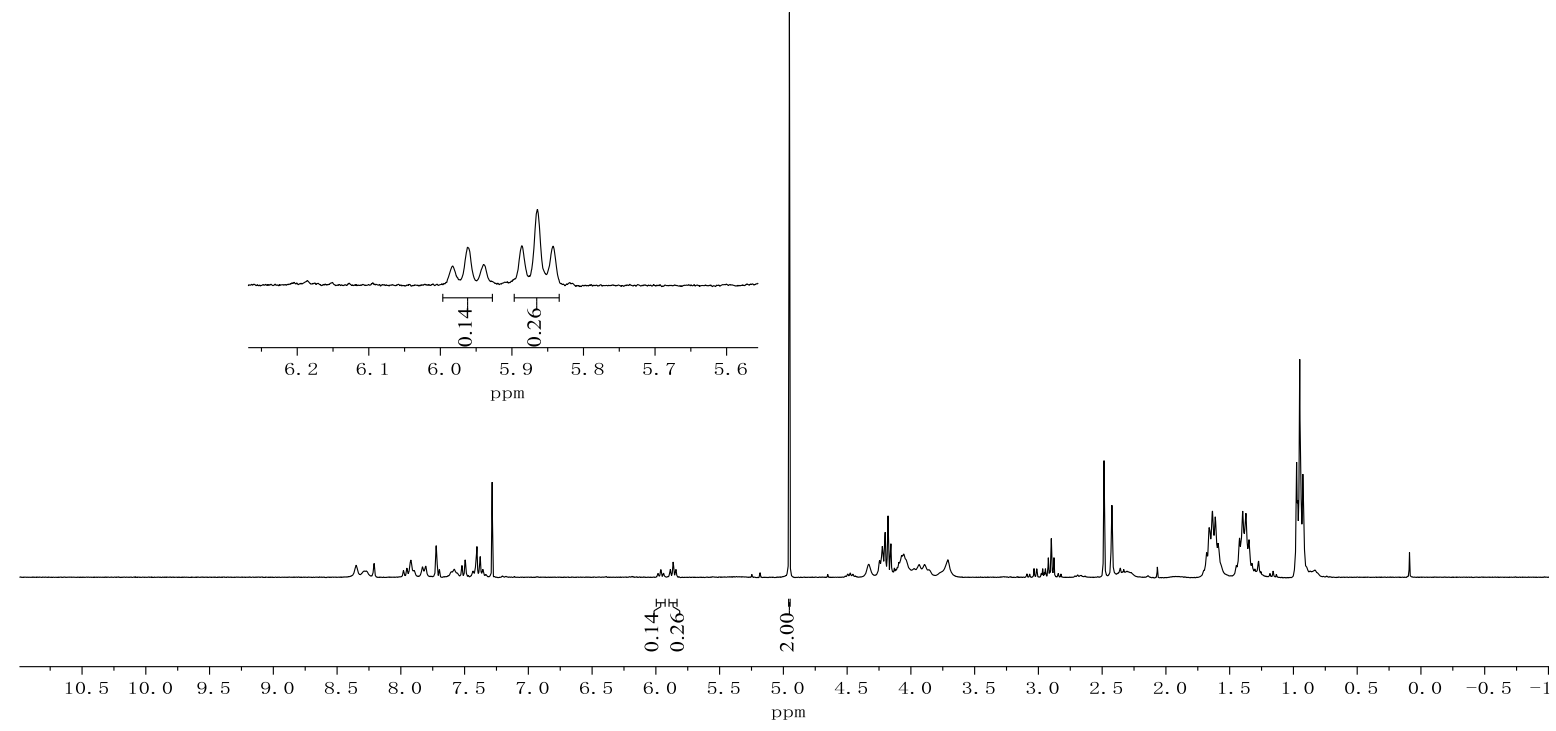

Scheme 5.5.21 Competition experiment with 398e and 398h. 
2) Procedure for competition experiment (2)

The General Procedure E was followed using naphthoic acid 398s (0.20 mmol, 1.0 equiv), 1,2-di- $p$ tolylethyne 401a ( $0.20 \mathrm{mmol}, 1.0$ equiv), 1,2-bis(4-fluorophenyl)ethyne 401d ( $0.20 \mathrm{mmol}, 1.0$ equiv), $\left[\mathrm{OsCl}_{2}(p \text {-cymene })\right]_{2}(5.0 \mathrm{~mol} \%), \mathrm{KI}(0.40 \mathrm{mmol}, 2.0$ equiv $), \mathrm{KOAc}(0.40 \mathrm{mmol}, 2.0$ equiv $)$ in HFIP (2.0 mL) and $\mathrm{H}_{2} \mathrm{O}(2.0 \mathrm{~mL})$ at $100{ }^{\circ} \mathrm{C}$ for $4 \mathrm{~h}$ at $4.0 \mathrm{~mA}$ of constant current under $\mathrm{N}_{2}$ (Scheme 5.5.22). After cooling to ambient temperature, the electrodes were washed with ethyl acetate $(3 \times 10 \mathrm{~mL})$. The reaction mixture was extracted with brine $(20 \mathrm{~mL})$, dried over $\mathrm{Na}_{2} \mathrm{SO}_{4}$, and concentrated under reduced pressure. The crude mixture was analyzed by ${ }^{1} \mathrm{H}$ NMR with $\mathrm{CH}_{2} \mathrm{Br}_{2}$ as the internal standard.

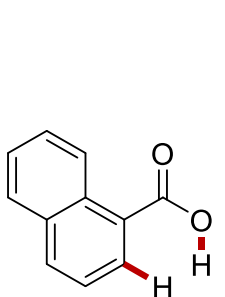

$398 \mathrm{~s}$

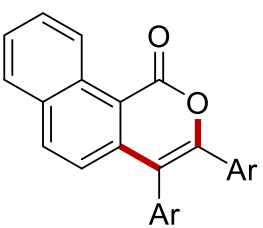

402a/402d: $24 \% / 42 \%$

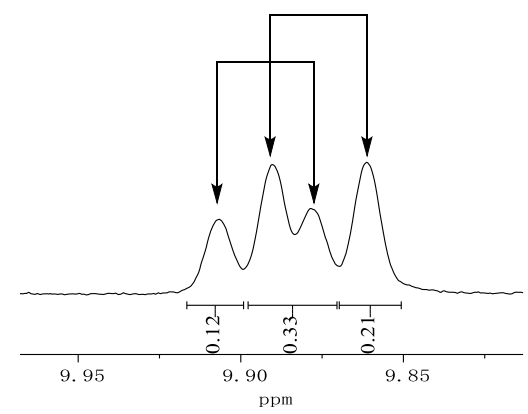

$100^{\circ} \mathrm{C}, 4 \mathrm{~h}, \mathrm{~N}_{2}$

CCE at $4.0 \mathrm{~mA}$

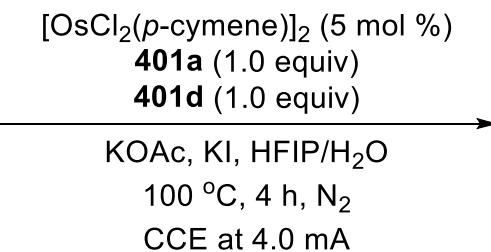




\subsubsection{Hammett Correlation}

A series of reactions were performed with different substrates under standard reaction conditions (Scheme 5.5.23).

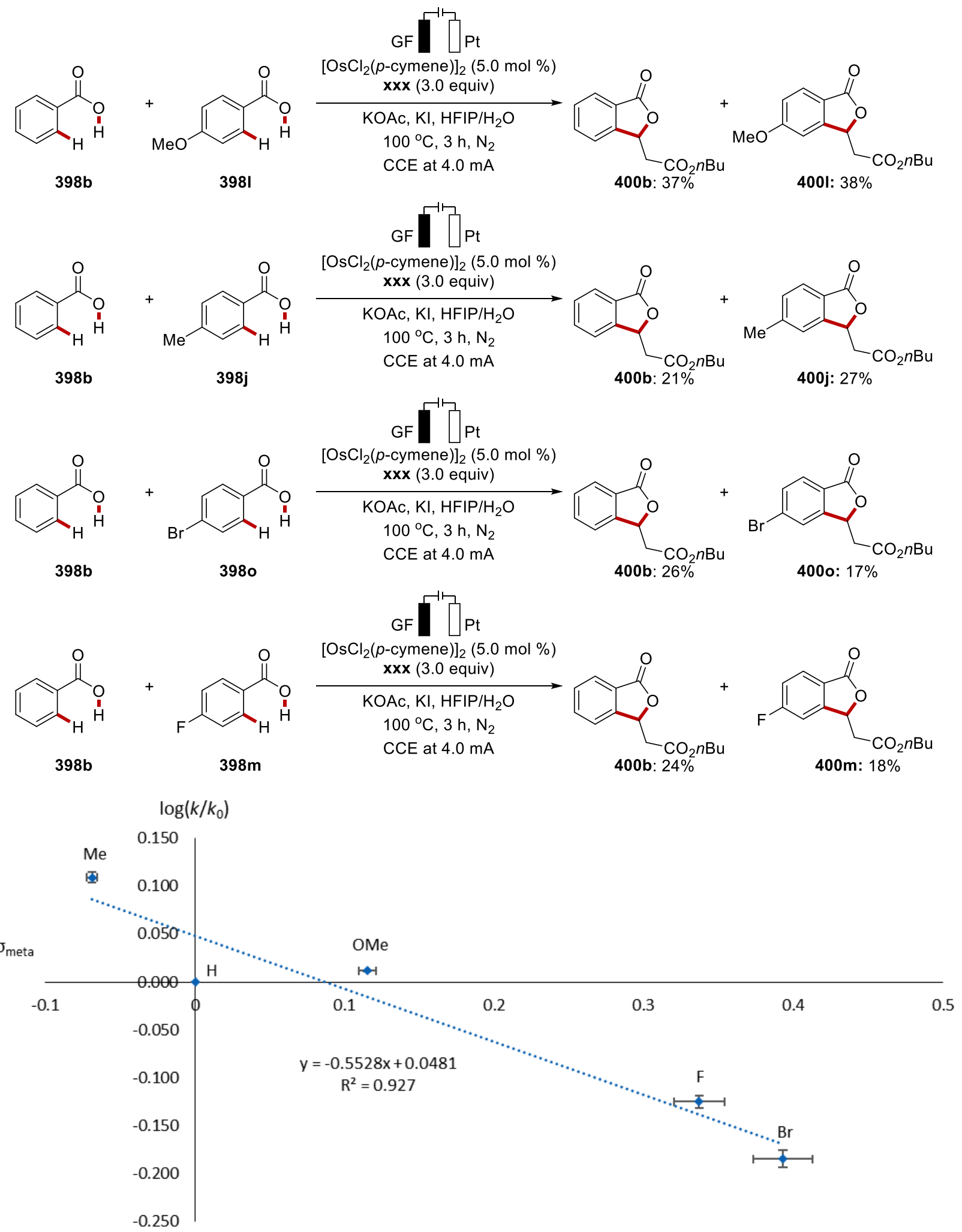

Scheme 5.5.23 Hammett correlarion plot. 


\subsubsection{KIE Study}

1) Procedure for KIE study (Intermolecular competition reaction)

The General Procedure D was followed using 398a ( $0.1 \mathrm{mmol}, 1.0$ equiv), [D]7-398a (0.1 mmol, 1.0 equiv), $n$-butyl acrylate 399a (0.3 mmol, 3.0 equiv), $\left[\mathrm{OsCl}_{2}(p \text {-cymene })\right]_{2}(5.0 \mathrm{~mol} \%), \mathrm{KI}(0.2 \mathrm{mmol}$, 2.0 equiv), KOAc (39.3 mg, 2.0 equiv) in $\operatorname{HFIP}(2.0 \mathrm{~mL})$ and $\mathrm{H}_{2} \mathrm{O}(2.0 \mathrm{~mL})$ at $100{ }^{\circ} \mathrm{C}$ for $16 \mathrm{~h}$ at 4.0 $\mathrm{mA}$ of constant current under $\mathrm{N}_{2}$ (Scheme 5.5.24).

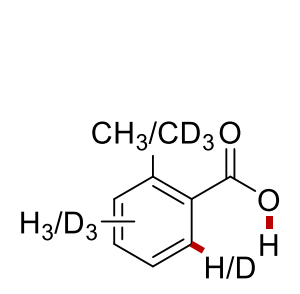

$398 a$ and $[D]_{7}-398 a$

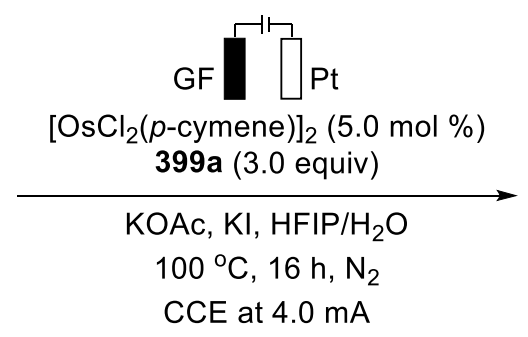

KIE $=1.1$

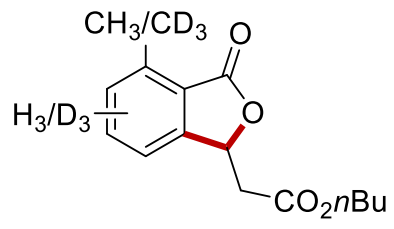

400a and $[D]_{n}-400 a: 71 \%$

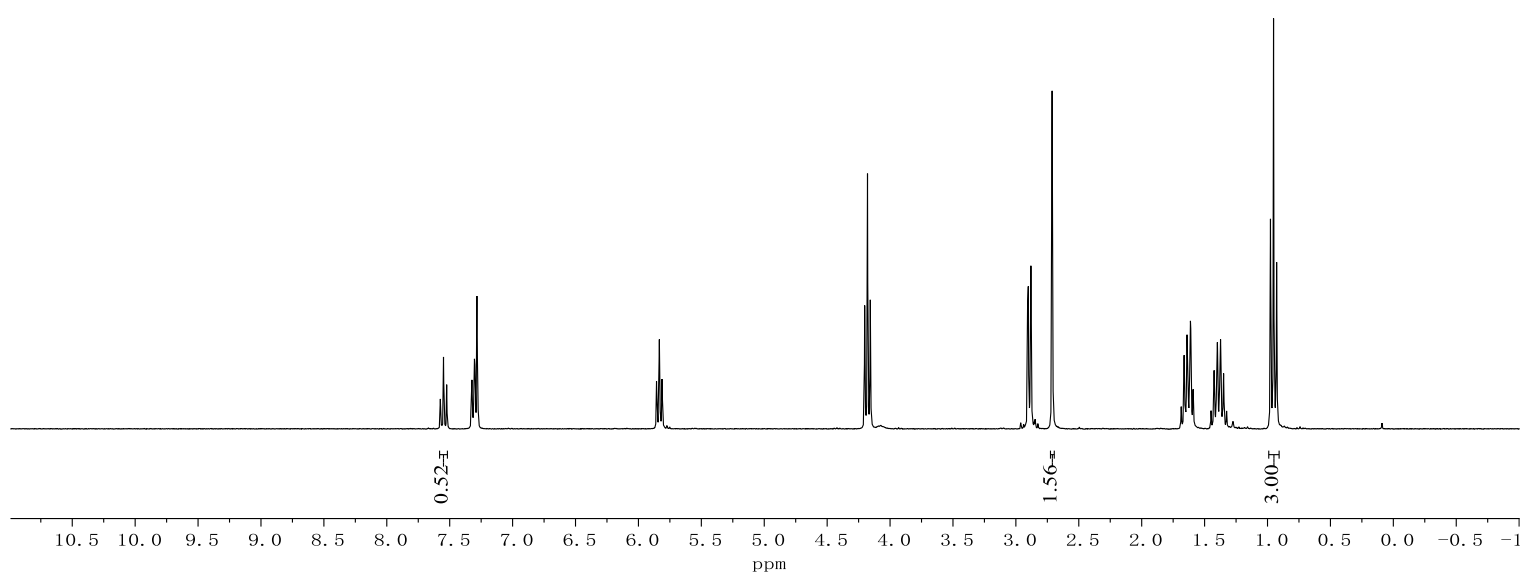

Scheme 5.5.24 Intermolecular kinetic isotope exchange. Note: $\mathrm{CH}_{3}$ of aromatic and $\mathrm{CH}_{3}$ of butyl group should be compared. Other $\mathrm{C}-\mathrm{H}$ bonds were isotopically labelled by post-catalysis $\mathrm{H} / \mathrm{D}$ exchange (Scheme 5.5.25). 

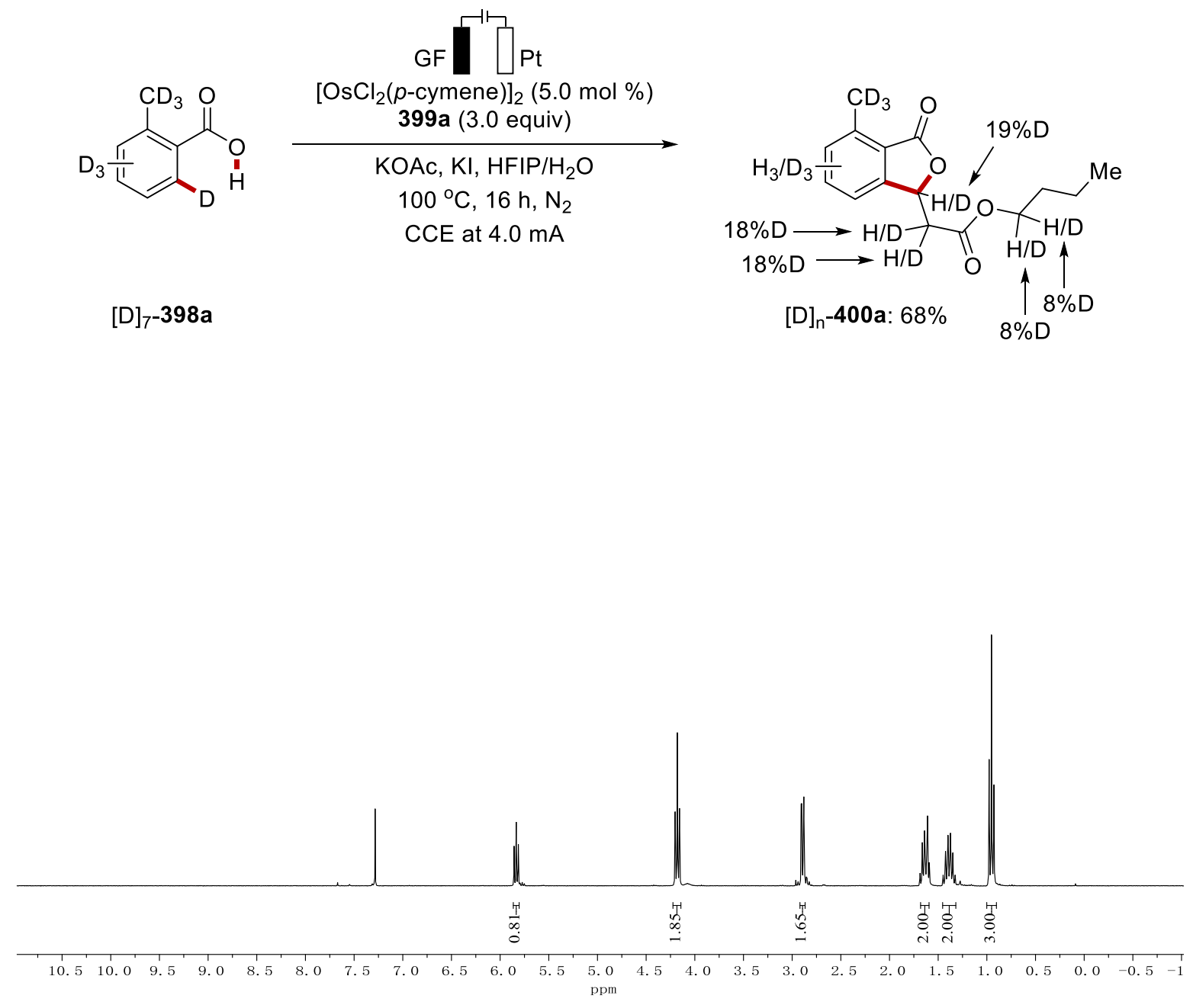

Scheme 5.5.25 H/D exchange study of $[D]_{7-398 a}$ 
2) Procedure for KIE study (Two parallel reactions)

The General Procedure D was followed for four independent reactions using substrate 398a $(0.20$ mmol) $n$-butyl acrylate 399a (3.0 equiv), and another four independent reactions using substrate [D]7398a $(0.20 \mathrm{mmol})$ and $n$-butyl acrylate 399a (3.0 equiv) for specified reaction time (30 min, $60 \mathrm{~min}$, $90 \mathrm{~min}$, and $120 \mathrm{~min}$ ). The crude mixture was dried in vacuo for $6 \mathrm{~h}$ and analyzed by ${ }^{1} \mathrm{H}$ NMR with $\mathrm{CH}_{2} \mathrm{Br}_{2}$ as the internal standard (Scheme 5.5.26). Blue line is for 400a and red line is for $[\mathrm{D}]_{\mathrm{n}}-\mathbf{4 0 0 a}$.
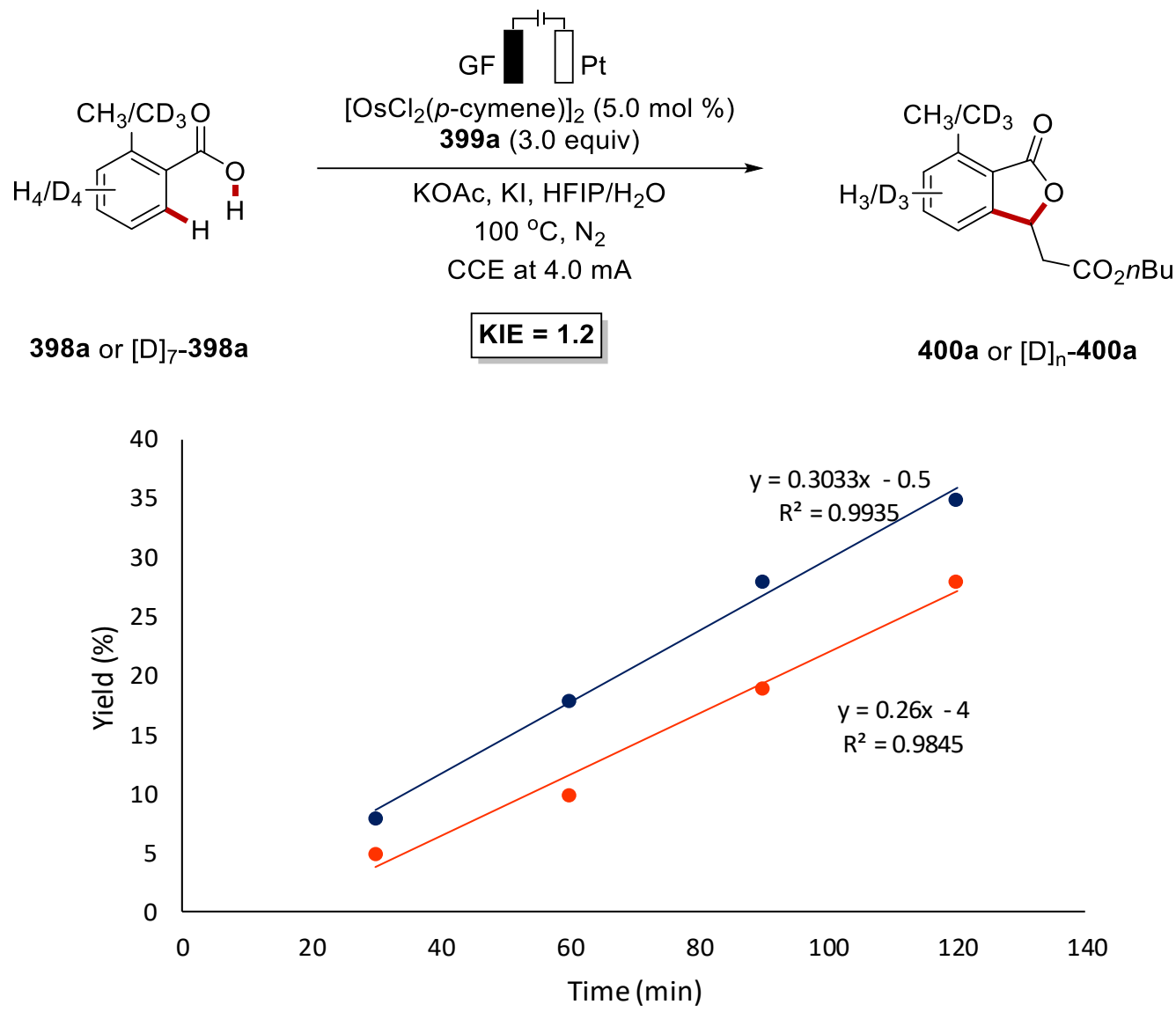

Scheme 5.5.26 Parallel kinetic isotope exchange study. 


\subsubsection{Crystallographic Information}

X-ray diffraction experiments for all of the compounds were carried out at 100(2) K on a Bruker D8 Venture four-circle-diffractometer from Bruker AXS GmbH equipped with a Photon II detector purchased from Bruker AXS GmbH and using microfocus $\mathrm{I} \mu \mathrm{S} \mathrm{Cu} / \mathrm{Mo}$ radiation from Incoatec $\mathrm{GmbH}$ with HELIOS mirror optics and single-hole collimator from Bruker AXS GmbH. Intensities were integrated and absorption corrections based on equivalent reflections were applied using SADABS. The structures were all solved using SHELXT ${ }^{[287]}$ and refined against all F2 in SHELXL using Olex 2. All of the non-hydrogen atoms were refined anisotropically while the carbon bond hydrogen atoms were located geometrically and refined using a riding model. Crystal structure and refinement data are given in Table 5.5.2, 5.5.3, and 5.5.4. Crystallographic data for the compounds have been deposited with the Cambridge Crystallographic Data Centre as supplementary publication CCDC 2085919, 2085920 and 2085921.

Table 5.5.2 Crystal data and structure refinement for $\mathrm{OsCl}(\mathrm{Me})(\mathrm{DMSO})(p$-cymene) (428).

Compound

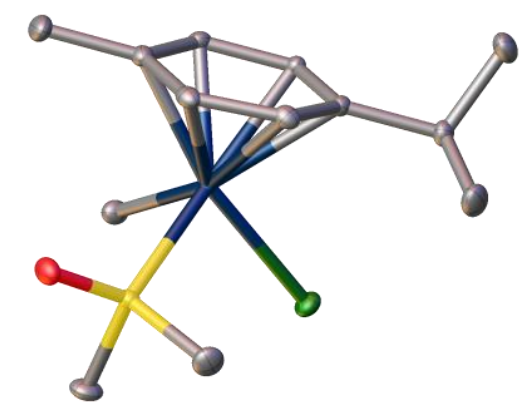

OsCl(Me)(DMSO)(p-cymene) (428)

Empirical formula

Formula weight

Temperature/K

Crystal system

Space group

$\mathrm{a} / \AA$

$\mathrm{b} / \AA$

$\mathrm{c} / \AA$
$\mathrm{C}_{13} \mathrm{H}_{23} \mathrm{ClOOsS}$

453.02

100

monoclinic

$\mathrm{Cc}$

$11.2960(8)$

$15.1437(12)$

$9.2214(8)$ 


\begin{tabular}{|c|c|}
\hline$\alpha /^{\circ}$ & 90 \\
\hline$\beta /{ }^{\circ}$ & $106.298(3)$ \\
\hline$\gamma /{ }^{\circ}$ & 90 \\
\hline Volume $/ \AA^{3}$ & $1514.1(2)$ \\
\hline $\mathrm{Z}$ & 4 \\
\hline$\rho_{\text {calc }} \mathrm{g} / \mathrm{cm}^{3}$ & 1.987 \\
\hline$\mu / \mathrm{mm}^{-1}$ & 4.684 \\
\hline $\mathrm{F}(000)$ & 872 \\
\hline Crystal size $/ \mathrm{mm}^{3}$ & $0.151 \times 0.113 \times 0.1$ \\
\hline Radiation & $\operatorname{AgK} \alpha(\lambda=0.56086)$ \\
\hline $2 \Theta$ range for data collection $/{ }^{\circ}$ & 4.244 to 57.874 \\
\hline Index ranges & $-19 \leq \mathrm{h} \leq 19,-25 \leq \mathrm{k} \leq 26,-15 \leq 1 \leq 15$ \\
\hline Reflections collected & 39100 \\
\hline Independent reflections & $7428\left[\mathrm{R}_{\text {int }}=0.0237, \mathrm{R}_{\text {sigma }}=0.0182\right]$ \\
\hline Data/restraints/parameters & $7428 / 71 / 160$ \\
\hline Goodness-of-fit on $\mathrm{F}^{2}$ & 1.116 \\
\hline Final $R$ indexes $[\mathrm{I}>=2 \sigma(\mathrm{I})]$ & $\mathrm{R}_{1}=0.0138, \mathrm{wR}_{2}=0.0311$ \\
\hline Final $\mathrm{R}$ indexes [all data] & $\mathrm{R}_{1}=0.0146, \mathrm{wR}_{2}=0.0322$ \\
\hline Largest diff. peak/hole / e $\AA^{-3}$ & $2.18 /-1.44$ \\
\hline
\end{tabular}


Table 5.5.4 Crystal data and structure refinement for $\mathbf{4 3 0}$.

\section{Compound}

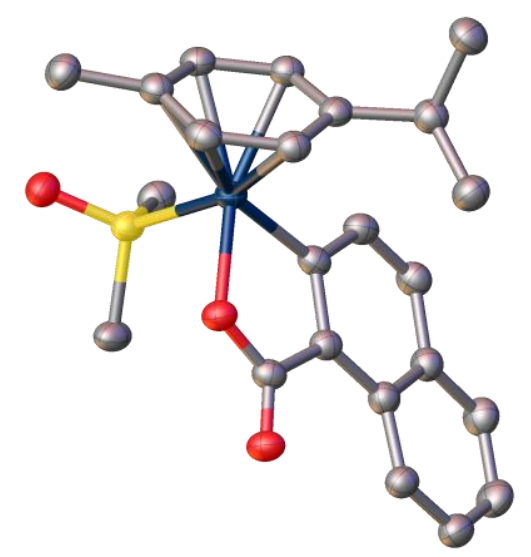

430

\section{Empirical formula}

Formula weight

Temperature/K

Crystal system

Space group

$\mathrm{a} / \AA$

$\mathrm{b} / \AA$

$\mathrm{c} / \AA$

$\alpha /{ }^{\circ}$

$\beta /{ }^{\circ}$

$\gamma /{ }^{\circ}$

Volume $/ \AA^{3}$

Z

$\rho_{\text {calc }} \mathrm{g} / \mathrm{cm}^{3}$

$\mu / \mathrm{mm}^{-1}$

$\mathrm{F}(000)$

Crystal size $/ \mathrm{mm}^{3}$

Radiation

$2 \Theta$ range for data collection ${ }^{\circ}$
$\mathrm{C}_{29} \mathrm{H}_{38} \mathrm{O}_{4.5} \mathrm{OsS}$

680.85

100

monoclinic

$\mathrm{C} 2 / \mathrm{c}$

26.302(3)

14.0767(14)

15.6684(13)

90

113.083(3)

90

5336.6(9)

8

1.695

4.892

2720

$0.121 \times 0.061 \times 0.029$

$\operatorname{MoK} \alpha(\lambda=0.71073)$

5.326 to 61.174 
Index ranges

Reflections collected

Independent reflections

Data/restraints/parameters

Goodness-of-fit on $\mathrm{F}^{2}$

Final $\mathrm{R}$ indexes $[\mathrm{I}>=2 \sigma(\mathrm{I})]$

Final $\mathrm{R}$ indexes [all data]

Largest diff. peak/hole / e $\AA^{-3}$
$-37 \leq \mathrm{h} \leq 37,-20 \leq \mathrm{k} \leq 20,-22 \leq 1 \leq 22$

83356

$8195\left[\mathrm{R}_{\text {int }}=0.0394, \mathrm{R}_{\text {sigma }}=0.0191\right]$

$8195 / 0 / 258$

1.046

$\mathrm{R}_{1}=0.0309, \mathrm{wR}_{2}=0.0793$

$\mathrm{R}_{1}=0.0356, \mathrm{wR}_{2}=0.0824$

$2.22 /-0.60$

Table 5.5.5 Crystal data and structure refinement for 431 .

\section{Compound}

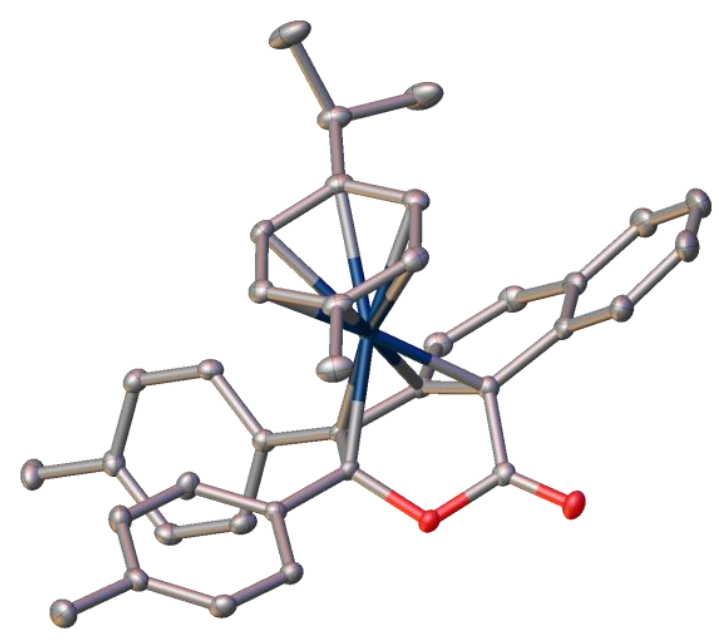

431

Empirical formula

Formula weight

Temperature/K

Crystal system

Space group

$\mathrm{a} / \AA$

$\mathrm{b} / \AA$

$\mathrm{c} / \AA$

$\alpha /{ }^{\circ}$

\section{$\mathrm{C}_{37} \mathrm{H}_{34} \mathrm{O}_{2} \mathrm{Os}$}

700.84

100

monoclinic

$\mathrm{P} 2{ }_{1} / \mathrm{n}$

$16.0104(13)$

11.3652(9)

$16.2343(13)$

90 
$\beta /{ }^{\circ}$

$108.231(2)$

$\gamma /{ }^{\circ}$

90

Volume $/ \AA^{3}$

2805.7(4)

Z

4

$\rho_{\text {calc }} \mathrm{g} / \mathrm{cm}^{3}$

1.659

$\mu / \mathrm{mm}^{-1}$

4.578

$\mathrm{F}(000)$

1392

Crystal size $/ \mathrm{mm}^{3}$

$0.123 \times 0.09 \times 0.045$

Radiation

$\operatorname{MoK} \alpha(\lambda=0.71073)$

$2 \Theta$ range for data collection $/{ }^{\circ}$

4.31 to 61.158

Index ranges

$-22 \leq \mathrm{h} \leq 22,-16 \leq \mathrm{k} \leq 16,-23 \leq 1 \leq 23$

Reflections collected

84089

Independent reflections

$8602\left[\mathrm{R}_{\text {int }}=0.0424, \mathrm{R}_{\text {sigma }}=0.0221\right]$

Data/restraints/parameters

$8602 / 0 / 366$

Goodness-of-fit on $\mathrm{F}^{2}$

1.041

Final R indexes $[\mathrm{I}>=2 \sigma(\mathrm{I})]$

$\mathrm{R}_{1}=0.0189, \mathrm{wR}_{2}=0.0375$

Final $\mathrm{R}$ indexes [all data]

$\mathrm{R}_{1}=0.0248, \mathrm{wR}_{2}=0.0395$

Largest diff. peak/hole / e $\AA^{-3}$

$0.75 /-0.57$ 


\subsection{Photo-Induced C-H Arylation by Reusable Heterogeneous Copper Catalyst}

\subsubsection{Characterization Data}

\section{2-(p-Tolyl)benzo $[d]$ thiazole (405a)}

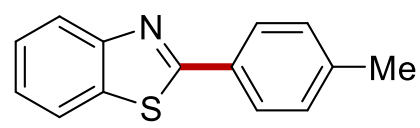

1) The General Procedure $\mathbf{F}$ was followed using benzothiazole 403a (34 mg, $0.25 \mathrm{mmol}$ ), 4iodotoluene 404a (273 mg, $1.25 \mathrm{mmol}), 406(30 \mathrm{mg}, 11 \mathrm{~mol} \%)$ and $\mathrm{LiO} t \mathrm{Bu}(60 \mathrm{mg}, 0.75 \mathrm{mmol})$ in $\mathrm{Et}_{2} \mathrm{O}(0.5 \mathrm{~mL})$. Purification by column chromatography on silica gel ( $n$-hexane/EtOAc: $\left.70 / 1\right)$ yielded 405a (52.4 mg, 93\%) as a light yellow solid.

2) The General Procedure $\mathbf{H}$ was followed using benzothiazole 403a (34 mg, $0.25 \mathrm{mmol}$ ), 4bromotoluene 447a (273 mg, $1.25 \mathrm{mmol}), 406(30 \mathrm{mg}, 11 \mathrm{~mol} \%)$ and $\mathrm{Cs}_{2} \mathrm{CO}_{3}(244 \mathrm{mg}, 0.75 \mathrm{mmol})$ in $\mathrm{Et}_{2} \mathrm{O}(0.5 \mathrm{~mL})$. Purification by column chromatography on silica gel ( $n$-hexane/EtOAc: $\left.70 / 1\right)$ yielded 405a (28.7 $\mathrm{mg}, 51 \%)$ as a light yellow solid.

M. p.: $86^{\circ} \mathrm{C}$.

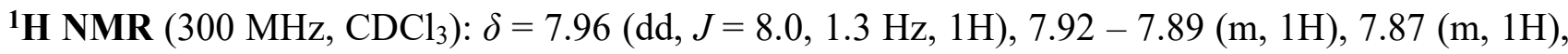
$7.78(\mathrm{dd}, J=8.0,1.3 \mathrm{~Hz}, 1 \mathrm{H}), 7.38(\mathrm{ddd}, J=8.0,7.2,1.3 \mathrm{~Hz}, 1 \mathrm{H}), 7.26(\mathrm{ddd}, J=8.0,7.2,1.3 \mathrm{~Hz}, 1 \mathrm{H})$, $7.22-7.19(\mathrm{~m}, 1 \mathrm{H}), 7.19-7.16(\mathrm{~m}, 1 \mathrm{H}), 2.32(\mathrm{~s}, 3 \mathrm{H})$.

${ }^{13} \mathrm{C}$ NMR $\left(75 \mathrm{MHz}, \mathrm{CDCl}_{3}\right): \delta=168.0\left(\mathrm{C}_{\mathrm{q}}\right), 154.0\left(\mathrm{C}_{\mathrm{q}}\right), 141.2\left(\mathrm{C}_{\mathrm{q}}\right), 134.8\left(\mathrm{C}_{\mathrm{q}}\right), 130.8\left(\mathrm{C}_{\mathrm{q}}\right), 129.6(\mathrm{CH})$, $127.4(\mathrm{CH}), 126.1(\mathrm{CH}), 124.9(\mathrm{CH}), 122.9(\mathrm{CH}), 121.4(\mathrm{CH}), 21.5\left(\mathrm{CH}_{3}\right)$.

IR (ATR): 3024, 2918, 1611, $1445,1074,816,756,691,485,434 \mathrm{~cm}^{-1}$.

MS (ESI) $m / z$ (relative intensity): $226(100)[\mathrm{M}+\mathrm{H}]^{+}, 248(60)[\mathrm{M}+\mathrm{Na}]^{+}$.

HR-MS (ESI): $m / z$ calcd for $\mathrm{C}_{14} \mathrm{H}_{12} \mathrm{NS}[\mathrm{M}+\mathrm{H}]^{+}: 226.0688$, found: 226.0688 .

The spectral data were in accordance with those reported in the literature. ${ }^{[94]}$

\section{2-Phenylbenzo[d] thiazole (405b)}

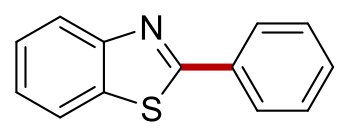

1) The General Procedure F was followed using benzothiazole 403a (34 mg, $0.25 \mathrm{mmol}$ ), 
iodobenzene 404b (255 mg, $1.25 \mathrm{mmol}), 406(30 \mathrm{mg}, 11 \mathrm{~mol} \%)$ and $\mathrm{LiO} t \mathrm{Bu}(60 \mathrm{mg}, 0.75 \mathrm{mmol})$ in $\mathrm{Et}_{2} \mathrm{O}(0.5 \mathrm{~mL})$. Purification by column chromatography on silica gel ( $n$-hexane/EtOAc: $\left.70 / 1\right)$ yielded 405b (49.7 mg, 94\%) as a light yellow solid.

2) The General Procedure $\mathbf{H}$ was followed using benzothiazole 403a (34 $\mathrm{mg}, 0.25 \mathrm{mmol}$ ), bromobenzene 447b (255 mg, $1.25 \mathrm{mmol}), 406$ (30 mg, $11 \mathrm{~mol} \%$ ) and $\mathrm{Cs}_{2} \mathrm{CO}_{3}(244 \mathrm{mg}, 0.75 \mathrm{mmol})$ in $\mathrm{Et}_{2} \mathrm{O}(0.5 \mathrm{~mL})$. Purification by column chromatography on silica gel ( $n$-hexane/EtOAc: $\left.70 / 1\right)$ yielded 405b (31.2 mg, 59\%) as a light yellow solid.

M. p.: $115^{\circ} \mathrm{C}$.

${ }^{1} \mathbf{H}$ NMR $\left(500 \mathrm{MHz}, \mathrm{CDCl}_{3}\right): \delta=8.11-8.04(\mathrm{~m}, 3 \mathrm{H}), 7.90-7.85(\mathrm{~m}, 1 \mathrm{H}), 7.51-7.44(\mathrm{~m}, 4 \mathrm{H}), 7.37$ (ddd, $J=8.3,7.2,1.2 \mathrm{~Hz}, 1 \mathrm{H})$.

${ }^{13} \mathrm{C}$ NMR $\left(125 \mathrm{MHz}, \mathrm{CDCl}_{3}\right): \delta=168.0\left(\mathrm{C}_{\mathrm{q}}\right), 154.1\left(\mathrm{C}_{\mathrm{q}}\right), 135.0\left(\mathrm{C}_{\mathrm{q}}\right), 133.5\left(\mathrm{C}_{\mathrm{q}}\right), 130.9(\mathrm{CH}), 128.9$ $(\mathrm{CH}), 127.5(\mathrm{CH}), 126.2(\mathrm{CH}), 125.1(\mathrm{CH}), 123.2(\mathrm{CH}), 121.5(\mathrm{CH})$.

IR (ATR): 3016, 1510, 1478, 1433, 1313, 1252, 1215, 963, 918, $750 \mathrm{~cm}^{-1}$.

MS (ESI) $m / z$ (relative intensity): $212(100)[\mathrm{M}+\mathrm{H}]^{+}$.

HR-MS (ESI): $m / z$ calcd for $\mathrm{C}_{13} \mathrm{H}_{10} \mathrm{NS}[\mathrm{M}+\mathrm{H}]^{+}: 212.0530$, found: 212.0528 .

The spectral data were in accordance with those reported in the literature. ${ }^{[94]}$

\section{2-(4-Methoxyphenyl)benzo[d] thiazole (405c)}

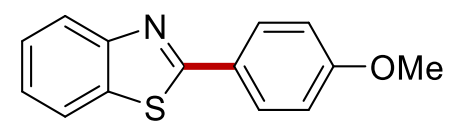

1) The General Procedure $\mathbf{F}$ was followed using benzothiazole 403a (34 mg, $0.25 \mathrm{mmol}$ ), 4iodoanisole 404c (293 mg, $1.25 \mathrm{mmol}), 406(30 \mathrm{mg}, 11 \mathrm{~mol} \%)$ and $\mathrm{LiO} t \mathrm{Bu}(60 \mathrm{mg}, 0.75 \mathrm{mmol})$ in $\mathrm{Et}_{2} \mathrm{O}(0.5 \mathrm{~mL})$. Purification by column chromatography on silica gel ( $n$-hexane/EtOAc: $\left.70 / 1\right)$ yielded 405c (47.7 mg, 79\%) as a light yellow solid.

2) The General Procedure $\mathbf{H}$ was followed using benzothiazole 403a (34 mg, $0.25 \mathrm{mmol}$ ), 4 bromoanisole 447c (293 mg, $1.25 \mathrm{mmol}), 406$ (30 mg, $11 \mathrm{~mol} \%)$ and $\mathrm{Cs}_{2} \mathrm{CO}_{3}(244 \mathrm{mg}, 0.75 \mathrm{mmol})$ in $\mathrm{Et}_{2} \mathrm{O}(0.5 \mathrm{~mL})$. Purification by column chromatography on silica gel ( $n$-hexane/EtOAc: $\left.70 / 1\right)$ yielded $405 \mathrm{c}(25.9 \mathrm{mg}, 43 \%)$ as a light yellow solid. 
M. p.: $134^{\circ} \mathrm{C}$.

${ }^{1}$ H NMR (400 MHz, $\left.\mathrm{CDCl}_{3}\right): \delta=8.04-7.98(\mathrm{~m}, 3 \mathrm{H}), 7.86(\mathrm{ddd}, J=8.0,1.3,0.7 \mathrm{~Hz}, 1 \mathrm{H}), 7.45(\mathrm{ddd}$, $J=8.3,7.2,1.3 \mathrm{~Hz}, 1 \mathrm{H}), 7.33(\mathrm{ddd}, J=8.0,7.2,1.3 \mathrm{~Hz}, 1 \mathrm{H}), 7.01-6.94(\mathrm{~m}, 2 \mathrm{H}), 3.86(\mathrm{~s}, 3 \mathrm{H})$.

${ }^{13} \mathrm{C}$ NMR $\left(100 \mathrm{MHz}, \mathrm{CDCl}_{3}\right): \delta=167.8\left(\mathrm{C}_{\mathrm{q}}\right), 161.9\left(\mathrm{C}_{\mathrm{q}}\right), 154.2\left(\mathrm{C}_{\mathrm{q}}\right), 134.8\left(\mathrm{C}_{\mathrm{q}}\right), 129.1(\mathrm{CH}), 126.4$ $\left(\mathrm{C}_{\mathrm{q}}\right), 126.2(\mathrm{CH}), 124.8(\mathrm{CH}), 122.8(\mathrm{CH}), 121.5(\mathrm{CH}), 114.4(\mathrm{CH}), 55.5\left(\mathrm{CH}_{3}\right)$.

IR (ATR): 3061, 2994, 2836, 1604, 1483, 1434, 1256, 1225, 1171, $1027 \mathrm{~cm}^{-1}$.

MS (ESI) $m / z$ (relative intensity): $242(100)[\mathrm{M}+\mathrm{H}]^{+}, 264(30)[\mathrm{M}+\mathrm{Na}]^{+}$.

HR-MS (ESI): $m / z$ calcd for $\mathrm{C}_{14} \mathrm{H}_{12} \mathrm{NOS}[\mathrm{M}+\mathrm{H}]^{+}: 242.0635$, found: 242.0634 .

The spectral data were in accordance with those reported in the literature. ${ }^{[94]}$

\section{2-(4-(Trifluoromethyl)phenyl)benzo[d]thiazole (405d)}

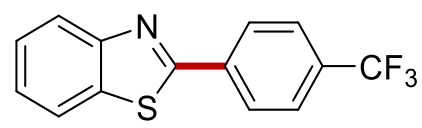

The General Procedure F was followed using benzothiazole 403a (34 mg, 0.25 mmol), 1-iodo-4(trifluoromethyl)benzene 404d (340 mg, $1.25 \mathrm{mmol}), 406(30 \mathrm{mg}, 11 \mathrm{~mol} \%)$ and $\mathrm{LiO} t \mathrm{Bu}(60 \mathrm{mg}, 0.75$ $\mathrm{mmol})$ in $\mathrm{Et}_{2} \mathrm{O}(0.5 \mathrm{~mL})$. Purification by column chromatography on silica gel ( $n$-hexane/EtOAc: $\left.70 / 1\right)$ yielded $405 f$ (64.9 mg, 93\%) as a light yellow solid.

M. p.: $161^{\circ} \mathrm{C}$.

${ }^{1}$ H NMR (400 MHz, $\left.\mathrm{CDCl}_{3}\right): \delta=8.22-8.14(\mathrm{~m}, 2 \mathrm{H}), 8.09$ (ddd, $\left.J=8.0,1.2,0.7 \mathrm{~Hz}, 1 \mathrm{H}\right), 7.91(\mathrm{ddd}$, $J=8.0,1.2,0.7 \mathrm{~Hz}, 1 \mathrm{H}), 7.76-7.69(\mathrm{~m}, 2 \mathrm{H}), 7.51(\mathrm{ddd}, J=8.2,7.2,1.2 \mathrm{~Hz}, 1 \mathrm{H}), 7.41(\mathrm{ddd}, J=8.2$, 7.2, $1.2 \mathrm{~Hz}, 1 \mathrm{H})$.

${ }^{13} \mathrm{C}$ NMR $\left(100 \mathrm{MHz}, \mathrm{CDCl}_{3}\right): \delta=166.0\left(\mathrm{C}_{\mathrm{q}}\right), 154.0\left(\mathrm{C}_{\mathrm{q}}\right), 136.8\left(\mathrm{~d}, J_{\mathrm{C}-\mathrm{F}}=2 \mathrm{~Hz}, \mathrm{C}_{\mathrm{q}}\right), 135.2\left(\mathrm{C}_{\mathrm{q}}\right), 132.4$ $\left(\mathrm{q}, J_{\mathrm{C}-\mathrm{F}}=33 \mathrm{~Hz}, \mathrm{C}_{\mathrm{q}}\right), 127.8(\mathrm{CH}), 126.6(\mathrm{CH}), 126.0\left(\mathrm{q}, J_{\mathrm{C}-\mathrm{F}}=4 \mathrm{~Hz}, \mathrm{CH}\right), 125.8(\mathrm{CH}), 123.8\left(\mathrm{~d}, J_{\mathrm{C}-\mathrm{F}}=\right.$ $\left.272 \mathrm{~Hz}, \mathrm{C}_{\mathrm{q}}\right) 123.6(\mathrm{CH}), 121.7(\mathrm{CH})$.

${ }^{19}$ F NMR (282 MHz, $\left.\mathrm{CDCl}_{3}\right): \delta=-62.86(\mathrm{~s})$.

IR (ATR): 3072, 1324, 1214, 1132, 1067, 970, 847, 744, 668, $624 \mathrm{~cm}^{-1}$.

MS (ESI) $m / z$ (relative intensity): $280(100)[\mathrm{M}+\mathrm{H}]^{+}$.

HR-MS (ESI): $m / z$ calcd for $\mathrm{C}_{14} \mathrm{H}_{9} \mathrm{~F}_{3} \mathrm{NS}[\mathrm{M}+\mathrm{H}]^{+}: 280.0403$, found: 280.0402 . 
The spectral data were in accordance with those reported in the literature. ${ }^{[94]}$

\section{2-(4-Fluorophenyl)benzo[d] thiazole (405e)}

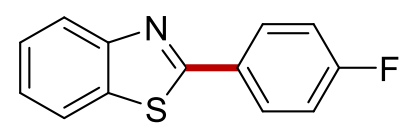

The General Procedure F was followed using benzothiazole 403a (34 mg, 0.25 mmol), 1-fluoro-4iodobenzene 404e (278 mg, $1.25 \mathrm{mmol}), 406$ (30 mg, $11 \mathrm{~mol} \%)$ and $\mathrm{LiO} t \mathrm{Bu}(60 \mathrm{mg}, 0.75 \mathrm{mmol})$ in $\mathrm{Et}_{2} \mathrm{O}(0.5 \mathrm{~mL})$. Purification by column chromatography on silica gel ( $n$-hexane/EtOAc: $\left.70 / 1\right)$ yielded 405e (54.5 mg, 95\%) as a light yellow solid.

M. p.: $101^{\circ} \mathrm{C}$.

${ }^{1} \mathbf{H}$ NMR $\left(500 \mathrm{MHz}, \mathrm{CDCl}_{3}\right): \delta=8.10-8.01(\mathrm{~m}, 3 \mathrm{H}), 7.88(\mathrm{ddd}, J=7.9,1.2,0.6 \mathrm{~Hz}, 1 \mathrm{H}), 7.48(\mathrm{ddd}$, $J=8.3,7.2,1.2 \mathrm{~Hz}, 1 \mathrm{H}), 7.37(\mathrm{ddd}, J=8.3,7.2,1.2 \mathrm{~Hz}, 1 \mathrm{H}), 7.20-7.11(\mathrm{~m}, 2 \mathrm{H})$.

${ }^{13} \mathrm{C}$ NMR $\left(125 \mathrm{MHz}, \mathrm{CDCl}_{3}\right): \delta=166.7\left(\mathrm{C}_{\mathrm{q}}\right), 164.4\left(\mathrm{~d}, J_{\mathrm{C}-\mathrm{F}}=252 \mathrm{~Hz}, \mathrm{C}_{\mathrm{q}}\right), 154.1\left(\mathrm{C}_{\mathrm{q}}\right), 135.0\left(\mathrm{C}_{\mathrm{q}}\right)$, $129.9\left(\mathrm{~d}, J_{\mathrm{C}-\mathrm{F}}=3 \mathrm{~Hz}, \mathrm{C}_{\mathrm{q}}\right), 129.49\left(\mathrm{~d}, J_{\mathrm{C}-\mathrm{F}}=9 \mathrm{~Hz}, \mathrm{CH}\right), 126.39(\mathrm{CH}), 125.22(\mathrm{CH}), 123.16(\mathrm{CH}), 121.59$ $(\mathrm{CH}), 116.13\left(\mathrm{~d}, J_{\mathrm{C}-\mathrm{F}}=22 \mathrm{~Hz}, \mathrm{CH}\right)$.

${ }^{19}$ F NMR $\left(282 \mathrm{MHz}, \mathrm{CDCl}_{3}\right) \delta-108.94(\mathrm{tt}, J=8.5,5.3 \mathrm{~Hz})$.

IR (ATR): 3063, 1602, 1519, 1481, 1434, 1314, 1250, 1097, 967, $831 \mathrm{~cm}^{-1}$.

MS (ESI) $m / z$ (relative intensity): $230(100)[\mathrm{M}+\mathrm{H}]^{+}$.

HR-MS (ESI): $m / z$ calcd for $\mathrm{C}_{13} \mathrm{H}_{9} \mathrm{FNS}[\mathrm{M}+\mathrm{H}]^{+}: 230.0436$, found: 230.0434 .

The spectral data were in accordance with those reported in the literature. ${ }^{[269]}$

\section{2-(4-Chlorophenyl)benzo[ $[d]$ thiazole (405f)}

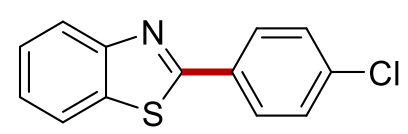

The General Procedure F was followed using benzothiazole 403a (34 mg, $0.25 \mathrm{mmol}$ ), 1-chloro-4iodobenzene $404 f(298 \mathrm{mg}, 1.25 \mathrm{mmol}), \mathbf{4 0 6}(30 \mathrm{mg}, 11 \mathrm{~mol} \%)$ and $\mathrm{LiO} t \mathrm{Bu}(60 \mathrm{mg}, 0.75 \mathrm{mmol})$ in $\mathrm{Et}_{2} \mathrm{O}(0.5 \mathrm{~mL})$. Purification by column chromatography on silica gel ( $n$-hexane/EtOAc: $\left.70 / 1\right)$ yielded 405f (56.5 $\mathrm{mg}, 92 \%)$ as a light yellow solid. 
M. p.: $112^{\circ} \mathrm{C}$.

${ }^{1} \mathbf{H}$ NMR $\left(500 \mathrm{MHz}, \mathrm{CDCl}_{3}\right): \delta=8.05(\mathrm{dt}, J=8.2,0.8 \mathrm{~Hz}, 1 \mathrm{H}), 8.02-7.98(\mathrm{~m}, 2 \mathrm{H}), 7.88(\mathrm{ddd}, J=$ 8.2, 0.8, $0.8 \mathrm{~Hz}, 1 \mathrm{H}), 7.48(\mathrm{ddd}, J=8.2,7.2,1.2 \mathrm{~Hz}, 1 \mathrm{H}), 7.46-7.43(\mathrm{~m}, 2 \mathrm{H}), 7.38(\mathrm{ddd}, J=8.2,7.2$, $1.2 \mathrm{~Hz}, 1 \mathrm{H})$

${ }^{13} \mathrm{C}$ NMR $\left(125 \mathrm{MHz}, \mathrm{CDCl}_{3}\right): \delta=166.6\left(\mathrm{C}_{\mathrm{q}}\right), 154.0\left(\mathrm{C}_{\mathrm{q}}\right), 137.0\left(\mathrm{C}_{\mathrm{q}}\right), 135.0\left(\mathrm{C}_{\mathrm{q}}\right), 132.1\left(\mathrm{C}_{\mathrm{q}}\right), 129.2$ $(\mathrm{CH}), 128.7(\mathrm{CH}), 126.5(\mathrm{CH}), 125.4(\mathrm{CH}), 123.3(\mathrm{CH}), 121.6(\mathrm{CH})$.

IR (ATR): 3062, 1590, 1474, 1433, 1399, 1314, 1287, 1225, 1091, 1015, $389 \mathrm{~cm}^{-1}$.

MS (ESI) $m / z$ (relative intensity): $246(100)[\mathrm{M}+\mathrm{H}]^{+}$.

HR-MS (ESI): $m / z$ calcd for $\mathrm{C}_{13} \mathrm{H}_{9} \mathrm{CINS}[\mathrm{M}+\mathrm{H}]^{+}: 246.0139$, found: 246.0139 .

The spectral data were in accordance with those reported in the literature. ${ }^{[268]}$

\section{2-(4-Bromophenyl)benzo[d] thiazole (405g)}

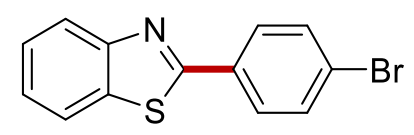

The General Procedure F was followed using benzothiazole 403a (34 mg, $0.25 \mathrm{mmol}$ ), 1-bromo-4iodobenzene 404g (354 mg, $1.25 \mathrm{mmol}), 406$ (30 mg, $11 \mathrm{~mol} \%$ ) and $\mathrm{LiO} t \mathrm{Bu}(60 \mathrm{mg}, 0.75 \mathrm{mmol})$ in $\mathrm{Et}_{2} \mathrm{O}(0.5 \mathrm{~mL})$. Purification by column chromatography on silica gel ( $n$-hexane/EtOAc: $\left.70 / 1\right)$ yielded 405g (66.0 mg, 91\%) as a light yellow solid.

M. p.: $132^{\circ} \mathrm{C}$.

${ }^{1}$ H NMR (500 MHz, $\left.\mathrm{CDCl}_{3}\right): \delta=8.05(\mathrm{dt}, J=8.2,0.9 \mathrm{~Hz}, 1 \mathrm{H}), 7.94-7.89(\mathrm{~m}, 2 \mathrm{H}), 7.86(\mathrm{ddd}, J=$ 8.2, 0.9, 0.9 Hz, 1H), $7.61-7.57(\mathrm{~m}, 2 \mathrm{H}), 7.48(\mathrm{ddd}, J=8.2,7.2,1.2 \mathrm{~Hz}, 1 \mathrm{H}), 7.37$ (ddd, $J=8.2,7.2$, $1.2 \mathrm{~Hz}, 1 \mathrm{H})$

${ }^{13} \mathrm{C}$ NMR $\left(125 \mathrm{MHz}, \mathrm{CDCl}_{3}\right): \delta=166.6\left(\mathrm{C}_{\mathrm{q}}\right), 154.0\left(\mathrm{C}_{\mathrm{q}}\right), 135.0\left(\mathrm{C}_{\mathrm{q}}\right), 132.4\left(\mathrm{C}_{\mathrm{q}}\right), 132.1(\mathrm{CH}), 128.8$ $(\mathrm{CH}), 126.4(\mathrm{CH}), 125.4(\mathrm{CH}), 125.4\left(\mathrm{C}_{\mathrm{q}}\right), 123.2(\mathrm{CH}), 121.6(\mathrm{CH})$.

IR (ATR): 3016, 1574, 1433, 1314, 1215, 1102, 1068, 820, 752, 683, $481 \mathrm{~cm}^{-1}$.

MS (ESI) $m / z$ (relative intensity): $289(100)\left({ }^{79} \mathrm{Br}\right)[\mathrm{M}+\mathrm{H}]^{+}, 291(100)\left({ }^{81} \mathrm{Br}\right)[\mathrm{M}+\mathrm{H}]^{+}$.

HR-MS (ESI): $m / z$ calcd for $\mathrm{C}_{13} \mathrm{H}_{9}{ }^{79} \mathrm{BrNS}[\mathrm{M}+\mathrm{H}]^{+}: 289.9635$, found: 289.9634 .

The spectral data were in accordance with those reported in the literature. ${ }^{[269]}$ 
2-(m-Tolyl)benzo[d] thiazole (405h)

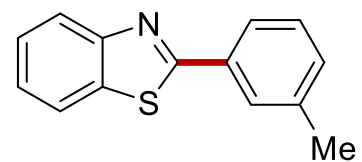

The General Procedure F was followed using benzothiazole 403a (34 mg, $0.25 \mathrm{mmol}$ ), 1-iodo-3methylbenzene 404h (273 mg, $1.25 \mathrm{mmol}), 406$ (30 mg, $11 \mathrm{~mol} \%$ ) and $\mathrm{LiO} t \mathrm{Bu}(60 \mathrm{mg}, 0.75 \mathrm{mmol})$ in $\mathrm{Et}_{2} \mathrm{O}(0.5 \mathrm{~mL})$. Purification by column chromatography on silica gel ( $n$-hexane/EtOAc: $\left.70 / 1\right)$ yielded $\mathbf{4 0 5 h}$ (52.9 $\mathrm{mg}, 94 \%)$ as a light yellow solid.

M. p.: $63^{\circ} \mathrm{C}$.

${ }^{1} \mathbf{H}$ NMR $\left(400 \mathrm{MHz}, \mathrm{CDCl}_{3}\right): \delta=8.06(\mathrm{dd}, J=8.2,1.2 \mathrm{~Hz}, 1 \mathrm{H}), 7.96-7.90(\mathrm{~m}, 1 \mathrm{H}), 7.89(\mathrm{dd}, J=8.0$, $1.2 \mathrm{~Hz}, 1 \mathrm{H}), 7.90-7.81(\mathrm{~m}, 1 \mathrm{H}), 7.48(\mathrm{ddd}, J=8.3,7.2,1.2 \mathrm{~Hz}, 1 \mathrm{H}), 7.37$ (ddd, $J=7.8,7.2,1.2 \mathrm{~Hz}$, 2H), $7.33-7.25(\mathrm{~m}, 1 \mathrm{H}), 2.44(\mathrm{~s}, 3 \mathrm{H})$.

${ }^{13}$ C NMR $\left(100 \mathrm{MHz}, \mathrm{CDCl}_{3}\right): \delta=168.3\left(\mathrm{C}_{\mathrm{q}}\right), 154.1\left(\mathrm{C}_{\mathrm{q}}\right), 138.8\left(\mathrm{C}_{\mathrm{q}}\right), 135.0\left(\mathrm{C}_{\mathrm{q}}\right), 133.5\left(\mathrm{C}_{\mathrm{q}}\right), 131.8$ $(\mathrm{CH}), 128.9(\mathrm{CH}), 128.0(\mathrm{CH}), 126.3(\mathrm{CH}), 125.1(\mathrm{CH}), 124.8(\mathrm{CH}), 123.1(\mathrm{CH}), 121.6(\mathrm{CH}), 21.3$ $\left(\mathrm{CH}_{3}\right)$.

IR (ATR): 3056, 2919, 1606, 1557, 1471, 1378, 1312, 1238, 1171, 1092, $1014 \mathrm{~cm}^{-1}$.

MS (ESI) $m / z$ (relative intensity): $226(100)[\mathrm{M}+\mathrm{H}]^{+}, 248(10)[\mathrm{M}+\mathrm{Na}]^{+}$.

HR-MS (ESI): $m / z$ calcd for $\mathrm{C}_{14} \mathrm{H}_{12} \mathrm{NS}[\mathrm{M}+\mathrm{H}]^{+}: 226.0683$, found: 226.0685 .

The spectral data were in accordance with those reported in the literature. ${ }^{[268]}$

\section{2-(3-Methoxyphenyl)benzo[d] thiazole (405i)}

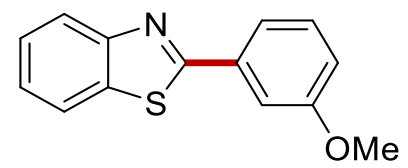

The General Procedure F was followed using benzothiazole 403a (34 mg, $0.25 \mathrm{mmol}$ ), 1-iodo-3methoxybenzene 404i (293 mg, $1.25 \mathrm{mmol})$, 406 (30 mg, $11 \mathrm{~mol} \%$ ) and $\mathrm{LiO} t \mathrm{Bu}(60 \mathrm{mg}, 0.75 \mathrm{mmol})$ in $\mathrm{Et}_{2} \mathrm{O}(0.5 \mathrm{~mL})$. Purification by column chromatography on silica gel ( $n$-hexane/EtOAc: $\left.70 / 1\right)$ yielded $\mathbf{4 0 5 i}(45.8 \mathrm{mg}, 76 \%)$ as a light yellow solid.

M. p.: $82^{\circ} \mathrm{C}$.

${ }^{1} \mathbf{H}$ NMR $\left(400 \mathrm{MHz}, \mathrm{CDCl}_{3}\right): \delta=8.06(\mathrm{ddd}, J=8.3,1.3,0.6 \mathrm{~Hz}, 1 \mathrm{H}), 7.88(\mathrm{ddd}, J=8.0,1.3,0.7 \mathrm{~Hz}$, 
1H), $7.66(\mathrm{dd}, J=2.6,1.6 \mathrm{~Hz}, 1 \mathrm{H}), 7.63(\mathrm{ddd}, J=7.6,1.6,0.9 \mathrm{~Hz}, 1 \mathrm{H}), 7.48(\mathrm{ddd}, J=8.3,7.2,1.3 \mathrm{~Hz}$, 1H), $7.41-7.34(\mathrm{~m}, 2 \mathrm{H}), 7.03(\mathrm{ddd}, J=8.3,2.6,0.9 \mathrm{~Hz}, 1 \mathrm{H}), 3.90(\mathrm{~s}, 3 \mathrm{H})$.

${ }^{13} \mathrm{C}$ NMR (100 MHz, $\left.\mathrm{CDCl}_{3}\right): \delta=167.9\left(\mathrm{C}_{\mathrm{q}}\right), 160.0\left(\mathrm{C}_{\mathrm{q}}\right), 154.0\left(\mathrm{C}_{\mathrm{q}}\right), 135.1\left(\mathrm{C}_{\mathrm{q}}\right), 134.9\left(\mathrm{C}_{\mathrm{q}}\right), 130.0$ $(\mathrm{CH}), 126.3(\mathrm{CH}), 125.2(\mathrm{CH}), 123.2(\mathrm{CH}), 121.6(\mathrm{CH}), 120.2(\mathrm{CH}), 117.3(\mathrm{CH}), 112.0(\mathrm{CH}), 55.5$ $\left(\mathrm{CH}_{3}\right)$.

IR (ATR): 3066, 2932, 2834, 2160, 2039, 1582, 1484, 1433, 1287, 1008, $758 \mathrm{~cm}^{-1}$.

MS (ESI) $m / z$ (relative intensity): $242(100)[\mathrm{M}+\mathrm{H}]^{+}, 264(35)[\mathrm{M}+\mathrm{Na}]^{+}$.

HR-MS (ESI): $m / z$ calcd for $\mathrm{C}_{14} \mathrm{H}_{12} \mathrm{NOS}[\mathrm{M}+\mathrm{H}]^{+}: 242.0637$, found: 242.0634 .

The spectral data were in accordance with those reported in the literature. ${ }^{[268]}$

\section{2-[3-(Trifluoromethyl)phenyl]benzo[d] thiazole (405j)}

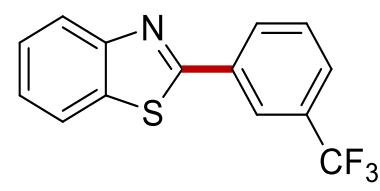

The General Procedure F was followed using benzothiazole 403a (34 mg, 0.25 mmol), 1-iodo-3(trifluoromethyl)benzene 404j (340 mg, $1.25 \mathrm{mmol}), 406$ (30 mg, $11 \mathrm{~mol} \%$ ) and $\mathrm{LiO} t \mathrm{Bu}(60 \mathrm{mg}, 0.75$ $\mathrm{mmol})$ in $\mathrm{Et}_{2} \mathrm{O}(0.5 \mathrm{~mL})$. Purification by column chromatography on silica gel ( $n$-hexane/EtOAc: $\left.70 / 1\right)$ yielded $\mathbf{4 0 5} \mathbf{j}$ (53.0 $\mathrm{mg}, 76 \%)$ as a light yellow solid.

M. p.: $87^{\circ} \mathrm{C}$.

${ }^{1}$ H NMR (400 MHz, $\left.\mathrm{CDCl}_{3}\right): \delta=8.38-8.34(\mathrm{~m}, 1 \mathrm{H}), 8.23(\mathrm{ddd}, J=7.2,1.3,0.7 \mathrm{~Hz}, 1 \mathrm{H}), 8.09$ (ddd, $J=8.2,1.3,0.7 \mathrm{~Hz}, 1 \mathrm{H}), 7.91(\mathrm{ddd}, J=8.0,1.3,0.7 \mathrm{~Hz}, 1 \mathrm{H}), 7.73(\mathrm{ddd}, J=7.8,1.3,0.7 \mathrm{~Hz}, 1 \mathrm{H}), 7.61$ $(\mathrm{ddd}, J=7.8,1.3,0.7 \mathrm{~Hz}, 1 \mathrm{H}), 7.51$ (ddd, $J=8.2,7.2,1.3 \mathrm{~Hz}, 1 \mathrm{H}), 7.41$ (ddd, $J=8.0,7.2,1.3 \mathrm{~Hz}$, $1 \mathrm{H})$.

${ }^{13}$ C NMR (100 MHz, $\left.\mathrm{CDCl}_{3}\right): \delta=166.1\left(\mathrm{C}_{\mathrm{q}}\right), 154.0\left(\mathrm{C}_{\mathrm{q}}\right), 135.1\left(\mathrm{C}_{\mathrm{q}}\right), 134.4\left(\mathrm{C}_{\mathrm{q}}\right), 131.6\left(\mathrm{q}, J_{\mathrm{C}-\mathrm{F}}=32\right.$ $\left.\mathrm{Hz}, \mathrm{C}_{\mathrm{q}}\right), 130.7(\mathrm{CH}), 129.6(\mathrm{CH}), 127.3\left(\mathrm{q}, J_{\mathrm{C}-\mathrm{F}}=4 \mathrm{~Hz}, \mathrm{CH}\right), 126.6(\mathrm{CH}), 125.7(\mathrm{CH}), 124.2\left(\mathrm{q}, J_{\mathrm{C}-\mathrm{F}}=\right.$ $4 \mathrm{~Hz}, \mathrm{CH}), 123.8\left(\mathrm{~d}, J_{\mathrm{C}-\mathrm{F}}=273 \mathrm{~Hz}, \mathrm{Cq}\right), 123.5(\mathrm{CH}), 121.7(\mathrm{CH})$.

${ }^{19}$ F NMR $\left(282 \mathrm{MHz}, \mathrm{CDCl}_{3}\right): \delta=-62.76(\mathrm{~s})$.

IR (ATR): 3066, 2923, 1613, 1584, 1479, 1442, 1257, 1152, 1076, 937, $880 \mathrm{~cm}^{-1}$.

MS (ESI) $m / z$ (relative intensity): $280(100)[\mathrm{M}+\mathrm{H}]^{+}$. 
HR-MS (ESI): $m / z$ calcd for $\mathrm{C}_{14} \mathrm{H}_{9} \mathrm{~F}_{3} \mathrm{NS}[\mathrm{M}+\mathrm{H}]^{+}: 280.0403$, found: 280.0402 .

The spectral data were in accordance with those reported in the literature. ${ }^{[268]}$

\section{2-(3-Fluorophenyl)benzo[d]thiazole (405k)}

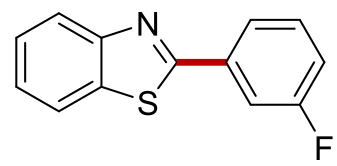

The General Procedure F was followed using benzothiazole 403a (34 mg, $0.25 \mathrm{mmol}$ ), 1-fluoro-3iodobenzene 404k (278 mg, $1.25 \mathrm{mmol}), 406(30 \mathrm{mg}, 11 \mathrm{~mol} \%)$ and $\mathrm{LiO} t \mathrm{Bu}(60 \mathrm{mg}, 0.75 \mathrm{mmol})$ in $\mathrm{Et}_{2} \mathrm{O}(0.5 \mathrm{~mL})$. Purification by column chromatography on silica gel ( $n$-hexane/EtOAc: $\left.70 / 1\right)$ yielded 405k (52.2 mg, 91\%) as a light yellow solid.

M. p.: $72^{\circ} \mathrm{C}$.

${ }^{1} \mathbf{H}$ NMR $\left(500 \mathrm{MHz}, \mathrm{CDCl}_{3}\right): \delta=8.07(\mathrm{dd}, J=8.2,0.8 \mathrm{~Hz}, 1 \mathrm{H}), 7.89(\mathrm{dd}, J=8.0,0.8 \mathrm{~Hz}, 1 \mathrm{H}), 7.86-$ $7.79(\mathrm{~m}, 2 \mathrm{H}), 7.49(\mathrm{ddd}, J=8.2,7.2,1.2 \mathrm{~Hz}, 1 \mathrm{H}), 7.44(\mathrm{ddd}, J=8.2,8.0,5.7 \mathrm{~Hz}, 1 \mathrm{H}), 7.39$ (ddd, $J=$ 8.2, 7.2, $1.2 \mathrm{~Hz}, 1 \mathrm{H}), 7.17$ (ddd, $J=8.2,2.6,1.2 \mathrm{~Hz}, 1 \mathrm{H})$.

${ }^{13} \mathrm{C}$ NMR $\left(125 \mathrm{MHz}, \mathrm{CDCl}_{3}\right): \delta=166.4\left(\mathrm{~d}, J_{\mathrm{C}-\mathrm{F}}=3 \mathrm{~Hz}, \mathrm{C}_{\mathrm{q}}\right), 163.0\left(\mathrm{~d}, J_{\mathrm{C}-\mathrm{F}}=247 \mathrm{~Hz}, \mathrm{C}_{\mathrm{q}}\right), 153.9\left(\mathrm{C}_{\mathrm{q}}\right)$, $135.6\left(\mathrm{~d}, J_{\mathrm{C}-\mathrm{F}}=8 \mathrm{~Hz}, \mathrm{C}_{\mathrm{q}}\right), 135.0\left(\mathrm{C}_{\mathrm{q}}\right), 130.6\left(\mathrm{~d}, J_{\mathrm{C}-\mathrm{F}}=8 \mathrm{~Hz}, \mathrm{CH}\right), 126.5(\mathrm{CH}), 125.5(\mathrm{CH}), 123.4(\mathrm{CH})$, $123.3\left(\mathrm{~d}, J_{\mathrm{C}-\mathrm{F}}=3 \mathrm{~Hz}, \mathrm{CH}\right), 121.6(\mathrm{CH}), 117.8\left(\mathrm{~d}, J_{\mathrm{C}-\mathrm{F}}=21 \mathrm{~Hz}\right), 114.26\left(\mathrm{~d}, J_{\mathrm{C}-\mathrm{F}}=24 \mathrm{~Hz}\right)$.

${ }^{19}$ F NMR $\left(282 \mathrm{MHz}, \mathrm{CDCl}_{3}\right): \delta=-112.02(\mathrm{ddd}, J=9.2,8.5,5.7 \mathrm{~Hz})$.

IR (ATR): 3053, 2162, 1590, 1457, 1423, 1312, 1230, 1160, 783, 700, $653 \mathrm{~cm}^{-1}$.

MS (ESI) $m / z$ (relative intensity): $230(100)[\mathrm{M}+\mathrm{H}]^{+}$.

HR-MS (ESI): $m / z$ calcd for $\mathrm{C}_{13} \mathrm{H}_{9} \mathrm{FNS}[\mathrm{M}+\mathrm{H}]^{+}: 230.0437$, found: 230.0435 .

The spectral data were in accordance with those reported in the literature. ${ }^{[268]}$

\section{2-(3-Chlorophenyl)benzo[d] thiazole (405I)}

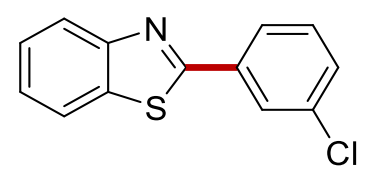

The General Procedure F was followed using benzothiazole 403a (34 mg, $0.25 \mathrm{mmol}$ ), 1-chloro-3iodobenzene $404 \mathrm{l}(298 \mathrm{mg}, 1.25 \mathrm{mmol}), \mathbf{4 0 6}(30 \mathrm{mg}, 11 \mathrm{~mol} \%)$ and $\mathrm{LiO} t \mathrm{Bu}(60 \mathrm{mg}, 0.75 \mathrm{mmol})$ in 
$\mathrm{Et}_{2} \mathrm{O}(0.5 \mathrm{~mL})$. Purification by column chromatography on silica gel ( $n$-hexane/EtOAc: $\left.70 / 1\right)$ yielded 405I (39.9 mg, 65\%) as a light yellow solid.

M. p.: $96^{\circ} \mathrm{C}$.

${ }^{1} \mathbf{H}$ NMR $\left(500 \mathrm{MHz}, \mathrm{CDCl}_{3}\right): \delta=8.11-8.09(\mathrm{~m}, 1 \mathrm{H}), 8.07(\mathrm{ddd}, J=8.2,1.2,0.7 \mathrm{~Hz}, 1 \mathrm{H}), 7.93(\mathrm{ddd}$, $J=8.0,7.2,1.2 \mathrm{~Hz}, 1 \mathrm{H}), 7.90(\mathrm{ddd}, J=8.0,1.2,0.7 \mathrm{~Hz}, 1 \mathrm{H}), 7.50(\mathrm{ddd}, J=8.2,7.2,1.2 \mathrm{~Hz}, 1 \mathrm{H}), 7.46$ $-7.37(\mathrm{~m}, 3 \mathrm{H})$.

${ }^{13}$ C NMR (125 MHz, $\left.\mathrm{CDCl}_{3}\right): \delta=166.3\left(\mathrm{C}_{\mathrm{q}}\right), 154.0\left(\mathrm{C}_{\mathrm{q}}\right), 135.2\left(\mathrm{C}_{\mathrm{q}}\right), 135.1\left(\mathrm{C}_{\mathrm{q}}\right), 135.1\left(\mathrm{C}_{\mathrm{q}}\right), 130.8$ $(\mathrm{CH}), 130.2(\mathrm{CH}), 127.4(\mathrm{CH}), 126.5(\mathrm{CH}), 125.7(\mathrm{CH}), 125.5(\mathrm{CH}), 123.4(\mathrm{CH}), 121.7(\mathrm{CH})$.

IR (ATR): 3060, 2924, 1693, 1562, 1457, 1312, 1227, 1070, 975, 862, $782 \mathrm{~cm}^{-1}$.

MS (ESI) $m / z$ (relative intensity): $246(100)[\mathrm{M}+\mathrm{H}]^{+}$.

HR-MS (ESI): $m / z$ calcd for $\mathrm{C}_{13} \mathrm{H}_{9} \mathrm{CINS}[\mathrm{M}+\mathrm{H}]^{+}: 246.0140$, found: 246.0139 .

The spectral data were in accordance with those reported in the literature. ${ }^{[268]}$

\section{2-(3-Bromophenyl)benzo $[d]$ thiazole $(405 \mathrm{~m})$}

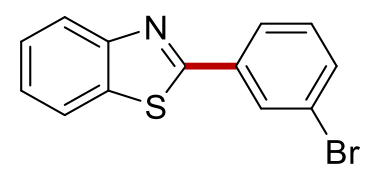

The General Procedure F was followed using benzothiazole 403a (34 mg, $0.25 \mathrm{mmol}$ ), 1-bromo-3iodobenzene 404m (354 mg, $1.25 \mathrm{mmol}), 406(30 \mathrm{mg}, 11 \mathrm{~mol} \%)$ and $\mathrm{LiO} t \mathrm{Bu}(60 \mathrm{mg}, 0.75 \mathrm{mmol})$ in $\mathrm{Et}_{2} \mathrm{O}(0.5 \mathrm{~mL})$. Purification by column chromatography on silica gel ( $n$-hexane/EtOAc: $\left.70 / 1\right)$ yielded 405m (42.8 mg, 59\%) as a light yellow solid.

M. p.: $88^{\circ} \mathrm{C}$.

${ }^{1}$ H NMR (500 MHz, $\left.\mathrm{CDCl}_{3}\right): \delta=8.27-8.25(\mathrm{~m}, 1 \mathrm{H}), 8.06(\mathrm{ddd}, J=8.0,0.9 \mathrm{~Hz}, 1 \mathrm{H}), 7.97(\mathrm{ddd}, J=$ 7.8, 1.7, $0.9 \mathrm{~Hz}, 1 \mathrm{H}), 7.90(\mathrm{ddd}, J=8.0,1,2,0.9 \mathrm{~Hz}, 1 \mathrm{H}), 7.60(\mathrm{ddd}, J=8.0,2.0,0.9 \mathrm{~Hz}, 1 \mathrm{H}), 7.50$ $(\mathrm{ddd}, J=8.2,7.2,1.2 \mathrm{~Hz}, 1 \mathrm{H}), 7.39(\mathrm{ddd}, J=8.2,7.2,1.2 \mathrm{~Hz}, 1 \mathrm{H}), 7.34(\mathrm{dd}, J=7.9 \mathrm{~Hz}, 1 \mathrm{H})$.

${ }^{13}$ C NMR (125 MHz, $\left.\mathrm{CDCl}_{3}\right): \delta=166.1\left(\mathrm{C}_{\mathrm{q}}\right), 153.9\left(\mathrm{C}_{\mathrm{q}}\right), 135.4\left(\mathrm{C}_{\mathrm{q}}\right), 135.1\left(\mathrm{C}_{\mathrm{q}}\right), 133.8(\mathrm{CH}), 130.5$ $(\mathrm{CH}), 130.2(\mathrm{CH}), 126.5(\mathrm{CH}), 126.1(\mathrm{CH}), 125.6(\mathrm{CH}), 123.4(\mathrm{CH}), 123.2\left(\mathrm{C}_{\mathrm{q}}\right), 121.7(\mathrm{CH})$.

IR (ATR): 3059, 2923, 1601, 1486, 1455, 1224, 1119, 957, 726, 630, $449 \mathrm{~cm}^{-1}$.

MS (ESI) $m / z$ (relative intensity): $289(100)\left({ }^{79} \mathrm{Br}\right)[\mathrm{M}+\mathrm{H}]^{+}, 291(100)\left({ }^{81} \mathrm{Br}\right)[\mathrm{M}+\mathrm{H}]^{+}$. 
HR-MS (ESI): $m / z$ calcd for $\mathrm{C}_{13} \mathrm{H}_{9}{ }^{79} \mathrm{BrNS}[\mathrm{M}+\mathrm{H}]^{+}: 289.9634$, found: 289.9634 .

The spectral data were in accordance with those reported in the literature. ${ }^{[270]}$

\section{2-(o-Tolyl)benzo $[d]$ thiazole (405n)}

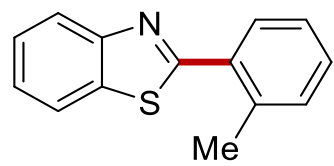

The General Procedure F was followed using benzothiazole 403a (34 mg, 0.25 mmol), 1-iodo-2methylbenzene 404n (273 mg, $1.25 \mathrm{mmol}), 406$ (30 mg, $11 \mathrm{~mol} \%$ ) and $\mathrm{LiO} t \mathrm{Bu}(60 \mathrm{mg}, 0.75 \mathrm{mmol})$ in $\mathrm{Et}_{2} \mathrm{O}(0.5 \mathrm{~mL})$. Purification by column chromatography on silica gel ( $n$-hexane/EtOAc: $\left.70 / 1\right)$ yielded 405n (20.3 mg, 36\%) as a yellow oil.

${ }^{1} \mathbf{H}$ NMR $\left(400 \mathrm{MHz}, \mathrm{CDCl}_{3}\right): \delta=8.09(\mathrm{ddd}, J=8.2,1.2,0.6 \mathrm{~Hz}, 1 \mathrm{H}), 7.92(\mathrm{ddd}, J=8.2,1.2,0.6 \mathrm{~Hz}$, 1H), $7.74(\mathrm{dd}, J=7.4,1.4 \mathrm{~Hz}, 1 \mathrm{H}), 7.49$ (ddd, $J=8.2,7.4,1.4 \mathrm{~Hz}, 1 \mathrm{H}), 7.42-7.37$ (m, 1H), $7.37-$ $7.27(\mathrm{~m}, 3 \mathrm{H}), 2.64(\mathrm{~s}, 3 \mathrm{H})$.

${ }^{13}$ C NMR (100 MHz, $\left.\mathrm{CDCl}_{3}\right): \delta=168.0\left(\mathrm{C}_{\mathrm{q}}\right), 153.7\left(\mathrm{C}_{\mathrm{q}}\right), 137.2\left(\mathrm{C}_{\mathrm{q}}\right), 135.6\left(\mathrm{C}_{\mathrm{q}}\right), 133.1\left(\mathrm{C}_{\mathrm{q}}\right), 131.5$ $(\mathrm{CH}), 130.5(\mathrm{CH}), 130.0(\mathrm{CH}), 126.1(\mathrm{CH}), 126.1(\mathrm{CH}), 125.1(\mathrm{CH}), 123.4(\mathrm{CH}), 121.3(\mathrm{CH}), 21.3$ $\left(\mathrm{CH}_{3}\right)$.

IR (ATR): 2924, 2838, 2612, 1977, 1571, 1500, 1115, 1021, 970, 754, $551 \mathrm{~cm}^{-1}$.

MS (ESI) $m / z$ (relative intensity): $226(100)[\mathrm{M}+\mathrm{H}]^{+}, 248(5)[\mathrm{M}+\mathrm{Na}]^{+}$.

HR-MS (ESI): $m / z$ calcd for $\mathrm{C}_{14} \mathrm{H}_{12} \mathrm{NO}[\mathrm{M}+\mathrm{H}]^{+}: 226.0686$, found: 226.0685 .

The spectral data were in accordance with those reported in the literature. ${ }^{[94]}$

\section{2-(2-Methoxyphenyl)benzo[d] thiazole (4050)}

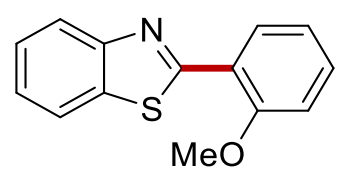

The General Procedure F was followed using benzothiazole 403a (34 mg, 0.25 mmol), 1-iodo-2methoxybenzene 404o (293 mg, $1.25 \mathrm{mmol})$, 406 (30 mg, $11 \mathrm{~mol} \%$ ) and $\mathrm{LiO} t \mathrm{Bu}(60 \mathrm{mg}, 0.75 \mathrm{mmol})$ in $\mathrm{Et}_{2} \mathrm{O}(0.5 \mathrm{~mL})$. Purification by column chromatography on silica gel ( $n$-hexane/EtOAc: $\left.70 / 1\right)$ yielded 4050 (21.7 $\mathrm{mg}, 36 \%)$ as a light yellow solid. 
M. p.: $108^{\circ} \mathrm{C}$.

${ }^{1} \mathbf{H}$ NMR $\left(400 \mathrm{MHz}, \mathrm{CDCl}_{3}\right): \delta=8.51(\mathrm{ddd}, J=7.9,1.8,0.6 \mathrm{~Hz}, 1 \mathrm{H}), 8.07(\mathrm{ddd}, J=8.2,1.1,0.6 \mathrm{~Hz}$, 1H), 7.91 (ddd, $J=7.9,1.1,0.6 \mathrm{~Hz}, 1 \mathrm{H}), 7.50-7.41(\mathrm{~m}, 2 \mathrm{H}), 7.38-7.32(\mathrm{~m}, 1 \mathrm{H}), 7.12$ (ddd, $J=7.9$, 7.3, $1.1 \mathrm{~Hz}, 1 \mathrm{H}), 7.06(\mathrm{dd}, J=8.2,1.1 \mathrm{~Hz}, 1 \mathrm{H}), 4.05(\mathrm{~s}, 3 \mathrm{H})$.

${ }^{13} \mathrm{C}$ NMR $\left(100 \mathrm{MHz}, \mathrm{CDCl}_{3}\right): \delta=163.1\left(\mathrm{C}_{\mathrm{q}}\right), 157.2\left(\mathrm{C}_{\mathrm{q}}\right), 152.2\left(\mathrm{C}_{\mathrm{q}}\right), 136.1\left(\mathrm{C}_{\mathrm{q}}\right), 131.7(\mathrm{CH}), 129.6$ $(\mathrm{CH}), 125.9(\mathrm{CH}), 124.6(\mathrm{CH}), 124.1(\mathrm{CH}), 122.8(\mathrm{CH}), 122.3\left(\mathrm{C}_{\mathrm{q}}\right), 121.2(\mathrm{CH}), 111.7(\mathrm{CH}), 55.7$ $\left(\mathrm{CH}_{3}\right)$.

IR (ATR): 3007, 2971, 1893, 1519, 1181,1122, 1054, 964, 825, 587, $416 \mathrm{~cm}^{-1}$.

MS (ESI) $m / z$ (relative intensity): $242(100)[\mathrm{M}+\mathrm{H}]^{+}, 264(30)[\mathrm{M}+\mathrm{Na}]^{+}$.

HR-MS (ESI): $m / z$ calcd for $\mathrm{C}_{14} \mathrm{H}_{12} \mathrm{NOS}[\mathrm{M}+\mathrm{H}]^{+}: 242.0637$, found: 242.0635 .

The spectral data were in accordance with those reported in the literature. ${ }^{[281]}$

\section{6-Methoxy-2-(p-tolyl)benzo[d] thiazole (405p)}

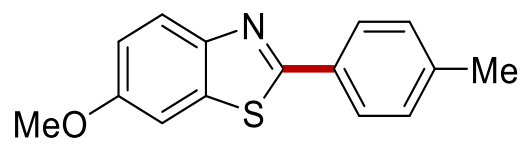

The General Procedure F was followed using 6-methoxybenzo[ $d]$ thiazole $403 \mathrm{~b}$ (41 mg, $0.25 \mathrm{mmol}$ ), 4-iodotoluene 404a (273 mg, $1.25 \mathrm{mmol}), \mathbf{4 0 6}(30 \mathrm{mg}, 11 \mathrm{~mol} \%$ ) and $\mathrm{LiO} t \mathrm{Bu}(60 \mathrm{mg}, 0.75 \mathrm{mmol})$ in $\mathrm{Et}_{2} \mathrm{O}(0.5 \mathrm{~mL})$. Purification by column chromatography on silica gel ( $n$-hexane/EtOAc: $\left.70 / 1\right)$ yielded 405p (35.1 mg, 55\%) as a light yellow solid.

M. p.: $115^{\circ} \mathrm{C}$.

${ }^{1} \mathbf{H}$ NMR $\left(400 \mathrm{MHz}, \mathrm{CDCl}_{3}\right): \delta=7.93-7.88(\mathrm{~m}, 3 \mathrm{H}), 7.33-7.30(\mathrm{~m}, 1 \mathrm{H}), 7.28-7.23(\mathrm{~m}, 2 \mathrm{H}), 7.06$ (dd, $J=8.9,2.6 \mathrm{~Hz}, 1 \mathrm{H}), 3.86(\mathrm{~s}, 3 \mathrm{H}), 2.39$ (s, 3H).

${ }^{13} \mathrm{C}$ NMR $\left(100 \mathrm{MHz}, \mathrm{CDCl}_{3}\right): \delta=165.7\left(\mathrm{C}_{\mathrm{q}}\right), 157.6\left(\mathrm{C}_{\mathrm{q}}\right), 148.7\left(\mathrm{C}_{\mathrm{q}}\right), 140.9\left(\mathrm{C}_{\mathrm{q}}\right), 136.2\left(\mathrm{C}_{\mathrm{q}}\right), 131.1$ $\left(\mathrm{C}_{\mathrm{q}}\right), 129.6(\mathrm{CH}), 127.1(\mathrm{CH}), 123.5(\mathrm{CH}), 115.4(\mathrm{CH}), 104.2(\mathrm{CH}), 55.7\left(\mathrm{CH}_{3}\right), 21.4\left(\mathrm{CH}_{3}\right)$.

IR (ATR): 3020, 1606, 1488, 1411, 1321, 1119, 968, 903, 747, 667, $479 \mathrm{~cm}^{-1}$.

MS (ESI) $m / z$ (relative intensity): $256(100)[\mathrm{M}+\mathrm{H}]^{+}$.

HR-MS (ESI): $m / z$ calcd for $\mathrm{C}_{15} \mathrm{H}_{14} \mathrm{NOS}[\mathrm{M}+\mathrm{H}]^{+}: 256.0795$, found: 256.0793 .

The spectral data were in accordance with those reported in the literature. ${ }^{[281]}$ 


\section{6-Fluoro-2-(p-tolyl)benzo $[d]$ thiazole (405q)}

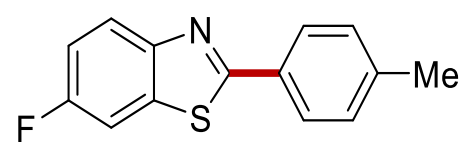

The General Procedure F was followed using 6-fluorobenzo[ $d]$ thiazole 403c (38 mg, $0.25 \mathrm{mmol})$, 4iodotoluene 404a (273 mg, $1.25 \mathrm{mmol}), 406(30 \mathrm{mg}, 11 \mathrm{~mol} \%)$ and $\mathrm{LiO} t \mathrm{Bu}(60 \mathrm{mg}, 0.75 \mathrm{mmol})$ in $\mathrm{Et}_{2} \mathrm{O}(0.5 \mathrm{~mL})$. Purification by column chromatography on silica gel ( $n$-hexane/EtOAc: $\left.70 / 1\right)$ yielded 405q (57.8 mg, 95\%) as a light yellow solid.

M. p.: $149^{\circ} \mathrm{C}$.

${ }^{1} \mathbf{H}$ NMR $\left(400 \mathrm{MHz}, \mathrm{CDCl}_{3}\right): \delta=7.96(\mathrm{dd}, J=8.9,4.9 \mathrm{~Hz}, 2 \mathrm{H}), 7.96-7.87(\mathrm{~m}, 3 \mathrm{H}), 7.53(\mathrm{ddd}, J=$ 8.1, 2.7, 0.5 Hz, 1H), $7.31-7.23(\mathrm{~m}, 2 \mathrm{H}), 7.19(\mathrm{dd}, J=8.9,2.7 \mathrm{~Hz}, 1 \mathrm{H}), 2.43-2.37(\mathrm{~m}, 3 \mathrm{H})$.

${ }^{13} \mathrm{C}$ NMR $\left(100 \mathrm{MHz}, \mathrm{CDCl}_{3}\right): \delta=167.9\left(\mathrm{C}_{\mathrm{q}}\right), 160.3\left(\mathrm{~d}, J_{\mathrm{C}-\mathrm{F}}=245 \mathrm{~Hz}, \mathrm{C}_{\mathrm{q}}\right), 150.8\left(\mathrm{C}_{\mathrm{q}}\right), 141.45\left(\mathrm{C}_{\mathrm{q}}\right)$, $135.87\left(\mathrm{~d}, J_{\mathrm{C}-\mathrm{F}}=11.2 \mathrm{~Hz}, \mathrm{C}_{\mathrm{q}}\right), 130.66\left(\mathrm{C}_{\mathrm{q}}\right), 129.71(\mathrm{CH}), 127.31(\mathrm{CH}), 123.86\left(\mathrm{~d}, J_{\mathrm{C}-\mathrm{F}}=9.3 \mathrm{~Hz}, \mathrm{CH}\right)$, $114.76\left(\mathrm{~d}, J_{\mathrm{C}-\mathrm{F}}=24.6 \mathrm{~Hz}, \mathrm{CH}\right), 107.74\left(\mathrm{~d}, J_{\mathrm{C}-\mathrm{F}}=26.7 \mathrm{~Hz}, \mathrm{CH}\right), 21.47\left(\mathrm{CH}_{3}\right)$.

${ }^{19}$ F NMR $\left(282 \mathrm{MHz}, \mathrm{CDCl}_{3}\right): \delta=-116.20(\mathrm{td}, J=8.5,4.8 \mathrm{~Hz})$.

IR (ATR): 2916, 2161, 1483, 1441, 1307, 1050, 867, 816, 761, 694, $491 \mathrm{~cm}^{-1}$.

MS (ESI) $m / z$ (relative intensity): $244(100)[\mathrm{M}+\mathrm{H}]^{+}$.

HR-MS (ESI): $m / z$ calcd for $\mathrm{C}_{14} \mathrm{H}_{11} \mathrm{FNS}[\mathrm{M}+\mathrm{H}]^{+}: 244.0593$, found: 244.0591 .

The spectral data were in accordance with those reported in the literature. ${ }^{[281]}$

\section{6-Chloro-2-(p-tolyl)benzo[d] thiazole (405r)}<smiles>Cc1ccc(-c2nc3ccc(Cl)cc3s2)cc1</smiles>

The General Procedure F was followed using 6-chlorobenzo[ $d]$ thiazole 403d (42 mg, $0.25 \mathrm{mmol}$ ), 4-iodotoluene 404a (273 mg, $1.25 \mathrm{mmol}), \mathbf{4 0 6}(30 \mathrm{mg}, 11 \mathrm{~mol} \%$ ) and $\mathrm{LiO} t \mathrm{Bu}(60 \mathrm{mg}, 0.75 \mathrm{mmol})$ in $\mathrm{Et}_{2} \mathrm{O}(0.5 \mathrm{~mL})$. Purification by column chromatography on silica gel ( $n$-hexane/EtOAc: $\left.70 / 1\right)$ yielded 405r (55.8 mg, 86\%) as a light yellow solid.

M. p.: $160^{\circ} \mathrm{C}$.

${ }^{1} \mathbf{H}$ NMR (400 MHz, $\left.\mathrm{CDCl}_{3}\right): \delta=7.95-7.89(\mathrm{~m}, 3 \mathrm{H}), 7.83(\mathrm{dd}, J=2.1,0.5 \mathrm{~Hz}, 1 \mathrm{H}), 7.41(\mathrm{dd}, J=8.7$, 
$2.1 \mathrm{~Hz}, 1 \mathrm{H}), 7.30-7.25(\mathrm{~m}, 2 \mathrm{H}), 2.41(\mathrm{~s}, 3 \mathrm{H})$.

${ }^{13} \mathrm{C}$ NMR $\left(100 \mathrm{MHz}, \mathrm{CDCl}_{3}\right): \delta=168.7\left(\mathrm{C}_{\mathrm{q}}\right), 152.7\left(\mathrm{C}_{\mathrm{q}}\right), 141.7\left(\mathrm{C}_{\mathrm{q}}\right), 136.1\left(\mathrm{C}_{\mathrm{q}}\right), 130.8\left(\mathrm{C}_{\mathrm{q}}\right), 130.5$ $\left(\mathrm{C}_{\mathrm{q}}\right), 129.8(\mathrm{CH}), 127.4(\mathrm{CH}), 127.0(\mathrm{CH}), 123.7(\mathrm{CH}), 121.1(\mathrm{CH}), 21.5\left(\mathrm{CH}_{3}\right)$.

IR (ATR): 2916, 1934, 1585, 1483, 1437, 1304, 1181, 1087, 963, 816, $561 \mathrm{~cm}^{-1}$.

MS (ESI) $m / z$ (relative intensity): $260(100)[\mathrm{M}+\mathrm{H}]^{+}$.

HR-MS (ESI): $m / z$ calcd for $\mathrm{C}_{14} \mathrm{H}_{11} \mathrm{ClNS}[\mathrm{M}+\mathrm{H}]^{+}: 260.0296$, found: 260.0295 .

The spectral data were in accordance with those reported in the literature. ${ }^{[272]}$

\section{6-Bromo-2-(p-tolyl)benzo[d] thiazole (405r)}

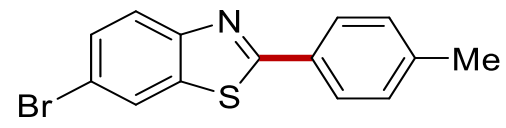

The General Procedure F was followed using 6-bromobenzo[ $d]$ thiazole 403e (53 mg, $0.25 \mathrm{mmol})$, 4-iodotoluene 404a (273 mg, $1.25 \mathrm{mmol}), 406(30 \mathrm{mg}, 11 \mathrm{~mol} \%$ ) and $\mathrm{LiO} t \mathrm{Bu}(60 \mathrm{mg}, 0.75 \mathrm{mmol})$ in $\mathrm{Et}_{2} \mathrm{O}(0.5 \mathrm{~mL})$. Purification by column chromatography on silica gel ( $n$-hexane/EtOAc: $\left.70 / 1\right)$ yielded 405r (50.2 mg, 66\%) as a light yellow solid.

M. p.: $152^{\circ} \mathrm{C}$.

${ }^{1} \mathbf{H}$ NMR $\left(400 \mathrm{MHz} \mathrm{CDCl}_{3}\right): \delta=8.00(\mathrm{dd}, J=2.0,0.5 \mathrm{~Hz}, 1 \mathrm{H}), 7.96-7.92(\mathrm{~m}, 2 \mathrm{H}), 7.87(\mathrm{dd}, J=8.7$, $0.5 \mathrm{~Hz}, 1 \mathrm{H}), 7.58-7.53(\mathrm{~m}, 1 \mathrm{H}), 7.31-7.25(\mathrm{~m}, 2 \mathrm{H}), 2.41(\mathrm{~s}, 3 \mathrm{H})$.

${ }^{13}$ C NMR (100 MHz, $\left.\mathrm{CDCl}_{3}\right): \delta=168.7\left(\mathrm{C}_{\mathrm{q}}\right), 153.0\left(\mathrm{C}_{\mathrm{q}}\right), 141.8\left(\mathrm{C}_{\mathrm{q}}\right), 136.6\left(\mathrm{C}_{\mathrm{q}}\right), 130.5\left(\mathrm{C}_{\mathrm{q}}\right), 129.8$ $(\mathrm{CH}), 129.7(\mathrm{CH}), 127.5(\mathrm{CH}), 124.1(\mathrm{CH}), 124.1(\mathrm{CH}), 118.5\left(\mathrm{C}_{\mathrm{q}}\right), 21.5\left(\mathrm{CH}_{3}\right)$.

IR (ATR): 3061, 1621, 1508, 1459, 1313, 1219, 1126, 1020, 694, 877, $802 \mathrm{~cm}^{-1}$.

MS (ESI) $m / z$ (relative intensity): $303(100)\left({ }^{79} \mathrm{Br}\right)[\mathrm{M}+\mathrm{H}]^{+}, 305(100)\left({ }^{81} \mathrm{Br}\right)[\mathrm{M}+\mathrm{H}]^{+}$.

HR-MS (ESI): $m / z$ calcd for $\mathrm{C}_{14} \mathrm{H}_{11}{ }^{79} \mathrm{BrNS}[\mathrm{M}+\mathrm{H}]^{+}: 303.9792$, found: 303.9790 .

The spectral data were in accordance with those reported in the literature. ${ }^{[273]}$

2-(3,4-Dichlorophenyl)benzo[d] thiazole (405t)<smiles>Clc1ccc(-c2nc3ccccc3s2)cc1Cl</smiles> 
The General Procedure F was followed using benzothiazole 403a (mg, 0.25 mmol), 1,2-dichloro-4iodobenzene 404p (341 mg, $1.25 \mathrm{mmol}), 406(30 \mathrm{mg}, 11 \mathrm{~mol} \%$ ) and $\mathrm{LiO} t \mathrm{Bu}(60 \mathrm{mg}, 0.75 \mathrm{mmol})$ in $\mathrm{Et}_{2} \mathrm{O}(0.5 \mathrm{~mL})$. Purification by column chromatography on silica gel ( $n$-hexane/EtOAc: $\left.70 / 1\right)$ yielded 405t (37.1 mg, 53\%) as a light yellow solid.

M. p.: $108^{\circ} \mathrm{C}$.

${ }^{1}$ H NMR $\left(500 \mathrm{MHz}, \mathrm{CDCl}_{3}\right): \delta=8.19(\mathrm{~d}, J=2.1 \mathrm{~Hz}, 1 \mathrm{H}), 8.05(\mathrm{dd}, J=8.3,0.9 \mathrm{~Hz}, 1 \mathrm{H}), 7.91-7.85$ $(\mathrm{m}, 2 \mathrm{H}), 7.54(\mathrm{~d}, J=8.3 \mathrm{~Hz}, 1 \mathrm{H}), 7.50(\mathrm{ddd}, J=8.3,7.2,1.2 \mathrm{~Hz}, 1 \mathrm{H}), 7.40(\mathrm{ddd}, J=8.3,7.2,1.2 \mathrm{~Hz}$, $1 \mathrm{H})$.

${ }^{13} \mathrm{C}$ NMR $\left(125 \mathrm{MHz}, \mathrm{CDCl}_{3}\right): \delta=165.1\left(\mathrm{C}_{\mathrm{q}}\right), 153.9\left(\mathrm{C}_{\mathrm{q}}\right), 135.1\left(\mathrm{C}_{\mathrm{q}}\right), 135.0\left(\mathrm{C}_{\mathrm{q}}\right), 133.5\left(\mathrm{C}_{\mathrm{q}}\right), 133.4$ $\left(\mathrm{C}_{\mathrm{q}}\right), 131.0(\mathrm{CH}), 129.0(\mathrm{CH}), 126.7(\mathrm{CH}), 126.5(\mathrm{CH}), 125.7(\mathrm{CH}), 123.5(\mathrm{CH}), 121.7(\mathrm{CH})$.

IR (ATR): 2919, 1621, 1555, 1500, 1451, 1215, 1109, 1054, 821, 742, $640 \mathrm{~cm}^{-1}$.

MS (ESI) $m / z$ (relative intensity): $279(100)[\mathrm{M}+\mathrm{H}]^{+}$.

HR-MS (ESI): $m / z$ calcd for $\mathrm{C}_{13} \mathrm{H}_{8} \mathrm{Cl}_{2} \mathrm{NS}[\mathrm{M}+\mathrm{H}]^{+}: 279.9748$, found: 279.9749 .

The spectral data were in accordance with those reported in the literature. ${ }^{[275]}$

\section{2-(p-Tolyl)thiazole (405u)}

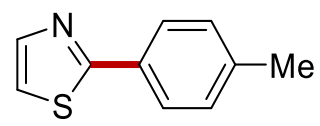

The General Procedure F was followed using thiazole $403 f$ ( $21 \mathrm{mg}, 0.25 \mathrm{mmol}$ ), 4-iodotoluene 404a (273 mg, $1.25 \mathrm{mmol}), 404 \mathrm{a}(30 \mathrm{mg}, 11 \mathrm{~mol} \%)$ and $\mathrm{LiO} t \mathrm{Bu}(60 \mathrm{mg}, 0.75 \mathrm{mmol})$ in $\mathrm{Et}_{2} \mathrm{O}(0.5 \mathrm{~mL})$. Purification by column chromatography on silica gel ( $n$-hexane/EtOAc: $70 / 1)$ yielded 405u (37.7 mg, $86 \%$ ) as a yellow oil.

${ }^{1} \mathbf{H}$ NMR $\left(500 \mathrm{MHz}, \mathrm{CDCl}_{3}\right): \delta=7.87-7.83(\mathrm{~m}, 2 \mathrm{H}), 7.82(\mathrm{~d}, J=3.3 \mathrm{~Hz}, 1 \mathrm{H}), 7.26(\mathrm{~d}, J=3.3 \mathrm{~Hz}$, 1H), $7.24-7.20(\mathrm{~m}, 2 \mathrm{H}), 2.37$ (s, 3H).

${ }^{13}$ C NMR (125 MHz, $\left.\mathrm{CDCl}_{3}\right): \delta=168.6\left(\mathrm{C}_{\mathrm{q}}\right), 143.5(\mathrm{CH}), 140.2\left(\mathrm{C}_{\mathrm{q}}\right), 130.9\left(\mathrm{C}_{\mathrm{q}}\right), 129.6(\mathrm{CH}), 126.4$ $(\mathrm{CH}), 118.3(\mathrm{CH}), 21.4\left(\mathrm{CH}_{3}\right)$.

IR (ATR): 3067, 1613, 1473, 1328, 1162, 1068, 970, 807, 648, $546 \mathrm{~cm}^{-1}$.

MS (ESI) $m / z$ (relative intensity): $176(100)[\mathrm{M}+\mathrm{H}]^{+}$. 
HR-MS (ESI): $m / z$ calcd for $\mathrm{C}_{10} \mathrm{H}_{10} \mathrm{NS}[\mathrm{M}+\mathrm{H}]^{+}: 176.0529$, found: 176.0528 .

The spectral data were in accordance with those reported in the literature. ${ }^{[278]}$

\section{5-Phenyl-2-(m-tolyl)thiazole (405w)}

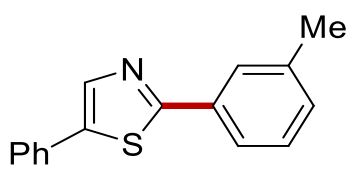

The General Procedure F was followed using 5-phenylthiazole 403g (40 mg, $0.25 \mathrm{mmol}$ ), 3iodotoluene 404h (273 mg, $1.25 \mathrm{mmol}), 406(30 \mathrm{mg}, 11 \mathrm{~mol} \%)$ and $\mathrm{LiO} t \mathrm{Bu}(60 \mathrm{mg}, 0.75 \mathrm{mmol})$ in $\mathrm{Et}_{2} \mathrm{O}(0.5 \mathrm{~mL})$. Purification by column chromatography on silica gel ( $n$-hexane/EtOAc: $\left.70 / 1\right)$ yielded 405w (52.2 $\mathrm{mg}, 83 \%)$ as a light yellow solid.

M. p.: $101^{\circ} \mathrm{C}$.

${ }^{1}$ H NMR $\left(300 \mathrm{MHz}, \mathrm{CDCl}_{3}\right): \delta=8.00(\mathrm{~s}, 1 \mathrm{H}), 7.82-7.79(\mathrm{~m}, 1 \mathrm{H}), 7.74(\mathrm{ddd}, J=7.7,1.8,1.2 \mathrm{~Hz}$, 1H), $7.62-7.59(\mathrm{~m}, 1 \mathrm{H}), 7.59-7.57(\mathrm{~m}, 1 \mathrm{H}), 7.45-7.28(\mathrm{~m}, 5 \mathrm{H}), 7.24-7.21(\mathrm{~m}, 1 \mathrm{H}), 2.42(\mathrm{~s}, 3 \mathrm{H})$ ${ }^{13}$ C NMR (100 MHz, $\left.\mathrm{CDCl}_{3}\right): \delta=167.3\left(\mathrm{C}_{\mathrm{q}}\right), 139.0\left(\mathrm{C}_{\mathrm{q}}\right), 139.0(\mathrm{CH}), 138.7\left(\mathrm{C}_{\mathrm{q}}\right), 133.5\left(\mathrm{C}_{\mathrm{q}}\right), 131.4$ $\left(\mathrm{C}_{\mathrm{q}}\right), 130.8(\mathrm{CH}), 129.0(\mathrm{CH}), 128.8(\mathrm{CH}), 128.2(\mathrm{CH}), 126.8(\mathrm{CH}), 126.6(\mathrm{CH}), 123.5(\mathrm{CH}), 21.4$ $\left(\mathrm{CH}_{3}\right)$.

IR (ATR): 2918, 2855, 1547, 1515, 1453, 1237, 1109, 1001, 956, 813, $792 \mathrm{~cm}^{-1}$.

MS (ESI) $m / z$ (relative intensity): $252(100)[\mathrm{M}+\mathrm{H}]^{+}, 274(3)[\mathrm{M}+\mathrm{Na}]^{+}$.

HR-MS (ESI): $m / z$ calcd for $\mathrm{C}_{16} \mathrm{H}_{14} \mathrm{NS}[\mathrm{M}+\mathrm{H}]^{+}: 252.0843$, found: 252.0841 .

The spectral data were in accordance with those reported in the literature. ${ }^{[268]}$

\section{4,5-Dimethyl-2-(p-tolyl)thiazole (405x)}

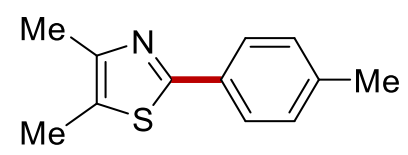

The General Procedure F was followed using 4,5-dimethylthiazole 403h (28 mg, $0.25 \mathrm{mmol})$, 4iodotoluene 404a (273 mg, $1.25 \mathrm{mmol}), 406(30 \mathrm{mg}, 11 \mathrm{~mol} \%)$ and $\mathrm{LiO} t \mathrm{Bu}(60 \mathrm{mg}, 0.75 \mathrm{mmol})$ in $\mathrm{Et}_{2} \mathrm{O}(0.5 \mathrm{~mL})$. Purification by column chromatography on silica gel ( $n$-hexane/EtOAc: $\left.70 / 1\right)$ yielded 405x (43.7 $\mathrm{mg}, 86 \%)$ as a light yellow solid. 
M. p.: $62^{\circ} \mathrm{C}$.

${ }^{1} \mathbf{H}$ NMR $\left(500 \mathrm{MHz}, \mathrm{CDCl}_{3}\right): \delta=7.77-7.68(\mathrm{~m}, 2 \mathrm{H}), 7.18(\mathrm{~d}, J=8.0 \mathrm{~Hz}, 2 \mathrm{H}), 2.36(\mathrm{~s}, 6 \mathrm{H}), 2.35(\mathrm{~s}$, $3 \mathrm{H})$.

${ }^{13} \mathrm{C}$ NMR $\left(125 \mathrm{MHz}, \mathrm{CDCl}_{3}\right): \delta=163.5\left(\mathrm{C}_{\mathrm{q}}\right), 149.0\left(\mathrm{C}_{\mathrm{q}}\right), 139.4\left(\mathrm{C}_{\mathrm{q}}\right), 131.3\left(\mathrm{C}_{\mathrm{q}}\right), 129.4(\mathrm{CH}), 126.0$ $(\mathrm{CH}), 125.9\left(\mathrm{C}_{\mathrm{q}}\right), 21.3\left(\mathrm{CH}_{3}\right), 14.8\left(\mathrm{CH}_{3}\right), 11.4\left(\mathrm{CH}_{3}\right)$.

IR (ATR): 2955, 2923, 2854, 1810, 1480, 1448, 1143, 1082, 847, 785, $689 \mathrm{~cm}^{-1}$.

MS (ESI) $m / z$ (relative intensity): 204 (100) $[\mathrm{M}+\mathrm{H}]^{+}$.

HR-MS (ESI): $m / z$ calcd for $\mathrm{C}_{12} \mathrm{H}_{14} \mathrm{NS}[\mathrm{M}+\mathrm{H}]^{+}: 204.0842$, found: 204.0841.

The spectral data were in accordance with those reported in the literature. ${ }^{[279]}$

\section{2-(4-Chlorophenyl)-4,5-dimethylthiazole (405y)}

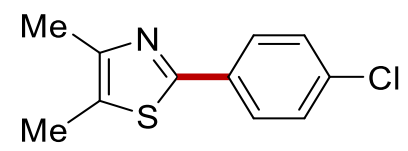

The General Procedure F was followed using 4,5-dimethylthiazole 403h (28 mg, $0.25 \mathrm{mmol}), 1$ chloro-4-iodobenzene $404 \mathrm{f}$ (298 mg, $1.25 \mathrm{mmol}), 406$ (30 mg, $11 \mathrm{~mol} \%$ ) and $\mathrm{LiO} t \mathrm{Bu}(60 \mathrm{mg}, 0.75$ $\mathrm{mmol}$ ) in $\mathrm{Et}_{2} \mathrm{O}(0.5 \mathrm{~mL})$. Purification by column chromatography on silica gel ( $n$-hexane/EtOAc: $\left.70 / 1\right)$ yielded $405 y$ (48.7 $\mathrm{mg}, 87 \%$ ) as a light yellow solid.

M. p.: $93^{\circ} \mathrm{C}$.

${ }^{1} \mathbf{H}$ NMR $\left(400 \mathrm{MHz}, \mathrm{CDCl}_{3}\right): \delta=7.78(\mathrm{ddd}, J=9.1,2.9,2.1 \mathrm{~Hz}, 2 \mathrm{H}), 7.35(\mathrm{ddd}, J=9.1,2.9,2.1 \mathrm{~Hz}$, $2 \mathrm{H}), 2.36(\mathrm{~s}, 6 \mathrm{H})$.

${ }^{13} \mathrm{C}$ NMR $\left(100 \mathrm{MHz}, \mathrm{CDCl}_{3}\right): \delta=161.9\left(\mathrm{C}_{\mathrm{q}}\right), 149.5\left(\mathrm{C}_{\mathrm{q}}\right), 135.2\left(\mathrm{C}_{\mathrm{q}}\right), 132.5\left(\mathrm{C}_{\mathrm{q}}\right), 129.0(\mathrm{CH}), 127.2$ $(\mathrm{CH}), 127.0\left(\mathrm{C}_{\mathrm{q}}\right), 14.8\left(\mathrm{CH}_{3}\right), 11.5\left(\mathrm{CH}_{3}\right)$.

IR (ATR): 2922, 1724, 1679, 1611, 1494, 1364, 1257, 1076, 918, $731 \mathrm{~cm}^{-1}$.

MS (ESI) $m / z$ (relative intensity): 224 (100) $[\mathrm{M}+\mathrm{H}]^{+}$.

HR-MS (ESI): $m / z$ calcd for $\mathrm{C}_{11} \mathrm{H}_{11} \mathrm{CINS}[\mathrm{M}+\mathrm{H}]^{+}:$224.0296, found: 224.0295 .

The spectral data were in accordance with those reported in the literature. ${ }^{[268]}$ 
2-(p-Tolyl)benzo[d]oxazole (447a)

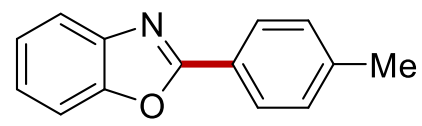

The General Procedure F was followed using benzoxazole 444a (30 mg, $0.25 \mathrm{mmol}$ ), 4-iodotoluene 404a (273 mg, $1.25 \mathrm{mmol}), 406(30 \mathrm{mg}, 11 \mathrm{~mol} \%)$ and $\mathrm{LiO} t \mathrm{Bu}(60 \mathrm{mg}, 0.75 \mathrm{mmol})$ in $\mathrm{Et}_{2} \mathrm{O}(0.5 \mathrm{~mL})$. Purification by column chromatography on silica gel ( $n$-hexane/EtOAc: $70 / 1)$ yielded $447 \mathbf{a}(41.3 \mathrm{mg}$, $79 \%$ ) as a light yellow solid.

M. p.: $123^{\circ} \mathrm{C}$.

${ }^{1} \mathbf{H}$ NMR $\left(500 \mathrm{MHz}, \mathrm{CDCl}_{3}\right): \delta=8.13(\mathrm{~d}, J=8.3 \mathrm{~Hz}, 2 \mathrm{H}), 7.79-7.69(\mathrm{~m}, 1 \mathrm{H}), 7.60-7.50(\mathrm{~m}, 1 \mathrm{H})$, $7.32-7.29(\mathrm{~m}, 3 \mathrm{H}), 2.41(\mathrm{~s}, 3 \mathrm{H})$.

${ }^{13} \mathrm{C}$ NMR $\left(125 \mathrm{MHz}, \mathrm{CDCl}_{3}\right): \delta=163.2\left(\mathrm{C}_{\mathrm{q}}\right), 150.6\left(\mathrm{C}_{\mathrm{q}}\right), 142.1\left(\mathrm{C}_{\mathrm{q}}\right), 142.0\left(\mathrm{C}_{\mathrm{q}}\right), 129.6(\mathrm{CH}), 127.5$ $(\mathrm{CH}), 124.8(\mathrm{CH}), 124.4(\mathrm{CH}), 124.3\left(\mathrm{C}_{\mathrm{q}}\right), 119.8(\mathrm{CH}), 110.4(\mathrm{CH}), 21.6\left(\mathrm{CH}_{3}\right)$.

IR (ATR): 3024, 2919, 1608, 1579, 1556, 1410, 1200, 1055, 926, 756, $380 \mathrm{~cm}^{-1}$.

MS (ESI) $m / z$ (relative intensity): $210(100)[\mathrm{M}+\mathrm{H}]^{+}$.

HR-MS (ESI): $m / z$ calcd for $\mathrm{C}_{14} \mathrm{H}_{12} \mathrm{NO}[\mathrm{M}+\mathrm{H}]^{+}: 210.0915$, found: 210.0913 .

The spectral data were in accordance with those reported in the literature. ${ }^{[273]}$

\section{5-Methyl-2-(p-tolyl)benzo[d] oxazole (447b)}

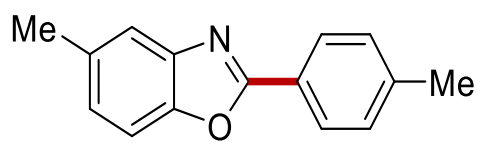

The General Procedure F was followed using 5-methylbenzo[ $d]$ oxazole 444b (33 mg, $0.25 \mathrm{mmol})$, 4-iodotoluene 404a (273 mg, $1.25 \mathrm{mmol}), 406(30 \mathrm{mg}, 11 \mathrm{~mol} \%)$ and $\mathrm{LiO} t \mathrm{Bu}(60 \mathrm{mg}, 0.75 \mathrm{mmol})$ in $\mathrm{Et}_{2} \mathrm{O}(0.5 \mathrm{~mL})$. Purification by column chromatography on silica gel ( $n$-hexane/EtOAc: $\left.70 / 1\right)$ yielded 447b (40.7 mg, 73\%) as a light yellow solid.

M. p.: $135^{\circ} \mathrm{C}$.

${ }^{1} \mathbf{H}$ NMR (400 MHz, $\left.\mathrm{CDCl}_{3}\right): \delta=8.14-8.07(\mathrm{~m}, 2 \mathrm{H}), 7.54-7.50(\mathrm{~m}, 1 \mathrm{H}), 7.41(\mathrm{~d}, J=8.2 \mathrm{~Hz}, 1 \mathrm{H})$, $7.33-7.26(\mathrm{~m}, 2 \mathrm{H}), 7.11(\mathrm{ddd}, J=8.2,1.7,0.7 \mathrm{~Hz}, 1 \mathrm{H}), 2.47-2.45(\mathrm{~m}, 3 \mathrm{H}), 2.41(\mathrm{~s}, 3 \mathrm{H})$.

${ }^{13} \mathrm{C}$ NMR $\left(100 \mathrm{MHz}, \mathrm{CDCl}_{3}\right): \delta=163.3\left(\mathrm{C}_{\mathrm{q}}\right), 148.9\left(\mathrm{C}_{\mathrm{q}}\right), 142.3\left(\mathrm{C}_{\mathrm{q}}\right), 141.8\left(\mathrm{C}_{\mathrm{q}}\right), 134.2\left(\mathrm{C}_{\mathrm{q}}\right), 129.6$ 
$(\mathrm{CH}), 127.5(\mathrm{CH}), 125.9(\mathrm{CH}), 124.5\left(\mathrm{C}_{\mathrm{q}}\right), 119.7(\mathrm{CH}), 109.8(\mathrm{CH}), 21.6\left(\mathrm{CH}_{3}\right), 21.5\left(\mathrm{CH}_{3}\right)$.

IR (ATR): 2958, 2866, 1616, 1581, 1268, 1018, 823, 807, 729, 650, $500 \mathrm{~cm}^{-1}$.

MS (ESI) $m / z$ (relative intensity): $224(100)[\mathrm{M}+\mathrm{H}]^{+}, 246(5)[\mathrm{M}+\mathrm{Na}]^{+}$.

HR-MS (ESI): $m / z$ calcd for $\mathrm{C}_{15} \mathrm{H}_{14} \mathrm{NO}[\mathrm{M}+\mathrm{H}]^{+}: 224.1068$, found: 224.1070 .

The spectral data were in accordance with those reported in the literature. ${ }^{[276]}$

\section{5-(tert-Butyl)-2-(p-tolyl)benzo[d]oxazole (447c)}

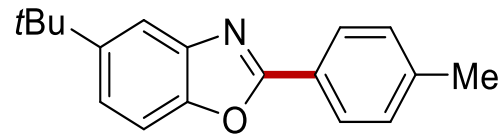

The General Procedure F was followed using 5-(tert-butyl)benzo[ $d]$ oxazole $444 \mathrm{c}$ (44 mg, 0.25 mmol), 4-iodotoluene 404a (273 mg, $1.25 \mathrm{mmol}), 406$ (30 mg, $11 \mathrm{~mol} \%$ ) and LiO $t \mathrm{Bu}(60 \mathrm{mg}, 0.75$ $\mathrm{mmol})$ in $\mathrm{Et}_{2} \mathrm{O}(0.5 \mathrm{~mL})$. Purification by column chromatography on silica gel ( $n$-hexane/EtOAc: $\left.70 / 1\right)$ yielded 447c (49.1 mg, 74\%) as a light yellow solid.

M. p.: $113^{\circ} \mathrm{C}$.

${ }^{1} \mathbf{H}$ NMR $\left(400 \mathrm{MHz}, \mathrm{CDCl}_{3}\right): \delta=8.30-8.25(\mathrm{~m}, 2 \mathrm{H}), 7.94(\mathrm{dd}, J=1.9,0.6 \mathrm{~Hz}, 1 \mathrm{H}), 7.62(\mathrm{dd}, J=8.6$, $0.6 \mathrm{~Hz}, 1 \mathrm{H}), 7.54$ (dd, $J=8.6,1.9 \mathrm{~Hz}, 1 \mathrm{H}), 7.49-7.44(\mathrm{~m}, 2 \mathrm{H}), 2.57$ (s, 3H), 1.54 (s, 9H).

${ }^{13}$ C NMR $\left(100 \mathrm{MHz}, \mathrm{CDCl}_{3}\right): \delta=163.4\left(\mathrm{C}_{\mathrm{q}}\right), 148.7\left(\mathrm{C}_{\mathrm{q}}\right), 148.0\left(\mathrm{C}_{\mathrm{q}}\right), 142.1\left(\mathrm{C}_{\mathrm{q}}\right), 141.8\left(\mathrm{C}_{\mathrm{q}}\right), 129.6$ $(\mathrm{CH}), 127.5(\mathrm{CH}), 124.6\left(\mathrm{C}_{\mathrm{q}}\right), 122.5(\mathrm{CH}), 116.3(\mathrm{CH}), 109.6(\mathrm{CH}), 34.9\left(\mathrm{C}_{\mathrm{q}}\right), 31.8\left(\mathrm{CH}_{3}\right), 21.6\left(\mathrm{CH}_{3}\right)$. IR (ATR): 2920, 1616, 1556, 1497, 1462, 1215, 1166, 1118, 1049, 919, $831 \mathrm{~cm}^{-1}$.

MS (ESI) $m / z$ (relative intensity): $266(100)[\mathrm{M}+\mathrm{H}]^{+}$.

HR-MS (ESI): $m / z$ calcd for $\mathrm{C}_{18} \mathrm{H}_{20} \mathrm{NO}[\mathrm{M}+\mathrm{H}]^{+}: 266.1542$, found: 266.1540 .

The spectral data were in accordance with those reported in the literature. ${ }^{[276]}$

\section{5-Chloro-2-(p-tolyl)benzo[d] oxazole (447d)}

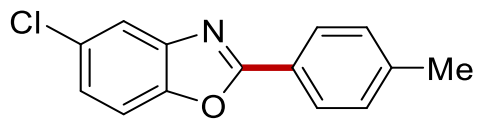

The General Procedure F was followed using 5-chlorobenzo[ $d]$ oxazole 444d (38 mg, $0.25 \mathrm{mmol}$ ), 4-iodotoluene 404a (273 mg, $1.25 \mathrm{mmol}), 406(30 \mathrm{mg}, 11 \mathrm{~mol} \%)$ and $\mathrm{LiO} t \mathrm{Bu}(60 \mathrm{mg}, 0.75 \mathrm{mmol})$ in 
$\mathrm{Et}_{2} \mathrm{O}(0.5 \mathrm{~mL})$. Purification by column chromatography on silica gel ( $n$-hexane/EtOAc: $\left.70 / 1\right)$ yielded 447d (31.1 mg, 51\%) as a light yellow solid.

M. p.: $124^{\circ} \mathrm{C}$.

${ }^{1}$ H NMR (400 MHz, $\left.\mathrm{CDCl}_{3}\right): \delta=8.27-8.22(\mathrm{~m}, 2 \mathrm{H}), 7.79(\mathrm{dd}, J=8.5,0.4 \mathrm{~Hz}, 1 \mathrm{H}), 7.71(\mathrm{dd}, J=2.1$, $0.4 \mathrm{~Hz}, 1 \mathrm{H}), 7.48-7.44(\mathrm{~m}, 3 \mathrm{H}), 2.58(\mathrm{~s}, 3 \mathrm{H})$.

${ }^{13}$ C NMR (100 MHz, $\left.\mathrm{CDCl}_{3}\right): \delta=163.9\left(\mathrm{C}_{\mathrm{q}}\right), 150.8\left(\mathrm{C}_{\mathrm{q}}\right), 142.4\left(\mathrm{C}_{\mathrm{q}}\right), 141.0\left(\mathrm{C}_{\mathrm{q}}\right), 130.4\left(\mathrm{C}_{\mathrm{q}}\right), 129.7$ $(\mathrm{CH}), 127.6(\mathrm{CH}), 125.1(\mathrm{CH}), 123.9\left(\mathrm{C}_{\mathrm{q}}\right), 120.2(\mathrm{CH}), 111.1(\mathrm{CH}), 21.7\left(\mathrm{CH}_{3}\right)$.

IR (ATR): 2956, 2851, 1737, 1461, 1377, 1190, 1121, 1082, 716, 649, $597 \mathrm{~cm}^{-1}$.

MS (ESI) $m / z$ (relative intensity): $244(100)[\mathrm{M}+\mathrm{H}]^{+}$.

HR-MS (ESI): $m / z$ calcd for $\mathrm{C}_{14} \mathrm{H}_{11} \mathrm{ClNO}[\mathrm{M}+\mathrm{H}]^{+}: 244.0524$, found: 244.0524 .

The spectral data were in accordance with those reported in the literature. ${ }^{[277]}$

\section{2-Phenylbenzo[d]oxazole (447e)}

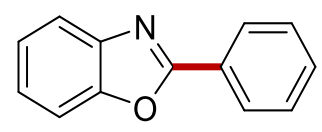

The General Procedure F was followed using benzoxazole 444a (30 mg, $0.25 \mathrm{mmol}$ ), iodobenzene 404b (255 mg, $1.25 \mathrm{mmol}), 406(30 \mathrm{mg}, 11 \mathrm{~mol} \%)$ and $\mathrm{LiO} t \mathrm{Bu}(60 \mathrm{mg}, 0.75 \mathrm{mmol})$ in $\mathrm{Et}_{2} \mathrm{O}(0.5 \mathrm{~mL})$. Purification by column chromatography on silica gel ( $n$-hexane/EtOAc: 70/1) yielded 447e (39.0 mg, $80 \%)$ as a light yellow solid.

M. p.: $100^{\circ} \mathrm{C}$.

${ }^{1}$ H NMR (400 MHz, $\left.\mathrm{CDCl}_{3}\right): \delta=8.28-8.22(\mathrm{~m}, 2 \mathrm{H}), 7.76(\mathrm{ddd}, J=6.0,3.3,0.7 \mathrm{~Hz}, 1 \mathrm{H}), 7.57$ (ddd, $J=6.0,3.3,0.7 \mathrm{~Hz}, 1 \mathrm{H}), 7.54-7.49(\mathrm{~m}, 3 \mathrm{H}), 7.34(\mathrm{dd}, J=6.0,3.3 \mathrm{~Hz}, 2 \mathrm{H})$.

${ }^{13}$ C NMR (100 MHz, $\left.\mathrm{CDCl}_{3}\right): \delta=163.0\left(\mathrm{C}_{\mathrm{q}}\right), 150.8\left(\mathrm{C}_{\mathrm{q}}\right), 142.1\left(\mathrm{C}_{\mathrm{q}}\right), 131.5(\mathrm{CH}), 129.9(\mathrm{CH}), 127.6$ $(\mathrm{CH}), 127.2\left(\mathrm{C}_{\mathrm{q}}\right), 125.1(\mathrm{CH}), 124.6(\mathrm{CH}), 120.0(\mathrm{CH}), 110.6(\mathrm{CH})$.

IR (ATR): 2922, 2020, 1973, 1555, 1474, 1263, 1182, 1057, 865, 791, $719 \mathrm{~cm}^{-1}$.

MS (ESI) $m / z$ (relative intensity): $196(100)[\mathrm{M}+\mathrm{H}]^{+}$.

HR-MS (ESI): $m / z$ calcd for $\mathrm{C}_{13} \mathrm{H}_{10} \mathrm{NO}[\mathrm{M}+\mathrm{H}]^{+}:$196.0755, found: 196.0756.

The spectral data were in accordance with those reported in the literature. ${ }^{[275]}$ 


\section{5-Methyl-2-(m-tolyl)benzo[d]oxazole (447f)}

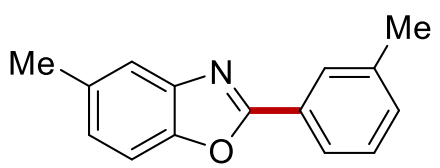

The General Procedure F was followed using 5-methylbenzo[ $[d]$ oxazole 444b (33 mg, $0.25 \mathrm{mmol})$, 3-iodotoluene 404h (273 mg, $1.25 \mathrm{mmol}), 406(30 \mathrm{mg}, 11 \mathrm{~mol} \%)$ and $\mathrm{LiO} t \mathrm{Bu}(60 \mathrm{mg}, 0.75 \mathrm{mmol})$ in $\mathrm{Et}_{2} \mathrm{O}(0.5 \mathrm{~mL})$. Purification by column chromatography on silica gel ( $n$-hexane/EtOAc: $\left.70 / 1\right)$ yielded 447f (43.0 mg, 77\%) as a light yellow solid.

M. p.: $85^{\circ} \mathrm{C}$.

${ }^{1}$ H NMR $\left(300 \mathrm{MHz}, \mathrm{CDCl}_{3}\right): \delta=8.11-8.02(\mathrm{~m}, 1 \mathrm{H}), 8.07-7.96(\mathrm{~m}, 1 \mathrm{H}), 7.41(\mathrm{ddd}, J=8.3,0.3 \mathrm{~Hz}$, 1H), $7.49-7.33(\mathrm{~m}, 2 \mathrm{H}), 7.38-7.26(\mathrm{~m}, 1 \mathrm{H}), 7.13(\mathrm{ddd}, J=8.3,1.7,0.7 \mathrm{~Hz}, 1 \mathrm{H}), 2.47(\mathrm{~s}, 3 \mathrm{H}), 2.44$ $(\mathrm{s}, 3 \mathrm{H})$.

${ }^{13} \mathrm{C} \mathrm{NMR}\left(75 \mathrm{MHz}, \mathrm{CDCl}_{3}\right): \delta=163.2\left(\mathrm{C}_{\mathrm{q}}\right), 148.9\left(\mathrm{C}_{\mathrm{q}}\right), 142.2\left(\mathrm{C}_{\mathrm{q}}\right), 138.6\left(\mathrm{C}_{\mathrm{q}}\right), 134.3\left(\mathrm{C}_{\mathrm{q}}\right), 132.1(\mathrm{CH})$, $128.7(\mathrm{CH}), 128.0(\mathrm{CH}), 127.1\left(\mathrm{C}_{\mathrm{q}}\right), 126.0(\mathrm{CH}), 124.6(\mathrm{CH}), 119.8(\mathrm{CH}), 109.8(\mathrm{CH}), 21.6\left(\mathrm{CH}_{3}\right)$, $21.4\left(\mathrm{CH}_{3}\right)$.

IR (ATR): 2919, 1613, 1483, 1423, 1143, 1055, 971, 873, 815, 631, $478 \mathrm{~cm}^{-1}$

MS (ESI) $m / z$ (relative intensity): $224(100)[\mathrm{M}+\mathrm{H}]^{+}, 246(5)[\mathrm{M}+\mathrm{Na}]^{+}$

HR-MS (ESI): $m / z$ calcd for $\mathrm{C}_{15} \mathrm{H}_{14} \mathrm{NO}[\mathrm{M}+\mathrm{H}]^{+}: 224.1071$, found: 224.1070 .

The spectral data were in accordance with those reported in the literature. ${ }^{[268]}$

\section{2-(p-Tolyl)oxazole $(447 \mathrm{~g})$}

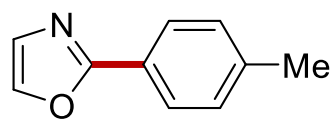

The General Procedure F was followed using oxazole 444e (17 mg, $0.25 \mathrm{mmol})$, 4-iodotoluene 404a (273 mg, $1.25 \mathrm{mmol}), 406(30 \mathrm{mg}, 11 \mathrm{~mol} \%)$ and $\mathrm{LiO} t \mathrm{Bu}(60 \mathrm{mg}, 0.75 \mathrm{mmol})$ in $\mathrm{Et}_{2} \mathrm{O}(0.5 \mathrm{~mL})$. Purification by column chromatography on silica gel ( $n$-hexane/EtOAc: 70/1) yielded $447 \mathrm{~g}(24.3 \mathrm{mg}$, $61 \%)$ as a yellow oil.

${ }^{1} \mathbf{H}$ NMR (400 MHz, $\left.\mathrm{CDCl}_{3}\right): \delta=7.93-7.89(\mathrm{~m}, 2 \mathrm{H}), 7.66(\mathrm{~d}, J=0.8 \mathrm{~Hz}, 1 \mathrm{H}), 7.27-7.25(\mathrm{~m}, 1 \mathrm{H})$, $7.25-7.23(\mathrm{~m}, 1 \mathrm{H}), 7.19(\mathrm{~d}, J=0.8 \mathrm{~Hz}, 1 \mathrm{H}), 2.38(\mathrm{~s}, 3 \mathrm{H})$. 
${ }^{13}$ C NMR (100 MHz, $\left.\mathrm{CDCl}_{3}\right): \delta=162.2\left(\mathrm{C}_{\mathrm{q}}\right), 140.6\left(\mathrm{C}_{\mathrm{q}}\right), 138.2(\mathrm{CH}), 129.5(\mathrm{CH}), 128.2(\mathrm{CH}), 126.3$ $(\mathrm{CH}), 124.8\left(\mathrm{C}_{\mathrm{q}}\right), 21.5\left(\mathrm{CH}_{3}\right)$.

IR (ATR): 2924, 2230, 2211, 2171, 2042, 1976, 714, 686, 585, $487 \mathrm{~cm}^{-1}$.

MS (ESI) $m / z$ (relative intensity): $160(100)[\mathrm{M}+\mathrm{H}]^{+}$.

HR-MS (ESI): $m / z$ calcd for $\mathrm{C}_{10} \mathrm{H}_{10} \mathrm{NO}[\mathrm{M}+\mathrm{H}]^{+}: 160.0759$, found: 160.0758 .

The spectral data were in accordance with those reported in the literature. ${ }^{[280]}$

\section{2,5-Diphenyloxazole (447h)}

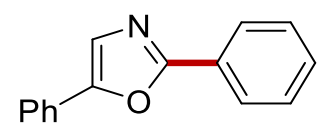

The General Procedure F was followed using 5-phenyloxazole 444f (36 mg, $0.25 \mathrm{mmol}$ ), iodobenzene 404b (255 mg, $1.25 \mathrm{mmol}), \mathbf{4 0 6}(30 \mathrm{mg}, 11 \mathrm{~mol} \%)$ and $\mathrm{LiO} t \mathrm{Bu}(60 \mathrm{mg}, 0.75 \mathrm{mmol})$ in $\mathrm{Et}_{2} \mathrm{O}(0.5 \mathrm{~mL})$. Purification by column chromatography on silica gel ( $n$-hexane/EtOAc: $\left.70 / 1\right)$ yielded 447h (42.0 mg, 76\%) as a light yellow solid.

M. p.: $70^{\circ} \mathrm{C}$.

${ }^{1} \mathbf{H}$ NMR $\left(300 \mathrm{MHz}, \mathrm{CDCl}_{3}\right): \delta=8.13-8.07(\mathrm{~m}, 2 \mathrm{H}), 7.74-7.72(\mathrm{~m}, 1 \mathrm{H}), 7.71-7.69(\mathrm{~m}, 1 \mathrm{H}), 7.49$ $-7.41(\mathrm{~m}, 6 \mathrm{H}), 7.37-7.29(\mathrm{~m}, 1 \mathrm{H})$.

${ }^{13} \mathrm{C}$ NMR (75 MHz, $\left.\mathrm{CDCl}_{3}\right): \delta=161.0\left(\mathrm{C}_{\mathrm{q}}\right), 151.2\left(\mathrm{C}_{\mathrm{q}}\right), 130.2(\mathrm{CH}), 128.8(\mathrm{CH}), 128.7(\mathrm{CH}), 128.3$ $(\mathrm{CH}), 128.0\left(\mathrm{C}_{\mathrm{q}}\right), 127.4\left(\mathrm{C}_{\mathrm{q}}\right), 126.2(\mathrm{CH}), 124.1(\mathrm{CH}), 123.4(\mathrm{CH})$.

IR (ATR): 2955, 2923, 2853, 1731, 1684, 1749, 1092, 1014, 934, $685 \mathrm{~cm}^{-1}$.

MS (ESI) $m / z$ (relative intensity): $222(100)[\mathrm{M}+\mathrm{H}]^{+}$.

HR-MS (ESI): $m / z$ calcd for $\mathrm{C}_{15} \mathrm{H}_{12} \mathrm{NO}[\mathrm{M}+\mathrm{H}]^{+}: 222.0913$, found: 222.0913.

The spectral data were in accordance with those reported in the literature. ${ }^{[268]}$

2-(4-Chlorophenyl)-5-phenyloxazole (447i)<smiles>Clc1ccc(-c2ncc(-c3ccccc3)o2)cc1</smiles>

The General Procedure F was followed using 5-phenyloxazole 444f (36 mg, 0.25 mmol), 1-chloro- 
4-iodobenzene 404f (298 mg, $1.25 \mathrm{mmol}), 406$ (30 mg, $11 \mathrm{~mol} \%$ ) and $\mathrm{LiO} t \mathrm{Bu}(60 \mathrm{mg}, 0.75 \mathrm{mmol})$ in $\mathrm{Et}_{2} \mathrm{O}(0.5 \mathrm{~mL})$. Purification by column chromatography on silica gel ( $n$-hexane/EtOAc: $\left.70 / 1\right)$ yielded 447i (50.5 mg, 79\%) as a light yellow solid.

M. p.: $115^{\circ} \mathrm{C}$.

${ }^{1}$ H NMR (400 MHz, $\left.\mathrm{CDCl}_{3}\right): \delta=8.05-7.99(\mathrm{~m}, 2 \mathrm{H}), 7.72-7.67(\mathrm{~m}, 2 \mathrm{H}), 7.47-7.40(\mathrm{~m}, 5 \mathrm{H}), 7.37$ $-7.30(\mathrm{~m}, 1 \mathrm{H})$.

${ }^{13}$ C NMR (100 MHz, $\left.\mathrm{CDCl}_{3}\right): \delta=160.2\left(\mathrm{C}_{\mathrm{q}}\right), 151.5\left(\mathrm{C}_{\mathrm{q}}\right), 136.4\left(\mathrm{C}_{\mathrm{q}}\right), 129.1(\mathrm{CH}), 129.0(\mathrm{CH}), 128.6$ $(\mathrm{CH}), 127.8\left(\mathrm{C}_{\mathrm{q}}\right), 127.5(\mathrm{CH}), 126.0\left(\mathrm{C}_{\mathrm{q}}\right), 124.2(\mathrm{CH}), 123.5(\mathrm{CH})$.

IR (ATR): 2956, 2923, 2855, 1727, 1682, 1471, 1133, 761, 725, $383 \mathrm{~cm}^{-1}$.

MS (ESI) $m / z$ (relative intensity): $256(100)[\mathrm{M}+\mathrm{H}]^{+}$.

HR-MS (ESI): $m / z$ calcd for $\mathrm{C}_{15} \mathrm{H}_{11} \mathrm{CINO}[\mathrm{M}+\mathrm{H}]^{+}: 256.0521$, found: 256.0523 .

The spectral data were in accordance with those reported in the literature. ${ }^{[268]}$

\section{5-Phenyl-2-(m-tolyl)oxazole (447j)}

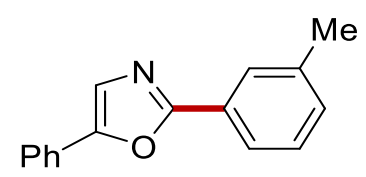

The General Procedure F was followed using 5-phenyloxazole 444f (36 mg, $0.25 \mathrm{mmol}$ ), 3iodotoluene 404h (273 mg, $1.25 \mathrm{mmol}), 406(30 \mathrm{mg}, 11 \mathrm{~mol} \%)$ and $\mathrm{LiO} t \mathrm{Bu}(60 \mathrm{mg}, 0.75 \mathrm{mmol})$ in $\mathrm{Et}_{2} \mathrm{O}(0.5 \mathrm{~mL})$. Purification by column chromatography on silica gel ( $n$-hexane/EtOAc: $\left.70 / 1\right)$ yielded 447j (43.5 mg, 74\%) as a light yellow solid.

M. p.: $89^{\circ} \mathrm{C}$.

${ }^{1} \mathbf{H}$ NMR $\left(300 \mathrm{MHz}, \mathrm{CDCl}_{3}\right): \delta=7.94-7.87(\mathrm{~m}, 2 \mathrm{H}), 7.74-7.69(\mathrm{~m}, 2 \mathrm{H}), 7.48-7.39(\mathrm{~m}, 3 \mathrm{H}), 7.39$ - $7.29(\mathrm{~m}, 2 \mathrm{H}), 7.29-7.24(\mathrm{~m}, 1 \mathrm{H}), 2.43(\mathrm{~s}, 3 \mathrm{H})$.

${ }^{13} \mathrm{C}$ NMR $\left(75 \mathrm{MHz}, \mathrm{CDCl}_{3}\right): \delta=161.3\left(\mathrm{C}_{\mathrm{q}}\right), 151.1\left(\mathrm{C}_{\mathrm{q}}\right), 138.6\left(\mathrm{C}_{\mathrm{q}}\right), 131.1(\mathrm{CH}), 128.9(\mathrm{CH}), 128.7$ $(\mathrm{CH}), 128.4(\mathrm{CH}), 128.0\left(\mathrm{C}_{\mathrm{q}}\right), 127.3\left(\mathrm{C}_{\mathrm{q}}\right), 126.8(\mathrm{CH}), 124.2(\mathrm{CH}), 123.4(\mathrm{CH}), 123.4(\mathrm{CH}), 21.4$ $\left(\mathrm{CH}_{3}\right)$.

IR (ATR): 3055, 1886, 1499, 1231, 1099, 851, 823, 686, 609, $512 \mathrm{~cm}^{-1}$.

MS (ESI) $m / z$ (relative intensity): $236(100)[\mathrm{M}+\mathrm{H}]^{+}, 258(3)[\mathrm{M}+\mathrm{Na}]^{+}$. 
HR-MS (ESI): $m / z$ calcd for $\mathrm{C}_{16} \mathrm{H}_{14} \mathrm{NO}[\mathrm{M}+\mathrm{H}]^{+}: 236.1071$, found: 236.1070 .

The spectral data were in accordance with those reported in the literature. ${ }^{[268]}$

\section{5-(4-Fluorophenyl)-2-phenyloxazole (447k)}

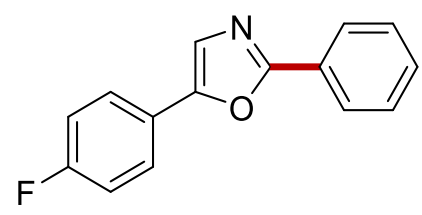

The General Procedure F was followed using 5-(4-fluorophenyl)oxazole 444g (41 mg, $0.25 \mathrm{mmol}$ ), iodobenzene 404b (255 mg, $1.25 \mathrm{mmol})$, $406(30 \mathrm{mg}, 11 \mathrm{~mol} \%)$ and $\mathrm{LiO} t \mathrm{Bu}(60 \mathrm{mg}, 0.75 \mathrm{mmol})$ in $\mathrm{Et}_{2} \mathrm{O}(0.5 \mathrm{~mL})$. Purification by column chromatography on silica gel ( $n$-hexane/EtOAc: $\left.70 / 1\right)$ yielded 447k (48.4 mg, 81\%) as a light yellow solid.

M. p.: $90^{\circ} \mathrm{C}$.

${ }^{1} \mathbf{H}$ NMR $\left(400 \mathrm{MHz}, \mathrm{CDCl}_{3}\right): \delta=8.11-8.06(\mathrm{~m}, 2 \mathrm{H}), 7.71-7.66(\mathrm{~m}, 2 \mathrm{H}), 7.50-7.43(\mathrm{~m}, 3 \mathrm{H}), 7.37$ (s, 1H), $7.16-7.10(\mathrm{~m}, 2 \mathrm{H})$.

${ }^{13} \mathrm{C}$ NMR $\left(100 \mathrm{MHz}, \mathrm{CDCl}_{3}\right): \delta=162.7\left(\mathrm{~d}, J_{\mathrm{C}-\mathrm{F}}=249 \mathrm{~Hz}, \mathrm{C}_{\mathrm{q}}\right), 161.1\left(\mathrm{C}_{\mathrm{q}}\right), 150.4\left(\mathrm{C}_{\mathrm{q}}\right), 130.4(\mathrm{CH})$, $128.8(\mathrm{CH}), 127.4\left(\mathrm{C}_{\mathrm{q}}\right), 126.3(\mathrm{CH}), 126.1\left(\mathrm{~d}, J_{\mathrm{C}-\mathrm{F}}=8 \mathrm{~Hz}, \mathrm{CH}\right), 124.4\left(\mathrm{~d}, J_{\mathrm{C}-\mathrm{F}}=3 \mathrm{~Hz}, \mathrm{C}_{\mathrm{q}}\right), 123.1(\mathrm{~d}$, $\left.J_{\mathrm{C}-\mathrm{F}}=1 \mathrm{~Hz}, \mathrm{CH}\right), 116.1\left(\mathrm{~d}, J_{\mathrm{C}-\mathrm{F}}=22 \mathrm{~Hz}, \mathrm{CH}\right)$.

${ }^{19}$ F NMR $\left(282 \mathrm{MHz}, \mathrm{CDCl}_{3}\right): \delta=-112.21(\mathrm{ddd}, J=13.8,8.7,5.1 \mathrm{~Hz})$.

IR (ATR): 2917, 1724, 1608, 1497, 1362, 1323, 1260, 1106, 963, 934, $752 \mathrm{~cm}^{-1}$.

MS (ESI) $m / z$ (relative intensity): $240(100)[\mathrm{M}+\mathrm{H}]^{+}$.

HR-MS (ESI): $m / z$ calcd for $\mathrm{C}_{15} \mathrm{H}_{11} \mathrm{FNO}[\mathrm{M}+\mathrm{H}]^{+}: 240.0818$, found: 240.0819 .

The spectral data were in accordance with those reported in the literature. ${ }^{[268]}$

\section{5-(Benzo[d][1,3]dioxol-5-yl)-2-(p-tolyl)oxazole (447l)}

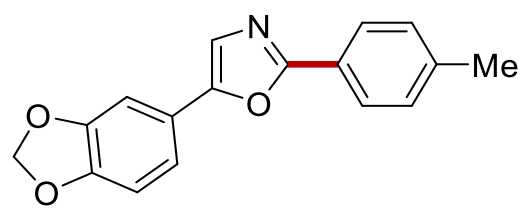

The General Procedure F was followed using 5-(benzo[ $d][1,3]$ dioxol-5-yl)oxazole 444h (47 mg, 0.25 mmol), 4-iodotoluene 404a (273 mg, $1.25 \mathrm{mmol}), 406$ (30 mg, $11 \mathrm{~mol} \%$ ) and $\mathrm{LiO} t \mathrm{Bu}(60 \mathrm{mg}, 0.75$ 
$\mathrm{mmol})$ in $\mathrm{Et}_{2} \mathrm{O}(0.5 \mathrm{~mL})$. Purification by column chromatography on silica gel ( $n$-hexane/EtOAc: $\left.70 / 1\right)$ yielded 4471 (58.7 mg, 84\%) as a light yellow solid.

M. p.: $125^{\circ} \mathrm{C}$.

${ }^{1} \mathbf{H}$ NMR $\left(400 \mathrm{MHz}, \mathrm{CDCl}_{3}\right): \delta=7.98-7.90(\mathrm{~m}, 2 \mathrm{H}), 7.28-7.26(\mathrm{~m}, 2 \mathrm{H}), 7.25-7.23(\mathrm{~m}, 1 \mathrm{H}), 7.20$ $(\mathrm{dd}, J=8.1,1.7 \mathrm{~Hz}, 1 \mathrm{H}), 7.14(\mathrm{dd}, J=1.7,0.4 \mathrm{~Hz}, 1 \mathrm{H}), 6.85(\mathrm{dd}, J=8.1,0.5 \mathrm{~Hz}, 1 \mathrm{H}), 5.99(\mathrm{~s}, 2 \mathrm{H})$, $2.39(\mathrm{~s}, 3 \mathrm{H})$.

${ }^{13}$ C NMR (100 MHz, $\left.\mathrm{CDCl}_{3}\right): \delta=160.9\left(\mathrm{C}_{\mathrm{q}}\right), 150.8\left(\mathrm{C}_{\mathrm{q}}\right), 148.2\left(\mathrm{C}_{\mathrm{q}}\right), 147.8\left(\mathrm{C}_{\mathrm{q}}\right), 140.5\left(\mathrm{C}_{\mathrm{q}}\right), 129.5$ $(\mathrm{CH}), 126.1(\mathrm{CH}), 124.7\left(\mathrm{C}_{\mathrm{q}}\right), 122.3\left(\mathrm{C}_{\mathrm{q}}\right), 122.2(\mathrm{CH}), 118.2(\mathrm{CH}), 108.8(\mathrm{CH}), 104.8(\mathrm{CH}), 101.3$ $\left(\mathrm{CH}_{2}\right), 21.5\left(\mathrm{CH}_{3}\right)$.

IR (ATR): 2898, 1726, 1683, 1609, 1545, 1363,1287, 1129, 1062, 963, $776 \mathrm{~cm}^{-1}$.

MS (ESI) $m / z$ (relative intensity): $280(100)[\mathrm{M}+\mathrm{H}]^{+}, 302(10)[\mathrm{M}+\mathrm{Na}]^{+}$.

HR-MS (ESI): $m / z$ calcd for $\mathrm{C}_{17} \mathrm{H}_{14} \mathrm{NO}_{3}[\mathrm{M}+\mathrm{H}]^{+}: 280.0967$, found: 280.0968 .

\section{5-(Benzo[d][1,3]dioxol-5-yl)-2-phenyloxazole (447m)}

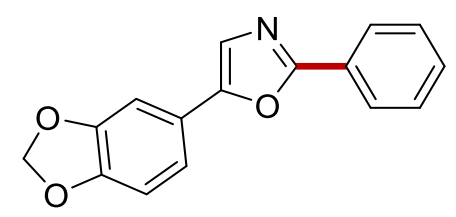

The General Procedure F was followed using 5-(benzo[ $d][1,3]$ dioxol-5-yl)oxazole 444h (47 mg, 0.25 mmol), iodobenzene 404b (255 mg, $1.25 \mathrm{mmol}), 406$ (30 mg, $11 \mathrm{~mol} \%$ ) and LiOt Bu (60 mg, 0.75 $\mathrm{mmol})$ in $\mathrm{Et}_{2} \mathrm{O}(0.5 \mathrm{~mL})$. Purification by column chromatography on silica gel ( $n$-hexane/EtOAc: $\left.70 / 1\right)$ yielded $447 \mathrm{~m}(57.7 \mathrm{mg}, 87 \%)$ as a light yellow solid.

M. p.: $136^{\circ} \mathrm{C}$.

${ }^{1}$ H NMR $\left(400 \mathrm{MHz}, \mathrm{CDCl}_{3}\right): \delta=8.10-8.03(\mathrm{~m}, 2 \mathrm{H}), 7.49-7.38(\mathrm{~m}, 3 \mathrm{H}), 7.28(\mathrm{~s}, 1 \mathrm{H}), 7.21(\mathrm{dd}, J$ $=8.1,1.7 \mathrm{~Hz}, 1 \mathrm{H}), 7.15(\mathrm{dd}, J=1.7,0.4 \mathrm{~Hz}, 1 \mathrm{H}), 6.86(\mathrm{dd}, J=8.1,0.4 \mathrm{~Hz}, 1 \mathrm{H}), 5.99(\mathrm{~s}, 2 \mathrm{H})$.

${ }^{13} \mathrm{C}$ NMR $\left(100 \mathrm{MHz}, \mathrm{CDCl}_{3}\right): \delta=160.6\left(\mathrm{C}_{\mathrm{q}}\right), 151.1\left(\mathrm{C}_{\mathrm{q}}\right), 148.2\left(\mathrm{C}_{\mathrm{q}}\right), 147.9\left(\mathrm{C}_{\mathrm{q}}\right), 130.2(\mathrm{CH}), 128.8$ $(\mathrm{CH}), 127.4\left(\mathrm{C}_{\mathrm{q}}\right), 126.1(\mathrm{CH}), 122.3(\mathrm{CH}), 122.2\left(\mathrm{C}_{\mathrm{q}}\right), 118.3(\mathrm{CH}), 108.8(\mathrm{CH}), 104.8(\mathrm{CH}), 101.4$ $\left(\mathrm{CH}_{2}\right)$.

IR (ATR): 2865, 1605, 1349, 1276, 1109, 1088, 964, 854, 774, 589, $422 \mathrm{~cm}^{-1}$. MS (ESI) $m / z$ (relative intensity): $266(100)[\mathrm{M}+\mathrm{H}]^{+}$. 
HR-MS (ESI): $m / z$ calcd for $\mathrm{C}_{16} \mathrm{H}_{12} \mathrm{NO}_{3}[\mathrm{M}+\mathrm{H}]^{+}: 266.0817$, found: 266.0815 .

The spectral data were in accordance with those reported in the literature. ${ }^{[268]}$

\section{1-Methyl-2-(p-tolyl)-1H-benzo[d]imidazole (446a)}

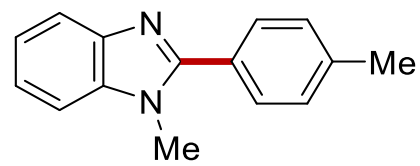

1) The General Procedure $\mathbf{G}$ was followed using 1-methyl-1 $H$-benzo[d]imidazole $445 a$ (33 mg, $0.25 \mathrm{mmol})$, 4-iodotoluene 404a (273 mg, $1.25 \mathrm{mmol}), 406(30 \mathrm{mg}, 11 \mathrm{~mol} \%)$ and $\mathrm{K}_{3} \mathrm{PO}_{4}(159 \mathrm{mg}$, $0.75 \mathrm{mmol})$ in THF $(0.5 \mathrm{~mL})$. Purification by column chromatography on silica gel ( $n$-hexane/EtOAc: 4/1) yielded 446a (35.0 mg, 63\%) as a light yellow solid.

2) The General Procedure $\mathbf{H}$ was followed using 1-methyl-1H-benzo $[d]$ imidazole $445 a(33 \mathrm{mg}$, $0.25 \mathrm{mmol})$, 4-bromotoluene $447 \mathrm{a}(273 \mathrm{mg}, 1.25 \mathrm{mmol}), 406(30 \mathrm{mg}, 11 \mathrm{~mol} \%)$ and $\mathrm{Cs}_{2} \mathrm{CO}_{3}(244 \mathrm{mg}$, $0.75 \mathrm{mmol})$ in $\mathrm{Et}_{2} \mathrm{O}(0.5 \mathrm{~mL})$. Purification by column chromatography on silica gel ( $n$-hexane/EtOAc: 4/1) yielded 446a (41.1 mg, 74\%) as a light yellow solid.

M. p.: $125^{\circ} \mathrm{C}$.

${ }^{1}$ H NMR $\left(400 \mathrm{MHz}, \mathrm{CDCl}_{3}\right) \delta 7.80(\mathrm{ddd}, J=5.4,2.4,0.7 \mathrm{~Hz}, 1 \mathrm{H}), 7.65(\mathrm{t}, J=1.9 \mathrm{~Hz}, 1 \mathrm{H}), 7.63(\mathrm{t}, J$ $=1.9 \mathrm{~Hz}, 1 \mathrm{H}), 7.35(\mathrm{ddd}, J=5.4,2.4,0.7 \mathrm{H}), 7.31-7.33(\mathrm{~m}, 1 \mathrm{H}), 7.30-7.31(\mathrm{~m}, 1 \mathrm{H}), 7.28(\mathrm{~m}, 2 \mathrm{H})$, $3.83(\mathrm{~s}, 3 \mathrm{H}), 2.42(\mathrm{~s}, 3 \mathrm{H})$.

${ }^{13}$ C NMR $\left(100 \mathrm{MHz}, \mathrm{CDCl}_{3}\right) \delta 153.9\left(\mathrm{C}_{\mathrm{q}}\right), 142.9\left(\mathrm{C}_{\mathrm{q}}\right), 139.8\left(\mathrm{C}_{\mathrm{q}}\right), 136.5\left(\mathrm{C}_{\mathrm{q}}\right), 129.3(\mathrm{CH}), 129.3\left(\mathrm{C}_{\mathrm{q}}\right)$, $127.3(\mathrm{CH}), 122.6(\mathrm{CH}), 122.3(\mathrm{CH}), 119.7(\mathrm{CH}), 109.5(\mathrm{CH}), 31.6\left(\mathrm{CH}_{3}\right), 21.4\left(\mathrm{CH}_{3}\right)$.

IR (ATR): 3419, 3402, 2919, 1936, 1613, 1459, 1381, 1276, 1005, 822, $748 \mathrm{~cm}^{-1}$.

MS (ESI) $m / z$ (relative intensity): $223(60)[\mathrm{M}+\mathrm{H}]^{+}, 245(40)[\mathrm{M}+\mathrm{Na}]^{+}$.

HR-MS (ESI): $m / z$ calcd for $\mathrm{C}_{15} \mathrm{H}_{15} \mathrm{~N}_{2}[\mathrm{M}+\mathrm{H}]^{+}: 223.1237$, found: 223.1235 .

The spectral data were in accordance with those reported in the literature. ${ }^{[282]}$

\section{1-Methyl-2-phenyl-1H-benzo $[d]$ imidazole (446b)}<smiles>Cn1c(-c2ccccc2)nc2ccccc21</smiles> 
1) The General Procedure $\mathbf{G}$ was followed using 1-methyl-1H-benzo[d]imidazole $445 \mathrm{a}$ (33 mg, $0.25 \mathrm{mmol})$, iodobenzene 404b (255 mg, $1.25 \mathrm{mmol}), 406(30 \mathrm{mg}, 11 \mathrm{~mol} \%)$ and $\mathrm{K}_{3} \mathrm{PO}_{4}(159 \mathrm{mg}$, $0.75 \mathrm{mmol})$ in THF $(0.5 \mathrm{~mL})$. Purification by column chromatography on silica gel ( $n$-hexane/EtOAc: 4/1) yielded 446b (36.4 mg, 70\%) as a light yellow solid.

2) The General Procedure $\mathbf{H}$ was followed using 1-methyl-1H-benzo $[d]$ imidazole $445 a(33 \mathrm{mg}$, $0.25 \mathrm{mmol}$ ), bromobenzene $447 \mathrm{~b}(255 \mathrm{mg}, 1.25 \mathrm{mmol}), 406(30 \mathrm{mg}, 11 \mathrm{~mol} \%)$ and $\mathrm{Cs}_{2} \mathrm{CO}_{3}(244 \mathrm{mg}$, $0.75 \mathrm{mmol})$ in $\mathrm{Et}_{2} \mathrm{O}(0.5 \mathrm{~mL})$. Purification by column chromatography on silica gel ( $n$-hexane/EtOAc: 4/1) yielded 446b (41.1 $\mathrm{mg}, 79 \%$ ) as a light yellow solid.

M. p.: $96^{\circ} \mathrm{C}$.

${ }^{1}$ H NMR $\left(400 \mathrm{MHz}, \mathrm{CDCl}_{3}\right) \delta 7.81(\mathrm{ddd}, J=5.4,2.4,0.7 \mathrm{~Hz}, 1 \mathrm{H}), 7.76-7.72(\mathrm{~m}, 2 \mathrm{H}), 7.54-7.47$ (m, 3H), $7.36(\mathrm{ddd}, J=5.4,2.4,0.7 \mathrm{~Hz}, 1 \mathrm{H}), 7.32-7.27(\mathrm{~m}, 2 \mathrm{H}), 3.83(\mathrm{~s}, 3 \mathrm{H})$.

${ }^{13}$ C NMR $\left(100 \mathrm{MHz}, \mathrm{CDCl}_{3}\right) \delta 153.7\left(\mathrm{C}_{\mathrm{q}}\right), 142.9\left(\mathrm{C}_{\mathrm{q}}\right), 136.5\left(\mathrm{C}_{\mathrm{q}}\right), 130.1\left(\mathrm{C}_{\mathrm{q}}\right), 129.7(\mathrm{CH}), 129.4(\mathrm{CH})$, $128.6(\mathrm{CH}), 122.7(\mathrm{CH}), 122.4(\mathrm{CH}), 119.8(\mathrm{CH}), 109.6(\mathrm{CH}), 31.6\left(\mathrm{CH}_{3}\right)$.

IR (ATR): 3059, 2924, 2159, 1469, 1442, 1382, 1328, 1006, 744, $698 \mathrm{~cm}^{-1}$.

MS (ESI) $m / z$ (relative intensity): $210(100)[\mathrm{M}+\mathrm{H}]^{+}$.

HR-MS (ESI): $m / z$ calcd for $\mathrm{C}_{14} \mathrm{H}_{13} \mathrm{~N}_{2}[\mathrm{M}+\mathrm{H}]^{+}: 210.1074$, found: 210.1073 .

The spectral data were in accordance with those reported in the literature. ${ }^{[283]}$

\section{2-(4-Methoxyphenyl)-1-methyl-1H-benzo[d]imidazole (446c)}

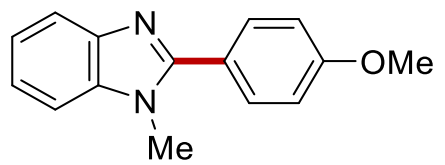

1) The General Procedure $\mathbf{G}$ was followed using 1-methyl-1 $H$-benzo[ $d]$ imidazole $445 a$ (33 mg, $0.25 \mathrm{mmol})$, 4-iodoanisole 404c (293 mg, $1.25 \mathrm{mmol}), 406$ (30 mg, $11 \mathrm{~mol} \%$ ) and $\mathrm{K}_{3} \mathrm{PO}_{4}(159 \mathrm{mg}$, $0.75 \mathrm{mmol})$ in THF $(0.5 \mathrm{~mL})$. Purification by column chromatography on silica gel ( $n$-hexane/EtOAc: 4/1) yielded 446c (36.3 mg, 61\%) as a light yellow solid.

2) The General Procedure $\mathbf{H}$ was followed using 1-methyl-1H-benzo $[d]$ imidazole $445 a$ (33 mg, $0.25 \mathrm{mmol})$, 4-bromoanisole 447c (255 mg, $1.25 \mathrm{mmol}), 406(30 \mathrm{mg}, 11 \mathrm{~mol} \%)$ and $\mathrm{Cs}_{2} \mathrm{CO}_{3}(244 \mathrm{mg}$, $0.75 \mathrm{mmol})$ in $\mathrm{Et}_{2} \mathrm{O}(0.5 \mathrm{~mL})$. Purification by column chromatography on silica gel ( $n$-hexane/EtOAc: 
4/1) yielded 446c (47.1 mg, 79\%) as a light yellow solid.

M. p.: $118^{\circ} \mathrm{C}$.

${ }^{1} \mathbf{H}$ NMR $\left(400 \mathrm{MHz} \mathrm{CDCl}_{3}\right) \delta 7.79(\mathrm{ddd}, J=4.9,2.3,0.7 \mathrm{~Hz}, 1 \mathrm{H}), 7.70(\mathrm{dd}, J=2.9,2.3 \mathrm{~Hz}, 1 \mathrm{H}), 7.68$ $(\mathrm{dd}, J=2.9,2.3 \mathrm{~Hz}, 1 \mathrm{H}), 7.35(\mathrm{ddd}, J=4.9,2.3,0.7 \mathrm{~Hz}, 1 \mathrm{H}), 7.29(\mathrm{dd}, J=2.9,2.3 \mathrm{~Hz}, 1 \mathrm{H}) 7.28(\mathrm{dd}$, $J=2.9,2.3 \mathrm{~Hz}, 1 \mathrm{H}), 7.03(\mathrm{dd}, \mathrm{J}=2.9,2.3 \mathrm{~Hz}, 1 \mathrm{H}), 7.02(\mathrm{dd}, \mathrm{J}=2.9,2.3 \mathrm{~Hz}, 1 \mathrm{H}) .3 .86(\mathrm{~s}, 3 \mathrm{H}), 3.83$ (s, $3 \mathrm{H})$.

${ }^{13} \mathrm{C}$ NMR $\left(100 \mathrm{MHz}, \mathrm{CDCl}_{3}\right) \delta 160.7\left(\mathrm{C}_{\mathrm{q}}\right), 142.9\left(\mathrm{C}_{\mathrm{q}}\right), 136.5\left(\mathrm{C}_{\mathrm{q}}\right), 130.8\left(\mathrm{C}_{\mathrm{q}}\right), 122.5(\mathrm{CH}), 122.5\left(\mathrm{C}_{\mathrm{q}}\right)$, $122.5(\mathrm{CH}), 122.3(\mathrm{CH}), 119.6(\mathrm{CH}), 114.1(\mathrm{CH}), 109.5(\mathrm{CH}), 55.4\left(\mathrm{CH}_{3}\right), 31.7\left(\mathrm{CH}_{3}\right)$.

IR (ATR): 2938, 2837, 1706, 1611, 1461, 1250, 1177, 1025, 838, $745 \mathrm{~cm}^{-1}$.

MS (ESI) $m / z$ (relative intensity): $239(80)[\mathrm{M}+\mathrm{H}]^{+}, 261(20)[\mathrm{M}+\mathrm{Na}]^{+}$

HR-MS (ESI): $m / z$ calcd for $\mathrm{C}_{15} \mathrm{H}_{15} \mathrm{~N}_{2} \mathrm{O}[\mathrm{M}+\mathrm{H}]^{+}: 239.1182$, found: 239.1180 .

The spectral data were in accordance with those reported in the literature. ${ }^{[282]}$

\section{2-(4-Fluorophenyl)-1-methyl-1 $H$-benzo $[d]$ imidazole (446d)}

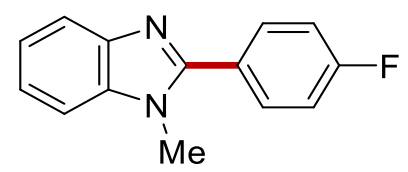

1) The General Procedure G was followed using 1-methyl-1H-benzo $[d]$ imidazole $445 a$ (33 mg, $0.25 \mathrm{mmol}), 1$-fluoro-4-iodobenzene 404e (278 mg, $1.25 \mathrm{mmol}), 406(30 \mathrm{mg}, 11 \mathrm{~mol} \%)$ and $\mathrm{K}_{3} \mathrm{PO}_{4}$ (159 mg, $0.75 \mathrm{mmol})$ in THF $(0.5 \mathrm{~mL})$. Purification by column chromatography on silica gel $(n-$ hexane/EtOAc: $4 / 1)$ yielded 446d (36.7 $\mathrm{mg}, 65 \%)$ as a light yellow solid.

2) The General Procedure $\mathbf{H}$ was followed using 1-methyl-1 $H$-benzo $[d]$ imidazole $445 a$ (33 mg, $0.25 \mathrm{mmol}$ ), 1-bromo-4-fluorobenzene $447 \mathrm{~d}$ (278 $\mathrm{mg}, 1.25 \mathrm{mmol}), 406\left(30 \mathrm{mg}, 11 \mathrm{~mol} \%\right.$ ) and $\mathrm{Cs}_{2} \mathrm{CO}_{3}$ (244 $\mathrm{mg}, 0.75 \mathrm{mmol})$ in $\mathrm{Et}_{2} \mathrm{O}(0.5 \mathrm{~mL})$. Purification by column chromatography on silica gel $(n$ hexane/EtOAc: 4/1) yielded 446d (39.6 mg, 70\%) as a light yellow solid

M. p.: $98^{\circ} \mathrm{C}$.

${ }^{1} \mathbf{H}$ NMR $\left(400 \mathrm{MHz}, \mathrm{CDCl}_{3}\right) \delta 7.80(\mathrm{ddd}, J=4.5,2.0,0.7 \mathrm{~Hz}, 1 \mathrm{H}), 7.75(\mathrm{ddd}, J=5.1,3.0,2.3 \mathrm{~Hz}$, 1H), $7.73(\mathrm{ddd}, J=5.1,3.0,2.3 \mathrm{~Hz}, 1 \mathrm{H}), 7.37$ (ddd, $J=4.5,2.0,0.7,1 \mathrm{H}), 7.33-7.28(\mathrm{~m}, 2 \mathrm{H}), 7.25-$ $7.17(\mathrm{~m}, 2 \mathrm{H}), 3.83(\mathrm{~s}, 3 \mathrm{H})$. 
${ }^{13} \mathrm{C}$ NMR $\left(100 \mathrm{MHz}, \mathrm{CDCl}_{3}\right) \delta 163.6\left(\mathrm{~d}, J_{\mathrm{C}-\mathrm{F}}=250.5 \mathrm{~Hz}, \mathrm{C}_{\mathrm{q}}\right), 152.8\left(\mathrm{C}_{\mathrm{q}}\right), 142.8\left(\mathrm{C}_{\mathrm{q}}\right), 136.5\left(\mathrm{C}_{\mathrm{q}}\right)$, $131.4\left(\mathrm{~d}, J_{\mathrm{C}-\mathrm{F}}=8.4 \mathrm{~Hz}, \mathrm{CH}\right), 126.3\left(\mathrm{~d}, J_{\mathrm{C}-\mathrm{F}}=3.4 \mathrm{~Hz}, \mathrm{C}_{\mathrm{q}}\right), 122.9(\mathrm{CH}), 122.5(\mathrm{CH}), 119.8(\mathrm{CH}), 115.9$ $\left.\left(\mathrm{d}, J_{\mathrm{C}-\mathrm{F}}=22.0 \mathrm{~Hz}, \mathrm{CH}\right)\right), 109.9(\mathrm{CH}), 109.6(\mathrm{CH}), 31.6\left(\mathrm{CH}_{3}\right)$.

${ }^{19}$ F NMR $\left(282 \mathrm{MHz}, \mathrm{CDCl}_{3}\right) \delta-110.60(\mathrm{ddd}, J=13.6,8.5,5.2 \mathrm{~Hz})$.

IR (ATR): 3059, 2951, 2158, 1645, 1606, 1461, 1225, 1097, 843, $744 \mathrm{~cm}^{-1}$.

MS (ESI) $m / z$ (relative intensity): $227(70)[\mathrm{M}+\mathrm{H}]^{+}, 249(30)[\mathrm{M}+\mathrm{Na}]^{+}$.

HR-MS (ESI): $m / z$ calcd for $\mathrm{C}_{14} \mathrm{H}_{12} \mathrm{FN}_{2}[\mathrm{M}+\mathrm{H}]^{+}: 227.0985$, found: 227.0983 .

The spectral data were in accordance with those reported in the literature. ${ }^{[282]}$

\section{1-(4-(1-Methyl-1H-benzo[d] imidazol-2-yl)phenyl)ethan-1-one (446e)}

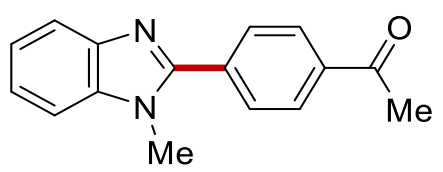

The General Procedure $\mathbf{G}$ was followed using 1-methyl-1 $H$-benzo $[d]$ imidazole 445a (33 mg, 0.25 mmol), 1-(4-iodophenyl)ethan-1-one 404q (308 mg, $1.25 \mathrm{mmol}), 406$ (30 mg, $11 \mathrm{~mol} \%$ ) and $\mathrm{K}_{3} \mathrm{PO}_{4}$ (159 mg, $0.75 \mathrm{mmol})$ in THF $(0.5 \mathrm{~mL})$. Purification by column chromatography on silica gel $(n-$ hexane/EtOAc: 4/1) yielded 446e (29.4 mg, 47\%) as a light yellow solid.

M. p.: $153^{\circ} \mathrm{C}$.

${ }^{1}$ H NMR $\left(400 \mathrm{MHz}, \mathrm{CDCl}_{3}\right) \delta 8.10(\mathrm{dd}, J=2.3,1.8 \mathrm{~Hz}, 1 \mathrm{H}), 8.8(\mathrm{dd}, J=2.3,1.8 \mathrm{~Hz}, 1 \mathrm{H}), 7.89(\mathrm{dd}$, $J=2.3,1.8 \mathrm{~Hz}, 1 \mathrm{H}), 7.87(\mathrm{dd}, J=2.3,1.8 \mathrm{~Hz}, 1 \mathrm{H}), 7.83-7.81(\mathrm{~m}, 1 \mathrm{H}), 7.41-7.39(\mathrm{~m}, 1 \mathrm{H}), 7.33$ (ddd, $J=6.7,4.1,1.8 \mathrm{~Hz}, 2 \mathrm{H}), 3.88$ (s, 3H), 2.66 (s, 3H).

${ }^{13} \mathrm{C}$ NMR $\left(100 \mathrm{MHz}, \mathrm{CDCl}_{3}\right) \delta 197.5\left(\mathrm{C}_{\mathrm{q}}\right), 152.4\left(\mathrm{C}_{\mathrm{q}}\right), 143.0\left(\mathrm{C}_{\mathrm{q}}\right), 137.6\left(\mathrm{C}_{\mathrm{q}}\right), 136.7\left(\mathrm{C}_{\mathrm{q}}\right), 134.6\left(\mathrm{C}_{\mathrm{q}}\right)$, 129.6 (CH), $128.6(\mathrm{CH}), 123.3(\mathrm{CH}), 122.8(\mathrm{CH}), 120.1(\mathrm{CH}), 109.7(\mathrm{CH}), 31.8\left(\mathrm{CH}_{3}\right), 26.8\left(\mathrm{CH}_{3}\right)$.

IR (ATR): 2932, 1682, 1608, 1463, 1355, 1262, 1011, 834, 744, $604 \mathrm{~cm}^{-1}$.

MS (ESI) $m / z$ (relative intensity): $251(80)[\mathrm{M}+\mathrm{H}]^{+}, 273(20)[\mathrm{M}+\mathrm{H}]^{+}$.

HR-MS (ESI): $m / z$ calcd for $\mathrm{C}_{16} \mathrm{H}_{15} \mathrm{~N}_{2} \mathrm{O}[\mathrm{M}+\mathrm{H}]^{+}: 251.1181$, found: 251.1179 . 


\section{Methyl 4-(1-methyl-1 $H$-benzo[d]imidazol-2-yl)benzoate (446f)}

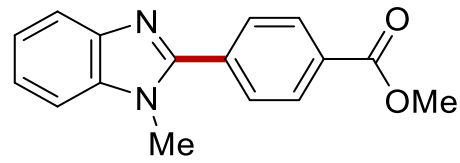

The General Procedure $\mathbf{G}$ was followed using 1-methyl-1H-benzo[ $d]$ imidazole 445a (33 mg, 0.25 mmol), methyl 4-iodobenzoate 404r (328 mg, $1.25 \mathrm{mmol}), 406$ (30 mg, $11 \mathrm{~mol} \%)$ and $\mathrm{K}_{3} \mathrm{PO}_{4}(159$ $\mathrm{mg}, 0.75 \mathrm{mmol})$ in THF $(0.5 \mathrm{~mL})$. Purification by column chromatography on silica gel $(n$ hexane/EtOAc: 4/1) yielded $\mathbf{4 4 6 f}$ (41.9 mg, 63\%) as a light yellow solid.

M. p.: $120^{\circ} \mathrm{C}$.

${ }^{1} \mathbf{H}$ NMR $\left(400 \mathrm{MHz}, \mathrm{CDCl}_{3}\right) \delta 8.20(\mathrm{dd}, J=2.3,1.7 \mathrm{~Hz}, 1 \mathrm{H}), 8.18(\mathrm{dd}, J=2.3,1.7 \mathrm{~Hz}, 1 \mathrm{H}), 7.87(\mathrm{dd}$, $J=2.3,1.7 \mathrm{~Hz}, 1 \mathrm{H}), 7.85(\mathrm{dd}, J=2.3,1.7 \mathrm{~Hz}, 1 \mathrm{H}), 7.82(\mathrm{ddd}, J=4.1,2.3,0.8 \mathrm{~Hz}, 1 \mathrm{H}), 7.40(\mathrm{ddd}, J$ $=4.1,2.3,0.8 \mathrm{~Hz}, 1 \mathrm{H}), 7.32(\mathrm{ddd}, J=6.6,4.1,1.7 \mathrm{~Hz}, 2 \mathrm{H}), 3.95(\mathrm{~s}, 3 \mathrm{H}), 3.88(\mathrm{~s}, 3 \mathrm{H})$.

${ }^{13}$ C NMR $\left(100 \mathrm{MHz}, \mathrm{CDCl}_{3}\right) \delta 166.5\left(\mathrm{C}_{\mathrm{q}}\right), 152.5\left(\mathrm{C}_{\mathrm{q}}\right), 143.0\left(\mathrm{C}_{\mathrm{q}}\right), 136.7\left(\mathrm{C}_{\mathrm{q}}\right), 134.5\left(\mathrm{C}_{\mathrm{q}}\right), 131.1\left(\mathrm{C}_{\mathrm{q}}\right)$, $129.9(\mathrm{CH}), 129.4(\mathrm{CH}), 123.2(\mathrm{CH}), 122.7(\mathrm{CH}), 120.1(\mathrm{CH}), 109.7(\mathrm{CH}), 52.4\left(\mathrm{CH}_{3}\right), 31.8\left(\mathrm{CH}_{3}\right)$. IR (ATR): 2950, 1719, 1612, 1530, 1460, 1274, 1016, 964, $743 \mathrm{~cm}^{-1}$.

MS (ESI) $m / z$ (relative intensity): $267(90)[\mathrm{M}+\mathrm{H}]^{+}, 289(10)[\mathrm{M}+\mathrm{H}]^{+}$.

HR-MS (ESI): $m / z$ calcd for $\mathrm{C}_{16} \mathrm{H}_{15} \mathrm{~N}_{2} \mathrm{O}_{2}[\mathrm{M}+\mathrm{H}]^{+}: 267.1132$, found: 267.1130 .

\section{1-Methyl-2-(m-tolyl)-1H-benzo[d]imidazole (446g)}

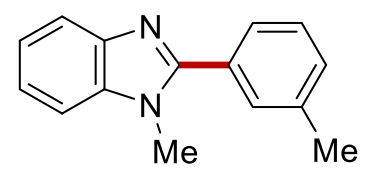

The General Procedure $\mathbf{G}$ was followed using 1-methyl-1H-benzo $[d]$ imidazole 445a (33 mg, 0.25 mmol), 1-iodo-3-methylbenzene 404h (273 mg, $1.25 \mathrm{mmol}), 406(30 \mathrm{mg}, 11 \mathrm{~mol} \%)$ and $\mathrm{K}_{3} \mathrm{PO}_{4}(159$ $\mathrm{mg}, 0.75 \mathrm{mmol})$ in THF $(0.5 \mathrm{~mL})$. Purification by column chromatography on silica gel $(n-$ hexane/EtOAc: $4 / 1)$ yielded $\mathbf{4 4 6 g}(34.5 \mathrm{mg}, 62 \%)$ as a light yellow solid.

M. p.: $119^{\circ} \mathrm{C}$.

${ }^{1} \mathbf{H}$ NMR $\left(400 \mathrm{MHz}, \mathrm{CDCl}_{3}\right) \delta 7.80(\mathrm{ddd}, J=5.2,2.3,0.9 \mathrm{~Hz}, 1 \mathrm{H}), 7.61-7.60(\mathrm{~m}, 1 \mathrm{H}), 7.50-7.49$ (m, 1H), $7.41(\mathrm{t}, J=7.8 \mathrm{~Hz}, 1 \mathrm{H}), 7.39-7.37(\mathrm{ddd}, J=5.2,2.3,0.9 \mathrm{~Hz}, 1 \mathrm{H}), 7.32-7.27(\mathrm{~m}, 3 \mathrm{H}), 3.84$ (s, 3H), 2.43 (s, 3H). 
${ }^{13} \mathrm{C}$ NMR $\left(100 \mathrm{MHz}, \mathrm{CDCl}_{3}\right) \delta 153.9\left(\mathrm{C}_{\mathrm{q}}\right), 142.9\left(\mathrm{C}_{\mathrm{q}}\right), 138.6\left(\mathrm{C}_{\mathrm{q}}\right), 136.5\left(\mathrm{C}_{\mathrm{q}}\right), 130.4(\mathrm{CH}), 130.2(\mathrm{CH})$, $130.1\left(\mathrm{C}_{\mathrm{q}}\right), 128.4(\mathrm{CH}), 126.3(\mathrm{CH}), 122.6(\mathrm{CH}), 122.3(\mathrm{CH}), 119.8(\mathrm{CH}), 109.5(\mathrm{CH}), 31.6\left(\mathrm{CH}_{3}\right)$, $21.4\left(\mathrm{CH}_{3}\right)$.

IR (ATR): 3050, 2920, 1609, 1589, 1456, 1325, 1256, 793, 742, $659 \mathrm{~cm}^{-1}$.

MS (ESI) $m / z$ (relative intensity): $223(100)[\mathrm{M}+\mathrm{H}]^{+}$.

HR-MS (ESI): $m / z$ calcd for $\mathrm{C}_{15} \mathrm{H}_{14} \mathrm{~N}_{2}[\mathrm{M}+\mathrm{H}]^{+}: 223.1236$, found: 223.1230 .

The spectral data were in accordance with those reported in the literature. ${ }^{[282]}$

\section{1-Methyl-2-(p-tolyl)-1H-benzo[d] imidazole (446h)}

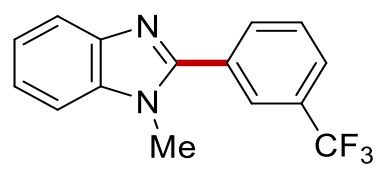

The General Procedure G was followed using 1-methyl- $1 H$-benzo $[d]$ imidazole 445a (33 mg, 0.25 mmol), 1-iodo-3-(trifluoromethyl)benzene 404j (340 mg, $1.25 \mathrm{mmol}), 406$ (30 mg, $11 \mathrm{~mol} \%$ ) and $\mathrm{K}_{3} \mathrm{PO}_{4}(159 \mathrm{mg}, 0.75 \mathrm{mmol})$ in THF $(0.5 \mathrm{~mL})$. Purification by column chromatography on silica gel ( $n$-hexane/EtOAc: $4 / 1)$ yielded $446 \mathrm{~h}(40.7 \mathrm{mg}, 59 \%)$ as a light yellow solid.

M. p.: $141{ }^{\circ} \mathrm{C}$.

${ }^{1} \mathbf{H}$ NMR $\left(400 \mathrm{MHz}, \mathrm{CDCl}_{3}\right) \delta 8.06-8.04(\mathrm{~m}, 1 \mathrm{H}), 7.97-7.93(\mathrm{~m}, 1 \mathrm{H}), 7.82(\mathrm{ddd}, J=3.6,1.6,0.8$ $\mathrm{Hz}, 1 \mathrm{H}), 7.77-7.73(\mathrm{~m}, 1 \mathrm{H}), 7.68-7.62(\mathrm{~m}, 1 \mathrm{H}), 7.40(\mathrm{ddd}, J=3.6,1.6,0.8 \mathrm{~Hz}, 1 \mathrm{H}), 7.34(\mathrm{ddd}, J=$ 6.4, 3.6, 1.6 Hz, 2H), $3.87(\mathrm{~s}, 3 \mathrm{H})$.

${ }^{13} \mathrm{C}$ NMR $\left(100 \mathrm{MHz}, \mathrm{CDCl}_{3}\right) \delta 152.0\left(\mathrm{C}_{\mathrm{q}}\right), 142.9\left(\mathrm{C}_{\mathrm{q}}\right), 136.6\left(\mathrm{C}_{\mathrm{q}}\right), 132.5(\mathrm{CH}), 131.3\left(\mathrm{~d}, J_{\mathrm{C}-\mathrm{F}}=32.8\right.$ $\left.\mathrm{Hz}, \mathrm{C}_{\mathrm{q}}\right), 131.1\left(\mathrm{C}_{\mathrm{q}}\right), 129.2(\mathrm{CH}), 126.6\left(\mathrm{q}, J_{\mathrm{C}-\mathrm{F}}=3.8 \mathrm{~Hz}, \mathrm{CH}\right), 125.1\left(\mathrm{C}_{\mathrm{q}}\right), 123.7\left(\mathrm{~d}, J_{\mathrm{C}-\mathrm{F}}=273.6 \mathrm{~Hz}\right.$, $\mathrm{CH}), 123.3(\mathrm{CH}), 122.8(\mathrm{CH}), 120.1(\mathrm{CH}), 109.7(\mathrm{CH}), 31.7\left(\mathrm{CH}_{3}\right)$.

${ }^{19}$ F NMR $\left(282 \mathrm{MHz}, \mathrm{CDCl}_{3}\right) \delta-62.73(\mathrm{~s})$.

IR (ATR): 3108, 3058, 2926, 1460, 1324, 1249, 1122, 1060, 743, $650 \mathrm{~cm}^{-1}$.

MS (ESI) $m / z$ (relative intensity): $277(100)[\mathrm{M}+\mathrm{H}]^{+}$.

HR-MS (ESI): $m / z$ calcd for $\mathrm{C}_{15} \mathrm{H}_{11} \mathrm{~F}_{3} \mathrm{~N}_{2}[\mathrm{M}+\mathrm{H}]^{+}: 277.0949$, found: 277.0947 . 
2-(2-Methoxyphenyl)-1-methyl-1 $H$-benzo[d] imidazole (446i)

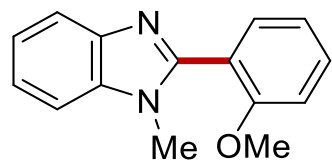

The General Procedure G was followed using 1-methyl- $1 H$-benzo $[d]$ imidazole 445a $(33 \mathrm{mg}, 0.25$ mmol), 1-iodo-2-methoxybenzene $404 \mathrm{o}$ (293 mg, $1.25 \mathrm{mmol}), 406\left(30 \mathrm{mg}, 11 \mathrm{~mol} \%\right.$ ) and $\mathrm{K}_{3} \mathrm{PO}_{4}(159$ $\mathrm{mg}, 0.75 \mathrm{mmol})$ in THF $(0.5 \mathrm{~mL})$. Purification by column chromatography on silica gel $(n$ hexane/EtOAc: $4 / 1)$ yielded $446 \mathbf{i}(16.6 \mathrm{mg}, 33 \%)$ as a light yellow oil.

M. p.: $97^{\circ} \mathrm{C}$.

${ }^{1} \mathbf{H}$ NMR $\left(400 \mathrm{MHz}, \mathrm{CDCl}_{3}\right) \delta 7.80(\mathrm{ddd}, J=3.5,1.7,0.7 \mathrm{~Hz}, 1 \mathrm{H}), 7.56(\mathrm{dd}, J=7.5,1.7 \mathrm{~Hz}, 1 \mathrm{H}), 7.47$ $(\mathrm{ddd}, J=8.3,7.5,1.7 \mathrm{~Hz}, 1 \mathrm{H}), 7.37$ (ddd, $J=3.5,1.7,0.7 \mathrm{~Hz}, 1 \mathrm{H}), 7.28$ (ddd, $J=7.5,3.5,1.7 \mathrm{~Hz}$, 2H), $7.08(\mathrm{td}, J=7.5,0.7 \mathrm{~Hz}, 1 \mathrm{H}), 7.00(\mathrm{dd}, J=8.3,0.7 \mathrm{~Hz}, 1 \mathrm{H}), 3.79(\mathrm{~s}, 3 \mathrm{H}), 3.63(\mathrm{~s}, 3 \mathrm{H})$.

${ }^{13} \mathbf{C}$ NMR $\left(100 \mathrm{MHz}, \mathrm{CDCl}_{3}\right) \delta 157.4\left(\mathrm{C}_{\mathrm{q}}\right), 152.0\left(\mathrm{C}_{\mathrm{q}}\right), 143.0\left(\mathrm{C}_{\mathrm{q}}\right), 136.0\left(\mathrm{C}_{\mathrm{q}}\right), 132.2(\mathrm{CH}), 131.5(\mathrm{CH})$, $122.3(\mathrm{CH}), 121.9(\mathrm{CH}), 120.9(\mathrm{CH}), 119.7(\mathrm{CH}), 119.5\left(\mathrm{C}_{\mathrm{q}}\right), 110.9(\mathrm{CH}), 109.3(\mathrm{CH}), 55.5\left(\mathrm{CH}_{3}\right)$, $30.8\left(\mathrm{CH}_{3}\right)$.

IR (ATR): 3059, 2941, 2837, 1458, 1437, 1251, 1117, 1201, 743, $640 \mathrm{~cm}^{-1}$.

MS (ESI) $m / z$ (relative intensity): $239(100)[\mathrm{M}+\mathrm{H}]^{+}$.

HR-MS (ESI): $m / z$ calcd for $\mathrm{C}_{15} \mathrm{H}_{15} \mathrm{~N}_{2} \mathrm{O}[\mathrm{M}+\mathrm{H}]^{+}: 239.1184$, found: 239.1182 .

The spectral data were in accordance with those reported in the literature. ${ }^{[283]}$

$(3 S, 8 S, 9 S, 10 R, 13 R, 14 S, 17 R)-10,13-D i m e t h y l-17-[(R)-6-m e t h y l h e p t a n-2-y l]-2,3,4$,

7,8,9,10,11,12,13,14,15,16,17-tetradecahydro-1H-cyclopenta[a]phenanthren-3-yl 4-(1-methyl$1 H$-benzo $[d]$ imidazol-2-yl)benzoate $(446 \mathbf{j})$

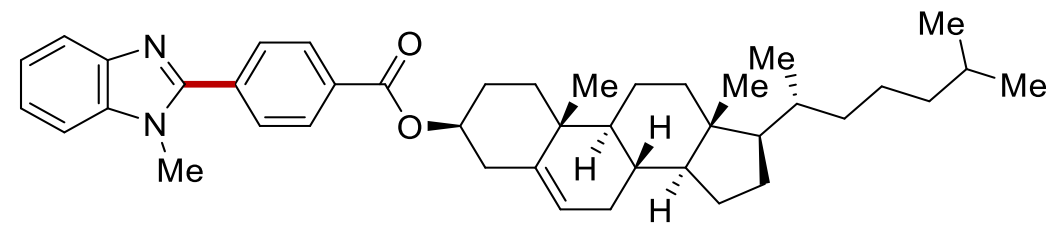

The General Procedure G was followed using 1-methyl-1H-benzo[ $d]$ imidazole 445a (33 mg, 0.25 mmol), (3S,8S,9S,10R,13R,14S,17R)-10,13-dimethyl-17-[(R)-6-methyl heptan-2-yl]-2,3,4,7,8,9,10, 11,12,13,14,15,16,17-tetradecahydro-1H-cyclopenta[a]phe nanthren-3-yl 4-iodobenzoate 404s $(770$ 
$\mathrm{mg}, 1.25 \mathrm{mmol}), 406(30 \mathrm{mg}, 11 \mathrm{~mol} \%)$ and $\mathrm{K}_{3} \mathrm{PO}_{4}(159 \mathrm{mg}, 0.75 \mathrm{mmol})$ in THF (0.5 mL). Purification by column chromatography on silica gel ( $n$-hexane/EtOAc: $4 / 1)$ yielded 446j $(63.6 \mathrm{mg}, 41 \%)$ as a white solid.

M. p.: $192{ }^{\circ} \mathrm{C}$.

${ }^{1} \mathbf{H}$ NMR $\left(400 \mathrm{MHz}, \mathrm{CDCl}_{3}\right) \delta 8.20(\mathrm{dd}, J=2.1,1.5 \mathrm{~Hz}, 1 \mathrm{H}), 8.17(\mathrm{dd}, J=2.1,1.5 \mathrm{~Hz}, 1 \mathrm{H}), 7.86(\mathrm{dd}$, $J=2.1,1.5 \mathrm{~Hz}, 1 \mathrm{H}), 7.84(\mathrm{dd}, J=2.1,1.5 \mathrm{~Hz}, 1 \mathrm{H}), 7.83-7.81(\mathrm{~m}, 1 \mathrm{H}), 7.40(\mathrm{ddd}, J=6.3,2.1,0.8$ $\mathrm{Hz}, 1 \mathrm{H}), 7.30$ (ddd, $J=6.3,3.8,1.5 \mathrm{~Hz}, 2 \mathrm{H}), 5.42(\mathrm{~d}, J=4.5 \mathrm{~Hz}, 1 \mathrm{H}), 4.90(\mathrm{~m}, 1 \mathrm{H}), 3.88(\mathrm{~s}, 3 \mathrm{H}), 2.49$ $(\mathrm{d}, J=7.7 \mathrm{~Hz}, 2 \mathrm{H}), 2.07-1.92(\mathrm{~m}, 4 \mathrm{H}), 1.88-1.62(\mathrm{~m}, 3 \mathrm{H}), 1.62-1.42(\mathrm{~m}, 5 \mathrm{H}), 1.34-1.30(\mathrm{~m}$, $3 \mathrm{H}), 1.27-1.16(\mathrm{~m}, 4 \mathrm{H}), 1.12-1.08(\mathrm{~m}, 3 \mathrm{H}), 1.07-0.95(\mathrm{~m}, 7 \mathrm{H}), 0.91(\mathrm{~d}, J=6.5 \mathrm{~Hz}, 3 \mathrm{H}), 0.86(\mathrm{~d}$, $J=1.8 \mathrm{~Hz}, 3 \mathrm{H}), 0.84(\mathrm{~d}, J=1.8 \mathrm{~Hz}, 3 \mathrm{H}), 0.68(\mathrm{~s}, 3 \mathrm{H})$.

${ }^{13}$ C NMR $\left(100 \mathrm{MHz}, \mathrm{CDCl}_{3}\right) \delta 165.4\left(\mathrm{C}_{\mathrm{q}}\right), 152.6\left(\mathrm{C}_{\mathrm{q}}\right), 143.0\left(\mathrm{C}_{\mathrm{q}}\right), 139.5\left(\mathrm{C}_{\mathrm{q}}\right), 136.7\left(\mathrm{C}_{\mathrm{q}}\right), 134.3\left(\mathrm{C}_{\mathrm{q}}\right)$, $131.8\left(\mathrm{C}_{\mathrm{q}}\right), 129.8(\mathrm{CH}), 129.3(\mathrm{CH}), 123.2(\mathrm{CH}), 122.9(\mathrm{CH}), 122.7(\mathrm{CH}), 120.1(\mathrm{CH}), 109.7(\mathrm{CH})$, $75.0(\mathrm{CH}), 56.7(\mathrm{CH}), 56.1(\mathrm{CH}), 50.0(\mathrm{CH}), 42.3\left(\mathrm{C}_{\mathrm{q}}\right), 39.7\left(\mathrm{CH}_{2}\right), 39.5\left(\mathrm{CH}_{2}\right), 38.2\left(\mathrm{CH}_{2}\right), 37.0\left(\mathrm{CH}_{3}\right)$, $36.7\left(\mathrm{CH}_{2}\right), 36.2\left(\mathrm{CH}_{2}\right), 35.8(\mathrm{CH}), 31.9\left(\mathrm{CH}_{2}\right), 31.9(\mathrm{CH}), 31.8\left(\mathrm{CH}_{3}\right), 28.2\left(\mathrm{C}_{\mathrm{q}}\right), 28.0(\mathrm{CH}), 27.9$ $\left(\mathrm{CH}_{2}\right), 24.3\left(\mathrm{CH}_{2}\right), 23.8\left(\mathrm{CH}_{2}\right), 22.8\left(\mathrm{CH}_{2}\right), 22.6\left(\mathrm{CH}_{3}\right), 21.1\left(\mathrm{CH}_{2}\right), 19.4\left(\mathrm{CH}_{3}\right), 18.7\left(\mathrm{CH}_{3}\right), 11.9\left(\mathrm{CH}_{3}\right)$. IR (ATR): 2936, 2867, 2248, 1674, 1714, 1465, 1273, 1119, 1016, $736 \mathrm{~cm}^{-1}$.

MS (ESI) $m / z$ (relative intensity): $621(100)[\mathrm{M}+\mathrm{H}]^{+}$.

HR-MS (ESI): $m / z$ calcd for $\mathrm{C}_{42} \mathrm{H}_{57} \mathrm{~N}_{2} \mathrm{O}_{2}[\mathrm{M}+\mathrm{H}]^{+}: 621.4412$, found: 621.4415 .

\section{2-[4-[[(1S,2S,5R)-2-Isopropyl-5-methylcyclohexyl]oxy]phenyl]-1-methyl-1H-benzo[d]imidazole} (446k)

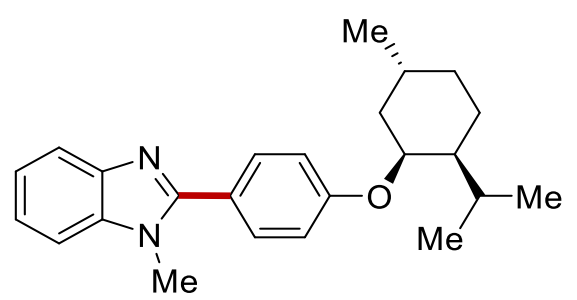

The General Procedure H was followed using 1-methyl-1H-benzo[ $d]$ imidazole 445a (33 mg, 0.25 mmol), 1-bromo-4-[[(1S,2S,5R)-2-isopropyl-5-methylcyclohexyl]oxy]benzene 447e (448 mg, 1.25 mmol), 406 (30 mg, $11 \mathrm{~mol} \%$ ) and $\mathrm{Cs}_{2} \mathrm{CO}_{3}(244 \mathrm{mg}, 0.75 \mathrm{mmol})$ in $\mathrm{Et}_{2} \mathrm{O}(0.5 \mathrm{~mL})$. Purification by 
column chromatography on silica gel ( $n$-hexane/EtOAc: $4 / 1)$ yielded 446k (48.9 mg, 87\%) as a light yellow solid.

M. p.: $137^{\circ} \mathrm{C}$.

${ }^{1} \mathbf{H}$ NMR $\left(400 \mathrm{MHz}, \mathrm{CDCl}_{3}\right) \delta 7.78(\mathrm{ddd}, J=5.3,2.3,0.7 \mathrm{~Hz}, 1 \mathrm{H}), 7.68(\mathrm{dd}, J=2.9,2.3 \mathrm{~Hz}, 1 \mathrm{H}), 7.66$ $(\mathrm{dd}, J=2.9,2.3 \mathrm{~Hz}, 1 \mathrm{H}), 7.36(\mathrm{ddd}, J=5.3,2.3,0.7 \mathrm{~Hz}, 1 \mathrm{H}), 7.28(\mathrm{ddd}, J=4.3,2.3,0.7 \mathrm{~Hz}, 2 \mathrm{H}), 7.02$ $(\mathrm{dd}, J=2.9,2.3 \mathrm{~Hz}, 1 \mathrm{H}), 7.00(\mathrm{dd}, J=2.9,2.3 \mathrm{~Hz}, 1 \mathrm{H}), 4.71(\mathrm{q}, J=2.6 \mathrm{~Hz}, 1 \mathrm{H}), 3.85(\mathrm{~s}, 3 \mathrm{H}), 2.12$ $(\mathrm{dd}, J=14.0,3.3 \mathrm{~Hz}, 1 \mathrm{H}), 1.83-1.61(\mathrm{~m}, 4 \mathrm{H}), 1.61-1.51(\mathrm{~m}, 1 \mathrm{H}), 0.97(\mathrm{~d}, J=6.7,3 \mathrm{H}), 0.93(\mathrm{~d}, J=$ $6.7 \mathrm{~Hz}, 3 \mathrm{H}), 0.86(\mathrm{~d}, J=6.7 \mathrm{~Hz}, 3 \mathrm{H}), 0.82(\mathrm{~d}, J=6.6 \mathrm{~Hz}, 3 \mathrm{H})$.

${ }^{13} \mathrm{C} \mathrm{NMR}\left(100 \mathrm{MHz}, \mathrm{CDCl}_{3}\right) \delta 159.6\left(\mathrm{C}_{\mathrm{q}}\right), 154.0\left(\mathrm{C}_{\mathrm{q}}\right), 143.0\left(\mathrm{C}_{\mathrm{q}}\right), 136.6\left(\mathrm{C}_{\mathrm{q}}\right), 130.8(\mathrm{CH}), 122.4(\mathrm{CH})$, $122.2(\mathrm{CH}), 121.9\left(\mathrm{C}_{\mathrm{q}}\right), 119.5(\mathrm{CH}), 115.7(\mathrm{CH}), 109.4(\mathrm{CH}), 73.5(\mathrm{CH}), 47.7(\mathrm{CH}), 37.6\left(\mathrm{CH}_{2}\right), 34.9$ $\left(\mathrm{CH}_{2}\right), 31.7\left(\mathrm{CH}_{3}\right), 29.3(\mathrm{CH}), 26.2(\mathrm{CH}), 24.8\left(\mathrm{CH}_{2}\right), 22.3(\mathrm{CH}), 21.0(\mathrm{CH}), 20.8(\mathrm{CH})$.

IR (ATR): 2922, 2867, 1609, 1460, 1436, 1246, 1172, 962, 836, $741 \mathrm{~cm}^{-1}$.

MS (ESI) $m / z$ (relative intensity): $363(100)[\mathrm{M}+\mathrm{H}]^{+}$.

HR-MS (ESI): $m / z$ calcd for $\mathrm{C}_{24} \mathrm{H}_{31} \mathrm{~N}_{2} \mathrm{O}[\mathrm{M}+\mathrm{H}]^{+}: 363.2435$, found: 363.2431 . 


\subsubsection{Synthesis of Hybrid Copper Catalyst}

1) Linker modification:

To a solution of DIPA (15 mmol, 1.1 equiv) in $40 \mathrm{~mL}$ of dried THF (50 mL) was added $n$-BuLi (2.1 $\mathrm{M}, 6.3 \mathrm{~mL}, 13.2 \mathrm{mmol}, 1.0$ equiv) dropwise at $0{ }^{\circ} \mathrm{C}$ under $\mathrm{N}_{2}$, in-situ generating LDA. After the reaction mixture was stirred for $1 \mathrm{~h}$, a solution of 4,4-dimethyl-2,2'-bipyridine (439) (13.2 mmol, 1.0 equiv) in dried THF (100 mL) was slowly added under $\mathrm{N}_{2}$, then color was changed to dark brown. After stirring the reaction mixture for $1 \mathrm{~h}$, a solution of (3-chloropropyl)trimethoxylsilane (440) (13.2 mmol, 1.0 equiv) in $10 \mathrm{~mL}$ of THF was slowly added at $0{ }^{\circ} \mathrm{C}$ under $\mathrm{N}_{2}$. The solution was further stirred for an additional $2 \mathrm{~h}$. The reaction mixture was warmed to room temperature and stirred for $24 \mathrm{~h}$. After the reaction was quenched with two drops of acetone, the remaining solvent was removed and then dried in vacuo at room temperature for $24 \mathrm{~h}$, affording 441 . The synthesized 441 are used for the next step without further purification (Scheme 5.6.1).<smiles>Cc1ccnc(-c2cc(C)ccn2)c1</smiles>

439<smiles>CO[Si](CCCCl)(OC)OC</smiles>

440

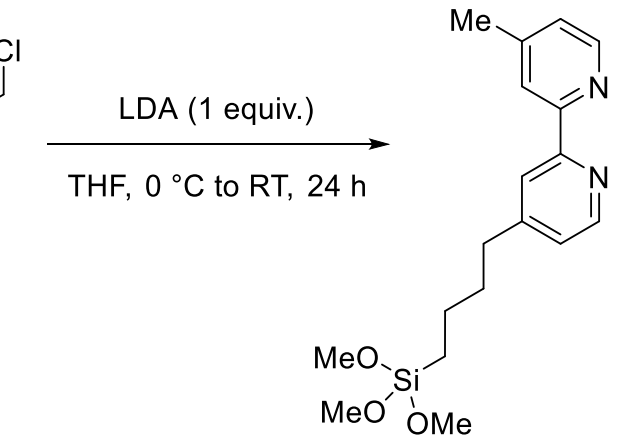

441

Scheme 5.6.1 Synthesis of 441 .

2) Grafting

A suspension of SBA-15 (5.0 g) and the synthesized 441 were refluxed in dried toluene under $\mathrm{N}_{2}$ for $24 \mathrm{~h}$. The powder was filtered off, washed with toluene, $n$-hexane, and DCM (each $50 \mathrm{~mL}$ ), and dried in vacuo at $100{ }^{\circ} \mathrm{C}$ for $24 \mathrm{~h}$, yielding 442 (Scheme 5.6.2). 


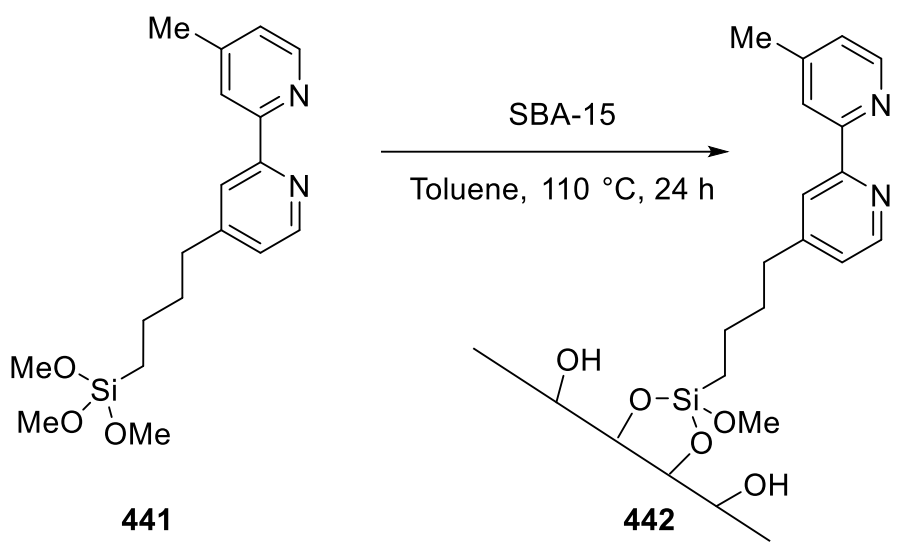

Scheme 5.6.2 Synthesis of $\mathbf{4 4 2}$.

\section{3) End-capping}

Hexamethyldisilazane $(20 \mathrm{~mL})$ and the isolated 442 in dried toluene $(50 \mathrm{~mL})$ was stirred at room temperature for $24 \mathrm{~h}$. The powder was filtered off, washed with toluene, $n$-hexane, and DCM (each 50 $\mathrm{mL}$ ), and dried in vacuo at $100{ }^{\circ} \mathrm{C}$ for $24 \mathrm{~h}$, providing 443 (Scheme 5.6.3).
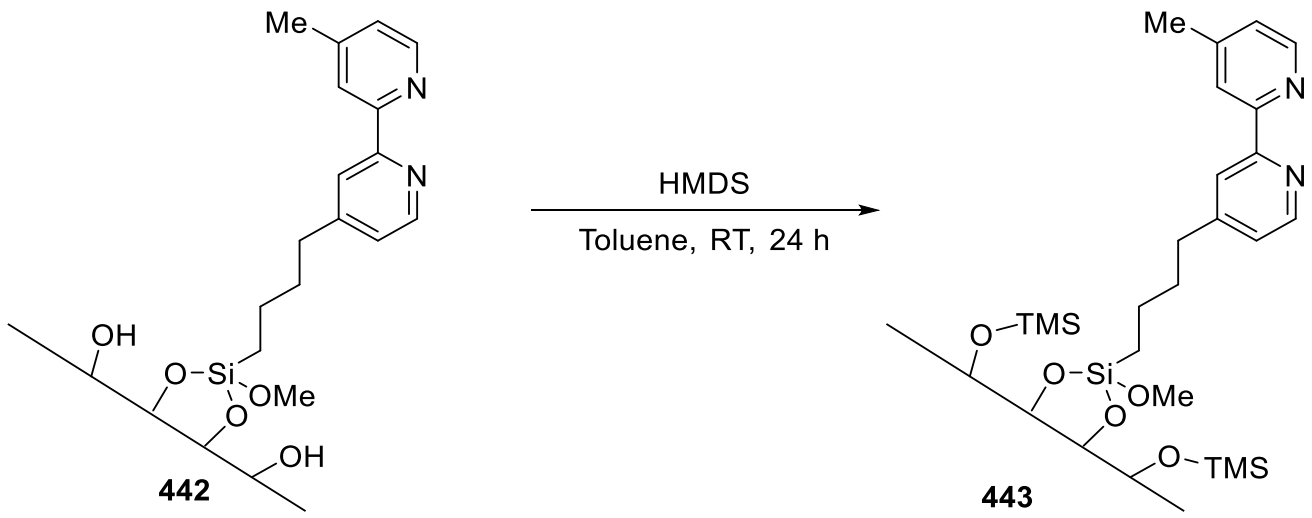

Scheme 5.6.3 Synthesis of 443 .

4) Metallation

A suspension of $\mathrm{CuI}(6.0 \mathrm{mmol})$ and the isolated 443 were stirred in DCM at room temperature for 24

h. The powder filtered off, washed with $\mathrm{DCM}, \mathrm{MeCN}$, and $\mathrm{MeOH}$ (each $50 \mathrm{~mL}$ ), and dried in vacuo at $100{ }^{\circ} \mathrm{C}$ for $24 \mathrm{~h}$, finally affording 406 . 

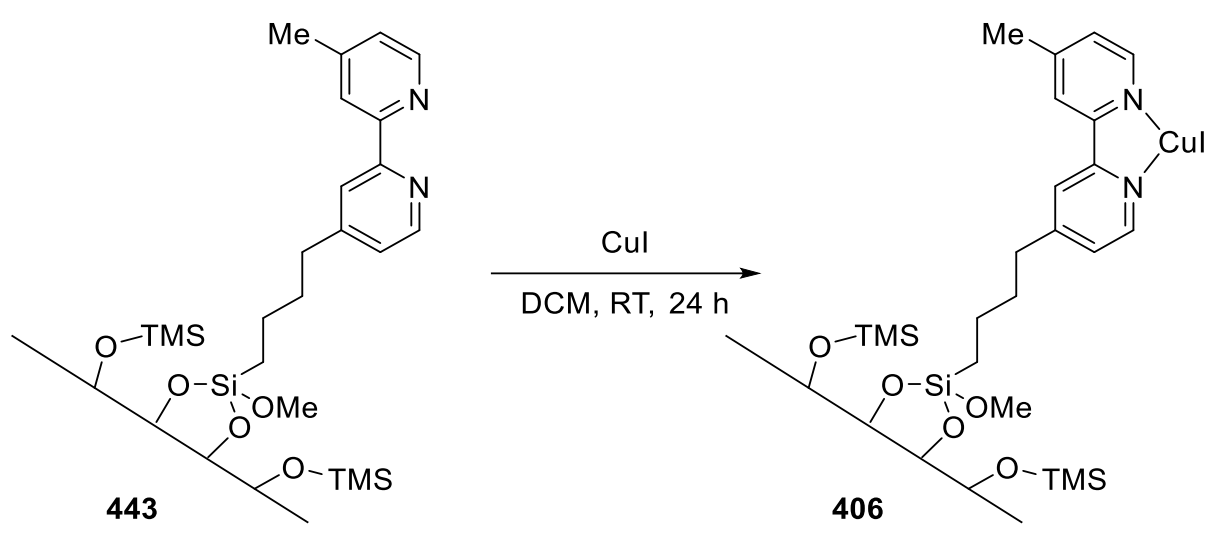

Scheme 5.6.4 Synthesis of 406 .

\subsubsection{Determination of Catalyst Loading}

ICP-OES analysis was performed by Dr. Volker Karius for the determination of hybrid copper catalyst 406 loading (Equation 5.6.1)

Amount of Catalyst $\times$ ICP-OES result $\div$ Molcular weight of copper $\div$ amount of substrates $\times 100 \mathrm{~mol} \%$

$=30 \mathrm{mg} \times \frac{58300 \mathrm{mg}}{1,000,000 \mathrm{mg}} \times \frac{1}{63.546 \mathrm{mg} / \mathrm{mmol}} \times \frac{1}{0.25 \mathrm{mmol}} \times 100 \mathrm{~mol} \%=11 \mathrm{~mol} \%$

Equation 5.6.1 Determination of hybrid copper catalyst loading. 


\subsubsection{Competition Experiment}

A suspension of 1-methyl-1H-benzo[d]imidazole $445 \mathrm{a}(0.25 \mathrm{mmol}, 1.0$ equiv), 4-iodoanisole $404 \mathrm{c}$ (1.25 mmol, 5.0 equiv), 1-fluoro-4-iodobenzene $404 \mathrm{e}$ (278 mg, 5.0 equiv), 406 (11 $\mathrm{mol} \%$ ) and $\mathrm{K}_{3} \mathrm{PO}_{4}$ (0.75 mmol, 3.0 equiv) in THF $(1.0 \mathrm{~mL})$ was stirred under photo-induced and nitrogen conditions. After $24 \mathrm{~h}$ the solvent was removed under reduced pressure. Purification by column chromatography on silica gel ( $n$-Hexane/EtOAc $=6 / 1$ to $1 / 1)$ afforded the desired products 446c and 446d respectively.

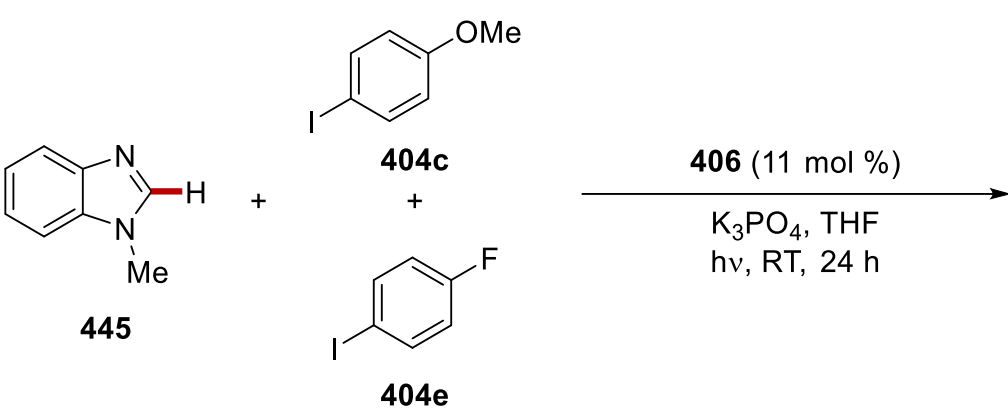

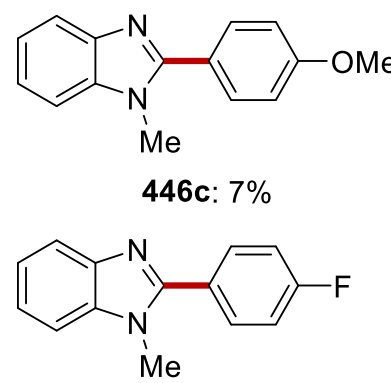

446d: $59 \%$

Scheme 5.6.5 Competition experiment with 445 and 404 .

\subsubsection{Radical Experiment}

A suspension of benzothiazole $403 \mathrm{a}$ ( $0.25 \mathrm{mmol}, 1.0$ equiv), 4-iodoanisole $404 \mathrm{c}$ (1.25 mmol, 5.0 equiv), 406 (11 mol \%), $\mathrm{LiO} t \mathrm{Bu}\left(0.75 \mathrm{mmol}, 3.0\right.$ equiv) and TEMPO (0.25 mmol, 1.0 equiv) in $\mathrm{Et}_{2} \mathrm{O}$ $(0.5 \mathrm{~mL})$ was stirred under photo-induced and nitrogen conditions. Purification by column chromatography on silica gel ( $n$-Hexane/EtOAc: 70/1) yielded 405 c.

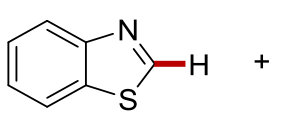

403a<smiles>COc1ccc(I)cc1</smiles>

404c

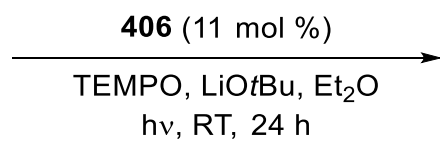

$h v, R T, 24 \mathrm{~h}$

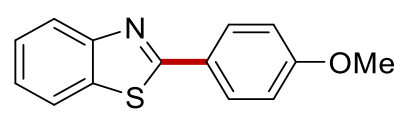

405c: $14 \%$

Scheme 5.6.6 Experiment with radical scavenger TEMPO. 


\subsubsection{On-Off Light Test}

The General Procedure F was followed using benzothiazole 403a (0.25 mmol, 1.0 equiv), 4 iodotoluene 404a (1.25 mmol, 5.0 equiv), 406 (11 mol \%) and $\mathrm{LiO} t \mathrm{Bu}\left(0.75 \mathrm{mmol}, 3.0\right.$ equiv) in $\mathrm{Et}_{2} \mathrm{O}$ $(0.5 \mathrm{~mL})$ for six independent reactions. Every two hours, the light was repeatedly turned off and the reaction was performed without irradiation for the next two hours. This process was repeated for 12 hours and at every time when light conditions were changed, a tube was removed from the photo reaction chamber and subjected to determine the yield (Table 5.3.6).

Table 5.3.6 On-Off light experiments.

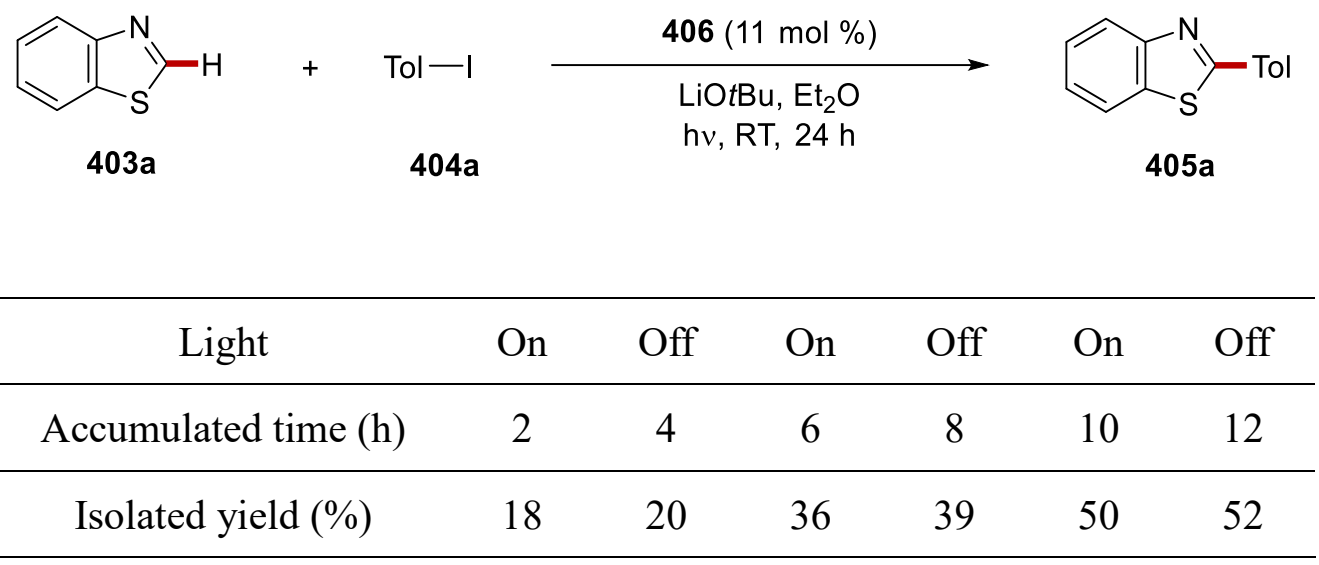




\subsubsection{Heterogeneity Test}

1) Reuse test

A suspension of 5-(benzo[ $d][1,3]$ dioxol-5-yl)oxazole $444 \mathrm{~h}(0.25 \mathrm{mmol}, 1.0$ equiv), iodobenzene $404 \mathrm{~b}$ (1.25 mmol, 5.0 equiv), 406 (22 $\mathrm{mol} \%)$ and $\mathrm{LiO} t \mathrm{Bu}\left(0.75 \mathrm{mmol}, 3.0\right.$ equiv) in $\mathrm{Et}_{2} \mathrm{O}(1.0 \mathrm{~mL})$ was stirred under photo-induced and nitrogen conditions (Scheme 5.6.7). After $24 \mathrm{~h}$ the reaction tube was transferred to a glovebox. 406 was carefully filtered through branched filter (Por. 3) with $\mathrm{Et}_{2} \mathrm{O}$ and DCM (each $10 \mathrm{~mL}$ ). Filtered $\mathbf{4 0 6}$ was dried in vacuo and used for next run. Filtrate was used for either obtaining desired product $\mathbf{4 4 7} \mathrm{m}$ by column chromatography on silica or measuring metal leaching by ICP-AES.
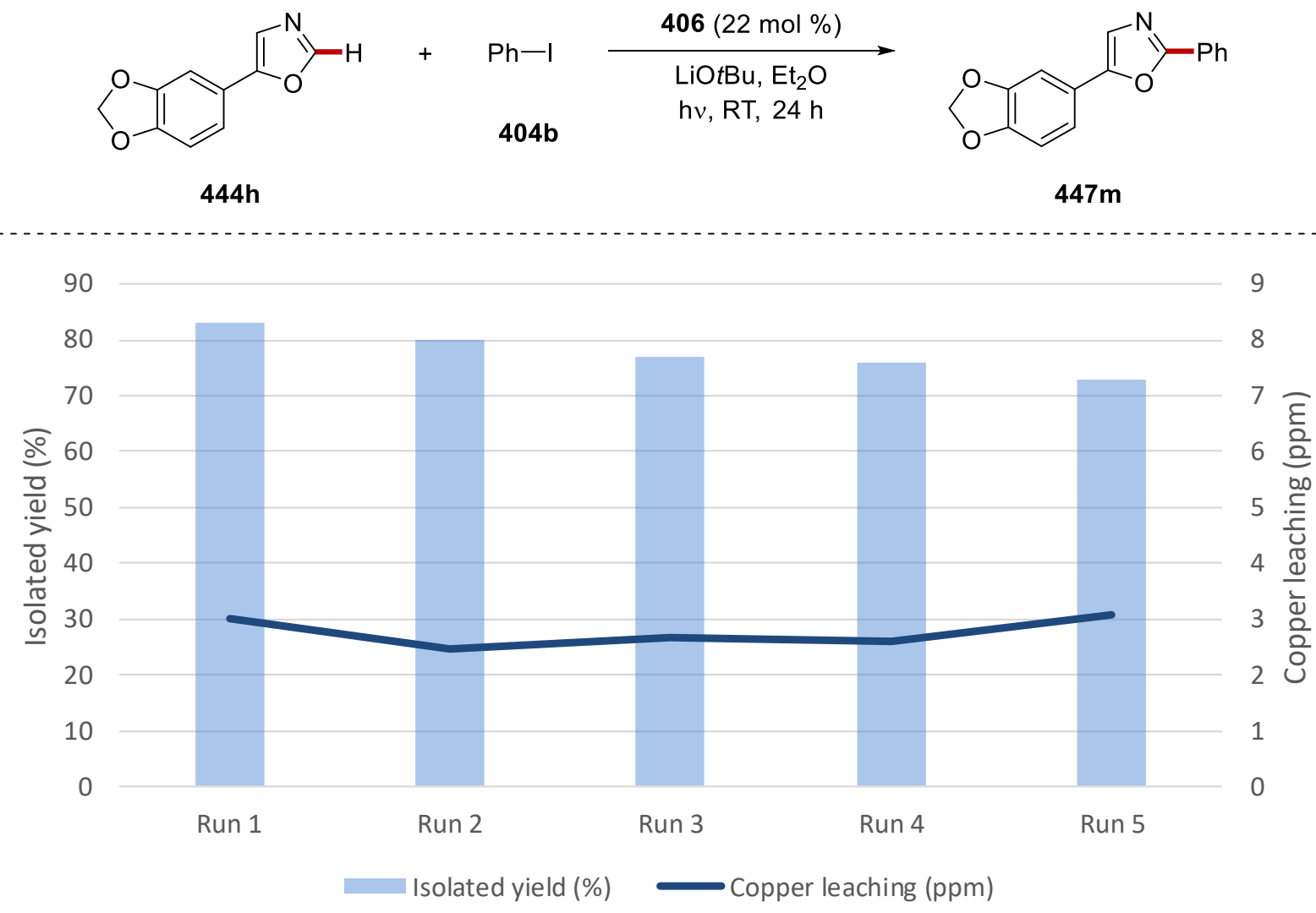

Scheme 5.6.7 Reuse tests and the determination of metal leaching. 
2) Scaled reuse test

A suspension of benzothiazole $403 \mathbf{a}$ (10 mmol, 1.0 equiv), 4-iodotoluene 404a (50 mmol, 5.0 equiv), 406 (11 mol \%) and $\mathrm{LiO} t \mathrm{Bu}\left(30 \mathrm{mmol}, 3.0\right.$ equiv) in $\mathrm{Et}_{2} \mathrm{O}(10 \mathrm{~mL})$ was stirred under photo-induced and nitrogen conditions (Scheme 5.6.8). After $24 \mathrm{~h}$ the reaction tube was transferred to a glovebox. 406 was carefully filtered through branched filter (Por. 3) with $\mathrm{Et}_{2} \mathrm{O}$ and DCM (each $20 \mathrm{~mL}$ ). Filtered 406 was dried in vacuo and used for the second run. The solvent of filtrate was removed under reduced pressure. Purification by column chromatography on silica gel afforded 405a.

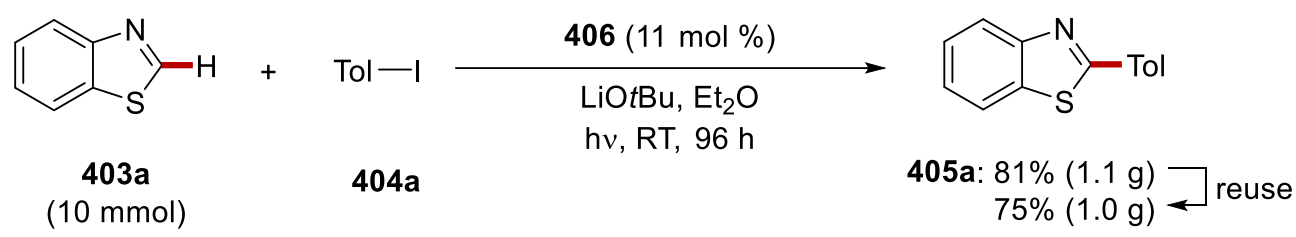

Scheme 5.6.8 Gram-scale reuse test.

\section{3) Filtration test}

A suspension of benzothiazole $403 \mathrm{a}$ ( $0.25 \mathrm{mmol}, 1.0$ equiv), 4-iodotoluene 404a (1.25 mmol, 5.0 equiv), 406 (11 mol \%) and $\mathrm{LiO} t \mathrm{Bu}\left(0.75 \mathrm{mmol}, 3.0\right.$ equiv) in $\mathrm{Et}_{2} \mathrm{O}(0.5 \mathrm{~mL})$ was stirred under photoinduced and nitrogen conditions (Scheme 5.6.9). After 6 hours, reaction tube was transferred to the Glove box. 406 was carefully filtered over Celite ${ }^{\circledR}$ with a branched filter (Por. 3). Filtrate was directly collected to another pre-dried $10 \mathrm{~mL}$ quartz tube and then sealed with septum. The sealed tube was transferred to the Luzchem LZC-ICH2 photoreactor and the reaction continued for $18 \mathrm{~h}$. Afterwards, the solvent was removed under reduced pressure. Purification by column chromatography on silica gel afforded the desired product $\mathbf{4 0 5}$ a.

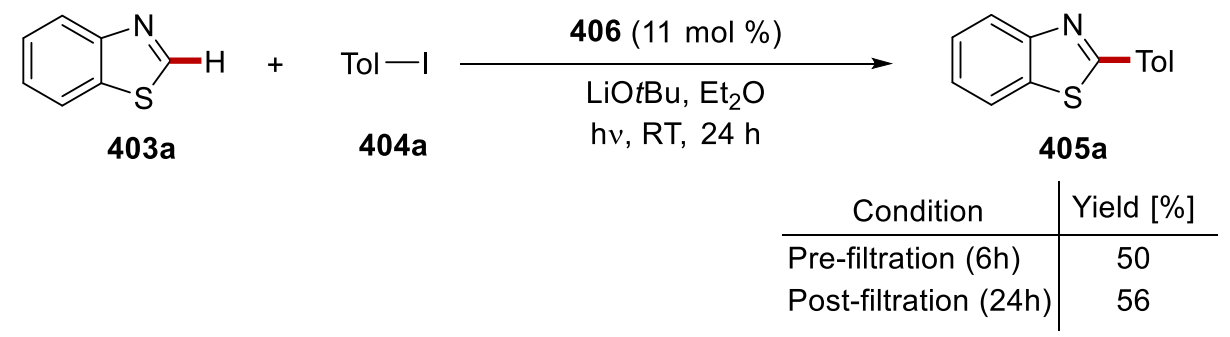

Scheme 5.6.9 Filtration test. 


\subsection{Distal C-H Activation by Reusable Heterogeneous Ruthenium Catalysis}

\subsubsection{Characterization Data}

Ethyl 2-(3-(pyridin-2-yl)phenyl)propanoate (409a)

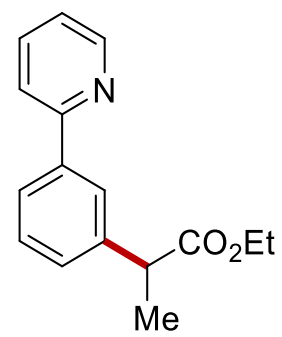

The General Procedure I was followed using 2-phenylpyridine 407a (38.8 mg, 0.25 mmol), ethyl 2bromopropanoate 408a (136 mg, $0.75 \mathrm{mmol}), 410$ (30.0 mg, $10 \mathrm{~mol} \%$ ) and KOAc (49.1 mg, $0.50 \mathrm{mmol})$ in 2-MeTHF $(2.0 \mathrm{~mL})$. Purification by column chromatography on silica gel $(n$ hexane/EtOAc: 10/1) yielded 409a (44.7 mg, 70\%) as a colorless oil.

${ }^{1}$ H NMR $\left(400 \mathrm{MHz}, \mathrm{CDCl}_{3}\right) \delta 8.62(\mathrm{dd}, J=4.8,1.4 \mathrm{~Hz}, 1 \mathrm{H}), 7.92(\mathrm{dd}, J=1.8,0.6 \mathrm{~Hz}, 1 \mathrm{H}), 7.82(\mathrm{dd}$, $J=7.5,1.8 \mathrm{~Hz}, 1 \mathrm{H}), 7.65(\mathrm{~d}, J=1.4 \mathrm{~Hz}, 1 \mathrm{H}), 7.64(\mathrm{dd}, J=2.3,1.4 \mathrm{~Hz}, 1 \mathrm{H}), 7.37(\mathrm{dd}, J=7.5,0.6 \mathrm{~Hz}$, 1H), $7.32(\mathrm{dd}, J=7.5,1.8 \mathrm{~Hz}, 1 \mathrm{H}), 7.15-7.11(\mathrm{~m}, 1 \mathrm{H}), 4.14-3.99(\mathrm{~m}, 2 \mathrm{H}), 3.76(\mathrm{q}, J=7.1 \mathrm{~Hz}, 1 \mathrm{H})$, $1.50(\mathrm{~d}, J=7.1 \mathrm{~Hz}, 3 \mathrm{H}), 1.14(\mathrm{t}, J=7.1 \mathrm{~Hz}, 3 \mathrm{H})$.

${ }^{13} \mathrm{C} \mathrm{NMR}\left(100 \mathrm{MHz}, \mathrm{CDCl}_{3}\right) \delta 174.2\left(\mathrm{C}_{\mathrm{q}}\right), 157.0\left(\mathrm{C}_{\mathrm{q}}\right), 149.4(\mathrm{CH}), 141.0\left(\mathrm{C}_{\mathrm{q}}\right), 139.5\left(\mathrm{C}_{\mathrm{q}}\right), 136.5(\mathrm{CH})$, $128.8(\mathrm{CH}), 127.7(\mathrm{CH}), 126.1(\mathrm{CH}), 125.4(\mathrm{CH}), 121.9(\mathrm{CH}), 120.4(\mathrm{CH}), 60.5\left(\mathrm{CH}_{2}\right), 45.4(\mathrm{CH})$, $18.5\left(\mathrm{CH}_{3}\right), 13.9\left(\mathrm{CH}_{3}\right)$.

IR (ATR): 2936, 2711, 1783, 1461, 1437, 1200, 1161, $773 \mathrm{~cm}^{-1}$.

MS (ESI) $m / z$ (relative intensity): $278(20)[\mathrm{M}+\mathrm{Na}]^{+}, 256(80)[\mathrm{M}+\mathrm{H}]^{+}$.

HR-MS (ESI) $m / z$ calcd. for $\mathrm{C}_{16} \mathrm{H}_{18} \mathrm{NO}_{2}[\mathrm{M}+\mathrm{H}]^{+}: 256.1334$, found: 256.1335 .

The spectral data were in accordance with those reported in the literature. ${ }^{[284]}$ 
Ethyl 2-(3-(pyrimidin-2-yl)phenyl)propanoate (409b)

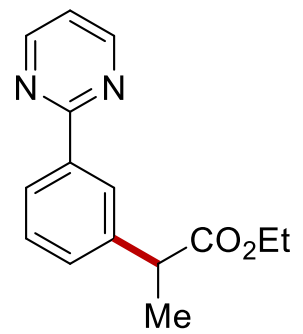

The General Procedure I was followed using 2-phenylpyrimidine 407b (39.0 mg, 0.25 mmol), ethyl 2-bromopropanoate 408a (136 mg, $0.75 \mathrm{mmol}), 410$ (30.0 mg, $10 \mathrm{~mol} \%$ ) and KOAc (49.1 mg, $0.50 \mathrm{mmol})$ in 2-MeTHF $(2.0 \mathrm{~mL})$. Purification by column chromatography on silica gel $(n$ hexane/EtOAc: $10 / 1)$ yielded $409 b(40.4 \mathrm{mg}, 63 \%)$ as a colorless oil.

${ }^{1} \mathbf{H}$ NMR $\left(400 \mathrm{MHz}, \mathrm{CDCl}_{3}\right) \delta 8.78(\mathrm{~d}, J=5.0 \mathrm{~Hz}, 2 \mathrm{H}), 8.38-8.36(\mathrm{~m}, 1 \mathrm{H}), 8.31$ (ddd, $J=5.0,4.2$, $1.7 \mathrm{~Hz}, 1 \mathrm{H}), 7.45-7.42(\mathrm{~m}, 2 \mathrm{H}), 7.16(\mathrm{t}, J=4.8 \mathrm{~Hz}, 1 \mathrm{H}), 4.18-4.04(\mathrm{~m}, 2 \mathrm{H}), 3.81(\mathrm{q}, J=7.2 \mathrm{~Hz}$, $1 \mathrm{H}), 1.54(\mathrm{~d}, J=7.1 \mathrm{~Hz}, 3 \mathrm{H}), 1.18(\mathrm{t}, J=7.1 \mathrm{~Hz}, 3 \mathrm{H})$.

${ }^{13}$ C NMR $\left(100 \mathrm{MHz}, \mathrm{CDCl}_{3}\right) \delta 174.4\left(\mathrm{C}_{\mathrm{q}}\right), 164.5\left(\mathrm{C}_{\mathrm{q}}\right), 157.2(\mathrm{CH}), 141.1\left(\mathrm{C}_{\mathrm{q}}\right), 137.8\left(\mathrm{C}_{\mathrm{q}}\right), 129.8(\mathrm{CH})$, $128.9(\mathrm{CH}), 127.5(\mathrm{CH}), 126.9(\mathrm{CH}), 119.1(\mathrm{CH}), 60.7\left(\mathrm{CH}_{2}\right), 45.6(\mathrm{CH}), 18.64\left(\mathrm{CH}_{3}\right), 14.1\left(\mathrm{CH}_{3}\right)$. IR (ATR): 2978, 2720, 2012, 1585, 1302, 1143, 1007, $769 \mathrm{~cm}^{-1}$.

MS (ESI) $m / z$ (relative intensity): $279(60)[\mathrm{M}+\mathrm{Na}]^{+}, 257(40)[\mathrm{M}+\mathrm{H}]^{+}$.

HR-MS (ESI) $m / z$ calcd. for $\mathrm{C}_{15} \mathrm{H}_{17} \mathrm{~N}_{2} \mathrm{O}_{2}[\mathrm{M}+\mathrm{H}]^{+}:$257.1286, found: 257.1285 .

\section{Ethyl 2-(3-(4,5-dihydrooxazol-2-yl)phenyl)propanoate (409c)}

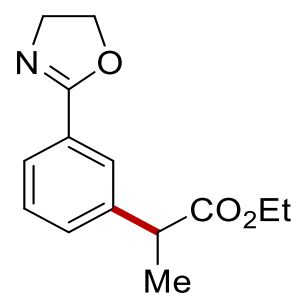

The General Procedure I was followed using 2-phenyl-4,5-dihydrooxazole 407c $(38.8 \mathrm{mg}, 0.25$ mmol), ethyl 2-bromopropanoate 408a (136 mg, $0.75 \mathrm{mmol}), 410$ (30.0 mg, $10 \mathrm{~mol} \%$ ) and KOAc (49.1 mg, $0.50 \mathrm{mmol})$ in 2-MeTHF $(2.0 \mathrm{~mL})$. Purification by column chromatography on silica gel $(n-$ hexane/EtOAc: $10 / 1)$ yielded 409c (34.0 mg, 55\%) as a colorless oil. 
${ }^{1} \mathbf{H}$ NMR $\left(400 \mathrm{MHz}, \mathrm{CDCl}_{3}\right) \delta 7.89(\mathrm{t}, J=1.6 \mathrm{~Hz}, 1 \mathrm{H}), 7.83(\mathrm{dt}, J=7.7,1.6 \mathrm{~Hz}, 1 \mathrm{H}), 7.43(\mathrm{dt}, J=7.7$, $1.6 \mathrm{~Hz}, 1 \mathrm{H}), 7.36(\mathrm{t}, J=7.7 \mathrm{~Hz}, 1 \mathrm{H}), 4.43(\mathrm{t}, J=9.5 \mathrm{~Hz}, 2 \mathrm{H}), 4.23-3.99$ (m, 4H), 3.74 (q, $J=7.2 \mathrm{~Hz}$, $1 \mathrm{H}), 1.51(\mathrm{~d}, J=7.2 \mathrm{~Hz}, 3 \mathrm{H}), 1.19(\mathrm{t}, J=7.1 \mathrm{~Hz}, 3 \mathrm{H})$.

${ }^{13} \mathrm{C}$ NMR $\left(100 \mathrm{MHz}, \mathrm{CDCl}_{3}\right) \delta 174.3\left(\mathrm{C}_{\mathrm{q}}\right), 164.7\left(\mathrm{C}_{\mathrm{q}}\right), 141.1\left(\mathrm{C}_{\mathrm{q}}\right), 130.5(\mathrm{CH}), 128.8(\mathrm{CH}), 128.2\left(\mathrm{C}_{\mathrm{q}}\right)$, 127.6 (CH), $127.1(\mathrm{CH}), 67.8\left(\mathrm{CH}_{2}\right), 61.0\left(\mathrm{CH}_{2}\right), 55.1\left(\mathrm{CH}_{2}\right), 45.6(\mathrm{CH}), 18.6\left(\mathrm{CH}_{3}\right), 14.3\left(\mathrm{CH}_{3}\right)$.

IR (ATR): 2980, 1732, 1650, 1362, 1194, 1067, 950, 711, $422 \mathrm{~cm}^{-1}$.

MS (EI) $m / z$ (relative intensity): 247 (21) [M] $]^{+}, 174$ (100), 131 (33), 103 (26).

HR-MS (EI+) $m / z$ calcd. for $\mathrm{C}_{14} \mathrm{H}_{17} \mathrm{NO}_{3}[\mathrm{M}]^{+}:$247.1208, found: 247.1210 .

\section{Ethyl 2-(3-(4-phenyl-4,5-dihydrooxazol-2-yl)phenyl)propanoate (409d)}

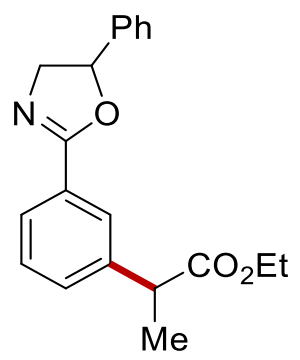

The General Procedure I was followed using 2,5-diphenyl-4,5-dihydrooxazole 407d (55.8 mg, 0.25 mmol), ethyl 2-bromopropanoate 408a (125.2 mg, $0.75 \mathrm{mmol}), 410$ (30.0 mg, $10 \mathrm{~mol} \%)$ and KOAc (49.1 mg, $0.50 \mathrm{mmol})$ in 2-MeTHF $(2.0 \mathrm{~mL})$. Purification by column chromatography on silica gel $(n-$ hexane/EtOAc: $10 / 1)$ yielded 409d (55.7 $\mathrm{mg}, 69 \%)$ as a colorless oil.

${ }^{1}$ H NMR $\left(400 \mathrm{MHz}, \mathrm{CDCl}_{3}\right) \delta 7.96(\mathrm{~s}, 1 \mathrm{H}), 7.91(\mathrm{dd}, J=7.6,1.5 \mathrm{~Hz}, 1 \mathrm{H}), 7.47(\mathrm{~d}, J=7.9 \mathrm{~Hz}, 1 \mathrm{H})$, $7.44-7.31(\mathrm{~m}, 6 \mathrm{H}), 5.66(\mathrm{dd}, J=10.2,8.0 \mathrm{~Hz}, 1 \mathrm{H}), 4.48(\mathrm{dd}, J=14.9,10.2 \mathrm{~Hz}, 1 \mathrm{H}), 4.20-4.05(\mathrm{~m}$, 2H), $4.00(\mathrm{dd}, J=14.9,8.0 \mathrm{~Hz}, 1 \mathrm{H}), 3.76(\mathrm{q}, J=7.2 \mathrm{~Hz}, 1 \mathrm{H}), 1.52(\mathrm{~d}, J=7.2 \mathrm{~Hz}, 3 \mathrm{H}), 1.20(\mathrm{t}, J=7.2$, $3 \mathrm{H})$.

${ }^{13} \mathrm{C}$ NMR $\left(100 \mathrm{MHz}, \mathrm{CDCl}_{3}\right) \delta 174.3\left(\mathrm{C}_{\mathrm{q}}\right), 164.0\left(\mathrm{C}_{\mathrm{q}}\right), 141.1\left(\mathrm{C}_{\mathrm{q}}\right), 130.7(\mathrm{CH}), 129.0(\mathrm{CH}), 129.0$ $(\mathrm{CH}), 128.9(\mathrm{CH}), 128.5(\mathrm{CH}), 128.1\left(\mathrm{C}_{\mathrm{q}}\right), 127.8\left(\mathrm{C}_{\mathrm{q}}\right), 127.2(\mathrm{CH}), 125.9(\mathrm{CH}), 81.3\left(\mathrm{CH}_{2}\right), 63.3(\mathrm{CH})$, $61.0\left(\mathrm{CH}_{2}\right), 45.6(\mathrm{CH}), 18.7\left(\mathrm{CH}_{3}\right), 14.3\left(\mathrm{CH}_{3}\right)$.

IR (ATR): 2979, 1731, 1651, 1337, 1193, 1064, $699 \mathrm{~cm}^{-1}$.

MS (EI) $m / z$ (relative intensity): 323 (4) [M] $]^{+}, 250$ (10), 217 (100), 189 (12).

HR-MS (EI+) $m / z$ calcd. for $\mathrm{C}_{20} \mathrm{H}_{21} \mathrm{NO}_{3}[\mathrm{M}]^{+}: 323.1521$, found: 323.1523 . 
Ethyl 2-(3-(1H-pyrazol-1-yl)phenyl)propanoate (409e)<smiles>CCOC(=O)C(C)c1cccc(-n2cccn2)c1</smiles>

The General Procedure I was followed using 1-phenyl-1H-pyrazole 407e (36.0 mg, $0.25 \mathrm{mmol})$, ethyl 2-bromopropanoate 408a (136 mg, $0.75 \mathrm{mmol}), \mathbf{4 1 0}(30.0 \mathrm{mg}, 10 \mathrm{~mol} \%)$ and KOAc (49.1 mg, $0.50 \mathrm{mmol})$ in 2-MeTHF $(2.0 \mathrm{~mL})$. Purification by column chromatography on silica gel $(n$ hexane/EtOAc: $10 / 1)$ yielded 409e (34.2 $\mathrm{mg}, 56 \%)$ as a colorless oil.

${ }^{1} \mathbf{H}$ NMR $\left(400 \mathrm{MHz}, \mathrm{CDCl}_{3}\right) \delta 7.91(\mathrm{dd}, J=2.5,0.6 \mathrm{~Hz}, 1 \mathrm{H}), 7.70(\mathrm{dd}, J=1.7,0.6 \mathrm{~Hz}, 1 \mathrm{H}), 7.66-$ $7.64(\mathrm{~m}, 1 \mathrm{H}), 7.55$ (ddd, $J=8.0,2.2,1.1 \mathrm{~Hz}, 1 \mathrm{H}), 7.38(\mathrm{t}, J=8.0 \mathrm{~Hz}, 1 \mathrm{H}), 7.22$ (dddd, $J=7.7,1.7$, 1.1, $0.6 \mathrm{~Hz}, 1 \mathrm{H}), 6.44(\mathrm{dd}, J=2.5,1.7 \mathrm{~Hz}, 1 \mathrm{H}), 4.17-4.06(\mathrm{~m}, 2 \mathrm{H}), 3.75(\mathrm{q}, J=7.1 \mathrm{~Hz}, 1 \mathrm{H}), 1.52(\mathrm{~d}$, $J=7.1 \mathrm{~Hz}, 3 \mathrm{H}), 1.19(\mathrm{t}, J=7.1 \mathrm{~Hz}, 3 \mathrm{H})$.

${ }^{13}$ C NMR $\left(100 \mathrm{MHz}, \mathrm{CDCl}_{3}\right) \delta 174.1\left(\mathrm{C}_{\mathrm{q}}\right), 142.2\left(\mathrm{C}_{\mathrm{q}}\right), 141.1(\mathrm{CH}), 140.4\left(\mathrm{C}_{\mathrm{q}}\right), 129.6(\mathrm{CH}), 126.8$ $(\mathrm{CH}), 125.5(\mathrm{CH}), 118.6(\mathrm{CH}), 117.9(\mathrm{CH}), 107.6(\mathrm{CH}), 60.9\left(\mathrm{CH}_{2}\right), 45.5(\mathrm{CH}), 18.54\left(\mathrm{CH}_{3}\right), 14.1$ $\left(\mathrm{CH}_{3}\right)$.

IR (ATR): 2853, 2749, 1987, 1582, 1461, 1203, 1170, $771 \mathrm{~cm}^{-1}$.

MS (ESI) $m / z$ (relative intensity): $245(70)[\mathrm{M}+\mathrm{H}]^{+}, 267(30)[\mathrm{M}+\mathrm{Na}]^{+}$.

HR-MS (ESI) $m / z$ calcd. for $\mathrm{C}_{14} \mathrm{H}_{17} \mathrm{~N}_{2} \mathrm{O}_{2}[\mathrm{M}+\mathrm{H}]^{+}: 245.1287$, found: 245.1285 .

The spectral data were in accordance with those reported in the literature. ${ }^{[284]}$

\section{Ethyl 2-(3-(9-isopropyl-9H-purin-6-yl)phenyl)propanoate (409f)}<smiles>CCOC(=O)c1cccc(-c2ncnc3c2ncn3C(C)C)c1</smiles>

The General Procedure I was followed using 9-isopropyl-6-phenyl-9H-purine 407f (59.6 mg, 0.25 mmol), ethyl 2-bromopropanoate $408 \mathrm{a}$ (136 mg, $0.75 \mathrm{mmol}), 410$ (30.0 mg, $10 \mathrm{~mol} \%$ ) and KOAc 
(49.1 mg, $0.50 \mathrm{mmol})$ in 2-MeTHF $(2.0 \mathrm{~mL})$. Purification by column chromatography on silica gel $(n-$ hexane/EtOAc: $3 / 1)$ yielded $\mathbf{4 0 9 f}(77.8 \mathrm{mg}, 92 \%)$ as a colorless oil.

${ }^{1} \mathbf{H}$ NMR $\left(400 \mathrm{MHz}, \mathrm{CDCl}_{3}\right) \delta 9.00(\mathrm{~s}, 1 \mathrm{H}), 8.72(\mathrm{dd}, J=7.4,1.7 \mathrm{~Hz}, 1 \mathrm{H}), 8.68(\mathrm{dd}, J=1.7,0.8 \mathrm{~Hz}$, 1H), $8.17(\mathrm{~s}, 1 \mathrm{H}), 7.55-7.45(\mathrm{~m}, 2 \mathrm{H}), 4.97(\mathrm{sept}, J=6.8 \mathrm{~Hz}, 1 \mathrm{H}), 4.12(\mathrm{q}, J=7.2 \mathrm{~Hz}, 2 \mathrm{H}), 3.86(\mathrm{q}, J$ $=7.2 \mathrm{~Hz}, 1 \mathrm{H}), 1.66(\mathrm{~d}, J=6.8 \mathrm{~Hz}, 6 \mathrm{H}), 1.57(\mathrm{~d}, J=7.2 \mathrm{~Hz}, 3 \mathrm{H}), 1.19(\mathrm{t}, J=7.2 \mathrm{~Hz}, 3 \mathrm{H})$.

${ }^{13}$ C NMR $\left(100 \mathrm{MHz}, \mathrm{CDCl}_{3}\right) \delta 174.6\left(\mathrm{C}_{\mathrm{q}}\right), 154.6\left(\mathrm{C}_{\mathrm{q}}\right), 152.2\left(\mathrm{C}_{\mathrm{q}}\right), 152.1(\mathrm{CH}), 142.1(\mathrm{CH}), 141.3\left(\mathrm{C}_{\mathrm{q}}\right)$, $136.2\left(\mathrm{C}_{\mathrm{q}}\right), 131.6\left(\mathrm{C}_{\mathrm{q}}\right), 129.9(\mathrm{CH}), 129.0(\mathrm{CH}), 129.0(\mathrm{CH}), 129.0(\mathrm{CH}), 60.9\left(\mathrm{CH}_{2}\right), 47.4(\mathrm{CH}), 45.8$ $(\mathrm{CH}), 22.7\left(\mathrm{CH}_{3}\right), 18.8\left(\mathrm{CH}_{3}\right), 14.2\left(\mathrm{CH}_{3}\right)$.

IR (ATR): 2979, 1727, 1568, 1446, 1325, 1219, 1176, 1064, 797, $647 \mathrm{~cm}^{-1}$.

MS (EI) $m / z$ (relative intensity): 338 (60) [M] ${ }^{+}, 265$ (81), 223 (100), 208 (52).

HR-MS (EI+) $m / z$ calcd. for $\mathrm{C}_{19} \mathrm{H}_{22} \mathrm{~N}_{4} \mathrm{O}_{2}[\mathrm{M}]^{+}: 338.1743$, found: 338.1735 .

\section{Ethyl 2-(2-methyl-5-(pyridin-2-yl)phenyl)propanoate (409g)}

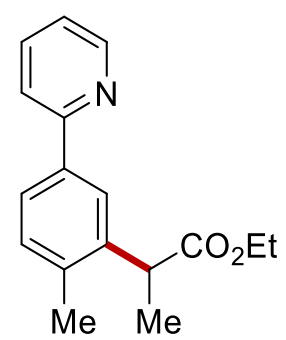

The General Procedure I was followed using 2-( $p$-tolyl)pyridine $\mathbf{4 0 7 g}$ (42.3 $\mathrm{mg}, 0.25 \mathrm{mmol})$, ethyl 2-bromopropanoate 408a (136 mg, $0.75 \mathrm{mmol}), 410$ (30.0 mg, $10 \mathrm{~mol} \%)$ and KOAc (49.1 mg, 0.50 mmol) in 2-MeTHF (2.0 mL). Purification by column chromatography on silica gel ( $n$-hexane/EtOAc: 10/1) yielded 409g (48.5 $\mathrm{mg}, 72 \%)$ as a colorless oil.

${ }^{1}$ H NMR $\left(400 \mathrm{MHz}, \mathrm{CDCl}_{3}\right) \delta 8.65(\mathrm{ddd}, J=4.8,1.8,1.1 \mathrm{~Hz}, 1 \mathrm{H}), 7.87(\mathrm{~d}, J=2.0 \mathrm{~Hz}, 1 \mathrm{H}), 7.78(\mathrm{dd}$, $J=7.9,2.0 \mathrm{~Hz}, 1 \mathrm{H}), 7.74-7.63(\mathrm{~m}, 2 \mathrm{H}), 7.25(\mathrm{~d}, J=7.9 \mathrm{~Hz}, 1 \mathrm{H}), 7.17(\mathrm{ddd}, J=6.7,4.8,1.8 \mathrm{~Hz}, 1 \mathrm{H})$, $4.17-4.06(\mathrm{~m}, 2 \mathrm{H}), 3.98(\mathrm{q}, J=7.1 \mathrm{~Hz}, 1 \mathrm{H}), 2.39(\mathrm{~s}, 3 \mathrm{H}), 1.53(\mathrm{~d}, J=7.1 \mathrm{~Hz}, 3 \mathrm{H}), 1.18(\mathrm{t}, J=7.1$ $\mathrm{Hz}, 3 \mathrm{H})$.

${ }^{13}$ C NMR $\left(100 \mathrm{MHz}, \mathrm{CDCl}_{3}\right) \delta 174.7\left(\mathrm{C}_{\mathrm{q}}\right), 157.3\left(\mathrm{C}_{\mathrm{q}}\right), 149.6(\mathrm{CH}), 139.5\left(\mathrm{C}_{\mathrm{q}}\right), 137.6\left(\mathrm{C}_{\mathrm{q}}\right), 136.7\left(\mathrm{C}_{\mathrm{q}}\right)$, $136.6(\mathrm{CH}), 130.9(\mathrm{CH}), 125.3(\mathrm{CH}), 125.2(\mathrm{CH}), 121.8(\mathrm{CH}), 120.3(\mathrm{CH}), 60.7\left(\mathrm{CH}_{2}\right), 41.6(\mathrm{CH})$, $19.4\left(\mathrm{CH}_{3}\right), 17.9\left(\mathrm{CH}_{3}\right), 14.1\left(\mathrm{CH}_{3}\right)$. 
IR (ATR): 2971, 2732, 1739, 1460, 1436, 1232, 1159, $771 \mathrm{~cm}^{-1}$.

MS (ESI) $m / z$ (relative intensity): $292(20)[\mathrm{M}+\mathrm{Na}]^{+}, 270(80)[\mathrm{M}+\mathrm{H}]^{+}$.

HR-MS (ESI) $m / z$ calcd. for $\mathrm{C}_{17} \mathrm{H}_{20} \mathrm{NO}_{2}[\mathrm{M}+\mathrm{H}]^{+}: 270.1492$, found: 270.1490 .

\section{Ethyl 2-(2-methoxy-5-(pyridin-2-yl)phenyl)propanoate (409h)}

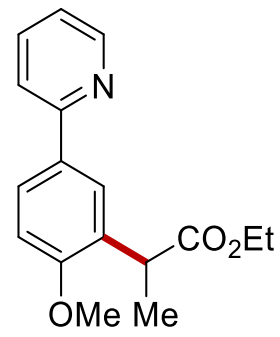

The General Procedure I was followed using 2-(4-methoxyphenyl)pyridine 407h (46.3 mg, 0.25 mmol), ethyl 2-bromopropanoate 408a (136 mg, $0.75 \mathrm{mmol}), \mathbf{4 1 0}(30.0 \mathrm{mg}, 10 \mathrm{~mol} \%)$ and KOAc (49.1 mg, $0.50 \mathrm{mmol})$ in 2-MeTHF $(2.0 \mathrm{~mL})$. Purification by column chromatography on silica gel $(n-$ hexane/EtOAc: $10 / 1)$ yielded $409 \mathrm{~h}(62.8 \mathrm{mg}, 88 \%)$ as a colorless oil.

${ }^{1} \mathbf{H}$ NMR $\left(400 \mathrm{MHz} \mathrm{CDCl}_{3}\right) \delta 8.62(\mathrm{ddd}, J=4.8,1.8,1.0 \mathrm{~Hz}, 1 \mathrm{H}), 7.87(\mathrm{dd}, J=8.4,2.3 \mathrm{~Hz}, 1 \mathrm{H}), 7.86$ $-7.85(\mathrm{~m}, 1 \mathrm{H}), 7.71-7.62(\mathrm{~m}, 2 \mathrm{H}), 7.14(\mathrm{ddd}, J=7.0,4.8,1.8 \mathrm{~Hz}, 1 \mathrm{H}), 6.94(\mathrm{~d}, J=8.4 \mathrm{~Hz}, 1 \mathrm{H}), 4.12$ $(\mathrm{q}, J=7.2 \mathrm{~Hz}, 2 \mathrm{H}), 4.02(\mathrm{q}, J=7.2 \mathrm{~Hz}, 1 \mathrm{H}), 3.85(\mathrm{~s}, 3 \mathrm{H}), 1.50(\mathrm{~d}, J=7.2 \mathrm{~Hz}, 3 \mathrm{H}), 1.18(\mathrm{t}, J=7.1 \mathrm{~Hz}$, $3 \mathrm{H})$.

${ }^{13}$ C NMR $\left(100 \mathrm{MHz}, \mathrm{CDCl}_{3}\right) \delta 174.9\left(\mathrm{C}_{\mathrm{q}}\right), 157.6\left(\mathrm{C}_{\mathrm{q}}\right), 157.1\left(\mathrm{C}_{\mathrm{q}}\right), 149.5(\mathrm{CH}), 136.5(\mathrm{CH}), 132.0\left(\mathrm{C}_{\mathrm{q}}\right)$, $129.9\left(\mathrm{C}_{\mathrm{q}}\right), 126.9(\mathrm{CH}), 126.7(\mathrm{CH}), 121.4(\mathrm{CH}), 119.9(\mathrm{CH}), 110.7(\mathrm{CH}), 60.5\left(\mathrm{CH}_{2}\right), 55.5\left(\mathrm{CH}_{3}\right)$, $39.9(\mathrm{CH}), 17.2\left(\mathrm{CH}_{3}\right), 14.2\left(\mathrm{CH}_{3}\right)$.

IR (ATR): 2960, 2697, 1731, 1463, 1434, 1205, 1162, $770 \mathrm{~cm}^{-1}$.

MS (ESI) $m / z$ (relative intensity): $308(20)[\mathrm{M}+\mathrm{Na}]^{+}, 286(80)[\mathrm{M}+\mathrm{H}]^{+}$.

HR-MS (ESI) $m / z$ calcd. for $\mathrm{C}_{17} \mathrm{H}_{20} \mathrm{NO}_{3}[\mathrm{M}+\mathrm{H}]^{+}: 286.1441$, found: 286.1439 .

The spectral data were in accordance with those reported in the literature. ${ }^{[284]}$ 


\section{Ethyl 2-(2-chloro-5-(pyridin-2-yl)phenyl)propanoate (409i)}

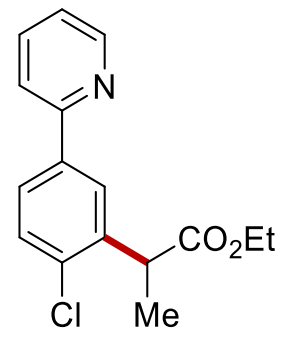

The General Procedure I was followed using 2-(4-chlorophenyl)pyridine 407i (47.4 mg, 0.25 mmol), ethyl 2-bromopropanoate 408a (136 mg, $0.75 \mathrm{mmol}), \mathbf{4 1 0}(30.0 \mathrm{mg}, 10 \mathrm{~mol} \%)$ and KOAc (49.1 mg, $0.50 \mathrm{mmol})$ in 2-MeTHF $(2.0 \mathrm{~mL})$. Purification by column chromatography on silica gel $(n$ hexane/EtOAc: 10/1) yielded 409i (39.1 mg, 54\%) as a colorless oil.

${ }^{1} \mathbf{H}$ NMR $\left(400 \mathrm{MHz}, \mathrm{CDCl}_{3}\right) \delta 8.66(\mathrm{ddd}, J=4.8,1.8,1.2 \mathrm{~Hz}, 1 \mathrm{H}), 7.95(\mathrm{~d}, J=2.2 \mathrm{~Hz}, 1 \mathrm{H}), 7.82(\mathrm{dd}$, $J=8.4,2.2 \mathrm{~Hz}, 1 \mathrm{H}), 7.72(\mathrm{ddd}, J=8.4,7.3,2.2 \mathrm{~Hz}, 1 \mathrm{H}), 7.67(\mathrm{ddd}, J=7.3,1.8,1.2 \mathrm{~Hz}, 1 \mathrm{H}), 7.45(\mathrm{~d}$, $J=8.4 \mathrm{~Hz}, 1 \mathrm{H}), 7.21(\mathrm{ddd}, J=7.3,4.8,1.2 \mathrm{~Hz}, 1 \mathrm{H}), 4.22(\mathrm{q}, J=7.2 \mathrm{~Hz}, 1 \mathrm{H}), 4.18-4.12(\mathrm{~m}, 2 \mathrm{H})$, $1.55(\mathrm{~d}, J=7.2 \mathrm{~Hz}, 3 \mathrm{H}), 1.20(\mathrm{t}, J=7.1 \mathrm{~Hz}, 3 \mathrm{H})$.

${ }^{13}$ C NMR $\left(100 \mathrm{MHz}, \mathrm{CDCl}_{3}\right) \delta 173.9\left(\mathrm{C}_{\mathrm{q}}\right), 156.1\left(\mathrm{C}_{\mathrm{q}}\right), 149.7(\mathrm{CH}), 138.8\left(\mathrm{C}_{\mathrm{q}}\right), 138.4\left(\mathrm{C}_{\mathrm{q}}\right), 136.8(\mathrm{CH})$, $134.5\left(\mathrm{C}_{\mathrm{q}}\right), 129.9(\mathrm{CH}), 127.0(\mathrm{CH}), 126.6(\mathrm{CH}), 122.3(\mathrm{CH}), 120.4(\mathrm{CH}), 60.9\left(\mathrm{CH}_{2}\right), 42.5(\mathrm{CH}), 17.5$ $\left(\mathrm{CH}_{3}\right), 14.1\left(\mathrm{CH}_{3}\right)$.

IR (ATR): 2960, 2697, 1731, 1463, 1434, 1205, 1162, $770 \mathrm{~cm}^{-1}$.

MS (ESI) $m / z$ (relative intensity): $312(20)[\mathrm{M}+\mathrm{Na}]^{+}, 290(80)[\mathrm{M}+\mathrm{H}]^{+}$.

HR-MS (ESI) $m / z$ calcd. for $\mathrm{C}_{16} \mathrm{H}_{17}{ }^{35} \mathrm{ClNO}_{2}[\mathrm{M}+\mathrm{H}]^{+}:$290.0945, found: 290.0943 . 
Methyl 2-(1-ethoxy-1-oxopropan-2-yl)-4-(pyridin-2-yl)benzoate (409j)<smiles>CCOC(=O)C(C)c1cc(-c2ccccn2)ccc1OCC</smiles>

The General Procedure I was followed using methyl 4-(pyridin-2-yl)benzoate 407j (53.3 mg, 0.25 mmol), ethyl 2-bromopropanoate $408 \mathrm{a}$ (136 mg, $0.75 \mathrm{mmol}), 410$ (30.0 mg, $10 \mathrm{~mol} \%$ ) and KOAc (49.1 mg, $0.50 \mathrm{mmol})$ in 2-MeTHF $(2.0 \mathrm{~mL})$. Purification by column chromatography on silica gel $(n-$ hexane/EtOAc: $10 / 1)$ yielded $\mathbf{4 0 9 j}$ (47.0 $\mathrm{mg}, 60 \%)$ as a colorless oil.

${ }^{1} \mathbf{H}$ NMR $\left(400 \mathrm{MHz} \mathrm{CDCl}_{3}\right) \delta 8.69(\mathrm{ddd}, J=4.8,1.8,1.1 \mathrm{~Hz}, 1 \mathrm{H}), 8.00(\mathrm{dd}, J=4.8,3.0 \mathrm{~Hz}, 2 \mathrm{H}), 7.92$ $(\mathrm{dd}, J=8.2,1.8 \mathrm{~Hz}, 1 \mathrm{H}), 7.78-7.71(\mathrm{~m}, 2 \mathrm{H}), 7.25(\mathrm{ddd}, J=6.0,4.8,3.0 \mathrm{~Hz}, 1 \mathrm{H}), 4.67(\mathrm{q}, J=7.1 \mathrm{~Hz}$, $1 \mathrm{H}), 4.36(\mathrm{q}, J=7.1 \mathrm{~Hz}, 2 \mathrm{H}), 4.16-4.05(\mathrm{~m}, 2 \mathrm{H}), 1.60(\mathrm{~d}, J=7.1 \mathrm{~Hz}, 3 \mathrm{H}), 1.39(\mathrm{t}, J=7.1 \mathrm{~Hz}, 3 \mathrm{H})$, $1.16(\mathrm{t}, J=7.1 \mathrm{~Hz}, 3 \mathrm{H})$.

${ }^{13}$ C NMR $\left(100 \mathrm{MHz}, \mathrm{CDCl}_{3}\right) \delta 174.5\left(\mathrm{C}_{\mathrm{q}}\right), 167.3\left(\mathrm{C}_{\mathrm{q}}\right), 156.1\left(\mathrm{C}_{\mathrm{q}}\right), 149.8(\mathrm{CH}), 142.7\left(\mathrm{C}_{\mathrm{q}}\right), 142.5\left(\mathrm{C}_{\mathrm{q}}\right)$, $136.8(\mathrm{CH}), 131.2(\mathrm{CH}), 129.9\left(\mathrm{C}_{\mathrm{q}}\right), 127.1(\mathrm{CH}), 125.1(\mathrm{CH}), 122.8(\mathrm{CH}), 120.9(\mathrm{CH}), 61.1\left(\mathrm{CH}_{2}\right)$, $60.7\left(\mathrm{CH}_{2}\right), 42.4(\mathrm{CH}), 18.3\left(\mathrm{CH}_{3}\right), 14.2\left(\mathrm{CH}_{3}\right), 14.1\left(\mathrm{CH}_{3}\right)$.

IR (ATR): 2936, 2711, 2594, 1617, 1455, 1202, 1158, $769 \mathrm{~cm}^{-1}$.

MS (ESI) $m / z$ (relative intensity): $350(30)[\mathrm{M}+\mathrm{Na}]^{+}, 328(70)[\mathrm{M}+\mathrm{H}]^{+}$.

HR-MS (ESI) $m / z$ calcd. for $\mathrm{C}_{19} \mathrm{H}_{22} \mathrm{NO}_{4}[\mathrm{M}+\mathrm{H}]^{+}: 328.1547$, found: 328.1546 .

The spectral data were in accordance with those reported in the literature. ${ }^{[284]}$

\section{Ethyl 2-(3-(pyridin-2-yl)phenyl)propanoate (409k)}

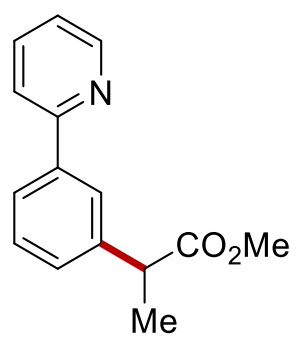

The General Procedure I was followed using 2-phenylpyridine 407a (38.8 mg, $0.25 \mathrm{mmol}$ ), ethyl 2bromopropanoate $\mathbf{4 0 8 b}$ (125 mg, $0.75 \mathrm{mmol}), 410$ (30.0 mg, $10 \mathrm{~mol} \%$ ) and KOAc (49.1 mg, 0.50 
mmol) in 2-MeTHF (2.0 mL). Purification by column chromatography on silica gel ( $n$-hexane/EtOAc: 10/1) yielded 409k (44.7 mg, 70\%) as a colorless oil.

${ }^{1} \mathbf{H}$ NMR $\left(400 \mathrm{MHz}, \mathrm{CDCl}_{3}\right) \delta 8.69(\mathrm{dt}, J=5.2,1.4 \mathrm{~Hz}, 1 \mathrm{H}), 8.02-7.91(\mathrm{~m}, 1 \mathrm{H}), 7.86(\mathrm{dt}, J=7.7$, $1.5 \mathrm{~Hz}, 1 \mathrm{H}), 7.80-7.68(\mathrm{~m}, 2 \mathrm{H}), 7.43$ (t, $J=7.7 \mathrm{~Hz}, 1 \mathrm{H}), 7.36$ (dt, $J=7.7,1.5 \mathrm{~Hz}, 1 \mathrm{H}), 7.23$ (ddd, $J$ $=6.6,4.8,2.0 \mathrm{~Hz}, 1 \mathrm{H}), 3.83(\mathrm{q}, J=7.1 \mathrm{~Hz}, 1 \mathrm{H}), 3.66(\mathrm{~s}, 3 \mathrm{H}), 1.56(\mathrm{~d}, J=7.2 \mathrm{~Hz}, 3 \mathrm{H})$.

${ }^{13}$ C NMR $\left(100 \mathrm{MHz}, \mathrm{CDCl}_{3}\right) \delta 175.1\left(\mathrm{C}_{\mathrm{q}}\right), 157.4\left(\mathrm{C}_{\mathrm{q}}\right), 149.8(\mathrm{CH}), 141.2\left(\mathrm{C}_{\mathrm{q}}\right), 139.9\left(\mathrm{C}_{\mathrm{q}}\right), 136.9(\mathrm{CH})$, $129.2(\mathrm{CH}), 128.1(\mathrm{CH}), 126.5(\mathrm{CH}), 125.9(\mathrm{CH}), 122.3(\mathrm{CH}), 120.8(\mathrm{CH}), 52.2\left(\mathrm{CH}_{3}\right), 45.6(\mathrm{CH})$, $18.8\left(\mathrm{CH}_{3}\right)$.

IR (ATR): 2980, 2951, 1733, 1585, 1462, 1435, 1202, 1165, $770 \mathrm{~cm}^{-1}$.

MS (EI) $m / z$ (relative intensity): $241(28)[\mathrm{M}]^{+}, 182$ (100), 167 (55).

HR-MS (EI+) $m / z$ calcd. for $\mathrm{C}_{15} \mathrm{H}_{15} \mathrm{NO}_{2}[\mathrm{M}]^{+}: 241.1103$, found: 241.1102 .

Isobutyl 2-(3-(pyridin-2-yl)phenyl)propanoate (409l)<smiles>CCOC(=O)C(C)c1cccc(-c2ccccn2)c1</smiles>

The General Procedure I was followed using 2-phenylpyridine 407a (38.8 mg, $0.25 \mathrm{mmol}$ ), isobutyl 2-bromopropanoate $408 \mathrm{c}(157 \mathrm{mg}, 0.75 \mathrm{mmol}), 410$ (30.0 mg, $10 \mathrm{~mol} \%$ ) and KOAc (49.1 mg, 0.50 mmol) in 2-MeTHF (2.0 mL). Purification by column chromatography on silica gel ( $n$-hexane/EtOAc: 10/1) yielded 4091 (45.3 mg, 64\%) as a colorless oil.

${ }^{1}$ H NMR $\left(400 \mathrm{MHz}, \mathrm{CDCl}_{3}\right) \delta 8.69(\mathrm{dd}, J=4.9,1.4 \mathrm{~Hz}, 1 \mathrm{H}), 7.94(\mathrm{dd}, J=1.6,1.4 \mathrm{~Hz}, 1 \mathrm{H}), 7.87$ (dt, $J=7.6,1.4 \mathrm{~Hz}, 1 \mathrm{H}), 7.81-7.67(\mathrm{~m}, 2 \mathrm{H}), 7.43(\mathrm{dd}, J=7.6,7.5 \mathrm{~Hz}, 1 \mathrm{H}), 7.39(\mathrm{dd}, J=7.5,1.6 \mathrm{~Hz}, 1 \mathrm{H})$, $7.23(\mathrm{ddd}, J=6.6,4.9,2.0 \mathrm{~Hz}, 1 \mathrm{H}), 3.88-3.83(\mathrm{~m}, 3 \mathrm{H}), 1.88(\mathrm{q}, J=6.7 \mathrm{~Hz}, 1 \mathrm{H}), 1.57(\mathrm{~d}, J=7.1 \mathrm{~Hz}$, $3 \mathrm{H}), 0.84(\mathrm{~d}, J=6.7 \mathrm{~Hz}, 6 \mathrm{H})$.

${ }^{13} \mathrm{C} \mathrm{NMR}\left(100 \mathrm{MHz}, \mathrm{CDCl}_{3}\right) \delta 174.6\left(\mathrm{C}_{\mathrm{q}}\right), 157.4\left(\mathrm{C}_{\mathrm{q}}\right), 149.8(\mathrm{CH}), 141.4\left(\mathrm{C}_{\mathrm{q}}\right), 139.8\left(\mathrm{C}_{\mathrm{q}}\right), 136.9(\mathrm{CH})$, $129.1(\mathrm{CH}), 128.2(\mathrm{CH}), 126.5(\mathrm{CH}), 125.8(\mathrm{CH}), 122.3(\mathrm{CH}), 120.8(\mathrm{CH}), 71.0\left(\mathrm{CH}_{2}\right), 45.9(\mathrm{CH})$, $27.9(\mathrm{CH}), 19.1\left(\mathrm{CH}_{3}\right), 18.7\left(\mathrm{CH}_{3}\right)$. 
IR (ATR): 2963, 1731, 1585, 1566, 1462, 1436, 1195, 1164, $769 \mathrm{~cm}^{-1}$.

MS (EI) $m / z$ (relative intensity): 283 (22) [M] ${ }^{+}, 225$ (13), 182 (100), 167 (53).

HR-MS (EI+) $m / z$ calcd. for $\mathrm{C}_{18} \mathrm{H}_{21} \mathrm{NO}_{2}[\mathrm{M}]^{+}:$283.1572, found: 283.1574 .

\section{Methyl 6-bromo-2-(3-(pyridin-2-yl)phenyl)hexanoate (409m)}

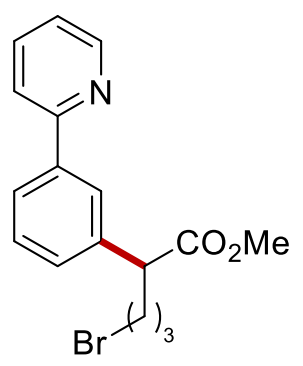

The General Procedure I was followed using 2-phenylpyridine 407a (38.8 mg, 0.25 mmol), methyl 2,6-dibromohexanoate 408d (216 mg, $0.75 \mathrm{mmol}), 410$ (30.0 mg, $10 \mathrm{~mol} \%)$ and KOAc (49.1 mg, $0.50 \mathrm{mmol})$ in 2-MeTHF $(2.0 \mathrm{~mL})$. Purification by column chromatography on silica gel $(n-$ hexane/EtOAc: 10/1) yielded 409m (50.3 mg, 58\%) as a brown oil.

${ }^{1}$ H NMR (400 MHz, $\left.\mathrm{CDCl}_{3}\right): \delta 8.69(\mathrm{dt}, J=5.0,1.2 \mathrm{~Hz}, 1 \mathrm{H}), 7.93(\mathrm{dd}, J=1.8,1.7 \mathrm{~Hz}, 1 \mathrm{H}), 7.88(\mathrm{dt}$, $J=7.7,1.7 \mathrm{~Hz}, 1 \mathrm{H}), 7.80-7.68(\mathrm{~m}, 2 \mathrm{H}), 7.44(\mathrm{dd}, J=7.8,7.7 \mathrm{~Hz}, 1 \mathrm{H}), 7.37(\mathrm{dt}, J=7.8,1.2 \mathrm{~Hz}, 1 \mathrm{H})$, $7.24(\mathrm{ddd}, J=6.6,5.0,1.8 \mathrm{~Hz}, 1 \mathrm{H}), 3.67(\mathrm{~s}, 3 \mathrm{H}), 3.67(\mathrm{t}, J=7.6 \mathrm{~Hz}, 1 \mathrm{H}), 3.39(\mathrm{t}, J=6.6 \mathrm{~Hz}, 2 \mathrm{H}), 2.30$ $-2.20(\mathrm{~m}, 1 \mathrm{H}), 2.10-2.00(\mathrm{~m}, 1 \mathrm{H}), 1.90-1.80(\mathrm{~m}, 2 \mathrm{H})$.

${ }^{13}$ C NMR $\left(100 \mathrm{MHz}, \mathrm{CDCl}_{3}\right) \delta 174.1\left(\mathrm{C}_{\mathrm{q}}\right), 157.2\left(\mathrm{C}_{\mathrm{q}}\right), 149.8(\mathrm{CH}), 140.1\left(\mathrm{C}_{\mathrm{q}}\right), 139.2\left(\mathrm{C}_{\mathrm{q}}\right), 136.9(\mathrm{CH})$, $129.3(\mathrm{CH}), 128.4(\mathrm{CH}), 126.8(\mathrm{CH}), 126.2(\mathrm{CH}), 122.4(\mathrm{CH}), 120.8(\mathrm{CH}), 52.3\left(\mathrm{CH}_{3}\right), 51.0(\mathrm{CH})$, $33.2\left(\mathrm{CH}_{2}\right), 32.1\left(\mathrm{CH}_{2}\right), 30.8\left(\mathrm{CH}_{2}\right)$.

IR (ATR): 2951, 1732, 1584, 1461, 1435, 1203, 1164, $771 \mathrm{~cm}^{-1}$.

MS (EI) $m / z$ (relative intensity): 347 (14) [M] $]^{+}, 288$ (18), 268 (100), 208 (61), 168 (61).

HR-MS (EI+) $m / z$ calcd. for $\mathrm{C}_{17} \mathrm{H}_{18}{ }^{79} \mathrm{BrNO}_{2}[\mathrm{M}]^{+}: 347.0521$, found: 347.0520 .

The spectral data were in accordance with those reported in the literature. ${ }^{[90]}$ 
$N, N$-Diethyl-2-(3-(pyridin-2-yl)phenyl)propanamide (409n)

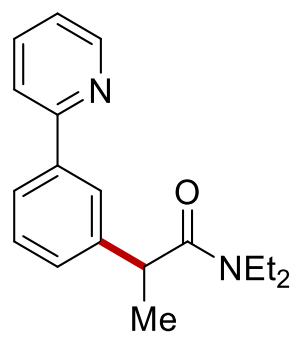

The General Procedure I was followed using 2-phenylpyridine 407a (38.8 mg, $0.25 \mathrm{mmol})$, 2-bromo$N, N$-diethylpropanamide 408e (156 mg, $0.75 \mathrm{mmol}), 410$ (30.0 mg, $10 \mathrm{~mol} \%)$ and KOAc (49.1 mg, $0.50 \mathrm{mmol})$ in 2-MeTHF $(2.0 \mathrm{~mL})$. Purification by column chromatography on silica gel $(n-$ hexane/EtOAc: 10/1) yielded 409n (49.4 mg, 70\%) as a yellow oil.

${ }^{1} \mathbf{H}$ NMR $\left(400 \mathrm{MHz}, \mathrm{CDCl}_{3}\right) \delta 8.69(\mathrm{~d}, J=5.0 \mathrm{~Hz}, 1 \mathrm{H}), 7.91(\mathrm{~s}, 1 \mathrm{H}), 7.85(\mathrm{dt}, J=7.6,1.2 \mathrm{~Hz}, 1 \mathrm{H})$, $7.76-7.70(\mathrm{~m}, 2 \mathrm{H}), 7.42(\mathrm{dd}, J=7.6,7.5 \mathrm{~Hz}, 1 \mathrm{H}), 7.35(\mathrm{dd}, J=7.6,1.2 \mathrm{~Hz}, 1 \mathrm{H}), 7.236-7.22(\mathrm{~m}$, $1 \mathrm{H}), 3.94(\mathrm{q},=7.0,1 \mathrm{H}), 3.53(\mathrm{dq}, J=7.6,7.1 \mathrm{~Hz}, 1 \mathrm{H}), 3.36(\mathrm{dq}, J=7.6,7.1 \mathrm{~Hz}, 1 \mathrm{H}), 3.23(\mathrm{dq}, J=$ 7.6, 7.1 Hz, 1H), $3.10(\mathrm{dq}, J=7.6,7.1 \mathrm{~Hz}, 1 \mathrm{H}), 1.49(\mathrm{~d}, J=6.8,3.1 \mathrm{~Hz}, 3 \mathrm{H}), 1.10(\mathrm{t}, J=7.1,3 \mathrm{H}), 1.01$ $(\mathrm{t}, J=7.1,3 \mathrm{H})$.

${ }^{13} \mathrm{C}$ NMR $\left(100 \mathrm{MHz}, \mathrm{CDCl}_{3}\right) \delta 172.8\left(\mathrm{C}_{\mathrm{q}}\right), 157.4\left(\mathrm{C}_{\mathrm{q}}\right), 149.8\left(\mathrm{C}_{\mathrm{q}}\right), 143.1(\mathrm{CH}), 140.0\left(\mathrm{C}_{\mathrm{q}}\right), 136.9(\mathrm{CH})$, $129.4(\mathrm{CH}), 127.9(\mathrm{CH}), 126.1(\mathrm{CH}), 125.4(\mathrm{CH}), 122.3(\mathrm{CH}), 120.8(\mathrm{CH}), 43.3\left(\mathrm{CH}_{2}\right), 41.8\left(\mathrm{CH}_{2}\right)$, $40.4(\mathrm{CH}), 21.2\left(\mathrm{CH}_{3}\right), 14.4\left(\mathrm{CH}_{3}\right), 13.0\left(\mathrm{CH}_{3}\right)$.

IR (ATR): 2973, 2932, 1636, 1584, 1461, 1433, 1264, 774, $702 \mathrm{~cm}^{-1}$.

MS (EI) $m / z$ (relative intensity): 282 (18) [M] $]^{+}, 225$ (14), 182 (26), 167 (30), 100 (100).

HR-MS (EI+) $m / z$ calcd. for $\mathrm{C}_{18} \mathrm{H}_{22} \mathrm{~N}_{2} \mathrm{O}[\mathrm{M}]^{+}: 282.1732$, found: 282.1730 .

\section{Ethyl 2-methyl-2-(3-(pyridin-2-yl)phenyl)propanoate (409o)}

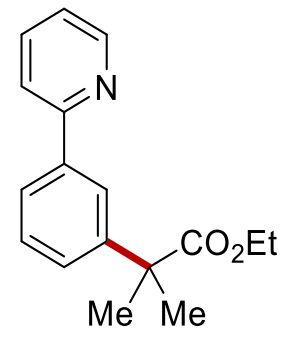

The General Procedure I was followed using 2-phenylpyridine 407a (38.8 mg, $0.25 \mathrm{mmol}$ ), 2-bromo2-methylpropanoate $408 f$ (146 mg, $0.75 \mathrm{mmol}), \mathbf{4 1 0}$ (30.0 mg, $10 \mathrm{~mol} \%$ ) and KOAc (49.1 mg, 0.50 
mmol) in 2-MeTHF (2.0 mL). Purification by column chromatography on silica gel ( $n$-hexane/EtOAc: 10/1) yielded 4090 (39.0 mg, 58\%) as a colorless oil.

${ }^{1} \mathbf{H}$ NMR $\left(400 \mathrm{MHz}, \mathrm{CDCl}_{3}\right) \delta 8.70(\mathrm{dt}, J=4.8,1.5 \mathrm{~Hz}, 1 \mathrm{H}), 7.99(\mathrm{dd}, J=1.9,1.5 \mathrm{~Hz}, 1 \mathrm{H}), 7.84(\mathrm{dt}$, $J=7.4,1.6 \mathrm{~Hz}, 1 \mathrm{H}), 7.78-7.67(\mathrm{~m}, 2 \mathrm{H}), 7.43(\mathrm{dd}, J=7.5,7.4 \mathrm{~Hz}, 2 \mathrm{H}), 7.23(\mathrm{ddd}, J=7.5,4.8,1.5$ $\mathrm{Hz}, 1 \mathrm{H}), 4.14$ (q, $J=7.1 \mathrm{~Hz}, 2 \mathrm{H}), 1.65(\mathrm{~s}, 6 \mathrm{H}), 1.19$ (t, $J=7.1 \mathrm{~Hz}, 3 \mathrm{H})$.

${ }^{13}$ C NMR $\left(100 \mathrm{MHz}, \mathrm{CDCl}_{3}\right) \delta 176.9\left(\mathrm{C}_{\mathrm{q}}\right), 157.7\left(\mathrm{C}_{\mathrm{q}}\right), 149.8(\mathrm{CH}), 145.5\left(\mathrm{C}_{\mathrm{q}}\right), 139.7\left(\mathrm{C}_{\mathrm{q}}\right), 136.8(\mathrm{CH})$, $128.9(\mathrm{CH}), 126.6(\mathrm{CH}), 125.4(\mathrm{CH}), 124.4(\mathrm{CH}), 122.2(\mathrm{CH}), 120.9(\mathrm{CH}), 61.0\left(\mathrm{CH}_{2}\right), 46.8\left(\mathrm{C}_{\mathrm{q}}\right), 26.7$ $\left(\mathrm{CH}_{3}\right), 14.2\left(\mathrm{CH}_{3}\right)$.

IR (ATR): 2979, 1726, 1585, 1463, 1253, 1146, 1025, $771 \mathrm{~cm}^{-1}$.

MS (EI) $m / z$ (relative intensity): 269 (20) [M] $]^{+}, 196(100), 180$ (21), 167 (18).

HR-MS (EI+) $m / z$ calcd. for $\mathrm{C}_{17} \mathrm{H}_{19} \mathrm{NO}_{2}[\mathrm{M}]^{+}: 269.1416$, found: 269.1415 .

The spectral data were in accordance with those reported in the literature. ${ }^{[84]}$

\section{(1R,2S,5R)-2-Isopropyl-5-methylcyclohexyl 2-[3-(pyridin-2-yl)phenyl]propanoate (409p)}

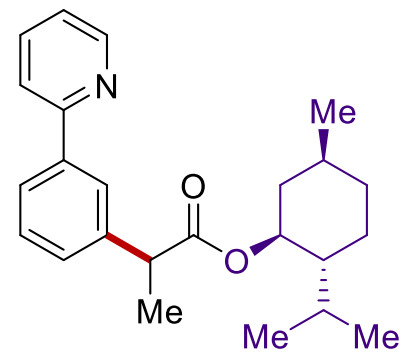

The General Procedure I was followed using 2-phenylpyridine 407a (38.8 mg, $0.25 \mathrm{mmol}$ ), $(1 R, 2 S, 5 R)$-2-isopropyl-5-methylcyclohexyl 2-bromopropanoate $\mathbf{4 0 8 g}$ (218 mg, $0.75 \mathrm{mmol}), 410$ (30.0 mg, $10 \mathrm{~mol} \%$ ) and KOAc (49.1 mg, $0.50 \mathrm{mmol})$ in 2-MeTHF (2.0 mL). Purification by column chromatography on silica gel ( $n$-hexane/EtOAc: $10 / 1)$ yielded 409p (52.1 mg, 57\%) as a colorless oil. ${ }^{1}$ H NMR $\left(400 \mathrm{MHz} \mathrm{CDCl}_{3}\right) \delta 8.69(\mathrm{dt}, J=4.9,1.4 \mathrm{~Hz}, 1 \mathrm{H}), 7.92(\mathrm{dd}, J=3.9,1.9 \mathrm{~Hz}, 1 \mathrm{H}), 7.87$ (dd, $J=7.7,1.5 \mathrm{~Hz}, 1 \mathrm{H}), 7.79-7.65(\mathrm{~m}, 2 \mathrm{H}), 7.49-7.32(\mathrm{~m}, 2 \mathrm{H}), 7.22(\mathrm{ddd}, J=6.5,4.8,2.1 \mathrm{~Hz}, 1 \mathrm{H})$, $4.69-4.60(\mathrm{~m}, 1 \mathrm{H}), 3.82-3.76(\mathrm{~m}, 1 \mathrm{H}), 2.06-1.76(\mathrm{~m}, 2 \mathrm{H}), 1.71-1.58(\mathrm{~m}, 2 \mathrm{H}), 1.56(\mathrm{~d}, J=2.7$ $\mathrm{Hz}, 1 \mathrm{H}), 1.54(\mathrm{~d}, J=2.7 \mathrm{~Hz}, 1 \mathrm{H}), 1.51-1.39(\mathrm{~m}, 1 \mathrm{H}), 1.38-1.23(\mathrm{~m}, 2 \mathrm{H}), 1.02-0.93(\mathrm{~m}, 2 \mathrm{H}), 0.95$ $-0.72(\mathrm{~m}, 7 \mathrm{H}), 0.71(\mathrm{~d}, J=6.9 \mathrm{~Hz}, 1 \mathrm{H}), 0.64(\mathrm{~d}, J=7.0 \mathrm{~Hz}, 1 \mathrm{H}), 0.49(\mathrm{~d}, J=6.9 \mathrm{~Hz}, 1 \mathrm{H})$. 
${ }^{13} \mathrm{C} \mathrm{NMR}\left(100 \mathrm{MHz}, \mathrm{CDCl}_{3}\right) \delta 174.2\left(\mathrm{C}_{\mathrm{q}}\right), 157.5\left(\mathrm{C}_{\mathrm{q}}\right), 149.8(\mathrm{CH}), 141.5\left(\mathrm{C}_{\mathrm{q}}\right), 139.8\left(\mathrm{C}_{\mathrm{q}}\right), 136.8(\mathrm{CH})$, 129.0 (CH), $128.1(\mathrm{CH}), 126.4(\mathrm{CH}), 125.7(\mathrm{CH}), 122.3(\mathrm{CH}), 120.7(\mathrm{CH}), 74.7(\mathrm{CH}), 47.1(\mathrm{CH}), 46.1$ $\left(\mathrm{CH}_{2}\right), 40.8(\mathrm{CH}), 34.4\left(\mathrm{CH}_{2}\right), 31.5\left(\mathrm{CH}_{2}\right), 26.1(\mathrm{CH}), 23.4(\mathrm{CH}), 22.1\left(\mathrm{CH}_{3}\right), 20.8\left(\mathrm{CH}_{3}\right), 18.7\left(\mathrm{CH}_{3}\right)$, $16.2\left(\mathrm{CH}_{3}\right)$.

IR (ATR): 2953, 2869, 1726, 1585, 1461, 1198, 1170, $768 \mathrm{~cm}^{-1}$.

MS (EI) $m / z$ (relative intensity): 365 (18) [M] $]^{+}, 228$ (28), 183 (100), 167 (42), 83 (72).

HR-MS (EI+) $m / z$ calcd. for $\mathrm{C}_{24} \mathrm{H}_{31} \mathrm{NO}_{2}[\mathrm{M}]^{+}:$365.2355, found: 365.2362 .

$(3 S, 8 S, 9 S, 10 R, 13 R, 14 S, 17 R)-10,13-D i m e t h y l-17-((R)-6-m e t h y l h e p t a n-2-y l)-2,3,4,7,8,9,10,11,12,1$ 3,14,15,16,17-tetradecahydro-1H-cyclopenta[a]phenanthren-3-yl 2-[3-(pyridin-2-yl)phenyl]pro panoate (409q)

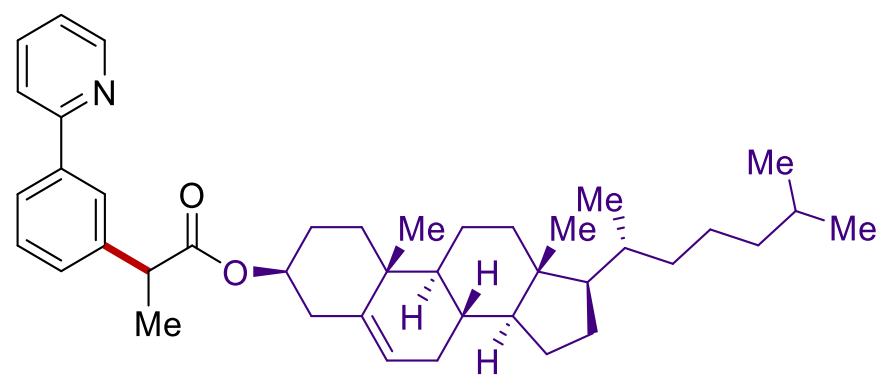

The General Procedure I was followed using 2-phenylpyridine 407a (38.8 mg, $0.25 \mathrm{mmol}$ ), (3S,8S,9S,10R,13R,14S,17R)-10,13-dimethyl-17-((R)-6-methylheptan-2-yl)-2,3,4,7,8,9,10,11,12,13,1 4,15,16,17-tetradecahydro-1H-cyclopenta[a]phenanthren-3-yl 2-bromopropanoate $\mathbf{4 0 8 h}$ (391 mg, $0.75 \mathrm{mmol}), 410(30.0 \mathrm{mg}, 10 \mathrm{~mol} \%)$ and KOAc (49.1 mg, $0.50 \mathrm{mmol})$ in 2-MeTHF (2.0 mL). Purification by column chromatography on silica gel ( $n$-hexane/EtOAc: $10 / 1)$ yielded 409q (93.9 mg, $63 \%$ ) as a colorless oil.

${ }^{1} \mathbf{H}$ NMR $\left(400 \mathrm{MHz}, \mathrm{CDCl}_{3}\right) \delta 8.70(\mathrm{dd}, J=5.0,1.5 \mathrm{~Hz}, 1 \mathrm{H}), 7.94(\mathrm{t}, J=1.7 \mathrm{~Hz}, 1 \mathrm{H}), 7.87(\mathrm{dt}, J=$ 7.6, 1.5 Hz, 1H), $7.74(\mathrm{dd}, J=6.6,1.7 \mathrm{~Hz}, 2 \mathrm{H}), 7.43$ (dd, $J=7.6,7.6 \mathrm{~Hz}, 2 \mathrm{H}), 7.23$ (ddd, $J=6.6,5.0$, $2.1 \mathrm{~Hz}, 1 \mathrm{H}), 5.33(\mathrm{ddd}, J=21.3,4.3,1.8 \mathrm{~Hz}, 1 \mathrm{H}), 4.75-4.51(\mathrm{~m}, 1 \mathrm{H}), 3.78(\mathrm{q}, J=7.2 \mathrm{~Hz}, 1 \mathrm{H}), 2.40$ $-2.27(\mathrm{~m}, 1 \mathrm{H}), 2.25-2.17(\mathrm{~m}, 1 \mathrm{H}), 2.05-1.75(\mathrm{~m}, 5 \mathrm{H}), 1.61-1.25(\mathrm{~m}, 14 \mathrm{H}), 1.22-0.95(\mathrm{~m}, 13 \mathrm{H})$, $0.94-0.88(\mathrm{~m}, 3 \mathrm{H}), 0.86(\mathrm{dd}, J=6.6,1.8 \mathrm{~Hz}, 6 \mathrm{H}), 0.66$ (s, 3H).

${ }^{13}$ C NMR $\left(100 \mathrm{MHz}, \mathrm{CDCl}_{3}\right) \delta 174.0\left(\mathrm{C}_{\mathrm{q}}\right), 157.4\left(\mathrm{C}_{\mathrm{q}}\right), 149.7(\mathrm{CH}), 141.6\left(\mathrm{C}_{\mathrm{q}}\right), 139.8\left(\mathrm{C}_{\mathrm{q}}\right), 139.7\left(\mathrm{C}_{\mathrm{q}}\right)$, $136.9(\mathrm{CH}), 129.1(\mathrm{CH}), 128.1(\mathrm{CH}), 126.5(\mathrm{CH}), 125.8(\mathrm{CH}), 122.7(\mathrm{CH}), 122.3(\mathrm{CH}), 120.8(\mathrm{CH})$, 
$74.4(\mathrm{CH}), 56.8(\mathrm{CH}), 56.3(\mathrm{CH}), 50.1(\mathrm{CH}), 46.0(\mathrm{CH}), 42.4\left(\mathrm{CH}_{2}\right), 39.9\left(\mathrm{CH}_{2}\right), 39.7\left(\mathrm{CH}_{2}\right), 38.1\left(\mathrm{C}_{\mathrm{q}}\right)$, $37.1\left(\mathrm{CH}_{2}\right), 36.7\left(\mathrm{CH}_{2}\right), 36.3\left(\mathrm{CH}_{2}\right), 35.9(\mathrm{CH}), 32.0\left(\mathrm{CH}_{2}\right), 32.0(\mathrm{CH}), 28.4\left(\mathrm{CH}_{2}\right), 28.2(\mathrm{CH}), 27.7$ $\left(\mathrm{C}_{\mathrm{q}}\right), 24.4\left(\mathrm{CH}_{2}\right), 24.0\left(\mathrm{CH}_{2}\right), 22.8\left(\mathrm{CH}_{3}\right), 21.2\left(\mathrm{CH}_{2}\right), 19.5\left(\mathrm{CH}_{3}\right), 19.0\left(\mathrm{CH}_{3}\right), 18.9\left(\mathrm{CH}_{3}\right), 12.0\left(\mathrm{CH}_{3}\right)$. IR (ATR): 2935, 2867, 1731, 1585, 1462, 1195, 1165, $769 \mathrm{~cm}^{-1}$. MS (ESI) $m / z$ (relative intensity): $618(100)[\mathrm{M}+\mathrm{Na}]^{+}, 596(30)[\mathrm{M}+\mathrm{H}]^{+}$.

HR-MS (ESI) $m / z$ calcd for $\mathrm{C}_{41} \mathrm{H}_{58} \mathrm{NO}_{2}[\mathrm{M}+\mathrm{H}]^{+}:$596.4462, found: 596.4465 . 


\subsubsection{Preparation of Hybrid Ruthenium Catalyst}

A suspension of $\left[\mathrm{RuCl}_{2}(p \text {-cymene })\right]_{2}(0.30 \mathrm{~g}, 0.50 \mathrm{mmol})$ and resin 448 (triphenylphosphine, polymer supported 1.4-2.0 mmol/g on polystyrene 200-400 mesh 2\% DVB loading, Fluorochem, $0.50 \mathrm{~g}$ ) in a solvent mixture of DCM $(15 \mathrm{~mL})$ and PhMe $(15 \mathrm{~mL})$ was refluxed at $110{ }^{\circ} \mathrm{C}$ for $2 \mathrm{~h}$ under $\mathrm{N}_{2}(\mathrm{Scheme}$ 5.7.1). After cooling to ambient temperature, the mixture was filtered with DCM $(50 \mathrm{~mL}) . \mathbf{4 1 0}$ was dried in vacuo at room temperature for $24 \mathrm{~h}$ (Scheme 5.7.1).

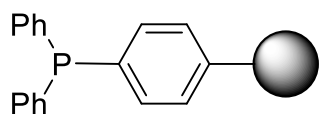

448

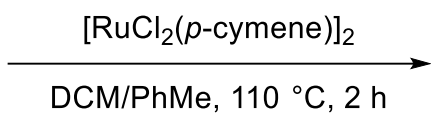

$\mathrm{DCM} / \mathrm{PhMe}, 110{ }^{\circ} \mathrm{C}, 2 \mathrm{~h}$

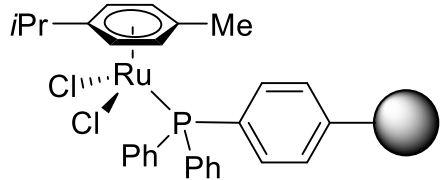

410

Scheme 5.7.1 Preparation of hybrid ruthenium catalyst.

\subsubsection{Determination of Catalyst Loading}

ICP-OES analysis was performed by Dr. Volker Karius for the determination of hybrid ruthenium catalyst 410 loading (Equation 5.7.1)

$$
\begin{gathered}
n_{\text {Cat }}=\frac{m_{\text {Cat }} \cdot \text { ICP-OES result }}{M_{\mathrm{Ru}}} \\
n_{\text {Cat }}=\frac{30 \mathrm{mg} \cdot 0.084}{101.07 \frac{\mathrm{mg}}{\mathrm{mmol}}}=2.49 \cdot 10^{-2} \mathrm{mmol}
\end{gathered}
$$

Catalyst loading $=\frac{n_{\text {Cat }}}{0.25 \mathrm{mmol}} \cdot 100 \mathrm{~mol} \%=9.96 \mathrm{~mol} \%$

Equation 5.7.1 Determination of hybrid ruthenium catalyst loading. 


\subsubsection{Competition Experiment}

A suspension of 2-(4-fluorophenyl)-4,5-dihydrooxazole $407 \mathbf{k}(0.25 \mathrm{mmol}, 1.0$ equiv) and 2-(4methoxyphenyl)-4,5-dihydrooxazole 4071 ( $0.25 \mathrm{mmol}, 1.0$ equiv), ethyl 2-bromopropanoate 408a (0.75 mmol, 1.0 equiv), 410 (10 mol \%), KOAc (0.50 mmol, 2.0 equiv) in 2-MeTHF (2.0 mL) was stirred at $60{ }^{\circ} \mathrm{C}$ for $24 \mathrm{~h}$ under $\mathrm{N}_{2}$. After cooling to ambient temperature, the mixture was concentrated in vacuo. Purification by column chromatography on silica gel afforded the desired products 409r and 409s respectively (Scheme 5.7.2).<smiles>Oc1ccc(C2=NCCO2)cc1</smiles>

$407 \mathrm{k} / 407 \mathrm{I}$<smiles>CCOC(C)Br</smiles>

$408 a$

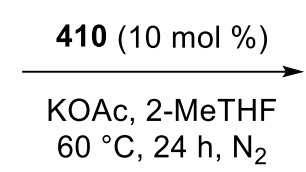

$60^{\circ} \mathrm{C}, 24 \mathrm{~h}, \mathrm{~N}_{2}$<smiles>CCOC(C)c1cc(OC)cc(C2=NCCO2)c1</smiles>

409r: $33 \%$<smiles>CCOC(C)c1cc(C2=NCCO2)ccc1F</smiles>

409s: $19 \%$

Scheme 5.7.2 Competition experiment between 407k and 4071. 


\subsubsection{H/D Exchange Study}

A suspension of 2-(4-methoxyphenyl)-4,5-dihydrooxazole $407 \mathbf{k}(0.25 \mathrm{mmol}, 1.0$ equiv), ethyl 2bromopropanoate $408 \mathrm{a}(0.75 \mathrm{mmol}, 3.0$ equiv), 410 (10 mol \%), KOAc (0.50 mmol, 2.0 equiv), $\mathrm{CD}_{3} \mathrm{OD}\left(0.1 \mathrm{~mL}, 10\right.$ equiv) in 2-MeTHF $(2.0 \mathrm{~mL})$ was stirred at $60{ }^{\circ} \mathrm{C}$ for $24 \mathrm{~h}$ under $\mathrm{N}_{2}$. After cooling to ambient temperature, the mixture was concentrated in vacuo. Purification by column chromatography on silica gel afforded the desired products $[D]_{n}-\mathbf{4 0 7 k}$ and $[D]_{n}-409 r$ respectively (Scheme 5.7.3).<smiles>COc1ccc(C2=NCCO2)cc1</smiles>

407k<smiles>[C+]C(C)C(Br)OCC</smiles>

408a

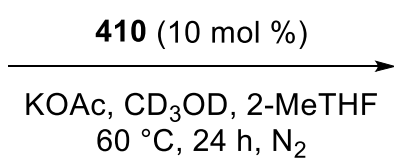
$60^{\circ} \mathrm{C}, 24 \mathrm{~h}, \mathrm{~N}_{2}$

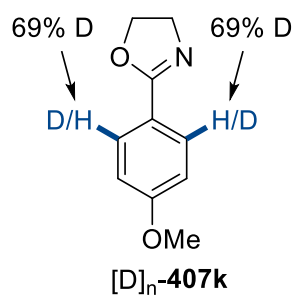

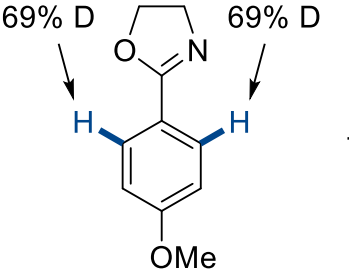

$[D]_{n}-407 k: 23 \%$

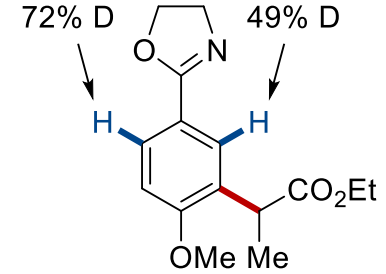

$[D]_{n}-409 r: 71 \%$

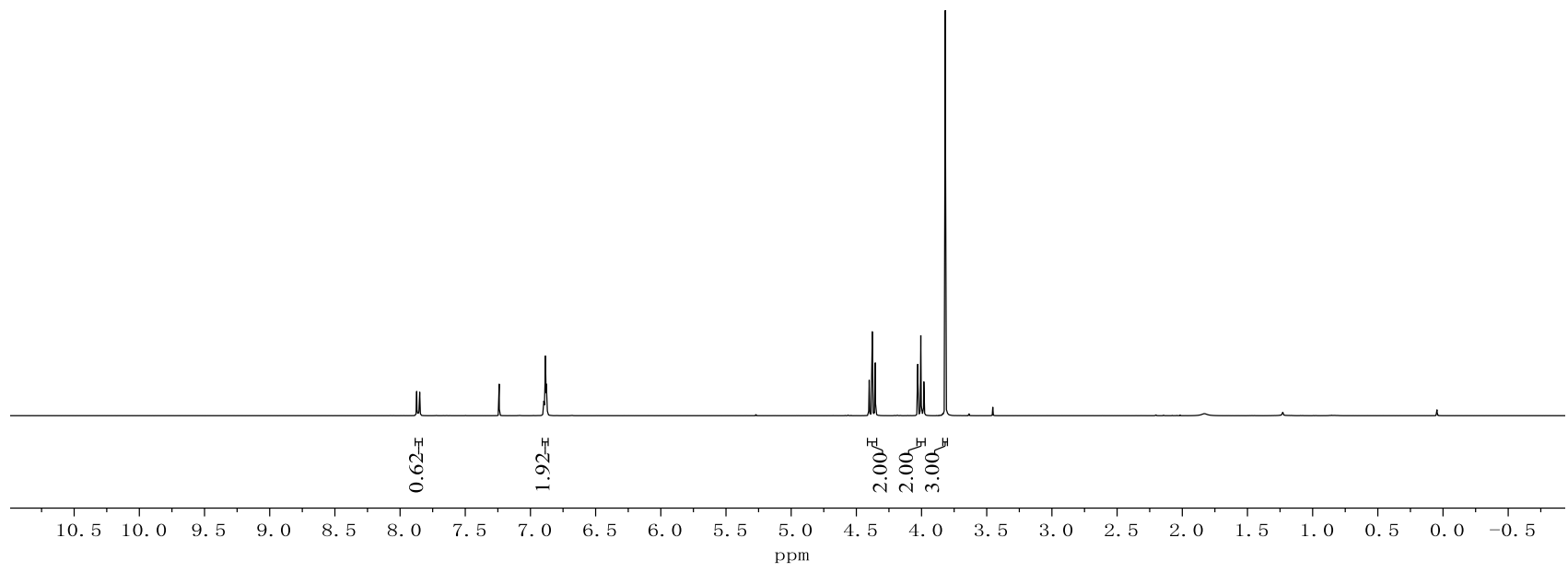

Scheme 5.7.3 H/D exchange study 1 . 


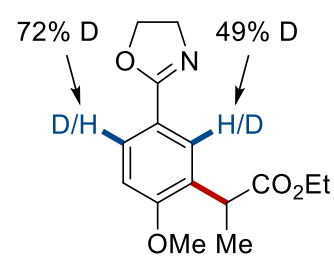

$[D]_{n}-409 r$

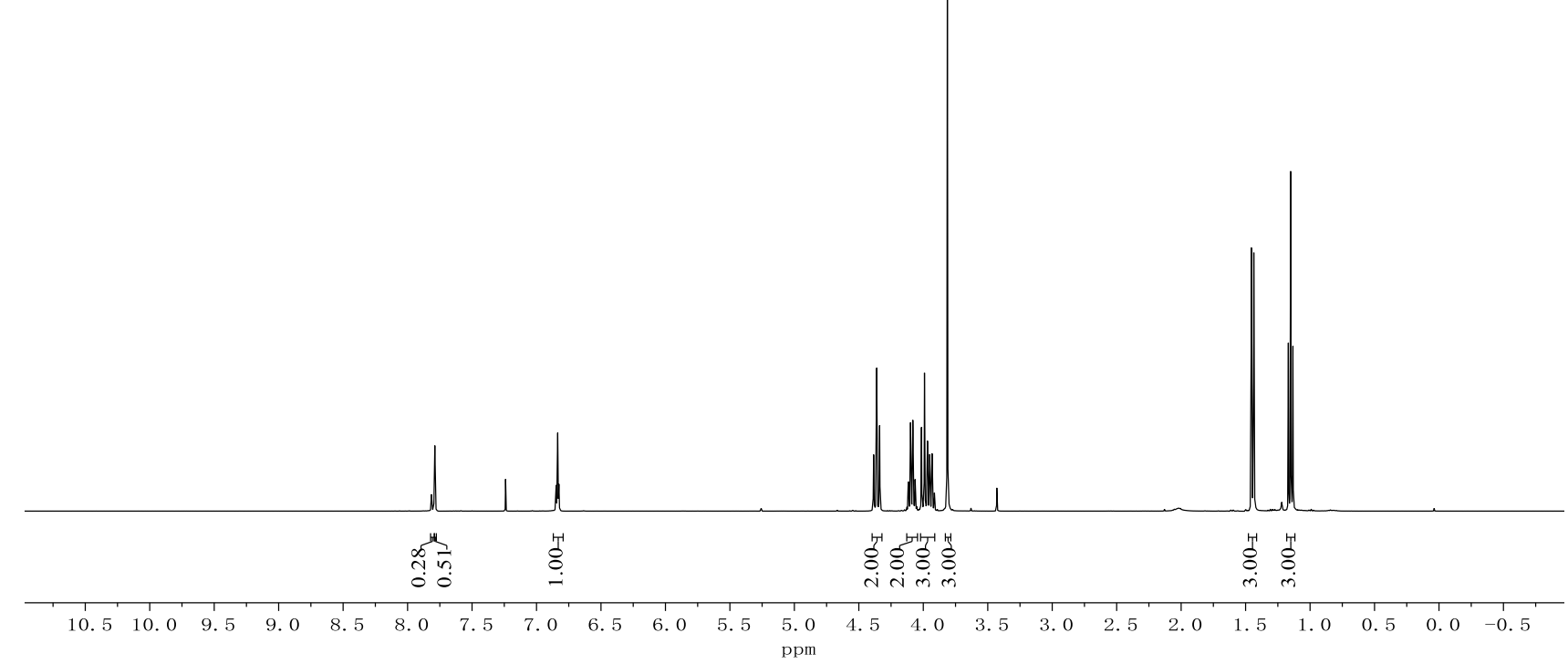

Scheme 5.7.4 H/D exchange study 2 . 


\subsubsection{KIE Study}

1) Procedure for KIE study (intermolecular competition reaction)

A suspension of $\mathbf{4 0 7 d}(0.25 \mathrm{mmol}, 1.0$ equiv) and [D]5-407d (0.25 mmol, 1.0 equiv), ethyl 2bromopropanoate 408a ( $0.75 \mathrm{mmol}, 3.0$ equiv), 410 (10 mol \%), KOAc (0.50 mmol, 2.0 equiv), in 2MeTHF $(2.0 \mathrm{~mL})$ was stirred at $60{ }^{\circ} \mathrm{C}$ for $24 \mathrm{~h}$ under $\mathrm{N}_{2}$ to determine the KIE by intermolecular competition fashion. Purification by column chromatography on silica gel afforded the desired mixed products of $409 \mathrm{~d}$ and $[\mathrm{D}]_{\mathrm{n}}-\mathbf{4 0 9 d}$. The kinetic isotope effect of this reaction was determined to be $k_{\mathrm{H}} / k_{\mathrm{D}}$ $=1.2$ as estimated by ${ }^{1} \mathrm{H}$ NMR spectroscopy (Scheme 5.7.5).<smiles>CCOC(=O)C(C)Br</smiles>

407d and $[D]_{5}-407 d$

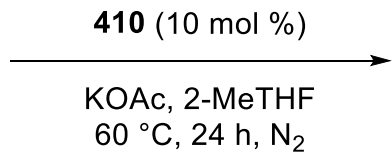

KIE by competition $k_{\mathrm{H}} / k_{\mathrm{D}}=1.2$<smiles>CCOC(=O)c1cc(O)c(O)c(-n2cccn2)c1</smiles>

409d and $[D]_{n}-409 d: 49 \%$

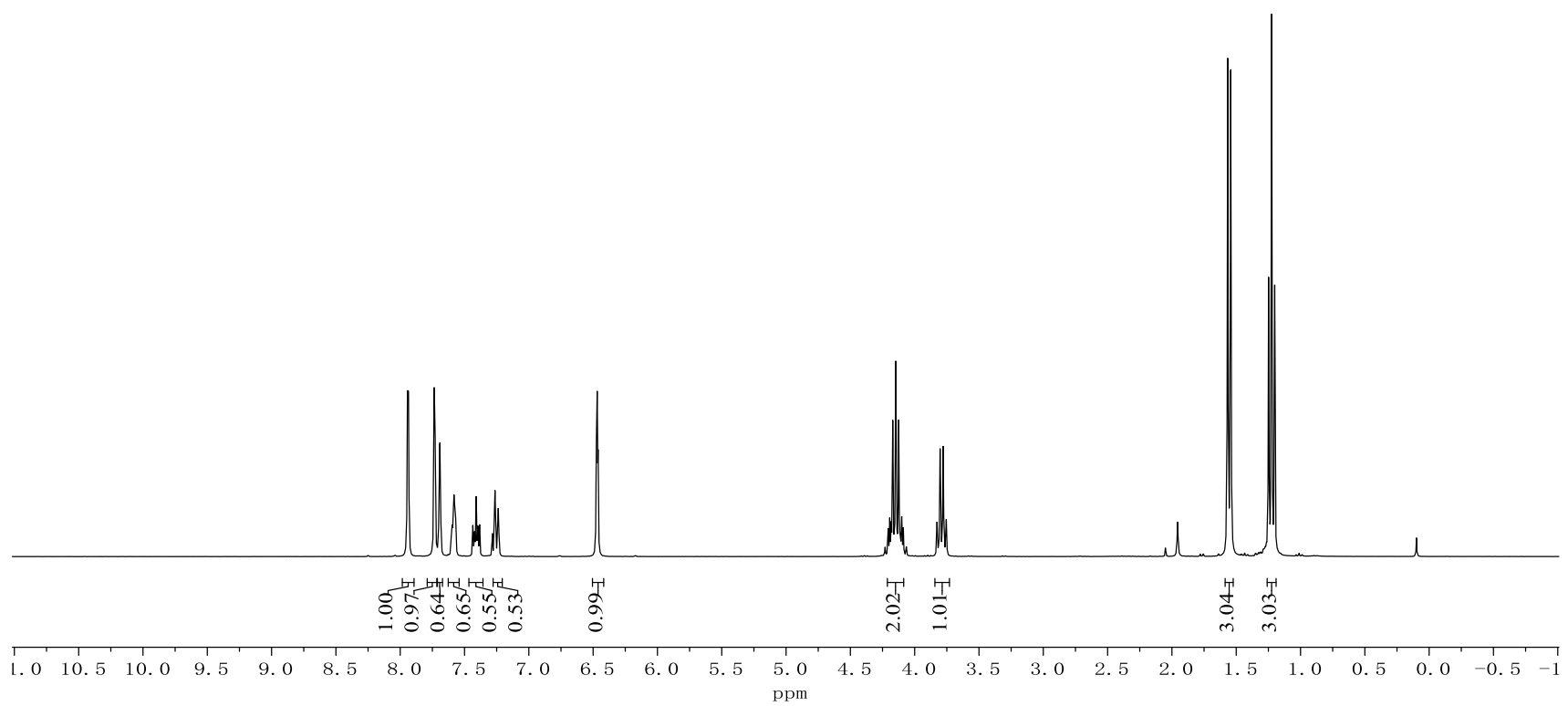

Scheme 5.7.5 Intermolecular kinetic isotope exchange study. 
2) Procedure for KIE study (two parallel reactions)

Two parallel reactions under the General Procedure I respectively using substrate $407 \mathbf{d}(0.25 \mathrm{mmol}$, 1.0 equiv) or $[\mathrm{D}]_{5} \mathbf{- 4 0 7} \mathbf{d}(0.25 \mathrm{mmol}, 1.0$ equiv) were performed to determine the KIE by comparison of the initial rates. Each conversion was determined after 2 h by ${ }^{1} \mathrm{H}$ NMR measurement using 1,3,5trimethoxybezene as the internal standard (Scheme 5.7.6). Blue line is for $409 \mathbf{d}$ and red line is for $[\mathrm{D}]_{\mathrm{n}^{-}}$ 409d.<smiles>CCOC(=O)C(C)Br</smiles>
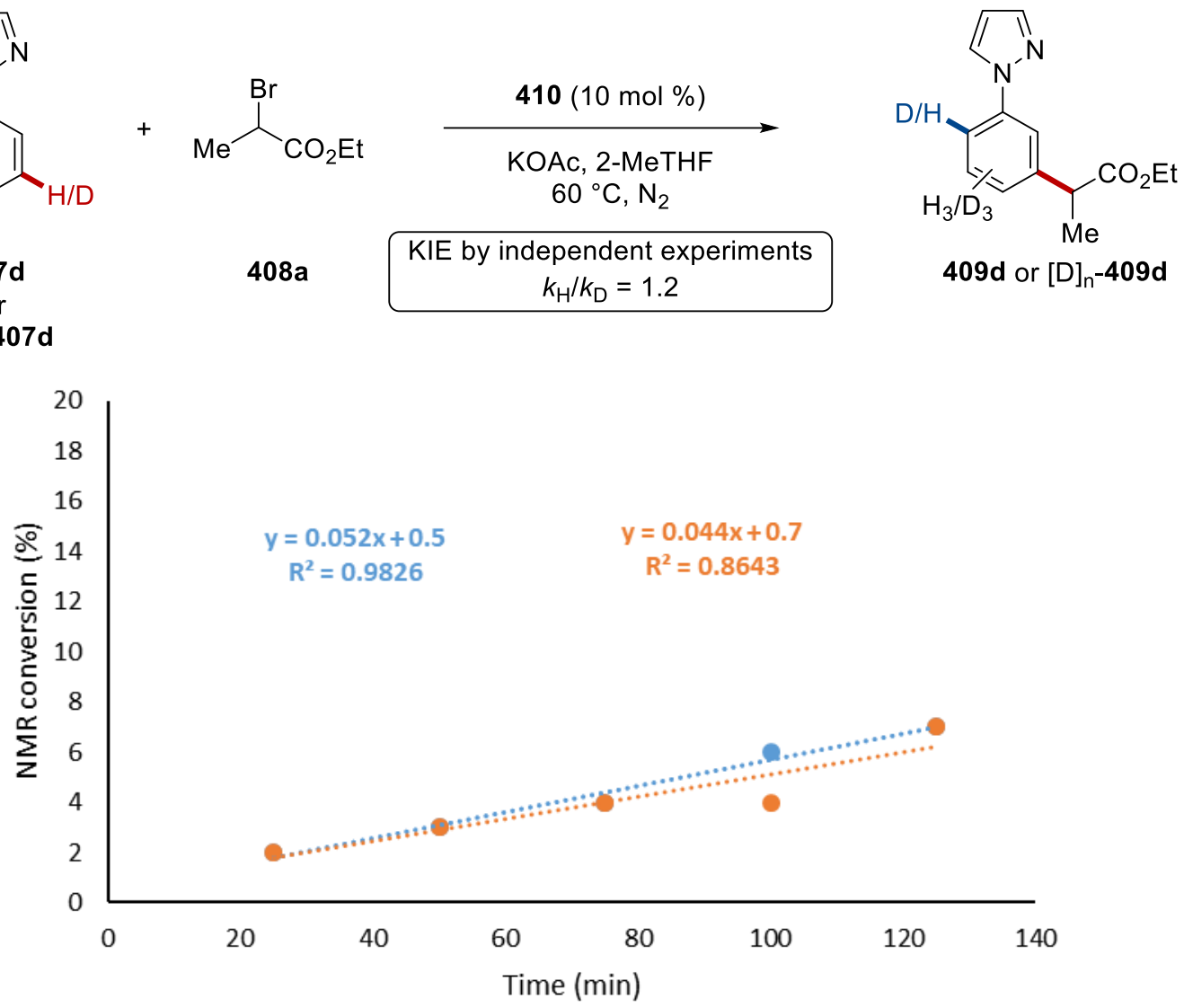

Scheme 5.7.6 Parallel kinetic isotope exchange study. 


\subsubsection{Heterogeneity test}

1) Reuse test

The General Procedure I was followed using 2-phenylpyridine 407a (0.25 mmol, 1.0 equiv), ethyl 2-bromopropanoate 408a (0.75 mmol, 3.0 equiv), 410 (10 mol \%) and KOAc (0.50 mmol, 2.0 equiv) in 2-MeTHF $(2.0 \mathrm{~mL})$. After $24 \mathrm{~h}$ the reaction tube was transferred to a glovebox. Hybrid-Ru was carefully filtered through branched filter (Por. 3) and washed with 2-MeTHF (30 mL). Filtered hybrid ruthenium catalyst 409a was dried in vacuo for $24 \mathrm{~h}$ and used for next run (Scheme 5.7.8).
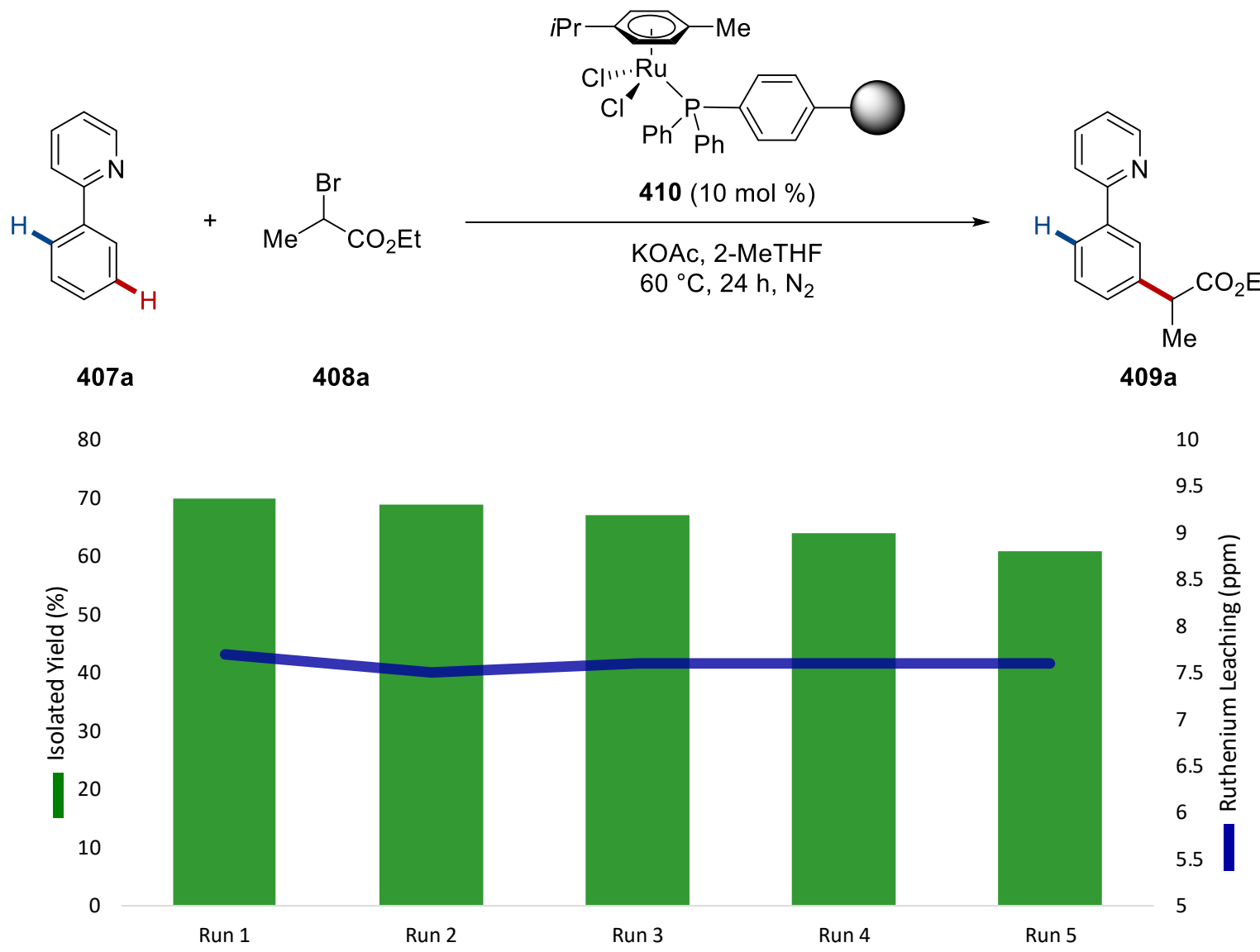

Scheme 5.7.7 Reuse test and determination of ruthenium leaching. 
$<$ Washing method 1 $>$

After the completion of the reaction, $\mathbf{4 1 0}$ was carefully filtered through branched filter (Por. 3) and washed with DCM, 2-MeTHF, and DCM (each $30 \mathrm{~mL}$ ). Filtered hybrid ruthenium catalyst was dried in vacuo for $24 \mathrm{~h}$. The dried catalyst was directly used for the next run.

$<$ Washing method 2>

After the completion of the reaction, $\mathbf{4 1 0}$ was carefully filtered through branched filter (Por. 3) and washed with DCM, 2-MeTHF, demineralized water, EtOH, and DCM (each $30 \mathrm{~mL}$ ). Filtered hybrid ruthenium catalyst was dried in vacuo for $24 \mathrm{~h}$. The dried catalyst was directly used for the next run.<smiles>c1ccc(-c2ccccc2)cc1</smiles>

$407 a$

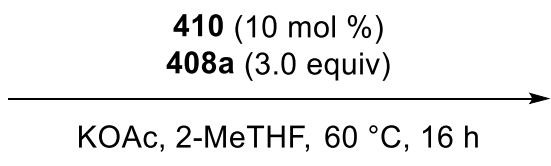

KOAc, 2-MeTHF, $60^{\circ} \mathrm{C}, 16 \mathrm{~h}$<smiles>CCOC(=O)C(C)c1cccc(-c2ccccn2)c1</smiles>

409a

\begin{tabular}{c||c|c||c|c} 
& First run & $\begin{array}{c}\text { Amount of } \\
\text { catalyst }\end{array}$ & Second run & $\begin{array}{c}\text { Amount of } \\
\text { catalyst }\end{array}$ \\
\hline Washing method 1 & $70 \%$ & $30 \mathrm{mg}$ & $69 \%$ & $37 \mathrm{mg}$ \\
Washing method 2 & $70 \%$ & $30 \mathrm{mg}$ & $57 \%$ & $28 \mathrm{mg}$
\end{tabular}

Scheme 5.7.8 Reusability varying from the washing methods. 
2) Gram-scale reuse test

The General Procedure I was followed using 2-phenylpyridine 407a (10.0 mmol, 1.0 equiv), ethyl 2-bromopropanoate $408 \mathrm{a}$ (30.0 mmol, 3.0 equiv), 410 (10 mol \%) and KOAc (20 mmol, 2.0 equiv) in 2-MeTHF $(10.0 \mathrm{~mL})$. After $24 \mathrm{~h}$ the reaction tube was transferred to a glovebox. Hybrid-Ru was carefully filtered through branched filter (Por. 3) with 2-MeTHF (60 mL). Filtered hybrid ruthenium catalyst was dried in vacuo and used for the second run. The solvent of filtrate was removed under reduced pressure. Purification by column chromatography on silica gel afforded 409a (first run: 2.04 g, 80\%; second run: $1.94 \mathrm{~g}, 76 \%$ ) as a colorless oil (Scheme 5.7.10).<smiles>c1ccc(-c2ccccn2)cc1</smiles>

407a<smiles>CCOC(C)Br</smiles>

$408 a$

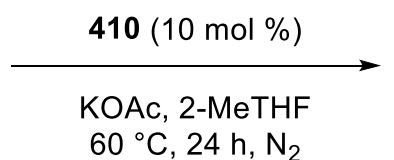

$60{ }^{\circ} \mathrm{C}, 24 \mathrm{~h}, \mathrm{~N}_{2}$<smiles>CCOC(=O)C(C)c1cccc(-c2ccccn2)c1</smiles>

409a

First run: $\quad 80 \%(2.04 \mathrm{~g})$ Second run: $76 \%(1.94 \mathrm{~g})$

Scheme 5.7.9 Scaled reuse test. 
3) Hot filtration test

The General Procedure I was followed using 2-phenylpyridine 407a (0.25 mmol, 1.0 equiv), ethyl 2-bromopropanoate 408a ( $0.75 \mathrm{mmol}, 3.0$ equiv), 410 (10 mol \%) and KOAc (0.50 mmol, 2.0 equiv) in 2-MeTHF (2.0 mL). After 2 or 4 hours, reaction tube was transferred to the Glove box. Hybrid-Ru was carefully filtered over pre-heated (to $60{ }^{\circ} \mathrm{C}$ ) Celite ${ }^{\circledR}$ with a branched filter (Por. 3). Filtrate was directly collected to another pre-dried Schlenk tube and then sealed with septum. The sealed tube was transferred to the same reaction batch and the reaction continued for 22 or $20 \mathrm{~h}$. After cooling to ambient temperature, the mixture was concentrated in vacuo. Purification by column chromatography on silica gel afforded the desired products 409a (Scheme 5.7.11).

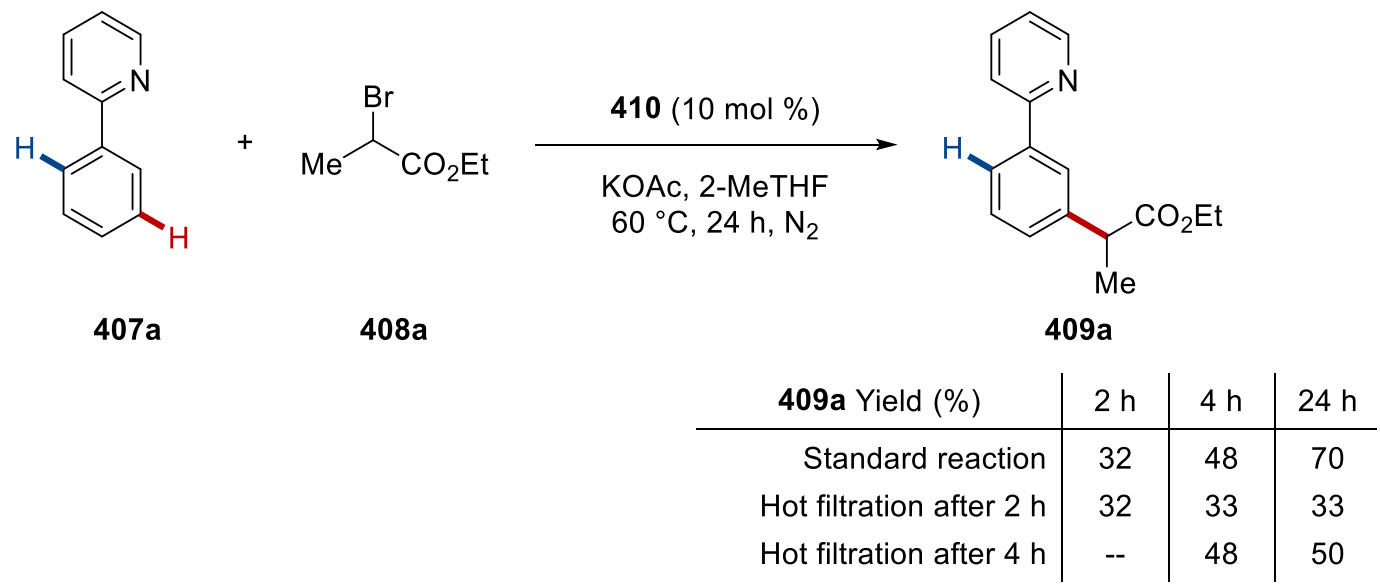

Scheme 5.7.10 Hot filtration test. 


\subsection{C-H Arylations and Alkylations by Reusable Heterogeneous Manganese Catalyst}

\subsubsection{Characterization Data}

N-Butyl-3-(4-methoxyphenyl)picolinamide (413a)<smiles>CCCCNC(=O)c1ncccc1-c1ccc(OC)cc1</smiles>

The General Procedure $\mathbf{J}$ was followed using $N$-butylpicolinamide 411a (44.6 mg, $0.25 \mathrm{mmol}$ ), (4methoxyphenyl)magnesium bromide 412a (1.0 mL, 1.0 M in THF, $1.00 \mathrm{mmol}), 416(30 \mathrm{mg}, 9.0 \mathrm{~mol}$ \%), TMEDA (58.1 mg, $0.50 \mathrm{mmol})$, and 2,3-DCB (95.3 $\mathrm{mg}, 0.75 \mathrm{mmol})$. Purification by column chromatography on silica gel ( $n$-hexane/EtOAc: $1 / 1)$ yielded 413a $(56.9 \mathrm{mg}, 80 \%)$ as a white solid. M. p. $97^{\circ} \mathrm{C}$.

${ }^{1}$ H NMR $\left(400 \mathrm{MHz}, \mathrm{CDCl}_{3}\right) \delta 8.48(\mathrm{dd}, J=4.6,1.6 \mathrm{~Hz}, 1 \mathrm{H}), 7.65(\mathrm{~s}, 1 \mathrm{H}), 7.64(\mathrm{dd}, J=7.8,1.6 \mathrm{~Hz}$, $1 \mathrm{H}), 7.38(\mathrm{dd}, J=7.8,4.6 \mathrm{~Hz}, 1 \mathrm{H}), 7.25(\mathrm{~d}, J=8.6 \mathrm{~Hz}, 2 \mathrm{H}), 6.92(\mathrm{~d}, J=8.6 \mathrm{~Hz}, 2 \mathrm{H}), 3.81(\mathrm{~s}, 3 \mathrm{H})$, $3.34-3.32(\mathrm{~m}, 2 \mathrm{H}), 1.57-1.48(\mathrm{~m}, 2 \mathrm{H}), 1.39-1.29(\mathrm{~m}, 2 \mathrm{H}), 0.90(\mathrm{t}, J=7.3 \mathrm{~Hz}, 3 \mathrm{H})$.

${ }^{13}$ C NMR $\left(100 \mathrm{MHz}, \mathrm{CDCl}_{3}\right) \delta 165.3\left(\mathrm{C}_{\mathrm{q}}\right), 159.1\left(\mathrm{C}_{\mathrm{q}}\right), 148.3\left(\mathrm{C}_{\mathrm{q}}\right), 146.5(\mathrm{CH}), 140.0(\mathrm{CH}), 137.7\left(\mathrm{C}_{\mathrm{q}}\right)$, $131.6\left(\mathrm{C}_{\mathrm{q}}\right), 129.6(\mathrm{CH}), 124.9(\mathrm{CH}), 113.4(\mathrm{CH}), 55.1\left(\mathrm{CH}_{3}\right), 39.1\left(\mathrm{CH}_{2}\right), 31.6\left(\mathrm{CH}_{2}\right), 20.1\left(\mathrm{CH}_{2}\right), 13.7$ $\left(\mathrm{CH}_{3}\right)$.

IR (ATR): 3398, 2928, 1652, 1510, 1245, 805, $523 \mathrm{~cm}^{-1}$.

MS (ESI) $m / z$ (relative intensity): $285(80)[\mathrm{M}+\mathrm{H}]^{+}, 307(20)[\mathrm{M}+\mathrm{Na}]^{+}$.

HR-MS (ESI) $\mathrm{C}_{17} \mathrm{H}_{21} \mathrm{~N}_{2} \mathrm{O}_{2}[\mathrm{M}+\mathrm{H}]^{+}:$285.1599, found: 285.1598 .

The spectral data were in accordance with those reported in the literature. ${ }^{[149]}$

\section{N-Butyl-4-(4-methoxyphenyl)nicotinamide (413b)}<smiles>CCCCNC(=O)c1cnccc1-c1ccc(OC)cc1</smiles> 
The General Procedure $\mathbf{J}$ was followed using $N$-butylnicotinamide $411 \mathbf{b}$ (44.6 mg, $0.25 \mathrm{mmol}$ ), (4methoxyphenyl)magnesium bromide 412a (1.0 mL, 1.0 M in THF, $1.00 \mathrm{mmol}), 416$ (30 mg, $9.0 \mathrm{~mol}$ \%), TMEDA (58.1 mg, $0.50 \mathrm{mmol})$, and 2,3-DCB (95.3 $\mathrm{mg}, 0.75 \mathrm{mmol})$. Purification by column chromatography on silica gel ( $n$-hexane/EtOAc: $1 / 1)$ yielded $413 \mathrm{~b}(24.2 \mathrm{mg}, 34 \%)$ as a white solid. M. p. $105^{\circ} \mathrm{C}$.

${ }^{1} \mathbf{H}$ NMR $\left(400 \mathrm{MHz} \mathrm{CDCl}_{3}\right) \delta 8.71(\mathrm{~s}, 1 \mathrm{H}), 8.52(\mathrm{~d}, J=5.2 \mathrm{~Hz}, 1 \mathrm{H}), 7.33(\mathrm{~d}, J=8.8 \mathrm{~Hz}, 2 \mathrm{H}), 7.20$ $(\mathrm{d}, J=5.2 \mathrm{~Hz}, 1 \mathrm{H}), 6.93(\mathrm{~d}, J=8.8 \mathrm{~Hz}, 2 \mathrm{H}), 5.66(\mathrm{~s}, 1 \mathrm{H}), 3.80(\mathrm{~s}, 3 \mathrm{H}), 3.21-3.16(\mathrm{~m}, 2 \mathrm{H}), 1.31-$ $1.19(\mathrm{~m}, 2 \mathrm{H}), 1.12-0.98(\mathrm{~m}, 2 \mathrm{H}), 0.78(\mathrm{t}, J=7.3 \mathrm{~Hz}, 3 \mathrm{H})$.

${ }^{13}$ C NMR $\left(100 \mathrm{MHz}, \mathrm{CDCl}_{3}\right) \delta 167.3\left(\mathrm{C}_{\mathrm{q}}\right), 160.3\left(\mathrm{C}_{\mathrm{q}}\right), 150.5(\mathrm{CH}), 149.5(\mathrm{CH}), 146.5\left(\mathrm{C}_{\mathrm{q}}\right), 131.2\left(\mathrm{C}_{\mathrm{q}}\right)$, 129.6 (CH), $129.4\left(\mathrm{C}_{\mathrm{q}}\right), 123.9(\mathrm{CH}), 114.3(\mathrm{CH}), 55.3\left(\mathrm{CH}_{3}\right), 39.6\left(\mathrm{CH}_{2}\right), 31.0\left(\mathrm{CH}_{2}\right), 19.8\left(\mathrm{CH}_{2}\right), 13.6$ $\left(\mathrm{CH}_{3}\right)$.

IR (ATR): 3274, 2929, 1638, 1516, 1251, 831, $532 \mathrm{~cm}^{-1}$.

MS (ESI) $m / z$ (relative intensity): $285(90)[\mathrm{M}+\mathrm{H}]^{+}, 307(10)[\mathrm{M}+\mathrm{Na}]^{+}$.

HR-MS (ESI) $\mathrm{C}_{17} \mathrm{H}_{21} \mathrm{~N}_{2} \mathrm{O}_{2}[\mathrm{M}+\mathrm{H}]^{+}$: 286.1561, found: 286.1550 .

The spectral data were in accordance with those reported in the literature. ${ }^{[149]}$

\section{$N$-Butyl-3-(4-methoxyphenyl)isonicotinamide (413c)}<smiles>CCCCNC(=O)c1ccncc1-c1ccc(OC)cc1</smiles>

The General Procedure $\mathbf{J}$ was followed using $N$-butylisonicotinamide 411c (44.6 mg, $0.25 \mathrm{mmol}$ ), (4-methoxyphenyl)magnesium bromide 412a (1.0 mL, $1.0 \mathrm{M}$ in THF, $1.00 \mathrm{mmol}), 416$ (30 mg, 9.0 mol \%), TMEDA (58.1 mg, $0.50 \mathrm{mmol}$ ), and 2,3-DCB (95.3 mg, $0.75 \mathrm{mmol})$. Purification by column chromatography on silica gel ( $n$-hexane/EtOAc: $1 / 1)$ yielded 413c $(21.3 \mathrm{mg}, 30 \%)$ as a white solid. M. p. $122^{\circ} \mathrm{C}$.

${ }^{1} \mathbf{H}$ NMR $\left(400 \mathrm{MHz}, \mathrm{CDCl}_{3}\right) \delta 8.61-8.57(\mathrm{~m}, 2 \mathrm{H}), 7.51(\mathrm{~d}, J=5.0 \mathrm{~Hz}, 1 \mathrm{H}), 7.33(\mathrm{~d}, J=8.9 \mathrm{~Hz}, 2 \mathrm{H})$, $6.96(\mathrm{~d}, J=8.9 \mathrm{~Hz}, 2 \mathrm{H}), 5.39(\mathrm{~s}, 1 \mathrm{H}), 3.83(\mathrm{~s}, 3 \mathrm{H}), 3.20-3.18(\mathrm{~m}, 2 \mathrm{H}), 1.26-1.17(\mathrm{~m}, 2 \mathrm{H}), 1.09-$ 
$0.97(\mathrm{~m}, 2 \mathrm{H}), 0.78(\mathrm{t}, J=7.3 \mathrm{~Hz}, 3 \mathrm{H})$.

${ }^{13} \mathrm{C} \mathrm{NMR}\left(100 \mathrm{MHz}, \mathrm{CDCl}_{3}\right) \delta 167.1\left(\mathrm{C}_{\mathrm{q}}\right), 160.0\left(\mathrm{C}_{\mathrm{q}}\right), 150.9(\mathrm{CH}), 148.7(\mathrm{CH}), 142.2\left(\mathrm{C}_{\mathrm{q}}\right), 133.5\left(\mathrm{C}_{\mathrm{q}}\right)$, $130.1(\mathrm{CH}), 128.5\left(\mathrm{C}_{\mathrm{q}}\right), 122.2(\mathrm{CH}), 114.4(\mathrm{CH}), 55.3\left(\mathrm{CH}_{3}\right), 39.5\left(\mathrm{CH}_{2}\right), 31.0\left(\mathrm{CH}_{2}\right), 19.8\left(\mathrm{CH}_{2}\right), 13.6$ $\left(\mathrm{CH}_{3}\right)$.

IR (ATR): $3275,2929,1642,1513,1250,834,548 \mathrm{~cm}^{-1}$.

MS (ESI) $m / z$ (relative intensity): $285(90)[\mathrm{M}+\mathrm{H}]^{+}, 307(10)[\mathrm{M}+\mathrm{Na}]^{+}$.

HR-MS (ESI) $\mathrm{C}_{17} \mathrm{H}_{21} \mathrm{~N}_{2} \mathrm{O}_{2}[\mathrm{M}+\mathrm{H}]^{+}:$285.1603, found: 285.1598 .

The spectral data were in accordance with those reported in the literature. ${ }^{[149]}$

\section{$N$-Butyl-3-(4-methoxyphenyl)pyrazine-2-carboxamide (413d)}<smiles>CCCCNC(=O)c1nccnc1-c1ccc(OC)cc1</smiles>

The General Procedure J was followed using $N$-butylpyrazine-2-carboxamide 411d (44.8 mg, 0.25 mmol), (4-methoxyphenyl)magnesium bromide 412a (1.0 mL, 1.0 M in THF, $1.00 \mathrm{mmol}), 416(30 \mathrm{mg}$, $9.0 \mathrm{~mol} \%)$, TMEDA (58.1 mg, $0.50 \mathrm{mmol})$, and 2,3-DCB (95.3 mg, $0.75 \mathrm{mmol})$. Purification by column chromatography on silica gel ( $n$-hexane/EtOAc: $1 / 1)$ yielded $\mathbf{4 1 3 d}(14.9 \mathrm{mg}, 21 \%)$ as a white solid.

M. p. $67^{\circ} \mathrm{C}$.

${ }^{1} \mathbf{H}$ NMR $\left(400 \mathrm{MHz}, \mathrm{CDCl}_{3}\right) \delta 8.67(\mathrm{~d}, J=2.3 \mathrm{~Hz}, 1 \mathrm{H}), 8.39(\mathrm{~d}, J=2.3 \mathrm{~Hz}, 1 \mathrm{H}), 7.58(\mathrm{~d}, J=8.9 \mathrm{~Hz}$, 2H), $7.33(\mathrm{~s}, 1 \mathrm{H}), 6.95(\mathrm{~d}, J=8.9 \mathrm{~Hz}, 2 \mathrm{H}), 3.83(\mathrm{~s}, 3 \mathrm{H}), 3.42-3.37(\mathrm{~m}, 2 \mathrm{H}), 1.58-1.54(\mathrm{~m}, 2 \mathrm{H})$, $1.41-1.32(\mathrm{~m}, 2 \mathrm{H}), 0.92(\mathrm{t}, J=7.3 \mathrm{~Hz}, 3 \mathrm{H})$.

${ }^{13} \mathrm{C}$ NMR $\left(100 \mathrm{MHz}, \mathrm{CDCl}_{3}\right) \delta 164.9\left(\mathrm{C}_{\mathrm{q}}\right), 160.6\left(\mathrm{C}_{\mathrm{q}}\right), 154.0\left(\mathrm{C}_{\mathrm{q}}\right), 144.9(\mathrm{CH}), 144.1\left(\mathrm{C}_{\mathrm{q}}\right), 139.9(\mathrm{CH})$, $130.5(\mathrm{CH}), 130.1\left(\mathrm{C}_{\mathrm{q}}\right), 113.6(\mathrm{CH}), 55.3\left(\mathrm{CH}_{3}\right), 39.4\left(\mathrm{CH}_{2}\right), 31.5\left(\mathrm{CH}_{2}\right), 20.1\left(\mathrm{CH}_{2}\right), 13.7\left(\mathrm{CH}_{3}\right)$.

IR (ATR): 3273, 2929, 1649, 1514, 1251, 812, $557 \mathrm{~cm}^{-1}$.

MS (ESI) $m / z$ (relative intensity): $286(55)[\mathrm{M}+\mathrm{H}]^{+}, 308(45)[\mathrm{M}+\mathrm{Na}]^{+}$.

HR-MS (ESI) $\mathrm{C}_{16} \mathrm{H}_{21} \mathrm{~N}_{3} \mathrm{O}_{2}[\mathrm{M}+\mathrm{H}]^{+}:$286.1561, found: 286.1550 . 
N-Butyl-3-(4-methoxyphenyl)-5-phenylpicolinamide (413f)<smiles>CCCCNC(=O)c1ncc(-c2ccccc2)cc1-c1ccc(OC)cc1</smiles>

The General Procedure $\mathbf{J}$ was followed using $N$-butyl-5-phenylpicolinamide 411f (63.6 mg, 0.25 mmol), (4-methoxyphenyl)magnesium bromide 412a (1.0 mL, 1.0 M in THF, $1.00 \mathrm{mmol}), 416$ (30 mg, $9.0 \mathrm{~mol} \%)$, TMEDA (58.1 mg, $0.50 \mathrm{mmol})$, and 2,3-DCB (95.3 mg, $0.75 \mathrm{mmol})$. Purification by column chromatography on silica gel ( $n$-hexane/EtOAc: $1 / 1)$ yielded $\mathbf{4 1 3 f}(46.0 \mathrm{mg}, 51 \%)$ as a white solid.

M. p. $90^{\circ} \mathrm{C}$.

${ }^{1} \mathbf{H}$ NMR $\left(400 \mathrm{MHz}, \mathrm{CDCl}_{3}\right) \delta 8.72(\mathrm{~d}, J=2.2 \mathrm{~Hz}, 1 \mathrm{H}), 7.83(\mathrm{~d}, J=2.2 \mathrm{~Hz}, 1 \mathrm{H}), 7.77-7.70(\mathrm{~m}, 1 \mathrm{H})$, $7.63-7.60(\mathrm{~m}, 2 \mathrm{H}), 7.53-7.38(\mathrm{~m}, 3 \mathrm{H}), 7.31(\mathrm{~d}, J=8.7 \mathrm{~Hz}, 2 \mathrm{H}), 6.95(\mathrm{~d}, J=8.7 \mathrm{~Hz}, 2 \mathrm{H}), 3.83(\mathrm{~s}$, $3 \mathrm{H}), 3.39-3.35(\mathrm{~m}, 2 \mathrm{H}), 1.58-1.53(\mathrm{~m}, 2 \mathrm{H}), 1.44-1.32(\mathrm{~m}, 2 \mathrm{H}), 0.91(\mathrm{t}, J=7.3 \mathrm{~Hz}, 3 \mathrm{H})$.

${ }^{13}$ C NMR $\left(100 \mathrm{MHz}, \mathrm{CDCl}_{3}\right) \delta 165.1\left(\mathrm{C}_{\mathrm{q}}\right), 159.2\left(\mathrm{C}_{\mathrm{q}}\right), 146.6\left(\mathrm{C}_{\mathrm{q}}\right), 144.9(\mathrm{CH}), 138.3(\mathrm{CH}), 137.9\left(\mathrm{C}_{\mathrm{q}}\right)$, $137.8\left(\mathrm{C}_{\mathrm{q}}\right), 136.7\left(\mathrm{C}_{\mathrm{q}}\right), 131.7\left(\mathrm{C}_{\mathrm{q}}\right), 129.7(\mathrm{CH}), 129.2(\mathrm{CH}), 128.7(\mathrm{CH}), 127.2(\mathrm{CH}), 113.5(\mathrm{CH}), 55.2$ $\left(\mathrm{CH}_{3}\right), 39.2\left(\mathrm{CH}_{2}\right), 31.7\left(\mathrm{CH}_{2}\right), 20.2\left(\mathrm{CH}_{2}\right), 13.8\left(\mathrm{CH}_{3}\right)$.

IR (ATR): 3399, 2926, 1652, 1510, 1244, 806, $645 \mathrm{~cm}^{-1}$.

MS (ESI) $m / z$ (relative intensity): $361(80)[\mathrm{M}+\mathrm{H}]^{+}, 383(20)[\mathrm{M}+\mathrm{Na}]^{+}$.

HR-MS (ESI) $\mathrm{C}_{23} \mathrm{H}_{25} \mathrm{~N}_{2} \mathrm{O}_{2}[\mathrm{M}+\mathrm{H}]^{+}: 361.1909$, found: 361.1911.

The spectral data were in accordance with those reported in the literature. ${ }^{[149]}$

\section{$N$-Hexyl-3-(4-methoxyphenyl)picolinamide (413g)}

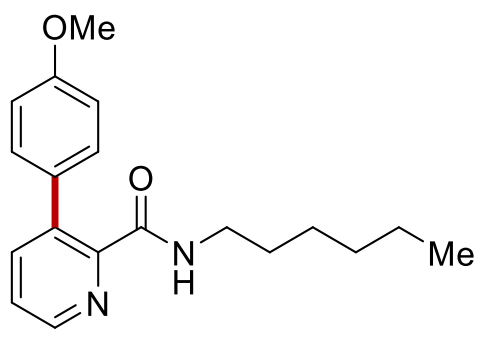

The General Procedure $\mathbf{J}$ was followed using $N$-hexylpicolinamide $411 \mathrm{~g}$ (51.6 mg, $0.25 \mathrm{mmol}$ ), (4- 
methoxyphenyl)magnesium bromide $412 \mathrm{a}(1.0 \mathrm{~mL}, 1.0 \mathrm{M}$ in THF, $1.00 \mathrm{mmol}), 416(30 \mathrm{mg}, 9.0 \mathrm{~mol}$ \%), TMEDA (58.1 mg, $0.50 \mathrm{mmol})$, and 2,3-DCB (95.3 $\mathrm{mg}, 0.75 \mathrm{mmol})$. Purification by column chromatography on silica gel ( $n$-hexane/EtOAc: $1 / 1)$ yielded $413 \mathrm{~g}(66.4 \mathrm{mg}, 85 \%)$ as a white solid. M. p. $156^{\circ} \mathrm{C}$.

${ }^{1}$ H NMR $\left(400 \mathrm{MHz} \mathrm{CDCl}_{3}\right) \delta 8.50(\mathrm{~s}, 1 \mathrm{H}), 7.65(\mathrm{~d}, J=7.8,2 \mathrm{H}), 7.43-7.39(\mathrm{~m}, 1 \mathrm{H}), 7.25(\mathrm{~d}, J=$ $8.7 \mathrm{~Hz}, 2 \mathrm{H}), 6.92(\mathrm{~d}, J=8.7 \mathrm{~Hz}, 2 \mathrm{H}), 3.82(\mathrm{~s}, 3 \mathrm{H}), 3.35-3.31(\mathrm{~m}, 2 \mathrm{H}), 1.58-1.50(\mathrm{~m}, 2 \mathrm{H}), 1.36-$ $1.21(\mathrm{~m}, 6 \mathrm{H}), 0.88-0.84(\mathrm{t}, J=6.9 \mathrm{~Hz}, 3 \mathrm{H})$.

${ }^{13}$ C NMR $\left(100 \mathrm{MHz}, \mathrm{CDCl}_{3}\right) \delta 165.2\left(\mathrm{C}_{\mathrm{q}}\right), 159.1\left(\mathrm{C}_{\mathrm{q}}\right), 148.3\left(\mathrm{C}_{\mathrm{q}}\right), 146.4(\mathrm{CH}), 140.1(\mathrm{CH}), 137.8\left(\mathrm{C}_{\mathrm{q}}\right)$, 131.6 $\left(\mathrm{C}_{\mathrm{q}}\right), 129.6(\mathrm{CH}), 125.0(\mathrm{CH}), 113.4(\mathrm{CH}), 55.2\left(\mathrm{CH}_{3}\right), 39.4\left(\mathrm{CH}_{2}\right), 31.5\left(\mathrm{CH}_{2}\right), 29.5\left(\mathrm{CH}_{2}\right), 26.6$ $\left(\mathrm{CH}_{2}\right), 22.5\left(\mathrm{CH}_{2}\right), 14.0\left(\mathrm{CH}_{3}\right)$.

IR (ATR): 3398, 2929, 1649, 1507, 1245, 807, $558 \mathrm{~cm}^{-1}$.

MS (ESI) $m / z$ (relative intensity): $313(80)[\mathrm{M}+\mathrm{H}]^{+}, 335(20)[\mathrm{M}+\mathrm{Na}]^{+}$.

HR-MS (ESI) $\mathrm{C}_{19} \mathrm{H}_{25} \mathrm{~N}_{2} \mathrm{O}_{2}[\mathrm{M}+\mathrm{H}]^{+}: 313.1912$, found: 313.1911.

\section{N-Cyclohexyl-3-(4-methoxyphenyl)picolinamide (413h)}<smiles>COc1ccc(-c2cccnc2C(=O)NC2CCCCC2)cc1</smiles>

The General Procedure J was followed using $N$-cyclohexylpicolinamide 411h (51.1 mg, $0.25 \mathrm{mmol}$ ), (4-methoxyphenyl)magnesium bromide 412a (1.0 mL, $1.0 \mathrm{M}$ in THF, $1.00 \mathrm{mmol}), 416$ (30 mg, 9.0 mol \%), TMEDA (58.1 mg, $0.50 \mathrm{mmol})$, and 2,3-DCB (95.3 mg, $0.75 \mathrm{mmol})$. Purification by column chromatography on silica gel ( $n$-hexane/EtOAc: $1 / 1)$ yielded 413h $(55.9 \mathrm{mg}, 72 \%)$ as a white solid. M. p. $99^{\circ} \mathrm{C}$.

${ }^{1}$ H NMR $\left(400 \mathrm{MHz}, \mathrm{CDCl}_{3}\right) \delta 8.49(\mathrm{dd}, J=4.6,1.7 \mathrm{~Hz}, 1 \mathrm{H}), 7.63(\mathrm{dd}, J=7.8,1.7 \mathrm{~Hz}, 1 \mathrm{H}), 7.55-$ $7.49(\mathrm{~m}, 1 \mathrm{H}), 7.38(\mathrm{dd}, J=7.8,4.6 \mathrm{~Hz}, 1 \mathrm{H}), 7.25$ (d, $J=8.8 \mathrm{~Hz}, 2 \mathrm{H}), 6.92(\mathrm{~d}, J=8.8 \mathrm{~Hz}, 2 \mathrm{H}), 3.82$ (s, 3H), $1.99-1.86(\mathrm{~m}, 2 \mathrm{H}), 1.74-1.65(\mathrm{~m}, 2 \mathrm{H}), 1.62-1.56(\mathrm{~m}, 1 \mathrm{H}), 1.40-1.27(\mathrm{~m}, 2 \mathrm{H}), 1.26-$ $1.10(\mathrm{~m}, 4 \mathrm{H})$. 
${ }^{13}$ C NMR $\left(100 \mathrm{MHz}, \mathrm{CDCl}_{3}\right) \delta 164.4\left(\mathrm{C}_{\mathrm{q}}\right), 159.1\left(\mathrm{C}_{\mathrm{q}}\right), 148.4\left(\mathrm{C}_{\mathrm{q}}\right), 146.5(\mathrm{CH}), 140.0(\mathrm{CH}), 137.8\left(\mathrm{C}_{\mathrm{q}}\right)$, $131.7\left(\mathrm{C}_{\mathrm{q}}\right), 129.6(\mathrm{CH}), 124.9(\mathrm{CH}), 113.4(\mathrm{CH}), 55.2\left(\mathrm{CH}_{3}\right), 48.0(\mathrm{CH}), 33.0\left(\mathrm{CH}_{2}\right), 25.6\left(\mathrm{CH}_{2}\right), 24.9$ $\left(\mathrm{CH}_{2}\right)$.

IR (ATR): 3397, 2933, 1671, 1508, 1244, 736, $557 \mathrm{~cm}^{-1}$.

MS (ESI) $m / z$ (relative intensity): $311(90)[\mathrm{M}+\mathrm{H}]^{+}, 333(10)[\mathrm{M}+\mathrm{Na}]^{+}$.

HR-MS (ESI) $\mathrm{C}_{19} \mathrm{H}_{23} \mathrm{~N}_{2} \mathrm{O}_{2}[\mathrm{M}+\mathrm{H}]^{+}: 311.1758$, found: 311.1754

The spectral data were in accordance with those reported in the literature. ${ }^{[149]}$

\section{3-(4-Methoxyphenyl)- $N$-(1,2,3,4-tetrahydronaphthalen-1-yl)picolinamide (413i)}

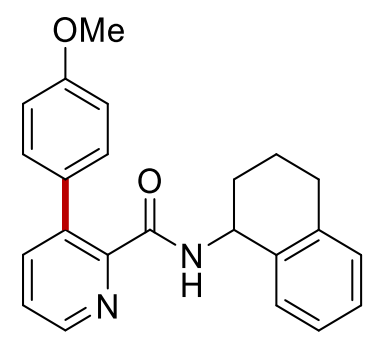

The General Procedure $\mathbf{J}$ was followed using $N$-(1,2,3,4-tetrahydronaphthalen-1-yl)picolinamide 411i (63.1 mg, $0.25 \mathrm{mmol}$ ), (4-methoxyphenyl)magnesium bromide 412a (1.0 mL, 1.0 M in THF, 1.00 mmol), 416 (30 mg, $9.0 \mathrm{~mol} \%$ ), TMEDA (58.1 mg, $0.50 \mathrm{mmol}$ ), and 2,3-DCB (95.3 mg, $0.75 \mathrm{mmol}$ ). Purification by column chromatography on silica gel ( $n$-hexane/EtOAc: $1 / 1)$ yielded 413i (69.9 mg, $78 \%)$ as a white solid.

M. p. $125^{\circ} \mathrm{C}$.

${ }^{1} \mathbf{H}$ NMR $\left(400 \mathrm{MHz}, \mathrm{CDCl}_{3}\right) \delta 8.47(\mathrm{dd}, J=4.6,1.7 \mathrm{~Hz}, 1 \mathrm{H}), 7.82(\mathrm{~d}, J=8.8 \mathrm{~Hz}, 1 \mathrm{H}), 7.66(\mathrm{dd}, J=$ 7.8, $1.7 \mathrm{~Hz}, 1 \mathrm{H}), 7.39$ (dd, $J=7.8,4.6 \mathrm{~Hz}, 1 \mathrm{H}), 7.31(\mathrm{~d}, J=8.8 \mathrm{~Hz}, 2 \mathrm{H}), 7.25-7.22(\mathrm{~m}, 1 \mathrm{H}), 7.19-$ $7.11(\mathrm{~m}, 1 \mathrm{H}), 7.11-7.05(\mathrm{~m}, 1 \mathrm{H}), 6.97(\mathrm{~d}, J=8.8 \mathrm{~Hz}, 2 \mathrm{H}), 5.28-5.22(\mathrm{~m}, 1 \mathrm{H}), 3.85(\mathrm{~s}, 3 \mathrm{H}), 2.86-$ $2.70(\mathrm{~m}, 2 \mathrm{H}), 2.12-1.96(\mathrm{~m}, 2 \mathrm{H}), 1.96-1.76(\mathrm{~m}, 3 \mathrm{H})$.

${ }^{13}$ C NMR $\left(100 \mathrm{MHz}, \mathrm{CDCl}_{3}\right) \delta 164.7\left(\mathrm{C}_{\mathrm{q}}\right), 159.2\left(\mathrm{C}_{\mathrm{q}}\right), 148.4\left(\mathrm{C}_{\mathrm{q}}\right), 146.7(\mathrm{CH}), 139.9(\mathrm{CH}), 137.7\left(\mathrm{C}_{\mathrm{q}}\right)$, $137.6\left(\mathrm{C}_{\mathrm{q}}\right), 136.8\left(\mathrm{C}_{\mathrm{q}}\right), 131.6\left(\mathrm{C}_{\mathrm{q}}\right), 129.7(\mathrm{CH}), 129.0(\mathrm{CH}), 128.8(\mathrm{CH}), 127.1(\mathrm{CH}), 126.1(\mathrm{CH})$, $125.0(\mathrm{CH}), 113.5(\mathrm{CH}), 55.2\left(\mathrm{CH}_{3}\right), 47.3(\mathrm{CH}), 30.1\left(\mathrm{CH}_{2}\right), 29.3\left(\mathrm{CH}_{2}\right), 20.0\left(\mathrm{CH}_{2}\right)$.

IR (ATR): 3398, 3032 1659, 1506, 1245, 698, $485 \mathrm{~cm}^{-1}$.

MS (ESI) $m / z$ (relative intensity): $359(90)[\mathrm{M}+\mathrm{H}]^{+}, 373(10)[\mathrm{M}+\mathrm{Na}]^{+}$. 
HR-MS (ESI) $\mathrm{C}_{23} \mathrm{H}_{23} \mathrm{~N}_{2} \mathrm{O}_{2}[\mathrm{M}+\mathrm{H}]^{+}: 359.1758$, found: 359.1754 .

The spectral data were in accordance with those reported in the literature. ${ }^{[149]}$

\section{$N$-Benzyl-3-(4-methoxyphenyl)picolinamide (413j)}<smiles>COc1ccc(-c2cccnc2C(=O)NCc2ccccc2)cc1</smiles>

The General Procedure J was followed using $N$-benzylpicolinamide 411j (53.1 mg, 0.25 mmol), (4methoxyphenyl)magnesium bromide 412a (1.0 mL, 1.0 M in THF, $1.00 \mathrm{mmol}), 416$ (30 mg, $9.0 \mathrm{~mol}$ \%), TMEDA (58.1 mg, $0.50 \mathrm{mmol}$ ), and 2,3-DCB (95.3 $\mathrm{mg}, 0.75 \mathrm{mmol})$. Purification by column chromatography on silica gel ( $n$-hexane/EtOAc: $1 / 1)$ yielded $\mathbf{4 1 3 \mathbf { j }}(60.5 \mathrm{mg}, 76 \%)$ as a white solid. M. p. $140^{\circ} \mathrm{C}$.

${ }^{1}$ H NMR $\left(400 \mathrm{MHz}, \mathrm{CDCl}_{3}\right) \delta 8.48(\mathrm{dd}, J=4.7,1.6 \mathrm{~Hz}, 1 \mathrm{H}), 8.00(\mathrm{~s}, 1 \mathrm{H}), 7.66(\mathrm{dd}, J=7.8,1.6 \mathrm{~Hz}$, 1H), $7.40(\mathrm{dd}, J=7.8,4.7 \mathrm{~Hz}, 1 \mathrm{H}), 7.34-7.21(\mathrm{~m}, 5 \mathrm{H}), 7.28(\mathrm{~d}, J=8.7 \mathrm{~Hz}, 2 \mathrm{H}), 6.94(\mathrm{~d}, J=8.7 \mathrm{~Hz}$, $2 \mathrm{H}), 4.57-4.53(\mathrm{~m}, 2 \mathrm{H}), 3.83(\mathrm{~s}, 3 \mathrm{H})$.

${ }^{13}$ C NMR $\left(100 \mathrm{MHz}, \mathrm{CDCl}_{3}\right) \delta 165.2\left(\mathrm{C}_{\mathrm{q}}\right), 159.1\left(\mathrm{C}_{\mathrm{q}}\right), 147.9\left(\mathrm{C}_{\mathrm{q}}\right), 146.6(\mathrm{CH}), 140.1(\mathrm{CH}), 138.4\left(\mathrm{C}_{\mathrm{q}}\right)$, $138.0\left(\mathrm{C}_{\mathrm{q}}\right), 131.5\left(\mathrm{C}_{\mathrm{q}}\right), 129.7(\mathrm{CH}), 128.6(\mathrm{CH}), 127.8(\mathrm{CH}), 127.3(\mathrm{CH}), 125.1(\mathrm{CH}), 113.4(\mathrm{CH})$, $55.2\left(\mathrm{CH}_{3}\right), 43.4\left(\mathrm{CH}_{2}\right)$.

IR (ATR): 3397, 2950, 1663, 1508, 1244, 728, $464 \mathrm{~cm}^{-1}$.

MS (ESI) $m / z$ (relative intensity): $319(90)[\mathrm{M}+\mathrm{H}]^{+}, 341(10)[\mathrm{M}+\mathrm{Na}]^{+}$.

HR-MS (ESI) $\mathrm{C}_{20} \mathrm{H}_{19} \mathrm{~N}_{2} \mathrm{O}_{2}[\mathrm{M}+\mathrm{H}]^{+}: 319.1447$, found: 319.1441 .

The spectral data were in accordance with those reported in the literature. ${ }^{[149]}$ 
$N$-(4-Methoxybenzyl)-3-(4-methoxyphenyl)picolinamide (413k)<smiles>COc1ccc(CNC(=O)c2ncccc2-c2ccc(OC)cc2)cc1</smiles>

The General Procedure J was followed using N-(4-methoxybenzyl)picolinamide 411 k (77.6 mg, 0.25 mmol), (4-methoxyphenyl)magnesium bromide 412a (1.0 mL, 1.0 M in THF, $1.00 \mathrm{mmol}), 416$ (30 mg, $9.0 \mathrm{~mol} \%)$, TMEDA (58.1 mg, $0.50 \mathrm{mmol})$, and 2,3-DCB (95.3 $\mathrm{mg}, 0.75 \mathrm{mmol})$. Purification by column chromatography on silica gel ( $n$-hexane/EtOAc: $1 / 1)$ yielded 413k $(65.3 \mathrm{mg}, 75 \%)$ as a white solid.

M. p. $95^{\circ} \mathrm{C}$.

${ }^{1}$ H NMR $\left(400 \mathrm{MHz}, \mathrm{CDCl}_{3}\right) \delta 8.47(\mathrm{dd}, J=4.6,1.7 \mathrm{~Hz}, 1 \mathrm{H}), 7.90(\mathrm{~s}, 1 \mathrm{H}), 7.65(\mathrm{dd}, J=7.8,1.7 \mathrm{~Hz}$, 1H), 7.39 (dd, $J=7.8,4.6 \mathrm{~Hz}, 1 \mathrm{H}), 7.27(\mathrm{~d}, J=8.7 \mathrm{~Hz}, 2 \mathrm{H}), 7.21(\mathrm{~d}, J=8.7 \mathrm{~Hz}, 2 \mathrm{H}), 6.93(\mathrm{~d}, J=8.8$ $\mathrm{Hz}, 2 \mathrm{H}), 6.84(\mathrm{~d}, J=8.8 \mathrm{~Hz}, 2 \mathrm{H}), 4.47$ (d, $J=5.9 \mathrm{~Hz}, 2 \mathrm{H}), 3.83(\mathrm{~s}, 3 \mathrm{H}), 3.77$ (s, 3H).

${ }^{13}$ C NMR $\left(100 \mathrm{MHz}, \mathrm{CDCl}_{3}\right) \delta 165.1\left(\mathrm{C}_{\mathrm{q}}\right), 159.1\left(\mathrm{C}_{\mathrm{q}}\right), 158.9\left(\mathrm{C}_{\mathrm{q}}\right), 148.0\left(\mathrm{C}_{\mathrm{q}}\right), 146.6(\mathrm{CH}), 140.1(\mathrm{CH})$, $137.9\left(\mathrm{C}_{\mathrm{q}}\right), 131.5\left(\mathrm{C}_{\mathrm{q}}\right), 130.5\left(\mathrm{C}_{\mathrm{q}}\right), 129.7(\mathrm{CH}), 129.2(\mathrm{CH}), 125.1(\mathrm{CH}), 114.0(\mathrm{CH}), 113.5(\mathrm{CH}), 55.3$ $\left(\mathrm{CH}_{3}\right), 55.2\left(\mathrm{CH}_{3}\right), 42.9\left(\mathrm{CH}_{2}\right)$.

IR (ATR): 3398, 2931, 1669, 1511, 1278, 806, $430 \mathrm{~cm}^{-1}$.

MS (ESI) $m / z$ (relative intensity): $349(90)[\mathrm{M}+\mathrm{H}]^{+}, 391(10)[\mathrm{M}+\mathrm{Na}]^{+}$.

HR-MS (ESI) $\mathrm{C}_{21} \mathrm{H}_{21} \mathrm{~N}_{2} \mathrm{O}_{3}[\mathrm{M}+\mathrm{H}]^{+}: 349.1551$, found: 349.1547 .

The spectral data were in accordance with those reported in the literature. ${ }^{[149]}$

\section{3-(4-Methoxyphenyl)- $N$-(p-tolyl)picolinamide (413I)}<smiles>COc1ccc(NC(=O)c2ncccc2-c2ccc(C)cc2)cc1</smiles>

The General Procedure J was followed using $N$-( $p$-tolyl)picolinamide 4111 (53.1 mg, $0.25 \mathrm{mmol})$, 
(4-methoxyphenyl)magnesium bromide 412a $(1.0 \mathrm{~mL}, 1.0 \mathrm{M}$ in THF, $1.00 \mathrm{mmol}), 416$ (30 mg, 9.0 mol \%), TMEDA (58.1 mg, $0.50 \mathrm{mmol}$ ), and 2,3-DCB (95.3 mg, $0.75 \mathrm{mmol})$. Purification by column chromatography on silica gel ( $n$-hexane/EtOAc: $1 / 1)$ yielded $4131(53.3 \mathrm{mg}, 67 \%)$ as a white solid.

M. p. $164^{\circ} \mathrm{C}$.

${ }^{1}$ H NMR $\left(400 \mathrm{MHz}, \mathrm{CDCl}_{3}\right) \delta 9.87(\mathrm{~s}, 1 \mathrm{H}), 8.56(\mathrm{dd}, J=4.6,1.6 \mathrm{~Hz}, 1 \mathrm{H}), 7.69(\mathrm{dd}, J=7.8,1.6 \mathrm{~Hz}$, $1 \mathrm{H}), 7.55(\mathrm{~d}, J=8.7 \mathrm{~Hz}, 2 \mathrm{H}), 7.45(\mathrm{dd}, J=7.8,4.6 \mathrm{~Hz}, 1 \mathrm{H}), 7.28(\mathrm{~d}, J=8.7 \mathrm{~Hz}, 2 \mathrm{H}), 7.10(\mathrm{~d}, J=8.7$ $\mathrm{Hz}, 2 \mathrm{H}), 6.94(\mathrm{~d}, J=8.7 \mathrm{~Hz}, 2 \mathrm{H}), 3.83(\mathrm{~s}, 3 \mathrm{H}), 2.29$ (s, 3H).

${ }^{13}$ C NMR $\left(100 \mathrm{MHz}, \mathrm{CDCl}_{3}\right) \delta 162.4\left(\mathrm{C}_{\mathrm{q}}\right), 159.1\left(\mathrm{C}_{\mathrm{q}}\right), 147.2\left(\mathrm{C}_{\mathrm{q}}\right), 146.3(\mathrm{CH}), 140.8(\mathrm{CH}), 138.7\left(\mathrm{C}_{\mathrm{q}}\right)$, $135.5\left(\mathrm{C}_{\mathrm{q}}\right), 133.6\left(\mathrm{C}_{\mathrm{q}}\right), 131.7\left(\mathrm{C}_{\mathrm{q}}\right), 129.7(\mathrm{CH}), 129.4(\mathrm{CH}), 125.4(\mathrm{CH}), 119.7(\mathrm{CH}), 113.5(\mathrm{CH}), 55.2$ $\left(\mathrm{CH}_{3}\right), 20.9\left(\mathrm{CH}_{3}\right)$.

IR (ATR): 3297, 2959, 1651, 1511, 839, 806, $579 \mathrm{~cm}^{-1}$.

MS (ESI) $m / z$ (relative intensity): $319(70)[\mathrm{M}+\mathrm{H}]^{+}, 341(30)[\mathrm{M}+\mathrm{Na}]^{+}$.

HR-MS (ESI) $\mathrm{C}_{20} \mathrm{H}_{19} \mathrm{~N}_{2} \mathrm{O}_{2}[\mathrm{M}+\mathrm{H}]^{+}: 319.1443$, found: 319.1441 .

\section{N,3-Bis(4-methoxyphenyl)picolinamide (413m)}<smiles>COc1ccc(NC(=O)c2ncccc2-c2ccc(OC)cc2)cc1</smiles>

The General Procedure J was followed using $N$-(4-methoxyphenyl)picolinamide 411m (57.1 mg, $0.25 \mathrm{mmol})$, (4-methoxyphenyl)magnesium bromide 412a (1.0 mL, 1.0 M in THF, $1.00 \mathrm{mmol}), 416$ (30 mg, $9.0 \mathrm{~mol} \%$ ), TMEDA (58.1 mg, $0.50 \mathrm{mmol})$, and 2,3-DCB (95.3 mg, $0.75 \mathrm{mmol})$. Purification by column chromatography on silica gel ( $n$-hexane/EtOAc: $1 / 1)$ yielded $413 \mathrm{~m}(49.3 \mathrm{mg}, 59 \%)$ as a white solid.

M. p. $127^{\circ} \mathrm{C}$.

${ }^{1} \mathbf{H}$ NMR $\left(400 \mathrm{MHz}, \mathrm{CDCl}_{3}\right) \delta 9.80(\mathrm{~s}, 1 \mathrm{H}), 8.55(\mathrm{dd}, J=4.6,1.6 \mathrm{~Hz}, 1 \mathrm{H}), 7.68(\mathrm{dd}, J=7.8,1.6 \mathrm{~Hz}$, 1H), $7.56(\mathrm{~d}, J=9.0 \mathrm{~Hz}, 2 \mathrm{H}), 7.44(\mathrm{dd}, J=7.8,4.6 \mathrm{~Hz}, 1 \mathrm{H}), 7.27(\mathrm{~d}, J=8.7 \mathrm{~Hz}, 2 \mathrm{H}), 6.93(\mathrm{~d}, J=8.7$ $\mathrm{Hz}, 2 \mathrm{H}), 6.82(\mathrm{~d}, J=9.0 \mathrm{~Hz}, 2 \mathrm{H}), 3.82(\mathrm{~s}, 3 \mathrm{H}), 3.76(\mathrm{~s}, 3 \mathrm{H})$. 
${ }^{13} \mathrm{C}$ NMR $\left(100 \mathrm{MHz}, \mathrm{CDCl}_{3}\right) \delta 162.3\left(\mathrm{C}_{\mathrm{q}}\right), 159.2\left(\mathrm{C}_{\mathrm{q}}\right), 156.2\left(\mathrm{C}_{\mathrm{q}}\right), 147.3\left(\mathrm{C}_{\mathrm{q}}\right), 146.3(\mathrm{CH}), 140.8(\mathrm{CH})$, 138.6 $\left(\mathrm{C}_{\mathrm{q}}\right), 131.7\left(\mathrm{C}_{\mathrm{q}}\right), 131.3\left(\mathrm{C}_{\mathrm{q}}\right), 129.7(\mathrm{CH}), 125.4(\mathrm{CH}), 121.3(\mathrm{CH}), 114.1(\mathrm{CH}), 113.5(\mathrm{CH}), 55.5$ $\left(\mathrm{CH}_{3}\right), 55.2\left(\mathrm{CH}_{3}\right)$.

IR (ATR): 3300, 2927, 1657, 1481, 1232, 805, $490 \mathrm{~cm}^{-1}$.

MS (ESI) $m / z$ (relative intensity): $335(70)[\mathrm{M}+\mathrm{H}]^{+}, 357(30)[\mathrm{M}+\mathrm{Na}]^{+}$.

HR-MS (ESI) $\mathrm{C}_{20} \mathrm{H}_{19} \mathrm{~N}_{2} \mathrm{O}_{3}[\mathrm{M}+\mathrm{H}]^{+}:$335.1394, found: 335.1390 .

\section{$N$-Butyl-3-(4-(tert-butyl)phenyl)picolinamide (413n)}

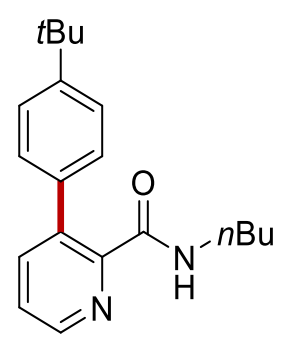

The General Procedure J was followed using $N$-butylpicolinamide 411a (44.6 mg, 0.25 mmol), (4methoxyphenyl)magnesium bromide 412b (1.0 mL, $1.0 \mathrm{M}$ in THF, $1.00 \mathrm{mmol}), 416$ (30 mg, $9.0 \mathrm{~mol}$ \%), TMEDA (58.1 mg, $0.50 \mathrm{mmol})$, and 2,3-DCB (95.3 $\mathrm{mg}, 0.75 \mathrm{mmol})$. Purification by column chromatography on silica gel ( $n$-hexane/EtOAc: $1 / 1)$ yielded 413n $(65.2 \mathrm{mg}, 84 \%)$ as a white solid. M. p. $110^{\circ} \mathrm{C}$.

${ }^{1}$ H NMR $\left(400 \mathrm{MHz}, \mathrm{CDCl}_{3}\right) \delta 8.49(\mathrm{dd}, J=4.6,1.6 \mathrm{~Hz}, 1 \mathrm{H}), 7.65(\mathrm{dd}, J=7.8,1.6 \mathrm{~Hz}, 1 \mathrm{H}), 7.63(\mathrm{~s}$, 1H), $7.41(\mathrm{~d}, J=8.7 \mathrm{~Hz}, 2 \mathrm{H}), 7.39(\mathrm{dd}, J=7.8,4.6 \mathrm{~Hz}, 1 \mathrm{H}), 7.27(\mathrm{~d}, J=8.7 \mathrm{~Hz}, 2 \mathrm{H}), 3.36-3.31(\mathrm{~m}$, 2H), $1.57-1.46(\mathrm{~m}, 2 \mathrm{H}), 1.37-3.31(\mathrm{~m}, 2 \mathrm{H}), 1.34(\mathrm{~s}, 9 \mathrm{H}), 0.90(\mathrm{t}, J=7.3 \mathrm{~Hz}, 3 \mathrm{H})$.

${ }^{13} \mathrm{C}$ NMR $\left(100 \mathrm{MHz}, \mathrm{CDCl}_{3}\right) \delta 165.2\left(\mathrm{C}_{\mathrm{q}}\right), 150.1\left(\mathrm{C}_{\mathrm{q}}\right), 148.2\left(\mathrm{C}_{\mathrm{q}}\right), 146.6(\mathrm{CH}), 140.1(\mathrm{CH}), 137.9\left(\mathrm{C}_{\mathrm{q}}\right)$, $136.3\left(\mathrm{C}_{\mathrm{q}}\right), 128.1(\mathrm{CH}), 124.9(\mathrm{CH}), 124.8(\mathrm{CH}), 39.1\left(\mathrm{CH}_{2}\right), 34.5\left(\mathrm{C}_{\mathrm{q}}\right), 31.5\left(\mathrm{CH}_{2}\right), 31.3\left(\mathrm{CH}_{3}\right), 20.1$ $\left(\mathrm{CH}_{2}\right), 13.7\left(\mathrm{CH}_{3}\right)$.

IR (ATR): $3285,3034,1685,1517,1245,809,487 \mathrm{~cm}^{-1}$.

MS (ESI) $m / z$ (relative intensity): $311(70)[\mathrm{M}+\mathrm{H}]^{+}, 333(30)[\mathrm{M}+\mathrm{Na}]^{+}$.

HR-MS (ESI) $\mathrm{C}_{20} \mathrm{H}_{27} \mathrm{~N}_{2} \mathrm{O}[\mathrm{M}+\mathrm{H}]^{+}: 311.2115$, found: 311.2118 .

The spectral data were in accordance with those reported in the literature. ${ }^{[149]}$ 


\section{$N$-Butyl-3-(4-phenoxyphenyl)picolinamide (413o)}<smiles>CCCCNC(=O)c1ncccc1-c1ccc(Oc2ccccc2)cc1</smiles>

The General Procedure J was followed using $N$-butylpicolinamide 411a (44.6 mg, 0.25 mmol), (4methoxyphenyl)magnesium bromide $412 \mathrm{c}(1.0 \mathrm{~mL}, 1.0 \mathrm{M}$ in THF, $1.00 \mathrm{mmol}), 416$ (30 mg, $9.0 \mathrm{~mol}$ \%), TMEDA (58.1 mg, $0.50 \mathrm{mmol}$ ), and 2,3-DCB (95.3 $\mathrm{mg}, 0.75 \mathrm{mmol}$ ). Purification by column chromatography on silica gel ( $n$-hexane/EtOAc: $1 / 1)$ yielded $4130(82.3 \mathrm{mg}, 95 \%)$ as a light yellow oil.

${ }^{1} \mathbf{H}$ NMR $\left(400 \mathrm{MHz}, \mathrm{CDCl}_{3}\right) \delta 8.51(\mathrm{dd}, J=4.7,1.6 \mathrm{~Hz}, 1 \mathrm{H}), 7.75(\mathrm{~s}, 1 \mathrm{H}), 7.65(\mathrm{dd}, J=7.8,1.6 \mathrm{~Hz}$, 1H), $7.39(\mathrm{dd}, J=7.8,4.7 \mathrm{~Hz}, 1 \mathrm{H}), 7.33(\mathrm{~d}, J=8.6 \mathrm{~Hz}, 2 \mathrm{H}), 7.28(\mathrm{~d}, J=8.6 \mathrm{~Hz}, 2 \mathrm{H}), 7.13-7.06(\mathrm{~m}$, $3 \mathrm{H}), 7.01(\mathrm{~d}, J=8.6 \mathrm{~Hz}, 2 \mathrm{H}), 3.38-3.34(\mathrm{~m}, 2 \mathrm{H}), 1.58-1.51(\mathrm{~m}, 2 \mathrm{H}), 1.41-1.30(\mathrm{~m}, 2 \mathrm{H}), 0.91(\mathrm{t}$, $J=7.2 \mathrm{~Hz}, 3 \mathrm{H})$.

${ }^{13} \mathrm{C}$ NMR $\left(100 \mathrm{MHz}, \mathrm{CDCl}_{3}\right) \delta 165.1\left(\mathrm{C}_{\mathrm{q}}\right), 156.9\left(\mathrm{C}_{\mathrm{q}}\right), 156.6\left(\mathrm{C}_{\mathrm{q}}\right), 148.0\left(\mathrm{C}_{\mathrm{q}}\right), 146.7(\mathrm{CH}), 140.0(\mathrm{CH})$, $137.5\left(\mathrm{C}_{\mathrm{q}}\right), 134.0\left(\mathrm{C}_{\mathrm{q}}\right), 129.8(\mathrm{CH}), 129.6(\mathrm{CH}), 125.0(\mathrm{CH}), 123.4(\mathrm{CH}), 119.4(\mathrm{CH}), 117.7(\mathrm{CH})$, $39.1\left(\mathrm{CH}_{2}\right), 31.5\left(\mathrm{CH}_{2}\right), 20.1\left(\mathrm{CH}_{2}\right), 13.7\left(\mathrm{CH}_{3}\right)$.

IR (ATR): 3288, 2931, 1655, 1519, 1290, 811, $488 \mathrm{~cm}^{-1}$.

MS (ESI) $m / z$ (relative intensity): $347(80)[\mathrm{M}+\mathrm{H}]^{+}, 369(20)[\mathrm{M}+\mathrm{Na}]^{+}$.

HR-MS (ESI) $\mathrm{C}_{22} \mathrm{H}_{23} \mathrm{~N}_{2} \mathrm{O}_{2}[\mathrm{M}+\mathrm{H}]^{+}: 347.1751$, found: 347.1754 .

\section{$N$-Butyl-3-methylpicolinamide (415a)}<smiles>CCCCNC(=O)c1ncccc1C</smiles>

The General Procedure K was followed using $N$-butylpicolinamide 411a (44.6 mg, $0.25 \mathrm{mmol}$ ), methylmagnesium bromide 414a $(0.3 \mathrm{~mL}, 3.0 \mathrm{M}$ in THF, $1.00 \mathrm{mmol}), 416(30 \mathrm{mg}, 9.0 \mathrm{~mol} \%)$, TMEDA (58.1 mg, $0.50 \mathrm{mmol})$, and 2,3-DCB $(95.3 \mathrm{mg}, 0.75 \mathrm{mmol})$. Purification by column chromatography ( $n$-hexane/EtOAc 8:1) yielded 415a (38.0 mg, 79\%) as a colorless oil. 
${ }^{1} \mathbf{H}$ NMR $\left(400 \mathrm{MHz}, \mathrm{CDCl}_{3}\right) \delta 8.32(\mathrm{dd}, J=4.6,1.2 \mathrm{~Hz}, 1 \mathrm{H}), 8.09$ (brs, $\left.1 \mathrm{H}\right), 7.53$ (dd, $J=7.8,1.2$ $\mathrm{Hz}, 1 \mathrm{H}), 7.24(\mathrm{dd}, J=7.8,4.6 \mathrm{~Hz}, 1 \mathrm{H}), 3.38(\mathrm{td}, J=7.1,6.1 \mathrm{~Hz}, 2 \mathrm{H}), 2.70(\mathrm{~s}, 3 \mathrm{H}), 1.66-1.51(\mathrm{~m}$, $2 \mathrm{H}), 1.46-1.31(\mathrm{~m}, 2 \mathrm{H}), 0.91(\mathrm{t}, J=7.3 \mathrm{~Hz}, 3 \mathrm{H})$.

${ }^{13} \mathrm{C}$ NMR $\left(100 \mathrm{MHz}, \mathrm{CDCl}_{3}\right) \delta 165.9\left(\mathrm{C}_{\mathrm{q}}\right), 147.4\left(\mathrm{C}_{\mathrm{q}}\right), 145.3(\mathrm{CH}), 140.7(\mathrm{CH}), 135.2\left(\mathrm{C}_{\mathrm{q}}\right), 125.4$ $(\mathrm{CH}), 38.9\left(\mathrm{CH}_{2}\right), 31.7\left(\mathrm{CH}_{2}\right), 20.5\left(\mathrm{CH}_{3}\right), 20.2\left(\mathrm{CH}_{2}\right), 13.7\left(\mathrm{CH}_{3}\right)$.

IR (ATR): 3384, 2927, 1574, 1465, 807, $711 \mathrm{~cm}^{-1}$.

MS (ESI) $m / z$ (relative intensity) $193(80)[\mathrm{M}+\mathrm{H}]^{+}, 215(20)[\mathrm{M}+\mathrm{Na}]^{+}$.

HR-MS (ESI) $m / z$ calcd for $\mathrm{C}_{11} \mathrm{H}_{17} \mathrm{~N}_{2} \mathrm{O}[\mathrm{M}+\mathrm{H}]^{+}$193.1335, found 193.1337.

The spectral data were in accordance with those reported in the literature. ${ }^{[285]}$

\section{$N$-Butyl-3-ethylpicolinamide (415b)}<smiles>CCCCNC(=O)c1ncccc1CC</smiles>

The General Procedure K was followed using $N$-butylpicolinamide 411a (44.6 mg, $0.25 \mathrm{mmol}$ ), ethylmagnesium bromide 414b (0.5 mL, 2.0 M in THF, $1.00 \mathrm{mmol}), \mathbf{4 1 6}(30 \mathrm{mg}, 9.0 \mathrm{~mol} \%$ ), TMEDA (58.1 mg, $0.50 \mathrm{mmol})$, and 2,3-DCB $(95.3 \mathrm{mg}, 0.75 \mathrm{mmol})$. Purification by column chromatography ( $n$-hexane/EtOAc 8:1) yielded $\mathbf{4 1 5 b}(35.1 \mathrm{mg}, 68 \%)$ as a colorless oil.

${ }^{1}$ H NMR $\left(300 \mathrm{MHz}, \mathrm{CDCl}_{3}\right) \delta 8.33(\mathrm{dd}, J=4.6,1.7 \mathrm{~Hz}, 1 \mathrm{H}), 8.04$ (brs, $\left.1 \mathrm{H}\right), 7.57$ (dd, $J=7.8,1.7$ $\mathrm{Hz}, 1 \mathrm{H}), 7.27(\mathrm{dd}, J=7.8,4.6 \mathrm{~Hz}, 1 \mathrm{H}), 3.41-3.37(\mathrm{~m}, 2 \mathrm{H}), 3.16(\mathrm{q}, J=7.5 \mathrm{~Hz}, 2 \mathrm{H}), 1.62-1.52(\mathrm{~m}$, 2H), $1.44-1.31(\mathrm{~m}, 2 \mathrm{H}), 1.23(\mathrm{t}, J=7.5 \mathrm{~Hz}, 3 \mathrm{H}), 0.91(\mathrm{t}, J=7.2 \mathrm{~Hz}, 3 \mathrm{H})$.

${ }^{13} \mathrm{C} \mathrm{NMR}\left(75 \mathrm{MHz}, \mathrm{CDCl}_{3}\right) \delta 165.6\left(\mathrm{C}_{\mathrm{q}}\right), 147.2\left(\mathrm{C}_{\mathrm{q}}\right), 145.1(\mathrm{CH}), 141.1\left(\mathrm{C}_{\mathrm{q}}\right), 139.2(\mathrm{CH}), 125.5(\mathrm{CH})$, $39.0\left(\mathrm{CH}_{2}\right), 31.8\left(\mathrm{CH}_{2}\right), 26.3\left(\mathrm{CH}_{2}\right), 20.3\left(\mathrm{CH}_{2}\right), 15.6\left(\mathrm{CH}_{3}\right), 13.8\left(\mathrm{CH}_{3}\right)$.

IR (ATR): 3387, 2962, 1673, 1515, $803 \mathrm{~cm}^{-1}$.

MS (ESI) $m / z$ (relative intensity) $207(70)[\mathrm{M}+\mathrm{H}]^{+}, 229(30)[\mathrm{M}+\mathrm{Na}]^{+}$.

HR-MS (ESI) $m / z$ calcd for $\mathrm{C}_{12} \mathrm{H}_{19} \mathrm{~N}_{2} \mathrm{O}[\mathrm{M}+\mathrm{H}]^{+}$207.1492, found 207.1494. 
N,3-Dibutylpicolinamide (415c)<smiles>CCCCNC(=O)c1ncccc1CCCC</smiles>

The General Procedure K was followed using $N$-butylpicolinamide 411a (44.6 mg, 0.25 mmol), $n$ butylmagnesium bromide 414c (0.5 mL, 2.0 M in THF, $1.00 \mathrm{mmol}), 416$ (30 mg, $9.0 \mathrm{~mol} \%$ ), TMEDA (58.1 $\mathrm{mg}, 0.50 \mathrm{mmol})$, and 2,3-DCB $(95.3 \mathrm{mg}, 0.75 \mathrm{mmol})$. Purification by column chromatography ( $n$-hexane/EtOAc 8:1) yielded 415c (52.1 mg, 89\%) as a colorless oil.

${ }^{1}$ H NMR $\left(300 \mathrm{MHz}, \mathrm{CDCl}_{3}\right) \delta 8.34(\mathrm{dd}, J=4.6,1.7 \mathrm{~Hz}, 1 \mathrm{H}), 8.05($ brs $1 \mathrm{H}), 7.56(\mathrm{dd}, J=7.8,1.7 \mathrm{~Hz}$, $1 \mathrm{H}), 7.27(\mathrm{dd}, J=7.8,4.6 \mathrm{~Hz}, 1 \mathrm{H}), 3.40(\mathrm{td}, J=7.1,6.0 \mathrm{~Hz}, 2 \mathrm{H}), 3.14(\mathrm{t}, J=7.7 \mathrm{~Hz}, 2 \mathrm{H}), 1.64-1.54$ $(\mathrm{m}, 4 \mathrm{H}), 1.45-1.34(\mathrm{~m}, 4 \mathrm{H}), 0.97-0.86(\mathrm{~m}, 6 \mathrm{H})$.

${ }^{13}$ C NMR $\left(100 \mathrm{MHz}, \mathrm{CDCl}_{3}\right) \delta 165.9\left(\mathrm{C}_{\mathrm{q}}\right), 147.6\left(\mathrm{C}_{\mathrm{q}}\right), 145.4(\mathrm{CH}), 140.1\left(\mathrm{C}_{\mathrm{q}}\right), 140.1(\mathrm{CH}), 125.5$ $(\mathrm{CH}), 39.1\left(\mathrm{CH}_{2}\right), 33.8\left(\mathrm{CH}_{2}\right), 33.0\left(\mathrm{CH}_{2}\right), 31.9\left(\mathrm{CH}_{2}\right), 22.9\left(\mathrm{CH}_{2}\right), 20.3\left(\mathrm{CH}_{2}\right), 14.1\left(\mathrm{CH}_{3}\right), 13.9\left(\mathrm{CH}_{3}\right)$. IR (ATR): 2927, 2864, 1667, 1511, 1434, 807, $605 \mathrm{~cm}^{-1}$.

MS (ESI) $m / z$ (relative intensity) $235(40)[\mathrm{M}+\mathrm{H}]^{+}, 257(60)[\mathrm{M}+\mathrm{Na}]^{+}$.

HR-MS (ESI) $m / z$ calcd for $\mathrm{C}_{14} \mathrm{H}_{22} \mathrm{~N}_{2} \mathrm{O}[\mathrm{M}+\mathrm{H}]^{+} 235.1805$, found 235.1801.

The spectral data were in accordance with those reported in the literature. ${ }^{[286]}$

\section{$N$-Butyl-3-octanoylpicolinamide (415d)}<smiles>CCCCCOc1cccnc1C(=O)NCCCC</smiles>

The General Procedure K was followed using $N$-butylpicolinamide 411a (44.6 mg, $0.25 \mathrm{mmol})$, octanemagnesium bromide 414d (1.3 mL, $0.8 \mathrm{M}$ in THF, $1.00 \mathrm{mmol}), 416(30 \mathrm{mg}, 9.0 \mathrm{~mol} \%)$, TMEDA (58.1 mg, $0.50 \mathrm{mmol})$, and 2,3-DCB (95.3 $\mathrm{mg}, 0.75 \mathrm{mmol})$. Purification by column chromatography ( $n$-hexane/EtOAc 8:1) yielded 415d (53.6 mg, 74\%) as a colorless oil.

${ }^{1}$ H NMR $\left(400 \mathrm{MHz}, \mathrm{CDCl}_{3}\right) \delta 8.35(\mathrm{dd}, J=4.6,1.6 \mathrm{~Hz}, 1 \mathrm{H}), 8.06$ (brs, 1H), 7.57 (dd, $J=7.8,1.6$ $\mathrm{Hz}, 1 \mathrm{H}), 7.28(\mathrm{dd}, J=7.8,4.6 \mathrm{~Hz}, 1 \mathrm{H}), 3.41(\mathrm{td}, J=7.0,6.0 \mathrm{~Hz}, 2 \mathrm{H}), 3.18-3.12(\mathrm{~m}, 2 \mathrm{H}), 1.66-1.56$ $(\mathrm{m}, 4 \mathrm{H}), 1.46-1.35(\mathrm{~m}, 3 \mathrm{H}), 1.33-1.22(\mathrm{~m}, 9 \mathrm{H}), 0.94(\mathrm{t}, J=7.3 \mathrm{~Hz}, 3 \mathrm{H}), 0.85(\mathrm{t}, J=7.0 \mathrm{~Hz}, 3 \mathrm{H})$. 
${ }^{13} \mathrm{C}$ NMR $\left(100 \mathrm{MHz}, \mathrm{CDCl}_{3}\right) \delta 165.8\left(\mathrm{C}_{\mathrm{q}}\right), 147.4\left(\mathrm{C}_{\mathrm{q}}\right), 145.2(\mathrm{CH}), 140.0\left(\mathrm{C}_{\mathrm{q}}\right), 139.9(\mathrm{CH}), 125.4$ $(\mathrm{CH}), 39.0\left(\mathrm{CH}_{2}\right), 33.1\left(\mathrm{CH}_{2}\right), 31.8\left(\mathrm{CH}_{2}\right), 31.7\left(\mathrm{CH}_{2}\right), 31.5\left(\mathrm{CH}_{2}\right), 29.7\left(\mathrm{CH}_{2}\right), 29.5\left(\mathrm{CH}_{2}\right), 29.3\left(\mathrm{CH}_{2}\right)$, $22.6\left(\mathrm{CH}_{2}\right), 20.2\left(\mathrm{CH}_{2}\right), 14.1\left(\mathrm{CH}_{3}\right), 13.8\left(\mathrm{CH}_{3}\right)$.

IR (ATR): 3390, 2925, 1673, 1514, 1461, 807, $613 \mathrm{~cm}^{-1}$.

MS (ESI) $m / z$ (relative intensity) $291(80)[\mathrm{M}+\mathrm{H}]^{+}, 313(20)[\mathrm{M}+\mathrm{Na}]^{+}$.

HR-MS (ESI) $m / z$ calcd for $\mathrm{C}_{18} \mathrm{H}_{31} \mathrm{~N}_{2} \mathrm{O}[\mathrm{M}+\mathrm{H}]^{+} 291.2431$, found 291.2432.

\section{$N$-Butyl-3-isopropylpicolinamide (415e)}<smiles>CCCCNC(=O)c1ncccc1C(C)C</smiles>

The General Procedure K was followed using $N$-butylpicolinamide 411a (44.6 mg, $0.25 \mathrm{mmol}$ ) and isopropylmagnesium bromide 414e $(0.33 \mathrm{~mL}, 3.0 \mathrm{M}$ in THF, $1.00 \mathrm{mmol}), 416(30 \mathrm{mg}, 9.0 \mathrm{~mol} \%)$, TMEDA (58.1 $\mathrm{mg}, 0.50 \mathrm{mmol})$, and 2,3-DCB (95.3 $\mathrm{mg}, 0.75 \mathrm{mmol})$. Purification by column chromatography ( $n$-hexane/EtOAc 8:1) yielded 415e (35.8 mg, 65\%) as a colorless oil.

${ }^{1}$ H NMR $\left(400 \mathrm{MHz}, \mathrm{CDCl}_{3}\right) \delta 8.33(\mathrm{dd}, J=4.5,1.5 \mathrm{~Hz}, 1 \mathrm{H}), 7.92$ (brs, 1H), 7.74 (dd, $J=8.1,1.5$ $\mathrm{Hz}, 1 \mathrm{H}), 7.31(\mathrm{dd}, J=8.1,4.5 \mathrm{~Hz}, 1 \mathrm{H}), 4.41$ (hept, $J=6.9 \mathrm{~Hz}, 1 \mathrm{H}), 3.40(\mathrm{td}, J=7.2,6.0 \mathrm{~Hz}, 2 \mathrm{H})$, $1.62-1.55(\mathrm{~m}, 2 \mathrm{H}), 1.44-1.35(\mathrm{~m}, 2 \mathrm{H}), 1.23(\mathrm{~d}, J=6.9 \mathrm{~Hz}, 6 \mathrm{H}), 0.93(\mathrm{t}, J=7.2 \mathrm{~Hz}, 3 \mathrm{H})$.

${ }^{13} \mathrm{C}$ NMR $\left(100 \mathrm{MHz}, \mathrm{CDCl}_{3}\right) \delta 166.2\left(\mathrm{C}_{\mathrm{q}}\right), 147.2\left(\mathrm{C}_{\mathrm{q}}\right), 145.6\left(\mathrm{C}_{\mathrm{q}}\right), 145.0(\mathrm{CH}), 135.4(\mathrm{CH}), 125.6$ $(\mathrm{CH}), 39.1\left(\mathrm{CH}_{2}\right), 31.7\left(\mathrm{CH}_{2}\right), 27.5(\mathrm{CH}), 23.6\left(\mathrm{CH}_{3}\right), 20.2\left(\mathrm{CH}_{2}\right), 13.7\left(\mathrm{CH}_{3}\right)$.

IR (ATR): 3386, 2958, 2866, 1662, 1511, 855, $655 \mathrm{~cm}^{-1}$.

MS (ESI) $m / z$ (relative intensity): $221(20)[\mathrm{M}+\mathrm{H}]^{+}, 243(80)[\mathrm{M}+\mathrm{Na}]^{+}$.

HR-MS (ESI) $m / z$ calcd for $\mathrm{C}_{13} \mathrm{H}_{21} \mathrm{~N}_{2} \mathrm{O}[\mathrm{M}+\mathrm{H}]^{+} 221.1646$ found 2212.1648.

\section{N-Butyl-3-(hexan-2-yl)picolinamide (415f)}<smiles>CCCCNC(=O)c1ncccc1C(CCCC)CCCC</smiles> 
The General Procedure K was followed using $N$-butylpicolinamide 411a (44.6 mg, 0.25 mmol), 2hexylmagnesium bromide 414f (1.4 mL, 0.7 M in THF, $1.00 \mathrm{mmol}$ ), 416 (30 mg, $9.0 \mathrm{~mol} \%$ ), TMEDA (58.1 mg, $0.50 \mathrm{mmol})$, and 2,3-DCB $(95.3 \mathrm{mg}, 0.75 \mathrm{mmol})$. Purification by column chromatography ( $n$-hexane/EtOAc 8:1) yielded $\mathbf{4 1 5 f}(36.7 \mathrm{mg}, 56 \%$ ) as a colorless oil.

${ }^{1} \mathbf{H}$ NMR $\left(300 \mathrm{MHz}, \mathrm{CDCl}_{3}\right) \delta 8.32(\mathrm{dd}, J=4.5,1.5 \mathrm{~Hz}, 1 \mathrm{H}), 7.89$ (brs, 1H), 7.72 (dd, $J=8.1,1.5$ $\mathrm{Hz}, 1 \mathrm{H}), 7.32$ (dd, $J=8.1,4.5 \mathrm{~Hz}, 1 \mathrm{H}), 4.30$ (sext, $J=7.2 \mathrm{~Hz}, 1 \mathrm{H}), 3.43-3.39(\mathrm{~m}, 2 \mathrm{H}), 1.63-1.49$ (m, 4H), $1.45-1.34(\mathrm{~m}, 2 \mathrm{H}), 1.30-1.19(\mathrm{~m}, 3 \mathrm{H}), 1.22(\mathrm{~d}, J=6.8 \mathrm{~Hz}, 3 \mathrm{H}), 1.16-1.08(\mathrm{~m}, 1 \mathrm{H}), 0.93$ $(\mathrm{t}, J=7.2 \mathrm{~Hz}, 3 \mathrm{H}), 0.81(\mathrm{t}, J=7.2 \mathrm{~Hz}, 3 \mathrm{H})$.

${ }^{13} \mathrm{C}$ NMR $\left(100 \mathrm{MHz}, \mathrm{CDCl}_{3}\right) \delta 166.3\left(\mathrm{C}_{\mathrm{q}}\right), 147.7\left(\mathrm{C}_{\mathrm{q}}\right), 145.0(\mathrm{CH}), 144.9\left(\mathrm{C}_{\mathrm{q}}\right), 136.0(\mathrm{CH}), 125.6$ $(\mathrm{CH}), 39.1\left(\mathrm{CH}_{2}\right), 37.7\left(\mathrm{CH}_{2}\right), 32.3(\mathrm{CH}), 31.7\left(\mathrm{CH}_{2}\right), 29.8\left(\mathrm{CH}_{2}\right), 22.8\left(\mathrm{CH}_{2}\right), 22.0\left(\mathrm{CH}_{3}\right), 20.2\left(\mathrm{CH}_{2}\right)$, $14.0\left(\mathrm{CH}_{3}\right), 13.8\left(\mathrm{CH}_{3}\right)$.

IR (ATR): 3387, 2955, 1665, 1511, 806, 708, $659 \mathrm{~cm}^{-1}$.

MS (ESI) $m / z$ (relative intensity): $263(70)[\mathrm{M}+\mathrm{H}]^{+}, 285(30)[\mathrm{M}+\mathrm{Na}]^{+}$.

HR-MS (ESI) $m / z$ calcd for $\mathrm{C}_{17} \mathrm{H}_{29} \mathrm{~N}_{2} \mathrm{O}[\mathrm{M}+\mathrm{H}]^{+} 263.4050$ found 263.4046 .

The spectral data were in accordance with those reported in the literature. ${ }^{[286]}$

\section{$N$-Butyl-3-cyclopropylpicolinamide (415g)}<smiles>CCCCNC(=O)c1ncccc1C1CC1</smiles>

The General Procedure K was followed using $N$-butylpicolinamide 411a (44.6 mg, $0.25 \mathrm{mmol}$ ), cyclopropylmagnesium bromide 414g (0.9 mL, 1.1 M in THF, $1.00 \mathrm{mmol}), \mathbf{4 1 6}(30 \mathrm{mg}, 9.0 \mathrm{~mol} \%)$, TMEDA (58.1 mg, $0.50 \mathrm{mmol})$, and 2,3-DCB (95.3 $\mathrm{mg}, 0.75 \mathrm{mmol})$. Purification by column chromatography ( $n$-hexane/EtOAc 8:1) yielded $\mathbf{4 1 5 g}$ (38.2 mg, 70\%) as a colorless oil.

${ }^{1} \mathbf{H}$ NMR $\left(400 \mathrm{MHz}, \mathrm{CDCl}_{3}\right) \delta 8.29(\mathrm{dd}, J=3.4,2.8 \mathrm{~Hz}, 1 \mathrm{H}), 8.02$ (brs, 1H), $7.26-7.25$ (m, 1H), $7.25-7.24(\mathrm{~m}, 1 \mathrm{H}), 3.45-3.40(\mathrm{~m}, 2 \mathrm{H}), 3.40-3.33(\mathrm{~m}, 1 \mathrm{H}), 1.65-1.57(\mathrm{~m}, 2 \mathrm{H}), 1.46-1.37(\mathrm{~m}$, $2 \mathrm{H}), 1.10-1.05(\mathrm{~m}, 2 \mathrm{H}), 0.94(\mathrm{t}, J=7.3 \mathrm{~Hz}, 3 \mathrm{H}), 0.69-0.65(\mathrm{~m}, 2 \mathrm{H})$.

${ }^{13}$ C NMR $\left(100 \mathrm{MHz}, \mathrm{CDCl}_{3}\right) \delta 166.2\left(\mathrm{C}_{\mathrm{q}}\right), 148.3\left(\mathrm{C}_{\mathrm{q}}\right), 144.3(\mathrm{CH}), 140.9\left(\mathrm{C}_{\mathrm{q}}\right), 133.4(\mathrm{CH}), 125.4$ $(\mathrm{CH}), 39.0\left(\mathrm{CH}_{2}\right), 31.7\left(\mathrm{CH}_{2}\right), 20.2\left(\mathrm{CH}_{2}\right), 13.8(\mathrm{CH}), 11.3\left(\mathrm{CH}_{3}\right), 9.7\left(\mathrm{CH}_{2}\right)$. 
IR (ATR): 3379, 2960, 1670, 1514, 1465, 805, $651 \mathrm{~cm}^{-1}$.

MS (ESI) $m / z$ (relative intensity) $219(80)[\mathrm{M}+\mathrm{H}]^{+}, 241(20)[\mathrm{M}+\mathrm{Na}]^{+}$.

HR-MS (ESI) $m / z$ calcd for $\mathrm{C}_{13} \mathrm{H}_{19} \mathrm{~N}_{2} \mathrm{O}[\mathrm{M}+\mathrm{H}]^{+} 219.1492$, found 219.1497.

\section{$N$-Butyl-3-cyclobutylpicolinamide (415h)}

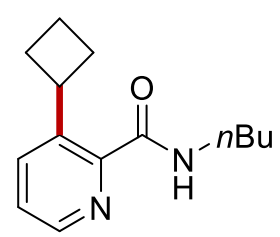

The General Procedure K was followed using $N$-butylpicolinamide 411a (44.6 mg, $0.25 \mathrm{mmol}$ ), cyclobutylmagnesium bromide $\mathbf{4 1 4 h}(1.3 \mathrm{~mL}, 0.8 \mathrm{M}$ in THF, $1.00 \mathrm{mmol}), \mathbf{4 1 6}(30 \mathrm{mg}, 9.0 \mathrm{~mol} \%)$, TMEDA (58.1 mg, $0.50 \mathrm{mmol})$, and 2,3-DCB (95.3 $\mathrm{mg}, 0.75 \mathrm{mmol})$. Purification by column chromatography ( $n$-hexane/EtOAc 8:1) yielded $\mathbf{4 1 5 h}$ (48.8 $\mathrm{mg}, 84 \%)$ as a colorless oil.

${ }^{1} \mathbf{H}$ NMR $\left(400 \mathrm{MHz}, \mathrm{CDCl}_{3}\right) \delta 8.32(\mathrm{dd}, J=4.6,1.6 \mathrm{~Hz}, 1 \mathrm{H}), 7.88(\mathrm{brs}, 1 \mathrm{H}), 7.80$ (dd, $J=8.0,1.6$ $\mathrm{Hz}, 1 \mathrm{H}), 7.34(\mathrm{dd}, J=8.0,4.6 \mathrm{~Hz}, 1 \mathrm{H}), 4.67-4.53(\mathrm{~m}, 1 \mathrm{H}), 3.44-3.34(\mathrm{~m}, 2 \mathrm{H}), 2.47-2.35(\mathrm{~m}, 2 \mathrm{H})$, $2.12-1.96(\mathrm{~m}, 3 \mathrm{H}), 1.83-1.73(\mathrm{~m}, 1 \mathrm{H}), 1.64-1.52(\mathrm{~m}, 2 \mathrm{H}), 1.47-1.32(\mathrm{~m}, 2 \mathrm{H}), 0.93(\mathrm{t}, J=7.3$ $\mathrm{Hz}, 3 \mathrm{H})$.

${ }^{13} \mathrm{C}$ NMR $\left(100 \mathrm{MHz}, \mathrm{CDCl}_{3}\right) \delta 165.9\left(\mathrm{C}_{\mathrm{q}}\right), 147.4\left(\mathrm{C}_{\mathrm{q}}\right), 144.8(\mathrm{CH}), 141.7\left(\mathrm{C}_{\mathrm{q}}\right), 136.0(\mathrm{CH}), 125.4$ $(\mathrm{CH}), 39.0\left(\mathrm{CH}_{2}\right), 36.6(\mathrm{CH}), 31.7\left(\mathrm{CH}_{2}\right), 29.1\left(\mathrm{CH}_{2}\right), 20.2\left(\mathrm{CH}_{2}\right), 18.2\left(\mathrm{CH}_{2}\right), 13.7\left(\mathrm{CH}_{3}\right)$.

IR (ATR): 3386, 2959, 1513, 1430, 1188, 807, $631 \mathrm{~cm}^{-1}$.

MS (ESI) $m / z$ (relative intensity) $233(60)[\mathrm{M}+\mathrm{H}]^{+}, 255(40)[\mathrm{M}+\mathrm{Na}]^{+}$.

HR-MS (ESI) $m / z$ calcd for $\mathrm{C}_{14} \mathrm{H}_{21} \mathrm{~N}_{2} \mathrm{O}[\mathrm{M}+\mathrm{H}]^{+} 233.1648$, found 233.1651.

\section{$N$-Butyl-3-cyclopentylpicolinamide (415i)}

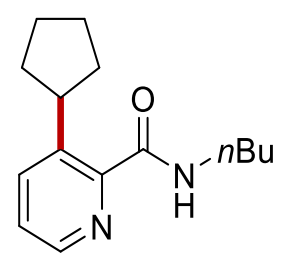

The General Procedure K was followed using $N$-butylpicolinamide 411a (44.6 mg, 0.25 mmol), cyclopentylmagnesium bromide 414i (1.3 mL, 0.8 M in THF, $1.00 \mathrm{mmol}), 416$ (30 mg, $9.0 \mathrm{~mol} \%$ ), 
TMEDA (58.1 mg, $0.50 \mathrm{mmol})$, and 2,3-DCB (95.3 $\mathrm{mg}, 0.75 \mathrm{mmol})$. Purification by column chromatography ( $n$-hexane/EtOAc 8:1) yielded 415i (49.4 mg, 64\%) as a colorless oil.

${ }^{1}$ H NMR $\left(300 \mathrm{MHz} \mathrm{CDCl}_{3}\right) \delta 8.34(\mathrm{dd}, J=4.5,1.5 \mathrm{~Hz}, 1 \mathrm{H}), 7.91$ (brs, $\left.1 \mathrm{H}\right), 7.76$ (dd, $J=8.1,1.5$ $\mathrm{Hz}, 1 \mathrm{H}), 7.32(\mathrm{dd}, J=8.1,4.5 \mathrm{~Hz}, 1 \mathrm{H}), 4.40(\mathrm{tt}, J=9.6,7.5 \mathrm{~Hz}, 1 \mathrm{H}), 3.42(\mathrm{td}, J=7.1,6.0 \mathrm{~Hz}, 2 \mathrm{H})$, $2.18-2.11(\mathrm{~m}, 2 \mathrm{H}), 1.77-1.70(\mathrm{~m}, 4 \mathrm{H}), 1.62-1.36(\mathrm{~m}, 6 \mathrm{H}), 0.93(\mathrm{t}, J=7.2 \mathrm{~Hz}, 3 \mathrm{H})$.

${ }^{13}$ C NMR $\left(75 \mathrm{MHz}, \mathrm{CDCl}_{3}\right) \delta=166.3\left(\mathrm{C}_{\mathrm{q}}\right), 147.9\left(\mathrm{C}_{\mathrm{q}}\right), 144.8(\mathrm{CH}), 143.3\left(\mathrm{C}_{\mathrm{q}}\right), 136.0(\mathrm{CH}), 125.5$ $(\mathrm{CH}), 39.7(\mathrm{CH}), 39.2\left(\mathrm{CH}_{2}\right), 34.7\left(\mathrm{CH}_{2}\right), 31.8\left(\mathrm{CH}_{2}\right), 25.9\left(\mathrm{CH}_{2}\right), 20.3\left(\mathrm{CH}_{2}\right), 13.9\left(\mathrm{CH}_{3}\right)$.

IR (ATR): 3385, 2947, 2859, 1660, 1508, 804, $654 \mathrm{~cm}^{-1}$.

MS (ESI) $m / z$ (relative intensity): $247(25)[\mathrm{M}+\mathrm{H}]^{+}, 269(75)[\mathrm{M}+\mathrm{Na}]^{+}$.

HR-MS (ESI) $m / z$ calcd for $\mathrm{C}_{15} \mathrm{H}_{23} \mathrm{~N}_{2} \mathrm{O}[\mathrm{M}+\mathrm{H}]^{+} 247.1803$ found 247.1805.

The spectral data were in accordance with those reported in the literature. ${ }^{[286]}$

\section{$N$-Butyl-3-cyclohexylpicolinamide (415j)}

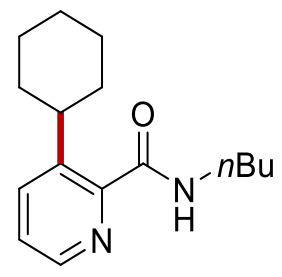

The General Procedure K was followed using $N$-butylpicolinamide 411a (44.6 mg, $0.25 \mathrm{mmol}$ ), cyclohexylmagnesium bromide $\mathbf{4 1 4 j}$ (0.6 mL, 1.8 M in THF, $1.00 \mathrm{mmol}), 416$ (30 mg, $9.0 \mathrm{~mol} \%$ ), TMEDA (58.1 $\mathrm{mg}, 0.50 \mathrm{mmol})$, and 2,3-DCB (95.3 $\mathrm{mg}, 0.75 \mathrm{mmol})$. Purification by column chromatography ( $n$-hexane/EtOAc 8:1) yielded $\mathbf{4 1 5 j}$ (53.4 mg, 82\%) as a colorless oil.

${ }^{1} \mathbf{H}$ NMR $\left(400 \mathrm{MHz}, \mathrm{CDCl}_{3}\right) \delta 8.33(\mathrm{dd}, J=4.5,1.5 \mathrm{~Hz}, 1 \mathrm{H}), 7.99$ (brs, 1H), 7.75 (dd, $J=8.1,1.5$ $\mathrm{Hz}, 1 \mathrm{H}), 7.31(\mathrm{dd}, J=8.1,4.5 \mathrm{~Hz}, 1 \mathrm{H}), 4.05(\mathrm{tt}, J=12.0,3.2 \mathrm{~Hz}, 1 \mathrm{H}), 3.40(\mathrm{td}, J=7.2,6.0 \mathrm{~Hz}, 2 \mathrm{H})$, $1.90-1.77(\mathrm{~m}, 5 \mathrm{H}), 1.62-1.18(\mathrm{~m}, 9 \mathrm{H}), 0.94(\mathrm{t}, J=7.2 \mathrm{~Hz}, 3 \mathrm{H})$.

${ }^{13} \mathrm{C}$ NMR $\left(100 \mathrm{MHz}, \mathrm{CDCl}_{3}\right) \delta 166.2\left(\mathrm{C}_{\mathrm{q}}\right), 147.2\left(\mathrm{C}_{\mathrm{q}}\right), 144.9(\mathrm{CH}), 144.6\left(\mathrm{C}_{\mathrm{q}}\right), 136.0(\mathrm{CH}), 125.5$ $(\mathrm{CH}), 39.1\left(\mathrm{CH}_{2}\right), 37.8(\mathrm{CH}), 34.1\left(\mathrm{CH}_{2}\right), 31.7\left(\mathrm{CH}_{2}\right), 26.7\left(\mathrm{CH}_{2}\right), 26.2\left(\mathrm{CH}_{2}\right), 20.2\left(\mathrm{CH}_{2}\right), 13.8\left(\mathrm{CH}_{3}\right)$. IR (ATR): 3382, 2922, 2850, 1663, 1504, 694, $498 \mathrm{~cm}^{-1}$.

MS (ESI) $m / z$ (relative intensity): $261(60)[\mathrm{M}+\mathrm{H}]^{+}, 283(40)[\mathrm{M}+\mathrm{Na}]^{+}$.

HR-MS (ESI) $m / z$ calcd for $\mathrm{C}_{16} \mathrm{H}_{25} \mathrm{~N}_{2} \mathrm{O}[\mathrm{M}+\mathrm{H}]^{+} 261.1964$ found 261.1962. 
The spectral data were in accordance with those reported in the literature. ${ }^{[286]}$

\section{$N$-Butyl-3-cycloheptylpicolinamide (415k)}<smiles>CCCCNC(=O)c1ncccc1C1CCCCCC1</smiles>

The General Procedure K was followed using $N$-butylpicolinamide 411a (44.6 mg, 0.25 mmol), cycloheptylmagnesium bromide 414k (1.7 mL, 0.6 M in THF, $1.00 \mathrm{mmol}), \mathbf{4 1 6}(30 \mathrm{mg}, 9.0 \mathrm{~mol} \%)$, TMEDA (58.1 mg, $0.50 \mathrm{mmol})$, and 2,3-DCB (95.3 $\mathrm{mg}, 0.75 \mathrm{mmol})$. Purification by column chromatography ( $n$-hexane/EtOAc 8:1) yielded 415k (37.0 mg, 54\%) as a colorless oil.

${ }^{1}$ H NMR $\left(300 \mathrm{MHz} \mathrm{CDCl}_{3}\right) \delta 8.33$ (dd, $\left.J=4.5,1.6 \mathrm{~Hz}, 1 \mathrm{H}\right), 7.98$ (brs, $\left.1 \mathrm{H}\right), 7.74$ (dd, $J=8.0,1.6 \mathrm{~Hz}$, $1 \mathrm{H}), 7.32(\mathrm{dd}, J=8.0,4.5 \mathrm{~Hz}, 1 \mathrm{H}), 4.32-4.18(\mathrm{~m}, 1 \mathrm{H}), 3.43(\mathrm{td}, J=7.2,5.9 \mathrm{~Hz}, 2 \mathrm{H}), 1.98-1.90$ $(\mathrm{m}, 2 \mathrm{H}), 1.84-1.52(\mathrm{~m}, 11 \mathrm{H}), 1.50-1.37(\mathrm{~m}, 3 \mathrm{H}), 0.96(\mathrm{t}, J=7.2 \mathrm{~Hz}, 3 \mathrm{H})$.

${ }^{13} \mathrm{C} \mathrm{NMR}\left(75 \mathrm{MHz}, \mathrm{CDCl}_{3}\right) \delta 166.1\left(\mathrm{C}_{\mathrm{q}}\right), 146.6\left(\mathrm{C}_{\mathrm{q}}\right), 146.2\left(\mathrm{C}_{\mathrm{q}}\right), 144.7(\mathrm{CH}), 136.3(\mathrm{CH}), 125.6(\mathrm{CH})$, $46.4(\mathrm{CH}), 39.4\left(\mathrm{CH}_{2}\right), 39.2\left(\mathrm{CH}_{2}\right), 36.7\left(\mathrm{CH}_{2}\right), 31.8\left(\mathrm{CH}_{2}\right), 31.4\left(\mathrm{CH}_{2}\right), 28.2\left(\mathrm{CH}_{2}\right), 27.9\left(\mathrm{CH}_{2}\right), 27.6$ $\left(\mathrm{CH}_{2}\right), 20.3\left(\mathrm{CH}_{2}\right), 13.9\left(\mathrm{CH}_{3}\right)$.

IR (ATR): 3383, 2923, 2859, 1670, 1514, 801, $624 \mathrm{~cm}^{-1}$.

MS (ESI) $m / z$ (relative intensity): $275(85)[\mathrm{M}+\mathrm{H}]^{+}, 297(15)[\mathrm{M}+\mathrm{Na}]^{+}$.

HR-MS (ESI) $m / z$ calcd for $\mathrm{C}_{17} \mathrm{H}_{27} \mathrm{~N}_{2} \mathrm{O}[\mathrm{M}+\mathrm{H}]^{+} 275.2123$ found 275.2118.

\section{N,3-dicyclohexylpicolinamide (415l)}<smiles>O=C(NC1CCCCC1)c1ncccc1C1CCCCC1</smiles>

The General Procedure K was followed using $N$-cyclohexylpicolinamide $411 \mathrm{~h}(51.1 \mathrm{mg}, 0.25 \mathrm{mmol})$, cyclohexylmagnesium bromide 414j (0.6 mL, 1.8 M in THF, $1.00 \mathrm{mmol}), 416$ (30 mg, $9.0 \mathrm{~mol} \%$ ), TMEDA (58.1 mg, $0.50 \mathrm{mmol})$, and 2,3-DCB (95.3 $\mathrm{mg}, 0.75 \mathrm{mmol})$. Purification by column 
chromatography on silica gel ( $n$-hexane/EtOAc: $1 / 1)$ yielded 4151 (49.4 mg, 69\%) as a colorless oil. ${ }^{1} \mathbf{H}$ NMR $\left(400 \mathrm{MHz}, \mathrm{CDCl}_{3}\right) \delta 8.30(\mathrm{dd}, J=4.5,1.6 \mathrm{~Hz}, 1 \mathrm{H}), 7.89(\mathrm{~d}, J=8.8 \mathrm{~Hz}, 1 \mathrm{H}), 7.72(\mathrm{dd}, J=$ 8.0, $1.6 \mathrm{~Hz}, 1 \mathrm{H}), 7.29(\mathrm{dd}, J=8.0,4.5 \mathrm{~Hz}, 1 \mathrm{H}), 4.09-3.99(\mathrm{~m}, 1 \mathrm{H}), 3.97-3.84(\mathrm{~m}, 1 \mathrm{H}), 2.02-1.93$ (m, 2H), $1.91-1.83(\mathrm{~m}, 2 \mathrm{H}), 1.81-1.68(\mathrm{~m}, 5 \mathrm{H}), 1.66-1.57(\mathrm{~m}, 1 \mathrm{H}), 1.53-1.46(\mathrm{~m}, 2 \mathrm{H}), 1.42-$ $1.35(\mathrm{~m}, 2 \mathrm{H}), 1.34-1.28(\mathrm{~m}, 2 \mathrm{H}), 1.27-1.11(\mathrm{~m}, 4 \mathrm{H})$.

${ }^{13}$ C NMR $\left(100 \mathrm{MHz}, \mathrm{CDCl}_{3}\right) \delta 165.2\left(\mathrm{C}_{\mathrm{q}}\right), 147.2\left(\mathrm{C}_{\mathrm{q}}\right), 144.8(\mathrm{CH}), 144.7\left(\mathrm{C}_{\mathrm{q}}\right), 136.0(\mathrm{CH}), 125.5$ $(\mathrm{CH}), 48.0(\mathrm{CH}), 37.9(\mathrm{CH}), 34.1\left(\mathrm{CH}_{2}\right), 33.1\left(\mathrm{CH}_{2}\right), 26.7\left(\mathrm{CH}_{2}\right), 26.2\left(\mathrm{CH}_{2}\right), 25.6\left(\mathrm{CH}_{2}\right), 25.0\left(\mathrm{CH}_{2}\right)$. IR (ATR): 338, 2925, 1665, 1503, 807, 593, $435 \mathrm{~cm}^{-1}$.

MS (ESI) $m / z$ (relative intensity): $287(90)[\mathrm{M}+\mathrm{H}]^{+}, 309(10)[\mathrm{M}+\mathrm{Na}]^{+}$.

HR-MS (ESI) $\mathrm{C}_{18} \mathrm{H}_{27} \mathrm{~N}_{2} \mathrm{O}[\mathrm{M}+\mathrm{H}]^{+}:$287.2121, found: 287.2118 .

\section{3-Cyclohexyl- $N-(1,2,3,4-$ tetrahydronaphthalen-1-yl)picolinamide (415m)}

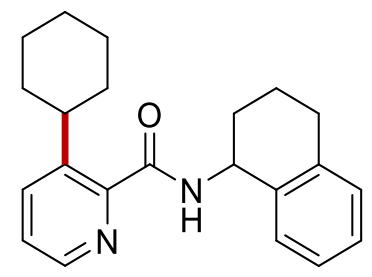

The General Procedure K was followed using $N$-(1,2,3,4-tetrahydronaphthalen-1-yl)picolinamide 411i (63.1 mg, $0.25 \mathrm{mmol}$ ), cyclohexylmagnesium bromide 414j (0.6 mL, $1.8 \mathrm{M}$ in THF, $1.00 \mathrm{mmol}$ ), 416 (30 mg, $9.0 \mathrm{~mol} \%)$, TMEDA (58.1 mg, $0.50 \mathrm{mmol})$, and 2,3-DCB (95.3 mg, $0.75 \mathrm{mmol})$. Purification by column chromatography on silica gel ( $n$-hexane/EtOAc: $1 / 1)$ yielded $\mathbf{4 1 5 m}(68.6 \mathrm{mg}$, $82 \%)$ as a colorless oil.

${ }^{1}$ H NMR $\left(400 \mathrm{MHz}, \mathrm{CDCl}_{3}\right) \delta 8.32(\mathrm{~d}, J=9.3 \mathrm{~Hz}, 1 \mathrm{H}), 8.28(\mathrm{dd}, J=4.5,1.6 \mathrm{~Hz}, 1 \mathrm{H}), 7.76(\mathrm{dd}, J=$ 8.1, 1.6 Hz, 1H), $7.37-7.33(\mathrm{~m}, 1 \mathrm{H}), 7.31(\mathrm{ddd}, J=8.1,4.5 \mathrm{~Hz}, 1 \mathrm{H}), 7.17-7.14(\mathrm{~m}, 2 \mathrm{H}), 7.13-7.09$ (m, 1H), $5.38-5.29(\mathrm{~m}, 1 \mathrm{H}), 4.15(\mathrm{tt}, J=11.8,3.1 \mathrm{~Hz}, 1 \mathrm{H}), 2.92-2.71(\mathrm{~m}, 2 \mathrm{H}), 2.20-2.10(\mathrm{~m}, 1 \mathrm{H})$, $2.02-1.74(\mathrm{~m}, 8 \mathrm{H}), 1.63-1.48(\mathrm{~m}, 2 \mathrm{H}), 1.43-1.32(\mathrm{~m}, 2 \mathrm{H}), 1.31-1.19(\mathrm{~m}, 1 \mathrm{H})$.

${ }^{13} \mathrm{C}$ NMR $\left(100 \mathrm{MHz}, \mathrm{CDCl}_{3}\right) \delta 165.5\left(\mathrm{C}_{\mathrm{q}}\right), 146.9\left(\mathrm{C}_{\mathrm{q}}\right), 145.0(\mathrm{CH}), 144.8\left(\mathrm{C}_{\mathrm{q}}\right), 137.6\left(\mathrm{C}_{\mathrm{q}}\right), 137.0\left(\mathrm{C}_{\mathrm{q}}\right)$, $136.0(\mathrm{CH}), 129.1(\mathrm{CH}), 128.8(\mathrm{CH}), 127.1(\mathrm{CH}), 126.1(\mathrm{CH}), 125.6(\mathrm{CH}), 47.3(\mathrm{CH}), 37.9(\mathrm{CH}), 34.2$ $\left(\mathrm{CH}_{2}\right), 30.3\left(\mathrm{CH}_{2}\right), 29.3\left(\mathrm{CH}_{2}\right), 26.8\left(\mathrm{CH}_{2}\right), 26.3\left(\mathrm{CH}_{2}\right), 20.2\left(\mathrm{CH}_{2}\right)$.

IR (ATR): 3380, 2923, 1664, 1493, 735, 596, $434 \mathrm{~cm}^{-1}$. 
MS (ESI) $m / z$ (relative intensity): $335(90)[\mathrm{M}+\mathrm{H}]^{+}, 357(10)[\mathrm{M}+\mathrm{Na}]^{+}$.

HR-MS (ESI) $\mathrm{C}_{22} \mathrm{H}_{27} \mathrm{~N}_{2} \mathrm{O}[\mathrm{M}+\mathrm{H}]^{+}: 335.2120$, found: 335.2118 .

\section{$N$-Benzyl-3-cyclohexylpicolinamide (415n)}<smiles>O=C(Nc1ccccc1)c1ncccc1C1CCCCC1</smiles>

The General Procedure K was followed using $N$-benzylpicolinamide 411j $(53.1 \mathrm{mg}, 0.25 \mathrm{mmol}$ ), cyclohexylmagnesium bromide 414j (0.6 mL, $1.8 \mathrm{M}$ in THF, $1.00 \mathrm{mmol}), 416(30 \mathrm{mg}, 9.0 \mathrm{~mol} \%)$, TMEDA (58.1 mg, $0.50 \mathrm{mmol})$, and 2,3-DCB (95.3 $\mathrm{mg}, 0.75 \mathrm{mmol})$. Purification by column chromatography on silica gel ( $n$-hexane/EtOAc: $1 / 1)$ yielded 415n (30.2 mg, 41\%) as a colorless oil. ${ }^{1}$ H NMR $\left(400 \mathrm{MHz}, \mathrm{CDCl}_{3}\right) \delta 8.38-8.32(\mathrm{~m}, 1 \mathrm{H}), 8.30(\mathrm{dd}, J=4.5,1.6 \mathrm{~Hz}, 1 \mathrm{H}), 7.89(\mathrm{dd}, J=8.8$, $1.6 \mathrm{~Hz}, 1 \mathrm{H}), 7.38-7.30(\mathrm{~m}, 5 \mathrm{H}), 7.28-7.24(\mathrm{~m}, 1 \mathrm{H}), 4.62(\mathrm{~d}, J=6.0 \mathrm{~Hz}, 2 \mathrm{H}), 4.16-4.03(\mathrm{~m}, 1 \mathrm{H})$, $1.95-1.86(\mathrm{~m}, 2 \mathrm{H}), 1.87-1.72(\mathrm{~m}, 2 \mathrm{H}), 1.60-1.44(\mathrm{~m}, 2 \mathrm{H}), 1.43-1.29(\mathrm{~m}, 2 \mathrm{H}), 1.29-1.16(\mathrm{~m}$, 2H).

${ }^{13} \mathrm{C} \mathrm{NMR}\left(100 \mathrm{MHz}, \mathrm{CDCl}_{3}\right) \delta 166.0\left(\mathrm{C}_{\mathrm{q}}\right), 146.8\left(\mathrm{C}_{\mathrm{q}}\right), 145.0\left(\mathrm{C}_{\mathrm{q}}\right), 144.9(\mathrm{CH}), 138.5\left(\mathrm{C}_{\mathrm{q}}\right), 136.1(\mathrm{CH})$, 128.6 (CH), $127.8(\mathrm{CH}), 127.3(\mathrm{CH}), 125.8(\mathrm{CH}), 43.4\left(\mathrm{CH}_{2}\right), 37.9(\mathrm{CH}), 34.2\left(\mathrm{CH}_{2}\right), 26.8\left(\mathrm{CH}_{2}\right), 26.3$ $\left(\mathrm{CH}_{2}\right)$.

IR (ATR): 3381, 2924, 1666, 1504, 698, 601, $480 \mathrm{~cm}^{-1}$.

MS (ESI) $m / z$ (relative intensity): $295(70)[\mathrm{M}+\mathrm{H}]^{+}, 317(30)[\mathrm{M}+\mathrm{Na}]^{+}$.

HR-MS (ESI) $\mathrm{C}_{19} \mathrm{H}_{23} \mathrm{~N}_{2} \mathrm{O}[\mathrm{M}+\mathrm{H}]^{+}:$295.1801, found: 295.1805 .

\section{3-Cyclohexyl- $N$-(4-methoxybenzyl)picolinamide (415o)}<smiles>COc1ccc(CNC(=O)c2ncccc2C2CCCCC2)cc1</smiles>

The General Procedure K was followed using $N$-(4-methoxybenzyl)picolinamide 4111 (77.6 mg, 0.25 mmol), cyclohexylmagnesium bromide 414j (0.6 mL, 1.8 M in THF, $1.00 \mathrm{mmol}), 416(30 \mathrm{mg}, 9.0 \mathrm{~mol}$ 
\%), TMEDA (58.1 mg, $0.50 \mathrm{mmol})$, and 2,3-DCB (95.3 $\mathrm{mg}, 0.75 \mathrm{mmol})$. Purification by column chromatography on silica gel ( $n$-hexane/EtOAc: $1 / 1)$ yielded 4150 (42.2 mg, 52\%) as a colorless oil. ${ }^{1} \mathbf{H}$ NMR $\left(400 \mathrm{MHz}, \mathrm{CDCl}_{3}\right) \delta 8.30(\mathrm{dd}, J=4.5,1.6 \mathrm{~Hz}, 1 \mathrm{H}), 8.28-8.23(\mathrm{~m}, 1 \mathrm{H}), 7.76(\mathrm{dd}, J=8.0$, $1.6 \mathrm{~Hz}, 1 \mathrm{H}), 7.31(\mathrm{dd}, J=8.0,4.5 \mathrm{~Hz}, 1 \mathrm{H}), 7.28(\mathrm{~d}, J=8.6 \mathrm{~Hz}, 2 \mathrm{H}), 6.86(\mathrm{~d}, J=8.6 \mathrm{~Hz}, 2 \mathrm{H}), 4.54(\mathrm{~d}$, $J=5.9 \mathrm{~Hz}, 2 \mathrm{H}), 4.13-4.05(\mathrm{~m}, 1 \mathrm{H}), 3.77(\mathrm{~s}, 3 \mathrm{H}), 1.93-1.72(\mathrm{~m}, 5 \mathrm{H}), 1.57-1.46(\mathrm{~m}, 2 \mathrm{H}), 1.40-$ $1.30(\mathrm{~m}, 2 \mathrm{H}), 1.27-1.20(\mathrm{~m}, 1 \mathrm{H})$.

${ }^{13} \mathrm{C} \mathrm{NMR}\left(100 \mathrm{MHz}, \mathrm{CDCl}_{3}\right) \delta 166.0\left(\mathrm{C}_{\mathrm{q}}\right), 158.9\left(\mathrm{C}_{\mathrm{q}}\right), 146.9\left(\mathrm{C}_{\mathrm{q}}\right), 144.9(\mathrm{CH}), 144.8\left(\mathrm{C}_{\mathrm{q}}\right), 136.1(\mathrm{CH})$, 130.6 ( $\left.\mathrm{C}_{\mathrm{q}}\right), 129.1(\mathrm{CH}), 125.7(\mathrm{CH}), 114.0(\mathrm{CH}), 55.3\left(\mathrm{CH}_{3}\right), 42.9\left(\mathrm{CH}_{2}\right), 37.9(\mathrm{CH}), 34.2\left(\mathrm{CH}_{2}\right), 26.8$ $\left(\mathrm{CH}_{2}\right), 26.3\left(\mathrm{CH}_{2}\right)$.

IR (ATR): 3387, 2925, 1666, 1508, 1247, 580, $416 \mathrm{~cm}^{-1}$.

MS (ESI) $m / z$ (relative intensity): $325(70)[\mathrm{M}+\mathrm{H}]^{+}, 347(30)[\mathrm{M}+\mathrm{Na}]^{+}$.

HR-MS (ESI) $\mathrm{C}_{20} \mathrm{H}_{25} \mathrm{~N}_{2} \mathrm{O}_{2}[\mathrm{M}+\mathrm{H}]^{+}: 325.1908$, found: 325.1911.

\section{3-Cyclohexyl- $N$-(4-methoxyphenyl)picolinamide (415p)}<smiles>COc1ccc(NC(=O)c2ncccc2C2CCCCC2)cc1</smiles>

The General Procedure K was followed using $N$-(4-methoxyphenyl)picolinamide 411 m (56.8 mg, $0.25 \mathrm{mmol})$, cyclohexylmagnesium bromide 414j (0.6 mL, $1.8 \mathrm{M}$ in THF, $1.00 \mathrm{mmol}), 416$ (30 mg, $9.0 \mathrm{~mol} \%)$, TMEDA (58.1 mg, $0.50 \mathrm{mmol})$, and 2,3-DCB (95.3 $\mathrm{mg}, 0.75 \mathrm{mmol})$. Purification by column chromatography ( $n$-hexane/EtOAc 8:1) yielded 415 p (32.6 mg, 42\%) as a colorless oil.

${ }^{1}$ H NMR $\left(300 \mathrm{MHz}, \mathrm{CDCl}_{3}\right) \delta 10.05$ (brs, $\left.1 \mathrm{H}\right), 8.41(\mathrm{dd}, J=4.5,1.5 \mathrm{~Hz}, 1 \mathrm{H}), 7.82(\mathrm{dd}, J=8.1,1.5$ $\mathrm{Hz}, 1 \mathrm{H}), 7.64(\mathrm{~d}, J=9.0 \mathrm{~Hz}, 2 \mathrm{H}), 7.38(\mathrm{dd}, J=8.1,4.5 \mathrm{~Hz}, 1 \mathrm{H}), 6.91(\mathrm{~d}, J=9.0 \mathrm{~Hz}, 2 \mathrm{H}), 4.24-4.15$ $(\mathrm{m}, 1 \mathrm{H}), 3.81(\mathrm{~s}, 3 \mathrm{H}), 1.96-1.77(\mathrm{~m}, 5 \mathrm{H}), 1.56-1.24(\mathrm{~m}, 5 \mathrm{H})$.

${ }^{13} \mathrm{C}$ NMR $\left(75 \mathrm{MHz}, \mathrm{CDCl}_{3}\right) \delta 163.5\left(\mathrm{C}_{\mathrm{q}}\right), 156.1\left(\mathrm{C}_{\mathrm{q}}\right), 146.3\left(\mathrm{C}_{\mathrm{q}}\right), 145.4\left(\mathrm{C}_{\mathrm{q}}\right), 144.6(\mathrm{CH}), 136.3(\mathrm{CH})$, $131.2\left(\mathrm{C}_{\mathrm{q}}\right), 125.9(\mathrm{CH}), 121.5(\mathrm{CH}), 114.1(\mathrm{CH}), 55.5\left(\mathrm{CH}_{3}\right), 37.9(\mathrm{CH}), 34.2\left(\mathrm{CH}_{2}\right), 26.8\left(\mathrm{CH}_{2}\right), 26.3$ $\left(\mathrm{CH}_{2}\right)$.

IR (ATR): 3319, 2922, 1673, 1240, 825, 689, $559 \mathrm{~cm}^{-1}$. 
MS (ESI) $m / z$ (relative intensity): $311(65)[\mathrm{M}+\mathrm{H}]^{+}, 333(35)[\mathrm{M}+\mathrm{Na}]^{+}$.

HR-MS (ESI) $m / z$ calcd for $\mathrm{C}_{19} \mathrm{H}_{23} \mathrm{~N}_{2} \mathrm{O}_{2}[\mathrm{M}+\mathrm{H}]^{+} 311.1756$ found 311.1753 .

The spectral data were in accordance with those reported in the literature. ${ }^{[286]}$

\section{3-Cyclohexyl- $N$-(2-fluorobenzyl)picolinamide (415q)}<smiles>O=C(NCc1ccccc1F)c1ncccc1C1CCCCC1</smiles>

The General Procedure K was followed using $N$-(2-fluorobenzyl)picolinamide 411n (57.8 mg, 0.25 mmol), cyclohexylmagnesium bromide 414j (0.6 mL, 1.8 M in THF, $1.00 \mathrm{mmol}), 416$ (30 mg, $9.0 \mathrm{~mol}$ \%), TMEDA (58.1 mg, $0.50 \mathrm{mmol})$, and 2,3-DCB (95.3 $\mathrm{mg}, 0.75 \mathrm{mmol})$. Purification by column chromatography ( $n$-hexane/EtOAc 8:1) yielded 415q (52.3 mg, 67\%) as a colorless oil.

${ }^{1} \mathbf{H}$ NMR $\left(300 \mathrm{MHz}, \mathrm{CDCl}_{3}\right) \delta 8.39(\mathrm{t}, J=6.3 \mathrm{~Hz}, 1 \mathrm{H}), 8.32(\mathrm{dd}, J=4.5,1.5 \mathrm{~Hz}, 1 \mathrm{H}), 7.75(\mathrm{dd}, J=$ $8.1,1.5 \mathrm{~Hz}, 1 \mathrm{H}), 7.40(\mathrm{td}, J=7.6,1.8 \mathrm{~Hz}, 1 \mathrm{H}), 7.31(\mathrm{dd}, J=8.1,4.5 \mathrm{~Hz}, 1 \mathrm{H}), 7.25-7.20(\mathrm{~m}, 1 \mathrm{H})$, $7.08(\mathrm{td}, J=7.6,1.2 \mathrm{~Hz}, 1 \mathrm{H}), 7.06-7.00(\mathrm{~m}, 1 \mathrm{H}), 4.67(\mathrm{~d}, J=6.3 \mathrm{~Hz}, 2 \mathrm{H}), 4.07$ (tt, $J=11.5,3.0 \mathrm{~Hz}$, $1 \mathrm{H}), 1.90-1.73(\mathrm{~m}, 5 \mathrm{H}), 1.56-1.45(\mathrm{~m}, 2 \mathrm{H}), 1.39-1.21(\mathrm{~m}, 3 \mathrm{H})$.

${ }^{13} \mathrm{C}$ NMR $\left(75 \mathrm{MHz}, \mathrm{CDCl}_{3}\right) \delta 165.9\left(\mathrm{C}_{\mathrm{q}}\right), 161.0\left(\mathrm{~d},{ }^{1} J_{\mathrm{C}-\mathrm{F}}=246.0 \mathrm{~Hz}, \mathrm{C}_{\mathrm{q}}\right), 146.7\left(\mathrm{C}_{\mathrm{q}}\right), 145.0(\mathrm{CH})$, $144.9\left(\mathrm{C}_{\mathrm{q}}\right), 136.0(\mathrm{CH}), 130.0\left(\mathrm{~d},{ }^{3} J_{\mathrm{C}-\mathrm{F}}=4.3 \mathrm{~Hz}, \mathrm{CH}\right), 129.0\left(\mathrm{~d},{ }^{3} J_{\mathrm{C}-\mathrm{F}}=8.1 \mathrm{~Hz}, \mathrm{CH}\right), 125.8(\mathrm{CH}), 125.5$ $\left(\mathrm{d},{ }^{2} J_{\mathrm{C}-\mathrm{F}}=14.9 \mathrm{~Hz}, \mathrm{C}_{\mathrm{q}}\right), 124.2\left(\mathrm{~d},{ }^{4} J_{\mathrm{C}-\mathrm{F}}=3.6 \mathrm{~Hz}, \mathrm{CH}\right), 115.3\left(\mathrm{~d},{ }^{2} J_{\mathrm{C}-\mathrm{F}}=21.3 \mathrm{~Hz}, \mathrm{CH}\right), 37.8(\mathrm{CH}), 37.1$ $\left(\mathrm{d},{ }^{3} J_{\mathrm{C}-\mathrm{F}}=4.2 \mathrm{~Hz}, \mathrm{CH}_{2}\right), 34.1\left(\mathrm{CH}_{2}\right), 26.7\left(\mathrm{CH}_{2}\right), 26.2\left(\mathrm{CH}_{2}\right)$.

${ }^{19}$ F NMR $\left(282 \mathrm{MHz}, \mathrm{CDCl}_{3}\right) \delta-118.7--118.8(\mathrm{~m})$.

IR (ATR): 3381, 2922, 1501, 1227, 805, $625 \mathrm{~cm}^{-1}$.

MS (ESI) $m / z$ (relative intensity): $313(20)[\mathrm{M}+\mathrm{H}]^{+}, 335(100)[\mathrm{M}+\mathrm{Na}]^{+}$.

HR-MS (ESI) $m / z$ calcd for $\mathrm{C}_{19} \mathrm{H}_{22} \mathrm{FN}_{2} \mathrm{O}[\mathrm{M}+\mathrm{H}]^{+} 313.1708$ found 313.1707 .

The spectral data were in accordance with those reported in the literature. ${ }^{[286]}$ 


\section{3-Cyclohexyl- $N$-phenethylpicolinamide (415r)}<smiles>O=C(NCCc1ccccc1)c1ncccc1C1CCCCC1</smiles>

The General Procedure K was followed using $N$-phenethylpicolinamide 4110 (56.3 mg, 0.25 mmol), cyclohexylmagnesium bromide $\mathbf{4 1 4 j}(0.6 \mathrm{~mL}, 1.8 \mathrm{M}$ in THF, $1.00 \mathrm{mmol}), \mathbf{4 1 6}(30 \mathrm{mg}, 9.0 \mathrm{~mol} \%$ ), TMEDA (58.1 mg, $0.50 \mathrm{mmol})$, and 2,3-DCB (95.3 $\mathrm{mg}, 0.75 \mathrm{mmol})$. Purification by column chromatography ( $n$-hexane/EtOAc 8:1) yielded 415 r (66.3 mg, $86 \%)$ as a colorless oil.

${ }^{1}$ H NMR $\left(300 \mathrm{MHz}, \mathrm{CDCl}_{3}\right) \delta 8.22(\mathrm{dd}, J=4.5,1.5 \mathrm{~Hz}, 1 \mathrm{H}), 8.01$ (brs, $\left.1 \mathrm{H}\right), 7.67(\mathrm{dd}, J=8.1,1.5$ $\mathrm{Hz}, 1 \mathrm{H}), 7.25-7.10(\mathrm{~m}, 6 \mathrm{H}), 3.97(\mathrm{tt}, J=11.8,3.0 \mathrm{~Hz}, 1 \mathrm{H}), 3.69-3.53(\mathrm{~m}, 2 \mathrm{H}), 2.86(\mathrm{t}, J=7.2 \mathrm{~Hz}$, 2H), $1.79-1.67(\mathrm{~m}, 5 \mathrm{H}), 1.55-1.08(\mathrm{~m}, 5 \mathrm{H})$.

${ }^{13}$ C NMR $\left(75 \mathrm{MHz}, \mathrm{CDCl}_{3}\right) \delta 166.0\left(\mathrm{C}_{\mathrm{q}}\right), 146.9\left(\mathrm{C}_{\mathrm{q}}\right), 144.7(\mathrm{CH}), 144.4\left(\mathrm{C}_{\mathrm{q}}\right), 138.9\left(\mathrm{C}_{\mathrm{q}}\right), 135.7(\mathrm{CH})$, 128.6 (CH), $128.3(\mathrm{CH}), 126.1(\mathrm{CH}), 125.4(\mathrm{CH}), 40.6\left(\mathrm{CH}_{2}\right), 37.8(\mathrm{CH}), 35.9\left(\mathrm{CH}_{2}\right), 34.1\left(\mathrm{CH}_{2}\right), 26.7$ $\left(\mathrm{CH}_{2}\right), 26.2\left(\mathrm{CH}_{2}\right)$.

IR (ATR): 3385, 2923, 1665, 1000, 806, 697, $497 \mathrm{~cm}^{-1}$.

MS (ESI) $m / z$ (relative intensity): $309(100)[\mathrm{M}+\mathrm{H}]^{+}, 331(40)[\mathrm{M}+\mathrm{Na}]^{+}$.

HR-MS (ESI) $m / z$ calcd for $\mathrm{C}_{20} \mathrm{H}_{25} \mathrm{~N}_{2} \mathrm{O}[\mathrm{M}+\mathrm{H}]^{+} 309.1965$ found 309.1961 .

The spectral data were in accordance with those reported in the literature. ${ }^{[286]}$ 


\subsubsection{Synthesis of Hybrid Manganese Catalyst}

1) Linker modification

To a solution of DIPA (15 mmol, $1.1 \mathrm{mmol})$ in $40 \mathrm{~mL}$ of dried THF $(50 \mathrm{~mL})$ was added $n$-BuLi $(2.1$ $\mathrm{M}, 6.3 \mathrm{~mL}, 13.2 \mathrm{mmol}, 1.0$ equiv) dropwise at $0{ }^{\circ} \mathrm{C}$ under $\mathrm{N}_{2}$, in-situ generating LDA. After the reaction mixture was stirred for $1 \mathrm{~h}$, a solution of 4,4-dimethyl-2,2'-bipyridine (439) (13.2 mmol, 1.0 equiv) in dried THF (100 mL) was slowly added under $\mathrm{N}_{2}$, then color was changed to dark brown. After stirring the reaction mixture for $1 \mathrm{~h}$, a solution of (3-chloropropyl)trimethoxylsilane (440) (13.2 mmol, 1.0 equiv) in $10 \mathrm{~mL}$ of THF was slowly added at $0^{\circ} \mathrm{C}$ under $\mathrm{N}_{2}$. The solution was further stirred for an additional $2 \mathrm{~h}$. The reaction mixture was warmed to room temperature and stirred for $24 \mathrm{~h}$. After the reaction was quenched with two drops of acetone, the remaining solvent was removed and then dried in vacuo at room temperature for $24 \mathrm{~h}$, affording 441. The synthesized 441 are used for the next step without further purification (Scheme 5.8.1).<smiles>Cc1ccnc(-c2cc(C)ccn2)c1</smiles>

439<smiles>CO[Si](C)(CCCCl)OC</smiles>

440

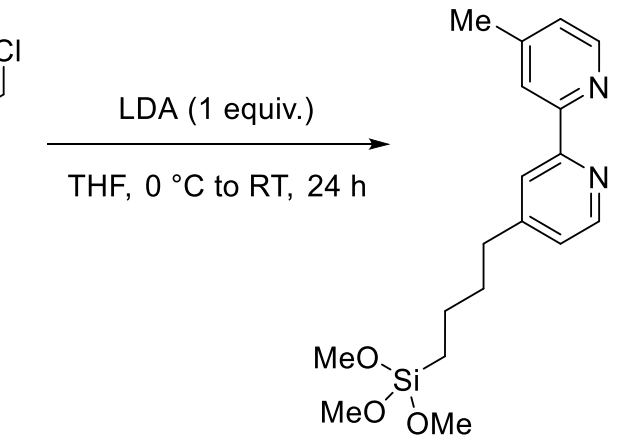

441

Scheme 5.8.1 Synthesis of 441 .

2) Grafting

A suspension of SBA-15 (5.0 g) and the synthesized 441 in dried toluene were refluxed under $\mathrm{N}_{2}$ for $24 \mathrm{~h}$. The powder was filtered off, washed with toluene, $n$-hexane, and DCM (each $50 \mathrm{~mL}$ ), and dried in vacuo at $100{ }^{\circ} \mathrm{C}$ for $24 \mathrm{~h}$, yielding 442 (Scheme 5.8.2). 


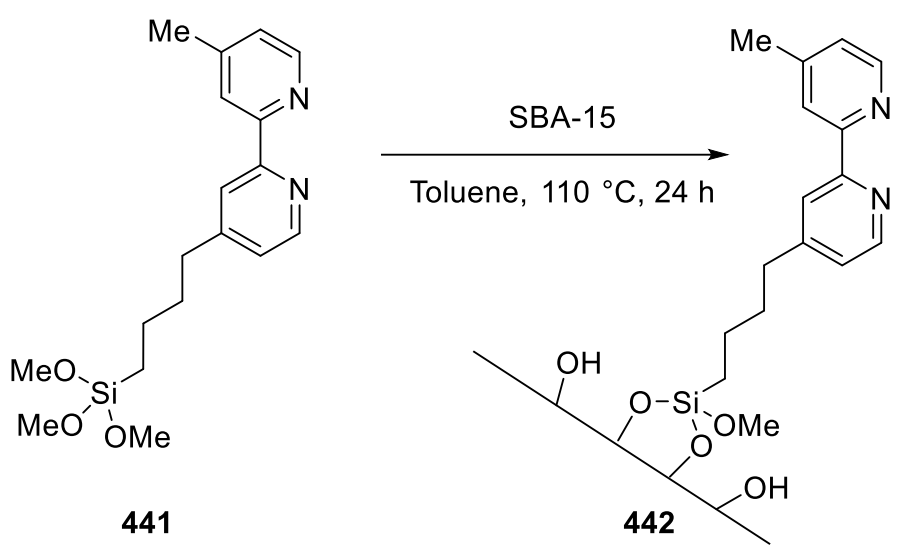

Scheme 5.8.2 Synthesis of $\mathbf{4 4 2}$.

\section{3) End-capping}

Hexamethyldisilazane $(20 \mathrm{~mL})$ and the isolated 442 in dried toluene $(50 \mathrm{~mL})$ was stirred at room temperature for $24 \mathrm{~h}$. The powder was filtered off, washed with toluene, $n$-hexane, and DCM (each 50 $\mathrm{mL}$ ), and dried in vacuo at $100{ }^{\circ} \mathrm{C}$ for $24 \mathrm{~h}$, providing 443 (Scheme 5.8.3).
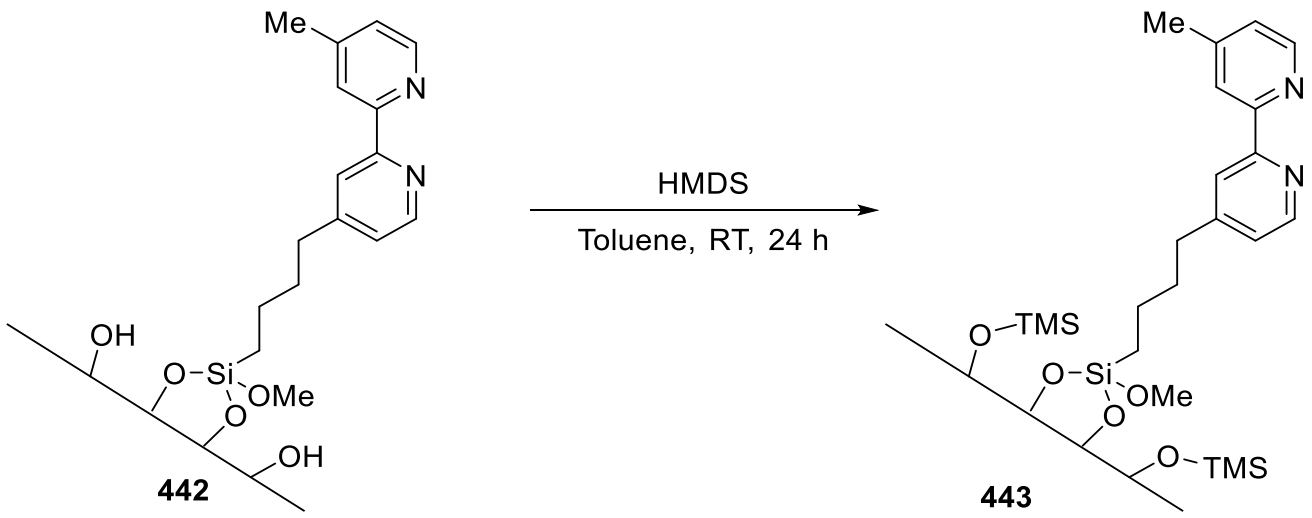

Scheme 5.8.3 Synthesis of 443 .

4) Metallation

A suspension of $\mathrm{MnCl}_{2} \cdot 4 \mathrm{H}_{2} \mathrm{O}(1.2 \mathrm{~g}, 6.0 \mathrm{mmol})$ and the isolated $443(1.9 \mathrm{~g})$ was stirred in EtOH (50 $\mathrm{mL})$ at $60{ }^{\circ} \mathrm{C}$ for $24 \mathrm{~h}$ under $\mathrm{N}_{2}$. The powder was filtered off, washed with excess EtOH $(3 \times 50 \mathrm{~mL})$, and dried in vacuo at $100{ }^{\circ} \mathrm{C}$ for $24 \mathrm{~h}$, affording 416 (Scheme 5.8.4). 


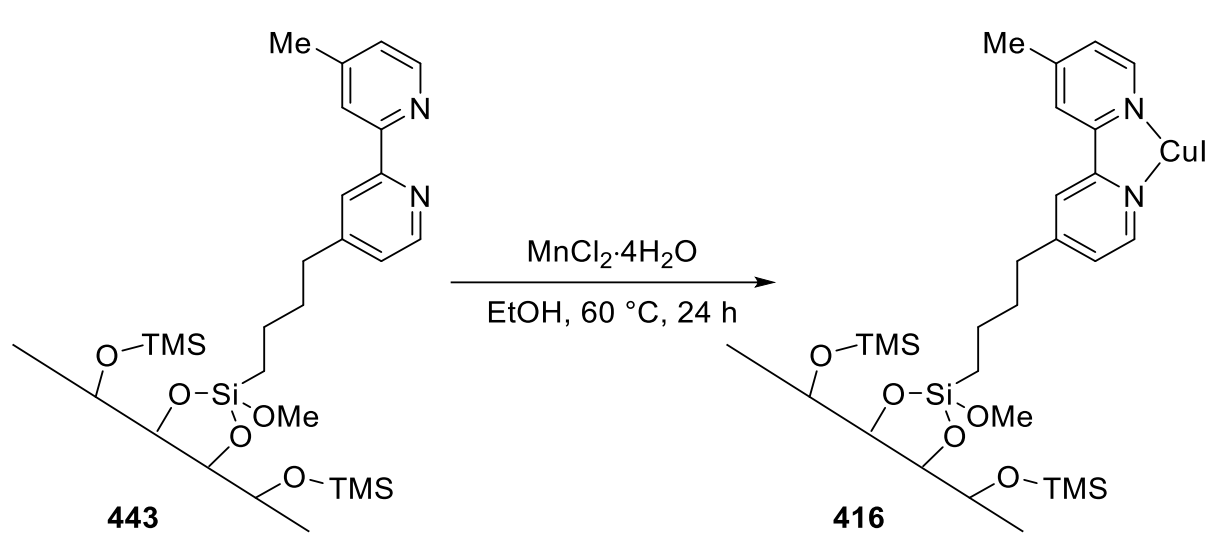

Scheme 5.8.4 Synthesis of 416 .

\subsubsection{Determination of Catalyst Loading}

ICP-OES analysis was performed by Dr. Volker Karius for the determination of hybrid manganese catalyst 416 loading (Equation 5.8.1).

Amount of Catalyst $\times$ ICP-OES result $\div$ Molcular weight of manganese $\div$ amount of substrates $\times 100 \mathrm{~mol} \%$

$=30 \mathrm{mg} \times \frac{40930 \mathrm{mg}}{1,000,000 \mathrm{mg}} \times \frac{1}{54.938 \mathrm{mg} / \mathrm{mmol}} \times \frac{1}{0.25 \mathrm{mmol}} \times 100 \mathrm{~mol} \%=\mathbf{9} \mathbf{m o l} \%$

Equation 5.8.1 Determination of hybrid manganese catalyst loading. 


\subsubsection{Heterogeneity Test}

1) Reuse test for hybrid-manganese-catalyzed $\mathrm{C}-\mathrm{H}$ arylations

The General Procedure J was followed using $N$-butylpicolinamide 411a (0.25 mmol, 1.0 equiv), (4methoxyphenyl)magnesium bromide $412 \mathrm{a}(1.00 \mathrm{mmol}, 4.0$ equiv, $1.0 \mathrm{~mL}, 1.0 \mathrm{M}$ in THF), 416 (9.0 mol \%), TMEDA ( $0.50 \mathrm{mmol}, 2.0$ equiv), and 2,3-DCB (0.75 mmol, 3.0 equiv). After $16 \mathrm{~h}$ the reaction tube was transferred to a glovebox. 416 was carefully filtered through branched filter (Por. 3) with $\mathrm{Et}_{2} \mathrm{O}(3 \times 10 \mathrm{~mL})$. Filtered 416 was dried in vacuo for $12 \mathrm{~h}$ and used for next run (Scheme 5.8.5).

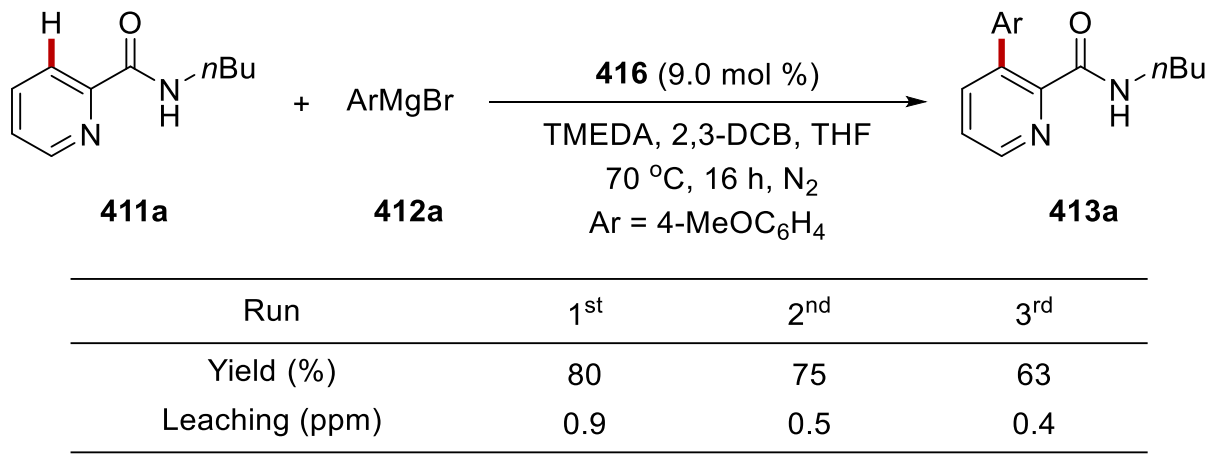

Scheme 5.8.5 Reuse test of hybrid manganese-catalyzed C-H arylation.

2) Reuse test for hybrid-manganese-catalyzed $\mathrm{C}-\mathrm{H}$ alkylations

The General Procedure K was followed using $N$-butylpicolinamide 411a (0.25 mmol, 1.0 equiv), cyclohexylmagnesium bromide 414j (1.00 mmol, 4.0 equiv, $1.0 \mathrm{~mL}, 1.0 \mathrm{M}$ in THF), $416(9.0 \mathrm{~mol} \%)$, TMEDA ( $0.50 \mathrm{mmol}, 2.0$ equiv), and 2,3-DCB ( $0.75 \mathrm{mmol}, 3.0$ equiv). Reuse procedure is same as described above (Scheme 5.8.6).

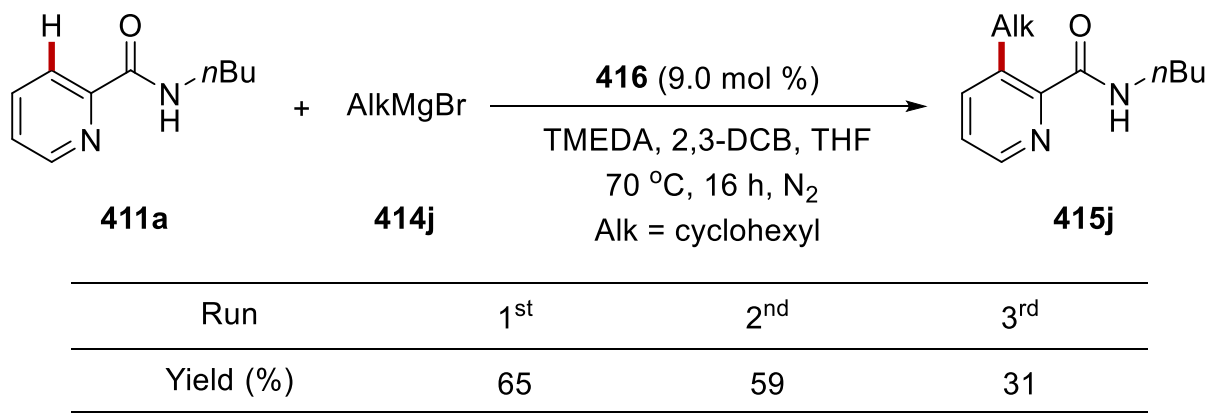

Scheme 5.8.6 Reuse test of hybrid manganese-catalyzed C-H alkylation. 
3) Mercury test

The General Procedure $\mathbf{J}$ was followed using $N$-butylpicolinamide 414a (0.25 mmol, 1.0 equiv), (4methoxyphenyl)magnesium bromide $412 \mathrm{a}(1.00 \mathrm{mmol}, 4.0$ equiv, $1.0 \mathrm{~mL}, 1.0 \mathrm{M}$ in THF), 416 (9.0 mol \%), TMEDA ( $0.50 \mathrm{mmol}, 2.0$ equiv), and 2,3-DCB ( $0.75 \mathrm{mmol}, 3.0$ equiv). After 2 hours, $\operatorname{Hg}(0)$ ( $0.12 \mathrm{~mL}, 400$ equiv to catalyst loading) was added to the Schlenk tube and then the reaction continued for $14 \mathrm{~h}$. Afterwards, a saturated aqueous $\mathrm{NH}_{4} \mathrm{Cl}(15 \mathrm{~mL})$ was added and the reaction mixture was extracted with EtOAc $(3 \times 15 \mathrm{~mL})$. The combined organic layers were dried over $\mathrm{Na}_{2} \mathrm{SO}_{4}$, filtered, and concentrated in vacuo. Purification by column chromatography on silica gel afforded the desired product 413a.

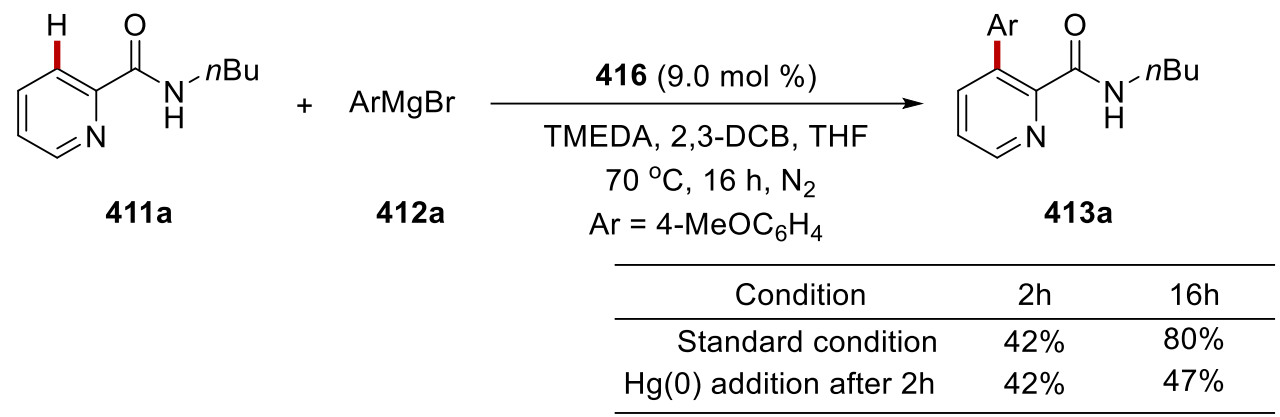

Scheme 5.8.7 Mercury test.

4) Hot-filtration test

The General Procedure $\mathbf{J}$ was followed using $N$-butylpicolinamide 414a (0.25 mmol, 1.0 equiv), (4methoxyphenyl)magnesium bromide $412 \mathrm{a}$ (1.00 mmol, 4.0 equiv, $1.0 \mathrm{~mL}, 1.0 \mathrm{M}$ in THF), 416 (9.0 mol \%), TMEDA ( 0.50 mmol, 2.0 equiv), and 2,3-DCB ( 0.75 mmol, 3.0 equiv). After 2 hours, Schlenk tube was transferred to a glovebox. 416 was carefully filtered over pre-heated Celite ${ }^{\circledR}$ with a branched filter (Por. 3). Filtrate was directly collected to another pre-dried Schlenk tube and then sealed with septum. The sealed Schlenk tube was directly transferred to pre-heated oil-bath and the reaction continued for $14 \mathrm{~h}$. Afterwards, saturated aqueous $\mathrm{NH}_{4} \mathrm{Cl}(15 \mathrm{~mL})$ was added and the reaction mixture was extracted with EtOAc $(3 \times 15 \mathrm{~mL})$. The combined organic layers were dried over $\mathrm{Na}_{2} \mathrm{SO}_{4}$, filtered, and concentrated in vacuo. Purification by column chromatography on silica gel afforded the desired product 413a (Scheme 5.8.8). 


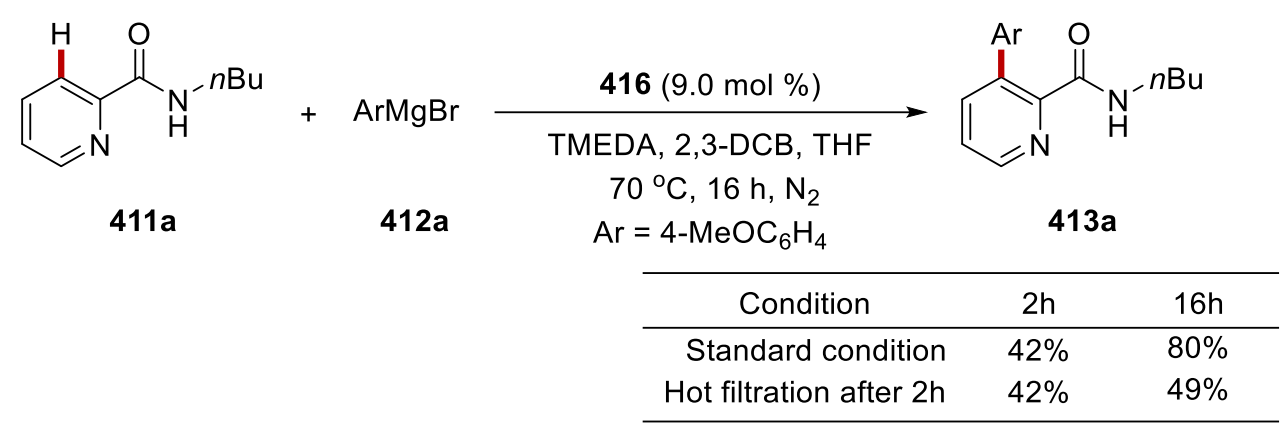

Scheme 5.8.8 Hot-filtration test. 


\section{References}

[1] a) P. Gandeepan, L. H. Finger, T. H. Meyer, L. Ackermann, Chem. Soc. Rev. 2020, 49, 42544272; b) T. H. Meyer, L. H. Finger, P. Gandeepan, L. Ackermann, Trends Chem. 2019, 1, 6376.

[2] B. Trost, Science 1991, 254, 1471-1477.

[3] a) P. T. Anastas, M. M. Kirchhoff, Acc. Chem. Res. 2002, 35, 686-694; b) P. T. Anastas, J. C. Warner, Oxford University Press, New York, 1998.

[4] U. Dhawa, N. Kaplaneris, L. Ackermann, Org. Chem. Front. 2021.

[5] C. C. C. Johansson Seechurn, M. O. Kitching, T. J. Colacot, V. Snieckus, Angew. Chem. Int. Ed. 2012, 51, 5062-5085.

[6] a) N. Miyaura, A. Suzuki, Chem. Rev. 1995, 95, 2457-2483; b) A. Suzuki, Acc. Chem. Res. 1982, 15, 178-184; c) N. Miyaura, A. Suzuki, J. Chem. Soc., Chem. Commun. 1979, 866-867; d) N. Miyaura, K. Yamada, A. Suzuki, Tetrahedron Lett. 1979, 20, 3437-3440.

[7] a) E.-i. Negishi, T. Takahashi, S. Baba, D. E. Van Horn, N. Okukado, J. Am. Chem. Soc. 1987, 109, 2393-2401; b) E.-i. Negishi, Acc. Chem. Res. 1982, 15, 340-348; c) A. O. King, N. Okukado, E.-i. Negishi, J. Chem. Soc., Chem. Commun. 1977, 683-684; d) E.-i. Negishi, A. O. King, N. Okukado, J. Org. Chem. 1977, 42, 1821-1823.

[8] a) H. A. Dieck, R. F. Heck, J. Org. Chem. 1975, 40, 1083-1090; b) H. A. Dieck, R. F. Heck, J. Am. Chem. Soc. 1974, 96, 1133-1136; c) R. F. Heck, J. P. Nolley, J. Org. Chem. 1972, 37, 23202322; d) T. Mizoroki, K. Mori, A. Ozaki, Bull. Chem. Soc. Jpn. 1971, 44, 581-581.

[9] a) R. J. P. Corriu, J. P. Masse, J. Chem. Soc., Chem. Commun. 1972, 144a-144a; b) K. Tamao, K. Sumitani, M. Kumada, J. Am. Chem. Soc. 1972, 94, 4374-4376.

[10] a) T. Hiyama, J. Organomet. Chem. 2002, 653, 58-61; b) Y. Hatanaka, T. Hiyama, J. Org. Chem. 1988, 53, 918-920.

[11] a) J. K. Stille, Angew. Chem. Int. Ed. 1986, 25, 508-524; b) D. Milstein, J. K. Stille, J. Am. Chem. Soc. 1979, 101, 4992-4998; c) D. Milstein, J. K. Stille, J. Am. Chem. Soc. 1978, 100, 3636-3638. 
[12] a) K. Sonogashira, J. Organomet. Chem. 2002, 653, 46-49; b) K. Sonogashira, Y. Tohda, N. Hagihara, Tetrahedron Lett. 1975, 16, 4467-4470.

[13] a) J. Tsuji, Tetrahedron 1986, 42, 4361-4401; b) B. M. Trost, Acc. Chem. Res. 1980, 13, $385-$ 393; c) B. M. Trost, T. J. Fullerton, J. Am. Chem. Soc. 1973, 95, 292-294; d) J. Tsuji, H. Takahashi, M. Morikawa, Tetrahedron Lett. 1965, 6, 4387-4388.

[14] a) I. Goldberg, Ber. Dtsch. Chem. Ges. 1906, 39, 1691-1692; b) F. Ullmann, Ber. Dtsch. Chem. Ges. 1903, 36, 2382-2384.

[15] a) A. S. Guram, S. L. Buchwald, J. Am. Chem. Soc. 1994, 116, 7901-7902; b) F. Paul, J. Patt, J. F. Hartwig, J. Am. Chem. Soc. 1994, 116, 5969-5970.

[17] T. Rogge, N. Kaplaneris, N. Chatani, J. Kim, S. Chang, B. Punji, L. L. Schafer, D. G. Musaev, J. Wencel-Delord, C. A. Roberts, R. Sarpong, Z. E. Wilson, M. A. Brimble, M. J. Johansson, L. Ackermann, Nature Reviews Methods Primers 2021, 1, 43.

[18] a) P. Gandeepan, T. Muller, D. Zell, G. Cera, S. Warratz, L. Ackermann, Chem. Rev. 2019, 119, 2192-2452; b) Z. Dong, Z. Ren, S. J. Thompson, Y. Xu, G. Dong, Chem. Rev. 2017, 117, 93339403; c) D.-S. Kim, W.-J. Park, C.-H. Jun, Chem. Rev. 2017, 117, 8977-9015; d) T. Gensch, M. N. Hopkinson, F. Glorius, J. Wencel-Delord, Chem. Soc. Rev. 2016, 45, 2900-2936; e) Q.-Z. Zheng, N. Jiao, Chem. Soc. Rev. 2016, 45, 4590-4627; f) O. Daugulis, J. Roane, L. D. Tran, Acc. Chem. Res. 2015, 48, 1053-1064; g) F. Kakiuchi, T. Kochi, S. Murai, Synlett 2014, 25, 2390-2414; h) G. Rouquet, N. Chatani, Angew. Chem. Int. Ed. 2013, 52, 11726-11743; i) L. Ackermann, R. Vicente, A. R. Kapdi, Angew. Chem. Int. Ed. 2009, 48, 9792-9826; j) R. Giri, B.-F. Shi, K. M. Engle, N. Maugel, J.-Q. Yu, Chem. Soc. Rev. 2009, 38, 3242-3272.

[19] a) A. M. Faisca Phillips, M. d. F. C. Guedes da Silva, A. J. L. Pombeiro, Catalysts 2020, 10, 529; b) A. K. Bagdi, M. Rahman, D. Bhattacherjee, G. V. Zyryanov, S. Ghosh, O. N. Chupakhin, A. Hajra, Green Chem. 2020, 22, 6632-6681; c) A. M. Faisca Phillips, A. J. L. Pombeiro, ChemCatChem 2018, 10, 3354-3383; d) S. A. Girard, T. Knauber, C.-J. Li, Angew. Chem. Int. Ed. 2014, 53, 74-100; e) W.-J. Yoo, C.-J. Li, in C-H Activation (Eds.: J.-Q. Yu, Z. Shi), Springer 
Berlin Heidelberg, Berlin, Heidelberg, 2010, pp. 281-302; f) C. J. Scheuermann, Chem. Asian J. 2010, 5, 436-451; g) C.-J. Li, Z. Li, Pure Appl. Chem. 2006, 78, 935-945.

[20] a) L. Ackermann, Chem. Rev. 2011, 111, 1315-1345; b) D. Balcells, E. Clot, O. Eisenstein, Chem. Rev. 2010, 110, 749-823.

[21] a) D. Lapointe, K. Fagnou, Chem. Lett. 2010, 39, 1118-1126; b) S. I. Gorelsky, D. Lapointe, K. Fagnou, J. Am. Chem. Soc. 2008, 130, 10848-10849.

[22] Y. Boutadla, D. L. Davies, S. A. Macgregor, A. I. Poblador-Bahamonde, Dalton Trans. 2009, $5820-5831$.

[23] T. Rogge, J. C. A. Oliveira, R. Kuniyil, L. Hu, L. Ackermann, ACS Catal. 2020, 10, 1055110558.

[24] D. Zell, M. Bursch, V. Müller, S. Grimme, L. Ackermann, Angew. Chem. Int. Ed. 2017, 56, 10378-10382.

[25] a) T. Piou, T. Rovis, Acc. Chem. Res. 2018, 51, 170-180; b) S.-S. Li, L. Qin, L. Dong, Org. Biomol. Chem. 2016, 14, 4554-4570; c) J. Wencel-Delord, F. W. Patureau, F. Glorius, in $C-H$ Bond Activation and Catalytic Functionalization I (Eds.: P. H. Dixneuf, H. Doucet), Springer International Publishing, Cham, 2016, pp. 1-27; d) B. Ye, N. Cramer, Acc. Chem. Res. 2015, 48, 1308-1318; e) D. A. Colby, A. S. Tsai, R. G. Bergman, J. A. Ellman, Acc. Chem. Res. 2012, 45, 814-825; f) G. Song, F. Wang, X. Li, Chem. Soc. Rev. 2012, 41, 3651-3678; g) J. Du Bois, Org. Process Res. Dev. 2011, 15, 758-762; h) D. A. Colby, R. G. Bergman, J. A. Ellman, Chem. Rev. 2010, 110, 624-655.

[26] a) P. Y. Choy, S. M. Wong, A. Kapdi, F. Y. Kwong, Org. Chem. Front. 2018, 5, 288-321; b) J. Le Bras, J. Muzart, Eur. J. Org. Chem. 2018, 2018, 1176-1203; c) O. Baudoin, Acc. Chem. Res. 2017, 50, 1114-1123; d) F. Kakiuchi, T. Kochi, Isr. J. Chem. 2017, 57, 953-963; e) N. Della Ca', M. Fontana, E. Motti, M. Catellani, Acc. Chem. Res. 2016, 49, 1389-1400; f) J. Ye, M. Lautens, Nat. Chem. 2015, 7, 863-870; g) C.-L. Sun, B.-J. Li, Z.-J. Shi, Chem. Commun. 2010, 46, 677-685; h) X. Chen, K. M. Engle, D.-H. Wang, J.-Q. Yu, Angew. Chem. Int. Ed. 2009, 48, 5094-5115; i) M. Catellani, E. Motti, N. Della Ca', Acc. Chem. Res. 2008, 41, 1512-1522. 
[27] a) C. Haldar, M. Emdadul Hoque, R. Bisht, B. Chattopadhyay, Tetrahedron Lett. 2018, 59, 1269-1277; b) J. Kim, S. Chang, Angew. Chem. Int. Ed. 2014, 53, 2203-2207; c) S. Pan, T. Shibata, ACS Catal. 2013, 3, 704-712.

[28] a) O. M. Ogba, N. C. Warner, D. J. O’Leary, R. H. Grubbs, Chem. Soc. Rev. 2018, 47, 45104544; b) B. M. Trost, F. D. Toste, A. B. Pinkerton, Chem. Rev. 2001, 101, 2067-2096.

[29] J. Chatt, J. M. Davidson, J. Chem. Soc. 1965, 843-855.

[30] L. N. Lewis, J. F. Smith, J. Am. Chem. Soc. 1986, 108, 2728-2735.

[31] S. Murai, F. Kakiuchi, S. Sekine, Y. Tanaka, A. Kamatani, M. Sonoda, N. Chatani, Nature 1993, $366,529-531$.

[32] T. Matsubara, N. Koga, D. G. Musaev, K. Morokuma, J. Am. Chem. Soc. 1998, 120, 1269212693.

[33] a) J. C. Gaunt, B. L. Shaw, J. Organomet. Chem. 1975, 102, 511-516; b) J. M. Duff, B. E. Mann, B. L. Shaw, B. Turtle, J. Chem. Soc., Dalton Trans. 1974, 139-145; c) J. M. Duff, B. L. Shaw, J. Chem. Soc., Dalton Trans. 1972, 2219-2225.

[34] D. L. Davies, O. Al-Duaij, J. Fawcett, M. Giardiello, S. T. Hilton, D. R. Russell, Dalton Trans. 2003, 4132-4138.

[35] a) L. Ackermann, Org. Process Res. Dev. 2015, 19, 260-269; b) J. Hubrich, T. Himmler, L. Rodefeld, L. Ackermann, ACS Catal. 2015, 5, 4089-4093; c) J. Li, L. Ackermann, Org. Chem. Front. 2015, 2, 1035-1039; d) M. Schinkel, I. Marek, L. Ackermann, Angew. Chem. Int. Ed. 2013, 52, 3977-3980; e) L. Ackermann, N. Hofmann, R. Vicente, Org. Lett. 2011, 13, 1875 1877.

[36] a) L. David, F. Keith, Chem. Lett. 2010, 39, 1118-1126; b) M. Lafrance, K. Fagnou, J. Am. Chem. Soc. 2006, 128, 16496-16497.

[37] A. Ricci, Amino group chemistry: from synthesis to the life sciences, John Wiley \& Sons, 2008.

[38] a) F. Ullmann, P. Sponagel, Ber. Dtsch. Chem. Ges. 1905, 38, 2211-2212; b) F. Ullmann, J. Bielecki, Ber. Dtsch. Chem. Ges. 1901, 34, 2174-2185.

[39] a) J. F. Hartwig, Acc. Chem. Res. 2008, 41, 1534-1544; b) J. F. Hartwig, Nature 2008, 455, 314-322; c) D. S. Surry, S. L. Buchwald, Angew. Chem. Int. Ed. 2008, 47, 6338-6361; d) J. F. 
Hartwig, Inorg. Chem. 2007, 46, 1936-1947; e) B. H. Yang, S. L. Buchwald, J. Organomet. Chem. 1999, 576, 125-146; f) J. F. Hartwig, Angew. Chem. Int. Ed. 1998, 37, 2046-2067; g) J. P. Wolfe, S. Wagaw, J.-F. Marcoux, S. L. Buchwald, Acc. Chem. Res. 1998, 31, 805-818.

[40] a) M. A. Ali, X. Yao, G. Li, H. Lu, Org. Lett. 2016, 18, 1386-1389; b) X.-H. Hu, X.-F. Yang, T.-P. Loh, ACS Catal. 2016, 6, 5930-5934; c) J. Wippich, N. Truchan, T. Bach, Adv. Synth. Catal. 2016, 358, 2083-2087; d) S. Yu, Y. Li, X. Zhou, H. Wang, L. Kong, X. Li, Org. Lett. 2016, 18, 2812-2815; e) C. Zhang, Y. Zhou, Z. Deng, X. Chen, Y. Peng, Eur. J. Org. Chem. 2015, 2015, 1735-1744; f) T. Ryu, J. Min, W. Choi, W. H. Jeon, P. H. Lee, Org. Lett. 2014, 16, 2810-2813; g) J. Shi, G. Zhao, X. Wang, H. E. Xu, W. Yi, Org. Biomol. Chem. 2014, 12, 68316836; h) N. Wang, R. Li, L. Li, S. Xu, H. Song, B. Wang, J. Org. Chem. 2014, 79, 5379-5385; i) R. J. Tang, C. P. Luo, L. Yang, C. J. Li, Adv. Synth. Catal. 2013, 355, 869-873; j) S. Yu, B. Wan, X. Li, Org. Lett. 2013, 15, 3706-3709; k) H. Zhao, Y. Shang, W. Su, Org. Lett. 2013, 15, 5106-5109; 1) B. Zhou, J. Du, Y. Yang, H. Feng, Y. Li, Org. Lett. 2013, 15, 6302-6305; m) B. Zhou, J. Du, Y. Yang, Y. Li, Org. Lett. 2013, 15, 2934-2937; n) B. Zhou, Y. Yang, J. Shi, H. Feng, Y. Li, Chem. Eur. J. 2013, 19, 10511-10515; o) T. Cochet, V. Bellosta, D. Roche, J.-Y. Ortholand, A. Greiner, J. Cossy, Chem. Commun. 2012, 48, 10745-10747; p) J. Y. Kim, S. H. Park, J. Ryu, S. H. Cho, S. H. Kim, S. Chang, J. Am. Chem. Soc. 2012, 134, 9110-9113; q) K.H. Ng, Z. Zhou, W.-Y. Yu, Org. Lett. 2012, 14, 272-275; r) K. P. Kornecki, J. F. Berry, Chem. Eur. J. 2011, 17, 5827-5832; s) M. Shen, B. E. Leslie, T. G. Driver, Angew. Chem. Int. Ed. 2008, 47, 5056-5059; t) R. P. Reddy, H. M. L. Davies, Org. Lett. 2006, 8, 5013-5016.

[41] a) K. Clagg, H. Hou, A. B. Weinstein, D. Russell, S. S. Stahl, S. G. Koenig, Org. Lett. 2016, 18, 3586-3589; b) S. Choi, T. Chatterjee, W. J. Choi, Y. You, E. J. Cho, ACS Catal. 2015, 5, 4796-4802; c) J. He, T. Shigenari, J.-Q. Yu, Angew. Chem. Int. Ed. 2015, 54, 6545-6549; d) W. A. Nack, G. Chen, Synlett 2015, 26, 2505-2511; e) M. Anand, R. B. Sunoj, H. F. Schaefer, J. Am. Chem. Soc. 2014, 136, 5535-5538; f) A. McNally, B. Haffemayer, B. S. L. Collins, M. J. Gaunt, Nature 2014, 510, 129-133; g) A. B. Weinstein, S. S. Stahl, Catal. Sci. Technol. 2014, 4, 4301-4307; h) R. Shrestha, P. Mukherjee, Y. Tan, Z. C. Litman, J. F. Hartwig, J. Am. Chem. Soc. 2013, 135, 8480-8483; i) G. He, Y. Zhao, S. Zhang, C. Lu, G. Chen, J. Am. Chem. Soc. 
2012, 134, 3-6; j) Á. Iglesias, R. Álvarez, Á. R. de Lera, K. Muñiz, Angew. Chem. Int. Ed. 2012, 51, 2225-2228; k) K. Sun, Y. Li, T. Xiong, J. Zhang, Q. Zhang, J. Am. Chem. Soc. 2011, 133, 1694-1697; 1) B. Xiao, T.-J. Gong, J. Xu, Z.-J. Liu, L. Liu, J. Am. Chem. Soc. 2011, 133, 14661474; m) Z. Ke, T. R. Cundari, Organometallics 2010, 29, 821-834; n) Y. Tan, J. F. Hartwig, J. Am. Chem. Soc. 2010, 132, 3676-3677; o) W. C. P. Tsang, R. H. Munday, G. Brasche, N. Zheng, S. L. Buchwald, J. Org. Chem. 2008, 73, 7603-7610; p) K. Inamoto, T. Saito, M. Katsuno, T. Sakamoto, K. Hiroya, Org. Lett. 2007, 9, 2931-2934; q) H.-Y. Thu, W.-Y. Yu, C.-M. Che, J. Am. Chem. Soc. 2006, 128, 9048-9049.

[42] a) X. Dong, P. Ma, T. Zhang, H. B. Jalani, G. Li, H. Lu, J. Org. Chem. 2020, 85, 13096-13107; b) T. Zhang, X. Dong, H. B. Jalani, J. Zou, G. Li, H. Lu, Org. Lett. 2019, 21, 3706-3710; c) C. Pan, Y. Wang, C. Wu, J.-T. Yu, Org. Biomol. Chem. 2018, 16, 3711-3715; d) M. Yu, T. Zhang, H. B. Jalani, X. Dong, H. Lu, G. Li, Org. Lett. 2018, 20, 4828-4832; e) T. Zhang, X. Hu, X. Dong, G. Li, H. Lu, Org. Lett. 2018, 20, 6260-6264; f) D. Mu, X. Wang, G. Chen, G. He, J. Org. Chem. 2017, 82, 4497-4503; g) Y. Kim, J. Park, S. Chang, Org. Lett. 2016, 18, 1892-1895; h) T. Zhang, X. Hu, Z. Wang, T. Yang, H. Sun, G. Li, H. Lu, Chem. Eur. J. 2016, 22, 29202924; i) H. Kim, S. Chang, ACS Catal. 2015, 5, 6665-6669; j) C. Suzuki, K. Hirano, T. Satoh, M. Miura, Org. Lett. 2015, 17, 1597-1600; k) T. Kang, Y. Kim, D. Lee, Z. Wang, S. Chang, J. Am. Chem. Soc. 2014, 136, 4141-4144; 1) H. Kim, K. Shin, S. Chang, J. Am. Chem. Soc. 2014, 136, 5904-5907.

[43] a) M. Ju, J. M. Schomaker, Nat. Rev. Chem. 2021, 5, 580-594; b) H. Hayashi, T. Uchida, Eur. J. Org. Chem. 2020, 2020, 909-916; c) T. Shimbayashi, K. Sasakura, A. Eguchi, K. Okamoto, K. Ohe, Chem. Eur. J. 2019, 25, 3156-3180; d) J. C. K. Chu, T. Rovis, Angew. Chem. Int. Ed. 2018, 57, 62-101; e) P. F. Kuijpers, J. I. van der Vlugt, S. Schneider, B. de Bruin, Chem. Eur. J. 2017, 23, 13819-13829; f) J. M. Alderson, J. R. Corbin, J. M. Schomaker, Acc. Chem. Res. 2017, 50, 2147-2158; g) A. I. O. Suarez, V. Lyaskovskyy, J. N. H. Reek, J. I. van der Vlugt, B. de Bruin, Angew. Chem. Int. Ed. 2013, 52, 12510-12529; h) D. N. Zalatan, J. D. Bois, in C-H Activation (Eds.: J.-Q. Yu, Z. Shi), Springer Berlin Heidelberg, Berlin, Heidelberg, 2010, pp. 347-378; i) H. M. L. Davies, J. R. Manning, Nature 2008, 451, 417-424. 
[44] a) S. J. Blanksby, G. B. Ellison, Acc. Chem. Res. 2003, 36, 255-263; b) Y.-R. Luo, Handbook of bond dissociation energies in organic compounds, CRC press, 2002.

[45] V. S. Thirunavukkarasu, K. Raghuvanshi, L. Ackermann, Org. Lett. 2013, 15, 3286-3289.

[46] X. Zhou, P. Luo, L. Long, M. Ouyang, X. Sang, Q. Ding, Tetrahedron 2014, 70, 6742-6748.

[47] X. Wang, C. Zhang, J. Li, C. Jiang, F. Su, Z. Zhan, L. Hai, Z. Chen, Y. Wu, RSC Adv. 2016, 6, 68929-68933.

[48] J. Kim, J. Kim, S. Chang, Chem. Eur. J. 2013, 19, 7328-7333.

[49] Q.-Z. Zheng, Y.-F. Liang, C. Qin, N. Jiao, Chem. Commun. 2013, 49, 5654-5656.

[50] Y. Shin, S. Han, U. De, J. Park, S. Sharma, N. K. Mishra, E.-K. Lee, Y. Lee, H. S. Kim, I. S. Kim, J. Org. Chem. 2014, 79, 9262-9271.

[51] C. Pan, A. Abdukader, J. Han, Y. Cheng, C. Zhu, Chem. Eur. J. 2014, 20, 3606-3609.

[52] M. R. Yadav, R. K. Rit, A. K. Sahoo, Org. Lett. 2013, 15, 1638-1641.

[53] M. van Eickels, S. Wassmann, A. Schäfer, J. Bauersachs, H. Strobel, H. Rütten, BMC Pharmacology 2007, 7, S4.

[54] K. Shin, J. Ryu, S. Chang, Org. Lett. 2014, 16, 2022-2025.

[55] M. Shang, S.-H. Zeng, S.-Z. Sun, H.-X. Dai, J.-Q. Yu, Org. Lett. 2013, 15, 5286-5289.

[56] K. Raghuvanshi, D. Zell, K. Rauch, L. Ackermann, ACS Catal. 2016, 6, 3172-3175.

[57] S.-M. Au, W.-H. Fung, M.-C. Cheng, C.-M. Che, S.-M. Peng, Chem. Commun. 1997, $1655-$ 1656.

[58] a) J. Wei, W. Xiao, C.-Y. Zhou, C.-M. Che, Chem. Commun. 2014, 50, 3373-3376; b) S. K.-Y. Leung, W.-M. Tsui, J.-S. Huang, C.-M. Che, J.-L. Liang, N. Zhu, J. Am. Chem. Soc. 2005, 127, 16629-16640; c) L. He, P. W. H. Chan, W.-M. Tsui, W.-Y. Yu, C.-M. Che, Org. Lett. 2004, 6, 2405-2408; d) S.-M. Au, J.-S. Huang, W.-Y. Yu, W.-H. Fung, C.-M. Che, J. Am. Chem. Soc. 1999, $121,9120-9132$.

[59] X.-Q. Yu, J.-S. Huang, X.-G. Zhou, C.-M. Che, Org. Lett. 2000, 2, 2233-2236.

[60] X.-G. Zhou, X.-Q. Yu, J.-S. Huang, C.-M. Che, Chem. Commun. 1999, 2377-2378.

[61] E. Milczek, N. Boudet, S. Blakey, Angew. Chem. Int. Ed. 2008, 47, 6825-6828. 
[62] S. Fantauzzi, E. Gallo, A. Caselli, F. Ragaini, N. Casati, P. Macchi, S. Cenini, Chem. Commun. 2009, 3952-3954.

[63] G. Manca, E. Gallo, D. Intrieri, C. Mealli, ACS Catal. 2014, 4, 823-832.

[64] M. E. Harvey, D. G. Musaev, J. Du Bois, J. Am. Chem. Soc. 2011, 133, 17207-17216.

[65] Y. Nishioka, T. Uchida, T. Katsuki, Angew. Chem. Int. Ed. 2013, 52, 1739-1742.

[66] Z. Zhou, S. Chen, J. Qin, X. Nie, X. Zheng, K. Harms, R. Riedel, K. N. Houk, E. Meggers, Angew. Chem. Int. Ed. 2019, 58, 1088-1093.

[67] Q. Xing, C.-M. Chan, Y.-W. Yeung, W.-Y. Yu, J. Am. Chem. Soc. 2019, 141, 3849-3853.

[68] T. W. Greulich, C. G. Daniliuc, A. Studer, Org. Lett. 2015, 17, 254-257.

[69] E. Ito, T. Fukushima, T. Kawakami, K. Murakami, K. Itami, Chem 2017, 2, 383-392.

[70] a) J.-i. Yoshida, A. Shimizu, R. Hayashi, Chem. Rev. 2018, 118, 4702-4730; b) J.-i. Yoshida, Y. Ashikari, K. Matsumoto, T. Nokami, J. Synth. Org. Chem Jpn. 2013, 71, 1136-1144; c) J.-i. Yoshida, S. Suga, Chem. Eur. J. 2002, 8, 2650-2658.

[71] T. Morofuji, G. Ikarashi, N. Kano, Org. Lett. 2020, 22, 2822-2827.

[72] a) A. Dey, S. K. Sinha, T. K. Achar, D. Maiti, Angew. Chem. Int. Ed. 2019, 58, 10820-10843;

b) M. T. Mihai, G. R. Genov, R. J. Phipps, Chem. Soc. Rev. 2018, 47, 149-171; c) J. A. Leitch, C. G. Frost, Chem. Soc. Rev. 2017, 46, 7145-7153; d) J. Li, S. De Sarkar, L. Ackermann, Top. Organomet. Chem. 2016, 55, 217-257; e) A. Dey, S. Agasti, D. Maiti, Org. Biomol. Chem. 2016, 14, 5440-5453; f) C. G. Frost, A. J. Paterson, ACS Cent. Sci. 2015, 1, 418-419.

[73] a) P. Wang, P. Verma, G. Xia, J. Shi, J. X. Qiao, S. Tao, P. T. W. Cheng, M. A. Poss, M. E. Farmer, K.-S. Yeung, J.-Q. Yu, Nature 2017, 551, 489-493; b) C. Cheng, J. F. Hartwig, Science 2014, 343, 853-857; c) R. J. Phipps, M. J. Gaunt, Science 2009, 323, 1593-1597; d) J.-Y. Cho, M. K. Tse, D. Holmes, R. E. Maleczka, M. R. Smith, Science 2002, 295, 305-308.

[74] a) S. Porey, X. Zhang, S. Bhowmick, V. Kumar Singh, S. Guin, R. S. Paton, D. Maiti, J. Am. Chem. Soc. 2020, 142, 3762-3774; b) R. Bisht, M. E. Hoque, B. Chattopadhyay, Angew. Chem. Int. Ed. 2018, 57, 15762-15766; c) R. Jayarajan, J. Das, S. Bag, R. Chowdhury, D. Maiti, Angew. Chem. Int. Ed. 2018, 57, 7659-7663; d) S. Bag, R. Jayarajan, U. Dutta, R. Chowdhury, R. Mondal, D. Maiti, Angew. Chem. Int. Ed. 2017, 56, 12538-12542; e) G. Cheng, P. Wang, J.-Q. 
Yu, Angew. Chem. Int. Ed. 2017, 56, 8183-8186; f) H. J. Davis, G. R. Genov, R. J. Phipps, Angew. Chem. Int. Ed. 2017, 56, 13351-13355; g) H. J. Davis, R. J. Phipps, Chem. Sci. 2017, 8, 864-877; h) M. E. Hoque, R. Bisht, C. Haldar, B. Chattopadhyay, J. Am. Chem. Soc. 2017, 139, 7745-7748; i) A. J. Neel, M. J. Hilton, M. S. Sigman, F. D. Toste, Nature 2017, 543, 637646; j) Z. Zhang, K. Tanaka, J.-Q. Yu, Nature 2017, 543, 538-542; k) H. J. Davis, M. T. Mihai, R. J. Phipps, J. Am. Chem. Soc. 2016, 138, 12759-12762; 1) S. Li, L. Cai, H. Ji, L. Yang, G. Li, Nat. Commun. 2016, 7, 10443; m) A. Maji, B. Bhaskararao, S. Singha, R. B. Sunoj, D. Maiti, Chem. Sci. 2016, 7, 3147-3153; n) Y. Kuninobu, H. Ida, M. Nishi, M. Kanai, Nat. Chem. 2015, 7, 712-717; o) D. Leow, G. Li, T.-S. Mei, J.-Q. Yu, Nature 2012, 486, 518-522; p) R. Breslow, Acc. Chem. Res. 1980, 13, 170-177.

[75] a) M. E. Farmer, P. Wang, H. Shi, J.-Q. Yu, ACS Catal. 2018, 8, 7362-7367; b) R. Li, G. Dong, Angew. Chem. Int. Ed. 2018, 57, 1697-1701; c) H. Shi, A. N. Herron, Y. Shao, Q. Shao, J.-Q. Yu, Nature 2018, 558, 581-585; d) K.-Y. Yoon, G. Dong, Angew. Chem. Int. Ed. 2018, 57, 8592-8596; e) Z. Dong, J. Wang, G. Dong, J. Am. Chem. Soc. 2015, 137, 5887-5890; f) P.-X. Shen, X.-C. Wang, P. Wang, R.-Y. Zhu, J.-Q. Yu, J. Am. Chem. Soc. 2015, 137, 11574-11577; g) X.-C. Wang, W. Gong, L.-Z. Fang, R.-Y. Zhu, S. Li, K. M. Engle, J.-Q. Yu, Nature 2015, 519, 334-338.

[76] a) K. Korvorapun, R. C. Samanta, T. Rogge, L. Ackermann, Synthesis 2021; b) K. Korvorapun, R. C. Samanta, T. Rogge, L. Ackermann, in Remote C-H Bond Functionalizations, 2021, pp. $137-167$.

[77] G. R. Clark, C. E. L. Headford, W. R. Roper, L. J. Wright, V. P. D. Yap, Inorganica Chim. Acta 1994, 220, 261-272.

[78] J.-P. Sutter, D. M. Grove, M. Beley, J.-P. Collin, N. Veldman, A. L. Spek, J.-P. Sauvage, G. van Koten, Angew. Chem. Int. Ed. 1994, 33, 1282-1285.

[79] C. Coudret, S. Fraysse, Chem. Commun. 1998, 663-664.

[80] a) A. M. Clark, C. E. F. Rickard, W. R. Roper, L. J. Wright, J. Organomet. Chem. 2000, 598, 262-275; b) A. M. Clark, C. E. F. Rickard, W. R. Roper, L. J. Wright, Organometallics 1999, $18,2813-2820$. 
[81] X. Guo, C.-J. Li, Org. Lett. 2011, 13, 4977-4979.

[82] N. Hofmann, L. Ackermann, J. Am. Chem. Soc. 2013, 135, 5877-5884.

[83] J. Li, S. Warratz, D. Zell, S. De Sarkar, E. E. Ishikawa, L. Ackermann, J. Am. Chem. Soc. 2015, 137, 13894-13901.

[84] A. J. Paterson, S. St John-Campbell, M. F. Mahon, N. J. Press, C. G. Frost, Chem. Commun. 2015, 51, 12807-12810.

[85] J. Li, K. Korvorapun, S. De Sarkar, T. Rogge, D. J. Burns, S. Warratz, L. Ackermann, Nat. Commun. 2017, 8, 15430.

[86] G. Li, X. Ma, C. Jia, Q. Han, Y. Wang, J. Wang, L. Yu, S. Yang, Chem. Commun. 2017, 53, 1261-1264.

[87] G. Li, P. Gao, X. Lv, C. Qu, Q. Yan, Y. Wang, S. Yang, J. Wang, Org. Lett. 2017, 19, 2682-2685.

[88] Z. Ruan, S.-K. Zhang, C. Zhu, P. N. Ruth, D. Stalke, L. Ackermann, Angew. Chem. Int. Ed. 2017, 56, 2045-2049.

[89] Z.-Y. Li, L. Li, Q.-L. Li, K. Jing, H. Xu, G.-W. Wang, Chem. Eur. J. 2017, 23, 3285-3290.

[90] K. Korvorapun, N. Kaplaneris, T. Rogge, S. Warratz, A. C. Stückl, L. Ackermann, ACS Catal. 2018, $8,886-892$.

[91] X.-G. Wang, Y. Li, H.-C. Liu, B.-S. Zhang, X.-Y. Gou, Q. Wang, J.-W. Ma, Y.-M. Liang, J. Am. Chem. Soc. 2019, 141, 13914-13922.

[92] F. Fumagalli, S. Warratz, S.-K. Zhang, T. Rogge, C. Zhu, A. C. Stückl, L. Ackermann, Chem. Eur. J. 2018, 24, 3984-3988.

[93] K. Jing, Z.-Y. Li, G.-W. Wang, ACS Catal. 2018, 8, 11875-11881.

[94] P. Gandeepan, J. Koeller, K. Korvorapun, J. Mohr, L. Ackermann, Angew. Chem. Int. Ed. 2019, $58,9820-9825$.

[95] A. Sagadevan, M. F. Greaney, Angew. Chem. Int. Ed. 2019, 58, 9826-9830.

[96] a) G. Li, X. Lv, K. Guo, Y. Wang, S. Yang, L. Yu, Y. Yu, J. Wang, Org. Chem. Front. 2017, 4, 1145-1148; b) G. Li, B. Zhu, X. Ma, C. Jia, X. Lv, J. Wang, F. Zhao, Y. Lv, S. Yang, Org. Lett. 2017, 19, 5166-5169; c) P. Marcé, A. J. Paterson, M. F. Mahon, C. G. Frost, Catal. Sci. Technol. 
2016, 6, 7068-7076; d) O. Saidi, J. Marafie, A. E. W. Ledger, P. M. Liu, M. F. Mahon, G. Kociok-Köhn, M. K. Whittlesey, C. G. Frost, J. Am. Chem. Soc. 2011, 133, 19298-19301.

[97] a) Z. Fan, H. Lu, Z. Cheng, A. Zhang, Chem. Commun. 2018, 54, 6008-6011; b) G. M. Reddy, N. S. Rao, H. Maheswaran, Org. Chem. Front. 2018, 5, 1118-1123; c) C. J. Teskey, A. Y. Lui, M. F. Greaney, Angew. Chem. Int. Ed. 2015, 54, 11677-11680; d) Q. Yu, L. a. Hu, Y. Wang, S. Zheng, J. Huang, Angew. Chem. Int. Ed. 2015, 54, 15284-15288.

[98] a) Z. Fan, H. Lu, A. Zhang, J. Org. Chem. 2018, 83, 3245-3251; b) Z. Fan, J. Li, H. Lu, D.-Y. Wang, C. Wang, M. Uchiyama, A. Zhang, Org. Lett. 2017, 19, 3199-3202; c) S. Warratz, D. J. Burns, C. Zhu, K. Korvorapun, T. Rogge, J. Scholz, C. Jooss, D. Gelman, L. Ackermann, Angew. Chem. Int. Ed. 2017, 56, 1557-1560; d) Z. Fan, J. Ni, A. Zhang, J. Am. Chem. Soc. 2016, $138,8470-8475$.

[99] J. A. Leitch, C. L. McMullin, A. J. Paterson, M. F. Mahon, Y. Bhonoah, C. G. Frost, Angew. Chem. Int. Ed. 2017, 56, 15131-15135.

[100] a) C. Yuan, L. Zhu, C. Chen, X. Chen, Y. Yang, Y. Lan, Y. Zhao, Nat. Commun. 2018, 9, 1189;

b) C. Yuan, L. Zhu, R. Zeng, Y. Lan, Y. Zhao, Angew. Chem. Int. Ed. 2018, 57, 1277-1281.

[102] a) G. B. Shul'pin, M. M. Vinogradov, L. S. Shul'pina, Catal. Sci. Technol. 2018, 8, 4287-4313; b) G. Chelucci, S. Baldino, W. Baratta, Acc. Chem. Res. 2015, 48, 363-379; c) S. D. R. Christie, A. D. Warrington, Synthesis 2008, 2008, 1325-1341; d) J. Gonzalez, W. D. Harman, in Category 1, Organometallics, Vol. Volume 1, Georg Thieme Verlag, Stuttgart, 2001; e) R. A. Sánchez-Delgado, M. Rosales, M. A. Esteruelas, L. A. Oro, J. Mol. Catal. A Chem. 1995, 96, 231-243; f) P. A. Shapley, in Encyclopedia of Inorganic and Bioinorganic Chemistry.

[103] a) M. L. Buil, M. A. Esteruelas, J. Herrero, S. Izquierdo, I. M. Pastor, M. Yus, ACS Catal. 2013, 3, 2072-2075; b) Y. Zhu, H. Yan, L. Lu, D. Liu, G. Rong, J. Mao, J. Org. Chem. 2013, 78, 9898 9905; c) Masruri, A. C. Willis, M. D. McLeod, J. Org. Chem. 2012, 77, 8480-8491; d) G. R. Morello, T. R. Cundari, T. B. Gunnoe, J. Organomet. Chem. 2012, 697, 15-22; e) W. Baratta, G. Bossi, E. Putignano, P. Rigo, Chem. Eur. J. 2011, 17, 3474-3481; f) M. Bertoli, A. Choualeb, A. J. Lough, B. Moore, D. Spasyuk, D. G. Gusev, Organometallics 2011, 30, 3479-3482; g) S. 
R. Hart, D. C. Whitehead, B. R. Travis, B. Borhan, Org. Biomol. Chem. 2011, 9, 4741-4744; h)

T. J. Donohoe, K. M. P. Wheelhouse, P. J. Lindsay-Scott, G. H. Churchill, M. J. Connolly, S. Butterworth, P. A. Glossop, Chem. Asian J. 2009, 4, 1237-1247; i) W. Baratta, M. Ballico, A. Del Zotto, K. Siega, S. Magnolia, P. Rigo, Chem. Eur. J. 2008, 14, 2557-2563; j) W. A. Braunecker, Y. Itami, K. Matyjaszewski, Macromolecules 2005, 38, 9402-9404; k) G. SüssFink, S. Haak, V. Ferrand, H. Stoeckli-Evans, J. Mol. Catal. A Chem. 1999, 143, 163-170.

[104] a) R. Criegee, B. Marchand, H. Wannowius, Justus Liebigs Ann. Chem. 1942, 550, 99-133; b) R. Criegee, Justus Liebigs Ann. Chem. 1936, 522, 75-96.

[105] T. Katsuki, K. B. Sharpless, J. Am. Chem. Soc. 1980, 102, 5974-5976.

[106] a. M. I. Bruce, B. L. Goodall, F. Gordon, A. Stone, J. Organomet. Chem. 1973, 60, 343-349.

[107] a) R. Cerón-Camacho, M. A. Roque-Ramires, A. D. Ryabov, R. Le Lagadec, Molecules 2021, 26, 1563; b) P. W. Wanandi, T. D. Tilley, Organometallics 1997, 16, 4299-4313; c) M. Beley, S. Chodorowski, J.-P. Collin, J.-P. Sauvage, L. Flamigni, F. Barigelletti, Inorg. Chem. 1994, 33, 2543-2547; d) J. M. Kisenyi, G. J. Sunley, J. A. Cabeza, A. J. Smith, H. Adams, N. J. Salt, P. M. Maitlis, J. Chem. Soc., Dalton Trans. 1987, 2459-2466.

[108] a) T. Iida, S. Ogawa, K. Hosoi, M. Makino, Y. Fujimoto, T. Goto, N. Mano, J. Goto, A. F. Hofmann, J. Org. Chem. 2007, 72, 823-830; b) S. Ogawa, K. Hosoi, T. Iida, Y. Wakatsuki, M. Makino, Y. Fujimoto, A. F. Hofmann, Eur. J. Org. Chem. 2007, 2007, 3555-3563.

[109] S. Ogawa, Y. Wakatsuki, M. Makino, Y. Fujimoto, K. Yasukawa, T. Kikuchi, M. Ukiya, T. Akihisa, T. Iida, Chem. Phys. Lipids 2010, 163, 165-171.

[110] G. Wang, Z. Zhou, X. Shen, S. Ivlev, E. Meggers, Chem. Commun. 2020, 56, 7714-7717.

[111] B. D. Ravetz, N. E. S. Tay, C. L. Joe, M. Sezen-Edmonds, M. A. Schmidt, Y. Tan, J. M. Janey, M. D. Eastgate, T. Rovis, ACS Cent. Sci. 2020, 6, 2053-2059.

[112] J. Yang, L. Wu, H. Xu, H. Gao, Z. Zhou, W. Yi, Org. Lett. 2019, 21, 9904-9908.

[113] a) Y. Nishii, M. Miura, ACS Catal. 2020, 10, 9747-9757; b) L. Ackermann, Acc. Chem. Res. 2014, 47, 281-295.

[114] a) A. Sigel, H. Sigel, R. K. O. Sigel, Interrelations between essential metal ions and human diseases, Vol. 13, Springer, 2013; b) P. B. Tchounwou, C. G. Yedjou, A. K. Patlolla, D. J. Sutton, 
in Molecular, Clinical and Environmental Toxicology: Volume 3: Environmental Toxicology (Ed.: A. Luch), Springer Basel, Basel, 2012, pp. 133-164; c) S. H. Gilani, Y. Alibhai, Journal of Toxicology and Environmental Health 1990, 30, 23-31.

[115] F. A. Cotton, G. Wilkinson, C. A. Murillo, M. Bochmann, R. Grimes, Advanced inorganic chemistry, Vol. 6, Wiley New York, 1988.

[116] a) E. M. McGarrigle, D. G. Gilheany, Chem. Rev. 2005, 105, 1563-1602; b) T. Katsuki, Synlett 2003, 2003, 0281-0297; c) R. Irie, K. Noda, Y. Ito, N. Matsumoto, T. Katsuki, Tetrahedron Lett. 1990, 31, 7345-7348; d) W. Zhang, J. L. Loebach, S. R. Wilson, E. N. Jacobsen, J. Am. Chem. Soc. 1990, 112, 2801-2803.

[117] a) X. Huang, T. Zhuang, P. A. Kates, H. Gao, X. Chen, J. T. Groves, J. Am. Chem. Soc. 2017, 139, 15407-15413; b) M. Milan, M. Bietti, M. Costas, ACS Cent. Sci. 2017, 3, 196-204; c) X. Huang, T. M. Bergsten, J. T. Groves, J. Am. Chem. Soc. 2015, 137, 5300-5303; d) S. M. Paradine, J. R. Griffin, J. Zhao, A. L. Petronico, S. M. Miller, M. Christina White, Nat. Chem. 2015, 7, 987-994; e) X. Huang, W. Liu, H. Ren, R. Neelamegam, J. M. Hooker, J. T. Groves, J. Am. Chem. Soc. 2014, 136, 6842-6845; f) D. Shen, C. Miao, S. Wang, C. Xia, W. Sun, Org. Lett. 2014, 16, 1108-1111; g) W. Liu, J. T. Groves, Angew. Chem. Int. Ed. 2013, 52, 6024-6027; h) W. Liu, X. Huang, M.-J. Cheng, R. J. Nielsen, W. A. Goddard, J. T. Groves, Science 2012, 337, 1322-1325; i) W. Liu, J. T. Groves, J. Am. Chem. Soc. 2010, 132, 12847-12849.

[118] a) G. Cahiez, O. Gager, F. Lecomte, Org. Lett. 2008, 10, 5255-5256; b) G. Cahiez, A. Moyeux, J. Buendia, C. Duplais, J. Am. Chem. Soc. 2007, 129, 13788-13789; c) M. Rueping, W. Ieawsuwan, Synlett 2007, 2007, 0247-0250.

[119] M. I. Bruce, M. Z. Iqbal, F. G. A. Stone, J. Chem. Soc. A 1970, 3204-3209.

[120] a) G. J. Depree, L. Main, B. K. Nicholson, N. P. Robinson, G. B. Jameson, J. Organomet. Chem. 2006, 691, 667-679; b) G. J. Depree, L. Main, B. K. Nicholson, J. Organomet. Chem. 1998, 551, 281-291; c) C. Morton, D. J. Duncalf, J. P. Rourke, J. Organomet. Chem. 1997, 530, 1925; d) W. Tully, L. Main, B. K. Nicholson, J. Organomet. Chem. 1995, 503, 75-92; e) R. C. Cambie, L. C. Mui Mui, P. S. Rutledge, P. D. Woodgate, J. Organomet. Chem. 1994, 464, 171 182; f) R. C. Cambie, M. R. Metzler, P. S. Rutledge, P. D. Woodgate, J. Organomet. Chem. 
1992, 429, 41-57; g) R. C. Cambie, M. R. Metzler, P. S. Rutledge, P. D. Woodgate, J. Organomet. Chem. 1990, 381, C26-C30; h) R. C. Cambie, M. R. Metzler, P. S. Rutledge, P. D. Woodgate, J. Organomet. Chem. 1990, 398, C22-C24; i) J. M. Cooney, L. H. P. Gommans, L. Main, B. K. Nicholson, J. Organomet. Chem. 1988, 349, 197-207; j) J. M. Ressner, P. C. Wernett, C. S. Kraihanzel, A. L. Rheingold, Organometallics 1988, 7, 1661-1663; k) N. P. Robinson, L. Main, B. K. Nicholson, J. Organomet. Chem. 1988, 349, 209-218; 1) L. H. P. Gommans, L. Main, B. K. Nicholson, J. Chem. Soc., Chem. Commun. 1987, 761-762; m) A. Suárez, J. Manuel Vila, M. Teresa Pereira, E. Gayoso, M. Gayoso, J. Organomet. Chem. 1987, 335, 359-363; n) M. I. Bruce, B. L. Goodall, M. Z. Iqbal, F. G. A. Stone, R. J. Doedens, R. G. Little, Journal of the Chemical Society D: Chemical Communications 1971, 1595-1596.

[121] Y. Kuninobu, Y. Nishina, T. Takeuchi, K. Takai, Angew. Chem. Int. Ed. 2007, 46, 6518-6520.

[122] B. Zhou, H. Chen, C. Wang, J. Am. Chem. Soc. 2013, 135, 1264-1267.

[123] a) L. A. Hammarback, I. P. Clark, I. V. Sazanovich, M. Towrie, A. Robinson, F. Clarke, S. Meyer, I. J. S. Fairlamb, J. M. Lynam, Nat. Catal. 2018, 1, 830-840; b) N. P. Yahaya, K. M. Appleby, M. Teh, C. Wagner, E. Troschke, J. T. W. Bray, S. B. Duckett, L. A. Hammarback, J. S. Ward, J. Milani, N. E. Pridmore, A. C. Whitwood, J. M. Lynam, I. J. S. Fairlamb, Angew. Chem. Int. Ed. 2016, 55, 12455-12459.

[124] C. Zhu, R. Kuniyil, L. Ackermann, Angew. Chem. Int. Ed. 2019, 58, 5338-5342.

[125] R. He, Z.-T. Huang, Q.-Y. Zheng, C. Wang, Angew. Chem. Int. Ed. 2014, 53, 4950-4953.

[126] a) B. Liu, Y. Yuan, P. Hu, G. Zheng, D. Bai, J. Chang, X. Li, Chem. Commun. 2019, 55, 1076410767; b) G. Zheng, J. Sun, Y. Xu, S. Zhai, X. Li, Angew. Chem. Int. Ed. 2019, 58, 5090-5094.

[127] Q. Lu, S. Greßies, F. J. R. Klauck, F. Glorius, Angew. Chem. Int. Ed. 2017, 56, 6660-6664.

[128] Z. Ruan, N. Sauermann, E. Manoni, L. Ackermann, Angew. Chem. Int. Ed. 2017, 56, $3172-$ 3176.

[129] B. Zhou, P. Ma, H. Chen, C. Wang, Chem. Commun. 2014, 50, 14558-14561.

[130] S. L. Liu, Y. Li, J. R. Guo, G. C. Yang, X. H. Li, J. F. Gong, M. P. Song, Org. Lett. 2017, 19, $4042-4045$.

[131] Q. Lu, S. Mondal, S. Cembellín, F. Glorius, Angew. Chem. Int. Ed. 2018, 57, 10732-10736. 
[132] W. Liu, S. C. Richter, Y. Zhang, L. Ackermann, Angew. Chem. Int. Ed. 2016, 55, 7747-7750.

[133] H. Wang, M. M. Lorion, L. Ackermann, Angew. Chem. Int. Ed. 2017, 56, 6339-6342.

[134] T. H. Meyer, W. Liu, M. Feldt, A. Wuttke, R. A. Mata, L. Ackermann, Chem. Eur. J. 2017, 23, 5443-5447.

[135] Q. Lu, F. J. R. Klauck, F. Glorius, Chem. Sci. 2017, 8, 3379-3383.

[136] S.-Y. Chen, Q. Li, H. Wang, J. Org. Chem. 2017, 82, 11173-11181.

[137] J. Ni, H. Zhao, A. Zhang, Org. Lett. 2017, 19, 3159-3162.

[138] Y.-F. Liang, V. Müller, W. Liu, A. Münch, D. Stalke, L. Ackermann, Angew. Chem. Int. Ed. 2017, 56, 9415-9419.

[139] W. Liu, D. Zell, M. John, L. Ackermann, Angew. Chem. Int. Ed. 2015, 54, 4092-4096.

[140] C. Zhu, J. L. Schwarz, S. Cembellín, S. Greßies, F. Glorius, Angew. Chem. Int. Ed. 2018, 57, $437-441$.

[141] a) S.-Y. Chen, X.-L. Han, J.-Q. Wu, Q. Li, Y. Chen, H. Wang, Angew. Chem. Int. Ed. 2017, 56, 9939-9943; b) S.-Y. Chen, Q. Li, X.-G. Liu, J.-Q. Wu, S.-S. Zhang, H. Wang, ChemSusChem 2017, 10, 2360-2364.

[142] C. Wang, A. Wang, M. Rueping, Angew. Chem. Int. Ed. 2017, 56, 9935-9938.

[143] C. Lei, L. Peng, K. Ding, Adv. Synth. Catal. 2018, 360, 2952-2958.

[144] J. R. Hummel, J. A. Boerth, J. A. Ellman, Chem. Rev. 2017, 117, 9163-9227.

[145] W. Liu, J. Bang, Y. Zhang, L. Ackermann, Angew. Chem. Int. Ed. 2015, 54, 14137-14140.

[146] B. Zhou, Y. Hu, C. Wang, Angew. Chem. Int. Ed. 2015, 54, 13659-13663.

[147] a) Y.-F. Liang, L. Massignan, L. Ackermann, ChemCatChem 2018, 10, 2768-2772; b) Y.-F. Liang, L. Massignan, W. Liu, L. Ackermann, Chem. Eur. J. 2016, 22, 14856-14859.

[148] a) C. Zhu, T. Pinkert, S. Greßies, F. Glorius, ACS Catal. 2018, 8, 10036-10042; b) B. Zhou, Y. Hu, T. Liu, C. Wang, Nat. Commun. 2017, 8, 1169.

[149] C. Zhu, J. C. A. Oliveira, Z. Shen, H. Huang, L. Ackermann, ACS Catal. 2018, 8, 4402-4407.

[150] C. Zhu, M. Stangier, J. C. A. Oliveira, L. Massignan, L. Ackermann, Chem. Eur. J. 2019, 25, 16382-16389. 
[151] Y.-F. Liang, R. Steinbock, L. Yang, L. Ackermann, Angew. Chem. Int. Ed. 2018, 57, 1062510629.

[152] a) W.-H. Rao, B.-F. Shi, Org. Chem. Front. 2016, 3, 1028-1047; b) X.-X. Guo, D.-W. Gu, Z. Wu, W. Zhang, Chem. Rev. 2015, 115, 1622-1651; c) J.-P. Wan, Y. Jing, Beilstein Journal of Organic Chemistry 2015, 11, 2209-2222; d) C. Sambiagio, S. P. Marsden, A. J. Blacker, P. C. McGowan, Chem. Soc. Rev. 2014, 43, 3525-3550; e) S. E. Allen, R. R. Walvoord, R. PadillaSalinas, M. C. Kozlowski, Chem. Rev. 2013, 113, 6234-6458; f) I. P. Beletskaya, A. V. Cheprakov, Coord. Chem. Rev. 2004, 248, 2337-2364.

[153] C. Glaser, Ber. Dtsch. Chem. Ges. 1869, 2, 422-424.

[154] a) J. Hassan, M. Sévignon, C. Gozzi, E. Schulz, M. Lemaire, Chem. Rev. 2002, 102, 1359-1470; b) P. E. Fanta, Chem. Rev. 1964, 64, 613-632.

[155] a) B. Maciá, in Progress in Enantioselective Cu(I)-catalyzed Formation of Stereogenic Centers (Ed.: S. R. Harutyunyan), Springer International Publishing, Cham, 2016, pp. 41-98; b) M. T. Pirnot, Y.-M. Wang, S. L. Buchwald, Angew. Chem. Int. Ed. 2016, 55, 48-57; c) X. Zhu, S. Chiba, Chem. Soc. Rev. 2016, 45, 4504-4523; d) S. D. McCann, S. S. Stahl, Acc. Chem. Res. 2015, 48, 1756-1766; e) B. L. Ryland, S. S. Stahl, Angew. Chem. Int. Ed. 2014, 53, 8824-8838; f) N. Yoshikai, E. Nakamura, Chem. Rev. 2012, 112, 2339-2372; g) C. Zhang, C. Tang, N. Jiao, Chem. Soc. Rev. 2012, 41, 3464-3484; h) T. Jerphagnon, M. G. Pizzuti, A. J. Minnaard, B. L. Feringa, Chem. Soc. Rev. 2009, 38, 1039-1075; i) A. Alexakis, J. E. Bäckvall, N. Krause, O. Pàmies, M. Diéguez, Chem. Rev. 2008, 108, 2796-2823; j) G. Evano, N. Blanchard, M. Toumi, Chem. Rev. 2008, 108, 3054-3131; k) S. Reymond, J. Cossy, Chem. Rev. 2008, 108, 5359-5406; 1) N. Armaroli, G. Accorsi, F. Cardinali, A. Listorti, in Photochemistry and Photophysics of Coordination Compounds I (Eds.: V. Balzani, S. Campagna), Springer Berlin Heidelberg, Berlin, Heidelberg, 2007, pp. 69-115; m) S. V. Ley, A. W. Thomas, Angew. Chem. Int. Ed. 2003, 42, 5400-5449.

[156] C. Björklund, M. Nilsson, T. Olson, T. Norin, Acta Chem. Scand. 1968, 22.

[157] H. Ljusberg, R. Wahren, Acta Chem. Scand 1973, 27, 2712-2721. 
[158] a) P.-A. Sommai, S. Tetsuya, K. Yoshiki, M. Masahiro, N. Masakatsu, Bull. Chem. Soc. Jpn. 1998, 71, 467-473; b) P.-A. Sommai, F. Yuka, M. Masahiro, N. Masakatsu, Bull. Chem. Soc. Jpn. 1996, 69, 2039-2042.

[159] J. Lindley, Tetrahedron 1984, 40, 1433-1456.

[160] H.-Q. Do, O. Daugulis, J. Am. Chem. Soc. 2007, 129, 12404-12405.

[161] H.-Q. Do, O. Daugulis, J. Am. Chem. Soc. 2008, 130, 1128-1129.

[162] H.-Q. Do, R. M. K. Khan, O. Daugulis, J. Am. Chem. Soc. 2008, 130, 15185-15192.

[163] L. Ackermann, H. K. Potukuchi, D. Landsberg, R. Vicente, Org. Lett. 2008, 10, 3081-3084.

[164] a) N.-N. Jia, X.-C. Tian, X.-X. Qu, X.-X. Chen, Y.-N. Cao, Y.-X. Yao, F. Gao, X.-L. Zhou, Scientific Reports 2017, 7, 43758; b) D. Kim, K. Yoo, S. E. Kim, H. J. Cho, J. Lee, Y. Kim, M. Kim, J. Org. Chem. 2015, 80, 3670-3676; c) R. Kadu, H. Roy, V. K. Singh, Appl. Organomet. Chem. 2015, 29, 746-755; d) T. Kawano, T. Yoshizumi, K. Hirano, T. Satoh, M. Miura, Org. Lett. 2009, 11, 3072-3075.

[165] C. Yang, H. M. Lee, S. P. Nolan, Org. Lett. 2001, 3, 1511-1514.

[166] D. Zhao, W. Wang, F. Yang, J. Lan, L. Yang, G. Gao, J. You, Angew. Chem. Int. Ed. 2009, 48, 3296-3300.

[167] C. Cheng, Y.-C. Shih, H.-T. Chen, T.-C. Chien, Tetrahedron 2013, 69, 1387-1396.

[168] a) S. Li, J. Tang, Y. Zhao, R. Jiang, T. Wang, G. Gao, J. You, Chem. Commun. 2017, 53, 34893492; b) D. P. Khambhati, K. A. N. Sachinthani, A. L. Rheingold, T. L. Nelson, Chem. Commun. 2017, 53, 5107-5109; c) Y. Cheng, G. Li, Y. Liu, Y. Shi, G. Gao, D. Wu, J. Lan, J. You, J. Am. Chem. Soc. 2016, 138, 4730-4738; d) J. Wu, Q. You, J. Lan, Q. Guo, X. Li, Y. Xue, J. You, Org. Biomol. Chem. 2015, 13, 5372-5375; e) Y.-T. Song, P.-H. Lin, C.-Y. Liu, Adv. Synth. Catal. 2014, 356, 3761-3768.

[169] a) F. Yang, J. Koeller, L. Ackermann, Angew. Chem. Int. Ed. 2016, 55, 4759-4762; b) P. Gandeepan, J. Mo, L. Ackermann, Chem. Commun. 2017, 53, 5906-5909.

[170] R. Jeyachandran, H. K. Potukuchi, L. Ackermann, Beilstein Journal of Organic Chemistry 2012, $8,1771-1777$.

[171] R. J. Phipps, N. P. Grimster, M. J. Gaunt, J. Am. Chem. Soc. 2008, 130, 8172-8174. 
[172] A. K. Pitts, F. O'Hara, R. H. Snell, M. J. Gaunt, Angew. Chem. Int. Ed. 2015, 54, 5451-5455.

[173] H. A. Duong, R. E. Gilligan, M. L. Cooke, R. J. Phipps, M. J. Gaunt, Angew. Chem. Int. Ed. 2011, 50, 463-466.

[174] B. Chen, X.-L. Hou, Y.-X. Li, Y.-D. Wu, J. Am. Chem. Soc. 2011, 133, 7668-7671.

[175] C.-L. Ciana, R. J. Phipps, J. R. Brandt, F.-M. Meyer, M. J. Gaunt, Angew. Chem. Int. Ed. 2011, $50,458-462$.

[176] I. Ban, T. Sudo, T. Taniguchi, K. Itami, Org. Lett. 2008, 10, 3607-3609.

[177] a) B. Musio, F. Mariani, E. P. Śliwiński, M. A. Kabeshov, H. Odajima, S. V. Ley, Synthesis 2016, 48, 3515-3526; b) Y. Shen, J. Chen, M. Liu, J. Ding, W. Gao, X. Huang, H. Wu, Chem. Commun. 2014, 50, 4292-4295; c) F. Yang, Z. Xu, Z. Wang, Z. Yu, R. Wang, Chem. Eur. J. 2011, 17, 6321-6325.

[178] M. Shang, S.-Z. Sun, H.-X. Dai, J.-Q. Yu, Org. Lett. 2014, 16, 5666-5669.

[179] a) Q. Zhang, Y. Liu, T. Wang, X. Zhang, C. Long, Y.-D. Wu, M.-X. Wang, J. Am. Chem. Soc. 2018, 140, 5579-5587; b) Y. Liu, C. Long, L. Zhao, M.-X. Wang, Org. Lett. 2016, 18, 50785081.

[180] W. I. Dzik, P. P. Lange, L. J. Gooßen, Chem. Sci. 2012, 3, 2671-2678.

[181] L. Chen, L. Ju, K. A. Bustin, J. M. Hoover, Chem. Commun. 2015, 51, 15059-15062.

[182] T. Patra, S. Nandi, S. K. Sahoo, D. Maiti, Chem. Commun. 2016, 52, 1432-1435.

[183] S. Zhao, Y.-J. Liu, S.-Y. Yan, F.-J. Chen, Z.-Z. Zhang, B.-F. Shi, Org. Lett. 2015, 17, 33383341.

[184] K. Takamatsu, K. Hirano, M. Miura, Angew. Chem. Int. Ed. 2017, 56, 5353-5357.

[185] J. A. Ashenhurst, Chem. Soc. Rev. 2010, 39, 540-548.

[186] a) S. Paul, R. Shrestha, T. N. J. I. Edison, Y. R. Lee, S. H. Kim, Adv. Synth. Catal. 2016, 358, 3050-3056; b) S. Lei, H. Cao, L. Chen, J. Liu, H. Cai, J. Tan, Adv. Synth. Catal. 2015, 357, 3109-3114; c) M. Zhu, K.-i. Fujita, R. Yamaguchi, Chem. Commun. 2011, 47, 12876-12878; d) Y. Li, J. Jin, W. Qian, W. Bao, Org. Biomol. Chem. 2010, 8, 326-330; e) D. Monguchi, A. Yamamura, T. Fujiwara, T. Somete, A. Mori, Tetrahedron Lett. 2010, 51, 850-852; f) H.-Q. Do, O. Daugulis, J. Am. Chem. Soc. 2009, 131, 17052-17053. 
[187] a) R. P. Pandit, J.-J. Shim, S. H. Kim, Y. R. Lee, $R S C A d v$. 2017, 7, 55288-55295; b) L.-H. Zou, J. Mottweiler, D. L. Priebbenow, J. Wang, J. A. Stubenrauch, C. Bolm, Chem. Eur. J. 2013, 19, 3302-3305; c) S. Fan, Z. Chen, X. Zhang, Org. Lett. 2012, 14, 4950-4953; d) X. Qin, B. Feng, J. Dong, X. Li, Y. Xue, J. Lan, J. You, J. Org. Chem. 2012, 77, 7677-7683; e) M. S. Reddy, Y. K. Kumar, N. Thirupathi, Org. Lett. 2012, 14, 824-827; f) H.-Q. Do, O. Daugulis, J. Am. Chem. Soc. 2011, 133, 13577-13586.

[188] a) K. N. Tripathi, D. Ray, R. P. Singh, Eur. J. Org. Chem. 2017, 2017, 5809-5813; b) D. Ray, T. Manikandan, A. Roy, K. N. Tripathi, R. P. Singh, Chem. Commun. 2015, 51, 7065-7068.

[189] a) A. K. Jha, N. Jain, Eur. J. Org. Chem. 2017, 2017, 4765-4772; b) J. Le, Y. Gao, Y. Ding, C. Jiang, Tetrahedron Lett. 2016, 57, 1728-1731; c) R. Odani, K. Hirano, T. Satoh, M. Miura, Angew. Chem. Int. Ed. 2014, 53, 10784-10788; d) M. Nishino, K. Hirano, T. Satoh, M. Miura, Angew. Chem. Int. Ed. 2012, 51, 6993-6997; e) M. Kitahara, N. Umeda, K. Hirano, T. Satoh, M. Miura, J. Am. Chem. Soc. 2011, 133, 2160-2162; f) X. Chen, G. Dobereiner, X.-S. Hao, R. Giri, N. Maugel, J.-Q. Yu, Tetrahedron 2009, 65, 3085-3089; g) X. Chen, X.-S. Hao, C. E. Goodhue, J.-Q. Yu, J. Am. Chem. Soc. 2006, 128, 6790-6791.

[190] a) A. Mandal, J. Selvakumar, S. Dana, U. Mukherjee, M. Baidya, Chem. Eur. J. 2018, 24, 34483454; b) B. K. Singh, R. Jana, J. Org. Chem. 2016, 81, 831-841; c) M. Wang, Y. Hu, Z. Jiang, H. C. Shen, X. Sun, Org. Biomol. Chem. 2016, 14, 4239-4246; d) R. Odani, K. Hirano, T. Satoh, M. Miura, J. Org. Chem. 2015, 80, 2384-2391; e) S. Zhao, J. Yuan, Y.-C. Li, B.-F. Shi, Chem. Commun. 2015, 51, 12823-12826; f) M. Nishino, K. Hirano, T. Satoh, M. Miura, Angew. Chem. Int. Ed. 2013, 52, 4457-4461; g) R. Odani, K. Hirano, T. Satoh, M. Miura, J. Org. Chem. 2013, $78,11045-11052$.

[191] S. Hübner, J. G. de Vries, V. Farina, Adv. Synth. Catal. 2016, 358, 3-25.

[192] a) M. Safaei, M. M. Foroughi, N. Ebrahimpoor, S. Jahani, A. Omidi, M. Khatami, Trends Anal. Chem. 2019, 118, 401-425; b) M. Liu, J. Wu, H. Hou, Chem. Eur. J. 2019, 25, 2935-2948; c) N. J. O’Connor, A. S. M. Jonayat, M. J. Janik, T. P. Senftle, Nat. Catal. 2018, 1, 531-539; d) L. Liu, A. Corma, Chem. Rev. 2018, 118, 4981-5079; e) N. Yang, S. F. Bent, J. Catal. 2017, 351, 49-58; f) D. Pla, M. Gomez, ACS Catal. 2016, 6, 3537-3552; g) E. Lam, J. H. Luong, ACS 
Catal. 2014, 4, 3393-3410; h) U. Díaz, D. Brunel, A. Corma, Chem. Soc. Rev. 2013, 42, $4083-$ 4097; i) N. Kann, Molecules 2010, 15, 6306-6331; j) J. Lu, P. H. Toy, Chem. Rev. 2009, 109, 815-838; k) M. R. Buchmeiser, Chem. Rev. 2009, 109, 303-321; 1) N. Madhavan, C. W. Jones, M. Weck, Acc. Chem. Res. 2008, 41, 1153-1165; m) F. Rodriguez-Reinoso, Carbon 1998, 36, $159-175$.

[193] a) J.-i. Yoshida, K. Itami, Chem. Rev. 2002, 102, 3693-3716; b) A. P. Wight, M. E. Davis, Chem. Rev. 2002, 102, 3589-3614; c) I. F. J. Vankelecom, Chem. Rev. 2002, 102, 3779-3810; d) R. van Heerbeek, P. C. J. Kamer, P. W. N. M. van Leeuwen, J. N. H. Reek, Chem. Rev. 2002, 102, 3717-3756; e) C. E. Song, S.-g. Lee, Chem. Rev. 2002, 102, 3495-3524; f) A. Roucoux, J. Schulz, H. Patin, Chem. Rev. 2002, 102, 3757-3778; g) D. Rechavi, M. Lemaire, Chem. Rev. 2002, 102, 3467-3494; h) T. Okuhara, Chem. Rev. 2002, 102, 3641-3666; i) C. A. McNamara, M. J. Dixon, M. Bradley, Chem. Rev. 2002, 102, 3275-3300; j) Z.-1. Lu, E. Lindner, H. A. Mayer, Chem. Rev. 2002, 102, 3543-3578; k) N. E. Leadbeater, M. Marco, Chem. Rev. 2002, 102, 3217-3274; 1) A. K. Kakkar, Chem. Rev. 2002, 102, 3579-3588; m) Q.-H. Fan, Y.-M. Li, A. S. C. Chan, Chem. Rev. 2002, 102, 3385-3466; n) J. Dupont, R. F. de Souza, P. A. Z. Suarez, Chem. Rev. 2002, 102, 3667-3692; o) R. Duchateau, Chem. Rev. 2002, 102, 3525-3542; p) T. J. Dickerson, N. N. Reed, K. D. Janda, Chem. Rev. 2002, 102, 3325-3344; q) D. E. De Vos, M. Dams, B. F. Sels, P. A. Jacobs, Chem. Rev. 2002, 102, 3615-3640; r) D. E. Bergbreiter, Chem. Rev. 2002, 102, 3345-3384; s) A. G. M. Barrett, B. T. Hopkins, J. Köbberling, Chem. Rev. 2002, $102,3301-3324$.

[194] I. Fechete, Y. Wang, J. C. Védrine, Catal. Today 2012, 189, 2-27.

[195] H. Davy, Phil. Trans. Roy. Soc. 1817, 107, 45-76.

[196] J. W. Döbereiner, Annls. Chim. Phys. 1823, 24, 91.

[197] M. W. M. Hisham, S. W. Benson, J. Phys. Chem. 1995, 99, 6194-6198.

[198] F. Haber, G. Van Oordt, Zeitschrift für anorganische Chemie 1905, 43, 111-115.

[199] S. Santoro, S. I. Kozhushkov, L. Ackermann, L. Vaccaro, Green Chem. 2016, 18, 3471-3493.

[200] N. Nakamura, Y. Tajima, K. Sakai, Hetrocycles 1982, 17, 235-245.

[201] M. Parisien, D. Valette, K. Fagnou, J. Org. Chem. 2005, 70, 7578-7584. 
[202] H. Miura, K. Wada, S. Hosokawa, M. Inoue, Chem. Eur. J. 2010, 16, 4186-4189.

[203] H. Miura, K. Wada, S. Hosokawa, M. Inoue, ChemCatChem 2010, 2, 1223-1225.

[204] a) R. Ye, J. Zhao, B. B. Wickemeyer, F. D. Toste, G. A. Somorjai, Nat. Catal. 2018, 1, 318-325; b) J. M. Notestein, A. Katz, Chem. Eur. J. 2006, 12, 3954-3965.

[205] H. M. L. Davies, A. M. Walji, Org. Lett. 2005, 7, 2941-2944.

[206] K. M. Chepiga, Y. Feng, N. A. Brunelli, C. W. Jones, H. M. L. Davies, Org. Lett. 2013, 15, 6136-6139.

[207] N. R. Candeias, C. A. M. Afonso, P. M. P. Gois, Org. Biomol. Chem. 2012, 10, 3357-3378.

[208] C.-J. Yoo, D. Rackl, W. Liu, C. B. Hoyt, B. Pimentel, R. P. Lively, H. M. L. Davies, C. W. Jones, Angew. Chem. Int. Ed. 2018, 57, 10923-10927.

[209] L.-C. Lee, J. He, J.-Q. Yu, C. W. Jones, ACS Catal. 2016, 6, 5245-5250.

[210] a) P. Gandeepan, L. Ackermann, Chem 2018, 4, 199-222; b) L. Ackermann, R. Vicente, Top. Curr. Chem. 2010, 292, 211-229; c) L. Ackermann, Synlett 2007, 507-526.

[211] I. Choi, A. M. Messinis, L. Ackermann, Angew. Chem. Int. Ed. 2020, 59, 12534-12540.

[212] I. Choi, V. Müller, L. Ackermann, Tetrahedron Lett. 2021, 72, 153064.

[213] I. Choi, V. Müller, G. Lole, R. Köhler, V. Karius, W. Viöl, C. Jooss, L. Ackermann, Chem. Eur. J. 2020, 26, 3509-3514.

[214] I. Choi, V. Müller, Y. Wang, K. Xue, R. Kuniyil, L. B. Andreas, V. Karius, J. G. Alauzun, L. Ackermann, Chem. Eur. J. 2020, 26, 15290-15297.

[215] a) Y. Park, S. Chang, Nat. Catal. 2019, 2, 219-227; b) D. A. Petrone, J. Ye, M. Lautens, Chem. Rev. 2016, 116, 8003-8104; c) P. B. Arockiam, C. Bruneau, P. H. Dixneuf, Chem. Rev. 2012, 112, 5879-5918; d) T. Satoh, M. Miura, Chem. Eur. J. 2010, 16, 11212-11222.

[216] P. Gandeepan, T. Müller, D. Zell, G. Cera, S. Warratz, L. Ackermann, Chem. Rev. 2019, 119, 2192-2452.

[217] J. Alvarez-Builla, J. J. Vaquero, J. Barluenga, Modern heterocyclic chemistry, 4 volume set, Vol. 2, John Wiley \& Sons, 2011.

[218] a) A. Srivastava, S. Pandeya, Int. J. Curr. Pharm. Rev. Res 2011, 4, 5-8; b) A. J. KochanowskaKaramyan, M. T. Hamann, Chem. Rev. 2010, 110, 4489-4497; c) F. R. de Sa Alves, E. J. 
Barreiro, C. A. Manssour Fraga, Mini-Rev. Med. Chem. 2009, 9, 782-793; d) G. W. Gribble, J. Chem. Soc., Perkin Trans. 1 2000, 1045-1075.

[219] J. A. Leitch, Y. Bhonoah, C. G. Frost, ACS Catal. 2017, 7, 5618-5627.

[220] T. A. Shah, P. B. De, S. Pradhan, T. Punniyamurthy, Chem. Commun. 2019, 55, 572-587.

[221] S. Santoro, F. Ferlin, L. Ackermann, L. Vaccaro, Chem. Soc. Rev. 2019, 48, 2767-2782.

[222] J. Kalepu, P. Gandeepan, L. Ackermann, L. T. Pilarski, Chem. Sci. 2018, 9, 4203-4216.

[223] a) W.-L. Wang, Z.-Y. Lu, H.-W. Tao, T.-J. Zhu, Y.-C. Fang, Q.-Q. Gu, W.-M. Zhu, J. Nat. Prod. 2007, 70, 1558-1564; b) J. G. Ondeyka, G. L. Helms, O. D. Hensens, M. A. Goetz, D. L. Zink, A. Tsipouras, W. L. Shoop, L. Slayton, A. W. Dombrowski, J. D. Polishook, D. A. Ostlind, N. N. Tsou, R. G. Ball, S. B. Singh, J. Am. Chem. Soc. 1997, 119, 8809-8816; c) R. J. Capon, J. K. Macleod, P. J. Scammells, Tetrahedron 1986, 42, 6545-6550; d) H. W. Dudley, C. Moir, Br. Med. J. 1935, 1, 520-523.

[224] a) V. Lanke, K. R. Prabhu, Chem. Commun. 2017, 53, 5117-5120; b) V. Lanke, K. Ramaiah Prabhu, Org. Lett. 2013, 15, 6262-6265.

[225] a) A. J. Borah, Z. Shi, Chem. Commun. 2017, 53, 3945-3948; b) Y. Yang, P. Gao, Y. Zhao, Z. Shi, Angew. Chem. Int. Ed. 2017, 56, 3966-3971; c) Y. Yang, R. Li, Y. Zhao, D. Zhao, Z. Shi, J. Am. Chem. Soc. 2016, 138, 8734-8737.

[226] G. Yang, P. Lindovska, D. Zhu, J. Kim, P. Wang, R.-Y. Tang, M. Movassaghi, J.-Q. Yu, J. Am. Chem. Soc. 2014, 136, 10807-10813.

[227] Y. Feng, D. Holte, J. Zoller, S. Umemiya, L. R. Simke, P. S. Baran, J. Am. Chem. Soc. 2015, $137,10160-10163$.

[228] a) H. Chen, C. Lin, C. Xiong, Z. Liu, Y. Zhang, Org. Chem. Front. 2017, 4, 455-459; b) J. A. Leitch, C. L. McMullin, M. F. Mahon, Y. Bhonoah, C. G. Frost, ACS Catal. 2017, 7, 26162623; c) L. Legnani, G. Prina Cerai, B. Morandi, ACS Catal. 2016, 6, 8162-8165; d) H. Liu, C. Zheng, S.-L. You, J. Org. Chem. 2014, 79, 1047-1054.

[229] a) G. Mihara, K. Ghosh, Y. Nishii, M. Miura, Org. Lett. 2020, 22, 5706-5711; b) K. Ueura, T. Satoh, M. Miura, Org. Lett. 2007, 9, 1407-1409. 
[230] a) S. Warratz, C. Kornhaaß, A. Cajaraville, B. Niepötter, D. Stalke, L. Ackermann, Angew. Chem. Int. Ed. 2015, 54, 5513-5517; b) M. Deponti, S. I. Kozhushkov, D. S. Yufit, L. Ackermann, Org. Biomol. Chem. 2013, 11, 142-148; c) L. Ackermann, J. Pospech, K. Graczyk, K. Rauch, Org. Lett. 2012, 14, 930-933.

[231] D. A. Frasco, C. P. Lilly, P. D. Boyle, E. A. Ison, ACS Catal. 2013, 3, 2421-2429.

[232] a) P. Sihag, M. Jeganmohan, J. Org. Chem. 2019, 84, 2699-2712; b) Q. Lu, S. Mondal, S. Cembellín, S. Greßies, F. Glorius, Chem. Sci. 2019, 10, 6560-6564; c) G. Liu, G. Kuang, X. Zhang, N. Lu, Y. Fu, Y. Peng, Y. Zhou, Org. Lett. 2019, 21, 3043-3047; d) X.-G. Liu, H. Gao, S.-S. Zhang, Q. Li, H. Wang, ACS Catal. 2017, 7, 5078-5086; e) S. L. Yedage, B. M. Bhanage, Green Chem. 2016, 18, 5635-5642; f) R. K. Chinnagolla, M. Jeganmohan, Chem. Commun. 2012, 48, 2030-2032.

[233] a) R. Santhoshkumar, C.-H. Cheng, Chem. Eur. J. 2019, 25, 9366-9384; b) V. P. Boyarskiy, D. S. Ryabukhin, N. A. Bokach, A. V. Vasilyev, Chem. Rev. 2016, 116, 5894-5986.

[234] a) L. F. T. Novaes, J. Liu, Y. Shen, L. Lu, J. M. Meinhardt, S. Lin, Chem. Soc. Rev. 2021; b) K. Yamamoto, M. Kuriyama, O. Onomura, Acc. Chem. Res. 2020, 53, 105-120; c) Q. Jing, K. D. Moeller, Acc. Chem. Res. 2020, 53, 135-143; d) K.-J. Jiao, Y.-K. Xing, Q.-L. Yang, H. Qiu, T.S. Mei, Acc. Chem. Res. 2020, 53, 300-310; e) T. Fuchigami, S. Inagi, Acc. Chem. Res. 2020, 53, 322-334; f) P. Xiong, H.-C. Xu, Acc. Chem. Res. 2019, 52, 3339-3350; g) M. Elsherbini, T. Wirth, Acc. Chem. Res. 2019, 52, 3287-3296; h) S. R. Waldvogel, S. Lips, M. Selt, B. Riehl, C. J. Kampf, Chem. Rev. 2018, 118, 6706-6765; i) S. Tang, Y. Liu, A. Lei, Chem 2018, 4, 27-45; j) G. S. Sauer, S. Lin, ACS Catal. 2018, 8, 5175-5187; k) J. E. Nutting, M. Rafiee, S. S. Stahl, Chem. Rev. 2018, 118, 4834-4885; 1) M. Yan, Y. Kawamata, P. S. Baran, Chem. Rev. 2017, 117, 13230-13319; m) R. Francke, R. D. Little, Chem. Soc. Rev. 2014, 43, 2492-2521; n) A. Jutand, Chem. Rev. 2008, 108, 2300-2347.

[235] a) Y. Qiu, C. Zhu, M. Stangier, J. Struwe, L. Ackermann, CCS Chem. 2021, 3, 1529-1552; b) R. C. Samanta, T. H. Meyer, I. Siewert, L. Ackermann, Chem. Sci. 2020, 11, 8657-8670; c) T. H. Meyer, L. H. Finger, P. Gandeepan, L. Ackermann, Trends Chem. 2019, 1, 63-76; d) Q.-L. Yang, P. Fang, T.-S. Mei, Chin. J. Chem . 2018, 36, 338-352; e) C. Ma, P. Fang, T.-S. Mei, ACS 
Catal. 2018, 8, 7179-7189; f) N. Sauermann, T. H. Meyer, Y. Qiu, L. Ackermann, ACS Catal. 2018, $8,7086-7103$.

[236] a) Y. Wang, J. C. A. Oliveira, Z. Lin, L. Ackermann, Angew. Chem. Int. Ed. 2021, 60, 64196424; b) X. Tan, X. Hou, T. Rogge, L. Ackermann, Angew. Chem. Int. Ed. 2021, 60, 4619-4624; c) L. Yang, R. Steinbock, A. Scheremetjew, R. Kuniyil, L. H. Finger, A. M. Messinis, L. Ackermann, Angew. Chem. Int. Ed. 2020, 59, 11130-11135; d) W.-J. Kong, L. H. Finger, J. C. A. Oliveira, L. Ackermann, Angew. Chem. Int. Ed. 2019, 58, 6342-6346; e) W.-J. Kong, L. H. Finger, A. M. Messinis, R. Kuniyil, J. C. A. Oliveira, L. Ackermann, J. Am. Chem. Soc. 2019, 141, 17198-17206; f) Y. Qiu, C. Tian, L. Massignan, T. Rogge, L. Ackermann, Angew. Chem. Int. Ed. 2018, 57, 5818-5822; g) Y. Qiu, M. Stangier, T. H. Meyer, J. C. A. Oliveira, L. Ackermann, Angew. Chem. Int. Ed. 2018, 57, 14179-14183; h) Y. Qiu, W.-J. Kong, J. Struwe, N. Sauermann, T. Rogge, A. Scheremetjew, L. Ackermann, Angew. Chem. Int. Ed. 2018, 57, 5828-5832; i) R. Mei, J. Koeller, L. Ackermann, Chem. Commun. 2018, 54, 12879-12882.

[237] a) Q.-L. Yang, H.-W. Jia, Y. Liu, Y.-K. Xing, R.-C. Ma, M.-M. Wang, G.-R. Qu, T.-S. Mei, H.M. Guo, Org. Lett. 2021, 23, 1209-1215; b) Y.-K. Xing, X.-R. Chen, Q.-L. Yang, S.-Q. Zhang, H.-M. Guo, X. Hong, T.-S. Mei, Nat. Commun. 2021, 12, 930; c) Q.-L. Yang, Y.-K. Xing, X.Y. Wang, H.-X. Ma, X.-J. Weng, X. Yang, H.-M. Guo, T.-S. Mei, J. Am. Chem. Soc. 2019, 141, 18970-18976; d) Z.-Q. Wang, C. Hou, Y.-F. Zhong, Y.-X. Lu, Z.-Y. Mo, Y.-M. Pan, H.-T. Tang, Org. Lett. 2019, 21, 9841-9845; e) M.-J. Luo, T.-T. Zhang, F.-J. Cai, J.-H. Li, D.-L. He, Chem. Commun. 2019, 55, 7251-7254; f) M.-J. Luo, M. Hu, R.-J. Song, D.-L. He, J.-H. Li, Chem. Commun. 2019, 55, 1124-1127; g) F. Xu, Y.-J. Li, C. Huang, H.-C. Xu, ACS Catal. 2018, 8, $3820-3824$.

[238] a) K. Naksomboon, J. Poater, F. M. Bickelhaupt, M. Á. Fernández-Ibáñez, J. Am. Chem. Soc. 2019, 141, 6719-6725; b) E. Tan, O. Quinonero, M. Elena de Orbe, A. M. Echavarren, ACS Catal. 2018, 8, 2166-2172; c) W. Ma, R. Mei, G. Tenti, L. Ackermann, Chem. Eur. J. 2014, 20, 15248-15251.

[239] a) K. Hirano, M. Miura, Chem. Lett. 2015, 44, 868-873; b) A. E. Wendlandt, A. M. Suess, S. S. Stahl, Angew. Chem. Int. Ed. 2011, 50, 11062-11087. 
[240] T. Yoshizumi, H. Tsurugi, T. Satoh, M. Miura, Tetrahedron Lett. 2008, 49, 1598-1600.

[241] a) L. Marzo, S. K. Pagire, O. Reiser, B. König, Angew. Chem. Int. Ed. 2018, 57, 10034-10072; b) K. L. Skubi, T. R. Blum, T. P. Yoon, Chem. Rev. 2016, 116, 10035-10074; c) O. Reiser, Acc. Chem. Res. 2016, 49, 1990-1996; d) D. C. Miller, K. T. Tarantino, R. R. Knowles, Top. Curr. Chem. 2016, 374, 30; e) M. D. Kärkäs, J. A. Porco, C. R. J. Stephenson, Chem. Rev. 2016, 116, 9683-9747; f) I. Ghosh, L. Marzo, A. Das, R. Shaikh, B. König, Acc. Chem. Res. 2016, 49, 1566-1577; g) D. C. Fabry, M. Rueping, Acc. Chem. Res. 2016, 49, 1969-1979; h) R. Brimioulle, D. Lenhart, M. M. Maturi, T. Bach, Angew. Chem. Int. Ed. 2015, 54, 3872-3890; i) S. Paria, O. Reiser, ChemCatChem 2014, 6, 2477-2483; j) D. Ravelli, M. Fagnoni, A. Albini, Chem. Soc. Rev. 2013, 42, 97-113; k) C. K. Prier, D. A. Rankic, D. W. C. MacMillan, Chem. Rev. 2013, 113, 5322-5363.

[242] a) J. He, C. Chen, G. C. Fu, J. C. Peters, ACS Catal. 2018, 8, 11741-11748; b) G. J. Choi, Q. Zhu, D. C. Miller, C. J. Gu, R. R. Knowles, Nature 2016, 539, 268-271; c) T. R. Blum, Z. D. Miller, D. M. Bates, I. A. Guzei, T. P. Yoon, Science 2016, 354, 1391-1395; d) T. S. Ratani, S. Bachman, G. C. Fu, J. C. Peters, J. Am. Chem. Soc. 2015, 137, 13902-13907; e) D. B. Bagal, G. Kachkovskyi, M. Knorn, T. Rawner, B. M. Bhanage, O. Reiser, Angew. Chem. Int. Ed. 2015, 54, 6999-7002; f) J. Du, K. L. Skubi, D. M. Schultz, T. P. Yoon, Science 2014, 344, 392-396; g) D. P. Hari, B. König, Angew. Chem. Int. Ed. 2013, 52, 4734-4743; h) J. D. Nguyen, E. M. D'Amato, J. M. R. Narayanam, C. R. J. Stephenson, Nat. Chem. 2012, 4, 854; i) D. P. Hari, P. Schroll, B. König, J. Am. Chem. Soc. 2012, 134, 2958-2961.

[243] a) W. Zhao, R. P. Wurz, J. C. Peters, G. C. Fu, J. Am. Chem. Soc. 2017, 139, 12153-12156; b) C. D. Matier, J. Schwaben, J. C. Peters, G. C. Fu, J. Am. Chem. Soc. 2017, 139, 17707-17710; c) J. M. Ahn, T. S. Ratani, K. I. Hannoun, G. C. Fu, J. C. Peters, J. Am. Chem. Soc. 2017, 139, 12716-12723; d) Q. M. Kainz, C. D. Matier, A. Bartoszewicz, S. L. Zultanski, J. C. Peters, G. C. Fu, Science 2016, 351, 681-684; e) S. E. Creutz, K. J. Lotito, G. C. Fu, J. C. Peters, Science 2012, 338, 647-651.

[244] Y. Liang, X. Zhang, D. W. C. MacMillan, Nature 2018, 559, 83-88.

[245] W.-J. Yoo, T. Tsukamoto, S. Kobayashi, Org. Lett. 2015, 17, 3640-3642. 
[246] a) D. C. Fabry, M. A. Ronge, J. Zoller, M. Rueping, Angew. Chem. Int. Ed. 2015, 54, 28012805; b) J. Zoller, D. C. Fabry, M. A. Ronge, M. Rueping, Angew. Chem. Int. Ed. 2014, 53, 13264-13268; c) D. C. Fabry, J. Zoller, S. Raja, M. Rueping, Angew. Chem. Int. Ed. 2014, 53, 10228-10231; d) D. Kalyani, K. B. McMurtrey, S. R. Neufeldt, M. S. Sanford, J. Am. Chem. Soc. 2011, 133, 18566-18569.

[247] P. Gandeepan, J. Mo, L. Ackermann, Chem. Commun. 2017, 53, 5906-5909.

[248] a) C. Xie, W. Sun, H. Lu, A. Kretzschmann, J. Liu, M. Wagner, H.-J. Butt, X. Deng, S. Wu, Nat. Commun. 2018, 9, 3842; b) D. Rackl, C.-J. Yoo, C. W. Jones, H. M. L. Davies, Org. Lett. 2017, 19, 3055-3058; c) M. Opanasenko, P. Štěpnička, J. Čejka, RSC Adv. 2014, 4, 6513765162; d) S. Shylesh, W. R. Thiel, ChemCatChem 2011, 3, 278-287; e) E. L. Margelefsky, R. K. Zeidan, M. E. Davis, Chem. Soc. Rev. 2008, 37, 1118-1126; f) F.-X. Felpin, E. Fouquet, ChemSusChem 2008, 1, 718-724; g) C. T. Kresge, M. E. Leonowicz, W. J. Roth, J. C. Vartuli, J. S. Beck, Nature 1992, 359, 710-712; h) J. S. Beck, J. C. Vartuli, W. J. Roth, M. E. Leonowicz, C. T. Kresge, K. D. Schmitt, C. T. W. Chu, D. H. Olson, E. W. Sheppard, S. B. McCullen, J. B. Higgins, J. L. Schlenker, J. Am. Chem. Soc. 1992, 114, 10834-10843.

[249] a) F. Wu, Y. Feng, C. W. Jones, ACS Catal. 2014, 4, 1365-1375; b) Y. Feng, E. G. Moschetta, C. W. Jones, Chem. Asian J. 2014, 9, 3142-3152.

[250] a) S. Kawamorita, R. Murakami, T. Iwai, M. Sawamura, J. Am. Chem. Soc. 2013, 135, 29472950; b) S. Kawamorita, T. Miyazaki, T. Iwai, H. Ohmiya, M. Sawamura, J. Am. Chem. Soc. 2012, 134, 12924-12927; c) S. Kawamorita, H. Ohmiya, T. Iwai, M. Sawamura, Angew. Chem. Int. Ed. 2011, 50, 8363-8366; d) S. Kawamorita, H. Ohmiya, M. Sawamura, J. Org. Chem. 2010, 75, 3855-3858; e) S. Kawamorita, H. Ohmiya, K. Hara, A. Fukuoka, M. Sawamura, J. Am. Chem. Soc. 2009, 131, 5058-5059.

[251] K. Korvorapun, R. Kuniyil, L. Ackermann, ACS Catal. 2020, 10, 435-440.

[252] C. J. Teskey, A. Y. W. Lui, M. F. Greaney, Angew. Chem. Int. Ed. 2015, 54, 11677-11680.

[253] a) G. Li, C. Jia, X. Cai, L. Zhong, L. Zou, X. Cui, Chem. Commun. 2020, 56, 293-296; b) B. Li, S.-L. Fang, D.-Y. Huang, B.-F. Shi, Org. Lett. 2017, 19, 3950-3953; c) Z. Fan, J. Li, H. Lu, D.-Y. Wang, C. Wang, M. Uchiyama, A. Zhang, Org. Lett. 2017, 19, 3199-3202. 
[254] P. Gandeepan, N. Kaplaneris, S. Santoro, L. Vaccaro, L. Ackermann, ACS Sustain. Chem. Eng. 2019, 7, 8023-8040.

[255] M. D. Hill, Chem. Eur. J. 2010, 16, 12052-12062.

[256] a) R. Alam, M. A. Alam, A. K. Panda, Rahisuddin, J. Heterocycl. Chem. 2017, 54, 1812-1821;

b) N. C. Desai, D. D. Pandya, V. V. Joshi, K. M. Rajpara, H. V. Vaghani, H. M. Satodiya, Med. Chem. Res. 2012, 21, 4463-4472; c) Y. Xia, C.-D. Fan, B.-X. Zhao, J. Zhao, D.-S. Shin, J.-Y. Miao, Eur. J. Med. Chem. 2008, 43, 2347-2353.

[257] Y. Nakao, Synthesis 2011, 2011, 3209-3219.

[258] a) Y. Hu, B. Zhou, C. Wang, Acc. Chem. Res. 2018, 51, 816-827; b) R. Cano, K. Mackey, G. P. McGlacken, Catal. Sci. Technol. 2018, 8, 1251-1266.

[259] a) S. Sueki, Z. Wang, Y. Kuninobu, Org. Lett. 2016, 18, 304-307; b) Y. Kuninobu, Y. Nishina, T. Takeuchi, K. Takai, Angew. Chem. Int. Ed. 2007, 46, 6518-6520.

[260] a) B. Zhou, Y. Hu, T. Liu, C. Wang, Nat. Commun. 2017, 8, 1169; b) B. Zhou, Y. Hu, C. Wang, Angew. Chem. Int. Ed. 2015, 54, 13659-13663.

[261] a) N. Kaplaneris, J. Son, L. Mendive-Tapia, A. Kopp, N. D. Barth, I. Maksso, M. Vendrell, L. Ackermann, Nat. Commun. 2021, 12, 3389; b) N. Kaplaneris, F. Kaltenhäuser, G. Sirvinskaite, S. Fan, T. De Oliveira, L.-C. Conradi, L. Ackermann, Sci. Adv. 2021, 7, eabe6202; c) H. Wang, N. Kaplaneris, L. Ackermann, Cell Rep. Phys. Sci. 2020, 1, 100178; d) N. Kaplaneris, T. Rogge, R. Yin, H. Wang, G. Sirvinskaite, L. Ackermann, Angew. Chem. Int. Ed. 2019, 58, 3476-3480; e) H. Wang, I. Choi, T. Rogge, N. Kaplaneris, L. Ackermann, Nat. Catal. 2018, 1, 993-1001.

[262] C. Wang, B. Maity, L. Cavallo, M. Rueping, Org. Lett. 2018, 20, 3105-3108.

[263] a) D. Aynetdinova, M. C. Callens, H. B. Hicks, C. Y. X. Poh, B. D. A. Shennan, A. M. Boyd, Z. H. Lim, J. A. Leitch, D. J. Dixon, Chem. Soc. Rev. 2021; b) S. D. Friis, M. J. Johansson, L. Ackermann, Nat. Chem. 2020, 12, 511-519.

[264] H. E. Gottlieb, V. Kotlyar, A. Nudelman, J. Org. Chem. 1997, 62, 7512-7515.

[265] L. Xu, C. Zhang, Y. He, L. Tan, D. Ma, Angew. Chem. Int. Ed. 2016, 55, 321-325.

[266] A. Bechtoldt, M. E. Baumert, L. Vaccaro, L. Ackermann, Green Chem. 2018, 20, 398-402. [267] S. W. Youn, H. J. Yoo, Adv. Synth. Catal. 2017, 359, 2176-2183. 
[268] J. R. Bolton, M. I. Stefan, P.-S. Shaw, K. R. Lykke, J. Photochem. Photobiol. A 2011, 222, 166-169.

[269] M. C. Biesinger, L. W. M. Lau, A. R. Gerson, R. S. C. Smart, Appl. Surf. Sci. 2010, 257, 887898.

[270] J. Crêpellière, P. L. Popa, N. Bahlawane, R. Leturcq, F. Werner, S. Siebentritt, D. Lenoble, J. Mater. Chem. C 2016, 4, 4278-4287

[271] J. Liu, Q. Gui, Z. Yang, Z. Tan, R. Guo, J.-C. Shi, Synthesis, 2013, 45, 943-951.

[272] S. K. Alla, P. Sadhu, T. Punniyamurthy, J. Org. Chem. 2014, 79, 7502-7511.

[273] D. Yang, K. Yan, W. Wei, L. Tian, Y. Shuai, R. Li, J. You, H. Wang, Asian J. Org. Chem. 2014, 3, 969-973.

[274] K. Gopalaiah, S. N. Chandrudua, RSC Adv. 2015, 5, 5015-5023.

[275] G. Naresh, R. Kant, T. Narender, J. Org. Chem. 2014, 79, 3821-3829.

[276] L. Yang, J. Yuan, P. Mao, Q. Guoa, RSC Adv. 2015, 5, 107601-107607.

[277] P. H. Tran, A.-H. T. Hanga, RSC Adv. 2018, 8, 11127-11133.

[278] M. J. Iglesias, A. Prieto, M. C. Nicasio, Org. Lett. 2012, 14, 4318-4321.

[279] B. Liu, Z. Wang, N. Wu, M. Li, J. You, J. Lan, Chem, Eur, J. 2012, 18, 1599-1603.

[280] X. Li, C. Li, B. Yin, C. Li, P. Liu, J. Li, Z. Shi, Chem. Asian J. 2013, 8, 1408-1411.

[281] S. Ray, P. Das, B, Banerjee, A. Bhaumikb, C. Mukhopadhyay, RSC Adv. 2015, 5, 72745-72754.

[282] Z.-S. Gu, W.-W. Chen, L.-X. Shao, J. Org. Chem. 2014, 79, 5806-5811.

[283] W. Zhang, Q. Zeng, X. Zhang, Y. Tian, Y. Yue, Y. Guo, Z. Wang, J. Org. Chem. 2011, 76, 47414745.

[284] A. J. Paterson, C. J. Heron, C. L. McMullin, M. F. Mahon, N. J. Press, C. G. Frost, Org. Biomol. Chem. 2017, 15, 5993-6000.

[285] H. Xie, Z. Ye, Z. Ke, J. Lan, H. Jiang, W. Zeng, Chem. Sci. 2018, 9, 985-989.

[286] Z. Shen, H. Huang, C. Zhu, S. Warratz, L. Ackermann, Org. Lett. 2019, 21, 571-574.

[287] G. Sheldrick, Acta Crystallographica Section A 2015, 71, 3-8. 


\section{Appendix: NMR Spectra}

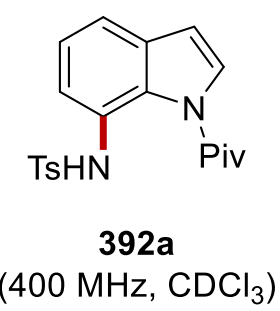

diul

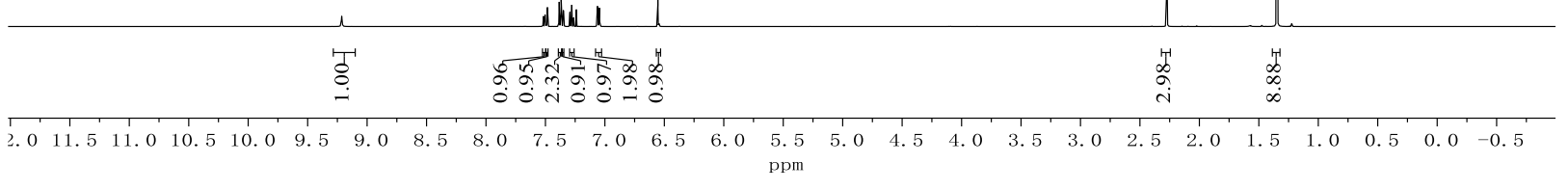

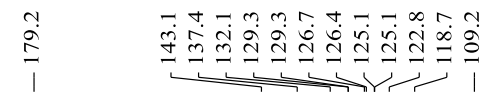

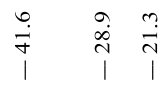<smiles>O=P(F)(F)n1ccc2cccc(N[AlH2])c21</smiles>

392a

(100 MHz, $\mathrm{CDCl}_{3}$ )

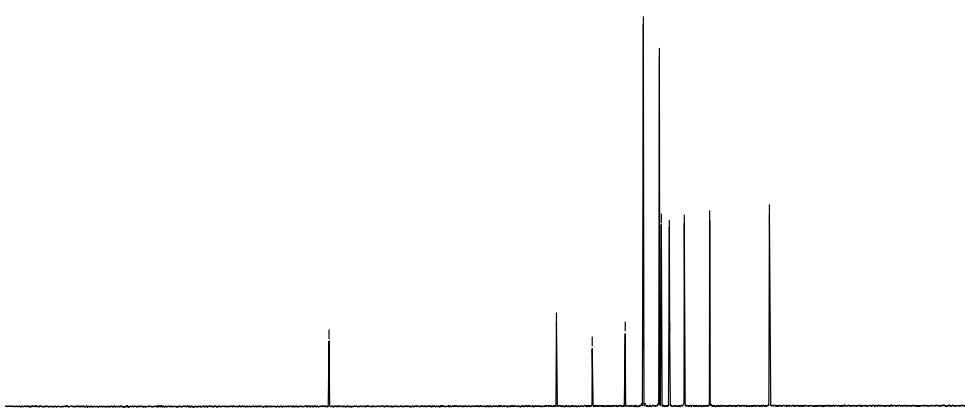

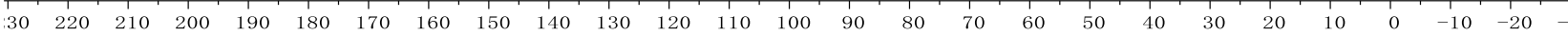


<smiles>Cc1cn(Pc2ccccc2)c2c(N)cccc12</smiles>

392b

(400 MHz, $\mathrm{CDCl}_{3}$ )
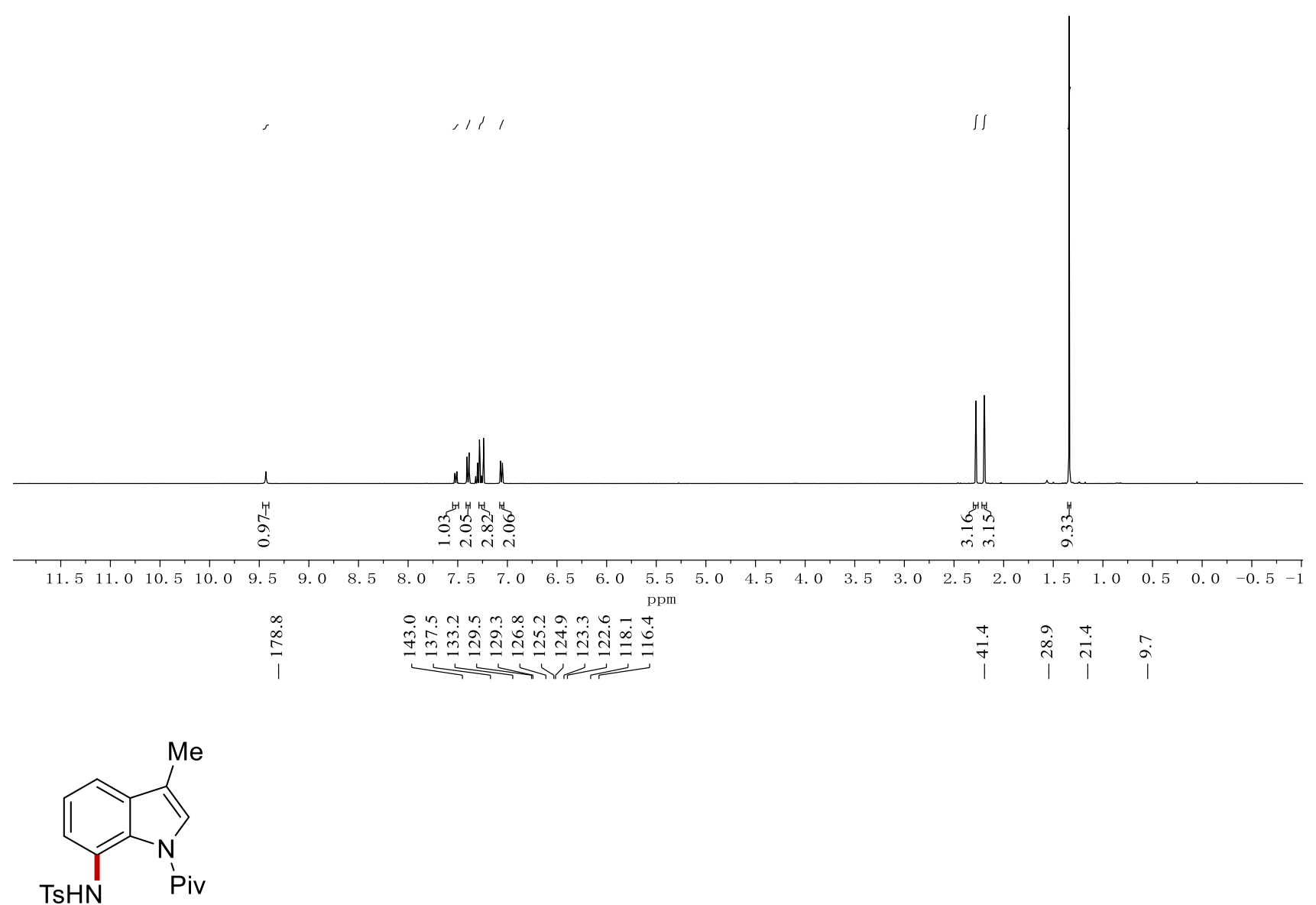

392b

(100 MHz, $\mathrm{CDCl}_{3}$ )

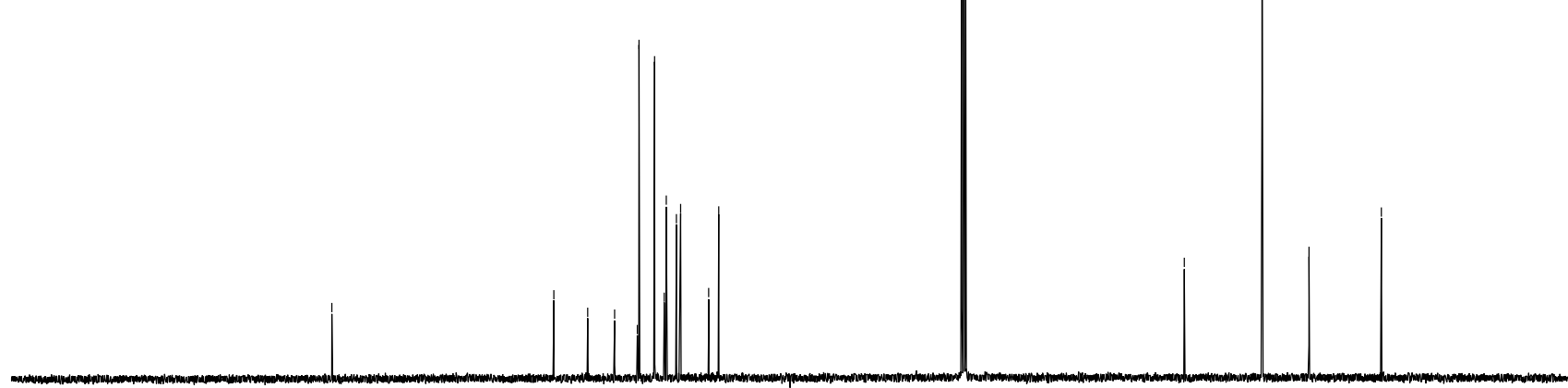

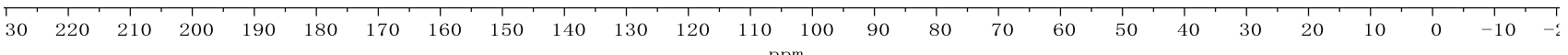


<smiles>Cc1ccc(N)c2c1ccn2[PH](=O)c1ccccc1</smiles>

392c

$\left(400 \mathrm{MHz}, \mathrm{CDCl}_{3}\right)$

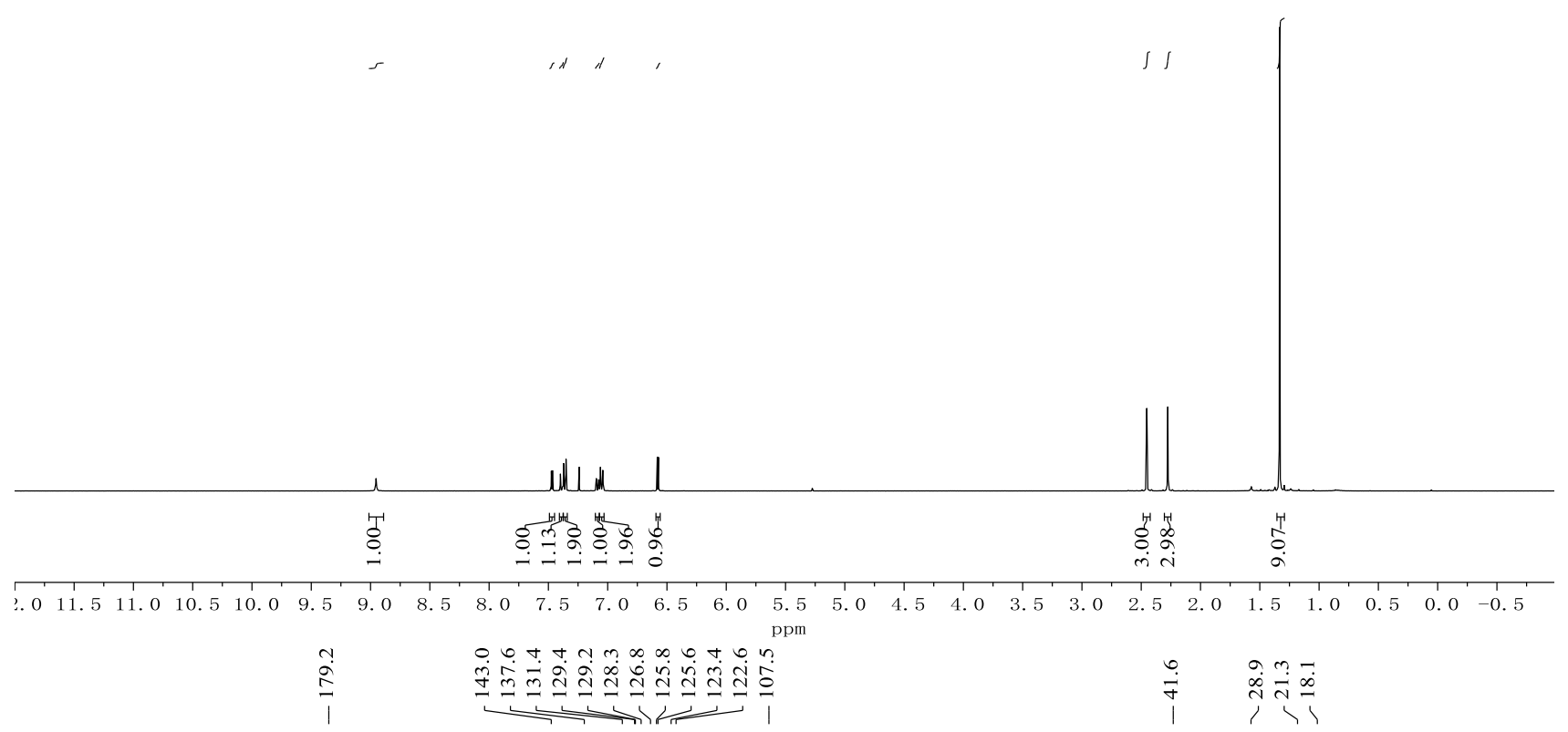<smiles>Cc1ccc(N)c2c1ccn2P(=O)(F)F</smiles>

392c

$\left(100 \mathrm{MHz}, \mathrm{CDCl}_{3}\right)$

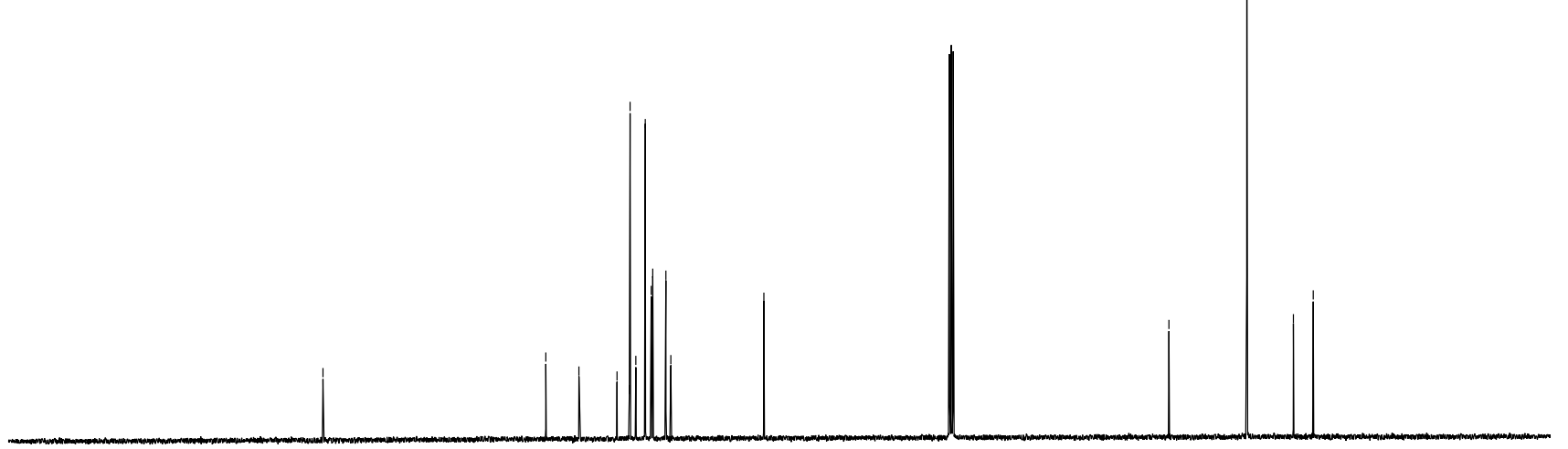

\begin{tabular}{lllllllllllllllllllllllllllllllll}
\hline 30 & 220 & 210 & 200 & 190 & 180 & 170 & 160 & 150 & 140 & 130 & 120 & 110 & 100 & 90 & 80 & 70 & 60 & 50 & 40 & 30 & 20 & 10 & 0 & -10 & -1
\end{tabular} 


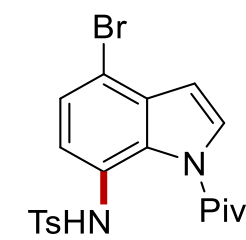

392d

(400 MHz, $\mathrm{CDCl}_{3}$ )

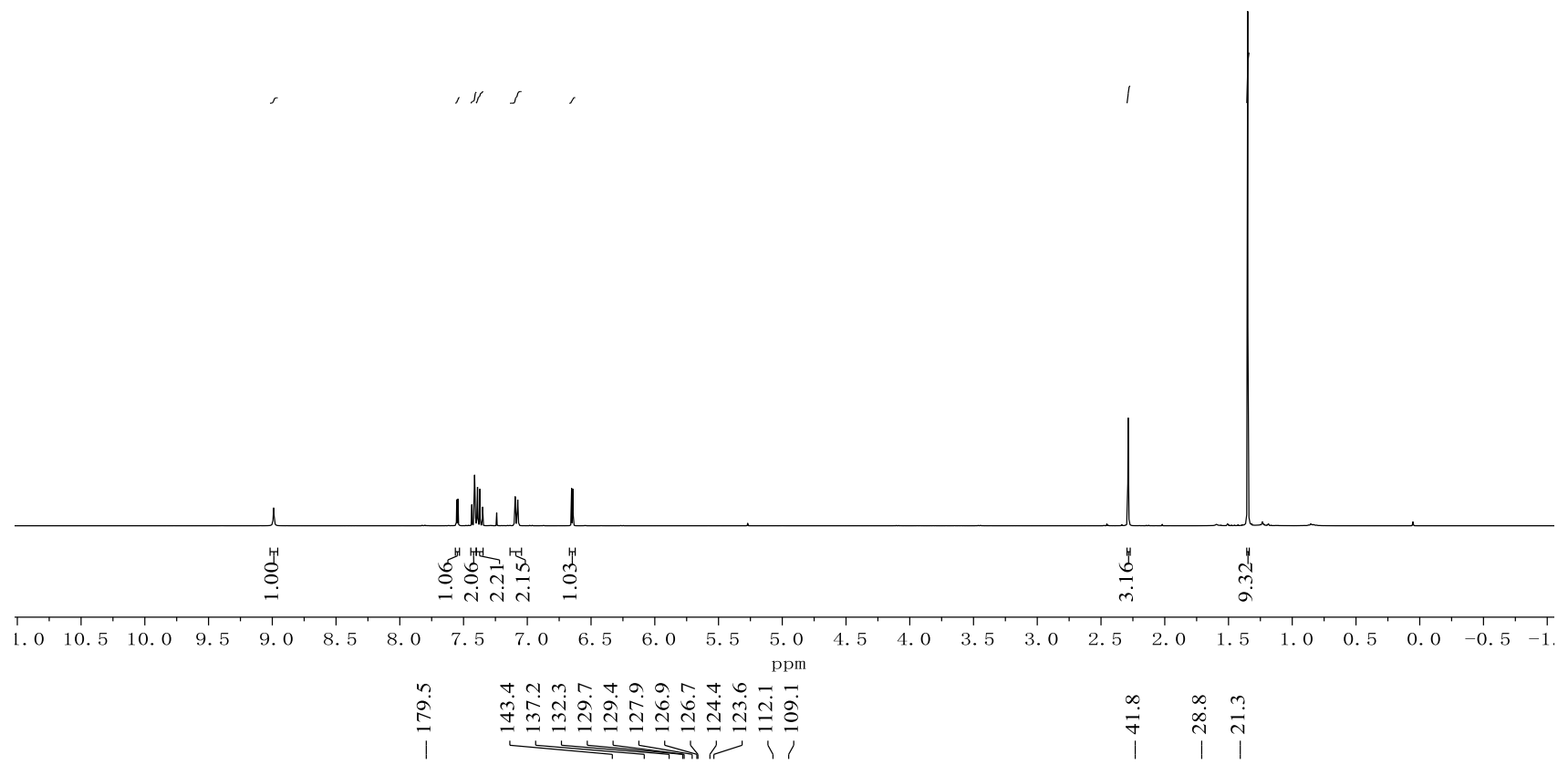<smiles>CCCCCNc1ccc(Br)c2ccn([PH](=O)c3ccccc3)c12</smiles>

392d

(100 MHz, $\mathrm{CDCl}_{3}$ )

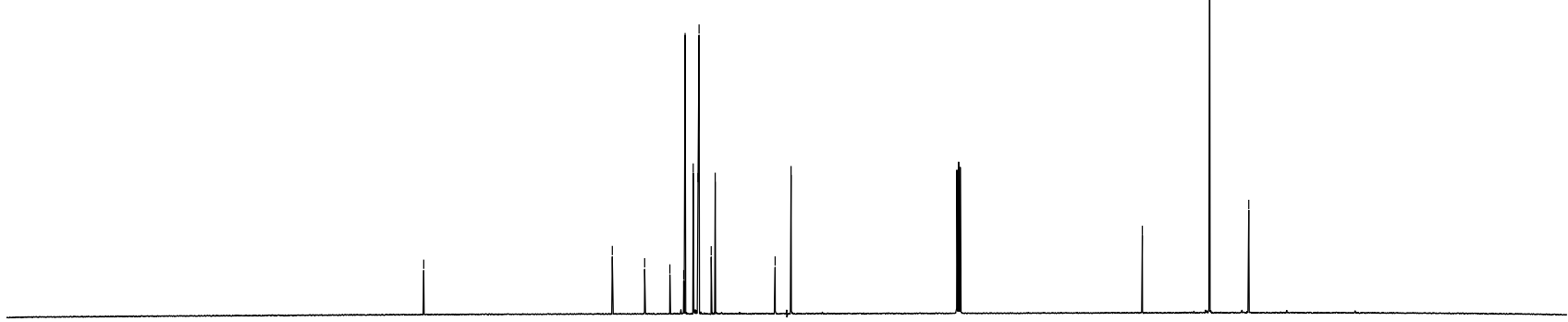

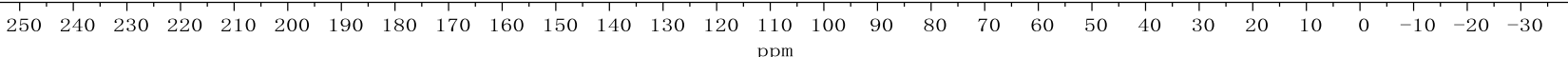




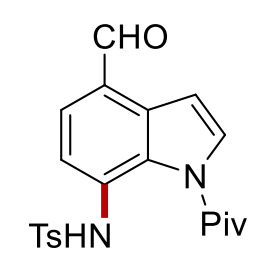

$392 e$

(400 MHz, $\mathrm{CDCl}_{3}$ )

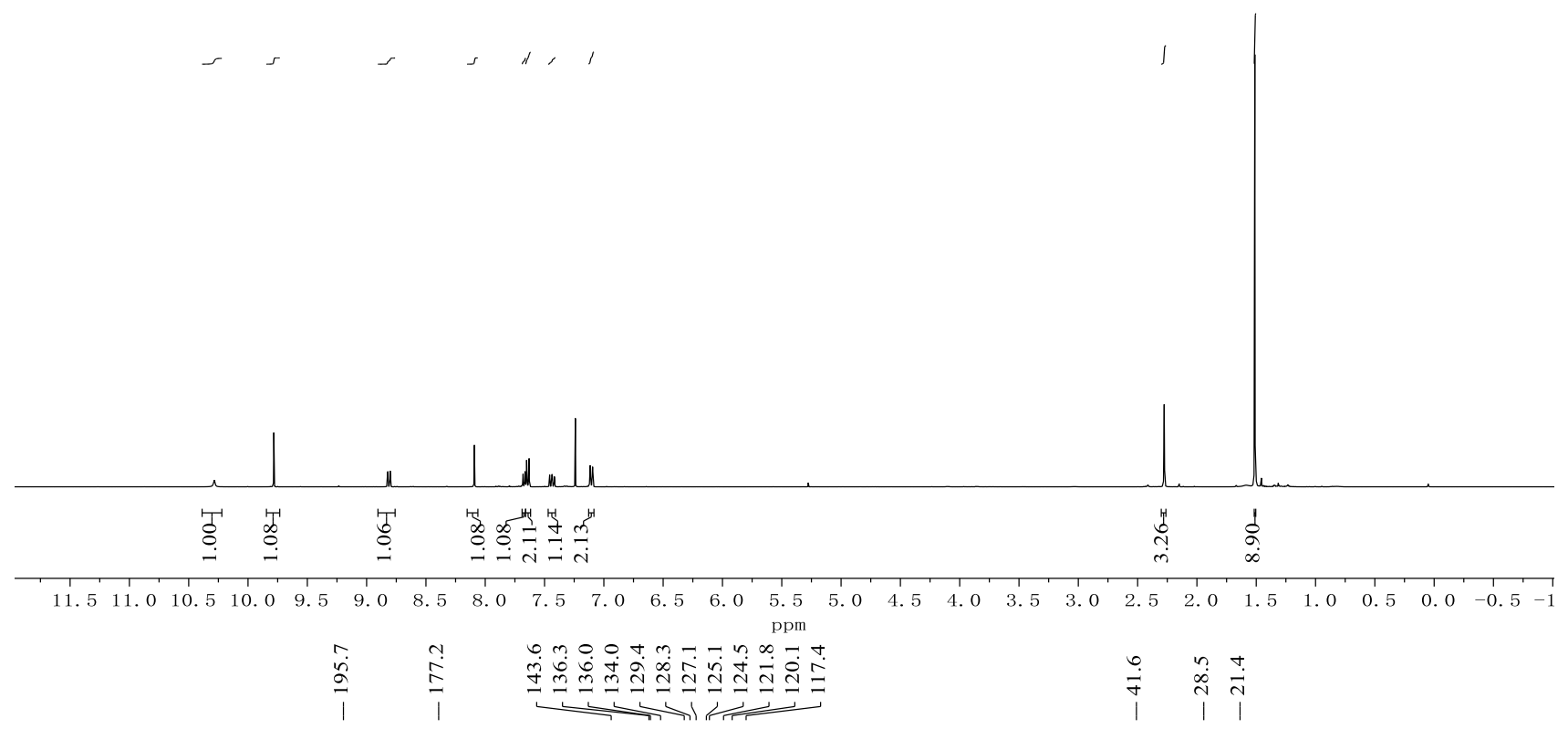<smiles>Nc1ccc(C=O)c2ccn([PH](=O)[Sn])c12</smiles>

392e

(100 MHz, $\mathrm{CDCl}_{3}$ )

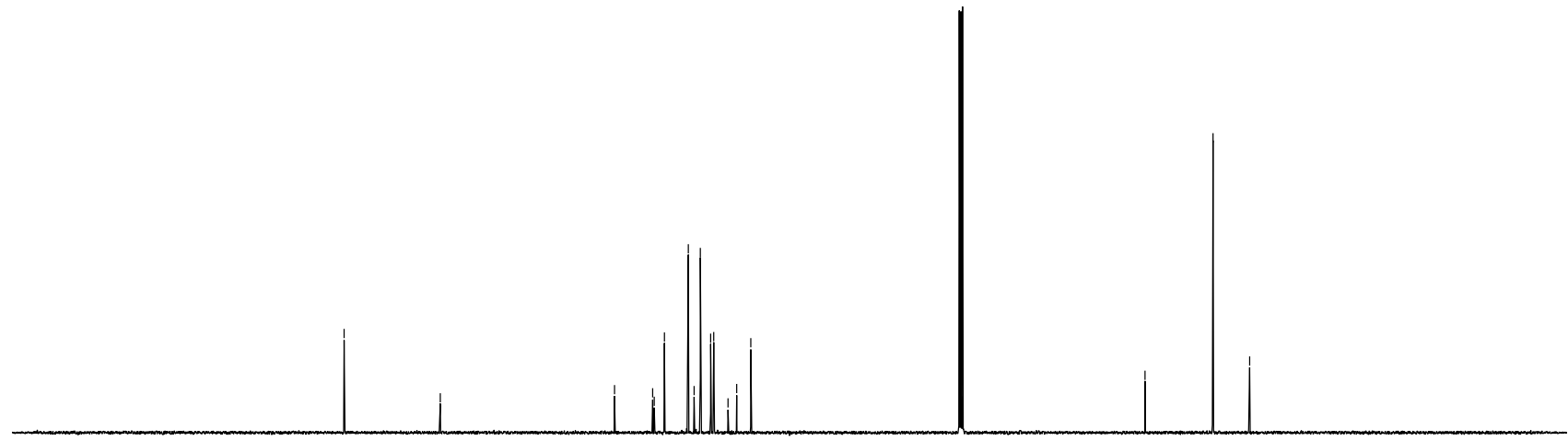

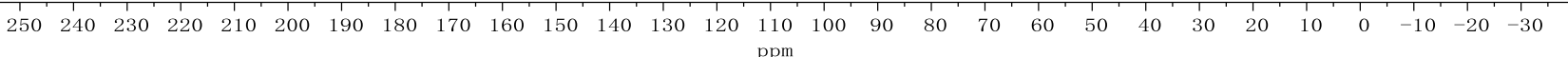




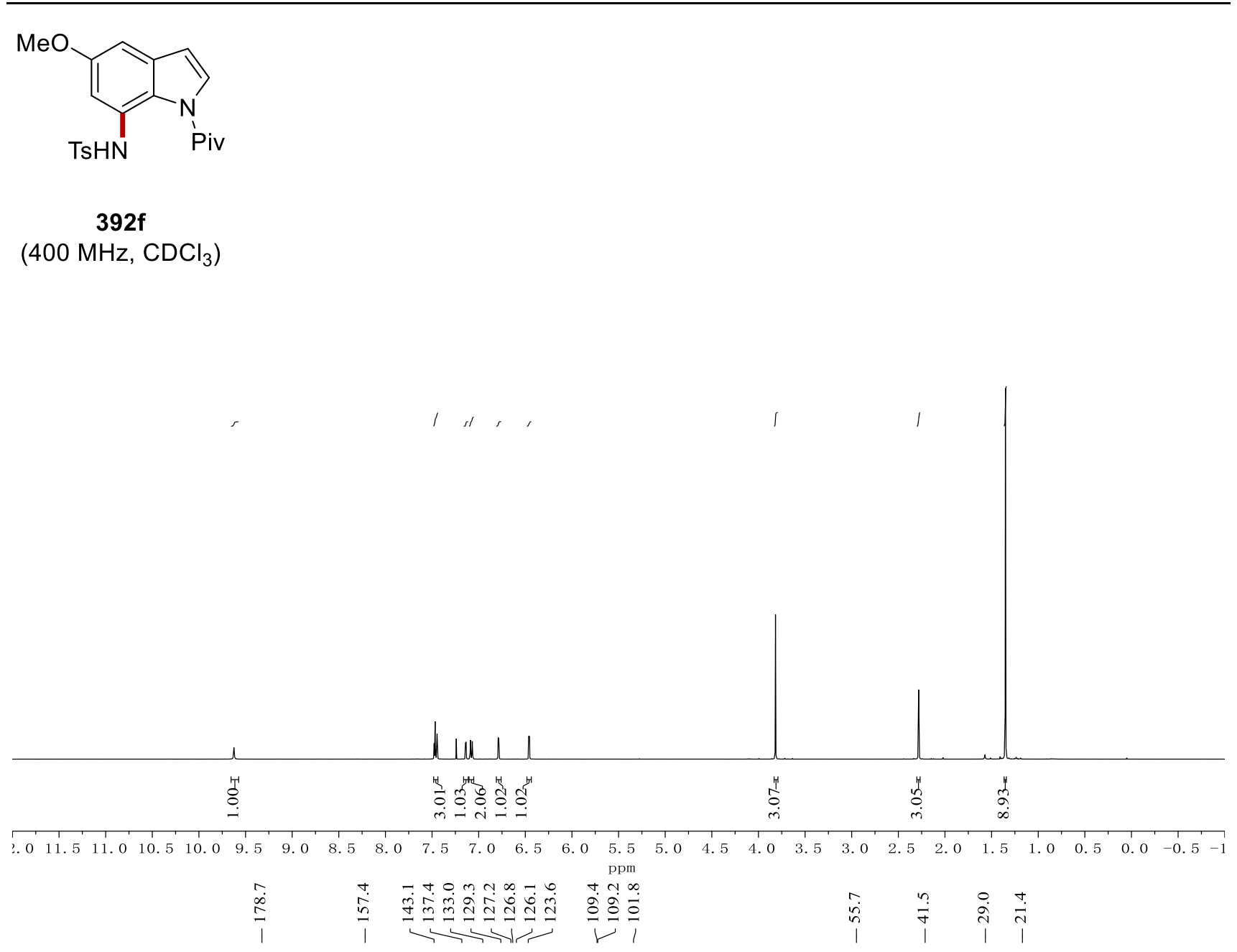<smiles>COc1cc(N)c2c(ccn2P)c1</smiles>

$392 f$

(100 MHz, $\mathrm{CDCl}_{3}$ )

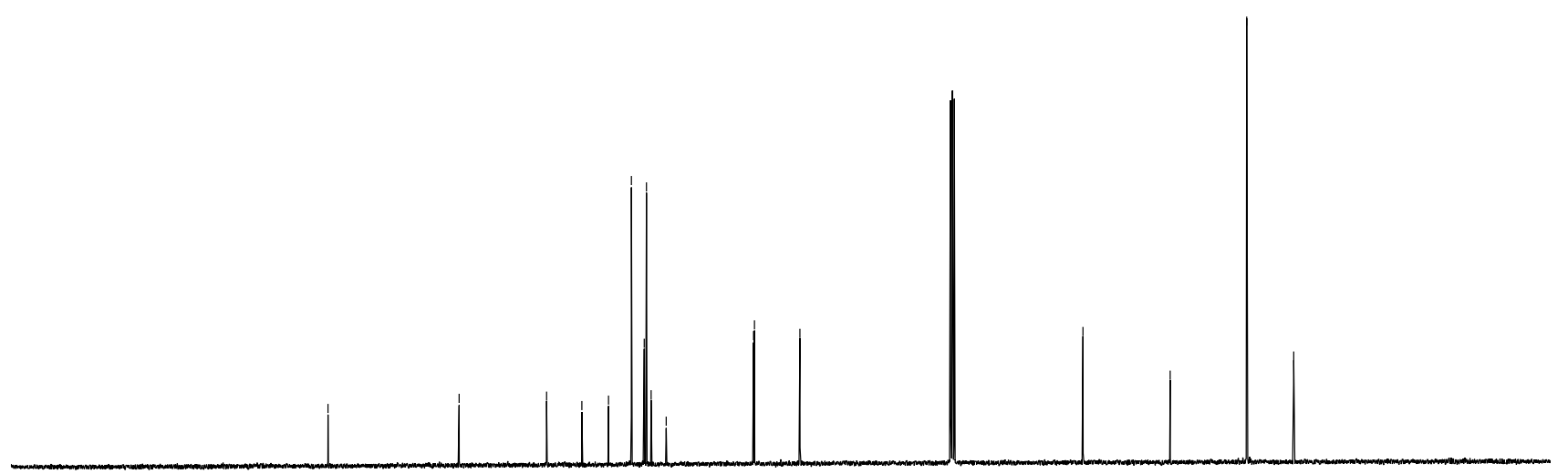

\begin{tabular}{llllllllllllllllllllllllllllllllll}
\hline 30 & 220 & 210 & 200 & 190 & 180 & 170 & 160 & 150 & 140 & 130 & 120 & 110 & 100 & 90 & 80 & 70 & 60 & 50 & 40 & 30 & 20 & 10 & 0 & -10 & -1
\end{tabular} 
<smiles>Nc1cc(F)cc2ccn(P)c12</smiles>

$392 \mathrm{~g}$

$\left(400 \mathrm{MHz}, \mathrm{CDCl}_{3}\right)$

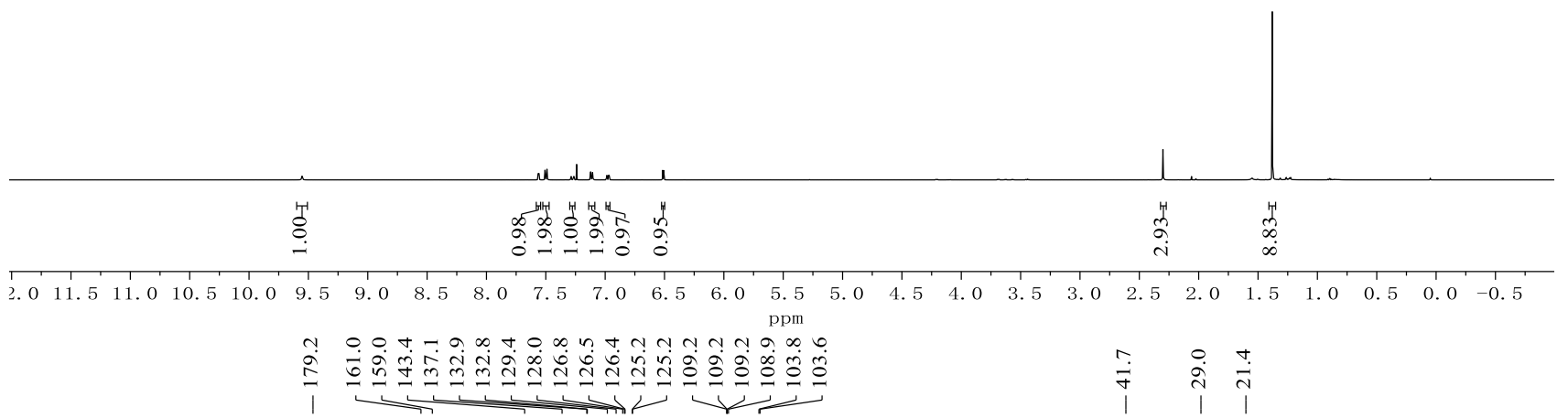<smiles>Nc1cc(F)cc2ccn(P)c12</smiles>

392g

$\left(100 \mathrm{MHz}, \mathrm{CDCl}_{3}\right)$

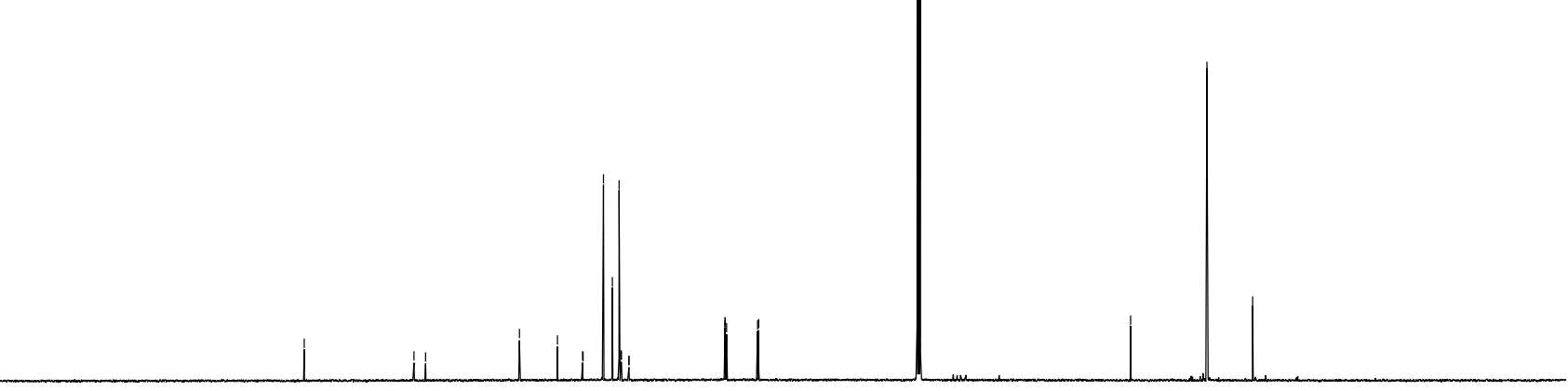

$\begin{array}{lllllllllllllllllllllllllllllll}30 & 220 & 210 & 200 & 190 & 180 & 170 & 160 & 150 & 140 & 130 & 120 & 110 & 100 & 90 & 80 & 70 & 60 & 50 & 40 & 30 & 20 & 10 & 0 & -10 & -20 & -3\end{array}$ 


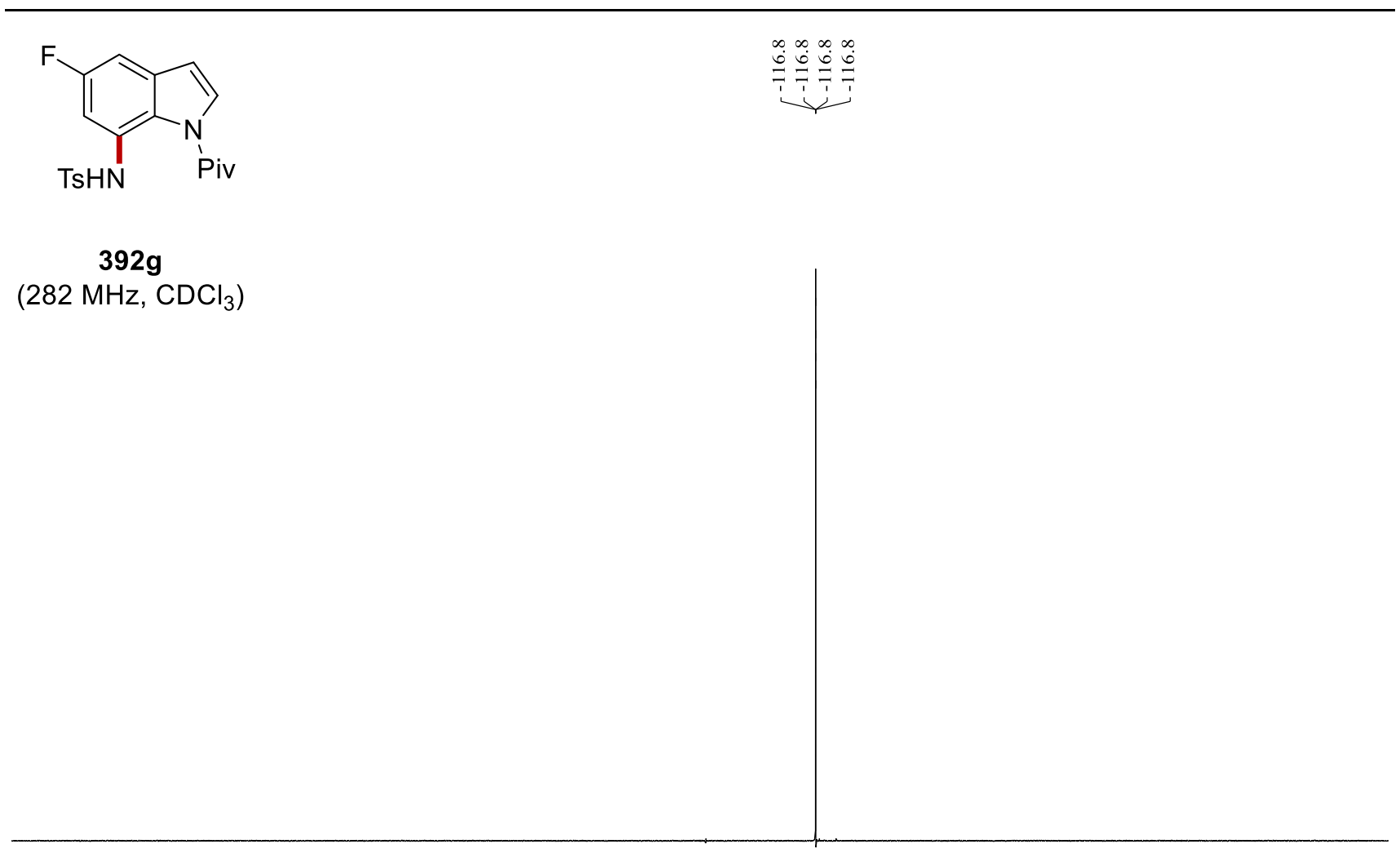

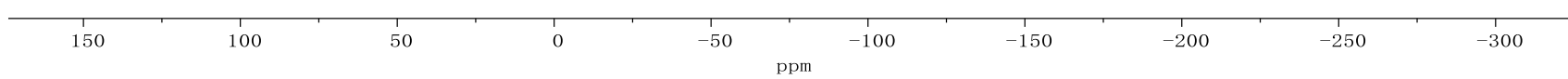


<smiles>Pn1ccc2cc(Cl)cc(N[123I])c21</smiles>

$392 \mathrm{~h}$

$\left(400 \mathrm{MHz}, \mathrm{CDCl}_{3}\right.$ )

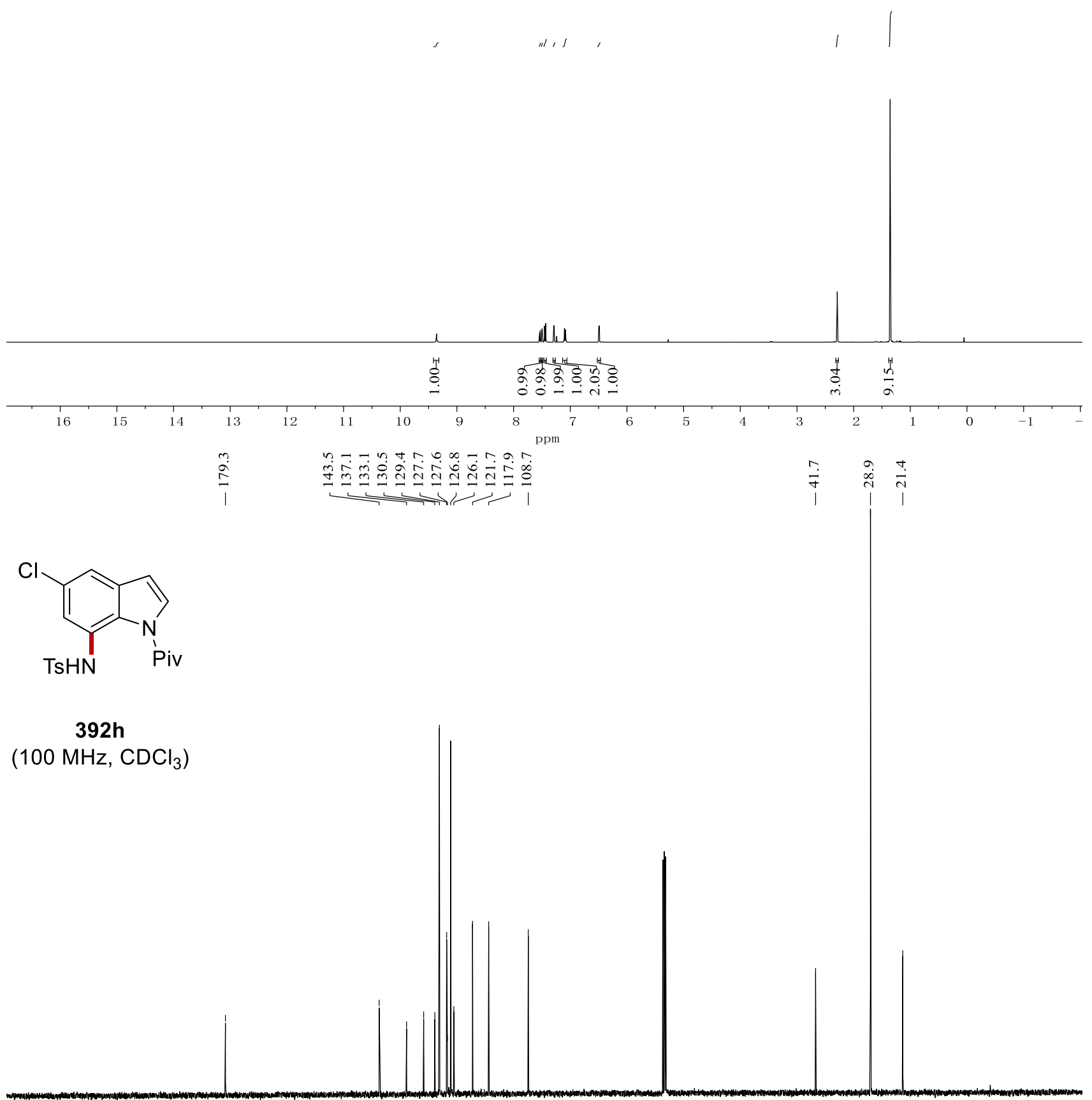

\begin{tabular}{lllllllllllllllllllllllllllllllllllllll}
\hline 30 & 220 & 210 & 200 & 190 & 180 & 170 & 160 & 150 & 140 & 130 & 120 & 110 & 100 & 90 & 80 & 70 & 60 & 50 & 40 & 30 & 20 & 10 & 0 & -10 & -1
\end{tabular} 
<smiles>Pn1ccc2cc(Br)cc(N[123I])c21</smiles>

392i

(400 MHz, $\mathrm{CDCl}_{3}$ )

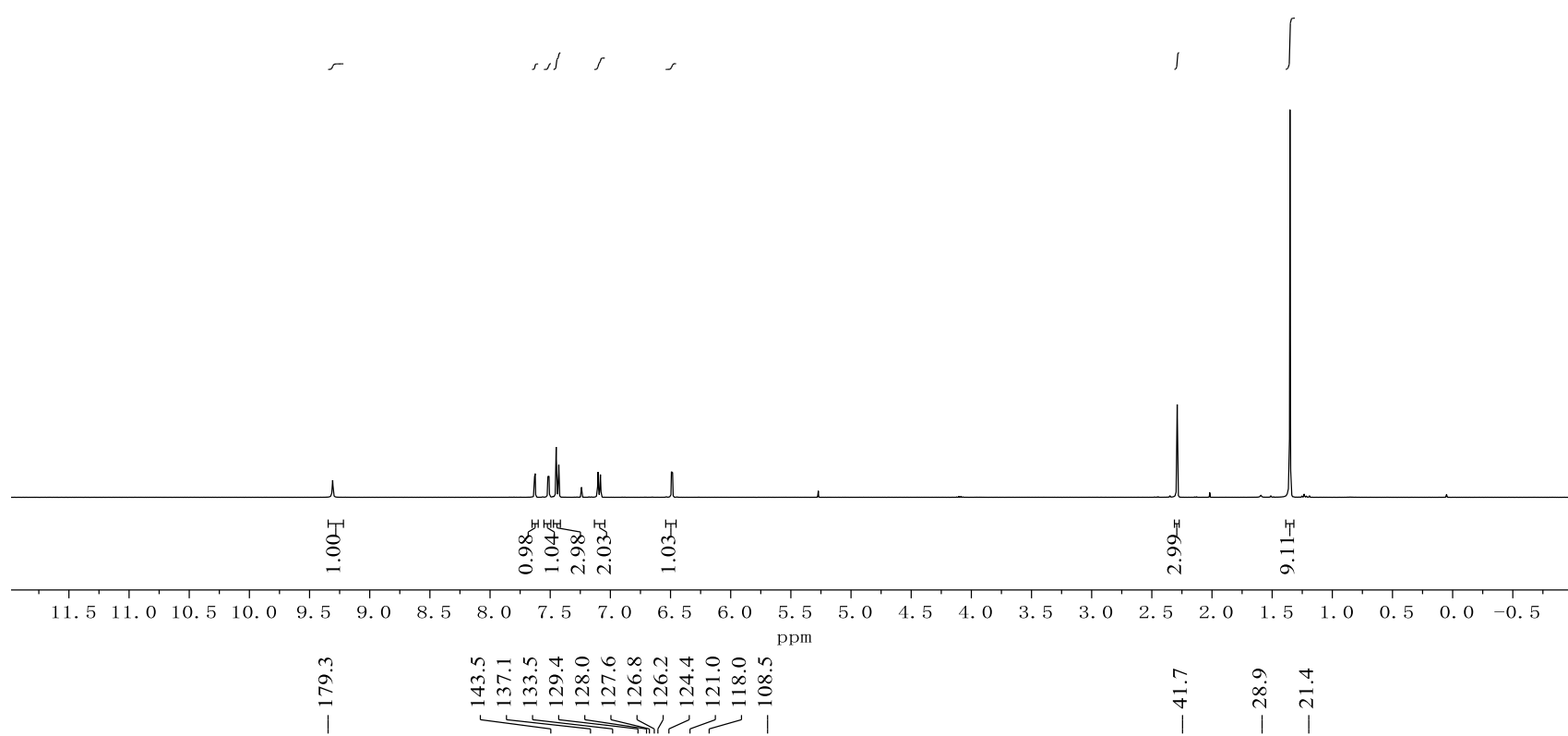<smiles>Pn1ccc2cc(Br)cc(N[123I])c21</smiles>

392i

$\left(100 \mathrm{MHz}, \mathrm{CDCl}_{3}\right.$ )

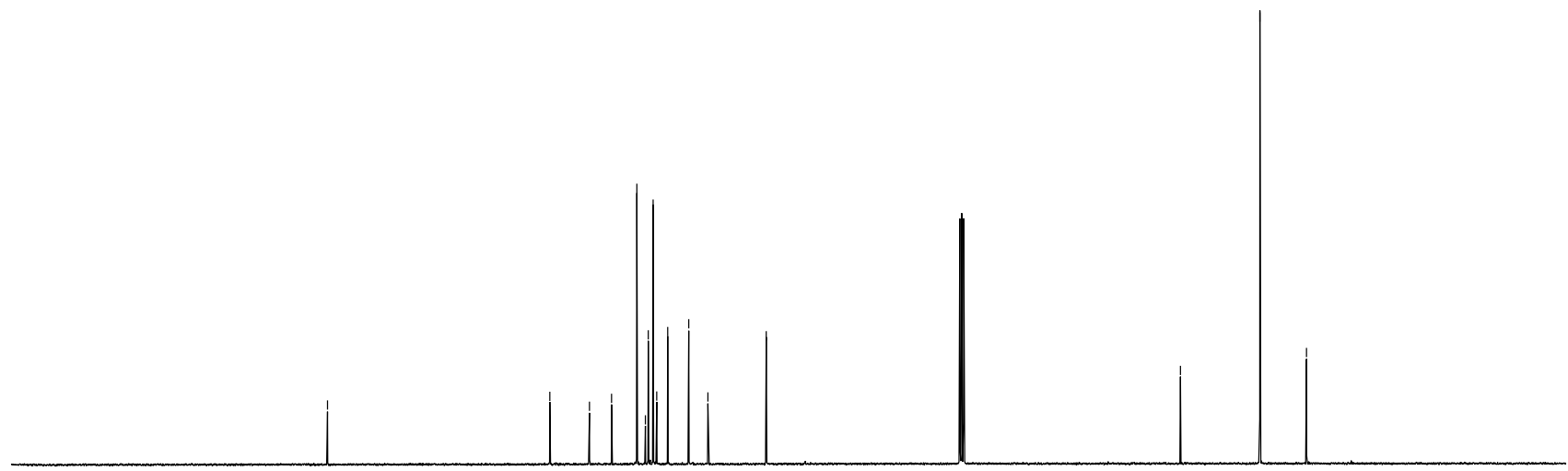

\begin{tabular}{llllllllllllllllllllllllllllllllllllll}
\hline 30 & 220 & 210 & 200 & 190 & 180 & 170 & 160 & 150 & 140 & 130 & 120 & 110 & 100 & 90 & 80 & 70 & 60 & 50 & 40 & 30 & 20 & 10 & 0 & -10 & -1
\end{tabular} 
<smiles>Pn1ccc2cc(I)cc(N[123I])c21</smiles>

392j

(400 MHz, $\mathrm{CDCl}_{3}$ )

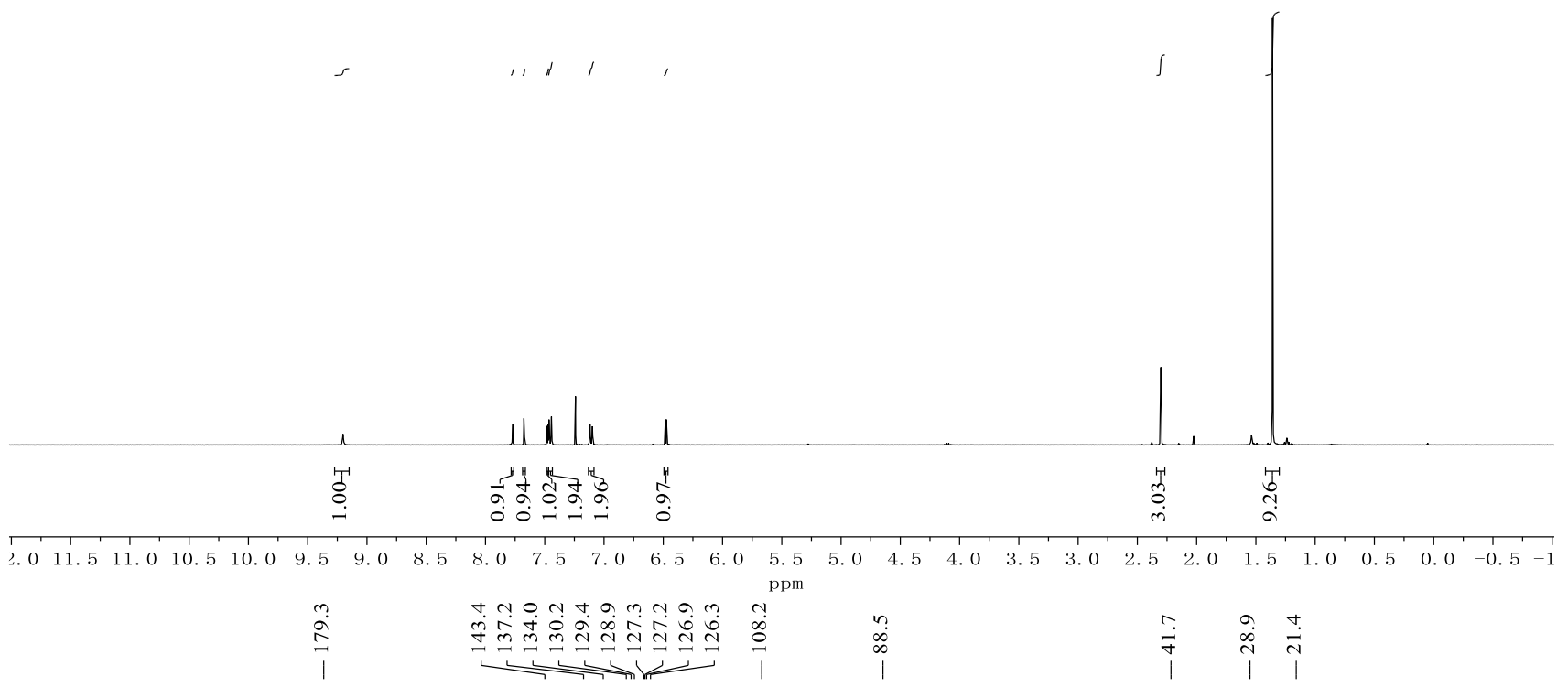<smiles>Pn1ccc2cc(I)cc([AsH3-])c21</smiles>

392j

$\left(100 \mathrm{MHz}, \mathrm{CDCl}_{3}\right)$

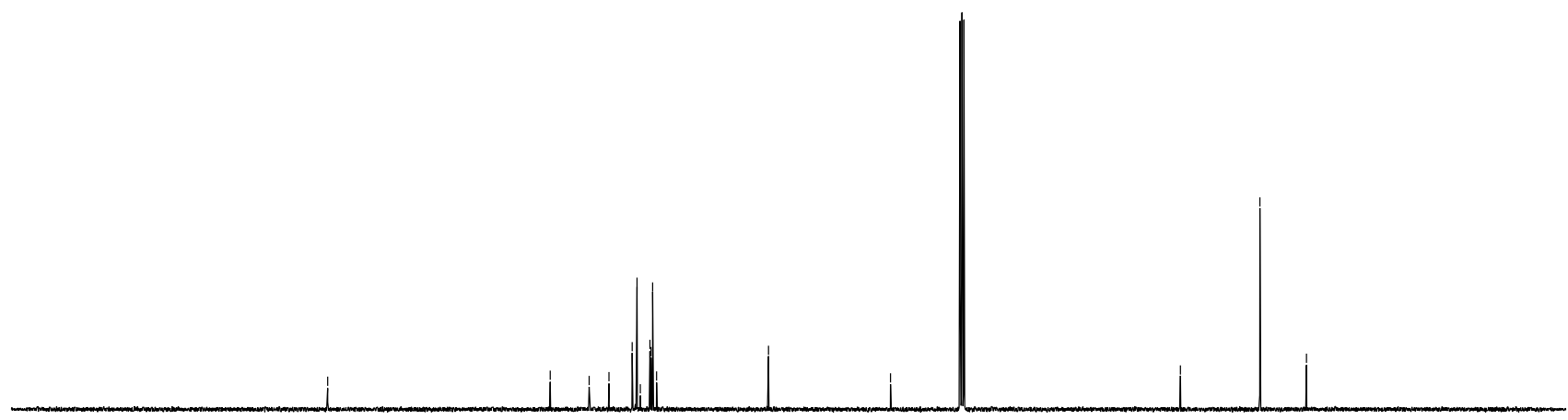

\begin{tabular}{llllllllllllllllllllllllllllllllllllll}
\hline 30 & 220 & 210 & 200 & 190 & 180 & 170 & 160 & 150 & 140 & 130 & 120 & 110 & 100 & 90 & 80 & 70 & 60 & 50 & 40 & 30 & 20 & 10 & 0 & -10 & -
\end{tabular} 
<smiles>Nc1c(F)ccc2ccn(P)c12</smiles>

392k

(400 MHz, $\mathrm{CDCl}_{3}$ )

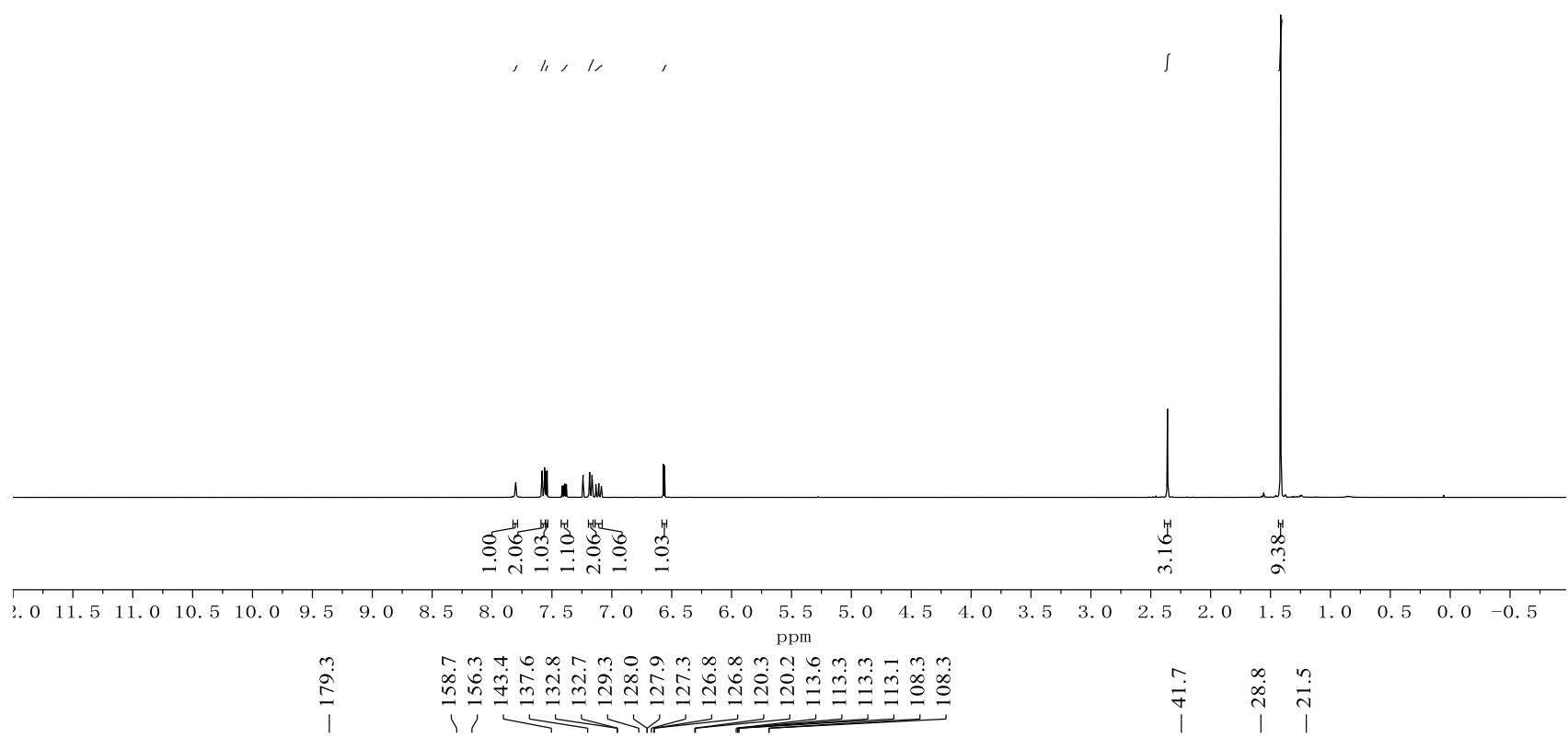<smiles>NPn1ccc2ccc(F)c(N)c21</smiles>

392k

(100 MHz, $\mathrm{CDCl}_{3}$ )

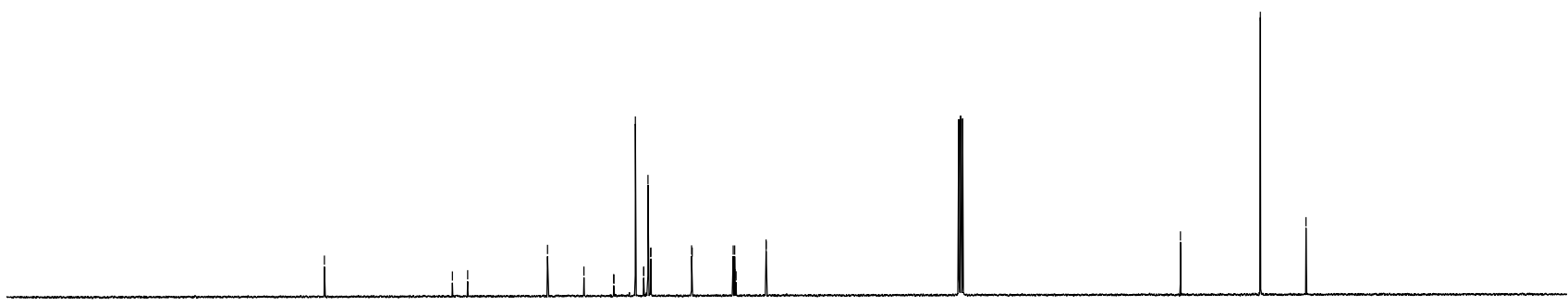

\begin{tabular}{llllllllllllllllllllllllllllllllllllllll}
\hline 30 & 220 & 210 & 200 & 190 & 180 & 170 & 160 & 150 & 140 & 130 & 120 & 110 & 100 & 90 & 80 & 70 & 60 & 50 & 40 & 30 & 20 & 10 & 0 & -10 & -1
\end{tabular} 


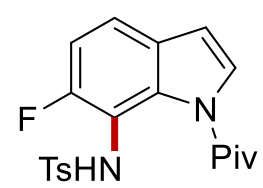

a 9

ㄱำ

is

392k

(282 MHz, $\mathrm{CDCl}_{3}$ )

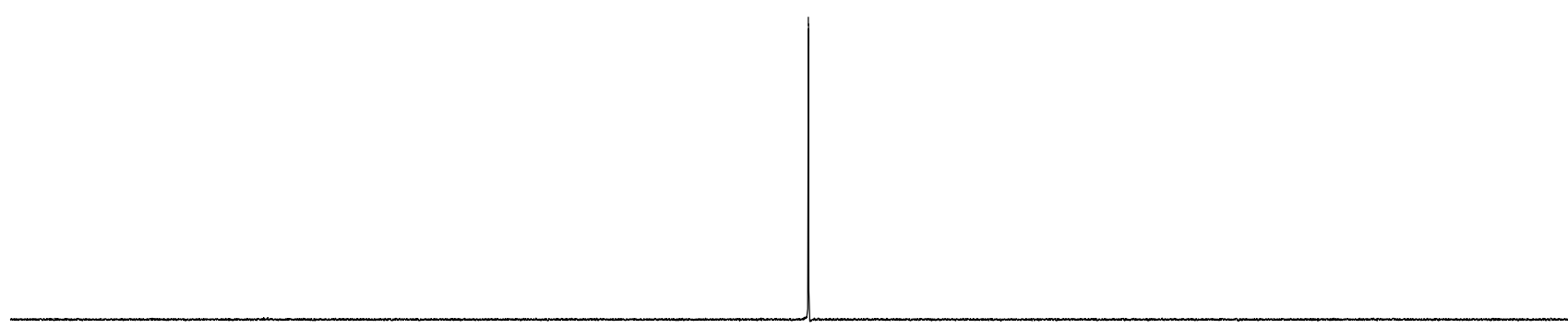

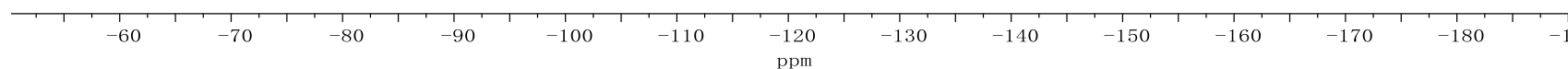


<smiles>O=S(=O)(Nc1cccc2ccn(P)c12)c1cccc(Br)c1</smiles>

3921

(400 MHz, $\mathrm{CDCl}_{3}$ )

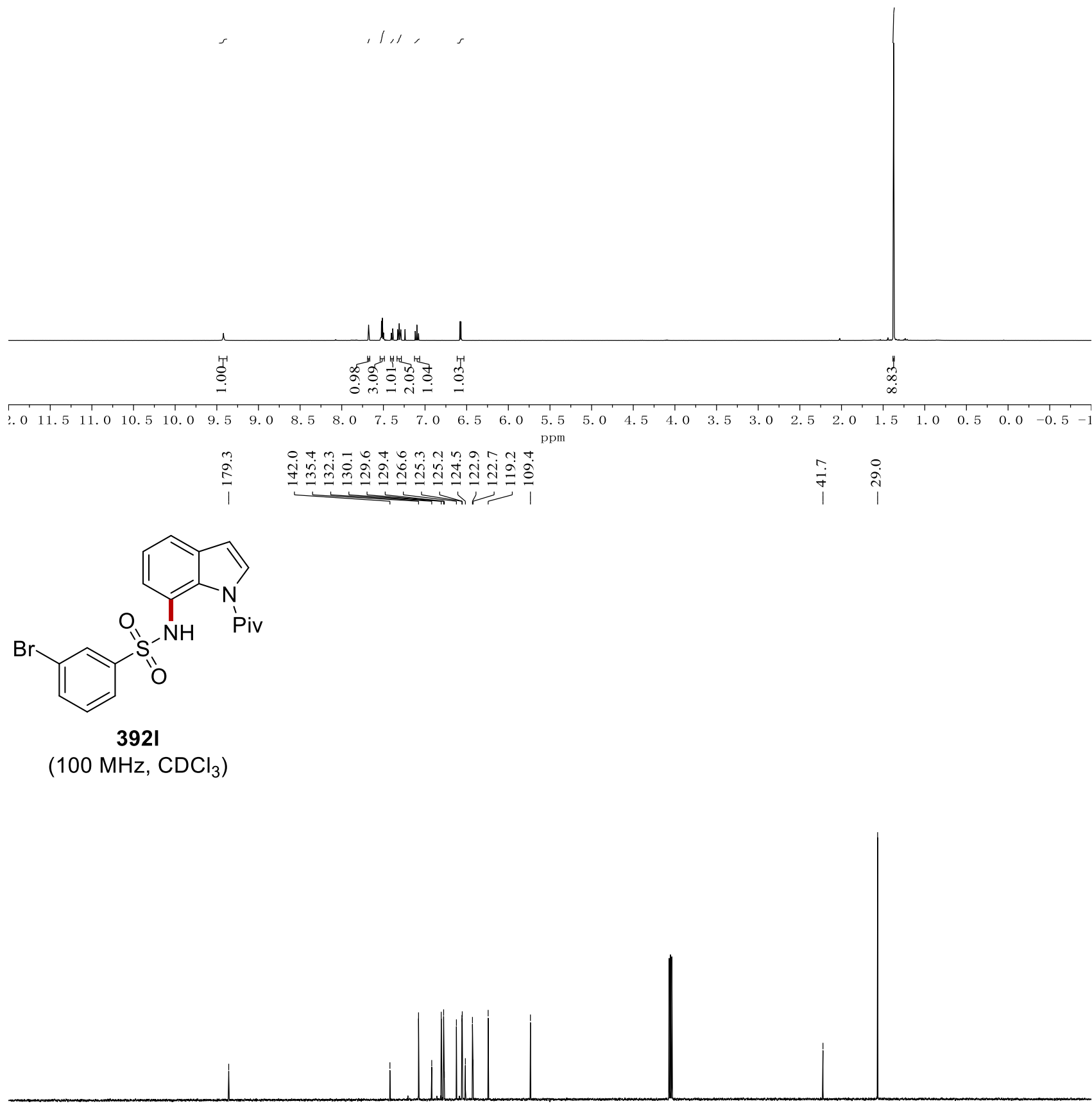

\begin{tabular}{llllllllllllllllllllllllllllllllllllll}
\hline 30 & 220 & 210 & 200 & 190 & 180 & 170 & 160 & 150 & 140 & 130 & 120 & 110 & 100 & 90 & 80 & 70 & 60 & 50 & 40 & 30 & 20 & 10 & 0 & -10 & -1
\end{tabular} 


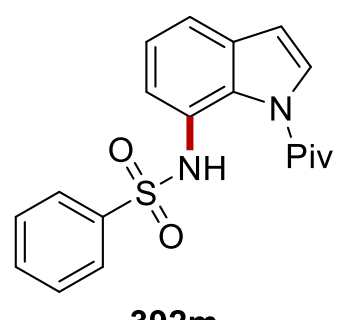

$392 \mathrm{~m}$

$\left(400 \mathrm{MHz} \mathrm{CDCl}_{3}\right)$

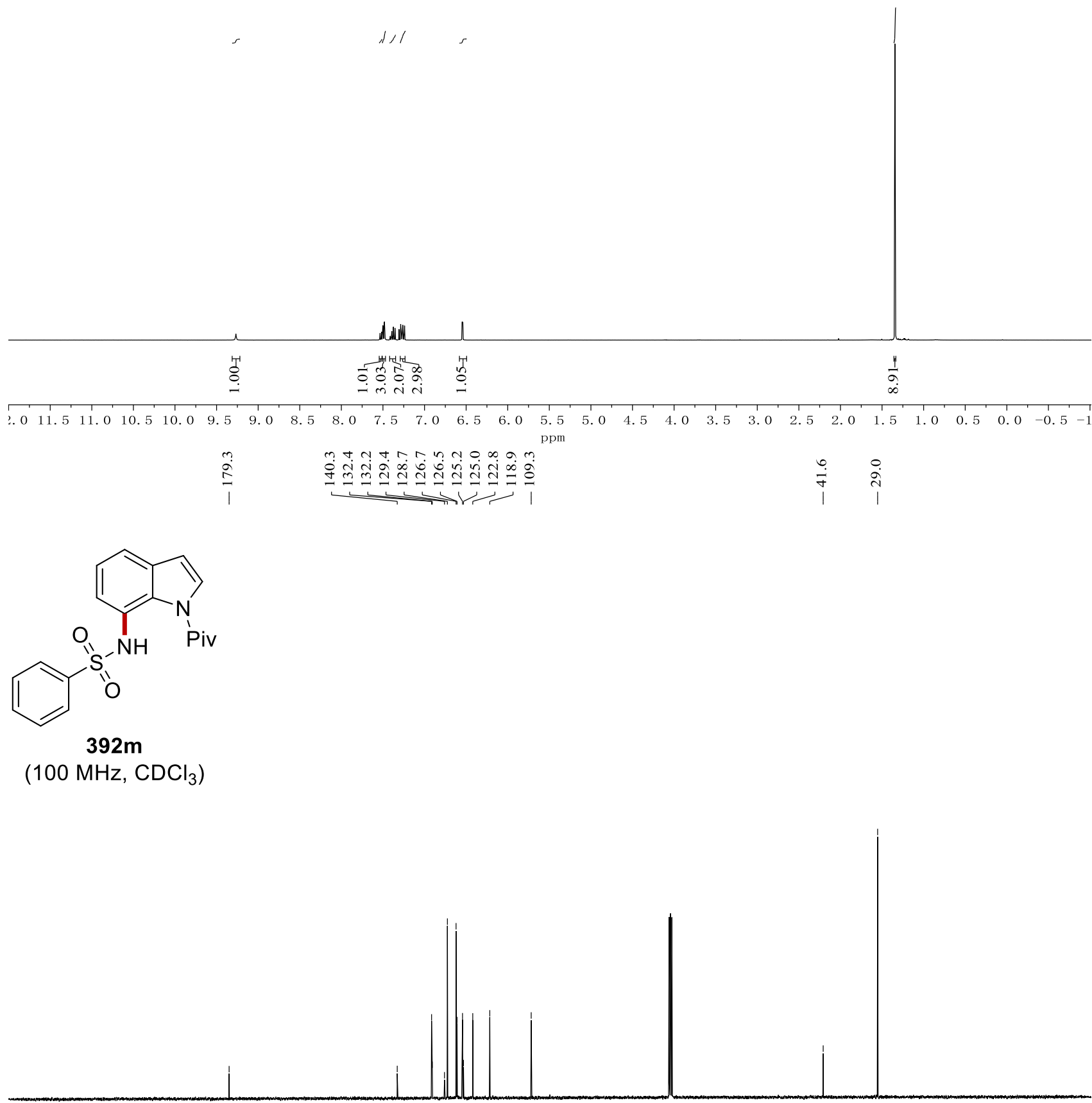

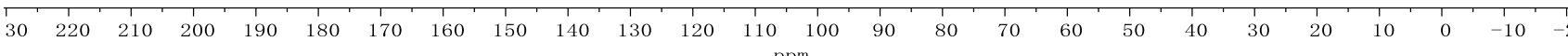


<smiles>CCCNc1cccc2ccn([PH](=O)(=O)Nc3ccccc3)c12</smiles>

392n

(400 MHz, $\mathrm{CDCl}_{3}$ )

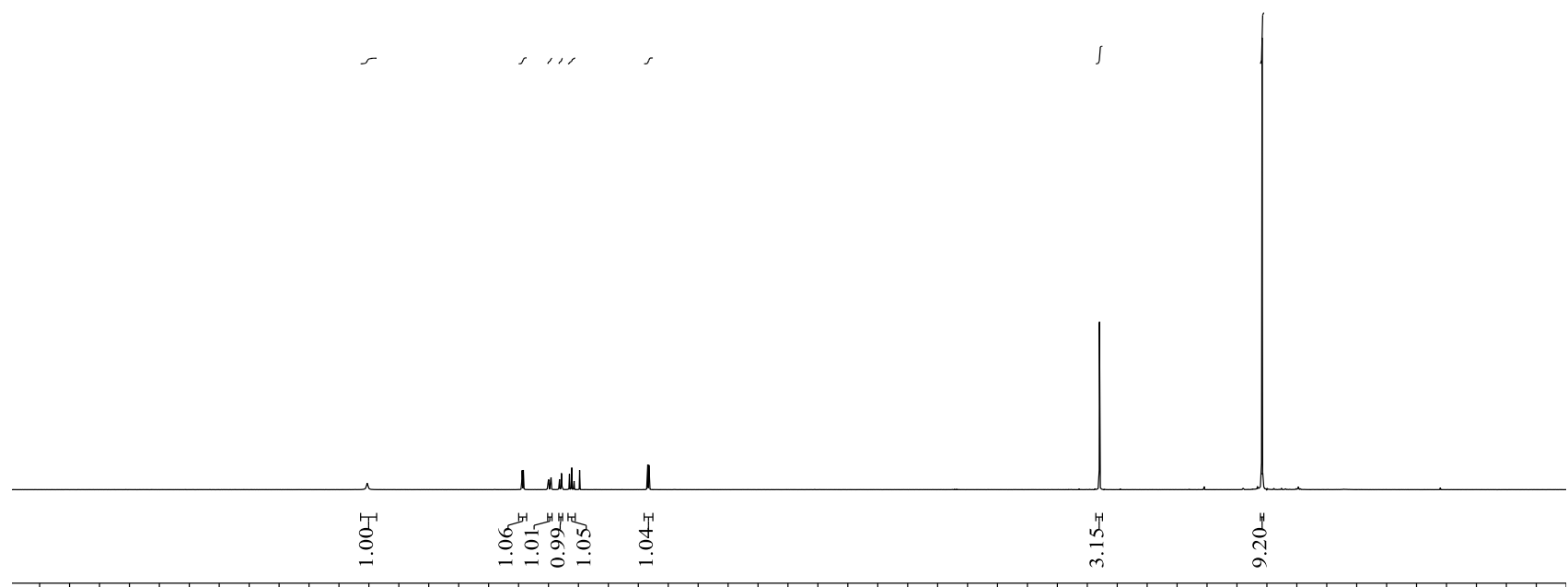

$\begin{array}{lllllllllllllllllllllllllllll}11.5 & 11.0 & 10.5 & 10.0 & 9.5 & 9.0 & 8.5 & 8.0 & 7.5 & 7.0 & 6.5 & 6.0 & 5.5 & 5.0 & 4.5 & 4.0 & 3.5 & 3.0 & 2.5 & 2.0 & 1.5 & 1.0 & 0.5 & 0.0 & -0.5 & -1\end{array}$

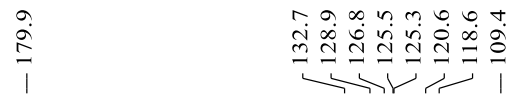

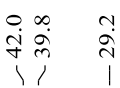<smiles>CS(=O)(=O)Nc1cccc2ccn(-c3ccccc3)c12</smiles>

392n

(100 MHz, $\mathrm{CDCl}_{3}$ )

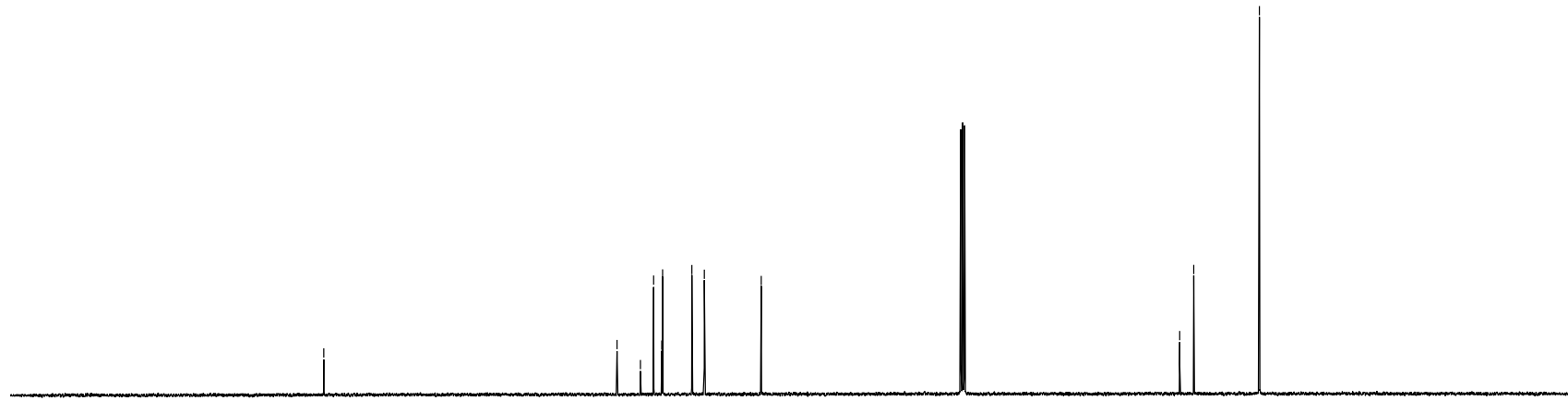

\begin{tabular}{lllllllllllllllllllllllllllllllllllll}
\hline 30 & 220 & 210 & 200 & 190 & 180 & 170 & 160 & 150 & 140 & 130 & 120 & 110 & 100 & 90 & 80 & 70 & 60 & 50 & 40 & 30 & 20 & 10 & 0 & -10 & -1
\end{tabular} 
<smiles>O=S(=O)(Nc1cccc2ccn(P)c12)C1CCCCC1</smiles>

3920

(400 MHz, $\mathrm{CDCl}_{3}$ )

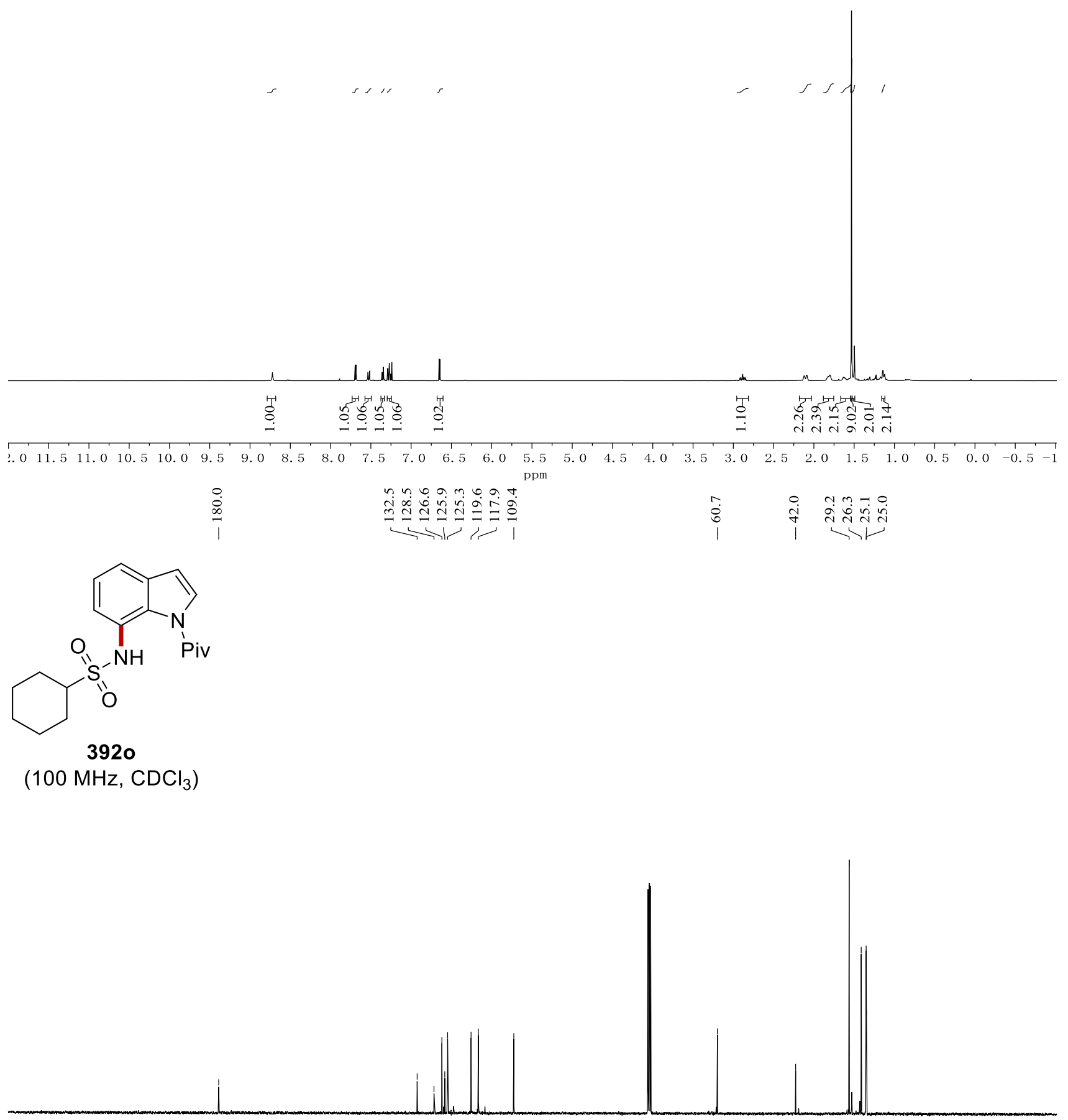

\begin{tabular}{lllllllllllllllllllllllllllllllllllllllll}
\hline 30 & 220 & 210 & 200 & 190 & 180 & 170 & 160 & 150 & 140 & 130 & 120 & 110 & 100 & 90 & 80 & 70 & 60 & 50 & 40 & 30 & 20 & 10 & 0 & -10 & -1
\end{tabular} 


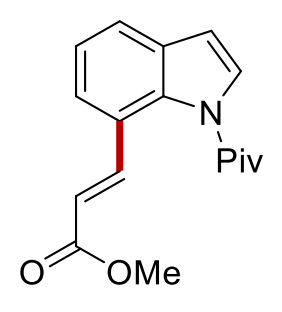

$394 a$

$\left(400 \mathrm{MHz}, \mathrm{CDCl}_{3}\right)$

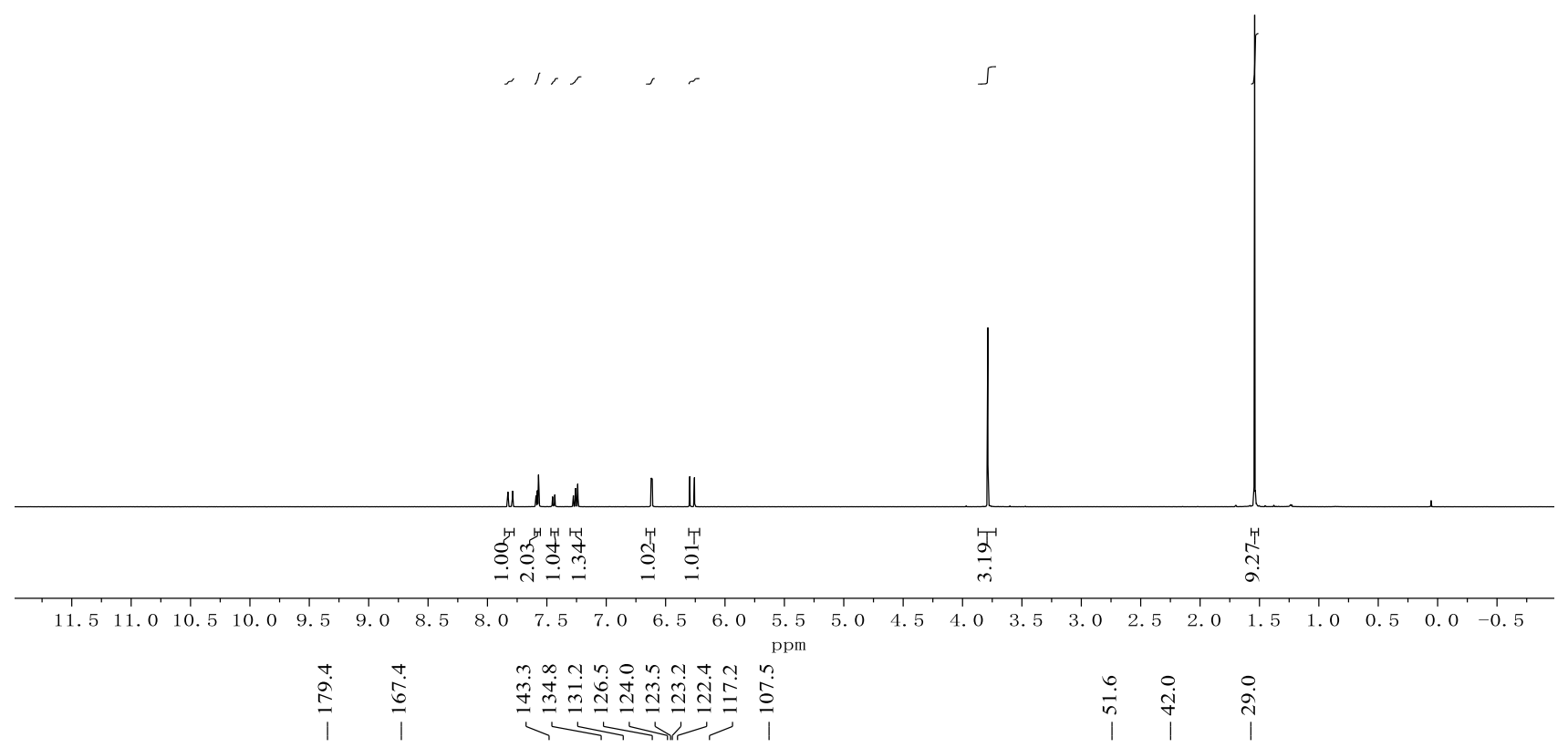<smiles>COC(=O)/C=C/c1cccc2ccn(P)c12</smiles>

394a

$\left(100 \mathrm{MHz}, \mathrm{CDCl}_{3}\right)$

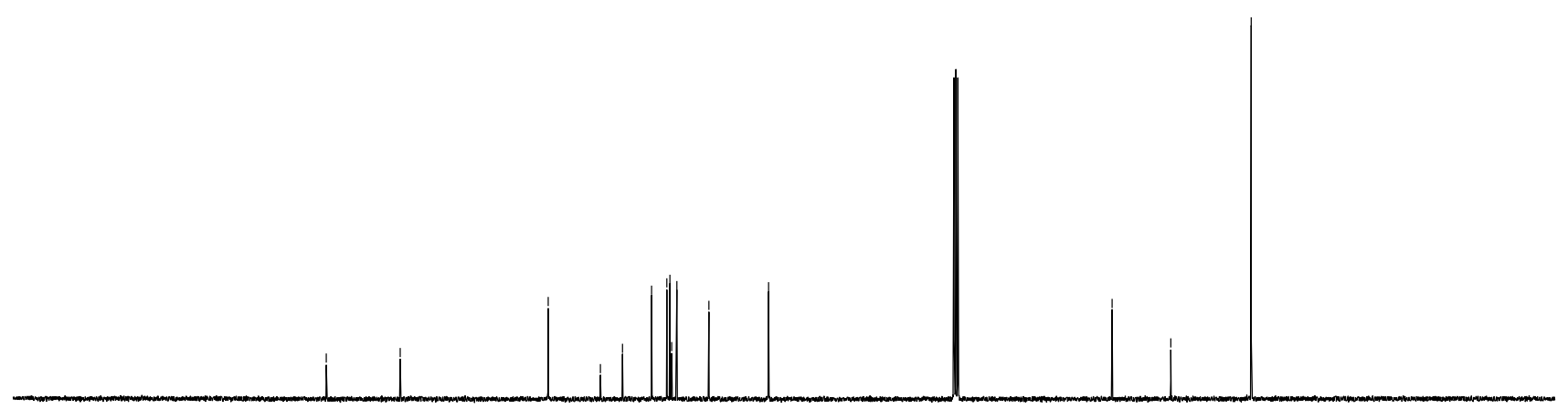

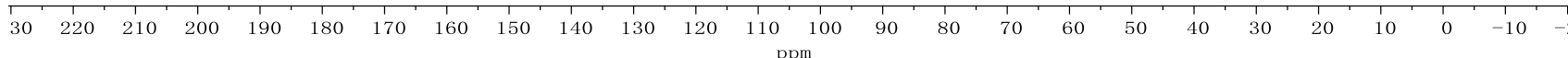


<smiles>COC(=O)/C=C/c1cccc2c(C)cn(P)c12</smiles>

394b

(400 MHz, $\mathrm{CDCl}_{3}$ )

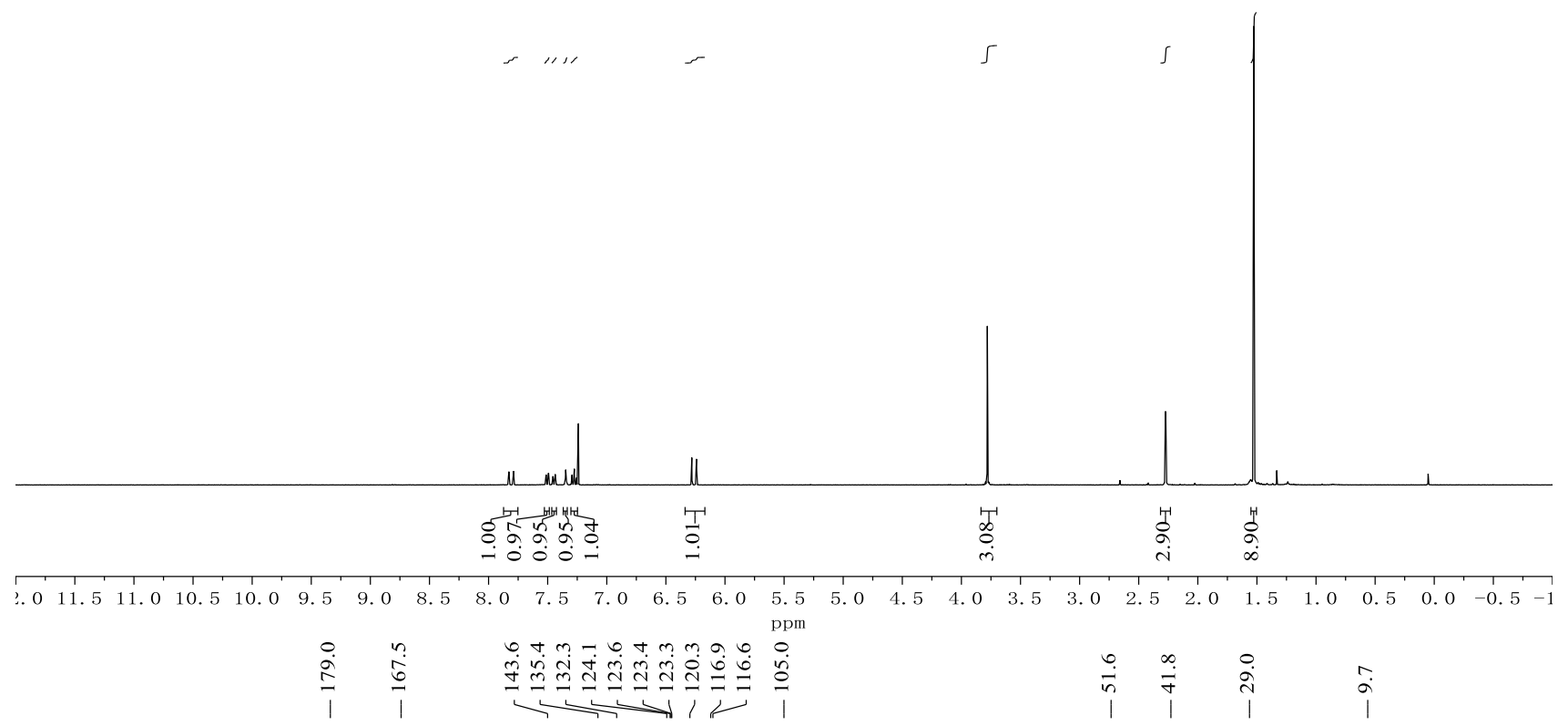<smiles>COC(=O)/C=C/c1cccc2c(C)cn(P)c12</smiles>

394b

$\left(100 \mathrm{MHz}, \mathrm{CDCl}_{3}\right.$ )

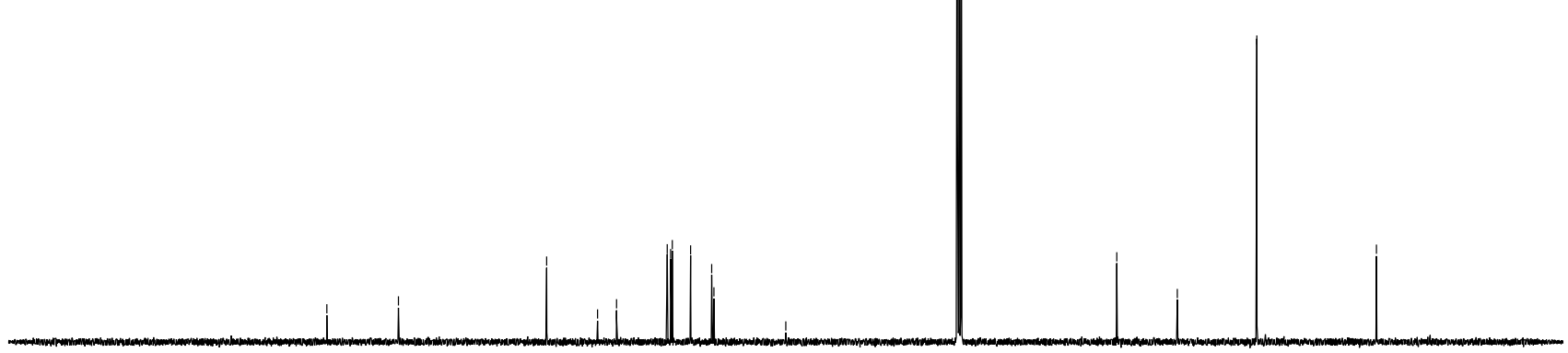

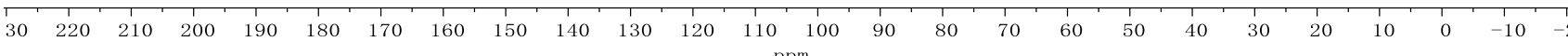


<smiles>COC(=O)/C=C/c1ccc(OC)c2ccn(P)c12</smiles>

$394 c$

(400 MHz, $\mathrm{CDCl}_{3}$ )

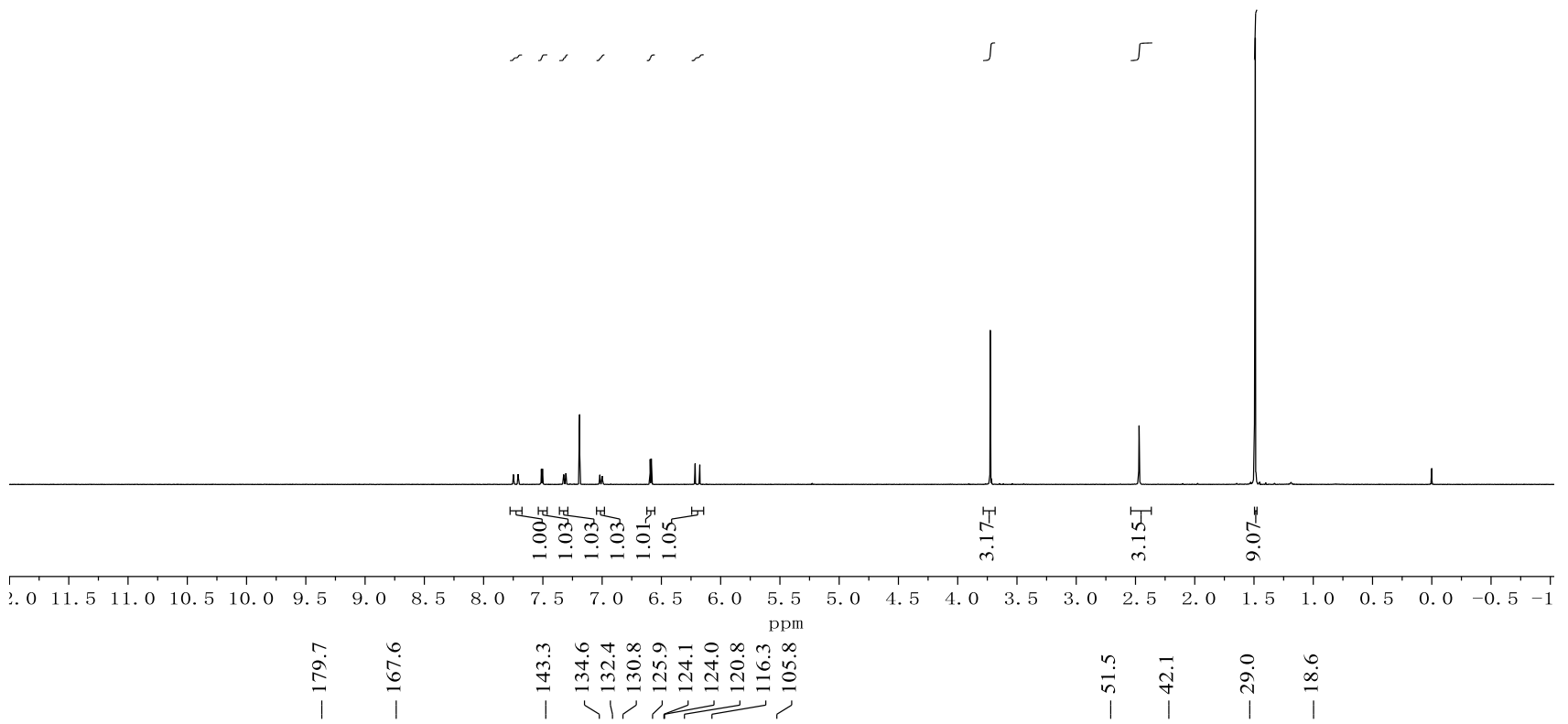<smiles>COC(=O)/C=C/c1ccc(OC)c2ccn(P)c12</smiles>

$394 \mathrm{c}$

$\left(100 \mathrm{MHz}, \mathrm{CDCl}_{3}\right)$

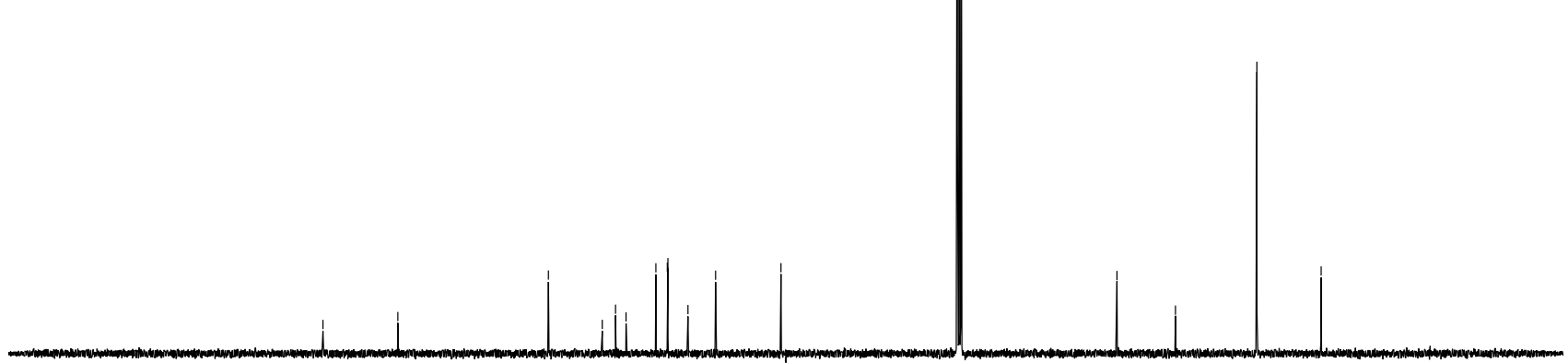

\begin{tabular}{lllllllllllllllllllllllllllllllllllll}
\hline 30 & 220 & 210 & 200 & 190 & 180 & 170 & 160 & 150 & 140 & 130 & 120 & 110 & 100 & 90 & 80 & 70 & 60 & 50 & 40 & 30 & 20 & 10 & 0 & -10 & -1
\end{tabular} 
<smiles>COC(=O)/C=C/c1ccc(OC)c2ccn(P)c12</smiles>

394d

$\left(400 \mathrm{MHz}, \mathrm{CDCl}_{3}\right)$

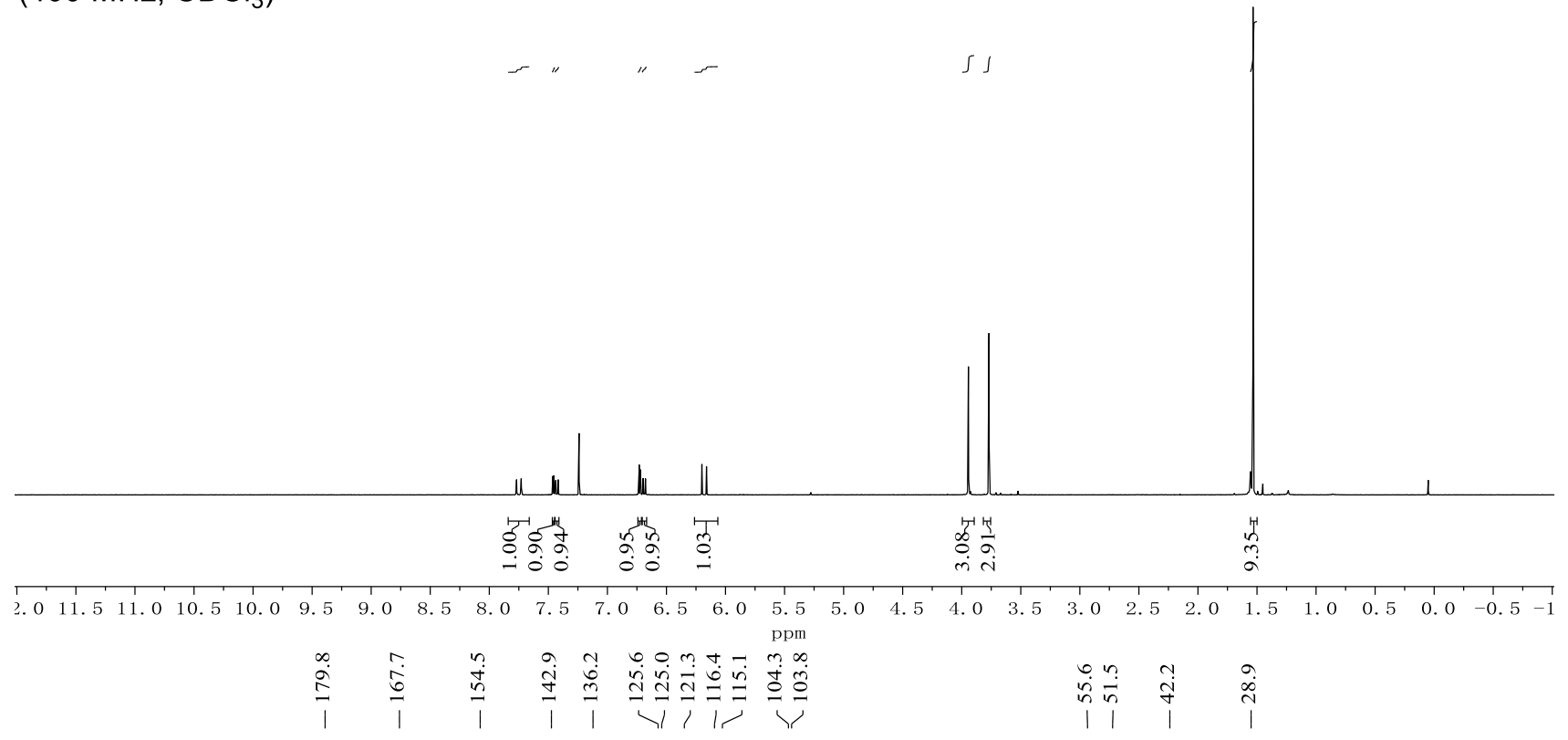<smiles>COC(=O)/C=C/c1ccc(OC)c2ccn(P)c12</smiles>

394d

(100 MHz, $\mathrm{CDCl}_{3}$ )

\begin{tabular}{lllllllllllllllllllllllllllllllllllllllll}
\hline 30 & 220 & 210 & 200 & 190 & 180 & 170 & 160 & 150 & 140 & 130 & 120 & 110 & 100 & 90 & 80 & 70 & 60 & 50 & 40 & 30 & 20 & 10 & 0 & -10 & $-\varepsilon$
\end{tabular} 
<smiles>COC(=O)/C=C/c1ccc(Br)c2ccn(P)c12</smiles>

394e $\left(400 \mathrm{MHz}, \mathrm{CDCl}_{3}\right)$

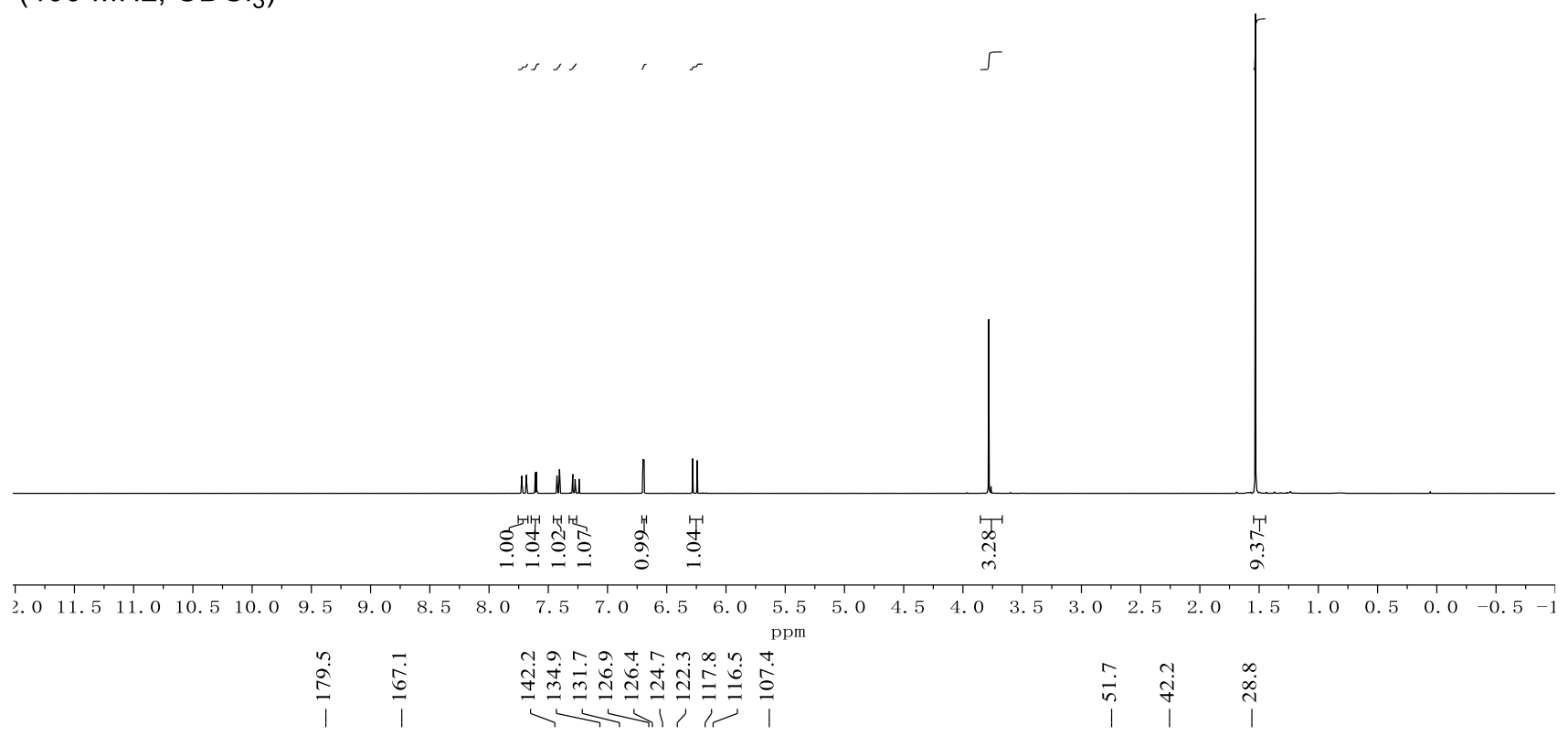<smiles>COC(=O)/C=C/c1ccc(Br)c2ccn(P)c12</smiles>

394e

$\left(100 \mathrm{MHz}, \mathrm{CDCl}_{3}\right)$

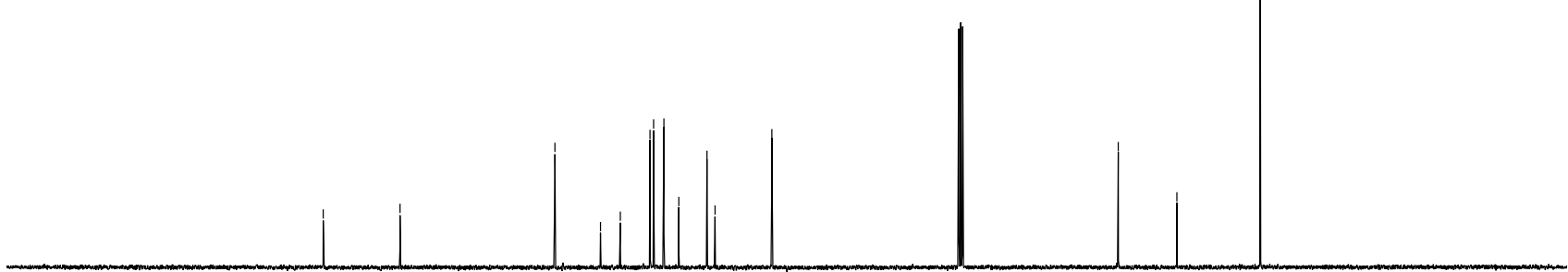

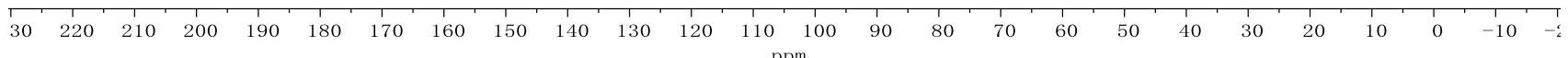




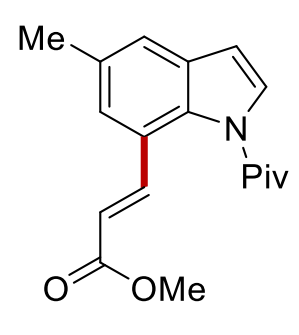

$394 f$

(400 MHz, $\mathrm{CDCl}_{3}$ )

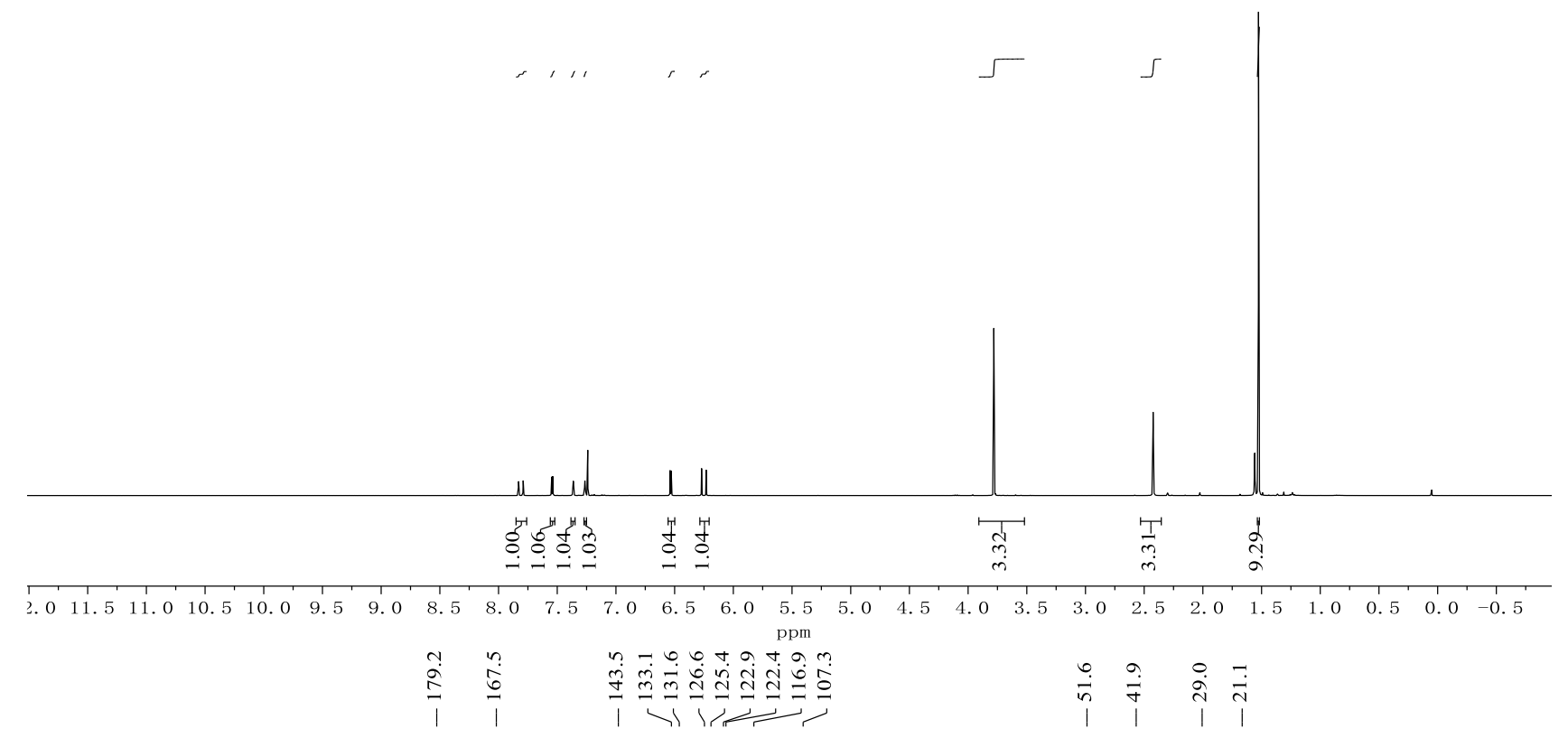<smiles>COC(=O)/C=C/c1cc(C)cc2ccn(P(#N)OC(=O)OCc3ccccc3)c12</smiles>

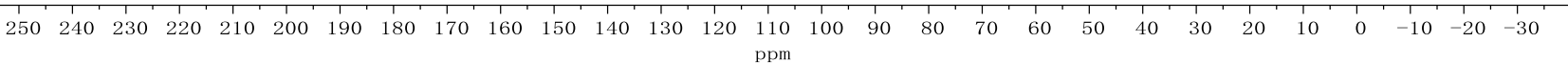




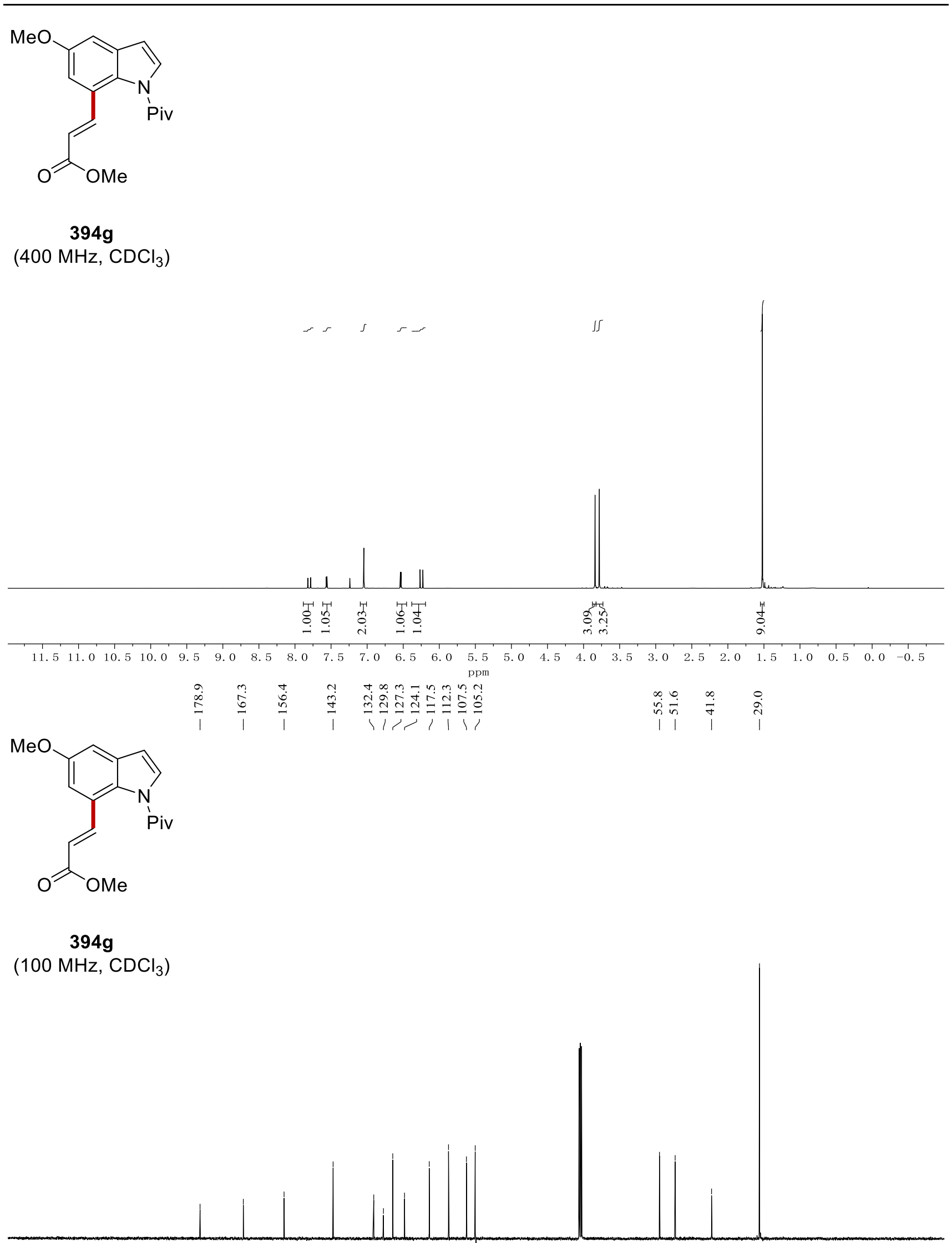

\begin{tabular}{llllllllllllllllllllllllllllllllllll}
\hline 30 & 220 & 210 & 200 & 190 & 180 & 170 & 160 & 150 & 140 & 130 & 120 & 110 & 100 & 90 & 80 & 70 & 60 & 50 & 40 & 30 & 20 & 10 & 0 & -10 & -1
\end{tabular} 


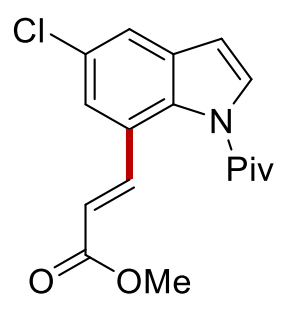

394h

(400 $\mathrm{MHz}, \mathrm{CDCl}_{3}$ )

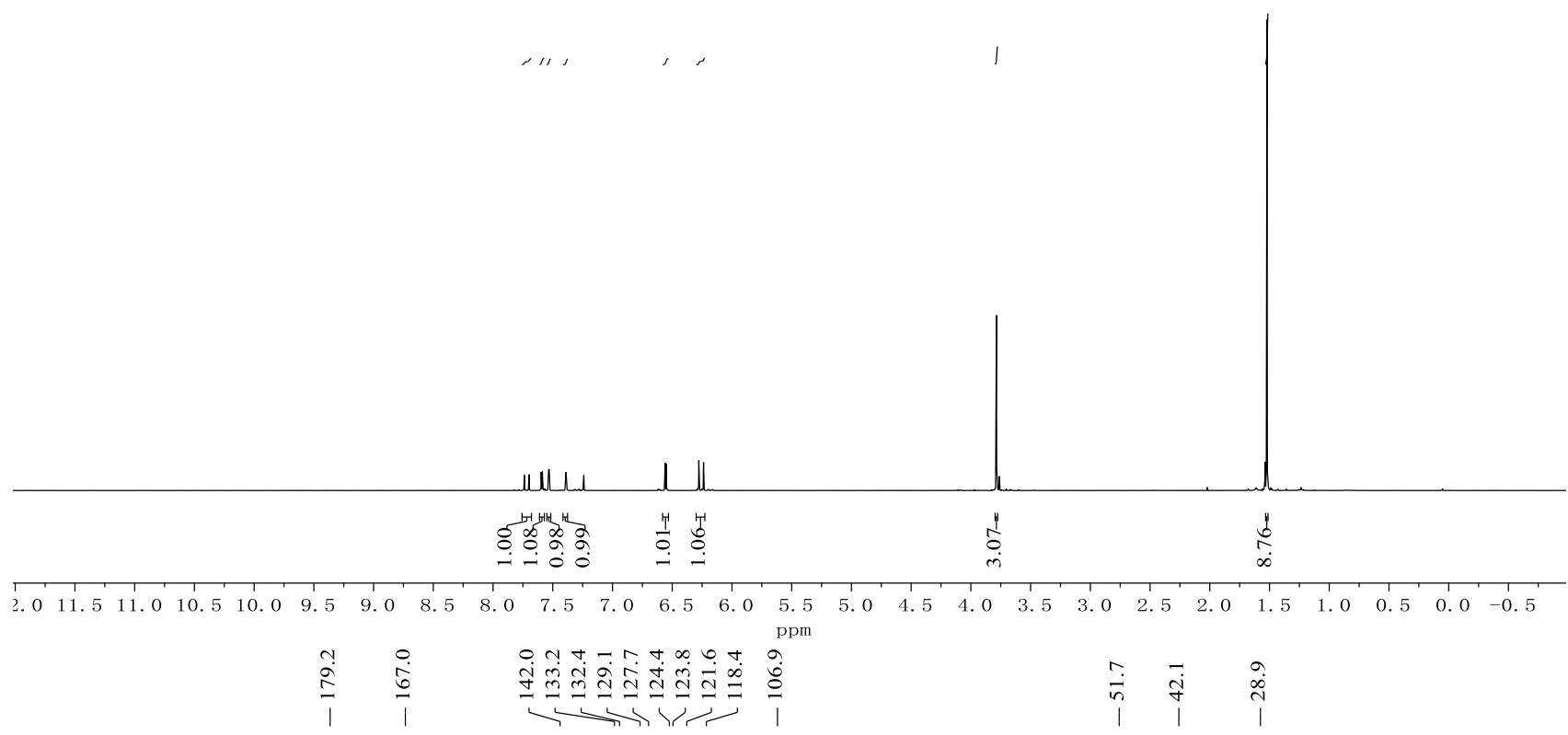<smiles>COC(=O)/C=C/c1cc(Cl)cc2ccn([PH](=O)c3ccccc3)c12</smiles>

394h

(100 MHz, $\mathrm{CDCl}_{3}$ )

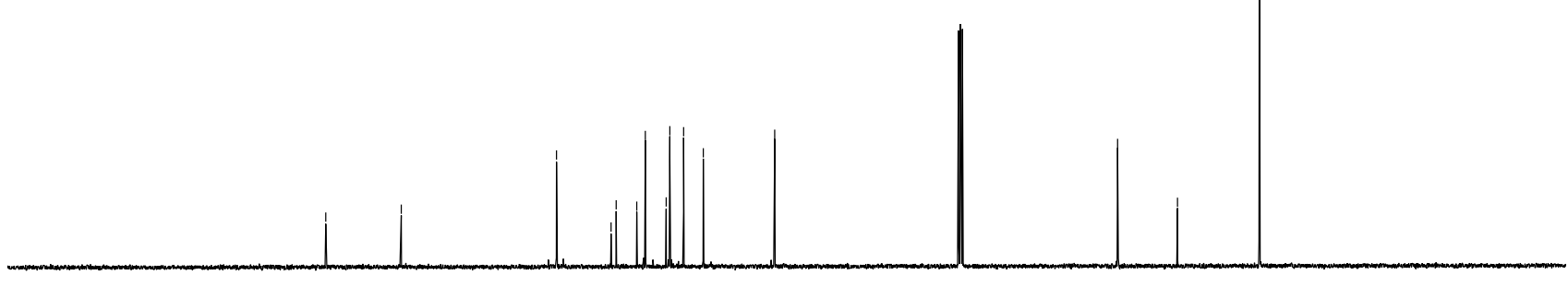

\begin{tabular}{lllllllllllllllllllllllllllllllllllll}
\hline 30 & 220 & 210 & 200 & 190 & 180 & 170 & 160 & 150 & 140 & 130 & 120 & 110 & 100 & 90 & 80 & 70 & 60 & 50 & 40 & 30 & 20 & 10 & 0 & -10 & -1
\end{tabular} 


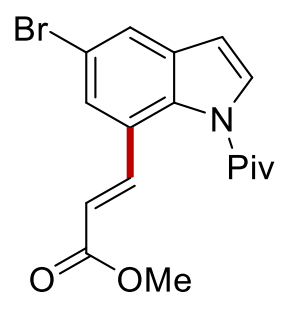

394i

$\left(400 \mathrm{MHz} \mathrm{CDCl}_{3}\right)$

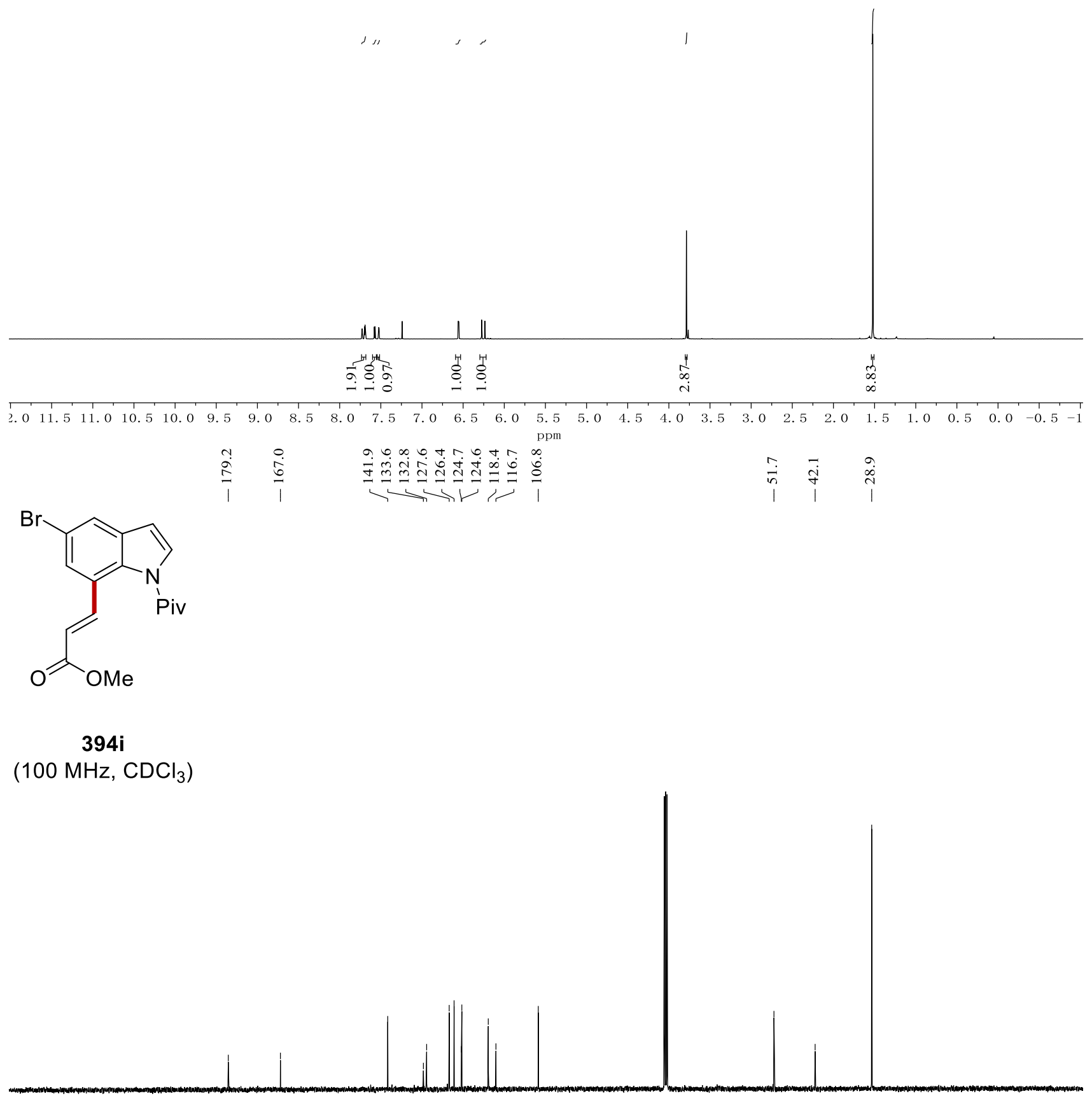

\begin{tabular}{llllllllllllllllllllllllllllllllllllllll}
\hline 30 & 220 & 210 & 200 & 190 & 180 & 170 & 160 & 150 & 140 & 130 & 120 & 110 & 100 & 90 & 80 & 70 & 60 & 50 & 40 & 30 & 20 & 10 & 0 & -10 & -4
\end{tabular} 
<smiles>CCOC(=O)/C=C/c1cccc2ccn(P)c12</smiles>

394j

(400 MHz, $\mathrm{CDCl}_{3}$ )

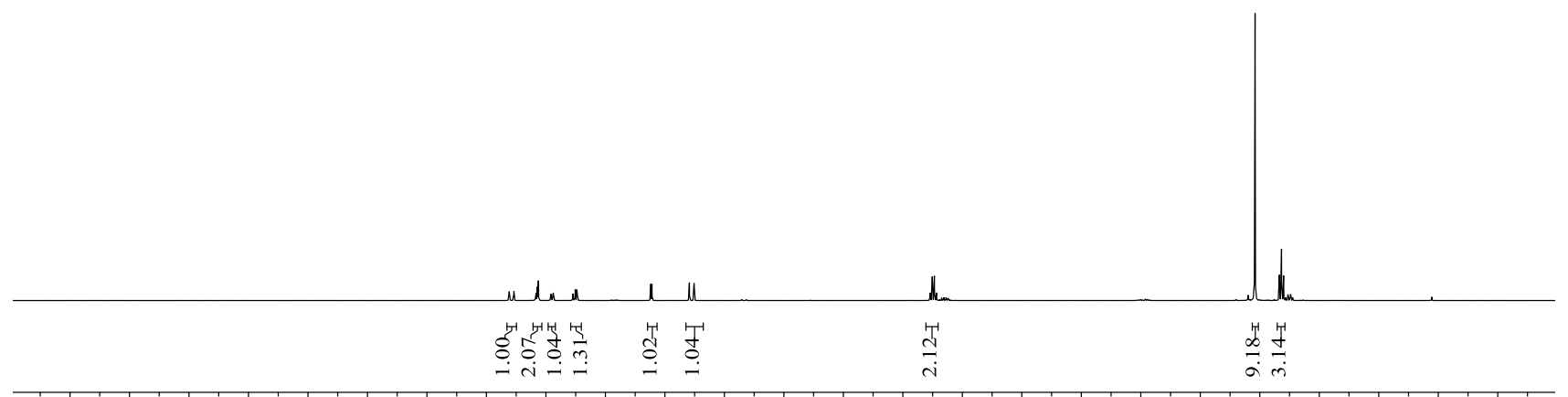

$\begin{array}{lllllllllllllllllllllllllllll}11.5 & 11.0 & 10.5 & 10.0 & 9.5 & 9.0 & 8.5 & 8.0 & 7.5 & 7.0 & 6.5 & 6.0 & 5.5 & 5.0 & 4.5 & 4.0 & 3.5 & 3.0 & 2.5 & 2.0 & 1.5 & 1.0 & 0.5 & 0.0 & -0.5\end{array}$

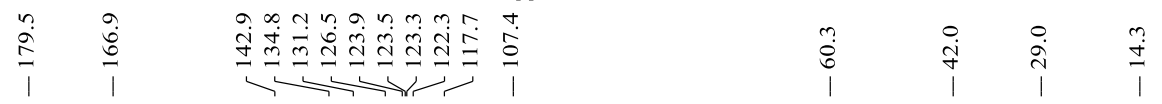<smiles>CCOC(=O)/C=C/c1cccc2ccn(P)c12</smiles>

394j

$\left(100 \mathrm{MHz}, \mathrm{CDCl}_{3}\right)$

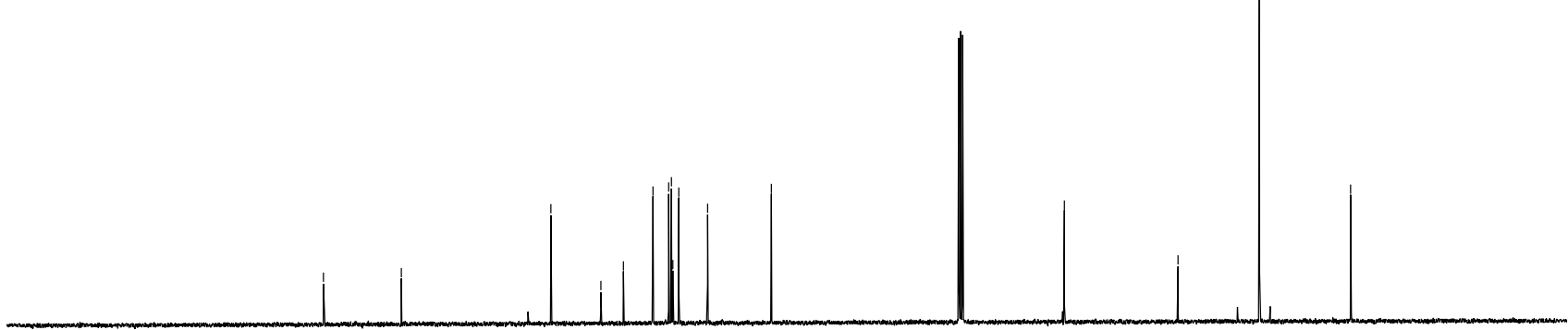

\begin{tabular}{lllllllllllllllllllllllllllllllllllllll}
\hline 30 & 220 & 210 & 200 & 190 & 180 & 170 & 160 & 150 & 140 & 130 & 120 & 110 & 100 & 90 & 80 & 70 & 60 & 50 & 40 & 30 & 20 & 10 & 0 & -10 & -1
\end{tabular} 


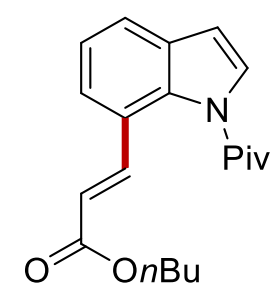

394k

$\left(400 \mathrm{MHz}, \mathrm{CDCl}_{3}\right)$

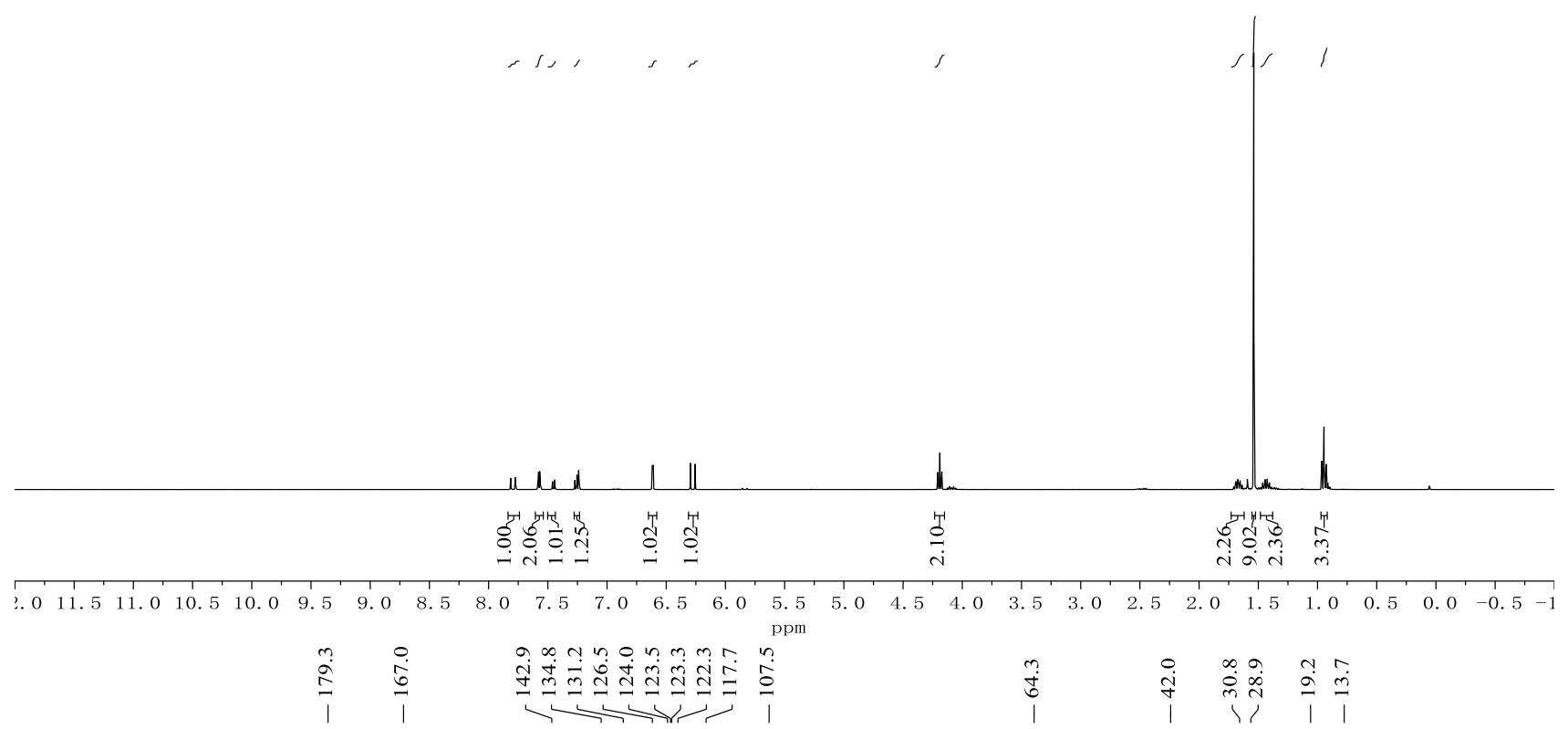

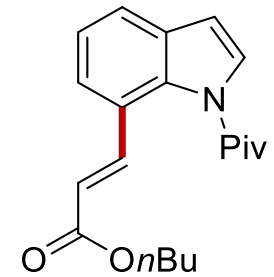

394k

(100 MHz, $\mathrm{CDCl}_{3}$ )

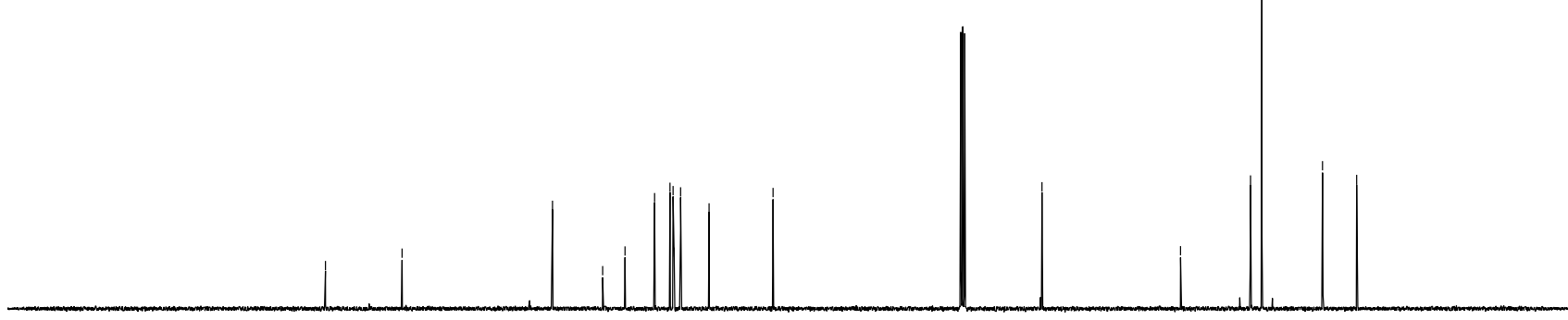

\begin{tabular}{lllllllllllllllllllllllllllllllllllllll}
\hline 30 & 220 & 210 & 200 & 190 & 180 & 170 & 160 & 150 & 140 & 130 & 120 & 110 & 100 & 90 & 80 & 70 & 60 & 50 & 40 & 30 & 20 & 10 & 0 & -10 & -1
\end{tabular} 
<smiles>O=C(/C=C/c1cccc2ccn(P)c12)OCc1ccccc1</smiles>

394I

(400 MHz, $\mathrm{CDCl}_{3}$ )

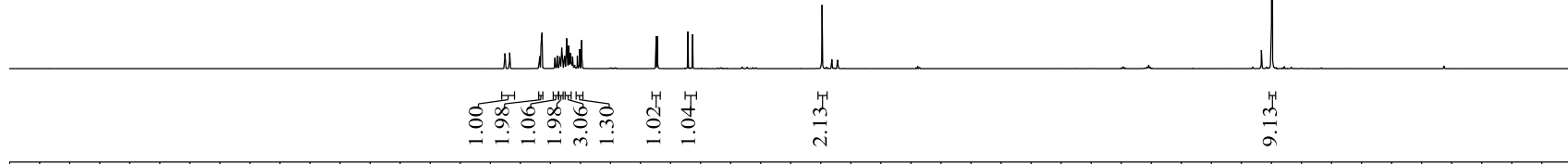
\begin{tabular}{llllllllllllllllllllllllllllll}
\hline .0 & 11.5 & 11.0 & 10.5 & 10.0 & 9.5 & 9.0 & 8.5 & 8.0 & 7.5 & 7.0 & 6.5 & 6.0 & 5.5 & 5.0 & 4.5 & 4.0 & 3.5 & 3.0 & 2.5 & 2.0 & 1.5 & 1.0 & 0.5 & 0.0 & -0.5
\end{tabular}

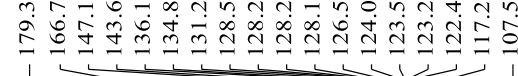<smiles>O=C(/C=C/c1cccc2ccn(P)c12)OCc1ccccc1</smiles>

3941

(100 MHz, $\mathrm{CDCl}_{3}$ )

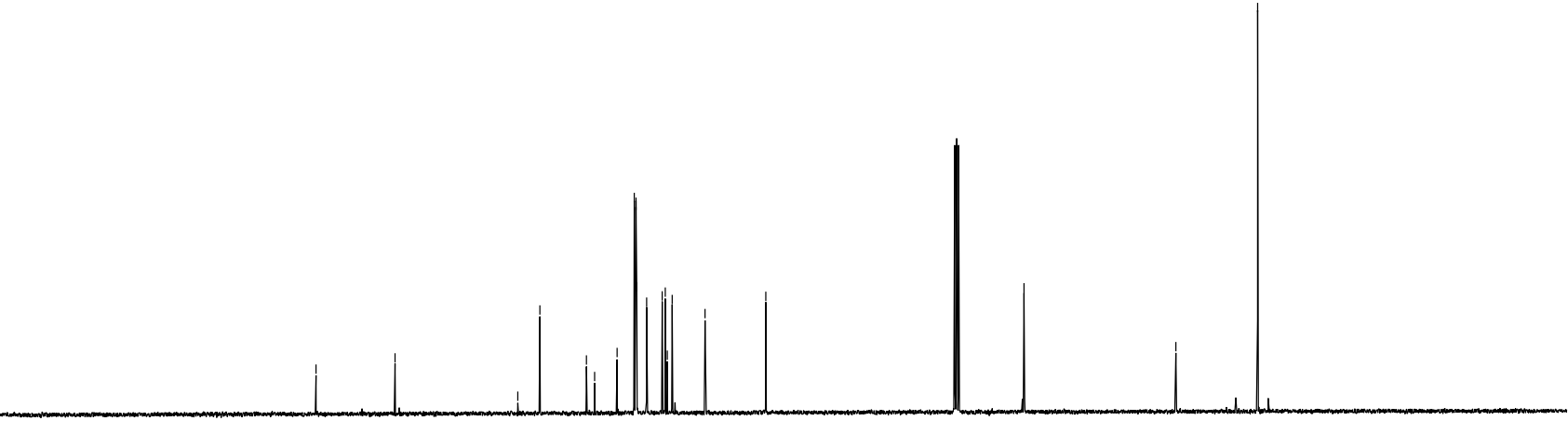

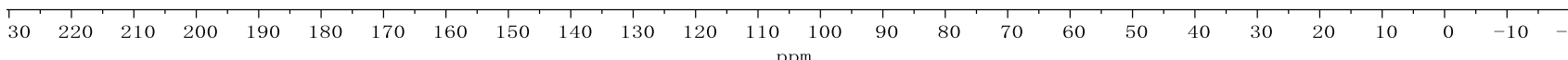


<smiles>ClC(Cl)Nc1cccc2cc[nH]c12</smiles>

TsHN

417

$\left(400 \mathrm{MHz}, \mathrm{CDCl}_{3}\right)$

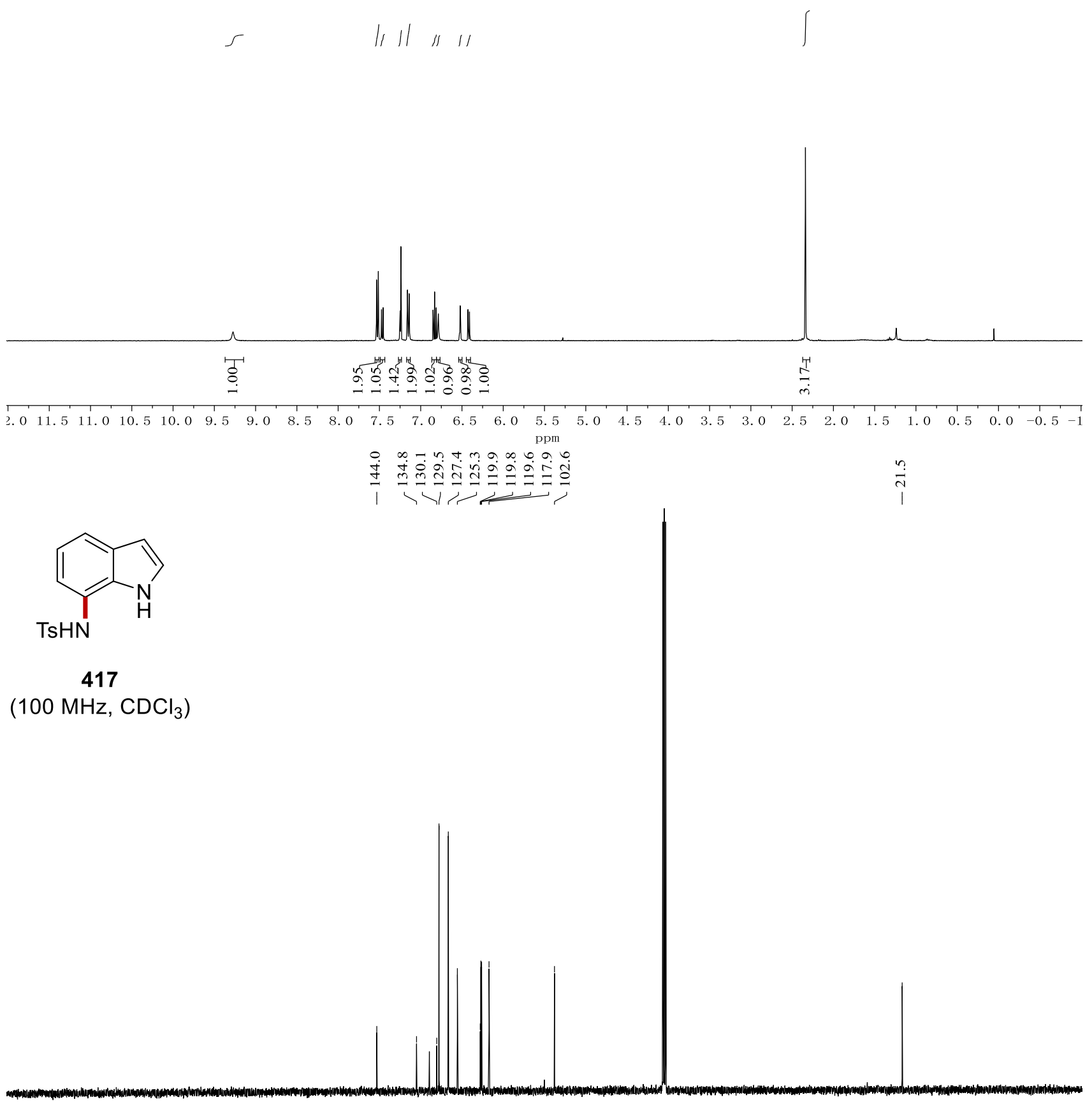

\begin{tabular}{lllllllllllllllllllllllllllllllllllllllll}
\hline 30 & 220 & 210 & 200 & 190 & 180 & 170 & 160 & 150 & 140 & 130 & 120 & 110 & 100 & 90 & 80 & 70 & 60 & 50 & 40 & 30 & 20 & 10 & 0 & -10 & -4
\end{tabular} 
<smiles>COC(=O)/C=C/c1cccc2cc[nH]c12</smiles>

418

$\left(400 \mathrm{MHz}, \mathrm{CDCl}_{3}\right)$

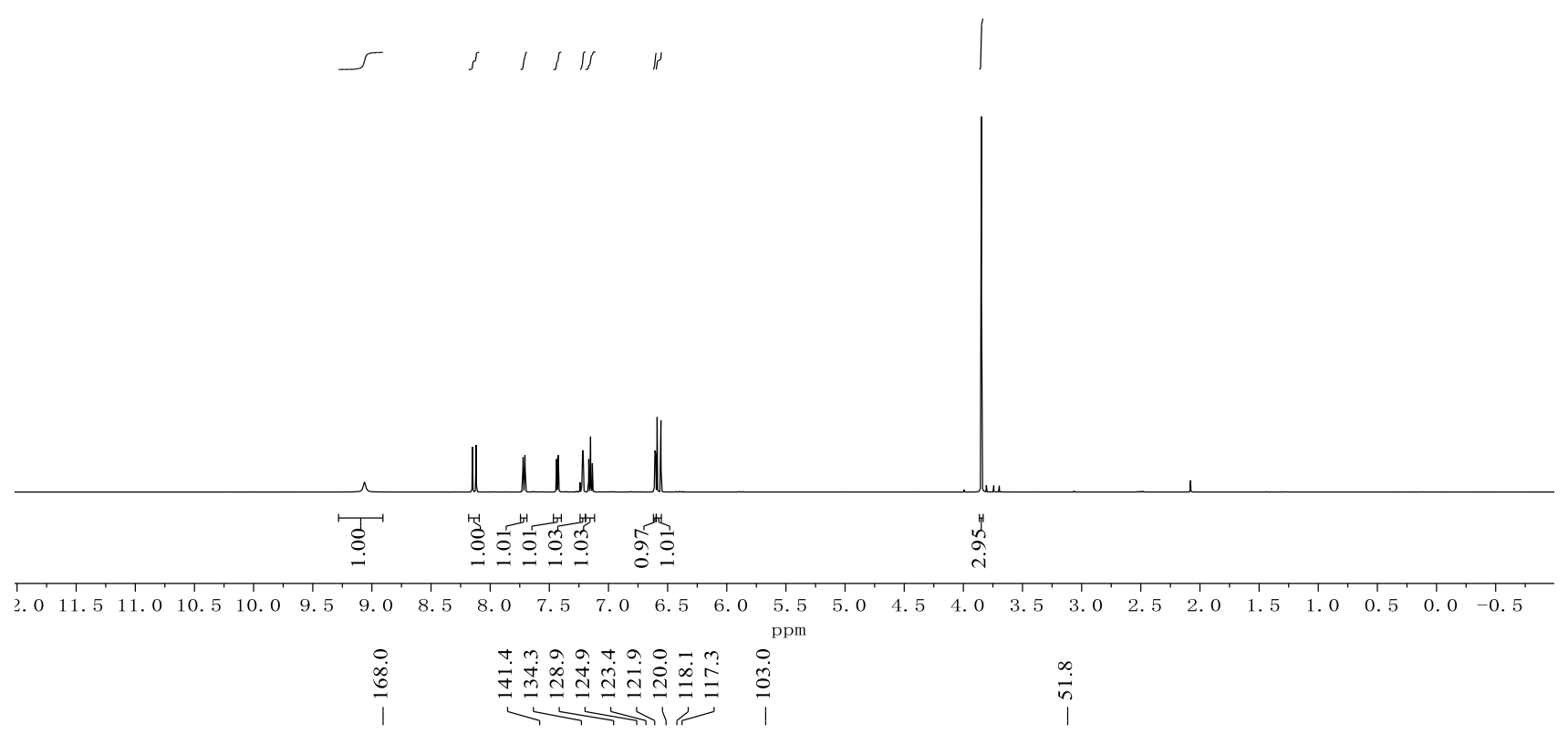<smiles>COC(=O)/C=C/c1cccc2cc[nH]c12</smiles>

418

$\left(100 \mathrm{MHz}, \mathrm{CDCl}_{3}\right.$ )

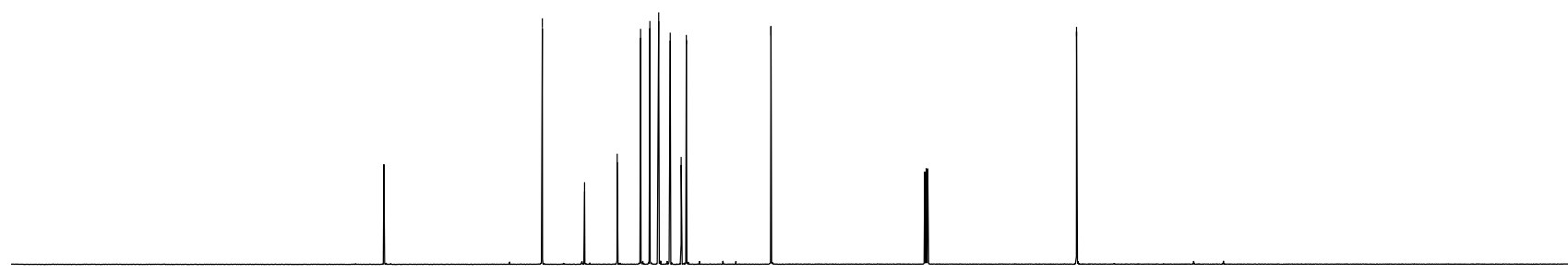

\begin{tabular}{llllllllllllllllllllllllllllllllll}
\hline 30 & 220 & 210 & 200 & 190 & 180 & 170 & 160 & 150 & 140 & 130 & 120 & 110 & 100 & 90 & 80 & 70 & 60 & 50 & 40 & 30 & 20 & 10 & 0 & -10 & -20 & -3
\end{tabular} 


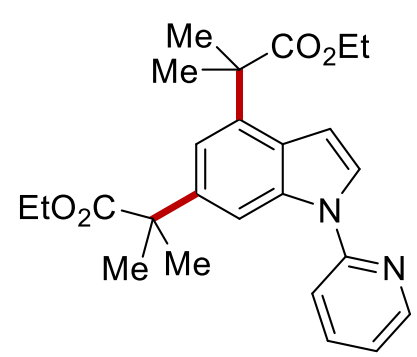

$397 a$

$\left(400 \mathrm{MHz} \mathrm{CDCl}_{3}\right)$
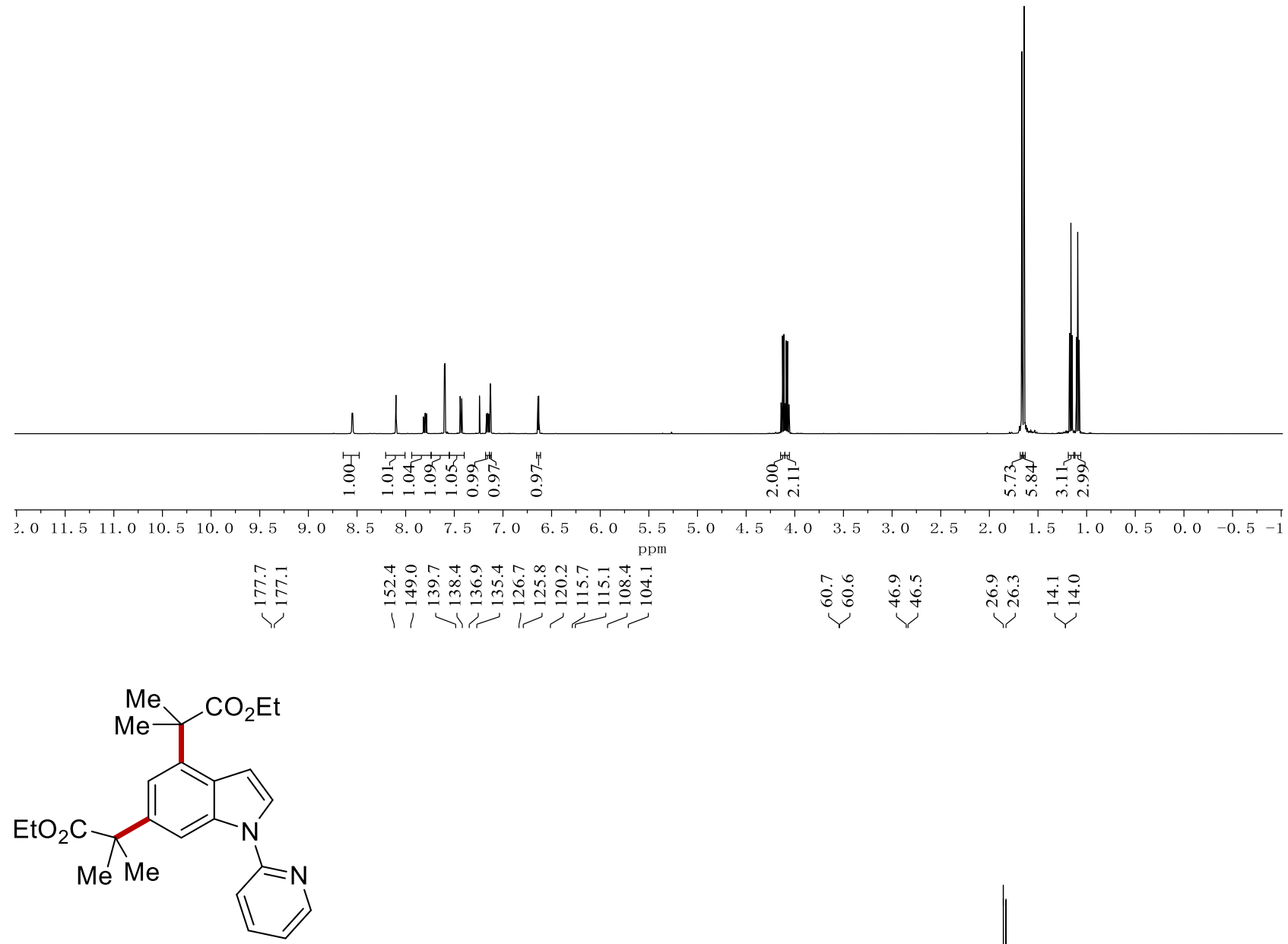

$397 a$

$\left.\left(100 \mathrm{MHz}^{\mathrm{CDCl}}\right)_{3}\right)$

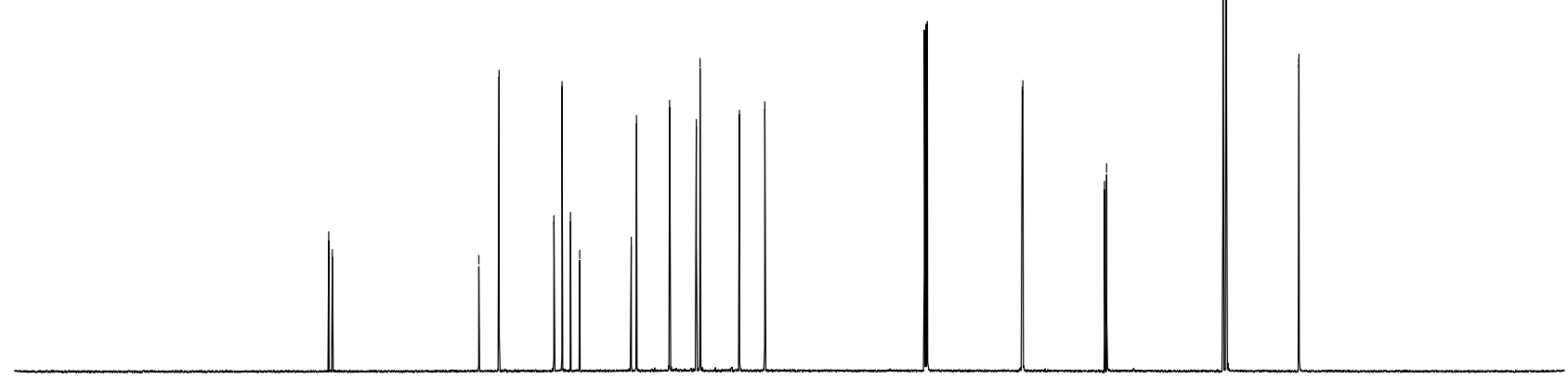

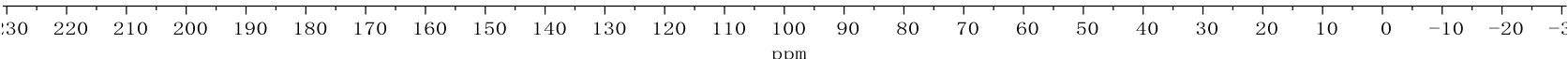




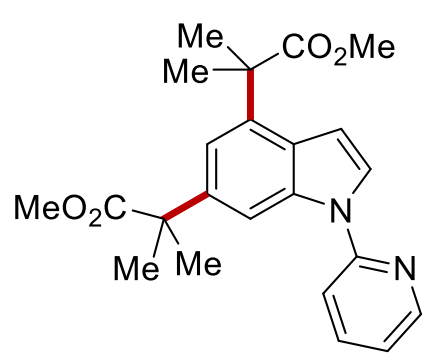

397b

$\left(400 \mathrm{MHz}, \mathrm{CDCl}_{3}\right)$
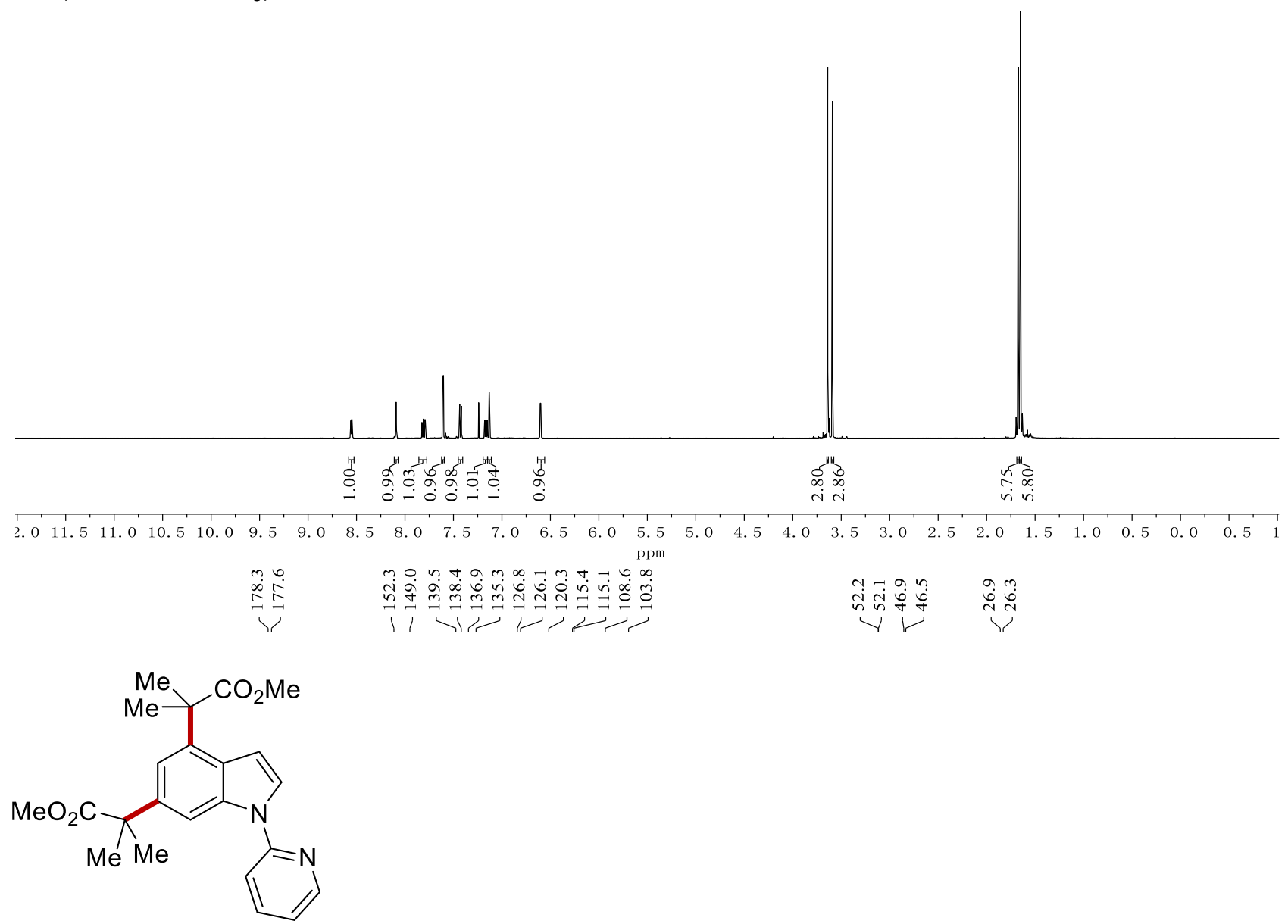

397b

$\left(100 \mathrm{MHz}, \mathrm{CDCl}_{3}\right)$

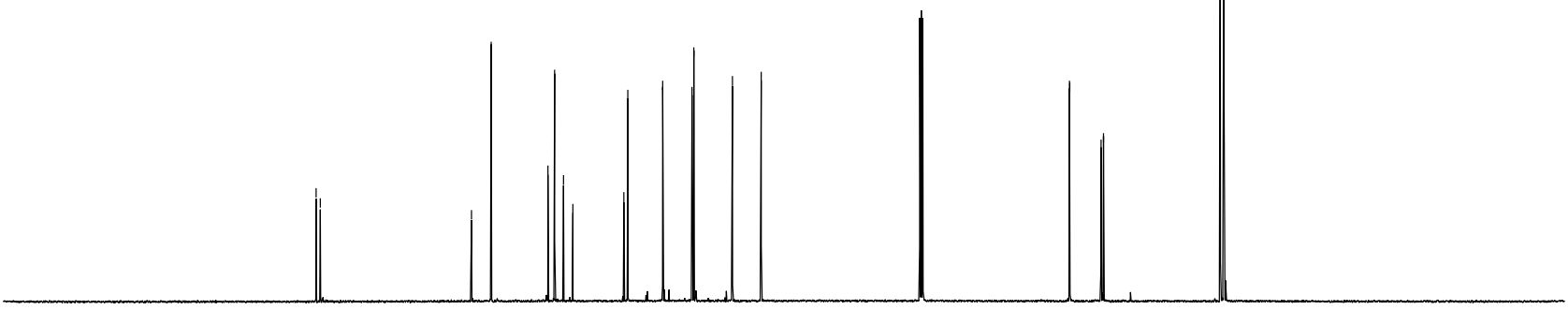

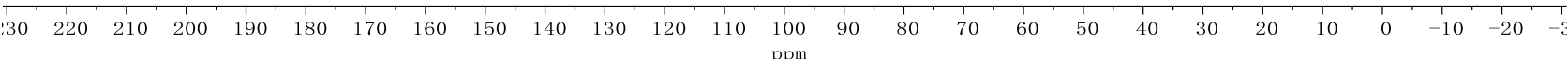



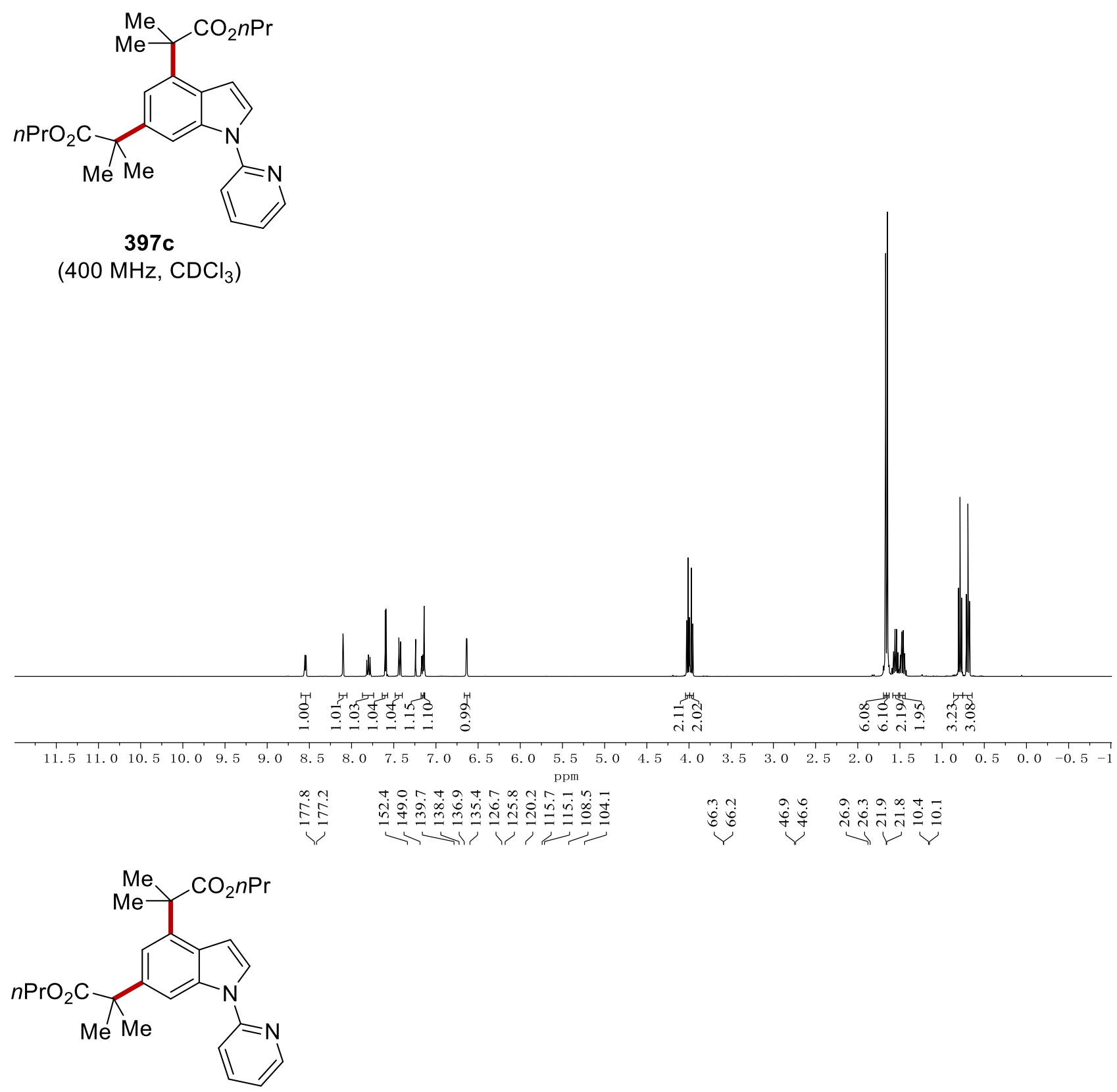

$397 \mathrm{c}$

(100 MHz, $\mathrm{CDCl}_{3}$ )

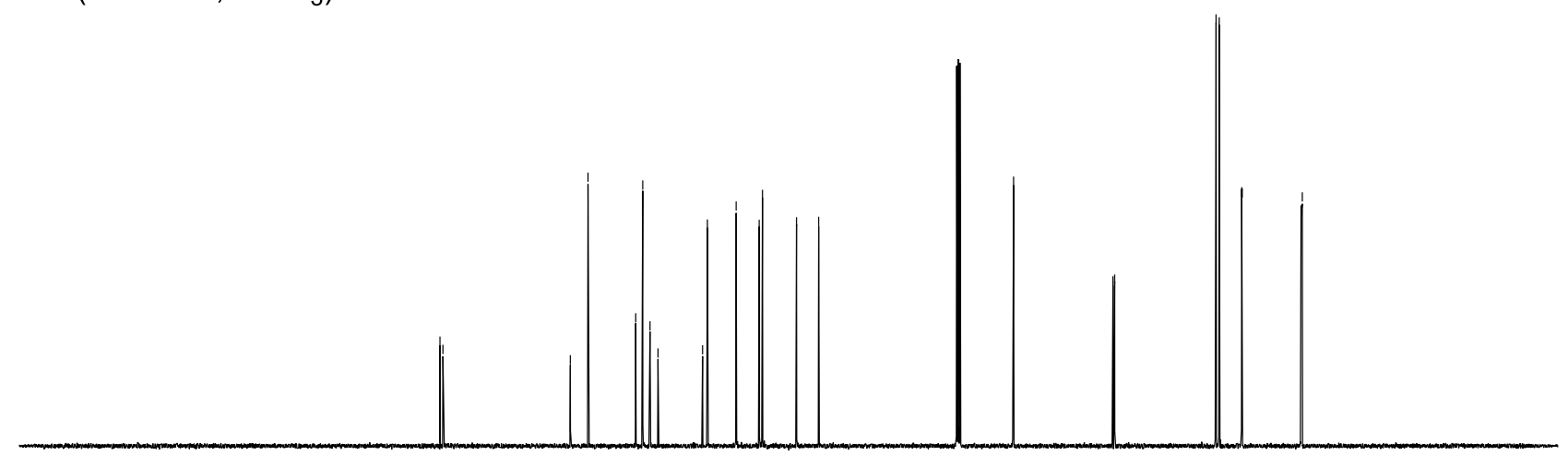

\begin{tabular}{llllllllllllllllllllllllllllllllll}
\hline 250 & 240 & 230 & 220 & 210 & 200 & 190 & 180 & 170 & 160 & 150 & 140 & 130 & 120 & 110 & 100 & 90 & 80 & 70 & 60 & 50 & 40 & 30 & 20 & 10 & 0 & -10 & -20 & -30
\end{tabular} 


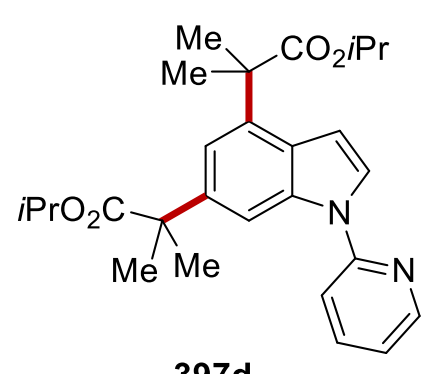

397d

(400 MHz, $\mathrm{CDCl}_{3}$ )

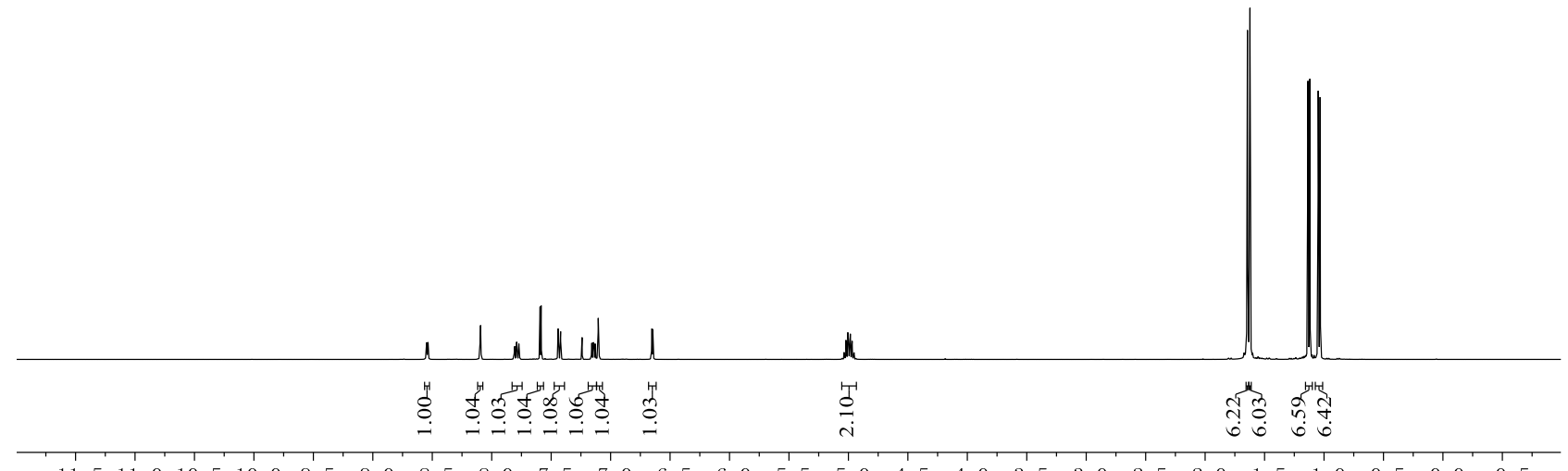

$\begin{array}{llllllllllllllllllllllllll}11.5 & 11.0 & 10.5 & 10.0 & 9.5 & 9.0 & 8.5 & 8.0 & 7.5 & 7.0 & 6.5 & 6.0 & 5.5 & 5.0 & 4.5 & 4.0 & 3.5 & 3.0 & 2.5 & 2.0 & 1.5 & 1.0 & 0.5 & 0.0 & -0.5\end{array}$

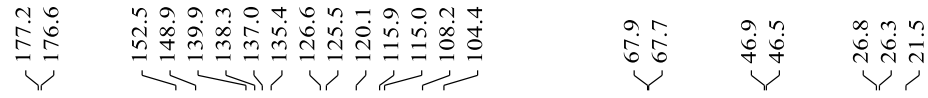<smiles>CC(C)OC(=O)C(C)(C)c1cc(C(C)(C)OC(C)C)cc2c1ccn2-c1ccccn1</smiles>

397d

(100 MHz, $\mathrm{CDCl}_{3}$ )

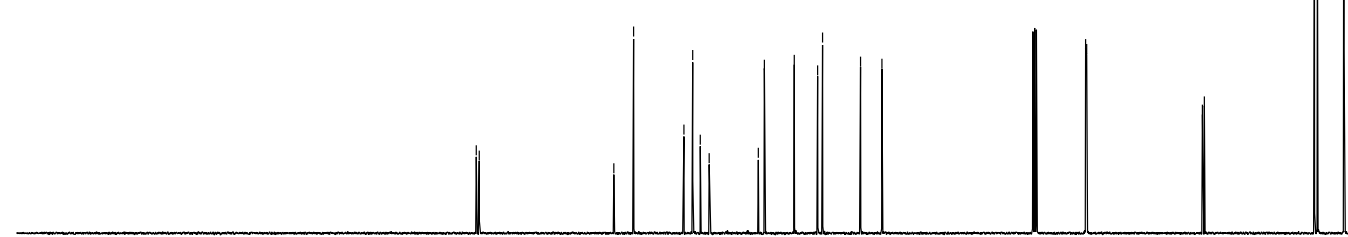

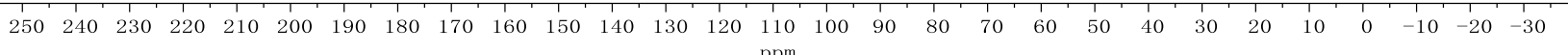




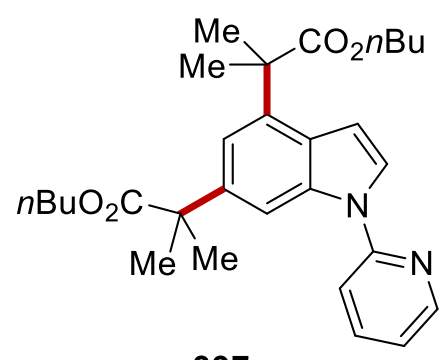

$397 e$

(400 MHz, $\mathrm{CDCl}_{3}$ )

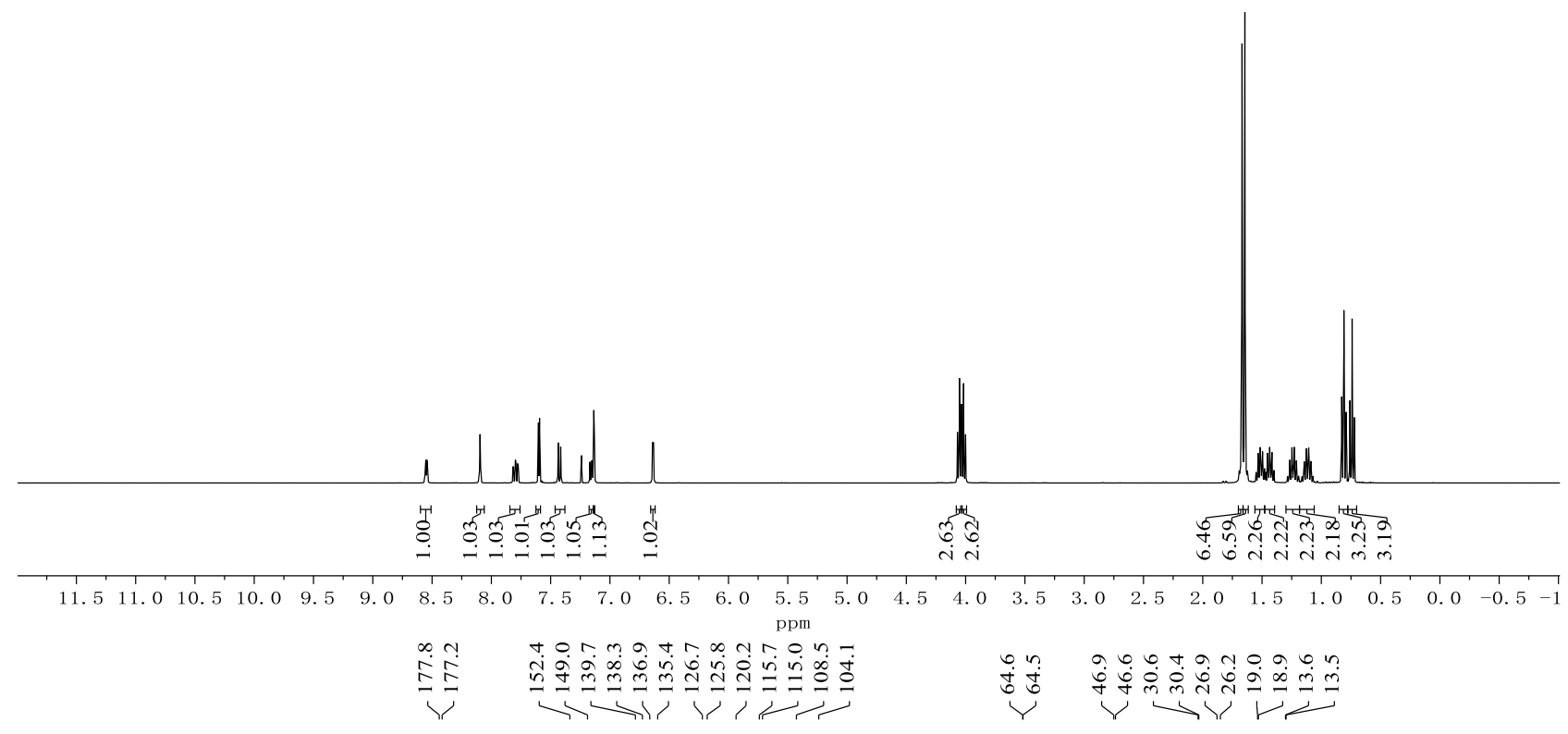<smiles>CCCCCC(C)(C)c1cc(C(C)(C)C(=O)OCCC)c2ccn(-c3ccccn3)c2c1</smiles>

397 e

$\left(100 \mathrm{MHz}, \mathrm{CDCl}_{3}\right)$

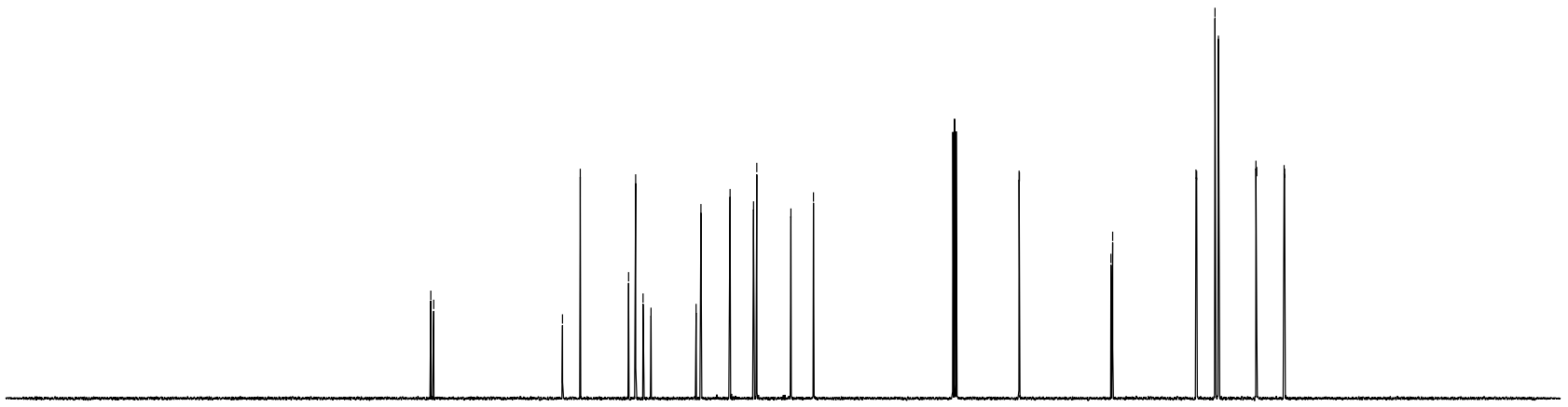

$\begin{array}{lllllllllllllllllllllllllllllllll}250 & 240 & 230 & 220 & 210 & 200 & 190 & 180 & 170 & 160 & 150 & 140 & 130 & 120 & 110 & 100 & 90 & 80 & 70 & 60 & 50 & 40 & 30 & 20 & 10 & 0 & -10 & -20 & -30\end{array}$ 


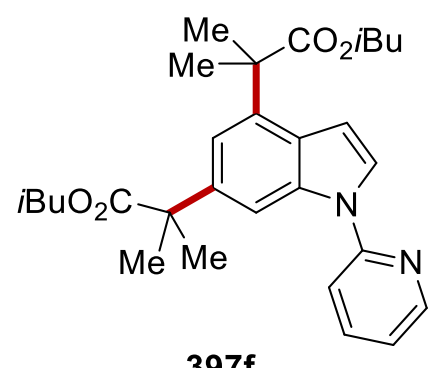

(400 MHz, $\mathrm{CDCl}_{3}$ )

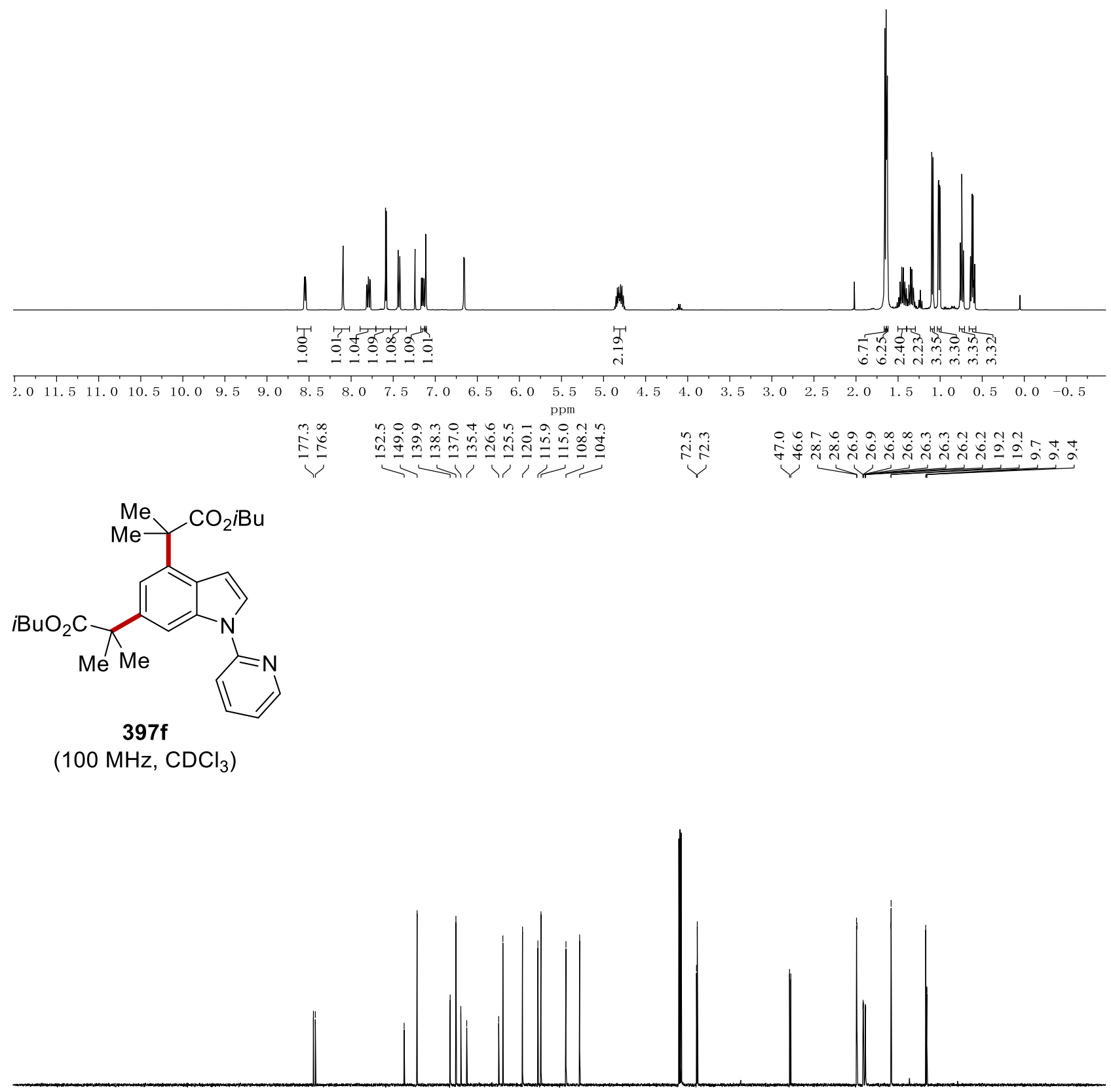

$\begin{array}{lllllllllllllllllllllllllllllllllllllllllllllllll}250 & 240 & 230 & 220 & 210 & 200 & 190 & 180 & 170 & 160 & 150 & 140 & 130 & 120 & 110 & 100 & 90 & 80 & 70 & 60 & 50 & 40 & 30 & 20 & 10 & 0 & -10 & -20 & -30\end{array}$ 

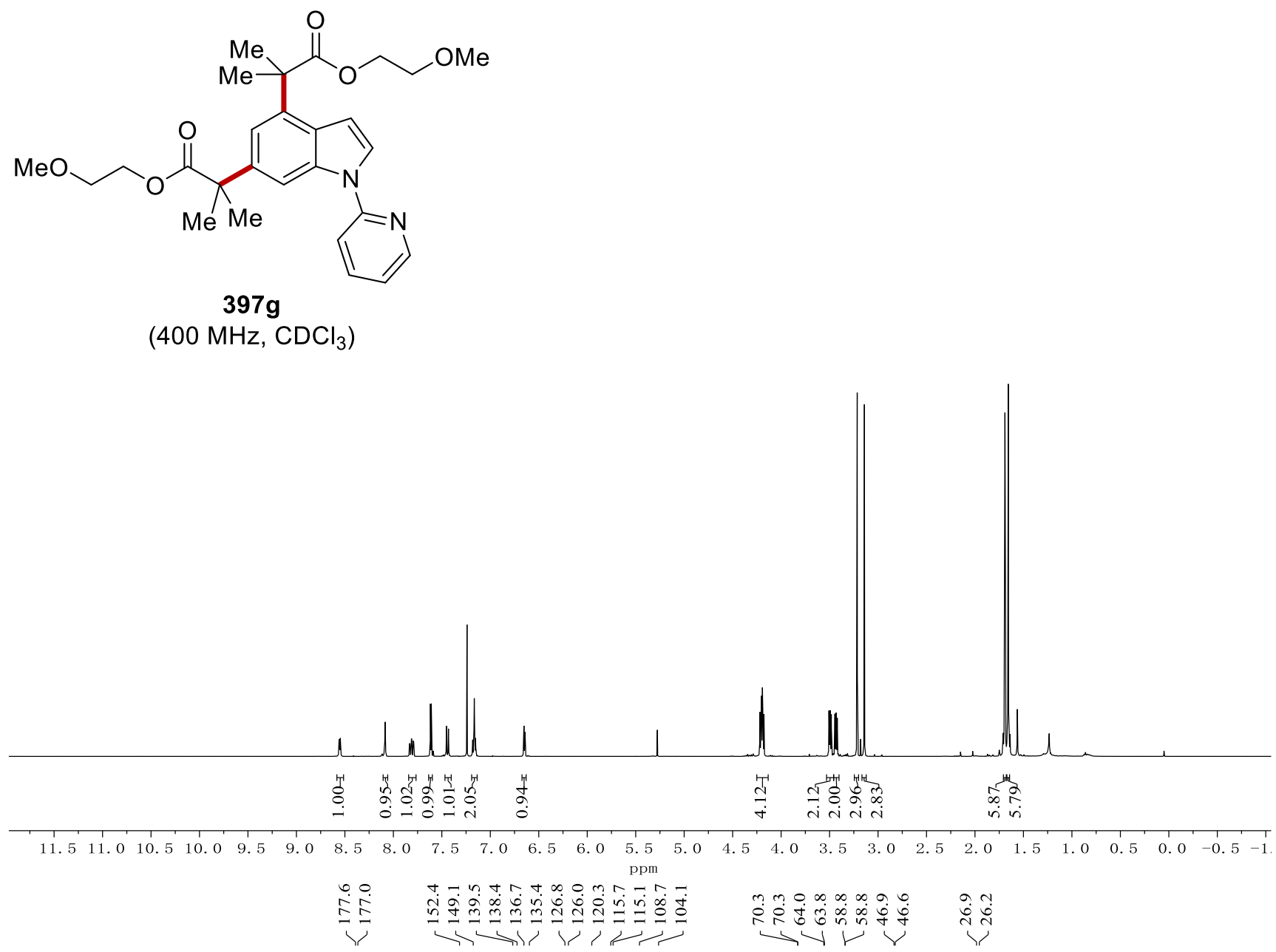<smiles>COCCOC(=O)C(C)(C)c1cc(C(C)(C)C(=O)OCCOC)c2ccn(-c3ccccn3)c2c1</smiles>

$\left(100 \mathrm{MHz}, \mathrm{CDCl}_{3}\right.$ ) 
<smiles>CCC(CC)COC(=O)C(C)(C)c1cc(C(C)(C)C(=O)OCC(CC)CC)c2ccn(-c3ccccn3)c2c1</smiles>

$397 \mathrm{~h}$

(400 MHz, $\mathrm{CDCl}_{3}$ )

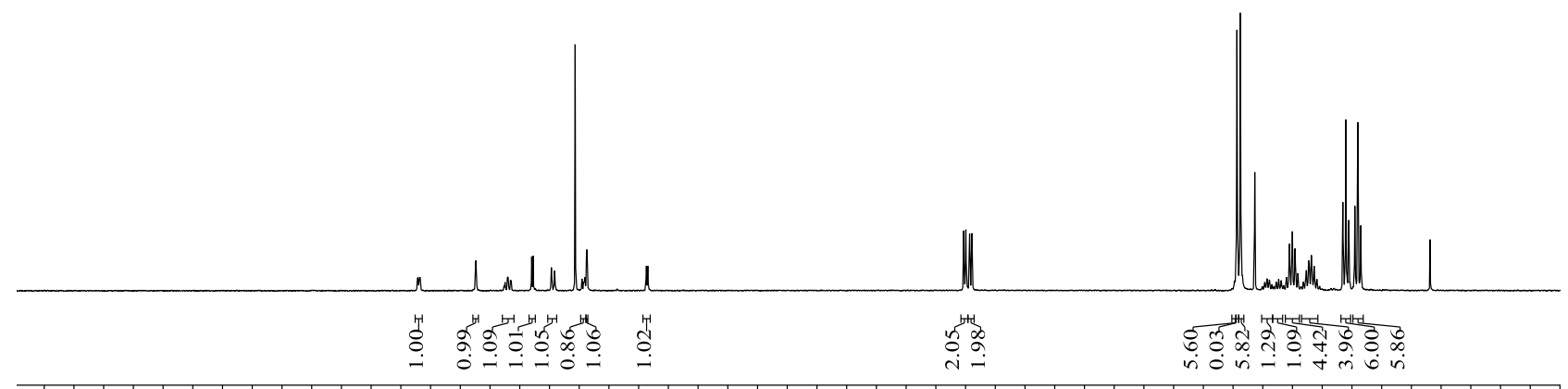

$\begin{array}{rllllllllllllllllllllllllllll}11.5 & 11.0 & 10.5 & 10.0 & 9.5 & 9.0 & 8.5 & 8.0 & 7.5 & 7.0 & 6.5 & 6.0 & 5.5 & 5.0 & 4.5 & 4.0 & 3.5 & 3.0 & 2.5 & 2.0 & 1.5 & 1.0 & 0.5 & 0.0 & -0.5 & -1\end{array}$ 采<smiles>CCC(CC)COC(=O)C(C)(C)c1cc(C(C)(C)C(=O)OCC(CC)CC)c2ccn(-c3ccccn3)c2c1</smiles>

397h

(100 MHz, $\mathrm{CDCl}_{3}$ )

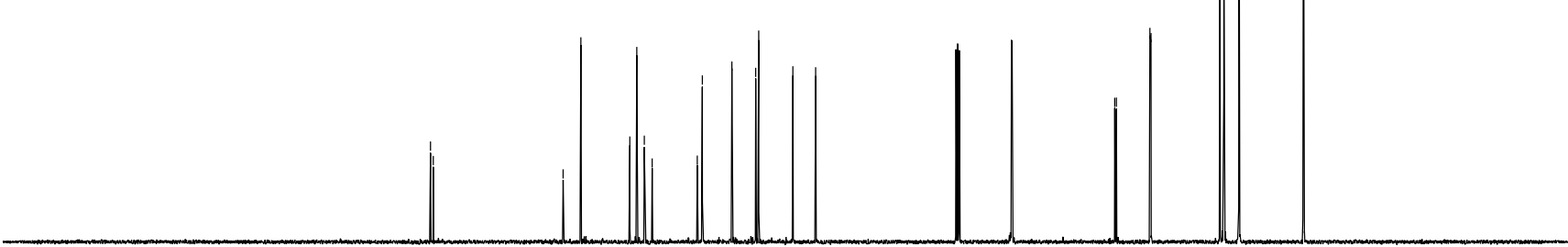

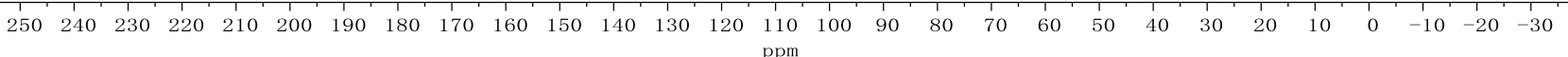




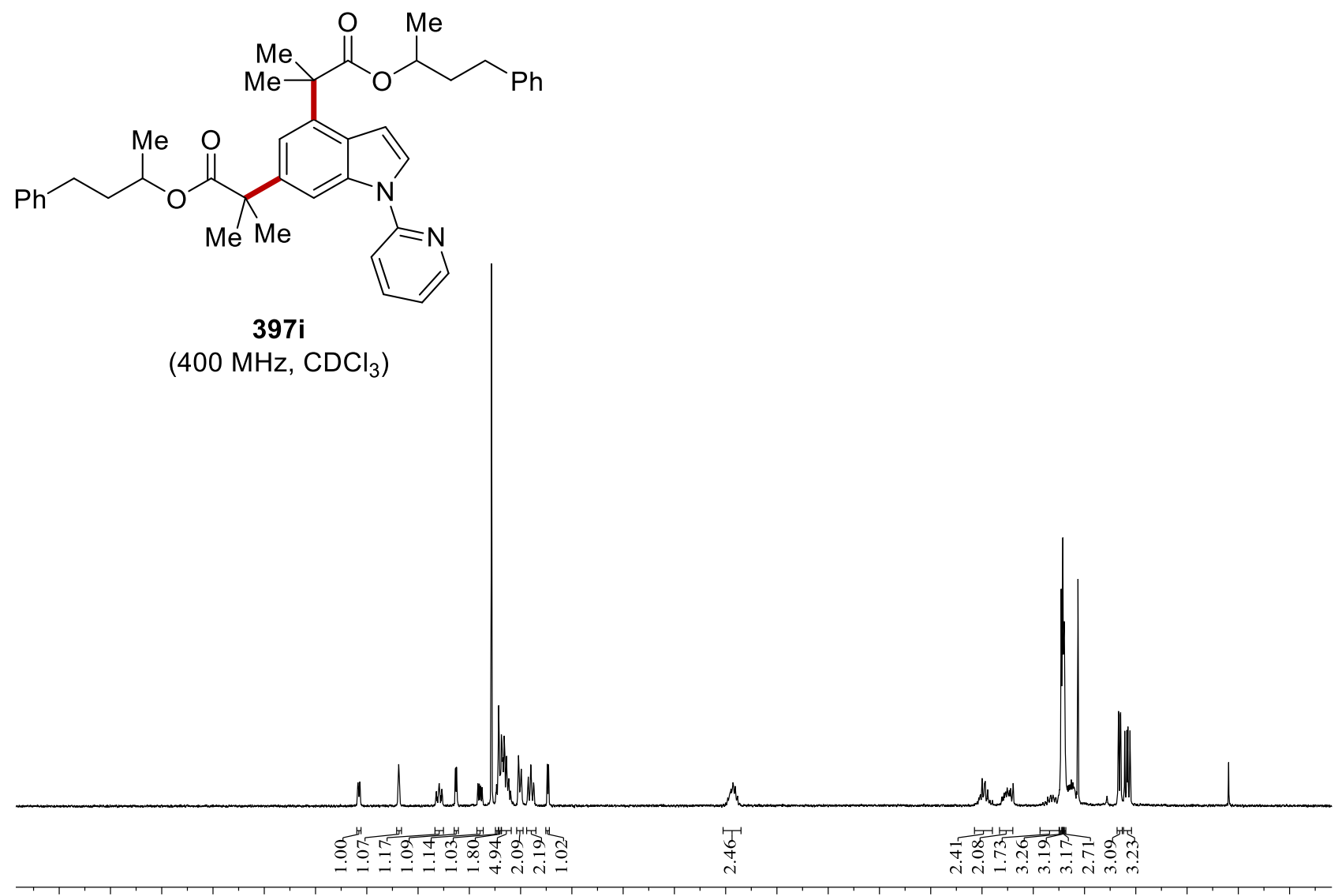

$\begin{array}{lllllllllllllllllllllllll}11.5 & 11.0 & 10.5 & 10.0 & 9.5 & 9.0 & 8.5 & 8.0 & 7.5 & 7.0 & 6.5 & 6.0 & 5.5 & 5.0 & 4.5 & 4.0 & 3.5 & 3.0 & 2.5 & 2.0 & 1.5 & 1.0 & 0.5 & 0.0 & -0.5\end{array}$

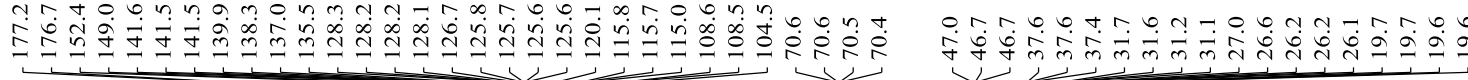<smiles>CC(CCc1ccccc1)OC(=O)C(C)(C)c1cc(C(C)(C)C(=O)OC(C)CCc2ccccc2)c2ccn(-c3ccccc3)c2c1</smiles>

$\left(100 \mathrm{MHz}, \mathrm{CDCl}_{3}\right.$ )

$\begin{array}{lllllllllllllllllllllllllllllllllllllll}250 & 240 & 230 & 220 & 210 & 200 & 190 & 180 & 170 & 160 & 150 & 140 & 130 & 120 & 110 & 100 & 90 & 80 & 70 & 60 & 50 & 40 & 30 & 20 & 10 & 0 & -10 & -20 & -30\end{array}$ 


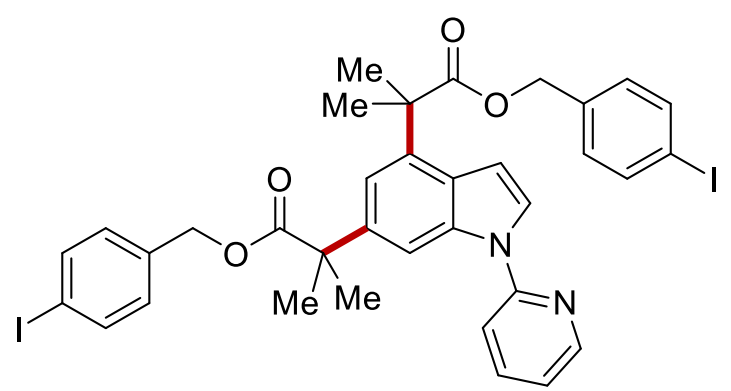

397j

(400 MHz, $\mathrm{CDCl}_{3}$ )

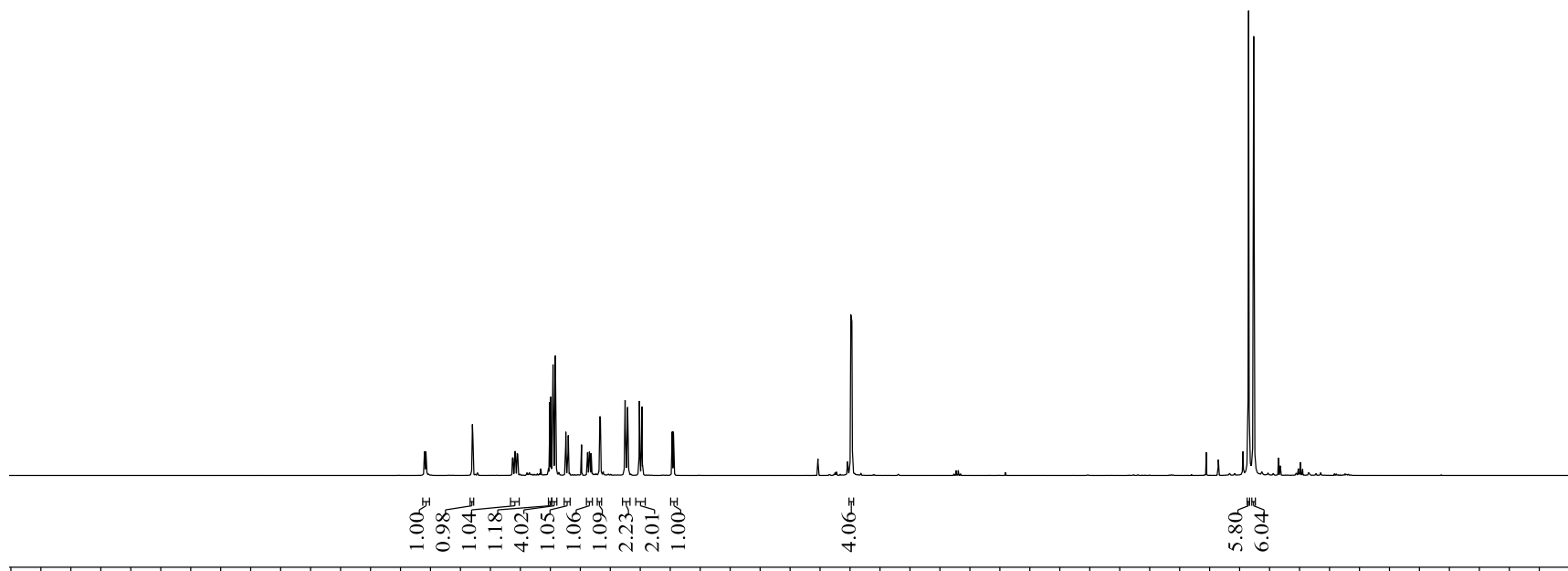

\begin{tabular}{llllllllllllllllllllllllllllllllllllll}
\hline 2.0 & 11.5 & 11.0 & 10.5 & 10.0 & 9.5 & 9.0 & 8.5 & 8.0 & 7.5 & 7.0 & 6.5 & 6.0 & 5.5 & 5.0 & 4.5 & 4.0 & 3.5 & 3.0 & 2.5 & 2.0 & 1.5 & 1.0 & 0.5 & 0.0 & -0.5
\end{tabular}

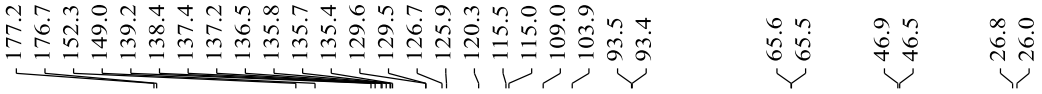<smiles>CC(C)(C(=O)OCc1ccc(I)cc1)c1cc(C(C)(C)C(=O)OCc2ccc(I)cc2)c2ccn(-c3ccccn3)c2c1</smiles>

$397 \mathbf{j}$

$\left(100 \mathrm{MHz}, \mathrm{CDCl}_{3}\right)$

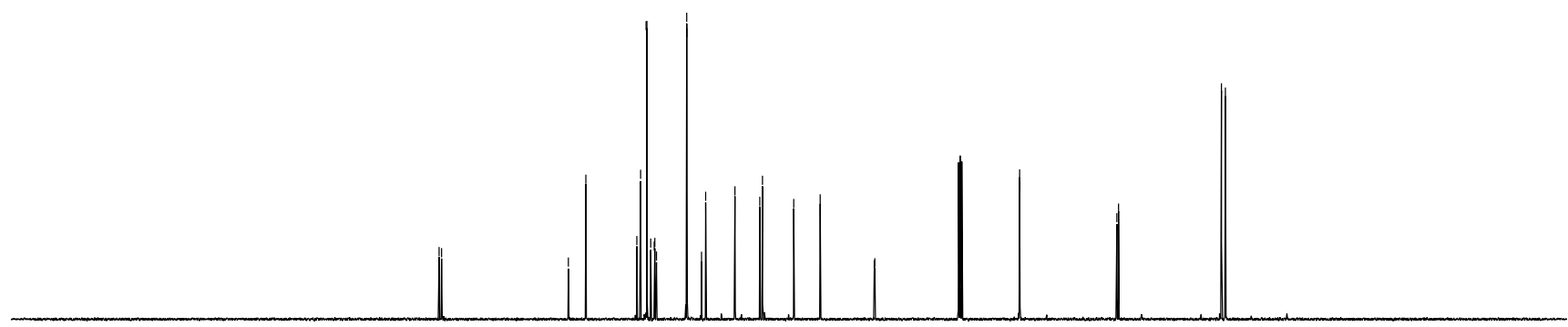

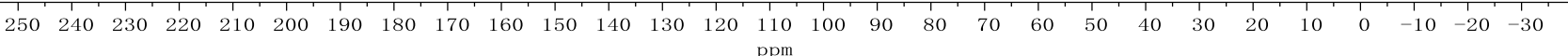




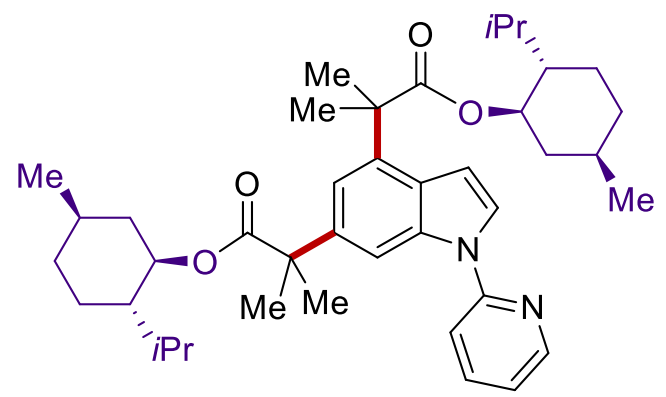

$397 k$

$\left(400 \mathrm{MHz}, \mathrm{CDCl}_{3}\right)$
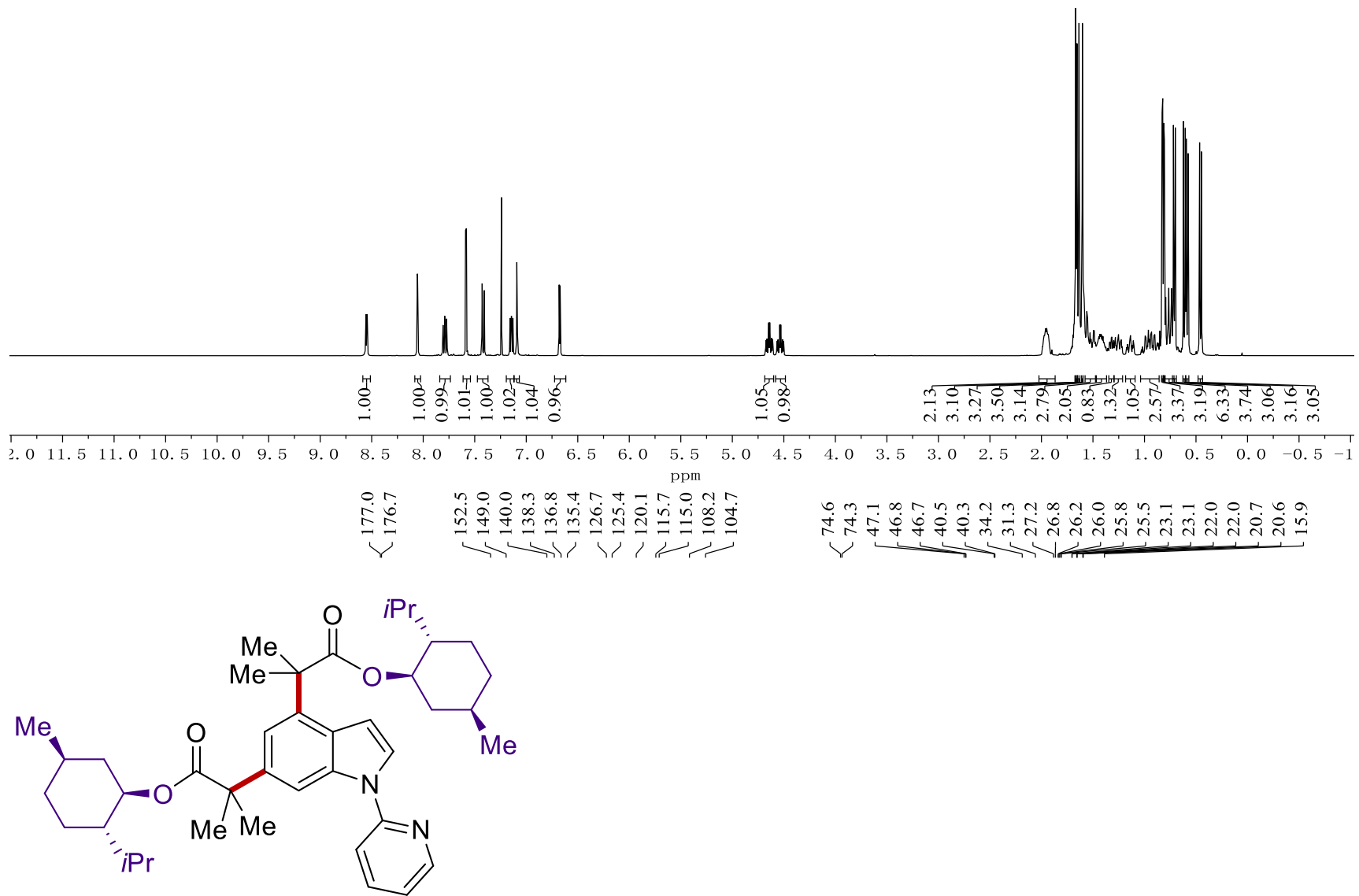

$397 k$

$\left(100 \mathrm{MHz}, \mathrm{CDCl}_{3}\right)$

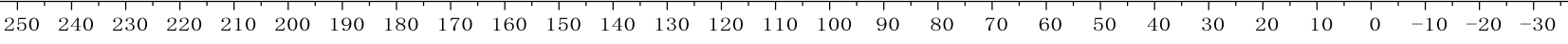




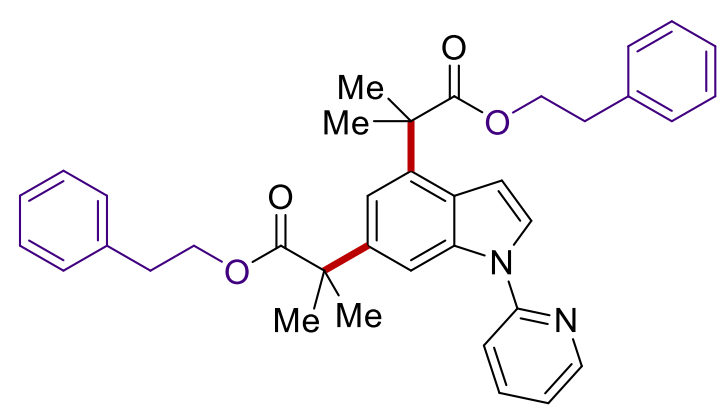

3971

$\left(400 \mathrm{MHz}, \mathrm{CDCl}_{3}\right)$

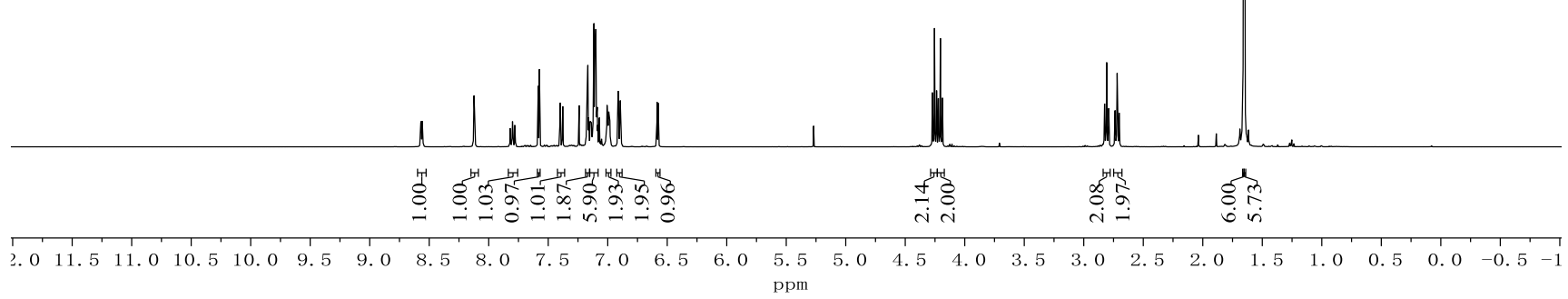

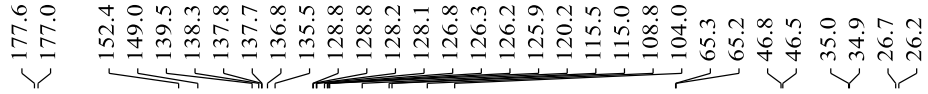

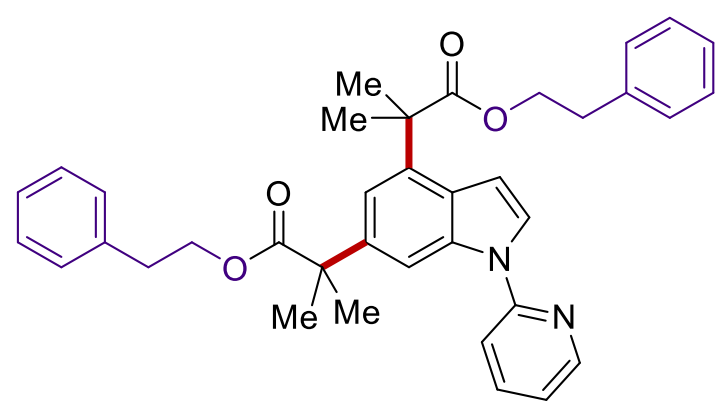

3971

$\left(100 \mathrm{MHz}, \mathrm{CDCl}_{3}\right.$ )

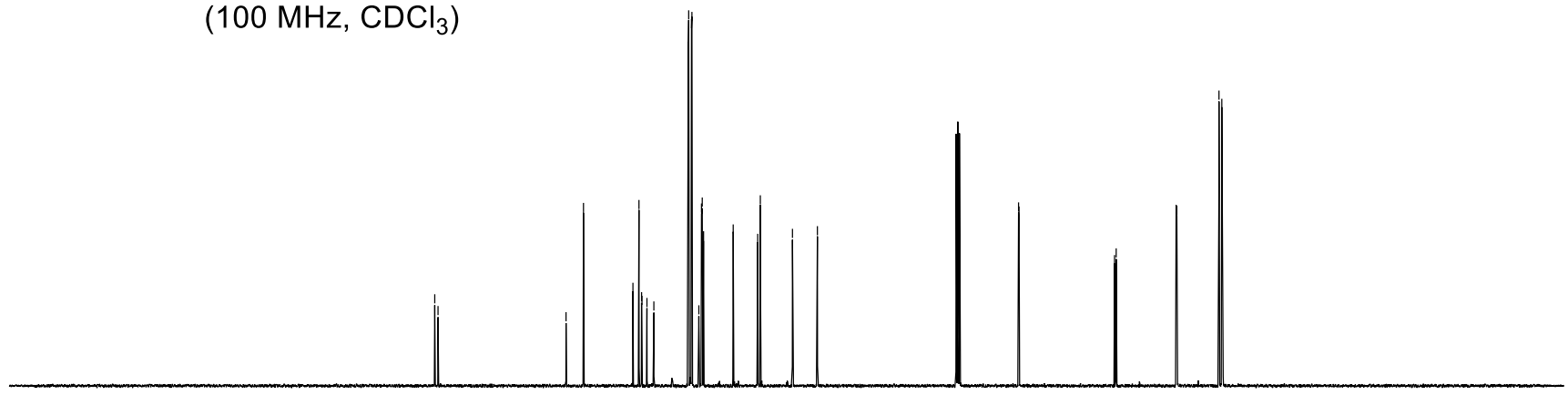

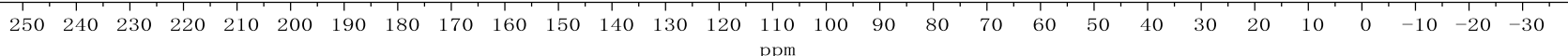




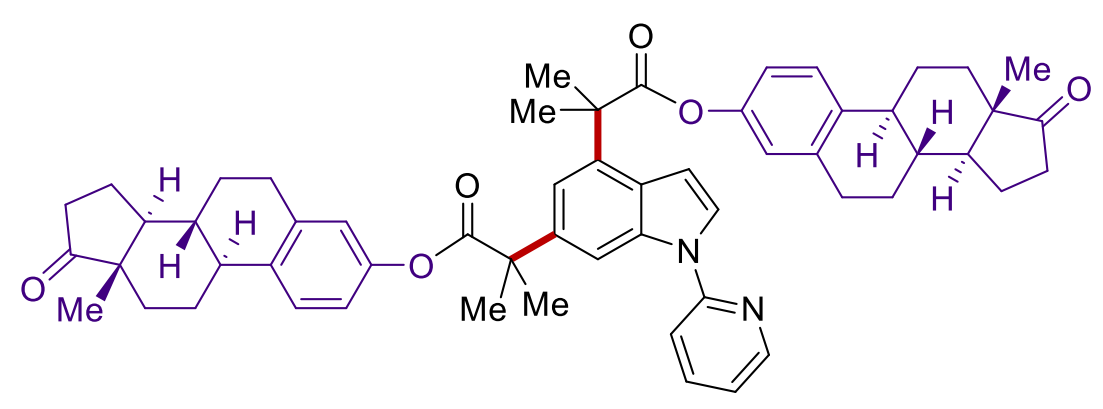

$397 \mathrm{~m}$

$\left(400 \mathrm{MHz} \mathrm{CDCl}_{3}\right)$

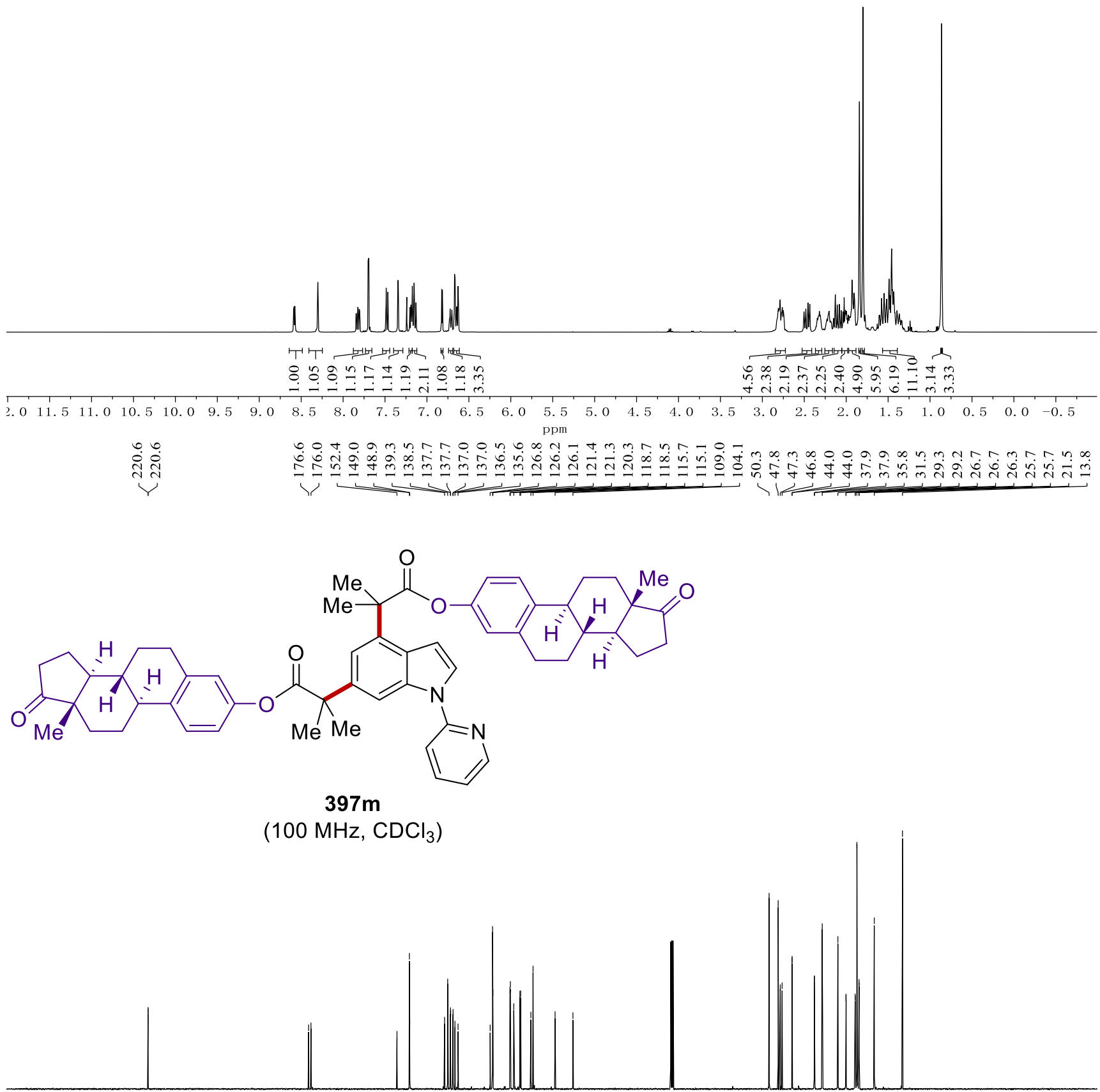

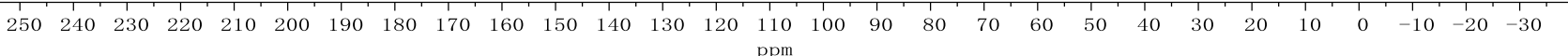




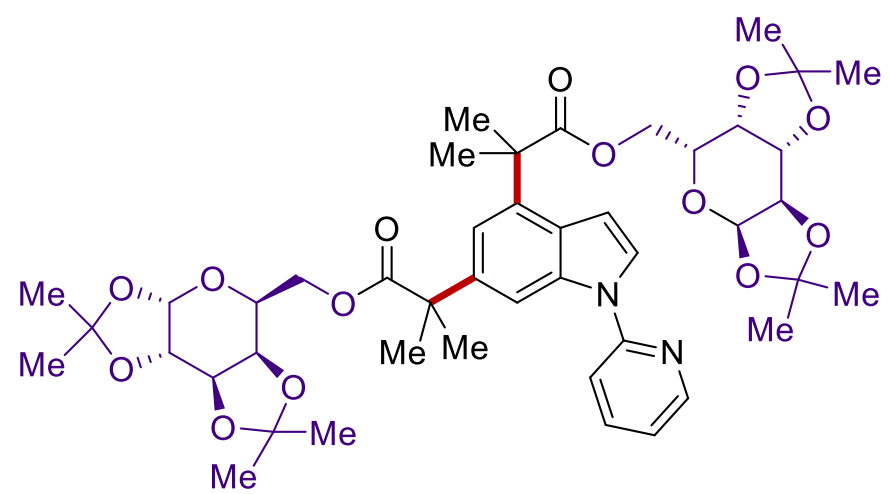

$397 n$

(400 MHz, $\mathrm{CDCl}_{3}$ )

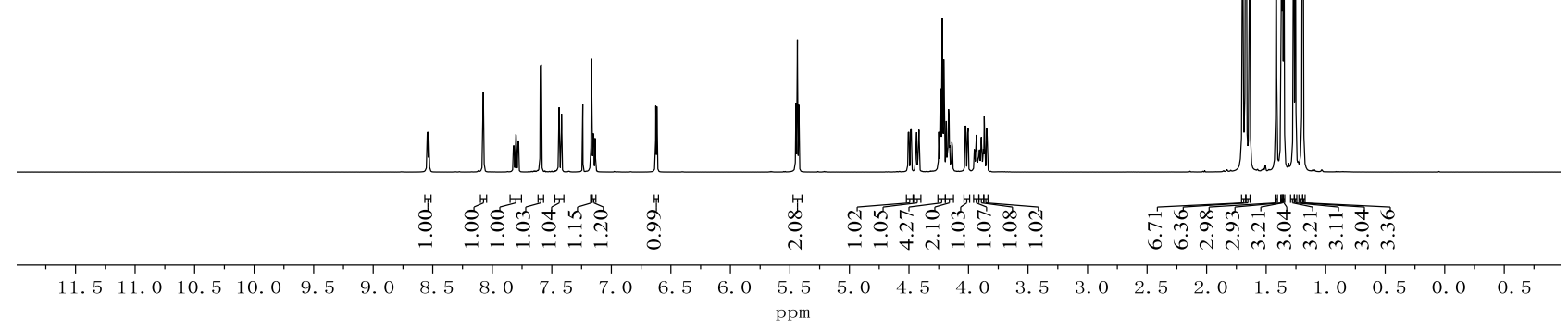

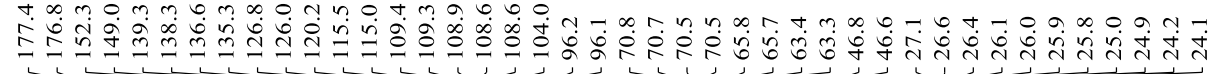

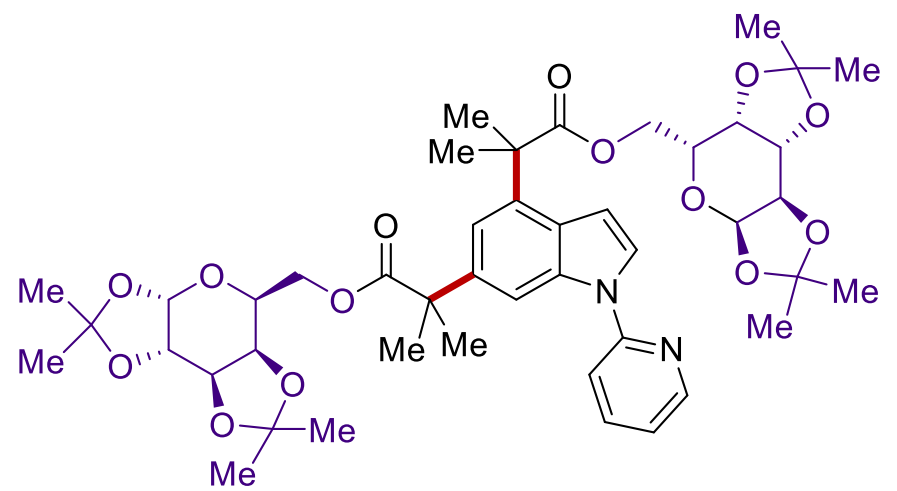

397n

$\left(100 \mathrm{MHz}, \mathrm{CDCl}_{3}\right)$

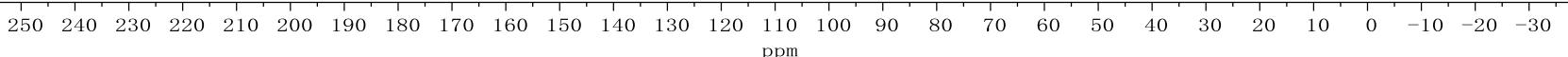




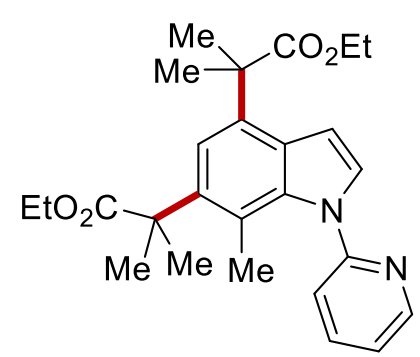

3970

$\left(400 \mathrm{MHz}, \mathrm{CDCl}_{3}\right)$

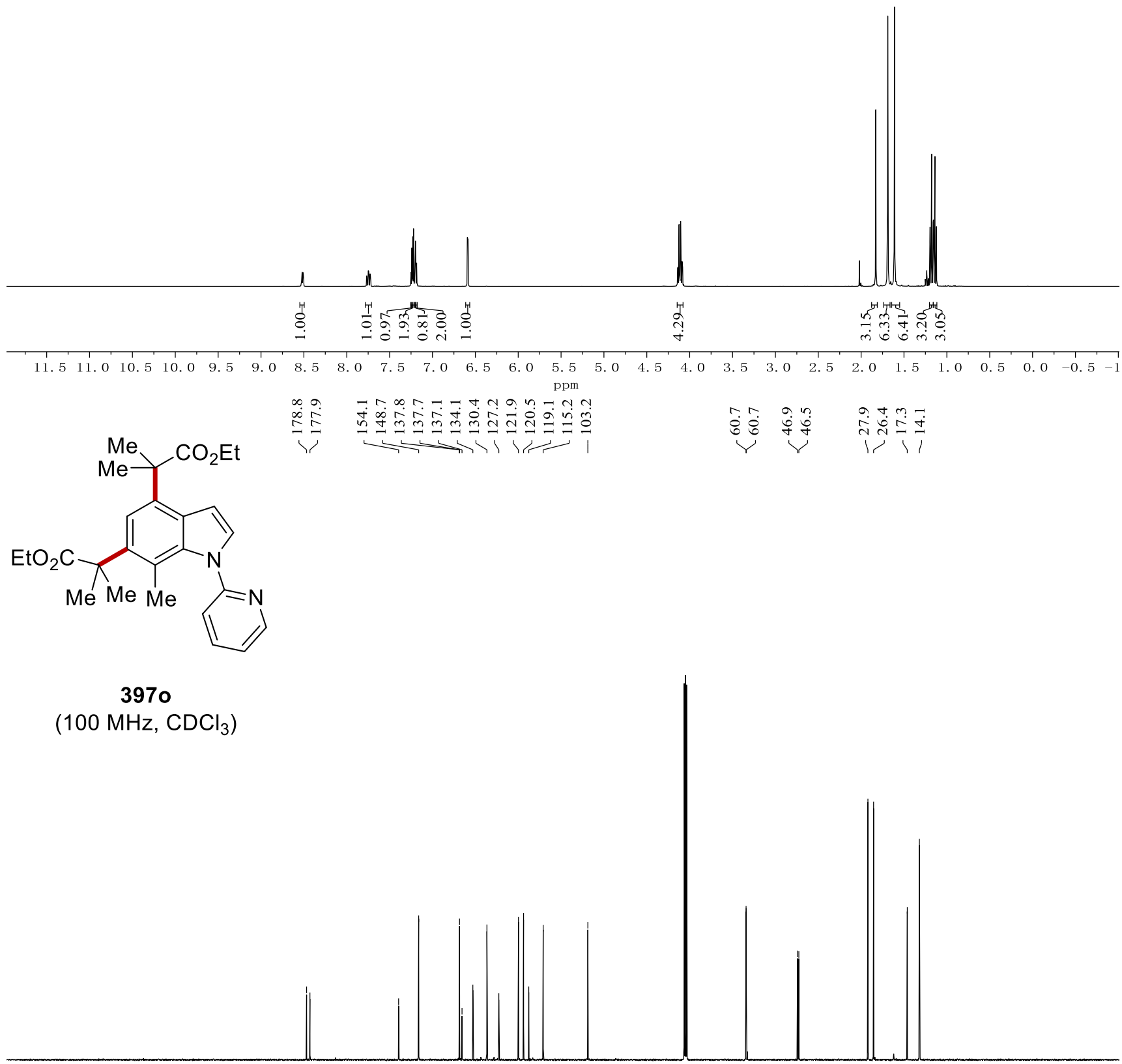

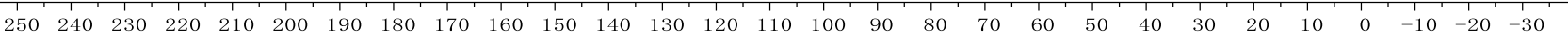



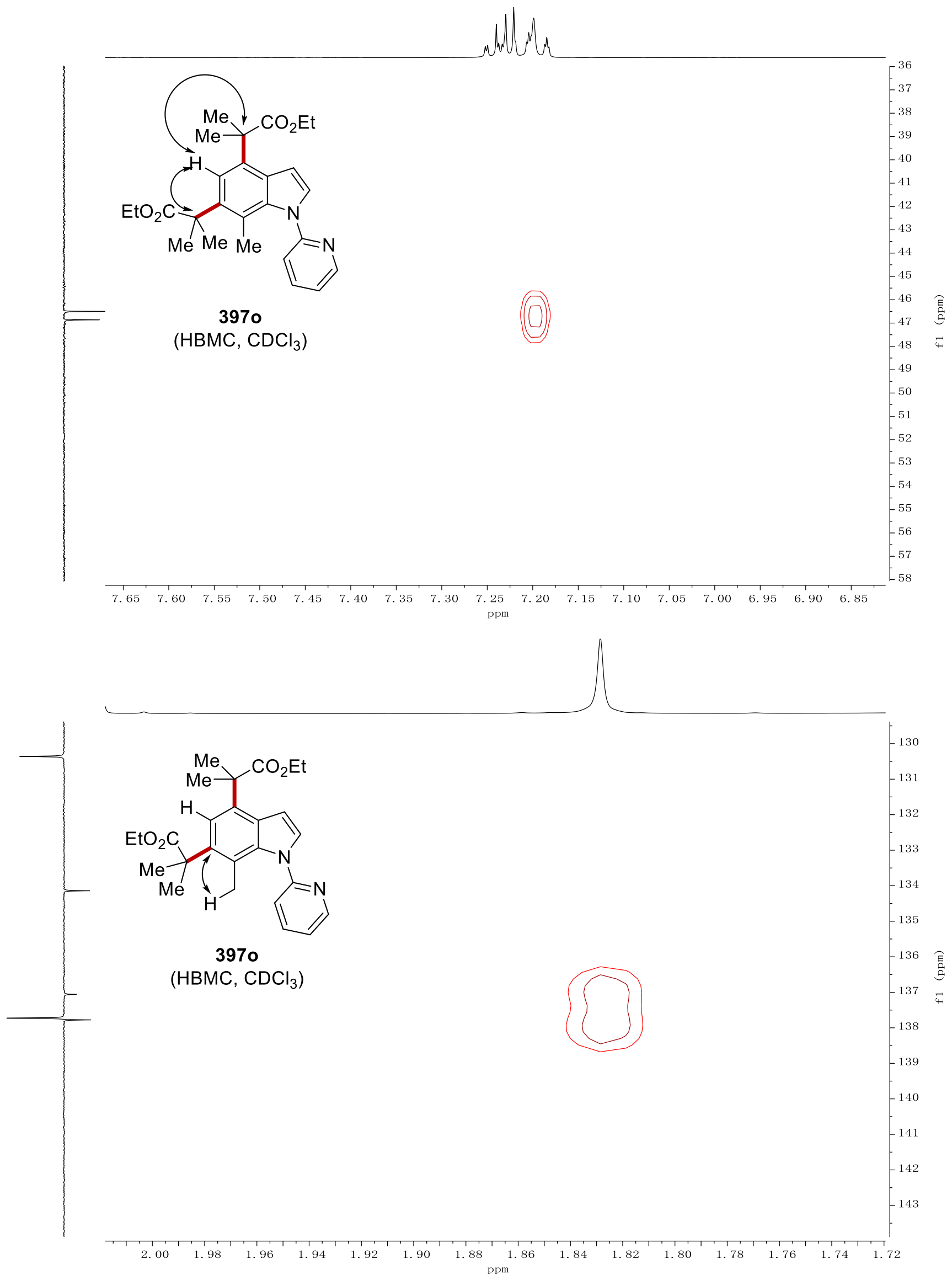


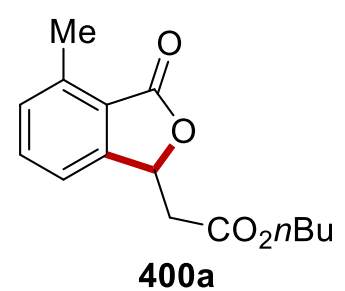

$\left(400 \mathrm{MHz}, \mathrm{CDCl}_{3}\right)$

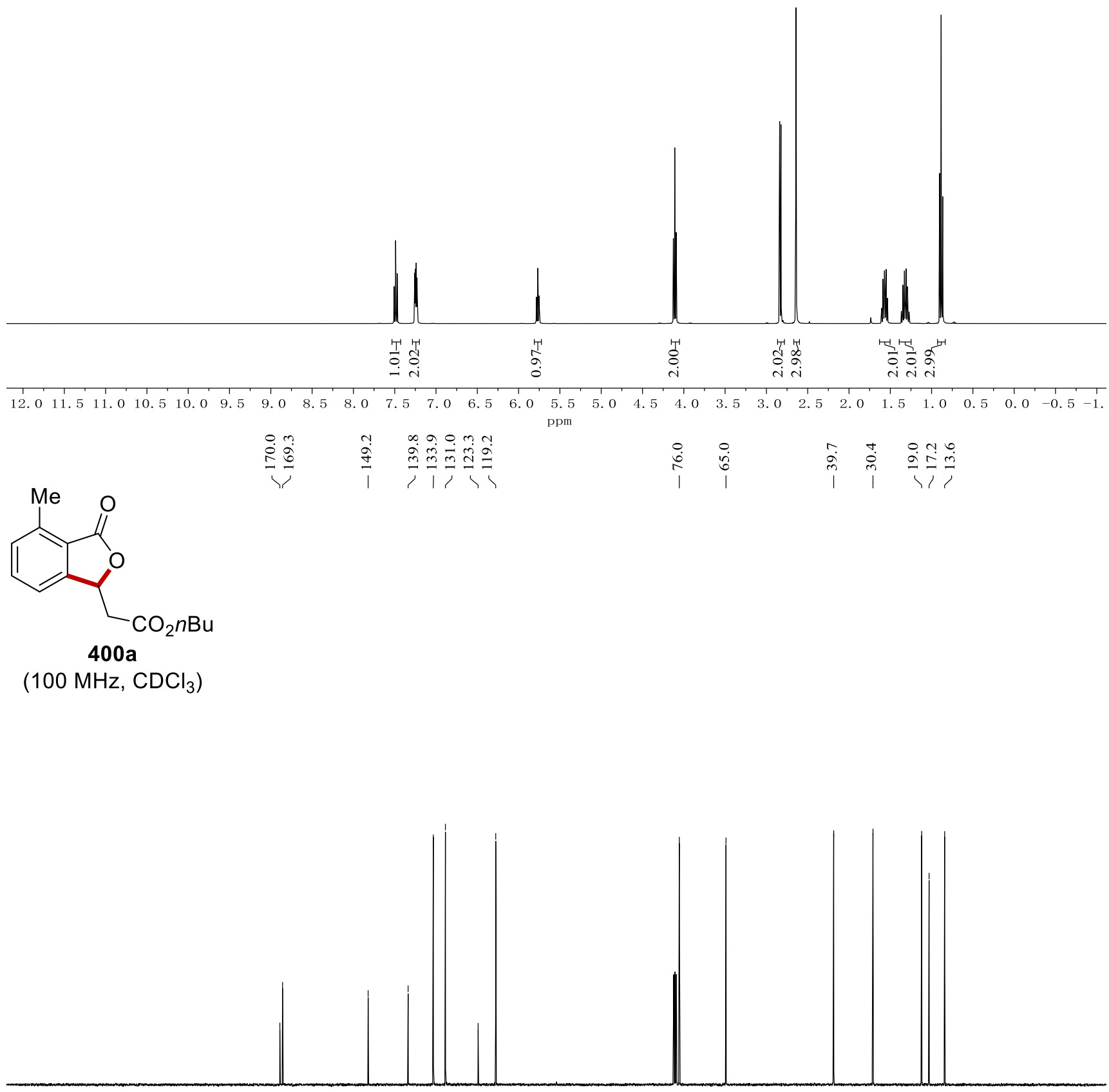

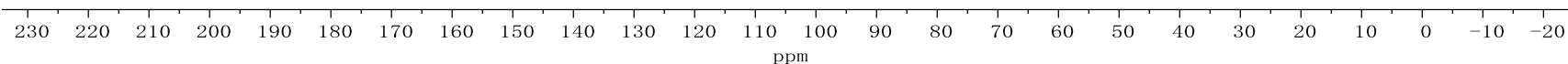




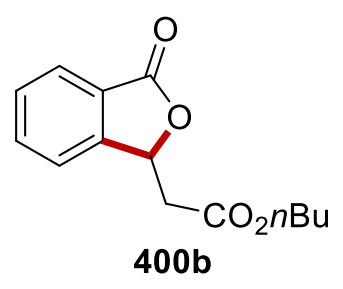

(400 MHz, $\mathrm{CDCl}_{3}$ )
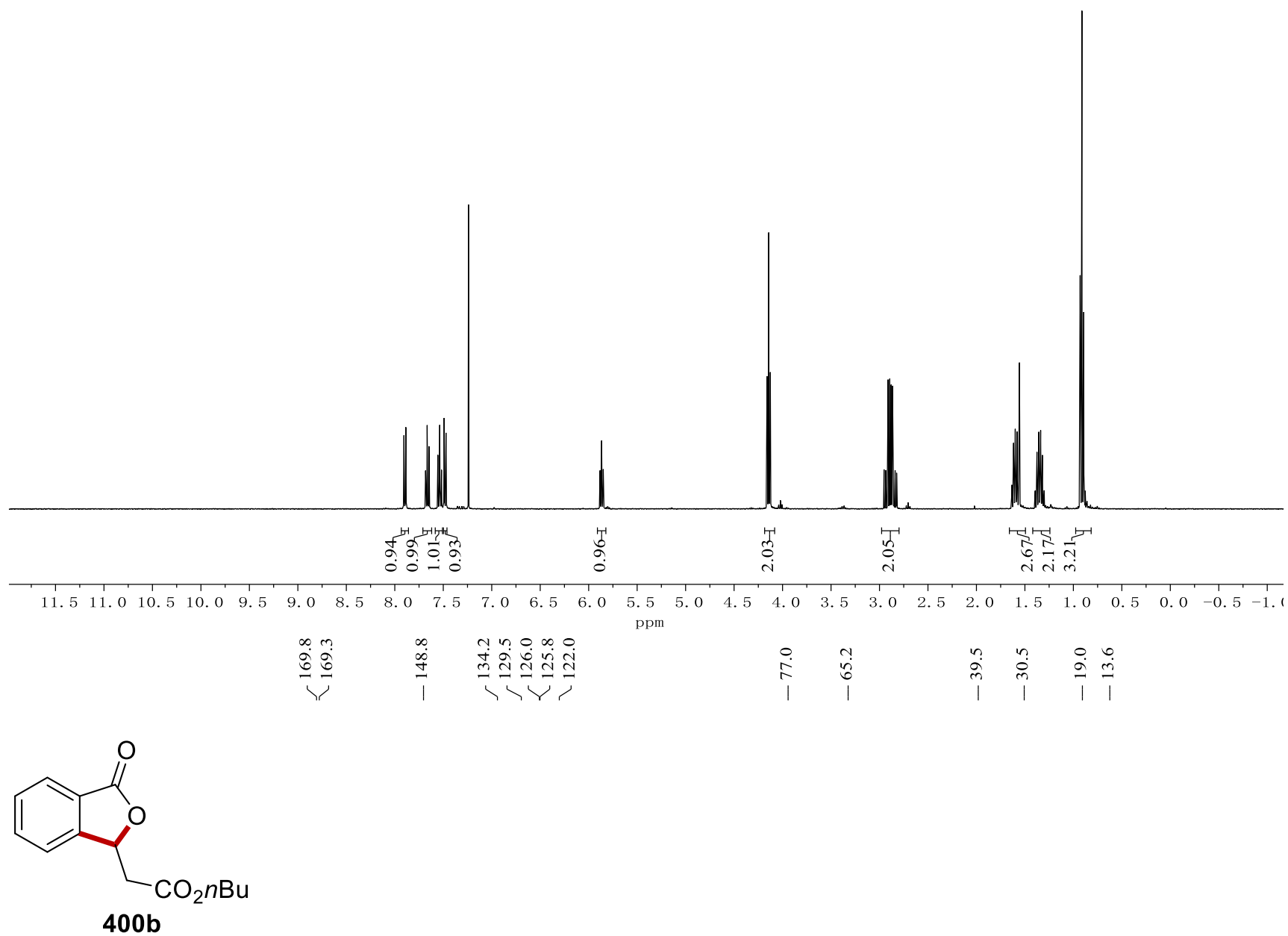

(100 MHz, $\mathrm{CDCl}_{3}$ )

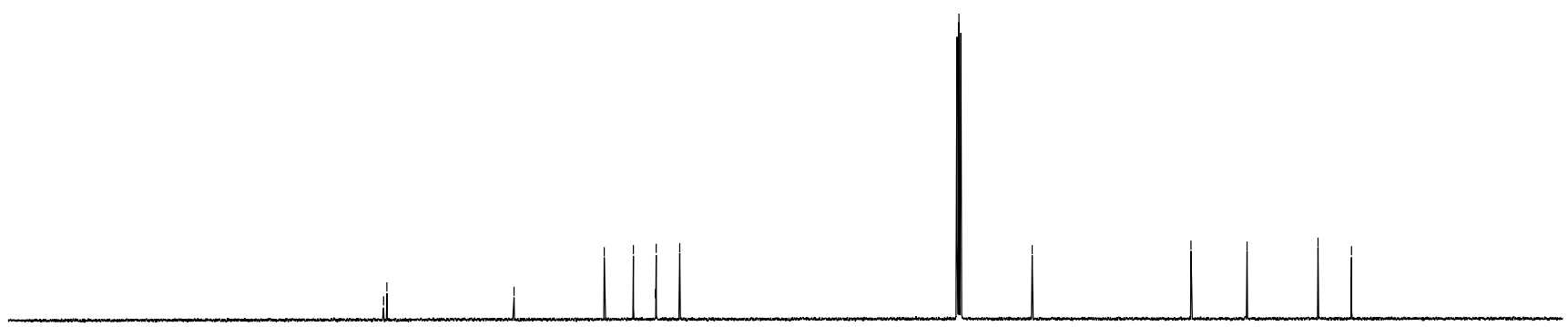

\begin{tabular}{lllllllllllllllllllllllllllll}
\hline 30 & 220 & 210 & 200 & 190 & 180 & 170 & 160 & 150 & 140 & 130 & 120 & 110 & 100 & 90 & 80 & 70 & 60 & 50 & 40 & 30 & 20 & 10 & 0 & -10 & -
\end{tabular} 


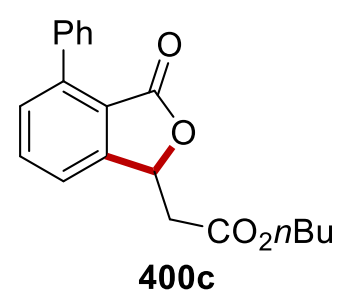

(400 MHz, $\mathrm{CDCl}_{3}$ )

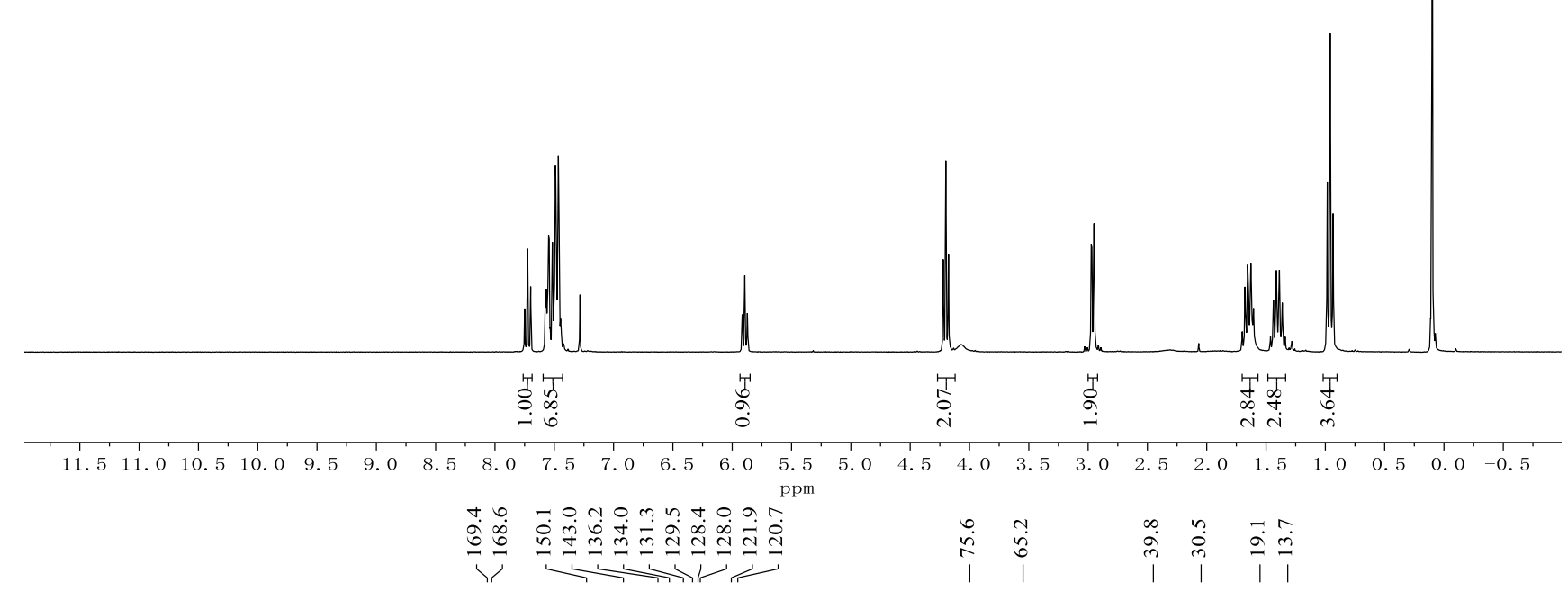<smiles>CCCOC(=O)CC1OC(=O)c2c(-c3ccccc3)cccc21</smiles>

(100 MHz, $\mathrm{CDCl}_{3}$ )

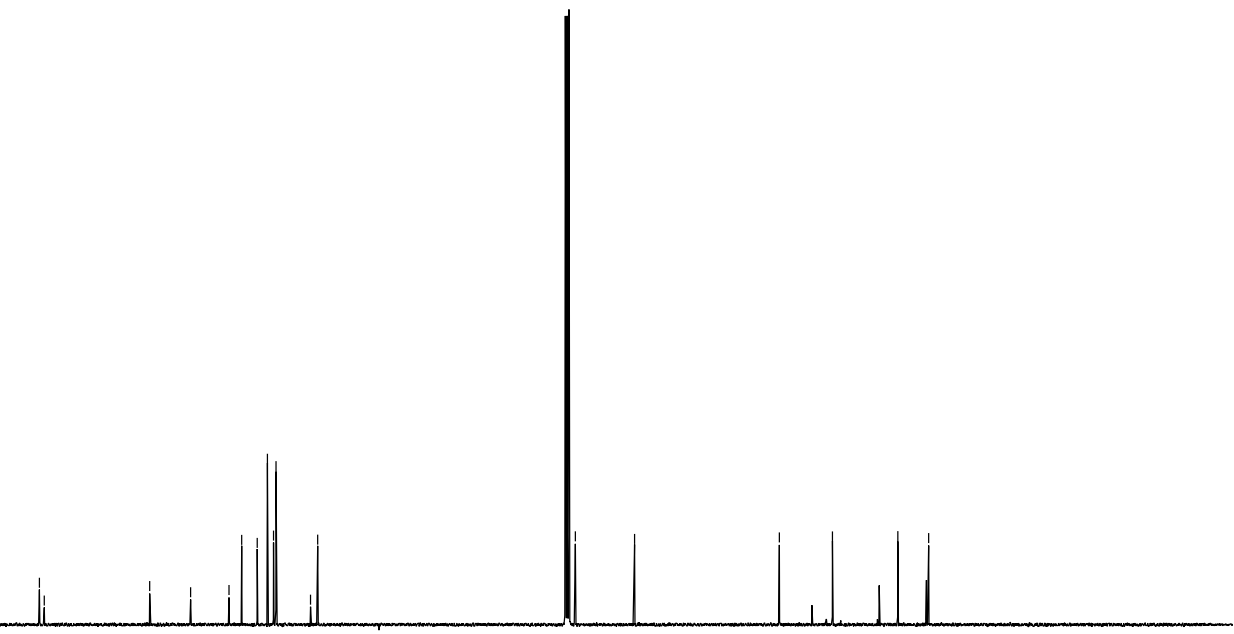

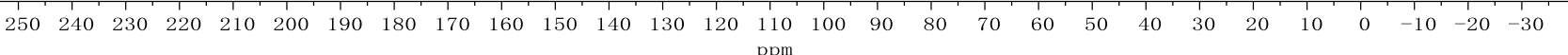



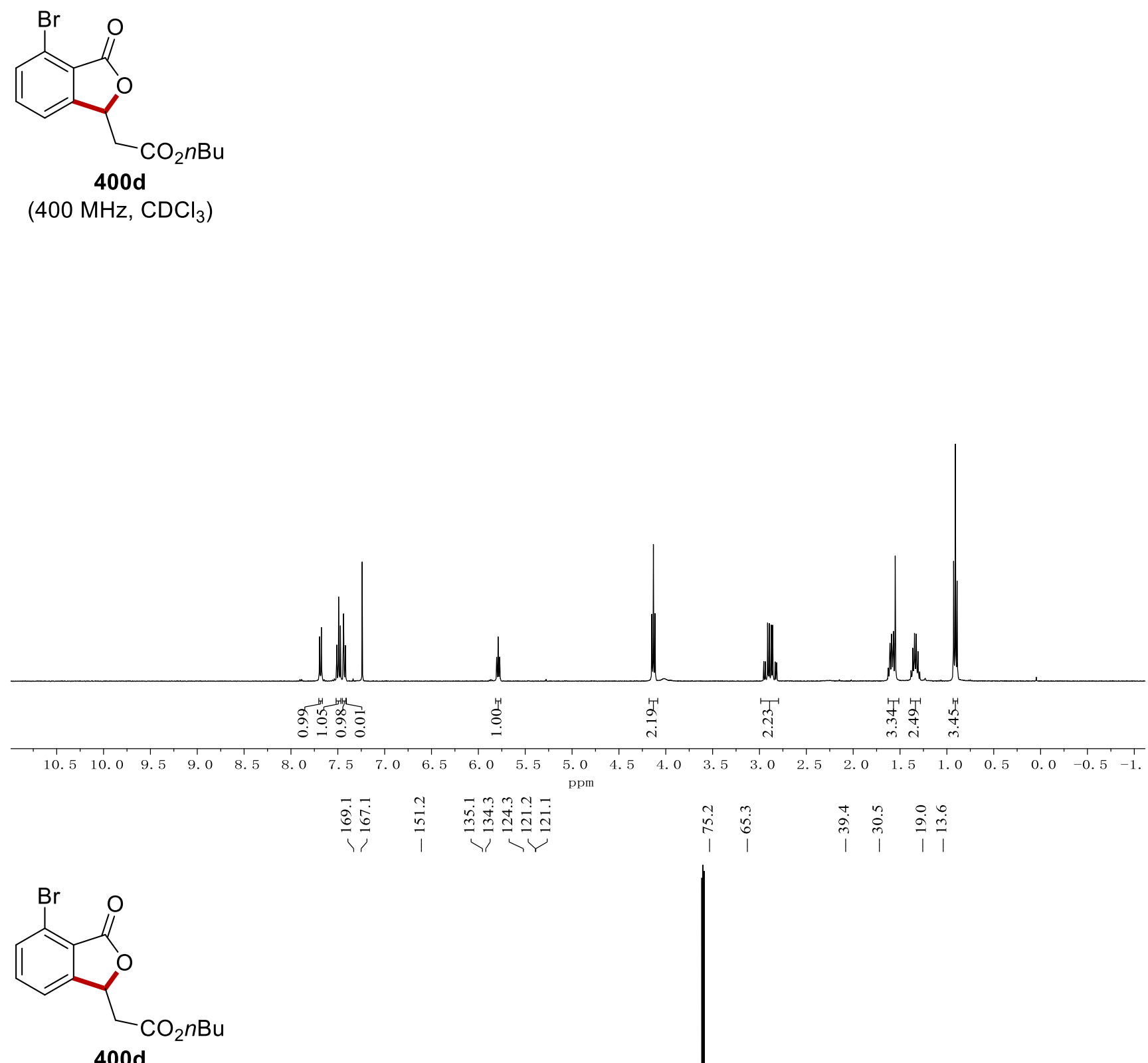

(100 MHz, $\mathrm{CDCl}_{3}$ ) 


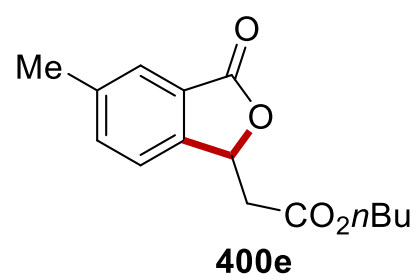

(400 MHz, $\mathrm{CDCl}_{3}$ )
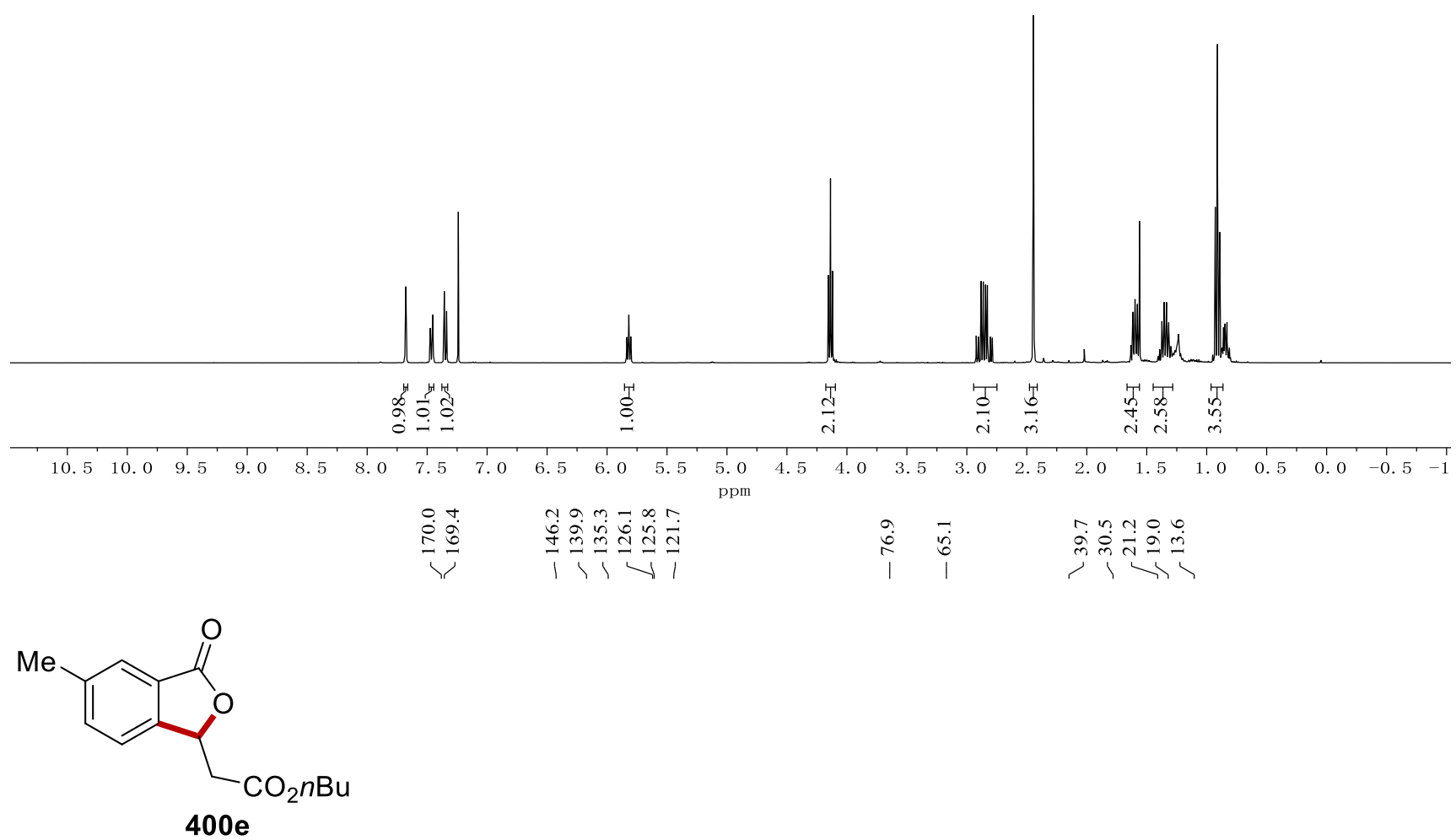

(100 MHz, $\mathrm{CDCl}_{3}$ )

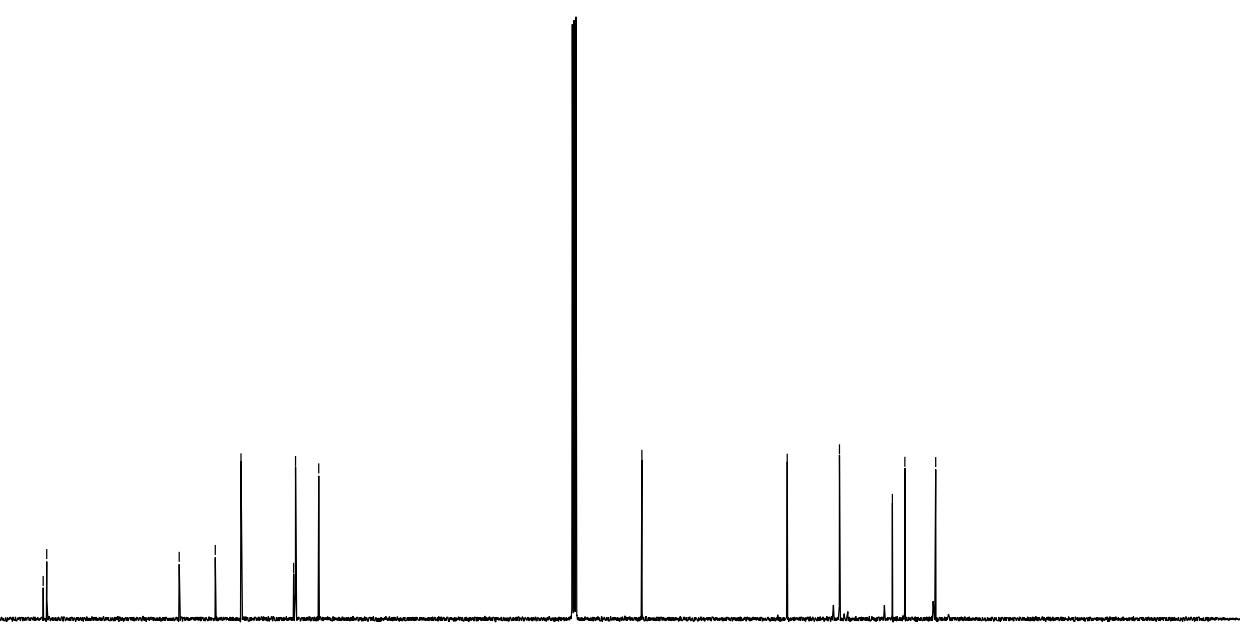

$\begin{array}{lllllllllllllllllllllllllllllllllllll}1 & 250 & 240 & 230 & 220 & 210 & 200 & 190 & 180 & 170 & 160 & 150 & 140 & 130 & 120 & 110 & 100 & 90 & 80 & 70 & 60 & 50 & 40 & 30 & 20 & 10 & 0 & -10 & -20 & -30\end{array}$ 


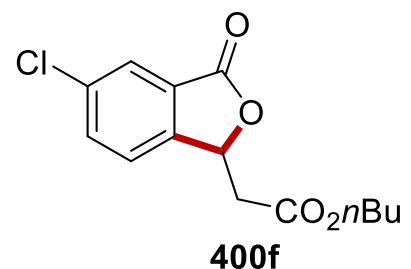

(400 MHz, $\mathrm{CDCl}_{3}$ )
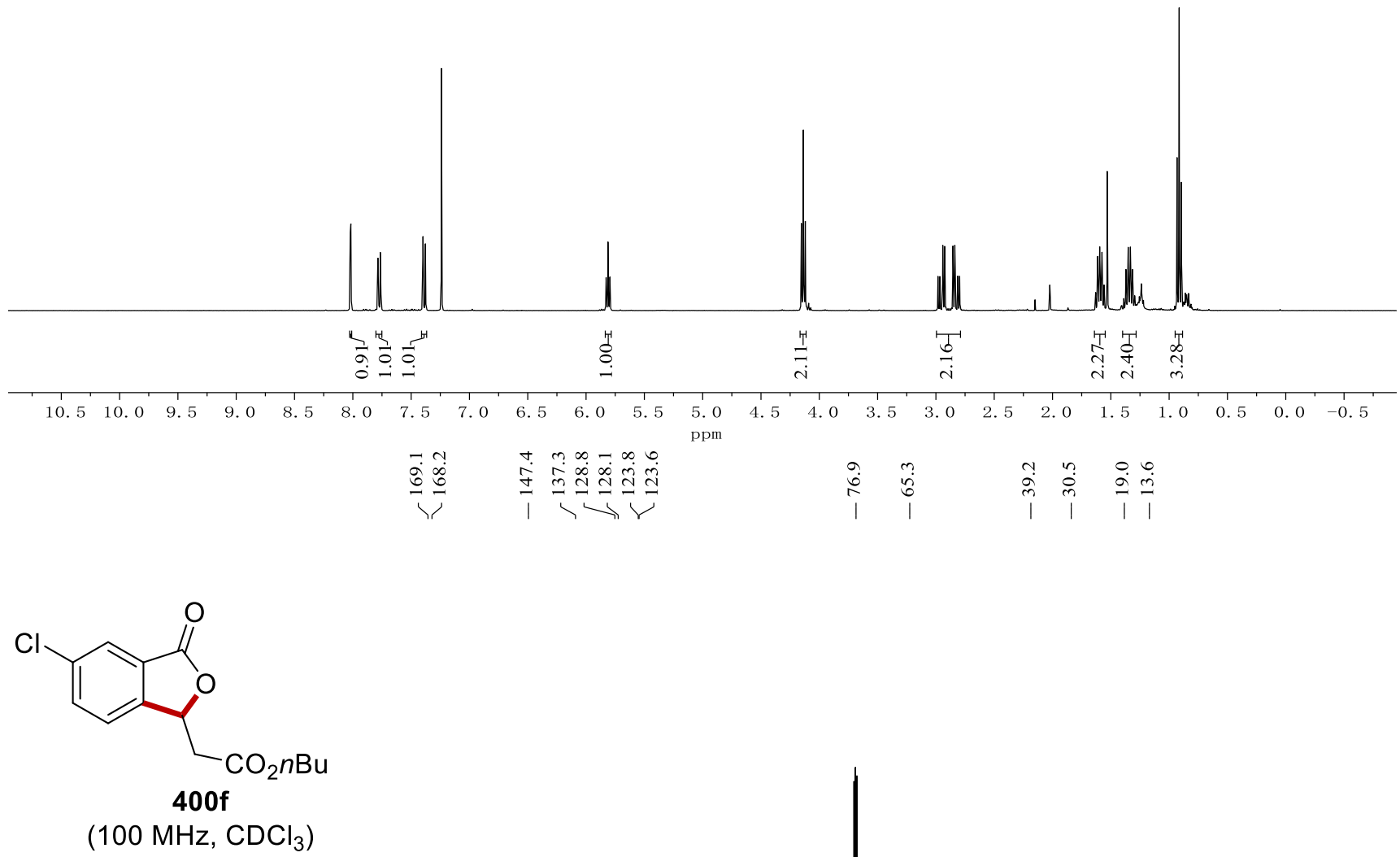

$\begin{array}{lllllllllllllllllllllllllllllllllllll}250 & 240 & 230 & 220 & 210 & 200 & 190 & 180 & 170 & 160 & 150 & 140 & 130 & 120 & 110 & 100 & 90 & 80 & 70 & 60 & 50 & 40 & 30 & 20 & 10 & 0 & -10 & -20 & -30\end{array}$ 


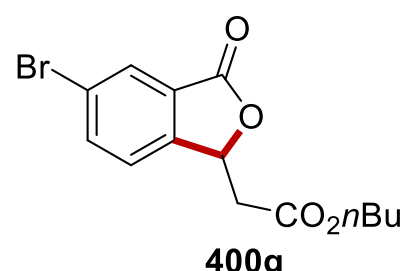

(400 MHz, $\mathrm{CDCl}_{3}$ )

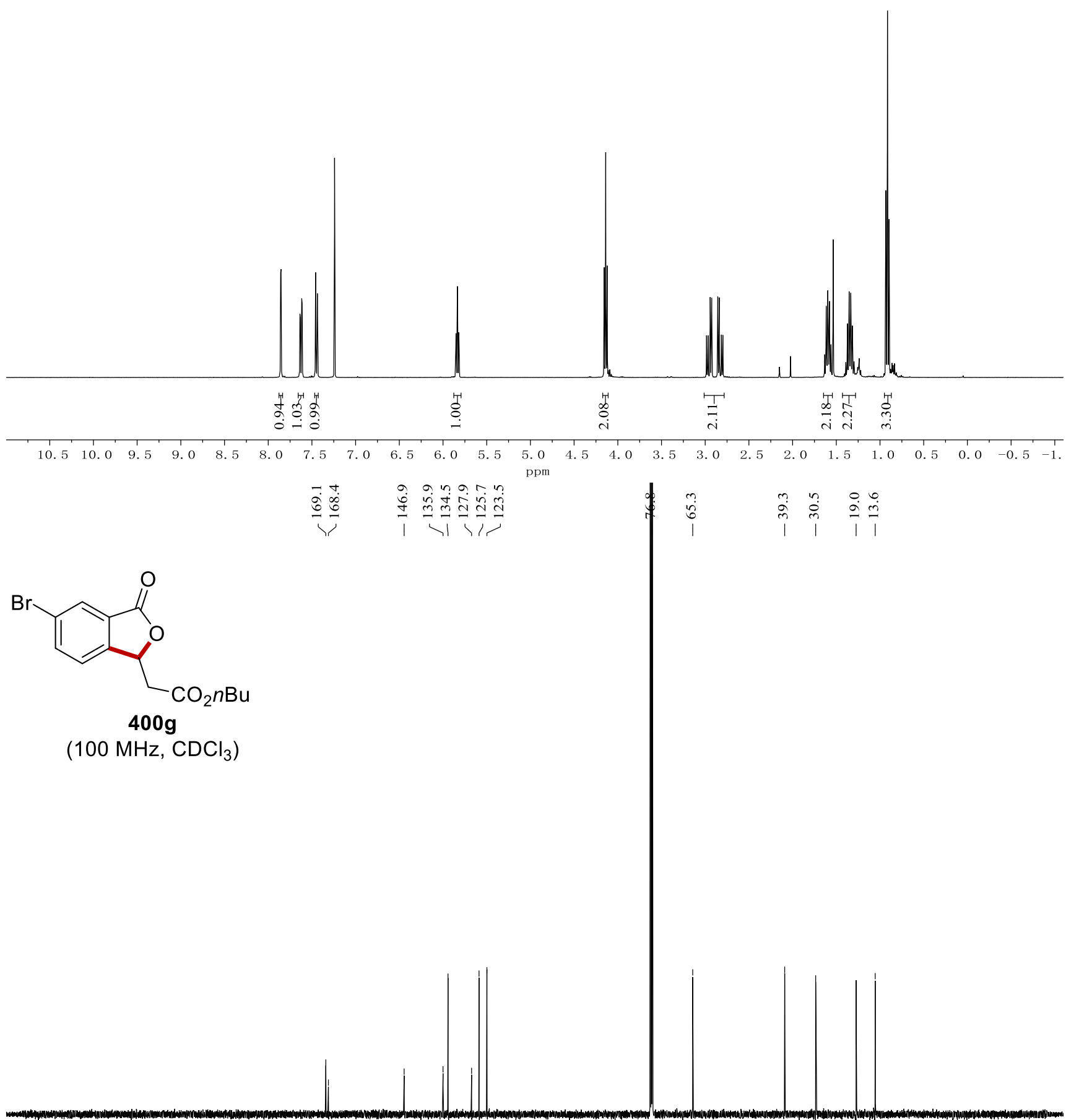

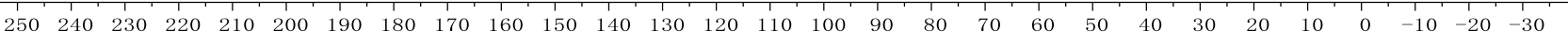



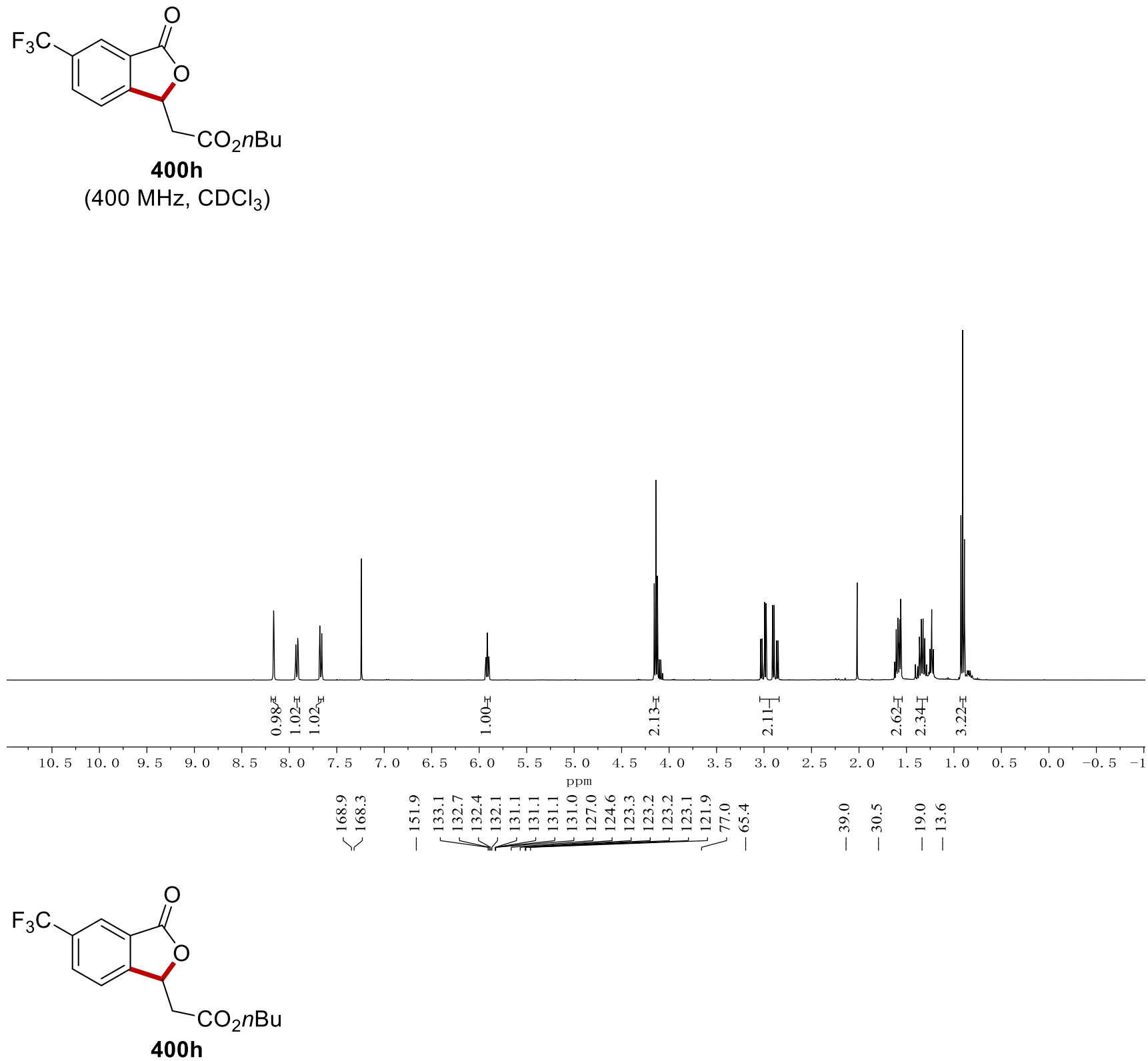

(100 MHz, $\mathrm{CDCl}_{3}$ )

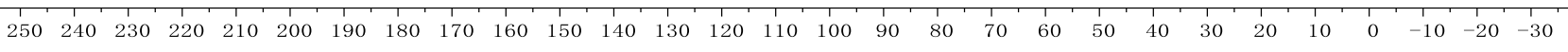




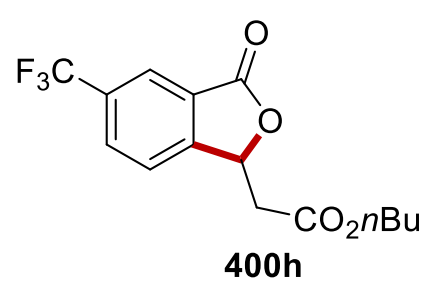

(282 MHz, $\mathrm{CDCl}_{3}$ )

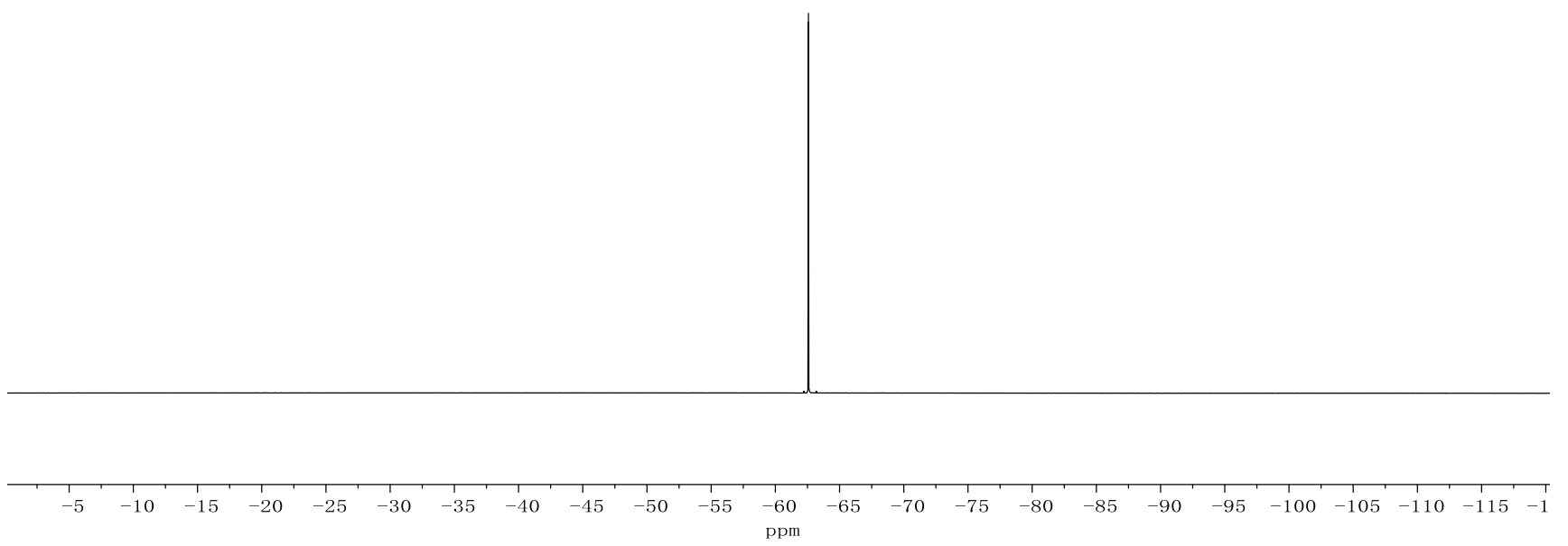




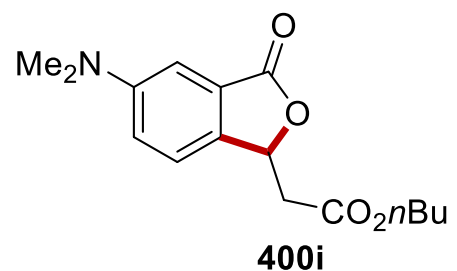

(400 MHz, $\mathrm{CDCl}_{3}$ )

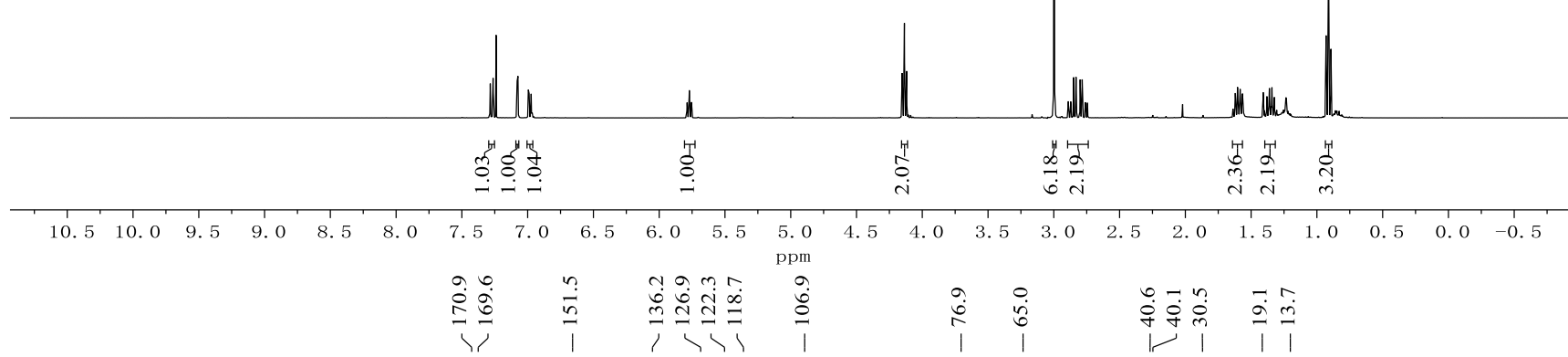<smiles>CCCOCC1OC(=O)c2cc(N(C)C)ccc21</smiles>

$400 \mathrm{i}$

(100 MHz, $\mathrm{CDCl}_{3}$ )

$\begin{array}{llllllllllllllllllllllllllllllll}1 & 250 & 240 & 230 & 220 & 210 & 200 & 190 & 180 & 170 & 160 & 150 & 140 & 130 & 120 & 110 & 100 & 90 & 80 & 70 & 60 & 50 & 40 & 30 & 20 & 10 & 0 & -10 & -20 & -30\end{array}$ 


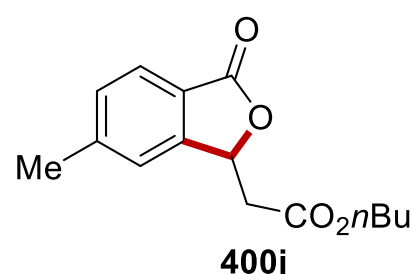

(400 MHz, $\mathrm{CDCl}_{3}$ )

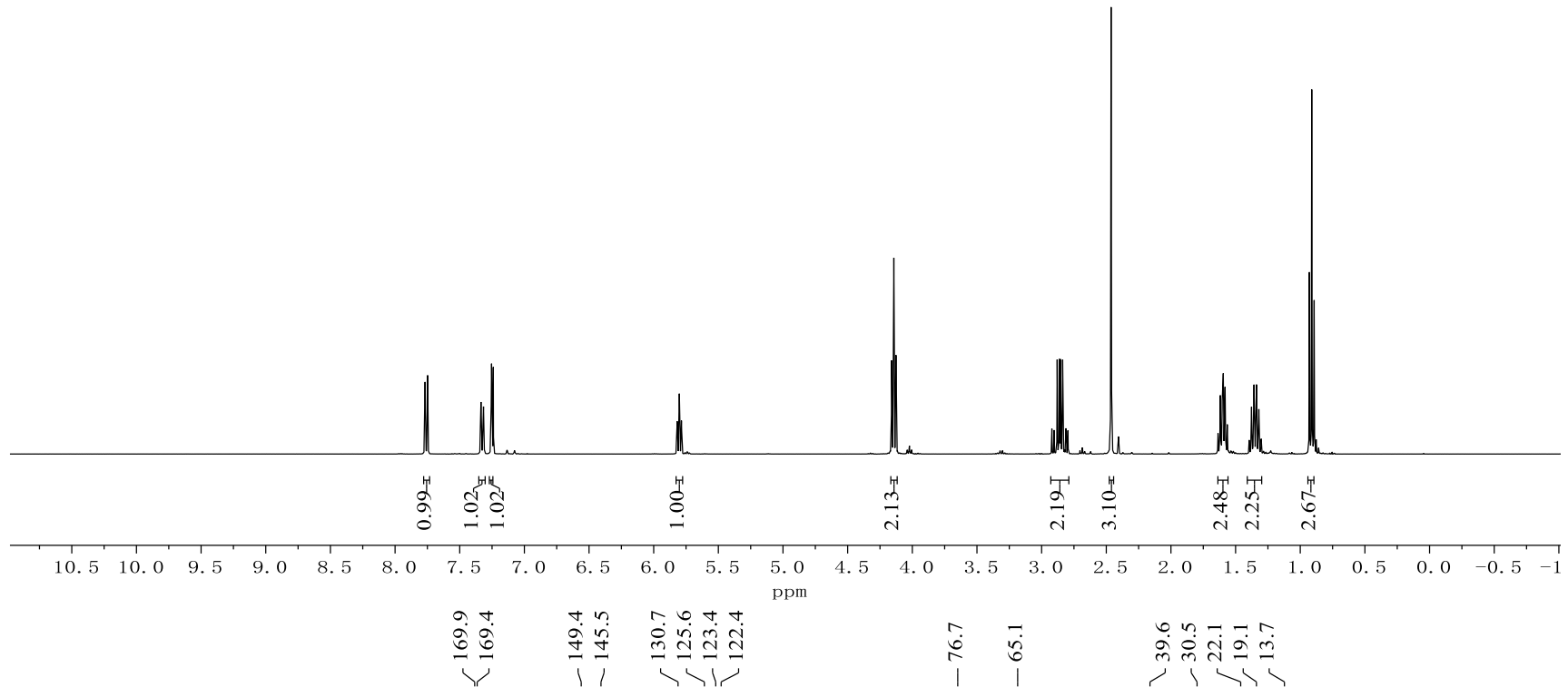<smiles>CCOC(=O)CC1OC(=O)c2ccc(C)cc21</smiles>

$\left(100 \mathrm{MHz}, \mathrm{CDCl}_{3}\right.$ )

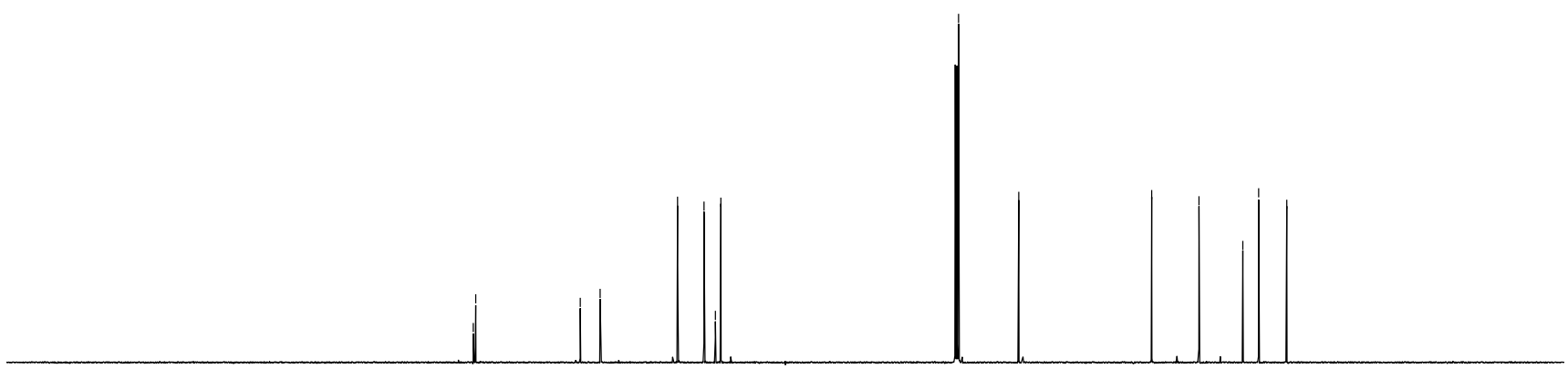

$250 \begin{array}{llllllllllllllllllllllllllllllllll}1 & 240 & 230 & 220 & 210 & 200 & 190 & 180 & 170 & 160 & 150 & 140 & 130 & 120 & 110 & 100 & 90 & 80 & 70 & 60 & 50 & 40 & 30 & 20 & 10 & 0 & -10 & -20 & -30\end{array}$ 
<smiles>CCOC(=O)CC1OC(=O)c2ccc(C(C)(C)C)cc21</smiles>

$\left(400 \mathrm{MHz}, \mathrm{CDCl}_{3}\right)$

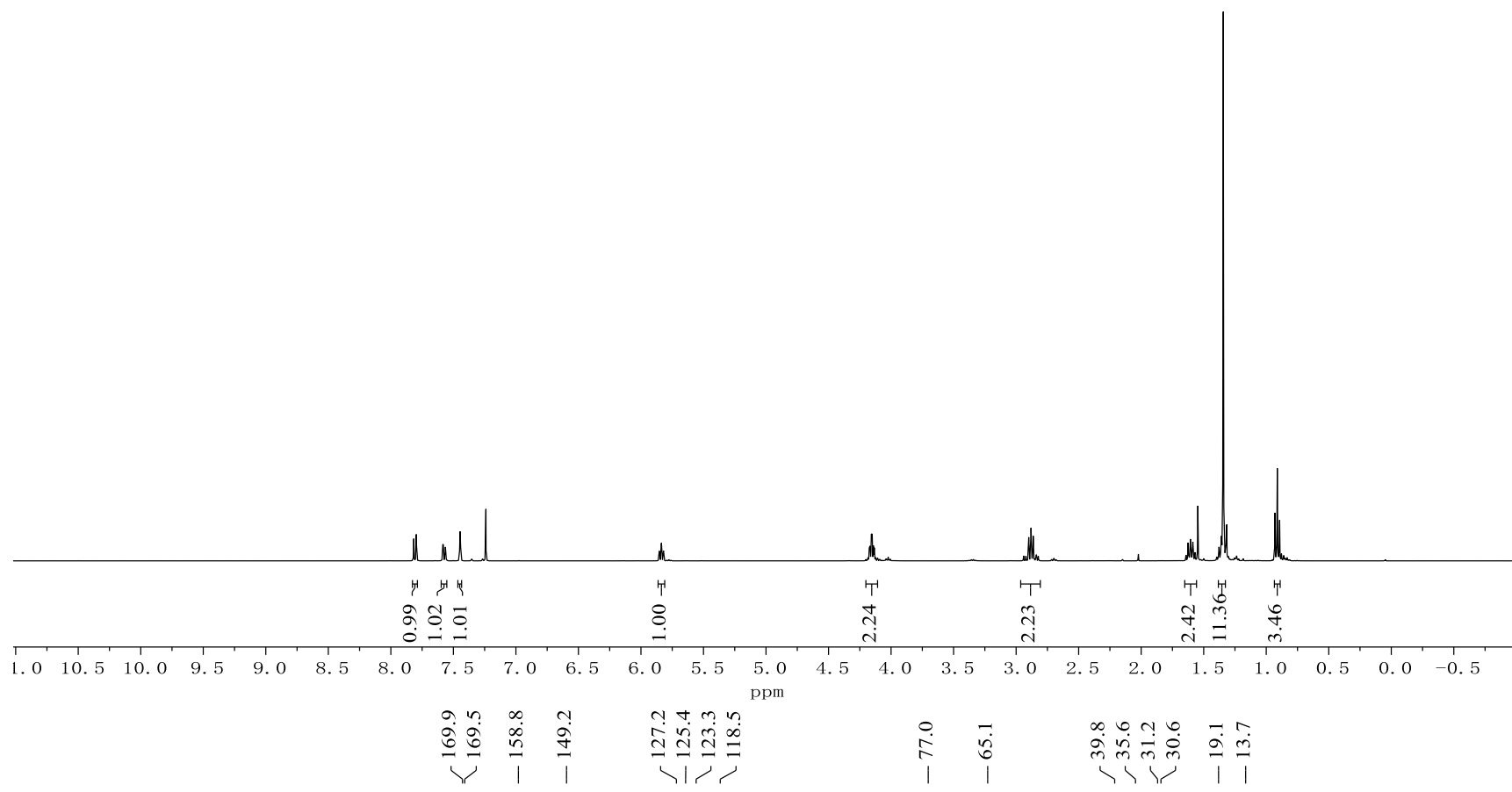<smiles>CCOC(=O)CC1OC(=O)c2ccc(C(C)(C)C)cc21</smiles>

(100 MHz, $\mathrm{CDCl}_{3}$ ) 


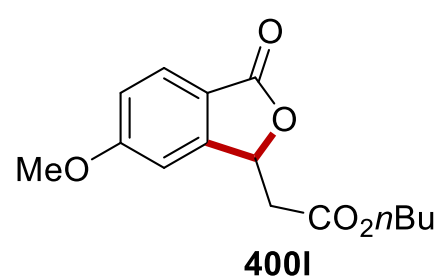

(400 MHz, $\mathrm{CDCl}_{3}$ )

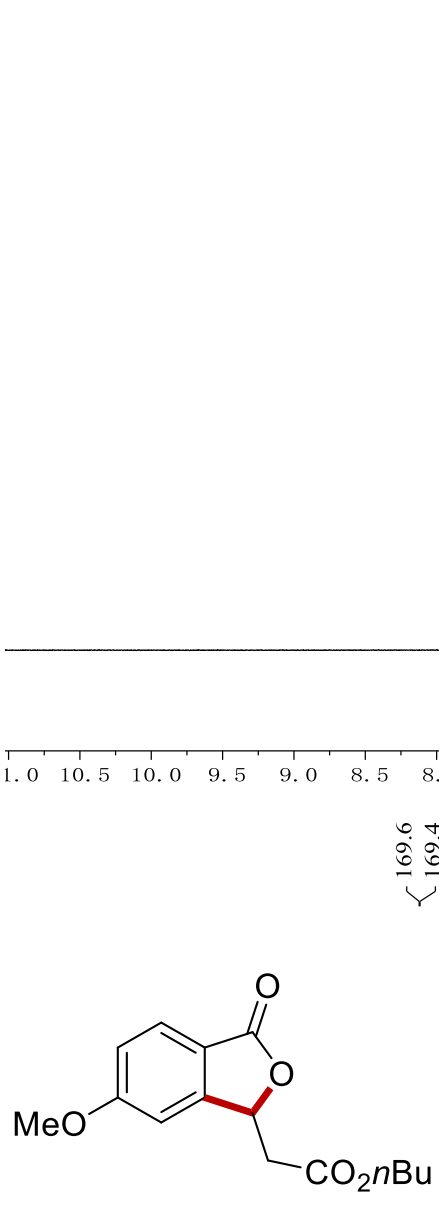

4001

(100 $\mathrm{MHz}, \mathrm{CDCl}_{3}$ )

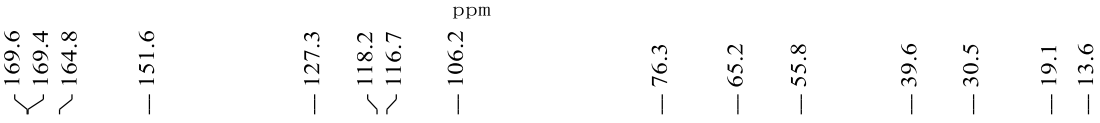


<smiles>CCCOCC1OC(=O)c2ccc(F)cc21</smiles>

$400 \mathrm{~m}$

$\left(400 \mathrm{MHz}, \mathrm{CDCl}_{3}\right)$

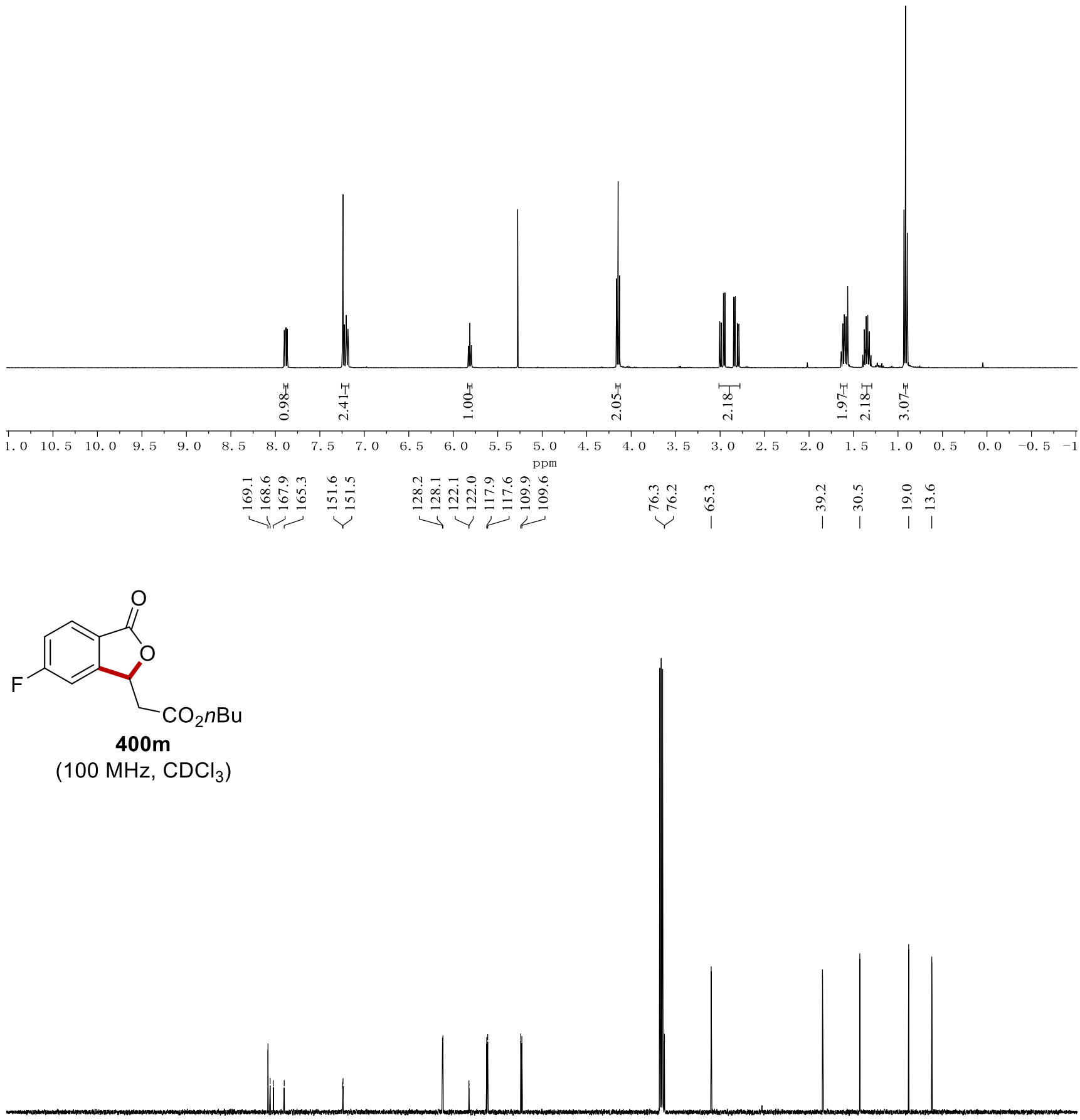

\begin{tabular}{lllllllllllllllllllllllllllllllll}
\hline 30 & 220 & 210 & 200 & 190 & 180 & 170 & 160 & 150 & 140 & 130 & 120 & 110 & 100 & 90 & 80 & 70 & 60 & 50 & 40 & 30 & 20 & 10 & 0 & -10 & -1
\end{tabular} 


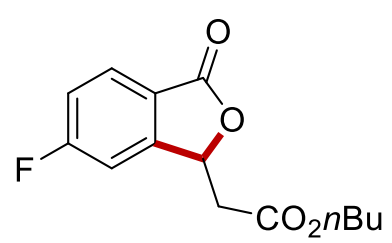

จ่

400m

$\left(282 \mathrm{MHz}^{\mathrm{CDCl}}\right)_{3}$

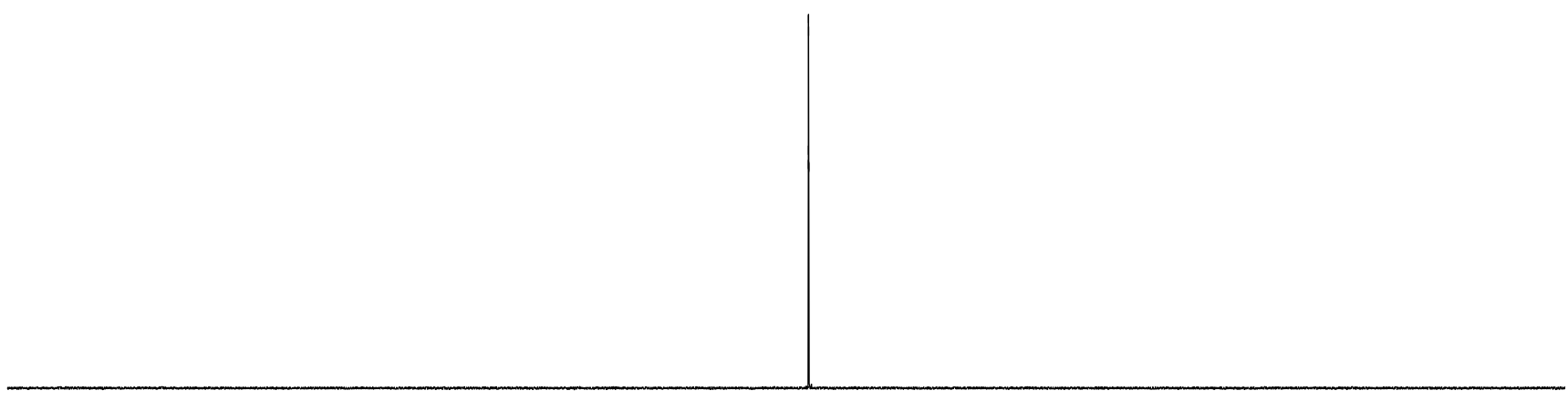

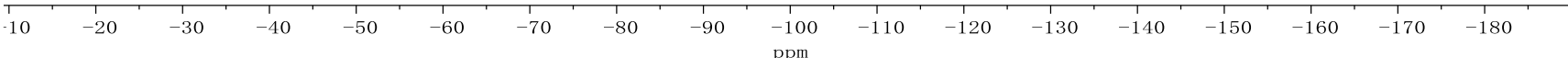


<smiles>CCCOC(=O)CC1OC(=O)c2ccc(Cl)cc21</smiles>

400n

(400 MHz, $\mathrm{CDCl}_{3}$ )

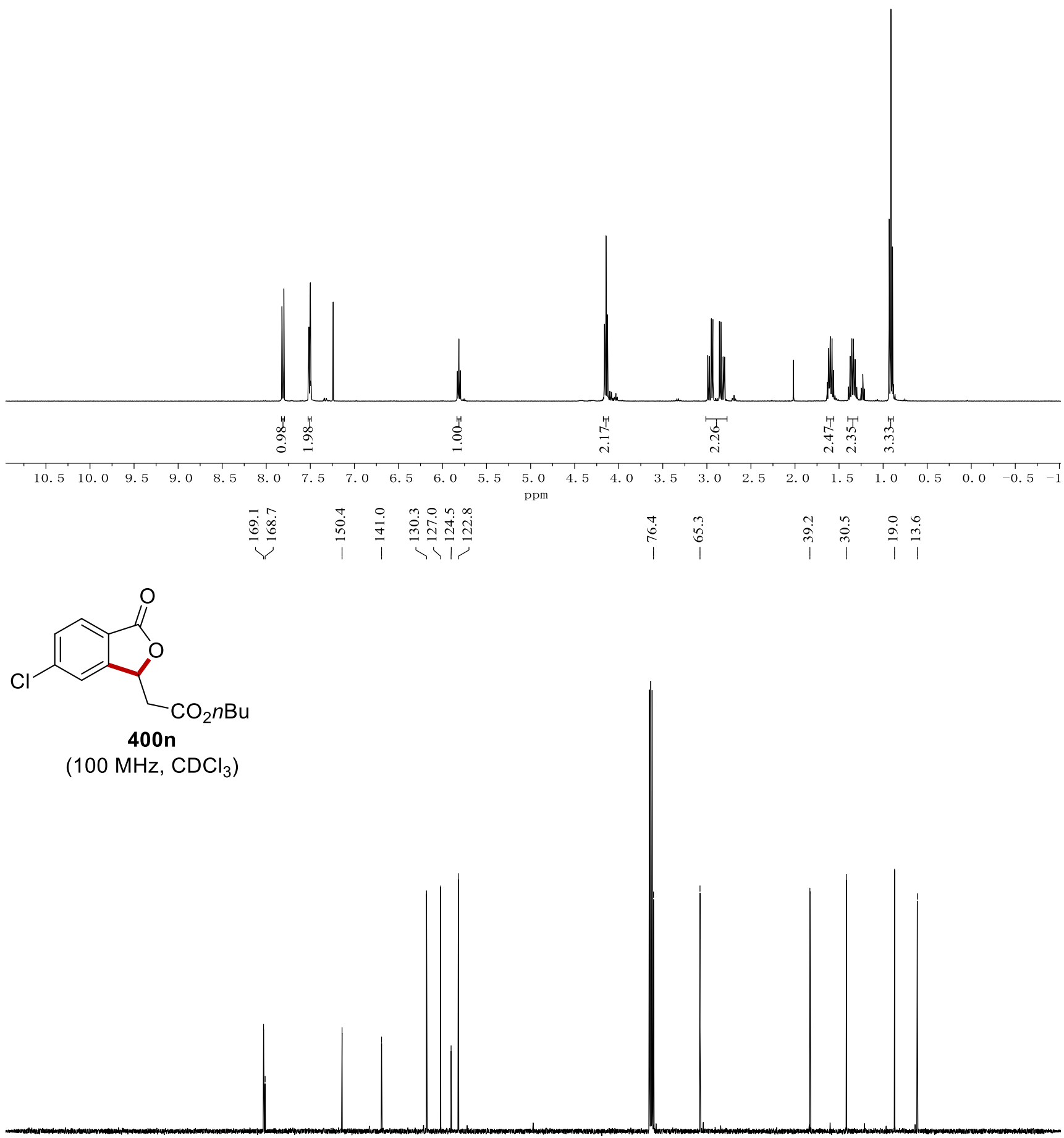

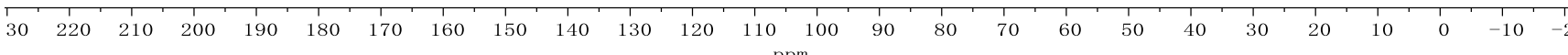


<smiles>CCOC(=O)CC1OC(=O)c2ccc(Br)cc21</smiles>

4000

$\left(400 \mathrm{MHz}, \mathrm{CDCl}_{3}\right)$

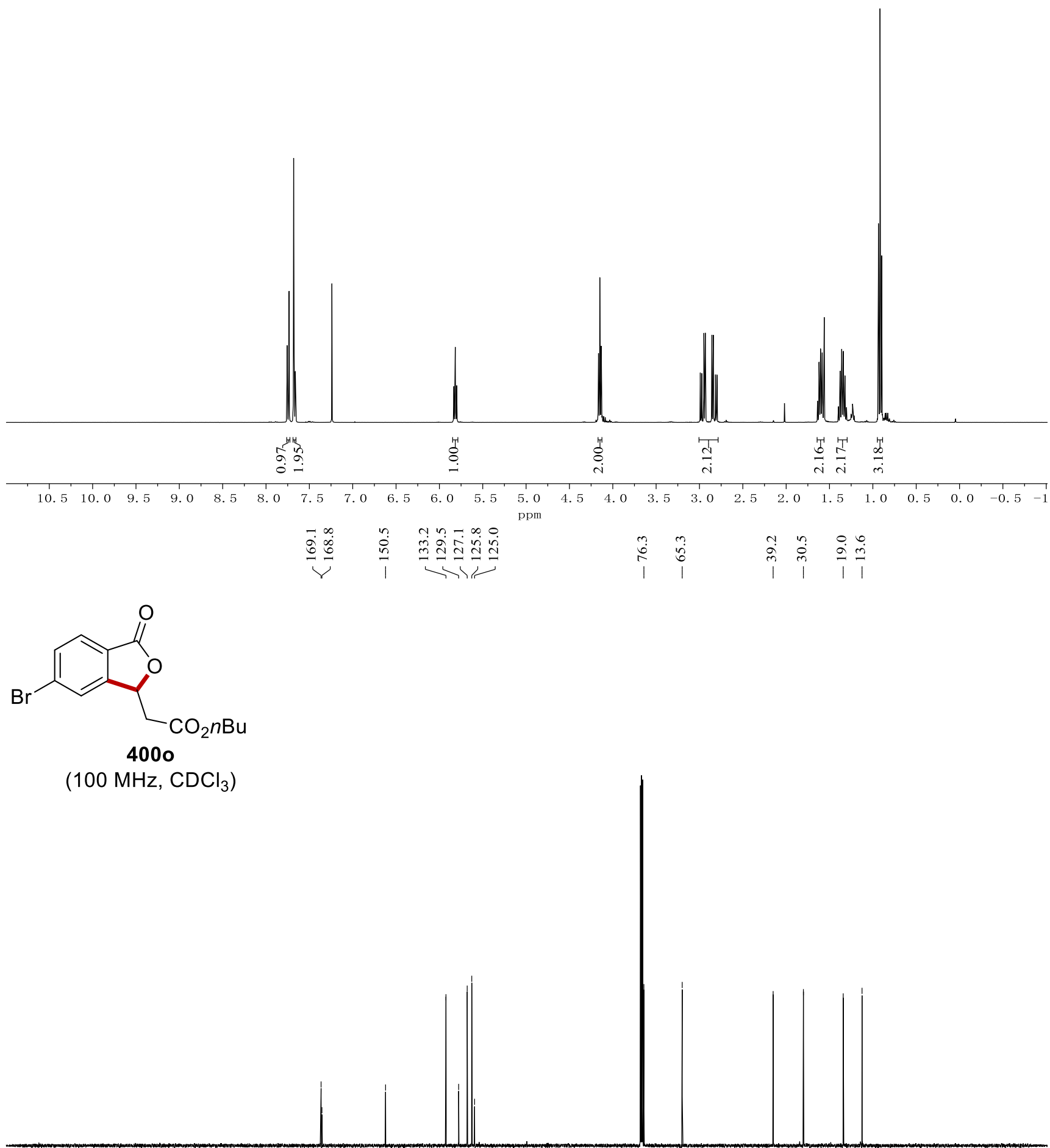

$\begin{array}{lllllllllllllllllllllllllllllllllllllllllll}250 & 240 & 230 & 220 & 210 & 200 & 190 & 180 & 170 & 160 & 150 & 140 & 130 & 120 & 110 & 100 & 90 & 80 & 70 & 60 & 50 & 40 & 30 & 20 & 10 & 0 & -10 & -20 & -30\end{array}$ 
<smiles>CCOC(=O)CC1OC(=O)c2ccc(I)cc21</smiles>

(400 MHz, $\mathrm{CDCl}_{3}$ )
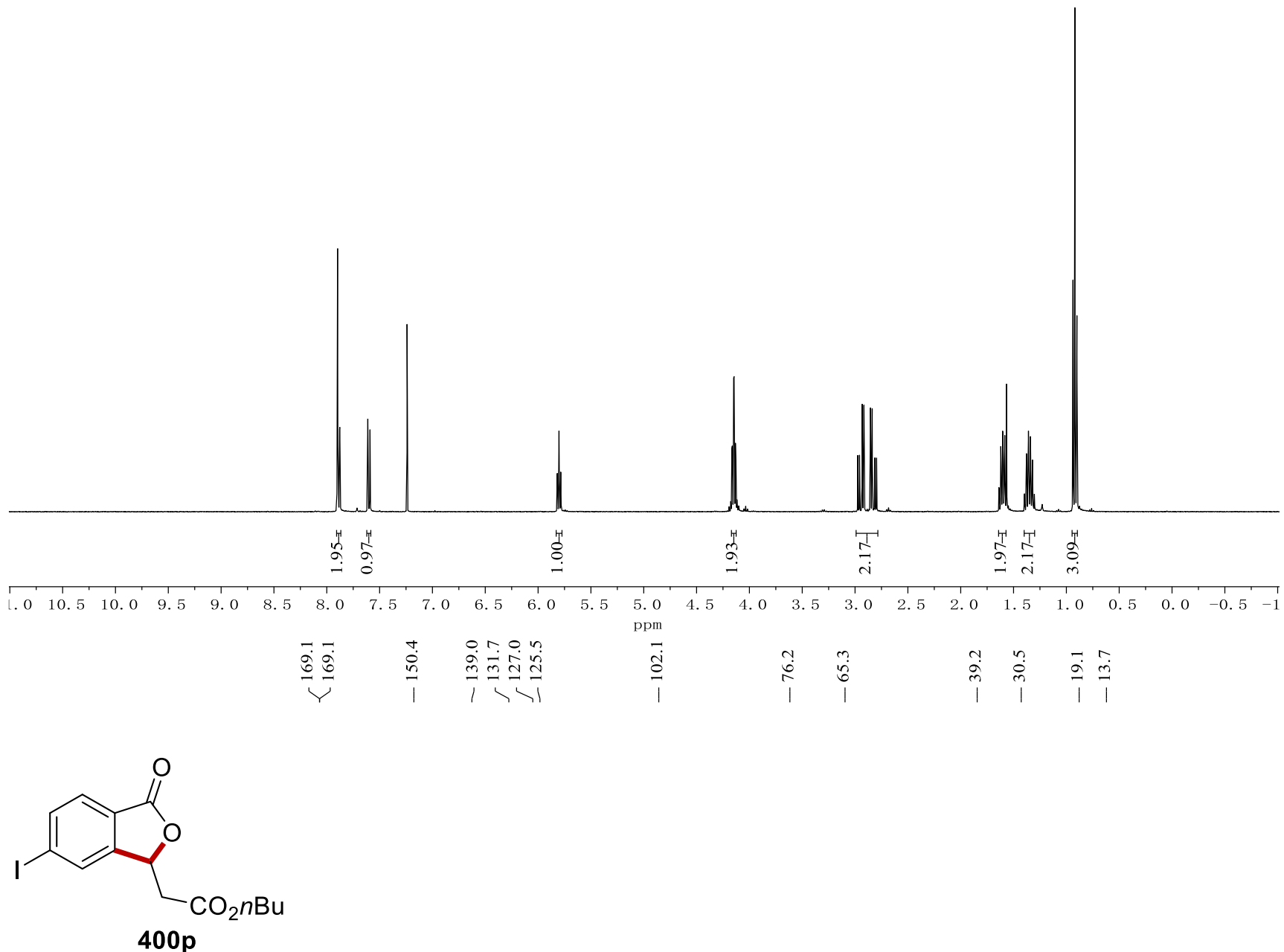

$\left(100 \mathrm{MHz}, \mathrm{CDCl}_{3}\right.$ )

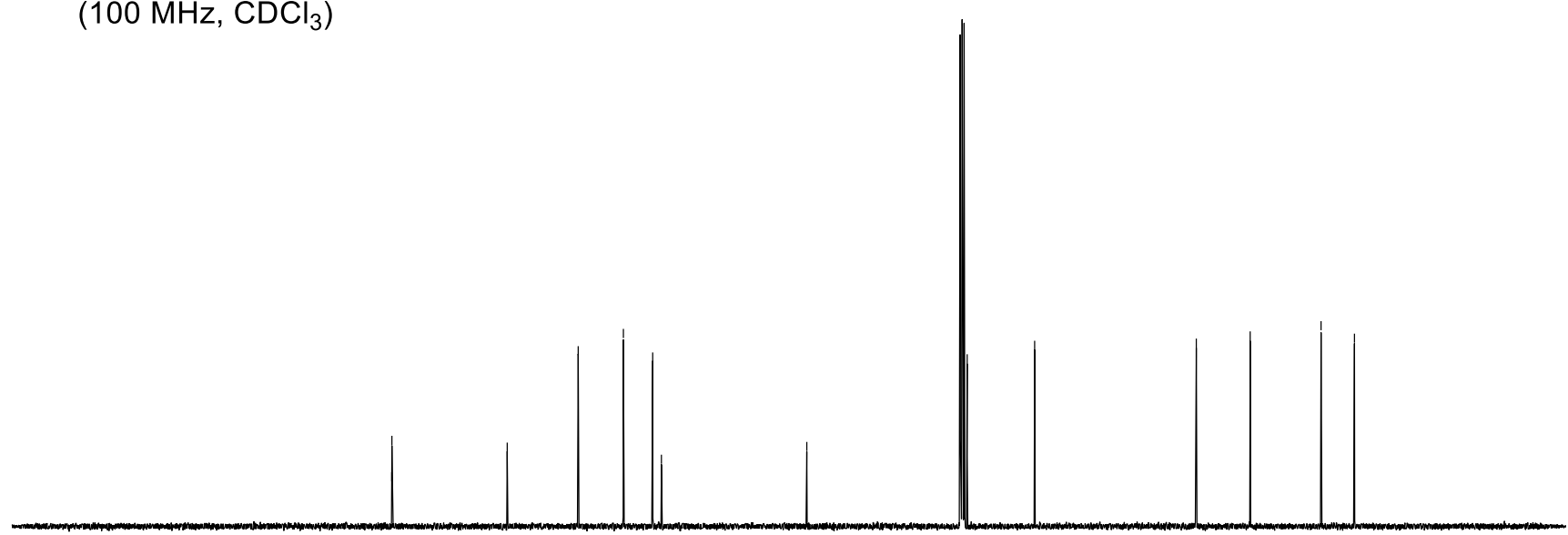

\begin{tabular}{lllllllllllllllllllllllllll}
\hline 30 & 220 & 210 & 200 & 190 & 180 & 170 & 160 & 150 & 140 & 130 & 120 & 110 & 100 & 90 & 80 & 70 & 60 & 50 & 40 & 30 & 20 & 10 & 0 & -10 & -1
\end{tabular} 


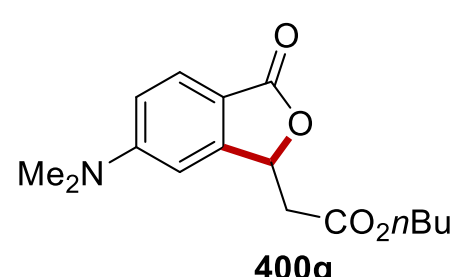

$\left(400 \mathrm{MHz}, \mathrm{CDCl}_{3}\right)$
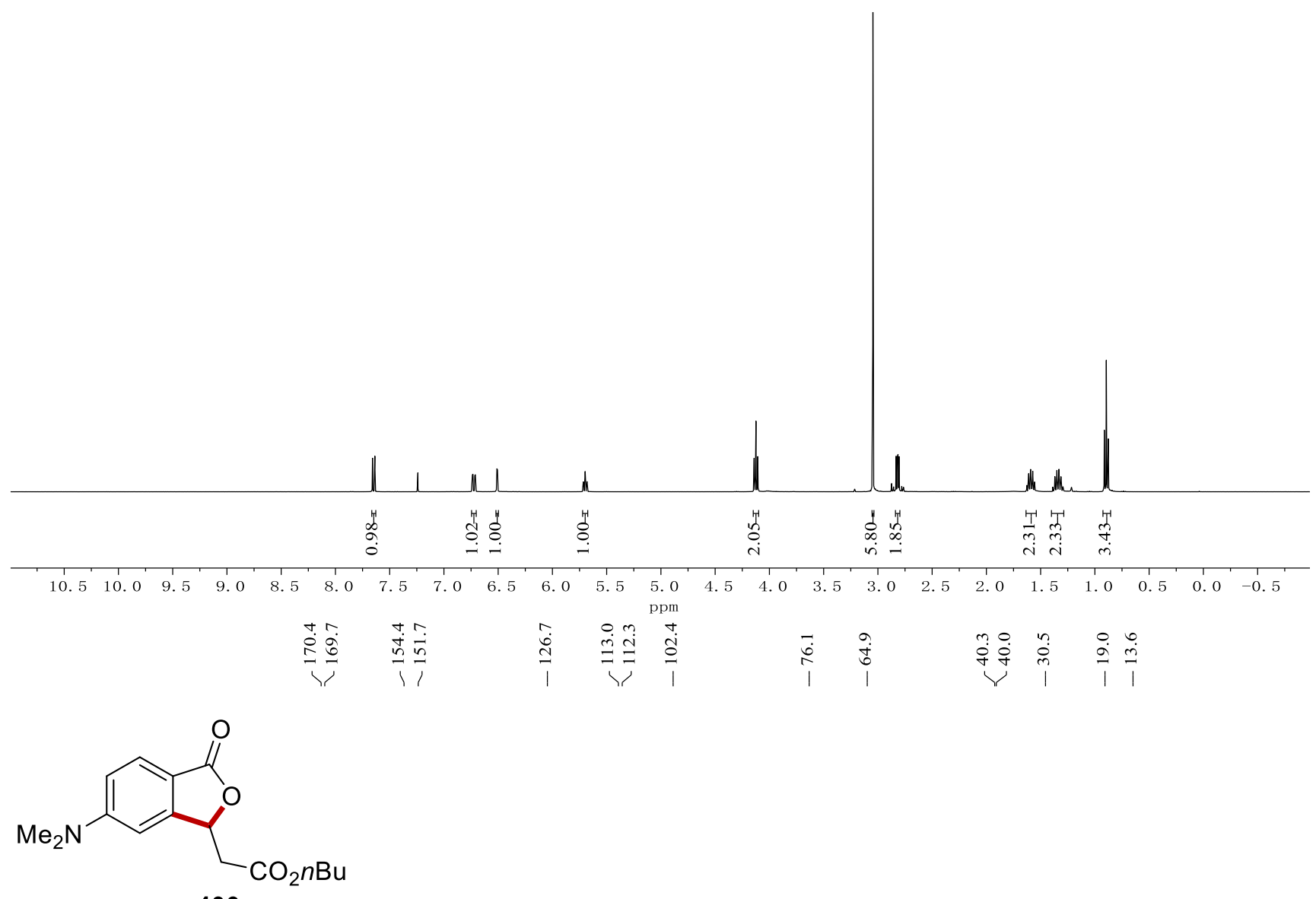

400q

$\left(100 \mathrm{MHz}, \mathrm{CDCl}_{3}\right)$

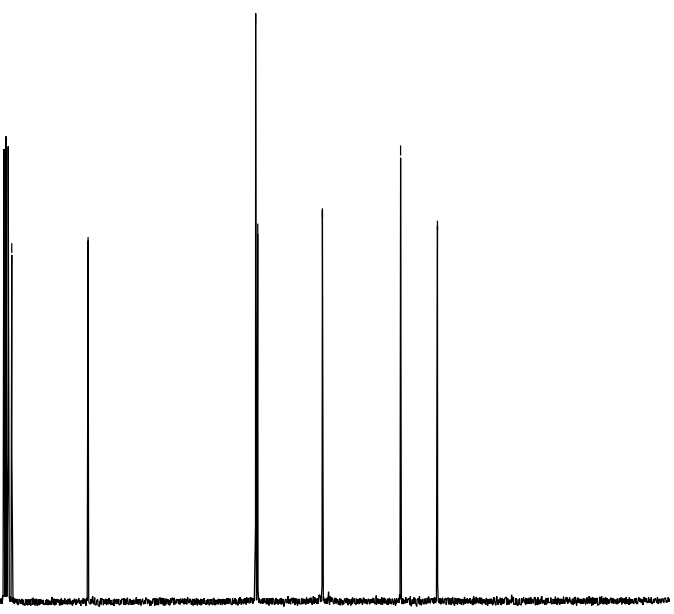

\begin{tabular}{llllllllllllllllllllllllllllllll}
\hline 30 & 220 & 210 & 200 & 190 & 180 & 170 & 160 & 150 & 140 & 130 & 120 & 110 & 100 & 90 & 80 & 70 & 60 & 50 & 40 & 30 & 20 & 10 & 0 & -10 & -1
\end{tabular} 


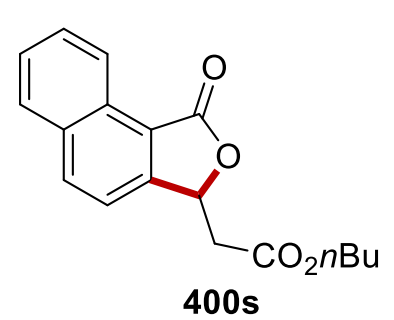

(400 MHz, $\mathrm{CDCl}_{3}$ )

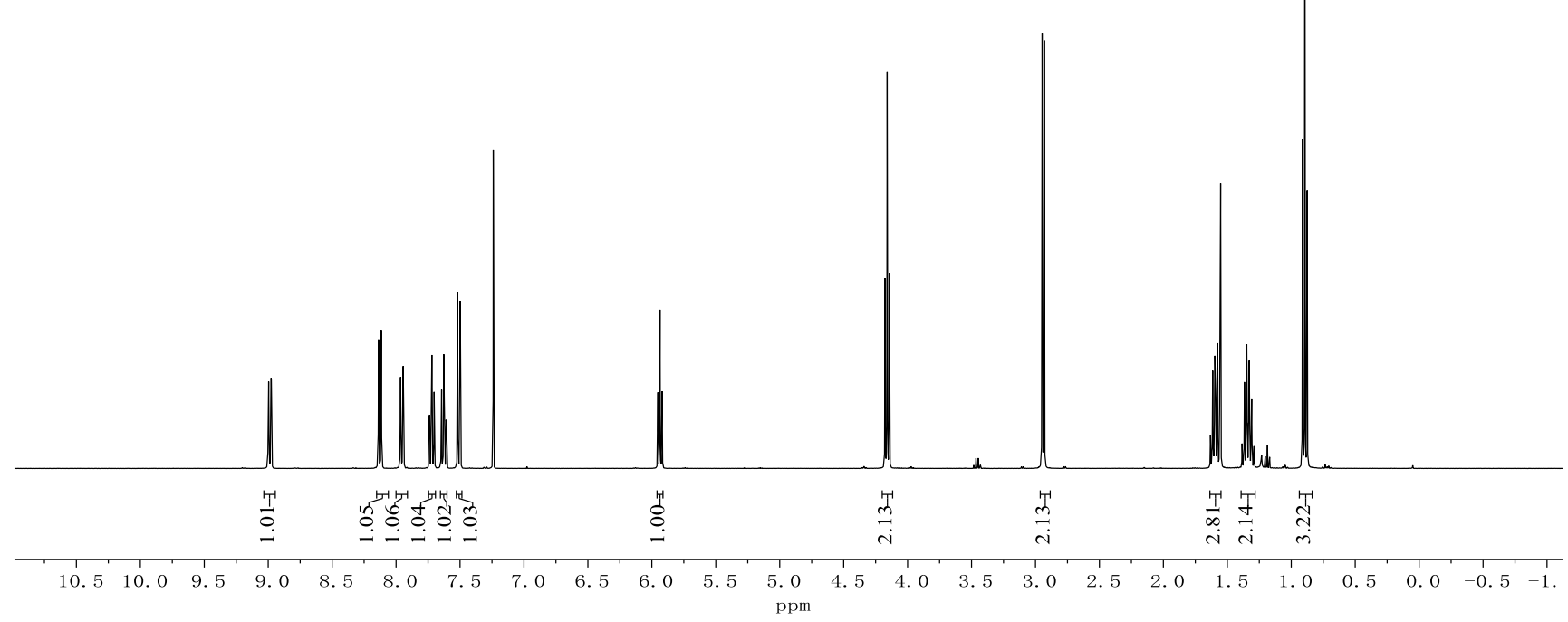

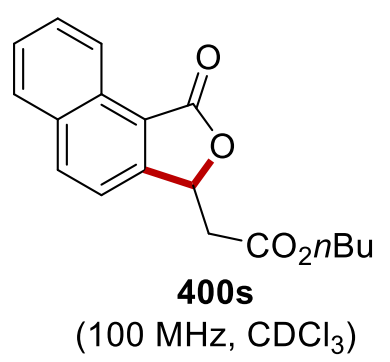

400s

(100 MHz, $\mathrm{CDCl}_{3}$ )

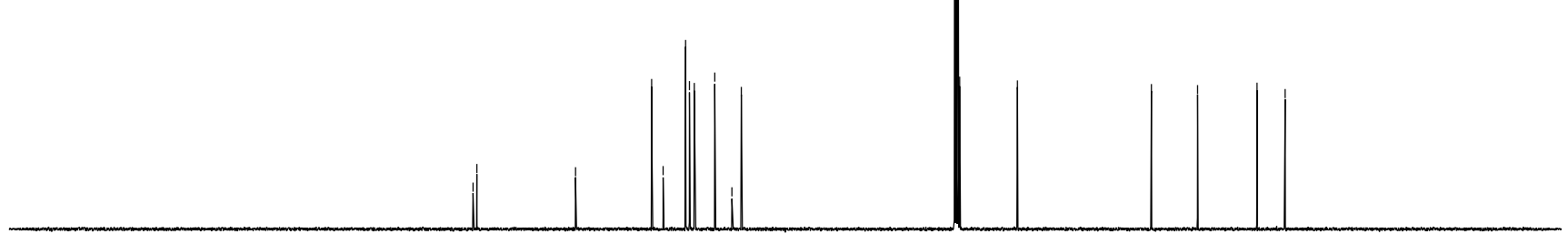

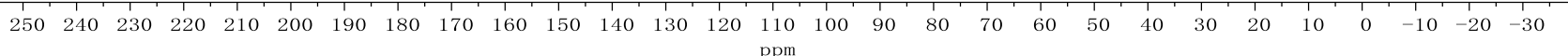




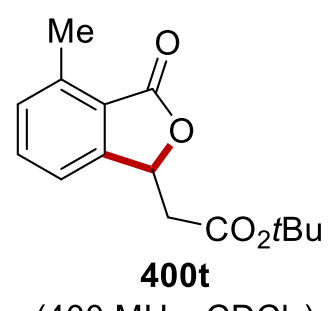

(400 MHz, $\mathrm{CDCl}_{3}$ )
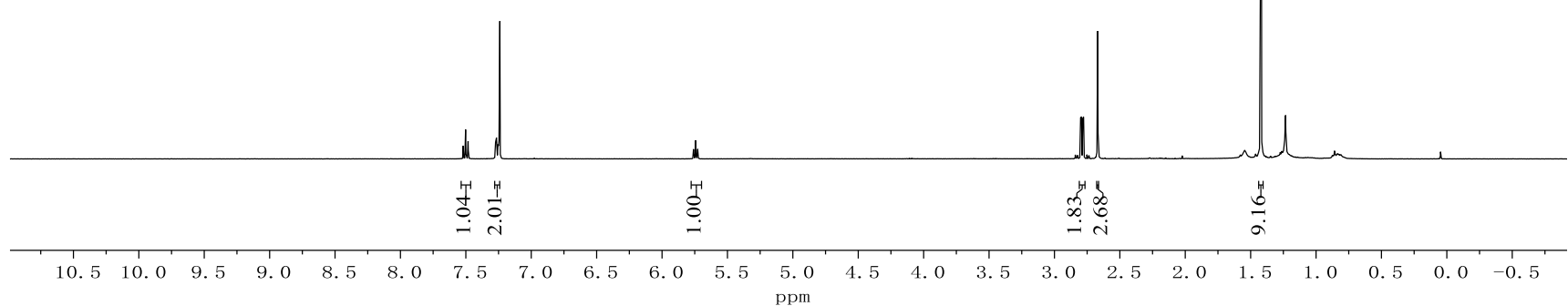

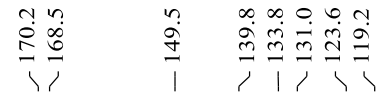

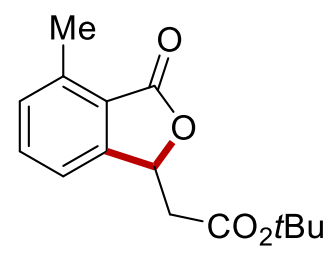

400t

$\left(100 \mathrm{MHz}, \mathrm{CDCl}_{3}\right)$

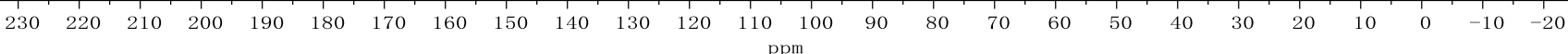




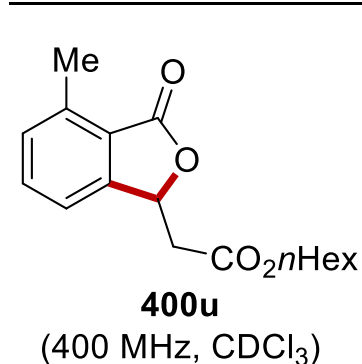

(400 MHz, $\mathrm{CDCl}_{3}$ )

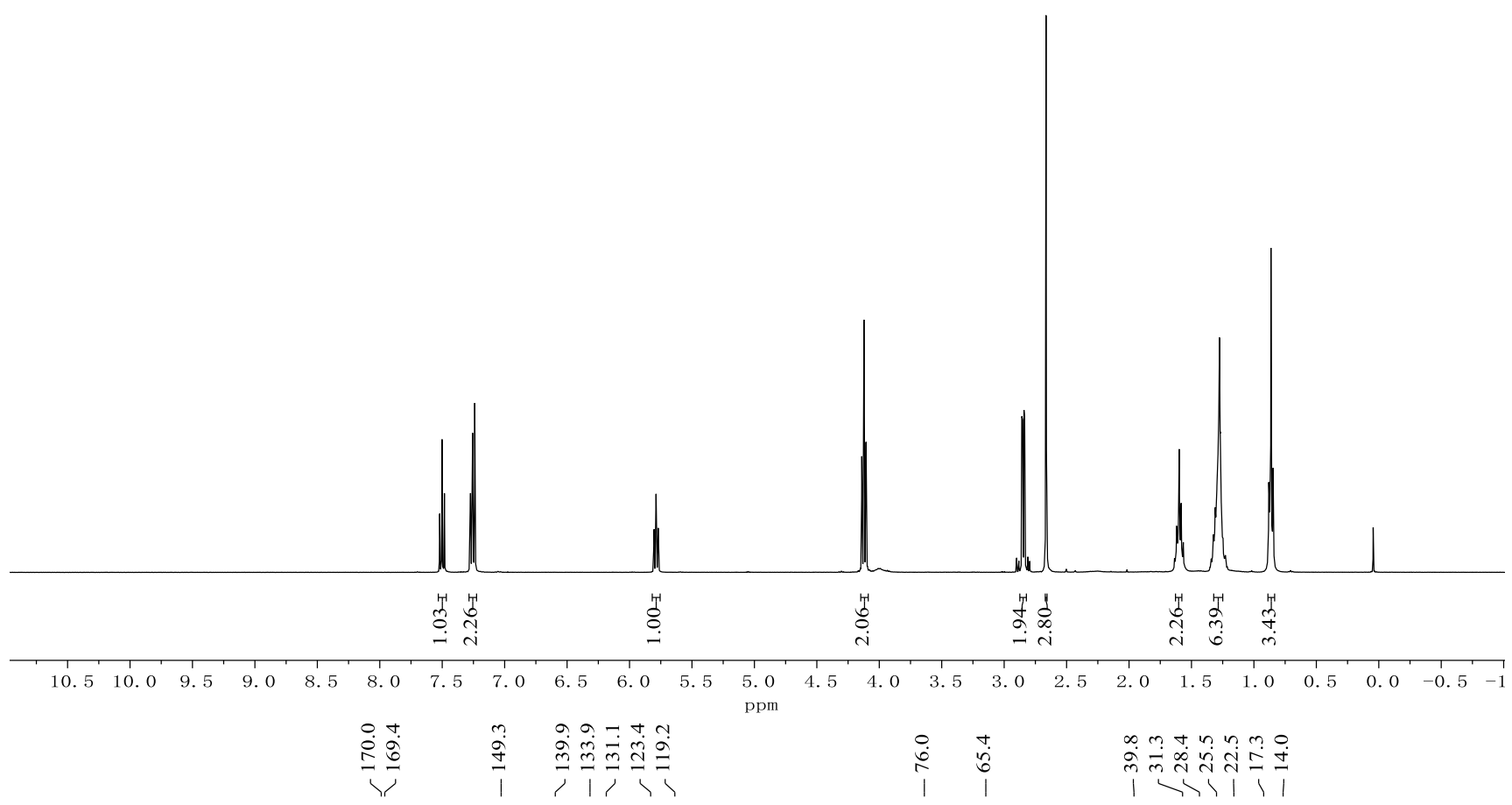<smiles>Cc1cccc2c1C(=O)OC2CC(=O)OCc1ccccc1</smiles>

400u

(100 MHz, $\mathrm{CDCl}_{3}$ )

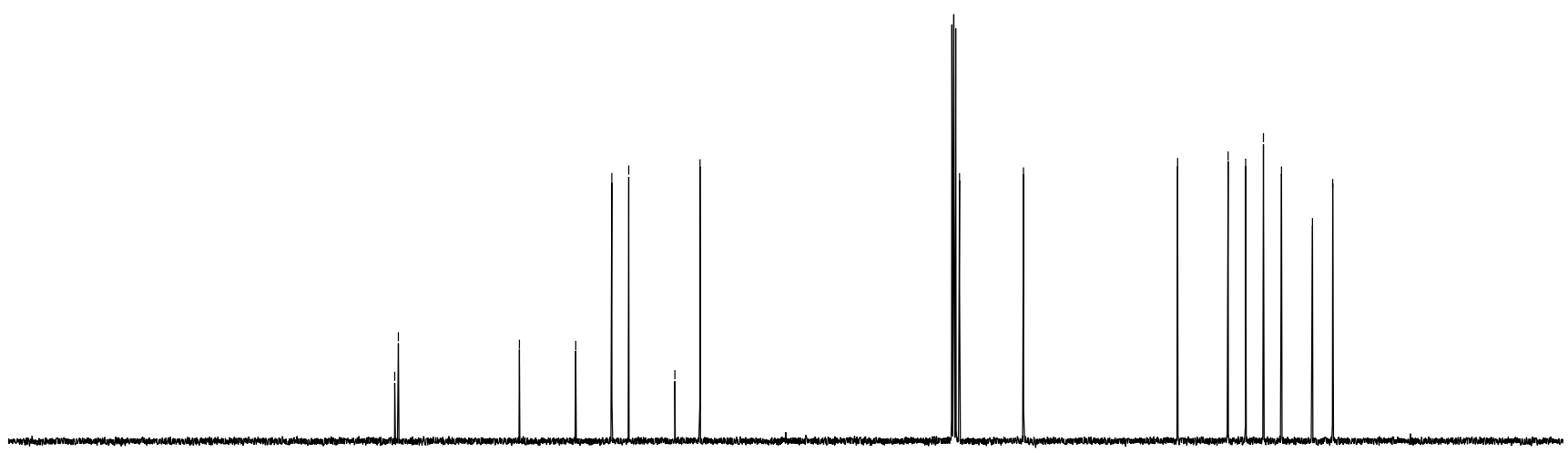

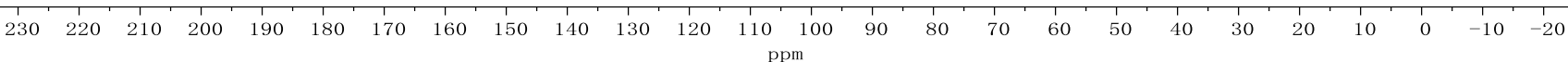




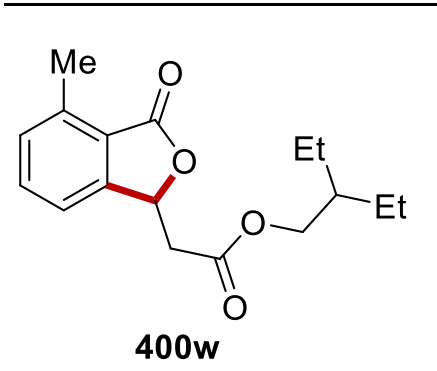

(400 MHz, $\mathrm{CDCl}_{3}$ )

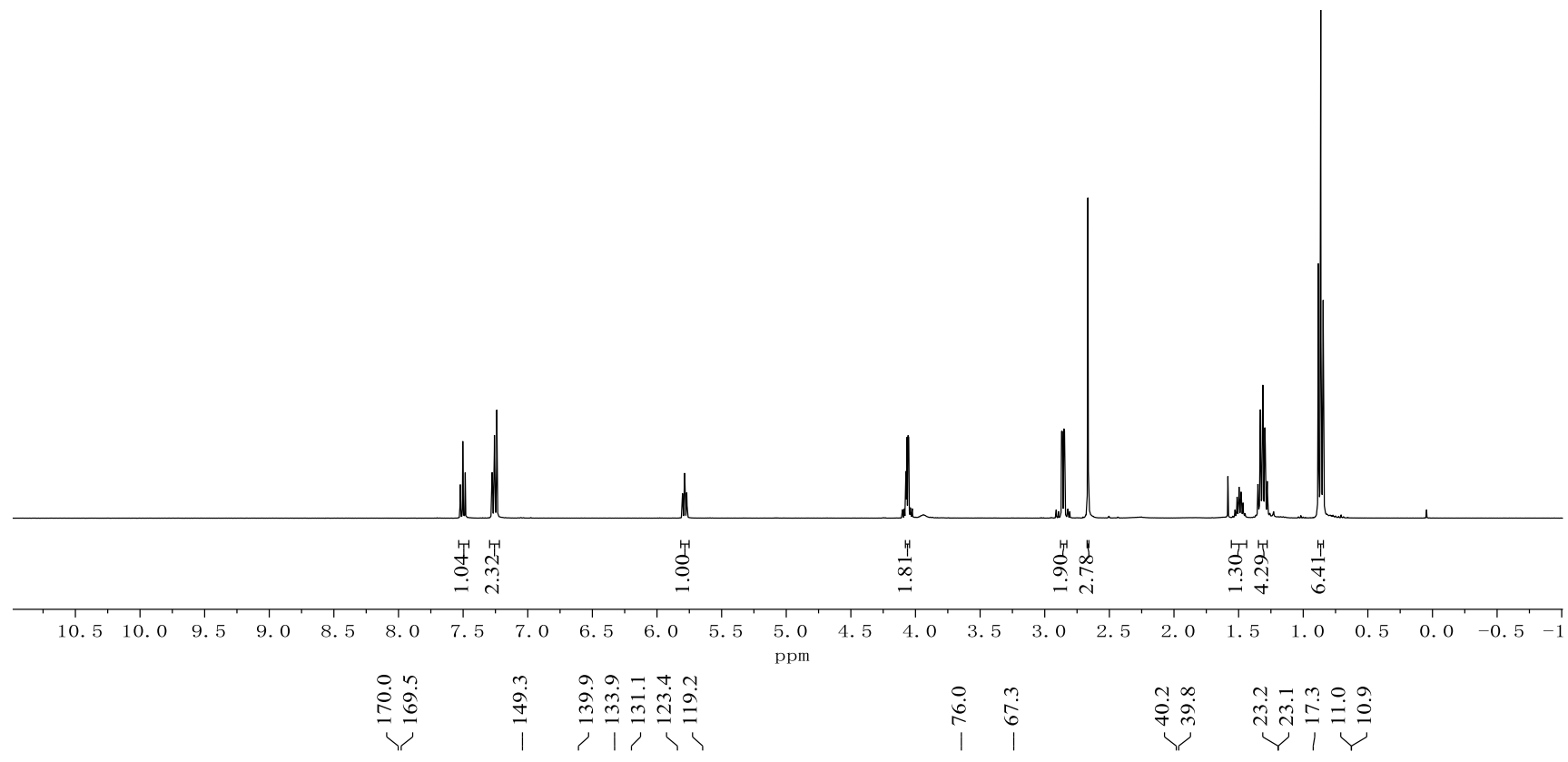<smiles>CCC(CC)COC(=O)CC1OC(=O)c2c(C)cccc21</smiles>

400w

(100 MHz, $\mathrm{CDCl}_{3}$ )

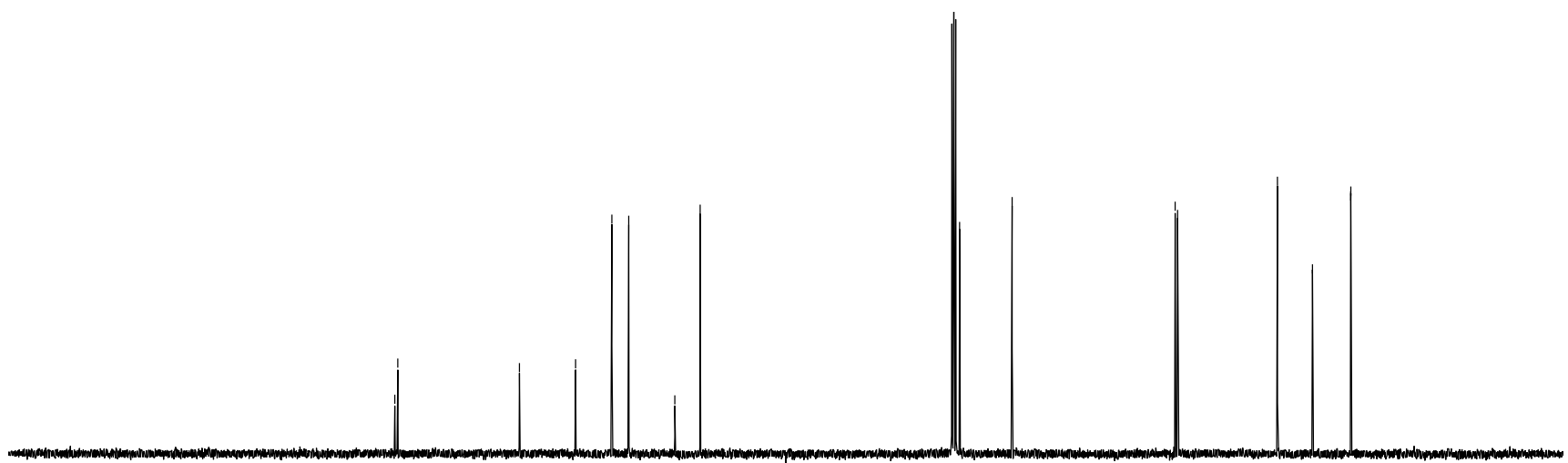

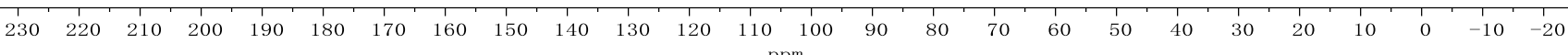




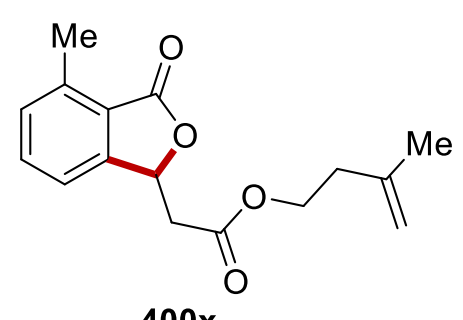

(400 MHz, $\mathrm{CDCl}_{3}$ )
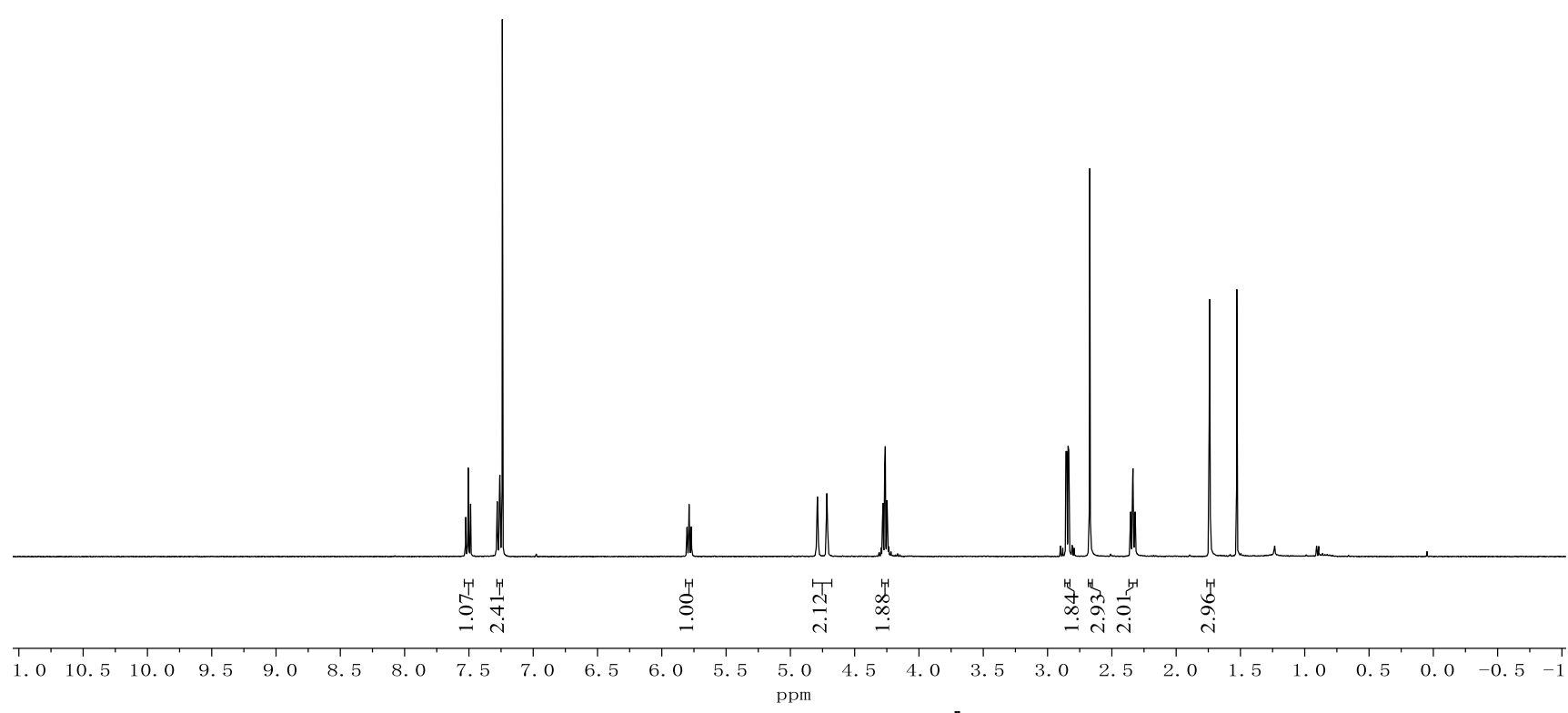

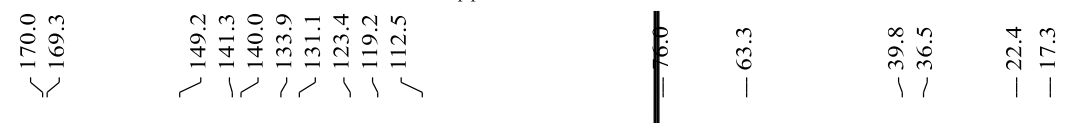<smiles>C=C(C)CCOC(=O)CC1OC(=O)c2c(C)cccc21</smiles>

400x

$\left(100 \mathrm{MHz}, \mathrm{CDCl}_{3}\right)$

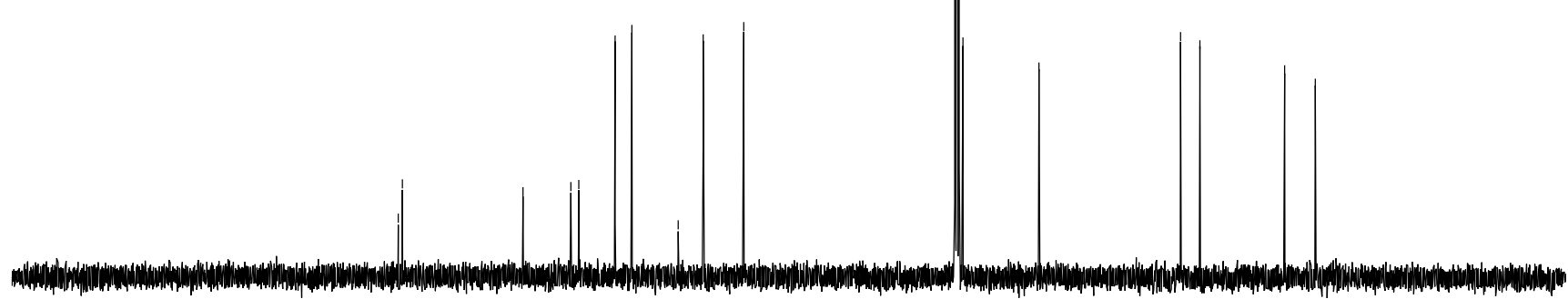

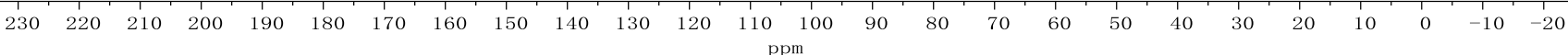




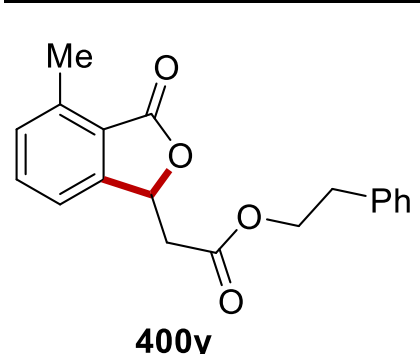

$\left(400 \mathrm{MHz}, \mathrm{CDCl}_{3}\right)$

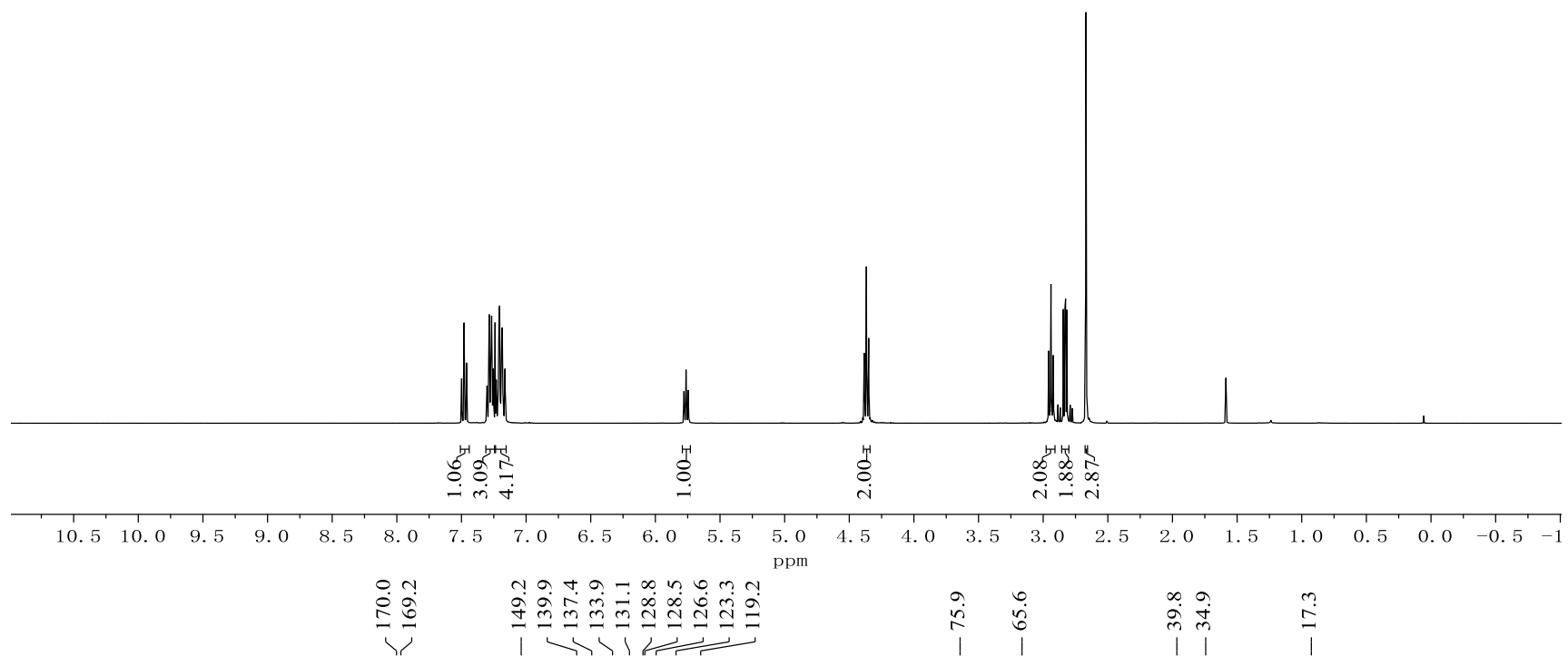<smiles>Cc1cccc2c1C(=O)OC2CC(=O)OCCc1ccccc1</smiles>

(100 MHz, $\mathrm{CDCl}_{3}$ )

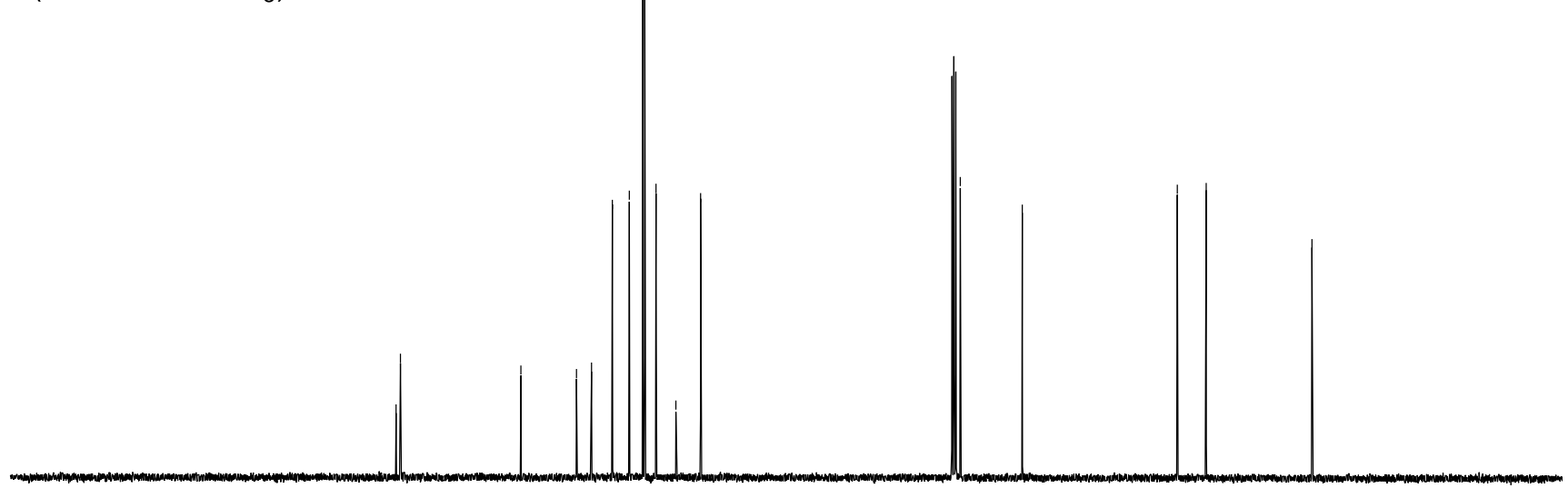

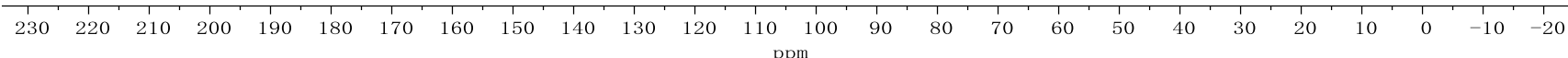




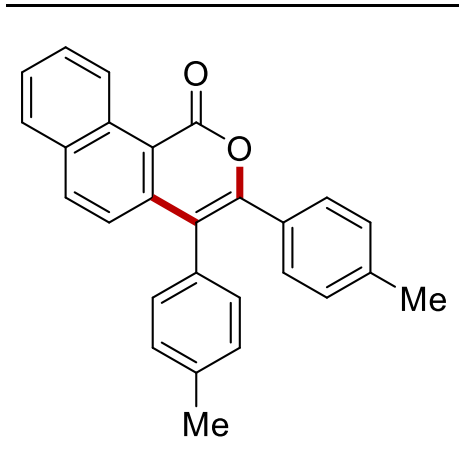

402a

(400 MHz, $\mathrm{CDCl}_{3}$ )

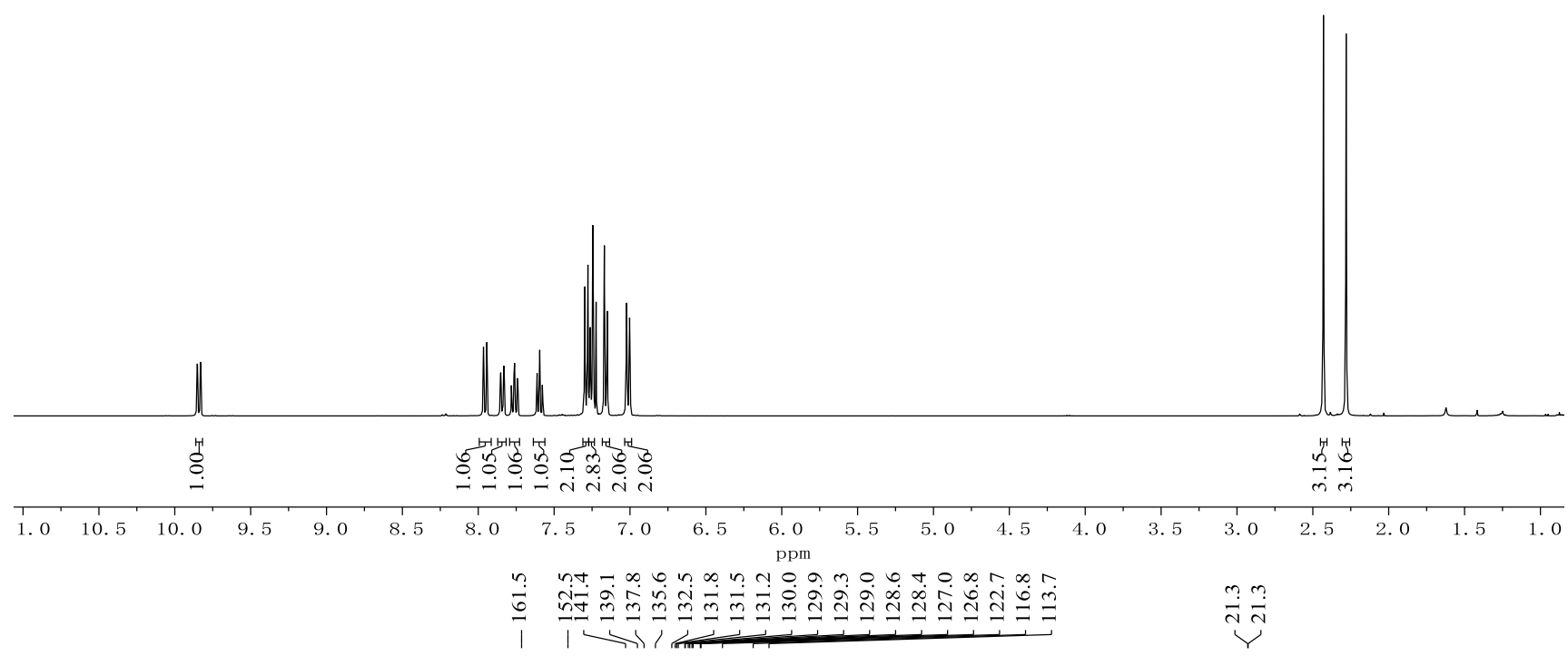<smiles>Cc1ccc(-c2oc(=O)c3ccccc3c2-c2ccc(C)cc2)cc1</smiles>

$402 a$

$\left(100 \mathrm{MHz}, \mathrm{CDCl}_{3}\right)$

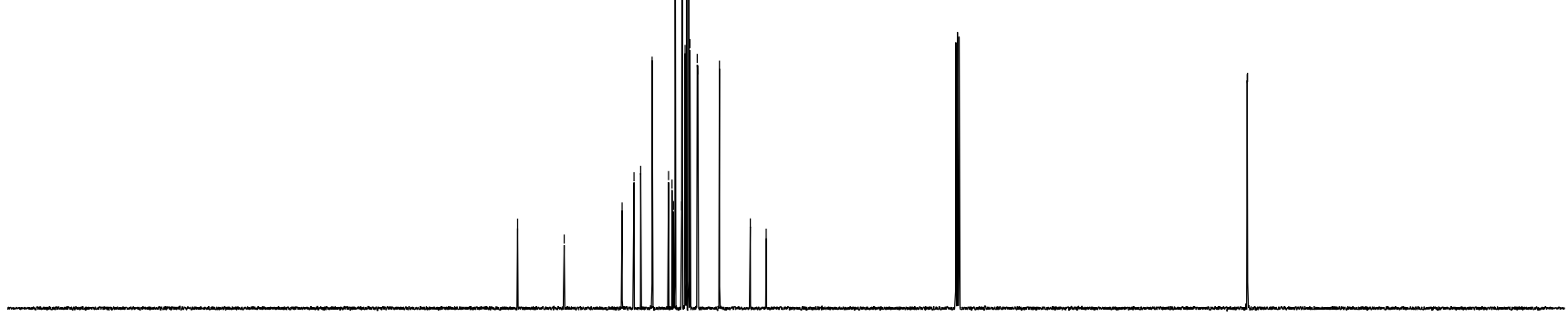

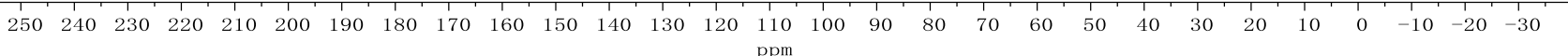




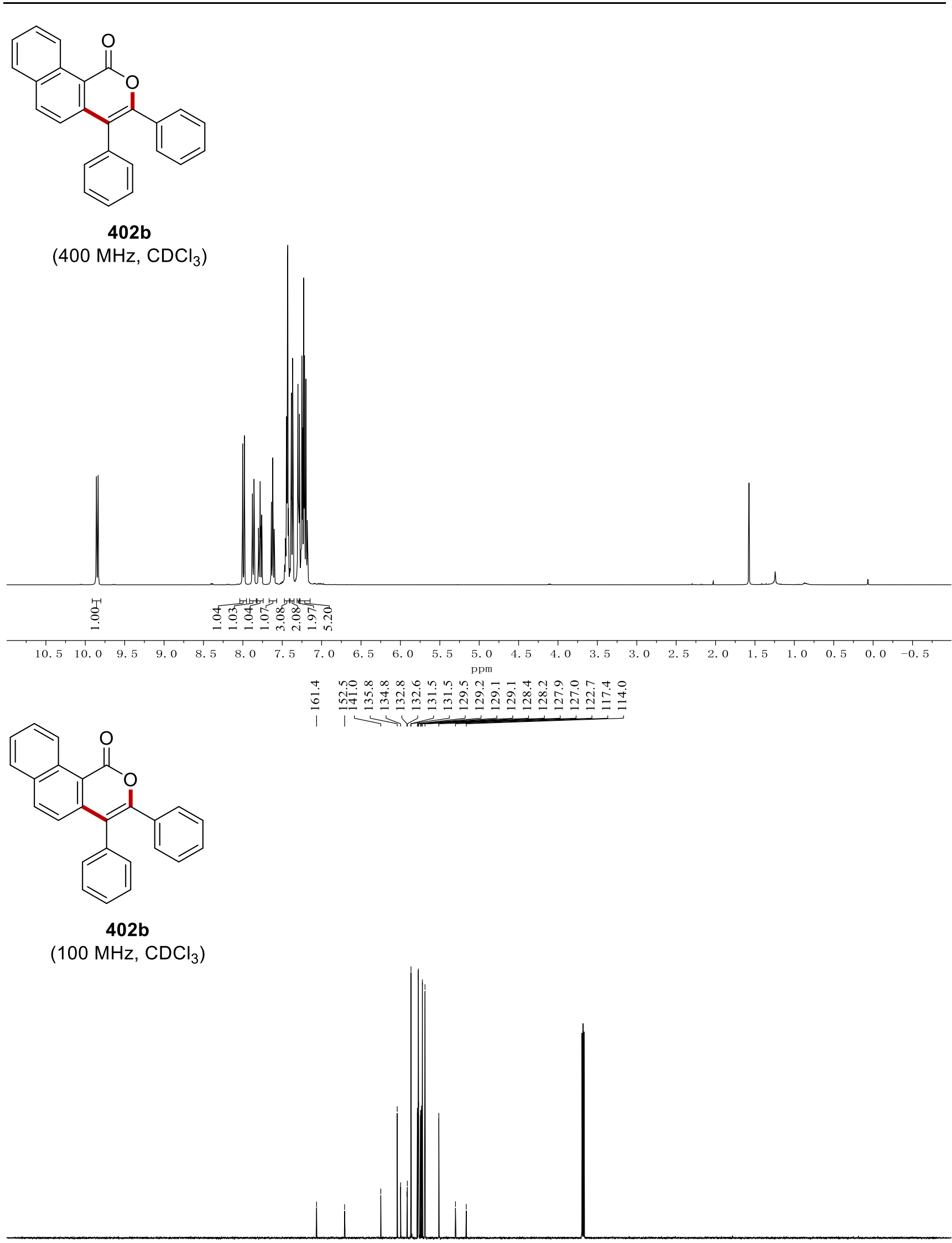

$\begin{array}{lllllllllllllllllllllllllllllllll}1 & 250 & 240 & 230 & 220 & 210 & 200 & 190 & 180 & 170 & 160 & 150 & 140 & 130 & 120 & 110 & 100 & 90 & 80 & 70 & 60 & 50 & 40 & 30 & 20 & 10 & 0 & -10 & -20 & -30\end{array}$ 


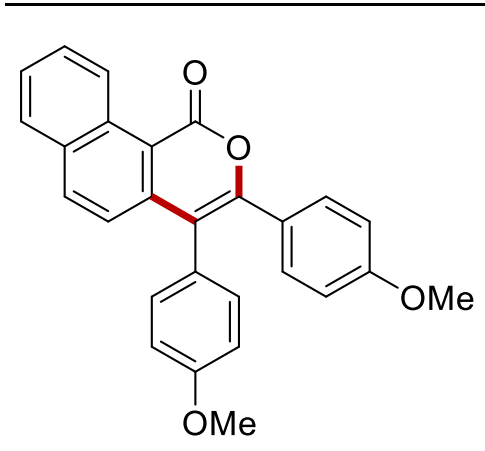

402c

(400 MHz, $\mathrm{CDCl}_{3}$ )

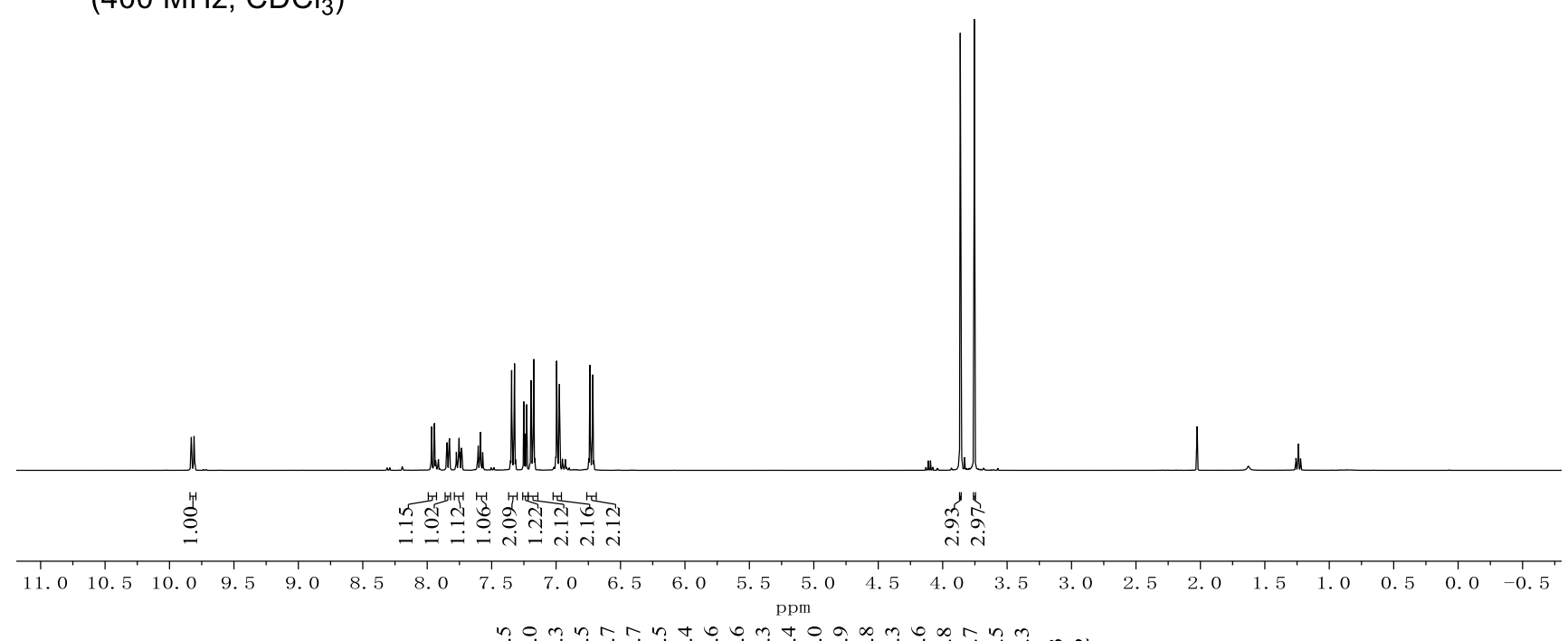

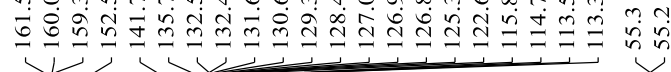<smiles></smiles>

402c

$\left(100 \mathrm{MHz}, \mathrm{CDCl}_{3}\right)$

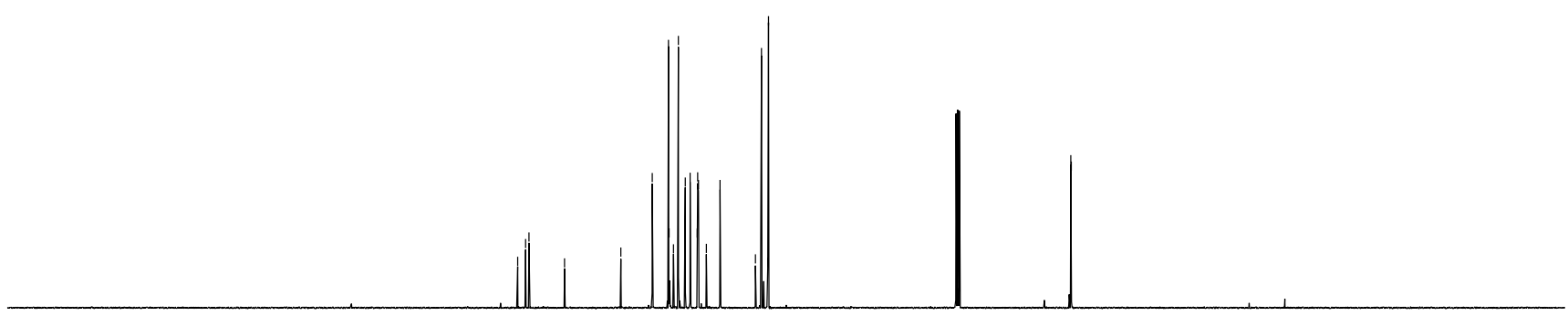

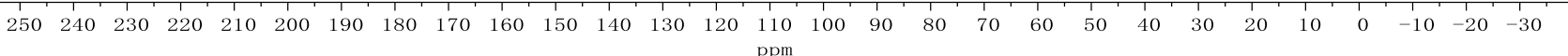




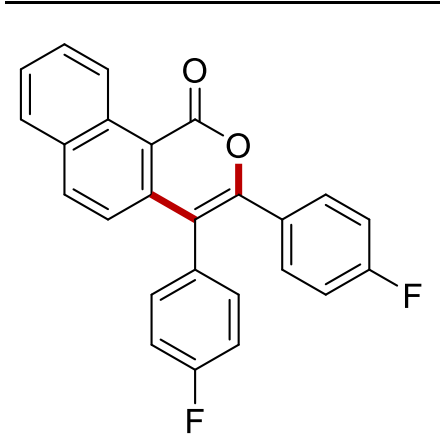

402d

(400 MHz, $\mathrm{CDCl}_{3}$ )

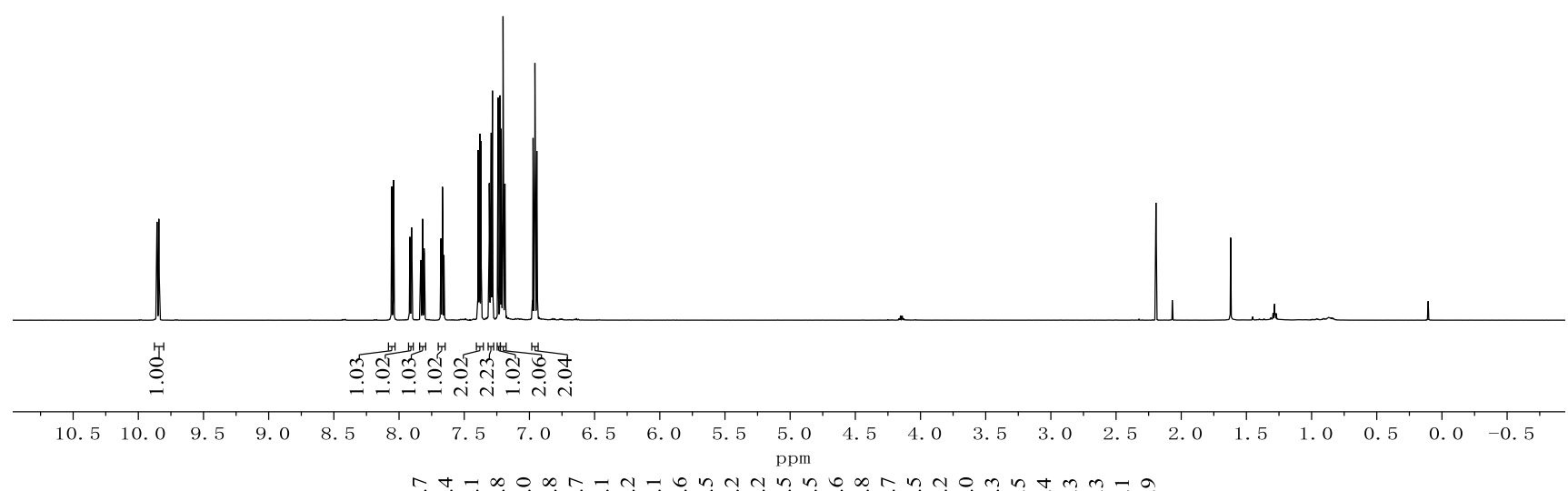

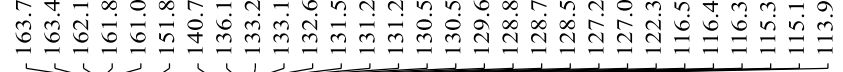<smiles>O=c1oc(-c2ccc(F)cc2)c(-c2ccc(F)cc2)c2ccc3ccccc3c12</smiles>

402d

$\left(100 \mathrm{MHz}, \mathrm{CDCl}_{3}\right.$ )

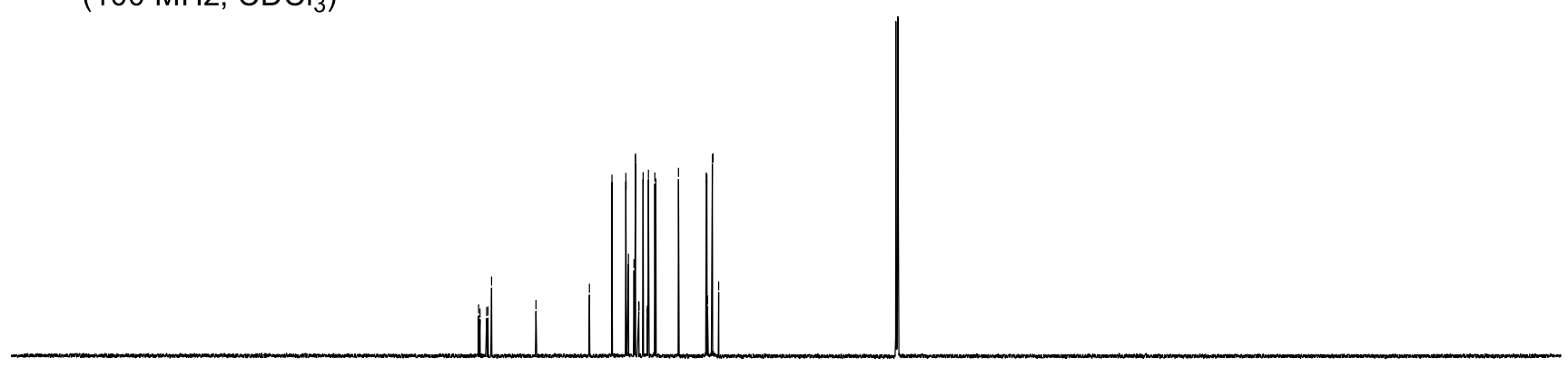

$\begin{array}{lllllllllllllllllllllllllllllllllll}60 & 250 & 240 & 230 & 220 & 210 & 200 & 190 & 180 & 170 & 160 & 150 & 140 & 130 & 120 & 110 & 100 & 90 & 80 & 70 & 60 & 50 & 40 & 30 & 20 & 10 & 0 & -10 & -20 & -30 & -40 & -50 & -\epsilon\end{array}$ 


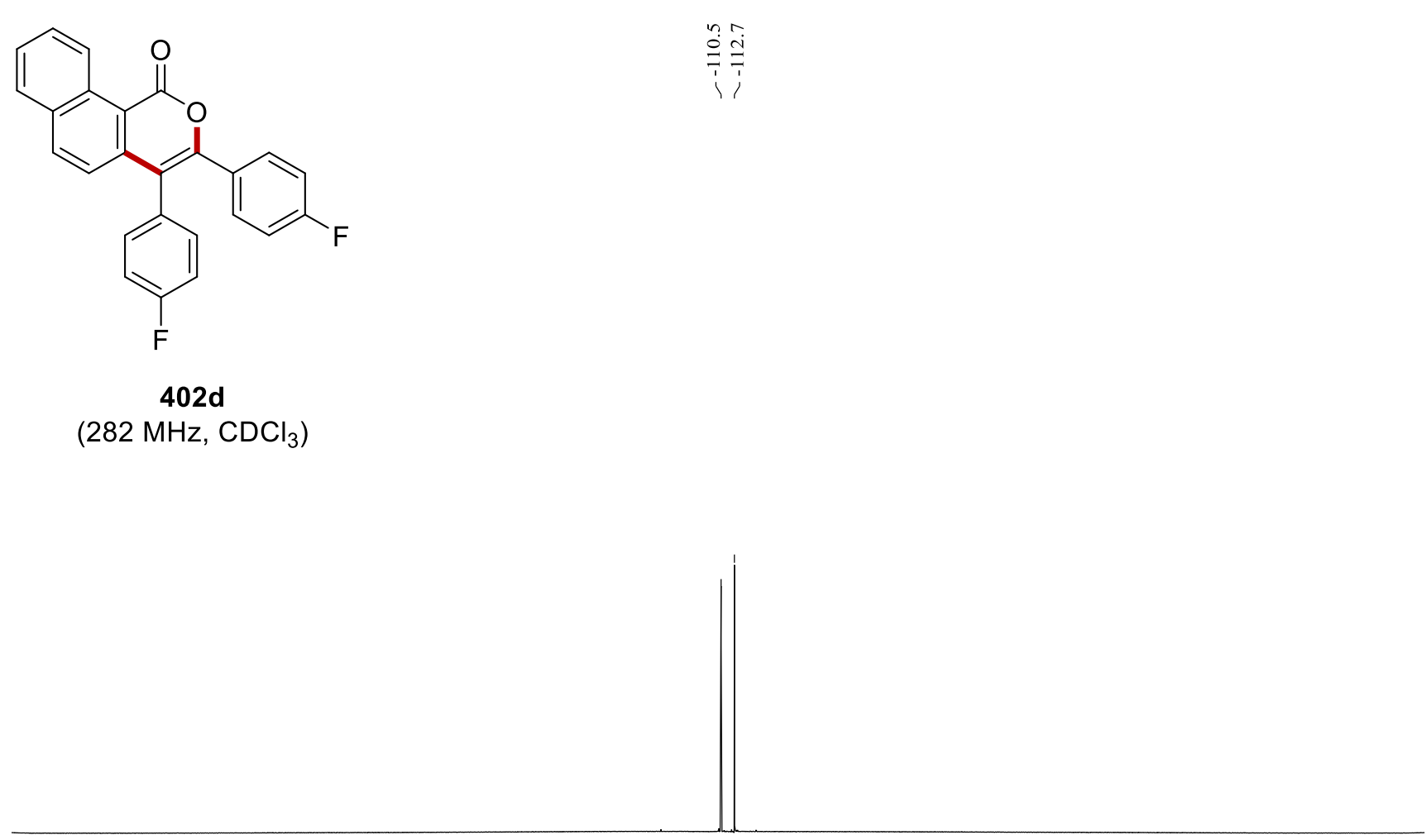

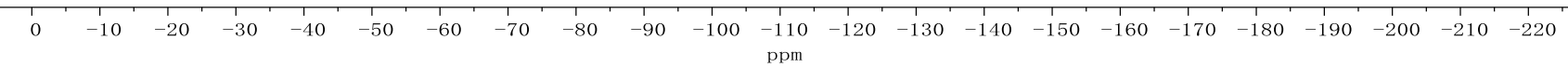




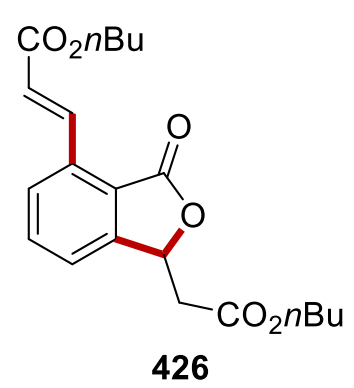

$\left(400 \mathrm{MHz}, \mathrm{CDCl}_{3}\right)$
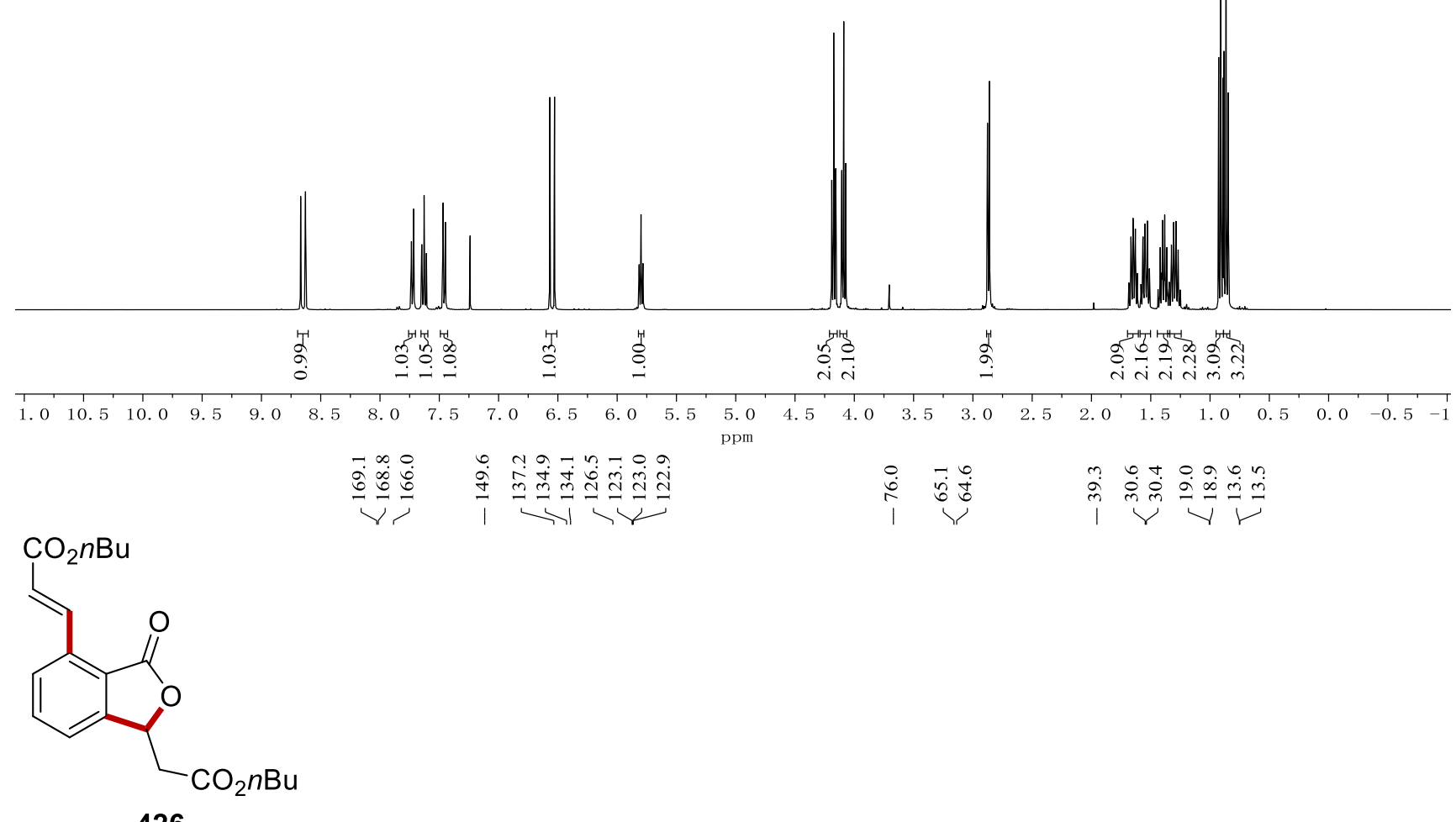

$\left(100 \mathrm{MHz}, \mathrm{CDCl}_{3}\right)$
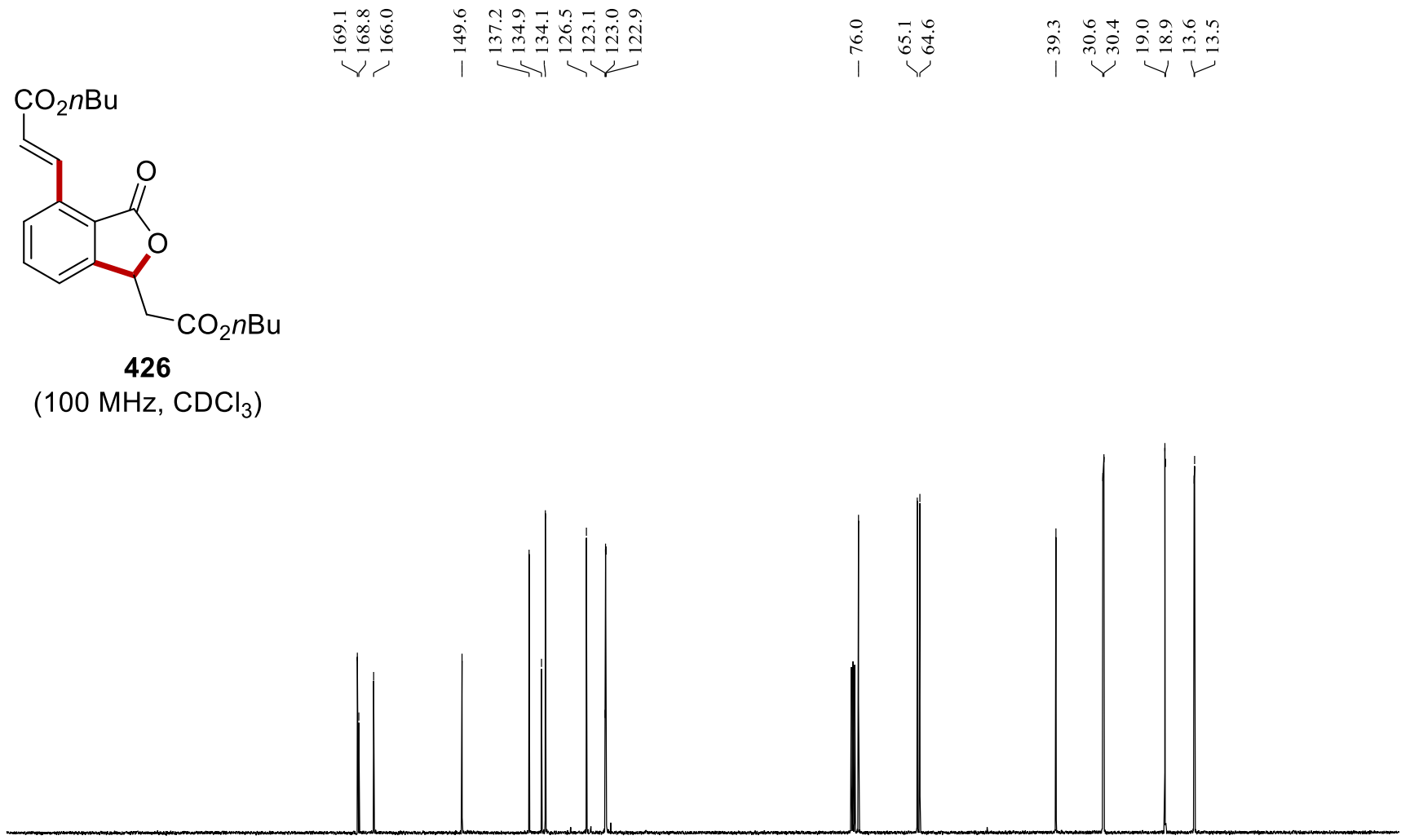

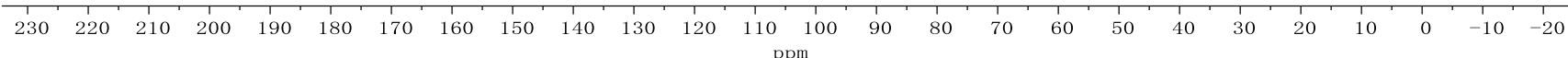




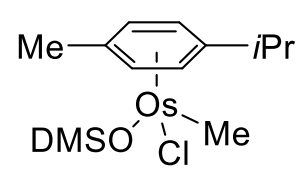

428

$\left(400 \mathrm{MHz}, \mathrm{C}_{6} \mathrm{D}_{6}\right)$

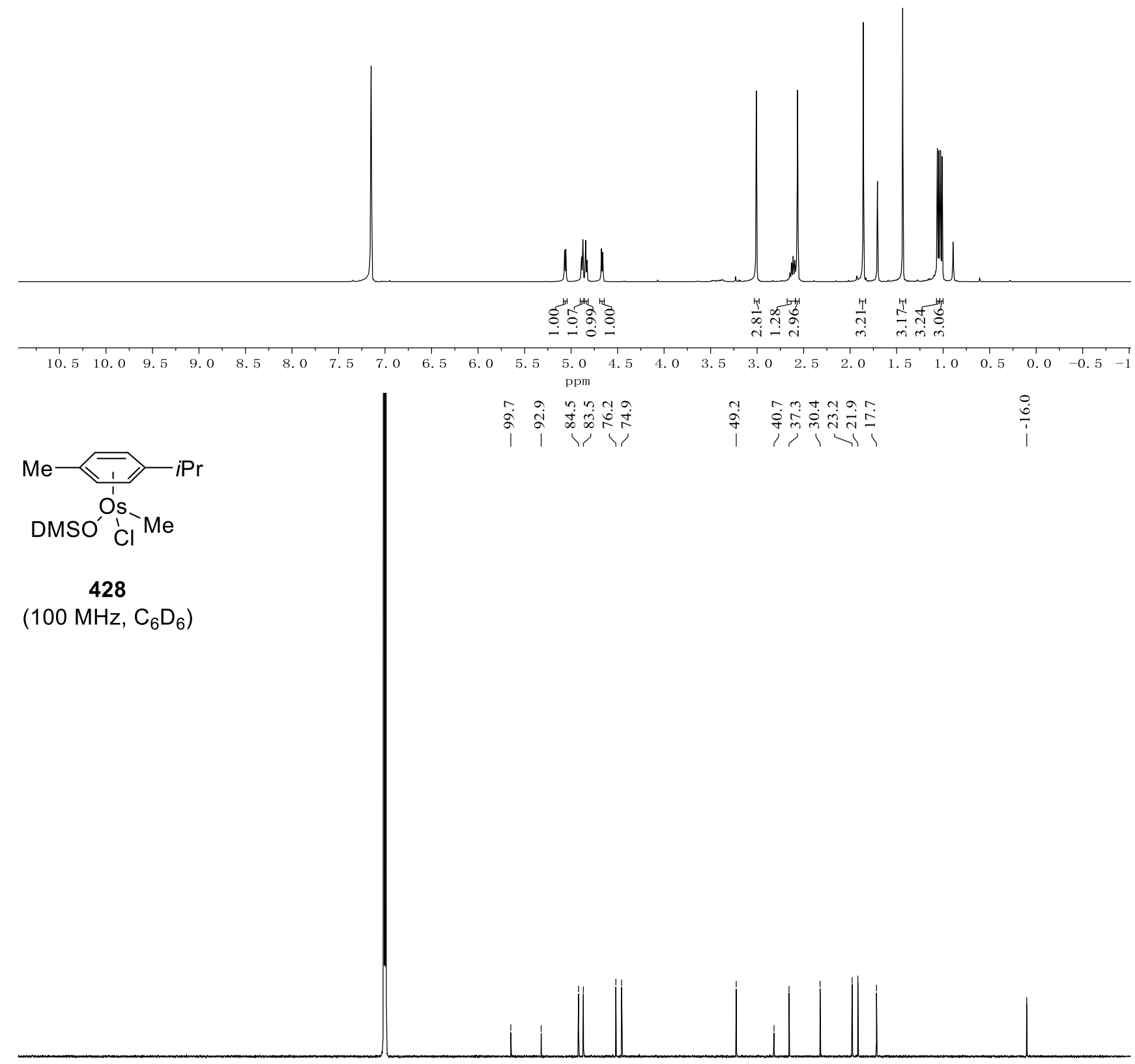

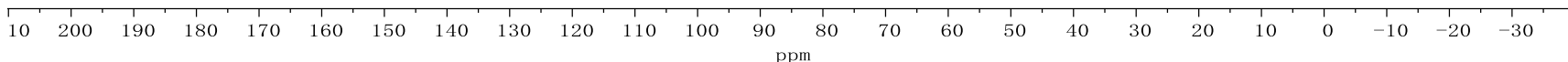




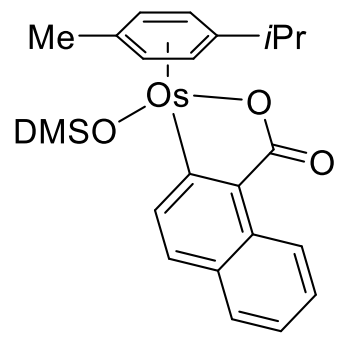

430

$\left(400 \mathrm{MHz}, \mathrm{CD}_{2} \mathrm{Cl}_{2}\right)$

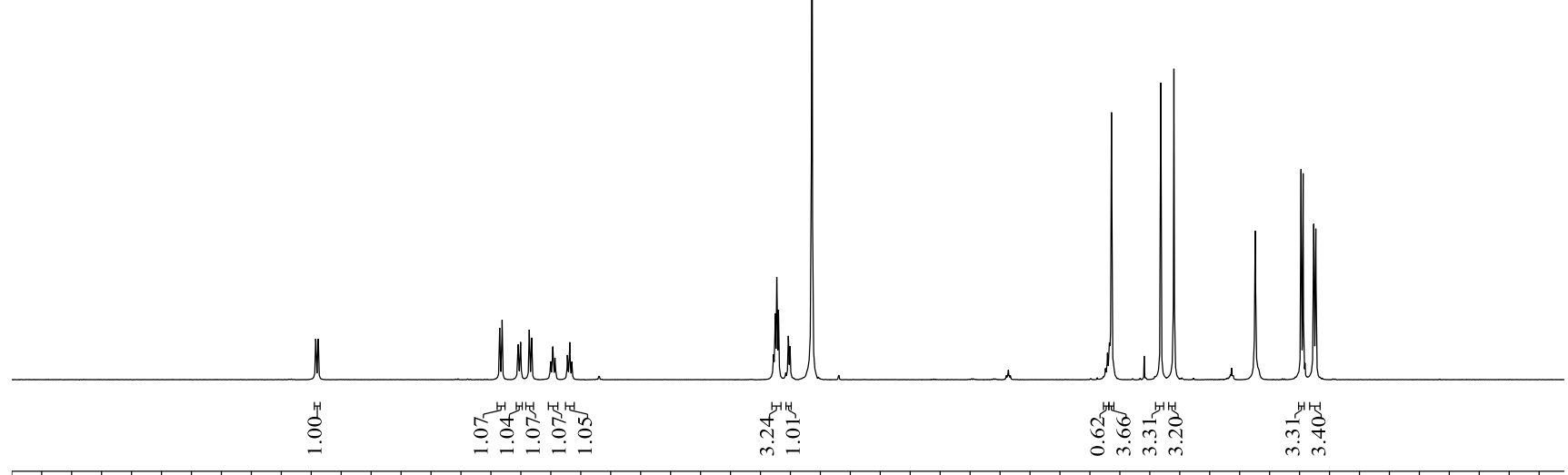

\begin{tabular}{llllllllllllllllllllllllllllllllll}
\hline .0 & 11.5 & 11.0 & 10.5 & 10.0 & 9.5 & 9.0 & 8.5 & 8.0 & 7.5 & 7.0 & 6.5 & 6.0 & 5.5 & 5.0 & 4.5 & 4.0 & 3.5 & 3.0 & 2.5 & 2.0 & 1.5 & 1.0 & 0.5 & 0.0 & -0.5
\end{tabular}

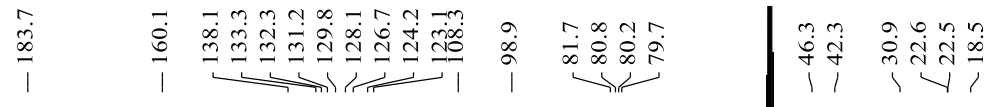<smiles>CO[SH](=O)(O[Na])c1ccc2ccccc2c1C(=O)Oc1ccc(C)cc1</smiles>

430

$\left(100 \mathrm{MHz}, \mathrm{CD}_{2} \mathrm{Cl}_{2}\right)$

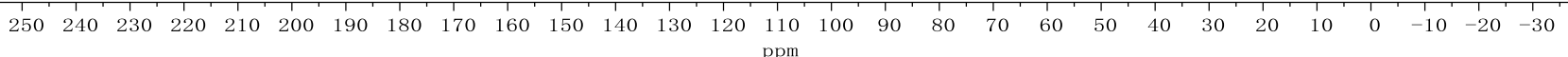




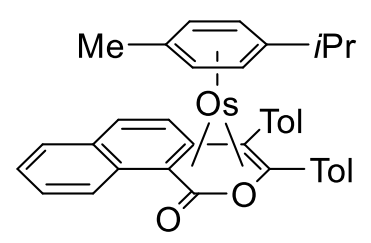

431

(400 MHz, $\mathrm{CDCl}_{3}$ )

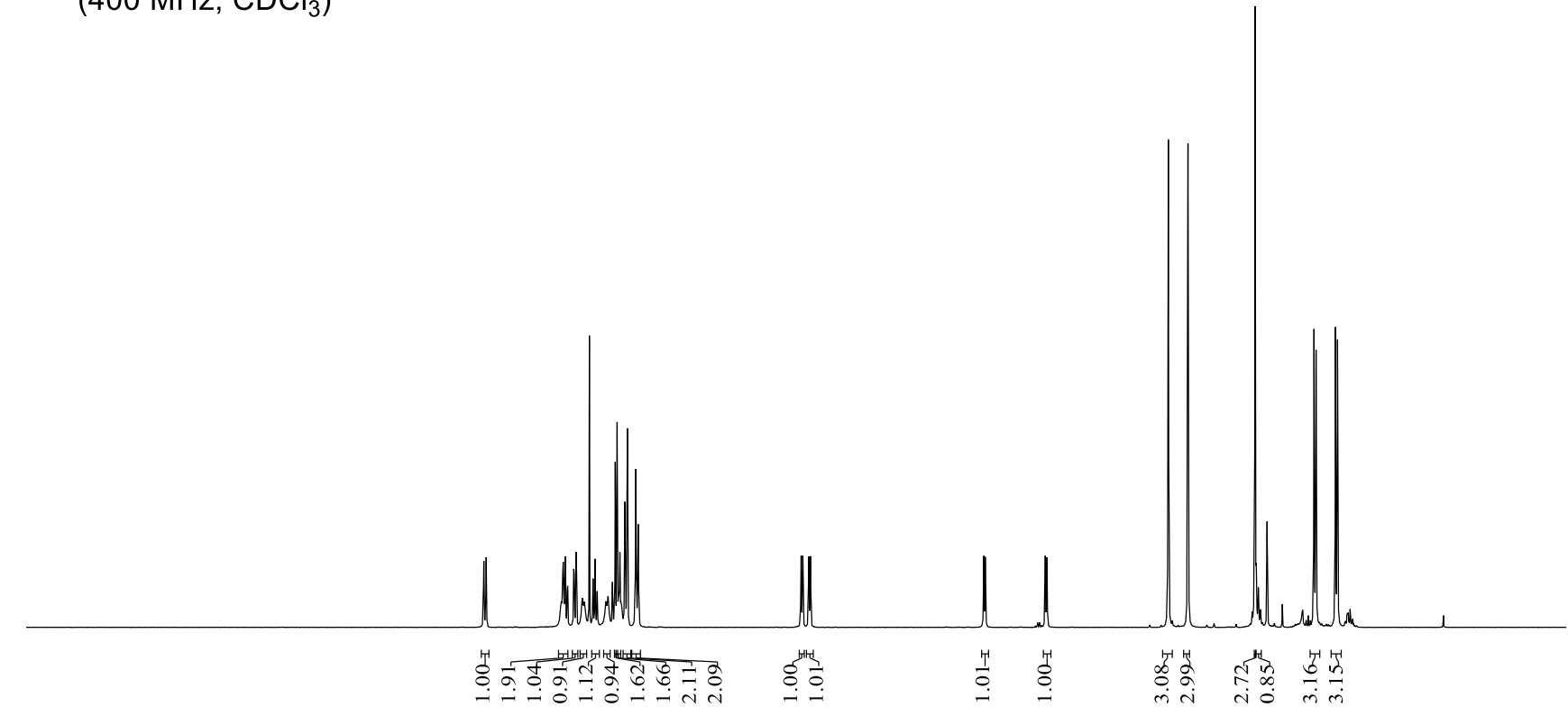

$\begin{array}{llllllllllllllllllllllllllllllllllllllll}11.5 & 11.0 & 10.5 & 10.0 & 9.5 & 9.0 & 8.5 & 8.0 & 7.5 & 7.0 & 6.5 & 6.0 & 5.5 & 5.0 & 4.5 & 4.0 & 3.5 & 3.0 & 2.5 & 2.0 & 1.5 & 1.0 & 0.5 & 0.0 & -0.5\end{array}$

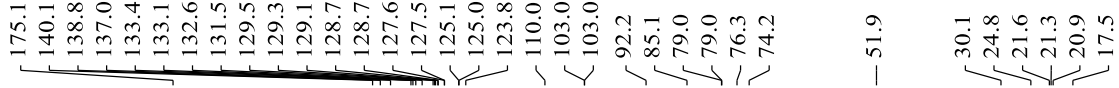

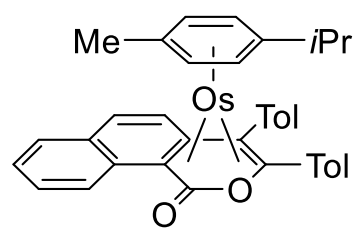

431

(100 MHz, $\mathrm{CDCl}_{3}$ )

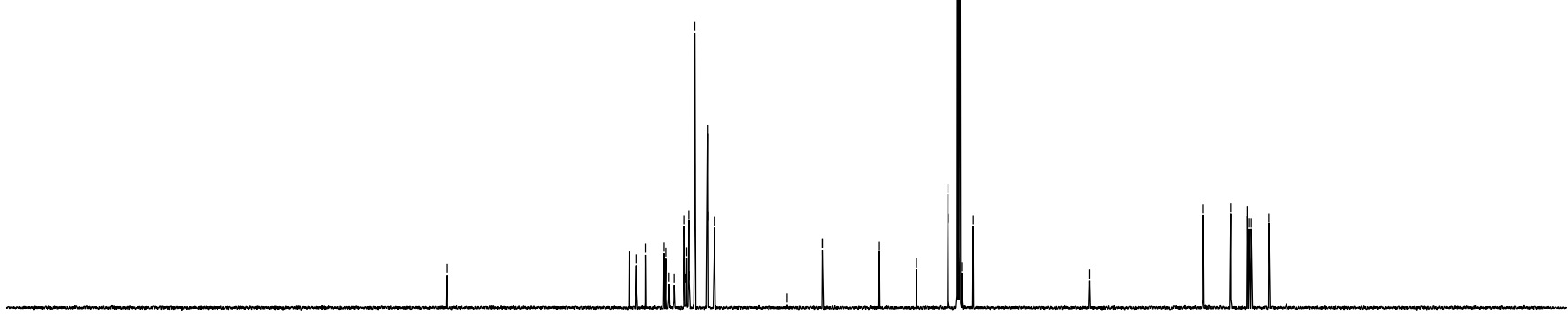

$\begin{array}{llllllllllllllllllllllllllllllllllll}1 & 250 & 240 & 230 & 220 & 210 & 200 & 190 & 180 & 170 & 160 & 150 & 140 & 130 & 120 & 110 & 100 & 90 & 80 & 70 & 60 & 50 & 40 & 30 & 20 & 10 & 0 & -10 & -20 & -30\end{array}$ 


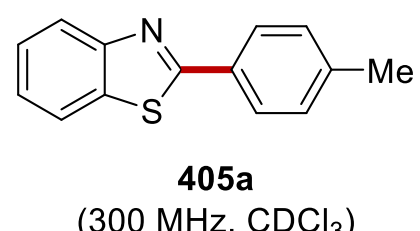

$\left(300 \mathrm{MHz}, \mathrm{CDCl}_{3}\right)$
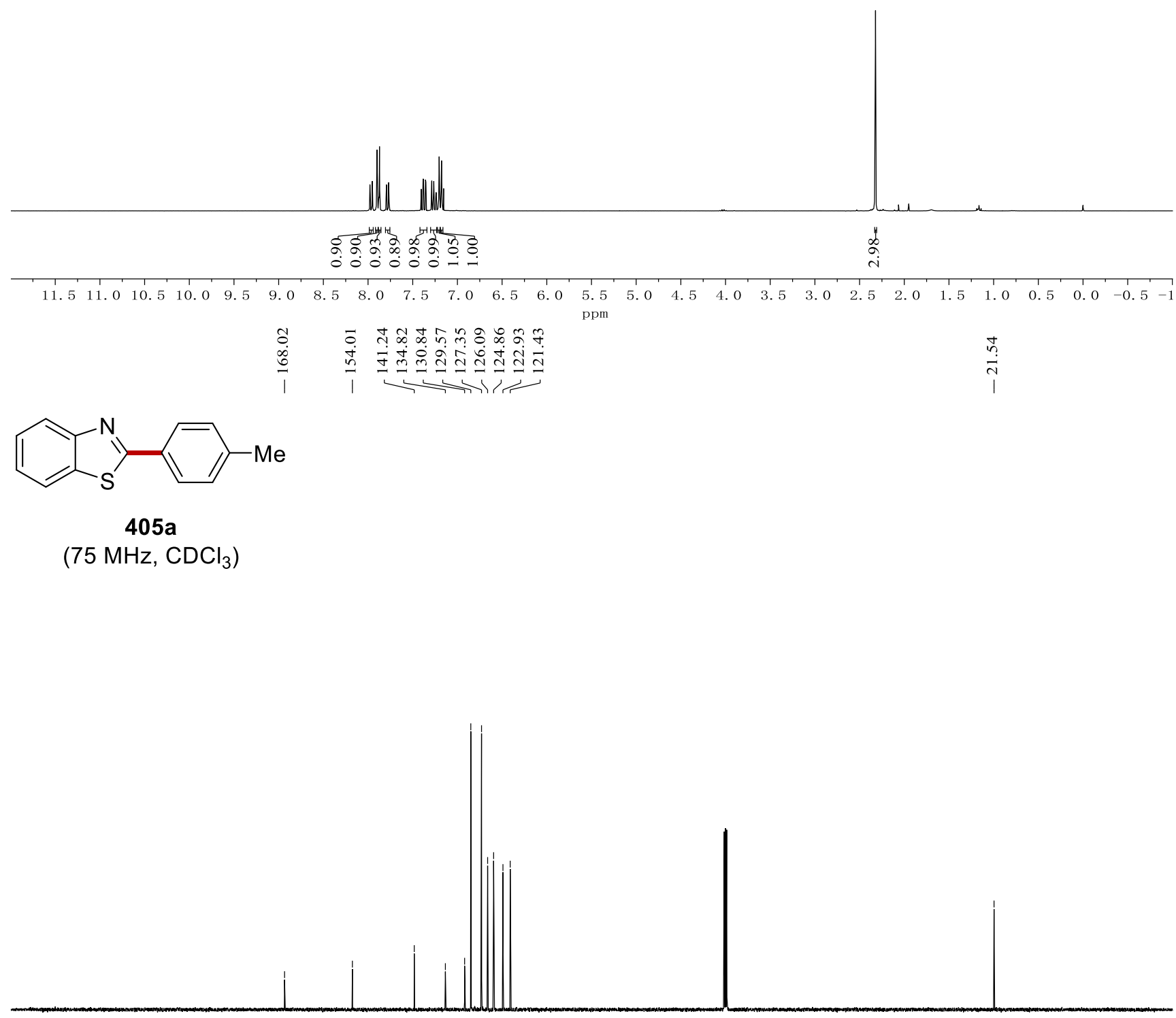

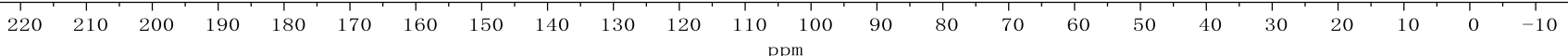




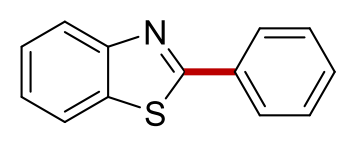

405b

(500 MHz, $\mathrm{CDCl}_{3}$ )

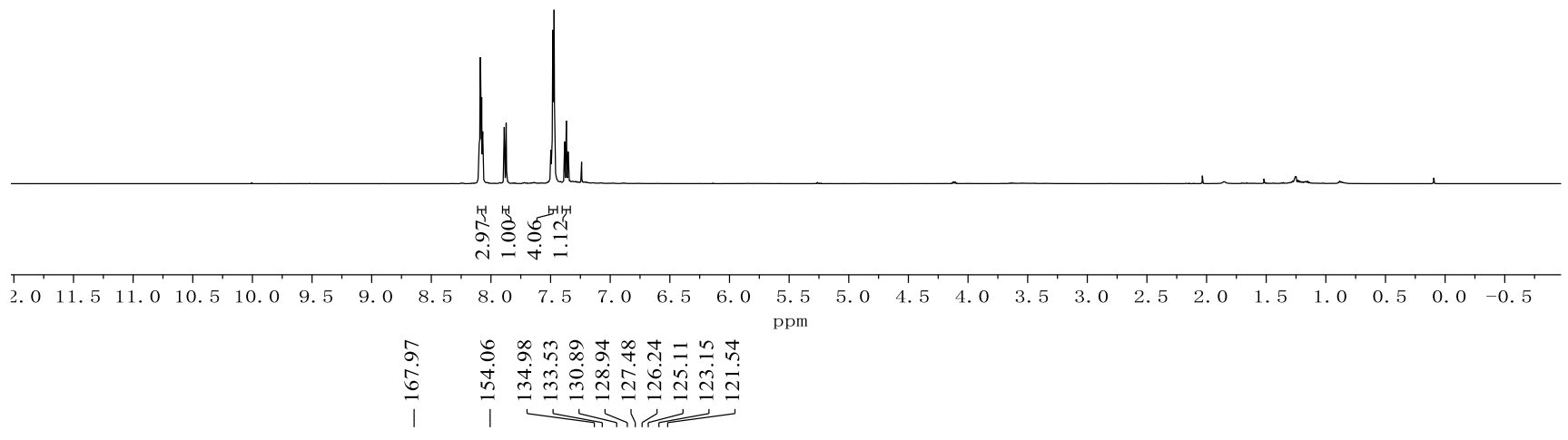<smiles>c1ccc(-c2nc3ccccc3s2)cc1</smiles>

405b

(125 MHz, $\mathrm{CDCl}_{3}$ )

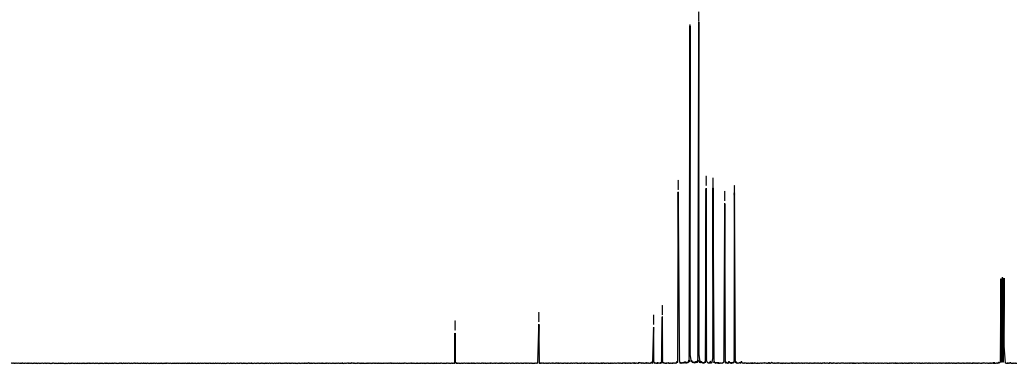

$\begin{array}{llllllllllllllllllllllllllllllllllllll}240 & 230 & 220 & 210 & 200 & 190 & 180 & 170 & 160 & 150 & 140 & 130 & 120 & 110 & 100 & 90 & 80 & 70 & 60 & 50 & 40 & 30 & 20 & 10 & 0 & -10 & -20 & -30 & -4\end{array}$ 


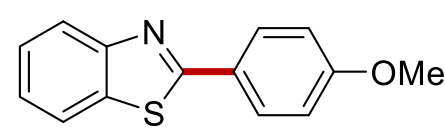

405c

$\left(400 \mathrm{MHz} \mathrm{CDCl}_{3}\right)$

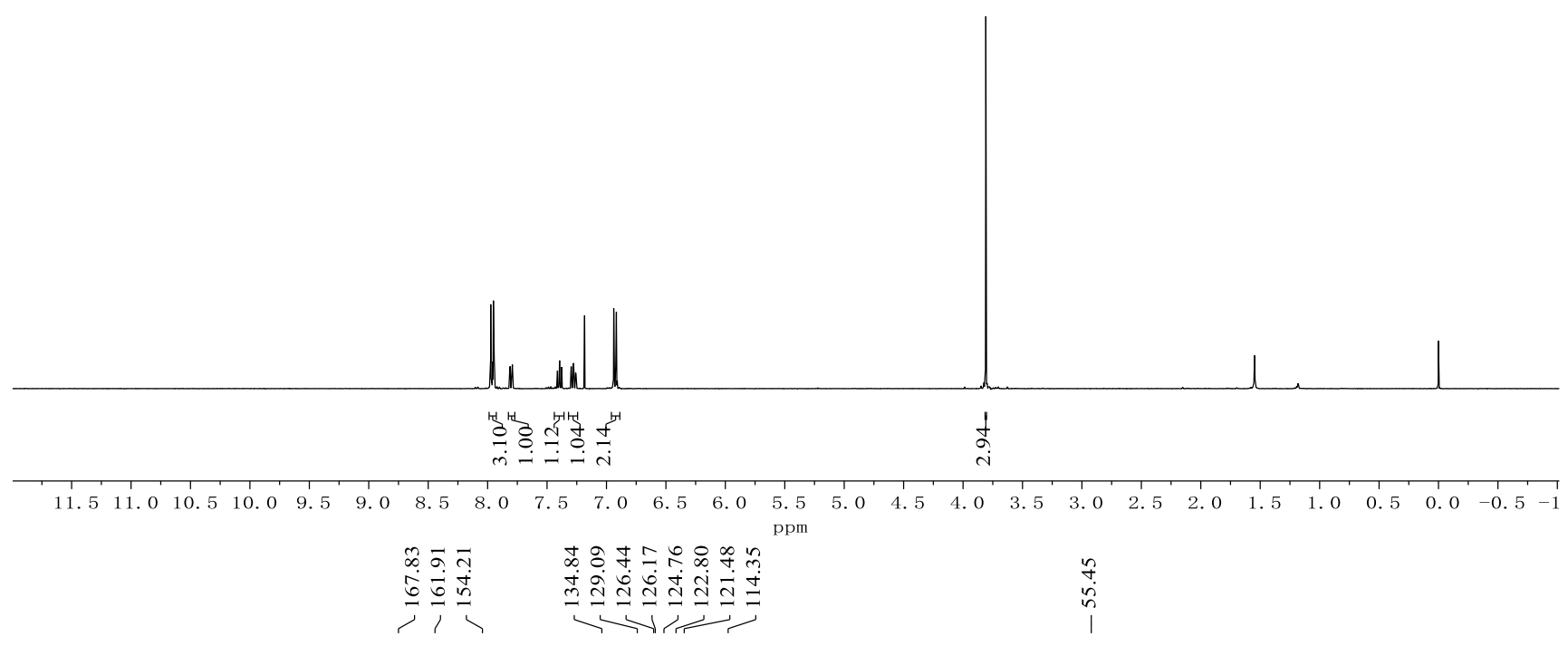<smiles>COc1ccc(-c2nc3ccccc3s2)cc1</smiles>

405c

$\left.\left(100 \mathrm{MHz}^{\mathrm{CDCl}}\right)_{3}\right)$

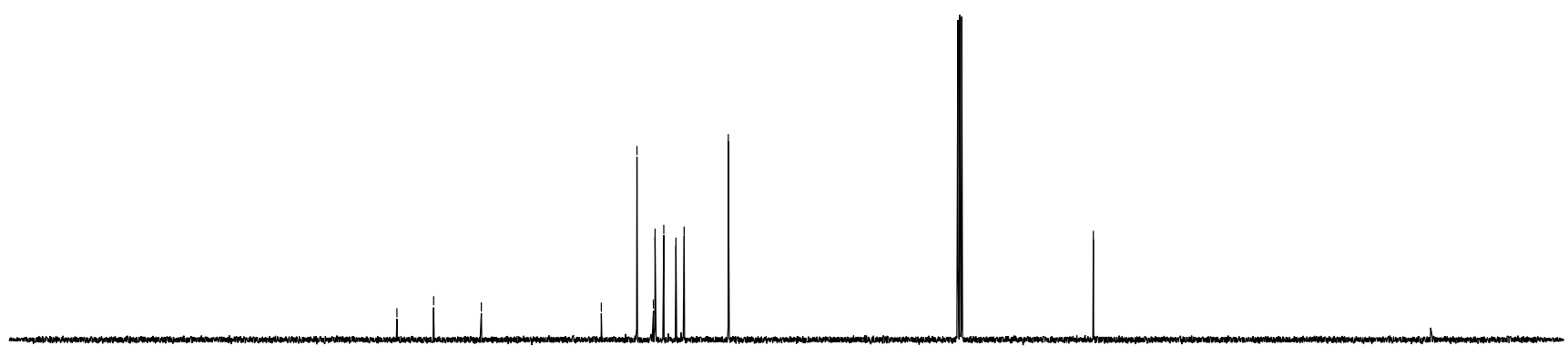

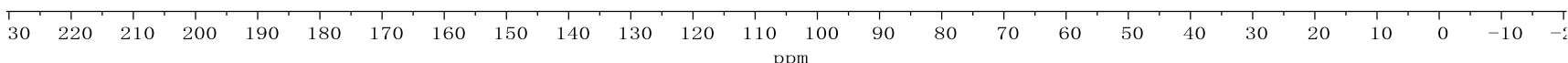




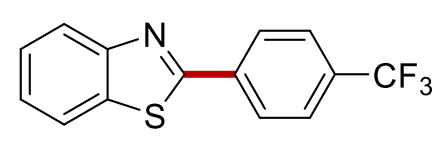

405d

(400 MHz, $\mathrm{CDCl}_{3}$ )

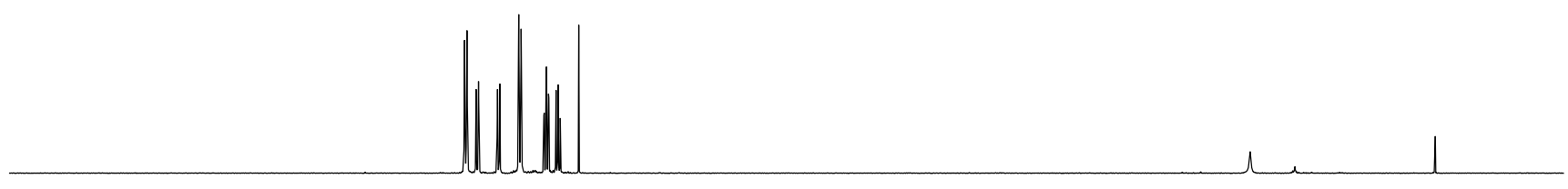

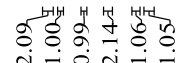

\begin{tabular}{llllllllllllllllllllllllllll}
\hline & 0 & 11.5 & 11.0 & 10.5 & 10.0 & 9.5 & 9.0 & 8.5 & 8.0 & 7.5 & 7.0 & 6.5 & 6.0 & 5.5 & 5.0 & 4.5 & 4.0 & 3.5 & 3.0 & 2.5 & 2.0 & 1.5 & 1.0 & 0.5 & 0.0 & -0.5 & -1
\end{tabular}

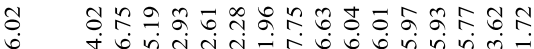

إ.

$\longrightarrow-\mathrm{CF}_{3}$

405d

$\left(100 \mathrm{MHz}, \mathrm{CDCl}_{3}\right)$

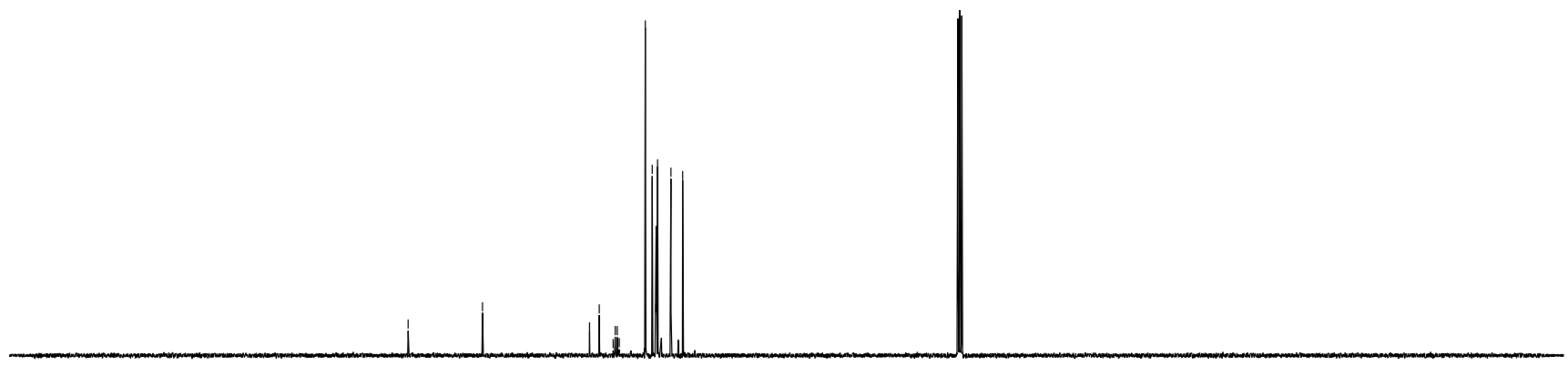

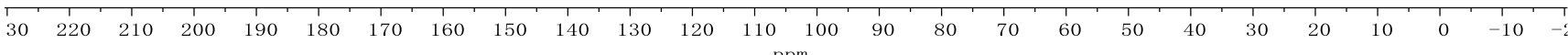




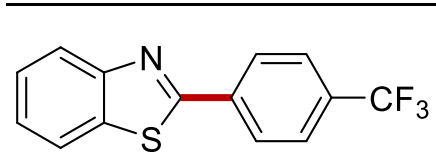

405d

(282 MHz, $\mathrm{CDCl}_{3}$ )

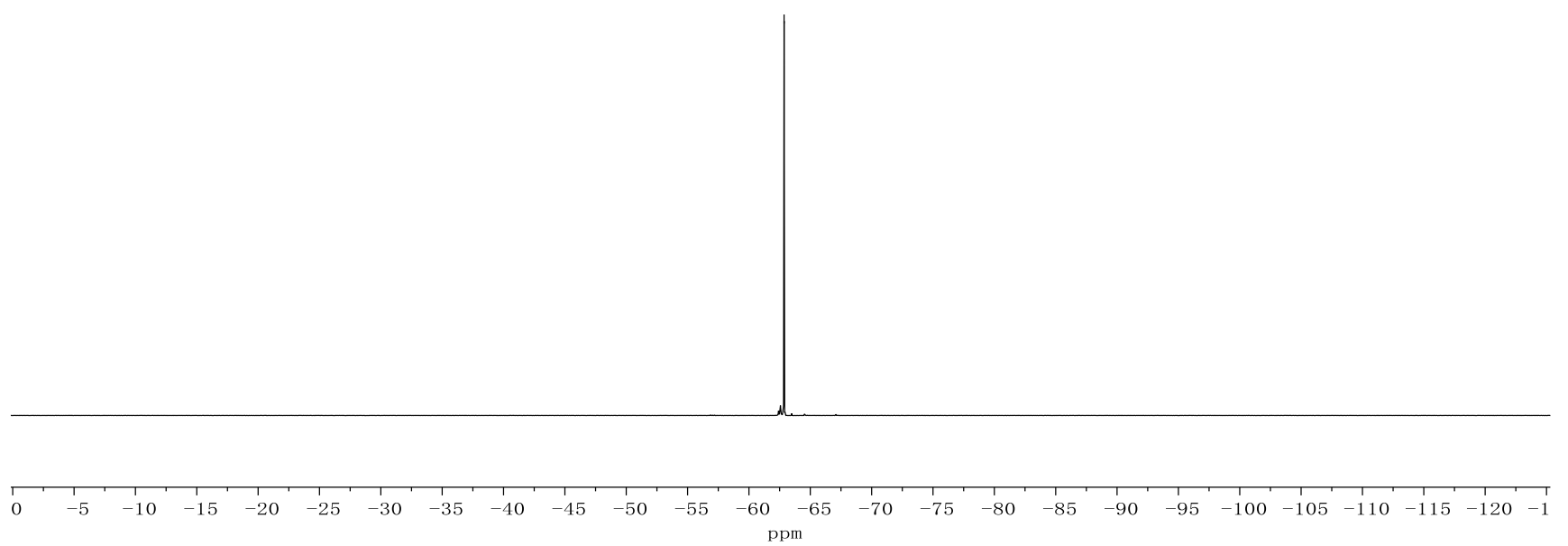




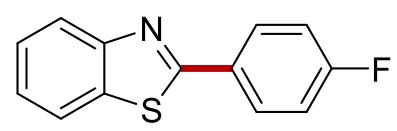

405e

$\left(500 \mathrm{MHz}, \mathrm{CDCl}_{3}\right)$

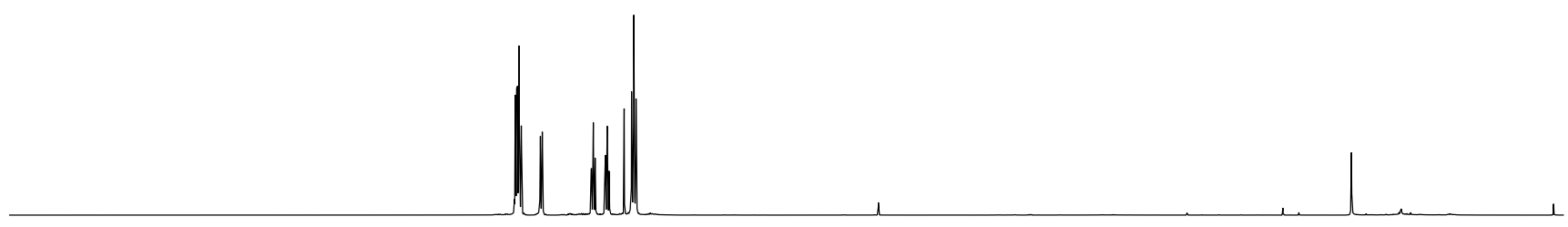

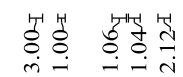

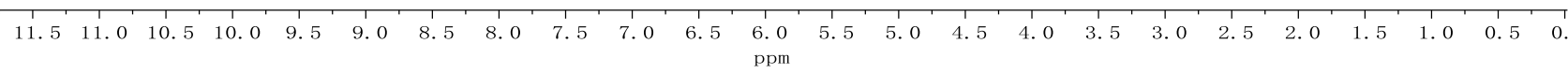
ㄱ. ₹. ₹

:<smiles>Fc1ccc(-c2nc3ccccc3s2)cc1</smiles>

405e

$\left(125 \mathrm{MHz}, \mathrm{CDCl}_{3}\right)$

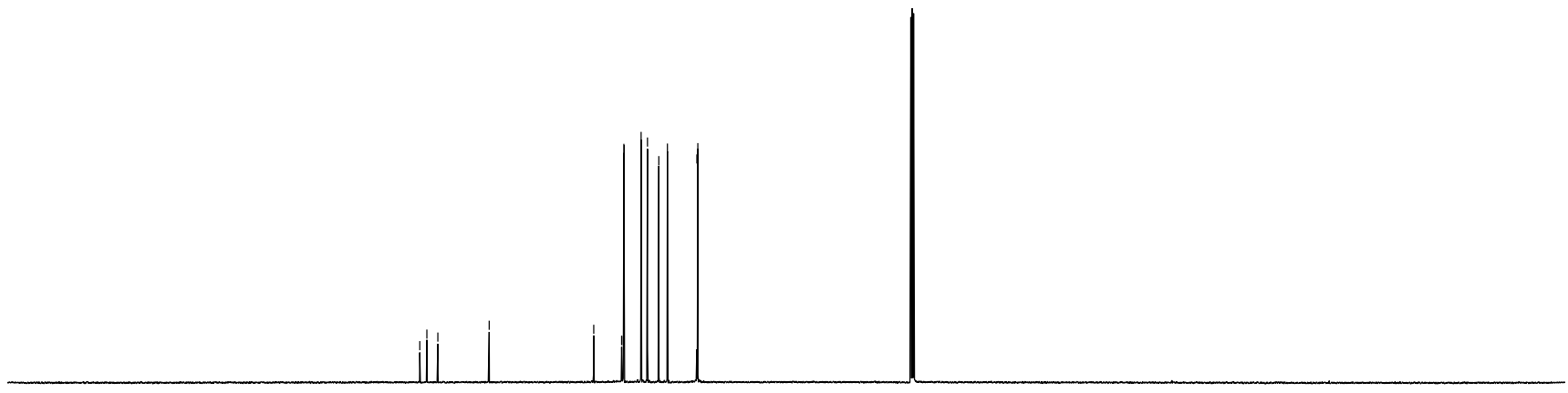

\begin{tabular}{llllllllllllllllllllllllllllll}
\hline & 140 & 230 & 220 & 210 & 200 & 190 & 180 & 170 & 160 & 150 & 140 & 130 & 120 & 110 & 100 & 90 & 80 & 70 & 60 & 50 & 40 & 30 & 20 & 10 & 0 & -10 & -20 & -30 & -4
\end{tabular} 


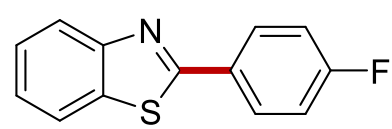

กֶׁ

$=\frac{1}{1}=\frac{1}{1}$

405e

$\left(282 \mathrm{MHz}, \mathrm{CDCl}_{3}\right)$

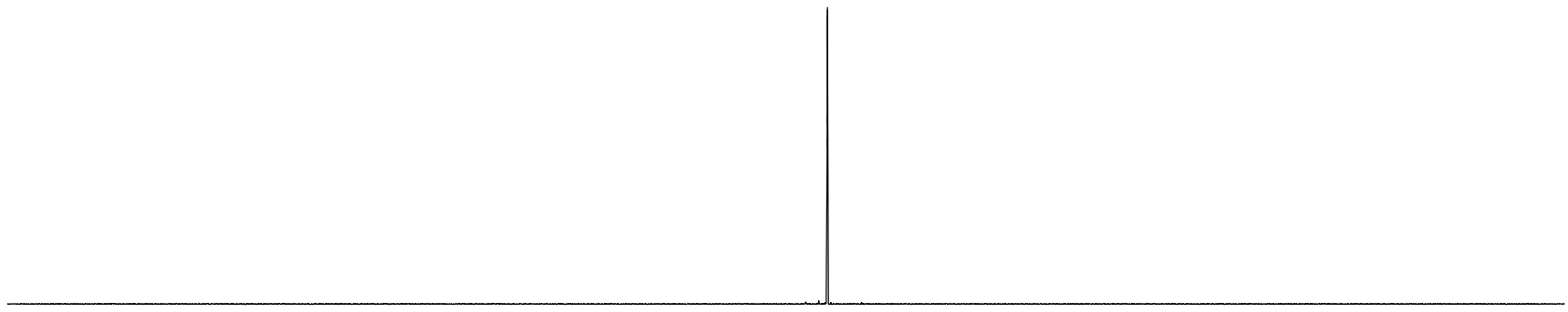

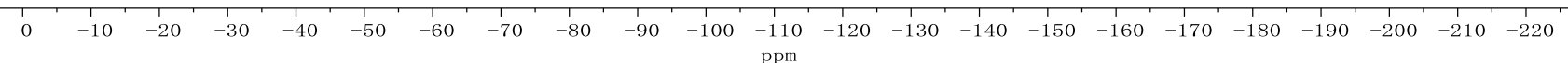




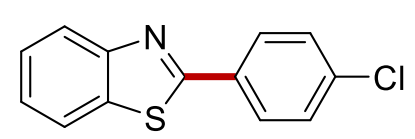

$405 f$

$\left(500 \mathrm{MHz}, \mathrm{CDCl}_{3}\right)$

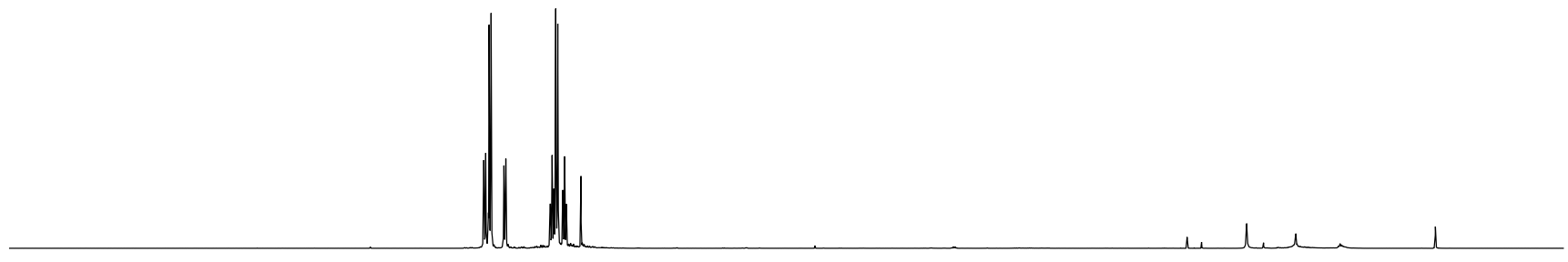
ठํ.

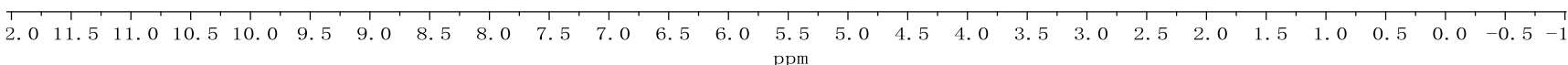

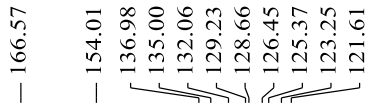<smiles>Clc1ccc(-c2nc3ccccc3s2)cc1</smiles>

$405 f$

$\left(125 \mathrm{MHz} \mathrm{CDCl}_{3}\right)$

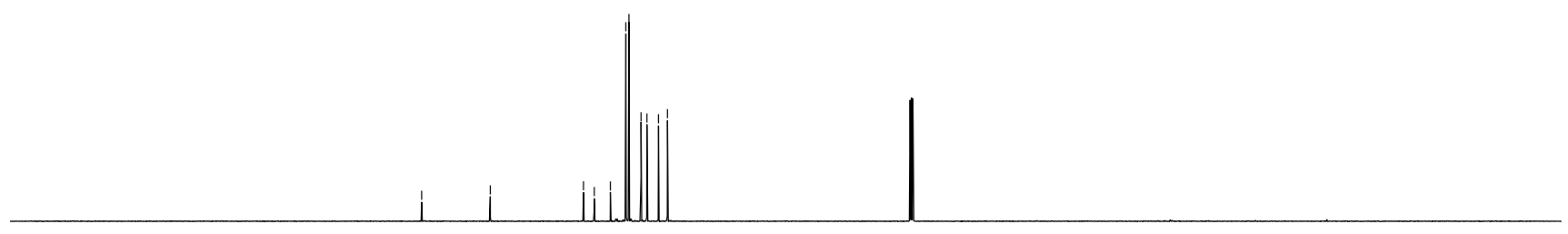

$\begin{array}{rlllllllllllllllllllllllllllllllllllll} & 240 & 230 & 220 & 210 & 200 & 190 & 180 & 170 & 160 & 150 & 140 & 130 & 120 & 110 & 100 & 90 & 80 & 70 & 60 & 50 & 40 & 30 & 20 & 10 & 0 & -10 & -20 & -30 & -4\end{array}$ 


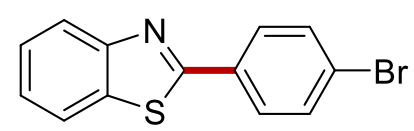

$405 \mathrm{~g}$

$\left(500 \mathrm{MHz} \mathrm{CDCl}_{3}\right)$

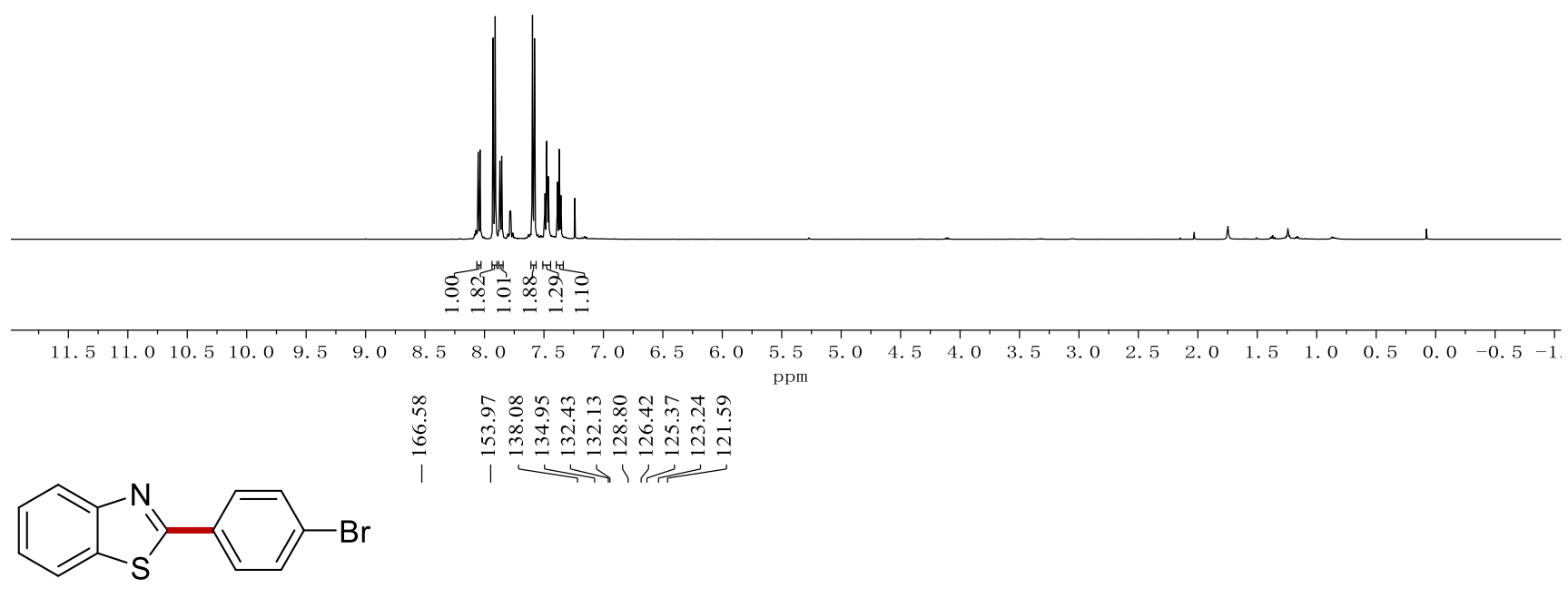

405g

$\left(125 \mathrm{MHz} \mathrm{CDCl}_{3}\right)$

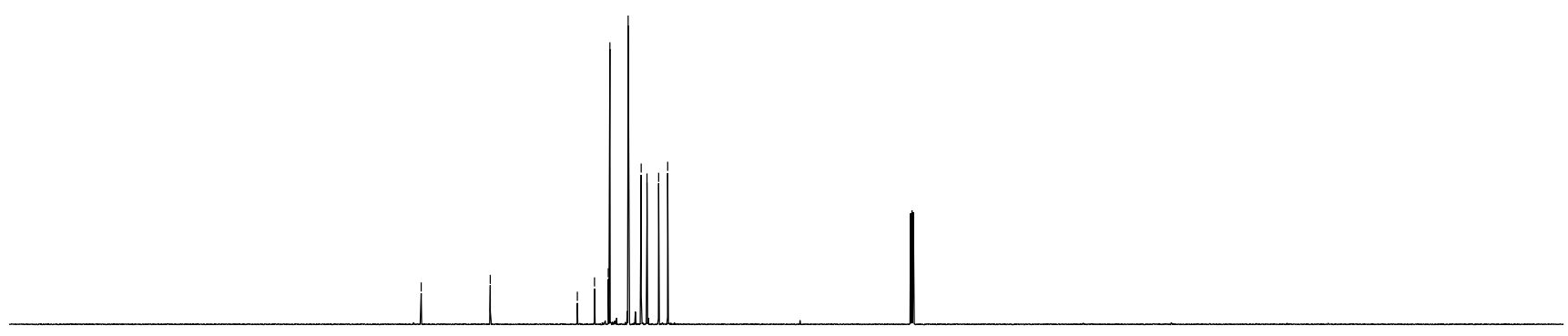

$\begin{array}{llllllllllllllllllllllllllllllllllllll}240 & 230 & 220 & 210 & 200 & 190 & 180 & 170 & 160 & 150 & 140 & 130 & 120 & 110 & 100 & 90 & 80 & 70 & 60 & 50 & 40 & 30 & 20 & 10 & 0 & -10 & -20 & -30 & -4\end{array}$ 


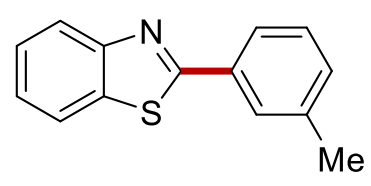

405h

$\left(400 \mathrm{MHz}, \mathrm{CDCl}_{3}\right)$

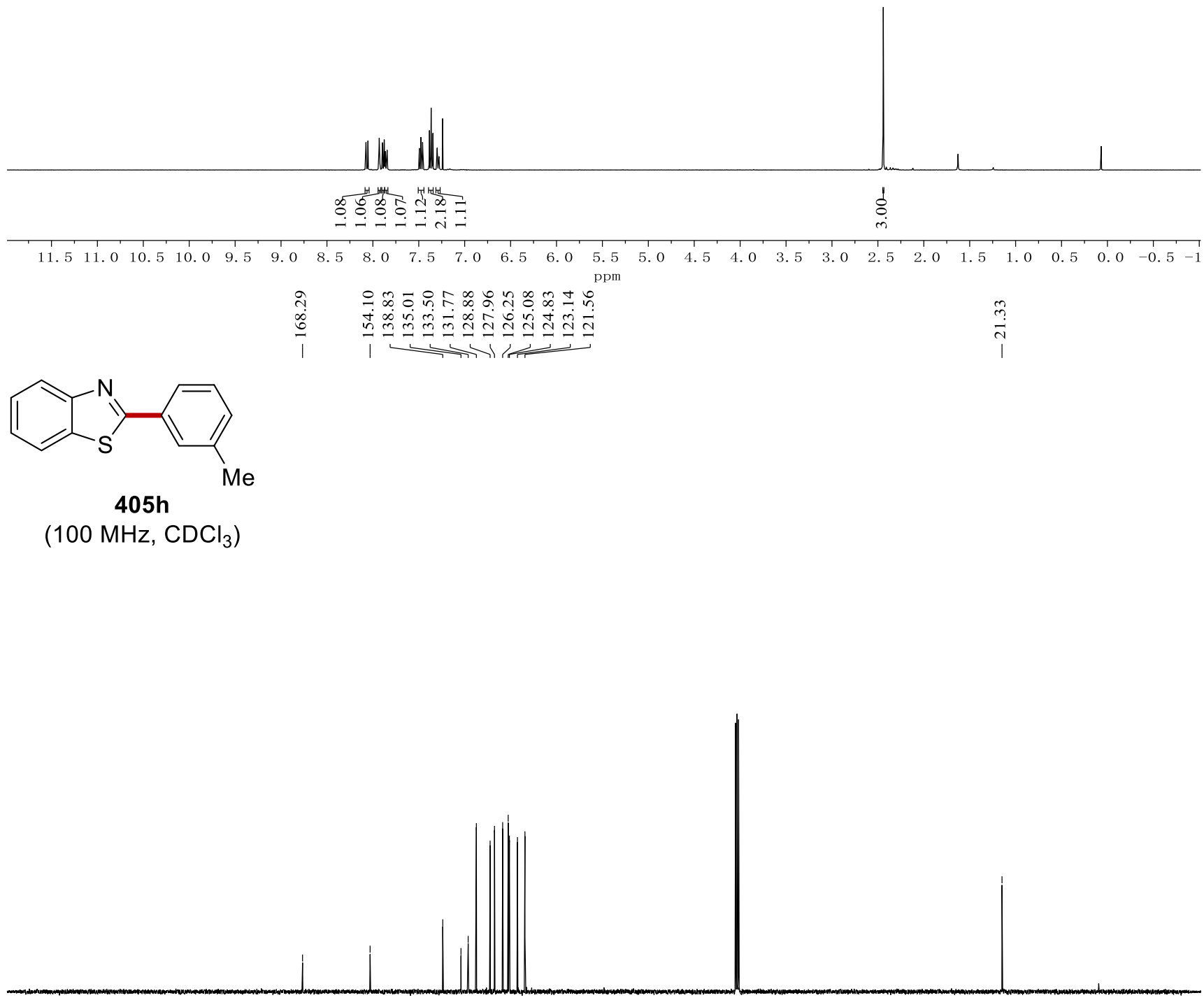

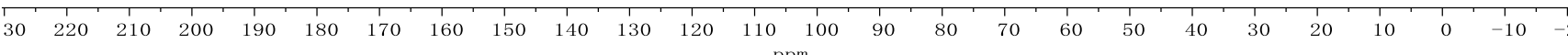




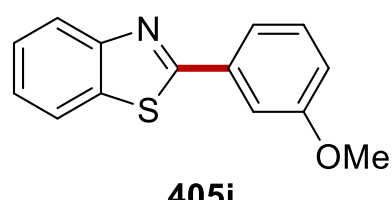

(400 MHz, $\mathrm{CDCl}_{3}$ )

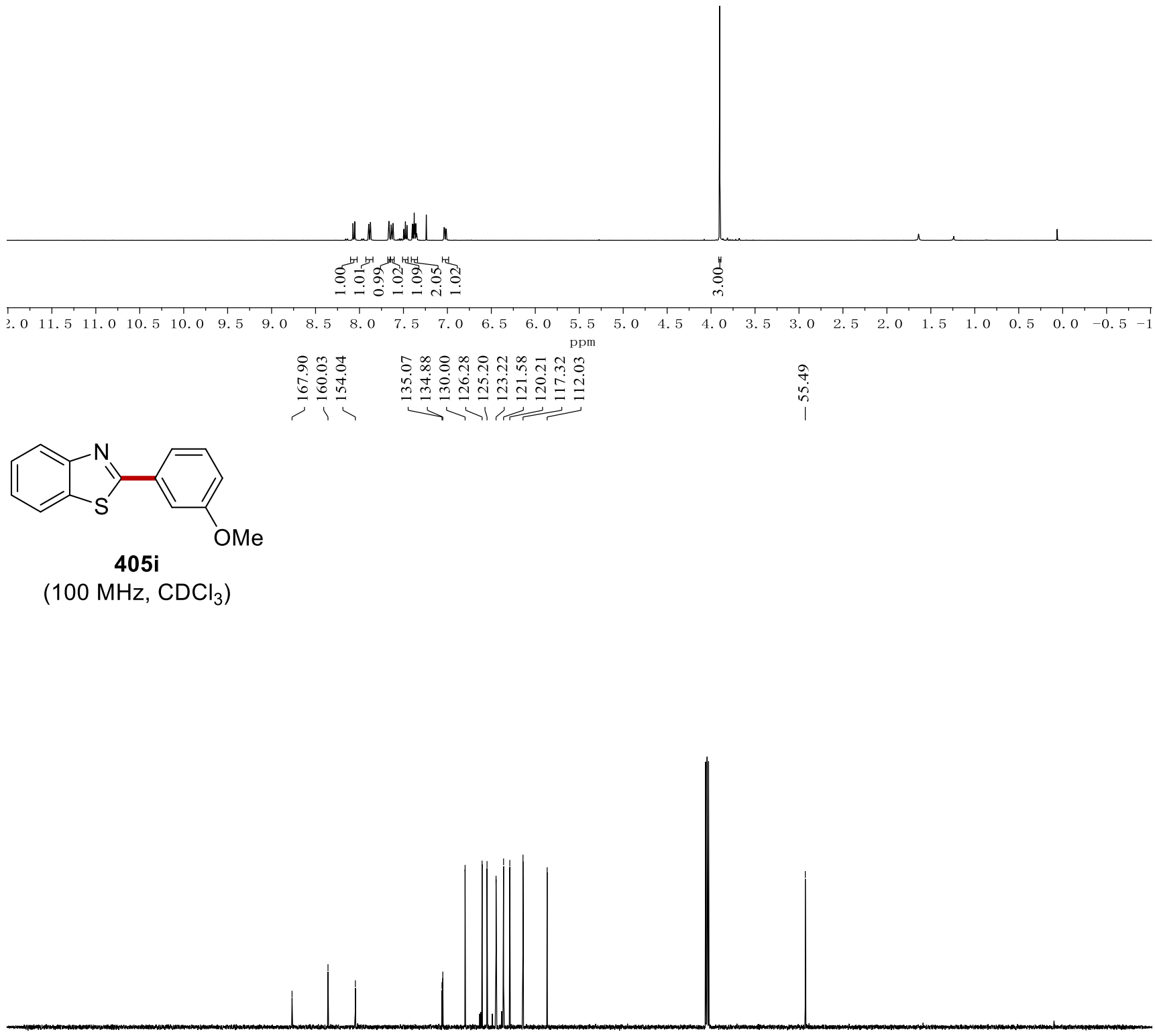

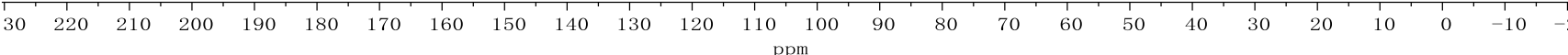




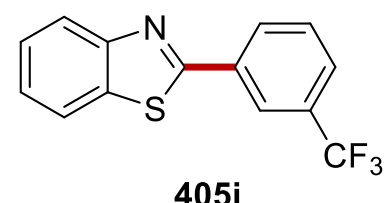

$\left(400 \mathrm{MHz}, \mathrm{CDCl}_{3}\right)$

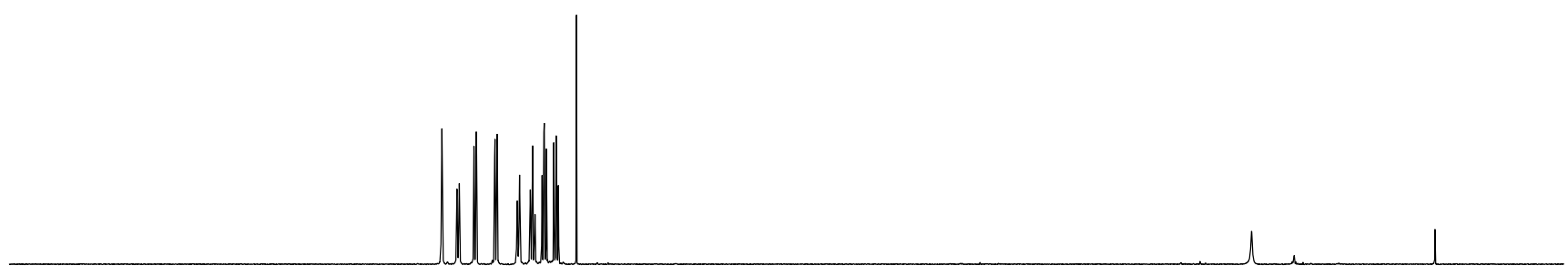

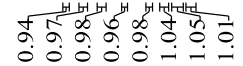

$\begin{array}{llllllllllllllllllllllllll}11.5 & 11.0 & 10.5 & 10.0 & 9.5 & 9.0 & 8.5 & 8.0 & 7.5 & 7.0 & 6.5 & 6.0 & 5.5 & 5.0 & 4.5 & 4.0 & 3.5 & 3.0 & 2.5 & 2.0 & 1.5 & 1.0 & 0.5 & 0.0 & -0.5 & -1\end{array}$

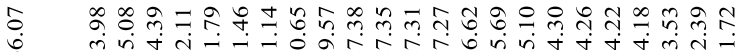

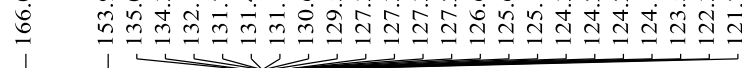

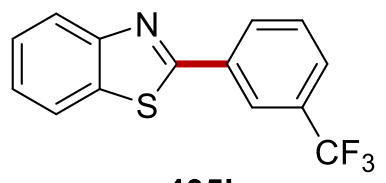

405j

$\left(100 \mathrm{MHz}, \mathrm{CDCl}_{3}\right)$

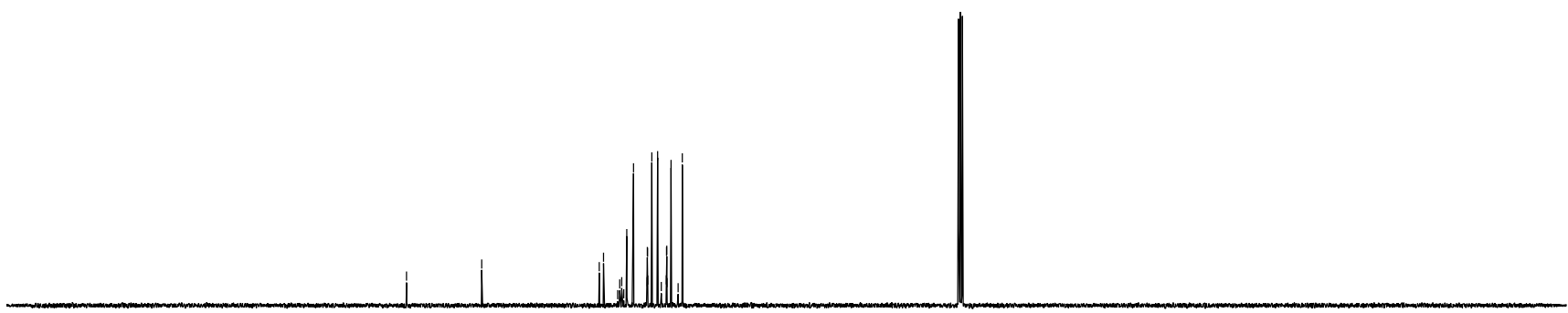

\begin{tabular}{lllllllllllllllllllllllllllllllllllll}
\hline 30 & 220 & 210 & 200 & 190 & 180 & 170 & 160 & 150 & 140 & 130 & 120 & 110 & 100 & 90 & 80 & 70 & 60 & 50 & 40 & 30 & 20 & 10 & 0 & -10 & -1
\end{tabular} 


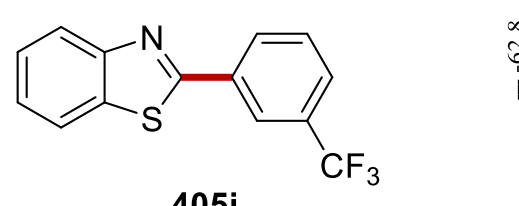

405j

(282 MHz, $\mathrm{CDCl}_{3}$ )

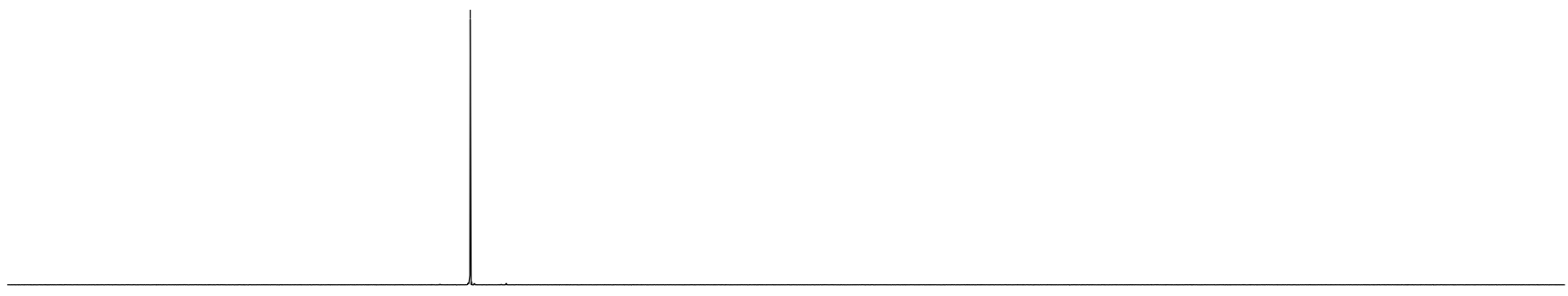

\begin{tabular}{lllllllllllllllllllllllllllllllllllllll}
\hline & -10 & -20 & -30 & -40 & -50 & -60 & -70 & -80 & -90 & -100 & -110 & -120 & -130 & -140 & -150 & -160 & -170 & -180 & -190 & -200 & -210 & -220
\end{tabular} 


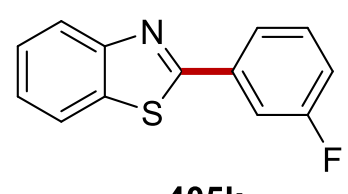

405k

(500 $\mathrm{MHz} \mathrm{CDCl}_{3}$ )

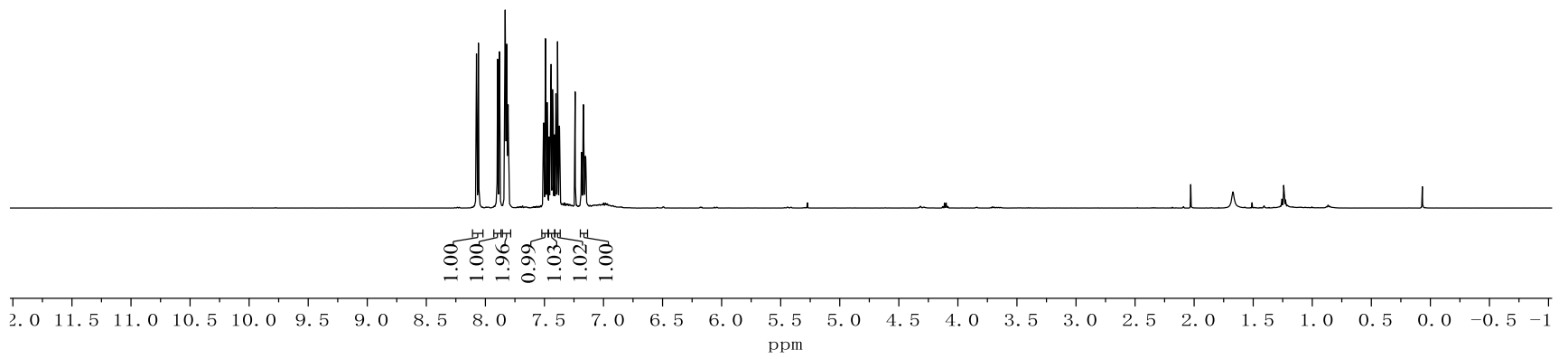

Ұ

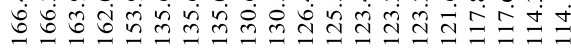

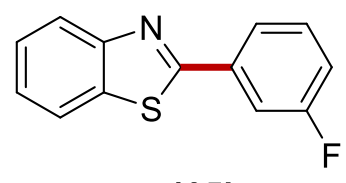

405k

(125 $\left.\mathrm{MHz} \mathrm{CDCl}_{3}\right)$

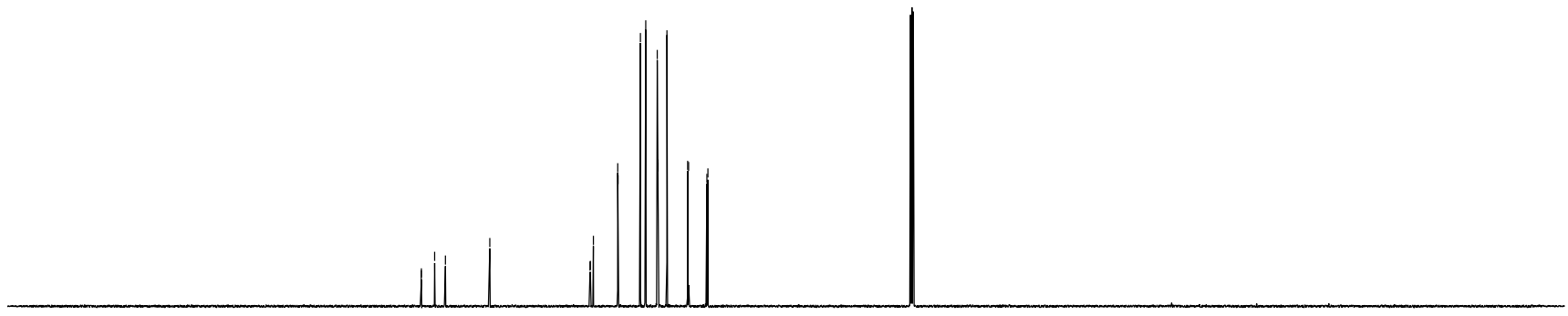

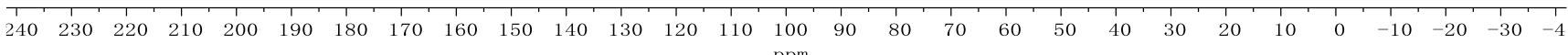




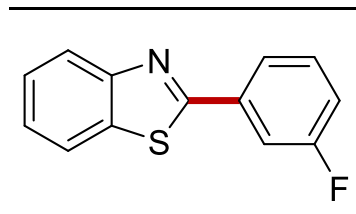

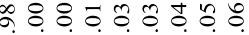

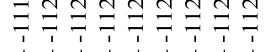

405k

(282 MHz, $\mathrm{CDCl}_{3}$ )

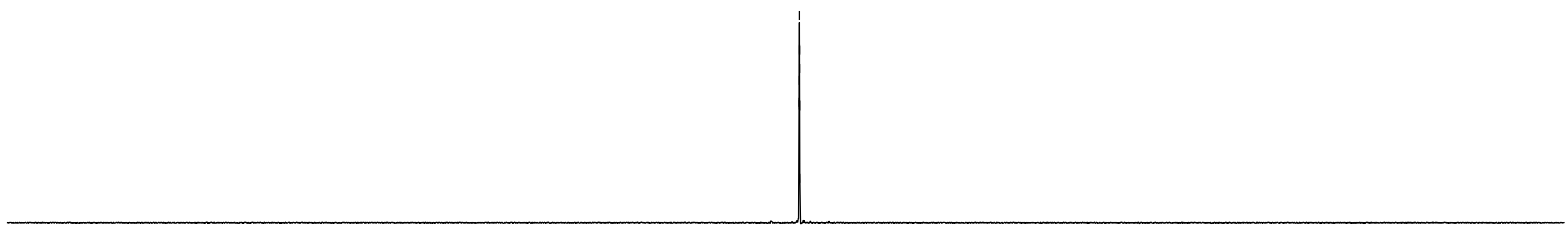

$\begin{array}{llllllllllllllllllllllllllllllllllllllll}0 & -10 & -20 & -30 & -40 & -50 & -60 & -70 & -80 & -90 & -100 & -110 & -120 & -130 & -140 & -150 & -160 & -170 & -180 & -190 & -200 & -210 & -220\end{array}$ 


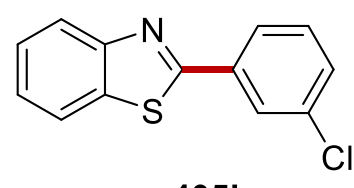

405I

$\left(500 \mathrm{MHz}, \mathrm{CDCl}_{3}\right)$

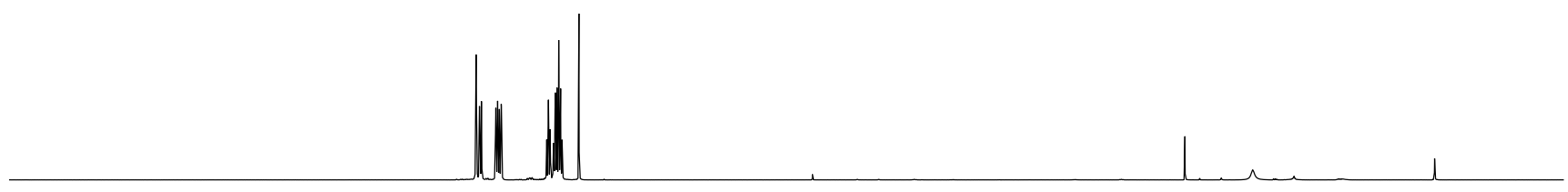

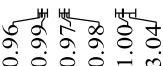

\begin{tabular}{lllllllllllllllllllllllllllll}
\hline 2.0 & 11.5 & 11.0 & 10.5 & 10.0 & 9.5 & 9.0 & 8.5 & 8.0 & 7.5 & 7.0 & 6.5 & 6.0 & 5.5 & 5.0 & 4.5 & 4.0 & 3.5 & 3.0 & 2.5 & 2.0 & 1.5 & 1.0 & 0.5 & 0.0 & -0.5 & -1
\end{tabular}

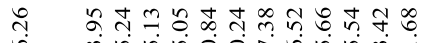

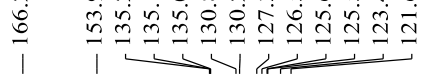<smiles>Clc1cccc(-c2nc3ccccc3s2)c1</smiles>

405I

$\left(125 \mathrm{MHz} \mathrm{CDCl}_{3}\right)$

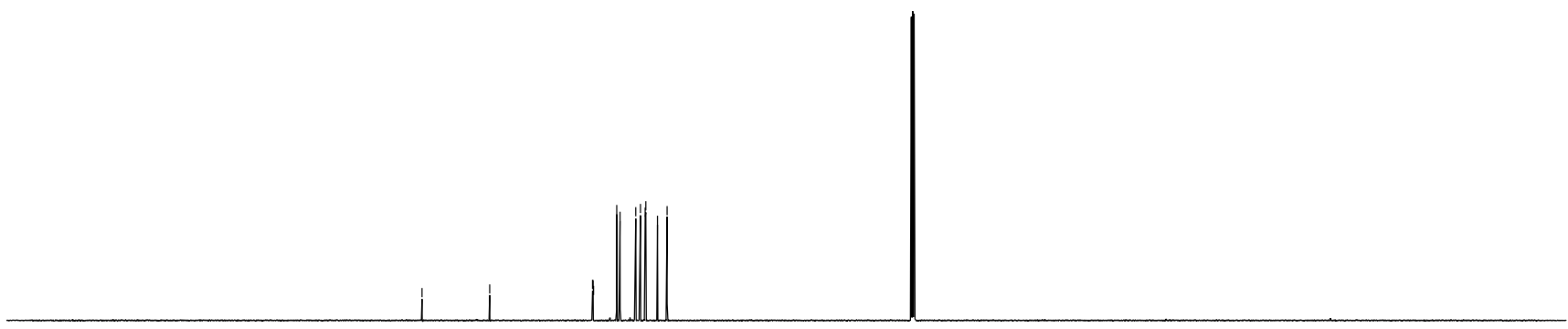

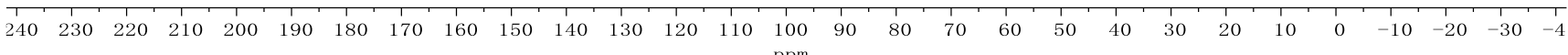




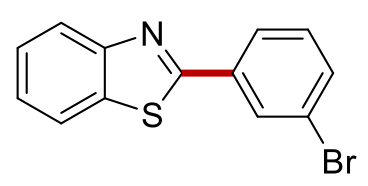

405m

$\left(500 \mathrm{MHz}, \mathrm{CDCl}_{3}\right)$

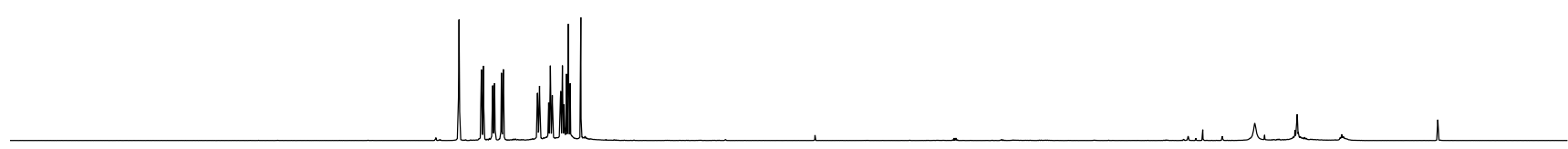

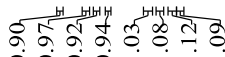

$\begin{array}{lllllllllllllllllllllllllllllllllllll}2.0 & 11.5 & 11.0 & 10.5 & 10.0 & 9.5 & 9.0 & 8.5 & 8.0 & 7.5 & 7.0 & 6.5 & 6.0 & 5.5 & 5.0 & 4.5 & 4.0 & 3.5 & 3.0 & 2.5 & 2.0 & 1.5 & 1.0 & 0.5 & 0.0 & -0.5 & -1\end{array}$

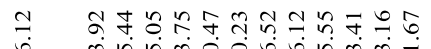

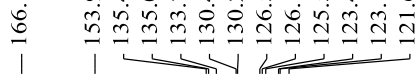

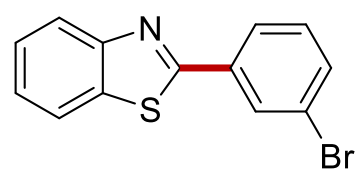

$405 \mathrm{~m}$

$\left(125 \mathrm{MHz} \mathrm{CDCl}_{3}\right)$

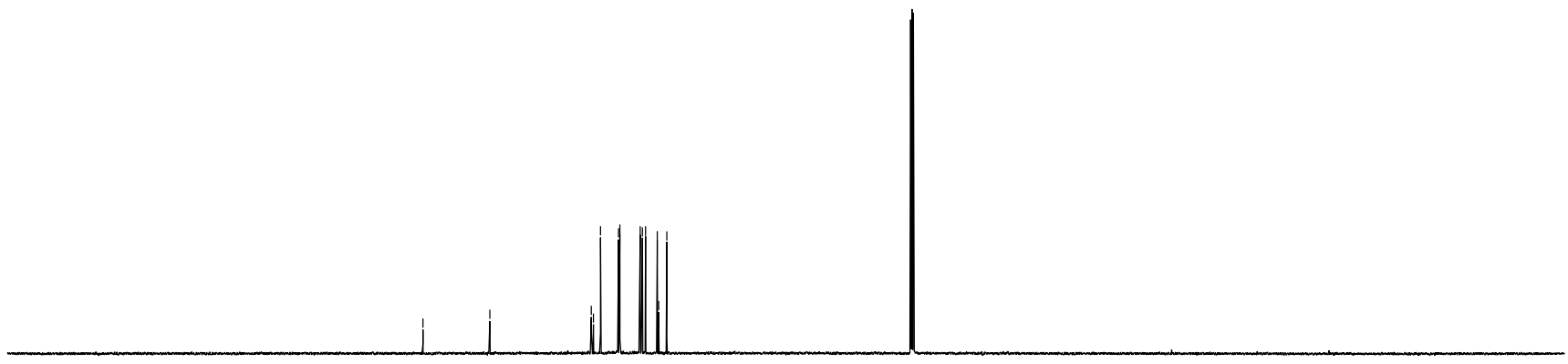

$\begin{array}{rlllllllllllllllllllllllllllllllllllll} & 240 & 230 & 220 & 210 & 200 & 190 & 180 & 170 & 160 & 150 & 140 & 130 & 120 & 110 & 100 & 90 & 80 & 70 & 60 & 50 & 40 & 30 & 20 & 10 & 0 & -10 & -20 & -30 & -4\end{array}$ 


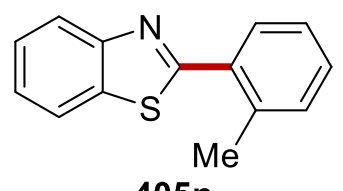

405n

(400 MHz, $\mathrm{CDCl}_{3}$ )
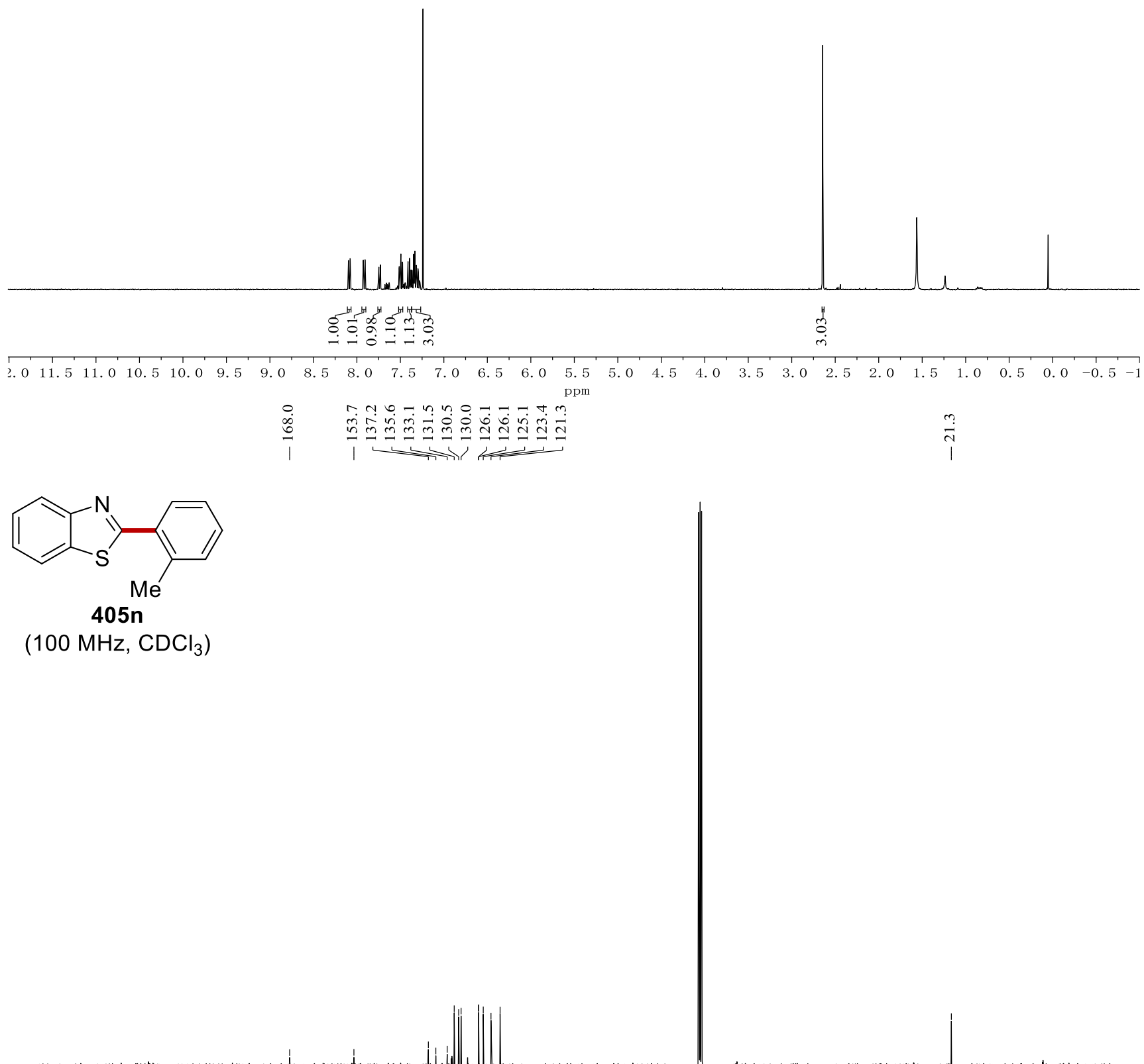

\begin{tabular}{llllllllllllllllllllllllllllllllll}
\hline 30 & 220 & 210 & 200 & 190 & 180 & 170 & 160 & 150 & 140 & 130 & 120 & 110 & 100 & 90 & 80 & 70 & 60 & 50 & 40 & 30 & 20 & 10 & 0 & -10 & -1
\end{tabular} 


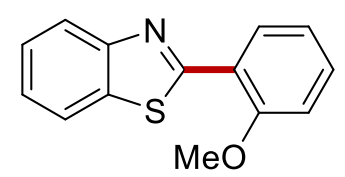

4050

(400 MHz, $\mathrm{CDCl}_{3}$ )

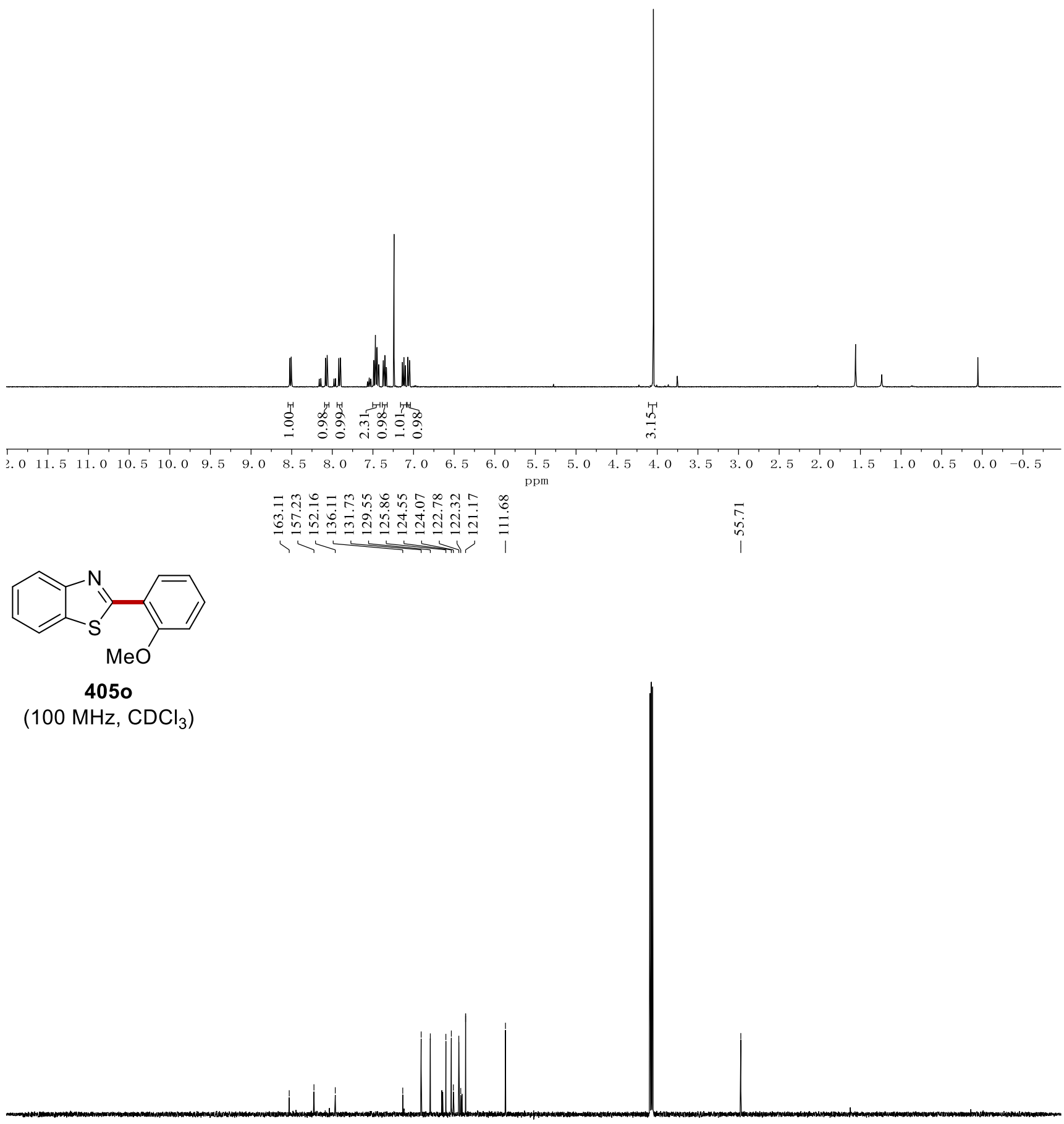

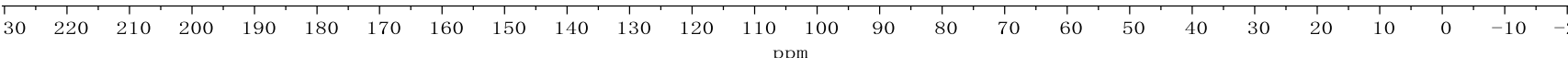




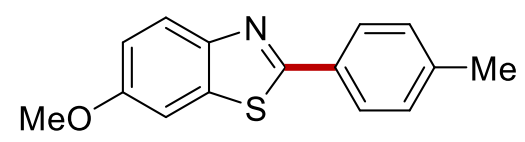

405p

(400 MHz, $\mathrm{CDCl}_{3}$ )

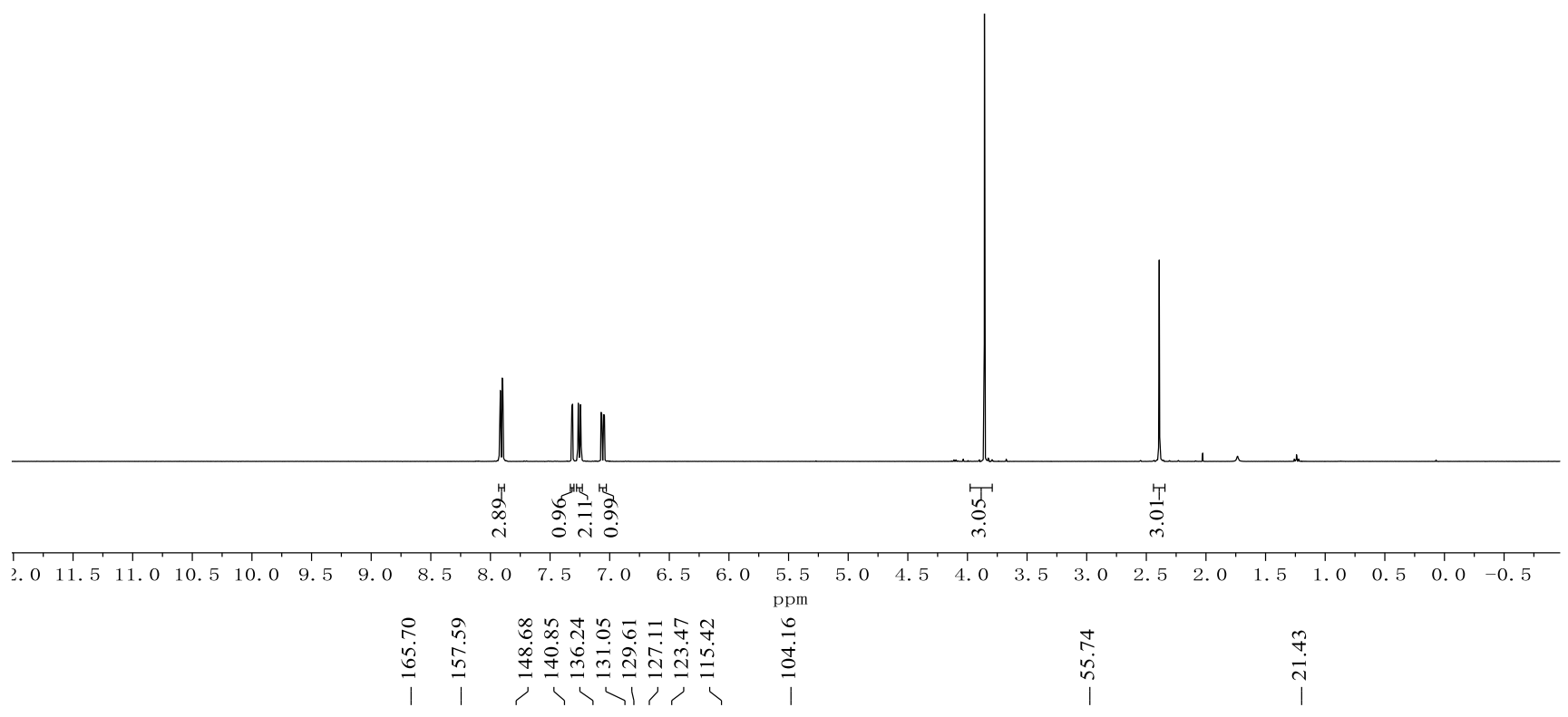

\section{5p}

(100 MHz, $\mathrm{CDCl}_{3}$ )

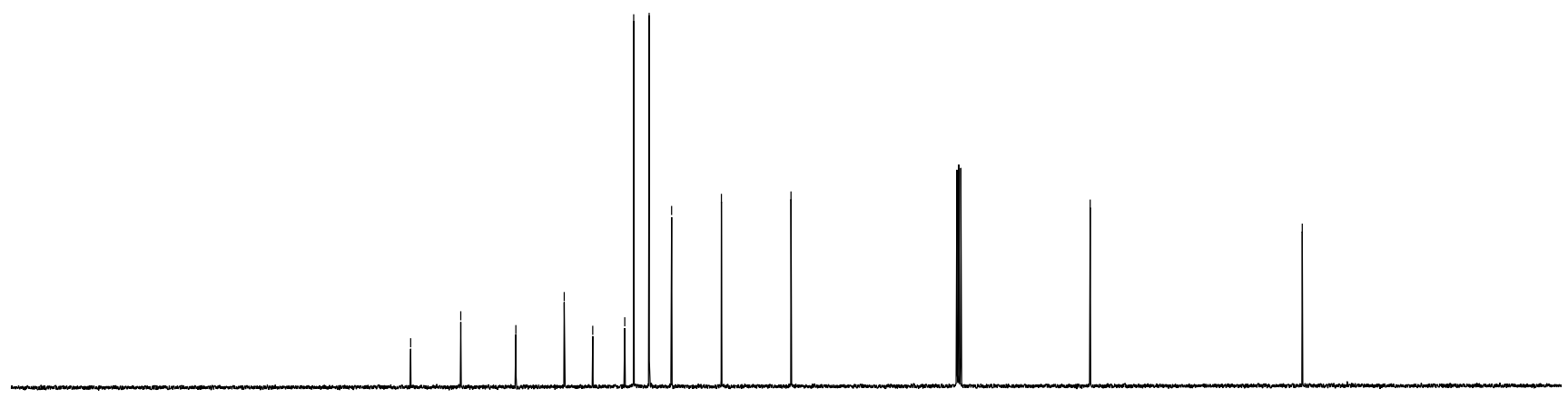

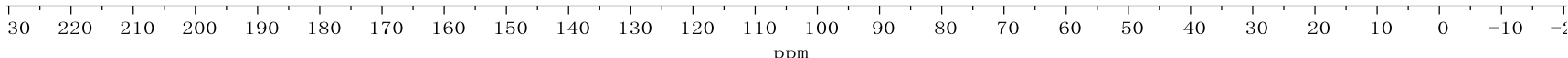


<smiles>Cc1ccc(-c2nc3ccc(F)cc3s2)cc1</smiles>

$405 q$

$\left(400 \mathrm{MHz} \mathrm{CDCl}_{3}\right)$

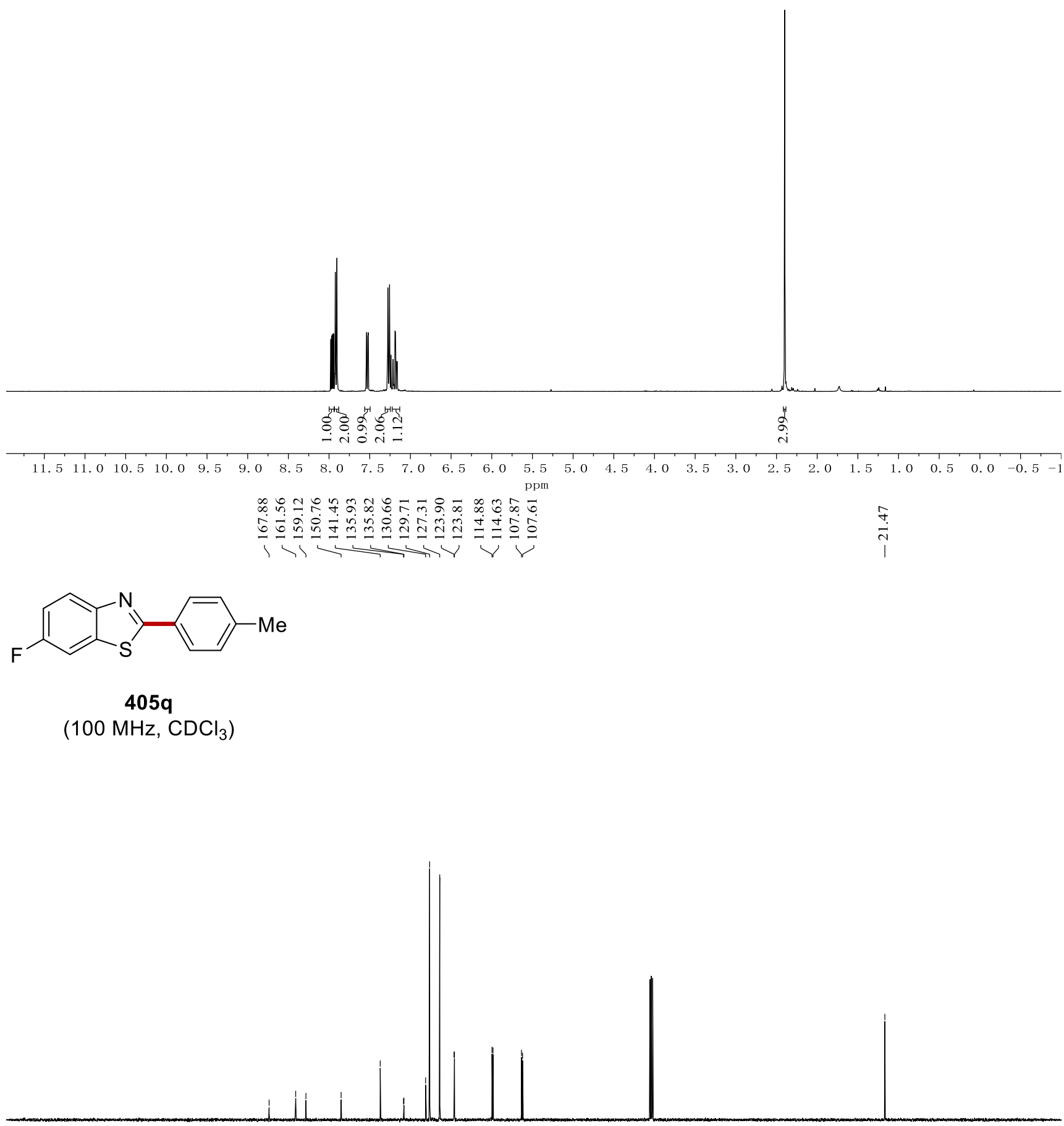

\begin{tabular}{lllllllllllllllllllllllllllllllll}
\hline 30 & 220 & 210 & 200 & 190 & 180 & 170 & 160 & 150 & 140 & 130 & 120 & 110 & 100 & 90 & 80 & 70 & 60 & 50 & 40 & 30 & 20 & 10 & 0 & -10 & -1
\end{tabular} 


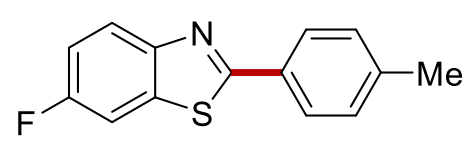

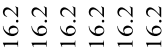

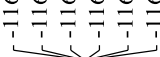

405q

(282 $\mathrm{MHz}, \mathrm{CDCl}_{3}$ )

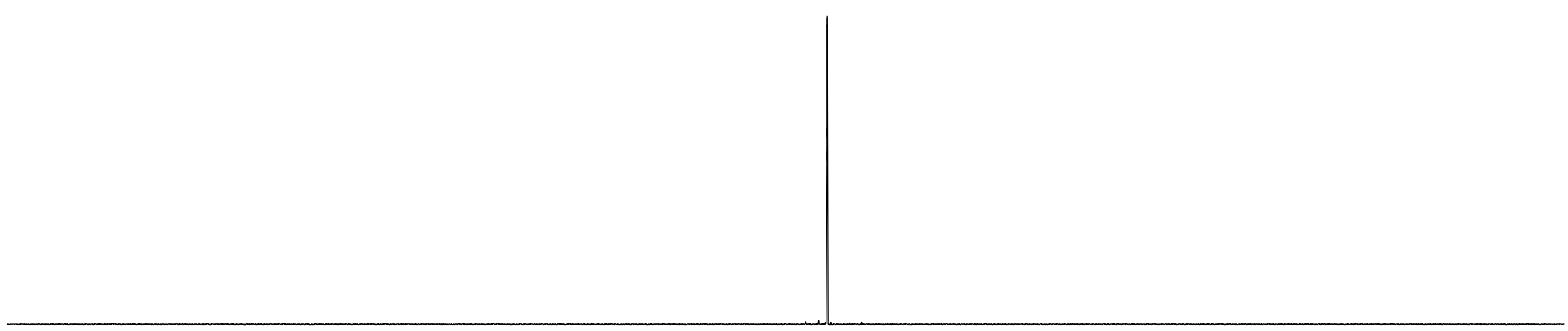

\begin{tabular}{|llllllllllllllllllllllll}
0 & -10 & -20 & -30 & -40 & -50 & -60 & -70 & -80 & -90 & -100 & -110 & -120 & -130 & -140 & -150 & -160 & -170 & -180 & -190 & -200 & -210 & -220
\end{tabular} 
<smiles>Cc1ccc(-c2nc3ccc(Cl)cc3s2)cc1</smiles>

405r

$\left(400 \mathrm{MHz}, \mathrm{CDCl}_{3}\right)$
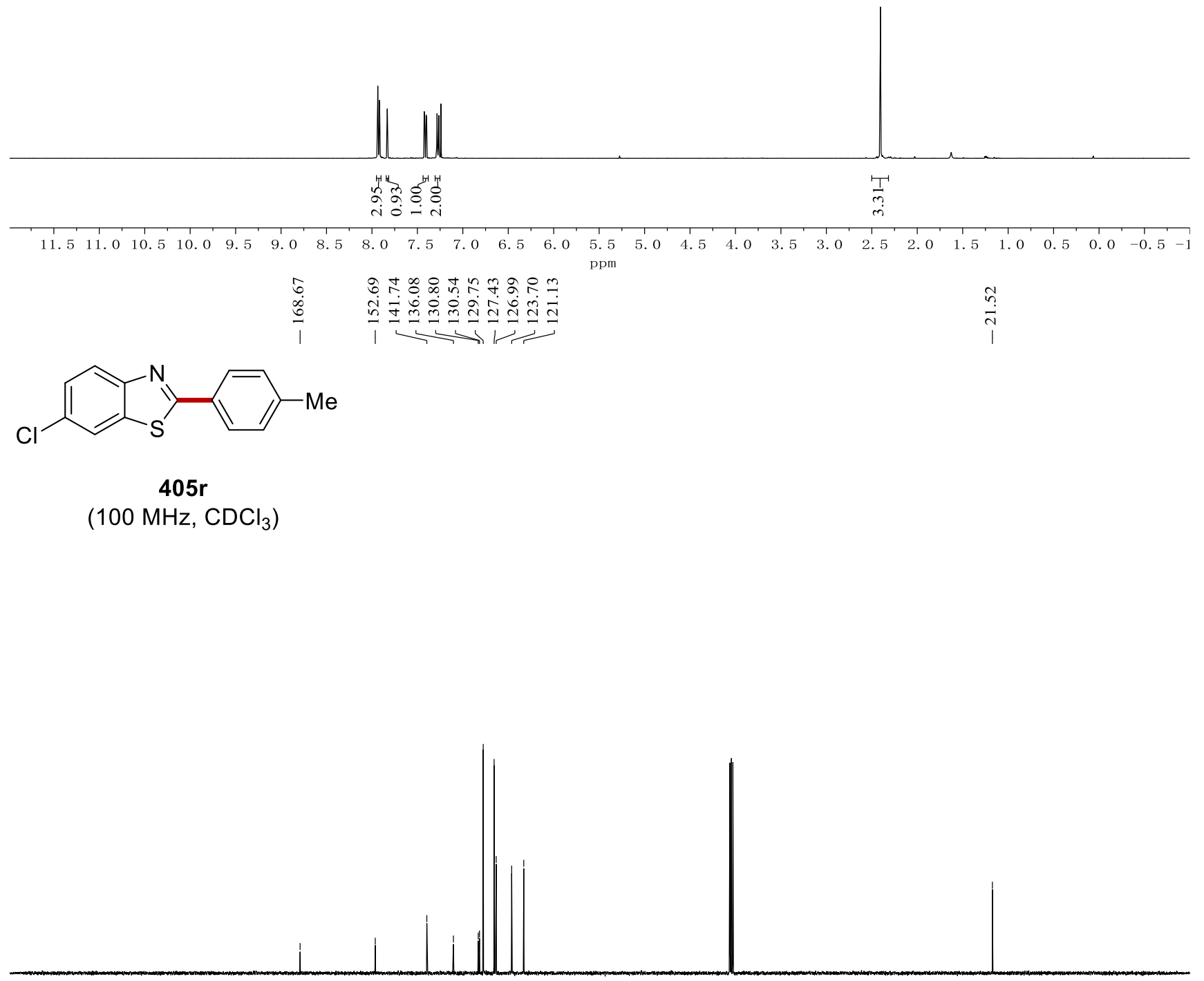

\begin{tabular}{llllllllllllllllllllllllllllllllll}
\hline 30 & 220 & 210 & 200 & 190 & 180 & 170 & 160 & 150 & 140 & 130 & 120 & 110 & 100 & 90 & 80 & 70 & 60 & 50 & 40 & 30 & 20 & 10 & 0 & -10 & $-!$
\end{tabular} 
<smiles>Cc1ccc(-c2nc3ccc(Br)cc3s2)cc1</smiles>

405s

(400 MHz, $\mathrm{CDCl}_{3}$ )

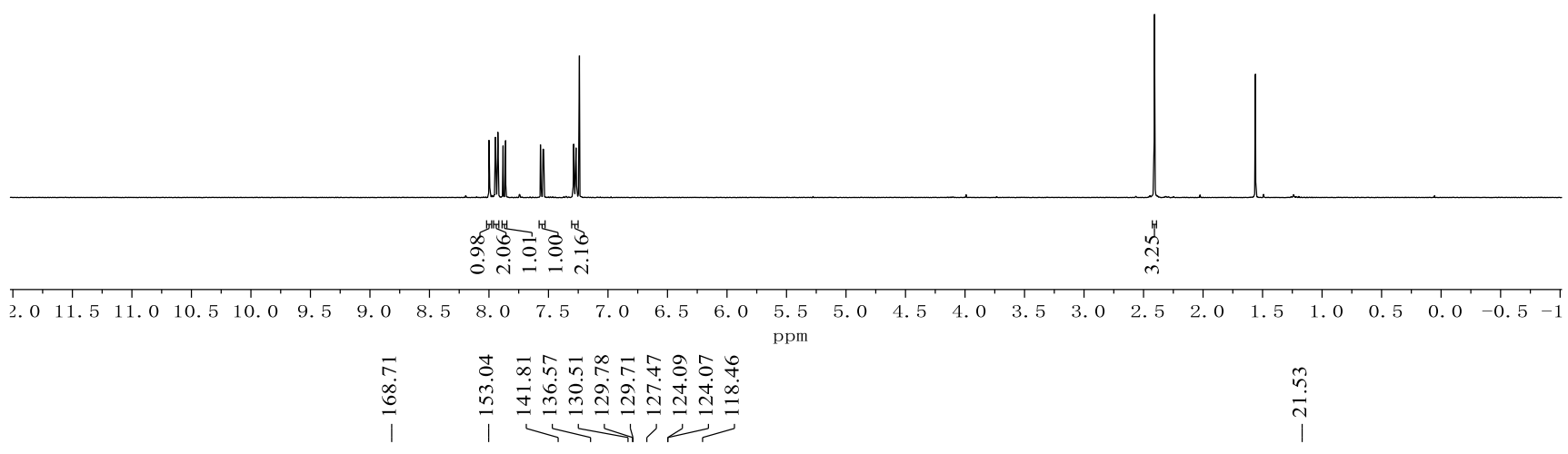<smiles>Cc1ccc(-c2nc3ccc(Br)cc3s2)cc1</smiles>

405s

(100 MHz, $\mathrm{CDCl}_{3}$ )

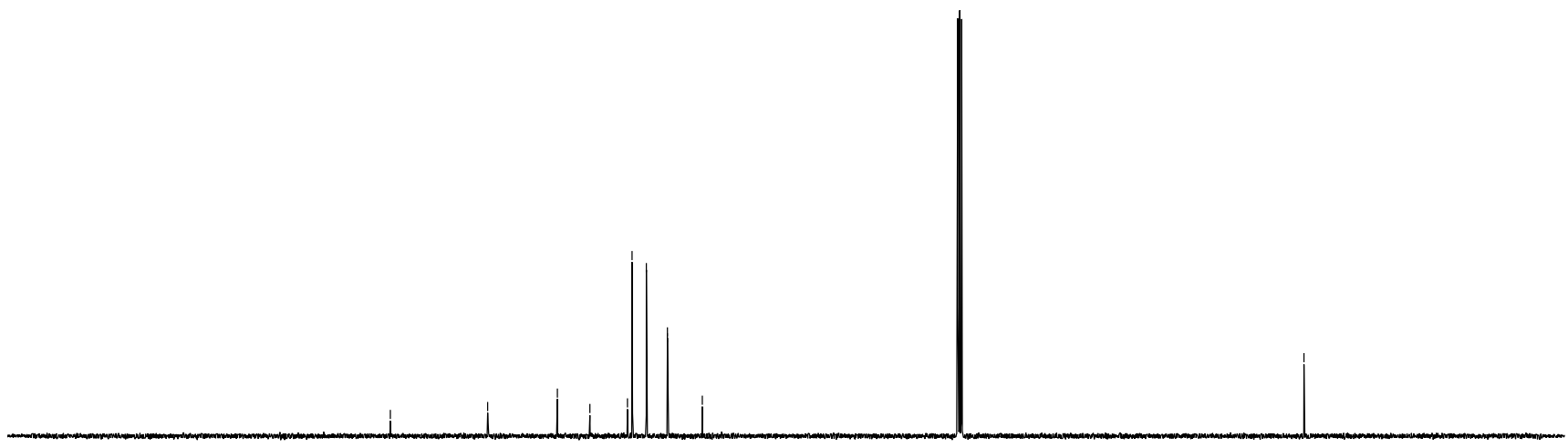

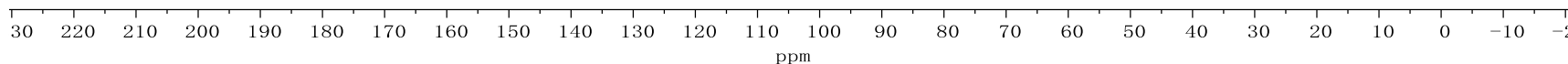




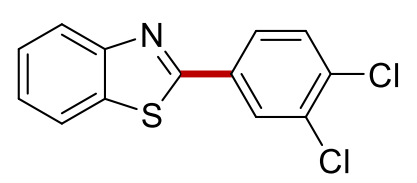

405t

(500 MHz, $\mathrm{CDCl}_{3}$ )

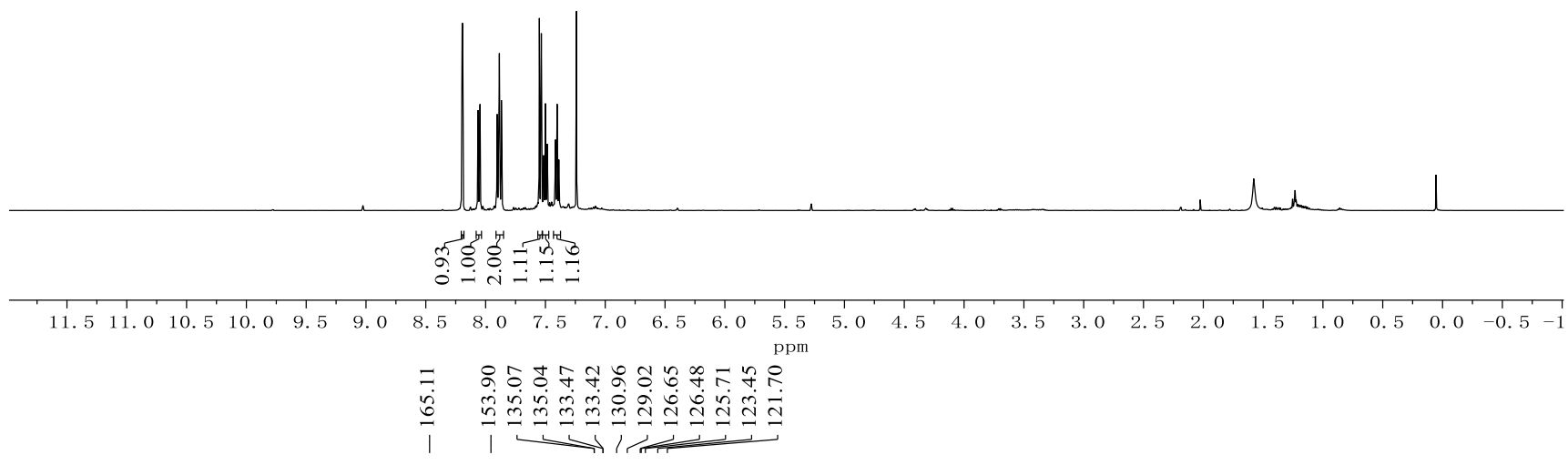<smiles>Clc1ccc(-c2nc3ccccc3s2)cc1Cl</smiles>

405t

(125 MHz, $\mathrm{CDCl}_{3}$ )

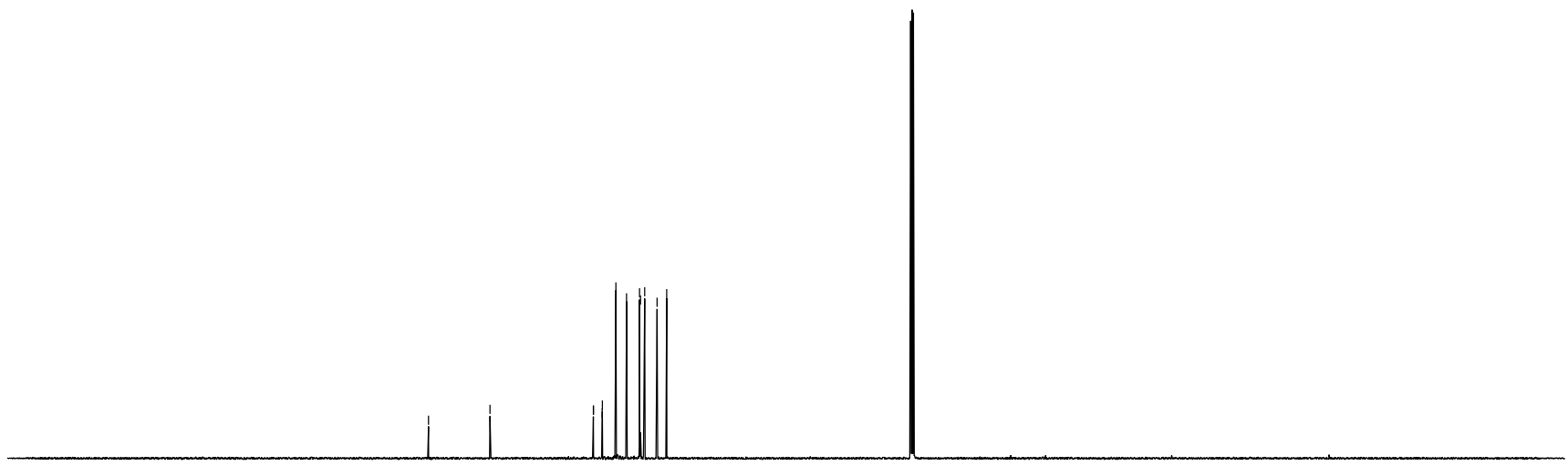

$\begin{array}{llllllllllllllllllllllllllllllllllll} & 240 & 230 & 220 & 210 & 200 & 190 & 180 & 170 & 160 & 150 & 140 & 130 & 120 & 110 & 100 & 90 & 80 & 70 & 60 & 50 & 40 & 30 & 20 & 10 & 0 & -10 & -20 & -30 & -4\end{array}$ 

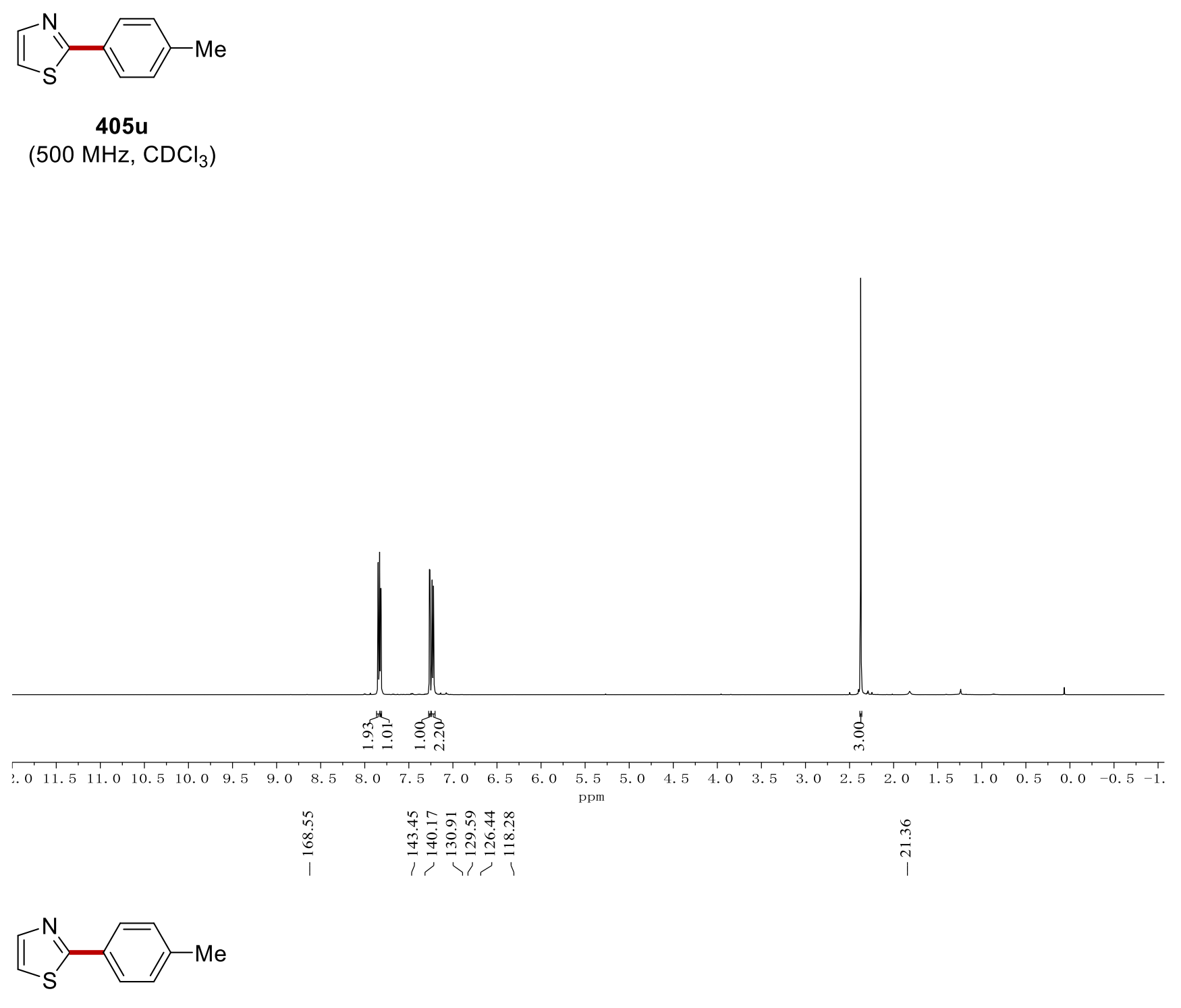

405u

$\left(125 \mathrm{MHz} \mathrm{CDCl}_{3}\right)$

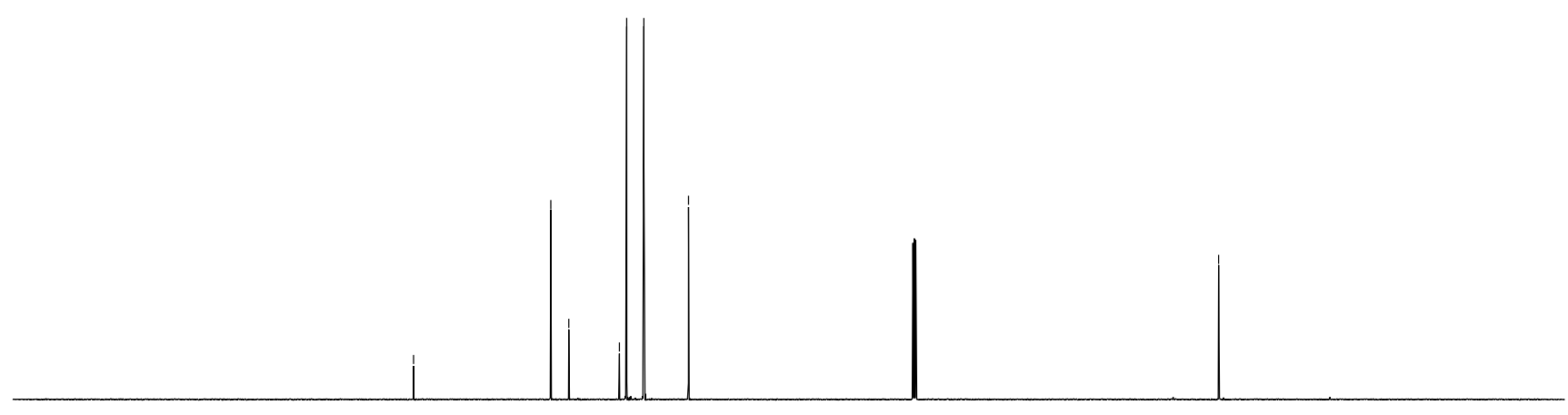

$\begin{array}{lllllllllllllllllllllllllllllllllllll}240 & 230 & 220 & 210 & 200 & 190 & 180 & 170 & 160 & 150 & 140 & 130 & 120 & 110 & 100 & 90 & 80 & 70 & 60 & 50 & 40 & 30 & 20 & 10 & 0 & -10 & -20 & -30 & -4\end{array}$ 


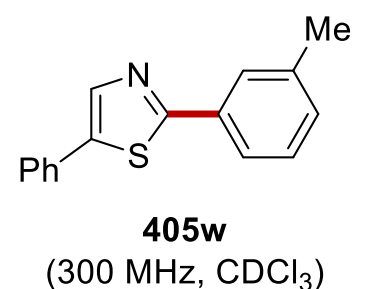

(300 MHz, $\mathrm{CDCl}_{3}$ )

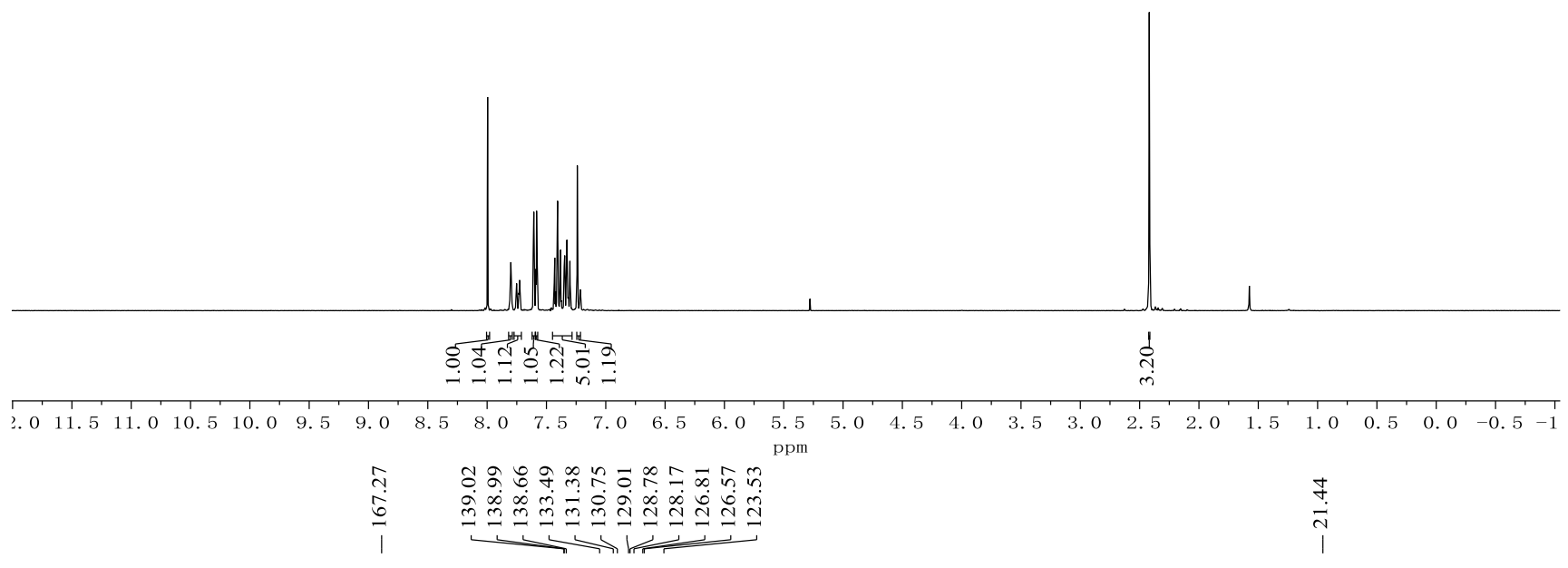<smiles>Cc1cccc(-c2ncc(-c3ccccc3)s2)c1</smiles>

405w

(75 MHz, $\mathrm{CDCl}_{3}$ )

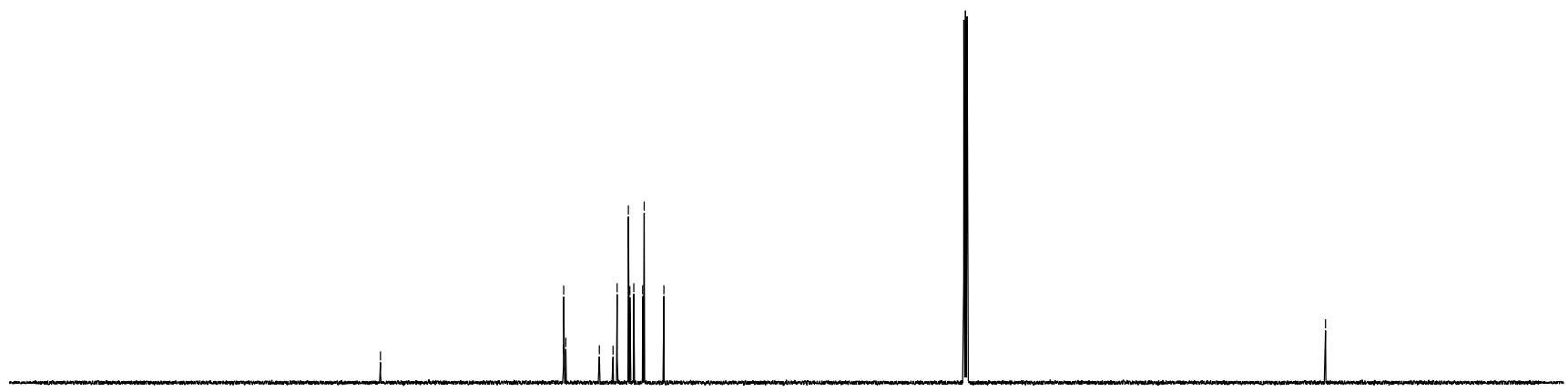

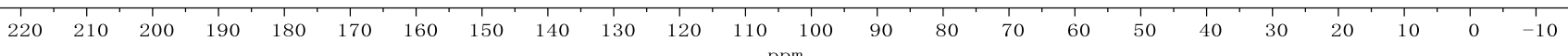



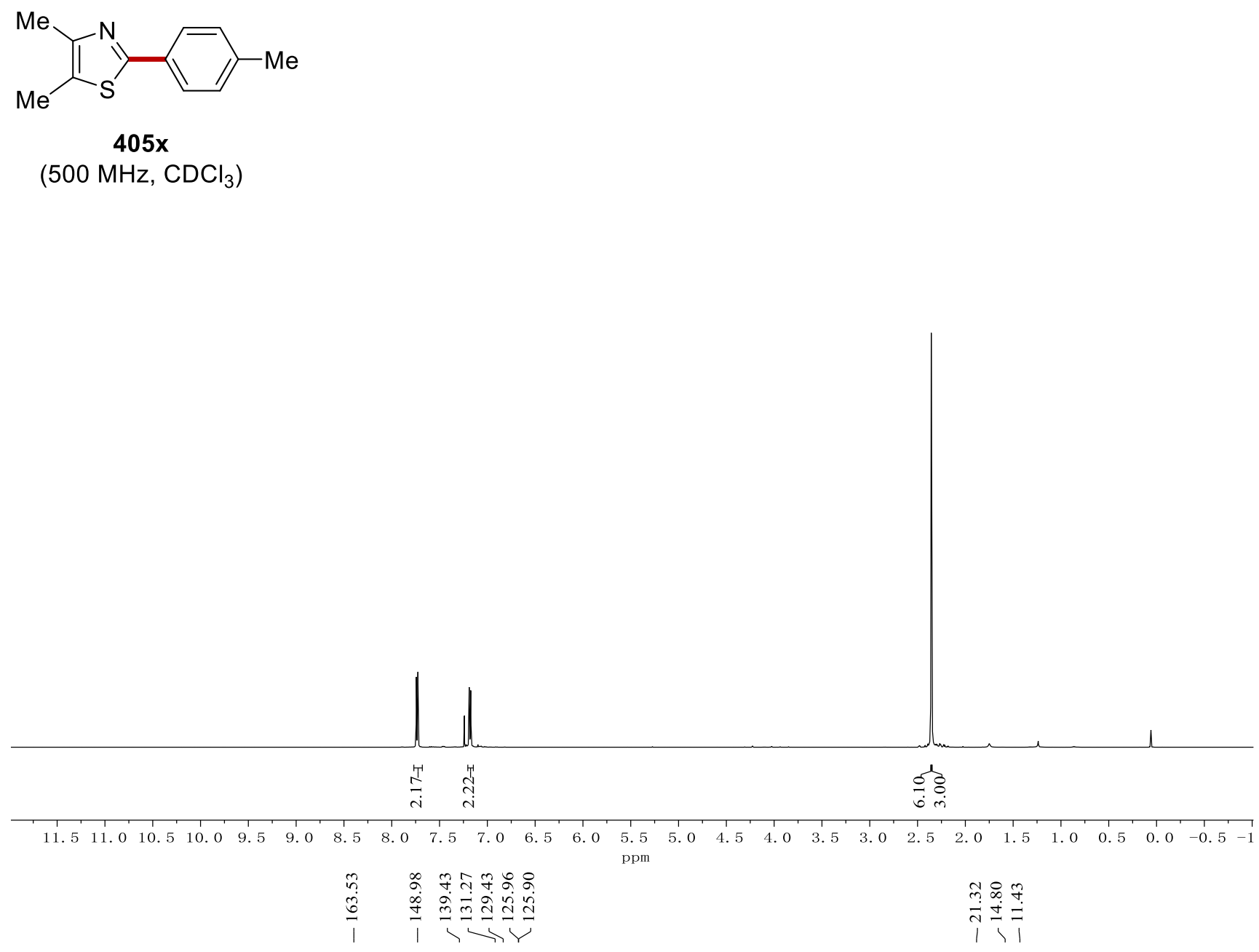<smiles>Cc1ccc(-c2nc(C)c(C)s2)cc1</smiles>

(125 MHz, $\mathrm{CDCl}_{3}$ )

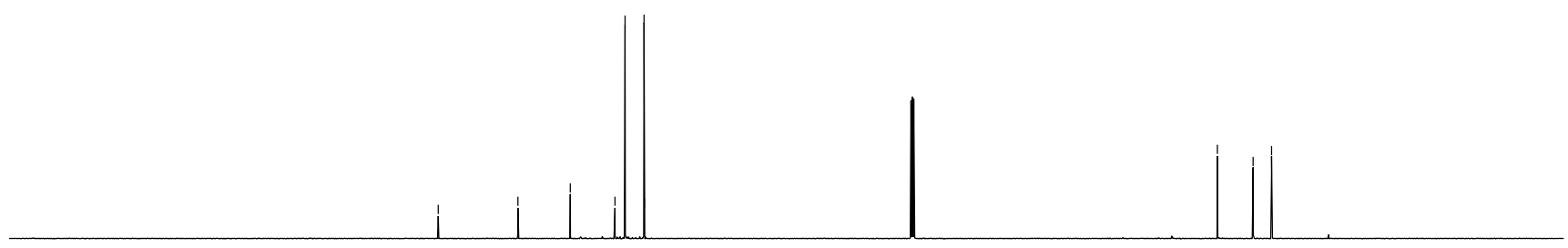

$\begin{array}{rllllllllllllllllllllllllllllllllllll} & 240 & 230 & 220 & 210 & 200 & 190 & 180 & 170 & 160 & 150 & 140 & 130 & 120 & 110 & 100 & 90 & 80 & 70 & 60 & 50 & 40 & 30 & 20 & 10 & 0 & -10 & -20 & -30 & -4\end{array}$ 


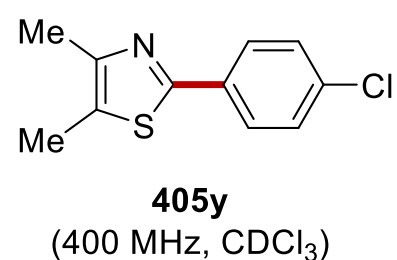

$\left(400 \mathrm{MHz} \mathrm{CDCl}_{3}\right)$

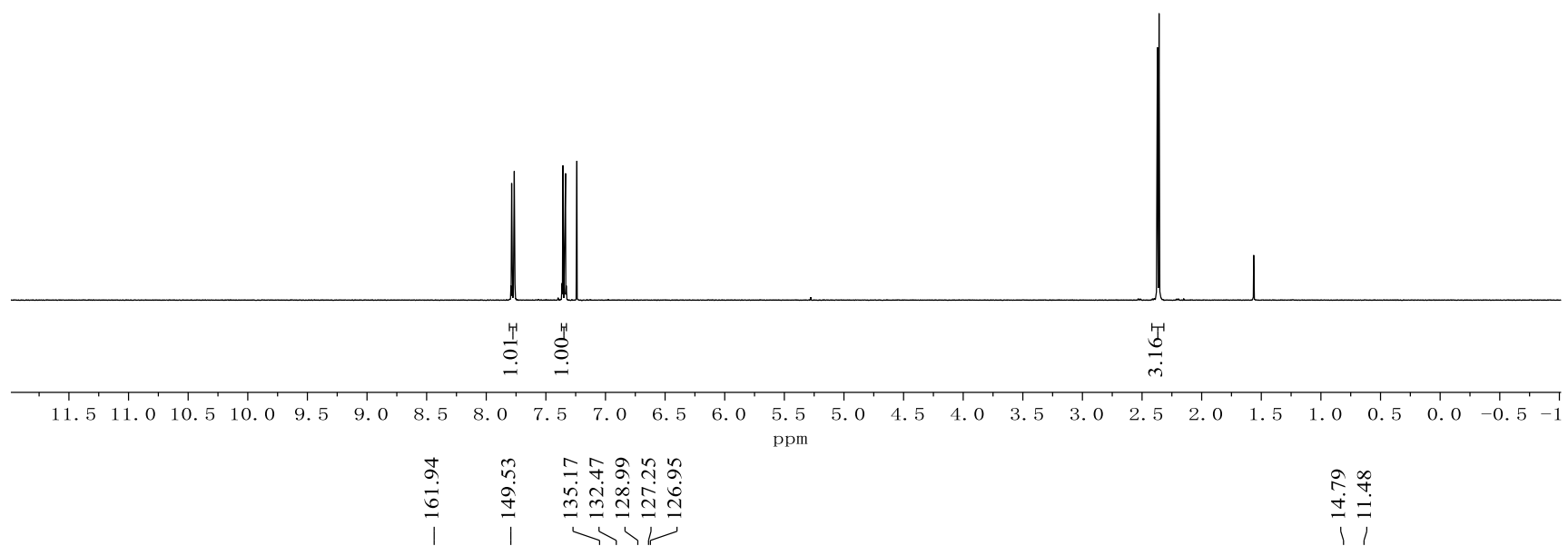<smiles>Cc1nc(-c2ccc(Cl)cc2)sc1C</smiles>

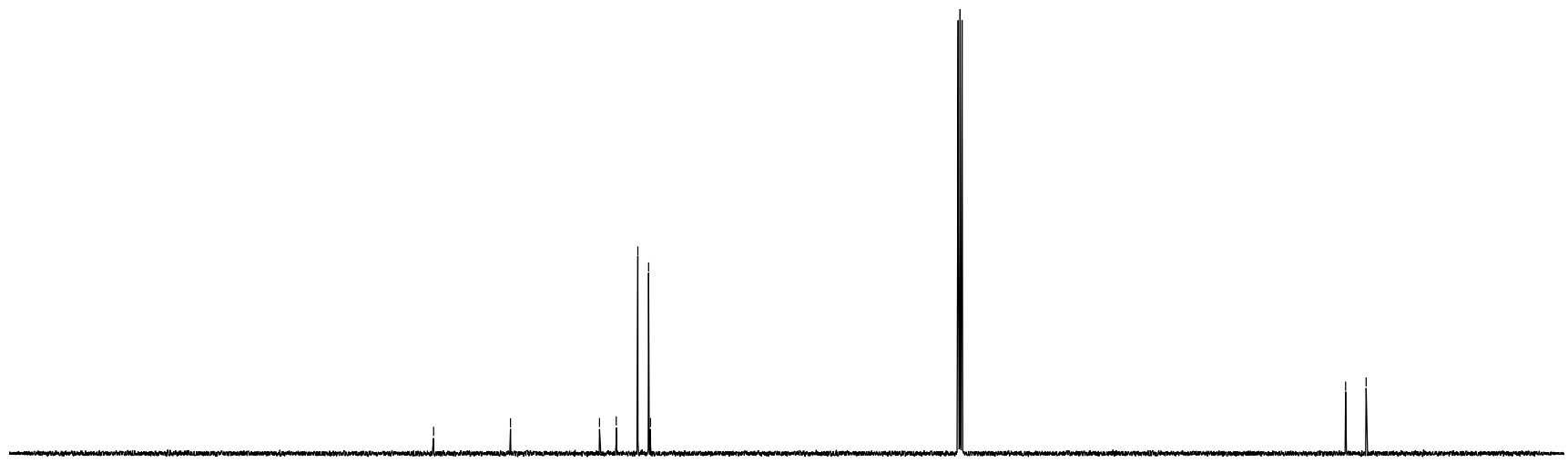

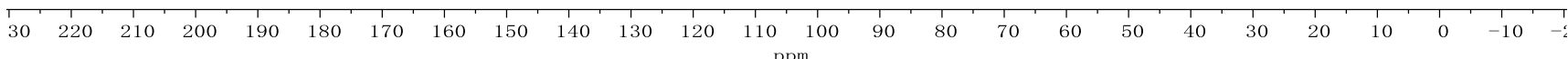




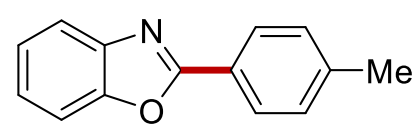

$447 a$

(500 MHz, $\mathrm{CDCl}_{3}$ )

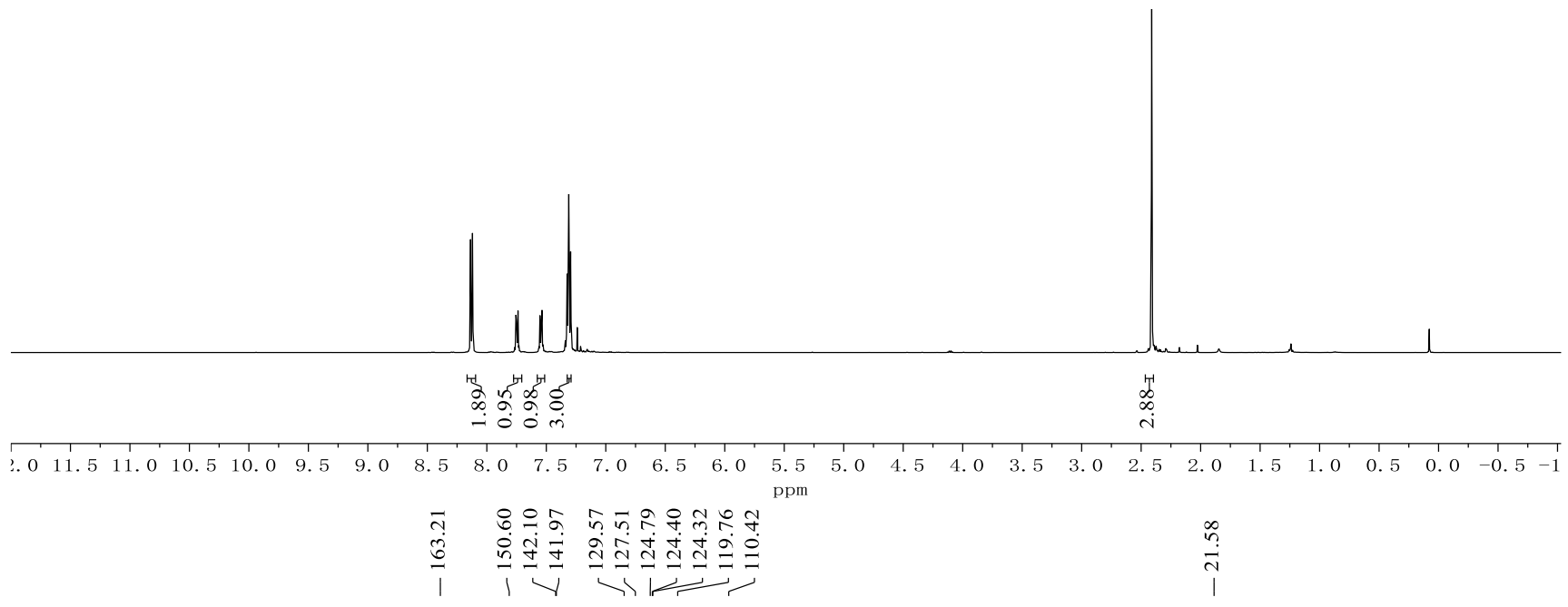<smiles>Cc1ccc(-c2nc3ccccc3o2)cc1</smiles>

\section{7a}

(125 MHz, $\mathrm{CDCl}_{3}$ )

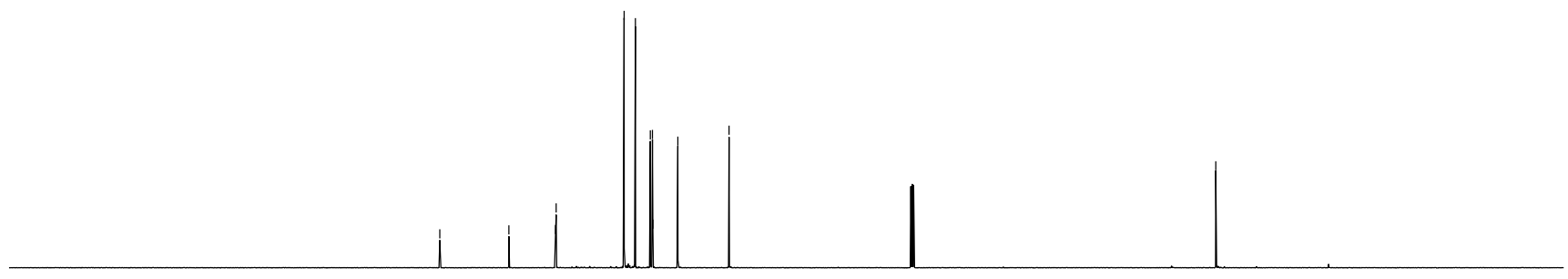

$\begin{array}{llllllllllllllllllllllllllllllllllllll}240 & 230 & 220 & 210 & 200 & 190 & 180 & 170 & 160 & 150 & 140 & 130 & 120 & 110 & 100 & 90 & 80 & 70 & 60 & 50 & 40 & 30 & 20 & 10 & 0 & -10 & -20 & -30 & -4\end{array}$ 

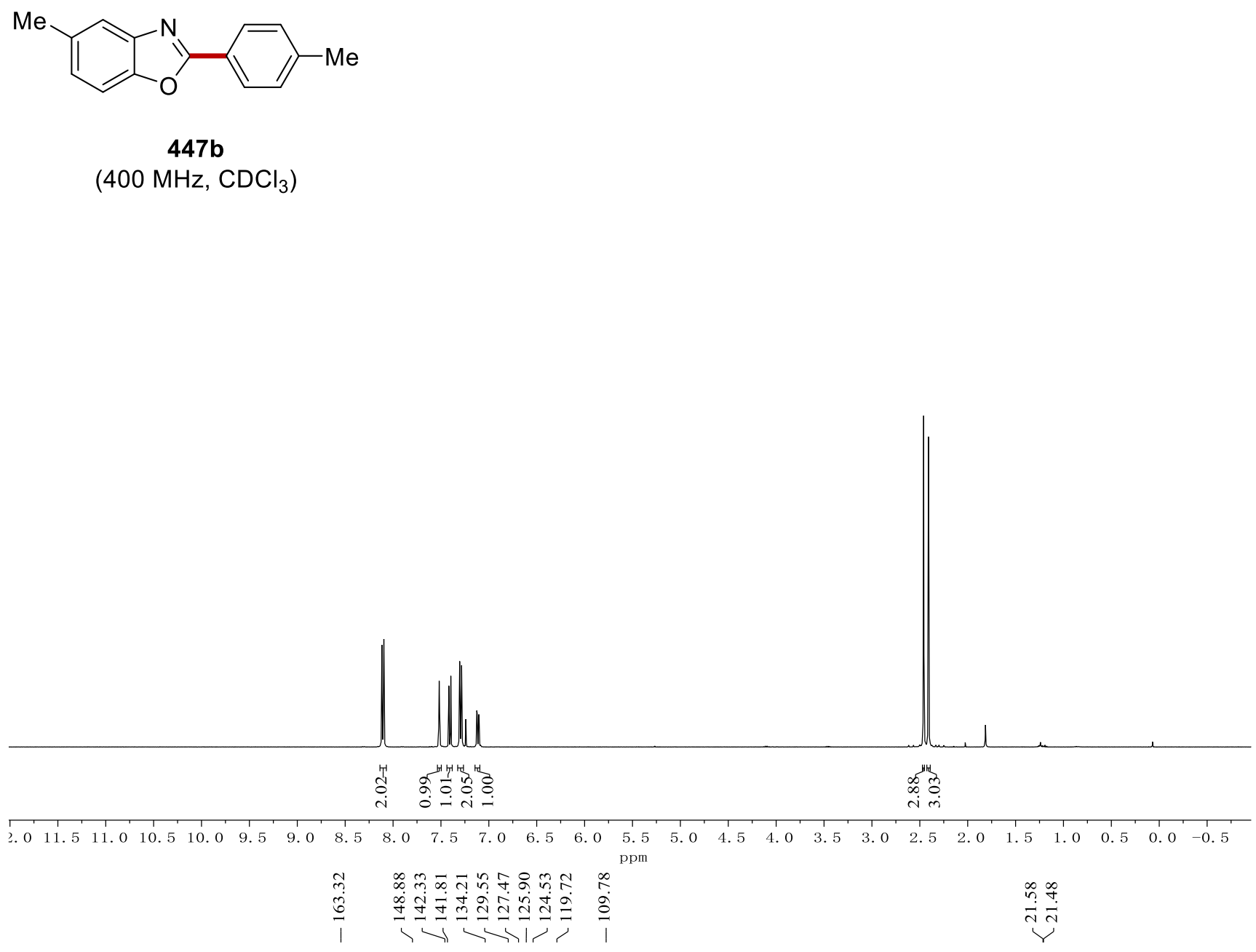<smiles>Cc1ccc(-c2nc3cc(C)ccc3o2)cc1</smiles>

447b

(100 MHz, $\mathrm{CDCl}_{3}$ )

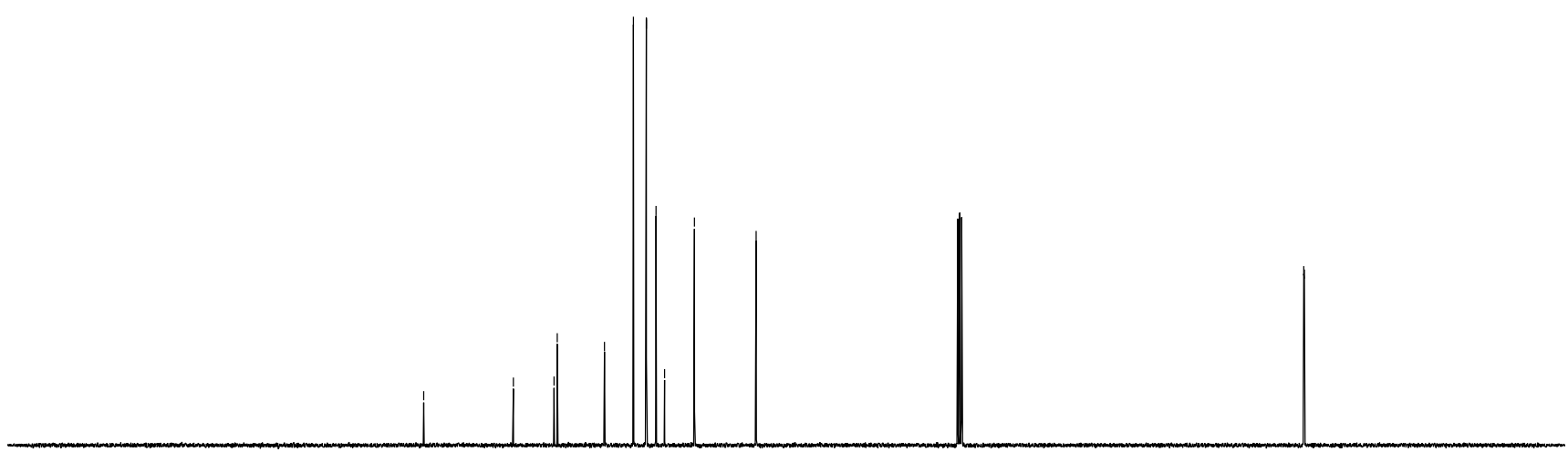

\begin{tabular}{lllllllllllllllllllllllllllllllllllll}
\hline 30 & 220 & 210 & 200 & 190 & 180 & 170 & 160 & 150 & 140 & 130 & 120 & 110 & 100 & 90 & 80 & 70 & 60 & 50 & 40 & 30 & 20 & 10 & 0 & -10 & -5
\end{tabular} 

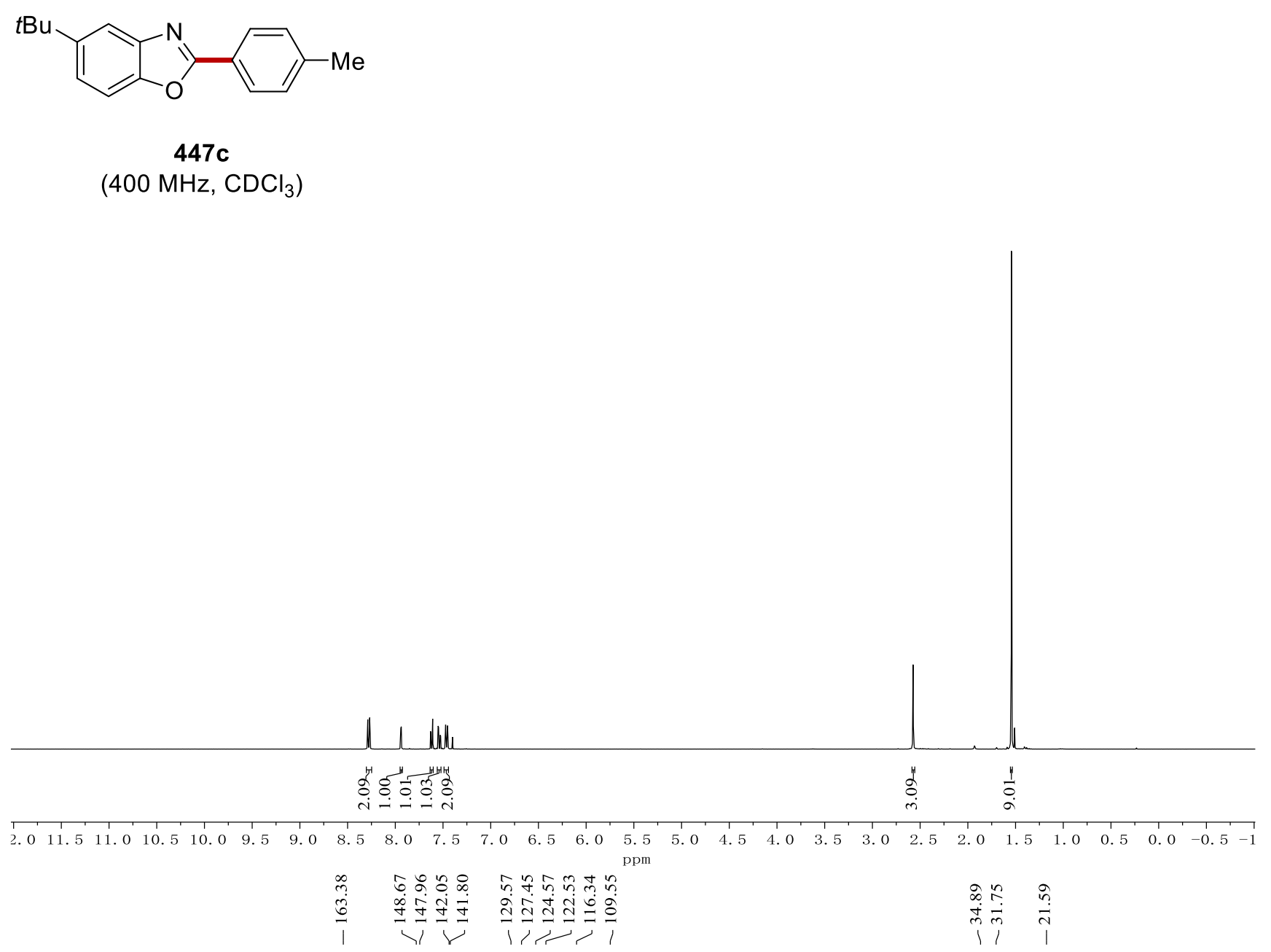<smiles>Cc1ccc(-c2nc3cc(C(C)(C)C)ccc3o2)cc1</smiles>

447c

$\left(100 \mathrm{MHz}, \mathrm{CDCl}_{3}\right)$

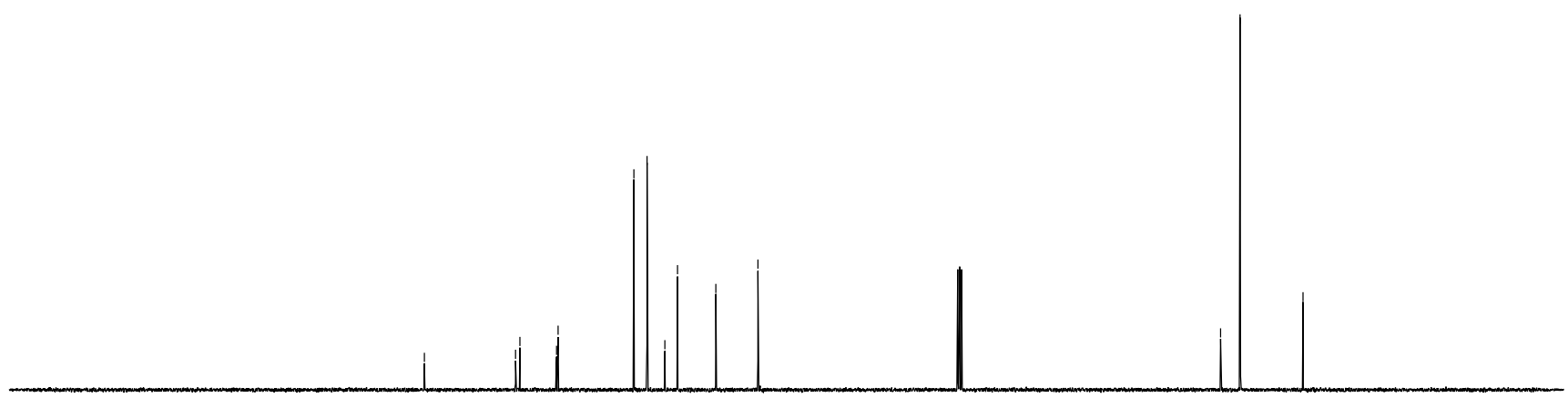

\begin{tabular}{lllllllllllllllllllllllllllllllllll}
\hline 30 & 220 & 210 & 200 & 190 & 180 & 170 & 160 & 150 & 140 & 130 & 120 & 110 & 100 & 90 & 80 & 70 & 60 & 50 & 40 & 30 & 20 & 10 & 0 & -10 & -1
\end{tabular} 

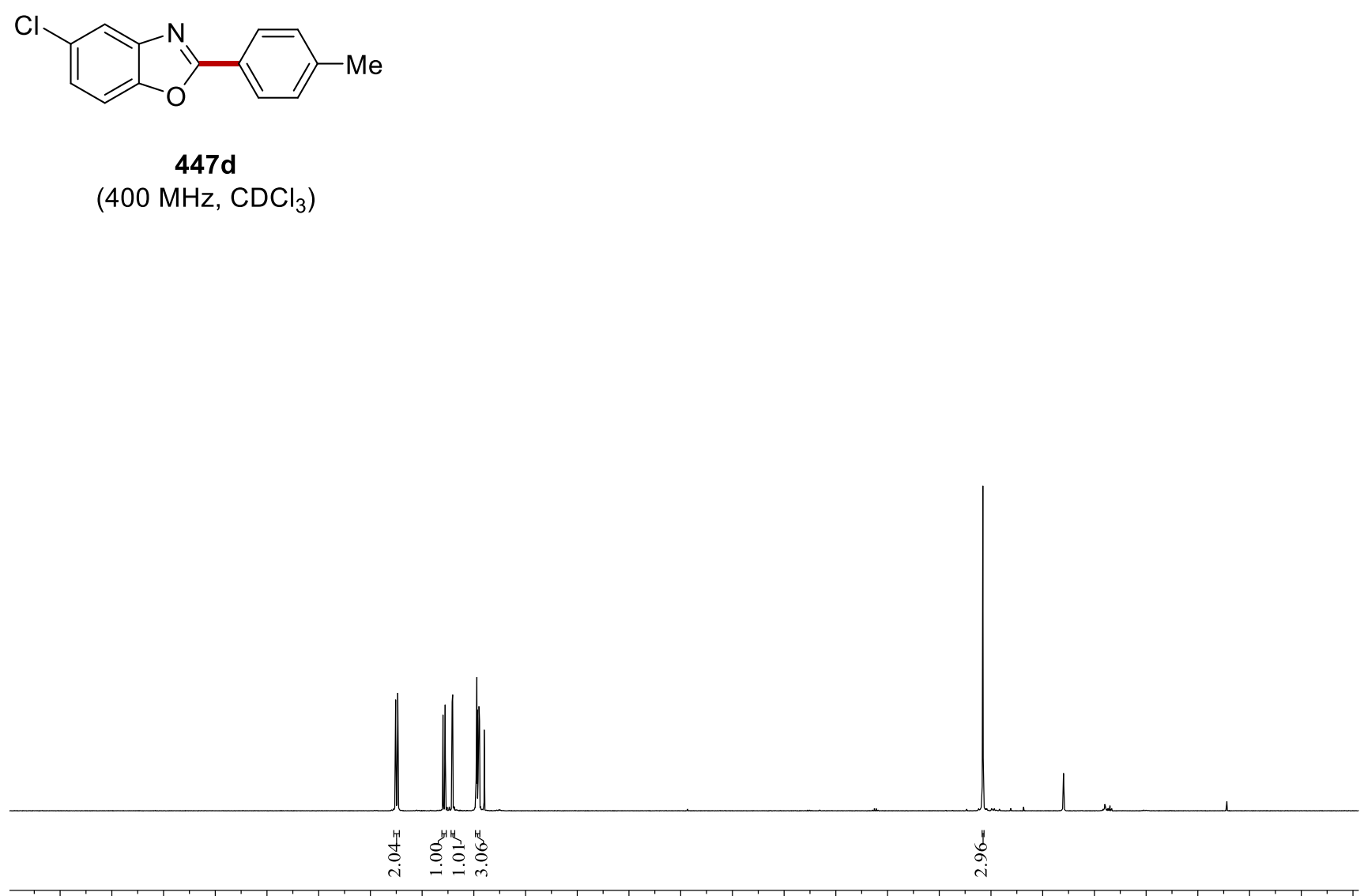

$\begin{array}{llllllllllllllllllllllllll}11.5 & 11.0 & 10.5 & 10.0 & 9.5 & 9.0 & 8.5 & 8.0 & 7.5 & 7.0 & 6.5 & 6.0 & 5.5 & 5.0 & 4.5 & 4.0 & 3.5 & 3.0 & 2.5 & 2.0 & 1.5 & 1.0 & 0.5 & 0.0 & -0.5 & -1\end{array}$

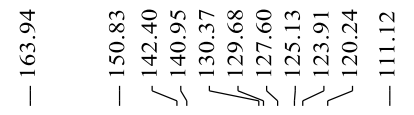<smiles>Cc1ccc(-c2nc3cc(Cl)ccc3o2)cc1</smiles>

447d

(100 MHz, $\mathrm{CDCl}_{3}$ )

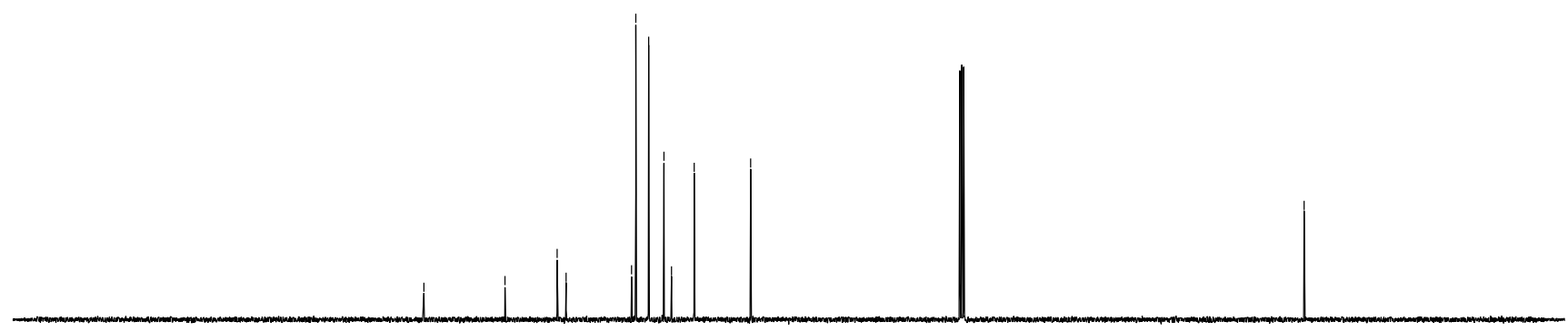

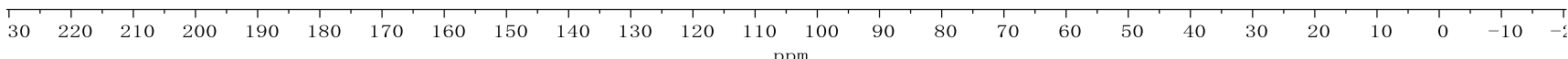




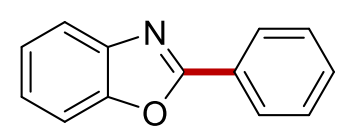

447e

(400 MHz, $\mathrm{CDCl}_{3}$ )
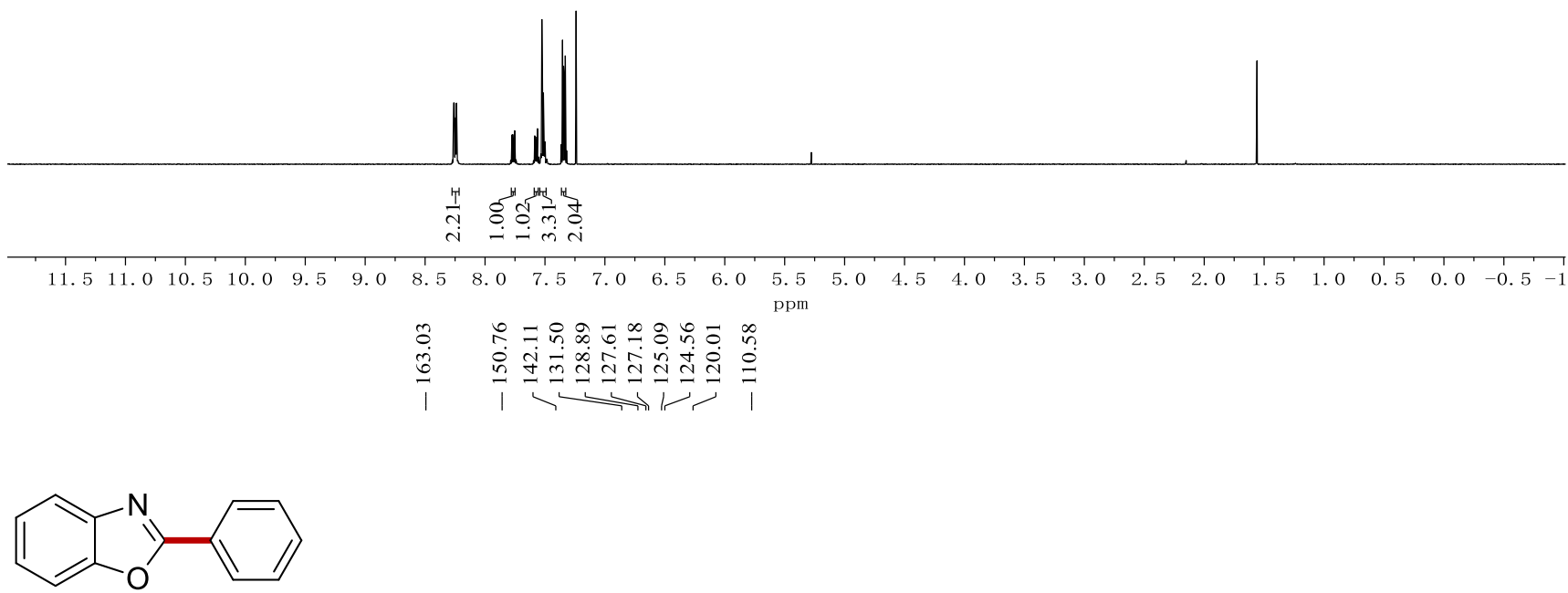

447e

(100 MHz, $\mathrm{CDCl}_{3}$ )

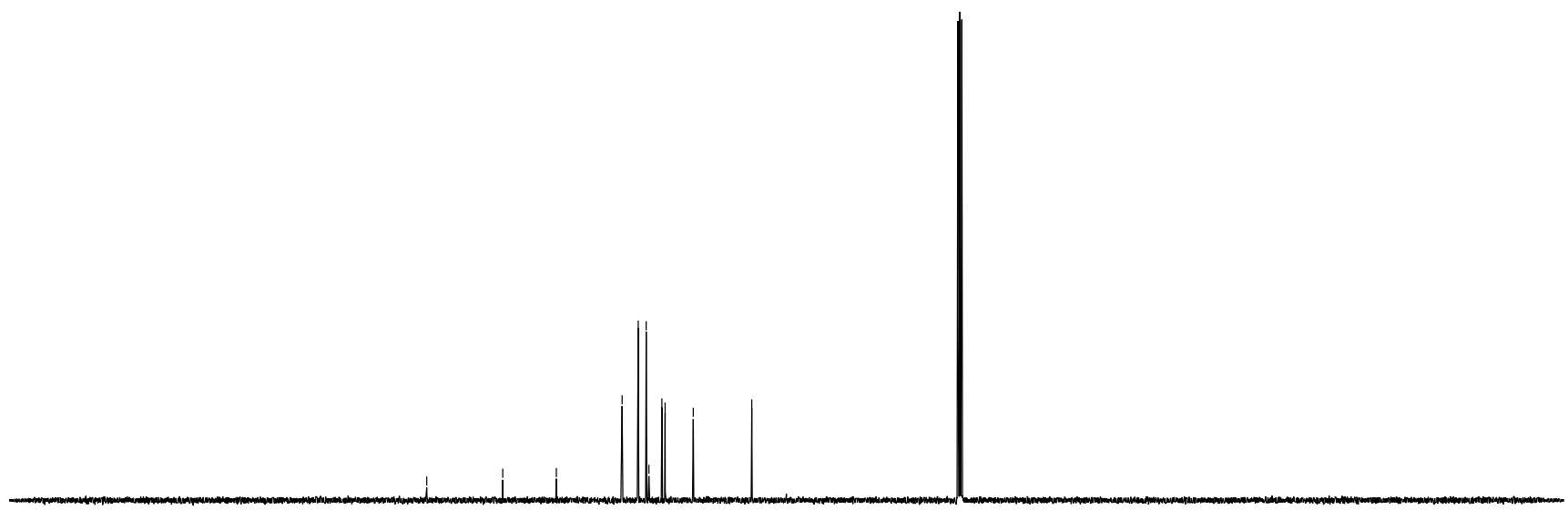

\begin{tabular}{llllllllllllllllllllllllll}
\hline 30 & 220 & 210 & 200 & 190 & 180 & 170 & 160 & 150 & 140 & 130 & 120 & 110 & 100 & 90 & 80 & 70 & 60 & 50 & 40 & 30 & 20 & 10 & 0 & -10 & -1
\end{tabular} 


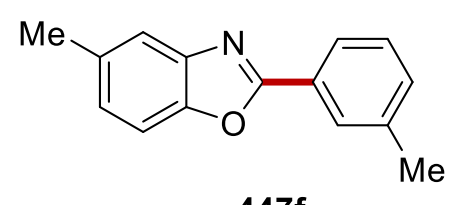

$447 f$

$\left(300 \mathrm{MHz}, \mathrm{CDCl}_{3}\right)$

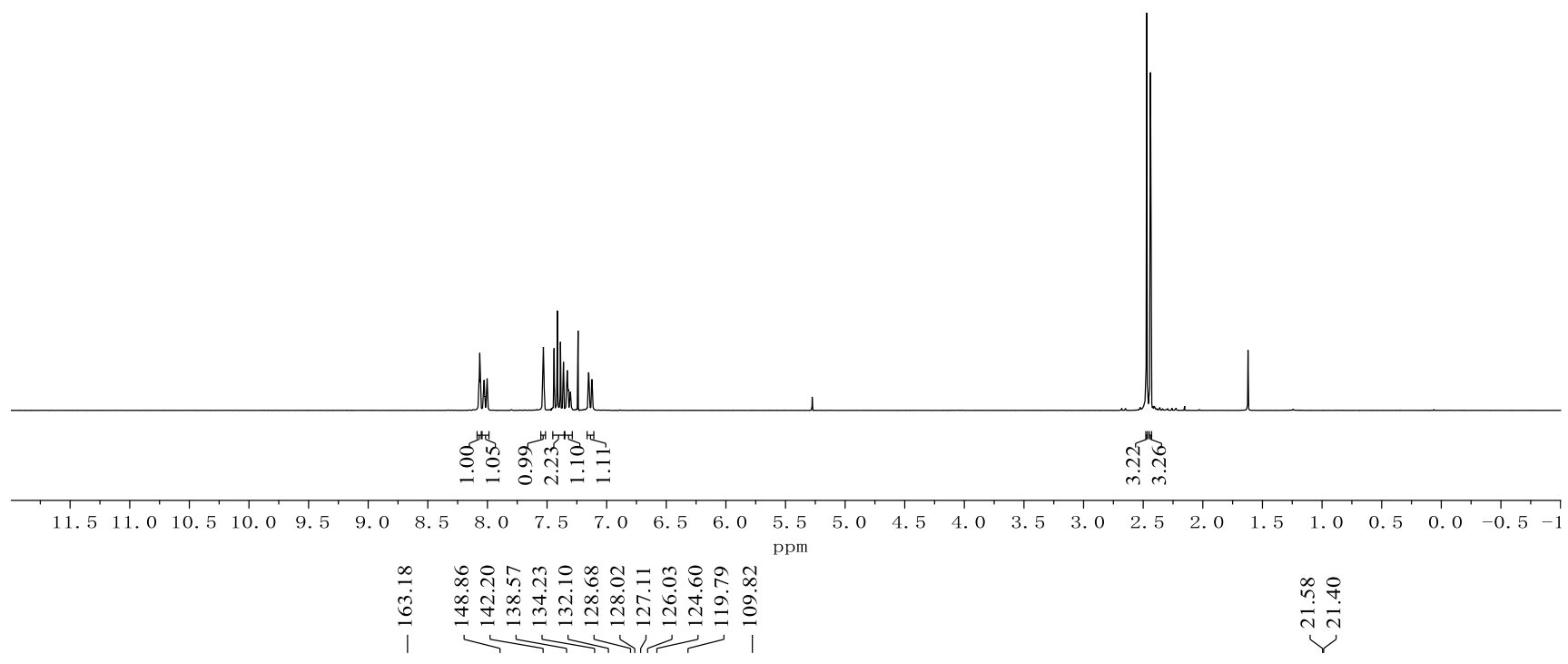<smiles>COc1cccc(-c2nc3cc(C)ccc3o2)c1</smiles>

$\left(75 \mathrm{MHz}, \mathrm{CDCl}_{3}\right)$

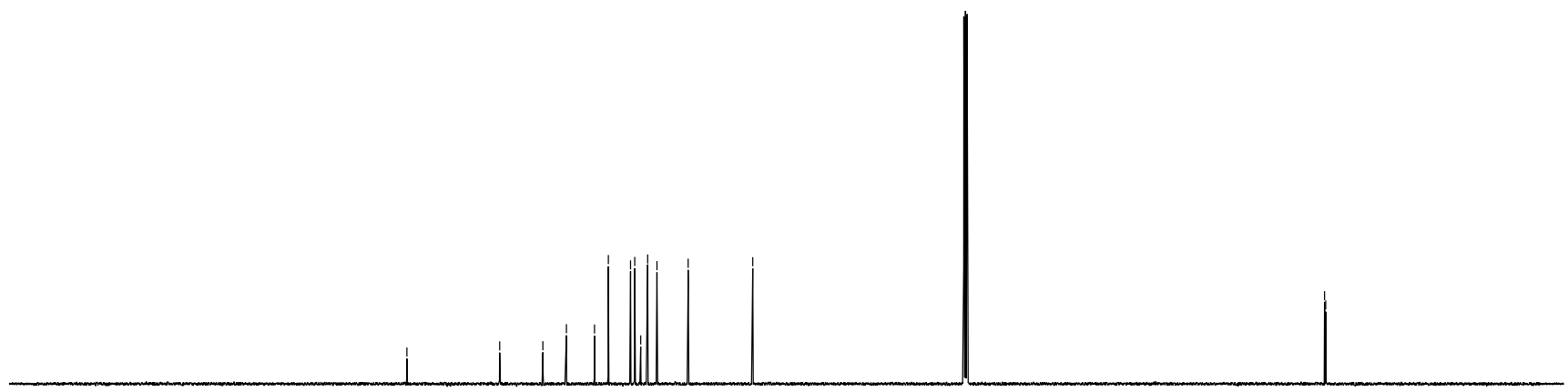

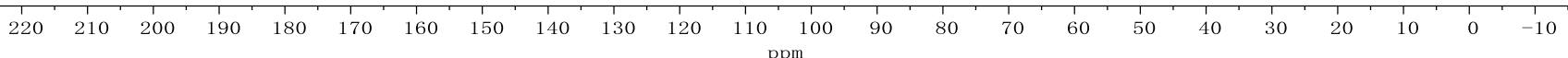


<smiles>Cc1ccc(-c2ncco2)cc1</smiles>

447g

$\left(400 \mathrm{MHz} \mathrm{CDCl}_{3}\right)$

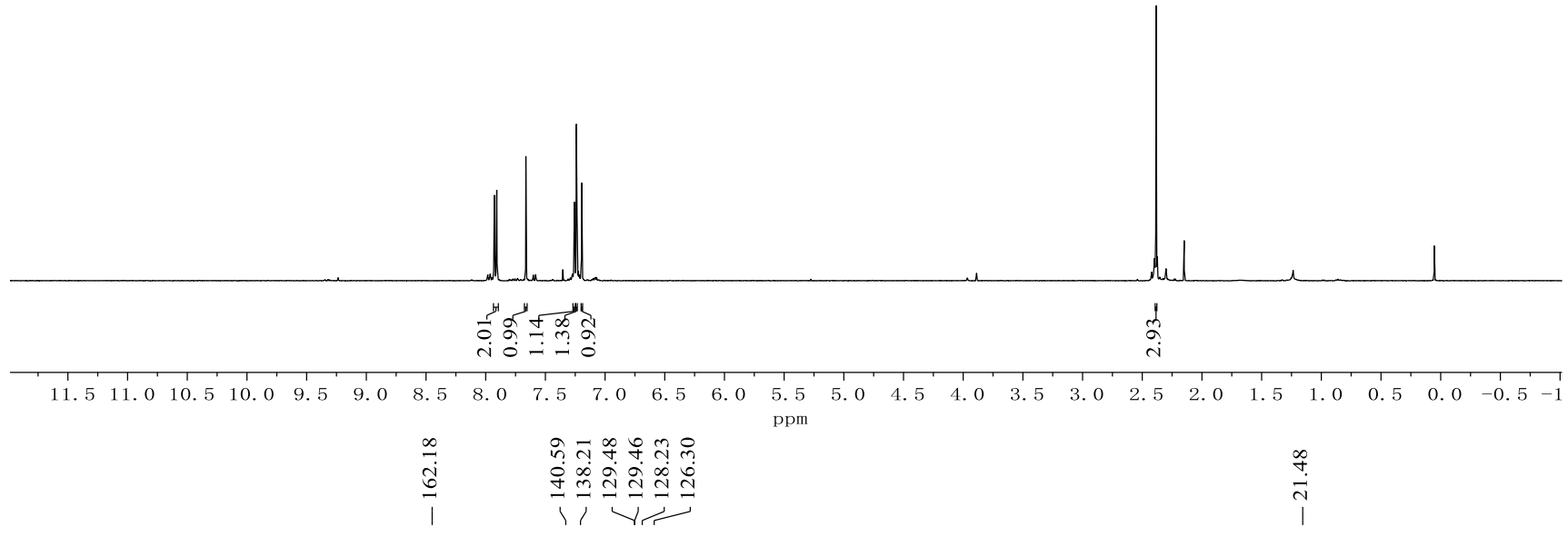<smiles>Cc1ccc(-c2ncco2)cc1</smiles>

$447 \mathrm{~g}$

$\left(100 \mathrm{MHz}, \mathrm{CDCl}_{3}\right)$

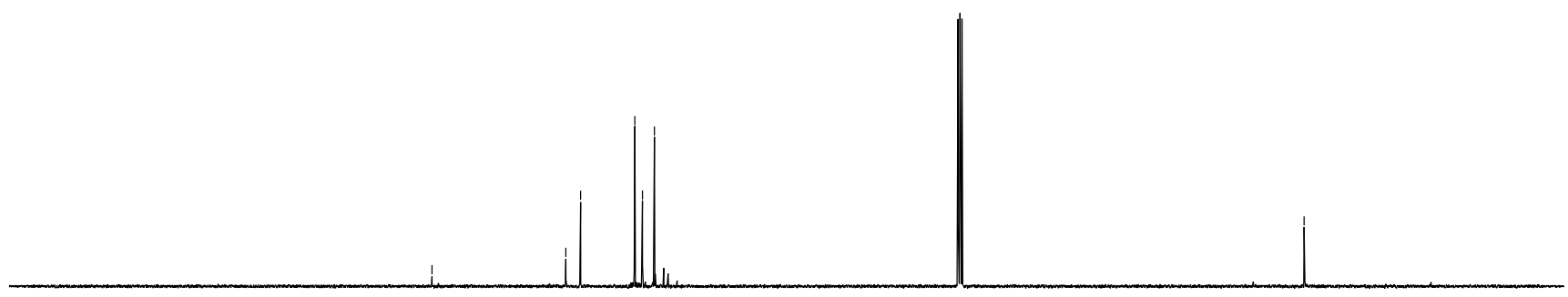

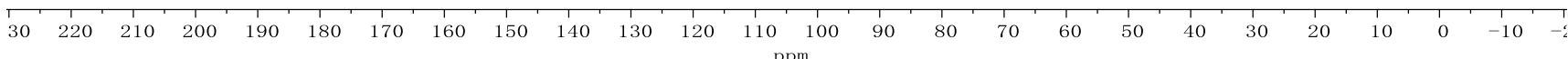



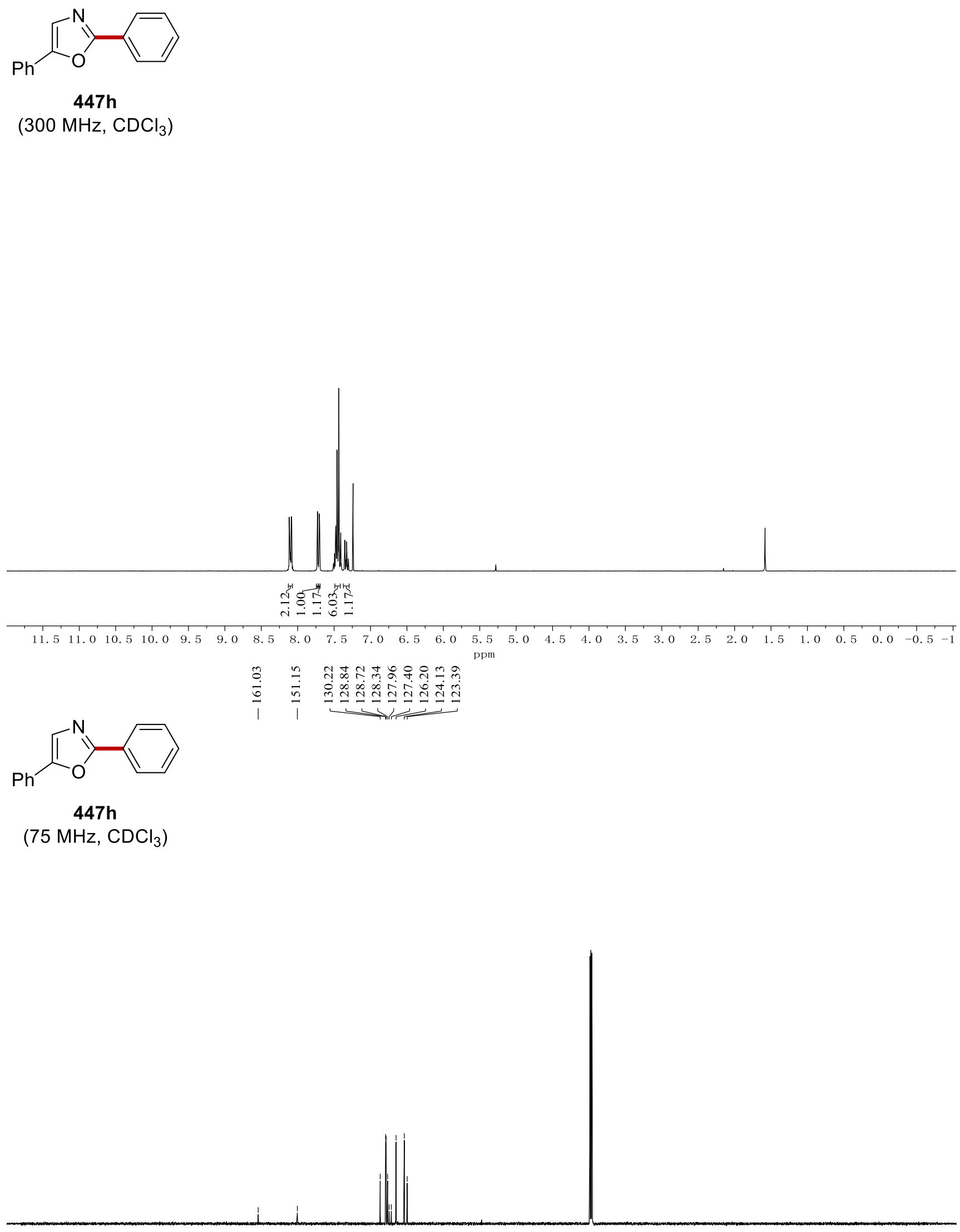

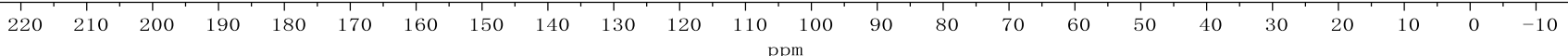



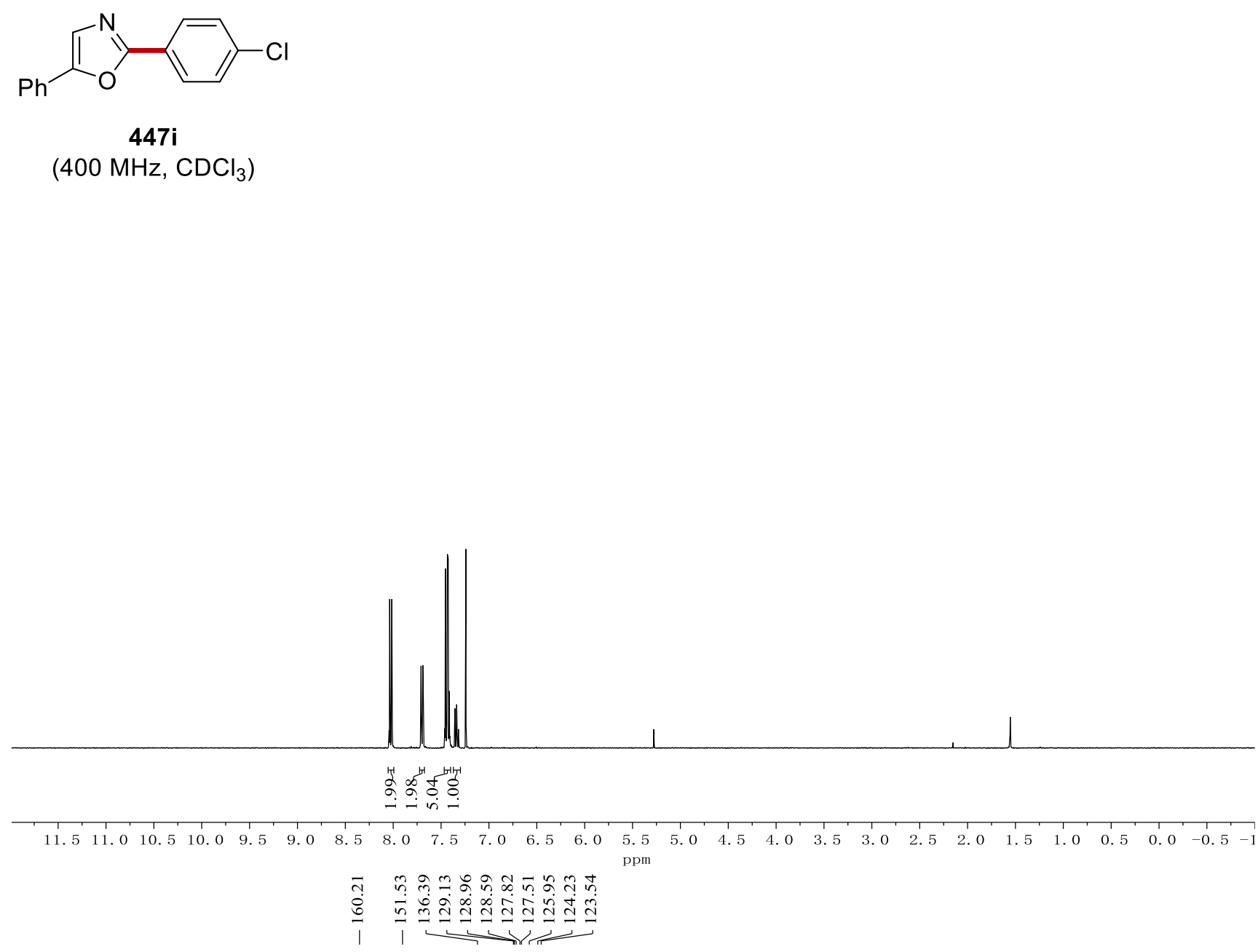<smiles>Clc1ccc(-c2ncc(-c3ccccc3)o2)cc1</smiles>

447i

(100 MHz, $\mathrm{CDCl}_{3}$ )

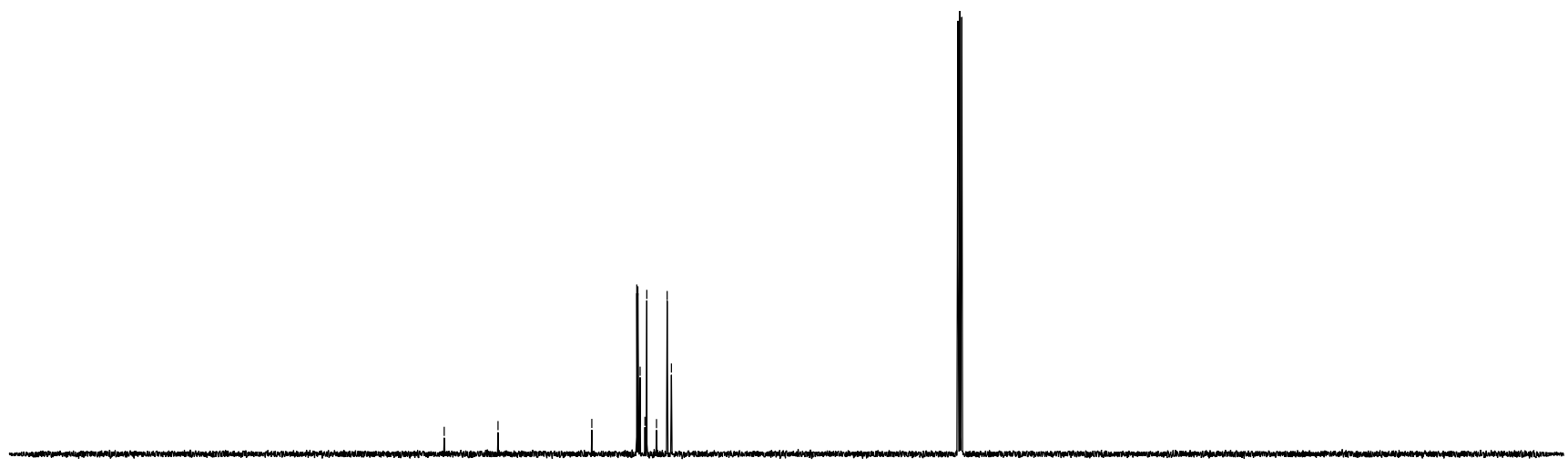

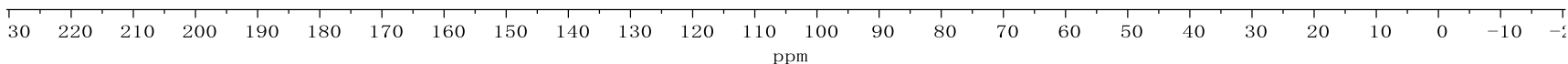


<smiles>Cc1cccc(-c2ncc(-c3ccccc3)o2)c1</smiles>

447j

$\left(300 \mathrm{MHz}, \mathrm{CDCl}_{3}\right)$

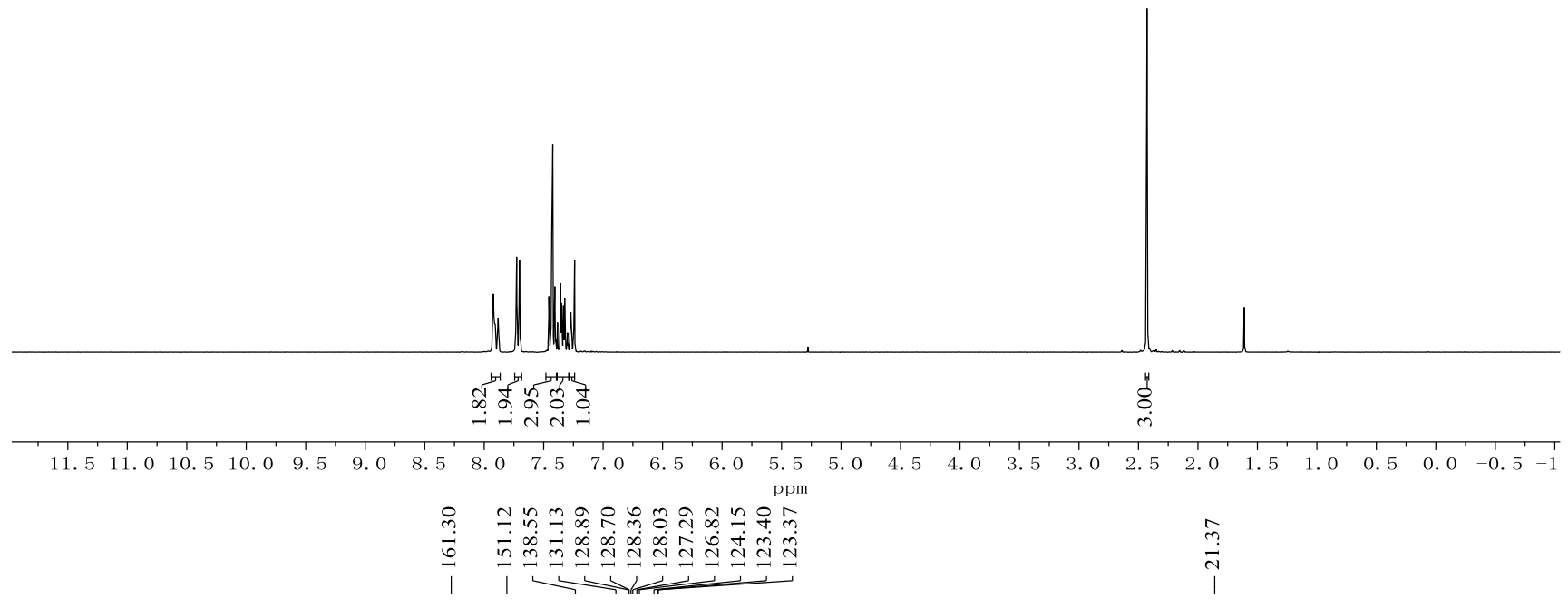<smiles>Cc1cccc(-c2ncc(-c3ccccc3)o2)c1</smiles>

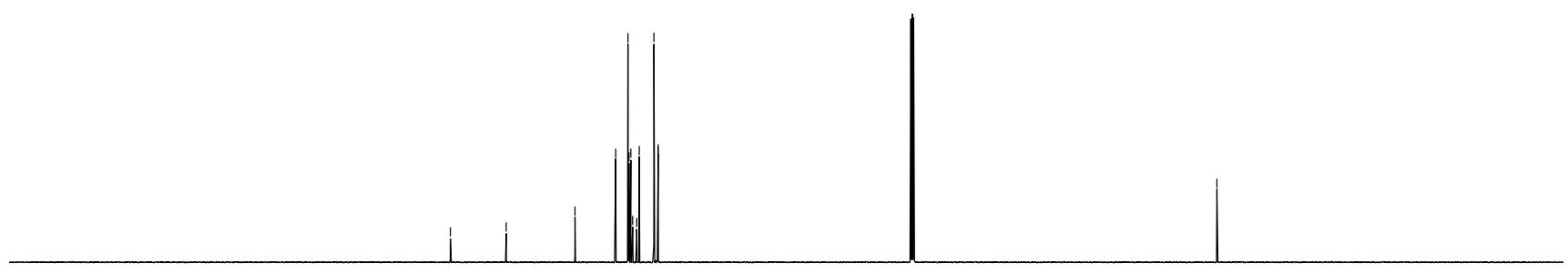

$\begin{array}{llllllllllllllllllllllllllllllllllll}740 & 230 & 220 & 210 & 200 & 190 & 180 & 170 & 160 & 150 & 140 & 130 & 120 & 110 & 100 & 90 & 80 & 70 & 60 & 50 & 40 & 30 & 20 & 10 & 0 & -10 & -20 & -30 & -4\end{array}$ 
<smiles>CC(C)(C)OC(=O)OCc1ccc(F)cc1</smiles>

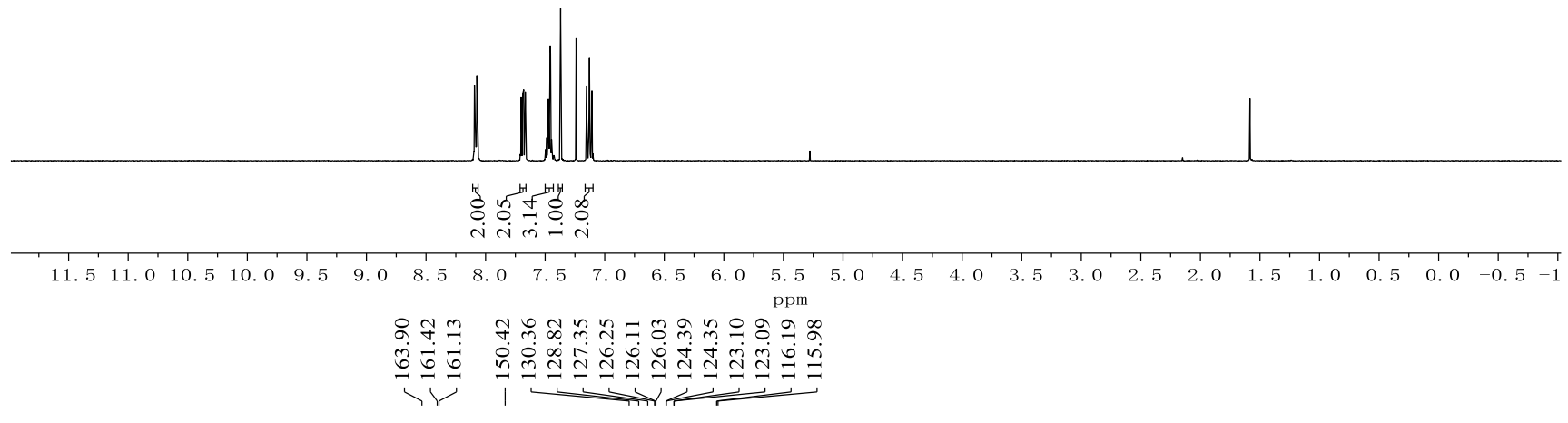<smiles>Fc1ccc(-c2cnc(-c3ccccc3)o2)cc1</smiles>

$\left(100 \mathrm{MHz}, \mathrm{CDCl}_{3}\right)$

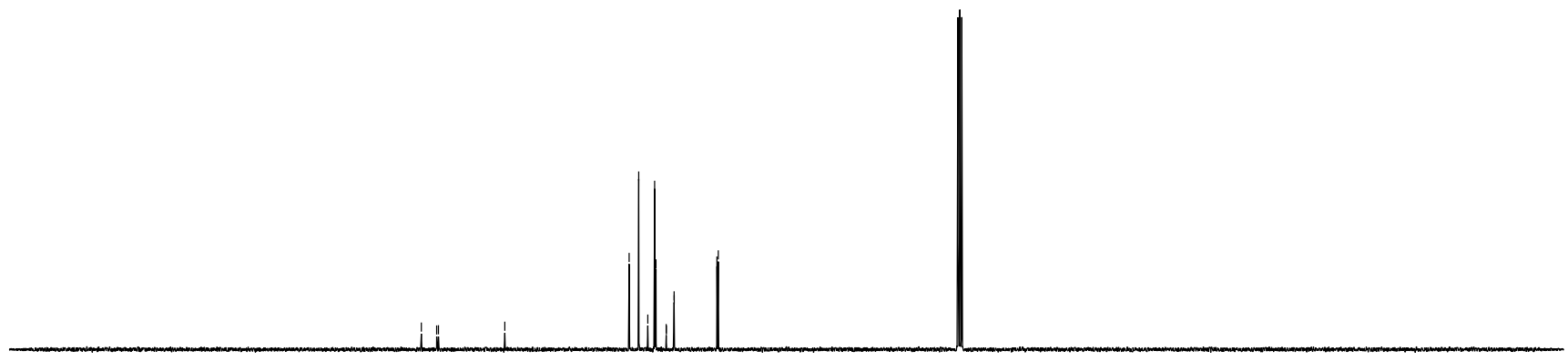

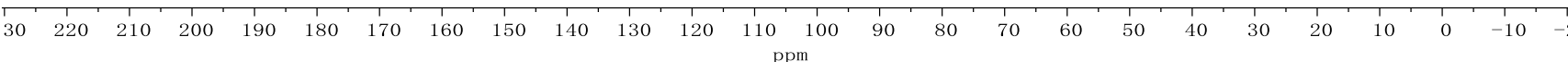




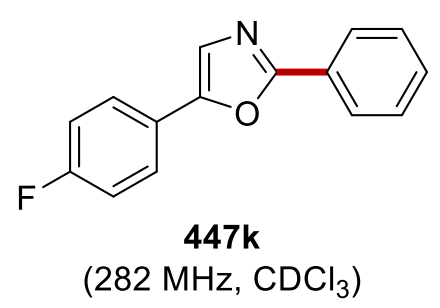

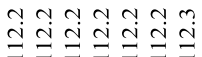

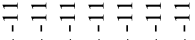

$\mathrm{MHz}_{2} \mathrm{CDCl}_{3}$

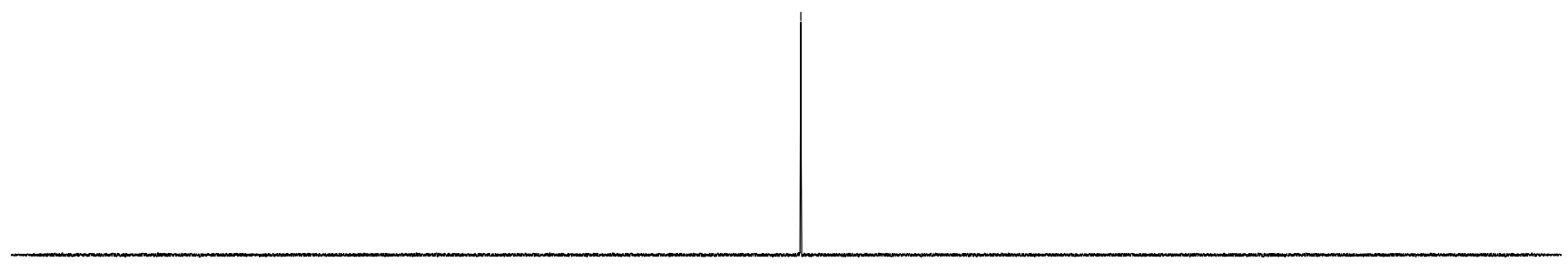

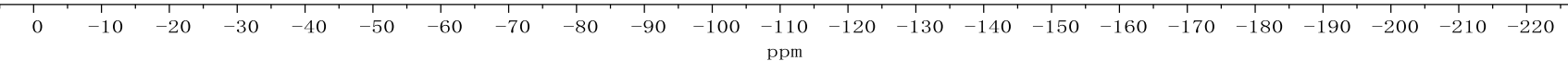



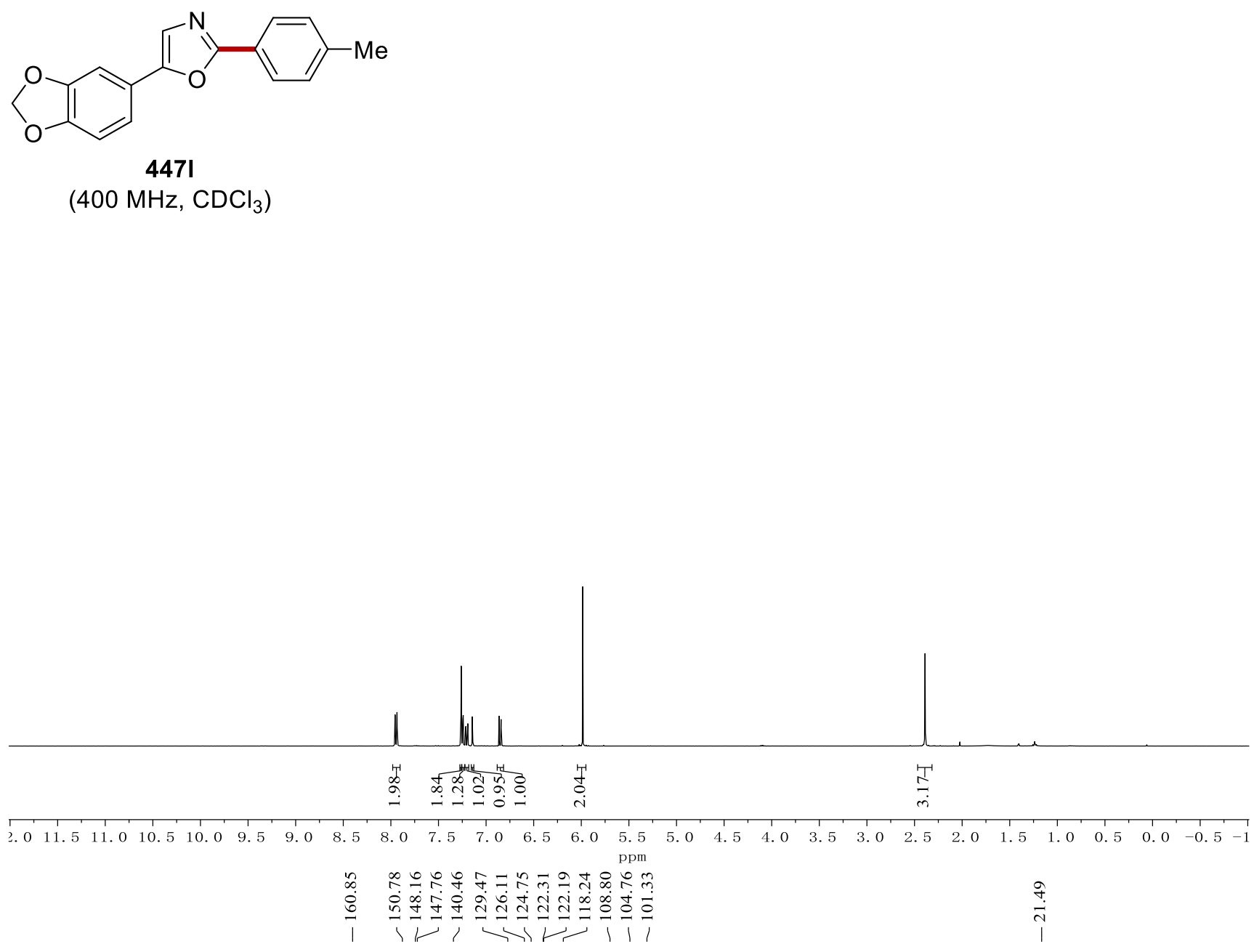<smiles>Cc1ccc(-c2ncc(-c3ccc4c(c3)OCO4)o2)cc1</smiles>

4471

(100 MHz, $\mathrm{CDCl}_{3}$ )

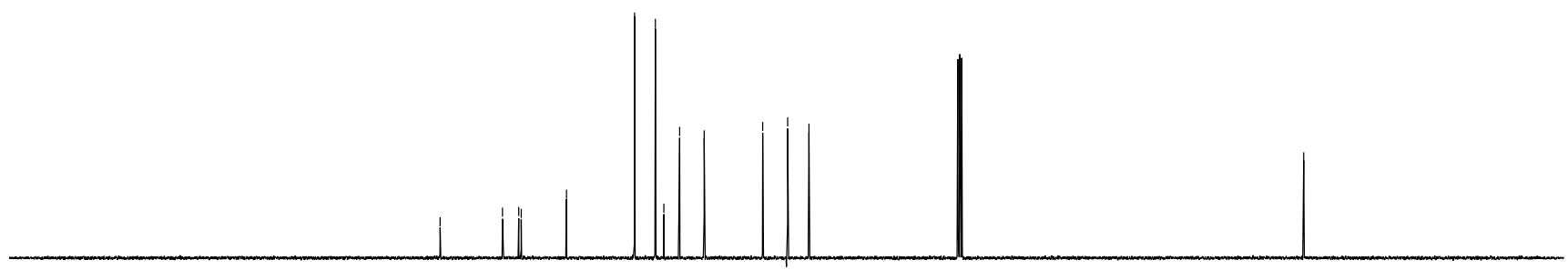

\begin{tabular}{lllllllllllllllllllllllllll}
\hline 30 & 220 & 210 & 200 & 190 & 180 & 170 & 160 & 150 & 140 & 130 & 120 & 110 & 100 & 90 & 80 & 70 & 60 & 50 & 40 & 30 & 20 & 10 & 0 & -10 & -
\end{tabular} 


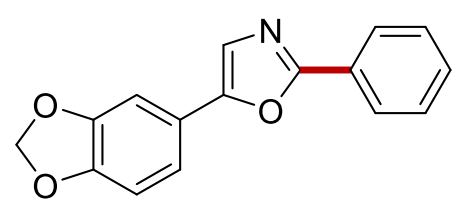

$447 \mathrm{~m}$

(400 MHz, $\mathrm{CDCl}_{3}$ )

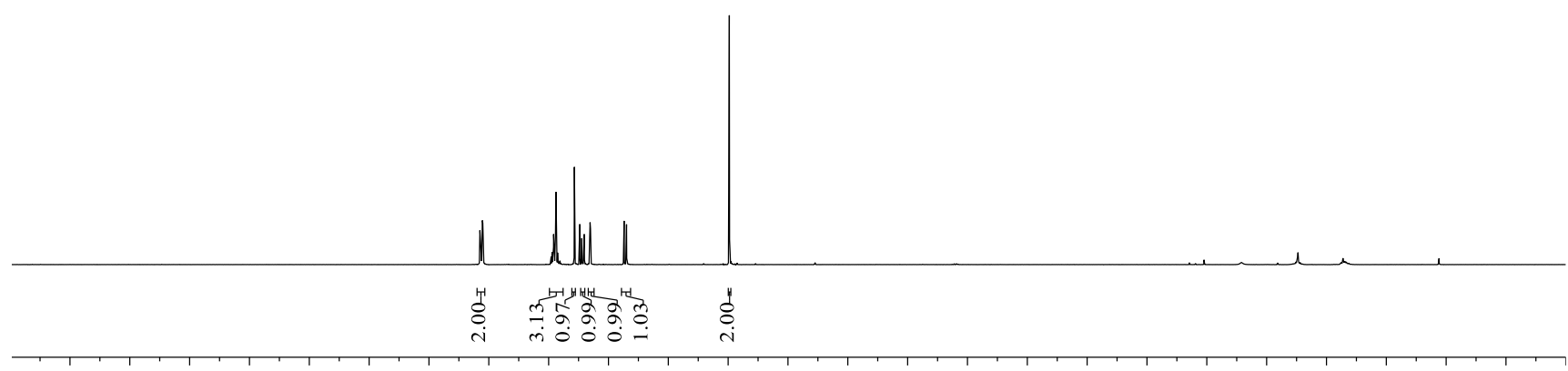

$\begin{array}{llllllllllllllllllllllllll}11.5 & 11.0 & 10.5 & 10.0 & 9.5 & 9.0 & 8.5 & 8.0 & 7.5 & 7.0 & 6.5 & 6.0 & 5.5 & 5.0 & 4.5 & 4.0 & 3.5 & 3.0 & 2.5 & 2.0 & 1.5 & 1.0 & 0.5 & 0.0 & -0.5 & -1\end{array}$

in

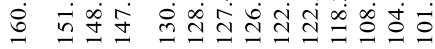<smiles>c1ccc(-c2ncc(-c3ccc4c(c3)OCO4)o2)cc1</smiles>

$447 \mathrm{~m}$

$\left(100 \mathrm{MHz}, \mathrm{CDCl}_{3}\right)$

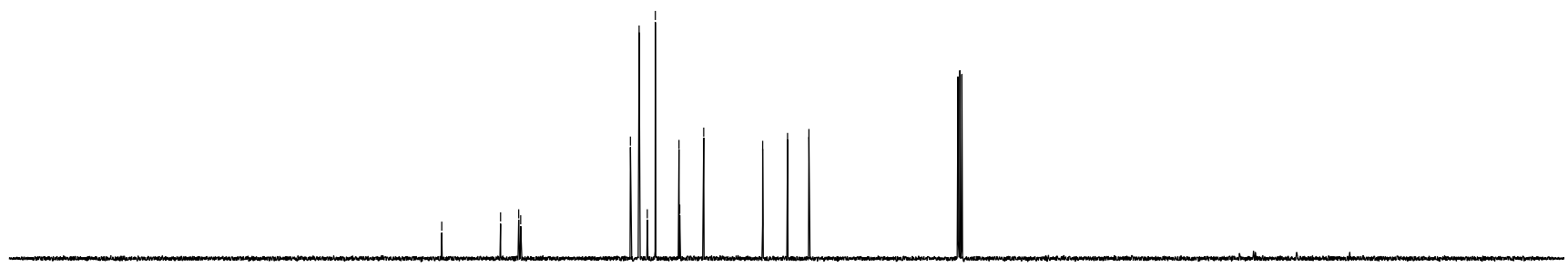

\begin{tabular}{llllllllllllllllllllllllll}
\hline 30 & 220 & 210 & 200 & 190 & 180 & 170 & 160 & 150 & 140 & 130 & 120 & 110 & 100 & 90 & 80 & 70 & 60 & 50 & 40 & 30 & 20 & 10 & 0 & -10 & -1
\end{tabular} 


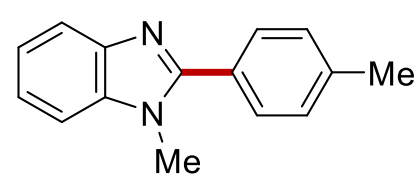

446a

$\left(400 \mathrm{MHz}, \mathrm{CDCl}_{3}\right)$

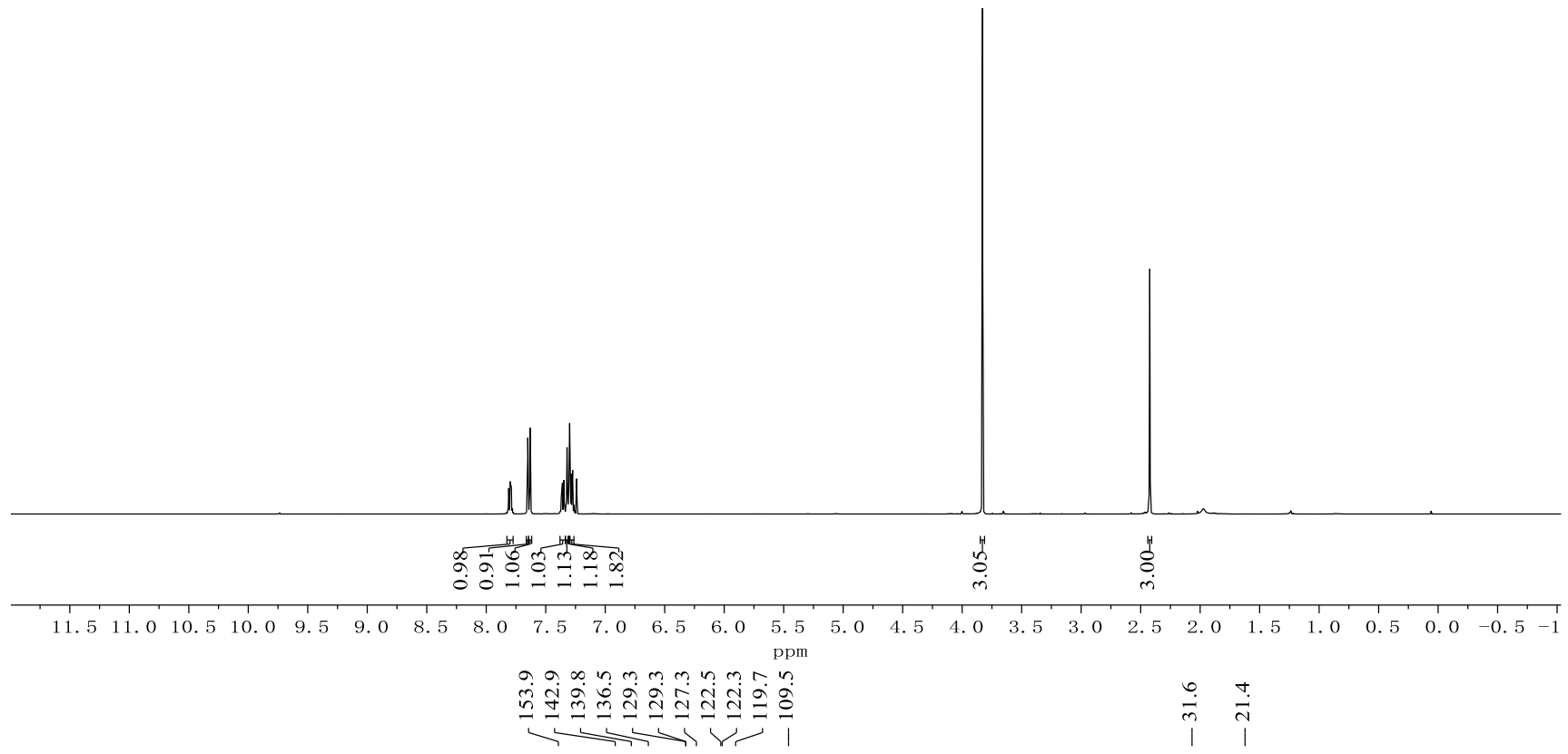<smiles>Cc1ccc(-c2nc3ccccc3n2C)cc1</smiles>

446a

$\left(100 \mathrm{MHz} \mathrm{CDCl}_{3}\right)$

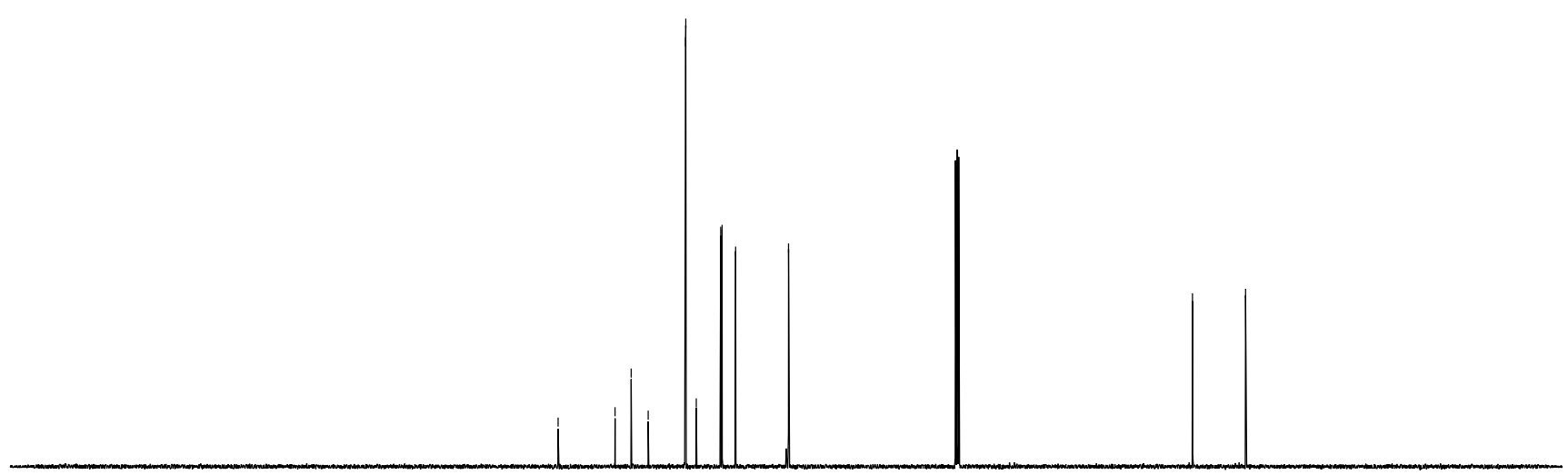

$\begin{array}{lllllllllllllllllllllllllllllllllll}1 & 250 & 240 & 230 & 220 & 210 & 200 & 190 & 180 & 170 & 160 & 150 & 140 & 130 & 120 & 110 & 100 & 90 & 80 & 70 & 60 & 50 & 40 & 30 & 20 & 10 & 0 & -10 & -20 & -30\end{array}$ 
<smiles>Cn1c(-c2ccccc2)nc2ccccc21</smiles>

446b

$\left(400 \mathrm{MHz}, \mathrm{CDCl}_{3}\right)$
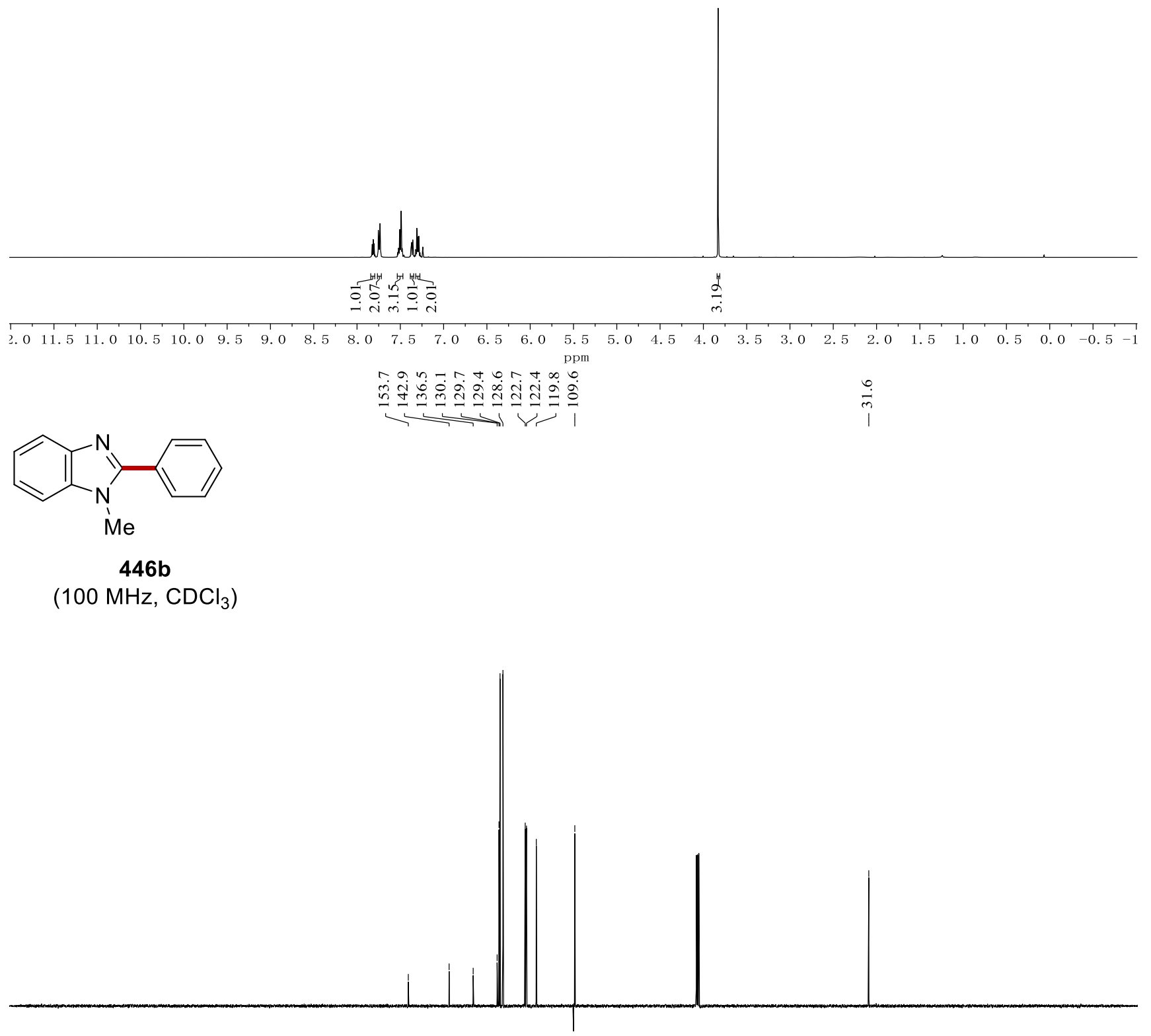

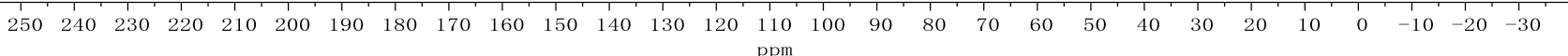


<smiles>COc1ccc(-c2nc3ccccc3n2C)cc1</smiles>

446c

$\left(400 \mathrm{MHz}, \mathrm{CDCl}_{3}\right)$

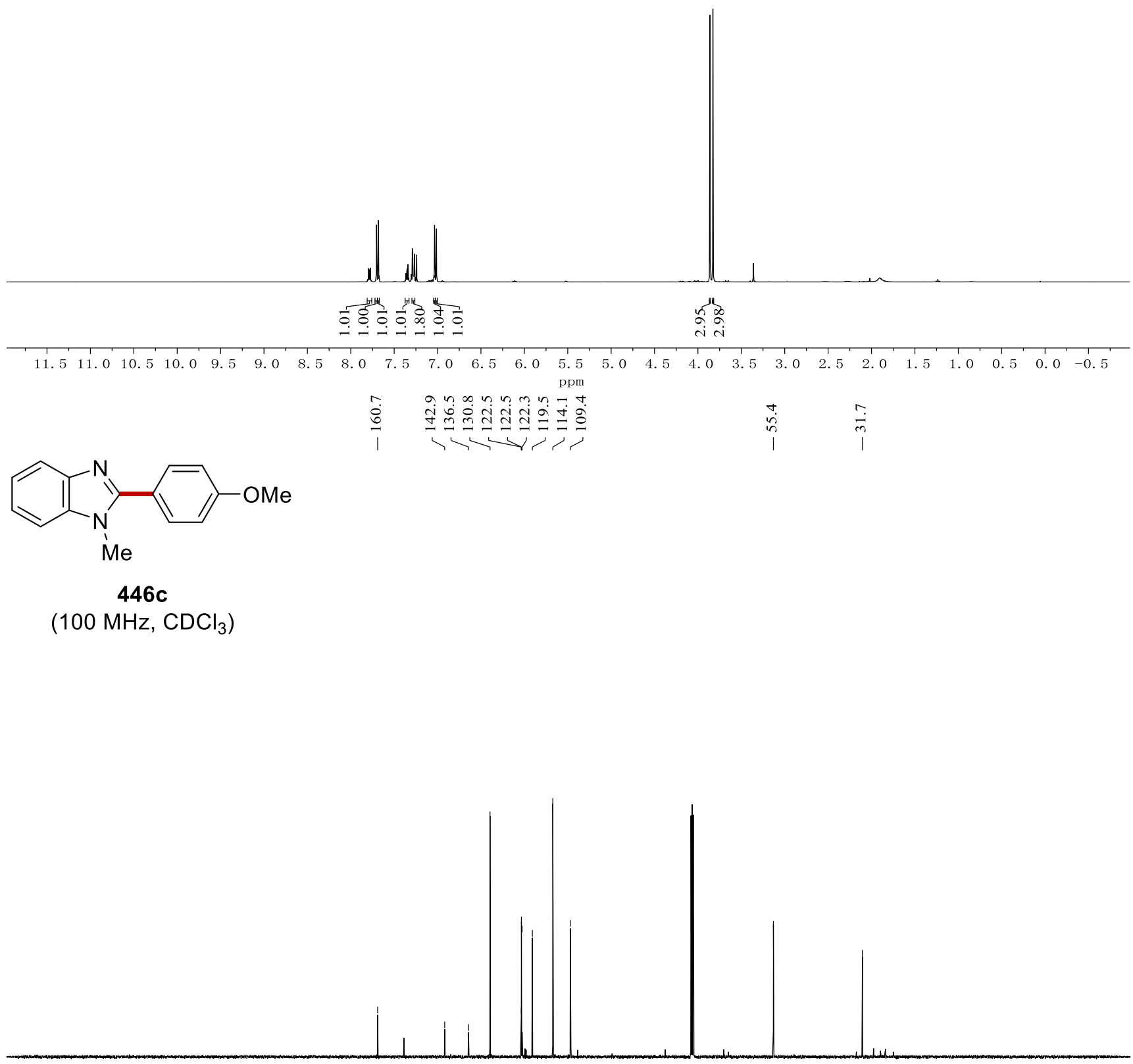

$\begin{array}{lllllllllllllllllllllllllllllllllll}1 & 250 & 240 & 230 & 220 & 210 & 200 & 190 & 180 & 170 & 160 & 150 & 140 & 130 & 120 & 110 & 100 & 90 & 80 & 70 & 60 & 50 & 40 & 30 & 20 & 10 & 0 & -10 & -20 & -30\end{array}$ 
<smiles>Cn1c(-c2ccc(F)cc2)nc2ccccc21</smiles>

446d

$\left(400 \mathrm{MHz}, \mathrm{CDCl}_{3}\right)$

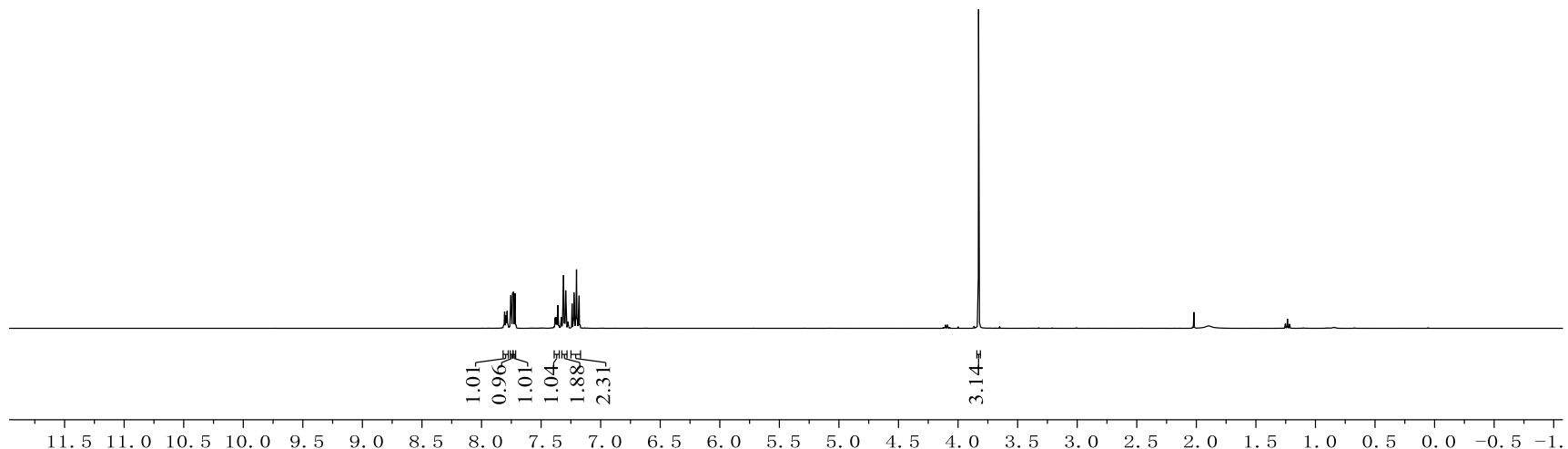

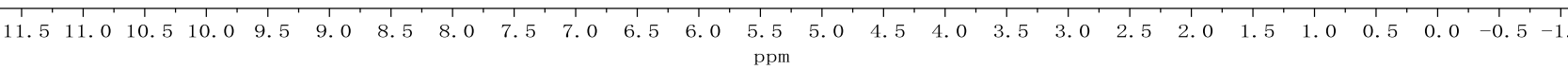

$\underbrace{0}$<smiles>Cn1c(-c2ccc(F)cc2)nc2ccccc21</smiles>

446d

$\left(100 \mathrm{MHz}, \mathrm{CDCl}_{3}\right)$

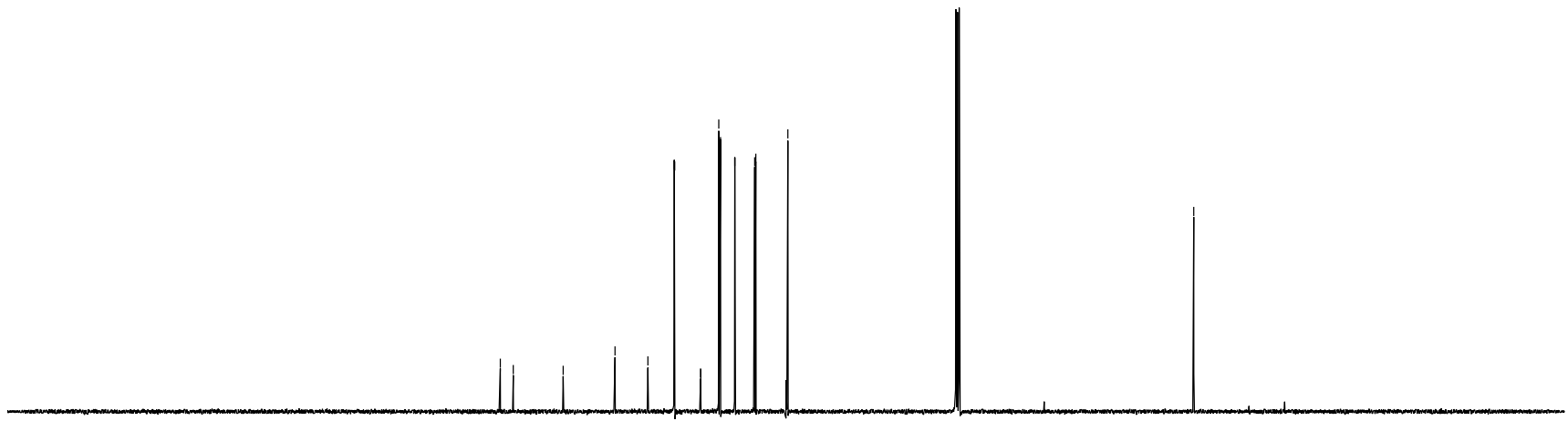

$\begin{array}{lllllllllllllllllllllllllllllllllll}1 & 250 & 240 & 230 & 220 & 210 & 200 & 190 & 180 & 170 & 160 & 150 & 140 & 130 & 120 & 110 & 100 & 90 & 80 & 70 & 60 & 50 & 40 & 30 & 20 & 10 & 0 & -10 & -20 & -30\end{array}$ 


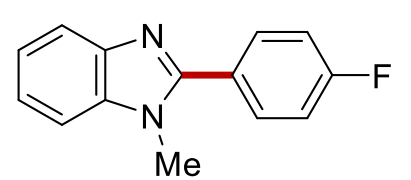

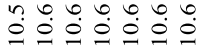

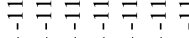

446d

$\left(282 \mathrm{MHz}, \mathrm{CDCl}_{3}\right)$

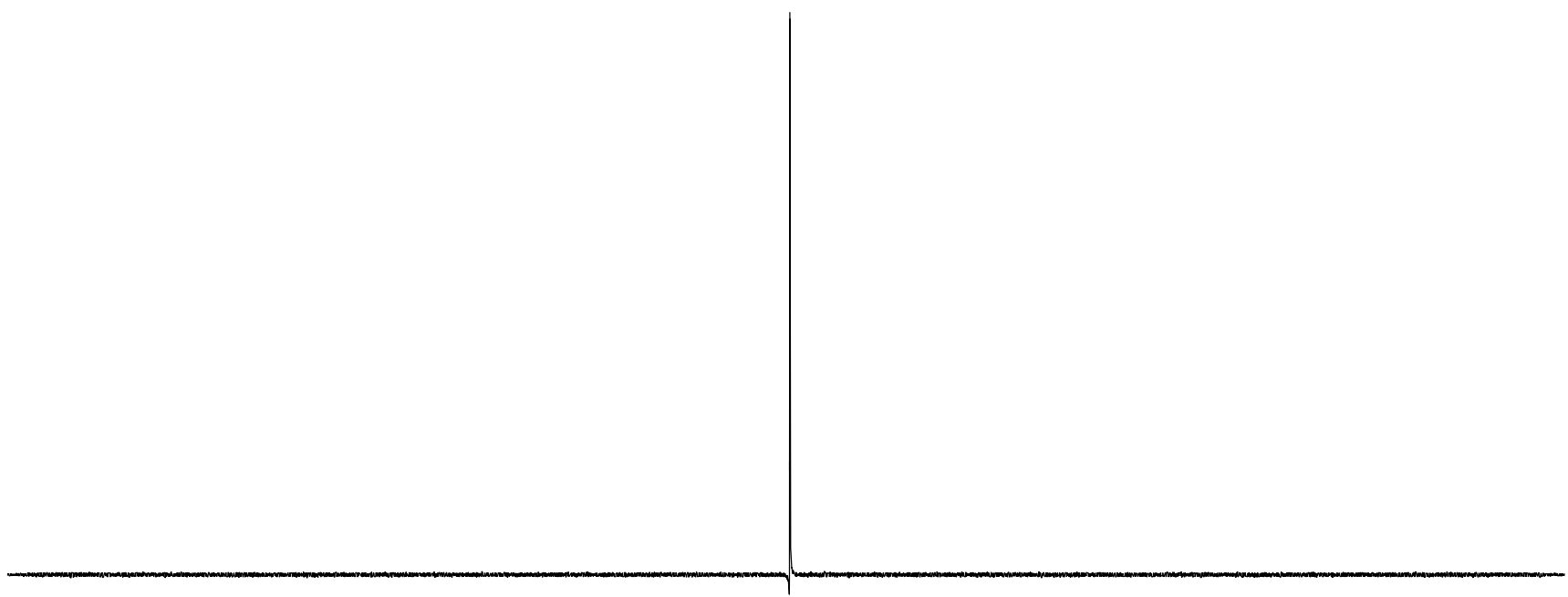

\begin{tabular}{|llllllllllllllllllllllll}
\hline & 0 & -10 & -20 & -30 & -40 & -50 & -60 & -70 & -80 & -90 & -100 & -110 & -120 & -130 & -140 & -150 & -160 & -170 & -180 & -190 & -200 & -210 & -220
\end{tabular} 


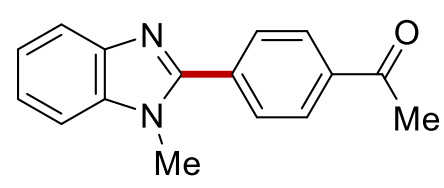

$446 e$

$\left(400 \mathrm{MHz}, \mathrm{CDCl}_{3}\right)$

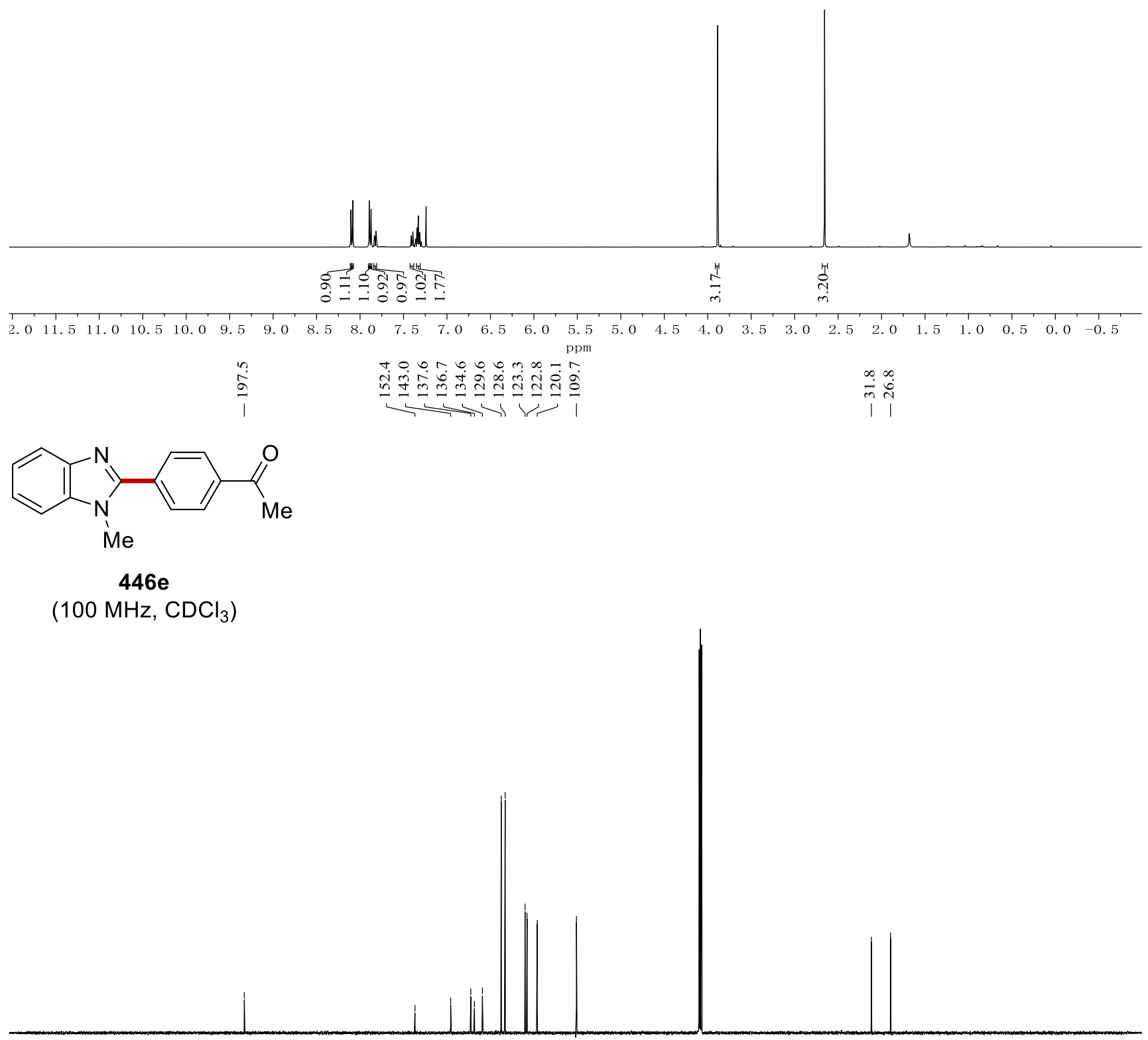

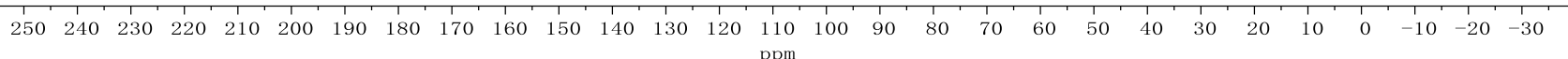



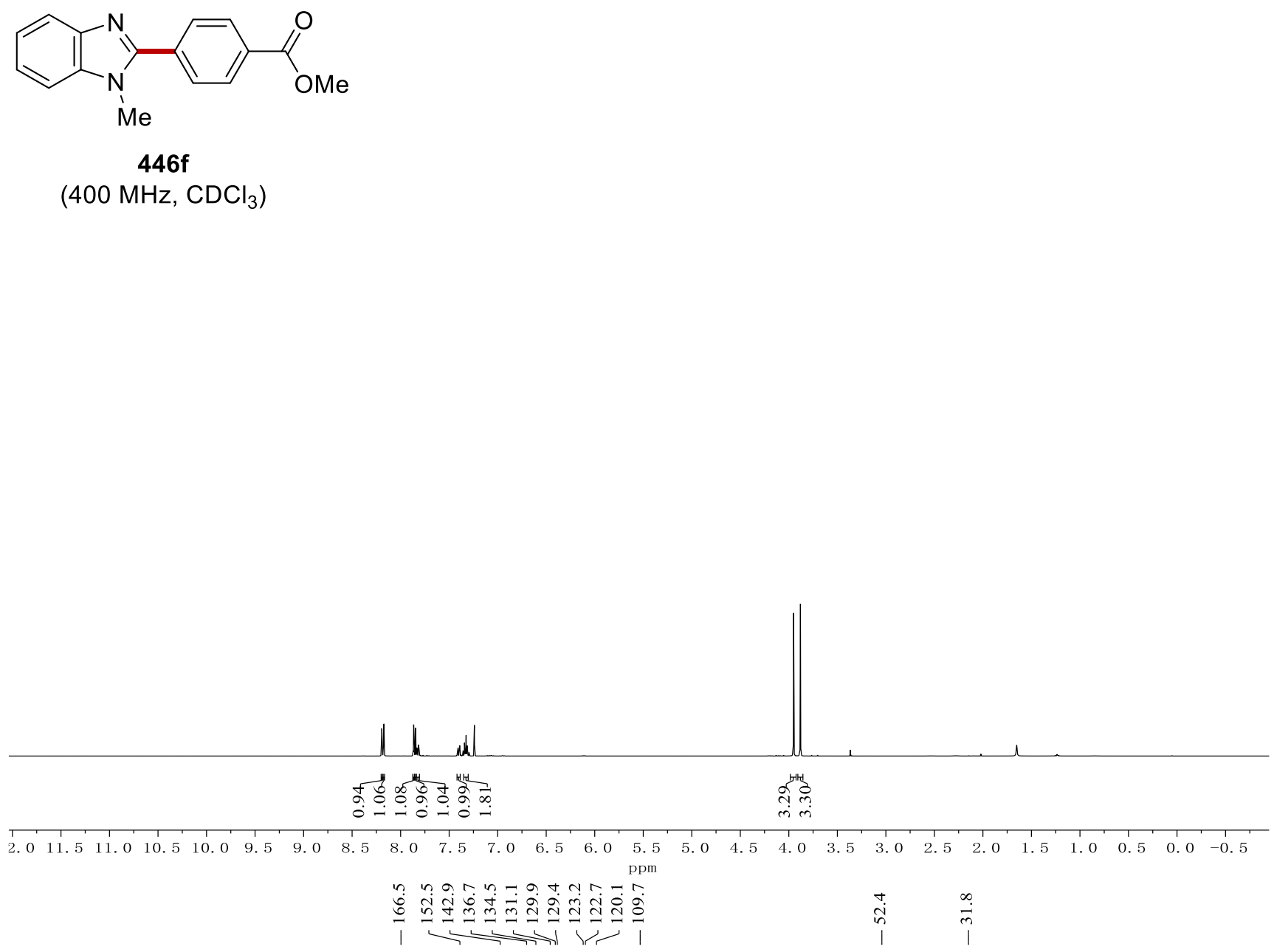<smiles>COC(=O)c1ccc(-c2nc3ccccc3n2C)cc1</smiles>

$446 f$

(100 MHz, $\mathrm{CDCl}_{3}$ )

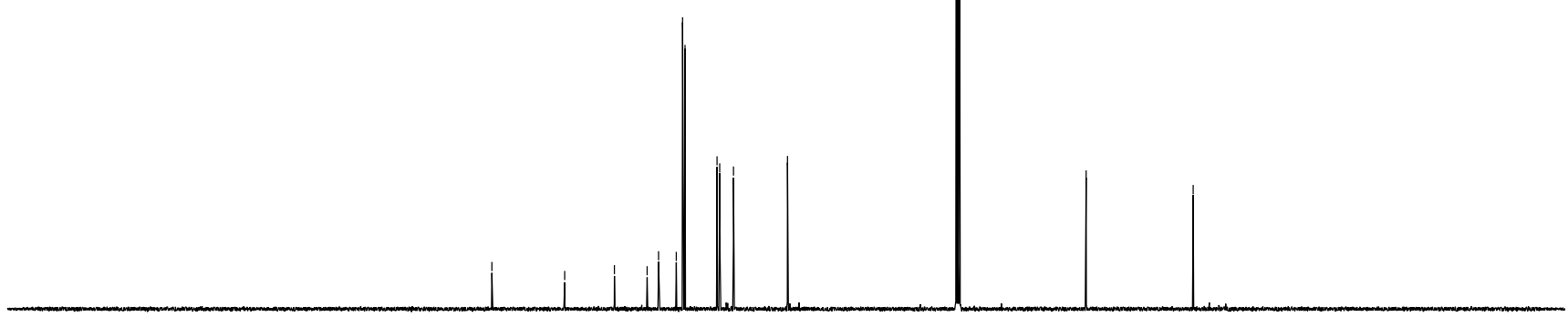

$\begin{array}{lllllllllllllllllllllllllllllllllllll}1 & 250 & 240 & 230 & 220 & 210 & 200 & 190 & 180 & 170 & 160 & 150 & 140 & 130 & 120 & 110 & 100 & 90 & 80 & 70 & 60 & 50 & 40 & 30 & 20 & 10 & 0 & -10 & -20 & -30\end{array}$ 


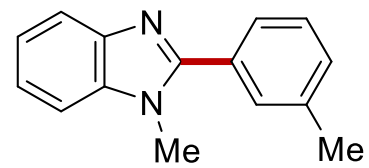

$446 \mathrm{~g}$

(400 MHz, $\mathrm{CDCl}_{3}$ )
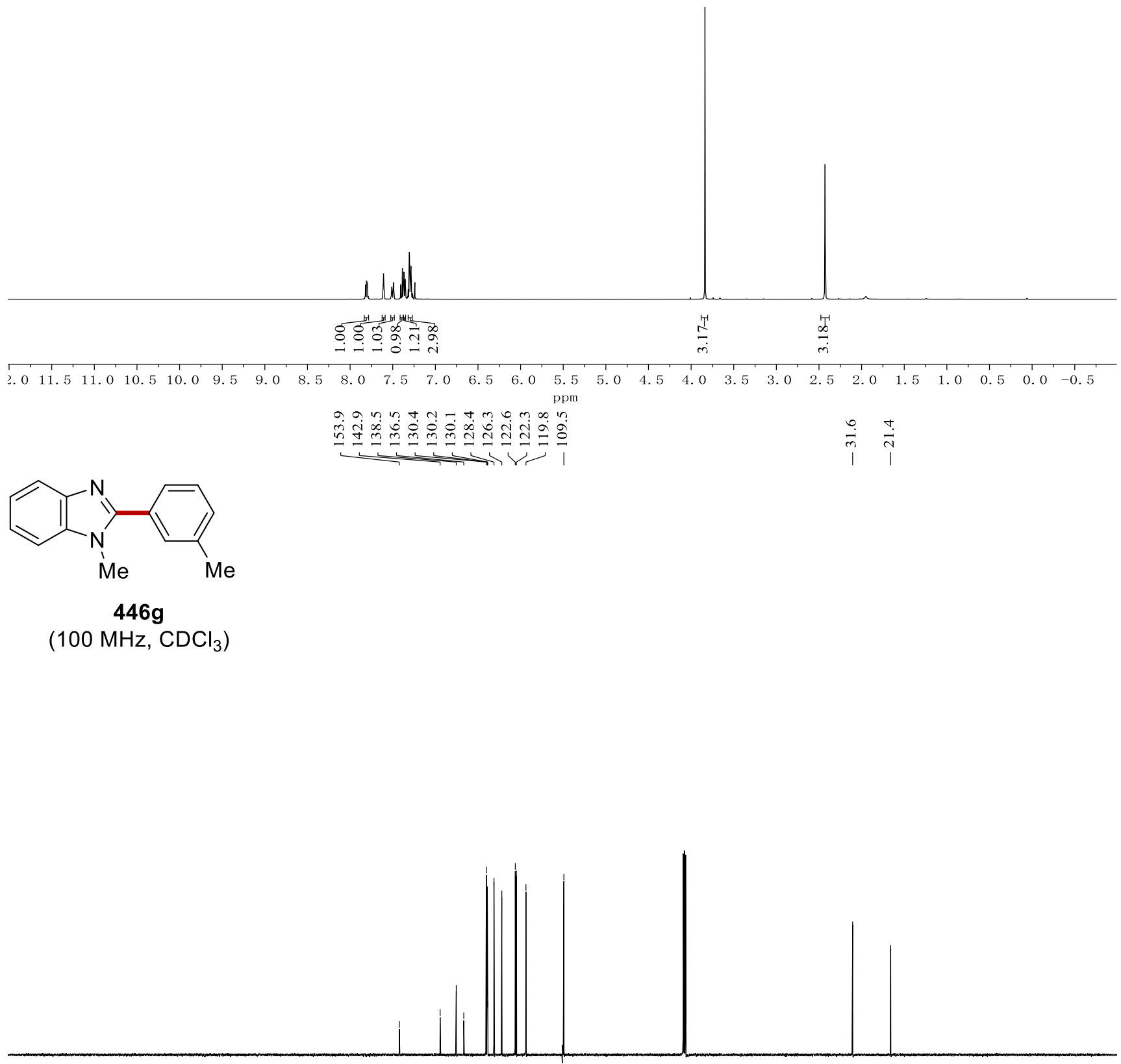

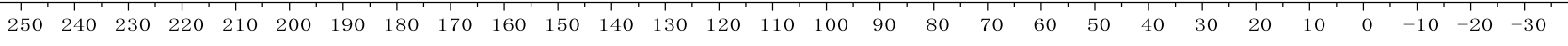
ppm 


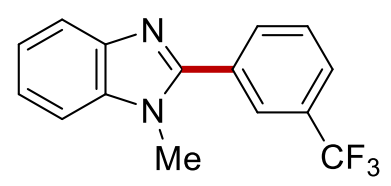

446h

$\left(500 \mathrm{MHz}, \mathrm{CDCl}_{3}\right)$

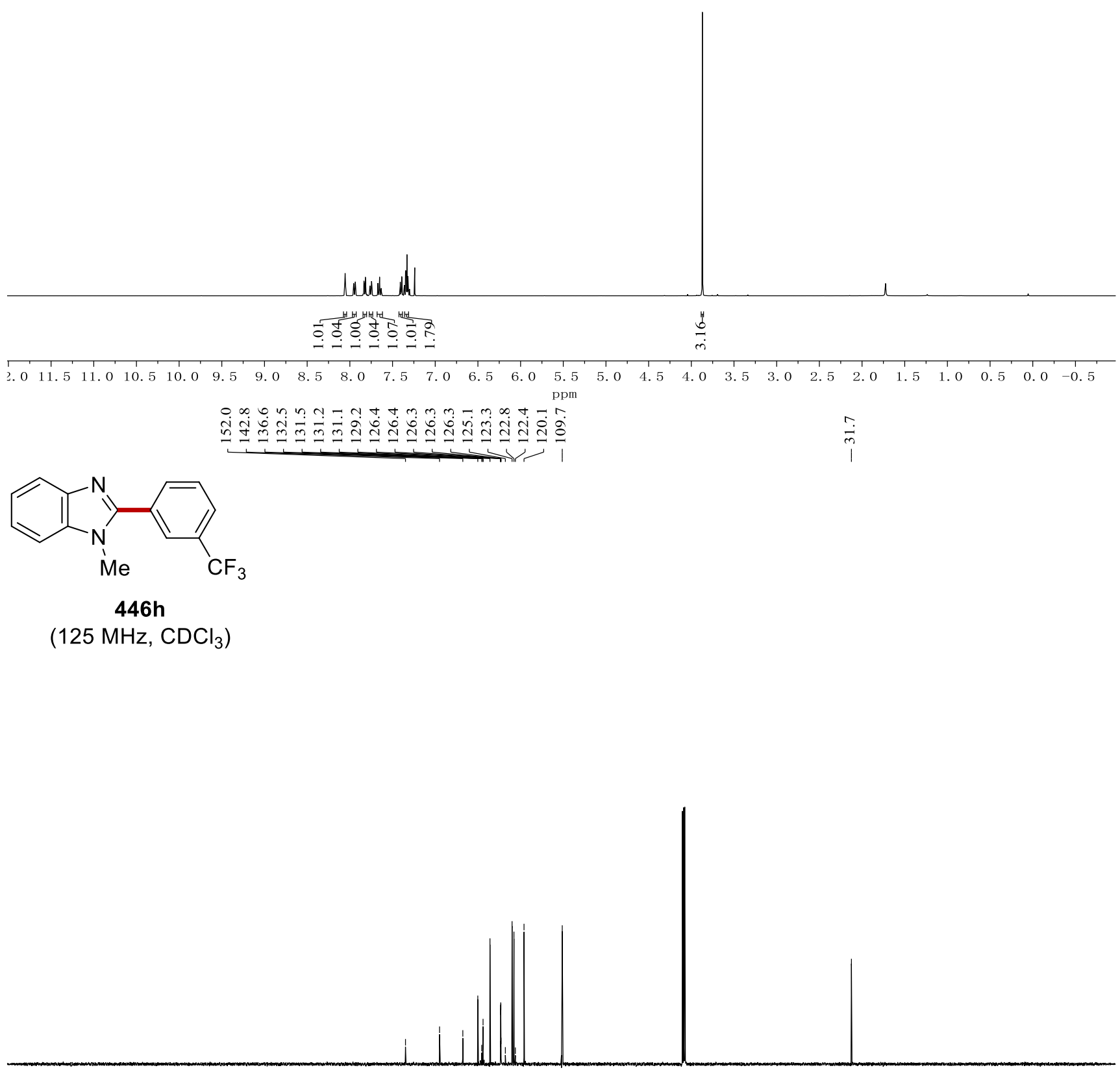

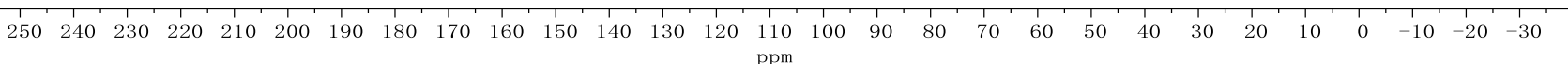




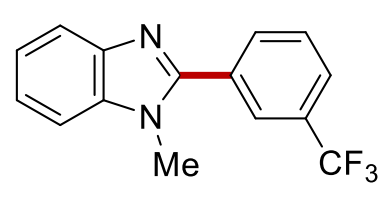

îj

446h

$\left(282 \mathrm{MHz} \mathrm{CDCl}_{3}\right)$

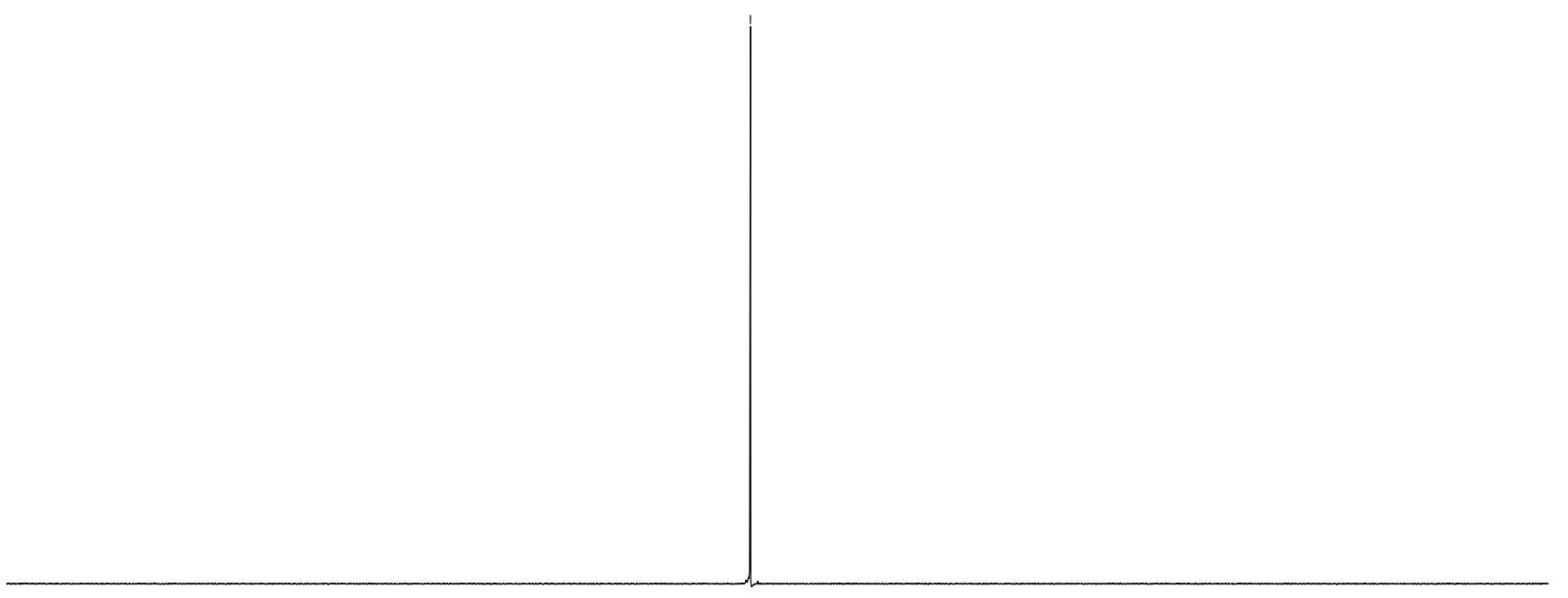

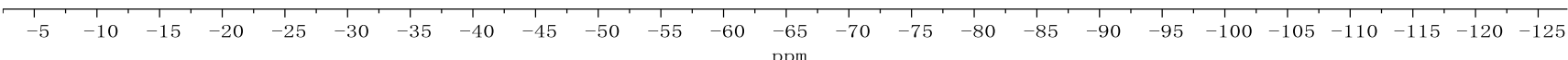




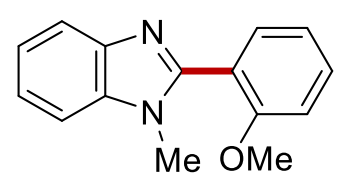

446i

$\left(400 \mathrm{MHz}, \mathrm{CDCl}_{3}\right)$

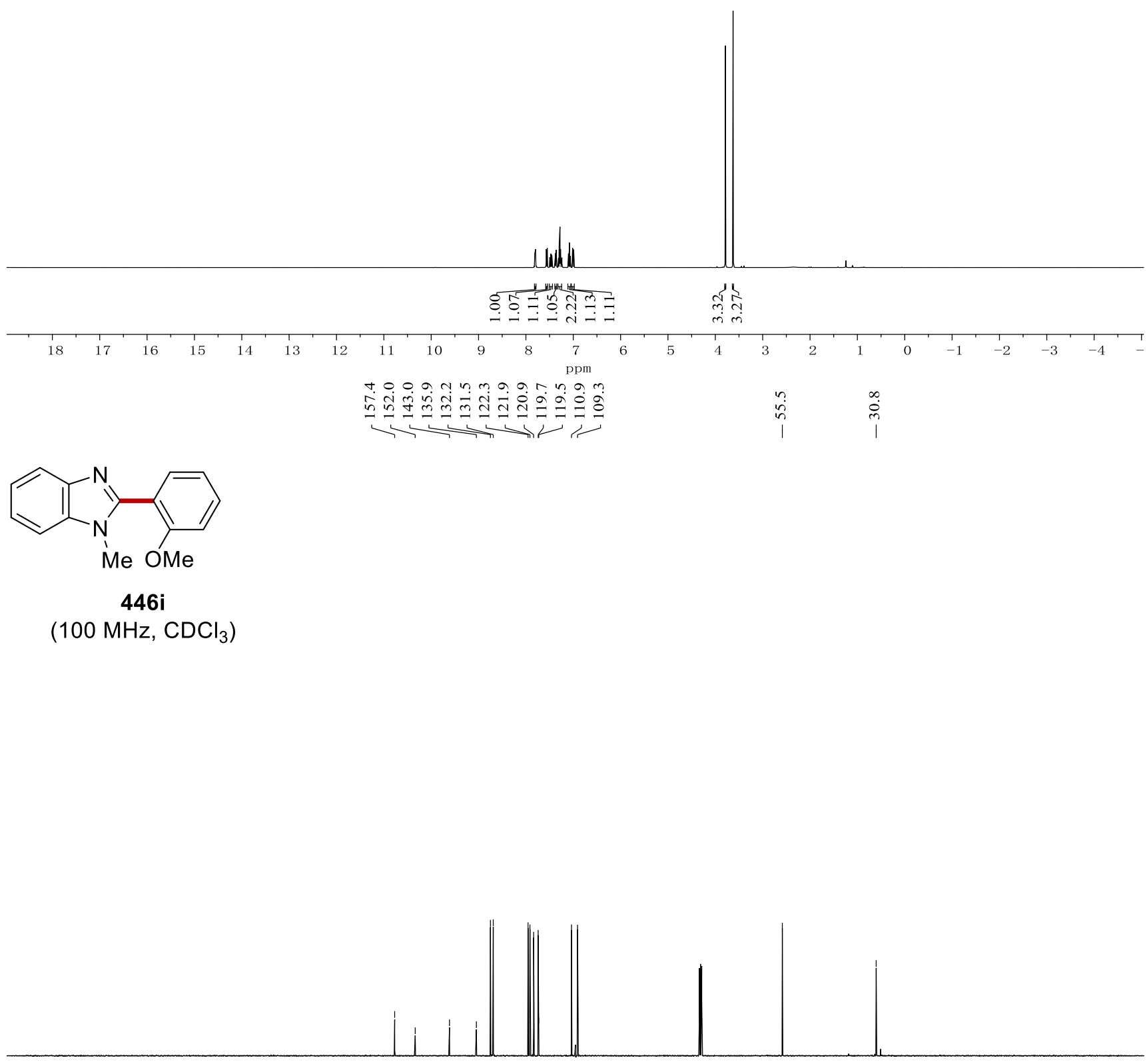

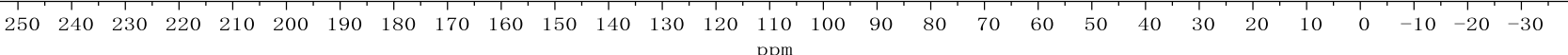




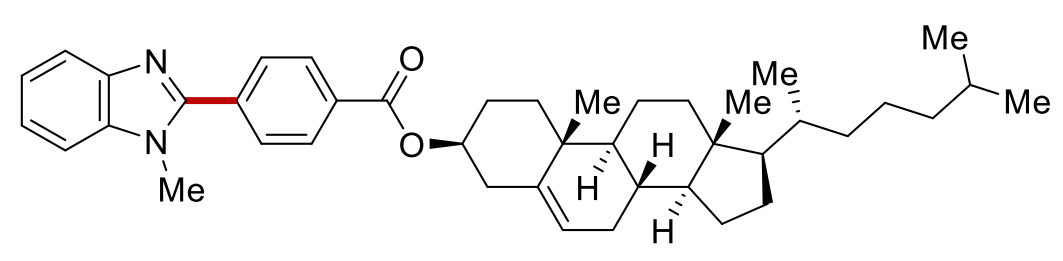

446j

$\left(400 \mathrm{MHz}, \mathrm{CDCl}_{3}\right)$

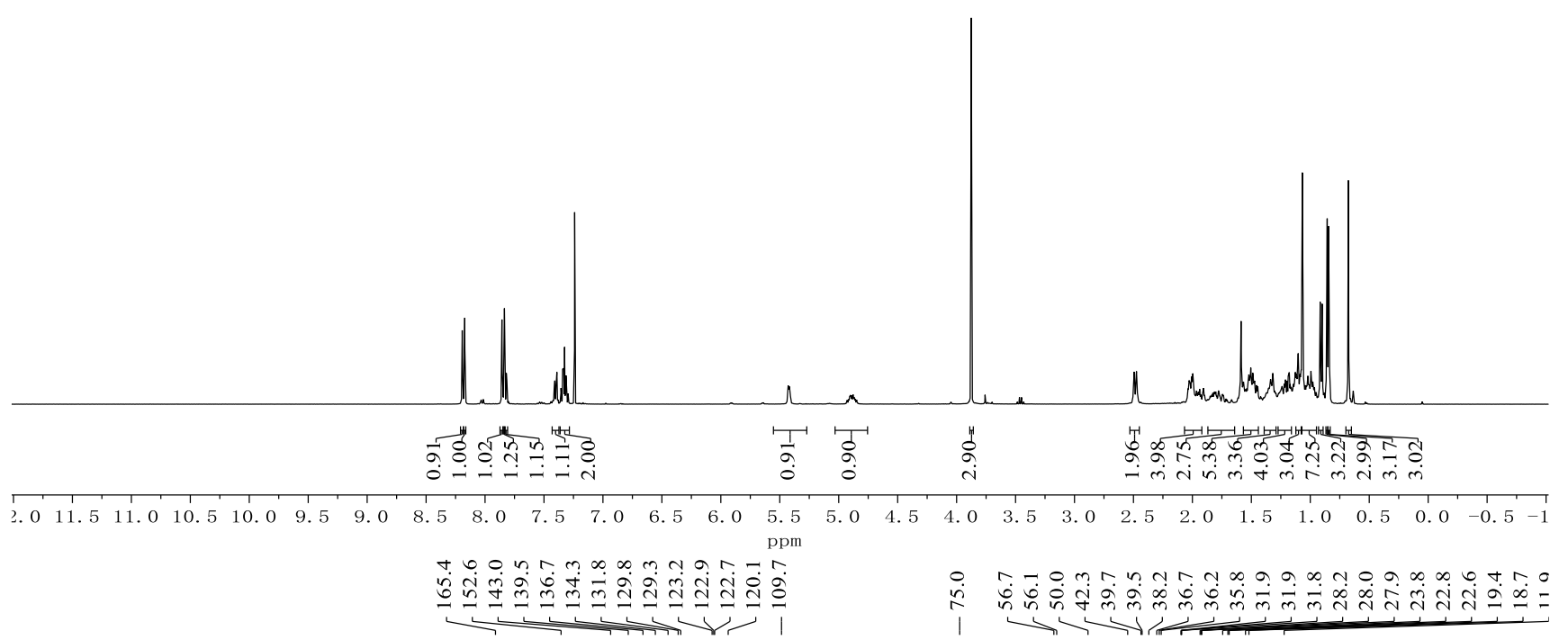

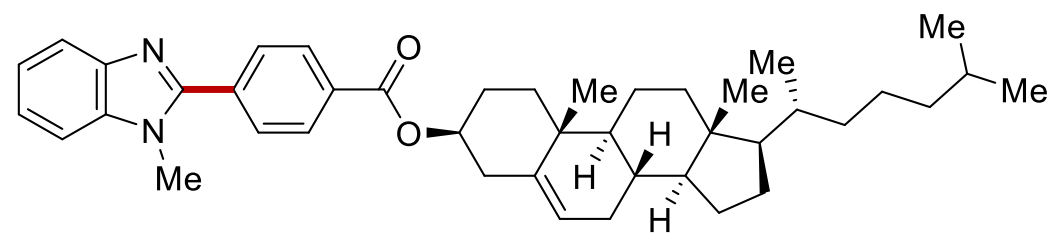

446j

(100 MHz, $\mathrm{CDCl}_{3}$ )

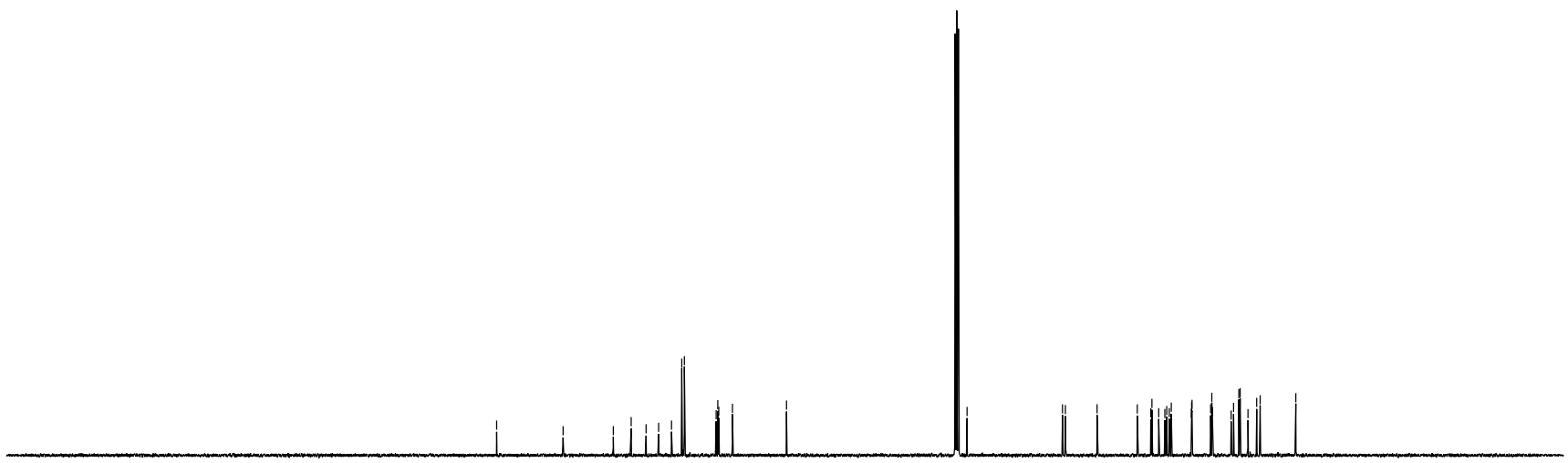

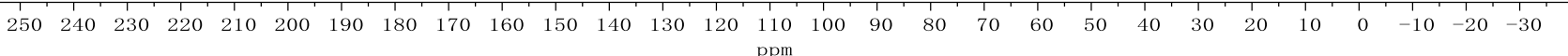




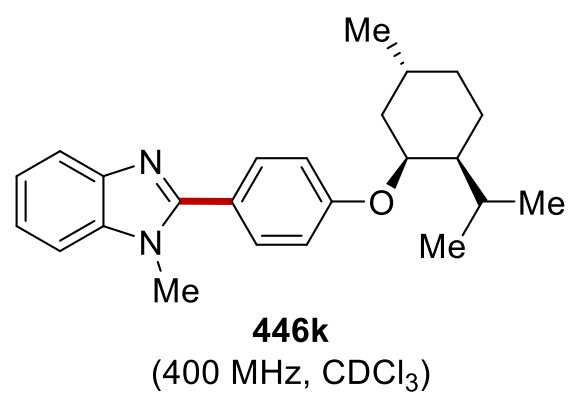

(400 MHz, $\mathrm{CDCl}_{3}$ )

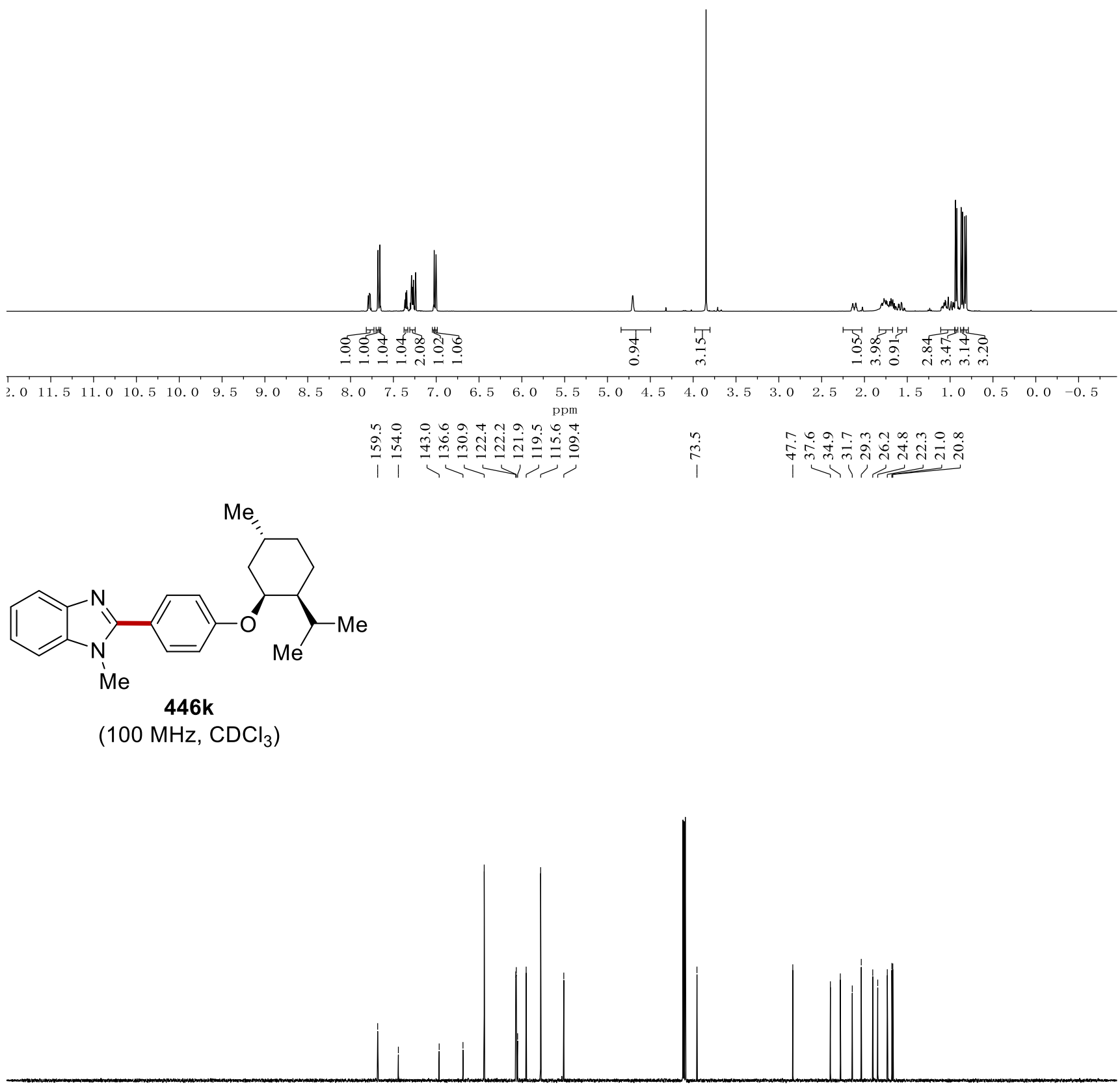

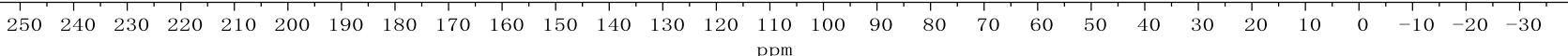




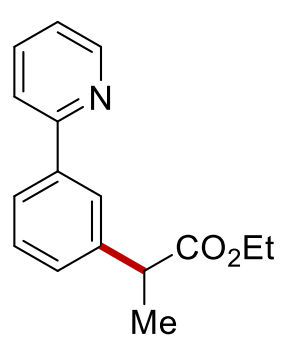

409a

$\left(400 \mathrm{MHz}, \mathrm{CDCl}_{3}\right)$

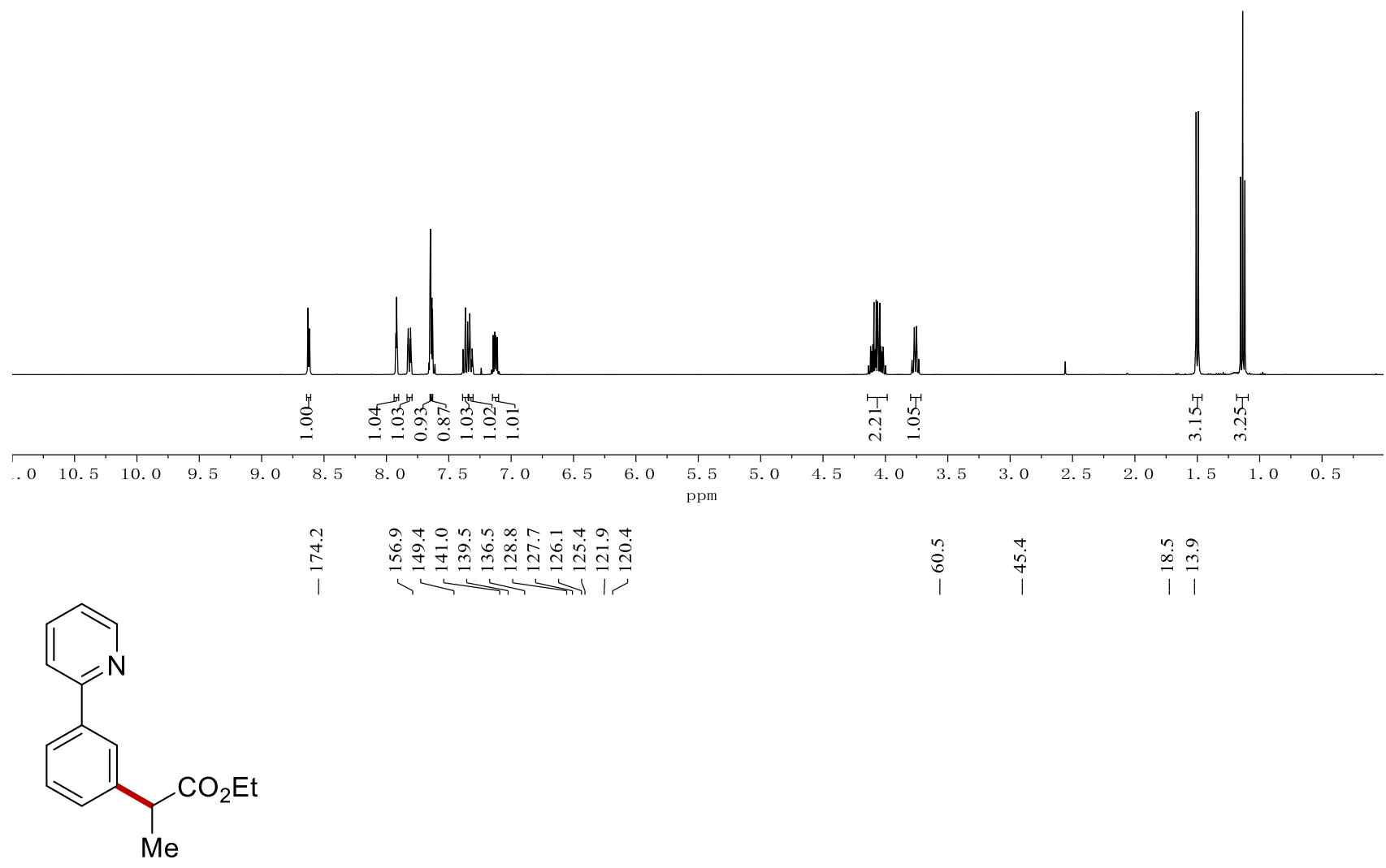

409a

$\left(100 \mathrm{MHz}, \mathrm{CDCl}_{3}\right)$

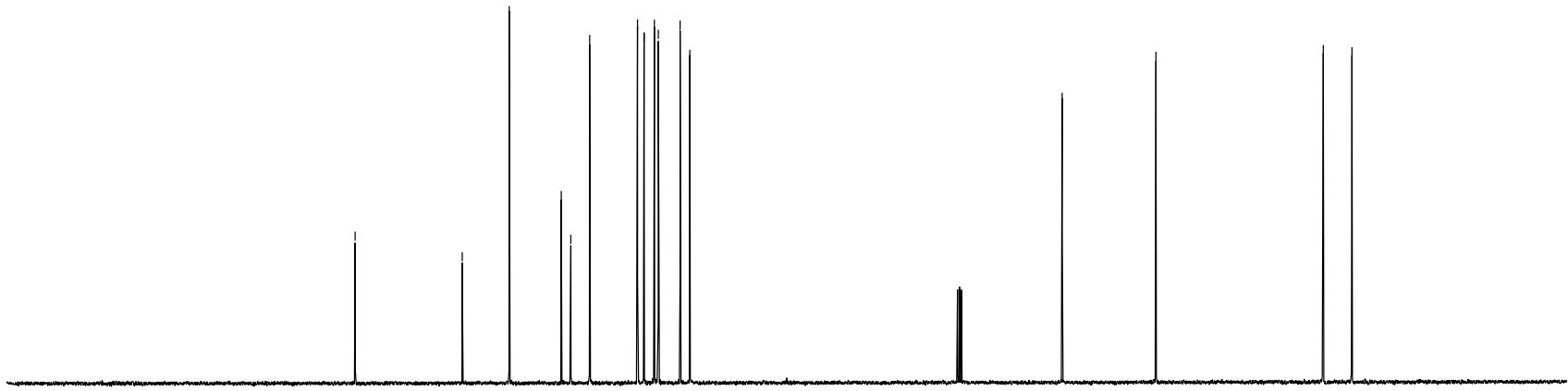

$\begin{array}{llllllllllllllllllllllllllllllll}30 & 220 & 210 & 200 & 190 & 180 & 170 & 160 & 150 & 140 & 130 & 120 & 110 & 100 & 90 & 80 & 70 & 60 & 50 & 40 & 30 & 20 & 10 & 0 & -10 & -\end{array}$ 


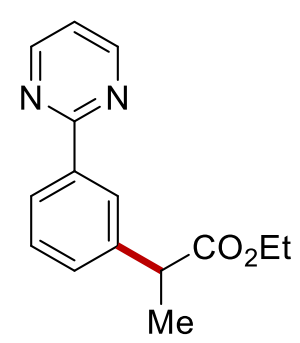

$409 b$

$\left(400 \mathrm{MHz}, \mathrm{CDCl}_{3}\right.$ )

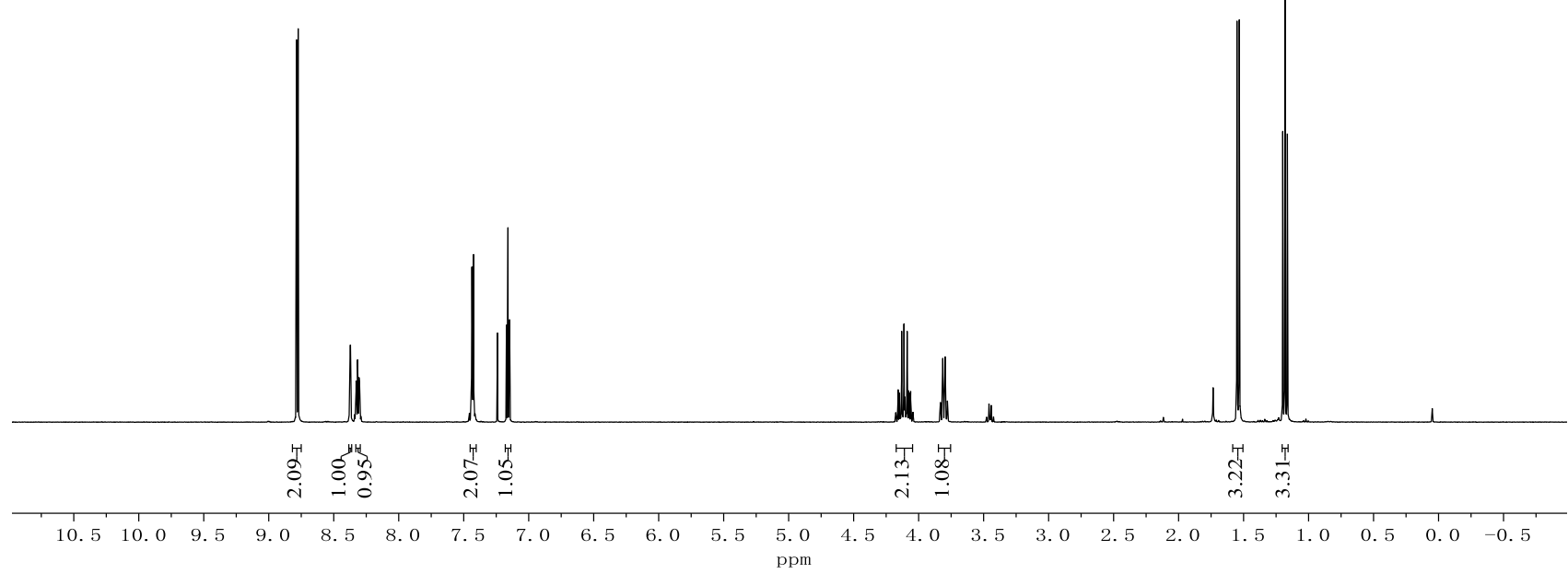

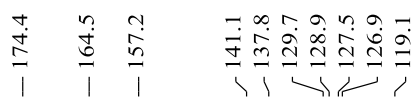

$\begin{array}{lll}r & 0 & 0 \\ \dot{8} & \dot{n} & \infty \\ 1 & 1 & 1\end{array}$

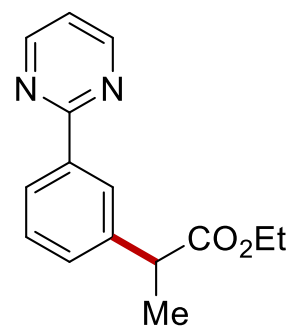

409b

(100 MHz, $\mathrm{CDCl}_{3}$ )

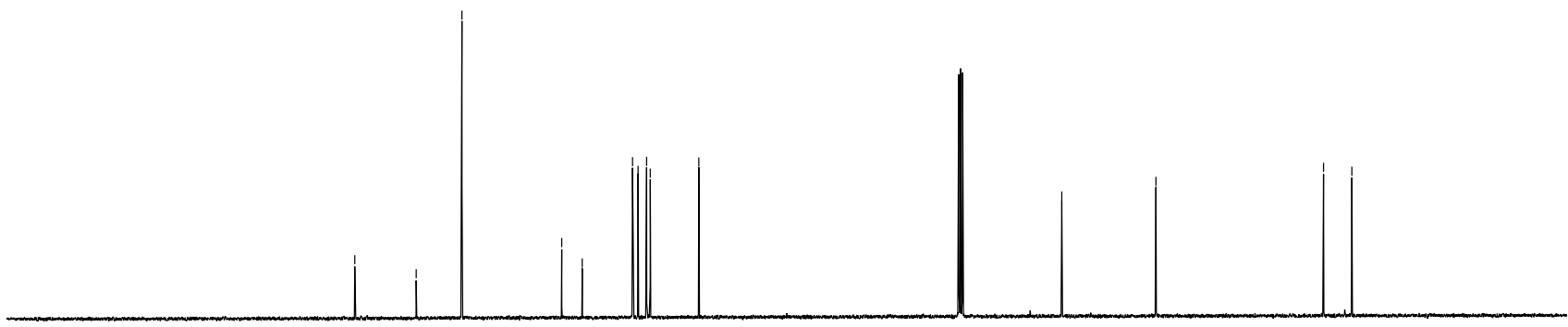

\begin{tabular}{lllllllllllllllllllllllllll}
\hline & 220 & 210 & 200 & 190 & 180 & 170 & 160 & 150 & 140 & 130 & 120 & 110 & 100 & 90 & 80 & 70 & 60 & 50 & 40 & 30 & 20 & 10 & 0 & -10 & -
\end{tabular} 


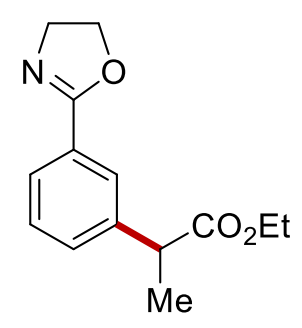

409c

$\left.\left(400 \mathrm{MHz}^{\mathrm{CDCl}}\right)_{3}\right)$

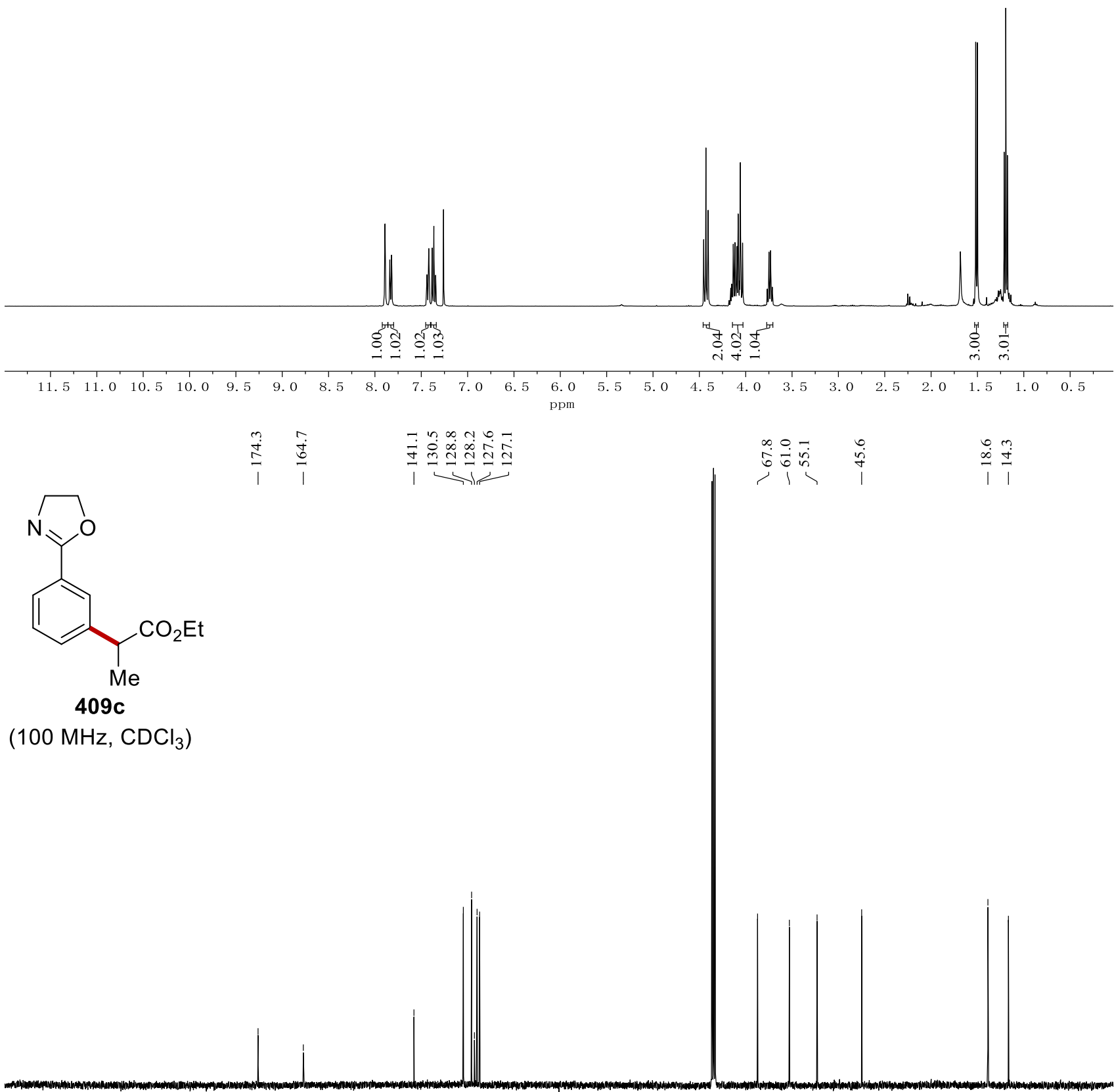

$\begin{array}{lllllllllllllllllllllll}220 & 210 & 200 & 190 & 180 & 170 & 160 & 150 & 140 & 130 & 120 & 110 & 100 & 90 & 80 & 70 & 60 & 50 & 40 & 30 & 20 & 10 & 0\end{array}$ 


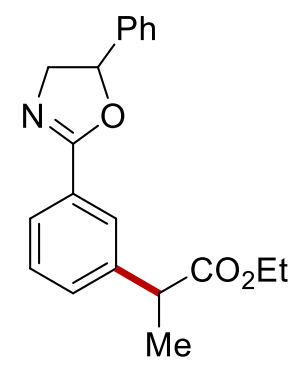

409d

$\left(400 \mathrm{MHz}, \mathrm{CDCl}_{3}\right)$
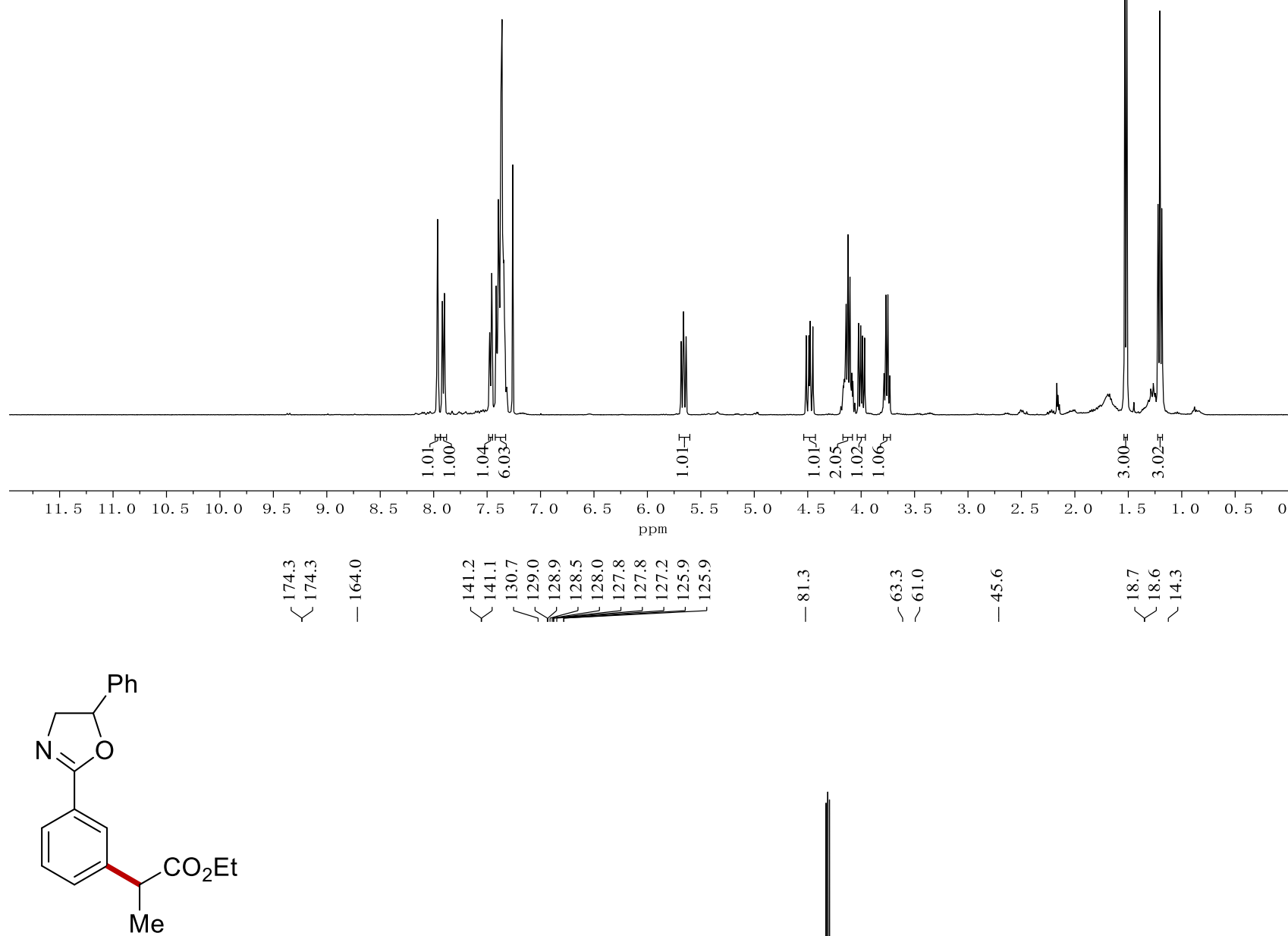

409d

$\left(100 \mathrm{MHz}, \mathrm{CDCl}_{3}\right)$

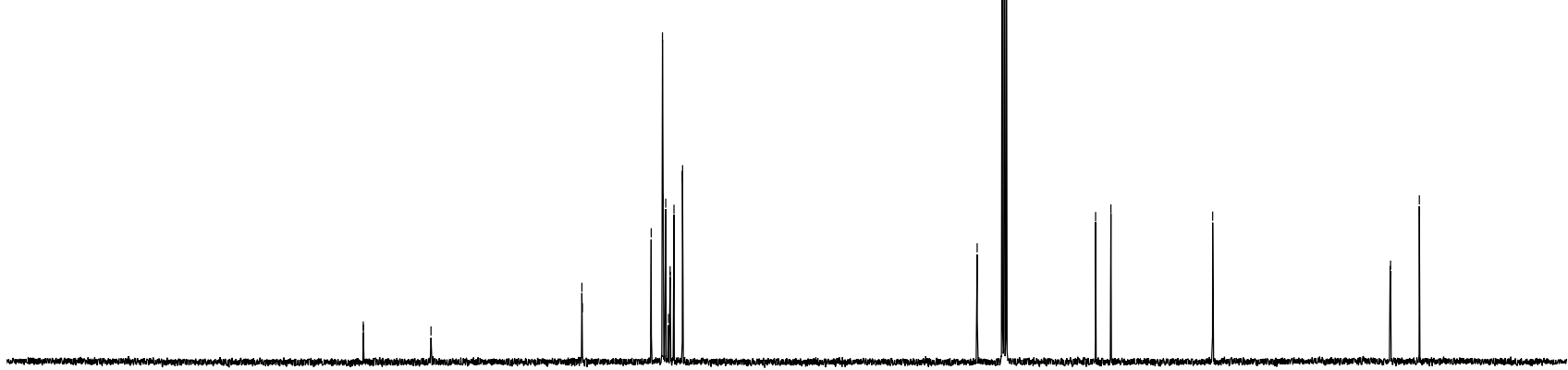

$\begin{array}{llllllllllllllllllllllll}220 & 210 & 200 & 190 & 180 & 170 & 160 & 150 & 140 & 130 & 120 & 110 & 100 & 90 & 80 & 70 & 60 & 50 & 40 & 30 & 20 & 10 & 0\end{array}$ 


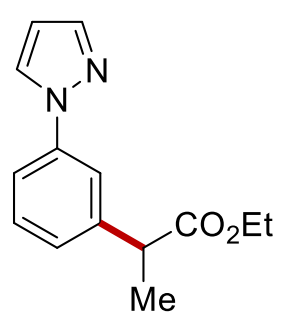

$409 \mathrm{e}$

(400 MHz, $\mathrm{CDCl}_{3}$ )
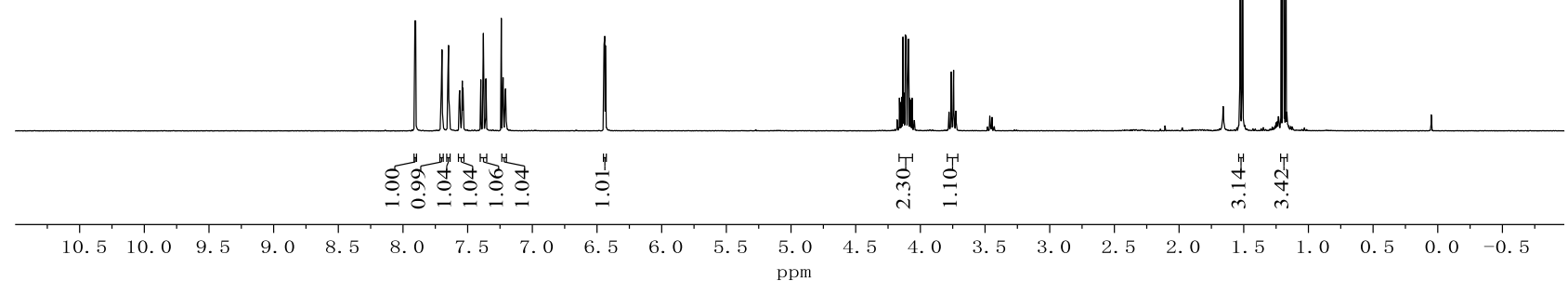

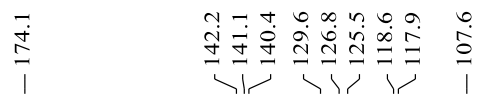

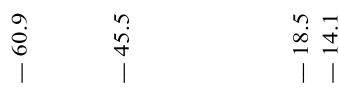

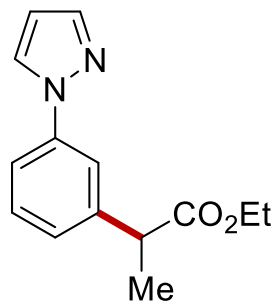

$409 \mathrm{e}$

$\left(100 \mathrm{MHz}, \mathrm{CDCl}_{3}\right.$ )

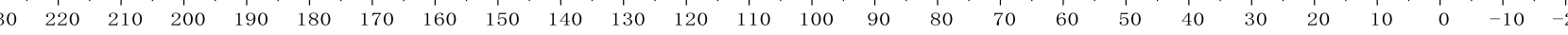




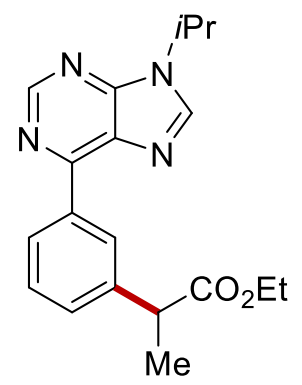

$409 f$

$\left(400 \mathrm{MHz} \mathrm{CDCl}_{3}\right)$

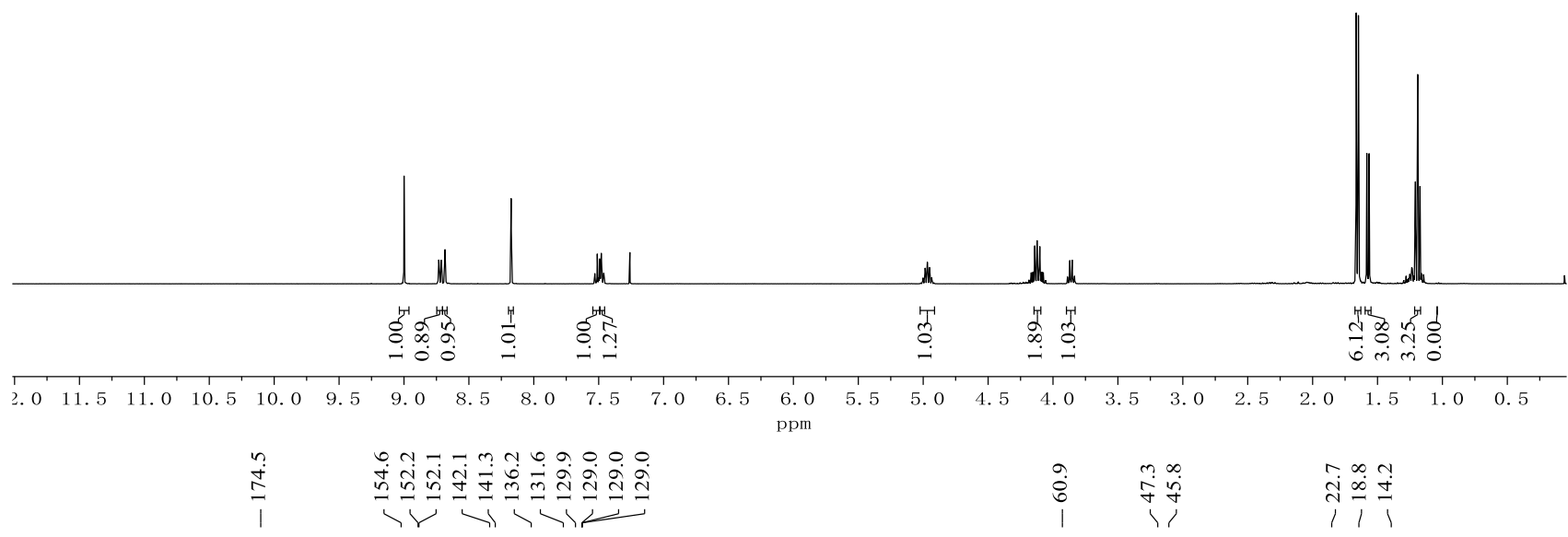<smiles>CCOC(=O)C(C)c1cccc(-c2ncnc3c2ncn3C(C)C)c1</smiles>

$409 f$

$\left(100 \mathrm{MHz} \mathrm{CDCl}_{3}\right)$

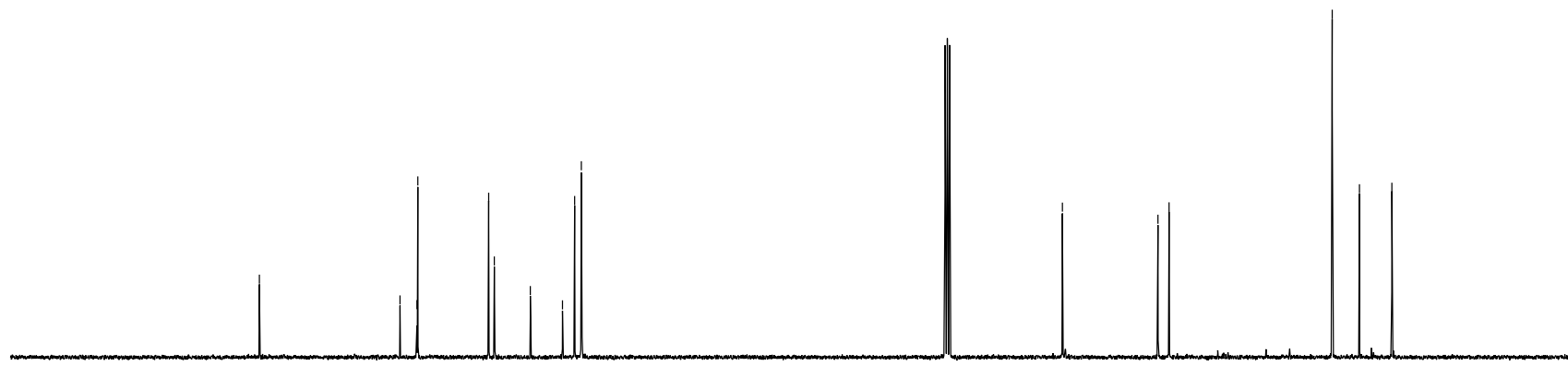

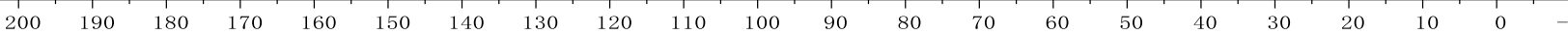




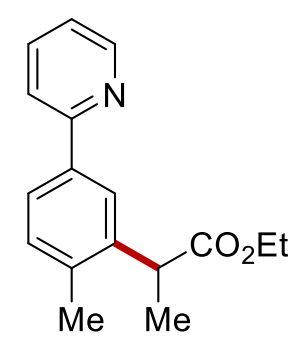

409g

(400 MHz, $\mathrm{CDCl}_{3}$ )
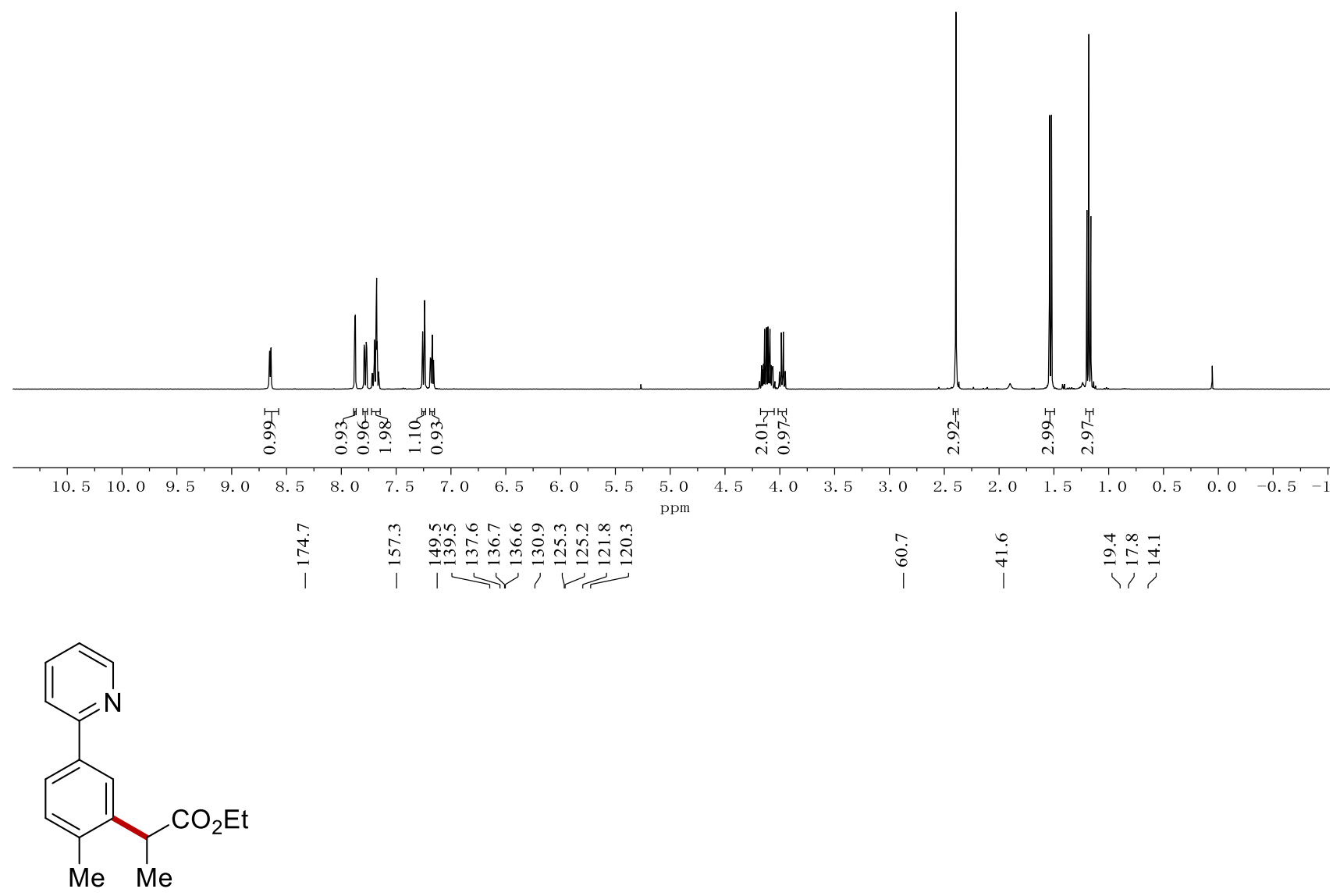

$409 \mathrm{~g}$

$\left(100 \mathrm{MHz}, \mathrm{CDCl}_{3}\right)$

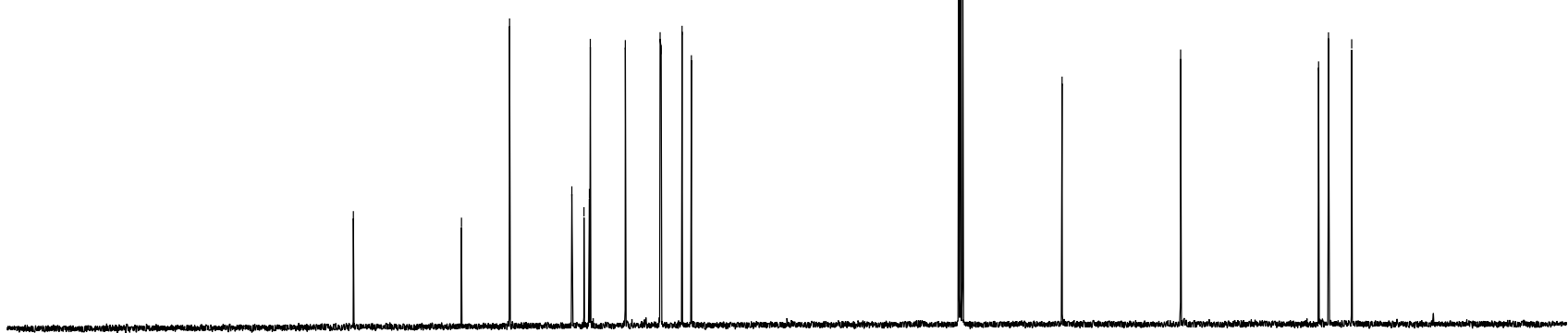

\begin{tabular}{llllllllllllllllllllllllllllllllllll}
\hline 30 & 220 & 210 & 200 & 190 & 180 & 170 & 160 & 150 & 140 & 130 & 120 & 110 & 100 & 90 & 80 & 70 & 60 & 50 & 40 & 30 & 20 & 10 & 0 & -10 & -1
\end{tabular} 


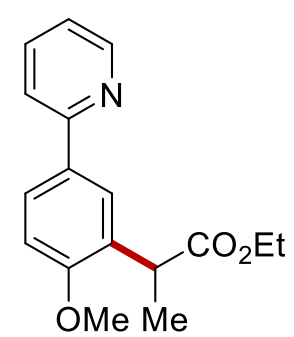

409h

$\left(400 \mathrm{MHz}, \mathrm{CDCl}_{3}\right)$
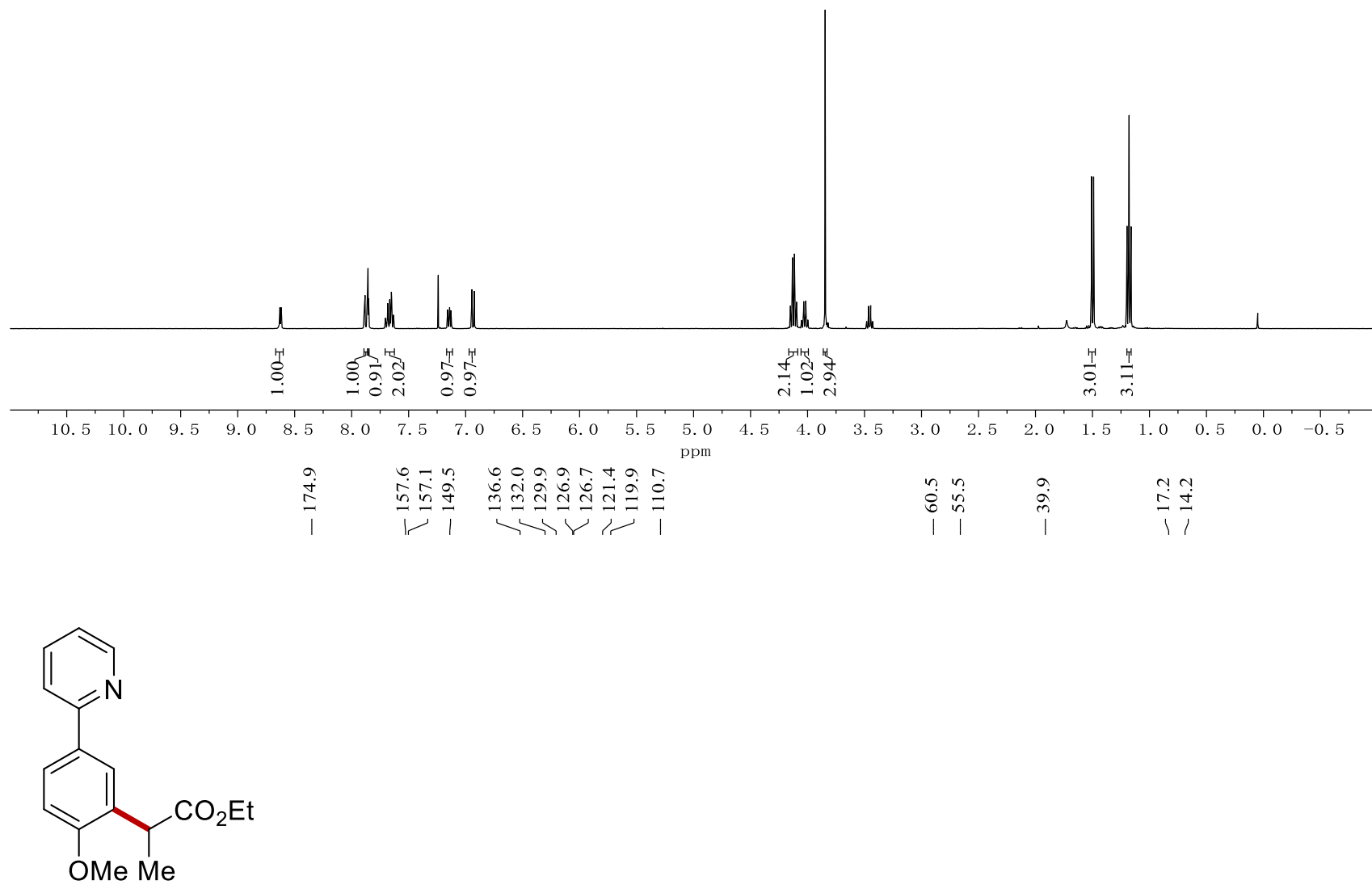

409h

$\left(100 \mathrm{MHz}, \mathrm{CDCl}_{3}\right)$

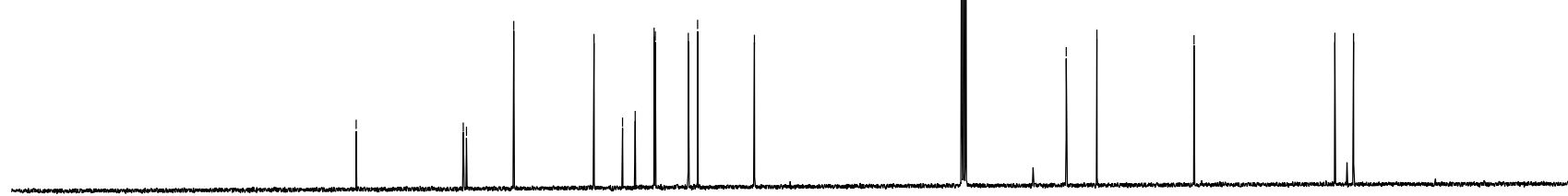

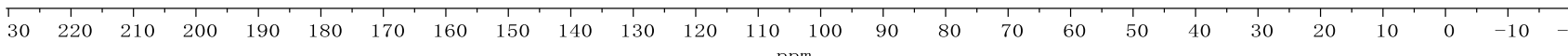




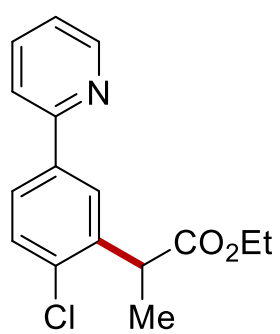

409i

(400 MHz, $\mathrm{CDCl}_{3}$ )

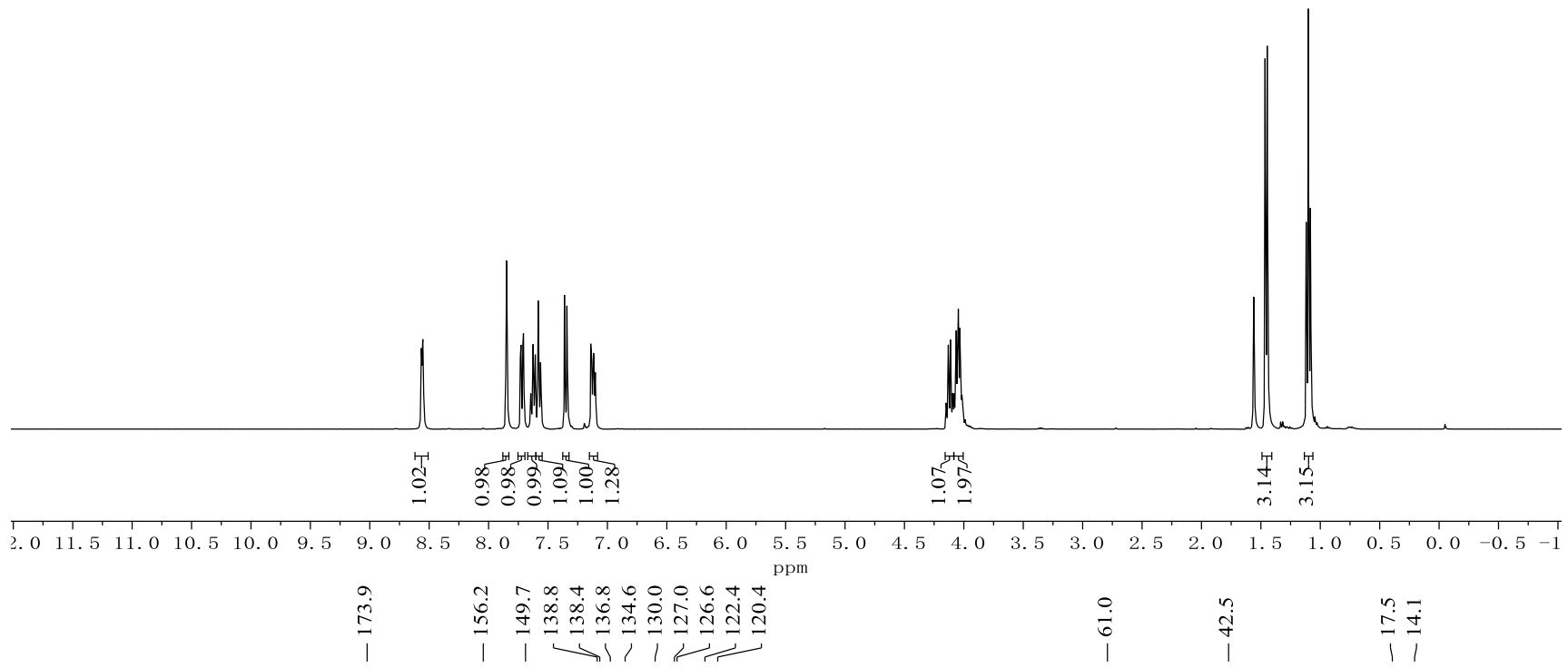<smiles>CCOC(C)c1cc(Cl)cc(-c2ccccn2)c1</smiles>

$409 i$

(100 MHz, $\mathrm{CDCl}_{3}$ )

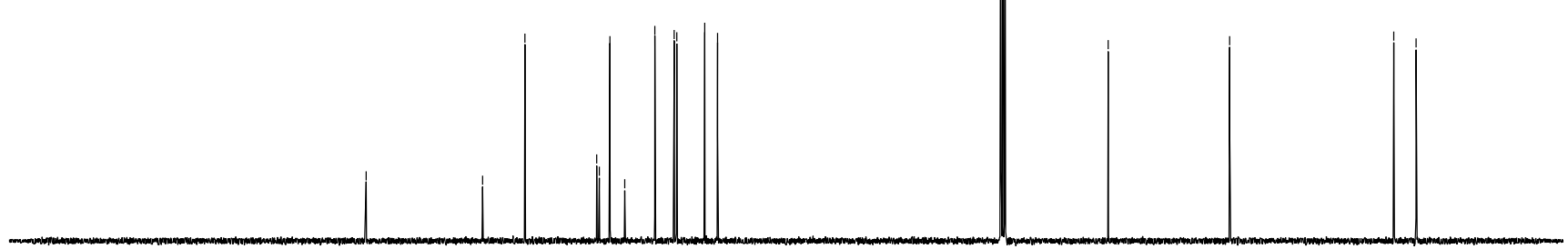

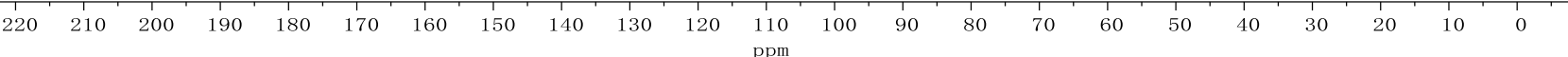




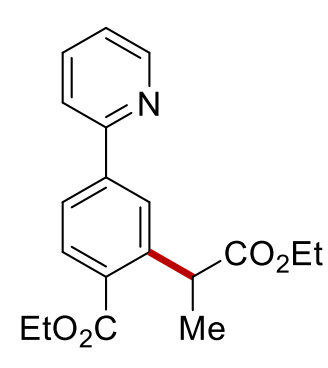

409j

(400 MHz, $\mathrm{CDCl}_{3}$ )

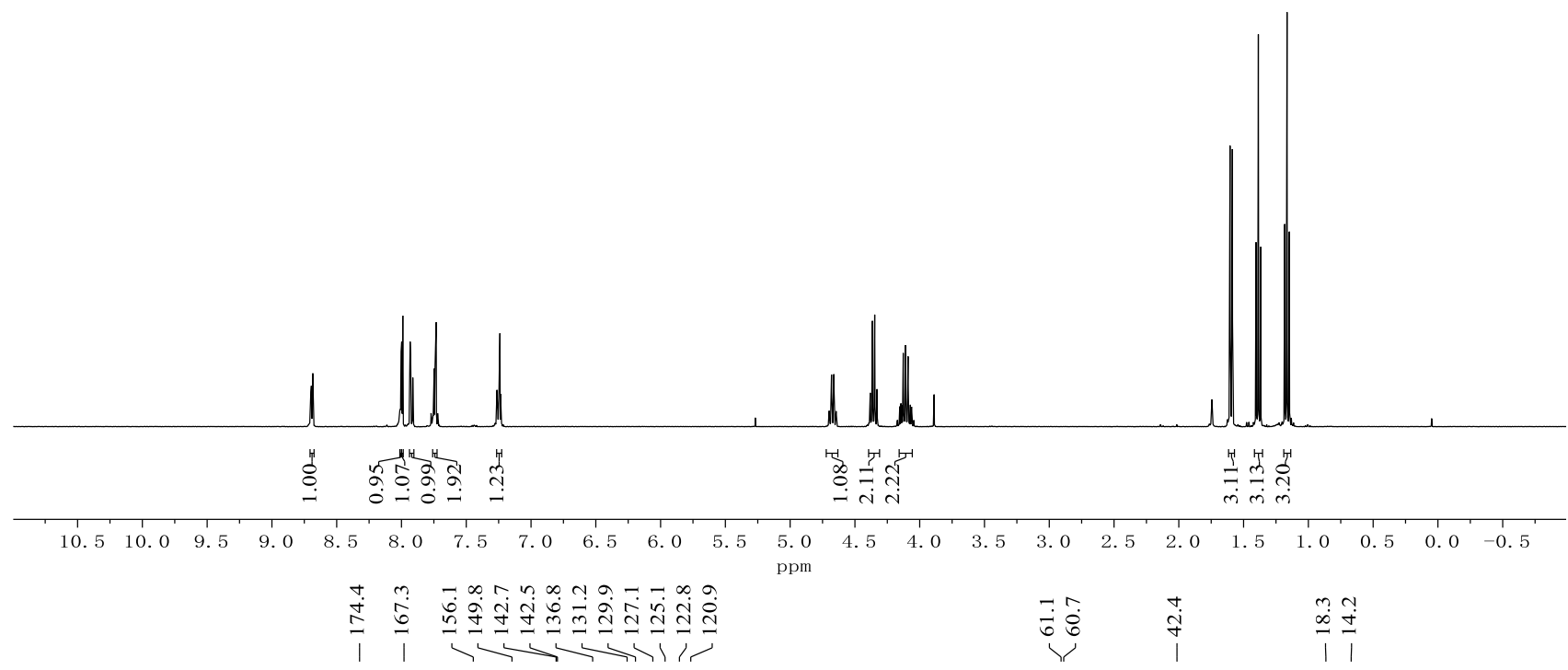<smiles>CCOC(=O)c1cc(-c2ccccn2)ccc1C(C)OCC</smiles>

409j

(100 MHz, $\mathrm{CDCl}_{3}$ )

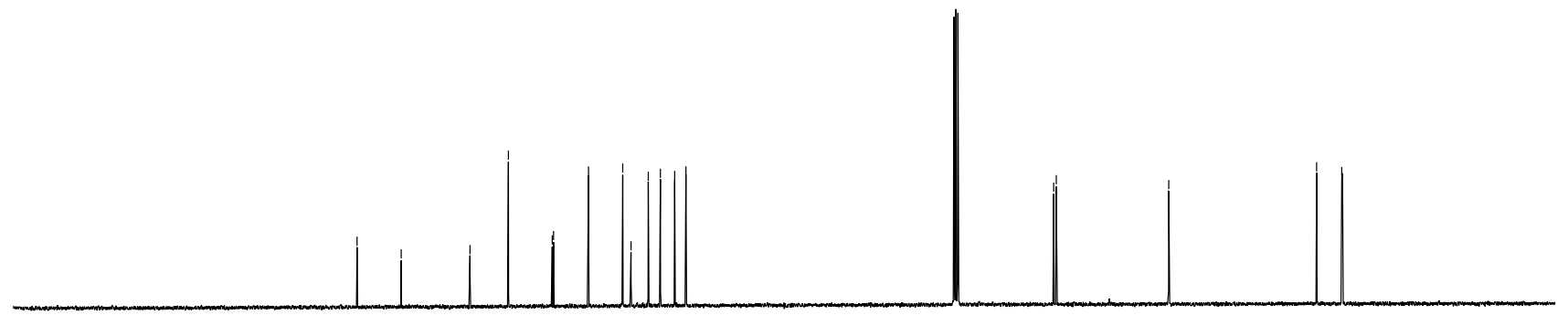

\begin{tabular}{lllllllllllllllllllllllllllllllllllllllll}
\hline 30 & 220 & 210 & 200 & 190 & 180 & 170 & 160 & 150 & 140 & 130 & 120 & 110 & 100 & 90 & 80 & 70 & 60 & 50 & 40 & 30 & 20 & 10 & 0 & -10 & -4
\end{tabular} 


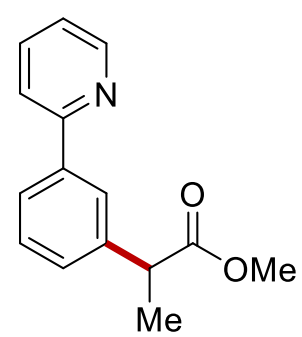

409k

$\left(400 \mathrm{MHz}, \mathrm{CDCl}_{3}\right)$
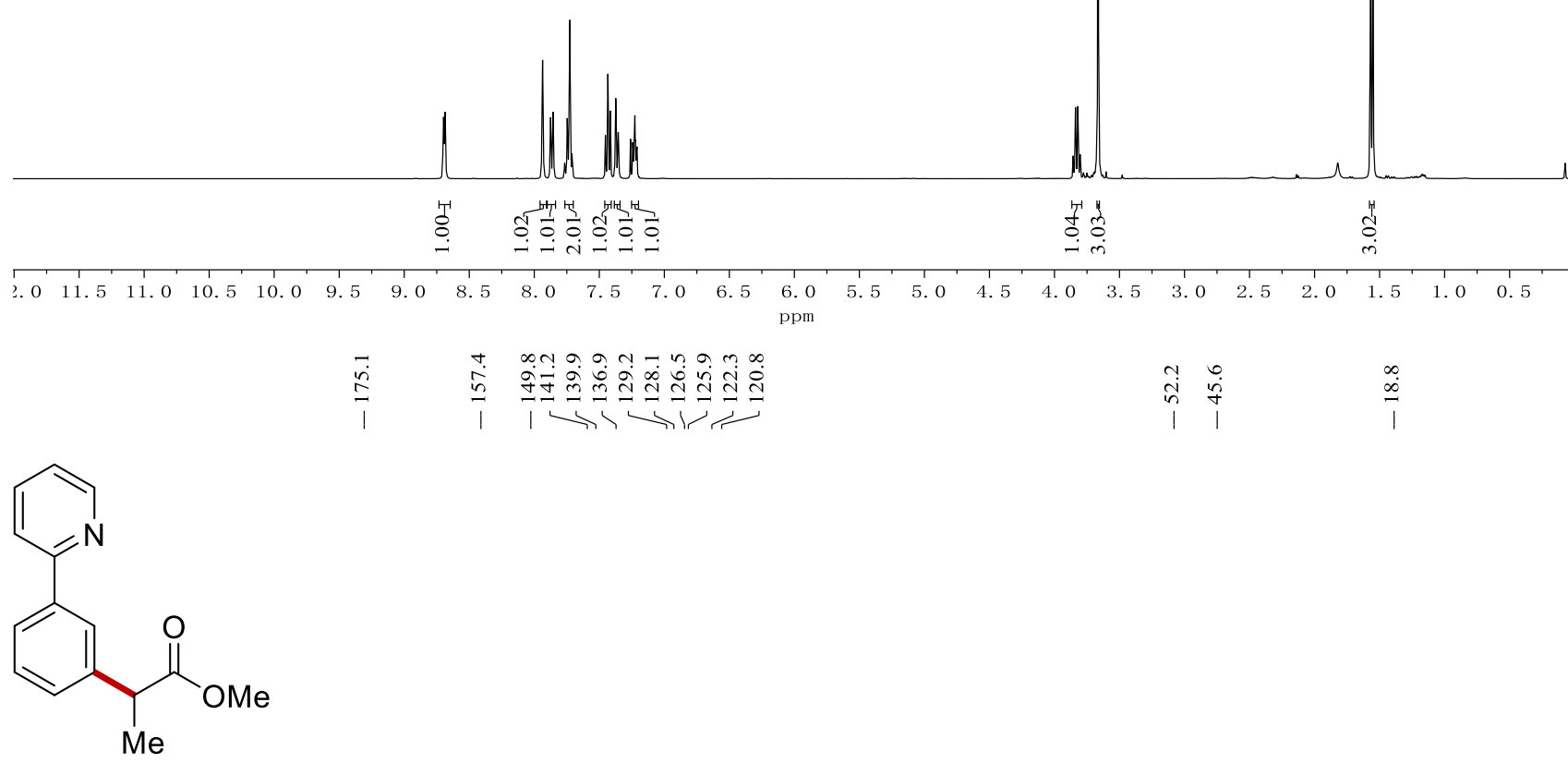

409k

$\left(100 \mathrm{MHz}, \mathrm{CDCl}_{3}\right)$

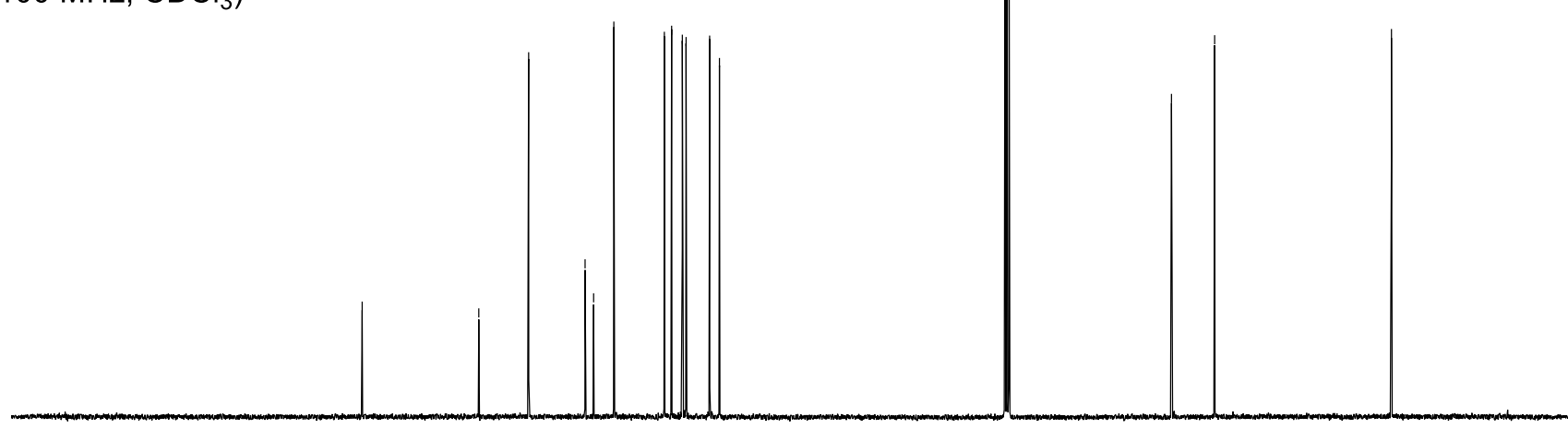

$\begin{array}{llllllllllllllllllllllllll}220 & 210 & 200 & 190 & 180 & 170 & 160 & 150 & 140 & 130 & 120 & 110 & 100 & 90 & 80 & 70 & 60 & 50 & 40 & 30 & 20 & 10 & 0 & 0\end{array}$ 
<smiles>CCOC(=O)C(C)c1cccc(-c2ccccn2)c1</smiles>

409I

(400 MHz, $\mathrm{CDCl}_{3}$ )

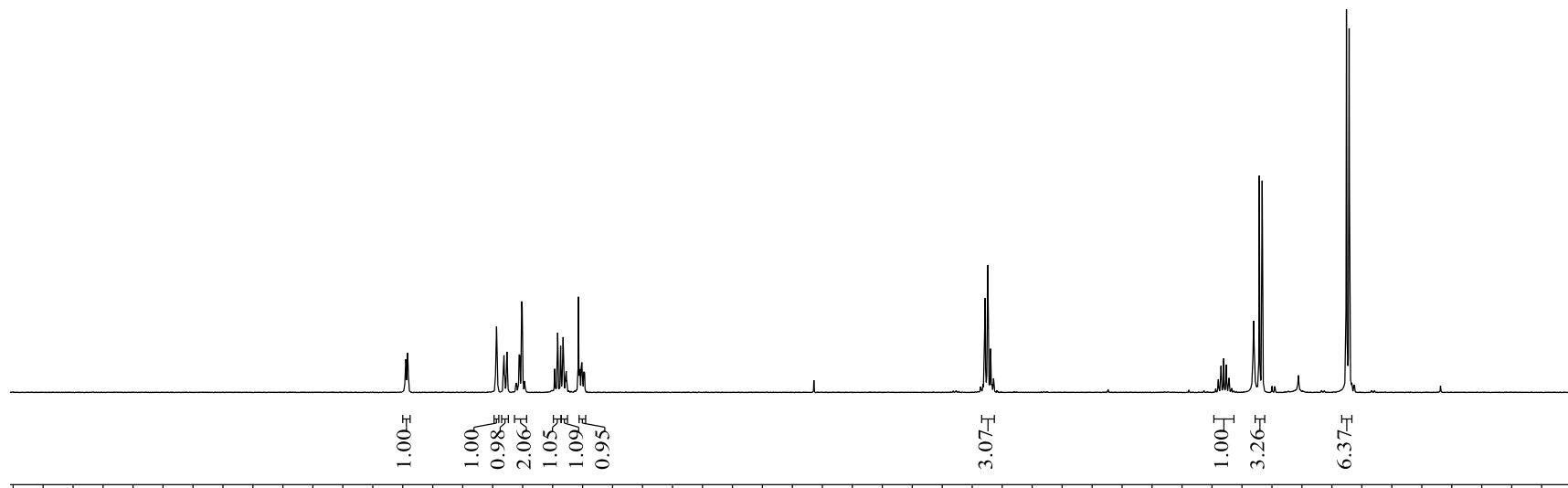
\begin{tabular}{llllllllllllllllllllllllllllllll}
\hline 2.0 & 11.5 & 11.0 & 10.5 & 10.0 & 9.5 & 9.0 & 8.5 & 8.0 & 7.5 & 7.0 & 6.5 & 6.0 & 5.5 & 5.0 & 4.5 & 4.0 & 3.5 & 3.0 & 2.5 & 2.0 & 1.5 & 1.0 & 0.5 & 0.0 & -0.5
\end{tabular}

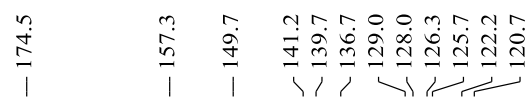<smiles>CCOC(=O)C(C)c1cccc(-c2ccccn2)c1</smiles>

409I

(100 MHz, $\mathrm{CDCl}_{3}$ ) 


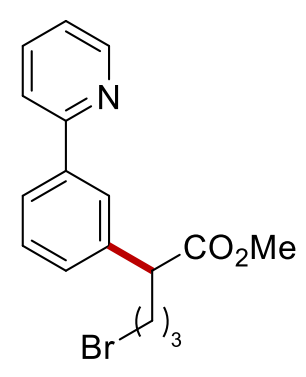

409m

(400 MHz, $\mathrm{CDCl}_{3}$ )

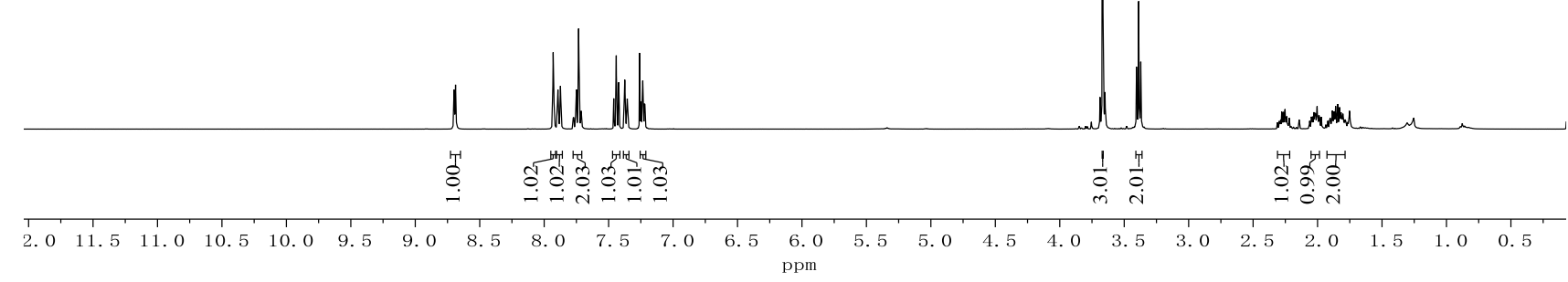<smiles>CC(=O)C(CBr)c1cccc(-c2ccccn2)c1</smiles>

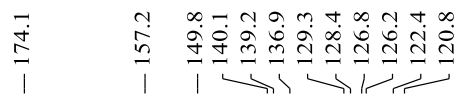

î.

409m

$\left(100 \mathrm{MHz}, \mathrm{CDCl}_{3}\right)$

$\begin{array}{lllllllllllllllllllllllll}1 & 210 & 200 & 190 & 180 & 170 & 160 & 150 & 140 & 130 & 120 & 110 & 100 & 90 & 80 & 70 & 60 & 50 & 40 & 30 & 20 & 10 & 0 & 1\end{array}$ 


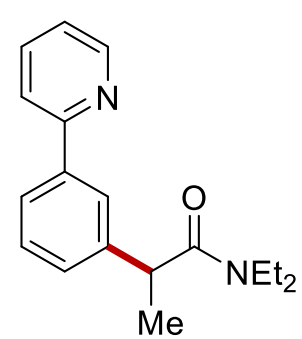

409n

(400 MHz, $\mathrm{CDCl}_{3}$ )

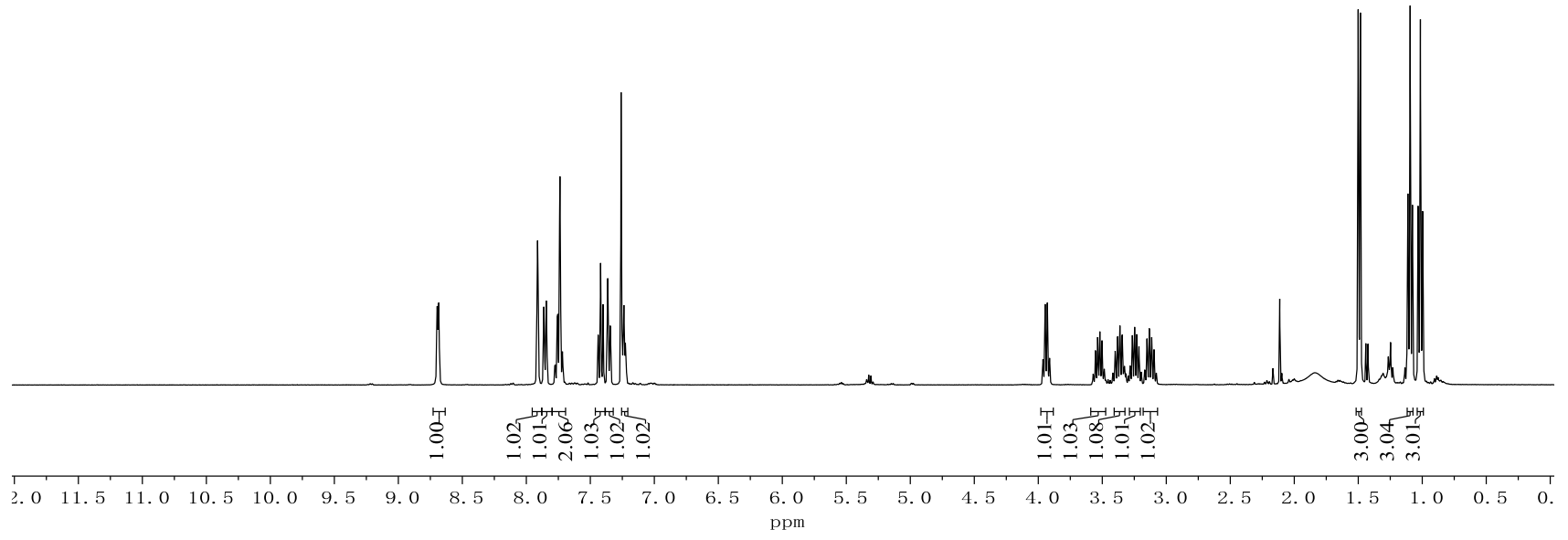<smiles>CCN(CC)C(=O)C(C)c1cccc(-c2ccccn2)c1</smiles>

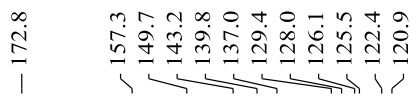

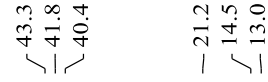

409n

(100 MHz, $\mathrm{CDCl}_{3}$ )

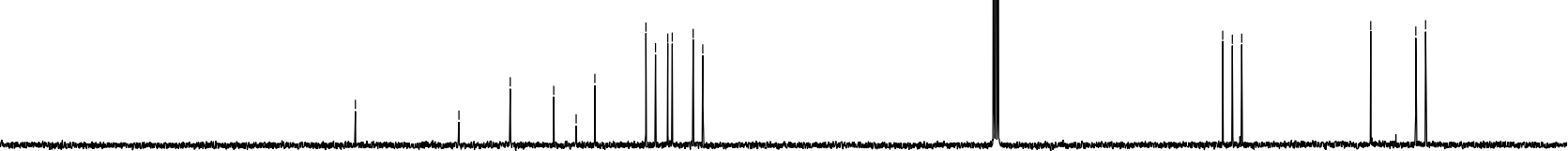

$\begin{array}{llllllllllllllllllllllll}220 & 210 & 200 & 190 & 180 & 170 & 160 & 150 & 140 & 130 & 120 & 110 & 100 & 90 & 80 & 70 & 60 & 50 & 40 & 30 & 20 & 10 & 0 & 0\end{array}$ 


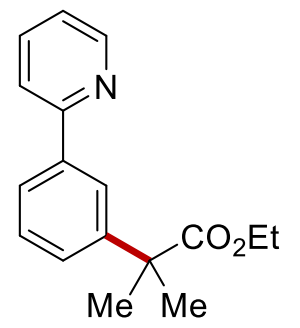

409o

$\left(400 \mathrm{MHz}^{\mathrm{CDCl}}\right)_{3}$
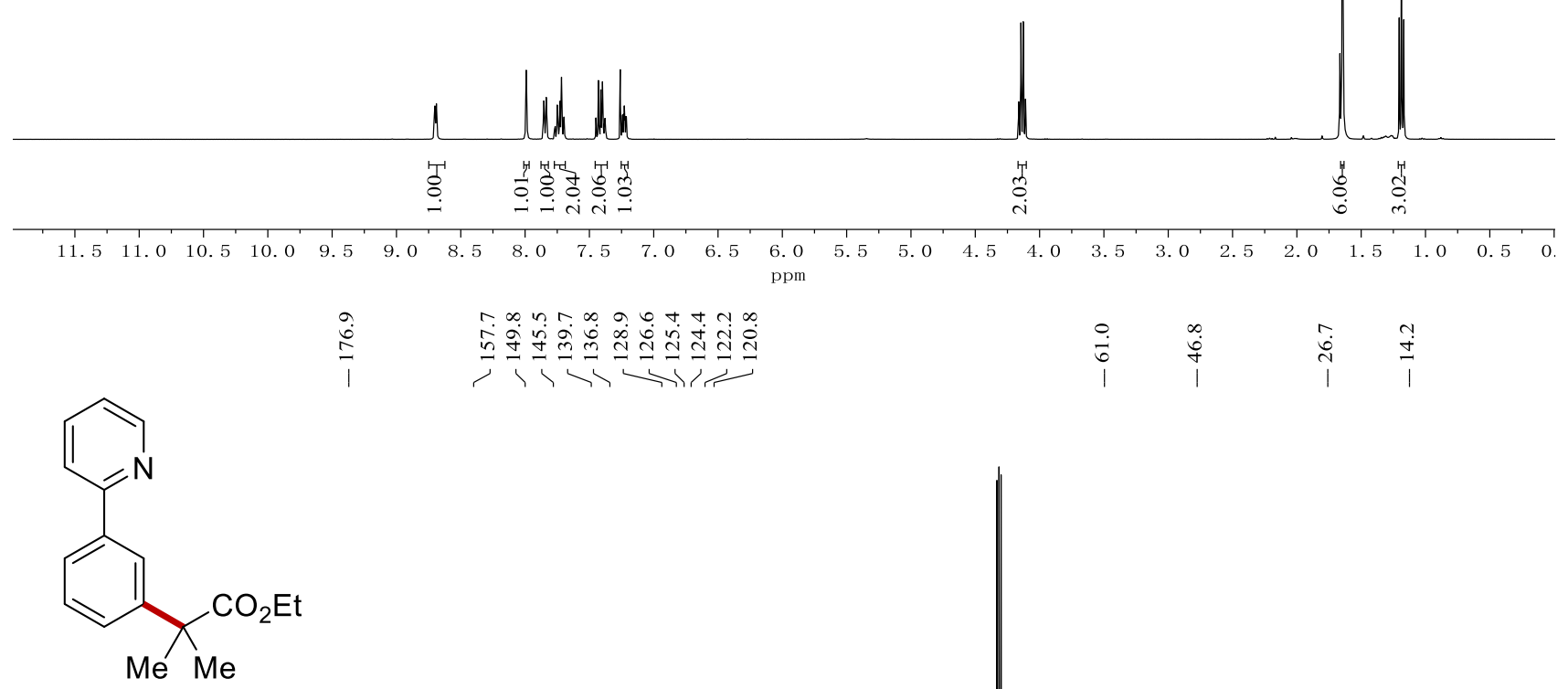

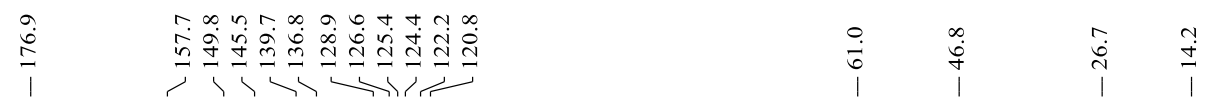

4090

$\left(100 \mathrm{MHz}, \mathrm{CDCl}_{3}\right)$

$\begin{array}{lllllllllllllllllllllllllll}1 & 20 & 210 & 200 & 190 & 180 & 170 & 160 & 150 & 140 & 130 & 120 & 110 & 100 & 90 & 80 & 70 & 60 & 50 & 40 & 30 & 20 & 10 & 0 & 0\end{array}$ 


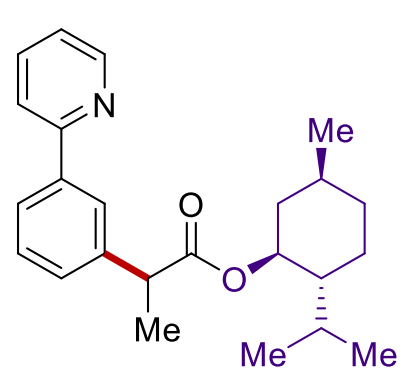

409p

$\left(400 \mathrm{MHz}, \mathrm{CDCl}_{3}\right)$

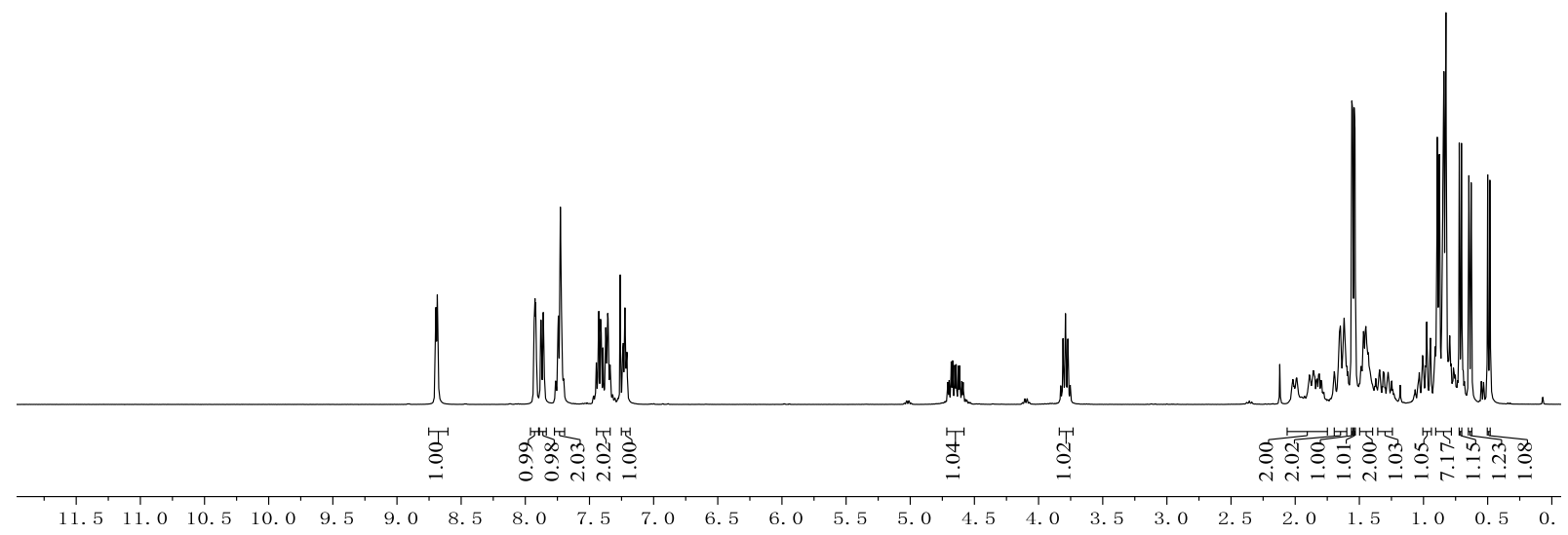

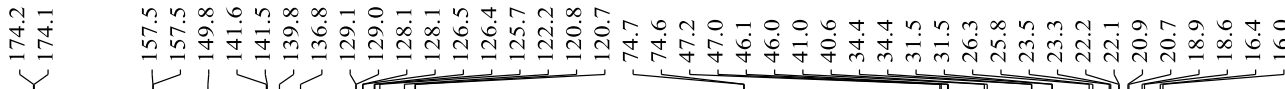<smiles>CC(C(=O)O[C@@H]1C[C@H](C)CC[C@@H]1C(C)C)c1cccc(-c2ccccn2)c1</smiles>

409p

$\left(100 \mathrm{MHz}, \mathrm{CDCl}_{3}\right)$

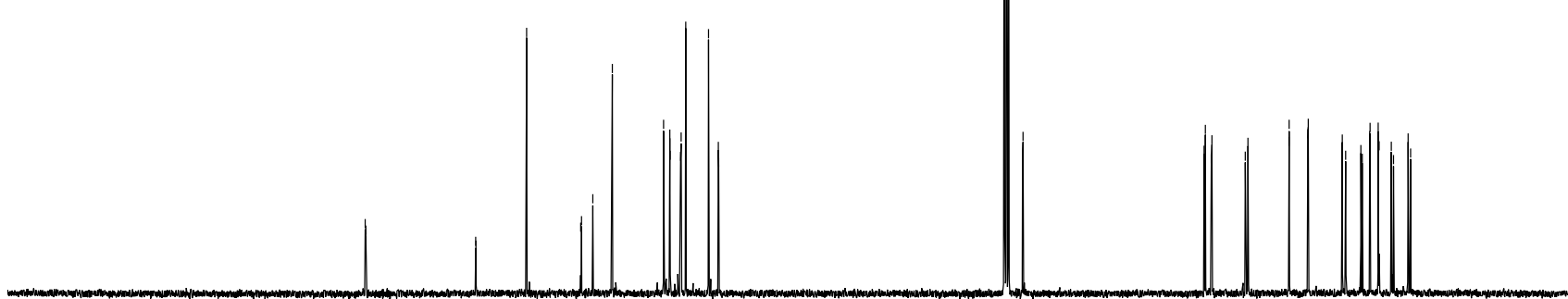

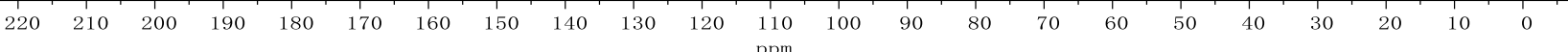



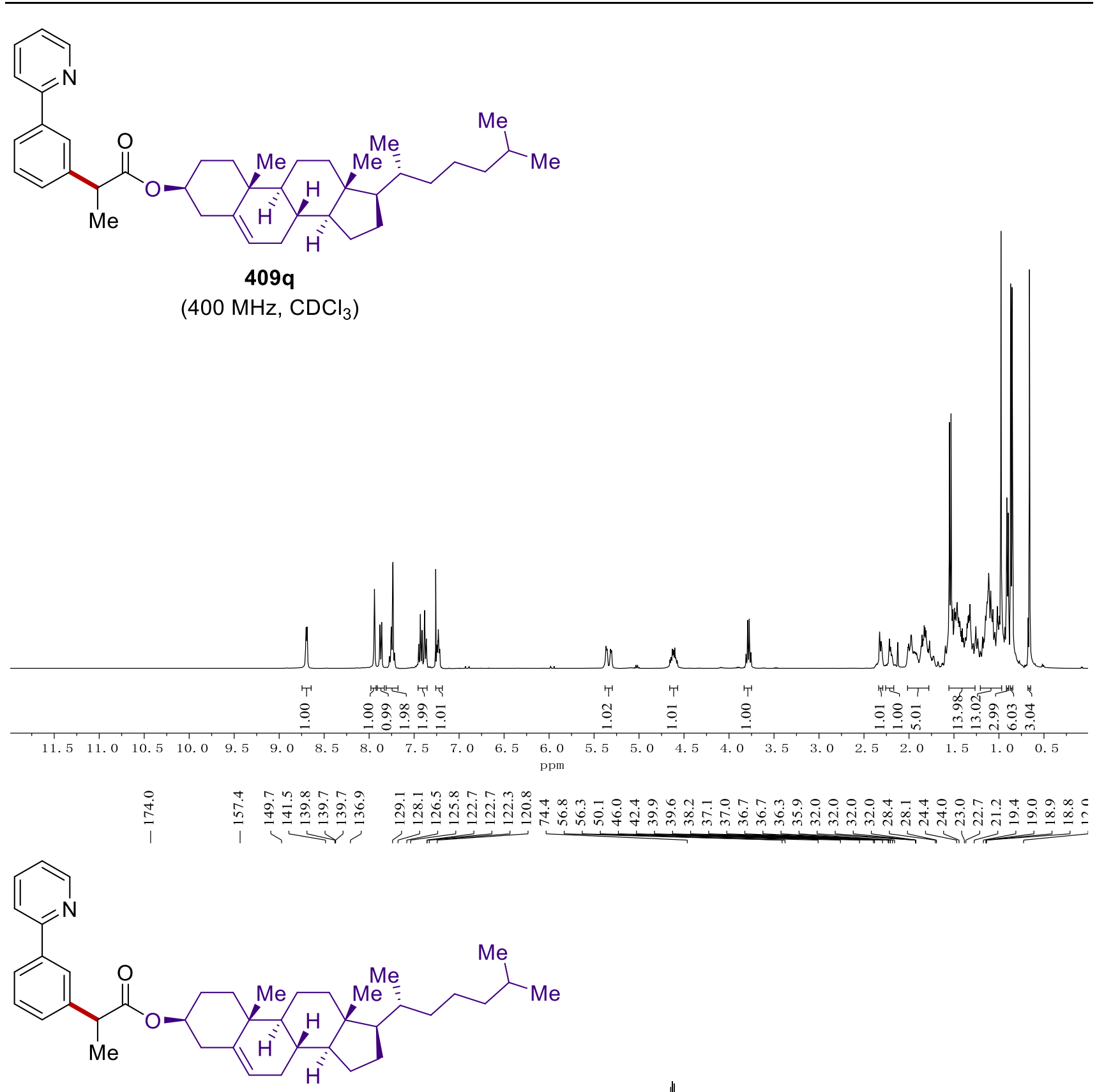

409q

(100 MHz, $\mathrm{CDCl}_{3}$ )

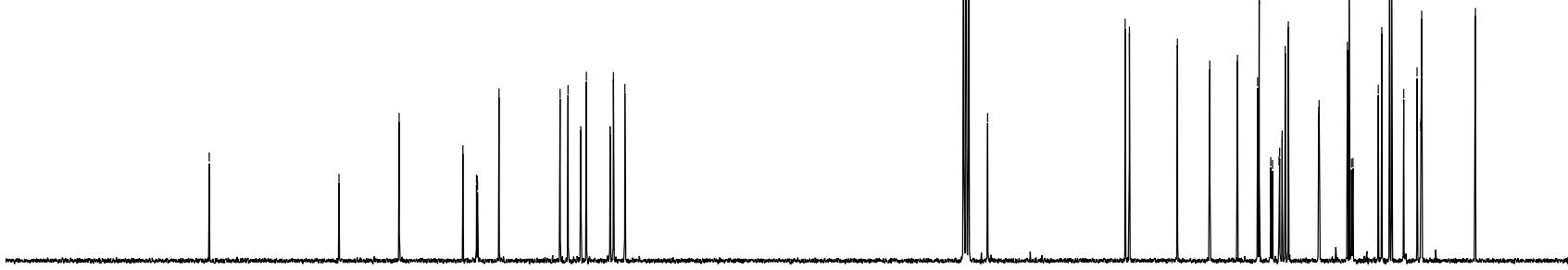


<smiles>CCCCNC(=O)c1ncccc1-c1ccc(OC)cc1</smiles>

413a

(400 MHz, $\mathrm{CDCl}_{3}$ )

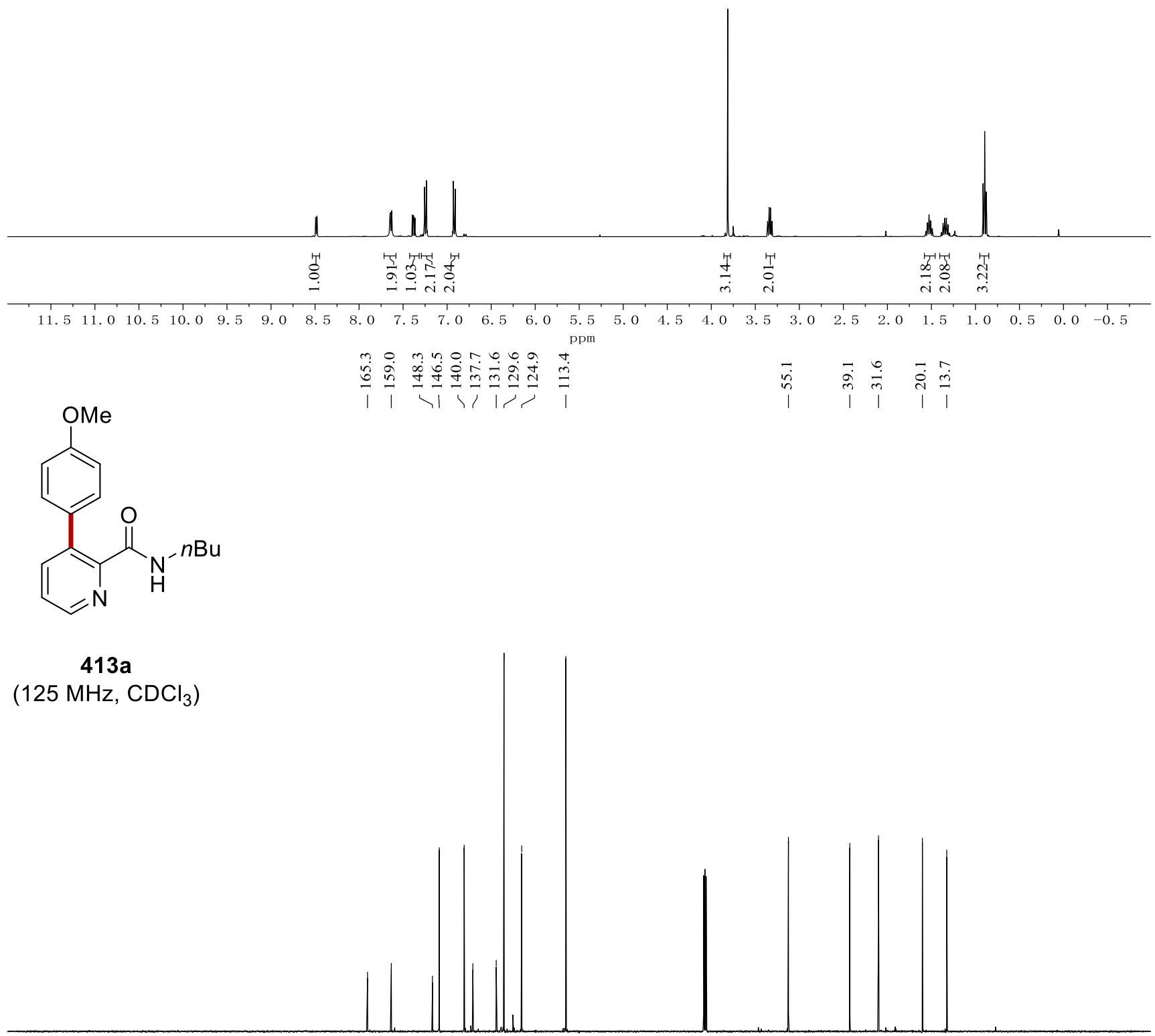

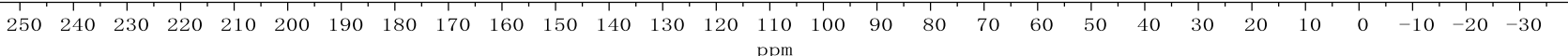


<smiles>CCCCNC(=O)c1cnccc1-c1ccc(OC)cc1</smiles>

413b

(400 MHz, $\mathrm{CDCl}_{3}$ )

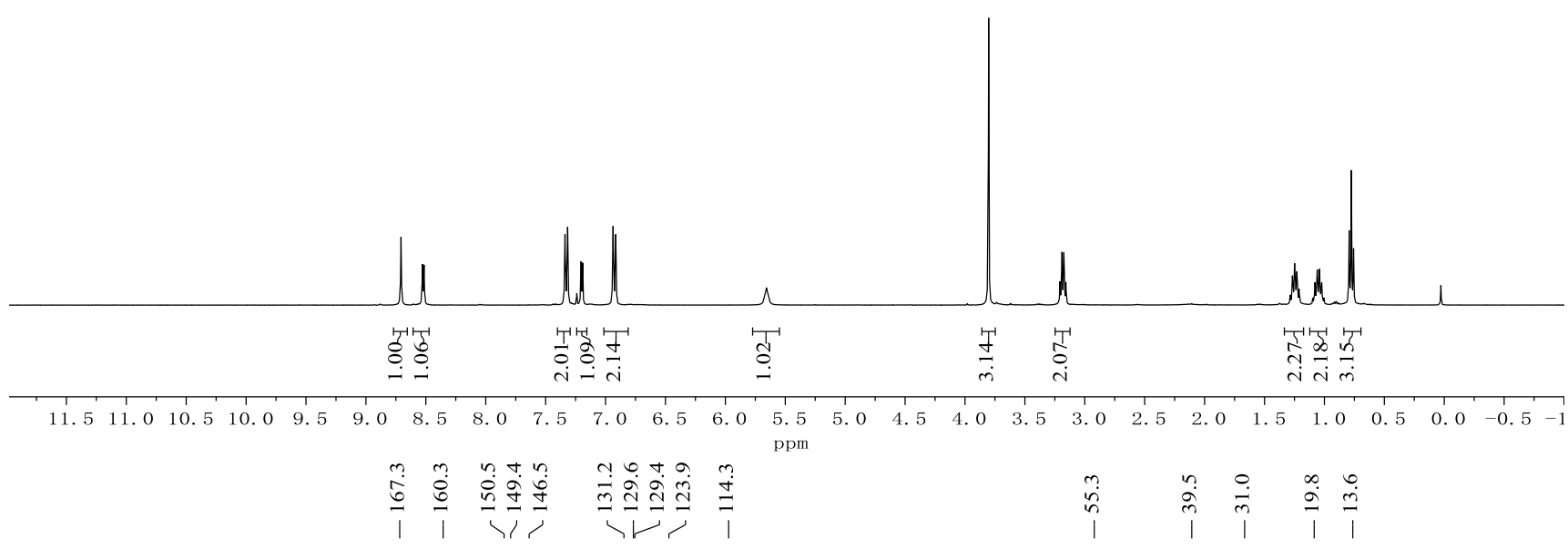<smiles>CCCCNC(=O)c1cnccc1-c1ccc(OC)cc1</smiles>

413b

$\left(100 \mathrm{MHz}, \mathrm{CDCl}_{3}\right.$ )

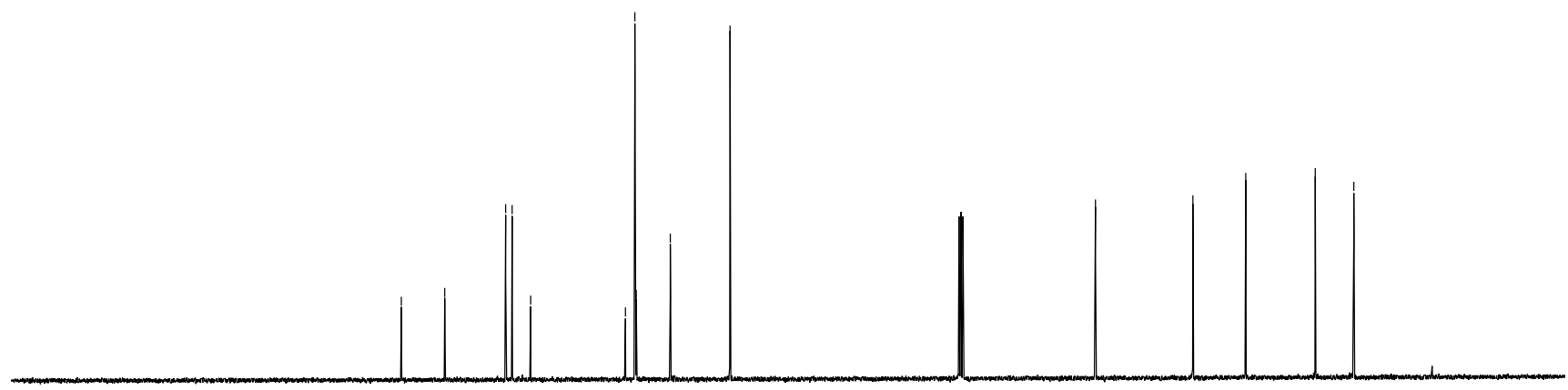

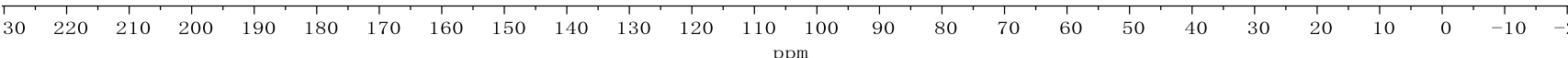




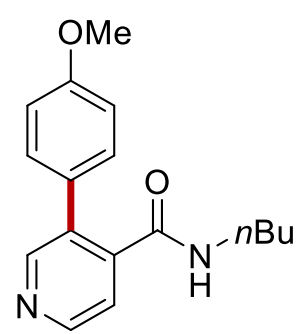

413c

(400 MHz, $\mathrm{CDCl}_{3}$ )
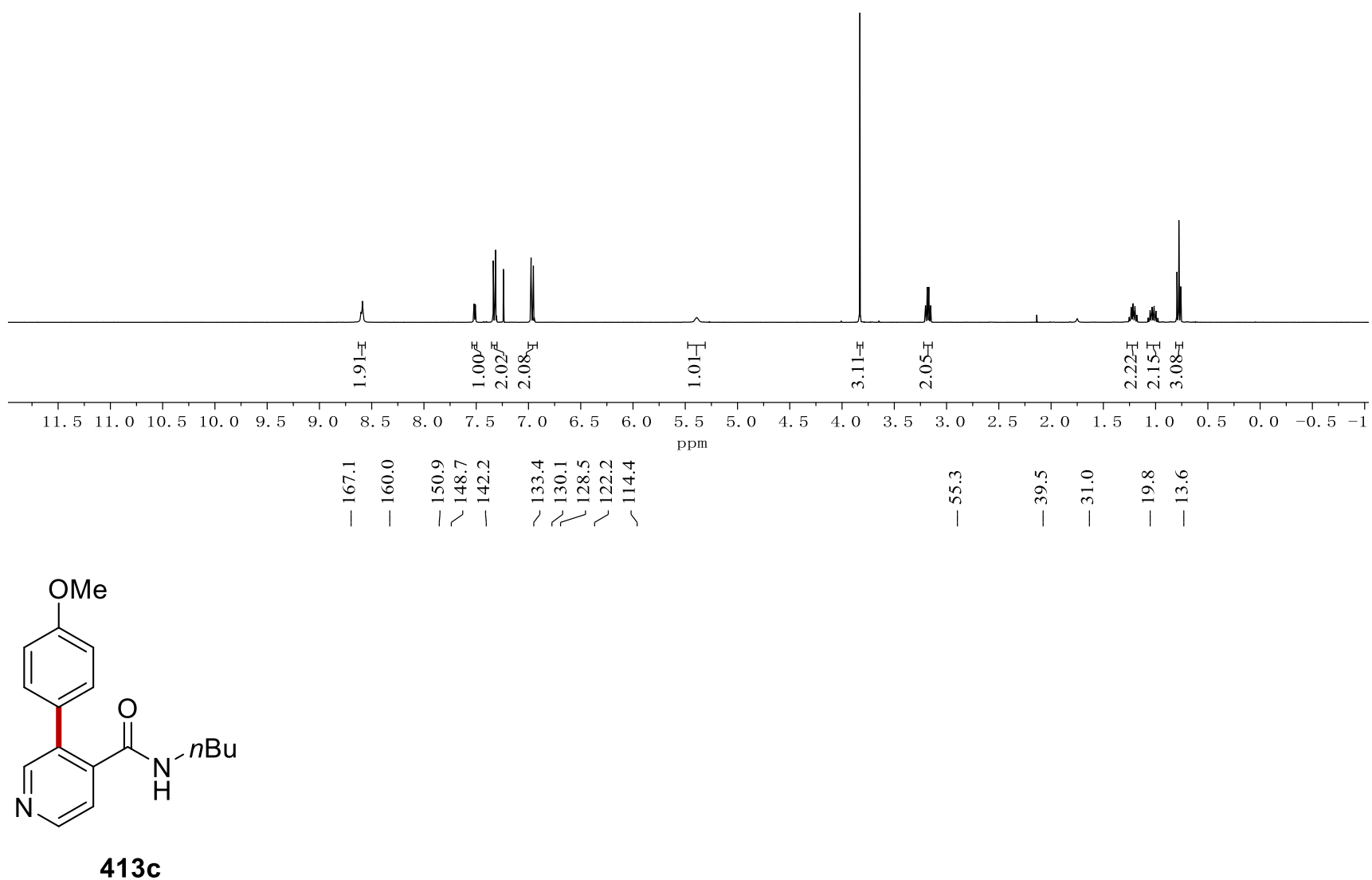

(100 MHz, $\mathrm{CDCl}_{3}$ )

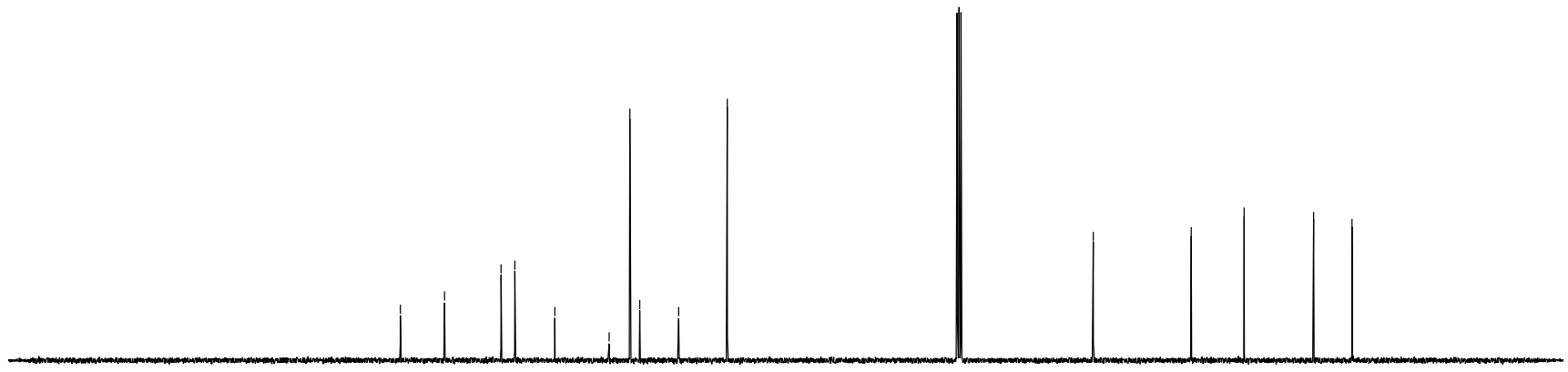

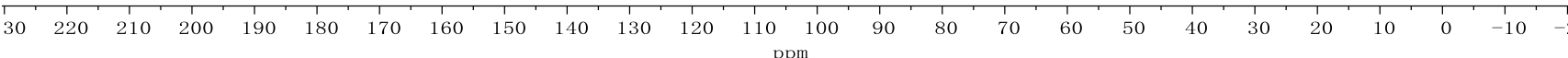


<smiles>CCCCNC(=O)c1nccnc1-c1ccc(OC)cc1</smiles>

413d

$\left(400 \mathrm{MHz}, \mathrm{CDCl}_{3}\right)$

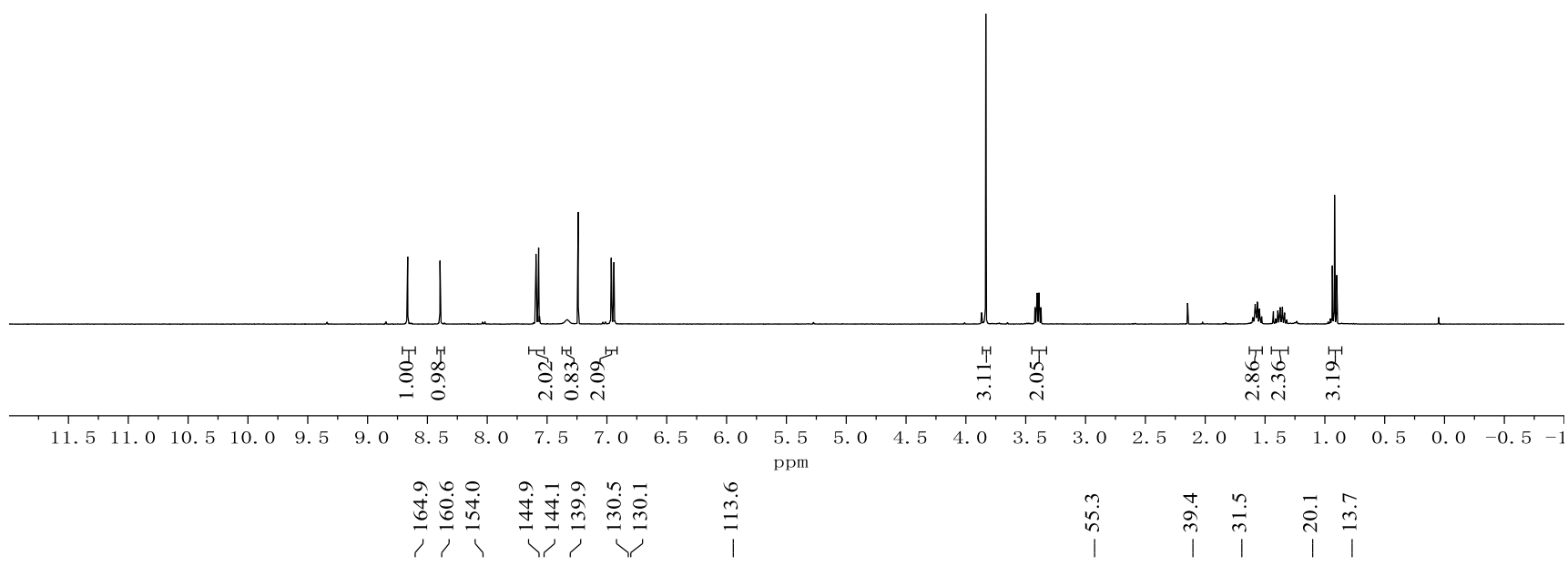<smiles>CCCCNC(=O)c1nccnc1-c1ccc(OC)cc1</smiles>

413d

$\left(100 \mathrm{MHz}, \mathrm{CDCl}_{3}\right)$

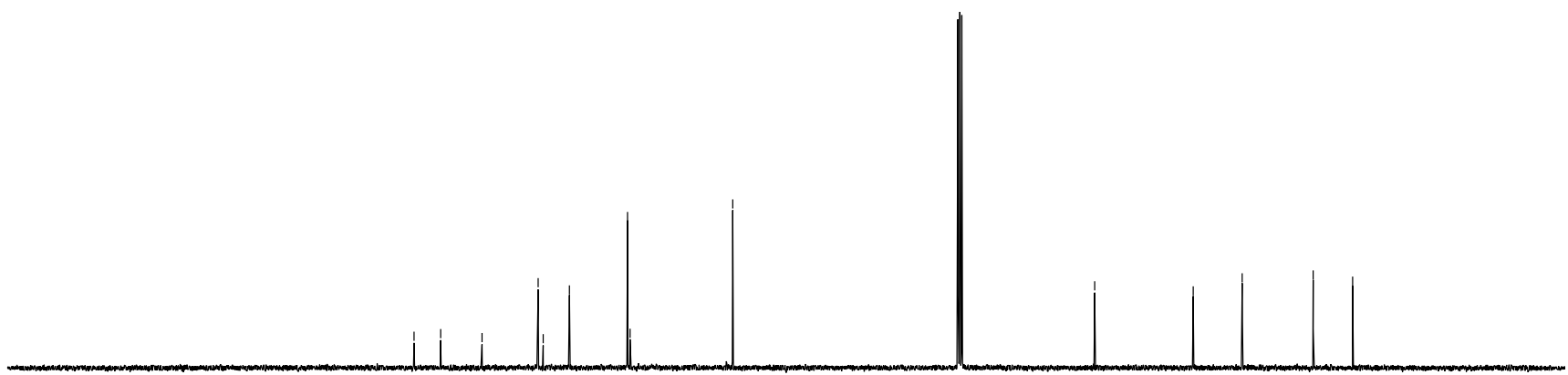

\begin{tabular}{llllllllllllllllllllllllllllllllllllll}
\hline 30 & 220 & 210 & 200 & 190 & 180 & 170 & 160 & 150 & 140 & 130 & 120 & 110 & 100 & 90 & 80 & 70 & 60 & 50 & 40 & 30 & 20 & 10 & 0 & -10 & -1
\end{tabular} 
<smiles>CCCCNC(=O)c1ncc(-c2ccccc2)cc1-c1ccc(OC)cc1</smiles>

$413 f$

$\left(400 \mathrm{MHz}, \mathrm{CDCl}_{3}\right)$

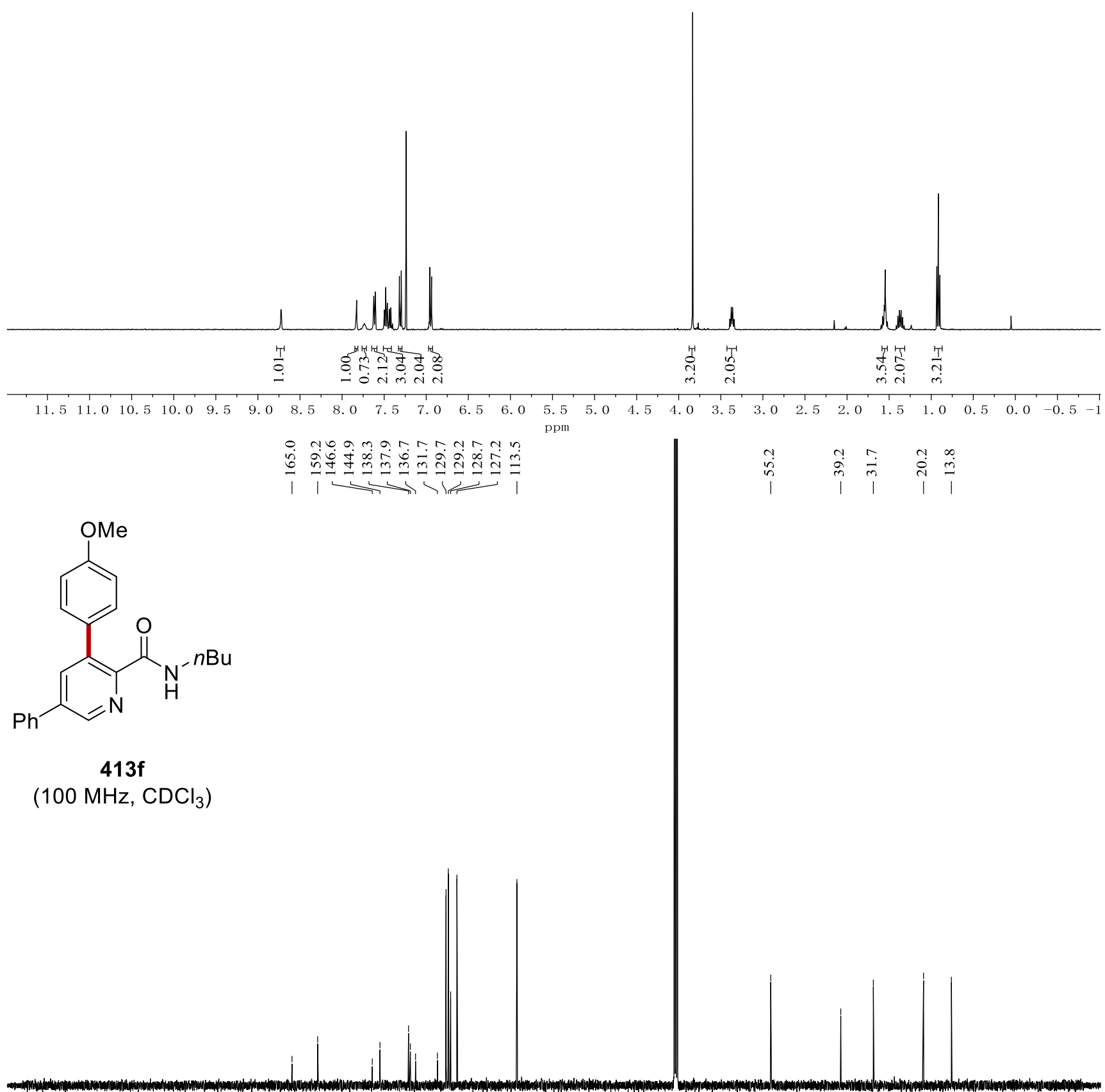

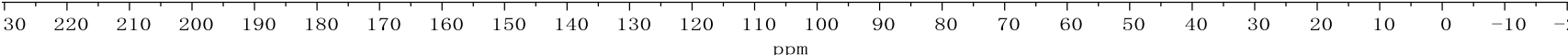




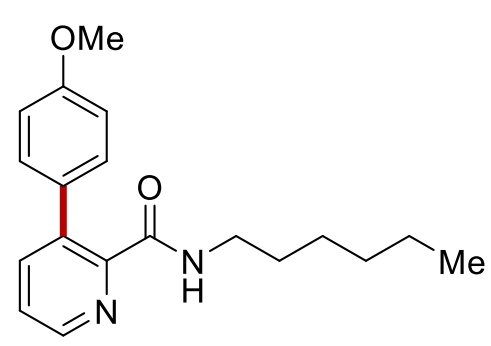

413g

(400 MHz, $\mathrm{CDCl}_{3}$ )

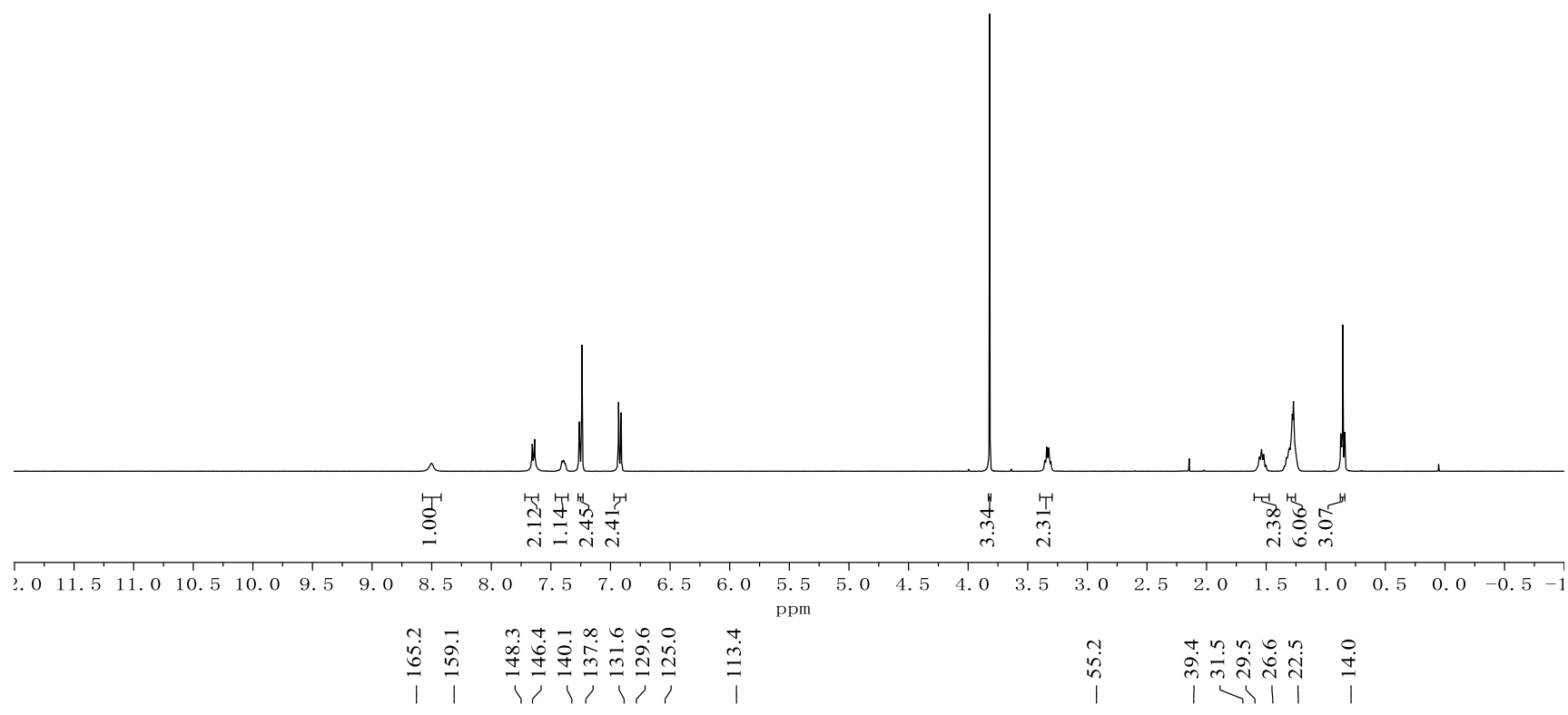<smiles>CCCCCCNC(=O)c1ncccc1-c1ccc(OC)cc1</smiles>

413g (100 MHz, $\mathrm{CDCl}_{3}$ )

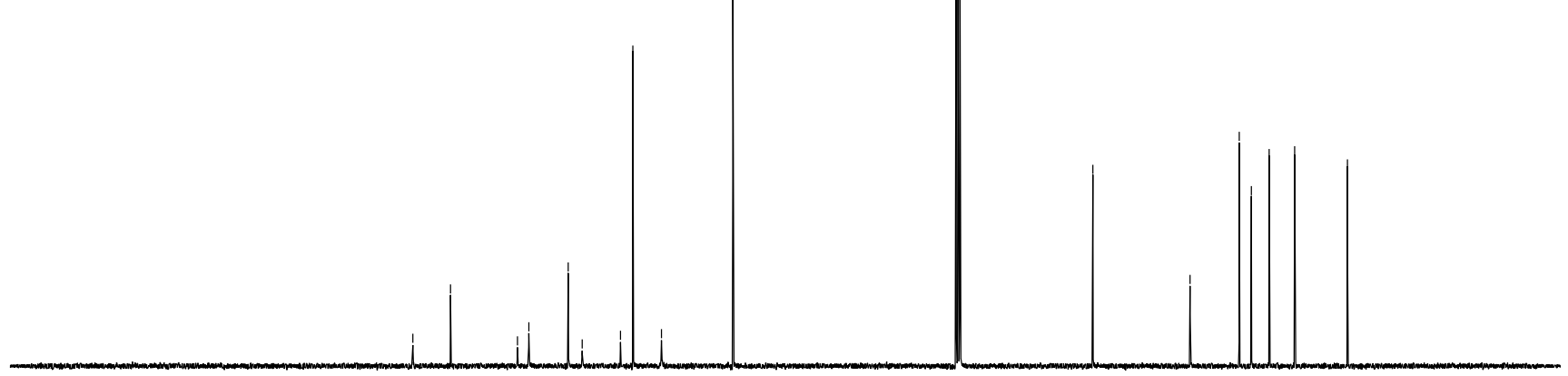

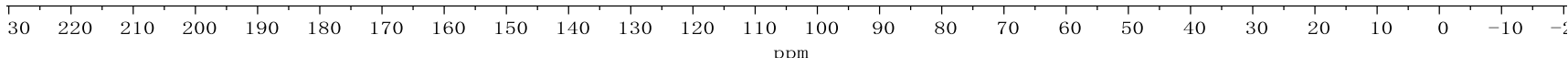


<smiles>COc1ccc(-c2cccnc2C(=O)NC2CCCCC2)cc1</smiles>

413h

(400 MHz, $\mathrm{CDCl}_{3}$ )

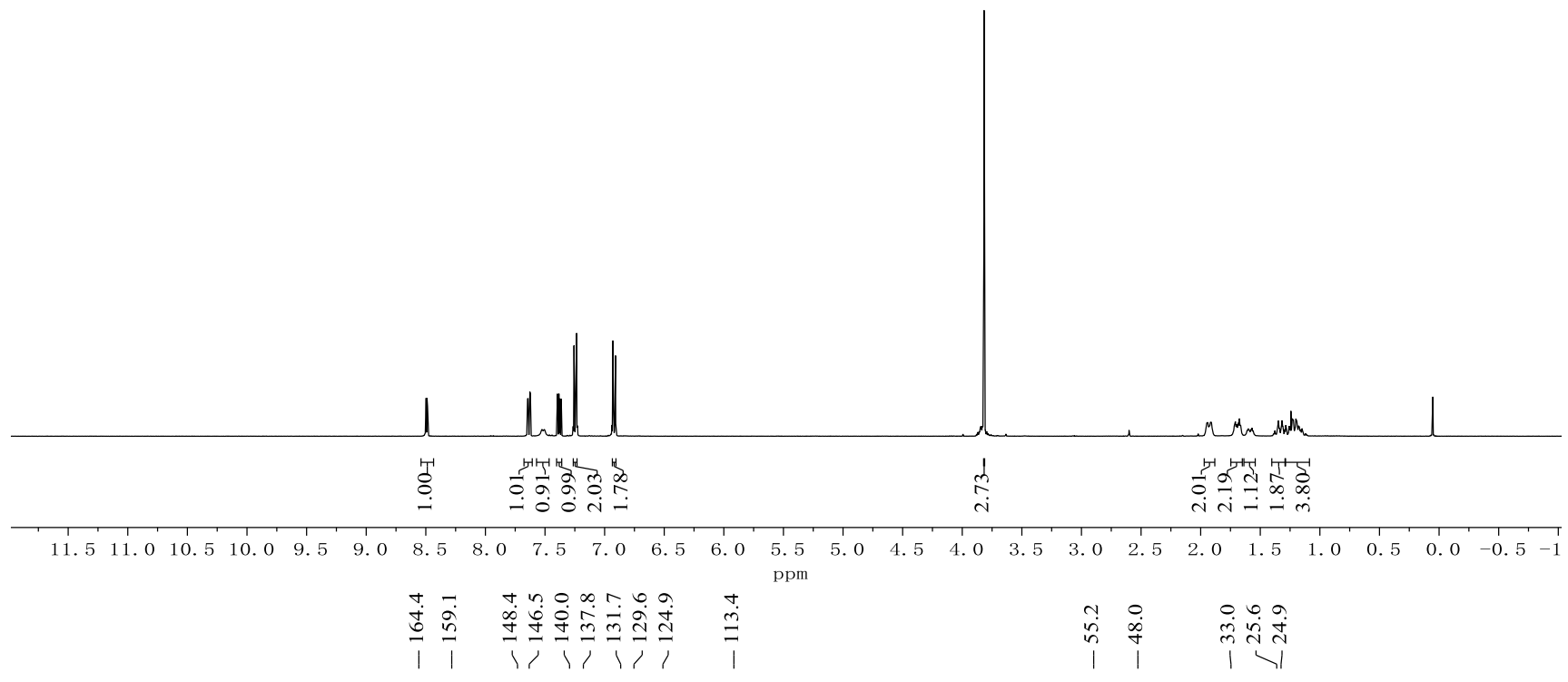<smiles>COc1ccc(-c2cccnc2C(=O)NC2CCCCC2)cc1</smiles>

413h

(100 MHz, $\mathrm{CDCl}_{3}$ )

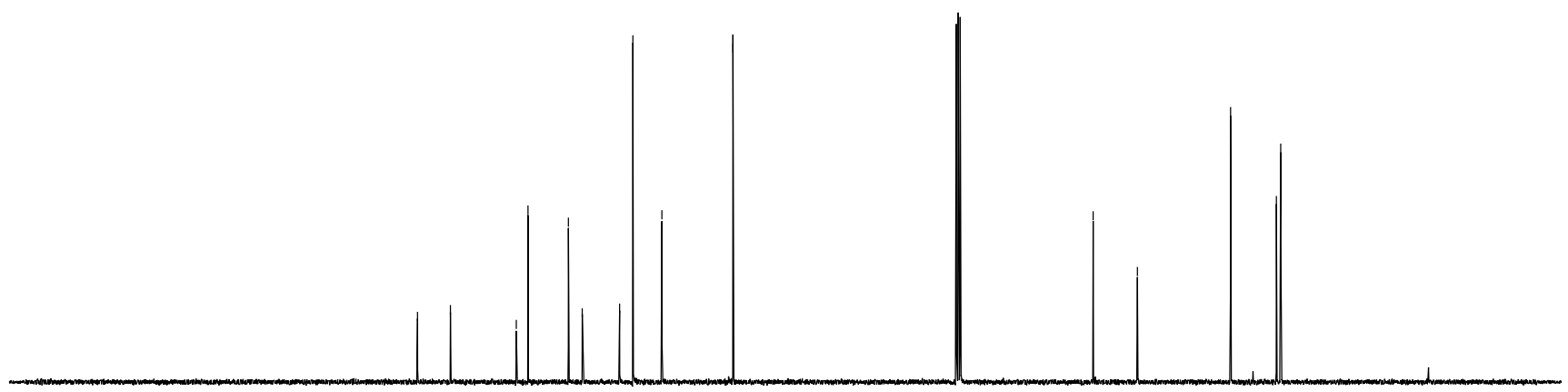

\begin{tabular}{lllllllllllllllllllllllllll}
\hline 30 & 220 & 210 & 200 & 190 & 180 & 170 & 160 & 150 & 140 & 130 & 120 & 110 & 100 & 90 & 80 & 70 & 60 & 50 & 40 & 30 & 20 & 10 & 0 & -10 & -1
\end{tabular} 
<smiles>COc1ccc(-c2cccnc2C(=O)NC2CCCc3ccccc32)cc1</smiles>

413i

(400 MHz, $\mathrm{CDCl}_{3}$ )

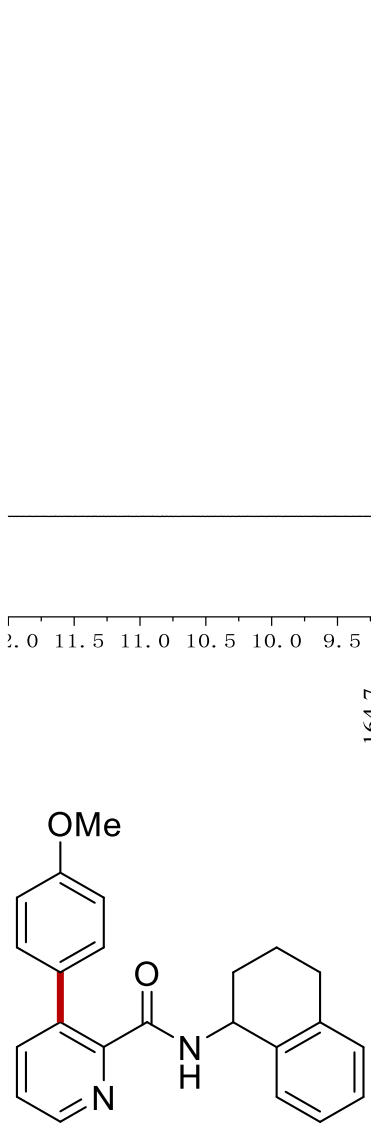

$413 i$

(100 MHz, $\mathrm{CDCl}_{3}$ )

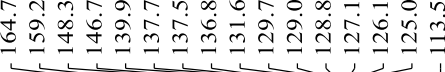

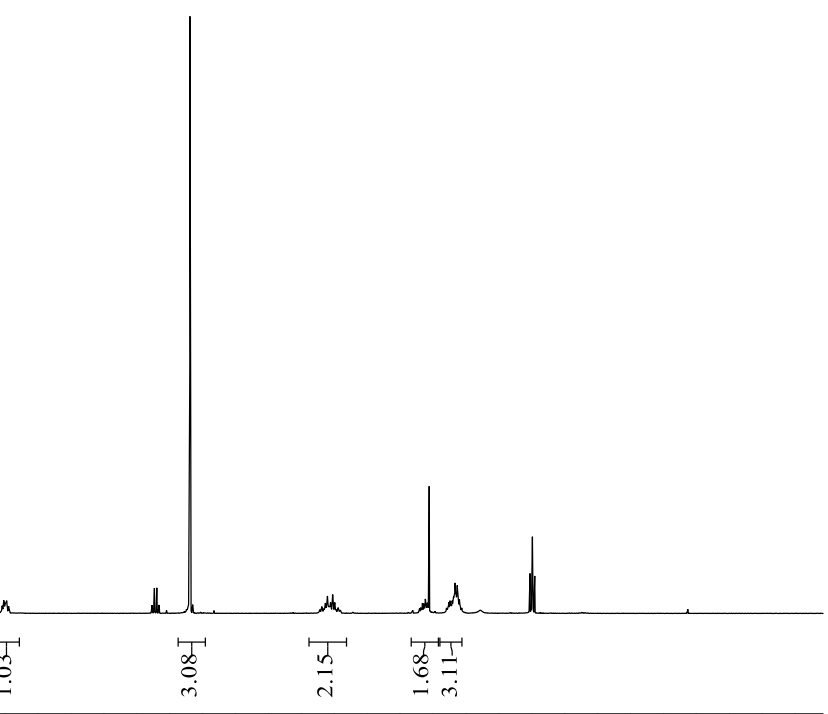

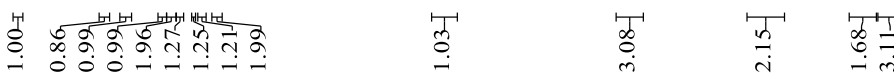

की

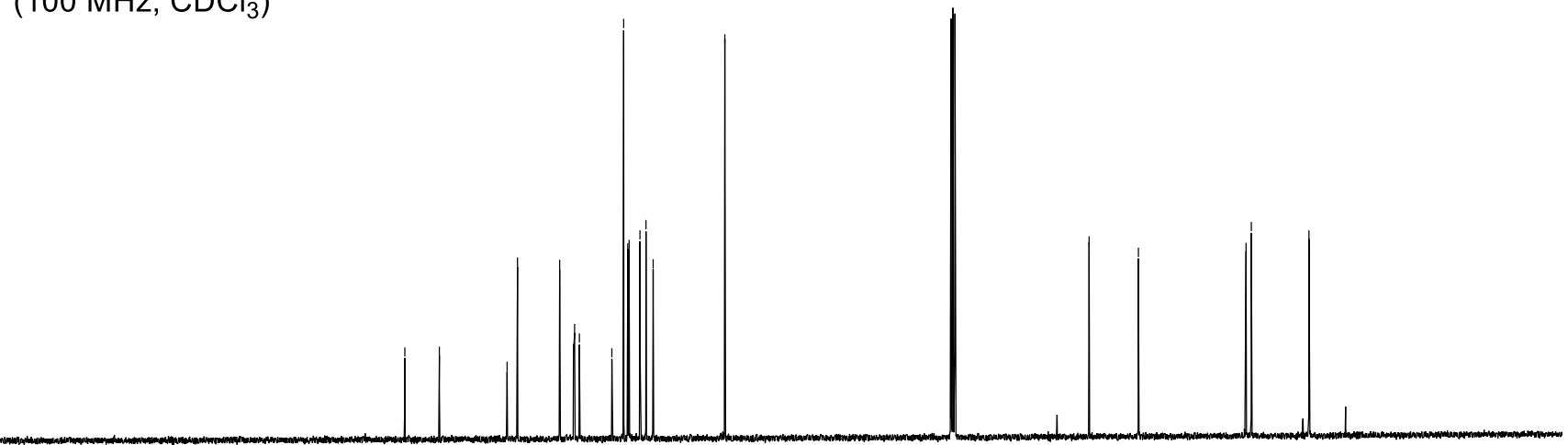

\begin{tabular}{llllllllllllllllllllllllllll}
\hline 30 & 220 & 210 & 200 & 190 & 180 & 170 & 160 & 150 & 140 & 130 & 120 & 110 & 100 & 90 & 80 & 70 & 60 & 50 & 40 & 30 & 20 & 10 & 0 & -10 & $-0^{\prime}$
\end{tabular} 
<smiles>COc1ccc(-c2cccnc2C(=O)NCc2ccccc2)cc1</smiles>

413j

(400 MHz, $\mathrm{CDCl}_{3}$ )

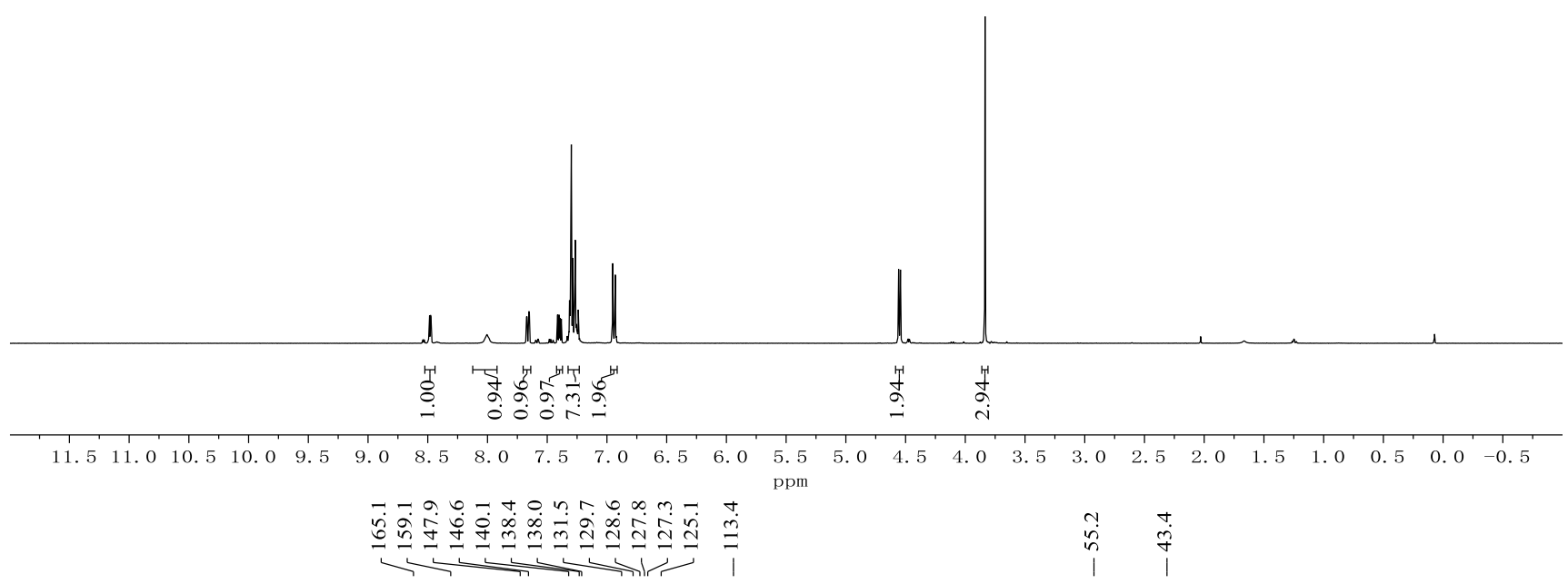<smiles>COc1ccc(-c2cccnc2C(=O)NCc2ccccc2)cc1</smiles>

413j

(100 MHz, $\mathrm{CDCl}_{3}$ )

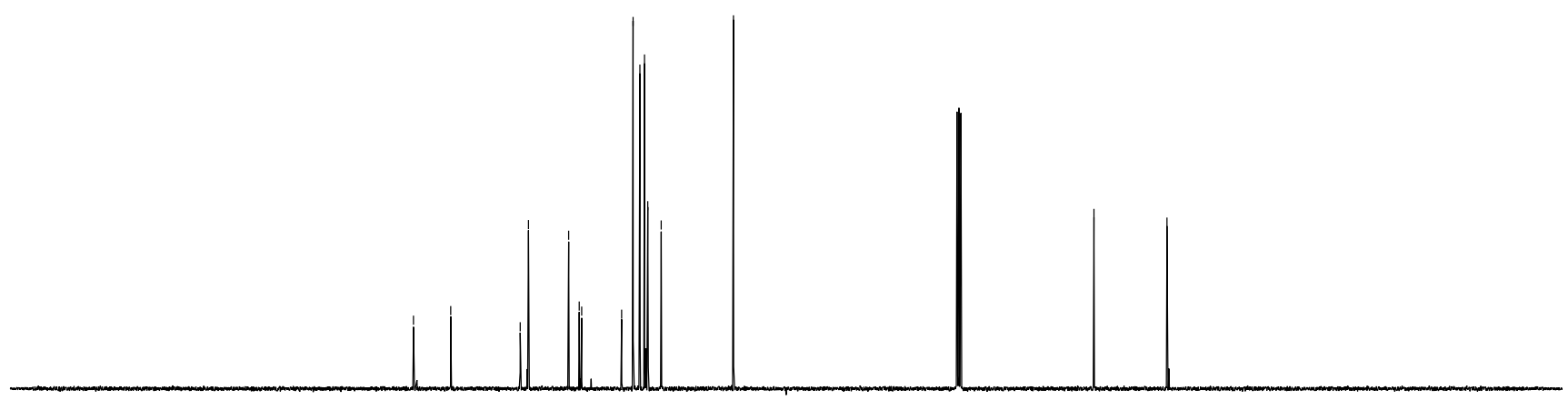

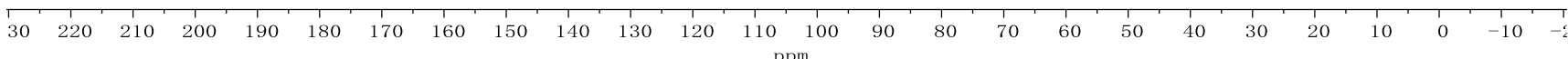




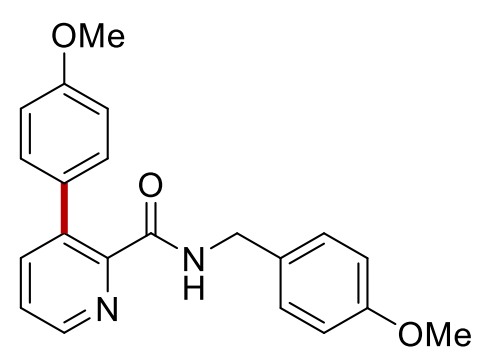

413k

(400 MHz, $\mathrm{CDCl}_{3}$ )

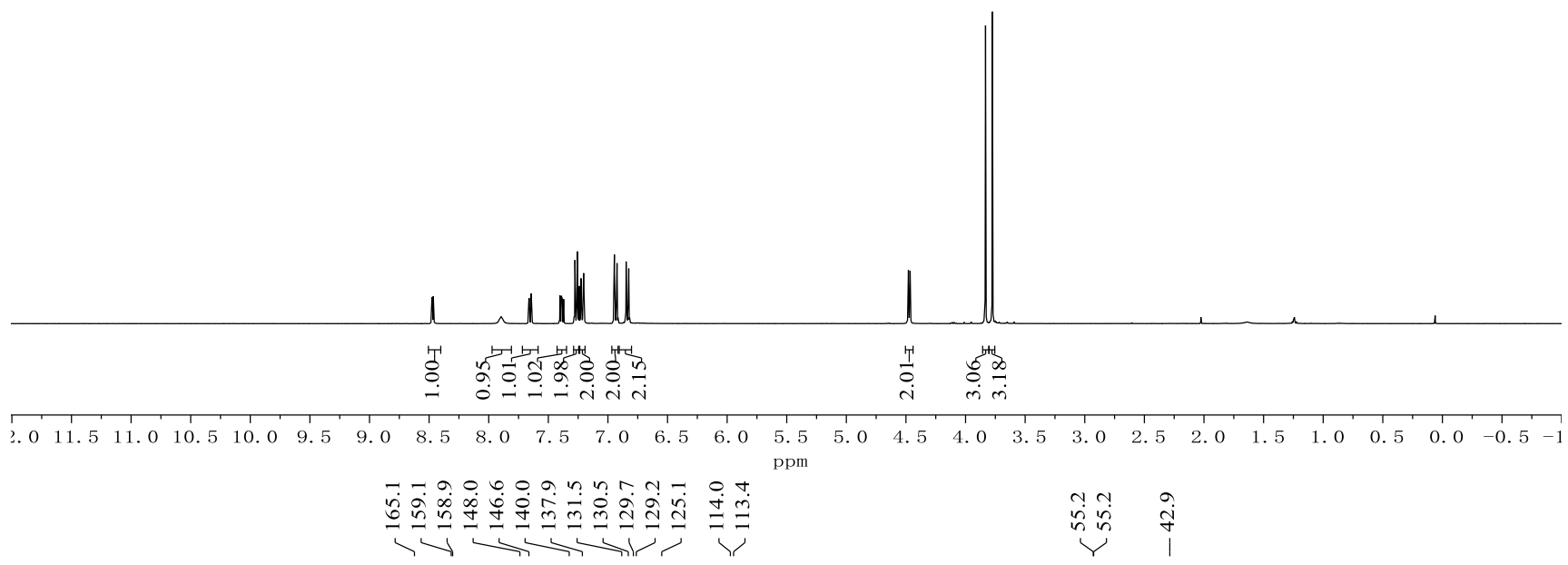<smiles>COc1ccc(CNC(=O)c2ncccc2-c2ccc(OC)cc2)cc1</smiles>

413k

(100 MHz, $\mathrm{CDCl}_{3}$ )

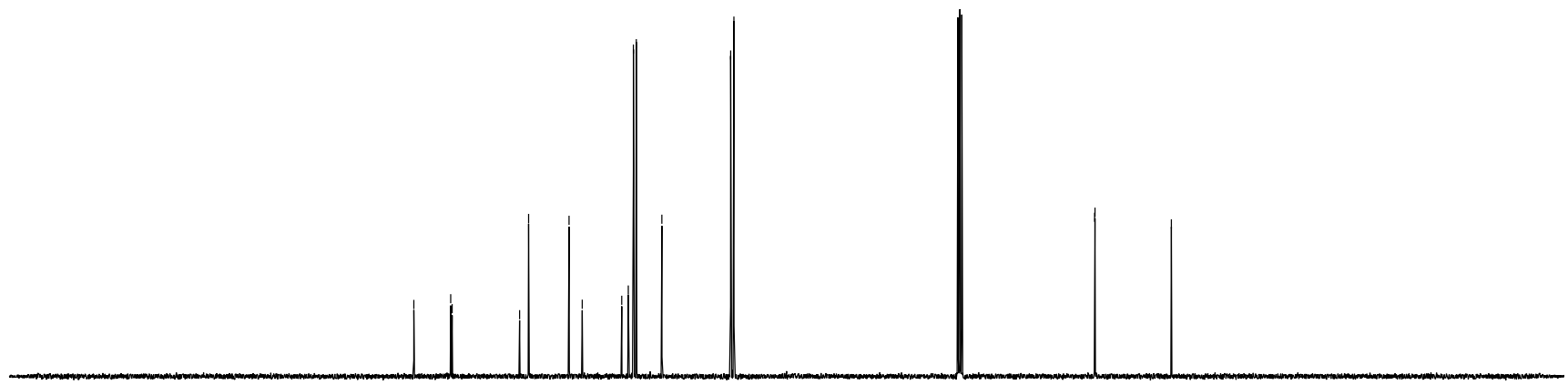

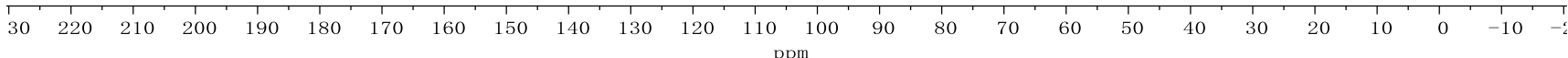


<smiles>COc1ccc(NC(=O)c2ncccc2-c2ccc(C)cc2)cc1</smiles>

413I

(400 MHz, $\mathrm{CDCl}_{3}$ )

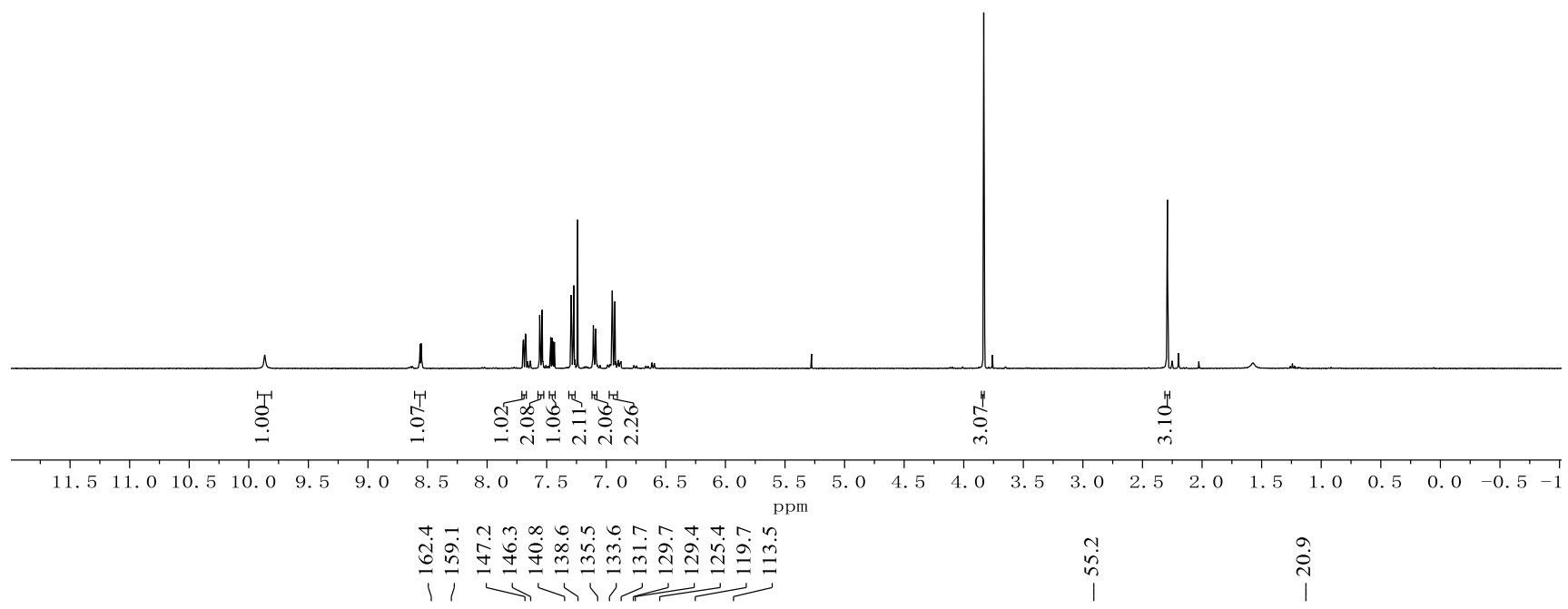<smiles>COc1ccc(NC(=O)c2ncccc2-c2ccc(C)cc2)cc1</smiles>

413I

(100 MHz, $\mathrm{CDCl}_{3}$ )

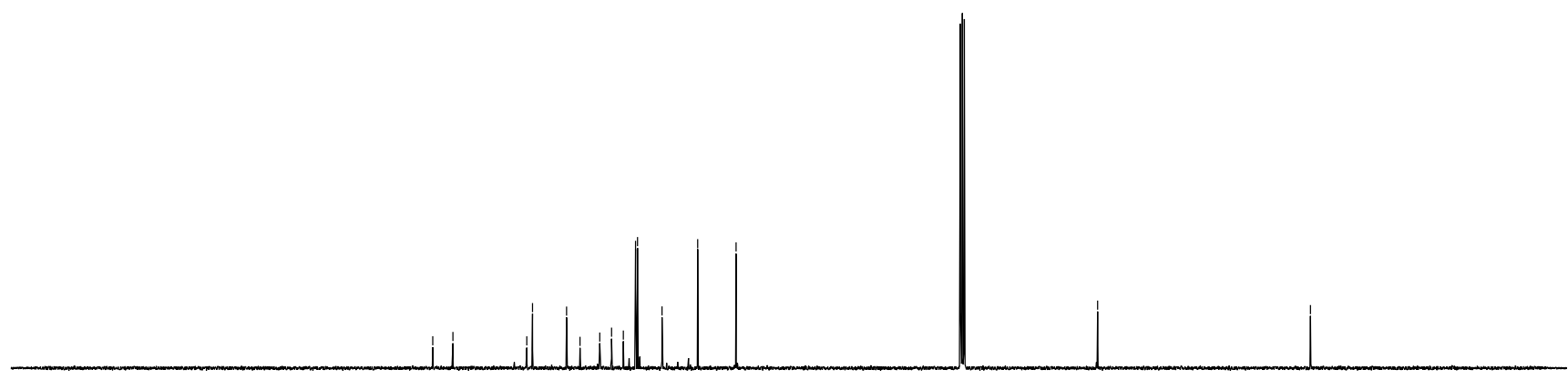

\begin{tabular}{llllllllllllllllllllllllllllllllllll}
\hline 30 & 220 & 210 & 200 & 190 & 180 & 170 & 160 & 150 & 140 & 130 & 120 & 110 & 100 & 90 & 80 & 70 & 60 & 50 & 40 & 30 & 20 & 10 & 0 & -10 & -5
\end{tabular} 
<smiles>COc1ccc(NC(=O)c2ncccc2-c2ccc(OC)cc2)cc1</smiles>

$413 \mathrm{~m}$

(400 MHz, $\mathrm{CDCl}_{3}$ )

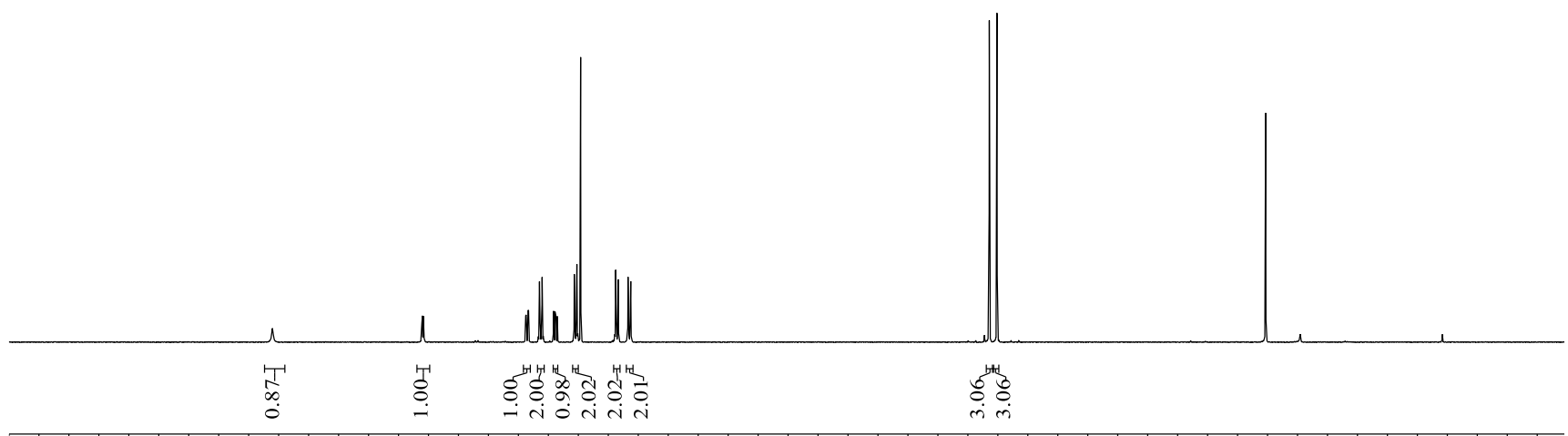
\begin{tabular}{lllllllllllllllllllllllllllllllllll}
\hline 0 & 11.5 & 11.0 & 10.5 & 10.0 & 9.5 & 9.0 & 8.5 & 8.0 & 7.5 & 7.0 & 6.5 & 6.0 & 5.5 & 5.0 & 4.5 & 4.0 & 3.5 & 3.0 & 2.5 & 2.0 & 1.5 & 1.0 & 0.5 & 0.0 & -0.5
\end{tabular}

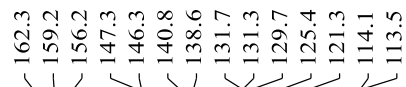<smiles>COc1ccc(NC(=O)c2ncccc2-c2ccc(OC)cc2)cc1</smiles>

$413 \mathrm{~m}$

(100 MHz, $\mathrm{CDCl}_{3}$ )

\begin{tabular}{lllllllllllllllllllllllllll}
\hline 30 & 220 & 210 & 200 & 190 & 180 & 170 & 160 & 150 & 140 & 130 & 120 & 110 & 100 & 90 & 80 & 70 & 60 & 50 & 40 & 30 & 20 & 10 & 0 & -10 & -1 & 10
\end{tabular} 
<smiles>CCCCNC(=O)c1ncccc1-c1ccc(Br)cc1</smiles>

413n

(400 MHz, $\mathrm{CDCl}_{3}$ )

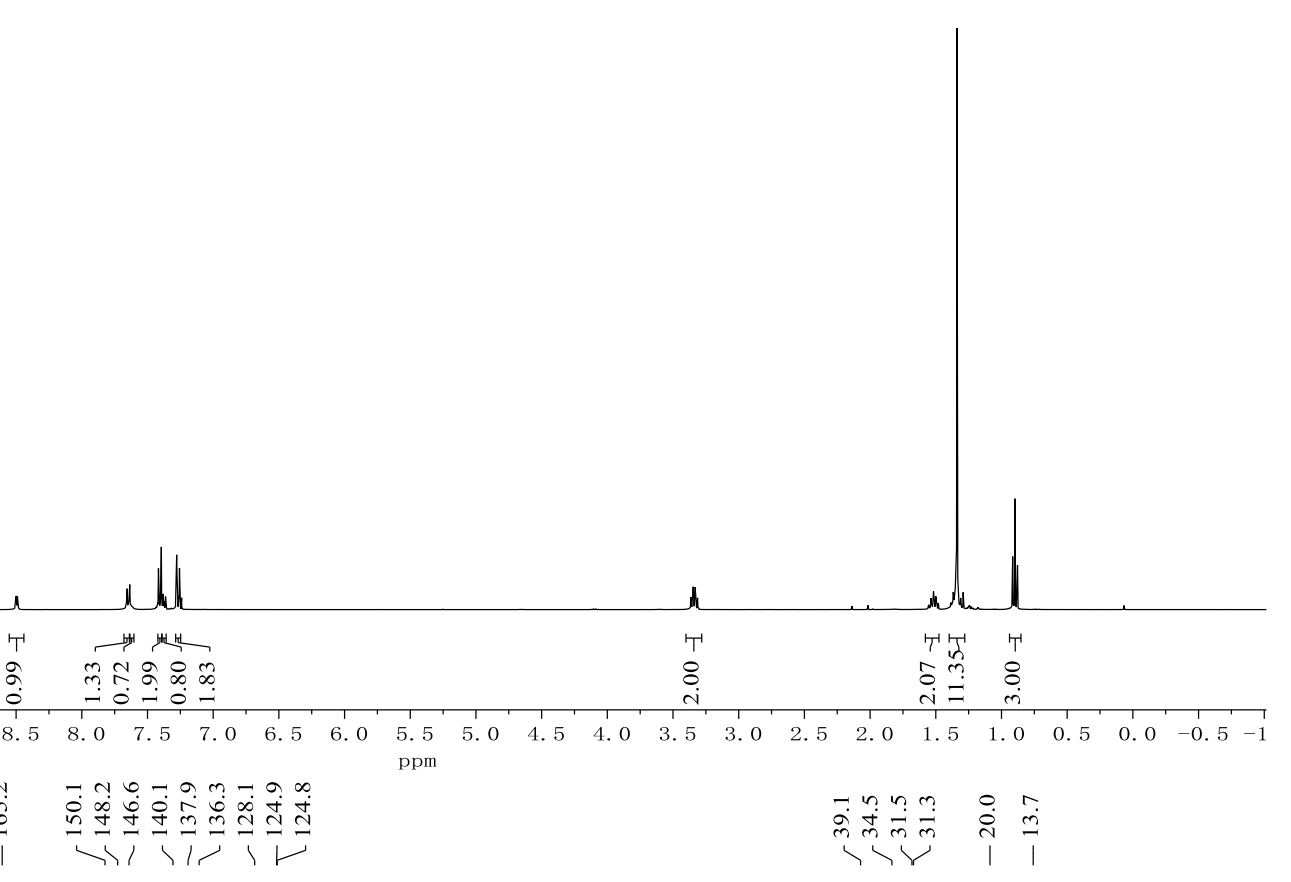

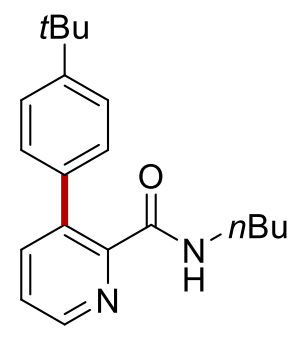

413n

$\left(100 \mathrm{MHz}, \mathrm{CDCl}_{3}\right)$

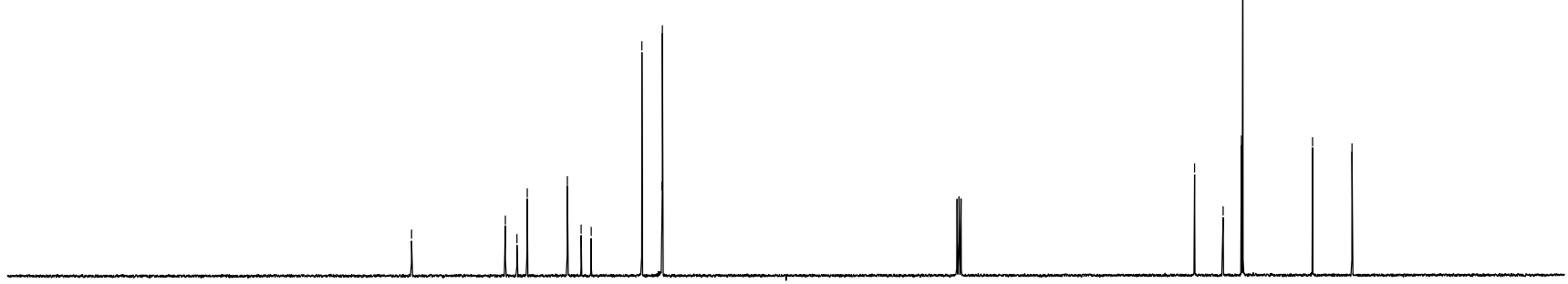

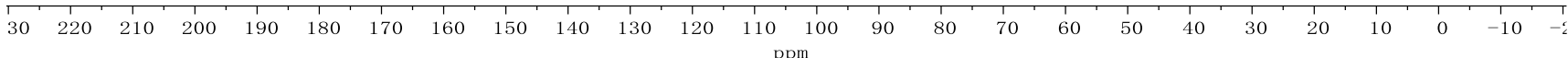




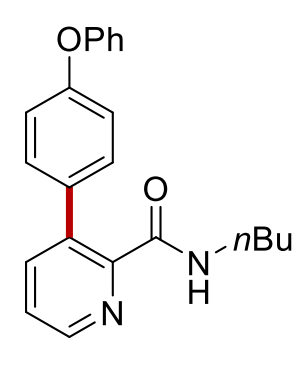

4130

(400 MHz, $\mathrm{CDCl}_{3}$ )

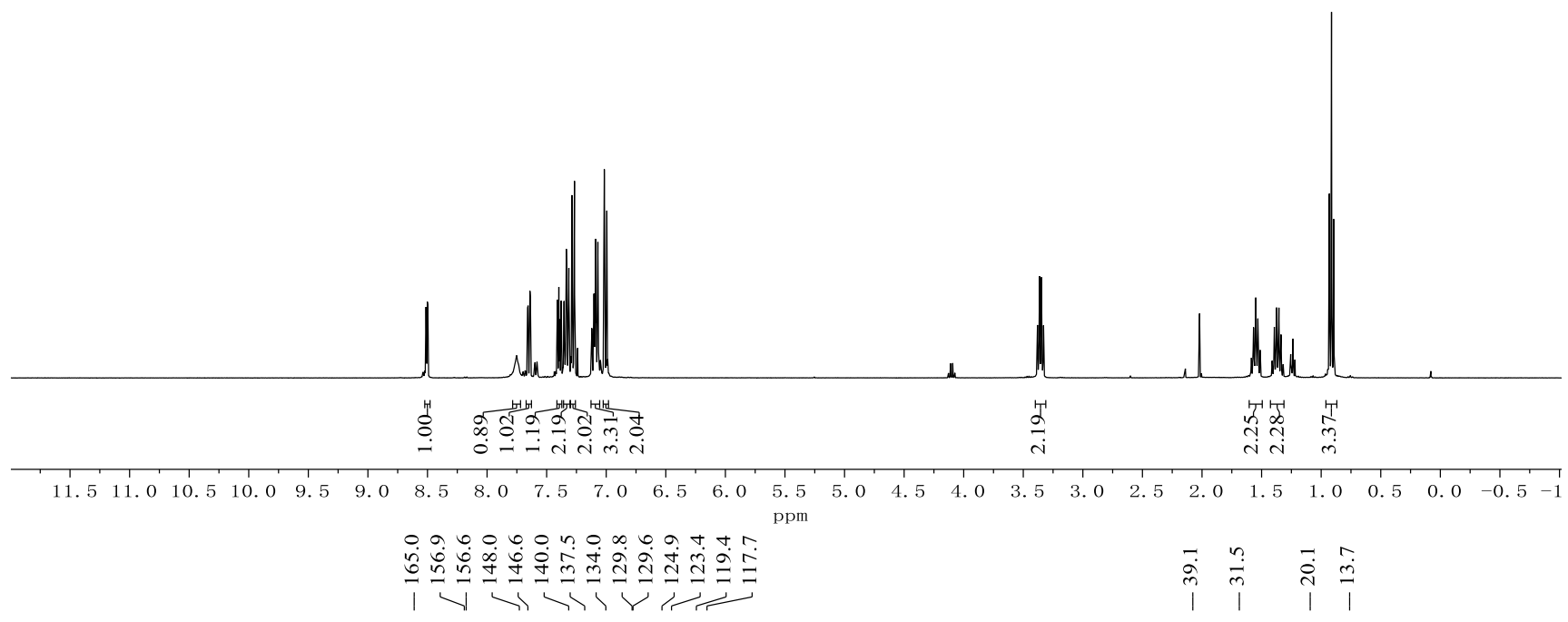<smiles>CCCCNC(=O)c1ncccc1-c1ccc(Oc2ccccc2)cc1</smiles>

4130

(100 MHz, $\mathrm{CDCl}_{3}$ )

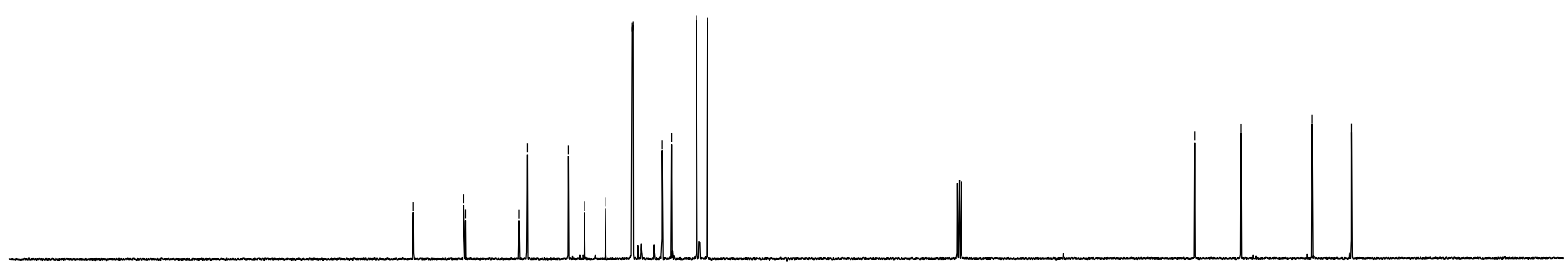

\begin{tabular}{llllllllllllllllllllllllllllllllllllllll}
\hline 30 & 220 & 210 & 200 & 190 & 180 & 170 & 160 & 150 & 140 & 130 & 120 & 110 & 100 & 90 & 80 & 70 & 60 & 50 & 40 & 30 & 20 & 10 & 0 & -10 & -2
\end{tabular} 
$\overbrace{N}^{M e} N_{\mathrm{H}^{-}}^{\mathrm{O} B u}$

415a

(300 MHz, $\mathrm{CDCl}_{3}$ )

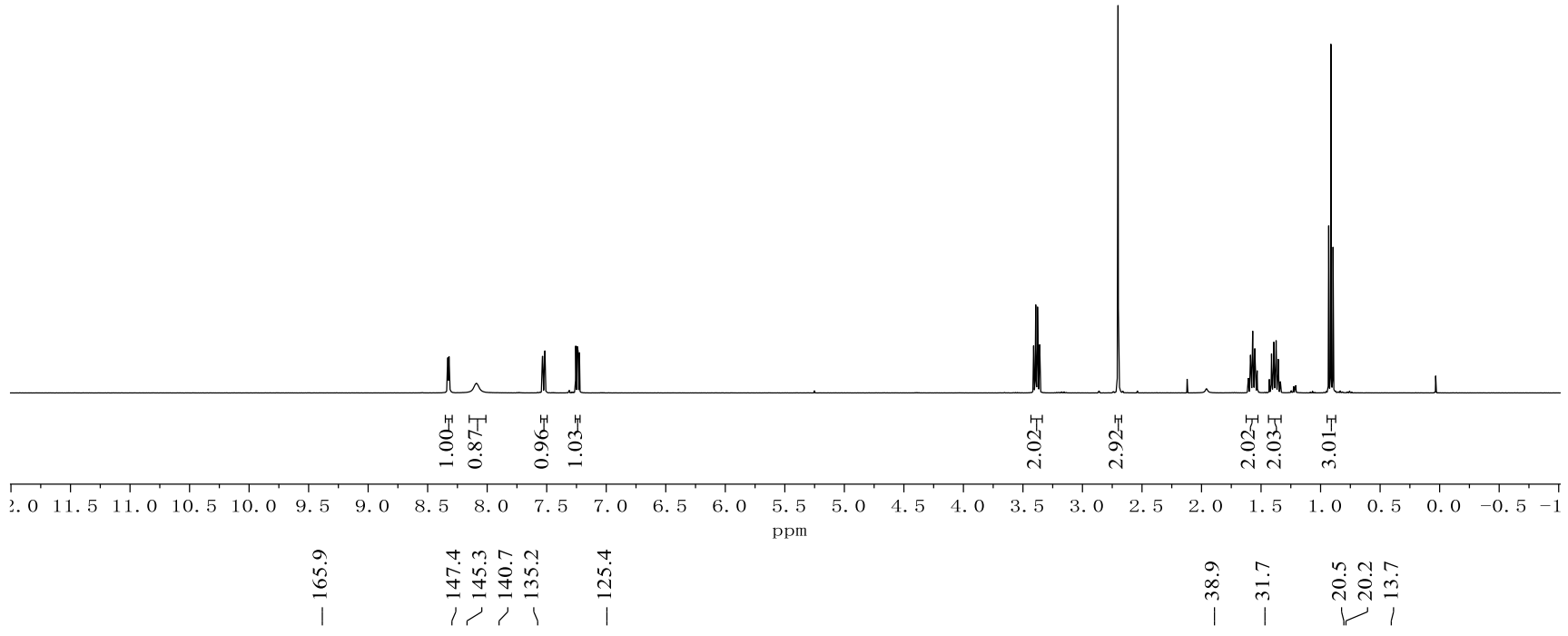

$\overbrace{N}^{M e} N_{N^{-n B u}}^{O}$

415a

$\left(75 \mathrm{MHz}, \mathrm{CDCl}_{3}\right.$ )

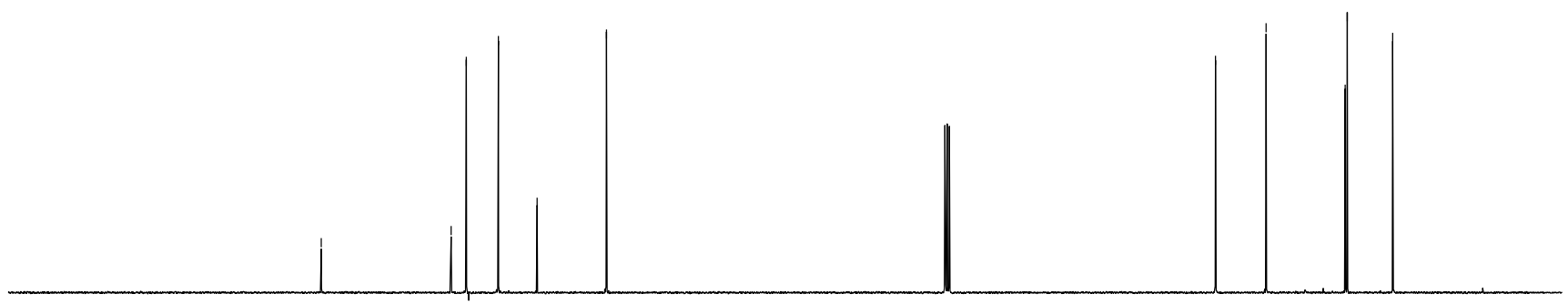

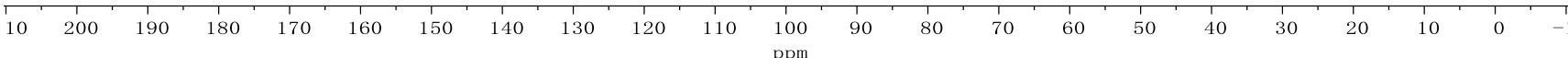


$\overbrace{N}^{\mathrm{E}} \mathrm{N}_{\mathrm{H}^{-}}^{\mathrm{O} B \mathrm{Bu}}$

415b

(300 MHz, $\mathrm{CDCl}_{3}$ )

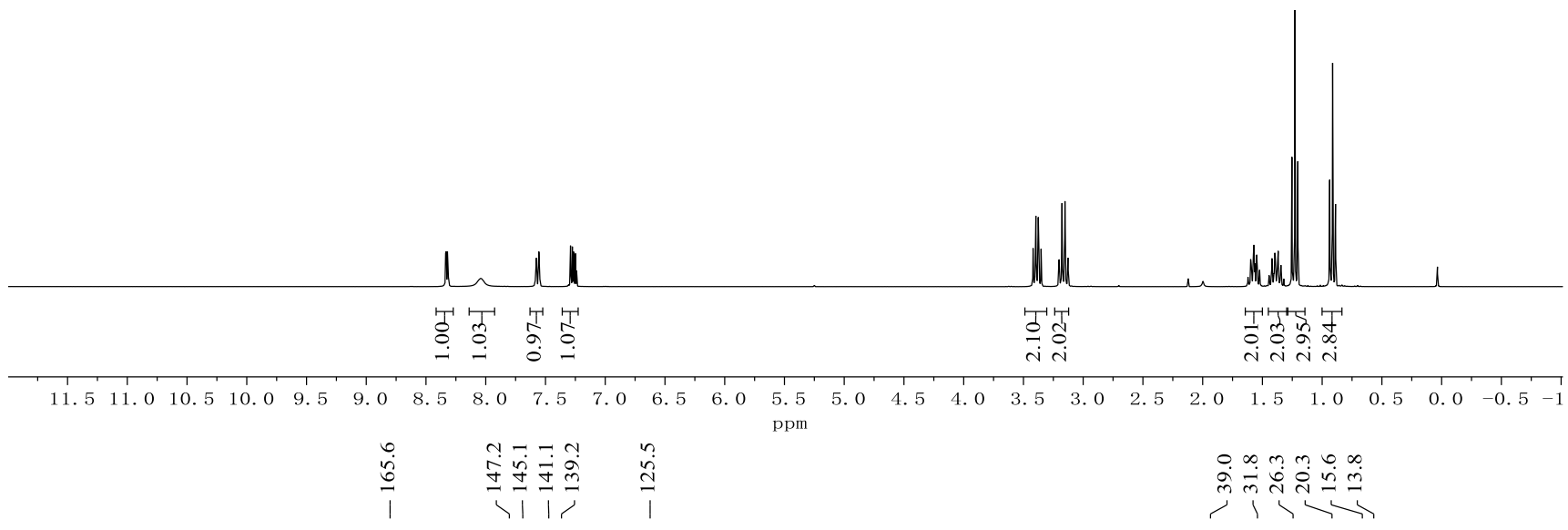

$\overbrace{N}^{E t} N_{N^{-n B u}}^{O}$

415b

$\left(75 \mathrm{MHz}, \mathrm{CDCl}_{3}\right.$ )

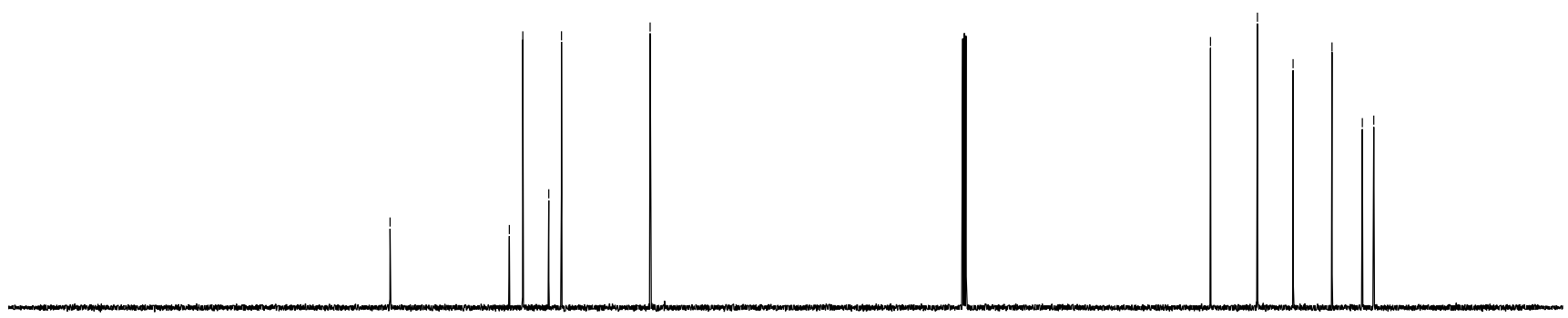

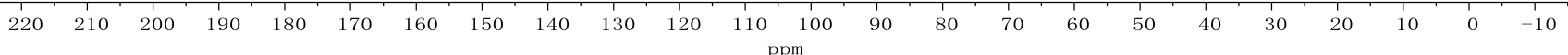




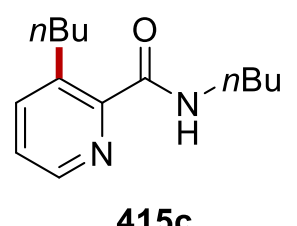

$\left(300 \mathrm{MHz}, \mathrm{CDCl}_{3}\right)$

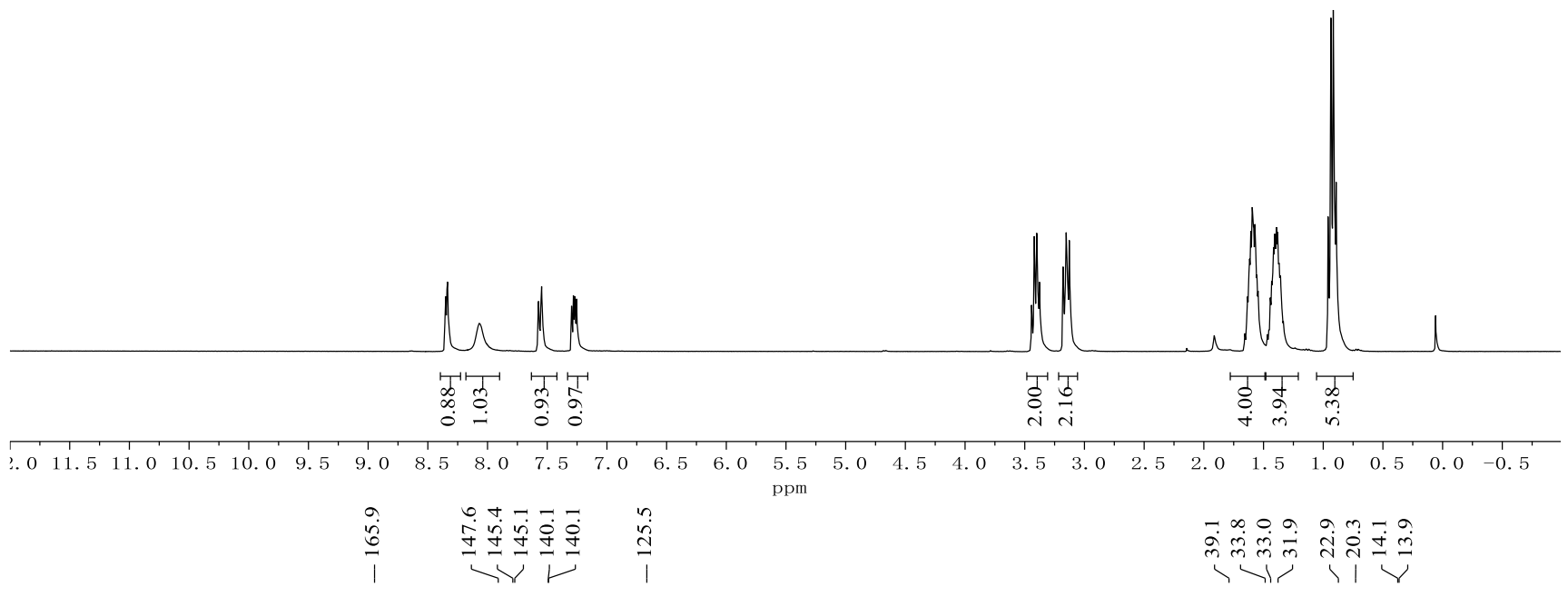<smiles>CCCCNC(=O)c1ncccc1CCCC</smiles>

$415 \mathrm{c}$

(75 MHz, $\mathrm{CDCl}_{3}$ )

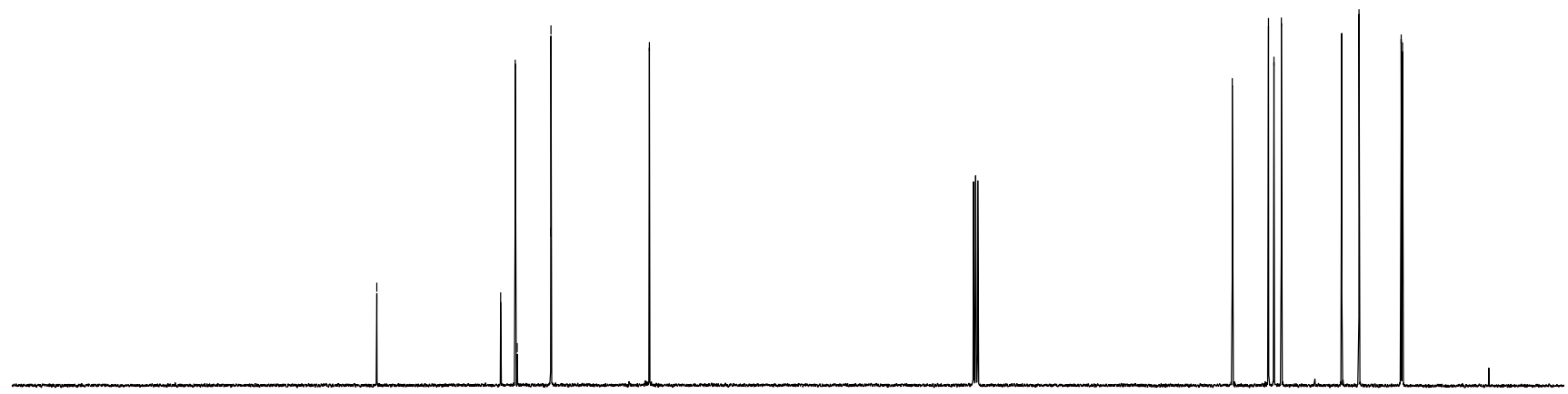

\begin{tabular}{llllllllllllllllllllllllll}
\hline & 210 & 200 & 190 & 180 & 170 & 160 & 150 & 140 & 130 & 120 & 110 & 100 & 90 & 80 & 70 & 60 & 50 & 40 & 30 & 20 & 10 & 0 & -
\end{tabular} 
$\underbrace{\mathrm{Oct}}_{=\mathrm{N}} \mathrm{N}_{\mathrm{H}^{-n \mathrm{Bu}}}^{\mathrm{O}}$

415d

$\left(400 \mathrm{MHz}, \mathrm{CDCl}_{3}\right)$

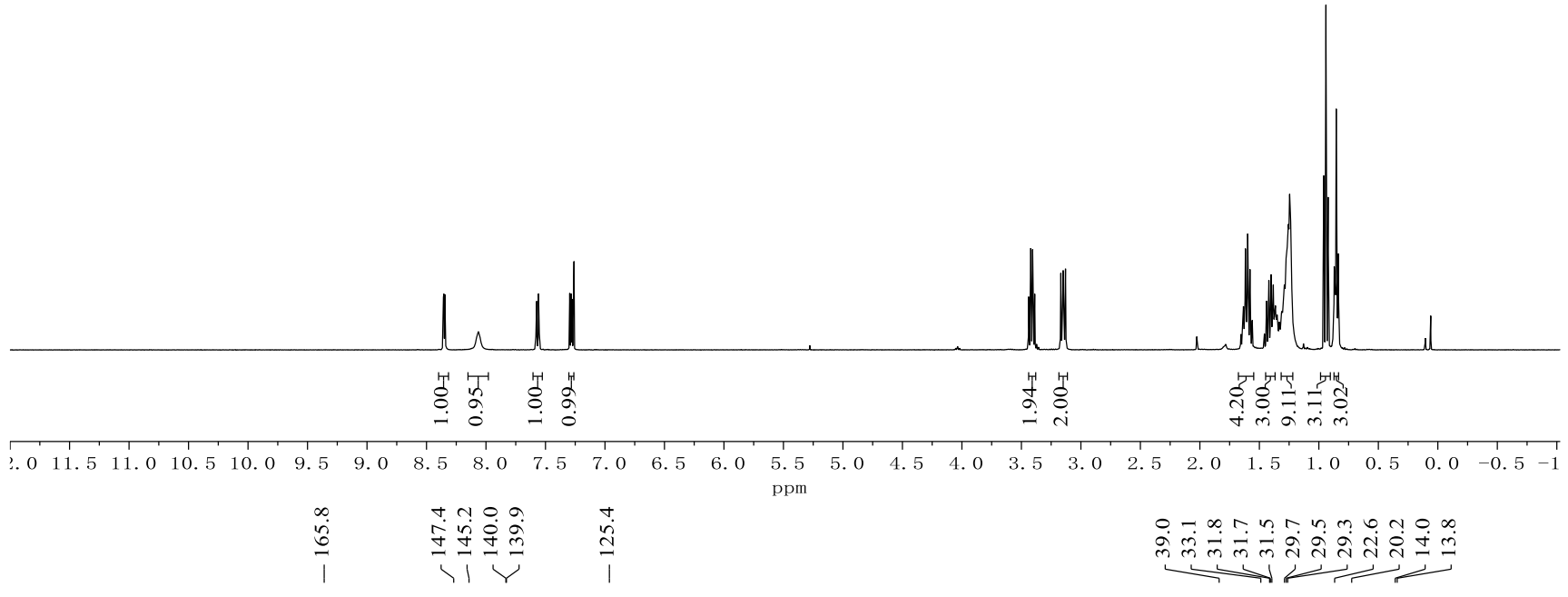

$\underbrace{\mathrm{Oct}}_{=\mathrm{N}} \underbrace{\mathrm{O}}_{\mathrm{H}^{-n B u}}$

415d

(100 MHz, $\mathrm{CDCl}_{3}$ )

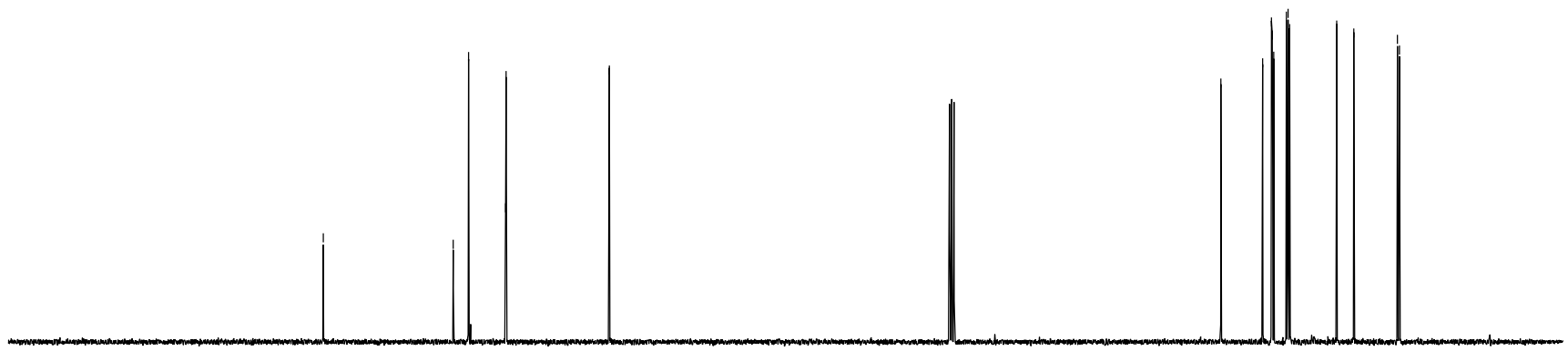

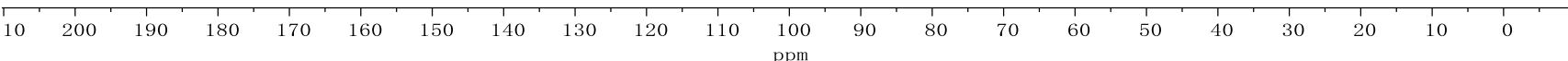


$\underbrace{i P r}_{=N} N_{N^{-n B u}}^{O}$

$415 e$

$\left(400 \mathrm{MHz}, \mathrm{CDCl}_{3}\right.$ )

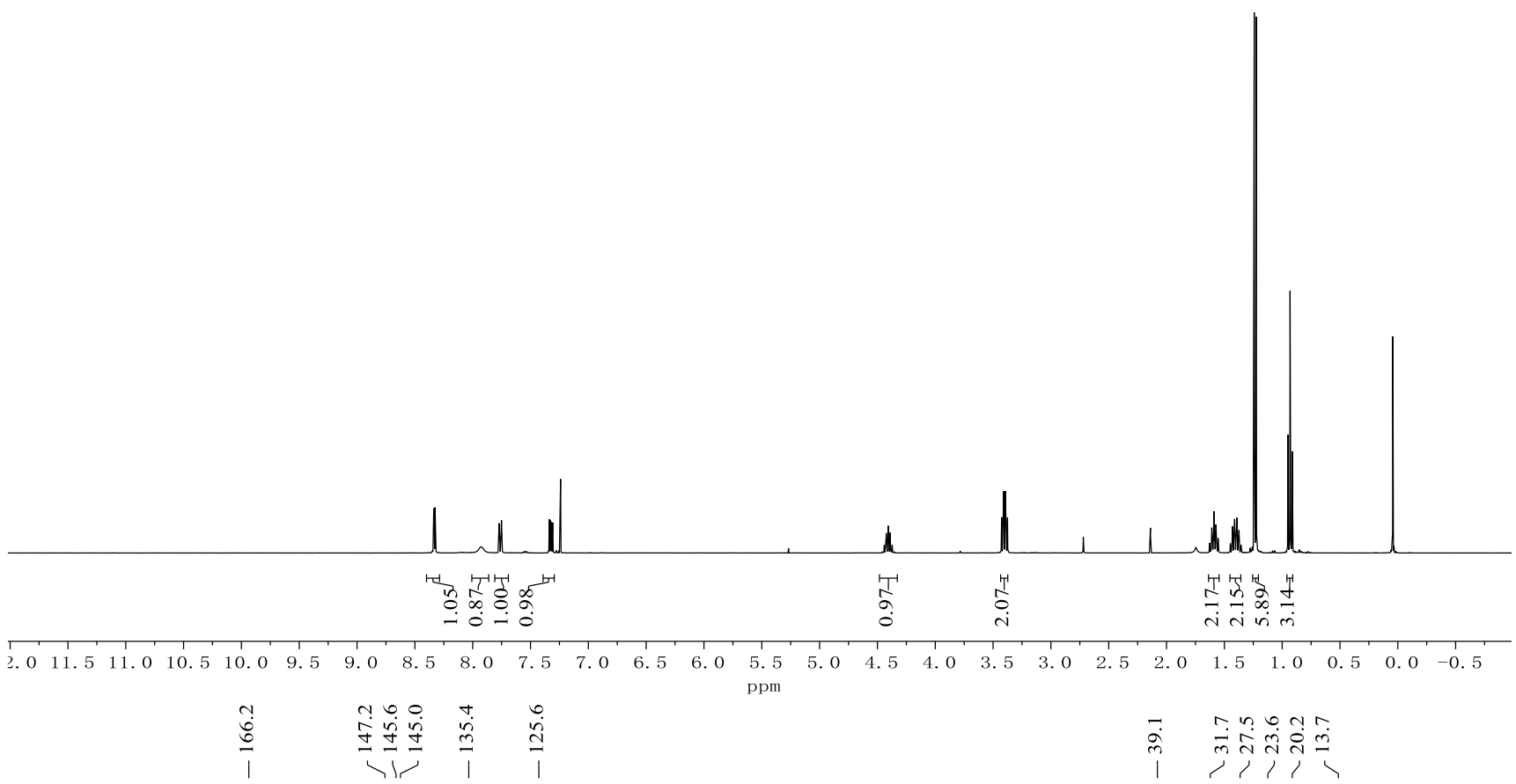

$\underbrace{i \mathrm{Pr}}_{=\mathrm{N}} \mathrm{N}_{\mathrm{H}^{-n B u}}^{\mathrm{O}}$

$415 e$

$\left(100 \mathrm{MHz}, \mathrm{CDCl}_{3}\right.$ )

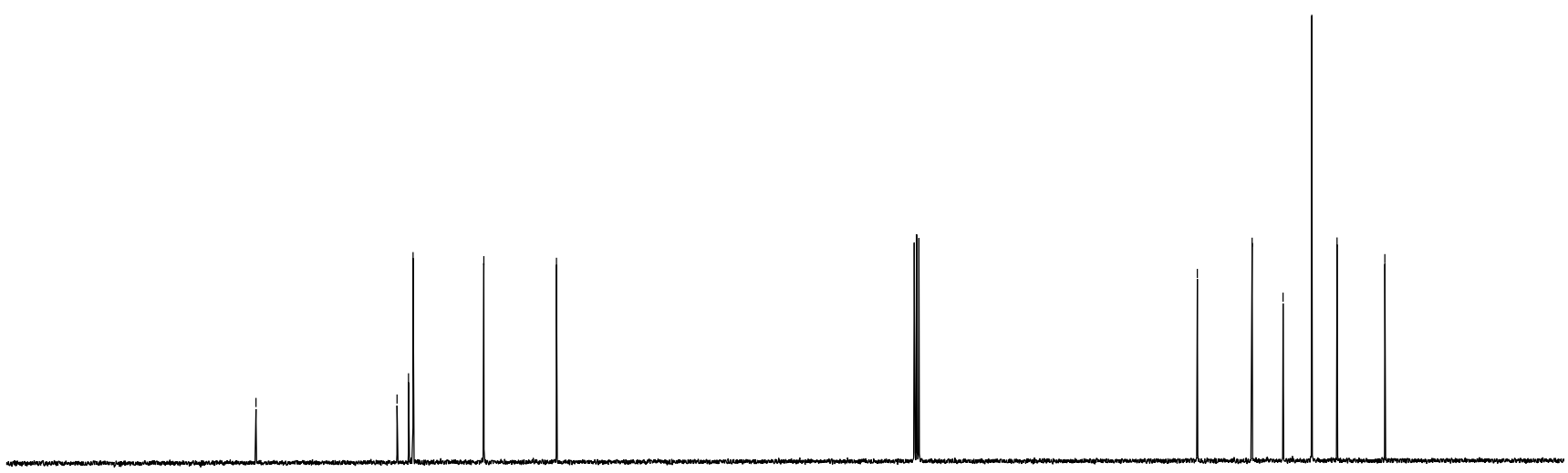

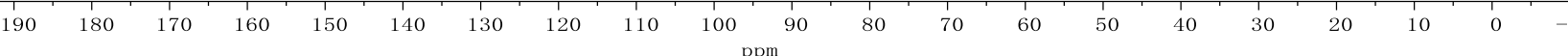




$$
\left(300 \mathrm{MHz}, \mathrm{CDCl}_{3}\right)
$$

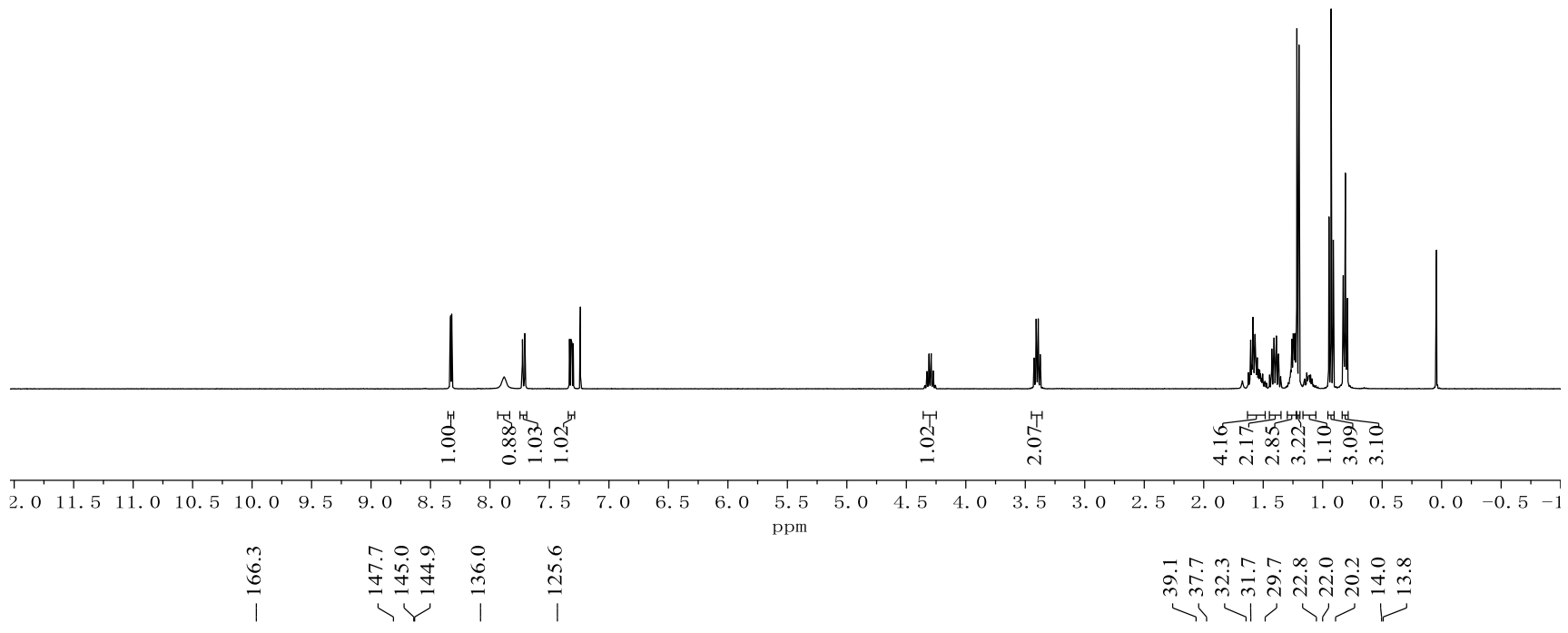<smiles>CCCCNC(=O)c1ncccc1C(CCCC)CCCC</smiles>

$415 f$

(75 $\mathrm{MHz}, \mathrm{CDCl}_{3}$ )

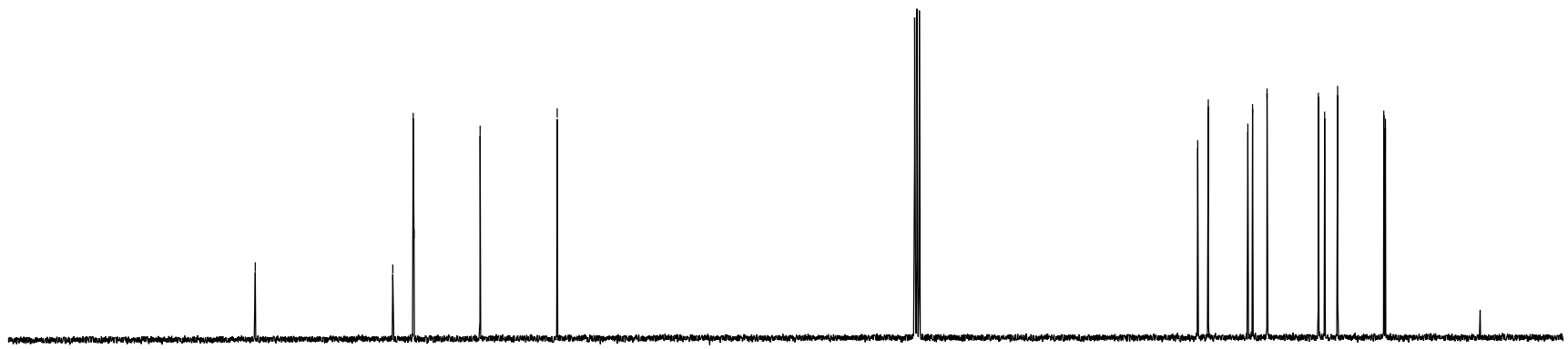

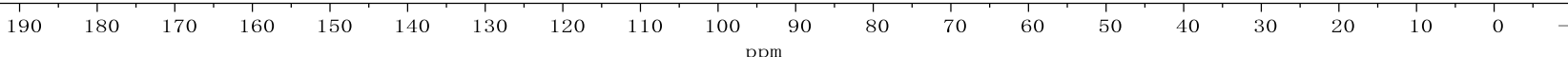


<smiles>CCCCNC(=O)c1ncccc1C1CC1</smiles>

$415 \mathrm{~g}$

$\left(400 \mathrm{MHz}, \mathrm{CDCl}_{3}\right)$

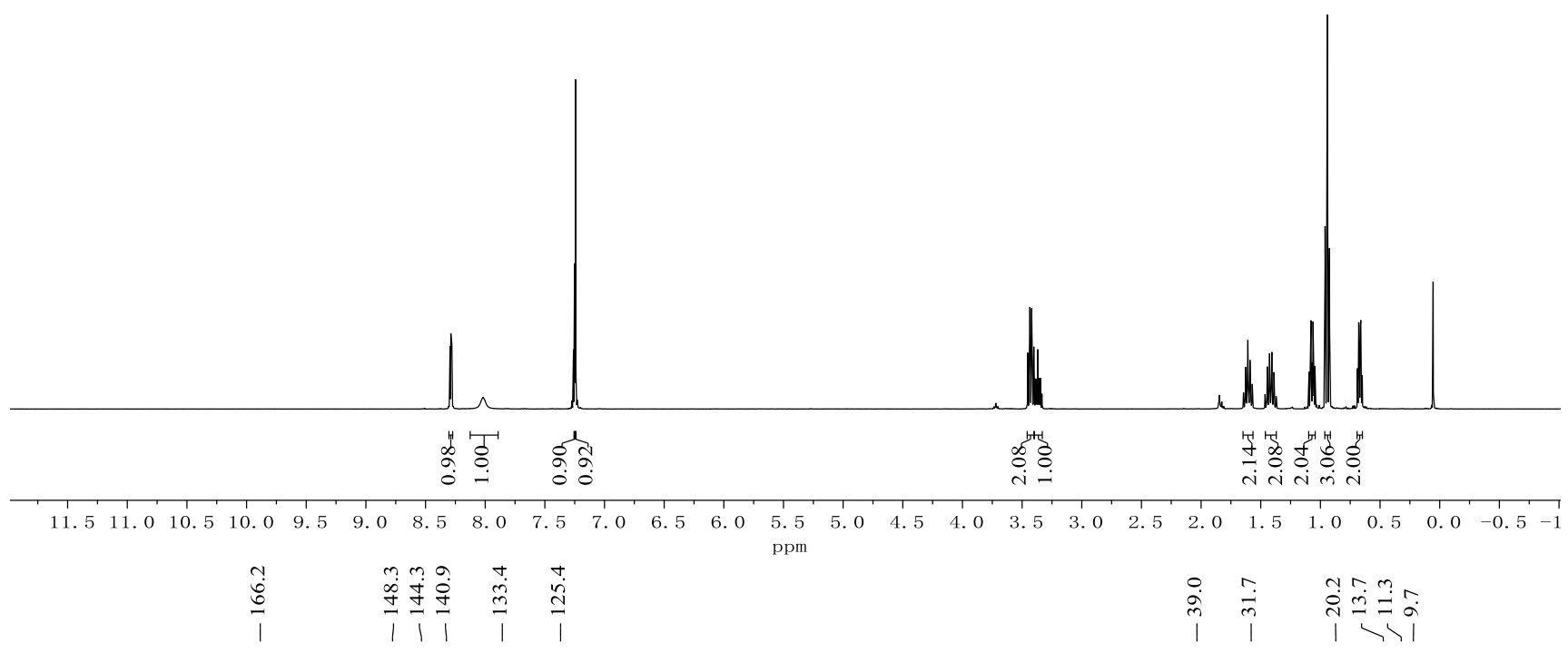

$\underbrace{O}_{=N} H_{H^{-n B u}}^{O}$

$415 \mathrm{~g}$

(100 MHz, $\mathrm{CDCl}_{3}$ )

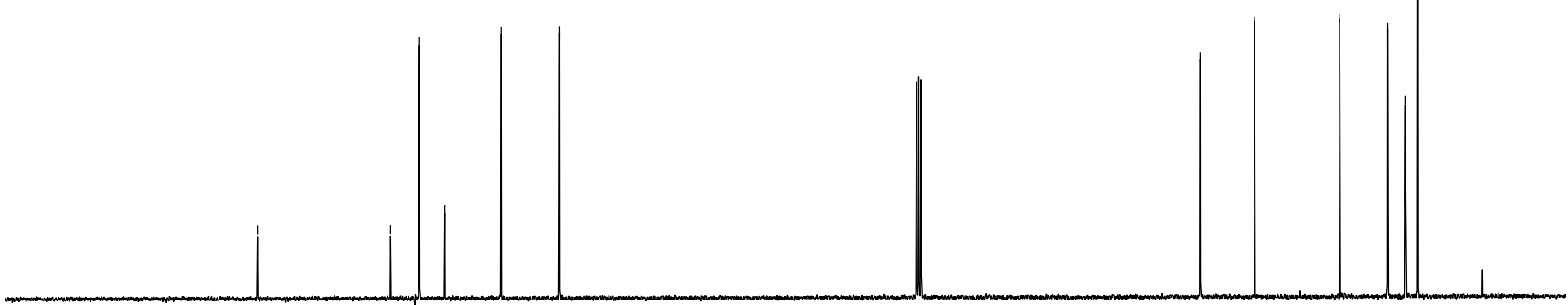

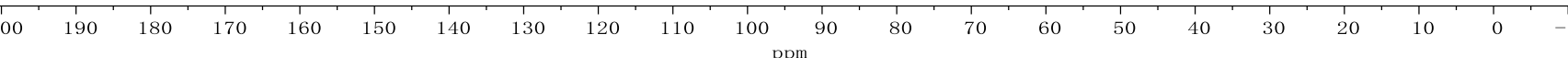




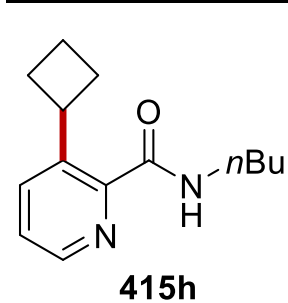

(400 MHz, $\mathrm{CDCl}_{3}$ )

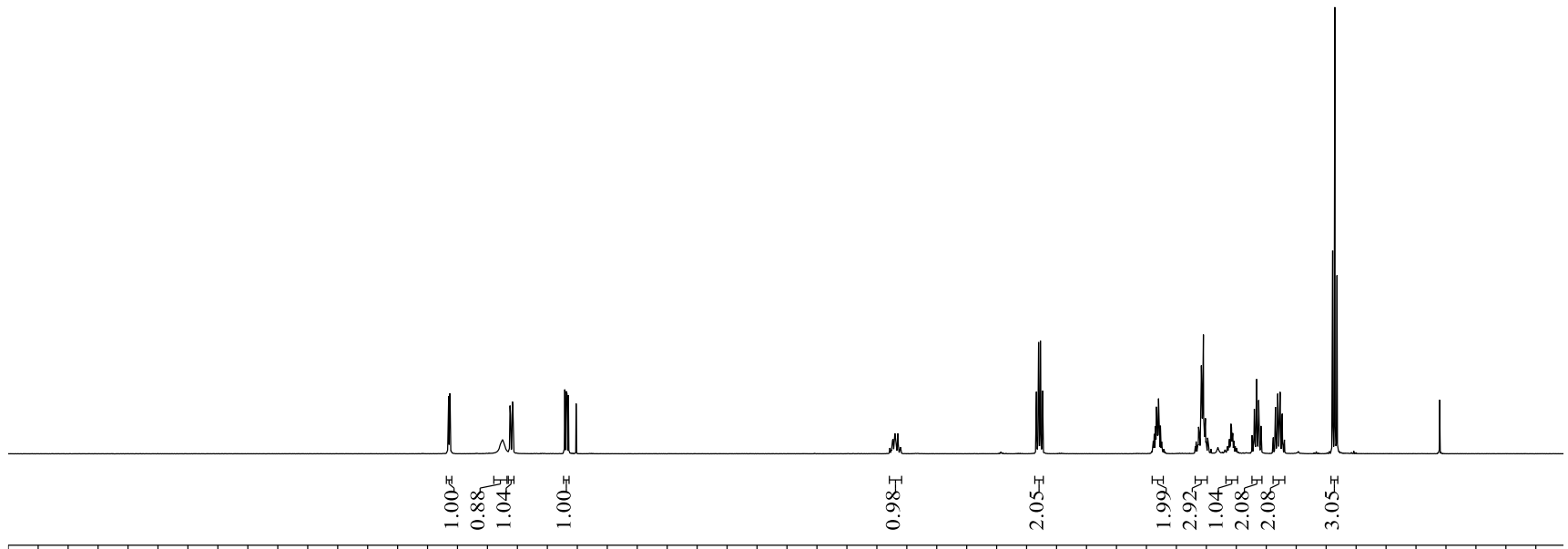

\begin{tabular}{llllllllllllllllllllllllllllllllllll}
\hline .0 & 11.5 & 11.0 & 10.5 & 10.0 & 9.5 & 9.0 & 8.5 & 8.0 & 7.5 & 7.0 & 6.5 & 6.0 & 5.5 & 5.0 & 4.5 & 4.0 & 3.5 & 3.0 & 2.5 & 2.0 & 1.5 & 1.0 & 0.5 & 0.0 & -0.5
\end{tabular}

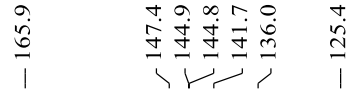

i்<smiles>CCCCNC(=O)c1ncccc1C1CCC1</smiles>

415h

(100 MHz, $\mathrm{CDCl}_{3}$ )

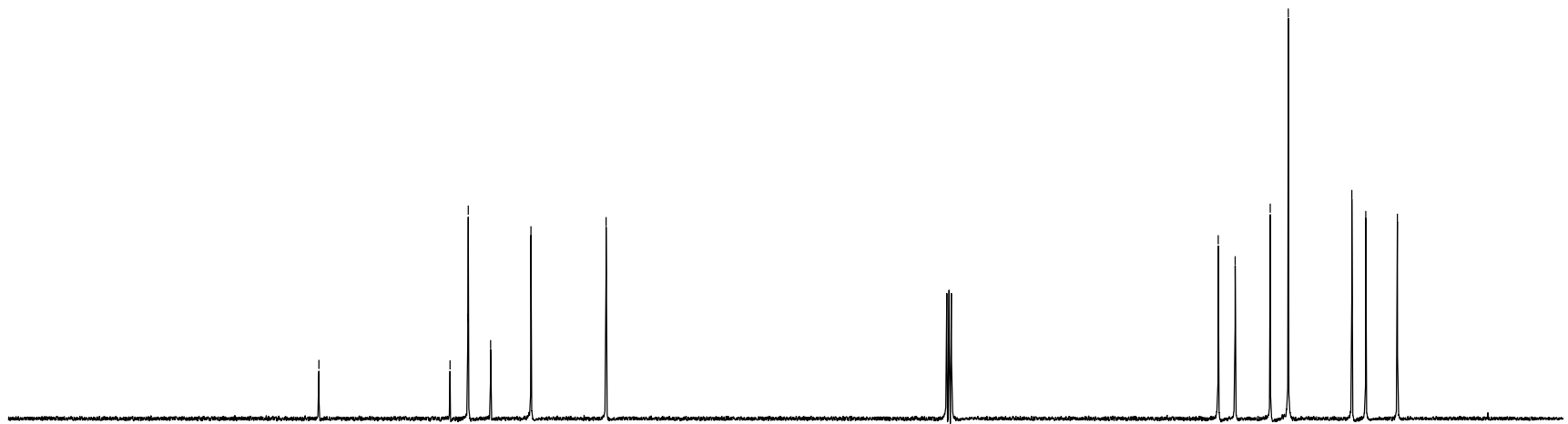

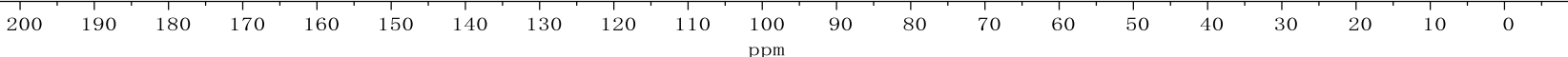


$\sum_{=\mathrm{N}}^{O} \sum_{\mathrm{H}^{-n B u}}$

415i

(300 MHz, $\mathrm{CDCl}_{3}$ )

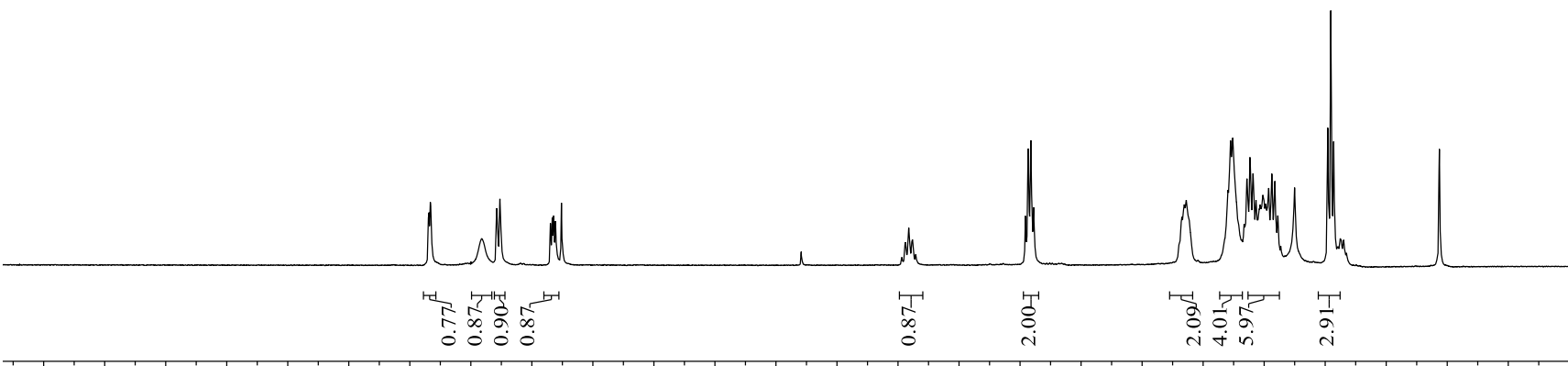
$\begin{array}{llllllllllllllllllllllllll}11.5 & 11.0 & 10.5 & 10.0 & 9.5 & 9.0 & 8.5 & 8.0 & 7.5 & 7.0 & 6.5 & 6.0 & 5.5 & 5.0 & 4.5 & 4.0 & 3.5 & 3.0 & 2.5 & 2.0 & 1.5 & 1.0 & 0.5 & 0.0 & -0.5\end{array}$

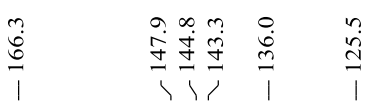

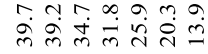
।<smiles>CCCCNC(=O)c1ncccc1C1CCCC1</smiles>

$415 i$

$\left(75 \mathrm{MHz}, \mathrm{CDCl}_{3}\right.$ )

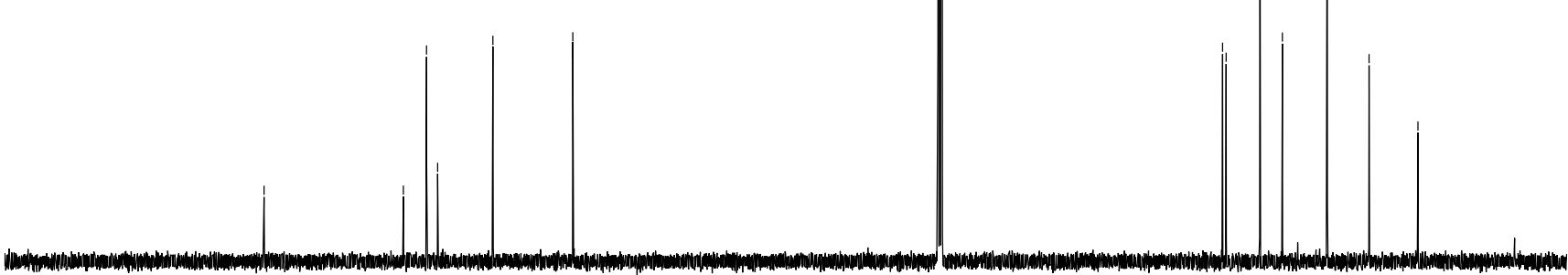

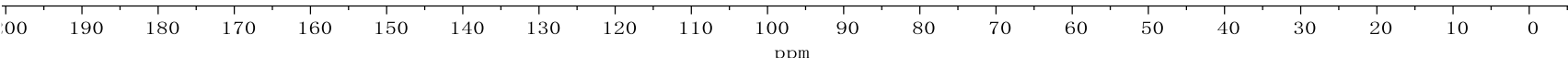


<smiles>CCCCNC(=O)c1ncccc1C1CCCCC1</smiles>

415j

$\left(400 \mathrm{MHz}, \mathrm{CDCl}_{3}\right)$

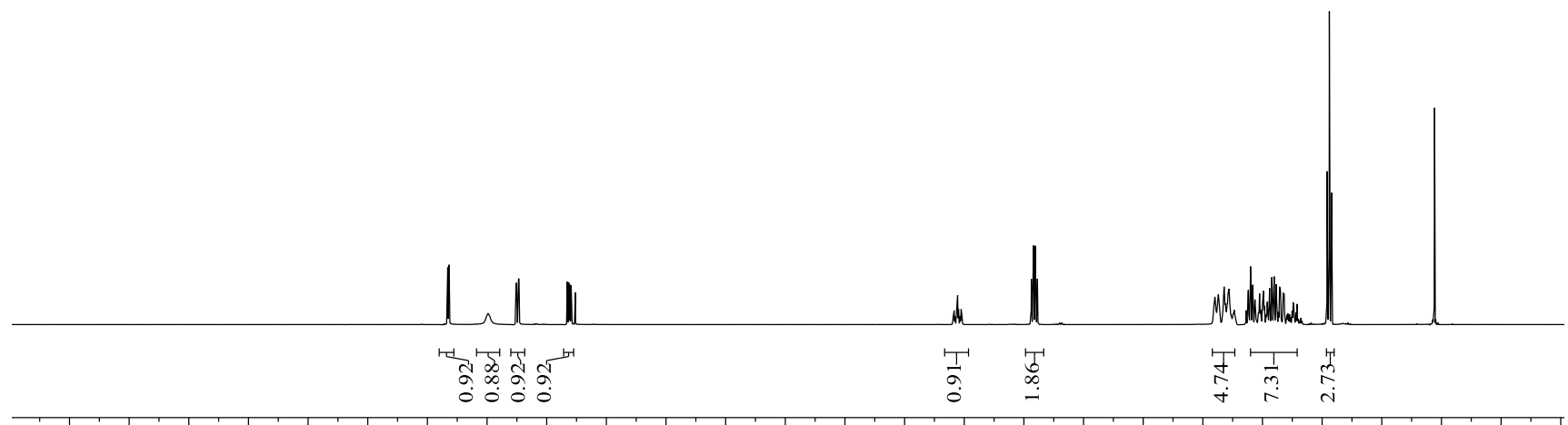

$\begin{array}{llllllllllllllllllllllllll}11.5 & 11.0 & 10.5 & 10.0 & 9.5 & 9.0 & 8.5 & 8.0 & 7.5 & 7.0 & 6.5 & 6.0 & 5.5 & 5.0 & 4.5 & 4.0 & 3.5 & 3.0 & 2.5 & 2.0 & 1.5 & 1.0 & 0.5 & 0.0 & -0.5 & -1\end{array}$

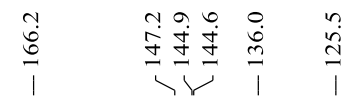

în<smiles>CCCCNC(=O)c1ncccc1C1CCCCC1</smiles>

$415 \mathrm{j}$

$\left(100 \mathrm{MHz}, \mathrm{CDCl}_{3}\right)$

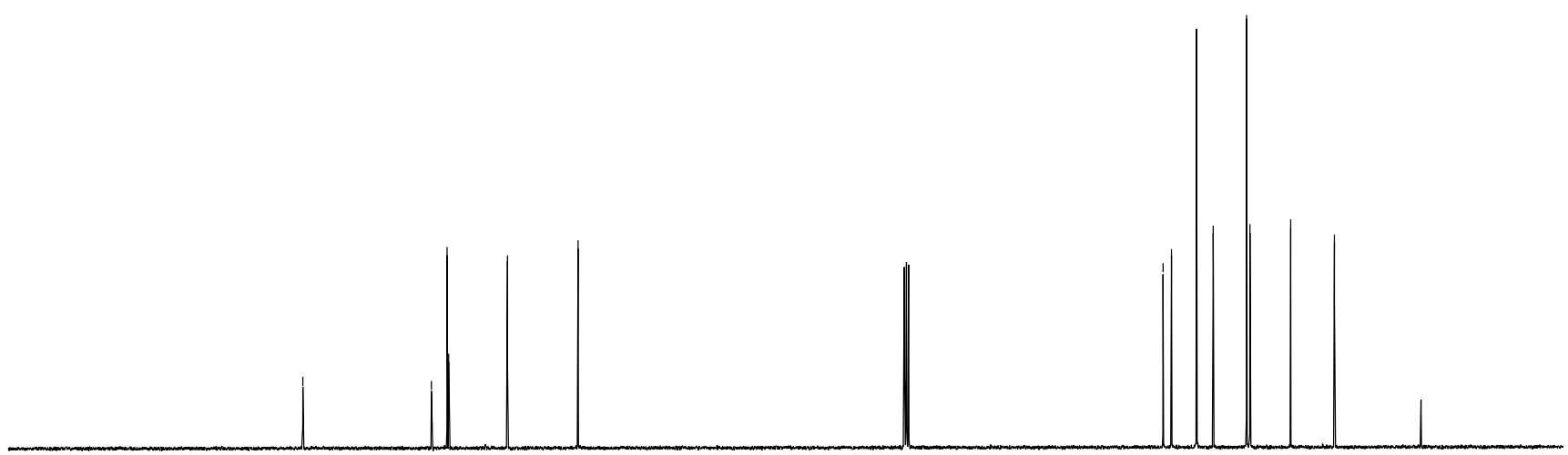

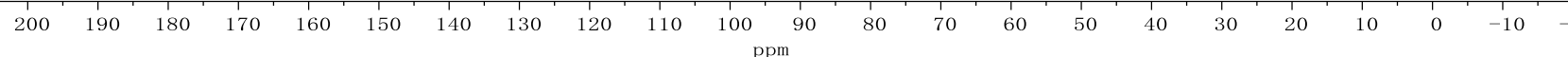




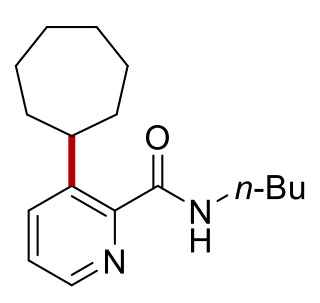

415k

$\left(300 \mathrm{MHz}, \mathrm{CDCl}_{3}\right)$
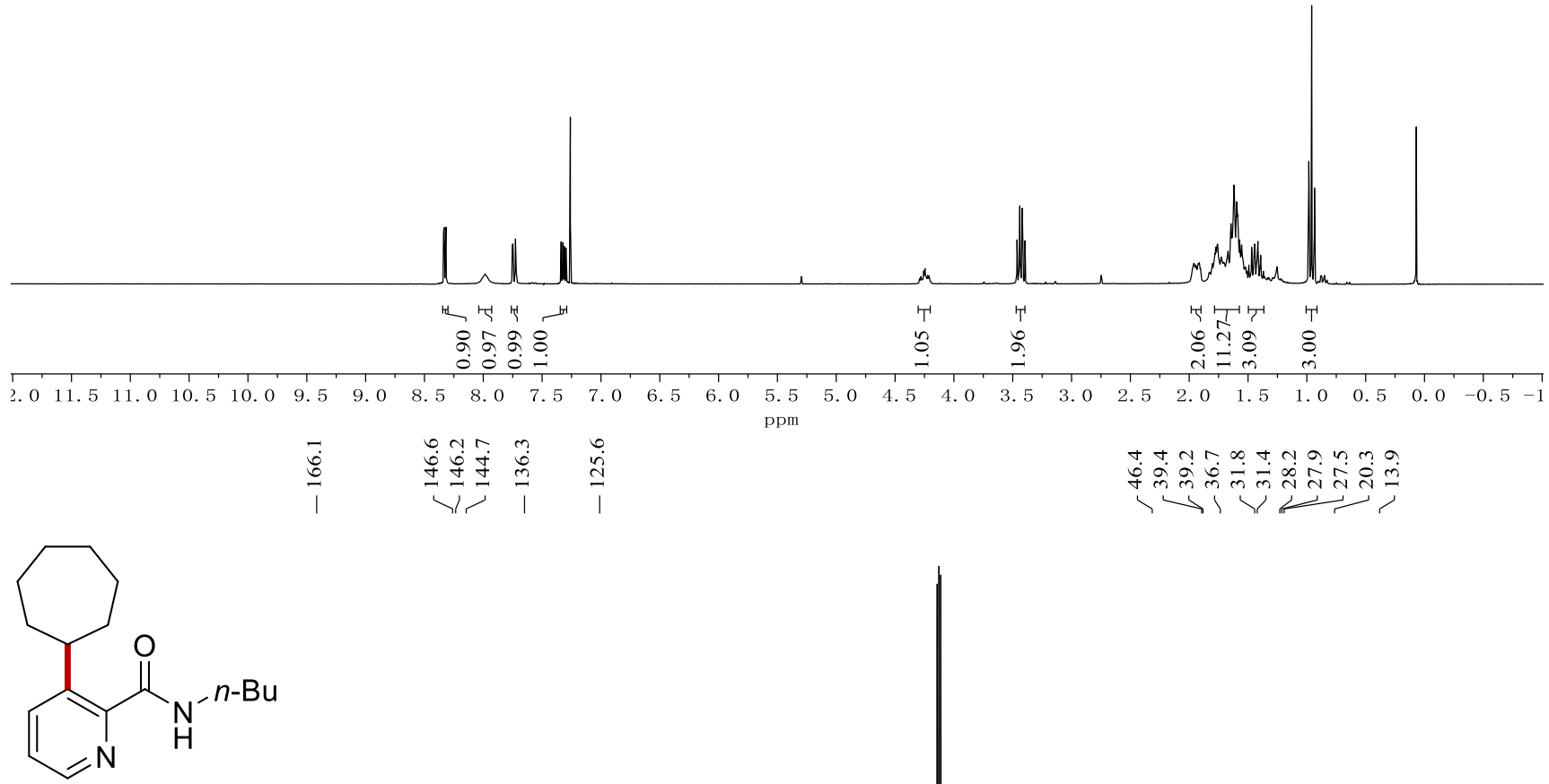

415k

$\left(75 \mathrm{MHz} \mathrm{CDCl}_{3}\right)$

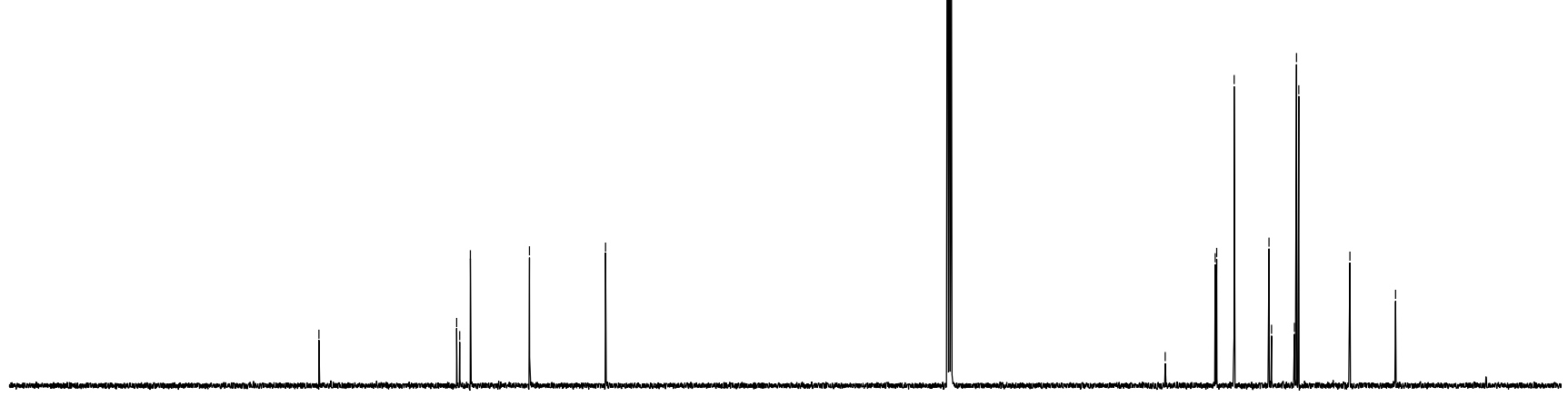

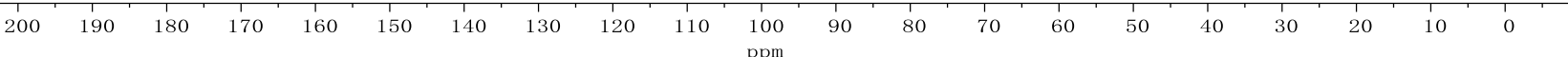


<smiles>O=C(NC1CCCCC1)c1ncccc1C1CCCCC1</smiles>

415I

$\left(400 \mathrm{MHz}, \mathrm{CDCl}_{3}\right)$

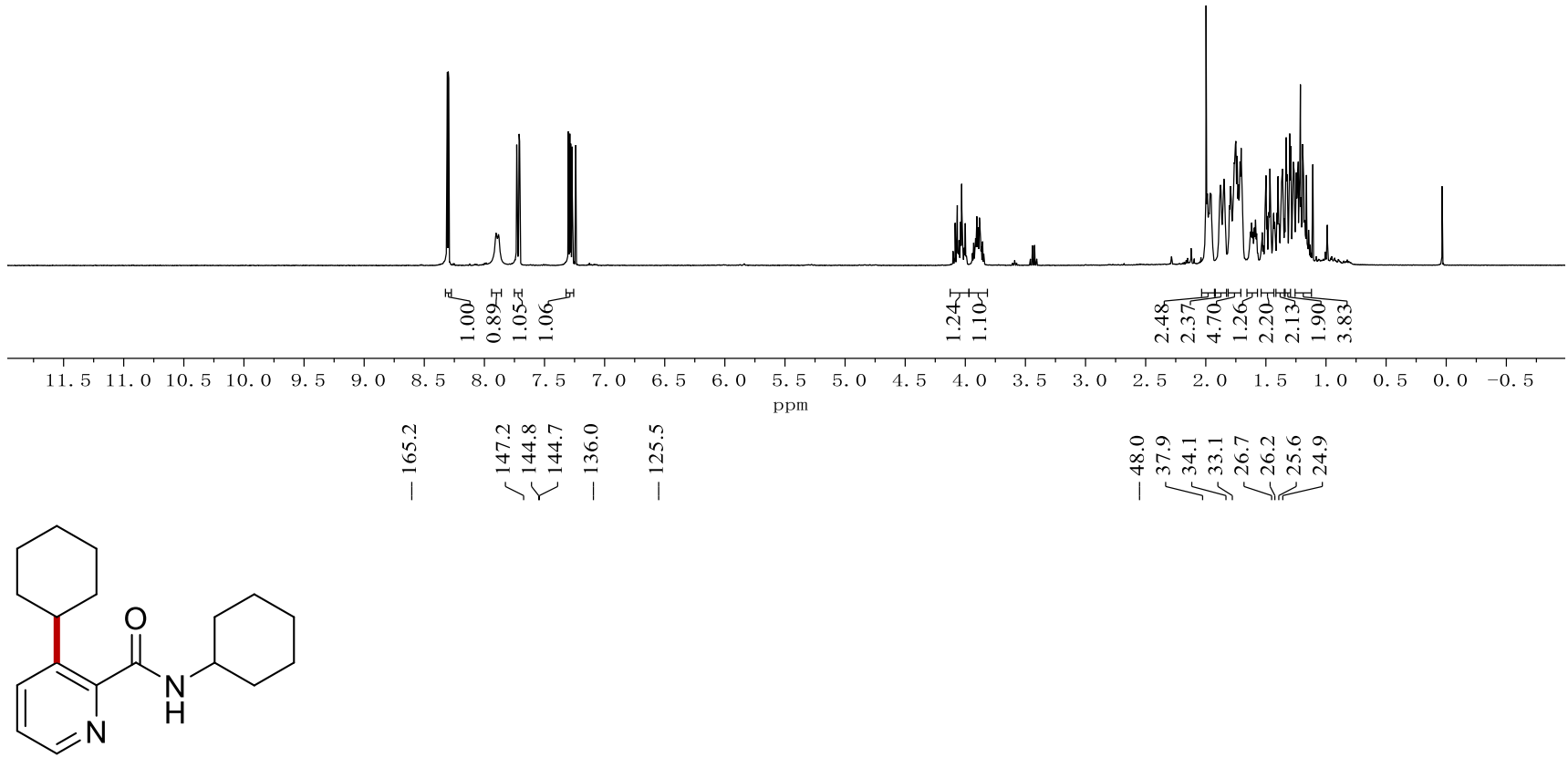

415

$\left(100 \mathrm{MHz}, \mathrm{CDCl}_{3}\right)$

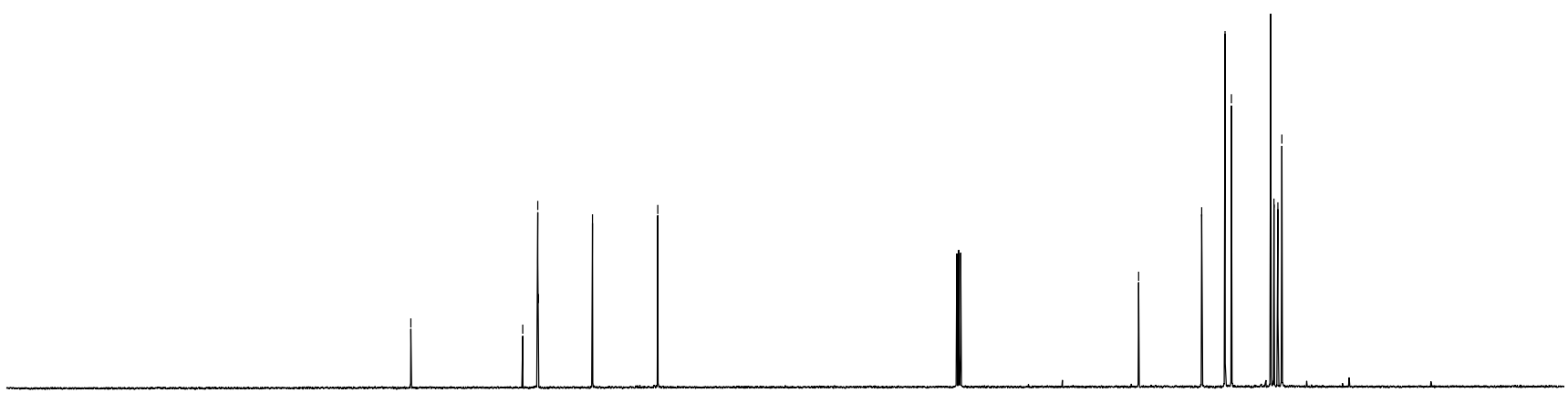

\begin{tabular}{lllllllllllllllllllllllllllllllllll}
\hline 30 & 220 & 210 & 200 & 190 & 180 & 170 & 160 & 150 & 140 & 130 & 120 & 110 & 100 & 90 & 80 & 70 & 60 & 50 & 40 & 30 & 20 & 10 & 0 & -10 & -1
\end{tabular} 
<smiles>O=C(NC1CCCc2ccccc21)c1ncccc1C1CCCCC1</smiles>

$415 \mathrm{~m}$

$\left(400 \mathrm{MHz}, \mathrm{CDCl}_{3}\right)$

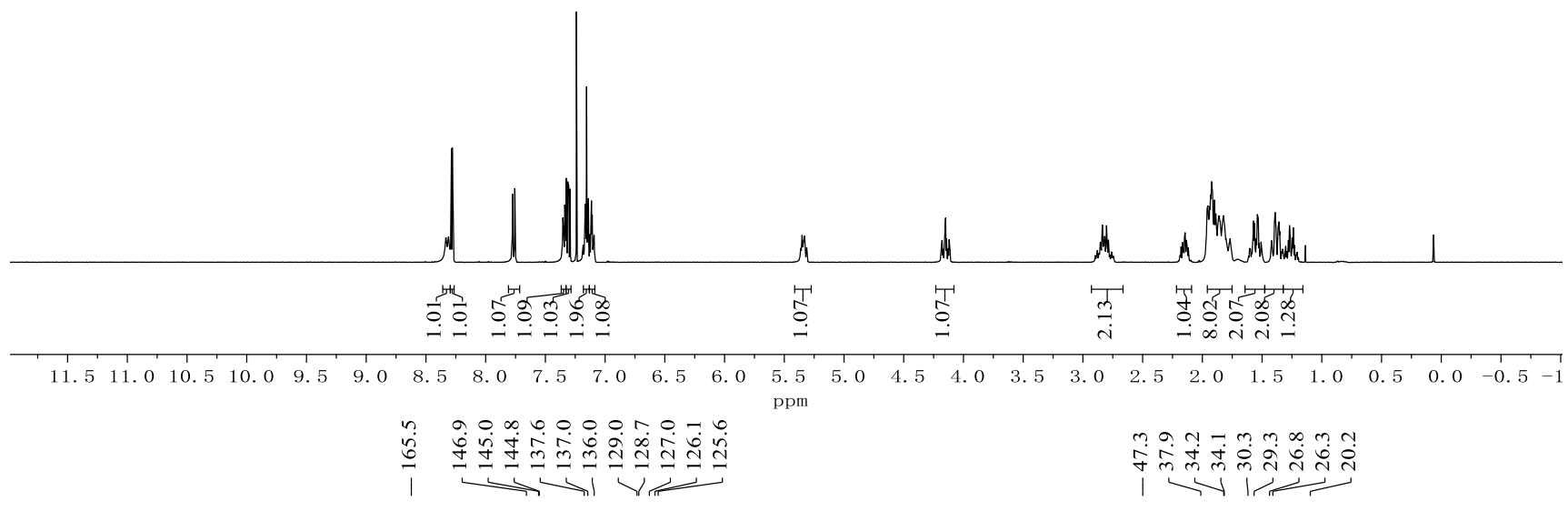<smiles>O=C(NC1CCCc2ccccc21)c1ncccc1C1CCCCC1</smiles>

$415 \mathrm{~m}$

$\left(100 \mathrm{MHz}, \mathrm{CDCl}_{3}\right.$ )

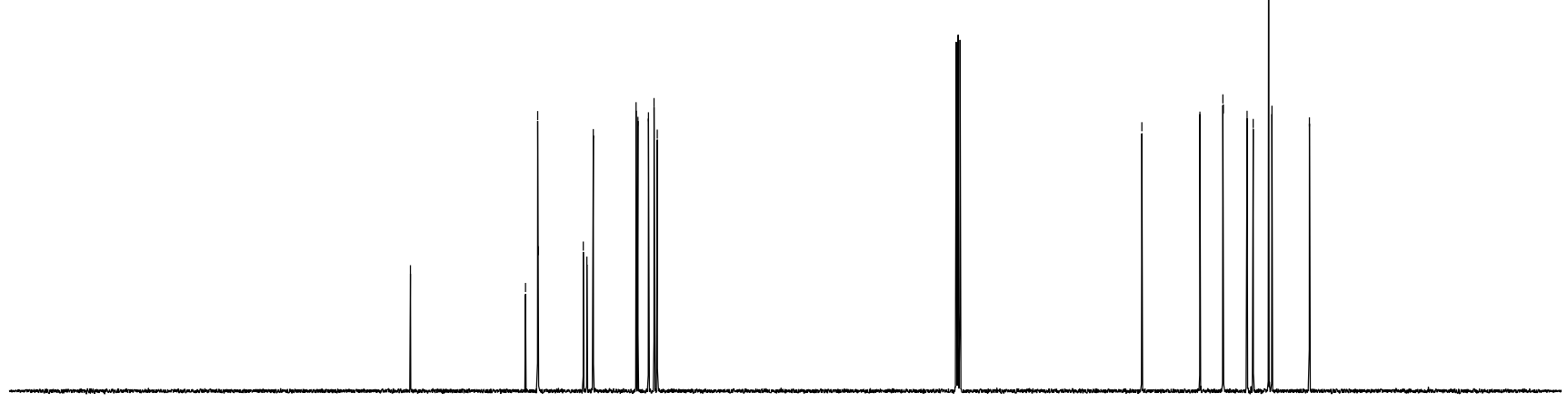

\begin{tabular}{lllllllllllllllllllllllllll}
\hline 30 & 220 & 210 & 200 & 190 & 180 & 170 & 160 & 150 & 140 & 130 & 120 & 110 & 100 & 90 & 80 & 70 & 60 & 50 & 40 & 30 & 20 & 10 & 0 & -10 & -1
\end{tabular} 
<smiles>O=C(NCc1ccccc1)c1ncccc1C1CCCCC1</smiles>

415n

(400 MHz, $\mathrm{CDCl}_{3}$ )

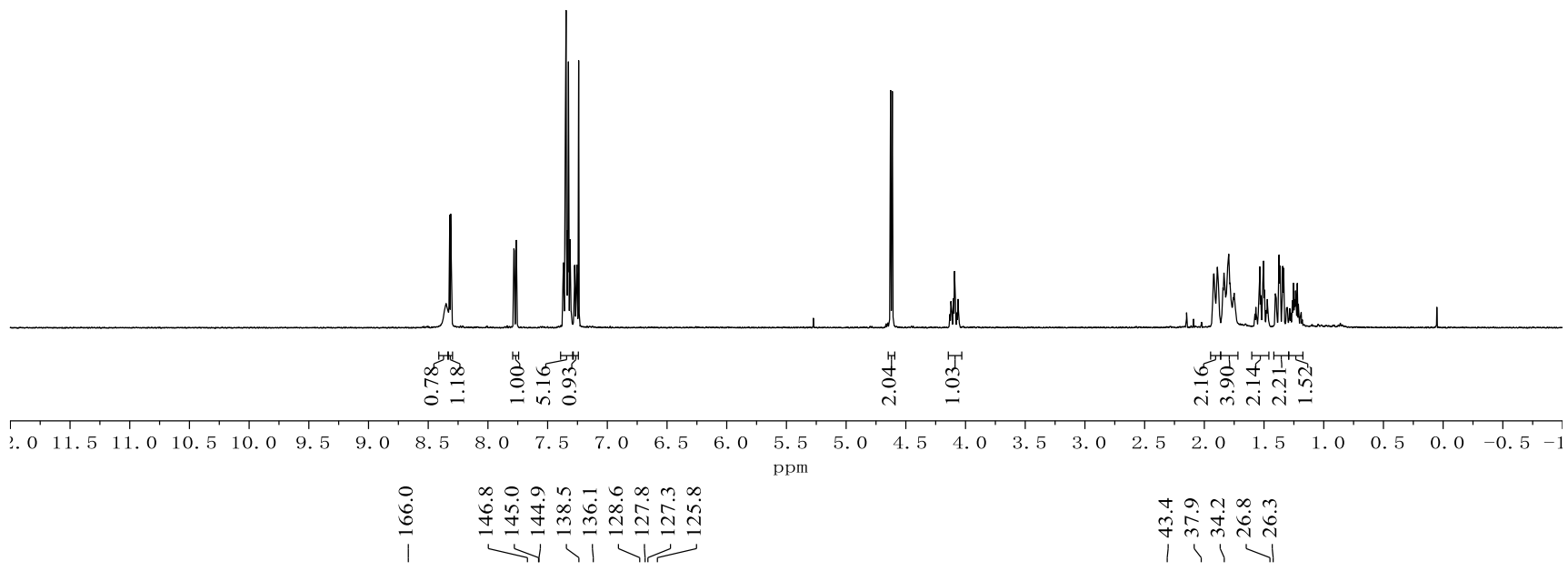<smiles>O=C(NCc1ccccc1)c1ncccc1C1CCCCC1</smiles>

415n

(100 MHz, $\mathrm{CDCl}_{3}$ )

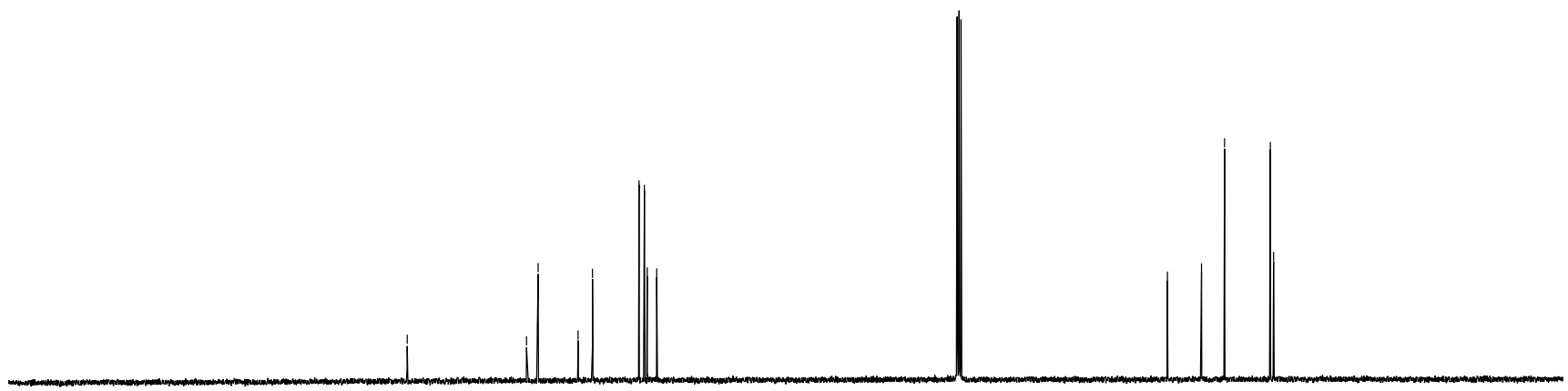

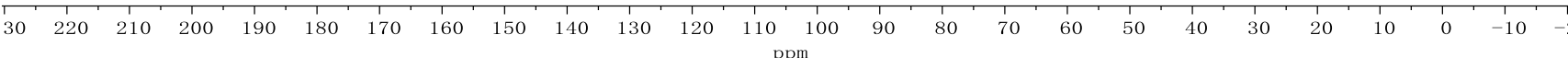




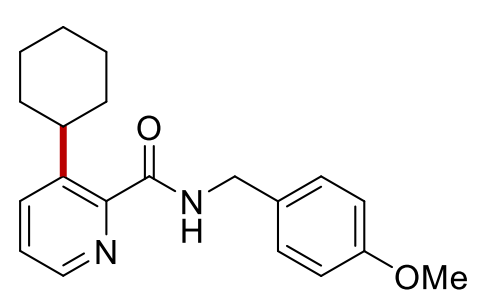

4150

$\left(400 \mathrm{MHz} \mathrm{CDCl}_{3}\right)$
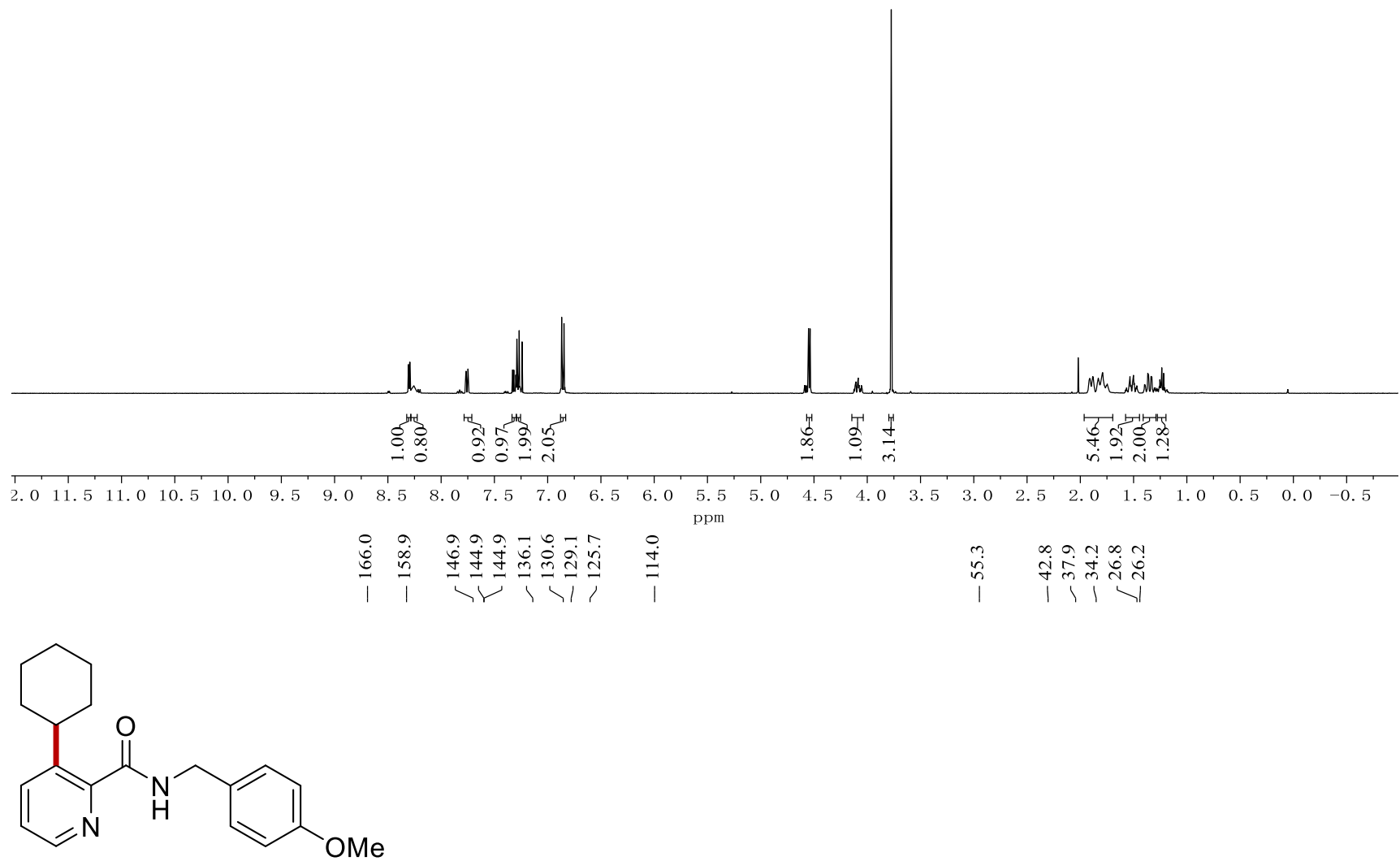

4150

(100 MHz, $\mathrm{CDCl}_{3}$ )

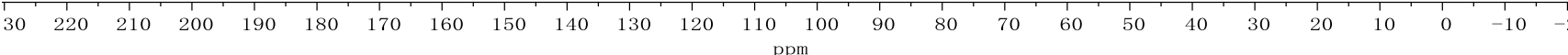


<smiles>COc1ccc(NC(=O)c2ncccc2C2CCCCC2)cc1</smiles>

415p

(300 MHz, $\mathrm{CDCl}_{3}$ )

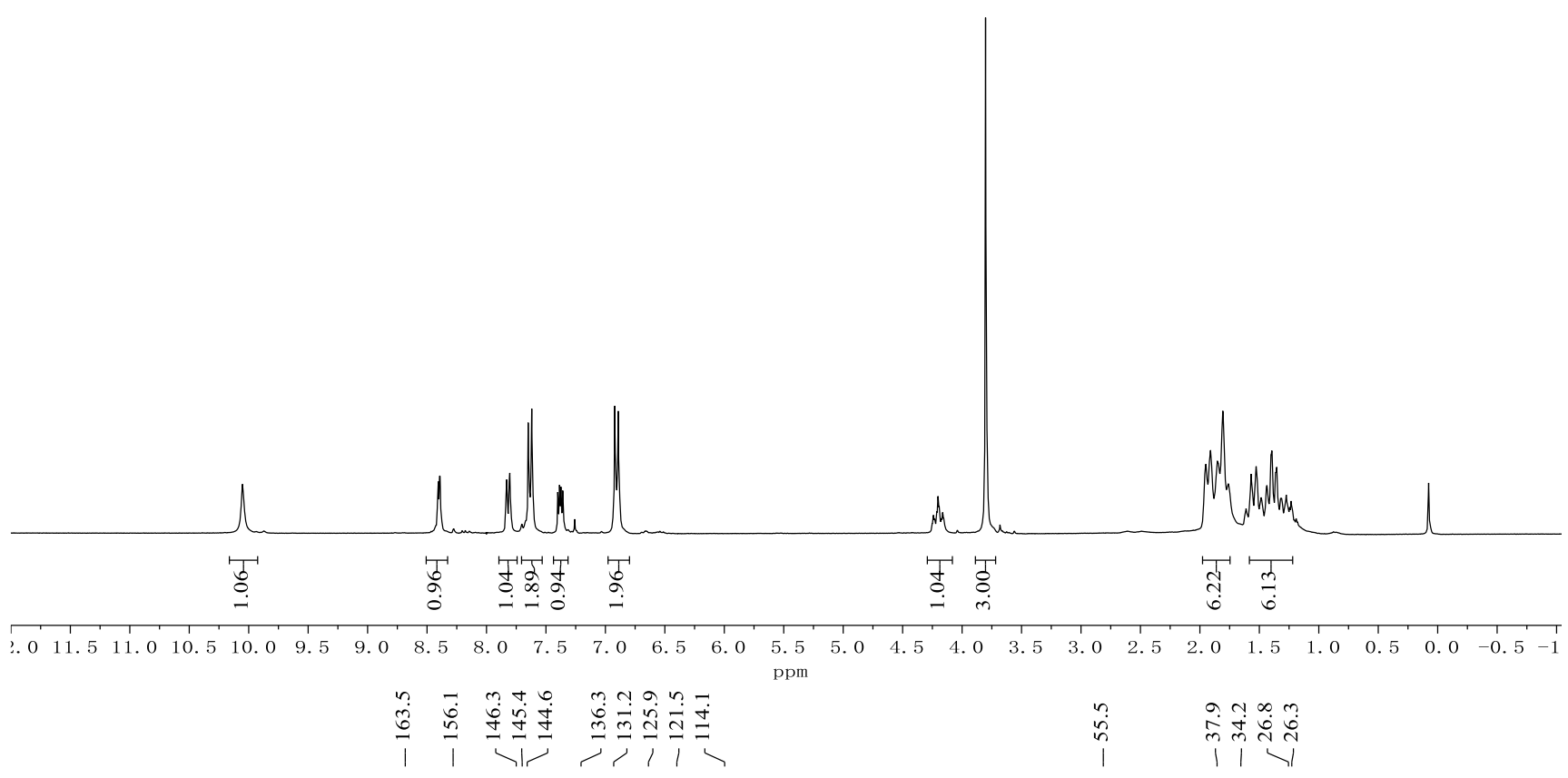<smiles>COc1ccc(NC(=O)c2ncccc2C2CCCCC2)cc1</smiles>

415p

(75 MHz, $\mathrm{CDCl}_{3}$ )

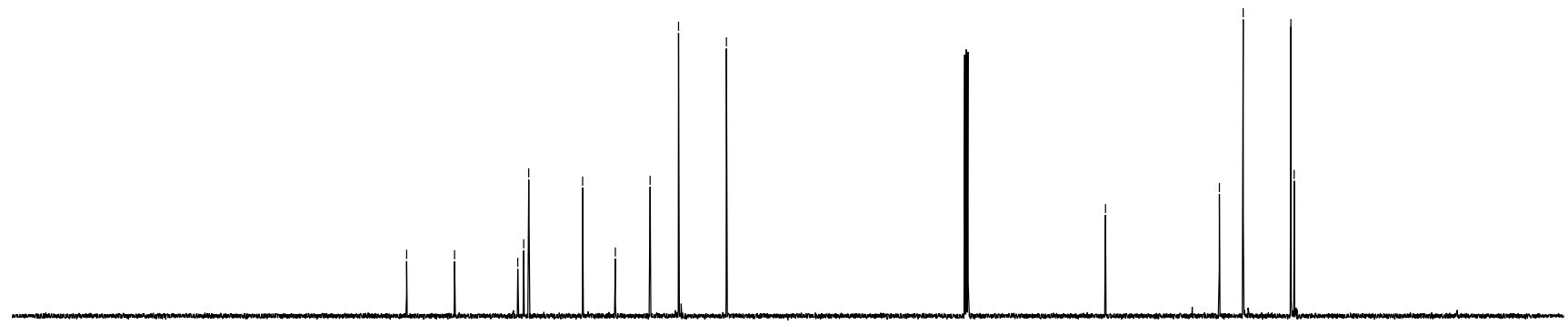

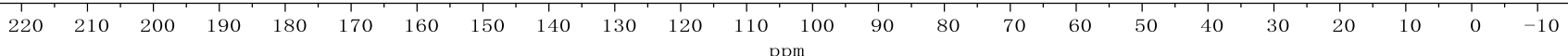




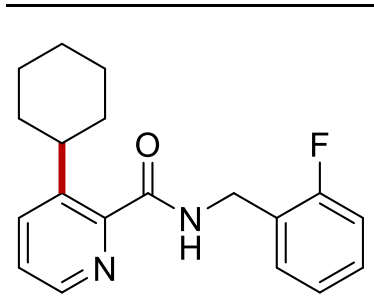

415q

(300 MHz, $\mathrm{CDCl}_{3}$ )

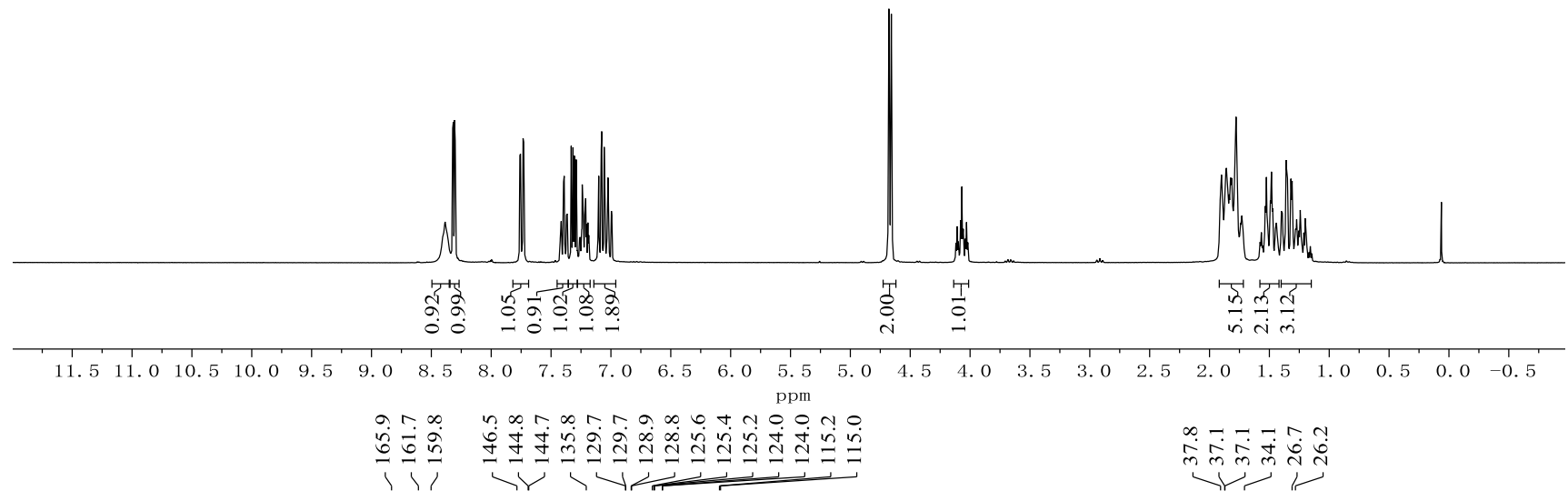<smiles>O=C(NCc1ccccc1F)c1ncccc1C1CCCCC1</smiles>

\section{$415 q$}

(75 MHz, $\mathrm{CDCl}_{3}$ )

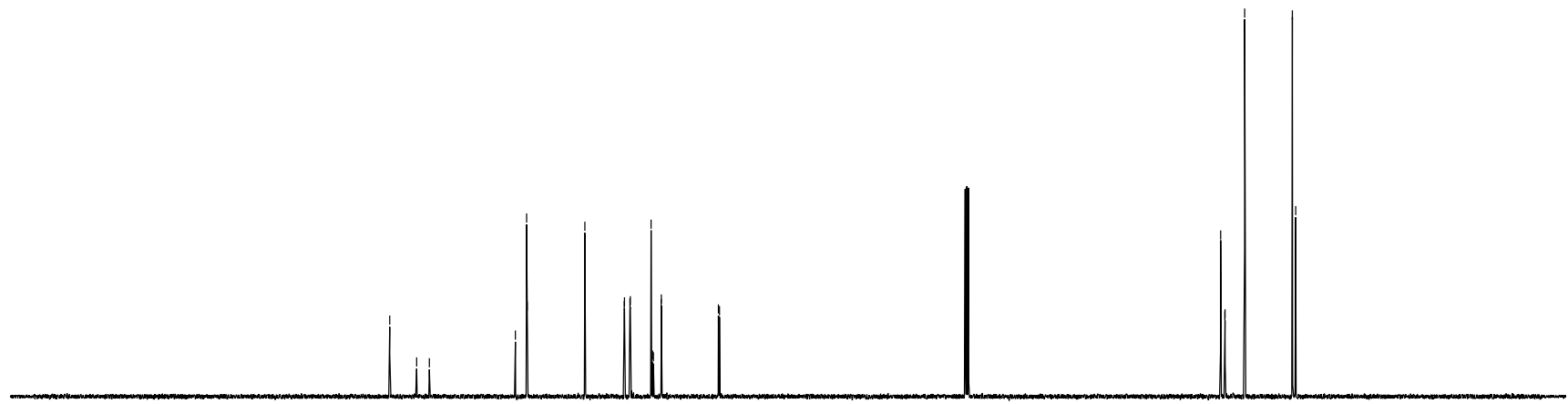

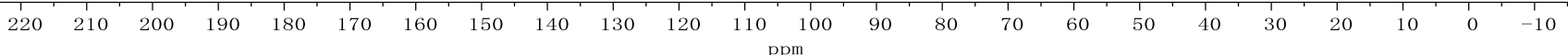




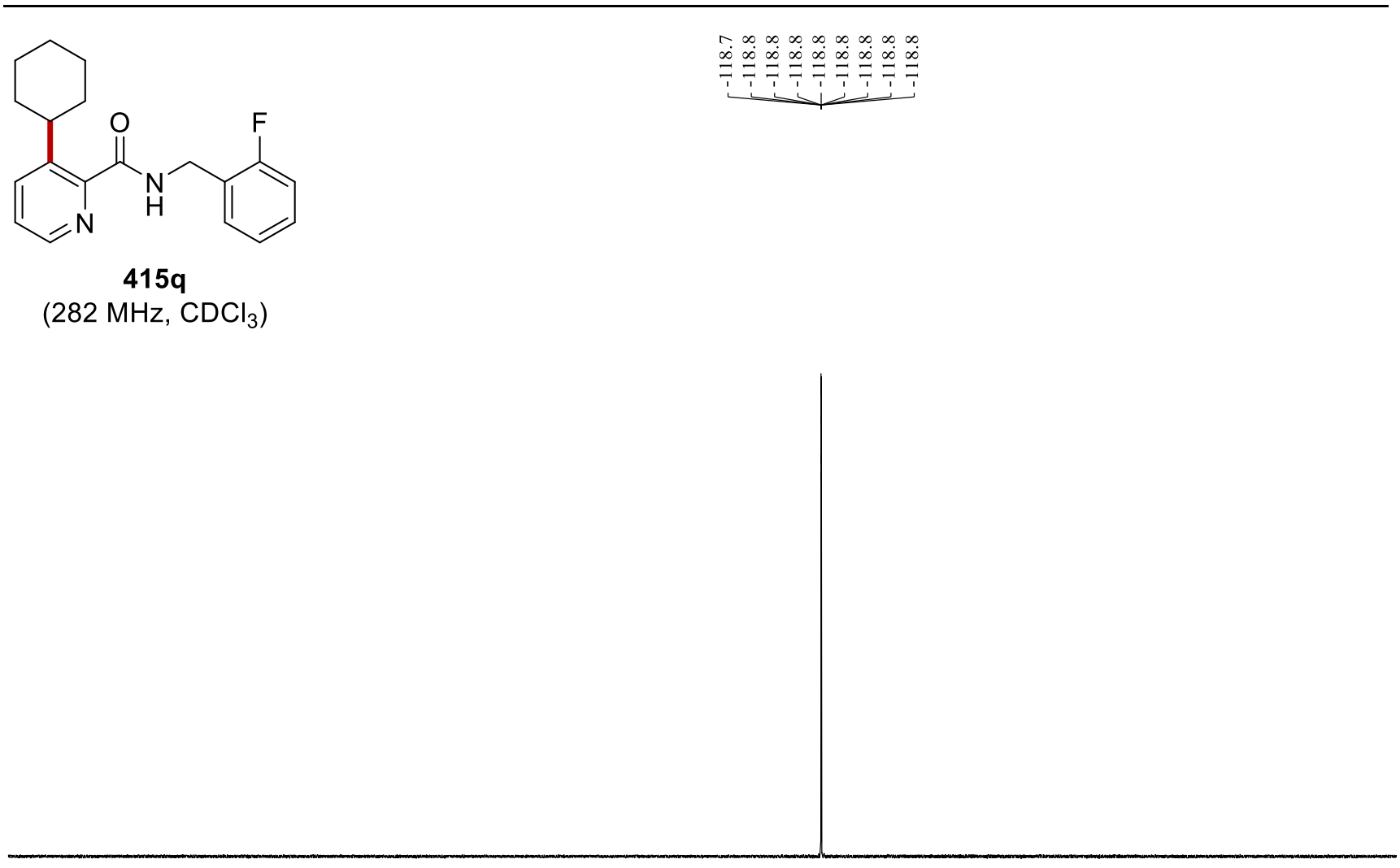

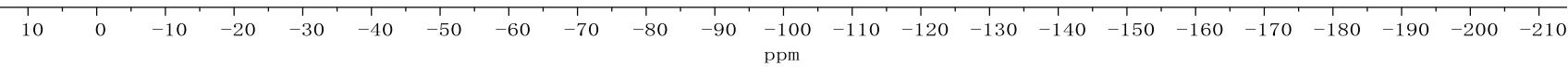


<smiles>O=C(NCCc1ccccc1)c1ncccc1C1CCCCC1</smiles>

$415 r$

(300 MHz, $\mathrm{CDCl}_{3}$ )

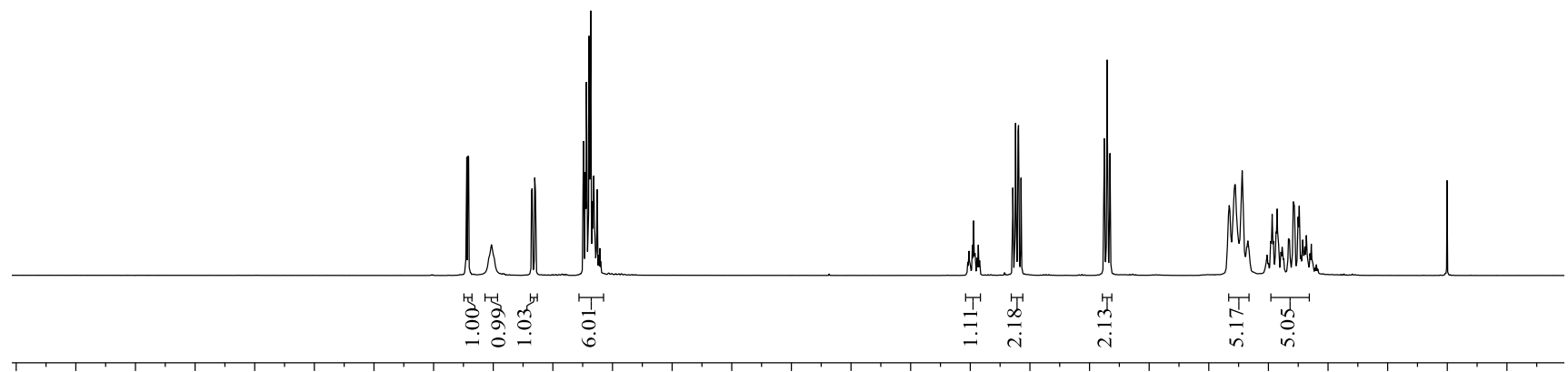
\begin{tabular}{llllllllllllllllllllllllllllllllllll}
\hline 2.0 & 11.5 & 11.0 & 10.5 & 10.0 & 9.5 & 9.0 & 8.5 & 8.0 & 7.5 & 7.0 & 6.5 & 6.0 & 5.5 & 5.0 & 4.5 & 4.0 & 3.5 & 3.0 & 2.5 & 2.0 & 1.5 & 1.0 & 0.5 & 0.0 & -0.5
\end{tabular}

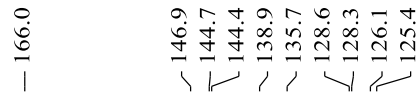

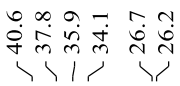<smiles>O=C(NCCc1ccccc1)c1ncccc1C1CCCCC1</smiles>

$415 r$

(75 $\mathrm{MHz}, \mathrm{CDCl}_{3}$ )

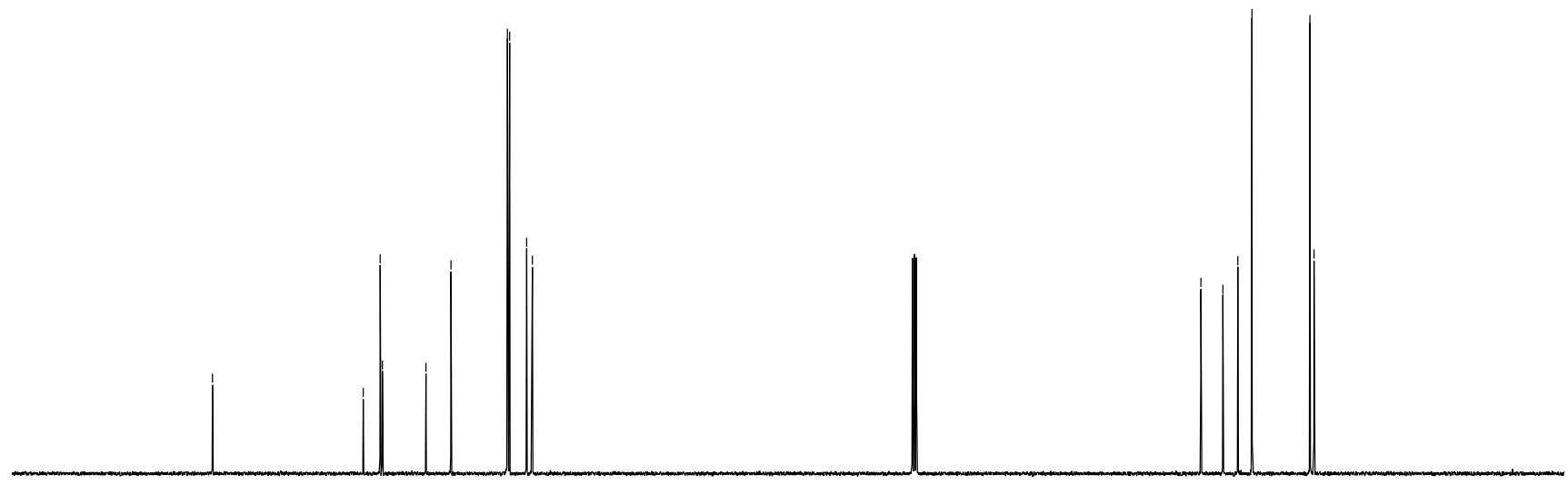

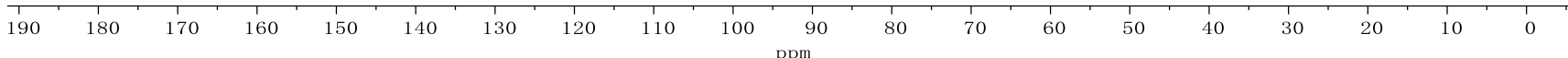




\section{Erklärung}

Ich versichere, dass ich die vorliegende Dissertation im Zeitraum von Mai 2017 bis September 2021 am Institut für Organische und Biomolekulare Chemie der

Georg-August-Universität Göttingen

auf Anregung und unter Anleitung von

\section{Professor Dr. Lutz Ackermann}

selbstständig durchgeführt und keine weiteren als die angegebenen Hilfsmittel und

Quellen verwendet habe.

Göttingen, den 12.08.2021

Isaac Choi 